\title{
Krieg und Kriegserinnerung im Museum
}

Der Zweite Weltkrieg in polnischen historischen Ausstellungen seit den 1980er-Jahren

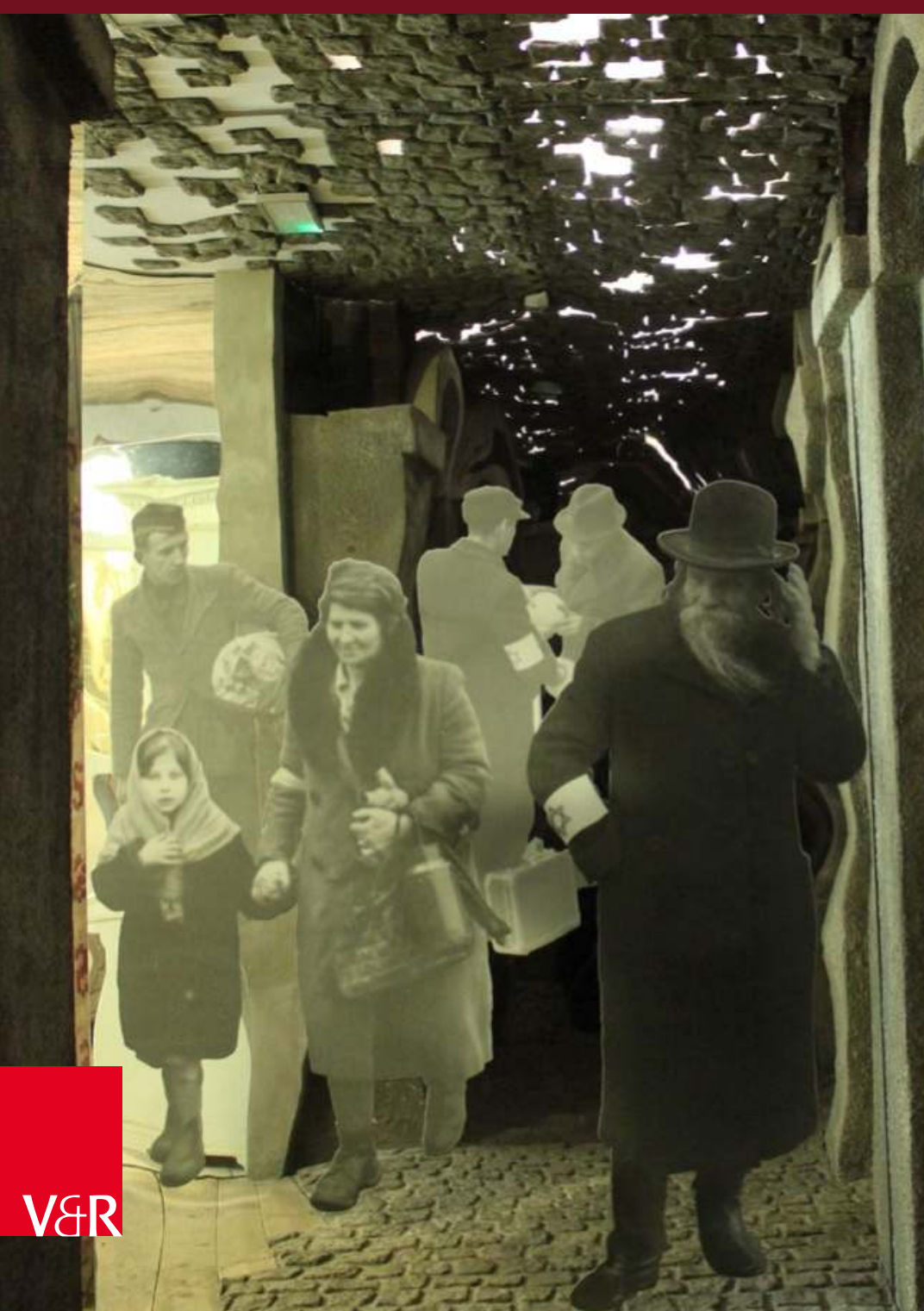


V£R Academic 


\section{Schnittstellen}

Studien zum östlichen und südöstlichen Europa

Herausgegeben von

Martin Schulze Wessel und Ulf Brunnbauer

Band 5 
Monika Heinemann

\section{Krieg und Kriegserinnerung im Museum}

Der Zweite Weltkrieg in polnischen historischen Ausstellungen seit den 1980er-Jahren

Mit 53 Abbildungen

Vandenhoeck \& Ruprecht 
Gedruckt mit freundlicher Unterstützung der Graduiertenschule für Ostund Südosteuropastudien der Ludwig-Maximilians-Universität München und der Universität Regensburg sowie des Schroubek Fonds Östliches Europa.

Bibliografische Information der Deutschen Nationalbibliothek:

Die Deutsche Nationalbibliothek verzeichnet diese Publikation in der Deutschen Nationalbibliografie; detaillierte bibliografische Daten sind im Internet über https://dnb.de abrufbar.

(C) 2017, Vandenhoeck \& Ruprecht GmbH \& Co. KG, Theaterstraße 13, D-37073 Göttingen

Umschlagabbildung: Schindler-Fabrik, Spiegelwand in der Sektion »Ghetto» Foto: @ Monika Heinemann

Satz: textformart, Göttingen | www.text-form-art.de

Vandenhoeck \& Ruprecht Verlage | www.vandenhoeck-ruprecht-verlage.com

ISSN 2566-6614

ISBN (Print) 978-3-525-30091-6

ISBN (PDF) 978-3-666-30091-2

https://doi.org/10.13109/9783666300912

Dieses Material steht unter der Creative-Commons-Lizenz Namensnennung Nicht kommerziell - Keine Bearbeitungen 4.0 International. Um eine Kopie dieser Lizenz zu sehen, besuchen Sie http://creativecommons.org/licenses/by-nc-nd/4.0/.

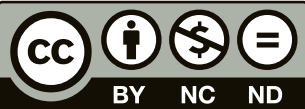




\section{Inhalt}

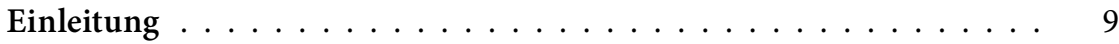

1. Museale Ausstellungen als Medien der Erinnerungskultur _. . . . . 11

2. Forschungsstand $\ldots \ldots \ldots \ldots \ldots \ldots \ldots \ldots \ldots$

3. Untersuchungsgegenstände . . . . . . . . . . . . 26

Historisches Museum der Hauptstadt Warschau . . . . . . . . . . 29

Gefängnismuseum Pawiak, Warschau . . . . . . . . . . 32

Museum des Warschauer Aufstands, Warschau . . . . . . . . . . 35

Jüdisches Historisches Institut, Warschau $\ldots \ldots \ldots$. . . . . . . 37

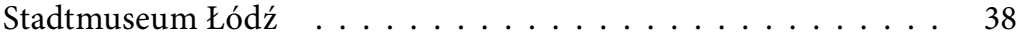

Martyrologiemuseum Radogoszcz, Łódź . . . . . . . . . . . 40

Historisches Museum der Stadt Krakau . . . . . . . . . . . . . . 42

Historisches Museum in Wrocław . . . . . . . . . . . . . . . 46

Historisches Museum der Stadt Lublin _ . . . . . . . . . . . . 48

Martyrologiemuseum »Unter der Uhr«, Lublin _. . . . . . . . 50

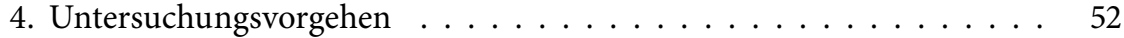

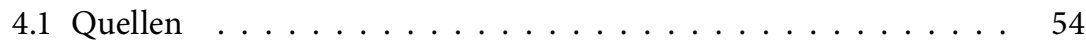

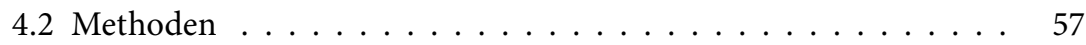

Teil 1

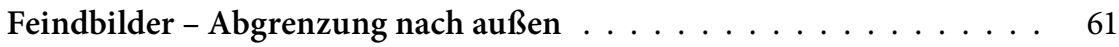

1. Das Feindbild »die Deutschen" . . . . . . . . . . . . . . . . . . 65

1.1 Das Feindbild in der Volksrepublik . . . . . . . . . . . . . 65

1.2 Kontinuitäten bis Anfang der 2000er-Jahre . . . . . . . . . . 71

1.3 Erweiterungen des traditionellen Deutungsangebots? . . . . . . . 78

Das Museum des Warschauer Aufstands . . . . . . . . . . . 78

Die Emaillewarenfabrik Oskar Schindlers _. . . . . . . . . . . . 91

Das Historische Museum in Wrocław . . . . . . . . . . . . . 98

1.4 Zwischenfazit . . . . . . . . . . . . . . . . . . . . . 103

2. Das Feindbild Sowjetunion _ . . . . . . . . . . . . . . 106

2.11989 - Wendepunkt musealer Narration? . . . . . . . . . . . . . . 107

Die musealen Erzählungen bis 1989 . . . . . . . . . . . . . . . 107

1989 - Kontinuitäten etablierter Darstellungsweisen _ . . . . . . 111 
1989 - Eruption der Erinnerungen _. . . . . . . . . . . . 113

Das museale Nebeneinander von Schweigen und Erinnern _. . . 118

2.2 Inklusion des "neuen« alten Feindbildes . . . . . . . . . . . . . 121

2.3 Zwischen Dämonisierung und Neutralität - neue Ausprägungen des musealen Bildes der Sowjetunion, 2004-2010 . . . . . . . . . 127

Die Inklusion der Sowjetunion in das national-martyrologische Geschichtsbild . . . . . . . . . . . . . . . . . . 128

Alternative Perspektiven auf das Feindbild _ . . . . . . . . 135

3. Zusammenfassung $\ldots \ldots \ldots \ldots \ldots \ldots \ldots \ldots \ldots$

Teil 2

Die Darstellung der Judenverfolgung - Abgrenzung nach innen . . . . 141

1. Wandlungen von Marginalisierungsstrategien -

museale Präsentationen der 1980er- und 1990er-Jahre . . . . . . . . 153

1.1 Die 1980er-Jahre - Marginalisierung durch Vereinnahmung .. 154

1.2 Die zweite Hälfte der 1990er-Jahre -

Marginalisierung durch Ausgrenzung . . . . . . . . . . . . . 168

1.3 Exkurs: Das Bild der Verfolgung von Juden

in der Alten Synagoge in Krakau sowie in Sonder- und

Wechselausstellungen . . . . . . . . . . . . . . . . . 173

1.4 Zwischenfazit . . . . . . . . . . . . . . . . . . . . 180

2. Die Verfolgung von Juden als »fremde» Geschichte _. . . . . . . . 182

2.1 Die Warschauer Museumslandschaft am Anfang des 21. Jahrhunderts . . . . . . . . . . . . . . . . . . . . 182

2.2 Ein Sonderfall? - Die Dauerausstellung des Jüdischen

Historischen Instituts . . . . . . . . . . . . . . . . . . . 200

2.3 Eine lokale Geschichtsperspektive? - Das Historische Museum

in Wrocław . . . . . . . . . . . . . . . . . . . . . . 207

2.4 Zwischenfazit . . . . . . . . . . . . . . . . . . . 213

3. Der Entwurf einer multiethnischen Stadtgeschichte -

Die Musealiserung des Ghettos Litzmannstadt . . . . . . . . . . . 215

3.1 Tradition versus Neuanfang - Musealisierungsstrategien

bis $2003 \ldots \ldots$. . . . . . . . . . . . . . . . . . 217

Die Erinnerung an das Ghetto im Stadtbild bis Anfang

der 2000er-Jahre . . . . . . . . . . . . . . . . . . . . . . 217

Das Stadtmuseum Łódź ． . . . . . . . . . . . . . . . 220

Das Ghetto im Martyrologiemuseum Radogoszcz . . . . . . . . . 228

3.2 Exkurs: »Mit den Opfern schreien« . . . . . . . . . . . . . . 238

3.3 Zwischenfazit . . . . . . . . . . . . . . . . . . . . 247 
4. Eine integrative Stadtgeschichte - Die »Emaillewarenfabrik

Oskar Schindlers" . . . . . . . . . . . . . . . . . . . . . . . 250

4.1 Die neue Wir-Gemeinschaft der Krakauer . . . . . . . . . . . . . . 252

4.2 Die »Gerechten« als Pointe der Erzählung . . . . . . . . . . . . . . 259

4.3 Zwischenfazit . . . . . . . . . . . . . . . . . . 267

5. Zusammenfassung und Ausblick . . . . . . . . . . . . . . 270

Teil 3

Das polnische museale Selbstbild . . . . . . . . . . . . . . 281

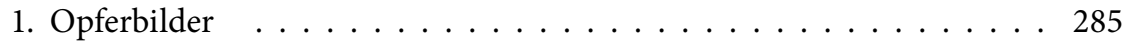

1.1 Die 1980er-Jahre - martyrologische Sinnstiftung . . . . . . . . . . . 286

1.2 Die 1990er-Jahre bis $2003 \ldots \ldots$. . . . . . . . . . . . . . . . . . 296

1.3 Der Museumsboom - Diversifizierung des Märtyrertopos . . . . . 314

Dominanz des Märtyrertopos . . . . . . . . . . . . . . . 314

Erste Abkehr vom Opfersyndrom . . . . . . . . . . . . . . . . . . . . . . . 331

1.4 Zwischenfazit . . . . . . . . . . . . . . . 337

2. Heldenbilder . . . . . . . . . . . . . . . . . . . . . . 340

2.1 Die Musealisierung des Widerstands in den 1980er-Jahren . . . . 340

2.2 Die Evolution des Heldenbildes nach 1989 . . . . . . . . . . . . . . 350

2.3 Der Heldentopos im Museumsboom . . . . . . . . . . . . . . . . . . . . 364

Der Mythos des Warschauer Aufstands 1944 . . . . . . . . . . . 375

2.4 Zwischenfazit . . . . . . . . . . . . . . . . 402

3. Der Besatzungsalltag . . . . . . . . . . . . . . . . . . . 404

3.1 Die »Entdeckung« der Zivilbevölkerung . . . . . . . . . . . . . . 404

Heroisierung des Alltags . . . . . . . . . . . . . . . . . . . . . . . . . . . . 412

"Normalisierung" des Alltags . . . . . . . . . . . . . . . . . . . . . . . . . . . . . . . . . . . .

3.2 Leerstellen des Besatzungsalltags . . . . . . . . . . . . . . . 421

4. Zusammenfassung . . . . . . . . . . . . . . . 434

Ausblick:

Neue Impulse für die Musealisierung des Zweiten Weltkriegs . . . . . . 441

1. Das Museum der Geschichte der Polnischen Juden . . . . . . . . . . . 443

2. Das Museum des Zweiten Weltkriegs . . . . . . . . . . . . . . . . 458

3. Fazit . . . . . . . . . . . . . . . . . 480

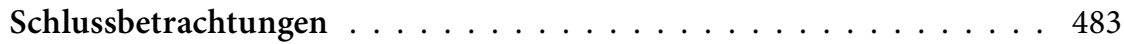


Inhalt

Dank . . . . . . . . . . . . . . . . . . . . . . . . . 493

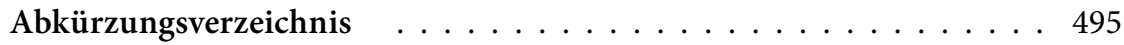

Quellen- und Literaturverzeichnis _ . . . . . . . . . . . . . . . . 497

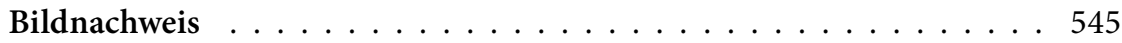

Personenregister . . . . . . . . . . . . . . . . . . . . 547 


\section{Einleitung}

Der Zweite Weltkrieg spielt bis in die Gegenwart in der polnischen Erinnerungskultur und Geschichtspolitik eine zentrale Rolle. Adam Krzemiński bezeichnet ihn gar als »den Gründungsmythos Polens in der zweiten Hälfte des 20. Jahrhunderts«. ${ }^{1}$ Denn die Jahre 1939 bis 1945 stellten den wesentlichen Anknüpfungspunkt für die Konstituierung der staatlichen und historischen Identität sowohl der Volksrepublik Polen (VRP) als auch der sogenannten Dritten Republik nach der politischen Wende von 1989 dar. Die Kriegsjahre wurden dabei in erster Linie als Zeit des heroischen Untergrundkampfes, des Märtyrertums und des Leids der Zivilbevölkerung unter der deutschen - seit 1989 auch der sowjetischen - Besatzung erinnert. Dieses zentrale Deutungsschema der polnischen Nation der "Helden und Opfer« ist in den vergangenen Jahrzehnten jedoch mehrfach durch wissenschaftliche Publikationen sowie gesellschaftliche und politische Debatten hinterfragt und korrigiert worden. Insbesondere neue Forschungsergebnisse differenzieren das Bild des Kriegs und der unmittelbaren Nachkriegszeit. So wurden in den 1990erJahren transnationale Forschungsprojekte zur wissenschaftlichen Aufarbeitung schwieriger bilateraler Ereignisse der Kriegsjahre initiiert. Zu diesen gehörten Projekte zur Erforschung der Aussiedlung und Vertreibung der Deutschen bei Kriegsende sowie des polnisch-ukrainischen Konflikts der Jahre 1943/44. ${ }^{2}$ Seit Anfang der 2000er-Jahre erlebt gerade die polnische Forschung zum Thema der polnisch-jüdischen Beziehungen während der Besatzungen einen Aufschwung. ${ }^{3}$

Für die Untersuchung der Folgen dieser Erweiterung und Infragestellung tradierter Geschichts- und damit verbundener Selbstbilder werden in der vor-

1 Krzemiński, Adam: Polen. In: Knigge, Volkhard/Frei, Norbert (Hg.): Verbrechen erinnern. Die Auseinandersetzung mit Holocaust und Völkermord. Bonn 2005, 282-291, hier 282.

2 Vgl. die Publikationen, die die Ergebnisse dieser Forschungsvorhaben zusammenfassen: Borodziej, Włodzimierz/Hajnicz, Artur (Hg.): Kompleks Wypędzenia [Der Komplex der Vertreibung]. Kraków 1998; Polska - Ukraina: trudna odpowiedź [Polen - Ukraine: eine schwierige Antwort]. Hg.v. Naczelna Dyrekcja Archiwów Państwowych und Ośrodek Karta. Warszawa 2003.

3 Auslöser hierfür war die bislang größte gesellschaftliche und wissenschaftliche Debatte zum Thema polnischer Täterschaft während des Kriegs, die durch Jan Tomasz Gross' Buch »Nachbarn« im Jahr 2000 angestoßen wurde. Gross, Jan Tomasz: Sąsiedzi. Historia zagłady żydowskiego miasteczka [Nachbarn. Die Geschichte der Vernichtung eines jüdischen Städtchens]. Sejny 2000. Näher wird auf die Debatten um das polnisch-jüdische Verhältnis der Jahre 1939 bis 1945 in Teil 2 eingegangen. 
liegenden Studie historische Museen als Medien der öffentlichen Repräsentation von Deutungen nationaler, staatlicher und regionaler Vergangenheiten analysiert. Hierbei sollen weniger die Institutionen in ihrer Gesamtheit betrachtet werden, als vielmehr die Geschichtsentwürfe, die sie in ihren Dauerausstellungen einer breiten Öffentlichkeit präsentieren. Das Medium der musealen (Dauer-)Ausstellung ist dabei vor dem Hintergrund seines aktuellen Erfolgs von besonderem Interesse: Seit 2004 findet in Polen ein veritabler Museumsboom statt. Im Bereich historischer Museen - dasselbe trifft auch auf Kunstmuseen $\mathrm{zu}$ - wurden und werden zahlreiche neue Institutionen geschaffen, neue Gebäude für Sammlungen und Präsentationen errichtet oder historische Bauten adaptiert; bestehende Häuser werden umfassend saniert und Dauerausstellungen neu konzipiert; auch das museumspädagogische Angebot der Häuser wird grundlegend überarbeitet. Diese Entwicklung ist derart markant, dass vereinzelt bereits die Frage danach gestellt wird, ob von einer "musealen Überproduktion" gesprochen werden muss. ${ }^{4}$ Die Bedeutung, die gerade historische Ausstellungen und Museen in den letzten Jahren in der polnischen Kulturpolitik und Öffentlichkeit gewonnen haben, zeigt sich nicht zuletzt in den scharfen Debatten, die sich immer wieder an einzelnen nationalen, aber auch ausländischen Projekten entzünden. Exemplarisch sei hier auf die breite Kritik verwiesen, die das deutsche Projekt eines "Zentrums gegen Vertreibungen« in Polen hervorgerufen hat. ${ }^{5}$ Die Idee für das "Museum des Zweiten Weltkriegs" (Muzeum II Wojny Światowej), dessen Dauerausstellung im März 2017 in Gdańsk (Danzig) eröffnet wurde, ist zu einem wesentlichen Teil in Reaktion darauf entwickelt worden. Das Museumskonzept wiederum hat von Beginn an erbitterte Kritik aufseiten der polnischen Rechten hervorgerufen und wird als geschichtspolitischer Gegenentwurf zu solch publikumswirksamen Projekten wie dem »Museum des Warschauer Aufstands« (Muzeum Powstania Warszawskiego) gesehen. ${ }^{6}$ Nach

4 So der Titel eines Beitrags zum polnischen Museumsboom: Jagodzińska, Katarzyna: Muzealna nadprodukcja? [Museale Überproduktion?]. In: Muzealnictwo 52 (2011), 215-225. Diese und alle folgende Übersetzungen aus dem Polnischen stammen, falls nicht anders angegeben, von der Verfasserin.

5 Die Debatten schildern ausführlich: Mazur, Zbigniew: Centrum przeciwko Wypędzeniom. (1999-2005) [Das Zentrum gegen Vertreibungen. (1999-2005)]. Poznań 2006; Łada, Agnieszka: Debata publiczna na temat powstania Centrum przeciw Wypędzeniom w prasie polskiej i niemieckiej [Die öffentliche Diskussion über die Entstehung des Zentrums gegen Vertreibungen in der polnischen und deutschen Presse]. Wrocław 2006; Mazur, Zbigniew: Widoczny Znak (2005-2009) [Das Sichtbare Zeichen (2005-2009)]. Poznań 2009; Hajduk, Jadwiga: Die publizistische Kontroverse um das "Zentrum gegen Vertreibungen«. Der Opfer-Täter-Diskurs in der deutschen und polnischen Presse (1999-2006). Łódź 2010.

6 Die wesentlichen Kritikpunkte schildert der Gründungsdirektor des Museums: Machcewicz, Paweł: »Museum statt Stacheldrahtverhaue«. Das Museum des Zweiten Weltkriegs 
dem Regierungswechsel Mitte November 2015, der die nationalkonservative Partei »Recht und Gerechtigkeit« (Prawo i Sprawiedliwość, PiS) an die Macht brachte, tobte ein erbitterter Kampf um das Museum. Der neue Minister für Kultur und Nationales Erbe Piotr Gliński konnte schließlich im April 2017 nach zweijährigen Bemühungen - die Führung des Museums austauschen mit dem Ziel, die bereits dem Publikum zugängliche Schau zu verändern. ${ }^{7}$

Geschichtsmuseen und deren Dauerausstellungen sind somit zu zentralen Medien avanciert, in denen die Interpretation der polnischen Vergangenheit verhandelt wird. Thematisch kreisen diese Debatten in erster Linie um die jüngste Geschichte - die Jahre des Zweiten Weltkriegs und der Volksrepublik Polen. Anhand der Analyse der inhaltlichen, symbolischen und ästhetischen Ausgestaltung musealer Narrationen des Zweiten Weltkriegs, die seit den 1980er-Jahren in fünf Großstädten des Landes (Warschau, Krakau, Lublin, Łódź und Wrocław) zu besichtigen waren und sind, wird in der vorliegenden Arbeit die Entwicklung polnischer Geschichtsbilder zu diesem zentralen Zeitraum nachvollzogen.

\section{Museale Ausstellungen als Medien der Erinnerungskultur}

Museen und ihre Ausstellungen werden hier als Medien betrachtet, mittels derer sich erinnerungskulturelle Entwicklungen auf öffentlich wirksamer Ebene analysieren lassen. Der Begriff "Erinnerungskultur« wird dabei Christoph Cornelißen folgend als "formale[r] Oberbegriff für alle denkbaren Formen der bewussten Erinnerung an historische Ereignisse, Persönlichkeiten und Prozesse [...], seien sie ästhetischer, politischer oder kognitiver Natur", verstanden. ${ }^{8}$ Wie Cornelißen feststellt, ist der Begriff in dieser Definition weitgehend übereinstimmend mit dem von Jörn Rüsen geprägten Konzept der »Geschichtskultur «. ${ }^{9}$ In Abgrenzung zu diesem hebt der Terminus »Erinnerungskultur« jedoch »stärker [...] auf das Moment des funktionalen Gebrauchs der Vergangenheit für gegenwärtige Zwecke, für die Formierung

in Danzig. In: Borodziej, Włodzimierz/Puttkamer, Joachim von (Hg.): Europa und sein Osten. Geschichtskulturelle Herausforderungen. München 2012, 81-103, hier 91-102.

7 Die Dauerausstellung in ihrer originalen Fassung vom März 2017 sowie der aktuelle Streit um diese werden näher im Kapitel 2 des Ausblicks betrachtet.

8 Cornelißen, Christoph: Was heißt Erinnerungskultur? Begriff - Methoden - Perspektiven. In: Geschichte in Wissenschaft und Unterricht 54 (2003), 548-563, hier 555.

9 Rüsen, Jörn: Was ist Geschichtskultur? Überlegungen zu einer neuen Art, über Geschichte nachzudenken. In: Ders. / Füßmann, Klaus/Grütter, Theo (Hg.): Historische Faszination. Geschichtskultur heute. Weimar 1994, 3-26. 
einer historisch begründeten Identität $\mathrm{ab} . \aleph^{10}$ Ebenso in Abgrenzung zu dem von Jan und Aleida Assmann geprägten Begriff des »kulturellen Gedächtnisses", der auf die Langfristigkeit von Erinnerungen und Vorstellungen fokussiert, ${ }^{11}$ werden in dieser Arbeit in Anlehnung an Katrin Pieper Erinnerungskulturen als dynamische Prozesse und Praktiken betrachtet, die ständigen Aushandlungsprozessen und Wandlungen unterworfen sowie von Heterogenität geprägt sind. Auch die Bezugsgruppen von Erinnerungskulturen sind divers. So können sie nationale oder transnationale Gemeinschaften ebenso wie regionale und lokale Gruppen avisieren. ${ }^{12}$ Ein weiteres zentrales Merkmal von Erinnerungskulturen ist ihre identitätsstiftende Wirkung:

Erinnerungskulturelle Diskurse haben stets eine identitätsstiftende Relevanz, sei es als Zustimmung, Ablehnung, Integration oder Ausgrenzung. Insofern umfasst Erinnerungskultur weniger einen Gegenstand, als vielmehr ein Verhältnis. Die erinnerungskulturellen Akteure verhandeln, konstruieren, negieren, fundieren Identitäten, sie positionieren sich selbst und andere. ${ }^{13}$

Für die Untersuchung solcher identitätsstiftender, pluraler und wandelbarer erinnerungskultureller Entwicklungsprozesse werden in der vorliegenden Studie historische Museen betrachtet. Die Untersuchung bezieht dabei nicht das gesamte Spektrum musealer Tätigkeit ein, ${ }^{14}$ sondern konzentriert sich auf das Element, das die größte Öffentlichkeitswirksamkeit entfaltet - die Ausstellung. Denn Schauen bilden denjenigen Teil musealer Arbeit, der sich direkt an ein breites Publikum richtet und von diesem vornehmlich rezipiert wird. ${ }^{15}$ Im Fokus der Analysen stehen dabei die Dauerausstellungen histori-

10 Cornelißen: Was heißt Erinnerungskultur, 555.

11 Assmann, Jan: Das kulturelle Gedächtnis. Schrift, Erinnerung und politische Identität in frühen Hochkulturen. München 1992; Assmann, Aleida/Assmann, Jan: Das Gestern im Heute. Medien und soziales Gedächtnis. In: Merten, Klaus/Schmidt, Siegfried J./Weischenberg, Siegfried (Hg.): Die Wirklichkeit der Medien. Eine Einführung in die Kommunikationswissenschaft. Opladen 1994, 114-140, hier 119-121.

12 Pieper, Katrin: Resonanzräume. Das Museum im Forschungsfeld Erinnerungskultur. In: Baur, Joachim (Hg.): Museumsanalyse. Methoden und Konturen eines neuen Forschungsfeldes. Bielefeld 2010, 187-212, hier $196 \mathrm{f}$.

13 Ebd., 198.

14 Entsprechend der Definition des International Council of Museums (ICOM) umfassen die Aufgaben von Museen das Sammeln, Bewahren, Erforschen, Vermitteln und Ausstellen von materiellen und immateriellen Zeugnissen. International Council of Museums: ICOM Statues. Vienna 2007, 2.

15 Vgl. Grütter, Heinrich Theodor: Zur Theorie historischer Museen und Ausstellungen. In: Blanke, Horst Walter/Jaeger, Friedrich/Sandkühler, Thomas (Hg.): Dimensionen der Historik. Geschichtstheorie, Wissenschaftsgeschichte und Geschichtskultur heute. Jörn Rüsen zum 60. Geburtstag. Köln u.a. 1998, 179-193, hier 190; Beier-De Haan, Rosmarie: Erinnerte Geschichte - Inszenierte Geschichte. Ausstellungen und Museen in der Zweiten Moderne. Frankfurt am Main 2005, 236. 
scher Museen, die ein Gesamtbild der Jahre 1939 bis 1944/45 zeichnen. Im Unterschied dazu konzentrieren sich Sonder- und Wechselausstellungen, die zudem nur über einen kurzen Zeitraum präsentiert werden, meist auf lediglich ein Ereignis oder Element der Besatzungserfahrungen. Ausstellungen werden dabei als Ausdrucksformen und zugleich Bestandteile erinnerungskultureller Wandlungsprozesse begriffen. Denn obgleich Dauerausstellungen von Museen verhältnismäßig lange bestehen - durchschnittlich bestehen sie etwa zehn bis fünfzehn Jahre - so sind sie doch niemals statisch. Immer wieder werden Teile überarbeitet oder ergänzt; Exponate werden ausgetauscht. ${ }^{16}$ Im Rahmen von Neuentwürfen von ständigen Präsentationen können schließlich neue Perspektiven auf vergangene Ereignisse entworfen und einer breiten Öffentlichkeit gezeigt werden.

Ausstellungen sind somit als Medien von Interesse, die gegenwärtige Geschichtsbilder und damit verbundene Identitätsentwürfe repräsentieren, sie gleichzeitig aber auch prägen und verändern. Zunächst entstehen museale Präsentationen in spezifischen erinnerungskulturellen und geschichtspolitischen Kontexten. So werden museale Konzepte unter Berücksichtigung eines jeweils spezifischen Erkenntnis- und Vermittlungsinteresses, des Forschungsstandes sowie gesellschaftlicher und politischer Diskussionen der Gegenwart ihres Entstehungszeitraums entwickelt. Sie geben somit einen Einblick in den jeweiligen Stand erinnerungskultureller Debatten einer Gemeinschaft. Unter den Bedingungen von staatlicher Überwachung durch Zensursysteme, wie etwa in den staatssozialistischen Ländern bis 1989, müssen Ausstellungsmacher sich zudem an den Leitlinien und Grenzen der offiziellen Geschichtspolitik orientieren. Dies bedeutet jedoch nicht, dass solche Vorgaben zwingend zu streng einheitlichen Repräsentationen führen. Auch unter der Kontrolle staatlicher Instanzen nutzten etwa in der VRP museale Akteure durchaus Spielräume, um Themen und Deutungen, die im offiziellen Diskurs tabuisiert waren, unterschwellig in die Schauen einzubringen, oder aber andere Elemente des offiziellen Geschichtsbildes, die als verfälschend angesehen wurden, zu vermeiden. Wie in den folgenden Analysen gezeigt werden wird, sind die Leerstellen musealer Erzählung ebenso bedeutsam wie ihre Schwerpunkte. Wiederum konnte bereits durch ein einzelnes Objekt in einer überfüllten Vitrine für aufmerksame Besucher ein tabuisiertes Thema in einer Ausstellung angesprochen werden. ${ }^{17}$ In diesem Sinne sind Ausstellungen Indikatoren der Verfasstheit zeitgenössischer Erinnerungskulturen. ${ }^{18}$

Andererseits entwerfen Museen in ihren Schauen selbst historische Narrative. Im Rahmen von Neuinterpretationen von Objekten und historischen $\mathrm{Zu}$ -

16 Pieper: Resonanzräume, 202.

17 Siehe Teil 3, Kapitel 2.1.

18 Vgl. Pieper: Resonanzräume, $200 \mathrm{f}$. 
sammenhängen, die sich in Anpassungen und Neukonzeptionen von Dauerausstellungen manifestieren, werden die präsentierten Geschichtsentwürfe immer wieder in den Rahmen gegenwärtiger Bezüge rekontextualisiert und damit aktualisiert. ${ }^{19}$ Dabei können etablierte Identitätsentwürfe beibehalten, aber auch neue Interpretationen eingeführt und Umwertungen bislang etablierter Geschichtsdeutungen vorgenommen werden. "Neu« bedeutet in diesem Zusammenhang nicht zwangsläufig, dass museale Ausstellungen ausschließlich eigene Forschungsergebnisse der Museumsmitarbeiter präsentieren. Vielmehr übersetzen Ausstellungsmacher wissenschaftliche Erkenntnisse in Formen und Arrangements, die ein breites Publikum erreichen sollen. Sie nehmen hierdurch eine wichtige Mittlerfunktion zwischen Wissenschaft und Öffentlichkeit ein. ${ }^{20}$ Die von den Ausstellungsmachern geschaffenen »musealen Erzählungen ${ }^{21}$ entfalten dabei eine eigene Wirkung auf das Publikum und tragen zur Prägung historischer Wahrnehmungen und damit verbundener Vorstellungen von Gemeinschaft und Identität bei. ${ }^{22}$

Wie Sharon Macdonald gezeigt hat, kam dem öffentlichen Museum seit seiner Entstehung im späten 18. Jahrhundert eine bedeutende Rolle bei der

19 Korff, Gottfried: Bildwelt Ausstellung. Die Darstellung von Geschichte im Museum. In: Borsdorf, Ulrich/Grütter, Heinrich Theodor (Hg.): Orte der Erinnerung. Denkmal, Gedenkstätte, Museum. Frankfurt am Main u.a. 1999, 319-335, hier 328; Grütter: Zur Theorie historischer Museen, 190-192.

20 Macdonald, Sharon: Theorizing Museums: An Introduction. In: Dies./Fyfe, Gordon (Hg.): Theorizing Museums. Representing Identity and Diversity in a Changing World. Cambridge, MA 1996, 1-18, hier 4.

21 Der in der Arbeit verwendete Begriff der »musealen Erzählung« orientiert sich an dem Terminus storyline, den Charlotte Martinz-Turek und Monika Sommer-Sieghart für die Beschreibung musealer Ausstellungen adaptiert haben: "Storyline bezeichnet im engerem Sinne eine Handlung, einen vorgestellten Ereignisverlauf mit definiertem Anfang und Ende. Auf das Museum übertragen bedeutete dies, die Aufmerksamkeit wegzulenken vom solitären Blick auf das einzelne Kunstwerk oder das spezifische kulturelle Objekt hin zu den Makro- und Mikronarrationen einer Ausstellung und ihrer Ensembles, die aus dem Zusammenspiel von Artefakten, Ausstellungsmöbeln, Licht, Ton, elektronischen Medien und Texten in unterschiedlichen Hierarchien entstehen." MartinzTurek, Charlotte/Sommer-Sieghart, Monika: Vorwort. In: Dies. (Hg.): Storyline. Narrationen im Museum. Wien 2009, 7-14, hier 7. Wie Martinz-Turek weiter fomuliert: »Storyline bedeutet zunächst grundsätzlich die Erzählung einer Ausstellung; der rote Faden demzufolge Objekte arrangiert, einander gegenübergestellt und mit Texten oder Medien kombiniert werden. Jede Ausstellung kann auf ihre Storylines hin befragt und analysiert werden; auf Erzählungen, die bewusst konzipiert wurden, ebenso wie auf diejenigen, die jenseits jeglicher Intention scheinbar feststehende gesellschaftliche Werte tradieren.« Martinz-Turek, Charlotte: Folgenreiche Unterscheidungen. Über Storylines im Museum. In: Dies./Sommer-Sieghart, Monika (Hg.): Storyline. Narrationen im Museum. Wien 2009, 15-29, hier 15. Die Termini »Erzählung«, »Narrativ« und »Narration« werden dabei synonym verwendet und verweisen in ihrem Gebrauch im Plural auf die mögliche Vielfalt von Erzählsträngen innerhalb einer Schau.

22 Pieper: Resonanzräume, 201. 
Etablierung insbesondere nationaler Identitäten zu. In jüngster Zeit wiederum werden Museen zunehmend zu Orten der Präsentation neuer Identitätskonstrukte, abseits etablierter nationaler Topoi. ${ }^{23}$ Diese bedeutende Funktion von Museen für nationale, aber auch darüber hinausgehende, plurale Identitätsbildungsprozesse wurde immer wieder von Forschern betont. ${ }^{24}$ Gottfried Korff hat hierfür den Begriff vom Museum als »Generator» von Geschichtsbildern geprägt. ${ }^{25}$ In ihrer Doppelfunktion als Indikatoren und Generatoren erinnerungskultureller Prozesse können Museen somit auch als »Resonanzräume« (Katrin Pieper) von öffentlichen Debatten und damit verbundenen Selbstverständigungsprozessen über Deutungen der Vergangenheit und darauf basierender Identitätskonzepte betrachtet werden. ${ }^{26}$

Der Konstruktcharakter der musealen »inszenierten Bedeutungssysteme ${ }^{27}$ wird vom Publikum meist nicht wahrgenommen. ${ }^{28}$ Besucher attestieren historischen Ausstellungen im Gegenteil - gerade wenn sie im Rahmen traditionsreicher Kulturinstitutionen wie Museen gezeigt werden - eine große Autorität in Bezug auf den »Wahrheitsgehalt» der in ihnen präsentieren Ereignisse. ${ }^{29}$ So suggerieren insbesondere Dauerausstellungen historischer $\mathrm{Mu}$ seen entgegen der starken Gegenwartsbezogenheit ihres Entstehungskontextes eine Beständigkeit, die das in ihrem Rahmen präsentierte Narrativ zusätzlich bestätigt. Dies ist zum einen auf die im Vergleich zu Sonder- und Wechselausstellungen relativ lange Präsentationszeit einer solchen Ausstellung zurückzuführen, zum anderen auf die Aura des »Museumstempels ${ }^{30}$

23 Macdonald, Sharon: Nationale, postnationale, transkulturelle Identitäten und das $\mathrm{Mu}-$ seum. In: Beier, Rosmarie (Hg.): Geschichtskultur in der zweiten Moderne. Frankfurt am Main, New York 2000, 123-148.

24 So etwa von Benedict Anderson für die Etablierung der »imaginierten politischen Gemeinschaften«, wie er Nationen bezeichnet. Anderson, Benedict: Imagined Communities. Reflections on the Origin and Spread of Nationalism. London, New York 2006 (Erstauflage 1983), 5 f., 178-185; Beier-De Haan: Erinnerte Geschichte. 53-110, 240.

25 Korff, Gottfried: Speicher und / oder Generator. Zum Verhältnis von Deponieren und Exponieren im Museum. In: Ders: Museumsdinge. Deponieren - Exponieren. 2. Aufl. Köln u. a. 2007, 167-178, hier 174 .

26 Pieper: Resonanzräume, 200, $203 \mathrm{f}$.

27 Korff, Gottfried: Vom Verlangen, Bedeutungen zu sehen. In: Borsdorf, Ulrich/Grütter, Heinrich Theodor/Rüsen, Jörn (Hg.): Die Aneignung der Vergangenheit. Musealisierung und Geschichte. Bielefeld 2004, 81-103, hier 82.

28 Teile der folgenden Ausführungen wurden bereits publiziert in Heinemann, Monika: Emotionalisierungsstrategien in historischen Ausstellungen am Beispiel ausgewählter Warschauer Museen. In: Dies. u.a. (Hg.): Medien zwischen Fiction-Making und Realitätsanspruch - Konstruktionen historischer Erinnerungen. München 2011, 213-236.

29 Kaplan, Flora E. S.: Exhibitions as Communicative Media. In: Hooper-Greenhill, Eilean (Hg.): Museum, Media, Message. London u. a. 1995, 37-58, hier 41.

30 Franzke, Jürgen: Sakral oder schockierend - Die Darstellung historischer Wirklichkeit im Museum.In:Rüsen, Jörn / Ernst, Wolfgang/Grütter, Heinrich Theodor (Hg.): Geschichte sehen. Beiträge zur Ästhetik historischer Museen. Pfaffenweiler 1988, 69-81, hier 79. 
die den präsentierten Ereignissen und Deutungen eine besondere Glaubhaftigkeit verleiht. In der Öffentlichkeit werden Museen daher weitgehend als Orte eines konsensualen, gewissermaßen institutionell sanktionierten Vergangenheitsentwurfs wahrgenommen, wodurch sie über kanonbildendes Potenzial verfügen. Wie Charlotte Martinz-Turek und Monika Sommer-Sieghart pointiert feststellen: »Trotz der zunehmenden (Selbst-)Kritik der Museen sind sie immer noch Orte, an denen Definitionen präsentiert und Ordnungen geschaffen werden. ${ }^{31}$ Die in Ausstellungen vermittelten Inhalte und Deutungen machen somit mit Nora Sternfeld gesprochen das qualifizierte Wissen aus, auf dem die Identitätskonstruktionen einer Gemeinschaft basieren, an die einzelne Schauen adressiert sind. ${ }^{32}$ Dass die in den Präsentationen entworfenen Narrative jeweils eigene Sinnzuschreibungen ihrer Autoren transportieren, ist den Betrachtern meist nicht bewusst, denn die Autorenschaft der Darstellung wird in Ausstellungen selbst kaum thematisiert. ${ }^{33}$

Ausstellungen kommunizieren dabei auf vielfältigen Ebenen: Sie vermitteln Informationen und Deutungen nicht nur über Ausstellungstexte, das Arrangement präsentierter Objekte und Bilder, sondern arbeiten heutzutage vermehrt mit dem Einsatz von Geräusch- und Lichtkulissen sowie szenografischer und inszenatorischer Interventionen. ${ }^{34}$ Auch die Architektur von $\mathrm{Mu}$ seums- und Ausstellungsräumlichkeiten hat entscheidende Wirkung auf die Betrachter. ${ }^{35}$ Zunehmend prägt daneben der Einsatz von digitalen Medien, beispielsweise von Computerstationen oder Filmvorführungen, die Vermittlung historischer Inhalte. Der Museumsbesuch stellt für die Rezipienten somit eine den gesamten Raum erfassende sinnliche Erfahrung dar; die auf den Besucher gerichtete Kommunikation ist vielschichtig und multimedial. Die

31 Martinz-Turek/Sommer-Sieghart: Vorwort, 8.

32 Sternfeld, Nora: Aufstand der unterworfenen Wissensarten - museale Gegenerzählungen. In: Martinz-Turek, Charlotte/Sommer-Sieghart, Monika (Hg.): Storyline. Narrationen im Museum. Wien 2009, 30-56, hier 30.

33 Martinz-Turek: Folgenreiche Unterscheidungen, 26. Dies hat Monika Flacke auch in Bezug auf den Gebrauch von Bildern in historischen Ausstellungen dargelegt. Vgl. Flacke, Monika: Geschichtsausstellungen. Zum `Elend der Illustration«. In: Helas, Philine u.a. (Hg.): Bild / Geschichte. Festschrift für Horst Bredekamp. Berlin 2007, 481-490, hier 487.

$34 \mathrm{Zu}$ Szenografie als Kommunikationselement in kulturhistorischen Ausstellungen, d.h. dem »konkrete[n] Entwerfen und Gestalten von Räumen als `Übersetzungen` der intendierten Inhalte«, vgl. Scholze, Jana: Medium Ausstellung. Lektüren musealer Gestaltung in Oxford, Leipzig, Amsterdam und Berlin. Bielefeld 2004, 225-228, hier 226. Unter »Inszenierung " werden dagegen Bemühungen der (Re-)Konstruktion historischer Kontexte subsumiert. Vgl. zu diesem Begriff ebd., 201 f.; Kaiser, Brigitte: Inszenierung und Erlebnis in kulturhistorischen Ausstellungen. Museale Kommunikation in kunstpädagogischer Perspektive. Bielefeld 2006, v. a. 21-50.

35 Paul, Stefan: Kommunizierende Räume. Das Museum. In: Geppert, Alexander C.T./ Jensen, Uffa / Weinhold, Jörn (Hg.): Ortsgespräche. Raum und Kommunikation im 19. und 20. Jahrhundert. Bielefeld 2005, 341-357, hier 349. 
Wirkung der visuellen, akustischen und symbolischen Kommunikation ist dabei nicht allein kognitiver Natur, sondern spricht oft kulturelle Codes an, deren Existenz dem Betrachter nicht zwingend bewusst sein muss, die jedoch die Rezeption der in einer Ausstellung transportierten Deutungen und Sinnzuschreibungen entscheidend beeinflussen. ${ }^{36}$ Gerade implizit vermittelte Interpretationen und Perspektiven zielen auf eine affektive, unterbewusste und daher unreflektierte Wahrnehmungsebene. Die Untersuchung musealer Geschichtserzählungen verlangt daher einen umfassenden Ansatz, der das Zusammenspiel verschiedener Medien berücksichtigt. Nicht allein Sprache bzw. Texte, sondern auch die präsentierten drei- und zweidimensionalen Objekte, Fotografien und andere Bildmedien, ihre gestalterische Komposition und Inszenierung müssen bei der Entschlüsselung der transportierten Deutungen berücksichtigt werden.

Vor diesem Hintergrund untersucht die vorliegende Studie, wie sich die musealen Darstellungen des Zweiten Weltkriegs in Polen seit den 1980er-Jahren inhaltlich, methodisch und ästhetisch entwickelt haben. Ziel ist es, Aufschlüsse zu gewinnen über die Wandlungen und Kontinuitäten polnischer historischer Selbstbilder, wie sie in Museen bzw. konkret deren Dauerausstellungen (re-)präsentiert und generiert werden. Die Aufmerksamkeit liegt sowohl auf Elementen der Ausstellungsnarrative, die bewusst integriert und arrangiert wurden, als auch auf solchen Inhalten und Deutungen, die als "unhinterfragte Vergangenheitsnarrative « konsensuale Perspektiven und Deutungen unbewusst transportieren. ${ }^{37}$ Es interessiert weiter die Frage nach Zäsuren in der musealen Darstellung von Krieg und Besatzung im Verlauf der betrachteten drei Jahrzehnte, das heißt von den 1980er-Jahren bis ins Jahr 2010. Folgen die historischen Ausstellungen nach dem Systemwechsel noch einem master narrative ${ }^{38}$ bzw. konstruieren sie ein solches? Inwieweit stellt das Jahr 1989 tatsächlich eine maßgebliche Zäsur für die öffentliche Geschichtsdarstellung in polnischen Museen dar? Inwiefern werden die Institutionen selbst zu Akteuren der gesellschaftlichen Aushandlungsprozesse über die jüngere Vergangenheit? Gefragt wird in diesem Zusammenhang auch nach eventuellen Hierarchien innerhalb der nationalen Museumslandschaft sowie der Existenz und dem Einfluss von Institutionen mit Vorbildcharakter. Sind regionale Ausdifferenzierungen und Tendenzen der Pluralisierung von

36 Kaplan: Exhibitions as Communicative Media, 37.

37 Martinz-Turek: Folgenreiche Unterscheidungen, 17.

38 Der Begriff »Meistererzählung« wird hier als »die in einer kulturellen Gemeinschaft zu einer gegebenen Zeit dominante Erzählweise des Vergangenen verstanden«. Zum Begriff der »Meistererzählung« siehe Jarausch, Konrad H. / Sabrow, Martin: »Meistererzählung« - Zur Karriere eines Begriffs. In: Dies. (Hg.): Die historische Meistererzählung. Deutungslinien der deutschen Nationalgeschichte nach 1945. Göttingen 2002, 9-32, hier 17. 
Erzählungen und damit verbundenen Gemeinschaftsvorstellungen zu konstatieren? Das Untersuchungsinteresse richtet sich dabei ebenso auf die Frage, in welchem Ausmaß die betrachteten musealen Präsentationen neue wissenschaftliche Erkenntnisse sowie gesellschaftliche und politische Debatten in ihren Neukonzeptionen reflektieren und abbilden. Insofern werden die untersuchten Museen dahingehend befragt, ob sie eher progressive oder konservative Institutionen des kollektiven Gedächtnisses sind, ob sie also infragegestellte Geschichtsbilder verändern oder aber versuchen, diese zu bewahren.

\section{Forschungsstand}

In den vergangenen zwei Jahrzehnten ist ein wachsendes wissenschaftliches Interesse an den Formen der Vergegenwärtigung und Medialisierung von Geschichte zu verzeichnen. Im Zuge dieses memory boom rücken auch Museen und historische Ausstellungen als Forschungsgegenstände zunehmend in den Blick. Auf die zentrale Bedeutung von Museen für die Vermittlung und Verfestigung nationaler Meistererzählungen wurde bereits verhältnismäßig früh hingewiesen. ${ }^{39}$ Jedoch rückten erst seit Ende der 1990er-Jahre im Zuge des cultural turn in den Geschichtswissenschaften historische Museen als Orte, an denen sich die Inszenierung von Geschichte als identitätsstiftende Erzählung exemplarisch untersuchen lassen, verstärkt in den Fokus wissenschaftlichen Interesses.

Erste Studien im deutschsprachigen Raum befassten sich mit den politischideologischen Funktionen von Ausstellungen in den europäischen Diktaturen der 1930er- und 1940er-Jahre ${ }^{40}$ sowie mit der Inszenierung und Instrumentalisierung der eigenen Vergangenheit in Geschichtsmuseen und Gedenkstätten der DDR und der BRD. ${ }^{41}$ Der thematische Schwerpunkt der Forschungen lag in den vergangenen Jahren auf der Musealisierung des Holocaus $\mathrm{t}^{42}$ sowie

39 Anderson: Imagined Communities, 178-185.

40 Kivelitz, Christoph: Die Propagandaausstellung in europäischen Diktaturen. Konfrontation und Vergleich: Nationalsozialismus in Deutschland, Faschismus in Italien und die UdSSR der Stalinzeit. Bochum 1999.

41 Ebenfeld, Stefan: Geschichte nach Plan? Die Instrumentalisierung der Geschichtswissenschaft in der DDR am Beispiel des Museums für Deutsche Geschichte in Berlin (1950 bis 1955). Marburg 2001; Faulenbach, Bernd/Jelich, Franz-Joseph (Hg.): »Asymmetrisch verflochtene Parallelgeschichte?« Die Geschichte der Bundesrepublik und der DDR in Ausstellungen, Museen und Gedenkstätten. Essen 2005.

42 Offe, Sabine: Ausstellungen, Einstellungen, Entstellungen. Jüdische Museen in Deutschland und Österreich. Berlin u. a. 2000; Engelhardt, Isabelle: A Topography of Memory. Representations of the Holocaust at Dachau and Buchenwald in Comparison with Auschwitz, Yad Vashem and Washington, DC. Bruxelles u. a. 2002; Haß, Matthias: Ge- 
Kriegsdarstellungen, insbesondere des Ersten und Zweiten Weltkriegs. ${ }^{43}$ Gerade in Bezug auf museale Präsentationen des Zweiten Weltkriegs hält das Forschungsinteresse gegenwärtig an, wie die Vielzahl jüngster Dissertationsprojekte und Abschlussarbeiten zeigt - wobei allmählich auch Institutionen und Erinnerungskulturen im östlichen Europa betrachtet werden. ${ }^{44}$ Ein weiteres Feld jüngster Forschungen ist die Entstehung musealer Großprojekte, die die Etablierung eines kanonisierten Entwurfs nationaler oder staatlicher Geschichtsbilder zum Ziel haben, sowie die damit einhergehenden öffent-

staltetes Gedenken. Yad Vashem, das US-Holocaust-Memorial-Museum und die Stiftung Topographie des Terrors. Frankfurt am Main, New York 2002; Pieper, Katrin: Die Musealisierung des Holocaust. Das Jüdische Museum Berlin und das U.S. Holocaust Memorial Museum in Washington D. C. Ein Vergleich. Köln u. a. 2006; Holtschneider, K. Hannah: The Holocaust and Representation of Jews. History and Identity in the Museum. London, New York 2011; Köhr, Katja: Die vielen Gesichter des Holocaust. Museale Repräsentationen zwischen Individualisierung, Universalisierung und Nationalisierung. Göttingen 2012; Schoder, Angelika: Die Vermittlung des Unbegreiflichen. Darstellungen des Holocaust im Museum. Frankfurt am Main, New York 2014.

43 Beil, Christine: Der ausgestellte Krieg. Präsentationen des Ersten Weltkriegs 1914-1939. Tübingen 2004; Thiemeyer, Thomas: Fortsetzung des Krieges mit anderen Mitteln. Die beiden Weltkriege im Museum. Paderborn u. a. 2010.

44 Die Dissertation von Ekaterina Makhotina thematisiert u. a. die Musealisierung des Holocaust in Litauen. Makhotina, Ekaterina: Erinnerungen an den Krieg - Krieg der Erinnerungen. Litauen und der Zweite Weltkrieg. Göttingen 2017. In München befasst sich Ekaterina Keding mit der Musealisierung des Zweiten Weltkriegs in Belarus. Keding, Ekaterina: Sieghafter Durchbruch oder vernichtende Niederlage? Deutsche Besatzung, sowjetischer Partisanenwiderstand und Kollaboration in Museen des Vitebsker Gebiets. In: Makhotina, Ekaterina u.a. (Hg.): Krieg im Museum. Präsentationen des Zweiten Weltkriegs in Museen und Gedenkstätten des östlichen Europa. Göttingen 2015, 29-59. Auch die Forschungen des Historikers Christian Ganzer befassen sich mit der Präsentation des »Großen Vaterländischen Kriegs« in belarussischen Museen, mit einem Schwerpunkt auf der Musealisierung des Kampfes um die Brester Festung. Ganzer, Christian: Musealisierung des Kriegsbeginns. Geschichtsbilder in der Dauerausstellung des »Museums der Verteidigung der Brester Festung«. In: Makhotina, Ekaterina u.a. (Hg.): Krieg im Museum. Präsentationen des Zweiten Weltkriegs in Museen und Gedenkstätten des östichen Europa. Göttingen 2015, 83-109. Am Europäischen Kolleg Jena arbeitet Nataša Jagdhuhn gegenwärtig an einer Dissertation zum Thema »Auf dem Wege zu einer performativen Museologie im (post-)jugoslawischen Raum. Eine komparative kulturgeschichtliche Analyse der Darstellungen des Zweiten Weltkrieges in Gedenkmuseen« (Arbeitstitel). Siehe URL: http://www.europaeisches-kolleg.uni-jena.de/personen/doktoranden/ (am 31.5.2017). Der Militärhistoriker Marc Hansen hat in seiner (noch unpublizierten) Dissertation die Darstellung des deutschen Militärs in zentralen Militärmuseen ehemaliger Siegermächte des Zweiten Weltkriegs untersucht. Siehe exemplarisch: Hansen, Marc: Die Toten der Schlacht im Großen Krieg und das Museum - Eine vergleichende Analyse der Darstellungspraxis deutscher und britischer Militärmuseen. In: Clauss, Martin (Hg.): Sterben im Krieg von der Antike bis zur Gegenwart. Paderborn 2017 (i.E.). Siehe auch Blume, Rebekka: Das lettische Okkupationsmuseum. Das Geschichtsbild des Museums im Kontext der Diskussionen über die Okkupationszeit in der lettischen Öffentlichkeit. In: Arbeitspapiere und Materialien der Forschungsstelle Osteuropa Bremen 83 (Juli 2007). 
lichen Debatten. ${ }^{45}$ Daneben werden in den letzten Jahren auch neue kulturwissenschaftliche Fragestellungen untersucht, wie die museale Darstellung von Migration ${ }^{46}$, Gender und Race ${ }^{47}$ oder den Identitätskonzepten von Minderheiten ${ }^{48}$. Museen und Ausstellungen als Medien gesellschaftlicher Erinnerungen und Objekte öffentlicher Debatten treten zunehmend auch auf Konferenzen und in den daraus hervorgehenden Sammelbänden in den Fokus, die sich thematisch übergreifend und transnational vergleichend mit Erinnerungskulturen und Geschichtspolitiken der jüngsten Vergangenheit befassen. ${ }^{49}$ Der Schwerpunkt dieser neueren Studien liegt auf aktuellen oder noch jungen Museen und Ausstellungen und somit auf Institutionen und Präsentationen, die für die Forscher direkt zugänglich sind. Parallel entwickelt sich auch eine historische Museologie, die sich für die Wandlungen nationaler und staatlicher Erinnerungskulturen sowie Ausstellungspraxen in weiter zurückliegenden Zeitabschnitten interessiert und hierfür nicht mehr existierende Schauen und Institutionen in den Blick nimmt. ${ }^{50}$

45 Seuthe, Rupert: »Geistig-moralische Wende«? Der politische Umgang mit der NS-Vergangenheit in der Ära Kohl am Beispiel von Gedenktagen, Museums- und Denkmalprojekten. Frankfurt am Main u. a. 2001; Leggewie, Claus/Meyer, Erik: »Ein Ort, an den man gerne geht«. Das Holocaust-Mahnmal und die deutsche Geschichtspolitik nach 1989. München, Wien 2005; Völkering, Tim: Flucht und Vertreibung im Museum. Zwei aktuelle Ausstellungen und ihre geschichtskulturellen Hintergründe im Vergleich. Berlin 2008; Ders.: "Flucht und Vertreibung« ausstellen - aber wie? Konzepte für die Dauerausstellung der »Stiftung Flucht, Vertreibung, Versöhnung« in der Diskussion. Bonn 2011; Bussenius, Daniel: Von der Hauptstadtposse zur Erfolgsgeschichte. Die Entstehung des Jüdischen Museums Berlin 1971-2001. Göttingen 2014.

46 Baur, Joachim: Die Musealisierung der Migration. Einwanderungsmuseen und die Inszenierung der multikulturellen Nation. Bielefeld 2009; Schlutow, Martin: Das Migrationsmuseum. Geschichtskulturelle Analyse eines neuen Museumstyps. Berlin u. a. 2012.

47 Muttenthaler, Roswitha/Wonisch, Regina: Gesten des Zeigens. Zur Repräsentation von Gender und Race in Ausstellungen. Bielefeld 2006.

48 Deme, Katalin: Jüdische Museen in Ostmitteleuropa. Kontinuitäten - Brüche - Neuanfänge: Prag, Budapest, Bratislava (1993-2012). Göttingen 2016.

49 Siehe die Sektionen zu musealen Geschichtsdarstellungen in den Bänden: Wahnich, Sophie/ Láśticová, Barbara/ Findor, Andrej (Hg.): Politics of Collective Memory. Cultural Patterns of Commemorative Practices in Post-War Europe. Wien, Berlin 2008; Weber, Matthias u.a. (Hg.): Erinnerungsorte in Ostmitteleuropa. Erfahrungen der Vergangenheit und Perspektiven. München 2011. Dem Projekt eines »Hauses der europäischen Geschichte« ist ein wesentlicher Teil des folgenden Sammelbandes gewidmet: Knigge, Volkhard u. a. (Hg.): Arbeit am europäischen Gedächtnis. Diktaturerfahrung und Demokratieentwicklung. Köln u. a. 2011. Heinemann, Monika u. a. (Hg.): Medien zwischen Fiction-Making und Realitätsanspruch - Konstruktionen historischer Erinnerungen. München 2011; François, Etienne u. a. (Hg.): Geschichtspolitik in Europa seit 1989. Deutschland, Frankreich und Polen im internationalen Vergleich. Göttingen 2013.

50 Beil: Der ausgestellte Krieg; Raffler, Marlies: Museum - Spiegel der Nation? Zugänge zur Historischen Museologie am Beispiel der Genese von Landes- und Nationalmuseen in der Habsburgermonarchie. Wien 2007. 
Museen und Ausstellungen im östlichen Europa werden bislang in der deutschsprachigen Forschung noch überwiegend in einzelnen Aufsätzen in Sammelbänden berücksichtigt. ${ }^{51}$ Die Bände, die vorwiegend die museale Aufarbeitung des Zweiten Weltkriegs und der sozialistischen Staatlichkeit im östlichen Europa behandeln, verbleiben jedoch meist auf einer deskriptiven Ebene. Eine kritisch-analytische Zugangsweise zu Museen und Ausstellungen ist darin in der Minderheit, während die Binnenperspektive von Museumsmitarbeitern vorherrscht. ${ }^{52}$ Weitere Publikationen konzentrieren sich auf die Musealisierung von Regionalgeschichte, wobei gerade die deutsch-polnische Beziehungsgeschichte verstärkte Aufmerksamkeit gewinnt. ${ }^{53}$ Auch eine der jüngeren Ausgaben der Zeitschrift Inter Finitimos ist dem Schwerpunktthema "Museen und Ausstellungen $"^{54}$ in Deutschland und Polen gewidmet. Diese Veröffentlichungen verweisen zum einen auf das deutlich gestiegene wissenschaftliche Interesse an diesen Medien in beiden Ländern in jüngster Zeit. Zugleich offenbaren sich in ihnen dieselben Problematiken wie in vielen breiter angelegten Sammelbänden: Gleichberechtigt nebeneinander präsentiert werden Selbstdarstellungen einzelner Institutionen bzw. ihrer Ausstellungen, die mehr Quellen- als analytischen Charakter besitzen, und wissen-

51 Hinz, Hans-Martin (Hg.): Der Krieg und seine Museen. Frankfurt am Main, New York 1997; Knigge, Volkhard/Mählert, Ulrich (Hg.): Der Kommunismus im Museum. Formen der Auseinandersetzung in Deutschland und Ostmitteleuropa. Köln u.a. 2005; Kurilo, Olga (Hg.): Der Zweite Weltkrieg im Museum: Kontinuität und Wandel. Berlin 2007; Puttkamer, Joachim von/Warneck, Dorothea (Hg.): Exhibiting Violence. Przegląd Historyczny 57 / 1 (2016). Erst jüngst erschienen die ersten monografischen Studien, in denen Museen im östlichen Europa im Zentrum stehen: Deme: Jüdische Museen in Ostmitteleuropa; Makhotina: Erinnerungen an den Krieg.

52 Einen breiteren, analytischen Zugang unternehmen etwa Bogumit, Zuzanna/Wawrzyniak, Joanna: Das Bild des »Deutschen«. Die Darstellung der NS-Besatzung in ausgewählten Warschauer Museen. In: Bingen, Dieter/Loew, Peter Oliver/Popp, Dietmar (Hg.): Visuelle Erinnerungskulturen und Geschichtskonstruktionen in Deutschland und Polen seit 1939. Warszawa 2009, 189-204; Ungváry, Krisztián: Orte der Erinnerung an kommunistische Verbrechen. Das »Haus des Terrors« und der »Zentralfriedhof«. In: Weber u.a. (Hg.): Erinnerungsorte in Ostmitteleuropa, 219-233. Auch der folgende Band enthält analytische Betrachtungen zu allgemeinen Fragestellungen der Musealisierung des Holocaust in KZ-Gedenkstätten: Ganzenmüller, Jörg/Utz, Raphael (Hg.): Orte der Shoah in Polen. Gedenkstätten zwischen Mahnmal und Museum. Köln u.a. 2016.

53 Dyroff, Stefan/Krzoska, Markus (Hg.): Geschichtsbilder und ihre museale Präsentation. Ausgewählte Beiträge zur Geschichte der Deutschen in Polen in Vergangenheit und Gegenwart. München 2008; Herget, Beate/Pleitner, Berit (Hg.): Heimat im Museum? Museale Konzeptionen zu Heimat und Erinnerungskultur in Deutschland und Polen. München 2008.

54 So der Titel des Themenschwerpunkts des Hefts, siehe Inter Finitimos. Jahrbuch zur deutsch-polnischen Beziehungsgeschichte 10 (2012). Hg.v. Peter Fischer, Basil Kerski, Isabel Röskau-Rydel, Krzysztof Ruchniewicz und Sabine Stekel. 
schaftliche Auseinandersetzungen mit ebensolchen Projekten. ${ }^{55}$ Im Falle der letzteren fehlt zudem meist eine methodische Basis der Analysen. Gerade bei den Untersuchungen von Geschichtsausstellungen durch Historiker - die in Deutschland außerhalb der Museologie das stärkste Interesse an diesem Medium zeigen - werden theoretische Ansätze der museologischen und bildwissenschaftlichen Forschung noch wenig berücksichtigt.

Übergreifend lässt sich festhalten, dass sich die Mehrheit der Forscher auf die Entstehungskontexte und Programme einzelner Institutionen sowie die medialen und politischen Debatten um museale Großprojekte konzentriert. Die (Dauer-)Ausstellungen der Museen bleiben zumeist im Hintergrund bzw. werden nur in kurzen Abschnitten kursorisch betrachtet. Eine Analyse der darin vermittelten Perspektiven und Interpretationen sowie deren Vermittlungsweisen bleiben oft oberflächlich, da sich die Betrachtung mehrheitlich auf einen überblicksartigen »Gang durch die Ausstellung « beschränkt. ${ }^{56}$

In Polen dagegen ist die wissenschaftliche Analyse der Formen und Praktiken der musealen Vergegenwärtigung von Erinnerung und Geschichte gerade im Entstehen begriffen. Während in der polnischen Soziologie eine lange Tradition der Beschäftigung mit Erinnerung und kollektiver Identität besteht ${ }^{57}$ und in den letzten Jahren Publikationen zu Fragen von Erinnerungskulturen und Geschichtspolitik eine starke Konjunktur hatten, ${ }^{58}$ ziehen

55 Siehe exemplarisch den programmatischen Text von Paweł Ukielski, dem stellvertretenden Direktor des Museums des Warschauer Aufstands, und den kritisch-analytischen Beitrag von Krisztian Ungváry zum Budapester »Haus des Terrors« (Terror Háza) unmittelbar danach in Weber u.a. (Hg.): Erinnerungsorte in Ostmitteleuropa.

56 Exemplarisch: Pieper: Die Musealisierung des Holocaust.

57 Für einen fundierten Überblick siehe Kończal, Kornelia/Wawrzyniak, Joanna: Polskie badania pamięcioznawcze: tradycje, koncepcje, (nie)ciągłości [Erinnerungsforschung in Polen. Traditionen, Konzepte, (Dis-)Kontinuitäten]. In: Kultura i Społeczeństwo 55/4 (2011), 11-63; deutsche Fassung des Beitrags: Kończal, Kornelia/Wawrzyniak, Joanna: Traditionen, Konzepte, (Dis-)Kontinuitäten. Erinnerungsforschung in Polen. In: Osteuropa 62 / 5 (2012), 19-46.

58 Das größte Projekt in diesem thematischen Rahmen war zugleich ein deutsch-polnisches Kooperationsvorhaben: Hahn, Hans Henning/Traba, Robert (Hg.): Deutsch-Polnische Erinnerungsorte/Polsko-niemieckie miejsca pamięci. 9 Bde. Paderborn und Warszawa 2012-2015. In dieser Reihe sind vier polnischsprachige und fünf deutschsprachige Bände erschienen. Vgl. des Weiteren exemplarisch Traba, Robert: Kraina tysiąca granic. Szkice o historii i pamięci [Das Land der tausend Grenzen. Skizzen zu Geschichte und Erinnerung]. Olsztyn 2003; Ders.: Historia - przestrzeń dialogu [Geschichte als Dialograum]. Warszawa 2006; Nijakowski, Lech M.: Polska polityka pamięci. Esej socjologiczny [Die polnische Geschichtspolitik. Ein soziologischer Essay]. Warszawa 2008; Traba, Robert: Przeszłość w teraźniejszości. Polskie spory o historię na początku XXI wieku [Die Gegenwart der Vergangenheit. Polnische Geschichtsdebatten zu Beginn des 21. Jahrhunderts]. Poznań 2009; Wawrzyniak, Joanna: ZBoWiD i pamięć drugiej wojny światowej. 19491969 [Der ZBoWiD und die Erinnerung an den Zweiten Weltkrieg. 1949-1969]. Warszawa 2009; Wóycicka, Zofia: Przerwana żałoba. Polskie spory wokół pamięci nazistowskich 
historische Museen und deren Schauen in den polnischen Kultur- und Sozialwissenschaften noch vergleichsweise geringes Interesse auf sich. ${ }^{59}$ Mit dem Einsetzen des polnischen Museumsbooms Mitte der 2000er-Jahre sind erste Beiträge von Historikern, Soziologen und Anthropologen erschienen, die diese Medien unter erinnerungskulturellen Fragestellungen betrachten. ${ }^{60}$

obozów koncentracyjnych i zagłady 1944-1950 [Unterbrochene Trauer. Polnische Auseinandersetzungen um die Erinnerung an die nationalsozialistischen Konzentrations- und Vernichtungslager 1944-1950]. Warszawa 2009; Filipkowski, Piotr: Historia mówiona i wojna: doświadczenie obozu koncentracyjnego w perspektywie narracji biograficznych [Oral history und Krieg: Die Erfahrung des Konzentrationslagers in der Perspektive biografischer Narrationen]. Wrocław 2010; Korzeniewski, Bartosz: Transformacja pamięci. Przewartościowania w pamięci przeszłości a wybrane aspekty funkcjonowania dyskursu publicznego o przeszłości w Polsce po 1989 roku [Die Transformation der Erinnerung. Die Veränderung der Bedeutung der Vergangenheit in der Erinnerung und ausgewählte Aspekte des öffentlichen Diskurses über die Vergangenheit in Polen nach 1989]. Poznań 2010; Saryusz-Wolska, Magdalena: Spotkania czasu z miejscem. Studia o pamięci i miastach [Begegnungen zwischen Zeit und Raum. Studien zu Gedächtnis und Städten]. Warszawa 2011; Napiórkowski, Marcin: Powstanie umarłych. Historia pamięci 1944-2014 [Der Aufstand der Toten. Die Geschichte der Erinnerung 1944-2014]. Warszawa 2016. Im Wissenschaftsverlag "Scholar" erscheint seit 2006 die Reihe »Współczesne Społeczeństwo Polskie wobec Przeszłości« (Die gegenwärtige polnische Gesellschaft und die Vergangenheit). Bislang (Stand Mai 2017) sind acht Bände erschienen, darunter Publikationen der prominentesten polnischen Forscher im Bereich Erinnerungskultur, Barbara Szacka, Andrzej Szpociński und Piotr Kwiatkowski. Siehe Band 1: Szpociński, Andrzej/Kwiatkowski, Piotr Tadeusz: Przeszłość jako przedmiot przekazu [Die Vergangenheit als Gegenstand der Vermittlung]. Warszawa 2006; Band 3: Szacka, Barbara: Czas przeszły, pamięć, mit [Vergangenheit, Erinnerung, Mythos]. Warszawa 2006. Einzelne Fachzeitschriften haben in den letzten Jahren Sonderausgaben diesem Themenspektrum gewidmet. Siehe u. a. Przegląd socjologiczny 49/2 (2000); Kultura Współczesna 53/ 3 (2007), 56/ 1 (2010); Kultura i Społeczeństwo 55 / 4 (2011), 58 / 3 (2014). Die Themen kollektive Erinnerung und Identität werden immer wieder in der Zeitschrift Borussia reflektiert, u. a. in den Ausgaben 41 (2007), 44/ 45 (2008), 47 (2010), 50 (2011) 55 (2015) und 56 (2015).

59 Breitere Reflexionen zur Rolle des Museums in Kultur und Gesellschaft gibt es im Bereich der Kunstgeschichte. Siehe beispielsweise Popczyk, Maria (Hg.): Muzeum sztuki. Od Luwru do Bilbao [Das Kunstmuseum. Vom Louvre bis Bilbao]. Katowice 2006.

60 Ziębińska-Witek, Anna: Wizualizacje pamięci - upamiętnianie Zagłady w muzeach [Visualisierungen der Erinnerung - die Erinnerung an den Holocaust in Museen]. In: Kwartalnik Historii Żydów 3 (2006), 366-378; Korzeniewski, Bartosz: Wystawy historyczne jako nośnik pamięci na przykładzie wystawy o zbrodniach Wehrmachtu [Historische Ausstellungen als Erinnerungsträger am Beispiel der Wehrmachtsausstellung]. In: Kultura Współczesna 53/3 (2007), 68-84; Ostolski, Adam: Przestrzeń muzeum a polityka traumy [Der Museumsraum und die Politik des Traumas]. In: Kultura i Społeczeństwo 53/3 (2009), 67-87; Żychlińska, Monika: Muzeum Powstania Warszawskiego jako wehikuł polskiej pamięci zbiorowej [Das Museum des Warschauer Aufstands als Vehikel der polnischen kollektiven Erinnerung]. In: Kultura i Społeczeństwo 53 / 3 (2009), 89-114; Bogumit, Zuzanna/ Wawrzyniak, Joanna: Narracje zniszczenia. Trauma wojenna w muzeach miejskich Petersburga, Warszawy i Drezna [Narrative der Zerstörung. Das Trauma des Kriegs in den Stadtmuseen St. Petersburgs, Warschaus und Dresdens]. In: Kultura i Społeczeństwo 54 / 4 (2010), 3-21. 
Thematisch fokussieren diese Publikationen auf die Musealisierung des Zweiten Weltkriegs und des Holocaust. In jüngster Zeit hat das Interesse an den Medien Museum, Gedenkstätte und Ausstellung noch deutlich zugenommen. ${ }^{61}$ Bemerkenswert dabei ist, dass die Reflexion der Museumspraktiker sich zunehmend für Beiträge verwandter Wissenschaften öffnet. ${ }^{62}$ Allerdings sind bislang erst einzelne polnische Monografien erschienen, die historische Museen und Gedenkstätten in das Zentrum ihrer Analysen stellen. Mit den Inhalten und der symbolischen Aufladung der Erinnerung an das Lager Auschwitz in der polnischen Gesellschaft um die Jahrtausendwende hat sich der Soziologe Marek Kucia befasst. ${ }^{63}$ Die Historikerin Anna Ziębińska-Witek analysiert in ihrer Studie verschiedene Konzepte der Darstellung des Holocaust in KZ-Gedenkstätten, Holocaust- und stadthistorischen Museen. ${ }^{64} \mathrm{Zu}$ zanna Bogumił schließlich untersucht in ihrer Doktorarbeit aus anthropologischer Perspektive die Entstehung, Aktivitäten und Ausstellungstätigkeiten von Gulag-Gedenkstätten in verschiedenen Regionen Russlands. ${ }^{65}$

Ausländische Forscher befassen sich bisher nur selten mit den in polnischen Museen transportierten Geschichtsbildern. ${ }^{66}$ Publizierte Einzelstudien konzentrieren sich wesentlich auf KZ-Gedenkstätten und damit spezifische Geschichts- und Gedenkinstitutionen. ${ }^{67}$ Erst in den bereits erwähnten

61 Ziębińska-Witek, Anna/Żuk, Grzegorz (Hg.): Muzea w kulturze współczesnej [Museen in der gegenwärtigen Kultur]. Lublin 2015. Beispiel hierfür ist auch das bereits erwähnte, von Joachim von Puttkammer und Dorothea Warneck herausgegebene Themenheft »Exhibiting Violence« des Przegląd Historyczny 57 / 1 (2016), in dem neben der Präsentation von Konzepten aktueller polnischer Museen durch deren Verantwortliche überwiegend Analysen westeuropäischer Forscher versammelt sind.

62 Siehe Fabiszak, Małgorzata / Owsiński, Marcin (Hg.): Obóz - muzeum. Trauma we współczesnym wystawiennictwie [Lager - Museum. Traumata im gegenwärtigen Ausstellungswesen]. Kraków 2013; Kostro, Robert/ Wóycicki, Kazimierz/ Wysocki, Michał (Hg.): Historia Polski od-nowa. Nowe narracje historii i muzealne reprezentacje przeszłości [Polnische Geschichte von Neuem/Erneuerung. Neue historische Narrationen und museale Geschichtsrepräsentationen]. Warszawa 2014.

63 Kucia, Marek: Auschwitz jako fakt społeczny. Historia, współczesność i świadomość społeczna KL Auschwitz w Polsce [Auschwitz als gesellschaftliche Tatsache. Geschichte, Gegenwart und gesellschaftliche Wahrnehmung des KZ Auschwitz in Polen]. Kraków 2005.

64 Ziębińska-Witek, Anna: Historia w Muzeach. Studium Ekspozycji Holokaustu [Geschichte im Museum. Eine Untersuchung von Holocaust-Ausstellungen]. Lublin 2011.

65 Bogumił, Zuzanna: Pamięć Gułagu [Die Erinnerung an den Gulag]. Kraków 2012.

66 Ein Beispiel hierfür ist eine in polnisch-deutsch-russischer Zusammenarbeit entstandene Studie, die drei stadthistorische Museen (Dresden, Warschau und St. Petersburg) in den Blick nimmt: Bogumit, Zuzanna u. a.: The Enemy on Display. The Second World War in Eastern European Museums. New York, Oxford 2015.

67 Klein, Nina: Die polnische Erinnerung an Auschwitz am Beispiel des staatlichen Museums Auschwitz-Birkenau. Konstanz 1999; Huener, Jonathan: Auschwitz, Poland, and the Politics of Commemoration. 1945-1979. Athens 2003. Den Streit um die Aufstellung von 
Sammelbänden jüngeren Datums werden auch weitere museale Institutionen berücksichtigt. $^{68}$

Der Großteil der publizierten Arbeiten, im deutschsprachigen Raum wie in Polen, unternimmt vergleichende Einzelfallstudien von wenigen Museen oder Gedenkstätten. Anhand der Analyse insbesondere der gesellschaftlichen, publizistischen und politischen Debatten um einzelne Institutionen werden dabei in erster Linie nationale Erinnerungskulturen untersucht. ${ }^{69}$ Diese synchronen Vergleiche bringen oft zugleich transnationale Vergleichsperspektiven ein, bei denen einzelne Museen als stellvertretend für nationale Erinnerungskulturen betrachtet werden. ${ }^{70}$ Bislang wurden ausschließlich in der Historischen Museologie auch diachrone Untersuchungsperspektiven gewählt. ${ }^{71}$ Eine Analyse der (Dauer-)Ausstellungen - ihrer Inhalte wie der gestalterischen und visuellen Umsetzung - stellt jedoch in der Regel lediglich einen (untergeordneten) Teilaspekt der Analysen dar. Auch übergreifende Querschnittsvergleiche einer größeren Anzahl von Museen und Ausstellungen sind selten. ${ }^{72}$

Die Mehrzahl der publizierten Studien verzichtet auf eine Analyse der von den Museen realisierten Schauen oder streift diese nur am Rande. Dies mag wesentlich damit zusammenhängen, dass eine etablierte Methodik der Ausstellungsanalyse bisher nicht existiert. ${ }^{73}$ Zwar hat die deutschsprachige und angelsächsische Museologie eine Vielzahl von Studien hervorgebracht, die sich mit der Wirkung und Inszenierung musealer Objekte sowie den sozialen und gesellschaftlichen Funktionen von Museen und deren Präsentationen

Kreuzen auf dem Gelände des ehemaligen KZ Auschwitz nimmt Geneviève Zubrzycki zum Ausgangspunkt für ihre Untersuchung der Bedeutung des Katholizismus für das polnische nationale Selbstbild. Zubrzycki, Geneviève: The Crosses of Auschwitz. Nationalism and Religion in Post-Communist Poland. Chicago, London 2006.

68 Dyroff/Krzoska: Geschichtsbilder; Herget/Pleitner: Heimat im Museum; Inter Finitimos 10 (2012).

69 Vgl. Haß: Gestaltetes Gedenken; Leggewie/Meyer: »Ein Ort, an den man gerne geht«. Dies trifft insbesondere auf die Beiträge - deutschsprachiger wie internationaler - Sammelbände zu: Wahnich, Sophie (Hg.): Fiction d'Europe. La guerre au musée. Paris 2002; Knigge / Mählert: Der Kommunismus im Museum; Sarkisova, Oksana / Apor, Péter (Hg.): Past for the Eyes. East European Representations of Communism in Cinema and Museums after 1989. Budapest, New York 2008.

70 Pieper: Die Musealisierung des Holocaust; Baur: Die Musealisierung der Migration; Schoder: Die Vermittlung des Unbegreiflichen.

71 Beil: Der ausgestellte Krieg; Raffler: Museum - Spiegel der Nation.

72 Beil: Der ausgestellte Krieg; Thiemeyer: Fortsetzung des Krieges; Kaiser, Wolfram/Krankenhagen, Stefan/Poehls, Kerstin: Europa ausstellen. Das Museum als Praxisfeld der Europäisierung. Köln u. a. 2012.

73 In vielen Publikationen, in denen Ausstellungen mitbetrachtet werden, fehlt daher meist eine methodische Einordnung des Untersuchungsvorgehens in Bezug auf dieses Medium. Exemplarisch: Haß: Gestaltetes Gedenken; Köhr: Die vielen Gesichter des Holocaust. 
befassen; ${ }^{74}$ Ansätze zur analytischen Betrachtung gerade des vielschichtigen Mediums der musealen Ausstellung werden jedoch erst entwickelt. ${ }^{75} \mathrm{Da}-$ bei wird auf verschiedene Methoden benachbarter Disziplinen zurückgegriffen, unter anderem auf semiotische Zugänge, ${ }^{76}$ die historische Quellenkritik der Geschichtswissenschaften ${ }^{77}$ und den Ansatz des aus der Literaturwissenschaft entlehnten close reading. ${ }^{78}$ Ein weiterer Ansatz ist die ethnologische Methode der »dichten Beschreibung ${ }^{79}{ }^{79}$ die auch in der vorliegenden Studie angewendet und im Folgenden noch näher erläutert wird.

\section{Untersuchungsgegenstände}

Historische Museen in fünf Großstädten Polens - Krakau, Lublin, Łódź, Warschau und Wrocław -, die das Thema des Zweiten Weltkriegs in ihren Dauerausstellungen behandeln, sind Gegenstand der Analysen und Betrachtungen der vorliegenden Studie. Die Auswahl der Städte fand unter der Maßgabe statt, eine möglichst breite Untersuchungsperspektive zu schaffen. Ziel war erstens, Museen aus Regionen mit relativ unterschiedlichen (Besatzungs-)Erfahrungen während des Zweiten Weltkriegs einzubeziehen, um damit wesentliche Phänomene und Ereignisse der Kriegsjahre erfassen zu können. Wrocław (Breslau) repräsentiert dabei die Territorien der heutigen Polnischen Republik, die 1939 Teil des Deutschen Reiches waren. Łódź steht als Teil des sogenannten Reichsgau Wartheland exemplarisch für die in das Reich eingegliederten Gebiete. Hier befand sich zudem das zweitgrößte Ghetto des Landes (nach dem Warschauer), das insgesamt am längsten bestand. Als Teil des Generalgouvernements wurden die Städte Warschau, Krakau und Lublin ge-

74 Zentral für die Theoriebildung in der deutschen Museologie sind nach wie vor die Arbeiten Gottfried Korffs und Friedrich Waidachers: Waidacher, Friedrich: Handbuch der Allgemeinen Museologie. Wien u. a. 1993; Korff, Friedrich: Museumsdinge. Deponieren Exponieren. 2. Aufl. Köln u.a. 2007. Zentral für die angelsächische Forschung sind bis heute: Karp, Ivan/Lavine, Steven D. (Hg.): Exhibiting Cultures. The Poetics and Politics of Display. Washington, London 1991; Karp, Ivan/Mullen Kreamer, Christine/Lavine, Steven D. (Hg.): Museums and Communities. The Politics of Public Culture. Washington, London 1992.

75 Einen ersten Überblick über Ansätze der Museums- und Ausstellungsanalyse bietet Baur, Joachim (Hg.): Museumsanalyse. Methoden und Konturen eines neuen Forschungsfeldes. Bielefeld 2010.

76 Scholze: Medium Ausstellung.

77 Thiemeyer, Thomas: Geschichtswissenschaft: Das Museum als Quelle. In: Baur: Museumsanalyse, 73-94.

78 Baur: Die Musealisierung der Migration, 71-77, bes. $72 \mathrm{f}$.

79 Muttenthaler/Wonisch: Gesten des Zeigens; Offe: Ausstellungen, Einstellungen, Entstellungen. 
wählt - Krakau als dessen Hauptstadt und Warschau als Hauptstadt des besetzten Landes sowie Schauplatz der beiden für die polnische Erinnerungskultur und Geschichtspolitik nach 1945 zentralen Aufstände: des Warschauer Ghettoaufstands im Jahr 1943 und des Aufstands der polnischen "Heimatarmee" (Armia Krajowa, AK) im Jahr 1944, des sogenannten Warschauer Aufstands. Lublin schließlich ist insofern von besonderem Interesse, als in dessen unmittelbarer Nähe eines der größten Konzentrationslager, das Lager Majdanek, entstand und der Ort 1942 zum Ausgangspunkt der »Aktion Reinhardt« und damit des Beginns der systematischen Ermordung der Juden im Generalgouvernement wurde. Nach dem Einmarsch sowjetischer Truppen wurde es zudem Sitz des "Polnischen Komitees der Nationalen Befreiung " (Polski Komitet Wyzwolenia Narodowego, PKWN), der von der Sowjetunion gestützten kommunistischen provisorischen Regierung, die sukzessive die Kontrolle über die von der Roten Armee besetzten polnischen Gebiete übernahm und damit die politische Grundlage für die polnische Nachkriegsordnung legte. Zweitens sollte durch die Auswahl mehrerer Orte in verschiedenen Regionen des Landes ein möglichst breiter Einblick in die polnische historische $\mathrm{Mu}-$ seumslandschaft und ihre Entwicklung im Untersuchungszeitraum ermöglicht werden. Die Studie erhebt keinen Anspruch auf Repräsentativität für das gesamte Land. Die relativ große Zahl untersuchter Städte bzw. ihrer Museen erlaubt dennoch einen vergleichsweise tiefen Einblick in die regionalen Entwicklungen und Ausdifferenzierungen musealer Interpretationsangebote und Vermittlungspraxen, wie sie insbesondere mit Beginn des Museumsbooms zu beobachten sind.

Anliegen des Untersuchungszuschnitts war des Weiteren, jeweils alle musealen Einrichtungen der untersuchten Städte zu erfassen, die in ihren Dauerausstellungen den Zweiten Weltkrieg behandeln. Die historischen Museen, die damit in das Spektrum der Analysen fielen, sind überwiegend zwei Kategorien zuzuordnen: Zum einen handelt es sich um Stadtmuseen, also Institutionen, die sich mit der Geschichte und Kultur einer Stadt, teilweise auch der sie umgebenden Region befassen und in denen der Zweite Weltkrieg meist Teil einer thematisch und zeitlich umfassenderen Dauerausstellung ist. Zum anderen werden historische Museen betrachtet, die sich an authentischen Orten von Verbrechen der Kriegsjahre befinden. Meist waren dies Gefängnisse und Inhaftierungsstätten, die von den deutschen Besatzern - zum Teil ab 1944/45 auch von den sowjetischen und den neuen kommunistischen polnischen Machthabern - genutzt und in denen Menschen gefoltert und ermordet wurden. In Polen werden diese Institutionen als »martyrologische Museen" (muzeum martyrologii, muzeum martyrologiczne) bezeichnet. Sie sind Orte der Musealisierung der Vergangenheit und präsentieren (Dauer-)Ausstellungen. Zugleich wirken sie als Gedenkorte bzw. Gedenkstätten. Paul Williams bezeichnet solche Institutionen auch als memorial 
museums. ${ }^{80}$ Als sogenannte martyrologische Abteilungen gehören diese Stätten heute meist zu Stadt- oder Regionalmuseen ${ }^{81}$ oder aber zu Institutionen, die der Geschichte der polnischen Unabhängigkeitsbewegungen gewidmet sind. ${ }^{82}$ In ihren Dauerausstellungen thematisieren sie überwiegend oder ausschließlich den Zeitraum des Zweiten Weltkriegs. Daneben werden in den untersuchten Städten auch Geschichtsmuseen einbezogen, die einen Aspekt oder ein Ereignis dieses Zeitraums herausgehoben thematisieren. Hierzu zählen in Warschau die Dauerausstellung des »)̈̈dischen Historischen Instituts« (Żydowski Instytut Historyczny, ŻIH) sowie das Museum des Warschauer Aufstands.

In ihren Dauerausstellungen präsentieren diese Museen jeweils ein Gesamtnarrativ der Kriegsjahre in der jeweiligen Stadt und Region. Keine der Schauen unternimmt dagegen eine übergreifende, gesamtpolnische Erzählung der Zeit des Zweiten Weltkriegs. Wie jedoch in den Analysen deutlich werden wird, verorten die meisten Präsentationen ihre lokale und regionale Geschichte stets in einem größeren staatlichen und nationalen Kontext, der sich in den untersuchten symbolischen und inhaltlichen Bezügen widerspiegelt.

Im Verlauf der Untersuchung haben sich drei Phasen der Entwicklung der Dauerausstellungen der betrachteten Einrichtungen herauskristallisiert. Ausgangspunkt der Analysen waren Schauen, die in den 1980er-Jahren zu besichtigen waren. Einige von ihnen waren bereits in den 1960er-Jahren eröffnet worden und erfuhren bis kurz vor der politischen Wende nur geringe Anpassungen. ${ }^{83}$ Weitere wurden Ende der 1970er- bzw. Anfang der 1980erJahre im Zuge eines kleinen Museumsbooms eröffnet. ${ }^{84}$ Dies betraf in erster Linie kleinere martyrologische Museen, etwa in Krakau und Lublin, zum Teil aber auch stadthistorische Museen, wie das Museum im »Krakauer Tor» in Lublin, dessen Gründung 1979 erfolgte. Anfang der 1990er-Jahre wurden nur wenige Dauerausstellungen neu eröffnet. Dabei handelte es sich in erster Linie um in Bezug auf ihre Vorgänger nur geringfügig angepasste Präsenta-

80 Williams, Paul: Memorial Museums. The Global Rush to Commemorate Atrocities. Oxford, New York 2007, 8, 21.

81 So im Fall des »Martyrologiemuseums Unter der Uhr« in Lublin, das zum »Lubliner Museum in Lublin« gehört, sowie der "Abteilung Pomorska-Straße» des »Historischen Museums der Stadt Krakau«.

82 Hierzu gehören das »Martyrologiemuseum Radogoszcz«, das eine Abteilung des »Museums der Unabhängigkeitstraditionen in Łódź« ist, sowie das "Gefängnismuseum Pawiak«, das zum »Unabhängigkeitsmuseum in Warschau« gehört.

83 So im Fall des Martyrologiemmuseums Radogoszcz, des Gefängnismuseums Pawiak sowie der 1965 eröffneten, grundlegend überarbeiteten Dauerausstellung des »Historischen Museums der Hauptstadt Warschau«.

84 Goldmann, Barbara: Muzea polskie, ich liczby i region działania w XIX i XX wieku [Polnische Museen, ihre Zahl und Tätigkeitsfelder im 19. und 20. Jahrhundert]. In: Muzealnictwo 43 (2001), 87-98, hier 96. 
tionen, deren Veränderung noch Ende der 1980er-Jahre geplant worden war. In den übrigen Schauen fanden nach dem politischen Wechsel von 1989 allenfalls minimale Anpassungen statt. Diese beschränkten sich auf die Veränderung oder Hinzufügung von Objektbeschriftungen; zum Teil wurden einige Texte und Musealien in den Schauen entfernt. Die Veränderungen führten die jeweils zuständigen Kuratoren meist nach eigenen Erwägungen und mit minimalem Materialaufwand durch; größere Eingriffe in die Schauen fanden nicht statt. Dies lag in erster Linie an fehlenden finanziellen Ressourcen der Institutionen Anfang der 1990er-Jahre. ${ }^{85}$ Die erste große Welle der grundlegenden Überarbeitung bestehender Dauerausstellungen und der Neuschaffung historischer Präsentationen in den betrachteten Institutionen - dies markiert die zweite Phase der musealen Entwicklung im Untersuchungszeitraum -, fand in den Jahren 1998 bis 2003 statt; lediglich im Historischen $\mathrm{Mu}$ seum der Stadt Lublin wurde sie bereits 1995 unternommen. 2004 schließlich setzte mit der Eröffnung des Museums des Warschauer Aufstands die dritte Phase ein - ein Boom im Bereich historischer Museen, ${ }^{86}$ der bis in die Gegenwart anhält.

Im Folgenden werden die in dieser Studie betrachteten Institutionen und ihre untersuchten Dauerausstellungen kurz vorgestellt; in den weiteren Analysen wird auf diese grundlegenden Informationen nicht mehr im Einzelnen Bezug genommen. Darüber hinausgehende Aspekte zu Entstehungskontexten und Akteuren finden dann unmittelbar in den einzelnen Untersuchungsabschnitten Berücksichtigung.

\section{Historisches Museum der Hauptstadt Warschau}

Die Institution wurde als »Museum des Alten Warschaus« (Muzeum Dawnej Warszawy) bereits 1936 als Abteilung des "Nationalmuseums« (Muzeum Narodowe) geschaffen. Nach dem Krieg folgte 1948 seine Wiedergründung ${ }^{87}$ als eigenständige Institution unter dem Namen »Historisches Museum der

85 Diese waren verbunden zum einen mit den ökonomischen Problemen der ersten Transformationsjahre, zum anderen mit strukturellen und organisatorischen Veränderungen innerhalb der polnischen Museumslandschaft in der ersten Hälfte der 1990er-Jahre. Folga-Januszewska, Dorota: Muzea w Polsce 1989-2008 [Museen in Polen 1989-2008]. In: Muzealnictwo 50 (2009), 18-46, hier 21, $26 \mathrm{f}$.

86 Der Boom erstreckt sich auch auf kunsthistorische Museen. Vgl. Jagodzińska: Muzealna nadprodukcja.

87 Soltan, Andrzej: Muzeum Historyczne m. st. Warszawy 1936-2006 [Das Historische Museum der Hauptstadt Warschau 1936-2006]. In: Almanach Muzealny [Museumsalmanach]. Bd. 5. Hg.v. Muzeum Historyczne m. st. Warszawy. Warszawa 2007, 7-54, hier 7 f., 14f.; Muzeum Historyczne m. st. Warszawy. Informator [Das Historische Museum der Hauptstadt Warschau. Ausstellungsführer]. Hg. v. Muzeum Historyczne m. st. Warszawy. Warszawa o. J. [2006], [2]. 
Hauptstadt Warschau« (Muzeum Historyczne m. st. Warszawy, MHW) ${ }^{88}$ Es befindet sich in der Altstadt, in einem Komplex miteinander verbundener rekonstruierter historischer Gebäude am zentralen Marktplatz. Am 17. Januar 1955 eröffnete seine erste Dauerausstellung, ${ }^{89}$ die 1965 nach umfangreichen Veränderungen unter dem Titel "Siedem Wieków Warszawy« (Sieben Jahrhunderte Warschaus) wiedereröffnet wurde. ${ }^{90}$ Die Dauerausstellung bzw. einzelne ihrer Sektionen wurden in den folgenden Jahrzehnten mehrfach ergänzt oder verändert; ${ }^{91}$ unter dem ursprünglichen Titel existierte sie jedoch bis zum Zeitpunkt der Recherchen im Jahr 2009.92 Sie umfasste zu diesem Zeitpunkt die Geschichte der Stadt vor ihrer Gründung um 1300 bis ins Jahr 1990.

Der Ausstellungsabschnitt zu den Jahren des Zweiten Weltkriegs blieb bis Ende der 1980er-Jahre weitgehend unverändert. ${ }^{93}$ Gegliedert war er - bis einschließlich 2010 - in einzelne thematische Sektionen, die in separaten Räumen untergebracht waren. 1990/91 erfuhr der Saal, der den Ereignissen des Septembers 1939 gewidmet war, eine umfassende Neugestaltung (siehe Abb. 1). ${ }^{94}$

882014 hat das Museum seinen Namen verändert zu "Museum Warschaus« (Muzeum Warszawy).

89 Żmuda-Liszewska, Krystyna: Muzeum Historyczne m.st. Warszawy 1936-1996 [Das Historische Museum der Hauptstadt Warschau 1936-1996]. Warszawa 1996, 53.

90 Płoszajska, Maria (Red.): Muzeum Historyczne m. st. Warszawy [Das Historische Museum der Hauptstadt Warschau]. Warszawa [198-], 1; Sołtan: Muzeum Historyczne, 32; Muzeum Historyczne. Informator, [3].

91 Sołtan: Muzeum Historyczne, 32; Żmuda-Liszewska: Muzeum Historyczne, 60f. Der Stand der Ausstellung vor 1990 lässt sich lediglich anhand des Manuskripts eines Ausstellungsführers rekonstruieren, da für den Zeitraum bis 1989 keine Ausstellungsdrehbücher erhalten sind. Dieser gibt ausführlich Auskunft über den Aufbau, die Inhalte, Gestaltung und einzelne Exponate der Ausstellung in den Jahren zwischen 1985 und 1990. Informator do ekspozycji: 1. „Warszawa w latach drugiej wojny światowej« (1939-1945) 2. »Warszawa - stolicą Polski Ludowej (III piętro). Archiwum Państwowe (Staatsarchiv, weiter AP), zespół 3195 / I (Muzeum Historyczne m. st. Warszawy), teczka 76, MHW-440, 45-57. Den folgenden Analysen liegt die Annahme zugrunde, dass die im Ausstellungsführer verwendeten Ausdrücke und Begriffe weitgehend den in der Ausstellung enthaltenen entsprachen, dass die in der Schau zu findenden Interpretationen, inhaltlichen Gewichtungen und gestalterischen Umsetzungen also unmittelbaren Einfluss auf die detaillierte schriftliche Beschreibung hatten. Zusätzliche Einblicke in die grundlegenden Interpretationsmuster der Schau bietet ein (vom Umfang her wesentlich kürzeres) Begleitheft zur Dauerausstellung, das in der zweiten Hälfte der 1980er-Jahre publiziert wurde: Płoszajska: Muzeum Historyczne, bes. 1, 19-21.

92 Die in den folgenden Analysen enthaltenen Verweise auf konkrete Inhalte der Dauerausstellung seit 1991 beruhen auf dem Besuch der Schau durch die Verfasserin am 9. und 12. Juni 2009. Die verwendete Nummerierung der Ausstellungssäle basiert auf den Angaben des zum Zeitpunkt der Recherchen aktuellen Ausstellungsführers: Muzeum Historyczne. Informator.

93 Płoszajska: Muzeum Historyczne, 1.

94 Żmuda-Liszewska: Muzeum Historyczne, 61. Siehe auch Meller, Beata: History, Ideology and Politics in the Historical Museum of Warsaw. In: Museum International 47 / 3 (1995), 22-27, hier 27. Dieser Raum bestand in dieser Form bis zum 9. Juni 2009. 


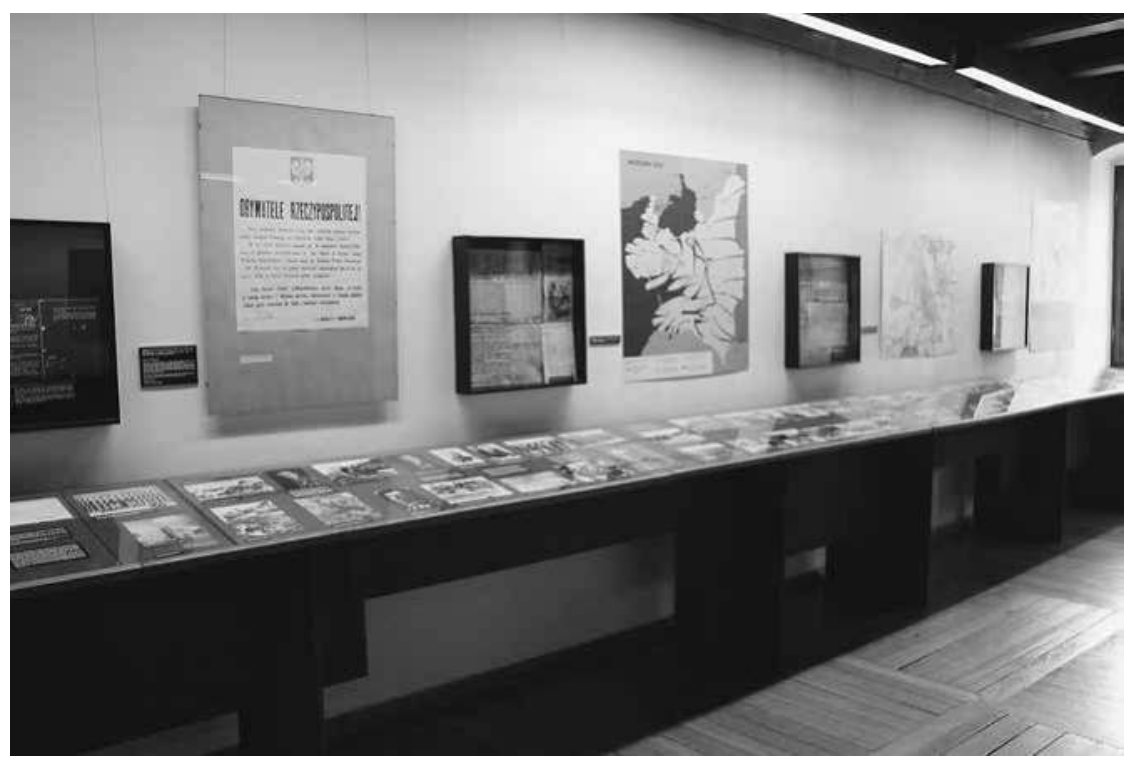

Abb.1: Saal „Die Verteidigung Warschaus im September 1939« in der Dauerausstellung des Historischen Museums der Hauptstadt Warschau.

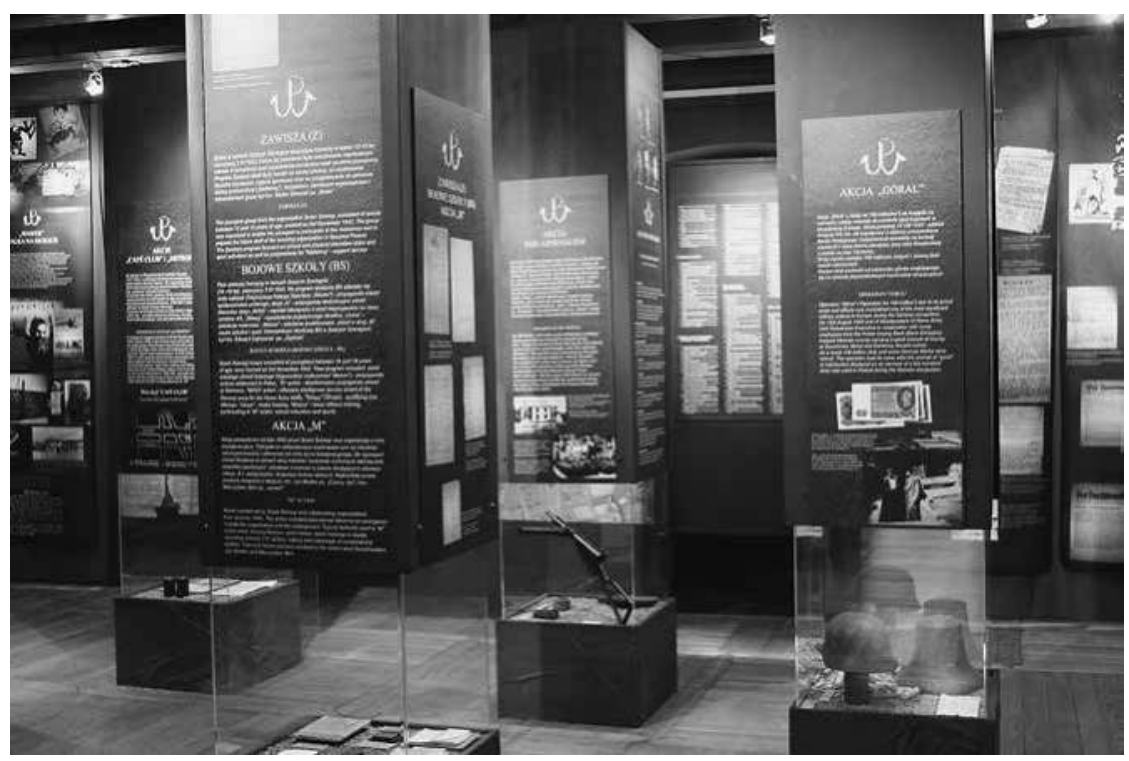

Abb. 2: Abschnitt »Der Polnische Untergrundstaat - Die Widerstandsbewegung in Warschau 1939-1944« in der Schau des MHW. 
Anfang der 1990er-Jahre wurden auch in den übrigen Sälen kleinere Ergänzungen und Veränderungen vorgenommen. ${ }^{95}$ Seit 2006 wurden schließlich sukzessive einzelne Räume des Abschnittes neugestaltet und wiedereröffnet. In diesem Zeitraum ersetzte man die vorherige objektzentrierte, buchstäblich schwarz-weiße Präsentationsweise durch multimediale Raumkompositionen (siehe Abb. 2). ${ }^{96}$ Alle seit 1990 überarbeiteten Räume waren zudem mit einer Vielzahl erläuternder Kuratorentexte ausgestattet. Die Ausstellungsfläche der Säle, die dem Zeitraum 1939 bis 1945 gewidmet waren, umfasste etwa 256 Quadratmeter. Die jährlichen Besucherzahlen der Dauerausstellung bewegten sich in den Jahren 2006 bis 2009 zwischen 31.000 und 38.000 Personen. ${ }^{97} 2010$ wurde die Präsentation aufgrund umfangreicher Renovierungsarbeiten der Museumsgebäude für das Publikum geschlossen. Am 26. Mai 2017 eröffnete schließlich eine unter der neuberufenen Leitung des Hauses vollständig neu konzipierte Dauerausstellung. ${ }^{98}$

\section{Gefängnismuseum Pawiak, Warschau}

Das Muzeum Więzienia Pawiak wurde 1965 auf den Ruinen des gleichnamigen, während des Warschauer Aufstands 1944 zerstörten Gefängnisses errichtet. ${ }^{99}$ Ein Teil der verbliebenen Mauerwände und Zellen des Kellertrakts blieben erhalten und wurden in das neue Gebäude integriert. Darüber hinaus schuf man eine 142 Quadratmeter große Ausstellungshalle, in der die zentrale Dauerausstellung untergebracht ist. Das umgebende Areal des früheren Gefängnisgeländes wurde architektonisch als Gedenkort arrangiert. So errichtete man auf dem früheren Hof ein Denkmal; der Rundgang für den Freigang der Häftlinge wurde im Hofpflaster nachgezeichnet. Zusätzlich ist der Ort markiert, an dem Schlacke abgeladen wurde, die die deutschen Besatzer zur Folter der Häftlinge verwendeten. In der das Museumsgelände umgebenden Mauer wurde zudem ein Grablicht installiert, das an Gedenktagen angezündet wird. ${ }^{100}$

95 Interview mit Joanna Maldis, Kuratorin der Sektion zum Zweiten Weltkrieg, am 30. Juni 2009.

96 Ebd. Die Neugestaltung umfasste die Räume 48 bis 52.

97 Auskunft des Museums, E-Mail vom 1. April 2015.

98 Wielkie odliczanie do otwarcia Muzeum Warszawy [Großer Countdown bis zur Eröffnung vom Museum Warschaus], URL: http://muzeumwarszawy.pl/wielkie-odliczaniedo-otwarcia-muzeum-warszawy/ (am 28.5.2017). Nähere Informationen zum Konzept der neuen Dauerausstellung finden sich unter: Wystawa Główna [Die Hauptausstellung], URL: http://wystawaglowna.muzeumwarszawy.pl (am 30.10.2016).

99 Pawiak 1835-1944. Przewodnik po ekspozycji stałej. Museumsführer durch die ständige Ausstellung. Hg.v. Muzeum Niepodległości w Warszawie. Warszawa 2004, 27.

100 Izdebska, Barbara: Muzeum Więzienia »Pawiak« - historia i teraźniejszość [Das Gefängnismuseum »Pawiak« - Geschichte und Gegenwart]. In: Niepodległość i Pamięć 2 / 3 (4) (1995), 247-275, hier $252 \mathrm{f}$. 
In den folgenden Jahrzehnten stellte man sukzessive kleinere Gedenktafeln auf. Bis 1990 war das Museum eine Abteilung des »Museums der Geschichte der Polnischen Revolutionären Bewegung « (Muzeum Historii Polskiego Ruchu Rewolucyjnego $)^{101}$, das 1990 vom "Unabhängigkeitsmuseum in Warschau" (Muzeum Niepodległości $w$ Warszawie, MNW) abgelöst wurde. ${ }^{102}$ Bis heute ist der Pawiak eine Abteilung dieses Museums.

Die erste Dauerausstellung vom 28. November 1965 im großen Saal bestand weitgehend unverändert bis $1990 .{ }^{103}$ Sie umfasste drei Abschnitte zur Geschichte des Gefängnisses als Inhaftierungsort politischer Gefangener, darunter die Zeit der zaristischen Herrschaft (1863-1918), die Jahre der Zweiten Polnischen Republik (1919-1939); der dritte Abschnitt war den Jahren 1939 bis 1944 gewidmet. In diesem Zeitraum war das Gefängnis zunächst der Verwaltung des Generalgouvernements und seit März 1940 der Gestapo unterstellt. Schätzungen ergeben, dass während der deutschen Besatzung insgesamt etwa 100.000 Menschen im Pawiak interniert waren, von denen 37.000 durch Exekutionen, Folter während der Verhöre oder im Gefängniskrankenhaus umgekommen sind und 60.000 in Konzentrationslager deportiert wurden. ${ }^{104}$ Am 19. April 1991 eröffnete eine überarbeitete Version der Schau, die nun die Gefängnisgeschichte während der deutschen Besatzung in das Zentrum rückte. ${ }^{105}$ Die Präsentation der Geschichte des Gefängnisses vor 1939 wurde in den Vorraum des Ausstellungsgebäudes sowie in die erhaltenen Zellen verlegt; in dieser Form geschieht dies bis heute. Die am 26. Juni 2001 eröffnete dritte Dauerausstellung, die bis in die Gegenwart zu besichtigen ist, basiert schließlich auf einer grundlegenden Neukonzeption, einschließlich

101 Einen Einblick in die Geschichte, Aufgaben und Zielsetzungen des Museums bietet der folgende Sammelband: Muzeum Historii Polskiego Ruchu Rewolucyjnego w Warszawie 1957-1977 [Das Museum der Geschichte der Polnischen Revolutionären Bewegung in Warschau 1957-1977]. Hg.v. Muzeum Historii Polskiego Ruchu Rewolucyjnego w Warszawie. Warszawa 1977.

1021990 wurde das Museum als »Museum der Geschichte der polnischen Unabhängigkeits- und gesellschaftlichen Bewegungen" (Muzeum Historii Polskich Ruchów Niepodległościowych i Społecznych) gegründet; 1991 erhielt es seinen heutigen Namen. Vgl. Stawarz, Andrzej (Hg.): Muzeum Niepodległości 1990-1995. Działalność i zbiory [Das Unabhängigkeitsmuseum 1990-1995. Tätigkeit und Sammlungen]. Warszawa 1995, 3 f.

103 Lediglich 1986 wurden kleinere Anpassungen und »konservatorische Maßnahmen« durchgeführt. Izdebska: Muzeum Więzienia »Pawiak«, 255. Den Stand der Schau aus dem Jahr 1987 gibt der erhaltene scenopis wieder, d.h. die schriftliche Dokumentation der Schau. Siehe: Scenopis stałej ekspozycji Muzeum Więzienia »Pawiak«. Warszawa 1987. Archiwum Muzeum Niepodległości w Warszawie (Archiv des Unabhängigkeitsmuseums in Warschau, weiter AMNW), Scen. 72.

104 Pawiak 1835-1944. Museumsführer, 12.

105 Izdebska, Barbara: Pawiak 1939-1945. Ekspozycja stała. Scenopis. Warszawa 1991. AMNW, Scen. 79. 


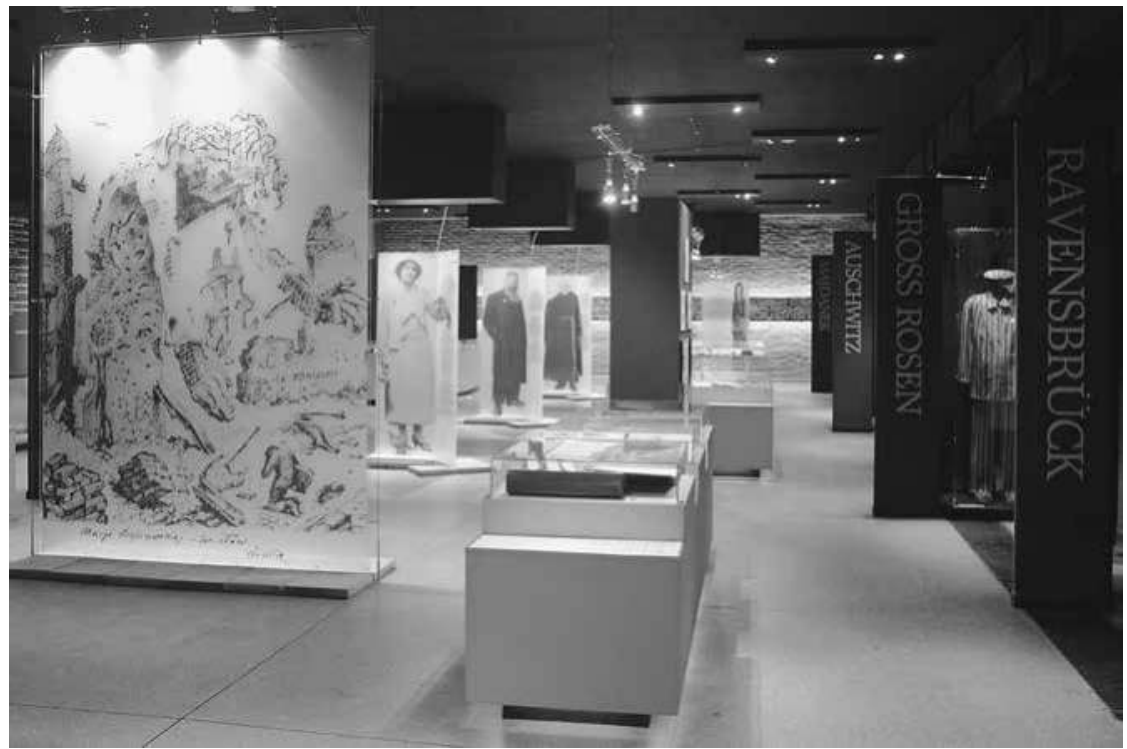

Abb. 3: Die aktuelle Dauerausstellung im großen Saal des Gefängnismuseums Pawiak.

einer umfassenden Erweiterung ihres thematischen Spektrums. ${ }^{106}$ Berücksichtigt werden nun auch Kriegs- und Besatzungsereignisse auf gesamtstaatlicher Ebene mit einem Schwerpunkt auf den Ereignissen in Warschau, der Warschauer Region und im Generalgouvernement. Besondere Aufmerksamkeit erhalten die Reaktionen im westlichen Ausland auf die Situation im besetzten Polen. In den Jahren 2009 bis 2011 schwankte die jährliche Besucherzahl des Museums zwischen knapp 37.900 und 42.600 Personen. ${ }^{107}$

Alle Dauerausstellungen des Museums setzten bzw. setzen auf eine exponatbasierte Vermittlung der historischen Ereignisse in einer chronologisch-thematischen Präsentation. Insbesondere die ersten beiden Schauen waren zusätzlich durch zahlreiche einordnende Kuratorentexte flankiert. Auch in der aktuellen Ausstellung bringen primär Zeitzeugnisse den Besuchern die Ereignisse nahe; dabei dominieren großformatige Kopien zeitgenössischer Publizistik wie Zeitungsbeiträge, Fotografien und Karikaturen; erläuternde Begleittexte werden hier äußerst sparsam eingesetzt. Neben diesen Exponaten präsentiert die Ausstellung an prominenter Stelle künstlerische Zeugnisse der Vergangenheit. Dominant platziert sind zahlreiche zeitgenössi-

106 Die in der Studie angeführten Verweise auf Inhalte dieser Schau beziehen sich auf den Ausstellungsbesuch am 3. Juli 2009.

107 Auskunft des Gefängnismuseums Pawiak, E-Mail vom 16. März 2015. 
sche Gedichte sowie Reproduktionen von Gemälden Bronisław Wojciech Linkes (siehe Abb. 3).

\section{Museum des Warschauer Aufstands, Warschau}

Das Muzeum Powstania Warszawskiego (MPW) gehört zu den jüngsten polnischen Geschichtsmuseen. Es wurde am 31. Juli 2004, am Vortag des sechzigsten Jahrestags des Aufstands, eröffnet. Seine Geschichte ist jedoch deutlich älter: Bereits 1981 begann der Aufbau einer Sammlung für das zukünftige Museum, 1983 erfolgte die Gründung als Abteilung des Historischen Museums der Hauptstadt Warschau. In den kommenden zwei Jahrzehnten wurde die weitere Entwicklung des Projekts jedoch immer wieder behindert. Obwohl bereits in den 1980er-Jahren ein Sitz für das Museum gefunden und auch ein Architektenwettbewerb zu dessen Realisierung entschieden worden war, verzögerte die sozialistische Regierung die Umsetzung. In den 1990erJahren verhinderten rechtliche Auseinandersetzungen um das Grundstück die Umsetzung des Projekts. Unter dem Ende 2002 neugewählten Stadtpräsidenten Lech Kaczyński von der Partei Recht und Gerechtigkeit wurde schließlich im Juli 2003 die Verwirklichung des Museums an einem anderen Ort, einem ehemaligen Straßenbahn-Elektrizitätswerk, und seine Eröffnung bis zum 60. Jahrestag des Aufstands beschlossen. ${ }^{108}$ Das vorgegebene Eröffnungsdatum wurde zwar eingehalten; bis zu diesem Zeitpunkt war jedoch erst ein kleiner Teil der geplanten Dauerausstellung realisiert, sodass das $\mathrm{Mu}-$ seum kurz nach seiner Eröffnung wieder geschlossen und die Schau erst Anfang Oktober 2004 für das Publikum geöffnet wurde. Ihre endgültige Fertigstellung zog sich über zwei weitere Jahre hin. Sukzessive kamen dann noch neue Sektionen hinzu, so ein umfassender Abschnitt zu den »Deutschen in Warschau « im Juni $2007^{109}$ und Mitte 2011 eine Sektion, die sich den Debatten der Nachkriegszeit um den Sinn des Aufstands widmet. ${ }^{110}$

108 Zur Geschichte der Bemühungen um das Museum seit Anfang der 1980er-Jahre bis 2003: Maliszewska, Izabella/Maliszewski, Stanisław: Kalendarium zmagań o Muzeum Powstania Warszawskiego [Chronik des Ringens um das Museum des Warschauer Aufstands]. In: Almanach Muzealny [Museumsalmanach]. Bd. 4. Hg.v. Muzeum Historyczne m. st. Warszawy. Warszawa 2003, 333-342.

109 Siehe Teil 1, Kapitel 1.3.

110 Dąkowska-Cichocka, Lena u.a. (Hg.): Przewodnik po Muzeum Powstania Warszawskiego [Führer durch das Museum des Warschauer Aufstands]. 3., ergänzte Aufl. Warszawa 2010, 25, 39, 48; Auskunft des MPW, E-Mail vom 30. Mai 2017. Hinweise auf Ausstellungsinhalte beziehen sich, falls nicht anders angegeben, auf den Ausstellungsbesuch am 8. und 9. Juli 2009. Die in den Quellenverweisen angegebene Nummerierung der Ausstellungssektionen folgt dem Ausstellungsflyer von 2009: Muzeum Powstania Warszawskiego. Plan. Warsaw Rising Museum. Map. Hg.v. Muzeum Powstania Warszawskiego. Warszawa o. J. [2009]. 


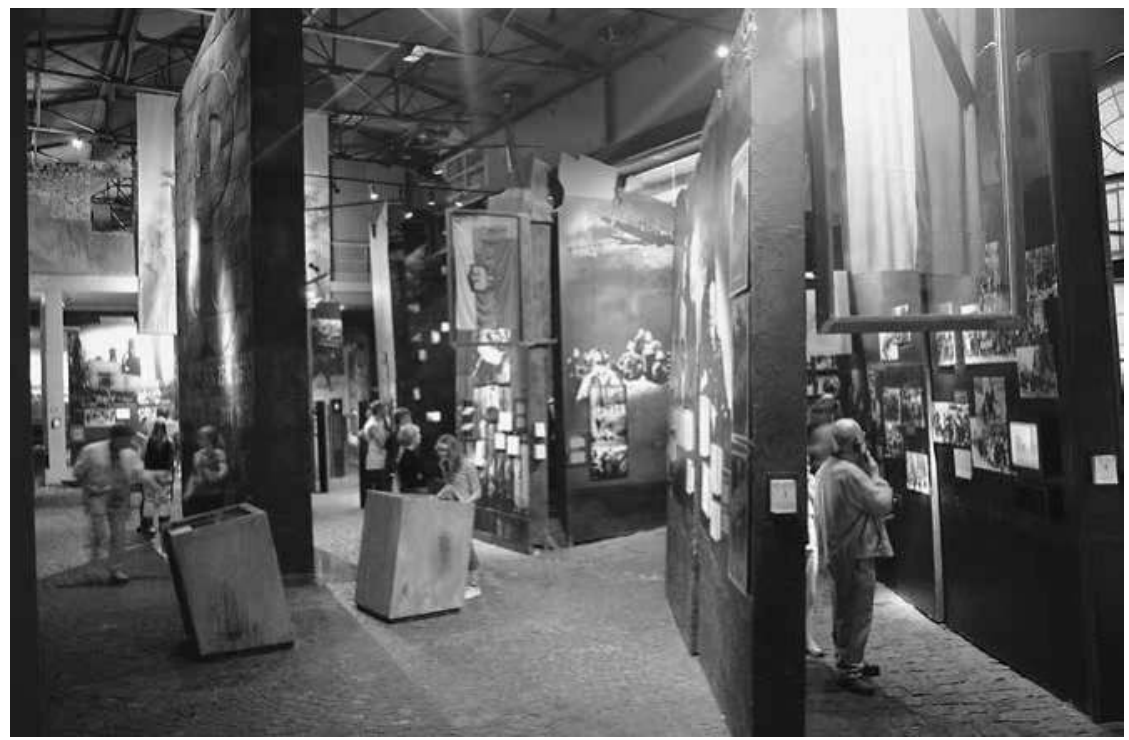

Abb. 4: Das Museum des Warschauer Aufstands, Blick in die erste Etage.

Thematischer Schwerpunkt der Dauerausstellung sind die Ereignisse während der 63 Tage des Aufstands der polnischen Heimatarmee gegen die deutschen Besatzer vom 1. August bis zum 2. Oktober 1944. Sie umfasst jedoch darüber hinaus den Zeitraum vom Kriegsausbruch 1939 bis zu den Prozessen gegen führende Vertreter des polnischen Untergrundstaates und Mitglieder der Heimatarmee in der Volksrepublik Polen bis Mitte der 1950er-Jahre. Die 3.000 Quadratmeter große Schau ist chronologisch gegliedert; der Rundgang ist zusätzlich um einzelne Themenräume ergänzt. Als erste ihrer Art in Polen setzte sie auf umfangreiche Inszenierungen und Szenografien, die den Besuchern den Eindruck vermitteln, die Welt der kämpfenden Stadt zu betreten (siehe Abb. 4). Das Außengelände des Museums wurde zudem mit zahlreichen Denkmälern und Gedenktafeln ausgestattet, die den Anspruch der Museumsverantwortlichen dokumentieren, ihre Institution als zentralen Informations- und Gedenkort für den Warschauer Aufstand und die gefallenen Kämpfer zu etablieren. ${ }^{111}$ Das MPW ist eines der beliebtesten Museen der Stadt; in den Jahren 2008 bis 2013 bewegte sich seine jährliche Besucherzahl zwischen annähernd 420.000 und 525.000. ${ }^{112}$

111 Kowal, Paweł: Jak budowaliśmy Muzeum [Wie wir das Museums geschaffen haben]. In: Dąbkowska-Cichocka: Przewodnik po Muzeum, 7-11, hier $8 \mathrm{f}$. Näher wird auf die memoriale Gestaltung des Museumsgeländes in Teil 3, Kapitel 1.3 eingegangen.

112 Auskunft des MPW, E-Mail vom 30. Juni 2014. 
Das Żydowski Instytut Historyczny (ŻIH) in Warschau wurde 1947 geschaffen. $\mathrm{Zu}$ seinen Tätigkeitsfeldern gehörte von Beginn an auch die Musealisierung der Vergangenheit der polnischen Juden. ${ }^{113}$ Realisiert wurde diese Aufgabe zwischen den 1970er-Jahren und der zweiten Hälfte der 2000er-Jahre institutionell in einem eigenen Museum, ${ }^{114}$ das allerdings in der zweiten Hälfte der 2000er-Jahre als eigene Abteilung aufgelöst wurde. Diese organisatorische Veränderung hatte jedoch keine Auswirkungen auf die Ausstellungstätigkeit des Instituts, die weiterhin in denselben Räumen stattfindet.

Bereits 1953 wurde eine erste Dauerausstellung eröffnet, die die Geschichte der polnischen Juden in den Jahren 1939 bis 1945 präsentierte. Diese Schau bestand bis Anfang der 1970er-Jahre. 1983 wurde eine neue ständige Präsentation installiert, deren historischer Teil sich demselben Thema widmete, von der jedoch keine Unterlagen erhalten sind. ${ }^{115}$ Im Juni 2001 wurde diese Präsentation von einer neuen abgelöst, die auf etwa 250 Quadratmetern die Geschichte des Warschauer Ghettos ins Zentrum rückte. ${ }^{116}$ Die Ausstellung mit dem Titel »Getto Warszawskie. 15 listopada 1940 - 16 maja 1943 r.» (Das Warschauer Ghetto. 15. November 1940-16. Mai 1943) nahm darüber hinaus auch an einigen Stellen Bezug auf die Geschichte der Judenverfolgung in anderen Regionen des Landes. Die Präsentation bestand überwiegend aus Fotografien und faksimilierten Dokumenten aus dem Untergrundarchiv des Warschauer

113 Sieramska, Magdalena: Muzeum Żydowskiego Instytutu Historycznego - Zbiory i działalność [Das Museum des Jüdischen Historischen Instituts - Sammlungen und Tätigkeit]. In: Żbikowski, Andrzej (Hg.): Żydowski Instytut Historyczny. 50 lat działalności. Materiały z konferencji jubileuszowej [Das Jüdische Historische Institut - 50 Jahre Tätigkeit. Beiträge der Jubiläumskonferenz]. Warszawa 1996, 55-61, hier 55.

114 Die Transformation der bisherigen musealen Abteilung des ŻIH in ein Museum schildern Głębocki, Wiesław/Mórawski, Karol: Nowy kształt Muzeum Żydowskiego Instytutu Historycznego w Warszawie [Die neue Gestalt des Museums des Jüdischen Historischen Instituts in Warschau]. In: Muzea Walki 10 (1977), 71-76, hier $71 \mathrm{f}$. Zum Zeitpunkt der Recherchen im Jahr 2010 stellte das Museum keine eigenständige institutionelle Einheit des ŻIH mehr da. Im Institutsführer von 2003 war es als solches jedoch noch aufgeführt, woraus zu schließen ist, dass die organisatorische Veränderung in der Zwischenzeit stattgefunden hat. Vgl. Tych, Feliks/Bergmann, Eleonora/Hensel, Jürgen (Hg.): Żydowski Instytut Historyczny. Przewodnik [Führer durch das Jüdische Historische Institut]. Warszawa 2003, 10, $27 \mathrm{f}$.

115 Sieramska: Muzeum Żydowskiego Instytutu Historycznego, 58. Lediglich ein Beitrag in der Zeitschrift Muzea Walki (Museen des Kriegs) dokumentiert die erste Planungsphase der Schau: Głębocki/Mórawski: Nowy kształt Muzeum Żydowskiego Instytutu Historycznego.

116 Auskunft des ŻIH, E-Mail vom 10. April 2015. Die folgenden Verweise auf Inhalte der Dauerausstellung basieren auf dem Besuch der Schau durch die Verfasserin am 19. Mai 2010. 


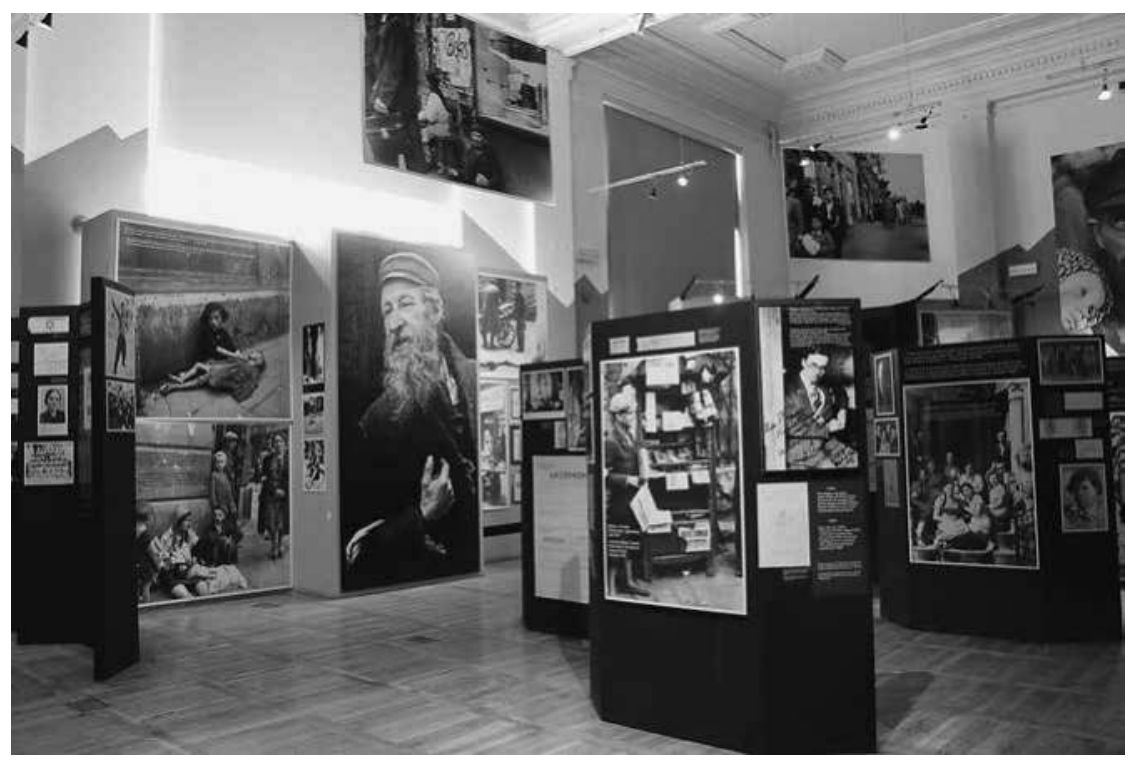

Abb.5: Die Dauerausstellung des Jüdischen Historischen Instituts namens Emanuel Ringelblum.

Ghettos »Oneg Schabbat« (siehe Abb.5). Die Schau bestand bis Dezember 2012. In diesem Jahr hatte sie ca. 11.500 Besucher. ${ }^{17}$

\section{Stadtmuseum Łódź}

Das »Historische Museum der Stadt Łódź« (Muzeum Historii Miasta Łodzi, MHMŁ) wurde 1975 gegründet. ${ }^{118}$ Im Jahr 2010 kam es zur Umbenennung in »Stadtmuseum Łódź« (Muzeum Miasta Łodzi, MMŁ). Das Museum zeigte in den Jahrzehnten seines Bestehens mehrere ständige Präsentationen; diese konzentrierten sich jedoch auf kulturgeschichtliche Themen. ${ }^{119}$ Die erste historische Dauerausstellung, die die gesamte Geschichte der Stadt bis 1945 in den Blick nahm, entstand 1998 unter dem Titel »Triada łódzka. Trzy wielkie społeczności. Polacy - Niemcy - Żydzi« (Łódźer Triade. Drei große Gemein-

117 Auskunft des ŻIH, E-Mail vom 10. April 2015.

118 Czubaczyński, Ryszard (Hg.): Pałac - Muzeum. Muzeum Historii Miasta Łodzi. Informator - przewodnik [Palast - Museum. Das Historische Museum der Stadt Łódź. Führer durch das Museum]. Łódź 1995, [3].

119 Eine solche Schau stellte auch die Präsentation »Z dziejów Łodzi« (Aus der Geschichte Łódźs) dar, die 1979 eröffnet wurde. Ebd., [4]. 


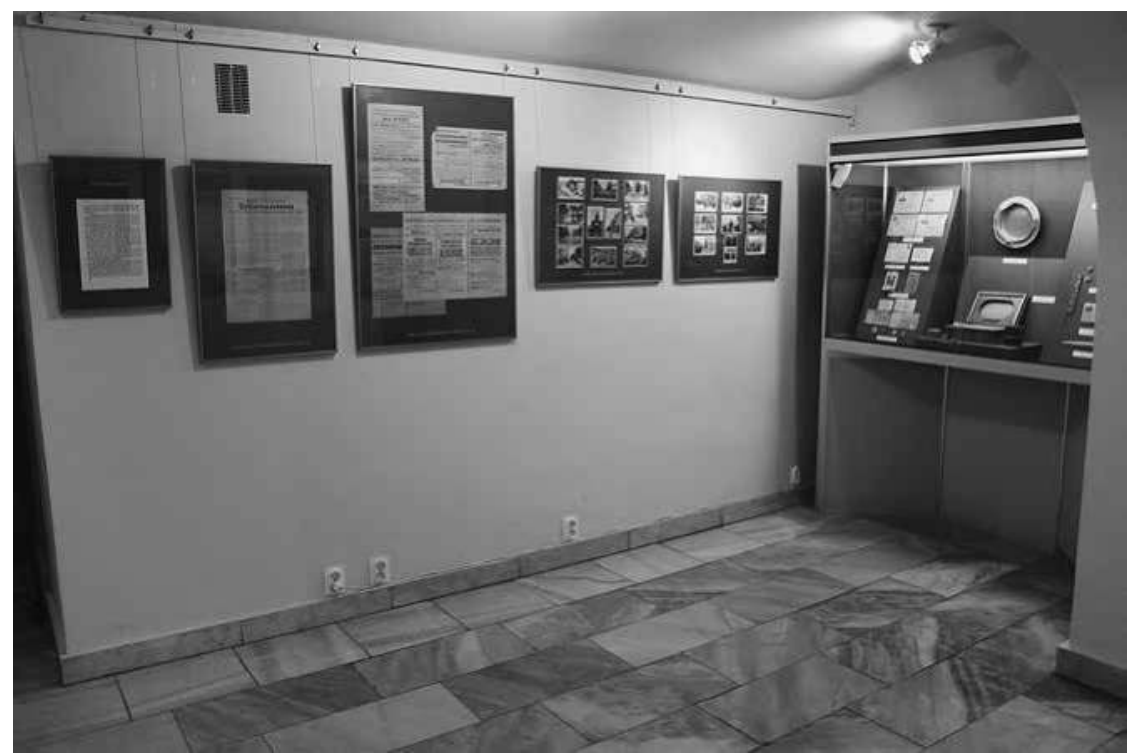

Abb. 6: Die Dauerausstellung »tódźer Triade«, Sektion »Lodsch - Litzmannstadt«.

schaften. Polen - Deutsche - Juden) ${ }^{120}$ und war bis Mitte $2015^{121}$ zu besichtigen. Die Schau gliederte sich in drei chronologisch-thematische Sektionen, deren Themen- und Bereichstexte ${ }^{122}$ jeweils eine eigene Farbcodierung aufwiesen. Die letzte Sektion mit einer Fläche von knapp 30 Quadratmetern war den Jahren des Zweiten Weltkriegs gewidmet. Die Darstellung erfolgte objektzentriert: Glasvitrinen und Bilderrahmen mit Fotografien und Dokumenten wurden von wenigen Kuratorentexten ergänzt (siehe Abb.6). Das Museum

120 Die Ausstellung war formal der übergreifenden, im Jahr 1991 eröffneten und sukzessive erweiterten Dauerausstellung des Hauses zugeordnet - »Z dziejów Łodzi. Historia Kultura - Codzienność (Aus der Geschichte Łódźs. Geschichte - Kultur - Alltag) -, funktionierte jedoch unabhängig von dieser. Die Verweise auf Inhalte der Dauerausstellung basieren auf dem Ausstellungsbesuch am 9. März 2010.

121 Auskunft des Museums, E-Mail vom 30. Mai 2017.

122 Ausstellungstexte sind hierarchisch in verschiedene Informationsebenen gegliedert. An oberster Stelle stehen die Thementexte, die einen Einstieg in ganze Ausstellungsräume oder übergreifende thematische Sektionen bieten. Diesen folgen Bereichstexte, die Informationen zu einzelnen Teilthemen oder Objektgruppen enthalten. Die kleinste Informationseinheit stellen Objektbeschriftungen dar, die in ihrer einfachsten Form das Objekt und seine Herkunft benennen, oft jedoch (auch) weiterführende Informationen etwa zum Inhalt einer Fotografie bieten. Dawid, Evelyn/Schlesinger, Robert: Texte in Museen und Ausstellungen. Ein Praxisleitfaden. Bielefeld 2002, 36 f., $159 \mathrm{f}$. 
und seine Dauerausstellungen hatten in den Jahren 2010 bis 2012 zwischen ca. 36.300 und 45.000 Besucher jährlich. ${ }^{123}$

\section{Martyrologiemuseum Radogoszcz, tódź}

Auf dem Gelände einer früheren Fabrik im Łódźer Stadteil Radogoszcz, die in den Jahren 1939 bis 1945 von den Deutschen als Gefängnis genutzt worden war, wurde 1961 ein »Mausoleum« (mauzoleum) eröffnet als Gedenkort für das Leiden und die Todesopfer der im Gefängnis Inhaftierten sowie die Opfer der deutschen Besatzung der Stadt.Seine Fertigstellung markierte die Eröffnung einer ersten Dauerausstellung im Jahr 1976. Als »Museum des Martyriums und des Kampfes in Radogoszcz« (Muzeum Martyrologii $i$ Walki w Radogoszczu) gehörte die Einrichtung als Abteilung zum »Museum der Geschichte der Revolutionsbewegung in Łódź« (Muzeum Historii Ruchu Rewolucyjnego $w$ Łodzi). ${ }^{124}$ Für die Ausstellung wurde das frühere Fertigungsgebäude der Fabrik umfassend umgebaut, sodass es kaum mehr an seine frühere Verwendung und Geschichte erinnert. ${ }^{125}$ Die übrige Fläche des im Januar 1945 zerstörten Areals wurde in einen Denkmalkomplex verwandelt, dessen zentrale Elemente ein Ruinenstück des ursprünglichen Hauptgebäudes, ein Sarkophag mit den Überresten der in der Nacht vom 17. zum 18. Januar 1945 vom deutschen Gefängnispersonal ermordeten Insassen sowie ein großes Denkmal in Form einer steinernen Spitze (iglica) auf dem Platz vor dem Museumsgelände sind. ${ }^{126}$ Auf der Außenwand des adaptierten Ausstellungsgebäudes wurde eine Skulptur integriert, die aus dem Mauerwerk hervortretende, sich windende menschliche Körper zeigt. Seit 1990 ist das »Martyrologiemuseum Radogoszcz« (Muzeum Martyrologii Radogoszcz) eine Abteilung des »Museums der Unabhängigkeitstraditionen in Łódź« (Muzeum Tradycji Niepodległościowych w Łodzi, MTNŁ).

Die Dauerausstellung von 1976 wurde im Jahr 1990 überarbeitet bzw. ergänzt. ${ }^{127} \mathrm{Zu}$ existierenden Archivmaterialien dieser Schauen gab es leider keinen Zugang, weswegen diese Präsentationen in den Analysen kaum be-

123 Auskunft des Museums, E-Mail vom 30. Mai 2017.

124 Iwanicki, Ryszard/Janaszek, Grażyna/Rukowiecki, Andrzej: Martyrologium Łódzkie. Przewodnik po Radogoszczu i Miejscach Pamięci Narodowej [Łódźer Martyrologium. Führer durch Radogoszcz und die Orte nationaler Erinnerung]. Łódź 2005, $10 \mathrm{f}$.

125 Iwanicki/Janaszek/Rukowiecki: Martyrologium Łódzkie, 17.

1261965 wurden auf dem Areal auch die Überreste namenloser Opfer einer Exekution in der Region beigesetzt. Ebd., 20.

127 Iwanicki/Janaszek/Rukowiecki: Martyrologium Łódzkie, 11; [rs]: Wojenna Łódź [Łódź während des Kriegs]. In: Dziennik Łódzki vom 10.9.1990, 4. Zitiert nach: Źródlak, Wojciech: Bibliografia radogoska [Radegaster Bibliografie], bibliografia_radogoska_nwe_ 2010-03-04.pdf, S. 109, Stand: 10.2.2010, URL: www.muzeumtradycji.pl (am 4.3.2010). 


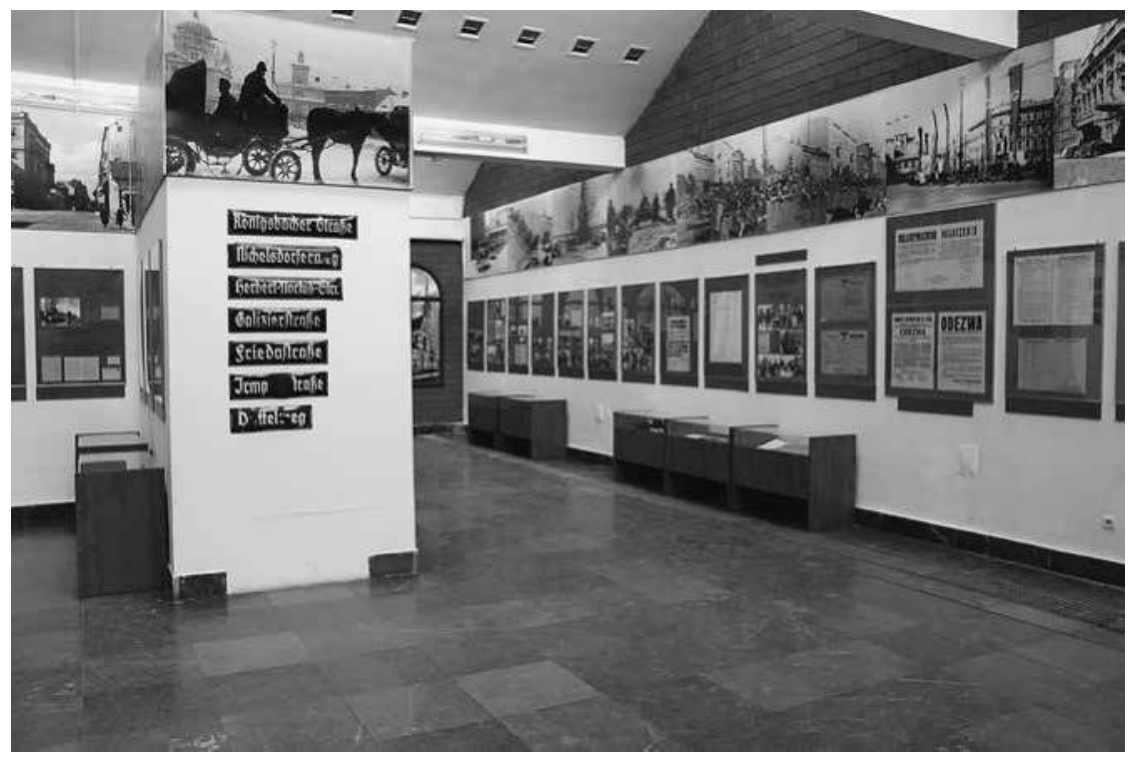

Abb. 7: Die Dauerausstellung »tódź und die tódźer Region in den Jahren des Kriegs und der Besatzung 1939-1945«.

rücksichtigt werden können. ${ }^{128}$ Eine neukonzipierte Schau aus dem Jahr 2003 eröffnete schließlich unter dem Titel »Łódź i ziemia łódzka w latach wojny i okupacji 1939-1945 (Łódź und die Łódźer Region in den Jahren des Kriegs und der Besatzung 1939-1945); ihre Fläche gehörte mit 570 Quadratmetern zu den größten hier untersuchten thematischen Schauen aus diesem Zeitraum. ${ }^{129}$ Sie stellte in einzelnen thematischen Sektionen, die weitgehend chronologisch gegliedert waren, die Geschichte der Stadt und Region vom Sommer 1939 bis zum Abzug der deutschen Truppen aus Łódź am 18. Januar 1945 dar. Es dominierten einfache Bilderrahmen mit Kuratorentexten, Fotografien sowie reproduzierten Karten und Dokumenten. Vitrinen mit originalen Exponaten ergänzten den Rundgang. Oberhalb der Bilderrahmen waren großformatige Fotografien angebracht, die die jeweiligen thematischen Ab-

128 Lediglich eine publizierte Beschreibung der Schau von 1976 gibt einige Einblicke in deren Aufbau und Gestaltung. Siehe Heinrich, Maria/Szczepaniak, Jacek: Muzeum Martyrologii i Walki w Radogoszczu [Das Museum des Martyriums und des Kampfes in Radogoszcz]. In: Muzea Walki 15 (1982), 95-108, hier 95, 98-101.

129 Information der Presseabteilung des Museums der Unabhängigkeitstraditionen in Łódź, E-Mail vom 27. März 2015. Die folgenden Verweise auf Inhalte der Dauerausstellung beziehen sich auf den Besuch am 7. März 2010. 
schnitte illustrierten (siehe Abb. 7). Im Jahr 2010 hatte die Ausstellung fast 13.000 Besucher. ${ }^{130}$

Im September 2011 wurde eine gestalterisch überarbeitete Version der Schau eröffnet. Von ihrer Vorgängerin unterscheidet sie sich in erster Linie durch die Integration szenografischer Installationen in den Rundgang; die Ausstellungsinhalte inklusive der Kuratorentexte wurden dagegen weitgehend identisch übernommen. Ergänzt wurden Informationen zu den Stadtbewohnern, die während des Kriegs in den polnischen Auslandsstreitkräften an verschiedenen Fronten kämpften, sowie ein kurzer Prolog, der das Ende der deutschen Besatzung der Stadt und die folgenden Ereignisse im Januar 1945 schildert. Da diese Ausstellung außerhalb des Untersuchungszeitraumes eröffnet wurde, wird sie in den Analysen nicht berücksichtigt.

\section{Historisches Museum der Stadt Krakau}

Das Muzeum Historyczne Miasta Krakowa (MHK) wurde 1899 als Teil des "Archivs der Historischen Akten" (Archiwum Aktów Dawnych) gegründet. Seit Dezember 1945 ist es eine eigenständige Kulturinstitution. ${ }^{131}$ Die erste Dauerausstellung dieses Museums, die ausschließlich der Geschichte der Stadt während des Zweiten Weltkriegs gewidmet war, entstand Anfang der 1980er-Jahre im "Schlesischen Haus" an der früheren Pomorska-Straße. ${ }^{132}$ In den Kellern des Gebäudes befanden sich von November 1939 bis Januar 1945 Arrestzellen der Gestapo, in denen Menschen gefangen gehalten und während der Verhöre gefoltert wurden. ${ }^{133} 1981$ entstand dort eine neue Abteilung des MHK unter dem offiziellen Namen »Der Kampf und das Martyrium der Polen in den Jahren 1939-1945 " (Walka i męczeństwo Polaków w latach 1939-1945). ${ }^{134}$ Die ehemaligen Arrestzellen im Keller gingen damit in die

130 Information der Presseabteilung des Museums der Unabhängigkeitstraditionen in Łódź, E-Mail vom 27. März 2015.

131 Wojak, Sławomir: Trzydzieści lat krakowskiego muzealnictwa (1945-1975) [Dreißig Jahre Krakauer Museumswesen (1945-1975)]. In: Krzysztofory 2 (1975), 11-32, hier 12.

132 In der 1979 eröffneten Dauerausstellung im Hauptgebäude des MHK, dem Krzysztofory-Palast, gab es kurzzeitig einen Raum, der der Geschichte der Stadt im Zweiten Weltkrieg gewidmet war. Passowicz, Wacław: Kronika działalności Muzeum Historycznego m. Krakowa za rok 1979 [Chronik der Tätigkeit des Historischen Museums der Stadt Krakau für das Jahr 1979]. In: Krzysztofory 7 (1980), 104-108, hier 105.

133 Salwiński, Jacek: Dom Śląski. Pomorska 2, Królewska 1 - historia gmachu [Das Schlesische Haus. Pomorska-Straße 2, Królewska-Straße 1 - die Geschichte des Gebäudes]. In: Bednarek, Monika/Salwiński, Jacek (Hg.): Pomorska. Przewodnik po miejscu pamięci narodowej i oddziale Muzeum Historycznego Miasta Krakowa [Pomorska. Führer durch den Ort nationaler Erinnerung und die Abteilung des Historischen Museums der Stadt Krakau]. Kraków 2003, 7-18, hier 13 f.

134 Gąsiorowski, Teodor: »Dom Śląski« przy ul. Pomorskiej 2 w Krakowie [Das »Schlesische Haus« an der Pomorska-Straße 2 in Krakau]. In: Krzysztofory 17 (1990), 82-84, 
Obhut des Museums über, das diese im Wesentlichen in ihrem ursprünglichen Zustand beließ, restaurierte und für Besucher zugänglich machte. ${ }^{135}$ Zusätzlich mietete es Ausstellungsräume in dem Gebäude an. Am 30. September 1982 wurde die erste Dauerausstellung der Abteilung unter dem gleichlautenden Titel »Walka i męczeństwo Polaków w latach 1939-1945« eröffnet, die in den folgenden zwanzig Jahren mehrfache Überarbeitungen und Ergänzungen erfuhr. Eine erste inhaltlich erweiterte Version wurde am 6. September 1990 unter dem Titel »Kraków 1939-1945 « wiedereröffnet. ${ }^{136}$ Größere Ergänzungen fanden sich in der am 14. April 1998 eröffneten Ausstellung "Kraków 1939-1956«, die in erster Linie um Ereignisse der Nachkriegszeit erweitert worden war, insbesondere um die Verfolgung des antikommunistischen Widerstands während des Stalinismus in Polen. ${ }^{137}$ Diese Schau wurde schließlich im Juni 2010 abgelöst von einer neuen Dauerausstellung in der ehemaligen »Emaillewarenfabrik Oskar Schindlers" (Fabryka Emalia Oskara Schindlera), die seit 2008 eine Abteilung des MHK ist und in der sich nun die zentrale Präsentation des Museums über die Zeit der deutschen Besatzung Krakaus befindet. ${ }^{138}$

Die Ausstellungsfläche in der Abteilung "Pomorska-Straße« war von Beginn an stark begrenzt; sie umfasste nur einen Saal mit knapp 100 Quadratmeter. ${ }^{139}$ Die Gestaltung basierte auf einfachsten Mitteln: Den Kern bildeten schwarze Ausstellungstafeln und einzelne Vitrinen, die bei den folgenden Überarbeitungen restauriert und teilweise um einige Materialien ergänzt wurden. In späteren Jahren wurden die Tafeln nummeriert, um den Besuchern die Orientierung entlang des chronologisch-thematischen Rundgangs zu erleichtern; hinzu kamen Ende der 1990er-Jahre einzelne thematische Fotorahmen

hier $82 \mathrm{f}$. Zur Geschichte der Entstehung der Museumsabteilung in der Pomorska-Straße vgl. auch Bednarek, Monika: Pamięć zbiorowa - muzeum jako miejsce pamięci [Kollektive Erinnerung - das Museum als Ort der nationalen Erinnerung]. In: Krzysztofory 25 (2007), 227-236, v. a. 232-235.

135 An den Wänden der Zellen sind bis heute Inschriften der Inhaftierten erhalten.

136 Die erste Dauerausstellung aus dem Jahr 1982 wurde aufgrund von dringenden konservatorischen Vorbehalten (u. a. Pilzbefall in den Ausstellungsräumen) am 30. April 1985 geschlossen. Die anschließenden Renovierungsarbeiten zogen sich über vier Jahre hin. Gąsiorowski: »Dom Śląski«, 84.

137 Salwiński, Jacek: Wystawa stała »Kraków 1939-1956« [Die Dauerausstellung "Krakau 1939-1956«]. In: Bednarek, Monika/Salwiński, Jacek (Hg.): Pomorska. Przewodnik po miejscu pamięci narodowej i oddziale Muzeum Historycznego Miasta Krakowa [Pomorska. Führer durch den Ort nationaler Erinnerung und die Abteilung des Historischen Museums der Stadt Krakau]. Kraków 2003, 37-79, hier 37. Die Verweise auf Inhalte der Dauerausstellung von 1998 basieren auf dem Besuch der Schau am 14. März 2010.

138 Passowicz, Wacław: Kronika działalności Muzeum Historycznego Miasta Krakowa w 2008 roku [Chronik der Tätigkeiten des Historischen Museums der Stadt Krakau im Jahr 2008]. In: Krzysztofory 27 (2009), 331-361, hier 331.

139 Wroński: Scenariusz wystawy, 2. 


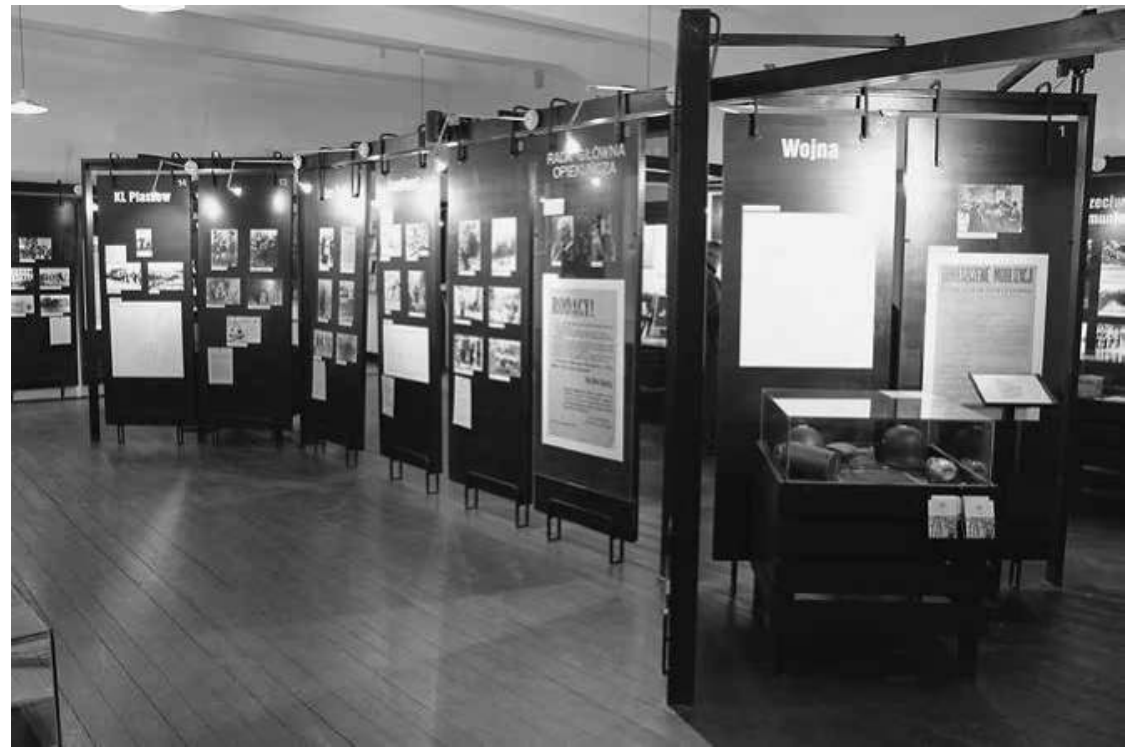

Abb. 8: Die Dauerausstellung »Kraków 1939-1956« in der Pomorska-Straße.

sowie verschiedene Musealien. Alle Präsentationen waren objektzentriert und die einzelnen thematischen Sektionen durch grafisch exponierte Überschriften markiert; Bildunterschriften und erläuternde Texte wurden nur sehr sparsam eingesetzt (siehe Abb. 8). ${ }^{140}$ Die Besucherzahlen waren vergleichsweise gering, was auch mit der weiten Entfernung des Museums vom Stadtzentrum verbunden ist; im Jahr 2009 hatte die Abteilung knapp 8.500 Besucher. $^{141}$

Abgelöst wurde diese Schau von der inhaltlich vollständig neu konzipierten Dauerausstellung in der sogenannten Schindler-Fabrik mit dem Titel »Kraków - czas okupacji 1939-1945« (Krakau - Die Besatzungszeit 1939-1945), die eine Fläche von etwa 1.200 Quadratmetern einnimmt. ${ }^{142}$ In die Pomorska-

140 Die Schau von 1990 wurde aufgrund der aus diesem Präsentationsansatz resultierenden mangelnden Allgemeinverständlichkeit in einem Zeitungsbericht als "schematisch und oberflächlich« kritisiert. Siehe: Muzeum Historyczne [Das Historische Museums]. In: Gazeta Wyborza vom 8.-9.9.1990. Archiwum Muzeum Historycznego Miasta Krakowa (Archiv des Historischen Museums der Stadt Krakau, weiter AMHK), OP-6422-13-2-90.

141 Salwiński, Jacek: Kronika działalności Muzeum Historycznego Miasta Krakowa w 2009 roku [Chronik der Tätigkeiten des Historischen Museums der Stadt Krakau im Jahr 2009]. In: Krzysztofory 28/ 2 (2010), 237-260, hier 255 f.

142 Die Verweise auf Inhalte dieser Präsentation beziehen sich auf den Besuch am 17. März 2010. Die Nummerierung und Bezeichnung der Ausstellungsabschnitte folgt dem Ausstellungsführer: Marszałek, Anna/Bednarek, Monika: Fabryka Emalia Oskara Schindlera. Przewodnik [Die Emaillewarenfabrik Oskar Schindlers. Ausstellungsführer]. Kraków 2010. 


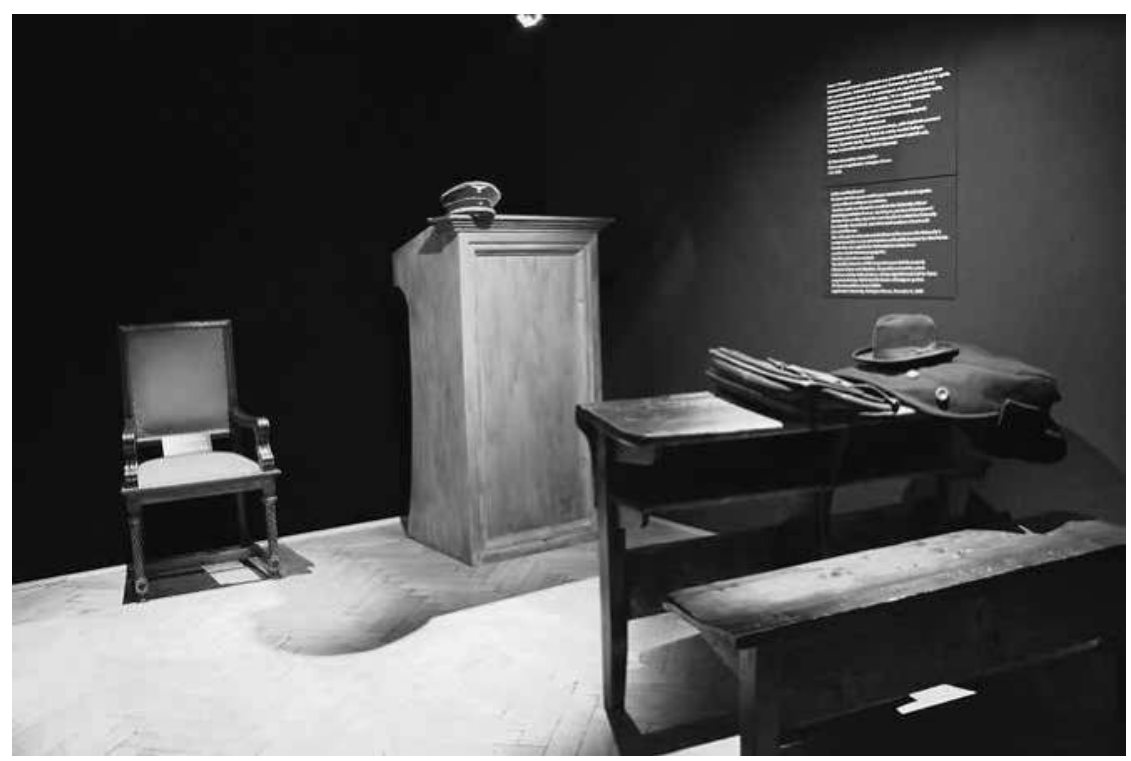

Abb. 9: Die Dauerausstellung in der Schindler-Fabrik, Sektion »Sonderaktion Krakau«.

Straße zog daraufhin eine neue Dauerausstellung ein, die sich auf die Darstellung des überwiegend gegen die polnische Bevölkerung Krakaus gerichteten Terrors in den Jahren 1939 bis 1956 konzentriert. Die Schau, die ebenso wie diejenige in der Schindler-Fabrik auf einer szenografischen, stark vom Theater geprägten Gestaltung basiert, wurde am 2. Juni 2011 eröffnet. ${ }^{143}$ Sie wird in der vorliegenden Studie nicht mehr berücksichtigt.

Der Rundgang der Präsentation in der Schindler-Fabrik ist chronologisch aufgebaut und wird von einzelnen Themenräumen ergänzt. Charakteristisch für die Schau sind raumumfassende Szenografien und szenische Arrangements; jeder Raum besitzt eine eigene Geräusch- und Lichtkulisse. Der Regisseur Łukasz Czuj und der Bühnenbildner Michał Urban, die mit der gestalterischen Umsetzung beauftragt waren, haben vom Theater inspirierte Raumkompositionen entworfen, in denen die Besucher - scheinbar eine Bühne betretend - zu Teilnehmern der sich vollziehenden Ereignisse werden (siehe Abb. 9). Die Ausstellung ist äußerst beliebt; im Jahr 2011 zählte sie knapp 200.000 Besucher. ${ }^{144}$

143 Vgl. Ulica Pomorska [Pomorska-Straße], URL: www.mhk.pl/oddzialy/ulica_pomorska (am 6.5.2011).

144 Salwiński, Jacek: Kronika działalności Muzeum Historycznego Miasta Krakowa w 2011 roku [Chronik der Tätigkeiten des Historischen Museums der Stadt Krakau im Jahr 2011]. In: Krzysztofory 30 (2012), 297-318, hier 297, 315. 
Historisches Museum in Wroctaw

Das Muzeum Historyczne we Wrocławiu (MH) wurde 1965 gegründet und ist seit dem Jahr 2000 eine Abteilung des »Stadtmuseums Wrocław« (Muzeum Miejskie Wrocławia, MMW). Es verortet sich selbst in der Tradition des ersten »Historischen Museums der Stadt Wrocław« (Muzeum Historyczne Miasta Wrocławia), das 1948 gegründet und nur wenige Jahre später Teil des »Schlesischen Museums« (Muzeum Śląskie) wurde. ${ }^{145}$ Am 19. April 2009 eröffnete im sogenannten Königspalast (Pałac Królewski) die neue Dauerausstellung des Museums unter dem Titel »1.000 lat Wrocławia« (1.000 Jahre Wrocław). Sie ist die erste ständige Präsentation dieser Institution, die die gesamte Geschichte der Stadt seit der ersten Siedlung bis ins Jahr 2000 umfasst. Im Zeitraum 2010 bis 2012 hatte sie jährlich zwischen knapp 38.000 und 47.600 Besucher. ${ }^{146}$

Das grundlegende Konzept dieser Dauerausstellung spiegelt den in Wrocław in den vergangenen zwei Dekaden erfolgten Aneignungsprozess der lokalen und regionalen Geschichte samt ihrer fremdnationalen und -staatlichen Teile wider: ${ }^{147}$ Die multiethnische und multistaatliche Vergangenheit der Stadt soll in ihrem jeweiligen historischen Kontext präsentiert werden, sodass ihre polnischen Anteile, aber eben auch die Herrschaft der Habsburger oder Preußen als gleichwertige Elemente gezeigt werden. ${ }^{148}$ Mit diesem Zugang wollen sich die Ausstellungsmacher von der etablierten nationalen Geschichtsperspektive distanzieren, die den Großteil der existierenden polnischen stadthistorischen Ausstellungen bis in die Gegenwart prägt. Ausdruck des expliziten Lokalbezugs sind die sogenannten »Meilensteine« der Stadtgeschichte, zentrale Daten, die sich im Museumshof auf steinernen Pfeilern

145 Muzeum Historyczne we Wrocławiu [Das Historische Museum in Wrocław], URL: www.muzeum.miejskie.wroclaw.pl/CMS/muzeum_historyczne/muzeum_historyczne. html (am 13.3.2015).

1462010 lag die Besucherzahl der Schau bei knapp 47.600, 2011 waren es knapp 38.000 Personen. Auskunft von Halina Okólska, der Leiterin des Historischen Museums, E-Mail vom 31. März 2015.

147 Vgl. Thum, Gregor: Die fremde Stadt. Breslau nach 1945. München 2006, 510-526; Zybura, Marek: Breslau und Wrocław. In: Kobylińska, Ewa/Lawaty, Andreas (Hg.): Erinnern, vergessen, verdrängen. Polnische und deutsche Erfahrungen. Wiesbaden 1998, 367-380, hier 378-380.

148 Dieser Ansatz hat dem Museum auch erhebliche Kritik eingebracht. So entbrannte etwa eine publizistische Debatte darüber, ob es gerechtfertigt sei, durch die Bezeichnung des Spätgen-Palais, in dem das Museum untergebracht ist, als »Königspalast«, die Herrschaft Friedrich II. von Preußen derart prominent zu würdigen, dessen Polen-Politik in der polnischen Geschichtsschreibung äußerst negativ bewertet ist. Die Diskussionen schildert Kretschmann, Vasco: Die neue Dauerausstellung des Breslauer Stadtmuseums und das multikulturelle historische Erbe der Stadt. Berlin: Freie Universität Berlin, 2012. Unveröffentlichte Masterarbeit, 33-35. 


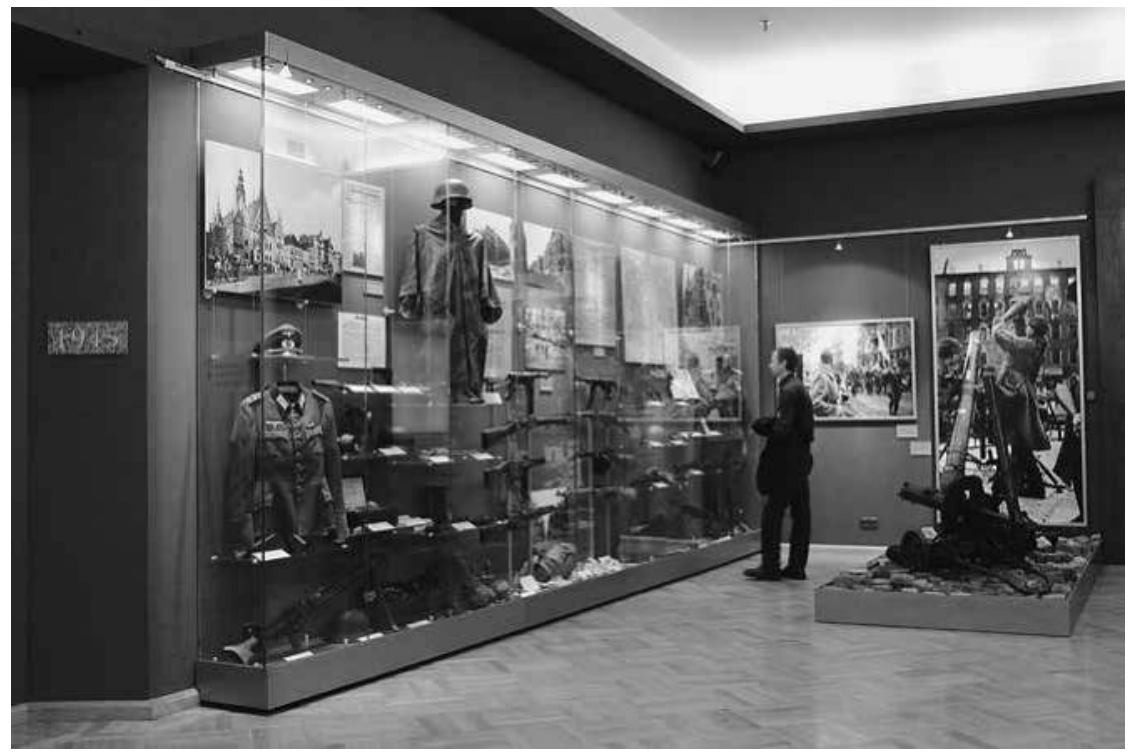

Abb. 10: Saal »Die hitleristische Diktatur - Der Zweite Weltkrieg« in der Dauerausstellung des Historischen Museums in Wroctaw.

und auch in den einzelnen Ausstellungssälen auf kleinen Steinplaketten deutlich sichtbar finden. Polnische Besucher vermissen dort etwa oft das Jahr 1939, mithin den Kriegsausbruch; markiert sind dagegen der Beginn der NSHerrschaft in Deutschland 1933 sowie das Jahr 1945, das Ende des Kriegs und der Übergang der Stadt an die Volksrepublik Polen. ${ }^{149}$

Innerhalb der tausendjährigen Geschichte, die der fast 1.600 Quadratmeter umfassende Rundgang schildert, ist ein eigener Saal von etwa 65 Quadratmetern ${ }^{150}$ den Jahren 1933 bis 1945 gewidmet (siehe Abb. 10). Die Präsentation ist wie im Rest der Schau rein objektzentriert; lediglich ein kleiner Thementext bietet einen Einblick in Inhalte und das Konzept des Raumes. Darüber hinaus gibt es nur kurze Objektbeschriftungen, die das jeweilige Exponat sowie das Archiv benennen, aus dem es stammt; punktuell werden frühere Besitzer oder Erschaffer einzelner Objekte genannt. Im Saal befindet sich auch eine Multimediastation. Diese zeigt verschiedene Filme aus der Nachkriegszeit, die den Kampf um die Stadt thematisieren. Das Arrangement

149 Vgl. Sala 1. Kamienie milowe Wrocławia [Saal 1. Die Meilensteine Wrocławs]. In: Łagiewski, Maciej/Okólska, Halina/Oszczanowski, Piotr (Hg.): 1000 lat Wrocławia. Przewodnik po wystawie [1000 Jahre Wrocław. Führer durch die Ausstellung]. Wrocław 2009, $16 \mathrm{f}$.

150 Information von Halina Okólska, E-Mail vom 31. März 2015. 
dieses Saales entspricht nicht mehr der originalen Präsentation bei der Museumseröffnung. Nach Kritik vonseiten der Direktion des Stadtmuseums wurde die zentrale Vitrinenwand Mitte März 2010 umgestaltet; ${ }^{151}$ diese Fassung wird in der vorliegenden Studie analysiert. ${ }^{152}$

\section{Historisches Museum der Stadt Lublin}

Das Muzeum Historii Miasta Lublina wurde im Juli 1979 gegründet. ${ }^{153}$ Es ist im »Krakauer Tor (Brama Krakowska) untergebracht, einem früheren Stadttor Lublins. Seine erste Dauerausstellung wurde am 18. Juli 1979 eröffnet. ${ }^{154}$ Diese Schau ersetzte man 1995 durch eine neue Fassung, ${ }^{155}$ die bis heute zu besichtigen ist. Das Museum ist seit seiner Gründung eine Abteilung des »Lubliner Museums in Lublin" (Muzeum Lubelskie w Lublinie, MLL), das als Regionalmuseum nicht nur mehrere Abteilungen in der Stadt Lublin selbst unterhält, sondern auch in anderen Städten der gleichnamigen Woiwodschaft. ${ }^{156}$

Die Ausstellungsräume im Krakauer Tor sind auf fünf Etagen des Gebäudes verteilt; etwa die Hälfte der verhältnismäßig geringen Fläche in der vierten Etage - etwa 15 Quadratmeter - war und ist den Jahren 1939 bis 1945 gewidmet. Beide bisherigen Dauerausstellungen schilderten bzw. schildern die

151 Interview mit Jerzy Zarawski, Leiter der militärhistorischen Abteilung des Stadtmuseums im Arsenal, am 31. März 2010. Zarawski hat die Umgestaltung dieser Sektion vorgenommen.

152 Die folgenden Verweise auf Inhalte der Ausstellung beziehen sich auf den Besuch am 30. März 2010. Der Ausstellungssal wurde Ende 2015/ Anfang 2016 umfassender überarbeitet und u. a. um mehrere Multimediapräsentationen ergänzt. Auskunft des Museums, E-Mail vom 4. Mai 2017.

153 Es entstand im Rahmen der Umgestaltung der ehemaligen Geschichtsabteilung des "Lubliner Museums« (geschaffen 1961) in eine institutionell eigenständige historische Abteilung (1965), die wiederum 1979 zum »Historischen Museum der Stadt Lublin« transformiert wurde. Jakimińska, Grażyna: Brama Krakowska. Historia [Das Krakauer Tor. Geschichte]. Lublin 1995, 13; Dies. / Nasalski, Zygmunt: 100 lat Muzeum Lubelskiego [100 Jahre des Lubliner Museums]. In: Studia i Materiały Lubelskie 15 (2008), 9-52, hier $39 \mathrm{f}$.

154 Der Titel lautete »Historia Miasta Lublin« (Die Geschichte der Stadt Lublin). Siehe: Wystawa: Historia miasta Lublina. Otwarcie - 18.VII.1979 r. Archiwum Muzeum Lubelskiego w Lublinie (Archiv des Lubliner Museums in Lublin, weiter AMLL), ohne Signatur. Von dieser Präsentation hat sich einzig ein Album mit Fotografien der einzelnen Ausstellungssektionen erhalten (siehe ebd.). Zu erkennen sind auf diesen Abbildungen der zweite Teil der Sektion zum Zweiten Weltkrieg, der in den folgenden Analysen berücksichtigt wird.

155 Information des Museums im Krakauer Tor, E-Mail vom 25. Juli 201. Der Titel der Dauerausstellung blieb fast unverändert: »Lublin - Historia Miasta« (Lublin - Die Geschichte der Stadt).

156 Einen Überblick bietet die Website des Museums, URL: www.muzeumlubelskie.pl (am 18.3.2015). Die Geschichte dieser Institution reicht bis ins Jahr 1906 zurück. Siehe Jakimińska/Nasalski: 100 lat Muzeum Lubelskiego, v. a. 10-12. 


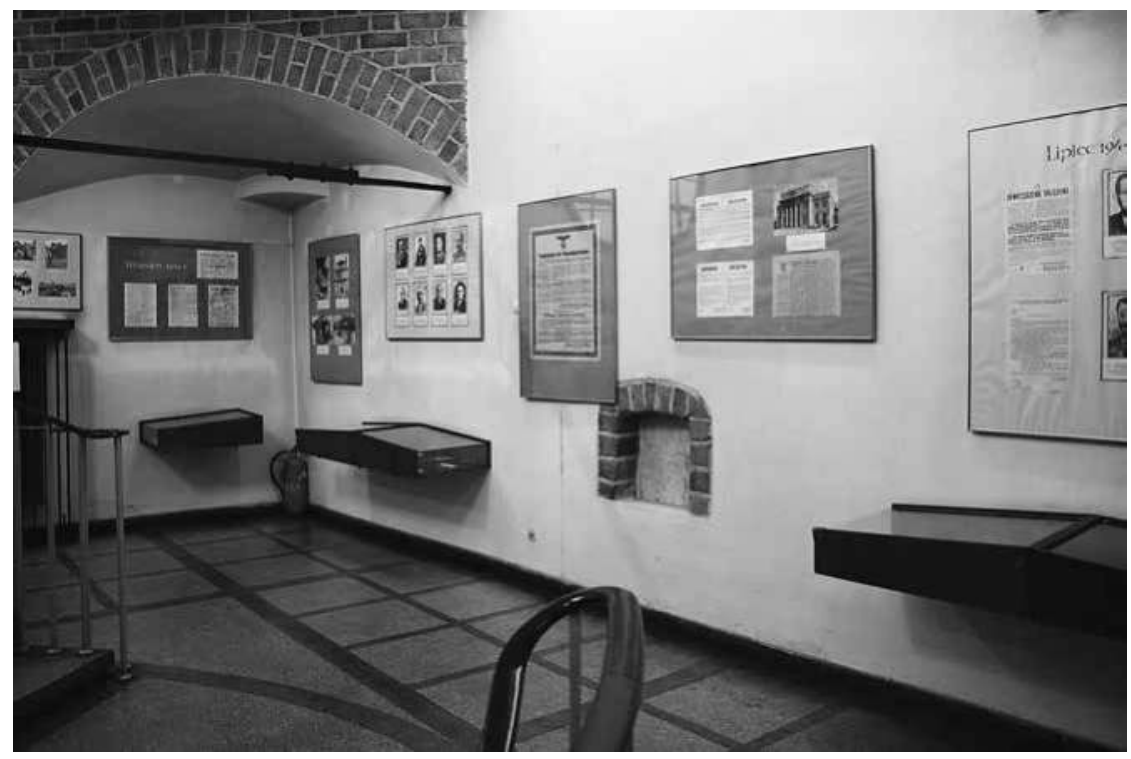

Abb. 11: Die Sektion zum Zweiten Weltkrieg im Krakauer Tor.

Stadtgeschichte von ihren Ursprüngen im 6. Jahrhundert bis zum Jahr 1944. Die erste ständige Präsentation bestand aus weißen Ausstellungstafeln mit großformatigen Faksimiles von Dokumenten und Fotografien. Abgesehen von einzelnen Überschriften fand sich nur auf einer Tafel der Sektion zum Zweiten Weltkrieg ein längerer Kuratorentext, der sich dem Widerstand in den Jahren 1939 bis 1944 widmete (siehe Abb. 11). ${ }^{157}$ Wenige dreidimensionale Exponate waren und sind in einzelnen Vitrinen untergebracht. Die aktuelle Dauerausstellung folgt einem ähnlichen Prinzip. ${ }^{158}$ Es dominieren Fotografien sowie Kopien von Zeitungsberichten und Dokumenten, die schlaglichtartig zentrale Ereignisse und Protagonisten der Kriegs- und Besatzungsjahre der Stadt vorstellen. Die Porträtfotografien einzelner politischer und militärischer Protagonisten sind mit kurzen biografischen Informationen versehen. Umfangreichere Kuratorentexte finden sich in dieser Schau nun dagegen nicht mehr. Zwischen 2008 und 2011 bewegte sich die jährliche Besucherzahl der Ausstellung im Bereich zwischen ca. 4.000 und 4.400 Personen. ${ }^{159}$

157 Wie die Bilder der übrigen Sektionen zeigen, war der Rest der Präsentation dagegen dominiert von großformatigen Ausstellungstexten, die die Erzählung maßgeblich leiteten. Vgl. Wystawa: Historia miasta Lublina.

158 Verweise auf Inhalte dieser Präsentation in den folgenden Analysen beziehen sich auf den Ausstellungsbesuch am 12. Mai 2010.

159 Auskunft des Museums, E-Mail vom 1. April 2015. 


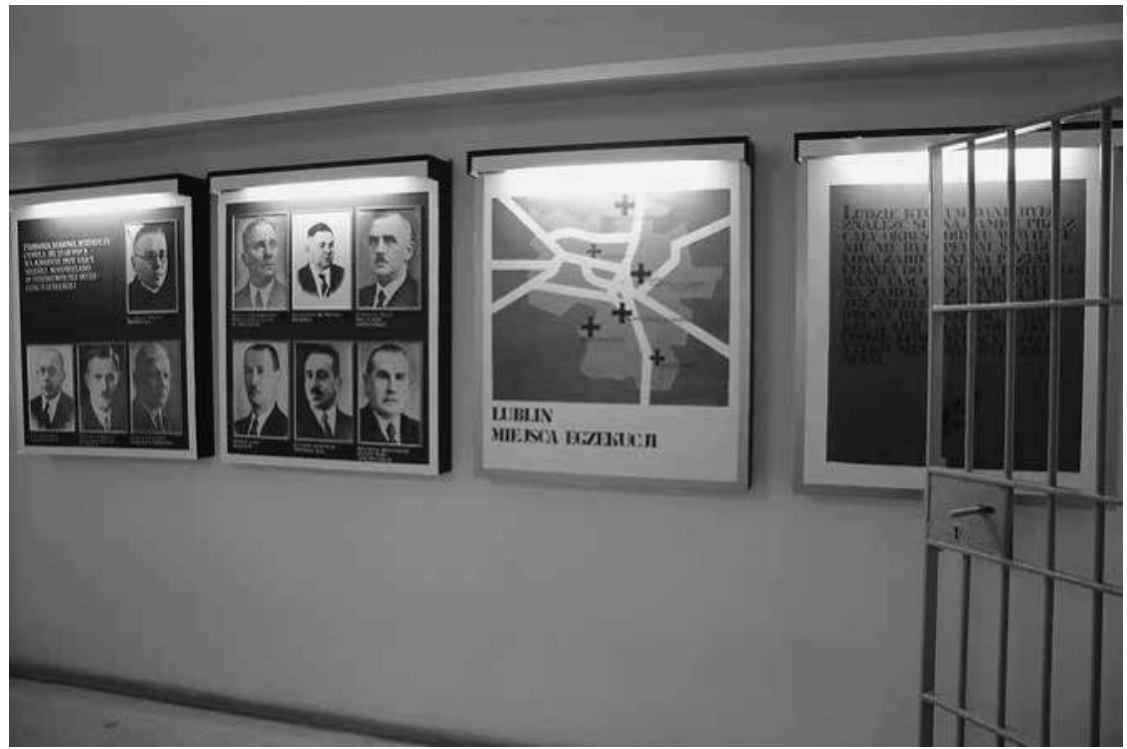

Abb. 12: Das Martyrologiemuseum »Unter der Uhr«, Blick in Zelle 9.

Martyrologiemuseum »Unter der Uhr«, Lublin

Das Muzeum Martyrologii »Pod Zegarem« entstand ebenfalls im Jahr 1979 und gehört, wie das Historische Museum der Stadt Lublin, seit seiner Gründung als eigenständige Abteilung zum Lubliner Museum in Lublin. Untergebracht ist es in ehemaligen Arrestzellen, die die Gestapo in den Jahren 1940 bis 1944 für Verhöre von Häftlingen des Gefängnisses auf dem Lubliner Schloss nutzte. An der Außenfassade des Gebäudes, in dem sie sich befinden, war eine große Uhr angebracht, von der seine Benennung durch die lokale Bevölkerung »Unter der Uhr« (Pod Zegarem) herrührt. In den Zellen haben sich Inschriften der Häftlinge erhalten, die vom Museum konserviert und dokumentiert wurden und bis in die Gegenwart zu besichtigen sind. ${ }^{160}$

Die Eröffnung der Dauerausstellung fand am 23. September 1979 statt. Die Schau stellt die Geschichte der Verfolgung der Einwohner Lublins und der Lubliner Region während der deutschen Besatzung der Jahre 1939 bis 1944 dar, mit einem Schwerpunkt auf den Ereignissen im Lubliner Schloss und den Gestapo-Zellen im Haus »Unter der Uhr«. Die Präsentation ist dominiert

160 Die Konservierungsarbeiten wurden dokumentiert in: Wzorek, Józef: Napisy i znaki w pomieszczeniach dawnej katowni Gestapo. Lublin, ul. Uniwersytecka 1. Lublin 1979. AMLL, ohne Signatur. 


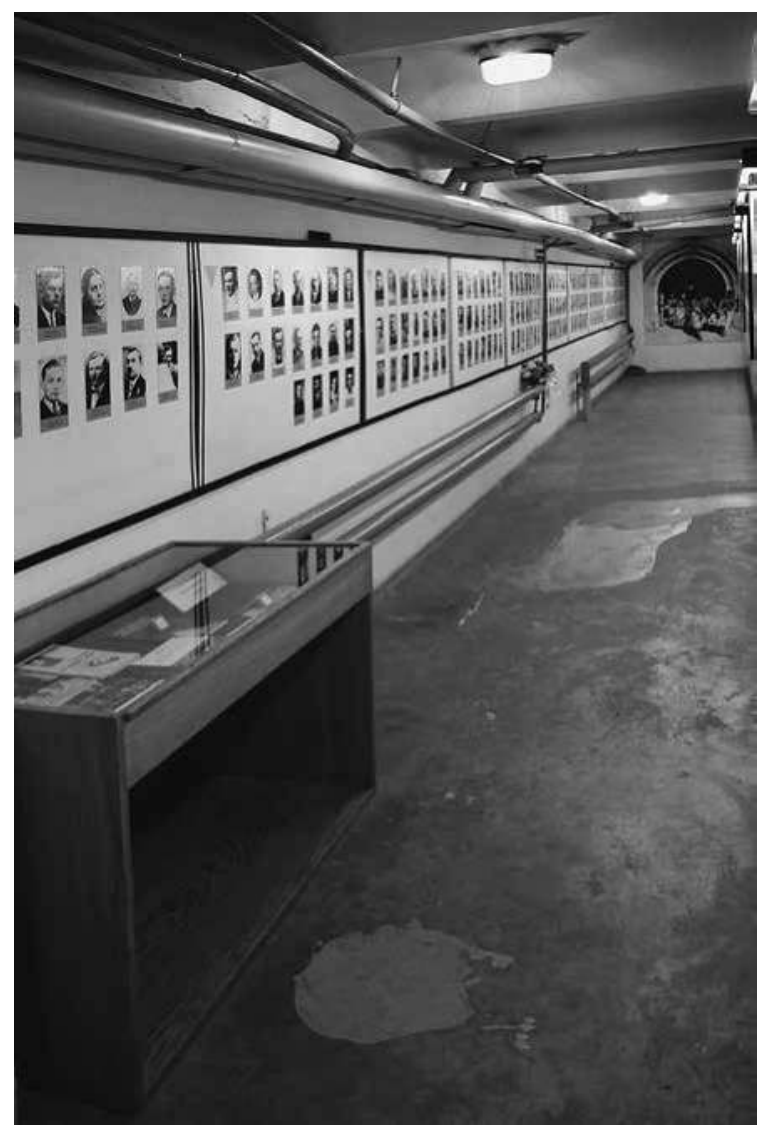

Abb. 13: Der rechte Zellengang des Martyrologiemuseums »Unter der Uhr».

von Ausstellungstafeln, die primär mittels großformatiger Kuratorentexte die Ereignisgeschichte skizzieren (siehe Abb. 12). Ein weiteres zentrales Element der Schau sind Namenslisten sowie eine Porträtgalerie von in Konzentrationslager deportierten und ermordeten Häftlingen des Lubliner Schlosses (siehe Abb. 13). Die Präsentation besteht in ihren wesentlichen Elementen bis in die Gegenwart. ${ }^{161}$ Einzelne thematische Ergänzungen und Verände-

161 Die Verweise auf die Dauerausstellung im Martyrologiemuseum »Unter der Uhr« beziehen sich, falls nicht anders angegeben, auf den Ausstellungsbesuch am 13. Mai 2010. In den Analysen wird die Nummerierung der Zellen verwendet, die im Protokoll der Restaurierungsarbeiten von 1978 vermerkt ist: Wzorek: Napisy i znaki, S. 19 (tabl. 1). Auf diese Nummerierung greifen auch die Museumsmitarbeiter zurück, etwa im Aus- 
rungen, die nach 1989 vorgenommen wurden, konnten anhand einer existierenden Fotodokumentation der originalen Fassung von 1979 sowie mehrerer Sonderausstellungen späterer Jahre nachvollzogen werden, die vom »Klub der ehemaligen politischen Häftlinge des Lubliner Schlosses und „Unter der Uhr « (Klub byłych Więźniów Politycznych Zamku Lubelskiego i "Pod Zegarem«) angefertigt worden sind. ${ }^{162}$ Weitere Veränderungen konnten mithilfe der $\mathrm{Mu}$ seumsleiterin rekonstruiert werden, die bereits seit den 1980er-Jahren vor Ort tätig ist. ${ }^{163}$ Hierzu zählte die Erweiterung des chronologischen und inhaltlichen Umfangs der Dauerausstellung um die Verfolgungsgeschichte des nichtkommunistischen Widerstands in den Jahren 1944 bis 1954, welche durch die Übernahme von Teilen einer Sonderausstellung Anfang 2009 erfolgt ist. In den Jahren 2008 bis 2010 betrug die jährliche Besucherzahl des Museums zwischen knapp 3.000 und 4.300 Personen. ${ }^{164}$

\section{Untersuchungsvorgehen}

Wie durch die vorangegangenen Ausführungen insbesondere zum Forschungsstand deutlich geworden ist, verfolgt die vorliegende Studie einen noch relativ neuen Ansatz. Es wird eine Querschnittsanalyse der Ausstellungen einer gröBeren Anzahl von Museen sowohl in einer synchronen als auch in einer diachronen Perspektive unternommen. Betrachtet wird dabei der Zeitraum von den 1980er-Jahren bis ins Jahr 2010. Die Ausstellungen von vor 1989 wurden dabei nicht zwingend in den 1980er-Jahren eröffnet. Vielmehr werden Präsentationen untersucht, die in den 1980er-Jahren für Besucher in den Museen zur Verfügung standen, in ihren damaligen Fassungen, wie sie das Quellenmaterial aus diesem Jahrzehnt widerspiegelt. Ausgehend von diesen Schauen können Veränderungen ebenso wie Kontinuitäten über den Systemwechsel

stellungsführer aus dem Jahr 1986: Kowalski, Zdzisław: Muzeum Martyrologii »Pod Zegarem « [Martyrologiemuseum »Unter der Uhr«]. Lublin 1986. Die Nummerierung ist nicht durchgängig, da nicht alle ehemaligen Verhörzellen für das Museum zur Verfügung gestellt wurden. Es handelt sich dabei lediglich um die Zellen 4 bis 11 entlang des Hauptkorridors, einschließlich dieses und des anschließenden Korridors, in denen die Ausstellung untergebracht wurde.

162 Der Verein führte Chroniken seiner Tätigkeit, die für die Jahre 1978 bis 2001 im Archiv des Museums »Unter der Uhr« erhalten sind. Siehe v. a. Kronika Klubu b. Więźniów Politycznych Zamku Lubelskiego i »Pod Zegarem« Nr. 3 (9/1978-8/1981). AMLL, ohne Signatur; Kronika Klubu b. Więźniów Politycznych Zamku Lubelskiego i Pod Zegarem, Nr. 16 (1/ 1990-6/ 1991). AMLL, ohne Signatur.

163 Interview mit Barbara Oratowska am 11. Mai 2010.

164 Auskunft des Martyrologiemuseums »Unter der Uhr«, E-Mail vom 13. April 2015. 
von 1989 hinweg identifiziert werden. Die Betrachtung bis ins Jahr 2010 wiederum ermöglicht das Nachvollziehen wesentlicher Entwicklungen des Museumsbooms. Aus arbeitspragmatischen Gründen wurden später eröffnete Ausstellungen der Museen überwiegend nicht mehr berücksichtigt. Der Schwerpunkt der Analysen liegt auf den ständigen Ausstellungen. Sonderund Wechselausstellungen werden lediglich ergänzend, zur breiteren Kontextualisierung einzelner Themen und Entwicklungen einbezogen. Im Fokus steht überdies nicht die detaillierte Präsentation von Einzelfallanalysen aller betrachteten Schauen, sondern eine übergreifende Darstellung der Entwicklung des musealen Umgangs mit einzelnen Themen und Elementen der Kriegserzählungen und der sich darin manifestierenden polnischen Selbstund Fremdbilder.

Analysiert wird somit das Produkt musealer Arbeit - die Ausstellung -, die einer breiten Öffentlichkeit präsentiert wird. Bei der Dekonstruktion der in den musealen Erzählungen transportierten Interpretationen und Perspektiven geht es zudem immer wieder um die Frage nach den Hintergründen einzelner Präsentationspraxen, Interpretationen und Inhalte. Hierfür werden übergreifende Entwicklungen in der Historiografie und in öffentlichen, das heißt zumeist publizistischen Debatten berücksichtigt. Ebenso bedeutend sind die Einstellungen und Absichten der zuständigen Kuratoren sowie innerinstitutionelle Gegebenheiten der Museen. Die Perspektive der Produzenten der Schauen wird somit immer wieder in die Untersuchungen einfließen, sofern sie rekonstruiert werden kann - etwa anhand von Experteninterviews, Konzeptpapieren, Ausstellungsführern oder Protokollen der Sitzungen wissenschaftlicher Beiräte. Die Perspektive der Rezipienten, der Museumsbesucher, ist dagegen nicht Gegenstand dieser Untersuchung. Entsprechendes Quellenmaterial, das einen Einblick in Besucherwahrnehmungen erlauben würde, liegt in den Museen selbst meist nicht vor; gerade bei nicht mehr existenten Schauen gibt es - wenn überhaupt - nur höchst lückenhafte Materialien. Besucherbücher bieten kaum Hinweise auf repräsentative Meinungsbilder, da ihre Verwendung durch eine Vielzahl von impliziten Verhaltensregeln gekennzeichnet ist, die dazu führen, dass allgemein positive und zugleich wenig konkrete Meinungsäußerungen dominieren. Bislang führen die wenigsten polnischen Museen eine eigene Besucherforschung durch. Dort, wo es sie gibt, werden ihre Erkenntnisse als rein interne Materialien behandelt und für externe Forscher nicht zur Verfügung gestellt. Eigene systematische Forschungen wiederum wären für jede einzelne der untersuchten Institutionen und jede Dauerausstellung äußerst aufwendig (für die nicht mehr existenten Schauen selbstredend unmöglich); eine solche Arbeit war bei der Vielzahl der untersuchten Museen und Ausstellungen nicht $\mathrm{zu}$ realisieren. Besucherforschung ist daher eigenständiger Gegenstand von Forschungsvorhaben, die diese Perspektive in das Zentrum ihrer Analysen 
stellen. ${ }^{165}$ In der vorliegenden Untersuchung werden jedoch einzelne Quellen berücksichtigt, die erste Hinweise auf die Rezeption der untersuchten Ausstellungen geben. Hierbei handelt es sich um publizierte Rezensionen aus Zeitungen und Zeitschriften sowie wissenschaftliche Beiträge, die sich einzelnen Museen oder ihren Präsentationen widmen. Diese Texte erfassen die Einschätzungen eines kulturinteressierten Publikums von Meinungsführern und können daher nicht als repräsentativ für eine breite Öffentlichkeit angesehen werden. ${ }^{166}$

\subsection{Quellen}

Das ausgewertete Quellenmaterial ist äußerst divers, denn betrachtet wurden sowohl zum Zeitpunkt der Recherchen zugängliche Ausstellungen als auch Schauen, die nicht mehr existieren und folglich allein über Archivmaterial rekonstruiert werden konnten. Die existierenden Dauerausstellungen wurden in allen Museen fotografisch dokumentiert. Zudem wurden die Eindrücke beim ersten Rundgang notiert, um deren Wirkung in den weiteren Analysen der Raum- und Exponatwirkungen, symbolischer und emotionalisierender Gestaltungsmittel sowie der Besucherführung reflektieren zu können. Dieses Vorgehen ermöglichte Rückbezüge auf ursprüngliche Wahrnehmungen, die von späteren detaillierten Betrachtungen überlagert werden konnten. Auch kam dem Projekt der Umstand zugute, dass die Recherchen in einem Zeitraum der Transformation von Dauerausstellungen in vielen Häusern stattfanden. So konnten in vielen Fällen die alten wie auch die neuen Präsentationen besichtigt werden, sowie gänzlich neu geschaffene Ausstellungen in der Untersuchung Aufnahme finden.

In den Archiven und Bibliotheken sämtlicher untersuchter Museen ${ }^{167}$ wurden interne Materialien zum Entstehungsprozess der jeweiligen Dauerausstellungen (Konzeptpapiere, Ausstellungsdrehbücher ${ }^{168}$, Exponatlisten, Entwürfe

165 Eine der jüngsten Studien im deutschsprachigen Raum zu diesem Thema verfasste Schröder, Vanessa: Geschichte ausstellen - Geschichte verstehen. Wie Besucher im Museum Geschichte und historische Zeit deuten. Bielefeld 2013. Einen Überblick über die Entwicklung der Besucherforschung im angelsächsischen Raum bietet Hooper-Greenhill: Studying Visitors. In: Macdonald, Sharon (Hg.): A Companion to Museum Studies. Malden, MA u. a. 2006, 362-376.

166 Vgl. Thiemeyer: Fortsetzung des Krieges, 33. Siehe auch Ders.: Geschichtswissenschaft, 82.

167 Die Unterlagen aus dem Archiv des Historischen Museums der Hauptstadt Warschau von vor 1989 waren bereits an das »Staatsarchiv« (Archiwum Państwowe, AP) übergeben worden und konnten dort eingesehen werden.

168 Das Drehbuch stellt die schriftliche Grundlage der Realisierung einer Ausstellung dar. Meist umfasst es Informationen zur Abfolge und Anordnung der Objekte, die Ausstellungstexte und Objektbeschriftungen sowie Gestaltungshinweise. 
von Katalogen oder Ausstellungsführern, Expertisen zu Ausstellungskonzepten, Protokolle der Sitzungen wissenschaftlicher Beiräte, Zeitungsausschnitte, Korrespondenz) und Eigenpublikationen der Institutionen (Kataloge, Ausstellungsführer, Publikationen zur Geschichte einzelner Museen, museumseigene Jahrbücher, Veröffentlichungen der Mitarbeiter) ausgewertet. Darüber hinaus wurden in allen Museen ergänzende Experteninterviews in Form fokussierter Leitfadeninterviews ${ }^{169}$ geführt. Befragt wurden die für den Zeitraum des Zweiten Weltkriegs zuständigen Kuratoren sowie Vertreter der Museumsleitung und Mitarbeiter museumspädagogischer Abteilungen. Schließlich wurde auch Sekundärliteratur über die jeweiligen Institutionen, Ausstellungen oder Museumsprojekte ausgewertet, die den Entstehungsprozess, damit verbundene Debatten sowie die Reaktionen auf oder einzelne Interpretationen der realisierten Schauen dokumentieren. Diese Materialien fanden sich in Form von Zeitungsbeiträgen, Jahrbüchern einzelner Städte und wissenschaftlichen Publikationen, in erster Linie Sammelbänden und Fachzeitschriften.

Die Analyse sowohl existierender als auch nicht mehr zugänglicher Ausstellungen ist gewissen Einschränkungen unterworfen, die sich aus der Überlieferungslage und der Art des Untersuchungs- bzw. Quellenmaterials ergeben. Dies betrifft zunächst den Umfang der möglichen Analysen und Schlussfolgerungen: Bei den Ausstellungen, die von der Verfasserin selbst besucht wurden, konnte das architektonische und gestalterische Gesamtarrangement inklusive Geräusch- und Lichtkulissen, mithin die sinnliche Wirkung der Präsentationen, erfasst werden. Hierdurch konnten auch implizite, allein durch die Verortung einzelner Ausstellungselemente innerhalb des Rundgangs vorgenommene Gewichtungen von Fakten, Raumwirkungen verwendeter Symboliken und damit auch affektiv und implizit transportierte Deutungen erschlossen werden. Der Großteil der nicht mehr existierenden Ausstellungen dagegen konnte ausschließlich anhand schriftlicher Quellen untersucht werden. In erster Linie handelte es sich hierbei um Ausstellungsdrehbücher ${ }^{170}$ und Exponatlisten. Diese enthalten zwar zum Teil Hinweise auf die Gestaltung einzelner Ausstellungselemente. Die Wirkung der Exponat- und Textensembles im Raum ebenso wie die visuelle Führung der Besucher durch die Schau sind hiermit jedoch kaum rekonstruierbar. ${ }^{171}$ Fotodokumentationen

169 Lamnek, Siegfried: Qualitative Sozialforschung. Band 2: Methoden und Techniken. 3., korrigierte Aufl. Weinheim 1995, 79-81.

170 In den untersuchten Museen lagen neben den Drehbüchern (scenariusz), die Ausgangspunkt für die Umsetzung von Ausstellungen sind, auch sogenannte Niederschriften von Ausstellungen (scenopis) vor, die erst im Nachhinein angefertigt wurden und den Stand der jeweiligen Ausstellung zum Zeitpunkt ihrer Dokumentation bzw. »Verschriftlichung" wiedergeben.

171 Auf diese grundlegende Problematik weist auch Thomas Thiemeyer hin. Thiemeyer: Geschichtswissenschaft, 81. 
früherer Ausstellungen standen nur selten zur Verfügung. ${ }^{172}$ Teilweise waren auch Ausstellungsführer (publiziert oder in Manuskriptform) vorhanden, die mittels der Beschreibung der Ausstellungsinhalte zugleich Einblicke in Interpretationen und konzeptuelle Überlegungen der Ausstellungsmacher bieten.

Weitere Einschränkungen ergeben sich aus der spezifischen Quellensituation: Die Überlieferungslage von früheren Ausstellungen - selbst der Dauerausstellungen, also einem der zentralen Tätigkeitsfelder ihrer Arbeit -, ist in den untersuchten Museen sehr disparat und oft unvollständig. ${ }^{173}$ Auch wenn die meisten Institutionen über interne Regelungen verfügen, wonach von den eigenen Ausstellungen die zentralen Dokumente - das Drehbuch sowie ein gegebenenfalls vorliegender Ausstellungsführer oder Katalog - archiviert werden sollen, so wird dies gerade seit der Wende von 1989 nicht mehr zwingend umgesetzt. ${ }^{174}$ Zudem sind die Anpassungen, die Anfang der 1990erJahre in den Dauerausstellungen vorgenomen wurden, in der Mehrzahl der untersuchten Institutionen nicht dokumentiert. Allein der Umstand, dass mehrere Schauen aus diesem Zeitraum zum Untersuchungszeitpunkt noch zugänglich und zum Teil Dokumentationen ihres Zustands aus den 1980erJahren vorhanden waren, erlaubte eine Rekonstruktion der einzelnen Schichten ihrer Veränderungen. Für die Jahre vor 1989 sind Ausstellungsdrehbücher häufiger überliefert, da diese der zuständigen Zensurbehörde zur Freigabe vorgelegt werden mussten. Nach der Abschaffung der staatlichen Zensur wurden Drehbücher dagegen oft nicht mehr verfasst. Gerade bei Sonder- und Wechselausstellungen, die nur wenige Wochen oder Monate gezeigt wurden, verzichteten (und verzichten bis heute) viele Kuratoren auf diese aufwendige

172 In einem Fall stellte eine solche Dokumentation wiederum sogar die einzige Überlieferung einer Dauerausstellung dar. Hierbei handelte es sich um die 1979 eröffnete Dauerausstellung des Historischen Museums der Stadt Lublin, zu der ein Album mit übergreifenden Raumansichten der einzelnen Sektionen der Schau erstellt worden ist. Die Fotos erlauben die Rekonstruktion eines Großteils der Sektion zum Zweiten Weltkrieg, da darauf sowohl Ausstellungstexte als auch verwendete Fotografien, teilweise sogar Dokumente zu erkennen sind. Siehe: Wystawa: Historia miasta Lublina. Im Fall der Dauerausstellung des Museums »Unter der Uhr« in Lublin konnten dank einer erhaltenen Fotodokumentation der Ausstellungseröffnung der Stand der Schau vor 1989 sowie Veränderungen, die erst nach der Wende vorgenommen wurden, rekonstruiert werden.

173 Dieses zentrale methodische Problem benennt auch Thomas Thiemeyer in seiner Studie. Thiemeyer: Fortsetzung des Krieges, 34. Siehe auch Ders.: Geschichtswissenschaft, 83 .

174 Als zentrales Problem für die Auseinandersetzung mit der eigenen Tätigkeit hat dies prägnant der Direktor des Historischen Museums der Stadt Krakau, Michał Niezabitowski, in seinem Vortrag auf der Konferenz »Polskie muzea historyczne w kontekście europejskim« (Polnische Geschichtsmuseen im europäischen Kontext, Warschau 27.-28. September 2012) benannt. Niezabitowski, Michał: Historia Polski w kreacjach muzeów historycznych po 1989 roku [Die Geschichte Polens in den Präsentationen von Geschichtsmuseen nach 1989]. Warschau, 27. September 2012. 
Arbeit. Andere liefern diese nicht zwingend im eigenen Archiv ab, was die zweite wesentliche Problematik der Quellenerschließung bedingt: Der $\mathrm{Zu}$ gang zu den vorhandenen Dokumenten für interessierte Forscherinnen hängt wesentlich von der Kooperationsbereitsschaft der zuständigen Kuratoren ab, denn diese agieren häufig als "Torwächter» der Materialien. Viele Unterlagen befinden sich noch nicht im Archiv - dies betrifft selbst Dokumentationen von Ausstellungen, die bereits fünf bis zehn Jahre alt sind -, sondern werden in den Büros der einzelnen Mitarbeiter aufbewahrt. Das ausgewertete Quellenmaterial umfasst daher jene Unterlagen, die im Laufe der Recherchen in den Jahren 2009 bis 2011 mit Unterstützung der Mitarbeiter der einzelnen Einrichtungen gesammelt werden konnten.

\subsection{Methoden}

Wie in der Darstellung des Forschungsstands bereits angemerkt, existiert bislang keine etablierte Methode der Ausstellungsanalyse. Die vorliegende Studie greift daher auf eine Kombination von Methoden aus Nachbardisziplinen der Museologie zurück. Für die Untersuchung nicht mehr zugänglicher wie auch aktueller Schauen wurde die historische Quellenkritik adaptiert, nach dem Vorbild des von Thomas Thiemeyer entworfenen Fragenkatalogs für die Analyse kulturhistorischer Ausstellungen. ${ }^{175}$ Herausgearbeitet wurden zunächst der Aufbau der Ausstellungen, ihre inhaltliche und interpretative Struktur, ihre Schwerpunktsetzungen und Leerstellen sowie ihre ästhetische Umsetzung (soweit sie rekonstruierbar war). Beachtung fanden dabei der Entstehungszeitpunkt und -kontext einzelner Präsentationen wie auch ihre Lokalisation. Gefragt wurde ferner sowohl nach den Produzenten, ihren jeweiligen Ansatzpunkten, Absichten und Interessen, als auch nach den avisierten Adressaten bzw. Rezipienten der Ausstellungen. Bei der Analyse zugänglicher Präsentationen kam zusätzlich die ethnologische Methode der dichten Beschreibung nach Clifford Geertz zum Einsatz, mithilfe derer insbesondere das "sinnliche Potenzial ${ }^{176}$ des Ausstellungsbesuchs umfassend berücksichtigt werden konnte. In der Übertragung dieses Vorgehens auf die Analyse von Ausstellungen wurde vorrangig auf die Überlegungen von Roswitha Muttenthaler und Regina Wonisch zurückgegriffen. ${ }^{177}$

Zentral für die Anwendung der dichten Beschreibung bei der Ausstellungsanalyse sind zwei ihrer Merkmale, die Geertz "mikroskopisch" und »deutend« nennt. Ersteres meint, dass anhand eines begrenzten Fallbeispiels,

175 Thiemeyer: Geschichtswissenschaft, 84-90.

176 Ebd., 89.

177 Muttenthaler/Wonisch: Gesten des Zeigens. 
das intensiv und aus unterschiedlichen Perspektiven betrachtet wird, »umfassende Interpretationen und abstraktere Analysen« über größere Zusammenhänge gewonnen werden können. ${ }^{178}$ Übertragen auf das Medium der Ausstellung bedeutet dies, dass anhand der intensiven Auseinandersetzung mit einem Teilbereich des Museums, der Ausstellung, Schlüsse in Bezug auf die Verortung der Institution, die von ihr vermittelten Interpretationen und Ansichten innerhalb eines größeren erinnerungskulturellen Umfelds getroffen werden können. ${ }^{179}$ Deutend ist die dichte Beschreibung zunächst insofern, als jede Darstellung eines Phänomens bereits Interpretationen des jeweiligen Betrachters enthält. Wie Clifford Geertz in Bezug auf die ethnologische Literatur feststellt:

Dieser Sachverhalt - daß nämlich das, was wir als unsere Daten bezeichnen, in Wirklichkeit unsere Auslegungen [...] sind [...] - tritt in den fertigen Texten [...] nicht mehr zutage, weil das meiste dessen, was wir zum Verständnis eines bestimmten Ereignisses, Rituals, Brauchs, Gedankens oder was immer sonst brauchen, sich als Hintergrundinformation einschleicht, bevor die Sache selbst direkt untersucht wird. ${ }^{180}$

Dieses Merkmal zielt somit wesentlich auf die Selbstreflexion des Forschers, der sich seiner eigenen Involviertheit im Untersuchungsprozess bewusst sein muss und damit der Tatsache, dass »Analysen [...] Interpretationen von Interpretationen [sind] « ${ }^{181}$

Die deutende Qualität der dichten Beschreibung zielt zudem darauf, über eine möglichst detaillierte Erfassung von kulturellen Aktivitäten hinauszugehen, die lediglich eine rekonstruktive, »dünne« Beschreibung ermöglicht. ${ }^{182}$ Vielmehr besteht die dichte Beschreibung im »Herausarbeiten von Bedeutungsstrukturen ${ }^{183}$, darin also, »Vermutungen über Bedeutungen anzustellen, diese Vermutungen zu bewerten und aus den besseren Vermutungen erklärende Schlüsse zu ziehen ${ }^{184}{ }^{18}$ Mithilfe der dichten Beschreibung einzelner Phänomene sollen demnach übergreifende Aussagen gewonnen werden über den Rahmen oder den Kontext der betrachteten Phänomene: die untersuchte

178 Geertz, Clifford: Dichte Beschreibung. Bemerkungen zu einer deutenden Theorie von Kultur. In: Ders.: Dichte Beschreibung. Beiträge zum Verstehen kultureller Systeme. Frankfurt am Main 1987, 7-43, hier 30 f. Siehe auch Ziegler, Meinrad: »Dichte Beschreibung « - Essayistisches Theoretisieren und persönlicher Standort in der Interpretation. In: Kannonier-Finster, Waltraud/Ziegler, Meinrad (Hg.): Exemplarische Erkenntnis. Zehn Beiträge zur interpretativen Erforschung sozialer Wirklichkeit. Innsbruck 1998, 65-91, hier 68.

179 Muttenthaler/Wonisch: Gesten des Zeigens, 50.

180 Geertz: Dichte Beschreibung, 14.

181 Muttenthaler/Wonisch: Gesten des Zeigens, 50.

182 Geertz: Dichte Beschreibung, $11 \mathrm{f}$.

183 Ebd., 15.

184 Ebd., 30. 
Kultur. ${ }^{185}$ Bezogen auf die Analyse musealer Präsentationen stehen in dieser Arbeit einzelne thematische und interpretative Topoi der Kriegs- und Besatzungserzählungen im Fokus, deren Konstruktion und Vermittlung erst durch »das Zusammenspiel visueller Elemente mit Text und Raum als Voraussetzung für die in der Ausstellung transportierten Narrative « erfolgt. ${ }^{186}$ Durch die Beschreibung der Beziehungen und des Zusammenspiels der verschiedenen Elemente einer Ausstellung werden immer neue »Bedeutungsschichten ${ }^{187}$ offengelegt. Mit Muttenthaler und Wonisch gesprochen, wird

[e]rst mit den wiederholten Reinterpretationen und dem Hervorheben verborgener Bedeutungen als weitere[n] Lesarten [...] einer rekostruktiven-dünnen Beschreibung eine spezifische konstruktive Dichte gegeben. [...] Dichte Beschreibungen bilden nicht nur physisch Beobachtbares ab, sondern arbeiten bestimmte Bedeutungsstrukturen heraus, legen am Konkreten auch Allgemeines offen. ${ }^{188}$

In der konkreten Untersuchung wurden die einzelnen Dauerausstellungen zunächst anhand eines einheitlichen Leitfragenkatalogs ausgewertet. Dieser wurde als offen behandelt, sodass auch neue Fragestellungen einflossen, die sich erst im Laufe der Arbeit oder aus dem Quellenmaterial ergaben. ${ }^{189}$ Bei den Dauerausstellungen, die einen größeren zeitlichen Rahmen einer Stadtoder Regionalgeschichte umfassten, konzentrierten sich die Analysen auf diejenigen Sektionen, die den Jahren 1939 bis 1944/ 45 gewidmet waren. Da auch Dauerausstellungen Anpassungen und Wandlungen unterliegen, ist hierbei anzumerken, dass die Analysen der persönlich besuchten Ausstellungen sich jeweils auf den konkreten Moment der Datenerhebung bzw. des Museumsbesuchs beziehen. In einem nächsten Schritt wurden der Entstehungsprozess der Schauen, die Konzepte der Ausstellungsmacher, ihre Vermittlungsabsichten und Interpretationen mittels des zur Verfügung stehenden Quellenmaterials, der Eigenpublikationen der Museen sowie der Experteninterviews soweit möglich rekonstruiert. Dort, wo solche Materialien vorhanden waren, wurden in einem dritten Schritt die aus den Analysen gewonnen eigenen Interpretationen den Deutungen und Lesarten Dritter gegenübergestellt, die in Form von Rezensionen in Zeitungen und wissenschaftlichen Publikationen zugänglich sind. Als Zwischenergebnis erfolgte zu allen untersuchten Präsentationen zunächst die Anfertigung von Einzelanalysen. Durch die synchrone und diachrone Analyse der Präsentationsweise einzelner thematischer Elemente der Ausstellungsnarrative wurde schließlich die dichte Beschreibung der Entwicklungen der musealen Erzählungen des Zweiten Welt-

185 Ebd., 20-30, bes. 22 f., 29f. Siehe auch Ziegler:»Dichte Beschreibung«, 66, 70.

186 Muttenthaler/Wonisch: Gesten des Zeigens, 51.

187 Ebd.

188 Ebd.

189 Thiemeyer: Fortsetzung des Krieges, $33 \mathrm{f}$. 
kriegs erarbeitet. In den Ausführungen der folgenden Abschnitte liegt der Schwerpunkt aus darstellungspragmatischen Gründen auf den so gewonnenen Ergebnissen. ${ }^{190}$

Im anschließenden ersten Teil werden zunächst die Entwicklungen der musealen Darstellung der zwei zentralen Feindbilder der polnischen Kriegsund Besatzungserzählungen erörtert: Deutschlands und der Sowjetunion. Der darauffolgende zweite Teil behandelt die musealen Schilderungen der Verfolgung der jüdischen Bevölkerung der Städte und Regionen und damit die sich wandelnden Verortungen dieses zentralen Fremdbildes polnischer Geschichtsdarstellungen im Verlauf der betrachteten drei Jahrzehnte. Im dritten Teil werden diese Ausführungen zusammengeführt in der Analyse des polnischen Selbstbildes im Krieg und dessen Veränderungen sowie Kontinuitäten, die es seit den 1980er-Jahren erfahren hat. Im folgenden Ausblick werden zwei zentrale Museums- und damit verbundene Ausstellungsprojekte vorgestellt, die kurz vor Publikation dieser Arbeit eröffnet wurden und von denen auszugehen ist, dass sie wesentlichen Einfluss auf die zukünftige Entwicklung des polnischen historischen Museumswesens und des musealen Umgangs mit dem Zweiten Weltkrieg haben werden. Im ersten Fall handelt es sich um die Dauerausstellung des »Museums der Geschichte der Polnischen Juden« (Muzeum Historii Żydów Polskich) in Warschau, im zweiten um diejenige des Museums des Zweiten Weltkriegs. Die Studie schließt mit einer Zusammenführung der zentralen Schlussfolgerungen. 


\section{Teil 1 \\ Feindbilder - Abgrenzung nach außen}

Die Vorstellungen vom Eigenen, von der eigenen Gemeinschaft und insbesondere der eigenen Nation, werden wesentlich geprägt durch Vergleiche mit oder Abgrenzung von weiteren, als »anders« bzw. »fremd « definierten Gruppen. Dabei kann die Darstellung von »Fremden« und »Anderen« zwar auch darauf abzielen, Gemeinsamkeiten aufzuzeigen; zumeist jedoch werden Unterschiede zur eigenen Gemeinschaft betont. Denn Fremdbilder dienen oftmals in erster Linie dazu, positive Eigenschaften hervorzuheben und zu bestätigen, die als spezifisch für die eigene Gruppe wahrgenommen werden. "Anderen« im Gegenzug negative Eigenschaften zuzuschreiben, geht dabei einher mit einer unreflektierten Perpetuierung von stereotypen Vorstellungen und bestärkt die positive Konstituierung der eigenen Gemeinschaft. ${ }^{1}$ Eine Abgrenzung von "Anderen " findet dabei in Bezug sowohl auf innere als auch auf äußere Gruppen statt. Im ersten Fall meint dies die Abgrenzung von als "fremd« empfundenen nationalen, ethnischen, religiösen oder sozialen Gruppierungen innerhalb der eigenen Staatsgrenzen. Der zweite Fall bezieht sich auf die Abgrenzung insbesondere zu Nachbarstaaten und -nationen. Eine besonders wirkmächtige, da emotional stark aufgeladene Abgrenzungsfolie bieten Feindbilder, die auf einseitig negative Zuschreibungen fokussieren und nur schwer von abweichenden Erkenntnissen und Darstellungen verändert oder gar revidiert werden können. ${ }^{2}$

1 Hahn, Hans Henning: Stereotypen in der Geschichte und Geschichte im Stereotyp. In: Ders.: Historische Stereotypenforschung. Methodische Überlegungen und empirische Befunde. Oldenburg 1995, 190-204, hier 201. Zu den Begriffen »Fremdbild« und »Feindbild« vgl. Berghold, Josef: Feindbilder aus der Sicht der politischen Psychologie. In: Bingen, Dieter/Loew, Peter O./Wóycicki, Kazimierz (Hg.): Die Destruktion des Dialogs. Zur innenpolitischen Instrumentalisierung negativer Fremd- und Feindbilder. Polen, Tschechien, Deutschland und die Niederlande im Vergleich, 1900-2005. Wiesbaden 2007, 15-22; Michlic, Joanna Beata: Poland's threatening other. The image of the Jew from 1880 to the present. Lincoln, London 2006.

2 Berghold: Feindbilder, 21. Siehe auch Lotz, Christian: Das (Re-)Arrangieren von Feindbildern im geteilten Deutschland, in Polen und Bulgarien in der unmittelbaren Nachkriegszeit, 1945-1952. In: Bingen, Dieter/Loew, Peter O./Wóycicki, Kazimierz (Hg.): Die Destruktion des Dialogs. Zur innenpolitischen Instrumentalisierung negativer Fremd- und Feindbilder. Polen, Tschechien, Deutschland und die Niederlande im Vergleich, 1900-2005. Wiesbaden 2007, 146-161, hier 149 f.; Hahn, Hans Henning / Hahn, Eva: Nationale Stereo- 
Mit dieser letzten Kategorie befasst sich dieser Teil der Studie. In diesem wird die Entwicklung der musealen Darstellungen der zwei für die polnische Geschichte des Zweiten Weltkriegs wichtigsten Gegner und Besatzungsmächte analysiert, des nationalsozialistischen Deutschlands und der Sowjetunion. Diese beiden Staaten repräsentieren die während der vergangenen zwei Jahrhunderte in der polnischen Kultur und Geschichte bedeutendsten Feindbilder: das »des Deutschen " und »des Russen . $^{3}$ Eine prägnante Illustration findet die lange Tradition der negativen Perzeption beider Nachbar- bzw. Teilungsmächte im Sprichwort »Jak świat światem nie będzie ... Polakowi bratem « (Solange die Welt besteht, wird ein ... niemals dem Polen ein Bruder sein). Wie Aleksandra Niewiara feststellt:

Je nach politischer Situation, dem historischen Moment, der regionalen Herkunft des Sprechers, konnte die leere Stelle in dem Sprichwort mit den Ethnonymen >Moskowiter` oder `Deutscher gefüllt werden. ${ }^{4}$

Die große Bedeutung bzw. starke Ausprägung der beiden Feindbilder ist mit der zentralen Bedeutung der beiden Mächte für die Geschichte Polens verbunden; insbesondere mit dem Aufkommen des modernen Nationalismus im 19. Jahrhundert stellten sie diejenigen Antipoden dar, gegen die sich polnischer Widerstand, Kampf und nationale Selbstbehauptung bzw. Identifikation richteten. Der Wandel staatlicher Verfasstheit der Länder im Laufe der Geschichte spielte dabei für ihre Wahrnehmung als Feindbilder nur eine marginale Rolle. So erfolgt die Perzeption der Sowjetunion in der Erinnerungskultur Polens im allgemeineren Kontext des Feindbildes »der Russen" bzw. Russlands, welches sowohl das Russländische Reich bis 1917 als auch die Union der Sozialistischen Sowjetrepubliken (UdSSR) umfasst. Die Bezeichnungen »Russland « (Rosja) oder »Russe" (Rosjanin, Ruski) wurden so etwa in der Volksrepublik Polen im Alltag synonym für die UdSSR und ihre Bewohner - unabhängig von deren Nationalität - verwendet; der Begriff »sowjetisch“

typen. Plädoyer für eine historische Stereotypenforschung. In: Hahn, Hans Henning (Hg.): Stereotyp, Identität und Geschichte. Die Funktion von Stereotypen in gesellschaftlichen Diskursen. Frankfurt am Main u. a. 2002, 17-56, hier 34 f., 43.

3 Die Wahrnehmung des Russländischen Reiches als Feindbild in der polnischen Gesellschaft hat bereits eine längere Geschichte als die der feindlichen Wahrnehmung der Deutschen, wie Aleksandra Niewiara in ihrer Untersuchung des »Bildes des ethnisch Anderen" (obraz innego etnicznie) in der polnischen Kultur bzw. der Kultur der Rzeczpospolita zwischen dem 16. und dem 19. Jahrhundert zeigt. Vgl. Niewiara, Aleksandra: Procesy kategoryzacyjne a kulturowe konstruowanie obrazu »innego « (Moskwicin - Moskal - Rosjanin) [Prozesse der Kategorisierung und die kulturelle Konstruktion des "Anderen« (Moskowiter - Moskal - Russe)]. In: Lazari, Andrzej de (Hg.): Katalog wzajemnych uprzedzeń Polaków i Rosjan [Katalog der gegenseitigen Vorurteile von Polen und Russen]. Warszawa 2006, 49-72.

4 Ebd., 54. 
(radziecki) fand fast ausschließlich im offiziellen Sprachgebrauch Verwendung. ${ }^{5}$ Ähnlich fügen sich Preußen, das 1871 vereinte Deutsche Kaiserreich, die Weimarer Republik sowie das nationalsozialistische Deutschland im Feindbild »der Deutschen « zu einer Einheit zusammen. ${ }^{6}$

Die Ereignisse des Zweiten Weltkriegs, der Einmarsch deutscher und sowjetischer Truppen und die folgenden Besatzungsregime haben die negativen Vorstellungen und Stereotype über beide Länder noch verstärkt.? Während die Deutschen im Gewand der »Hitleristen (hitlerowcy) $^{8}$ jedoch in der Geschichtserzählung der Volksrepublik eine eindeutige Rolle als Erzfeind einnahmen, war die negative Erinnerung an den zweiten Angreifer und Besatzer Polens, die Sowjetunion, in der offiziellen Sphäre der Erinnerungskultur tabuisiert. ${ }^{9}$ Lediglich im privaten Rahmen pflegte man die Erinnerung an offiziell verdrängte Ereignisse wie die Deportationen von Soldaten und Zivilisten in die UdSSR oder den Massenmord an polnischen Offizieren und Polizisten durch den NKVD (Narodnyj komissariat vnutrennich del/»Volkskommissariat des Inneren«) im Jahr 1940, ${ }^{10}$ während im offiziellen historischen Narrativ die Sowjetunion und die Rote Armee ausschließlich als Befreier des Landes von der deutschen Besatzung beschrieben wurden. Das Wissen um diese Ereignisse blieb jedoch in der polnischen Gesellschaft präsent; in den 1980er-Jahren wurde es schließlich zunehmend artikuliert. Über den Publikationsweg des Untergrunds, den »Zweiten Umlauf« erschienen nicht nur verstärkt Nachdrucke von Büchern polnischer Exilautoren, die in der VRP tabuisierte Themen

5 Głowiński, Michał: Język jako bariera [Die Sprache als Barriere]. In: Magdziak-Miszewska, Agnieszka/Zuchniak, Monika/Kowal, Paweł: Polacy i Rosjanie. 100 kluczowych pojęć [Polen und Russen. 100 Schlüsselbegriffe]. Warszawa 2002, 11-20, hier $13 \mathrm{f}$.

6 Niewiara: Procesy kategoryzacyjne, 62.

7 Dmitrów, Edmund: Die Polen: Zum Wandel historischer Selbst- und Fremdbilder einer Opfernation seit dem Zweiten Weltkrieg. In: Buschmann, Nikolaus/Langewiesche, Dieter (Hg.): Der Krieg in den Gründungsmythen europäischer Nationen und der USA. Frankfurt, New York 2003, 331-350, hier 332-334, 338.

8 Zum Begriff des »Hitleristen« siehe die Einleitung zu Kapitel 1 in diesem Teil der Arbeit.

9 Stobiecki, Rafał: Rosja i Rosjanie w polskiej myśli historycznej XIX i XX wieku [Russland und die Russen im polnischen historischen Denken des 19. und 20. Jahrhunderts]. In: Lazari, Andrzej de (Hg.): Katalog wzajemnych uprzedzeń Polaków i Rosjan [Katalog der gegenseitigen Vorurteile von Polen und Russen]. Warszawa 2006, 159-201, hier 185 f.; Grabski, Andrzej F.: Zarys historii historiografii polskiej [Abriss der Geschichte der polnischen Historiografie]. Poznań 2000, 226-228.

10 Ruchniewicz, Krzysztof: Die Erinnerung an die Opfer des Stalinismus als Thema der öffentlichen Diskussion in Polen. In: Ders.: "Noch ist Polen nicht verloren«. Das historische Denken der Polen. Berlin 2007, 32-42, hier 32. Zu den Ereignissen von 1940 und die Erinnerung daran siehe Ruchniewicz, Małgorzata/Ruchniewicz, Krzysztof: Katyn 1940. In: Ueberschär, Gerd R. (Hg.): Orte des Grauens. Verbrechen im Zweiten Weltkrieg. Darmstadt 2003, 71-82; Sanford, George: Katyn and the Soviet Massacre of 1940. Truth, Justice and Memory. London, New York 2005; Przewoźnik, Andrzej/Adamska, Jolanta: Katyń. Zbrodnia, prawda, pamięć [Katyń. Verbrechen, Wahrheit, Erinnerung]. Warszawa 2010. 
aufgriffen, wie insbesondere die polnisch-sowjetischen Beziehungen der Kriegsund unmittelbaren Nachkriegsjahre. Auch Bücher polnischer Historiker zu ähnlichen Themen wurden über diesen die Zensur umgehenden Verbreitungsweg veröffentlicht. Es entstanden regierungsunabhängige Kreise wie die Organisation "Karta", die damit begann, Informationen und Zeitzeugenberichte über das Schicksal jener zu sammeln, die in die UdSSR deportiert worden waren. In der zweiten Hälfte der 1980er-Jahre wurde schließlich auch von Regierungsseite das Schlagwort der "weißen Flecken" der Geschichte aufgegriffen, die thematisiert werden müssten. ${ }^{11}$ So entstand etwa 1987 eine sowjetisch-polnische Historikerkommission, die sich der Aufarbeitung der Massenmorde von Katyń (Katyn') ${ }^{12}$ widmen sollte. ${ }^{13}$

Demnach bestanden auch in der Zeit der Volksrepublik die Feindbilder »der Deutschen« und »der Russen« fort, auch wenn nur eines von ihnen in der Öffentlichkeit artikuliert werden konnte. Eine regelrechte Eruption der Erinnerung an negative Aspekte des polnisch-sowjetischen Verhältnisses setzte bereits in den 1980er-Jahren ein und führte nach dem Zusammenbruch des sozialistischen Regimes Anfang der 1990er-Jahre zu einer Flut von Publikationen, Denkmalssetzungen und Ausstellungen, die die große Bedeutung dieser Themen für die polnische Erinnerungskultur belegen. Dies zeigte sich auch in den musealen Darstellungen polnischer Geschichte. Wie im Folgenden näher geschildert wird, wurde das Thema des zweiten Angreifers und Besatzers, also der Sowjetunion, nach der politischen Wende in den historischen Dauerausstellungen sukzessive aufgenommen. Dies geschah selbst in Museen, deren Regionen weder unmittelbar vom Einmarsch der Roten Armee im September 1939 noch von der folgenden sowjetischen Besatzung der Jahre 1939 bis 1941 betroffen waren. Dass das Thema dennoch Eingang in die Schauen fand, ist mit der zentralen Bedeutung dieser Ereignisse für das polnische Geschichtsbild sowie das damit korrespondierende nationale Selbstbild nach 1989 verbunden.

11 Ruchniewicz, Krzysztof: Zeitgeschichte in Polen nach 1989. Forschungsschwerpunkte, "weiße Flecken« und historische Kontroversen. In: Jahrbuch für Europäische Geschichte 4 (2003), 39-69, hier 40; Ders.: Die Erinnerung an die Opfer, 35 f., 38.

12 Der in der ehemaligen Sowjetunion gelegene Exekutionsort polnischer Offiziere und Polizisten Katyn' wird im Weiteren in seiner polnischen Schreibweise »Katyń« verwendet, in der er in Polen zu einem Symbol sowjetischer Kriegsverbrechen wurde.

13 Sanford: Katyn and the Soviet Massacre, 215. 


\section{Das Feindbild »die Deutschen«}

Nach der Entstehung der DDR im Jahr 1949 als sozialistischer Bruderstaat erschien die Rede von der »deutschen" Besatzung in der Volksrepublik Polen nicht mehr politisch angebracht. Zur Unterscheidung der beiden deutschen Staaten und des ihnen jeweils zugeschriebenen historischen Erbes wurde nach dem Abschluss des Görlitzer Abkommens 1950 der Ausdruck »Hitlerist« (hitlerowiec) für die Anhänger und Vertreter des nationalsozialistischen Deutschlands geprägt. Verwendung fand er ausschließlich mit Bezug auf die BRD, während die DDR in dieser Lesart die Erben der »guten" Deutschen in der Zeit des Nationalsozialismus repräsentierte, also der kommunistischen Widerstandsbewegung. Wie Hans-Jürgen Bömelburg feststellt, betraf "[d]iese durch offizielle Sprachregelungen gelenkte Entnationalisierung [...] Titel und Diskurse, in denen insbesondere herausgehobene Täter nicht vorrangig als $>$ Deutsche $<$, sondern als $>$ Hitleristen $<$ charakterisiert wurden..${ }^{14}$ Verbindlich blieb diese Sprachpraxis bis zur politischen Wende von 1989. Ihre Spuren finden sich jedoch deutlich länger und zum Teil bis in die Gegenwart.

\subsection{Das Feindbild in der Volksrepublik}

Bis 1989 wurden in den Dauerausstellungen historischer Museen allein die Deutschen bzw. »die Hitleristen« als Kriegsgegner dargestellt. Der Fokus lag auf ihrer Rolle als Besatzer, deren Charakterisierung in allen untersuchten Ausstellungen einem einheitlichen Schema folgte. So präsentierte die Ausstellung des MHK von 1982 in der Pomorska-Straße die Deutschen im Distrikt und der Stadt Krakau ausschließlich als Okkupanten. ${ }^{15}$ Die in den Schauen gezeigten Abbildungen, Plakate und Objekte sowie deren Beschriftungen zeichneten ein maskulines, militärisches, überwiegend anonymes und auf verbre-

14 Bömelburg, Hans-Jürgen: Die Erinnerung an die deutsche Besatzung während des Zweiten Weltkriegs in Polen - Transformationen und Kontinuitäten der polnischen Erinnerungskultur 1980-2005. In: Faulenbach, Bernd/Jelich, Franz-Josef (Hg.): »Transformationen« der Erinnerungskulturen in Europa nach 1989. Essen 2006, 55-78, hier 59. Siehe auch Mańkowski, Zygmunt: Die polnische Geschichtsschreibung über die NS-Verbrechen. In: Kranz, Tomasz (Hg.): Die Verbrechen des Nationalsozialismus im Geschichtsbewußtsein und in der historischen Bildung in Deutschland und Polen. Lublin 1998, 75-98, hier 86.

15 Teile der folgenden Ausführungen zur Darstellung der deutschen Besatzer in den Dauerausstellungen des MHK seit den 1980er-Jahren wurden publiziert in Heinemann, Monika: Die »Emaillewarenfabrik Oskar Schindlers« - Die neue Dauerausstellung vor dem Hintergrund der Musealisierung des Zweiten Weltkrieges seit den 1980er Jahren. In: Makhotina, Ekaterina u. a. (Hg.): Krieg im Museum. Präsentationen des Zweiten Weltkriegs in Museen und Gedenkstätten des östlichen Europa. Göttingen 2015, 255-284. 
cherische Handlungen fokussiertes Bild von den Besatzern. Die Deutschen waren allein in militärischen Funktionen und in der Ausübung von Zwangsmaßnahmen, insbesondere Exekutionen, abgebildet. ${ }^{16}$ In diesem Museum, wie etwa auch in der Schau des Pawiak-Museums und des Museums »Unter der Uhr" in Lublin, wurden zudem in den Objektbeschreibungen und Ausstellungstexten überwiegend entpersonalisierte Kollektivbezeichnungen wie »die Hitleristen« oder »der Besatzer" verwendet. Alternativ standen verschiedene Organisationsbezeichnungen stellvertretend für die Besatzungsmacht (»Gestapo«, »Sicherheitspolizei $\ll) .{ }^{17}$ Hinter diesen Begriffen verschwanden individuelle Akteure; die Deutschen in Krakau, wie auch die Deutschen in Warschau und Lublin, erschienen als entindividualisierte, einheitliche Masse.

Die Grausamkeit und Unrechtmäßigkeit ihres Handelns wurde insbesondere dadurch vermittelt, dass die bei Verhören und in der Haft angewendeten Foltermethoden ausführlich beschrieben wurden. Vor allem Zeitzeugenberichte und teilweise auch Zeichnungen oder Fotos brachten diese den Besuchern nahe, so etwa in der Schau des MHK von $1982,{ }^{18} \mathrm{im} \mathrm{Pawiak}^{19}$ sowie im Martyrologiemuseum von Lublin ${ }^{20}$. In vielen Ausstellungen zeigte man zudem Schlagstöcke und andere »Werkzeuge«, mit denen Häftlinge gefoltert wurden ${ }^{21}$

16 In der Schau wurden neben Fotografien von Militärparaden, Verhaftungen und Exekutionen Plakate der Besatzungsorgane mit Bekanntmachungen von Todesurteilen und deren Vollstreckung ausgestellt. Wroński, Tadeusz: Scenariusz wystawy Oddziału Muzeum Historycznego m. Krakowa przy ul. Wybickiego 2 (dawniej ul. Pomorska) pt. »Walka i męczeństwo Polaków w latach 1939-1945«. Kraków 26.5.1981. AMHK, PA-202 / 25/81, $2-4$.

17 Ebd., 2, 7, 10; Scenopis stałej ekspozycji Muzeum Więzienia »Pawiak«. Warszawa 1987. AMNW, Scen. 72, u. a. 70, 72; MLL-Unter der Uhr, Zelle 6, 9.

18 In dieser Ausstellung wurden u. a. Zeichnungen eines ehemaligen Gefangenen präsentiert, »die die Arten der Folter illustrierten, die durch die Gestapo-Leute in der Pomorska-Straße 2 angewendet wurden."Wroński: Scenariusz wystawy, $7 \mathrm{f}$.

19 Zeitzeugenberichte, die die Grausamkeit der Besatzer illustrierten, fanden sich sowohl in der Ausstellung von 1965 als auch in derjenigen von 1991. Scenopis stałej ekspozycji, 66, 69; Izdebska, Barbara: Pawiak 1939-1945. Ekspozycja stała. Scenopis. Warszawa 1991. AMNW, Scen. 79, 24.

20 In diesem Museum waren die schriftlichen Berichte ehemaliger Inhaftierter von Fotos begleitet, auf denen ein ehemaliger Häftling die Foltermethoden nachstellte. MLL-Unter der Uhr, Zelle 7.

21 Im Pawiak zeigte man etwa eine Peitsche und einen Schlagstock, die - so war der begleitenden Objektbeschriftung zu entnehmen - beim Verhör der Häftlinge zum Einsatz kamen. Scenopis stałej ekspozycji, 63, 66. In der überarbeiteten Schau des Museums von 1991 präsentierte man diese mit der Beschriftung »Folterwerkzeuge« (narzędzia kaźni). Izdebska: Pawiak 1939-1945, 26. Auch im MHK wurden in den 1980er-Jahren Gegenstände »zum Schlagen der Häftlinge« ausgestellt. Wroński: Scenariusz wystawy, 7. Ebenso im stadthistorischen Museum von Warschau. Informator do ekspozycji: 1. „Warszawa w latach drugiej wojny światowej« (1939-1945) 2. »Warszawa - stolicą Polski Ludowej« (III piętro). AP, zespół 3195 / I (Muzeum Historyczne m. st. Warszawy), teczka 76, MHW440, 45-57, hier 48. 
Diese Objekte und Zeugnisse verwiesen in unmittelbarer und emotionalisierender Weise auf die Grausamkeit der Besatzer. Die Unrechtmäßigkeit dieser Handlungen betonte die normative Ausdrucksweise der begleitenden Kuratorentexte. Diese charakterisierten etwa im Pawiak-Museum die Verhöre von Häftlingen durch die Gestapo in der gefürchteten Szucha-Allee als »Untersuchung, deren Methoden auf Schlägen, dem Brechen von Knochen und raffinierter Folter beruhten «. ${ }^{22}$ Unmittelbar danach wurde eine Liste angeführt mit den »Namen der Häftlinge, die während der Verhöre ermordet wurden oder aufgrund der während der Folter erlittenen Verletzungen starben $\ll^{23} \mathrm{Im}$ Lubliner Museum »Unter der Uhr" stellte man das Gefängnis auf dem Lubliner Schloss als Ort vor, der sich »während der hitleristischen Besatzung blutig in die Geschichte der Lubliner Region eingeschrieben hat ${ }^{24}{ }^{24}$ Auch für die Schilderung des deutschen Besatzungsregimes insgesamt wurden stark wertende Begriffe wie "Verbrechen und "Terror « verwendet. ${ }^{25}$ Im Pawiak beispielsweise beschrieb man den Beginn des deutschen Besatzungsregimes mit folgenden Worten:

Im Terrorsystem des Besatzers wurde Warschau [...] zum Objekt eines bestialischen Angriffs. In diesem System ist der Pawiak einer von vielen, aber welch ein grausamer Brennpunkt des Terrors. ${ }^{26}$

Wie diese Beispiele illustrieren, betonte man nicht nur die Unrechtmäßigkeit des deutschen Angriffs auf Polen und der folgenden Besatzung, sondern auch die Brutalität und Unmenschlichkeit der deutschen Besatzungsorgane. Bereits durch die gewählte Sprache wurde eine völkerrechtliche Legitimität der Zerschlagung des polnischen Staates eindeutig verneint.

Namentlich benannt waren in den Ausstellungen nur wenige Einzelpersonen, meist solche, die Führungspositionen innerhalb des Besatzungsregimes innehatten. ${ }^{27}$ In den Schauen fanden sich Namenslisten mit eindeutig pejorativen Zuschreibungen wie »Folterknechte» (oprawcy). Unter diesem auch gra-

22 Scenopis stałej ekspozycji, 67.

23 Ebd.

24 Thementext. MLL-Unter der Uhr, Zelle 6.

25 Eine Ausstellungstafel in der Schau des MHK von 1982 war mit dem Titel versehen »Der hitleristische Terrorapparat und seine verbrecherische Tätigkeit«. Wroński: Scenariusz wystawy, 2. Hier wie im Folgenden werden aus Gründen der Lesbarkeit sämtliche Titel von Ausstellungssektionen, -abschnitten und -texten - falls nicht anders vermerkt - in deutscher Übersetzung angegeben. Die Übersetzungen stammen von der Verfasserin.

26 Scenopis stałej ekspozycji, 53. In einer leicht umformulierten Form fanden sich diese Zeilen, unter Verwendung derselben normativen Ausdrücke, auch in einem Thementext der Schau von 1991 wieder. Izdebska: Pawiak 1939-1945, 10.

27 Im MHW etwa wurden Adolf Hitler und Hans Frank, der Leiter des Generalgouvernements, einzeln thematisiert. Den Angriff Deutschlands auf Polen stellte man mit dem handschriftlich signierten Angriffsbefehl Hitlers dar. Das deutsche Besatzungsregime 
fisch hervorgehobenen Titel präsentierte man zum Beispiel in der Krakauer Pomorska-Straße seit 1982 eine Sammlung von Fotografien und Dokumenten politischer und militärischer Führungspersonen des Distrikts Krakau. Zu diesen gehörte unter anderem Amon Goeth, der Leiter des Zwangsarbeitsund späteren Konzentrationslagers Płaszów. ${ }^{28}$ Auch in den Schauen des Gefängnismuseums Pawiak sowie des Martyrologiemuseums »Unter der Uhr" in Lublin fanden sich Listen der "Folterknechte der Gestapo" (Oprawcy $z$ gestapo).$^{29}$ Hierbei handelte es sich jedoch nicht um politisch und militärisch exponierte Personen, sondern um konkrete Individuen, die für die brutale Behandlung der Insassen der Gefängnisse direkt verantwortlich waren. ${ }^{30}$ Diese Namenslisten überraschen gerade in den "martyrologischen Abteilungen" der Museen nicht. Diese Institutionen entstanden meist auf Initiative ehemaliger Häftlinge, die zugleich eine wesentliche Informations- und Quellenbasis für die neuen Ausstellungen darstellten. Die Schauen befanden sich zudem direkt an den Orten der Verbrechen oder im selben Gebäude (wie im Fall des Pawiak und des Museums »Unter der Uhr«). Sie erfüllten daher von Beginn an eine zweifache Funktion: Sie sollten als Lernort die Besucher informieren, aber auch als Gedenkort an die Opfer sowie der Mahnung der Verbrechen dienen. In späteren Dauerausstellungen, auch der martyrologischen Museen bzw. Abteilungen, finden sich solche Elemente hingegen nicht mehr. Eine mögliche Ursache hierfür sind die allmählich zurückgehende Rolle und der sinkende Einfluss der Zeitzeugen in der Tätigkeit dieser Institutionen. Seit Ende der 1990er-Jahre trat in allen untersuchten Dauerausstellungen die Informationsvermittlung als primäre Aufgabe in den Vordergrund. So werden etwa die Rolle führender Vertreter des Generalgouvernements umfangreicher beschrieben und die übergreifenden Mechanismen des Besatzungsregimes kenntlich gemacht. Mit diesem Wandel der Präsentationspraxis passten sich die Ausstellungsverantwortlichen den veränderten erinnerungskulturellen Gegebenheiten an: Den jüngeren Generationen, die keine persönlichen und nur sehr entfernt familiäre Beziehungen zu den Kriegsereignissen haben, ist

wiederum wurde u. a. mit dem Tagebuch von Hans Frank illustriert. Informator do ekspozycji, 46,48 .

28 Wroński: Scenariusz wystawy, 9f. Eine Ausstellungstafel mit demselben Titel, erweitert um weitere Namen, fand sich auch in der Ausstellungsversion von 1990 wieder. Gąsiorowski, Teodor/Kuler, Andrzej/Natkaniec, Marek: Scenariusz wystawy "Kraków 1939-1945« (wersja V - zrealizowana). o. J. [1990]. AMHK, OP-6411-11-90, 7 f.

29 Überschrift in der Ausstellung des Pawiak von 1965. Scenopis stałej ekspozycji, 63.

30 Im Museum »Unter der Uhr» wurde die Namensliste mit den Worten eingeleitet: »Am blutigsten haben sich in die Erinnerung derjenigen, die die Keller der Gestapo durchlitten haben, folgende Personen eingeschrieben «. MLL-Unter der Uhr, Zelle 7. Die vorletzte Tafel der ursprünglichen Schau von 1979 zeigte ein Bild salutierender deutscher Soldaten mit der Unterschrift »Folterknechte« (Oprawcy). Ebd., Zelle 10. 
das alleinige Nennen der Namen individueller Täter nicht mehr verständlich, da die Kontexte der Ereignisse nicht zwingend bekannt sind.

Die Handlungsmotive der einzeln genannten Täter wurden in keiner der in den 1980er-Jahren existierenden Ausstellungen thematisiert. Den einzigen Verweis auf die übergreifenden Intentionen und Ziele des deutschen Besatzungsregimes bot in der Krakauer Pomorska-Straße ein Zitat Adolf Hitlers mit dem Befehl, »ohne Gnade und Erbarmen alle Männer, Frauen und Kinder polnischer Rasse und Sprache zu töten ${ }^{31},{ }^{11}$ das - grafisch exponiert die Ausstellung eröffnete. Ähnliche Argumentationsmuster finden sich auch in der Präsentation des Gefängnismuseums Pawiak, wo etwa in Bezug auf den Sitz der Gestapo in der Szucha-Allee in Warschau die Aussage getroffen wurde: »[...] hier entstanden die Pläne der Terroraktionen, deren endgültiges Ziel die Ausrottung der polnischen Nation war. ${ }^{32}$ Die deutsche Besatzungspolitik fasste man somit in allen Ausstellungen als unmissverständliche Vernichtungsabsicht gegenüber der polnischen Bevölkerung zusammen. Die Unmenschlichkeit der Deutschen unterstrich man auch durch die Betonung der Gewalt gegenüber Zivilisten, insbesondere Frauen und Kindern als Symbolen der Unschuld. ${ }^{33}$

Die Ausstellungen zeichneten somit ein stereotypes Feindbild, in dem die Grausamkeit und Unehrenhaftigkeit der Besatzer im Vordergrund standen. Die wenigen präsentierten Einzelpersonen fungierten - als leitende Verantwortliche und Befehlsgeber für Gewalt und Terror - als Repräsentanten der Okkupanten bzw. der »Hitleristen«. Die Deutschen in Krakau, Warschau und Lublin, wie sie die jeweiligen Schauen zeichneten, waren Inkarnationen des entmenschlichten, abstrakten Bösen. Die Ausstellungen schrieben somit das ausschließlich auf negative Eigenschaften reduzierte stereotype Bild der Deutschen fort, wie es sich endgültig in den Jahren des Zweiten Weltkriegs in der Bevölkerung verfestigt hatte. ${ }^{34} \mathrm{Wie}$ bereits erwähnt, wurde dieses Stereotyp

31 Das vollständige Zitat Adolf Hitlers mit dem Datum vom 20. August 1939 lautete: »Ich schicke meine Totenkopfverbände nach Osten mit dem Befehl, ohne Gnade und Erbarmen alle Männer, Frauen und Kinder polnischer Rasse und Sprache zu töten«. Wroński: Scenariusz wystawy, 2.

32 Scenopis stałej ekspozycji, 67.

33 In der Beschreibung des Gefängnisses im Lubliner Schloss wird ausgeführt: »Inhaftiert waren hier Menschen unterschiedlichen Alters (von Alten bis Kindern) [...].« MLL-Unter der Uhr, Zelle 6. Bei der Aufzählung der Opfer von Massenexekutionen wurden in der Schau des Pawiak-Museums die Zahlen von Frauen unter den Exekutierten einzeln genannt; unter diesen hob man noch einmal Schwangere und Neugeborene hervor. Scenopis stałej ekspozycji, 55, 57, 70-72.

34 Die negative Wahrnehmung der Deutschen als Gegner und Feinde begann sich erst seit Ende des 18. Jahrhunderts herauszubilden. Während der Teilungszeit schrieb man dem Bild der Deutschen jedoch noch sowohl positive als auch negative Eigenschaften zu. Seit der zweiten Hälfte des 19. Jahrhunderts begannen negative Stereotype bei der Bewer- 
in der Volksrepublik jedoch durch die Begriffswahl der »Hitleristen« einseitig auf die Bewohner der Bundesrepublik fokussiert, die als alleinige Erben der Nationalsozialisten angesehen wurden. Die Verantwortungs- bzw. Schuldzuweisung, die der Terminus »Hitleristen" enthielt, war damit eine primär politische, nicht aber ethnisch-nationale und nahm damit die Bewohner des "anderen" Deutschland, der DDR, als "gute Deutsche« davon aus. Der Rückgriff auf die »deutsche Bedrohung" mit Bezug auf den Zweiten Weltkrieg, dessen sich die sozialistischen Regierungen Polens immer wieder bedienten, zielte auf die Legitimierung der kommunistischen Regierung und die Integration der Gesellschaft nach dem Krieg ab, wie dies auch das Verschweigen der sowjetische Besatzung und ihrer Folgen unterstützen sollte. ${ }^{35}$ Die untersuchten Ausstellungen, die Anfang der 1980er-Jahren entstanden oder bereits seit den 1960er-Jahren präsentiert wurden, perpetuierten dieses Interpretationsschema: Das klare Feindbild der »Hitleristen « fungierte als Gegenpol für die Darstellung der ähnlich einseitig, jedoch eindeutig positiv konnotierten Gemeinschaft der Verfolgten. ${ }^{36}$

tung der Beziehungen Deutschlands mit anderen Nationen zu dominieren, darunter diejenige, wonach sie »für die Polen nicht einfache Nachbarn waren [...], sondern eine Nation, die beständige Feindschaft zeigte und Konflikte initiierte«. An dieser Überhand der negativen Wahrnehmung änderte sich bis Ende der Zwischenkriegszeit nichts Wesentliches. Der Zweite Weltkrieg schließlich führte zu einer »Vereinfachung des Stereotyps des Deutschen«. Die Deutschen wurden nun als homogene Massen mit ausschließlich negativen Eigenschaften gezeichnet, darunter unzivilisiertes und bestialisches Verhalten Anderen gegenüber. Wrzesinski, Wojciech: Niemiec w stereotypach polskich XIX i XX wieku [Der Deutsche in den polnischen Stereotypen des 19. und 20. Jahrhunderts]. In: Walas, Teresa (Hg.): Narody i stereotypy [Nationen und Stereotype]. Kraków 1995, 183-189, hier 184-188, Zitate: 186, 188. Siehe auch Niewiara: Procesy kategoryzacyjne, 62. Den Einfluss des Kreuzritter-Mythos auf das negative Deutschen-Bild der Polen beschreibt Zybura, Marek: Krzyżak. Zur Entstehung des negativen Deutschenbildes in der polnischen Romantik. In: Surynt, Izabela/Zybura, Marek (Hg.): Narrative des Nationalen. Deutsche und polnische Nationsdiskurse im 19. und 20. Jahrhundert. Osnabrück 2010, 147-158.

35 Madajczyk, Piotr: Die Rolle antideutscher Instrumentalisierungen in Polen, 1944-1989. In: Bingen, Dieter/Loew, Peter O./Wóycicki, Kazimierz (Hg.): Narrative des Nationalen. Deutsche und polnische Nationsdiskurse im 19. und 20. Jahrhundert. Osnabrück 2010, 131-145, bes. 132-135. Siehe auch Zybura, Marek: Von der »deutschen Gefahr« zum »deutschen Tor nach Europa«. Polnische Deutschland und Deutschenbilder im Wandel. In: Ders.: Querdenker Vermittler Grenzüberschreiter. Beiträge zur deutschen und polnischen Literatur- und Kulturgeschichte. Dresden 2007, 353-371, hier 360-368.

36 Diesen Zusammenhang stellen mit Bezug auf die Schau des MHW auch Zuzanna Bogumił und Joanna Wawrzyniak her. Siehe Bogumił/Wawrzyniak: Das Bild des »Deutschen«, $194 \mathrm{f}$. 


\subsection{Kontinuitäten bis Anfang der 2000er-Jahre}

Diese Interpretationsweise blieb auch in den Anfang der 1990er-Jahre neu eröffneten Dauerausstellungen zunächst bestehen, da es sich bei diesen Schauen meist um lediglich angepasste Versionen ihrer Vorgängerinnen handelte. ${ }^{37}$ Sie waren noch Ende der 1980er-Jahre erarbeitet worden, und nach dem politischen Umbruch nahm man kaum Veränderungen an den bereits bestehenden Drehbüchern vor. Die Darstellung der Deutschen war weiterhin auf ihre militärische Präsenz beschränkt. Neben Zeugnissen der Brutalität und Gewalt der Besatzer präsentierte man nun allerdings auch Objekte, die von der Hoheitsgewalt des Besatzungsregimes im Alltag der Zivilbevölkerung zeugten - beispielsweise Kennkarten, Arbeitsausweise, Lebensmittelkarten und Bekanntmachungen einzelner Besatzungsverordnungen. ${ }^{38}$ In der Ausstellung im Pawiak aus dem Jahr 1991 fügte man zudem eine Vielzahl von Fotografien des Besatzungsalltags ein, die unter anderem die Umbenennung von Straßen dokumentierten oder die Präsenz deutscher Militärs und Gendarmen im Straßenbild zeigten, aber auch Straßenrazzien. ${ }^{39}$ Auch diese Materialien kennzeichneten die Besatzer weiterhin in erster Linie als grausame, homogene und weitgehend anonyme Masse, deren Ziel die Vernichtung der polnischen Nation war. So wurde $1991 \mathrm{im} \mathrm{MHW} \mathrm{das} \mathrm{Besatzungsregime} \mathrm{wie} \mathrm{folgt} \mathrm{vorgestellt:}$

In Polen war das System der deutschen Besatzungsregierung besonders rücksichtslos und grausam. [...] Das hitleristische `Rechtssystem entschuldigte jedes Verbrechen. Das Ziel des Besatzers war die Ausrottung der polnischen Bevölkerung und die vollständige Vernichtung der Juden. ${ }^{40}$

Auch im Pawiak sowie in der Pomorska-Straße in Krakau bestand der einzige Hinweis auf die Motive der Besatzer in übergreifenden Aussagen zu ihrem Willen, die polnische Nation zu vernichten. ${ }^{41}$

37 Dies war sowohl bei der neuen Dauerausstellung in der Pomorska-Straße von 1990 als auch bei der Schau des Pawiak von 1991 der Fall.

38 So etwa in der 1990 neu eröffneten Schau der Abteilung Pomorska-Straße des MHK. Gąsiorowski/Kuler/Natkaniec: Scenariusz wystawy, 4. Ähnliche Dokumente wurden auch in Bezug auf die Geschichte Łódźs in der 1998 neu eröffneten Dauerausstellung des Stadtmuseums Łódź gezeigt. Dort fand sich auch eine größere Zahl deutscher Postkarten mit Stadtansichten von »Litzmannstadt«, auf denen die Vielzahl der Hakenreuzflaggen im Stadtbild besonders hervorstach.

39 Izdebska: Pawiak 1939-1945, 43 f., $144 \mathrm{f}$.

40 Thementext »Der hitleristische Terror in Warschau in den Jahren 1939-1944«. MHW, Saal 47.

41 Wie bereits ihre Vorgängerin wurde die Dauerausstellung des MHK von 1990 von einem Hitler-Zitat eröffnet, das fast wortgleich zu dem aus der Schau von 1982 war, aber nun mit dem Datum vom 28. August 1939 versehen: »Ich schicke meine Totenkopfverbände nach Osten mit dem Befehl, ohne Gnade alle Männer, Frauen und Kinder polnischer Rasse 
Die einzige merkliche Veränderung der musealen Präsentationsweisen stellte die Wandlung der verwendeten Begriffe dar: In ersten Ausstellungen begann man damit, anstelle des in der Volksrepublik geprägten Ausdrucks "Hitleristen« nun "Deutsche«/»deutsch" (Niemcy/niemiecki) zur Bezeichnung der Besatzer zu verwenden. Umfassend geschah dies in der Dauerausstellung des Historischen Museums der Hauptstadt Warschau: In dem 1990/91 neu gestalteten Saal zur Verteidigung Warschaus im September 1939 war ausnahmslos von »den Deutschen « und »deutschen Truppen« die Rede. ${ }^{42}$ Auch bei anderen Sektionen zum Zweiten Weltkrieg passte man die Bild- und Objektbeschriftungen an, sodass der Begriff der "Deutschen« den der »Hitleristen « weitgehend ablöste. Dass dieser Prozess jedoch nicht in aller Konsequenz geschah, zeigt sich im Thementext $»$ Der hitleristische Terror in Warschau in den Jahren 1939-1944«, in dem sich die Begriffe »deutsch« und "hitleristisch " noch abwechselten. ${ }^{43}$ In anderen Dauerausstellungen behielt man die etablierte Sprachpraxis dagegen weitgehend bei. ${ }^{44}$ Im Historischen Museum der Stadt Lublin sprach und spricht man auch nach 1995 fast ausschließlich von der "hitleristischen Besatzung ${ }^{45}{ }^{45}$

und Sprache zu töten."Gąiorowski/Kuler/Natkaniec: Scenariusz wystawy, 1. Auch die Schau des Pawiak von 1991 leitete ein Zitat Adolf Hitlers ein: »[...] dass das Ziel des Kriegs [...] die physische Vernichtung des Gegners ist. Mit diesem Ziel habe ich zunächst nur im Osten meine Totenkopf-Verbände vorbereitet, denen ich befohlen habe, ohne Erbarmen, ohne Mitleid Frauen und Kinder polnischer Herkunft und polnischer Sprache zu töten.« Das Zitat war datiert vom 22. August 1939. Izdebska: Pawiak 1939-1945, 9.

42 So etwa im Thementext »Die Verteidigung Warschaus 1.IX.-28.IX.1939« und den Bereichstexten sowie in Bildunterschriften im Raum 46. MHW, Saal 46, 47.

43 Thementext »Der hitleristische Terror in Warschau in den Jahren 1939-1944«. MHW, Saal 47. Sämtliche Objektbeschriftungen und Bereichstexte in diesem Raum verwendeten jedoch ausschließlich die Ausdrücke »Deutsche« und »deutsch».

44 In der 1990 eröffneten Dauerausstellung in der Pomorska-Straße in Krakau wurde fast ausschließlich von der »hitleristischen Besatzung" gesprochen. Lediglich in einer Bildunterschrift fand sich der Begriff »Deutsche«. Gąsiorowski/Kuler/Natkaniec: Scenariusz wystawy, 3, 6, $14 \mathrm{f}$. Auch die 1991 eröffnete Schau im Pawiak behielt die etablierten Begriffe bei. Izdebska: Pawiak 1939-1945.

45 Lediglich in einer Objektbeschriftung der 1995 eröffneten Ausstellung findet sich eine andere Wortwahl: Eine Ausgabe des Nowy Głos Lubelski (Neue Lubliner Stimme) wird als »deutsche Propagandazeitung» vorgestellt. Vitrine 4. MLL-Krakauer Tor, Sektion »Zweiter Weltkrieg«. Im Ausstellungsführer der Schau aus dem Jahr 2000 halten sich die Begriffe »deutsch» und »hitleristisch" noch die Waage. Chmielak, Jadwiga/Jakimińska, Grażyna/Polańska, Magdalena: Historia Miasta Lublina. Informator do wystawy stałej w Muzeum Historii Miasta Lublina [Die Geschichte der Stadt Lublin. Führer zur Dauerausstellung im Historischen Museum der Stadt Lublin]. Lublin 2000, 57-64. Im Ausstellungsführer von 2008 wird - bis auf zwei Ausnahmen - fast ausschließlich von der »deutschen Besatzung« und den »Deutschen« gesprochen. Polańska, Magdalena/Jakimińska, Grażyna/Piwowarska, Magdalena: Lublin - historia miasta. Informator do wystawy stałej w Muzeum Historii Miasta Lublina [Die Geschichte der Stadt Lublin. Führer zur Dauerausstellung im Historischen Museum der Stadt Lublin]. Lublin 2008, 88-98. 
Erst in den zwischen 1998 und 2003 erstmals umfassender überarbeiteten oder neu eröffneten Dauerausstellungen fand ein deutlicherer Wechsel der Begrifflichkeiten statt. In der Dauerausstellung der Pomorska-Straße von 1998 ebenso wie in der 2001 eröffneten Schau des Pawiak-Museums wird konsequent nur noch von "Deutschen $"$ gesprochen. ${ }^{46}$ Damit erhielt das Feindbild der Besatzer nun eine dezidiert nationale Komponente zurück. Die in den Schauen gezeichnete primäre Opposition zwischen deutschen Besatzern und polnischer Bevölkerung bzw. polnischem Widerstand wurde damit zugleich als ethnisch-nationaler Antagonismus gekennzeichnet und nicht mehr, wie noch in der Volksrepublik, als politischer.

Diese nationale Kontrastierung war um die Jahrhundertwende jedoch (noch) kein allgemeines Phänomen. Die Łódźer Museen etwa sind Beispiele dafür, dass der Begriffswechsel und der damit verbundene Wandel in der Wahrnehmung der Besatzer nicht in allen Institutionen stattfand. In der Schau des Stadtmuseums sprach man auch nach 1998 noch überwiegend von »hitleristischer « Besatzung. ${ }^{47}$ Selbst in der erst 2003 eröffneten neuen Dauerausstellung des Martyrologiemuseums Radogoszcz hielten sich beide Begriffsvarianten die Waage. Hintergründe dieser Persistenz volksrepublikanischer Ausdrücke sind in erster Linie in personellen Kontinuitäten zu suchen. In beiden Museen wurden die neuen Dauerausstellungen maßgeblich von Mitarbeitern kuratiert, die bereits seit langer Zeit in den Institutionen gearbeitet und damit auch zahlreiche Sonder- und Wechselausstellungen zum Zweiten Weltkrieg und der deutschen Besatzung betreut hatten. ${ }^{48}$ Etablierte Sprachgewohnheiten sowie die Routine im Umgang mit diesem Themenbereich können daher als wesentliche Ursachen für die Kontinuität der tradierten Feinddarstellung angesehen werden. In der Dauerausstellung des

46 Beispiel hierfür ist der Titel einer Ausstellungstafel: »Deutsche Ordnung«. MHK-Pomorska-Straße, Tafel 6. Siehe beispielhaft im Pawiak-Museum die Sektion »Besatzung «.

47 Thementext »Lodsch - Litzmannstadt«. MMŁ, Sektion »Lodsch - Litzmannstadt«. Siehe auch Laurentowicz, Małgorzata/Budziarek, Marek (Red.): Triada. Trzy wielkie społeczności. Polacy - Niemcy - Żydzi [Triade. Drei große Gemeinschaften. Polen Deutsche - Juden] [Katalog zur Dauerausstellung]. Łódź 2001, 53 f.; Bereichstext »Der Vorhof der Vernichtung« (Przedsionek zagłady). Sektion »Lodsch - Litzmannstadt«. Siehe auch Laurentowicz/Budziarek: Triada, 59 f. In den Objektbeschriftungen wird sogar ausschließlich der Terminus »hitleristisch" verwendet.

48 Die Dauerausstellung des Stadtmuseums von Łódź wurde maßgeblich von Marek Budziarek mit erarbeitet, der seit 1984 an diesem Museum tätig und für die Geschichte der Jahre 1939 bis 1945 verantwortlich war. Warzecha, Małgorzata: Kustosz znaczy obrońca. Marek Budziarek (1951-2006) [Der Kustos als Verteidiger. Marek Budziarek (19512006)]. In: Kronika miasta Łodzi 1 (2006), 193-196, hier 194. Zu den langjährigen Mitarbeitern des Martyrologiemuseums Radogoszcz, die die Dauerausstellung von 2003 verantworteten und bereits vor 1989 am Museum bzw. seiner Vorgängerinstitution tätig waren, gehört Ryszard Iwanicki, der auch zu den Mitverfassern des Ausstellungsführers zählt. Vgl. Iwanicki/Janaszek/Rukowiecki: Martyrologium Łódzkie. 
Stadtmuseums, für die ein langjähriger Kurator des Museums hauptverantwortlich war, wurden sogar Texte einer Sonderausstellung von 1985 wiederverwendet, an der er wesentlich mitgearbeitet hatte. ${ }^{49}$ Eine Anpassung früherer Ausdrucksweisen und Kontextualisierungen schien offenbar weder dem Verantwortlichen noch der Mitkuratorin der Dauerausstellung und der $\mathrm{Mu}-$ seumsleitung geboten..$^{50}$

Der Begriff »hitleristische Besatzung « ist gerade bei älteren Kuratoren oft derart verinnerlicht, dass der Ausdruck bis in die Gegenwart in polnischen Museen zu finden ist. So ergänzte man beispielsweise die Dauerausstellung des Martyrologiemuseums »Unter der Uhr» in Lublin erst im Januar 2009 um Materialien, die die Geschichte des Gefängnisses im Lubliner Schloss in den Jahren 1944 bis 1954 illustrieren. Im einleitenden Text des Ausstellungsabschnitts, der die Geschichte des Gefängnisses in den Jahren 1939 bis 1954 skizziert, ist jedoch ausschließlich von der "hitleristischen Besatzung" die Rede, zur Nachkriegszeit finden sich hier noch keine Informationen. ${ }^{51}$ In anderen Institutionen dagegen gab es bereits seit der zweiten Hälfte der 1990er-Jahre eine größere Sensibilität auch langjähriger Mitarbeiter bei diesem Aspekt, so etwa in der Abteilung Pomorska-Straße des MHK. ${ }^{52}$

49 Es handelte sich dabei um die Sonderausstellung »Łódź w planach eksterminacyjnych okupanta hitlerowskiego 1939-1945 r.« (Łódź in den Vernichtungsplänen des hitleristischen Besatzers 1939-1945), die von April bis Mai 1985 gezeigt wurde. Große Teile eines Textes des begleitenden Ausstellungsflyers von 1985, der von Budziarek verfasst worden war, verwendete man 1998 für den Thementext »Lodsch - Litzmannstadt« wieder. [Budziarek, Marek]: Łódź w planach eksterminacyjnych okupanta hitlerowskiego 1939-1945 [Ausstellungsflyer]. Łódź 1985. Archiwum Muzeum Miasta Łodzi (Archiv des Stadtmuseums Łódź, weiter AMMŁ), teczka 6/60, Dz. Historii, [o.S.].

50 Neben Budziarek gab es eine zweite Drehbuchautorin, Małgorzata Laurentowicz-Granas. $\mathrm{Zu}$ weiteren Auswirkungen dieser Zweitverwendung der Materialien von 1985 auf das museale Narrativ der Dauerausstellung von 1998 siehe Teil 2, Kapitel 3.1.

51 Diese Ausstellungselemente stammen aus einer Sonderausstellung mit dem Titel »Więźniowie Zamku Lubelskiego straceni w latach 1944-1954 (Häftlinge des Lubliner Schlosses, die in den Jahren 1944-1954 hingerichtet wurden). Das Drehbuch der Schau stammte von Zofia Leszczyńska, einer Zeitzeugin der Kriegs- und Besatzungszeit und langjährigen Mitarbeiterin des "Staatlichen Museums Majdanek" (Państwowe Muzeum na Majdanku). Die Sonderausstellung wurde im Jahr 2000 (im Hauptgebäude des Lubliner Museums) und noch einmal 2008 (im Martyrologiemuseum »Unter der Uhr«) gezeigt. Das Material hängt in der Dauerausstellung im Haus "Unter der Uhr» etwa seit Januar 2009. Interview mit Barbara Oratowska, Leiterin der Abteilung »Unter der Uhr», am 11. Mai 2010. Siehe auch den Ausstellungsführer der Schau von 2008: Oratowska, Barbara: Więźniowie Zamku Lubelskiego straceni w latach 1944-1954 [Die in den Jahren 1944-1954 erschossenen Häftlinge des Lubliner Schlosses]. Lublin 2008.

52 Die Dauerausstellungen von 1990 und 1998, die sich in dieser Begriffswahl deutlich unterschieden, wurden beide von Andrzej Kuler und Teodor Gąsiorowski (mit-)entwickelt. Gąsiorowski/Kuler/Natkaniec: Scenariusz wystawy; Bednarek, Monika/Salwiński, Jacek: 
Wie bereits erwähnt, ging der Wandel der Terminologie jedoch nicht mit einer Veränderung der Darstellungsweise bzw. Charakterisierung der Besatzer einher. Auch nach 1998 tauchen sie einzig in militärischen und politischen Zusammenhängen auf und sind auch visuell in erster Linie über uniformierte Personen repräsentiert. In der Ausstellung der Abteilung des MHK von 1998 nahm man etwa einige zusätzliche Fotografien auf, die repräsentative Großveranstaltungen der Besatzungsmacht sowie zentrale Gebäude der Verwaltung des Generalgouvernements (GG) zeigten. Die in der Vorgängerausstellung bereits enthaltene Tafel mit Fotografien aus dem Alltag der okkupierten Stadt - auf denen bislang keine Deutschen zu sehen waren oder erwähnt wurden - ergänzte man um eine Fotografie Hans Franks, des Gouverneurs des GG, beim Besuch einer Ausstellung deutscher Kunst. ${ }^{53}$ Bei den genannten Abbildungen handelte es sich jedoch ausschließlich um Propagandamaterial, das die visuelle Präsenz der Besatzungsmacht im öffentlichen Stadtraum dokumentierte. Die wenigen namentlich benannten Deutschen waren in allen Schauen aus diesem Zeitraum - in Kontinuität der Darstellungsweise früherer Ausstellungen - militärische und politische Führungspersönlichkeiten und damit herausgehobene Repräsentanten der Besatzungsmacht. ${ }^{54}$ Die auf einzelnen Fotos zu erkennenden Soldaten blieben dagegen anonym. Dass zudem allein Männer die deutsche Besatzungsmacht repräsentierten, verstärkte ihr maskulines, militarisiertes und ausschließlich mit Gewalt konnotiertes Bild. Von der Präsenz deutscher Zivilisten in der Hauptstadt des GG Krakau, in Warschau oder Lublin erfuhren die Besucher nichts.

Lediglich in zwei Dauerausstellungen aus diesem Zeitraum fanden sich erste Hinweise auf die Präsenz deutscher Einwohner: Das Stadtmuseum von Lódź zeigte Ausweispapiere und Arbeitsunterlagen von Mitgliedern der »Deutschen Volksliste« und deutschen Łódźern. ${ }^{55}$ In der umfangreichen

Pomorska. Przewodnik po miejscu pamięci narodowej i oddziale Muzeum Historycznego Miasta Krakowa [Pomorska. Führer durch den Ort der nationalen Erinnerung und die Abteilung des Historischen Museums der Stadt Krakau]. Kraków 2003, 4.

53 MHK-Pomorska-Straße, Tafel 9.

54 In der Pomorska-Straße in Krakau wurden neben Hans Frank mit einem kurzen Biogramm und einer Fotografie Amon Goeth, der Leiter des Konzentrationslagers Płaszów, sowie Friedrich Krüger und Wilhelm Koppe, Höhere SS- und Polizeiführer im Generalgouvernement, als Vertreter des »Terrorapparats« vorgestellt. MHK-Pomorska-Straße, Tafel 14: KZ Płaszów, Tafel 16: Terrorapparat. In der Dauerausstellung des PawiakMuseums von 2001 treten führende Vertreter des deutschen Besatzungsregimes durch Verordnungen in Erscheinung, darunter Hans Frank mit der Proklamation der Gründung des Generalgouvernements und Adolf Hitler mit dem Dekret, das der Gründung vorausging. Ein Foto zeigt Adolf Hitler bei der Siegesparade am 5. Oktober 1939 in Warschau. Daneben werden leitende Mitglieder des deutschen Gefängnispersonals namentlich auf einem Foto vorgestellt. Ebenso findet sich eine Liste der Gefängnisleiter und ihrer Stellvertreter. MNW-Pawiak, Sektionen »Besatzung« und »Pawiak«. 
Dauerausstellung des Museums Radogoszcz von 2003 zeugte eine Vitrine mit Dokumenten, darunter ein Mitgliedsausweis der Hitler-Jugend sowie ein »Inländer-Jahresjagdschein«, vom Alltag der Deutschen in der Stadt. ${ }^{56}$ Näheres über diese neuen (und alten) Bewohner, insbesondere über die Erfahrungen und Einstellungen Einzelner erfuhren die Besucher jedoch nicht. Sie blickten aus der Perspektive der polnischen Łódźer auf sie. So dienten etwa die in den Łódźer Museen herangezogenen Zitate einzelner Deutscher - alle führende Vertreter des Besatzungsregimes - der Illustration der Ziele der deutschen Politik gegenüber dem besetzten Land:

Der Führer hat mich hierhergeschickt zur Ausrottung der polnischen Nation, damit das deutsche Volk leben kann. ${ }^{57}$

Wir Deutschen sind hierhergekommen als Herren und die Polen sollen unsere Diener sein. $^{58}$

Auf Befehl Hitlers erfolgt die intensive Eindeutschung des Warthelandes in schnellem Tempo. $[\ldots]^{59}$

Nur vereinzelt fanden sich Hinweise etwa auf die Veränderungen von Łódź unter dem Einfluss des starken Zuzugs von Deutschen, wie sie in der Ausstellung des Museums Radogoszcz mittels Zitaten eines polnischen Zeitzeugen beschrieben wurden:

Jedes Betreten des Zentrums von Łódź, das so sehr, wenn auch nur oberflächlich, sein Aussehen verändert hatte, konnte die Überzeugung hervorrufen, man sei in einer völlig fremden, fast unbekannten Stadt, obwohl an ihren Straßen weiterhin dieselben, aus der Kindheit bekannten Gebäude standen. Deutsche Schilder, Beschriftungen, die ringsherum ertönende deutsche, lärmende Sprache, Gruppen verschieden uniformierter Deutscher schafften eine Atmosphäre, in der sich ein gebürtiger Łódźer Pole verloren fühlte. $^{60}$

56 Weiter wurden präsentiert u. a. ein Ausweis eines Mitglieds der »Deutschen Volksliste«, ein Mitgliedsbuch der »Deutschen Arbeitsfront« und ein NSDAP-Mitgliedsausweis. Ebd.

57 Zitat von Artur Greiser, dem Reichstatthalter des Warthelandes. Dieses Zitat leitet die thematische Sektion über Gewaltmaßnahmen gegenüber der polnischen Bevölkerung ein. MTNŁ-Radogoszcz.

58 Zitat von Artur Greiser. Das Zitat leitet die thematische Sektion über Einschränkungen der polnischen Bevölkerungen im Alltag ein. MTNŁ-Radogoszcz.

59 Dieses Zitat von Friedrich Ueberlhoer, der als Regierungspräsident in Kalisz für die Region Łódź zuständig war, war an den Anfang des Thementextes gestellt, der der Bedeutung der Stadt innerhalb der nationalsozialistischen Bevölkerungspolitik gewidmet war. Thementext »Lodsch - Litzmannstadt«. MMŁ, Sektion »Lodsch - Litzmannstadt«.

60 Zitat von Ryszard Małecki aus dem Buch »Pod herbem Wandalów« (Unter dem Wappen der Vandalen). MTNŁ-Radogoszcz. 
In den meisten Schauen wurde die deutsche Präsenz im Alltag aus ähnlich indirekter Perspektive geschildert. Im Stadtmuseum von Łódź etwa zeigte man neben den erwähnten Objekten deutsche Straßenschilder und Postkarten mit Stadtansichten von »Litzmannstadt« ebenso wie eine Reihe von Werbegegenständen und Souvenirs, die den Namen "Litzmannstadt« trugen.

Diese weitgehend abstrakte und anonyme Darstellung der deutschen Einwohner mag gerade im Stadtmuseum Łódź angesichts des dezidierten Anspruchs der Dauerausstellung, die Geschichte der drei großen ethnischen Gruppen der Stadt zu porträtieren - darunter die der deutschen Łódźer -, überraschen. ${ }^{61}$ Neben den genannten Ausweispapieren fand sich nur in einem Text eine knappe Erwähnung »einheimischer Deutscher « (miejscowi Niemcy). ${ }^{62}$ Im Gegensatz zu den ausführlichen Darstellungen der deutschen Łódźer in den vorangegangenen Sektionen der Schau deutete man ihre Präsenz während des Zweiten Weltkriegs somit nur an. Die Kontakte zwischen dieser und den restlichen Bevölkerungsgruppen der Stadt - inklusive der "neuen« deutschen Bewohner - wurden hingegen nicht mehr thematisiert. Die deutschen Łódźer wurden somit weitgehend mit den »hitleristischen Besatzern« gleichgesetzt; in ihrer Darstellung griff man auch hier auf tradierte Interpretationstopoi zurück.

Zusammenfassend lässt sich festhalten, dass im Zeitraum 1989 bis 2003, also vom Beginn der Transformation bis zum Einsetzen des Museumsbooms, das museale Feindbild der Deutschen kaum Veränderungen erfahren hat. Die einsetzende Abkehr von der Terminologie der Volksrepublik ging nicht mit einer Wandlung der Darstellungsweisen des "vertrauten Feindes ${ }^{63}$ einher. Das Bild des Besatzers blieb weiterhin weitgehend von Stereotypen geprägt, mithin also ein abstraktes, brutalisiertes und entmenschlichtes. Damit wahrte man die eindeutige Gegenüberstellung und Distanz zwischen den Besatzern und den Unterdrückten, der als geschlossener nationaler Gemeinschaft konnotierten polnischen Bevölkerung. ${ }^{64}$ Diese Kontinuität kann

61 Der Titel der Schau lautete entsprechend: »Triada łódzka - trzy wielkie społeczności. Polacy - Niemcy - Żydzi« (Łódźer Triade - drei große Gemeinschaften. Polen - Deutsche Juden). Siehe auch Laurentowicz, Małgorzata/Budziarek, Marek (Red.): Triada. Trzy wielkie społeczności. Polacy - Niemcy - Żydzi [. Polen - Deutsche - Juden] [Katalog zur Dauerausstellung]. Łódź 2001.

62 In einem Satz des Thementextes der Sektion wurden die Bemühungen der »einheimischen Deutschen« als einer der Gründe für die letztendliche Inkorporation der Stadt in das Reichsterritorium genannt. Thementext »Lodsch - Litzmannstadt«. MMŁ, Sektion »Lodsch - Litzmannstadt $«$.

63 Diesen Begriff für das Feindbild des Deutschen in den Dauerausstellungen des MHW und des MPW verwenden Zuzanna Bogumił und Joanna Wawrzyniak. Bogumit/Wawrzyniak: Das Bild des »Deutschen«, $200 \mathrm{f}$.

64 Zur Darstellung der polnischen Bevölkerung in diesem Zeitraum siehe Teil 3, Kapitel 1.2 und 2.2. 
auf das nachlassende Interesse an der deutschen Besatzung in der polnischen Historiografie und Publizistik der 1980er- und beginnenden 1990er-Jahre zurückgeführt werden. Andere Themen - vormalige Tabus wie die Rolle der Sowjetunion während des Kriegs - rückten in diesem Zeitraum in den Vordergrund des wissenschaftlichen und öffentlichen Interesses ${ }^{65}$ Zudem galt die deutsche Besatzung Polens unter Wissenschaftlern als umfangreich erforscht; eine Veränderung von Perspektiven oder deren Ergänzung wurde nicht als notwendig erachtet. ${ }^{66}$ Diese Einstellung spiegeln auch die untersuchten musealen Präsentationen wider.

\subsection{Erweiterungen des traditionellen Deutungsangebots?}

Mit dem ab 2004 einsetzenden Museumsboom ist eine spürbare Diversifizierung der Museumslandschaft und der in den Dauerausstellungen der untersuchten Museen präsentierten Perspektiven und Interpretationen erkennbar. Viele der seitdem neu entstandenen Institutionen und Dauerausstellungen streben an, eine neue oder veränderte Sichtweise auf die polnische und die lokale bzw. regionale Geschichte zu entwerfen. Inwieweit dieses Bestreben sich in den Darstellungen der Kriegsgegner und Besatzungsmacht, also der Deutschen, in den Jahren 1939 bis 1944/ 45 niederschlägt, wird im Folgenden für die drei größten neuen Präsentationen analysiert.

\section{Das Museum des Warschauer Aufstands}

Trotz der Einführung neuer gestalterischer und medialer Zugänge in jüngsten Ausstellungen zeichnet sich der eine Pol des gegenwärtigen musealen Interpretationsspektrums der Kriegszeit durch eine bemerkenswerte Kontinuität

65 Bömelburg: Die Erinnerung an die deutsche Besatzung, 64 f.; Mańkowski: Die polnische Geschichtsschreibung, 98.

66 Die Erforschung bisheriger Tabuthemen der deutsch-polnischen Beziehungen der Kriegsund unmittelbaren Nachkriegszeit, insbesondere der Aussiedlung und Vertreibung der deutschen Bevölkerung, begann erst Mitte der 1990er-Jahre. Erste Forschungsergebnisse in diesem Bereich wurden Ende des Jahrzehnts publiziert. Borodziej/Hajnicz: Kompleks Wypędzenia; Borodziej, Włodzimierz/Lemberg, Hans (Hg.): Niemcy w Polsce 19451950. Wybór dokumentów [Die Deutschen in Polen 1945-1950. Eine Auswahl von Dokumenten]. 4 Bde. Warszawa 2000-2001. Deutsche Parallelausgabe: Borodziej, Włodzimierz/Lemberg, Hans (Hg.): >Unsere Heimat ist uns ein fremdes Land geworden ...< Die Deutschen östlich von Oder und Neiße 1945-1950. Dokumente aus polnischen Archiven. 4 Bde. Marburg 2000-2004. Siehe auch Górny, Maciej: From the Splendid Past into the Unknown Future: Historical Studies in Poland after 1989. In: Antohi, Sorin/ Trencsénye, Balász/Apor, Péter (Hg.): Narratives Unbound. Historical Studies in PostCommunist Eastern Europe. Budapest, New York 2007, 101-172, hier 119. 
von Inhalten und Deutungen aus. Herausragendes Beispiel für diese Institutionen ist das 2004 eröffnete Museum des Warschauer Aufstands, das auch bei der Darstellung der deutschen Besatzer in traditionellen Interpretationsmustern verhaftet bleibt. Dabei ist zunächst anzumerken, dass in der ursprünglichen Fassung der Dauerausstellung die Besatzer nur relativ knapp vertreten waren; lediglich ein kleiner Themenraum ist dort explizit »den Deutschen " gewidmet. ${ }^{67}$ Zusätzlich erwähnt man sie an einigen Stellen, wie im Folgenden noch näher geschildert wird. Dominiert wird die Schau jedoch von den polnischen Aufständischen sowie vom zweiten Feindbild, den »Sowjets $«{ }^{68}$ Erst durch die interne Besucherforschung des Museums wurden die Verantwortlichen darauf aufmerksam, dass die Besucher eine Darstellung derjenigen vermissten, gegen die die Aufständischen 1944 unmittelbar gekämpften hatten. ${ }^{69}$ Vor diesem Hintergrund entschloss man sich zu einer Erweiterung der Dauerausstellung und erarbeitete eine zusätzlichen Sektion im Keller, in der »Die Deutschen in Warschau« nun seit Juni 2007 eingehender dargestellt werden. ${ }^{70}$

Die auffälligen Ähnlichkeiten zur Präsentationspraxis der Volksrepublik in der Dauerausstellung des MPW, wie sie schließlich zum Zeitpunkt der Recherche im Sommer 2009 existierte, finden sich zunächst in der weitgehenden Konzentration auf politische und militärische Aspekte der deutschen Besatzung Polens und Warschaus zwischen 1939 und 1944. Die neuen Machthaber werden in der Schau fast ausschließlich durch Militärangehörige oder politische Vertreter des Besatzungsregimes repräsentiert. So zeigen die präsentierten Fotografien überwiegend uniformierte Soldaten. Bei der Mehrzahl der ausgestellten Objekte mit Bezug zu den Besatzern handelt es sich ebenfalls um militärische Attribute wie beispielsweise Uniformen, ein Helm und Waffen. ${ }^{71}$ Neben anonymen Kollektivbezeichnungen wie »die Deutschen« (Niemcy) oder »deutsche Einheiten« (formacje niemieckie) werden - in Kontinuität traditioneller Präsentationspraxen - nur wenige Einzelpersonen vorgestellt; bei

67 MPW, Sektion 38: Die Deutschen. Mit der ursprünglichen Fassung ist die geplante Dauerausstellung gemeint, die schrittweise bis zum Frühjahr 2006 fertiggestellt wurde. Zur Entwicklung der Ausstellung des MPW siehe Kapitel 3 der Einleitung.

68 Siehe hierzu Teil 1, Kapitel 2.3.

69 Das Museum führt regelmäßig Besucherbefragungen zur Rezeption einzelner Teile der Dauerausstellung durch, die jedoch als internes Material behandelt und nicht veröffentlicht werden. Interview mit Paweł Ukielski, dem stellvertretenden Direktor des Museums für inhaltliche Fragen, am 8. Juli 2009.

70 MPW, Sektion 56: Die Deutschen in Warschau. Siehe Dabkowska-Cichocka: Przewodnik po Muzeum, 206f., 216-219. Die Sektion wurde am 21. Juni 2007 eröffnet. Ebd., 48.

71 Vitrinen in den Abschnitten "Die Deutschen im Aufstand « und »Alltag«. MPW, Sektion 56: Die Deutschen in Warschau. Im Themenraum "Die Deutschen « auf der ersten Etage des MPW ist das Gewehr eines deutschen Scharfschützen ausgestellt. MPW, Sektion 38: Die Deutschen. 
diesen handelt es sich um führende Vertreter aus Politik und Militär wie etwa Oskar Dirlewanger, den Anführer der SS-Sondereinheit »Dirlewanger«, oder Hans Frank, den Gouverneur des Generalgouvernements. Beide werden sowohl mit Fotografien als auch ausführlichen Biogrammen bzw. Informationen zu ihren Aktivitäten und Verbrechen im besetzten Polen präsentiert. ${ }^{72}$ Die weiteren auf Fotografien zu sehenden deutschen Soldaten bleiben hingegen namenlos.

Der Schwerpunkt der Darstellung der Deutschen liegt auf den von den Besatzern ausgeübten Gewalttaten und deren besonderer Grausamkeit. Diese vermittelt man insbesondere durch die Betonung der Brutalität gegenüber der Zivilbevölkerung. So wird etwa in einem Text das Vorgehen deutscher Truppen gegen diese detailliert geschildert:

Während des Aufstands begehen die Deutschen massenhafte Verbrechen an der Zivilbevölkerung. [...] Sie töten ohne Rücksicht auf Alter und Geschlecht. Sie ermorden kleine Kinder und Schwangere. Viele Personen verbrennen sie bei lebendigem Leibe. Verletzte werden mit Kopfschüssen getötet. Während der Angriffe auf die Barrikaden der Aufständischen treiben sie Zivilisten vor den Panzern her und verstecken sich hinter den >lebendigen Schutzschilden.$^{73}$

Unterstützt wird diese drastische Schilderung durch eine Vielzahl von in der Ausstellung verteilt platzierten Fotos und Filmmaterial, die Exekutionen und Leichen zeigen. $^{74}$

In der Schilderung dieser Ereignisse wird insbesondere die Völkerrechtswidrigkeit der Taten betont und damit die Unmenschlichkeit der Täter hervorgehoben. Exemplarisches Beispiel hierfür ist die Darstellung der Massaker an etwa 40.000 Zivilisten im Stadtteil Wola, die am 5. August 1944 und den folgenden Tagen begangen wurden: Auf der Rückseite eines inszenierten

72 Hans Frank wird etwa im Themenraum »Die Deutschen« ausführlich vorgestellt. Dort findet sich nicht nur ein raumhohes Porträt von ihm und seiner Familie, sondern auch ein Biogramm seiner Person. MPW, Sektion 38. Oskar Dirlewanger ist sowohl im Hauptteil der Dauerausstellung in der Halle A ausführlich porträtiert, wie im Weiteren noch näher ausgeführt wird, als auch im Ausstellungsabschnitt »Die Deutschen in Warschau« in der Halle B. MPW, Sektion 56: Die Deutschen in Warschau. In der Halle B werden daneben die "Machthaber Warschaus« (Władcy Warszawy) mittels Porträts und Biogrammen vorgestellt. Ebd., Zitat: Titel des zur Sektion gehörenden Bereichstextes.

73 Bereichstext "Das Schicksal der Zivilisten«. MPW, Sektion 22: Das Krankenhaus der Aufständischen.

74 In der Ausstellung auf den drei Etagen der Halle A finden sich solche Fotos unter anderem auf Monitoren, die hinter erhöhten Mauern verborgen und mit Hinweisschildern versehen sind, sodass die Besucher sich entscheiden können, ob sie sich diese ansehen möchten. In der Ausstellung in den Kellerräumlichkeiten wird diese Methode ebenfalls verwandt; daneben sind jedoch solche drastischen Bilder auch ohne Warnhinweise in den Rundgang integriert, was die Vermittlung eines entmenschlichten und auf Grausamkeit konzentrierten Bildes der Besatzer unterstützt. 
Zeltes, in dem Exhumierungsprotokolle der Opfer präsentiert werden und das in seiner Gestaltung an diese Exhumierungsarbeiten erinnert, werden jeweils in einem kurzen Text die Kommandierenden jener Einheiten vorgestellt, die diese Verbrechen begangen haben - Oskar Dirlewanger und Heinrich-Friedrich Reinefarth, Leiter der »Kampfgruppe Reinefarth". Unmittelbar neben diesen Informationen sind in deutscher Sprache und polnischer Übersetzung die »10 Gebote für die Kriegsführung des deutschen Soldaten« angebracht mit dem Hinweis, dass diese Gebote »im Soldbuch jedes Wehrmachtssoldaten abgedruckt « waren. ${ }^{75}$ In diesen Vorschriften ist unter anderem aufgeführt:

1. Der deutsche Soldat kämpft ritterlich für den Sieg seines Volkes. Grausamkeiten und nutzlose Zerstörung sind seiner unwürdig. [...]

3. Es darf kein Gegner getötet werden, der sich ergibt [...]. [...]

6. Das Rote Kreuz ist unverletzlich. [...]

7. Die Zivilbevölkerung ist unverletzlich. Der Soldat darf nicht plündern oder mutwillig zerstören[.] Geschichtliche Denkmäler und Gebäude, die dem Gottesdienst, der Kunst, Wissenschaft oder Wohltätigkeit dienen, sind besonderes zu achten [...]. ${ }^{76}$

Die Gegenüberstellung dieser Regeln mit den Verbrechen, die während der Niederschlagung des Aufstands begangen wurden, schafft einen deutlichen Kontrast, vor dem die Rechtswidrigkeit und Unehrenhaftigkeit der deutschen Taten in Warschau in besonderem Maße hervorsticht. Unmittelbar neben dieser Aufstellung werden - unter einer an der Decke befestigten Flagge des Roten Kreuzes - die Massaker in Krankenhäusern der Aufständischen geschildert. In einem Text betont man insbesondere, dass dieses Vorgehen gegen die Genfer Konvention von 1929 verstieß.$^{77}$ Im weiteren Verlauf der Ausstellung werden die Massenexekutionen als "Völkermord« zusammengefasst und zugespitzt:

Als Himmler am 1. August den Befehl erteilt, jeden Warschauer zu töten, geht er von der Ermordung einer Million Menschen aus. Am umfassendsten wird dieser Befehl in Wola ausgeführt, wo infolge eines geplanten Völkermords über 40.000 Zivilisten sterben. Die Vernichtung [eksterminacja] wird jedoch in der gesamten Stadt durchgeführt, jeder errungene Stadtteil wird pazifiziert, womit massenhafte Exekutionen und Morde, Vergewaltigungen und Raubzüge einhergehen. Die Luftwaffe bombardiert Krankenhäuser trotz der Zeichen des Roten Kreuzes, die Soldateska [żołdacy] mordet Personal und Patienten. [... $]^{78}$

75 MPW, Sektion 20: Der Völkermord von Wola.

76 Zitate aus der deutschen Textvariante: »10 Gebote für die Kriegsführung des deutschen Soldaten«. Ebd.

77 Bereichstext »Die Deutschen und die Genfer Konvention«. MPW, Sektion 22: Das Krankenhaus der Aufständischen.

78 Bereichstext»Völkermord«(Ludobójstwo). MPW, Sektion 56: Die Deutschen in Warschau. 
Das Vorgehen der Besatzer brandmarkt man somit als völker- und menschenrechtswidrig, womit sie in klaren Gegensatz zu den Aufständischen gestellt werden, die als ehrenhafte Soldaten und als für eine legitime und gerechte Sache Kämpfende porträtiert werden. Diese Zuschreibung spiegelt sich auch in der Verwendung des Begriffs "Soldat" wider: Dieser wird in der gesamten Ausstellung kaum in Bezug auf Angehörige des deutschen Militärs gebraucht, die zumeist unter der übergreifenden Bezeichnung "Die Deutschen« (Niemcy) gefasst sind. Die Benennung "Soldat« findet hingegen in fast jedem Biogramm und jeder Information über die polnischen Aufständischen Verwendung, deren Handlungen damit staatliche und implizit auch moralische Legitimität zugeschrieben wird, als Ausdruck der rechtmäßigen Verteidigung des Vaterlandes. ${ }^{79}$ Die Opposition von "Gut" und »Böse» wird somit auch sprachlich vermittelt. Die Deutschen erscheinen im Resultat als Inkarnationen des absoluten, entmenschlichten Bösen.

Auch die Gestaltung der den Besatzern gewidmeten Sektionen unterstreicht ihr militärisches, mit Gewaltausübung konnotiertes Bild. So wird der Themenraum »Die Deutschen« im älteren Teil der Dauerausstellung dominiert von Metall, aus dem sowohl der Boden als auch die Vitrinen und der Schrank gefertigt sind, in dem die Biogramme einzelner Vertreter der Regimes untergebracht sind (siehe Abb. 14). Der hierdurch bereits vermittelte sinnliche Eindruck von Rohheit, Kühle und Gefühllosigkeit wird noch durch die Dunkelheit in diesem Raum verstärkt, der lediglich mit kühlem Neonlicht gering beleuchtet wird. Im Hintergrund sind die bedrohlichen Geräusche marschierender Soldaten zu hören. Diese Präsentationsweise wurde in der 2007 hinzugefügten Sektion "Die Deutschen in Warschau« fortgesetzt. In der Lichtgestaltung ergänzte man das weiße Neonlicht durch ein rötliches Licht, welches Assoziationen zu den Farben der Hakenkreuzflagge hervorruft. Diese taucht in der Sektion mehrfach auf; ein Hakenkreuz ist auch das erste, was die Besucher beim Betreten der Sektion wahrnehmen - es wird großformatig auf den Boden des Eingangsbereichs projiziert, sodass die Besucher es buchstäblich mit Füßen treten (siehe Abb. 15). ${ }^{80}$ Daneben ruft die Farbgestaltung Assoziationen an Blut, an die Gewalt der Besatzer und an das dadurch verursachte Leid hervor. Im gesamten Ausstellungsbereich ist das Licht insgesamt sehr zurückgenommen, und die Besucher befinden sich in einem permanenten Halbdunkel. Die Dunkelheit wirkt dabei als Hinweis auf die Abgründe, die in den jeweiligen Sektionen geschildert werden. Auch die verwendeten Materialien unterstützen diesen Eindruck: Es dominieren

79 Siehe auch Teil 3, Kapitel 2.2 und 2.3.

80 Zudem befindet sich auf der Wand direkt gegenüber dem Eingang eine Collage von Fotografien der Deutschen im September 1939, die in Form eines Hakenkreuzes angeordnet sind. 


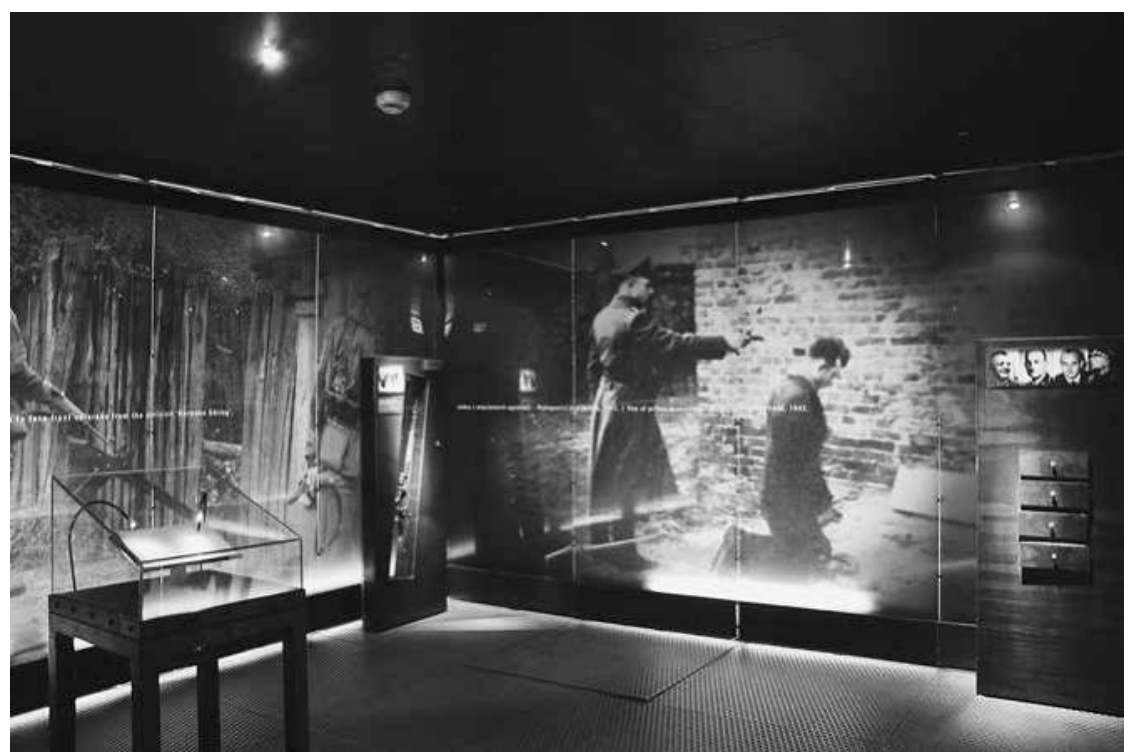

Abb. 14: MPW, Sektion »Die Deutschen«.

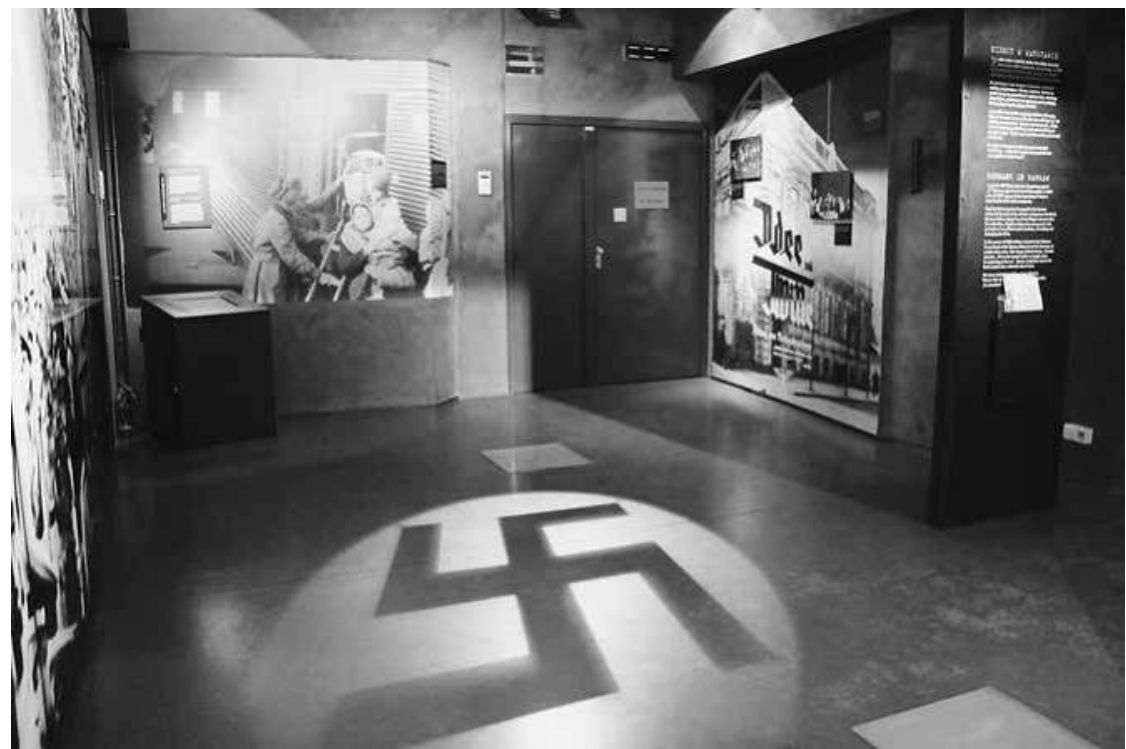

Abb. 15: MPW, Eingangsbereich der Sektion »Die Deutschen in Warschau«. 
metallene Wände und Gitter; einzelne Informationen und Fotografien sind auf metallenen Panelen angebracht, die von den Besuchern bewegt und offengelegt werden müssen; der Boden ist aus Beton (siehe Abb. 16 und 17). Die gesamte Sektion vermittelt damit den Eindruck von Härte, die auf die Brutalität und die Maschinerie der Gewalt der Besatzer verweist. ${ }^{81}$ Auch die Geräuschkulisse unterstützt diesen Eindruck: Neben Marschgeräuschen sind an mehreren Stellen deutsche, aggressiv artikulierte Befehle zu hören. So wird etwa der Befehl Heinrich Himmlers zur Zerstörung der Stadt als Strafe für den Aufstand durch eine laute, bellende Männerstimme vorgelesen. Durch diese spezifische Gestaltungsweise heben sich die beiden thematischen Bereiche, die einzig den Besatzern gewidmet sind, deutlich von der übrigen Ausstellung ab, die in warmen Farben und Lichtkulissen gehalten ist, wodurch die Atmosphäre angenehmer und menschlicher erscheint.

Ein weiterer Aspekt, der eine Kontinuität der Präsentationsweisen der VRP darstellt, ist die stark normative Sprache und Ausdrucksweise, die die gesamte Schau kennzeichnet, darunter auch die Sektionen zu den deutschen Besatzern. Viele der Kuratorentexte sind derart überspitzt, dass man sie als sarkastisch bezeichnen muss. Ein Beispiel findet sind in einem Ausstellungsabschnitt, der dem Alltag der Deutschen in der besetzten Stadt gewidmet ist: Auf einer großformatigen Fotografie ist ein Straßenbahnwagon zu sehen, aus dem eine Gruppe lachender Kinder herausschaut; unter den Fenstern des Wagons ist deutlich sichtbar ein Schild mit der Aufschrift »Nur für Deutsche/ Tylko dla Niemców« angebracht. Die Szene wirkt wie ein fröhlicher Schulausflug. Der Kommentar hierzu seitens der Ausstellungsmacher verleiht der scheinbar unschuldigen Situation eine eindeutige Lesart: „Die Aufschrift „nur für Deutsche verbessert das Wohlbefinden der reisenden Jugendlichen. ${ }^{82}$ Selbst Alltagsgegenstände werden überwiegend in einen militärischen oder politischen Kontext gestellt. So ist etwa Geschirr mit Reichsadlern darauf ausgestellt, dessen Objektbeschriftungen darauf hinweisen, dass Tonschüsseln für die deutsche Armee produziert wurden oder aber dass »die Deutschen [...] ihre Mahlzeiten zum Ruhme des Dritten Reiches [einnehmen] ${ }^{83}$ Mit derart sarkastischen Kommentaren wird die emotionale Wahrnehmung der

81 Anliegen der Ausstellungsgestalter der Sektion - das Büro Nizio Design International war es, »ein allegorisches Stahlmodell [zu schaffen], das den Charakter und die Atmosphäre eines Staates wiedergibt, der einer riesigen Maschine gleicht, in der Tausende aufeinander abgestimmte Prozesse auf ein erschreckendes und entmenschlichtes Ziel hinarbeiten - die rücksichtslose Vernichtung der Menschen und der Stadt."Nizio Design International: Scenariusz ekspozycji »Niemcy«. Muzeum Powstania Warszawskiego. Hala B. Warszawa [o. J.]. Archiwum Muzeum Powstania Warszawskiego (Archiv des Museums des Warschauer Aufstands, weiter AMPW), ohne Signatur, 1.

82 Bildunterschrift. MPW, Sektion 56: Die Deutschen in Warschau.

83 Objektbeschriftung in einer Vitrine. Ebd., Abschnitt »Alltag«. 

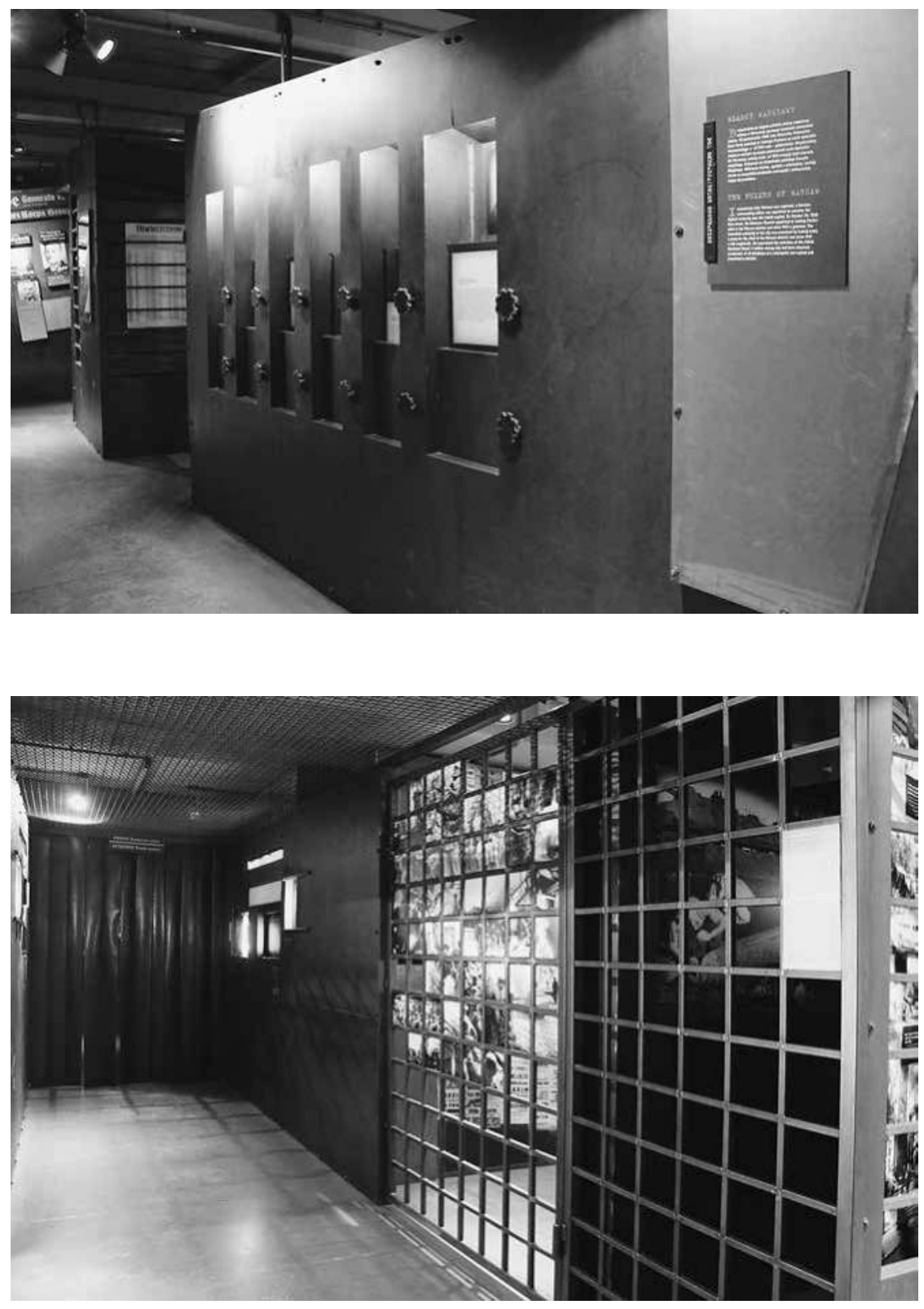

Abb. 16 und 17: MPW, Sektion »Die Deutschen in Warschau«. 
dargestellten Kontexte durch die Besucher stark beeinflusst. Offensichtlich soll eine Differenzierung des einseitigen Bildes »der Deutschen« im Besatzungskontext verhindert werden, indem ambivalente Aspekte des Besatzungsalltags in ein eindeutiges Schwarz-Weiß-Schema gepresst werden. Eine Objektbeschriftung am Ende der Sektion, in der die systematische Zerstörung der Stadt geschildert wird, lautet: »Ordnung muss sein«, das Ausführen von Befehlen wird daher von besonderen Kommissionen überprüft. ${ }^{84}$ Diese Verwendung eines der bekanntesten Stereotype in Bezug auf Deutsche ist ein weiteres Beispiel dafür, wie traditionelle schematische Denkmuster in der Ausstellung als Vermittlungsstrategie bewusst eingesetzt werden. Damit werden auch existierende Vorurteile, insbesondere negative Vorstellungen der Besucher, aufgegriffen und bestärkt.

Neben diesen traditionellen, wenn auch mit modernen technischen und gestalterischen Mitteln umgesetzten Interpretationstopoi, finden sich auch einige neue Elemente. Besonders auffällig ist die konsequente Verwendung der Begriffe »deutsch" und »Deutsche«, die den in der VRP geschaffenen Terminus "Hitleristen " abgelöst haben. ${ }^{85}$ Diese Begriffswahl war eine bewusste Entscheidung der Ausstellungsverantwortlichen. Ziel war es, die breite Verantwortung des Deutschen Reiches kenntlich zu machen, da die Gefahr gesehen wurde, mit den heute üblichen Begriffen »Nazis« bzw. »Nationalsozialisten" (naziści) würde die Verantwortung für den Angriffskrieg und die Verbrechen auf die kleinere Gruppe der Mitglieder der NSDAP und Anhänger der NS-Ideologie verengt. ${ }^{86}$ In diesem Sinne richtet sich die Wortwahl auch gegen eine als im Westen verbreitet wahrgenommene Entwicklung, die deutsche Verantwortung für den Krieg und die Besatzung zu einer "nationalsozialistischen« zu verkürzen. Zugleich soll die eindeutige Terminologie jüngsten Tendenzen im Ausland, gerade in Presseberichten, entgegenwirken, von "polnischen « Konzentrations- und Vernichtungslagern zu sprechen. Als Ursache der großen Verbreitung dieses Phänomens wird von den Museumsmachern unter anderem angesehen, dass nicht mehr von »deutschen « Verbrechen, sondern von »NS-« bzw. »nationalsozialistischen« Gräueltaten die Rede ist, was vermeintlich die Verantwortlichkeit für den Kriegsausbruch und die verübten Verbrechen gegen die Menschlichkeit verwische. ${ }^{87}$

Die Verwendung des Begriffs »die Deutschen« - stellvertretend für die Besatzungsmacht und die deutsche (Zivil-)Bevölkerung im besetzten Land -

84 MPW, Sektion 56: Die Deutschen in Warschau.

85 Die einzige Abweichung von dieser Regel findet sich in einem kurzen Text am Anfang der Dauerausstellung, bei der Schilderung der Besatzung Polens. Im Bereichstext »Die Verfolgung von Protestanten« ist überraschenderweise von »Hitleristen« die Rede. MPW, Sektion 6: Die Besatzung.

86 Interview mit Paweł Ukielski, dem stellvertretenden Direktor des MPW, am 8. Juli 2009.

87 Ebd. 
fügt der Charakterisierung des Feindes eine ethnisch-nationale Komponente hinzu. Hierdurch erscheinen »die Deutschen« zugleich in erster Linie als homogene und auch anonyme Masse, denn konkrete Individuen werden - wie bereits beschrieben - nur sehr vereinzelt dargestellt. ${ }^{88}$ Dieser Terminus fasst zudem weitgehend undifferenziert alle Gruppen zusammen, die vor und während des Warschauer Aufstands aufseiten der Deutschen kämpften. Lediglich an wenigen Stellen wird erwähnt, dass etwa »zur Kampfgruppe >Reinefarth Kollaborationseinheiten [gehören], die sich aus Russen, Ukrainern, Aserbaidschanern und Turkmenen zusammensetzen «. ${ }^{89}$ In der übrigen Schau werden diese Gruppen und ihre Taten jedoch undifferenziert unter dem Ausdruck »die Deutschen« subsumiert.

Eine weitere Neuerung in Bezug auf die Darstellung der deutschen Feinde führten die Ausstellungsmacher 2007 mit der Sektion »Die Deutschen in Warschau« ein: individuelle Zeugnisse von Repräsentanten der Besatzungsmacht. Neben offiziellen Dokumenten wie Lageberichten über den Fortgang der Kämpfe sind auch Selbstzeugnisse in die Schau integriert, darunter Tagebucheinträge von Erich von dem Bach-Zelewski, dem Oberbefehlshaber der deutschen Truppen während der Niederschlagung des Aufstands, aber auch Berichte einfacher Soldaten. Der Schwerpunkt dieser Schilderungen liegt auf den Kämpfen während des Aufstands. Ein Soldat beschreibt in seinem Tagebuch stichpunktartig die eigenen Erlebnisse, insbesondere den großen Hunger, das Sterben und die Selbstmorde von Kameraden sowie die allumgebende Gefahr..$^{90}$ Der Überlebenswille der Soldaten wird darin deutlich. In ihrer Gesamtkomposition fügen sich diese Einblicke in die individuellen Wahr-

88 Nur an einer Stelle wird sehr knapp erwähnt, dass die Definition »deutsch" im Generalgouvernement unterschiedliche Gruppen bezeichnete - »Reichsdeutsche«, »Volksdeutsche« und "Stammdeutsche«; weiter thematisiert werden diese jedoch nicht. Bereichstext »Die Deutschen im besetzten Warschau«. MPW, Sektion 56: Die Deutschen in Warschau.

89 Weiter heißt es: »Undiszipliniert und halbwild bevorzugen sie es zu morden, zu vergewaltigen und zu stehlen.« Bildunterschrift. MPW, Sektion 56. Im ersten kleinen Themenraum »Die Deutschen« wird dieser Zusammenhang noch kürzer dargestellt: »Zu den Strukturen der SS gehören Einheiten von Kriminellen und östliche Kollaborationseinheiten.« Bereichstext »Die deutschen Verbände«. Daneben wird in diesem Raum ein kurzes Biogramm von Bronislav Vladislavovič Kaminskij gezeigt, dem Gründer der Freiwilligenbrigade RONA (Russkaja Osvoboditel'naja Narodnaja Armija/Russische Volksbefreiungsarmee). MPW, Sektion 38: Die Deutschen. In einer anderen Sektion der Schau, bei der Schilderung der Kämpfe im Stadtteil Ochota im Zwischengeschoss der Halle A, wird eine Flagge dieser Abteilung gezeigt.

90 »Aufzeichnungen von Kurt Haller, einem deutschen Soldaten der Besatzung der PASTa, die im `Biuletyn Informacyjny` [Informationsbulletin] Nr. 59 (267) vom 22. August 1944 unter dem Titel `überall lauert der Tod` publiziert wurden«. MPW, Sektion 56: Die Deutschen in Warschau. 
nehmungen der Gegner jedoch in erster Linie zu einem detaillierten Bild ihrer Brutalität - denn die Autoren waren an der beschriebenen Gewalt unmittelbar beteiligt.

Eine Besonderheit stellen zwei Zeugnisse von nichtdeutschen Kämpfern dar, die ihre Erfahrungen kritisch reflektieren: einem Soldaten der mit den Deutschen kollaborierenden »Russischen Volksbefreiungsarmee« (Russkaja Osvoboditel'naja Narodnaja Armija, RONA) sowie dem Belgier Mathias Schenk. In einem abgetrennten Raum wird ein Videomitschnitt eines Interviews mit Schenk ausgestrahlt. Dieser war während des Kriegs in die Wehrmacht zwangsrekrutiert worden und in Warschau zeitweise der SS-Brigade Dirlewanger zugewiesen. In den Aussagen des alten Mannes wird seine Abscheu gegenüber den Grausamkeiten, die er erlebt hat, deutlich: »Warschau war das Furchtbarste, was ich erlebt hab. [...] Das sind die Bilder, die man nie vergessen kann [...] «. ${ }^{91}$ In seiner Mimik und Ausdrucksweise sind deutlich die Betroffenheit und das Grauen angesichts der Gräueltaten insbesondere der SS-Brigade Dirlewanger zu sehen. Gerade die Verurteilung der Gewalt durch eine Person, die aufseiten der Täter agiert hat, unterstreicht die Abscheulichkeit der geschilderten Verbrechen nochmals. Als Belgier - damit Nicht-Deutscher - und zudem als Zwangsrekrutierter, der immer wieder eigene positive Verhaltensweisen während der Kämpfe erwähnt, erscheint Mathias Schenk zugleich fast als Außenstehender bzw. als Ausnahme, die die Unmenschlichkeit der deutschen Kämpfer bestätigt. Bemerkenswerter ist jedoch das (schriftliche) Tagebuch eines Soldaten der RONA, Ivan Ivanovič Vašenko. ${ }^{92}$ In seinen recht umfangreichen Notizen vom August 1944 finden sich immer wieder Aussagen, die die Brutalität seiner Einheit ebenso wie das Vorgehen der alliierten Deutschen - auch gegenüber seiner eigenen Nation - hinterfragen und kritisieren:

4. August [...] Wir marschieren in die Stadt ein, Soldaten suchen Einwohner heraus, der Anführer der Kompanie erschießt die Gefundenen. Wozu das? Was haben sie damit zu tun - diese Frauen und Kinder. [...] 22. August [...] Wofür sind diese Soldaten gestorben, zu wessen Nutzen? Es ist schwer zu verstehen, wofür man hunderte junger Leute in den sicheren Tod treibt, die leben und nochmals leben wollen. Auf diese Art starben und sterben hunderte, tausende und sogar zehntausenden Russen - zum Nutzen der Deutschen, die im Laufe von drei Jahren für die russische Nation nichts als Böses getan haben. [...] Man muss die Waffen gegen diese Barbaren des 20. Jahrunderts richten, die niemanden ausstehen können und keine Nation außer ihrer eigenen respektieren. ${ }^{93}$

91 Deutschsprachige Originalaussagen aus der Videoaufzeichnung. Ebd.

92 »Tagebuch von Ivan Ivanovič Vašenko, eines Soldaten der RONA-Brigade«. Ebd.

93 Ebd. 
Mehrfach wird zudem der Mut der polnischen Aufständischen betont:

9. August [...] Wie ich bemerkt habe, sind die Polen die Nation, die die Freiheit am meisten schätzt, die nur ihre eigene Führung und ihren eigenen nationalen Staat liebt. Ein Volk, das seine Nation liebt und respektiert, ist im wahrsten Sinne des Wortes eine Nation. [...] Wir sind gegen sie machtlos, machtlos ist die SS. ${ }^{94}$

Diese beiden Zeugnisse diversifizieren damit in Teilen das uniforme Bild der Besatzer, wie es in der Ausstellung gezeichnet wird. Sie verweisen darauf, dass sich auch unter den Tätern Menschen mit unterschiedlichen Wahrnehmungen und Einstellungen befanden. Zugleich stehen beide Akteure jedoch in gewissem Maße außerhalb des Feindbilds »der Deutschen«, als sie selbst der deutschen Nation nicht angehören und sich von ihr abheben. Als ausländische Kämpfer, die die verübten Gräueltaten aus einer Binnenperspektive eindrücklich schildern, unterstreichen sie letztlich das einheitliche, entmenschlichte Bild »der Deutschen«. Die Überlegungen Vašenkos unterstützen nicht nur das Feindbild, sondern auch das polnische Selbstbild, das die Schau vermittelt: Seine Schilderung der Ausnutzung und Unterdrückung der alliierten Russen durch die Deutschen unterstreicht die Grausamkeit Letzterer, die sich sogar gegen die eigenen Verbündeten richtet. Seine Aversion gegen das Töten unschuldiger polnischer Frauen und Kinder ebenso wie seine Bewunderung des Patriotismus der Aufständischen fügt sich wiederum in das Bild der polnischen Helden und Märtyrer ein, das die Ausstellung zeichnet. ${ }^{95}$

Beide Zeugnisse und die jeweils spezifische Perspektive, die sie in die Erzählung einbringen, nimmt jedoch nur wahr, wer sich die Zeit nimmt, den umfangreichen Text der Aufzeichnungen Vašenkos sowie die relativ lange Aufnahme von Schenk zu lesen bzw. anzusehen. ${ }^{96}$ Dies ist jedoch gerade bei Vašenkos Ausführung nur wenig wahrscheinlich. Die Sektion zu den »Deutschen in Warschau « ist verhältnismäßig umfangreich; beide Zeugnisse finden sich erst in ihrem letzten Drittel. Die meisten Besucher werden also bereits erschöpft oder gesättigt von Eindrücken und Informationen sein, wenn sie die entsprechenden Stellen erreichen. ${ }^{97}$ Zudem erschwert das kontinuierliche Halbdunkel, das in dieser Ausstellungssektion herrscht, das Lesen der Texte, die in recht kleiner Schriftgröße abgedruckt sind. Auch wenn somit diese Zeugnisse ergänzende und zum Teil alternative Perspektiven in die Feind-

94 Ebd.

95 Siehe Teil 3, Kapitel 1.3 und 2.3.

96 Die Aufzeichnungen Ivan Ivanovič Vašenko umfassen sieben eng bedruckte Texttafeln. Das Interview mit Schenk dauert fast zehn Minuten.

97 Bei mehrfachen Besuchen der Ausstellung in den Jahren 2009 bis 2014 war für die Verfasserin auffällig, dass die meisten Besucher diesen Abschnitt der Schau relativ schnell durchlaufen und nur wenige kurze Augenblicke vor einzelnen Ausstellungsobjekten und -texten verweilen. 
darstellung einbringen, ist anzunehmen, dass sie nur wenige Besucher wahrnehmen. Dominiert wird die Narration von den zahlreicheren Dokumenten, Objekten und Kommentaren, die das Bild des einheitlichen Kollektivs »der Deutschen« fokussieren.

Auch der Alltag der deutschen Bevölkerung vor dem Ausbruch der Kämpfe bleibt weitgehend abstrakt. Zwar wird die deutsche Zivilbevölkerung seit 2007 nun ebenfalls thematisiert. Die Schilderung ihres Lebens in der besetzten Stadt beschränkt sich jedoch auf die Darstellung zentraler Gebäude der Besatzungsverwaltung und deutscher Organisationen sowie auf Fotografien von Propaganda- und Massenveranstaltungen. Gezeigt werden etwa Bilder der Feierlichkeiten anlässlich der Umbenennung des ehemaligen PiłsudskiPlatzes in Adolf-Hitler-Platz. Der dazugehörige Kommentar präsentiert die vermeintlichen »Gewohnheiten« der Deutschen als stellvertretend für den militärischen Charakter des NS-Regimes: „Gellende Reden, laute Märsche, ihre Lieblingslieder und die unabdingbaren Fackeln - die Deutschen in Warschau halten damit Verbindung zu ihrer stausendjährigen ${ }^{2}$ Heimat. ${ }^{98}{ }^{8}$ Daneben konzentriert sich die Darstellung des deutschen Alltags in der Stadt auf die Ausgrenzung der nichtdeutschen Bevölkerung. Emblematisch hierfür ist die Formel, die auf Schildern in der ganzen Stadt zu sehen war: »Nur für Deutsche«. ${ }^{99}$ Alltagskontakte mit anderen Bevölkerungsgruppen bleiben auf Verwaltungsakte, Vorschriften und Gewaltmaßnahmen beschränkt. Die Deutschen in Warschau vor dem Aufstand werden somit den Besuchern aus der Außenperspektive der damaligen polnischen Stadtbewohner präsentiert - ausschließlich im öffentlichen Raum und ohne einen näheren Einblick in Erfahrungen und Einstellungen einzelner Personen. Im Umgang mit diesem Aspekt der Besatzungszeit perpetuiert die Schau damit Interpretationsmuster, die bereits vor 1989 etabliert waren. Diese eindimensionale Präsentationsweise korrespondiert mit einer ähnlich einseitigen, heroisierenden Darstellung der Aufständischen. Letztere wird in ihrer Eindeutigkeit gerade erst durch die klare Abgrenzungsfolie der zugespitzten Feinddarstellung ermöglicht. ${ }^{100}$

98 Bildunterschrift. MPW, Sektion 56.

99 Auch ein Bereichstext in diesem Abschnitt ist mit diesem Ausdruck überschrieben. Mehrere Fotografien mit deutlich sichtbaren Schildern, die diesen Hinweis tragen, sind in der Sektion zum Alltag verteilt. Es findet sich zudem ein originales Schild. MPW, Sektion 56.

100 Siehe Teil 3. 
Die Emaillewarenfabrik Oskar Schindlers

Einen wesentlichen Schritt in Richtung einer Veränderung dieser weitgehend traditionellen Darstellungsweise unternimmt die Ausstellung der 2010 neueröffneten Abteilung des MHK in der Emaillewarenfabrik Oskar Schindlers. In diesen Räumlichkeiten ist der Darstellung der deutschen Bewohner der Stadt und Region ein einzelner Themenabschnitt unter dem Titel »Generalgouvernement « gewidmet. ${ }^{101}$ Neben der ausführlichen Schilderung der politischen und militärischen Führung des GG wird in dieser Sektion ein Einblick in den Alltag der neuen Bewohner der Stadt geboten. ${ }^{102}$ Auch das Leben der deutschen Zivilbevölkerung thematisiert man verhältnismäßig umfangreich. In erster Linie mittels Fotografien werden etwa der Unterricht an deutschen Schulen, Aktivitäten der »Hitlerjugend « und des »Bund Deutscher Mädel « abgebildet. Damit wird in diesem Museum erstmals eine ambivalente, da auch menschliche Dimension der Besatzungsmacht angedeutet. Insbesondere verengt man die Deutschen in Krakau nicht mehr nur auf militärische Kontexte, sondern zeigt auch deutsche Kinder und Jugendliche sowie Frauen im Besatzungsalltag. ${ }^{103}$ Die Verbindung von militärischen und zivilen Kontexten spiegelt sich auch in der Geräuschkulisse dieser Sektion wider: Abwechselnd erklingt Marschmusik und Opernmusik. Daneben wird auch auf die Zusammensetzung der »Deutschen Volksgemeinschaft« in Krakau eingegangen, wobei auch die Hierarchieunterschiede zwischen Reichsdeutschen und den Mitgliedern verschiedener Stufen der Deutschen Volksliste deutlich benannt werden. Ebenso kommen Gründe für die Unterzeichnung der Volksliste zur Sprache, darunter in erster Linie die Hoffung auf Vergünstigungen, aber auch teilweise der Zwang durch die Besatzungsorgane.

Trotz dieser deutlichen Schritte hin zu einer Differenzierung der Darstellung der Besatzer bleiben die Deutschen in Krakau - in Kontinuität der Praxis der Vorgängerschauen - weitgehend anonym und abstrakt. Zum einen sind nur wenige - wiederum in erster Linie politische und militärische - Führungspersönlichkeiten auf den einzelnen Fotos namentlich benannt, während

101 MHK-Schindler-Fabrik, Sektion 7: Generalgouvernement. Teile der folgenden Ausführungen wurden publiziert in Heinemann: Die »Emaillewarenfabrik Oskar Schindlers».

102 Daneben werden Fotografien von Deutschen auch in anderen Sektionen gezeigt, die verschiedenen Zeiträumen und Aspekten des Alltags gewidmet sind, insbesondere in den Sektionen 5: Öffentlicher Raum I, 9: Alltag, 1940-1941, 10: Bahnhof und 15: Alltag, 1943.

103 Gezeigt werden etwa Fotos von Begräbnisfeierlichkeiten und einer "Hochzeit auf Entfernung" (Bildunterschrift) zwischen deutschen Frauen in Krakau und Soldaten an der Front. Des Weiteren werden die deutschen Pläne für eine architektonische Umgestaltung der Stadt ausführlich thematisiert. MHK-Schindler-Fabrik, Sektion 7: Generalgouvernement. 
die Übrigen dem Betrachter unbekannt bleiben. ${ }^{104}$ Zum anderen werden in der Darstellung der deutschen Stadtbevölkerung - im Unterschied zur Präsentation sowohl der polnischen als auch der jüdischen Bevölkerung - keinerlei individuelle Zeugnisse oder Materialien verwendet, die einen Einblick in persönliche Wahrnehmungen und Erfahrungen der neuen Bewohner Krakaus geben könnten. ${ }^{105}$ Die wenigen Zitate in diesem Ausstellungsabschnitt stammen von polnischen Zeitzeugen und beschreiben in erster Linie deren Gefühl der Entfremdung in der eigenen Stadt, das durch die Präsenz der Besatzungsmacht im öffentlichen Raum hervorgerufen wurde. ${ }^{106}$ Das einzige in diesem Ausstellungsabschnitt verwendete zeitgenössische Zitat eines Deutschen stammt von Hans Frank, dem Leiter des Generalgouvernements:

Jeder Deutsche, der in dieses Gebiet kommt, findet hier seine Heimat. Auch ihr, meine Jungen und Mädchen, solltet hier eure wahre Heimat finden. Ihr solltet hier starke Wurzeln in den neuen deutschen Lebensraum schlagen. ${ }^{107}$

Mit dieser Aussage werden allein die politischen Ziele der neuen Herrscher verdeutlicht - ähnlich wie dies in früheren Ausstellungen des MHK in der Pomorska-Straße bereits gehandhabt wurde.

Auch die Gestaltung der Sektion unterstützt die Abgrenzung zwischen der Lebenswelt der deutschen und derjenigen der jüdischen und polnischen Stadtbewohner: Der Raum ist schwarz-weiß gestaltet; der Boden wie auch die Wände sind weiß gehalten, wodurch ein Eindruck von Kühle, Distanz und Gefühllosigkeit unbewusst vermittelt wird. Der Boden ist zudem mit weißen Fliesen mit Hakenkreuzen darauf gekachelt (siehe Abb. 18). Allein durch diese Verwendung des mit dem NS-Regime verbundenen und daher eindeutig negativ konnotierten Symbols wird das Betreten einer feindlichen Welt kenntlich gemacht. Bei den Besuchern baut sich hierdurch bereits von Beginn

104 Auf Fotografien offizieller Anlässe der Regierung des Generalgouvernements werden u.a. Hans Frank, Heinrich Himmler und Ernst Zörner, der Gouverneur des Distrikts Lublin, namentlich genannt. Ebd.

105 Das einzige Dokument, das eine gewisse Binnenperspektive der Besatzer zeigt, ist ein Ausschnitt aus einer Reportage des deutschen Radios vom Herbst 1939 über ein deutsches Geschäft in Krakau, das Führer-Devotionalien verkaufte. Dieser Bericht zeichnet jedoch das Propagandaselbstbild der Besatzer nach, da er die private Äußerung einer Einzelperson präsentiert. MHK-Schindler-Fabrik, Sektion 5: Öffentlicher Raum I.

106 Gleich beim Betreten der Sektion treffen die Besucher auf ein Zitat von Karolina Lanckorońska, die die gefühlte Exklusion des von den Deutschen besetzten Wawel aus dem Alltag der Stadt beschreibt. An anderer Stelle berichtet Edward Kubalski: »Es ist traurig, jetzt über den Marktplatz zu gehen [...]. Seit dem Krieg ist der Hejnał verstummt, und die Kirchenglocken sind verstummt, und so ist es geblieben - nur das lautstarke deutsche Radio plärrt auf dem Marktplatz und dem Szczepański-Platz seine Tiraden, denen niemand zuhört.« MHK-Schindler-Fabrik, Sektion 7: Generalgouvernement.

107 Das Zitat ist im Themenraum »Generalgouvernement« an herausragender Stelle platziert und sticht durch seine große Schriftgröße hervor. Ebd. 


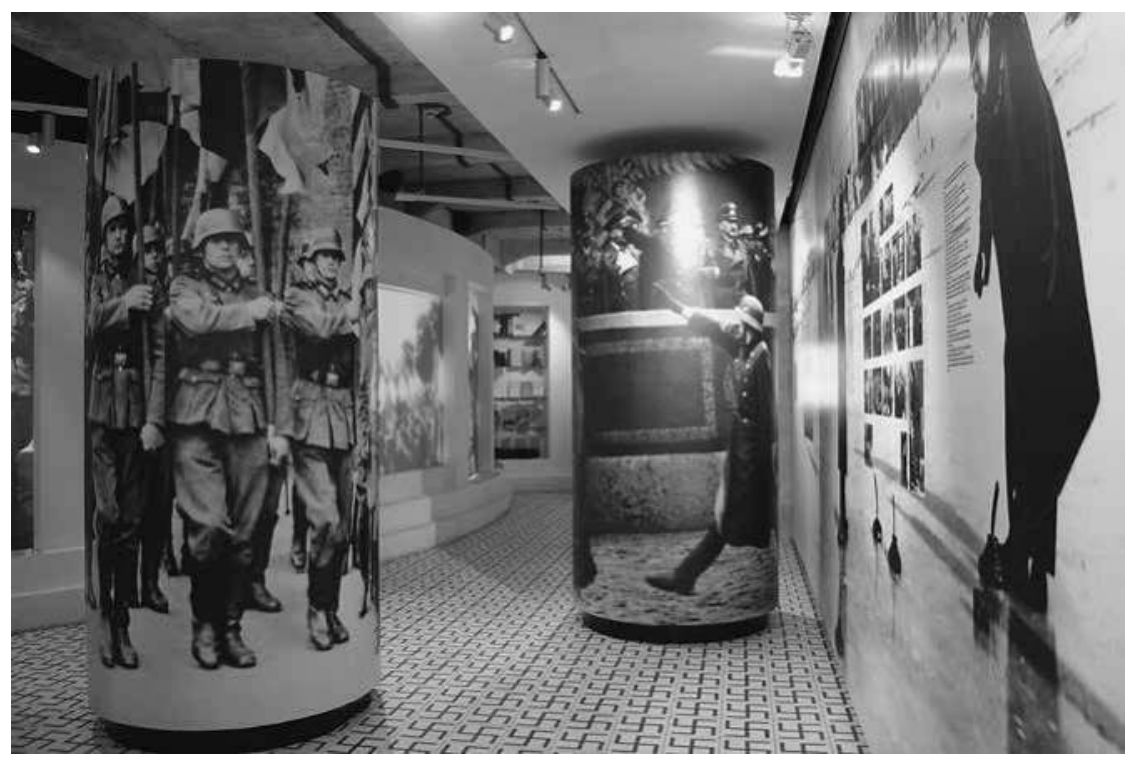

Abb. 18: Schindler-Fabrik, Sektion »Generalgouvernement«.

an eine Distanz zu dem Dargestellten auf. Farbe kommt erst im späteren Abschnitt der Sektion zum Einsatz: Ein arrangiertes Architektenbüro in warmen Holztönen illustriert die Pläne der Besatzer für die Umgestaltung der Stadt; eine schwarz-rot-gestreifte Wand mit dem Schild »Staatstheater des Generalgouvernements« weist auf kulturelle Ereignisse der deutschen Bevölkerung hin. Verbunden bleiben diese Elemente jedoch mit der übrigen Sektion durch den durchgängigen Boden aus Hakenkreuz-Fliesen.

Unmittelbar an diese Sektion schließt sich der Themenbereich »Terror« an, der innerhalb der Ausstellungserzählung eine komplementäre Funktion zur Sektion »Generalgouvernement « einnimmt. ${ }^{108}$ Nach der Helligkeit und Kühle Letzterer betreten die Besucher nun einen dunklen Trakt mit inszenierten Gefängniszellen, in dem sie von der Deportation der Juden aus der Stadt in den Jahren 1940 bis 1941 sowie von der Folter und den Exekutionen in Krakauer Gefängnissen erfahren (siehe Abb. 19). Der scheinbar harmlose deutsche Alltag der Militärparaden, Regierungstreffen, Sport- und Kulturveranstaltungen wird hierdurch mit der Brutalität und Gewalt gegenüber der Bevölkerung des besetzten Landes kontrastiert und damit die sprichwörtlich »andere« Seite des Regimes in unmittelbaren Bezug zu dieser gestellt. Eine 


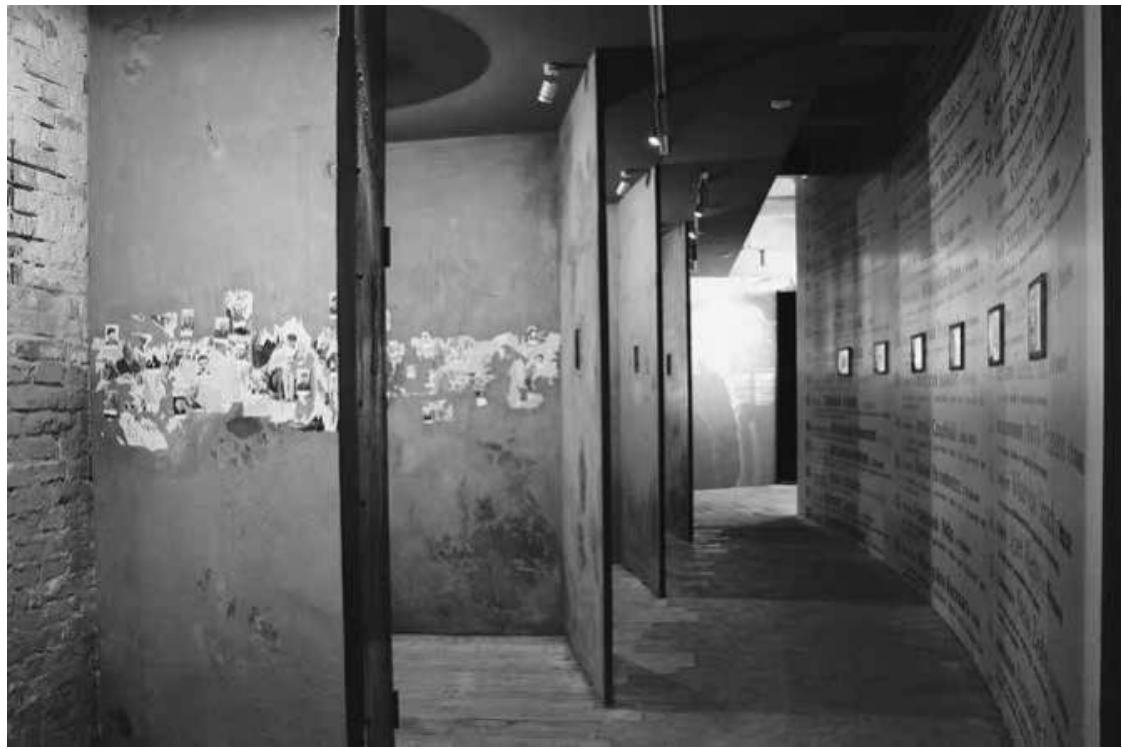

Abb. 19: Schindler-Fabrik, Sektion »Terror«.

gestalterische Verbindung dieser zwei Gesichter der Besatzungsmacht stellt eine Litfasssäule her, die mit Plakaten beklebt ist, die Konzerte, Ausstellungen und politische Großveranstaltungen in deutscher Sprache ankündigen. Die Säule steht symbolisch auf der Grenze zwischen den beiden Seiten der Besatzungsrealität; sie reicht je zur Hälfte in beide Sektionen hinein, wodurch die schwarz-weiße, abstrakte Welt der Besatzer mit der farbigen, damit sinnbildlich realen Erfahrungswelt der Besetzten in Verbindung gebracht wird (siehe Abb. 20).

Schließlich fällt auf, dass sowohl deutsche Zivilisten als auch Militärangehörige den Besuchern in der gesamten Ausstellung allein in öffentlichen Stadträumen begegnen und damit außerhalb der privaten, persönlichen Sphäre. Während der übrige Ausstellungsrundgang sowohl durch eine inszenierte Wohnung polnischer Widerstandskämpfer als auch überfüllte Wohnräume des Ghettos führt, treffen die Besucher auf die deutschen Bewohner der Stadt ausschließlich in Straßenszenen, auf dem Bahnhof, bei Militärparaden, in Ämtern oder im Theater. ${ }^{109}$ Trotz des somit eingenommenen externen Blickwinkels auf die deutsche Bevölkerung ist in dieser Schau auffällig, dass Be-

109 Dies geschieht in erster Linie mittels Fotografien, die - teilweise auf Lebensgröße vergrößert - Deutsche in der Stadt in der Öffentlichkeit zeigen, so etwa in den Sektionen 5: Öffentlicher Raum I, 9: Alltag, 1940-1941, 10: Bahnhof und 18: Öffentlicher Raum II. 


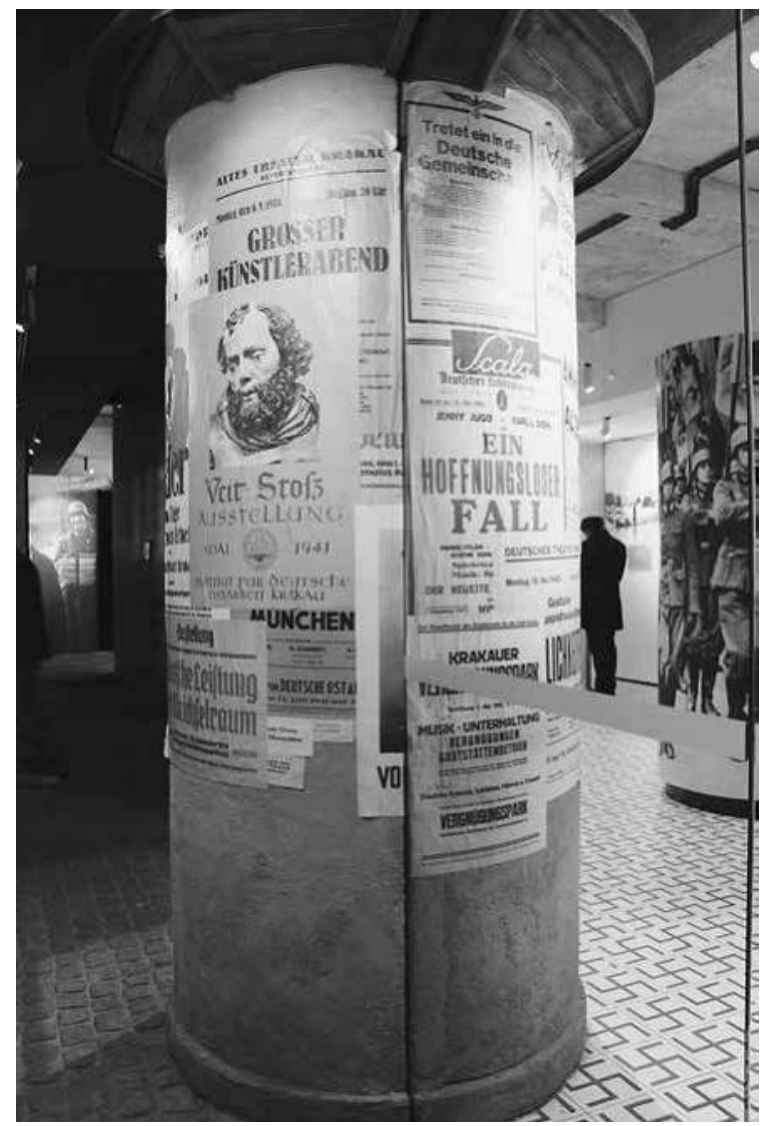

Abb. 20: Schindler-Fabrik, Sektion »Terror«.

gegnungsräume und alltägliche Kontakte zwischen deutschen und nichtdeutschen Einwohnern gleichwohl immer wieder aufgegriffen werden. So wird etwa bei der Darstellung des Alltags der Jahre 1940-1941 auf die Beteiligung der Wehrmacht am Schwarzmarkt verwiesen. ${ }^{110}$ Im Weiteren sieht man unter anderem einen deutschen Offizier und eine junge Frau bei einer fröhlichen Kutschfahrt auf dem Marktplatz, daneben polnische Marktfrauen sowie Polen und Deutsche bei ihren Einkäufen. ${ }^{111}$ Diese verschränkte Perspektive auf die Lebenswelten der drei größten Bevölkerungsgruppen Kra-

110 Im Thementext zur Sektion heißt es: »Gestohlene Ware lieferte auch die Wehrmacht, die alles verkaufte - Essen, Medikamente, Kohle und sogar Waffen«. Thementext »Alltag«. MHK-Schindler-Fabrik, Sektion 9: Alltag, 1940-1941.

111 MHK-Schindler-Fabrik, Sektion 9. 
kaus, ${ }^{112}$ darunter eben auch jene der Besatzer, unterscheidet den Ansatz der Ausstellung in der Schindler-Fabrik bis heute am stärksten von anderen aktuellen polnischen musealen Erzählungen über den Zweiten Weltkrieg. Wie bereits am Beispiel des MPW geschildert, vermeiden oder ignorieren die meisten Museen bis heute das Thema ziviler und alltäglicher Kontakte oder auch nur von Begegnungsräumen zwischen Besatzern und Besetzten; diese werden meist allein auf gewalttätige Übergriffe und Zwangsmaßnahmen verengt.

Auch in dieser Ausstellung ist konsequent von den »Deutschen « die Rede und nicht etwa von »Hitleristen « oder »Nazis«/»Nationalsozialisten«. Das Feindbild der Besatzer ist somit in erster Linie ethnisch-national und nicht politisch bzw. ideologisch konnotiert. Dennoch wird im Laufe des Rundgangs für die Besucher deutlich, dass die Gruppe »der Deutschen« in Krakau durchaus divers war. Hierzu trägt nicht zuletzt die Art der Darstellung von Oskar Schindler bei. Er bleibt der einzige Deutsche, der in der Ausstellung ausführlicher porträtiert wird. Nicht nur erscheint er bereits im Laufe des Rundgangs durch die Ausstellung an verschiedenen Stellen. ${ }^{113}$ Seiner Person und seinen Aktivitäten im Generalgouvernement, insbesondere der Rettung von mehr als 1.000 Juden, sind zwei eigene Räume innerhalb des Ausstellungsrundgangs gewidmet - das erhaltene Sekretariat und Büro der ehemaligen »Deutschen Emaillewarenfabrik«, die für die Ausstellung zum Teil mit originalen Elementen der Ausstattung wieder hergerichtet wurden. Diese Räume funktionieren weitgehend unabhängig vom Rest der Schau. Im Sekretariat wird ausführlich die Geschichte der Emaillewarenfabrik sowie das Leben Schindlers und damit auch die Ambivalenz und Widersprüchlichkeit seiner Person dargestellt, ohne ihn einseitig zu glorifizieren. So wird er unter anderem als Frauenheld und Ehebrecher sowie Kriegsgewinnler mit einem Hang zu illegalen Aktivitäten charakterisiert. ${ }^{114}$ Das folgende Büro ist der Geschichte der historischen "Schindlers Liste " gewidmet. ${ }^{115}$ Eine Installation dominiert das Büro: ein Glaskubus, der mit Rohformen von Emailleschüsseln gefüllt ist (siehe Abb. 21). Das Innere des Kubus bildet einen ovalen Raum, dessen

112 Gelegentlich wird auch auf Ukrainer, die viertgrößte Bevölkerungsgruppe, hingewiesen. So etwa im Thementext "Alltag" der Sektion 9.

113 So wird bereits bei der Darstellung der zentralen Ereignisse in Krakau im September 1939 erwähnt, dass zusammen mit der Wehrmacht »deutsche militärische Agenten« in die Stadt gekommen sind, darunter Oskar Schindler. Bereichstext. MHK-SchindlerFabrik, Sektion 4: Kriegsausbruch. In der Sektion »Alltag, 1940-1941« findet sich ein Foto von ihm zusammen »mit Zygmunt Pithart auf dem Gelände der DEF [Deutsche Emaillewarenfabrik - d.Vf.]«. Bildunterschrift. MHK-Schindler-Fabrik, Sektion 9. In der inszenierten Wohnung im überfüllten Ghetto hört man Stimmen über Oskar Schindler sprechen. MHK-Schindler-Fabrik, Sektion 14: Ghetto.

114 MHK-Schindler-Fabrik, Sektion 16: Schindlers Sekretariat.

115 MHK-Schindler-Fabrik, Sektion 17: Schindlers Büro. 


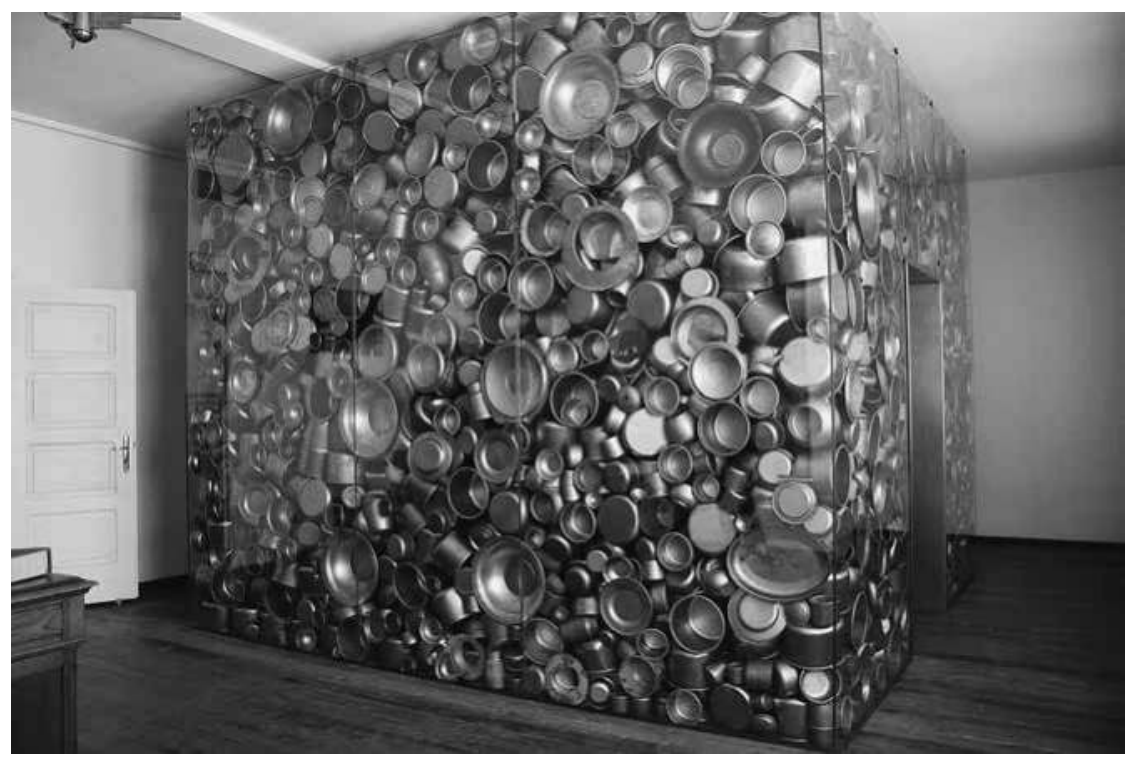

Abb. 21: Schindler-Fabrik, Installation in »Schindlers Büro«.

Wände mit den Namen der von Schindler Geretteten beschrieben sind; diese Namen werden von einer Stimme aus dem Off vorgelesen. Hinter der Installation werden in zwei Videostationen Interviews mit Überlebenden der Liste gezeigt. Das Objekt, das von den Ausstellungsverantwortlichen »Arche» genannt wird, ${ }^{116}$ stellt damit die Personen in den Mittelpunkt, die von Schindler gerettet wurden. Die Überlebenden stehen somit in diesem Raum im Zentrum der Aufmerksamkeit, weniger die Person Oskar Schindlers, auch wenn durch die Verortung der Installation in seinem Büro seine entscheidende Rolle bei diesem Prozess deutlich wird. ${ }^{117}$ Diese exponierte Darstellung seiner Figur innerhalb der Ausstellung ist eine Referenz an ihren konkreten Ort,

116 Kursa, Magdalena: Zabłocie: Arka z naczyń emaliowanych [Zabłocie: Eine Arche aus Emailwaren]. In: Gazeta Wyborcza Kraków vom 27.2.2009, Online-Ausgabe, URL: http:// krakow.gazeta.pl/krakow/1,35798,6324647,Zablocie__Arka_z_naczyn_emaliowanych. html (am 6.1.2014).

117 Zugleich gibt die Installation keine Deutung vor - weder sind ihre Bezeichnung noch ein erläuternder Kommentar angegeben. Die Besucher können sich somit eigene Gedanken über die Umstände und Erfahrungen der Beteiligten an Schindlers Liste sowie der darin Aufgenommenen machen. Das Objekt fungiert als ein Ort der freien Reflexion, als "reflective pause« (Christopher Marshall) innerhalb des informationsgeladenen Rundgangs. Marshall, Christopher R.: When Worlds Collide. The Contemporary Museum as Art Gallery. In: Macleod, Suzanne (Hg.): Reshaping Museum Space: Architecture, Design, Exhibitions. London 2005, 170-184, hier 175. 
das originale Verwaltungsgebäude seiner ehemaligen Krakauer Fabrik, die seit Steven Spielbergs Film »Schindler's List« (USA, 1993) zu einem Touristenmagneten für Krakau-Besucher aus der ganzen Welt geworden ist.

Zusammenfassend lässt sich festhalten, dass die Besucher auf die Deutschen in Krakau aus einer externen Perspektive blicken, mit den Augen der polnischen und jüdischen Einwohner der besetzten Stadt. Während in der gesamten Ausstellung immer wieder Zeitzeugenberichte die (auch emotionale) Auseinandersetzung mit den Lebenswelten verschiedener polnischer und jüdischer Einwohner ermöglichen, bleiben die Erfahrungswelten der deutschen Stadtbewohner abstrakt. Hierdurch manifestiert sich eine Abgrenzung zwischen der polnischen und jüdischen Bevölkerung auf der einen Seite sowie der Besatzungsmacht auf der anderen, die auch für die Vorgängerausstellungen des Museums in der Abteilung Pomorska-Straße prägend war. ${ }^{118}$ Im Gegensatz zur Schau des MPW finden sich allerdings keinerlei emotionale und wertende Kommentare der Ausstellungsmacher in Bezug auf die Deutschen, etwa in Themen- und Bereichstexten oder Objektbeschriftungen. Die Ambivalenz des alltäglichen Nebeneinanders mit den Besatzern wird somit zugelassen bzw. angedeutet. Die Deutschen in Krakau bleiben somit - bis auf die Ausnahme Oskar Schindlers - zwar eine weitgehend anonyme, unpersönliche und fremde Bevölkerungsmasse; dennoch erscheinen sie erstmals als Teil auch des zivilen Alltags der Stadt und nicht ausnahmslos im Kontext von Gewaltverbrechen. Eine ambivalente, da menschliche Komponente wird ihnen damit zugestanden; sie erscheinen nicht mehr stereotyp als Kollektiv von »Bestien ${ }^{119}$

\section{Das Historische Museum in Wroctaw}

Einen dritten Weg der Verortung der Deutschen in einem musealen Narrativ strebt die 2009 neu eröffnete Dauerausstellung des Historischen Museums von Wrocław an. Diese Schau konzentriert sich auf die lokale Geschichte

118 Eine derartige »Distanzierung« zwischen den Lebenswelten der verschiedenen Bevölkerungsgruppen der Stadt ist in den Beratungen des Programmrates diskutiert worden. So vertrat eine der Teilnehmerinnen der Debatten, Lili Haber vom »Verein der Krakauer in Israel« (Zwiazek Krakowian w Izraelu), die Position, den Besuchern solle vermittelt werden, dass in den Jahren 1939 bis 1945 in Krakau de facto »zwei Welten nebeneinander bestanden: die der Besatzer (der Deutschen) und die der Opfer (der Polen polnischer und jüdischer Nationalität).« Bednarek, Monika: II posiedzenie rady programowej Muzeum Pamięci. Fabryka Oskara Schindlera. 18. März 2008. AMHK, OP-520-1/ 08, 4.

119 Dies stellt auch Zuzanna Bogumił fest: Bogumił, Zuzanna: Miejsce pamięci versus symulacja przeszłości - druga wojna światowa na wystawach historycznych [Gedenkort versus Simulation der Vergangenheit - Der Zweite Weltkrieg in historischen Ausstellungen]. In: Kultura i Społeczeństwo 55 / 4 (2011), 149-170, hier 164. 
und versucht, ihre vielfältigen nationalen und kulturellen Elemente, darunter auch die deutsche Vergangenheit der Stadt, in eine Erzählung zu integrieren. ${ }^{120}$ In diesem Sinne kann man die konzeptionellen Ankündigungen der Ausstellungsmacher als Versuch interpretieren, eine Orientierung an einem ausschließlich ethnisch-nationalen polnischen Meisternarrativ zu vermeiden.

Eine unmittelbare Wirkung zeigt dieser Ansatz in der inhaltlichen Kontextualisierung der Jahre des Zweiten Weltkriegs: Dieser zentrale Zeitraum der polnischen Geschichte wird in der Stadtgeschichte in den Kontext des Nationalsozialismus in Deutschland eingeordnet, dessen Teil Breslau bis 1945 war. Die Eckdaten der Thematisierung des Kriegs sind daher die Jahre 1933 bis $1945 .^{121}$ Folglich werden in der Ausstellung die Deutschen nicht per se als Besatzer betrachtet. Vielmehr schildert der erste Teil des Ausstellungsabschnitts im Saal 22 die zunehmende Bedeutung der Nationalsozialisten im politischen und kulturellen Alltag der Stadt seit der Machtergreifung 1933. Dies geschieht mithilfe von Fotografien mehrerer Massenveranstaltungen, so etwa des »Turn- und Sportfests« von 1938 oder der »Feierlichkeiten anlässlich der 125-Jahr-Feier der Stiftung des Eisernen Kreuzes in der Jahrhunderthalle «. ${ }^{122}$ Daneben stellt man auch die Inhaftierung politischer Gegner der Nationalsozialisten, konkret führender Sozialdemokraten im Konzentrationslager Breslau-Dürrgoy im Jahr 1933, mithilfe zweier Fotografien dar. Dieser Hinweis ist innerhalb der polnischen Erzählung über Konzentrationslager verhältnismäßig neu: ${ }^{123}$ Es wird damit implizit darauf verwiesen, dass nicht allein nichtdeutsche Nationalitäten von der Verfolgung und Inhaftierung betroffen waren und dass Deutsche die ersten Insassen der KZs waren. Dieses Ausstellungselement ist insofern von Bedeutung, als die weitere Geschichte der Stadt von 1939 bis zum Jahr 1944 weitgehend der Darstellung von Zwangs- und Gewaltmaßnahmen - in erster Linie gegenüber der polnischen Bevölkerung - gewidmet ist, wie beispielsweise der Inhaftierung in Konzentrationslagern oder der Zwangsarbeit. ${ }^{124}$

120 Łagiewski, Maciej: Pałac z historią - historia w pałacu [Ein Palast mit Geschichte Geschichte im Palast]. In: Ders./Okólska, Halina/Oszczanowski, Piotr (Hg.): 1000 lat Wrocławia. Przewodnik po wystawie [1000 Jahre Wrocław. Führer durch die Ausstellung]. Wrocław 2009, 9-15, hier 10, 12.

121 MMW-MH, Saal 22: Die hitleristische Diktatur - Der Zweite Weltkrieg.

122 Objektbeschriftung. MMW-MH, Saal 22.

123 Üblicherweise werden Konzentrationslager bislang überwiegend in Bezug auf das polnische und jüdische Schicksal unter der Besatzung thematisiert. Ihre Vorgeschichte im Deutschen Reich bleibt dabei meist ausgespart, da diese angesichts der lokalen oder regionalen Ausrichtung der meisten Schauen nicht relevant ist.

124 Mehr hierzu in Teil 2, Kapitel 2.3 und Teil 3, Kapitel 1.3. 
Für den Zeitraum ab 1939 erscheinen deutsche Breslauer einzig in militärischen Kontexten, zum einen als Wachpersonal der Konzentrationslager, ${ }^{125}$ zum anderen als Soldaten der am 25. August 1944 zur Festung erklärten Stadt im Kampf gegen die Rote Armee. Die Grausamkeit Ersterer wird unter anderem durch die ausgestellten Zwangsmittel betont, einer Metall- und einer Lederpeitsche sowie eines Holzknüppels. ${ }^{126}$ Letztere porträtiert man mithilfe verschiedener Militaria, darunter einer Uniformjacke eines Hauptmanns der Infanterie, zweier Helme, Schusswaffen, Granaten und militärischer Ausrüstungsgegenstände. Auch die ausgestellten Dokumente haben alle einen militärischen bzw. politischen Bezug. ${ }^{127}$ Das einzige Ausstellungselement, das einen zivilen Alltag der Stadt andeutet, ist eine großformatige Fotografie des Marktplatzes, auf der neben einigen Uniformierten auf Fahrrädern auch Zivilisten zu sehen sind. Bei diesem Bild fehlt jedoch eine Erläuterung der Ausstellungsmacher; die Personen, die darauf zu sehen sind, bleiben anonym. Die Besucher können somit lediglich deduzieren, dass es während des Kriegs bzw. bis ins Jahr 1944 auch einen weitgehend «normalen «, friedlichen Alltag in der Stadt gab. Dass dieser jedoch nicht alle Bewohner umfasste bzw. dass lediglich die deutsche Bevölkerung weitgehend ihrem Alltag nachgehen konnte, geht daraus nicht hervor. Die Breslauer Bevölkerungsmehrheit fehlt somit im musealen Narrativ.

Auch wenn die Jahre 1939 bis 1945 in dieser Ausstellung in einem anderen (politischen) Rahmen verortet werden als in den übrigen untersuchten Schauen, in denen die Eckdaten der ethnisch-national verstandenen Geschichte des polnischen Staates den Rahmen bilden, so folgt die Präsentation der deutschen Breslauer während des Kriegs doch bekannten stereotypen Interpretationsmustern: Sie erscheinen fast ausnahmslos in einem militärischen und politischen, durch Gewaltausübung gegen Polen (und Juden) gekennzeichneten Kontext; ihre Darstellung bleibt zudem weitgehend anonym. Auch der Alltag der deutschen Stadtbewohner wird vollständig ausgeblendet. Die Kriegsjahre werden somit unter Rückgriff auf die tradierte Gegenüberstellung polnischer Helden und Opfer einerseits und deutscher Täter andererseits präsentiert.

125 Ausgestellt werden etwa Holzfiguren, die das Leben im Konzentrationslager illustrieren. Darunter befinden sich die Figur eines Mannes in der Uniform der SS-Totenkopfdivisionen sowie die einer Frau in der Uniform des SS-Gefolges mit einem Schlagstock in der Hand.

126 Diese Objekte wurden im Konzentrationslager Groß-Rosen eingesetzt. Objektbeschriftungen. MMW-MH, Saal 22.

127 So etwa der Durchhalteaufruf des Festungskommandanten an die Bevölkerung anlässlich des Einschlusses der Stadt durch sowjetische Truppen am 15. Februar 1945 oder die Frontausgabe der Schlesischen Tageszeitung vom 2. Mai 1945, in der vom Tod Adolf Hitlers berichtet wird. 
Eine Besonderheit bzw. Neuerung der untersuchten Ausstellungssektion liegt in den wenigen Ansätzen hin zu einer Differenzierung des homogenen Bildes der Deutschen im musealen Narrativ; allerdings finden sich diese lediglich in der Darstellung der Jahre unmittelbar vor und nach dem Krieg. Wie bereits erwähnt, wird zunächst auch auf die politische Verfolgung von deutschen Oppositionellen innerhalb des Deutschen Reiches vor Kriegsausbruch verwiesen und damit kenntlich gemacht, dass »die Deutschen" keine politisch und ideologisch homogene Gemeinschaft waren - eine Differenzierung, die jedoch für die Jahre nach 1939 nicht fortgeführt wird. Vielleicht noch bemerkenswerter ist jedoch die Darstellung der Aussiedlungen der deutschen Bevölkerung aus der Stadt in der Nachkriegszeit. Diese bildet den Einstieg der unmittelbar auf den Saal 22 folgenden Sektion zu »Wrocław nach $1945 \lll{ }^{128}$ Auf einer Fotowand, die den Zeitraum 1945 bis 1947 illustriert, wird ein Bild von deutschen Aussiedlern gezeigt. Auf diesem sticht die große Zahl hochbeladener Wagen ins Auge. Unmittelbar daneben finden sich Optimismus ausstrahlende Bilder von der Ankunft polnischer Umsiedler und der gemeinschaftlichen Aufräumarbeiten in der zerstörten Stadt. Zwei darüber angebrachte Plakate der neuen polnischen Verwaltungsorgane verweisen auf Bestimmungen zur Ausreise der Deutschen und zum Melden »ehemals deutscher Besitztümer« (mienie poniemieckie). Die darin enthaltenen Strafandrohungen weisen indirekt auf das Phänomen des szabronictwo, der illegalen Aneignung herrenloser Besitztümer, sowie von Übergiffen auf deutsche »Repatrianten« hin. Ein drittes Plakat auf einer gegenüberliegenden Wand benennt die für die Aussiedler zugelassenen Lebensmittelmengen; zugleich verurteilt es das massive Aufkaufen der knappen Güter durch Deutsche. Da die ersten beiden Plakate sich jedoch in großer Höhe befinden, ist der umfangreiche Text für Besucher nur schwer zu lesen. Die peripheren Verweise auf negative Verhaltensweisen von Polen gegenüber den Aussiedlern ebenso wie auf den verbreiteten Diebstahl werden somit die meisten Besucher kaum wahrnehmen. ${ }^{129}$ Prominenter sind das Foto der scheinbar geordneten und friedlichen Aussiedlung und der Hinweis auf das Horten von Lebensmitteln platziert. Eine der auf einem Bildschirm ausgestrahlten originalen Filmchroniken aus diesen Jahren unterstützt dieses Bild noch: Der Kommentator betont, unter welch günstigeren Bedingungen die Deutschen im Vergleich zu den Umsiedlungen und Verbre-

128 Das Thema des Saales, im Titel des Thementextes zugespitzt formuliert, lautet »Wrocław nach 1945 - Kriegsfolgen - Stalinismus«. MMW-MH, Saal 23.

129 Im Text des Ausstellungsführers erst wird erwähnt, dass die Aussiedlung "unter sehr schwierigen Bedingungen« stattfand und es viele Todesopfer gab. Okólska, Halina: Sala 23. Wrocław po 1945 - następstwa wojny - stalinizm [Saal 23. Wrocław nach $1945-$ Kriegsfolgen - Stalinismus]. In: Łagiewski, Maciej/Okólska, Halina/Oszczanowski, Piotr (Hg.): 1000 lat Wrocławia. Przewodnik po wystawie [1000 Jahre Wrocław. Führer durch die Ausstellung]. Wrocław 2009, 287-294, hier 288. 
chen, die während der NS-Besatzung stattfanden, nun ausreisen und wie großzügig die polnischen Behörden gegenüber den Aussiedlern sind. ${ }^{130}$

Die Aussiedlung der deutschen Stadtbewohner wird in dieser Ausstellung somit erstmals direkt thematisiert. Im Vordergrund der Darstellung steht jedoch der geregelte Ablauf dieser Ereignisse. Auf Verweise der sie begleitenden negativen Phänomene können die aufmerksamen Besucher in den präsentierten Dokumenten zwar stoßen; die leicht zugänglichen Quellen, wie das Foto und die ausgestrahlte Filmchronik, lenken die Aufmerksamkeit jedoch in erster Linie auf deren vermeintlich unproblematischen Ablauf. In der Darstellung der unmittelbaren Kriegsjahre bleibt die primäre Gegenüberstellung zwischen einem Kollektiv deutscher Täter und dem als ähnlich homogen suggerierten Kollektiv nichtdeutscher Opfer erhalten. Während die Leidtragenden des Regimes - mit einem deutlichen Schwerpunkt auf Polen - mit einer Vielzahl von Exponaten porträtiert werden, bleiben die deutschen Breslauer und damit die überwiegende Mehrheit der Stadtbevölkerung ${ }^{131}$ anonym und abstrakt.

Die Ausstellung folgt damit in Bezug auf die Jahre 1933 bis 1945 keinem durchgehenden Deutungsschema; vielmehr überlagern sich hier alte Topoi und neue inhaltliche und Interpretationsmotive. Bei der Darstellung der Kriegsjahre greifen die Ausstellungsverantwortlichen - entgegen ihrem Anspruch - auf das tradierte Feindbild der vergangenen Jahrzehnte zurück, das zugleich eine Konzentration auf die hier nun wiederum ethnisch-polnisch definierte Wir-Gemeinschaft erlaubt. ${ }^{132}$ Die Mischung neuer und traditioneller Darstellungsweisen schlägt sich auch in den verwendeten Begrifflichkeiten nieder. Während in allen Objektbeschriftungen ausschließlich die Termini »deutsch « und »Deutsche« verwendet werden, ist im Titel des Themenraums von der »hitleristischen Diktatur» (dyktatura hitlerowska) die Rede. ${ }^{133} \mathrm{Zu}$ -

130 Die Filmchroniken werden ohne jeglichen Kommentar ausgestrahlt. Es ist daher fraglich, inwieweit die Besucher hier abstrahieren können und sich bewusst machen, dass dieses Medium der offiziellen Propaganda diente und daher ein äußerst geschöntes Bild der Ereignisse der Jahre nach 1945 zeigt.

1311939 betrug die Einwohnerzahl Breslaus 629.000. In den Kriegsjahren stieg die Bevölkerungszahl stark an: Hinzu kamen ca. 200.000 deutsche Arbeiter; im Jahr 1943 zählte man zudem knapp 44.000, ein Jahr später ca. 51.500 Zwangsarbeiter in der Stadt; 1944 gab es fast 10.000 westliche Kriegsgefangene. Insgesamt stieg die Bevölkerung Breslaus im Krieg bis auf knapp eine Million an. Davies, Norman/Moorhouse, Roger: Breslau Die Blume Europas. Die Geschichte einer mitteleuropäischen Stadt. München 2002, 464, 483.

132 Siehe hierzu Teil 2, Kapitel 2.3 und Teil 3, Kapitel 1.3.

133 Der Titel des Thementextes im Saal 22 lautet »Hitleristische Diktatur - Zweiter Weltkrieg«. Dieser Begriff fällt auch im begleitenden Ausstellungsführer, sowohl bei der Nennung des Jahres 1933 als "Meilenstein« der städtischen Geschichte (»Die Machtergreifung der Hitleristen«) als auch im entsprechenden Abschnitt zum Saal 22 selbst (Titel: »Hit- 
gleich taucht im Thementext selbst der Begriff »Nationalsozialismus« / NNazismus« (nazizm) auf.

Die Hintergründe für diesen Eklektizismus von Deutungen und inhaltlichen Ansätzen finden sich im Entstehungsprozess der Ausstellung, konkret in der Vielzahl der an der Sektion beteiligten Museumsmitarbeiter. Der Abschnitt zu den Kriegsjahren wurde von einem langjährigen Mitarbeiter zusammengestellt, dessen Arbeitsschwerpunkt die Militärgeschichte des Zweiten Weltkriegs ist. Es ist davon auszugehen, dass er sich in seiner Arbeit auf seine bisherigen Themenschwerpunkte konzentriert hat - Militaria und die gesamtpolnische (martyrologische) Geschichte des Kriegs und der Besatzung. ${ }^{134}$ Seine Arbeit stellte jedoch eine grundlegende Überarbeitung einer vorherigen Variante der Sektion dar, die von einem anderen Mitarbeiter konzipiert worden war. ${ }^{135}$ Vermutlich haben sich daher bei der Abänderung gewisse Aspekte erhalten, etwa die Wortwahl in den - bereits produzierten - Objektbeschriftungen. Die Sektion zur Vorkriegszeit und insbesondere der jüdischen Verfolgungsgeschichte basiert dagegen auf Vorarbeiten des Direktors des Stadtmuseums Maciej Łagiewski. ${ }^{136}$ Die Sektion nach 1945 hat dagegen die Leiterin des Historischen Museums verantwortet. ${ }^{137}$

\subsection{Zwischenfazit}

Wie gezeigt wurde, zeichnet die Darstellung der Deutschen in den untersuchten Dauerausstellungen bis in die Gegenwart eine bemerkenswerte Kontinuität aus. So wie bereits in der VRP werden bis heute die deutschen Besatzer

leristische Diktatur - Zweiter Weltkrieg«). Siehe Lagiewski, Maciej/Okólska, Halina/ Oszczanowski, Piotr (Hg.): 1000 lat Wrocławia. Przewodnik po wystawie [1000 Jahre Wrocław. Führer durch die Ausstellung]. Wrocław 2009, 17, 277.

134 Jerzy Zarawski arbeitete bereits seit mehreren Jahrzehnten im Museum und war bis Mai 2016 Leiter des zum Stadtmuseum gehörenden »Militärhistorischen Museums« (Muzeum Militariów) im Arsenal. Im Interview berichtete Zarawski in Bezug auf die jüngste Umgestaltung des Ausstellungssaals 22, die er vorgenommen hatte, in erster Linie von der umfangreichen Ergänzung im Bereich Militaria, wodurch eine gleichgewichtige Darstellung von Deutschen und Russen erreicht werden sollte. Interview mit Jerzy Zarawski am 31. März 2010.

135 Autor des Vorgängerprojekts dieser Sektion war ein früherer Mitarbeiter der Abteilung für Militaria im Arsenal, Bartłomiej Błaszkowski. Nach Kritik seitens der Museumsleitung an dessen Arbeit beauftragte man Zarawski mit einer grundlegenden Überarbeitung, die Mitte März 2010 abgeschlossen wurde. Interview mit Jerzy Zarawski am 31. März 2010. Spuren dieser nachträglichen Veränderung der Schau finden sich u. a. im Thementext des Saals, der noch eine andere Themenabfolge skizziert. Gegenstand der Analysen dieser Studie war die überarbeitete Fassung der Schau.

136 Siehe Teil 2, Kapitel 2.3.

137 Okólska: Sala 23. 
aus einer externen Perspektive als homogene, maskulin und militärisch konnotierte Gruppe präsentiert. Der Fokus liegt dabei auf Gewaltverbrechen gegen die polnische und jüdische Bevölkerung, deren Völkerrechtswidrigkeit und Unehrenhaftigkeit betont wird. Insgesamt zeichnen fast alle Schauen ein entmenschlichtes Bild der Besatzer, das die stereotypen Feindvorstellungen der Kriegsjahre bis in die Gegenwart perpetuiert. Individuelle Erfahrungen deutscher Militärangehöriger ebenso wie die Existenz und der Alltag einer deutschen Zivilbevölkerung bleiben dabei außen vor oder werden - wie im Museum des Warschauer Aufstands - in die schematische Feindkonstruktion integriert. Erst eine der jüngsten Dauerausstellungen, die Schau in der Schindler-Fabrik in Krakau, unternimmt eine Differenzierung des Feindbildes bzw. ergänzt seine Darstellung um zivile und alltagsbezogene Kontexte. Erstmals wird hierdurch nicht nur eine menschliche Komponente der Besatzungsmacht eingeführt, auch ambivalente und bislang weitgehend tabuisierte Aspekte des Alltags der (nichtdeutschen) Stadtbevölkerung kommen zur Sprache, darunter die zivilen Kontakte zwischen Besatzern und Besetzten.

Allgemein ist in den Ausstellungen nach 1989 bei der Benennung der Besatzungsmacht der Wechsel von »hitleristisch « $\mathrm{zu}$ »deutsch « als übergreifende Veränderung zu konstatieren, der den Wandel von einem politisch konnotierten Feindbild hin zu einem ethnisch-nationalen Antagonismus markiert. Diese Veränderung fand jedoch nicht unmittelbar mit dem Systemwechsel statt, sondern erfolgte in den sich anschließenden zwei Dekaden. Während viele Ausstellungen heute konsequent von »Deutschen« sprechen, ist in einigen Institutionen nach wie vor eine Mischung von Begriffen zu verzeichnen, unter denen sich noch immer die »Hitleristen« der VRP finden. Ursache hierfür sind meist personelle Kontinuitäten in den Museen. Ältere Kuratoren, die bereits seit Jahrzehnten an den Häusern zum Bereich der Geschichte des Zweiten Weltkriegs arbeiten, greifen - meist wohl unreflektiert - auf verinnerlichte Terminologien zurück. ${ }^{138}$ Die konsequenteste Abkehr in der Wortwahl von »Hitleristen« hin zu »Deutschen« ist daher in jenen Ausstellungen $\mathrm{zu}$ verzeichnen, die von vergleichsweise jungen Museumsmitarbeitern konzipiert und realisiert wurden, so in der Schindler-Fabrik in Krakau und im Museum des Warschauer Aufstands. ${ }^{139}$ Die terminologische Veränderung erfolgte in diesen Institutionen sehr bewusst. Ziel war es, die umfassende Verantwortlichkeit des angreifenden Deutschland für den Krieg, die Besat-

138 Dies ist der Fall bei den Dauerausstellungen des Museums Radogoszcz in Łódź und des Stadtmuseums von Wrocław ebenso wie in den Schauen der beiden Lubliner Museen.

139 Monika Bednarek etwa, unter deren inhaltlicher Leitung die Schau des MHK in der Schindler-Fabrik erarbeitet wurde, ist erst seit der Jahrtausendwende am MHK. Interview mit Monika Bednarek am 16. März 2010. 
zung und die verübten Verbrechen kenntlich zu machen. ${ }^{140}$ Zugleich bleibt festzuhalten, dass die verbreitete Verwendung von Kollektivbezeichnungen wie »die Deutschen« ein abstraktes Feindbild unterstützt, in dem Abstufungen von Verantwortung und Schuld, von individuellen Überzeugungen und Wahrnehmungen nur schwer zu integrieren sind. Die auch zwei Dekaden nach dem Ende der VRP noch in öffentlichen Geschichtsdarstellungen zu findende sozialistische Terminologie ist darüber hinaus auch ein Hinweis auf die Persistenz der stereotypen Feindvorstellungen in den Köpfen der Ausstellungsmacher. Am Entstehungsprozess der Schauen sind jeweils zahlreiche Personen involviert; so wird die finale Version eines Drehbuchs meist von der Museumsleitung freigegeben. Dass diese Begriffe dennoch übersehen oder akzeptiert werden, zeigt, dass nach wie vor die etablierten Schemata in Bezug auf das Feindbild der deutschen Besatzer wirken. »Hitlerist« wird wohl oft einfach als Synonym oder aber als allgemeinverständlicher Ausdruck unhinterfragt verwendet. Dieses Phänomen ist ein weiterer Verweis auf die weitgehende Kontinuität des Bildes der deutschen Besatzer, wie es die historischen Ausstellungen bis heute zeichnen.

Wie in Teil 3 eingehend ausgeführt wird, stellt diese einseitige und stereotype Darstellungsweise des Feindes in der Mehrzahl der Ausstellungen den Hintergrund für eine ähnlich eindeutige Konstruktion der Wir-Gemeinschaft der polnischen Helden und Märtyrer dar. Der deutliche und undifferenzierte Kontrast zwischen deutschen Verbrechen einerseits und polnischer Selbstbehauptung und Widerstand andererseits bietet dabei die Folie für die Wahrung eindeutiger moralischer Zuordnungen von "gut« und »böse«. Die Art der Feinddarstellung korrespondiert somit unmittelbar mit dem in den Schauen jeweils vermittelten polnischen Selbstbild: Je schablonenhafter die Besatzer gezeichnet werden, desto einseitiger und undifferenziert positiv erfolgt die Darstellung von Polen in den Jahren 1939 bis $1945 .^{141}$

Vor dem Hintergrund der historiografischen und publizistischen Debatten der vergangenen zwanzig Jahre, die das polnische Selbstbild im Krieg betreffen, ${ }^{142}$ lässt sich folgende These formulieren: Eine Differenzierung des

140 Ähnliche Überlegungen sieht man auch bei anderen Begriffsveränderungen in den Institutionen und ihren Ausstellungen. So wird etwa in den jüngeren Präsentationen in Łódź nicht mehr vom »Łódźer Ghetto« (getto łódzkie) gesprochen, sondern die (deutsche) Terminologie der Besatzer verwendet, "Ghetto Litzmannstadt" (Litzmannstadt getto). Vor diesem Hintergrund wählte man auch den Namen der neuen Abteilung des $\mathrm{Mu}$ seums der Unabhängigkeitstraditionen - »Station Radegast« (Stacja Radegast), anstelle der polnischen Bezeichnung des Stadtbezirks »Radogoszcz«. Siehe Teil 2, Kapitel 3.

141 Siehe hierzu auch Teil 3, Kapitel 2.3.

142 Beispielhaft sei hier auf zwei wesentliche Themen verwiesen: die Frage polnischer Gleichgültigkeit und (Mit-)Täterschaft während des Holocaust sowie die Debatte um Kollaboration während des Zweiten Weltkriegs. Beide Punkte werden näher in den folgenden zwei Teilen der Arbeit behandelt. 
stereotypen Feindbildes wird angesichts möglicher Auswirkungen auf die Darstellung der Identifikationsfiguren der musealen Erzählungen, also der polnischen Bevölkerung, gefürchtet oder vermieden. Eine nähere Beschäftigung mit dem Alltag der deutschen Bevölkerung in den Städten würde auch ambivalente Aspekte des Lebens der polnischen Bevölkerung während der Besatzung aufzeigen, etwa die Frage nach Kontakten mit dem Feind beim Schmuggel und Schwarzmarkthandel oder der Zusammenarbeit in der Verwaltung. Eine Differenzierung der vermeintlich homogenen Gruppe »der Deutschen « hätte somit auch eine Differenzierung der noch immer als ebenso homogen dargestellten Gruppe »der Polen« zur Folge. In der Gesellschaft gibt es bislang kein übergreifendes Wissen und keine breite Akzeptanz auch ambivalenter und negativer Phänomene der Besatzungszeit im Hinblick auf die polnische Bevölkerung und ebenso scheinen nur wenige Museen ihre Inklusion in die eigene Geschichtsdarstellung $\mathrm{zu}$ unternehmen. Einen ersten Ansatz hierzu bietet von den untersuchten Museen bislang allein die Dauerausstellung in der ehemaligen Emaillewarenfabrik Oskar Schindlers des Historischen Museums der Stadt Krakau.

\section{Das Feindbild Sowjetunion}

Entgegen dieser starken Kontinuität in der Darstellung der Deutschen hat die Behandlung der zweiten Besatzungsmacht, der Sowjetunion, in den vergangenen Jahrzehnten eine deutliche Entwicklung durchlaufen. Bis 1989 unterlag dieses Thema, wie eingangs erwähnt, erheblichen Interpretationsvorgaben und Tabus, die erst ab Ende der 1980er-Jahre langsam öffentlich angesprochen werden konnten. Inhaltliche Aspekte, die die Auseinandersetzung mit der Rolle der Sowjetunion während des Zweiten Weltkriegs und damit auch ihre museale Präsentation seit dem Systemwechsel markierten, betrafen dabei erstens die Schilderung des Kriegsanfangs, insbesondere der Ereignisse im September 1939. Zweitens fand eine deutliche Neubewertung der Rolle der UdSSR bei Kriegsende statt, die unter dem Schlagwort »vom Befreier zum Besatzer« zusammengefasst werden kann. Drittens beinhaltet die Darstellung der Sowjetunion die Frage nach sowjetischen Kriegsverbrechen, insbesondere den Massenmorden von Katyń und an anderen Orten sowie die Deportationen von Polen in die Sowjetunion. Die Umwertung und Inklusion dieser drei thematischen Aspekte in die musealen Präsentationen war eng miteinander verbunden.

Bevor ihre Evolution im Folgenden entlang der drei Hauptphasen der musealen Entwicklung in Polen seit den 1980er-Jahren analysiert wird, ist noch ein zentraler Hinweis notwendig: Keine der untersuchten Städte war wäh- 
rend der Jahre 1939 bis 1944 von sowjetischen Truppen besetzt worden; erst mit dem sukzessiven Zurückdrängen der Deutschen ab dem Sommer 1944 kamen diese Gebiete unter den Einfluss der Roten Armee. Die Sowjetunion als Element des breiteren Kontextes der Weltkriegsgeschichte war jedoch für alle Museen der betrachteten Orte von Relevanz, die ihre lokale und regionale Geschichte stets in einem nationalen Narrativ verorteten. Nicht zuletzt war die Sowjetunion bzw. die Rote Armee als entscheidender Akteur in den letzten Kriegsmonaten bedeutend: Zum einen betraf dies ihre Rolle während des Warschauer Aufstandes von 1944, die in der VRP bis 1989 tabuisiert war. Zum anderen legte sie durch die Unterstützung und Protektion des Polnischen Komitees der Nationalen Befreiung bereits im Sommer 1944 die Grundlage für das sozialistische Nachkriegsregime.

\subsection{9 - Wendepunkt musealer Narration?}

Die musealen Erzählungen bis 1989

In den Dauerausstellungen, die vor 1989 entstanden sind, thematisierte man die Rolle der Sowjetunion während des Zweiten Weltkriegs auf polnischem Territorium nur sehr sparsam; in den meisten Schauen der 1980er-Jahre waren die UdSSR und die Rote Armee sogar weitestgehend abwesend. Dies trifft insbesondere auf die Darstellung des Kriegsbeginns zu. So erwähnte man weder den Einmarsch sowjetischer Truppen auf polnisches Gebiet am 17. September 1939 noch die folgende Besetzung der östlichen Gebiete Polens. Gleichermaßen fand die Vorgeschichte des Kriegsausbruchs keinerlei Erwähnung, namentlich der Hitler-Stalin-Pakt mit seinem geheimen Zusatzprotokoll, in dem die Aufteilung Ostmitteleuropas zwischen dem Deutschen Reich und der Sowjeunion vereinbart worden war. Auch in begleitenden $\mathrm{Pu}-$ blikationen der Museen, die den Besuchern einen erläuternden Einblick in die Ereignisgeschichte geben sollten, benannte man die Rolle der Sowjetunion im September 1939 nicht. Ein Beispiel hierfür ist der Ausstellungsführer des Martyrologiemuseums »Unter der Uhr« in Lublin aus dem Jahr 1981, in dem der Beginn des Kriegs und der Besatzung in allgemeiner Form, ausschließlich unter Benennung der deutschen Angreifer dargestellt wurde: „Nach dem endgültigen Erlöschen der Kriegshandlungen im Jahr 1939 fand sich das Lubliner Gebiet, ähnlich wie die zentralen Landesteile, unter der Verwaltung der Wehrmacht wieder. ${ }^{143}$ Ebenso unterlagen wesentliche Ereignisse und Elemente der sowjetischen Besatzungspolitik, insbesondere die Deportationen von Polen in die UdSSR sowie der Massenmord an polnischen Offizieren in 
Mednoe, Charkov, Katyń und anderen Orten, bis 1989 einem Tabu, ${ }^{144}$ das sich auch auf die musealen Darstellungen dieses Zeitraums erstreckte. ${ }^{145}$

Selbst die Rolle der Roten Armee bei Kriegsende wurde lediglich in einigen wenigen der untersuchten Schauen erwähnt. Die meisten Expositionen schilderten das Ende der deutschen Besatzung und die damit verbundenen militärischen Ereignisse dagegen überhaupt nicht, so zum Beispiel die Schau in der Abteilung Pomorska-Straße des Historischen Museums der Stadt Krakau. Die Ausstellung aus dem Jahr 1982 endete mit der Präsentation ranghoher deutscher »Folterknechte (oprawcy) des Distrikts Krakau, in der auch auf deren Verurteilung nach dem Krieg hingewiesen wurde. Ereignisse, die zum Ende der deutschen Besatzung geführt hatten oder auch nur die zeitliche Einordnung des Abzugs der Deutschen blieben dagegen unerwähnt. ${ }^{146}$ Die musealen Narrative endeten meist mit Vorkommnissen von lokaler Bedeutung. Im Fall des Pawiak-Museums war dies die Zerstörung des Gefängnisses durch ein deutsches Sprengkommando am 21. August $1944 .{ }^{147}$ Im Martyrologiemuseum »Unter der Uhr« schloss die Ausstellung mit der Darstellung des Massakers an Häftlingen des Gefängnisses im Lubliner Schloss, das deutsche Einheiten am 22. Juli 1944 verübt hatten. ${ }^{148}$ Die Kontexte der jeweiligen Geschehnisse wurden in diesen Präsentationen ausgeblendet. In der Schau des Pawiak betraf dies den Warschauer Aufstand, während dem die Zerstörung des Gefängnisses stattfand und die Rote Armee ihren Vormarsch kurz vor der Stadt unterbrach, ohne die Aufständischen im Kampf gegen die Deutschen wesentlich zu unterstützen. Die Schau im Museum »Unter der Uhr« thematisierte ebenso wenig den Grund für den Abzug der deutschen Truppen aus Lublin: die heranrückenden sowjetischen Einheiten. Die Rolle der Roten Armee bei Kriegsende wurde in diesen Ausstellungen somit vollständig außer

144 Zur sowjetischen Besatzungspolitik bis Juni 1941 vgl. exemplarisch Borodziej, Włodzimierz: Geschichte Polens im 20. Jahrhundert. München 2010, 195-198. Zu den Tabuthemen der polnisch-sowjetischen Beziehungen in den Jahren der Volksrepublik Polen vgl. Grabski: Zarys historii historiografii, 226-228; Ruchniewicz: Die Erinnerung an die Opfer, 32-36; Ders.: Zeitgeschichte in Polen, 57.

145 Diese prägnanten Leerstellen fanden sich sowohl im Pawiak-Museum und im Historischen Museum der Hauptstadt Warschau, im Martyrologiemuseum »Unter der Uhr« in Lublin als auch in der Schau der Abteilung Pomorska-Straße des MHK. Diese Ausstellungen konzentrierten sich allein auf die deutsche Aggression im September 1939. Siehe: Scenopis stałej ekspozycji, 53; Informator do ekspozycji, 46 f.; Wroński: Scenariusz wystawy, 2.

146 Wroński: Scenariusz wystawy, $9 \mathrm{f}$.

147 Scenopis stałej ekspozycji, 57.

148 Ausstellungstafel »Mord na Zamku 22. VII. 1944 r.« MLL-Unter der Uhr. Im Korridor des Museums wurden zudem Fotografien von an diesem Tag ermordeten Häftlingen ausgestellt. In Übereinstimmung mit dieser Darstellungsweise erfolgt auch die zeitliche und thematische Eingrenzung der Geschichte des Ortes und der Region im begleitenden Ausstellungsführer. Kowalski: Muzeum Martyrologii, 2, 15, 18. 
Acht gelassen. Beispielhaft hierfür ist die Wortwahl eines begleitenden Ausstellungsführers der Lubliner Schau, der das Ende der Besatzung in neutraler Ausdrucksweise, ohne die Andeutung einer Ursache, mit dem »Verlassen der Stadt« durch die Deutschen umschrieb. ${ }^{149}$

Lediglich in zwei der untersuchten Ausstellungen findet sich das Besatzungsende als mit der Sowjetunion verbundenes und eindeutig positiv konnotiertes Ereignis. In der Schau des Historischen Museums der Hauptstadt Warschau wurde das militärische Ende der deutschen Besatzung sogar ausführlich geschildert: Auf einer Ausstellungstafel stellte man die »Januaroffensive der 1. Weißrussischen Front der sowjetischen Armee [armia radziecka]« grafisch dar. ${ }^{150}$ Das Resultat der sowjetischen Offensive wurde zudem mit dem Begriff »Befreiung " gefasst. ${ }^{151}$ Auch in der Schau des Historischen $\mathrm{Mu}-$ seums der Stadt Lublin aus dem Jahr 1979 charakterisierte man das Ende der deutschen Besatzung als »Befreiung Lublins «. ${ }^{152}$ Hier wurde ebenfalls der Anteil der sowjetischen Armee an deren Herbeiführung deutlich hervorgehoben: Auf den Fotografien, die den Ausstellungsabschnitt zur Befreiung illustrierten, waren neben Soldaten der Polnischen Armee auch sowjetische Soldaten prominent abgebildet. ${ }^{153}$

Die zwei stadthistorischen Museen folgten in ihren Schauen somit dem ideologisierten Geschichtsbild der VRP, in dem die Sowjetunion und die Rote Armee als Befreier und Unterstützer der neuen sozialistischen Übergangsregierung, des PKWN, präsentiert wurden. ${ }^{154}$ In diesem einseitigen Bild verschwieg man alle Ereignisse, die die rein positive Darstellung der UdSSR oder

$149 »$ Kurz vor dem Verlassen der Stadt [...] ermordeten Gestapoangehörige in bestialischer Weise ungefähr 450 Häftlinge des Lubliner Schlosses.« Kowalski: Muzeum Martyrologii, 15.

150 Text auf der Ausstellungstafel »17. Januar 1945«. MHW, Saal 53.

151 Objektbeschriftung der Tafel »17. Januar 1945«, in der das Datum als »Tag der Befreiung« bezeichnet wird. Dieselbe Wortwahl findet sich auf der Tafel selbst (»im Zuge derer Warschau befreit wurde«), die auch nach 1989 unverändert in der Ausstellung erhalten blieb. Ebd; vgl. auch: Informator do ekspozycji, 54 .

152 So lautete der Titel einer Ausstellungstafel. Fotodokumentation der Dauerausstellung: Wystawa: Historia Miasta Lublina. Otwarcie 18. VII. 1979 r. AMLL, ohne Signatur, [12].

153 Vgl. ebd. Die polnischen Soldaten gehörten den in der Sowjetunion geschaffenen und unter sowjetischer Hoheit agierenden "Polnischen Streitkräften in der Sowjetunion" (Polskie Sity Zbrojne w ZSSR) an, aus denen im März 1944 die 1. Polnische Armee hervorgegangen war.

154 Beide Schauen boten einen Ausblick auf die unmittelbare Nachkriegsgeschichte des Landes mittels der Präsentation des Polnischen Komitees der Nationalen Befreiung. Im MHW geschah dies durch die Präsentation des Manifests des PKWN, das auch in der Schau im Krakauer Tor in Lublin gezeigt wurde. Dort hob man zudem die besondere Rolle Lublins als Ausgangspunkt der kommunistischen Nachkriegsentwicklung Polens hervor: Die letzte Ausstellungstafel der Schau, auf der u.a. die ersten Sitzungen des Komitees fotografisch dokumentiert wurden, war mit den Worten »Lublin - Sitz des PKWN« betitelt. Wystawa: Historia Miasta Lublina, [12]; MHW, Saal 53. 
der Roten Armee stören konnten. Hintergrund für diese am offiziellen Geschichtsbild ausgerichtete Darstellungsweise war vermutlich die Rolle dieser Institutionen als (stadt-)historische Museen, denen in der Volksrepublik in Ermangelung eines zentralen, der nationalen und staatlichen Geschichte gewidmeten Museums - die Aufgabe der Vermittlung des staatlichen Geschichtsbildes zukam. Das Historische Museum der Hauptstadt Warschau nahm hierbei eine zentrale Vorbildfunktion ein, an der sich andere Institutionen, wie etwa das Lubliner Museum, orientierten. ${ }^{155}$

Die untersuchten martyrologischen Einrichtungen hingegen, die an Schauplätzen von Verbrechen der deutschen Besatzungsorgane entstanden sind, vermieden in ihren Präsentationen eine breitere Kontextualisierung des Besatzungsendes, indem sie sich, wie beschrieben, auf die konkrete Geschichte des jeweiligen Ortes konzentrierten. Ein Grund hierfür ist wohl darin zu sehen, dass einige der Gefängnisse nach Ende der deutschen Besatzung vom sowjetischen NKVD oder dem »Ministerium für Öffentliche Sicherheit» (Ministerstwo Bezpieczeństwa Publicznego) der neuen sowjetisch kontrollierten polnischen Regierung für die Inhaftierung von Mitgliedern nichtkommunistischer Widerstandsbewegungen (weiter-)verwendet wurden. So wurde beispielsweise das Lubliner Schloss bereits kurz nach dem Abzug der deutschen Truppen ab der zweiten Augusthälfte 1944 wieder als Gefängnis genutzt, in dem insbesondere Mitglieder der Heimatarmee gefangen gehalten und exekutiert wurden. Erst 1954 löste man das Gefängnis auf. ${ }^{156}$ Im Gefängnis Montelupich in Krakau - das ebenfalls in der Schau der Pomorska-Straße thematisiert wurde - waren nach dem Einmarsch der Roten Armee ehemalige Untergrundkämpfer interniert. ${ }^{157}$ Durch das Auslassen der Rolle der Sowjetunion bei Kriegsende und in der unmittelbaren Nachkriegszeit, die andernorts ideologiekonform positiv dargestellt wurde, vermied man in diesen Ausstellungen eine direkte und für die ortsansässige Bevölkerung offensicht-

155 Durko, Janusz: Muzeum Historyczne m. st. Warszawy w latach 1948-1973 [Das Historische Museum der Hauptstadt Warschau in den Jahren 1948-1973]. In: Ders. (Hg.): Muzeum Historyczne Warszawy [Das Historische Museum von Warschau]. Warszawa 1973, 40-69, hier 47.

156 Vgl. Chmielak/Jakimińska/Polańska: Historia Miasta Lublina, 96.

157 Chwalba, Andrzej: Dzieje Krakowa [Die Geschichte Krakaus]. Bd.6: Kraków w latach 1945-1989 [Krakau in den Jahren 1945-1989]. Kraków 2004, 193-196. Auch in den Zellen im Schlesischen Haus in der Pomorska-Straße waren möglicherweise unmittelbar nach dem Ende der deutschen Besatzung Mitglieder des nichtkommunistischen Widerstands inhaftiert. So lauteten zumindest Gerüchte in der Stadt, die insbesondere in den 1990er-Jahren kolportiert wurden. Historische Recherchen haben lediglich Indizienhinweise auf eine mögliche Nutzung der Räumlichkeiten im Schlesischen Haus für Verhöre durch das »Amt für Öffentliche Sicherheit« (Urząd Bezpieczeństwa Publicznego) ergeben, die jedoch bislang nicht verlässlich belegt werden konnten. Vgl. Salwiński: Dom Śląski, $15 \mathrm{f}$. 
liche Verfälschung der Geschichte der Orte, was wiederum der Legitimierung der Ausstellungsnarrative diente. Darüber hinaus kann das Schweigen über die Rolle der UdSSR in den Jahren 1944 / 45, das für die in den 1980er-Jahren entstandenen Schauen zu konstatieren ist, als Verweis darauf gewertet werden, dass die offizielle Interpretation der Kriegsereignisse an Deutungshoheit verloren hatte und zunehmend kritisch gesehen wurde. Der prägnanteste Hinweis hierfür ist das Fehlen des Begriffs "Befreiung" in den untersuchten Präsentationen aus dieser Dekade, der in früheren Ausstellungen selbstverständlich gewesen war.

\section{9 - Kontinuitäten etablierter Darstellungsweisen}

Der Systemwechsel von 1989 hatte auf die Dauerausstellungen der historischen Museen zunächst nur geringe Auswirkungen. Die existierenden Schauen ergänzte man in der ersten Hälfte der 1990er-Jahre lediglich um wenige Themen; ${ }^{158}$ einige als besonders ideologisch aufgeladen wahrgenommene Beschriftungen und Texte wurden verändert, ergänzt oder entfernt. Auch in den Anfang der 1990er-Jahre neu eröffneten Schauen (in der Abteilung Pomorska-Straße des MHK 1990 und im Gefängnismuseum Pawiak 1991) fanden sich nur wenige Veränderungen der präsentierten Inhalte und Interpretationen. Lediglich in der Dauerausstellung des MHW wurde der Saal, in dem die Septemberereignisse von 1939 geschildert wurden, im Zuge einer Umgestaltung in den Jahren 1990/91 um die Rolle der Sowjetunion in den ersten Kriegswochen ergänzt: Der Thementext erwähnte nun die Besetzung der östlichen Gebiete Polens nach dem Einmarsch sowjetischer Truppen mit einem Halbsatz: »[...] am 17. September nahmen die sowjetischen Armeen die östlichen Gebiete Polens ein [...].«Zusätzlich fand sich hier eine Karte, auf der der Vormarsch der deutschen und sowjetischen Truppen auf polnisches Territorium eingezeichnet war. ${ }^{159}$ In den Schauen der drei martyrologischen Institutionen blieb die Rolle der Sowjetunion bei Kriegsbeginn dagegen weiterhin ausgespart. In der Schau des Museums »Unter der Uhr« in Lublin bestand diese Situation noch zum Zeitpunkt der Recherchen im Jahr 2010 fort. Auch in der neuen Ausstellung des Gefängnismuseums Pawiak - im Wesent-

158 Siehe Teil 3, Kapitel 2.2.

159 Die Beschreibung der Karte lautete: »September 1939. Die militärische Situation Polens angesichts der deutschen und sowjetischen [sowiecka] Aggression." MHW, Saal 46. In dem vorgelagerten Ausstellungsraum, in dem die Besucher erstmalig die dritte Etage und damit den Teil zum Zweiten Weltkrieg betraten, wurde zudem in den folgenden Jahren eine Karte eingefügt, die die "administrative Aufteilung der polnischen Gebiete" im Zeitraum vom 28. September 1939 bis zum 22. Juni 1941 zeigte. Auf dieser war der Grenzverlauf und die Aufteilung der polnischen Gebiete zwischen UdSSR und Deutschem Reich eingetragen. MHW, Saal 47, Zitat: Titel der Karte. 
lichen eine modernisierte Fassung der Vorgängerpräsentation - wurde dieses Thema nicht eingefügt. ${ }^{160}$ Ebenso wie in der Krakauer Schau von 1990 in der Pomorska-Straße blieb die Darstellung militärischer Ereignisse auf die jeweilige Region beschränkt und vermied damit eine Erwähnung des sowjetischen Einmarsches. ${ }^{161}$ Auch in der Dauerausstellung des Historischen Museums der Stadt Lublin von 1995 verfolgte man diesen Ansatz.

Ähnliches ist in Bezug auf die Darstellung der militärischen Bedeutung der Roten Armee bei Kriegsende festzustellen. Lediglich in der PomorskaStraße in Krakau wurde der Aspekt in die Präsentation aufgenommen. Einige Fotografien illustrierten den Kampf der Roten Armee um die Stadt; eine Karte zeigte die Frontentwicklung zwischen dem 12. und dem 18. Januar 1945. Einzeln erwähnt wurde die Person Marschall Ivan Konevs, der die sowjetische Offensive angeführt hatte. ${ }^{162}$ Eine Bewertung dieser Ereignisse, etwa hinsichtlich der Folgen des Eintreffens der Roten Armee, fand hingegen nicht statt. Diesen Abschnitt der Kriegs- und Besatzungsgeschichte betitelte man mit dem allgemeineren Ausdruck "Ende der hitleristischen Besatzung «. ${ }^{163}$ Die Erzählungen der übrigen Museen hingegen änderten sich bezüglich dieses Teils der Besatzungsgeschichte nach 1989 nicht. In der Schau im Gefängnismuseum Pawiak sowie im Museum »Unter der Uhr« wurde weiterhin das Ende der deutschen Okkupation nicht thematisiert. ${ }^{164}$ Im Historischen Museum der Stadt Lublin blieben die Ausstellungstafeln, die den Abzug der Deutschen als »Befreiung « feierten und diese polnischen und sowjetischen Truppen zuschrieben, bis 1995 hängen. ${ }^{165}$ In der Schau des MHW hatte die Interpretation von vor 1989 sogar noch länger Bestand. ${ }^{166}$ Parallel zu

160 Izdebska: Pawiak 1939-1945, 9 f.

161 Das Drehbuch der Schau des MHK beschreibt den ersten Themenabschnitt der Ausstellung folgendermaßen: »Der erste Teil der Ausstellung zeigt die Pläne und Aktivitäten der zwei kämpfenden Seiten während des September-Feldzugs des Jahres 1939.«Die Schau thematisierte dementsprechend in diesem Abschnitt lediglich die Armee »Krakau« der Polnischen Armee sowie den Angriff deutscher Truppen. Gąsiorowski/Kuler/ Natkaniec: Scenariusz wystawy, $1 \mathrm{f}$.

162 Ebd., $14 \mathrm{f}$.

163 Tafel 37. Ebd., 14.

164 Die Schau im Pawiak endete wie ihre Vorgängerin mit der Darstellung der Sprengung des Gefängnisses durch deutsche Einheiten. Izdebska: Pawiak 1939-1945, $165 \mathrm{f}$.

165 Auskunft des Historischen Museums der Stadt Lublin, E-Mail vom 25. Juli 2012.

166 Zum Zeitpunkt der Recherche im Juni 2009 war die Tafel zu diesem Ausstellungsabschnitt noch immer unverändert in der Schau zu finden. Zwar bewertete die zuständige Kuratorin diese Präsentationsweise kritisch; bis zu ihrem Wechsel im Jahr 2004 lehnte die Direktion des Museums eine Veränderung der Interpretation dieses Teils der Besatzungsgeschichte jedoch ab. Nach dem Antritt einer neuen Direktorin und der Verbesserung der finanziellen Situation des Museums begann 2006 die sukzessive Umgestaltung der Ausstellungsräume zum Zweiten Weltkrieg. Eine Neugestaltung des Ausstellungsabschnitts zum Kriegsende und der Nachkriegszeit war 2009 für die nahe 
dieser Darstellungsweise fanden auch die sowjetischen Kriegsverbrechen sowie die Verfolgung nichtkommunistischer Widerstandsgruppen bei Kriegsende bzw. nach dem Abzug der deutschen Truppen in keiner der untersuchten Dauerausstellungen dieses Zeitraums Erwähnung.

\section{9 - Eruption der Erinnerungen}

Die weitgehende Kontinuität der Darstellungsweisen in den Dauerausstellungen der historischen Museen bedeutete jedoch nicht, dass dieser Themenbereich bis zum Beginn der Neugestaltung der meisten permanenten Präsentationen in den Jahren 1998 bis 2003 in den Institutionen abwesend war. Im Gegenteil: Die als am dringlichsten empfundenen Leerstellen der bis 1989 präsentierten Geschichtsbilder wurden in den 1990er-Jahren in einer regelrechten Flut von Sonder- und Wechselausstellungen thematisiert. Eines der ersten Themen, das aufgegriffen wurde, waren die Massaker an polnischen Offizieren durch den NKVD im Jahr 1940, für die synonym der Ort Katyń stand. Die ersten Schauen hierzu zeigte man bereits 1990 und 1993, zum Jahrestag der Massaker bzw. dem Jahrestag ihrer Entdeckung und Bekanntmachung durch die deutschen Besatzer. Da nicht immer eigene Recherchen und Quellenmaterial zu diesem Thema vorlagen, griffen die Museen mittels Kooperationen mit anderen Institutionen auf externe Schauen zurück. Besonders weite Verbreitung fand die im Herbst 1989 vom Krakauer »Museum der Geschichte der Fotografie» (Muzeum Historii Fotografii) und der »Krakauer Fotografischen Gesellschaft« (Krakowskie Towarzystwo Fotograficzne) vorbereitete Präsentation "Zginęli w Katyniu» (Sie starben in Katyń). ${ }^{167}$ Im Krakauer Tor in Lublin zeigte man 1990 eine eigene Ausstellung: »Generał Brygady Mieczysław M. Smorawiński - w pięćdziesiątą rocznicę zbrodni katyńskiej« (Brigadegeneral Mieczysław M. Smorawiński - zum 50. Jahres-

Zukunft geplant. Interview mit Joanna Maldis am 30. Juni 2009. Aufgrund der Schließung der Dauerausstellung im Jahr 2010 im Zusammenhang mit umfassenden Renovierungsarbeiten in den Kellern des Museums sind diese Pläne jedoch zunächst zurückgestellt worden. Ende Mai 2017 wurde eine unter der neuen Leitung des Hauses grundlegend neu konzipierte ständige Ausstellung eröffnet, in der die besprochenen Themenräume nicht mehr enthalten sind.

167 Diese wurde am 2. November 1989 in Krakau eröffnet. Siehe: Wystawa dla uczczenia: 50-lecia wybuchu II wojny 1939-1989 oraz 150-lecia wynalazku fotografii 1839-1989 [Faltblatt zur Ausstellung in Krakau]. AMMŁ, teczka 6/68, 1. 1990 wurde sie auch im Stadtmuseum Łódź gezeigt. Siehe: Budziarek, Marek: Zginęli w Katyniu [Faltblatt zur Ausstellung in Łódź]. AMMŁ, teczka 6/68, 3. Daneben wanderte sie u.a. nach Poznań und ins Historische Museum von Wrocław. Einladungskarte zur Eröffnung der Schau in Poznań am 9. Januar 1990. Archiwum Muzeum Miejskiego Wrocławia (Archiv des Stadtmuseums Wrocław, weiter AMMW), teczka 16/14, W-41, 2; Einladungskarte zur Eröffnung der Schau in Wrocław am 2. März 1990. AMMW, teczka 16/14, W-41, 3. 
tag des Verbrechens von Katyń), in der am Beispiel der Biografie des Generals, der die militärische Verteidigung Lublins während der ersten Septemberhälfte 1939 geleitet hatte, das Schicksal der im Jahr 1940 ermordeten polnischen Offiziere geschildert wurde. ${ }^{168}$ Auch das Historische Museum der Stadt Łódź präsentierte 1993 eine eigene Schau zu dem Thema unter dem Titel "Zanim zginęli w Katyniu, Charkowie i Kalininie« (Bevor sie in Katyń, Charkov und Kalinin umkamen). ${ }^{169}$ Spätestens seit dem Jahr 1995, das in Polen zum staatlichen Katyń-Gedenkjahr erklärt wurde ${ }^{170}$ werden regelmäßig Sonderausstellungen zu diesem Themenkomplex gezeigt. ${ }^{171}$

In den zwei Lubliner Museen arbeitete man Anfang der 1990er-Jahre insbesondere die unmittelbare Nachkriegsgeschichte des Gefängnisses im Lubliner Schloss auf und stellte erstmals öffentlich seine Nutzung durch den NKVD und anschließend das »Amt für Öffentliche Sicherheit« (Urząd Bezpieczeństwa Publicznego, umgangssprachlich UB abgekürzt) zwischen 1944 und 1954 für die Internierung von Mitgliedern nichtkommunistischer Widerstandsbewegungen dar. ${ }^{172}$ Auch die Deportationen von Polen in die UdSSR - mit den Schlagworten Sybir (Sibirien) oder Sybiracy (die nach Sibirien Deportierten) gefasst - wurden nun in Wechselausstellungen präsentiert. Bereits 1990 zeig-

168 Einladungskarte zur Ausstellungseröffnung am 23. April 1990. AMLL, Oddział Muzeum Historii Miasta Lublina, teczka »Gen. Mieczysław Smorawiński«, ohne Signatur; Chmielak, Jadwiga: Scenariusz wystawy »Generał Mieczysław Smorawiński. W 50. rocznicę zbrodni katyńskiej«. AMLL, Oddział Muzeum Historii Miasta Lublina, teczka »Gen. Mieczysław Smorawiński«, ohne Signatur. General Mieczysław Smorawiński hat im September 1939 die Verteidigung Lublins mitgeleitet. Er kam später in sowjetische Kriegsgefangenschaft und wurde 1940 bei Katyń erschossen.

169 Faltblatt zur Ausstellung. AMMŁ, teczka 6/75, ohne Signatur.

170 Der damalige Präsident Lech Wałęsa hatte dieses Jahr zum »Internationalen KatyńGedenkjahr» (Międzynarodowy Rok Katyński) erklärt. Vgl. Przewoźnik/Adamska: Katyń, 508.

1711995 zeigte das Martyrologiemuseum Radogoszcz in Łódź seine erste Schau zu dem Thema unter dem Titel »Rozstrzelany życia los« (Das erschossene Schicksal). Faltblatt zur Ausstellung. Archiwum Muzeum Tradycji Niepodległościowych w Łodzi (Archiv des Museums der Unabhängigkeitstraditionen in Łódź, weiter AMTNŁ), ohne Signatur. Auch im Historischen Museum in Wrocław war dem Thema Katyń eine Sonderausstellung gewidmet: „Katyń - 1940«, in der Grafiken der Künstler Jerzy Jakubów und Marek Lercher gezeigt wurden. Faltblatt zur Ausstellung. AMMW, teczka 16/17, W-41, 7.

172 Im Martyrologiemuseum »Unter der Uhr« wurde am 25. Oktober 1990 eine Sonderausstellung mit dem Titel »Więzienie na Zamku Lubelskim. 1944-1954« (Das Gefängnis im Lubliner Schloss. 1944-1954) eröffnet. Einladungskarte zur Ausstellungseröffnung. In: AMLL, Kronika Klubu b. Więźniów Politycznych Zamku Lubelskiego i Pod Zegarem, Nr. 16 (1 / 1990-6/ 1991), ohne Signatur, o. S. Im Hauptsitz des Lubliner Museums, dem Lubliner Schloss, wurde 1991 eine neue Dauerausstellung mit demselben Titel eröffnet. Sil, Jan: Kronika Muzeum Lubelskiego za lata 1988-1995 [Chronik des Lubliner Museums für die Jahre 1988-1995]. In: Studia i Materiały Lubelskie 14 (1997), 229-248, hier 233. Es ist unklar, wie lange diese Schau zu sehen war. 
ten dazu das Historische Museum der Stadt Krakau sowie das Unabhängigkeitsmuseum in Warschau Sonderausstellungen. ${ }^{173}$ Die letztgenannte Institution widmete sich Anfang der 1990er-Jahre auch dem Thema der sowjetischen Verbrechen während des Kriegs sowie dem Prozess gegen die Führer des nichtkommunistischen Widerstands nach Kriegsende. ${ }^{174}$ Das einzige $\mathrm{Mu}-$ seum, das sich ähnlichen Initiativen der Aufarbeitung bisheriger Tabuthemen in Bezug auf die Rolle der Sowjetunion während des Kriegs nicht anschloss, war das Historische Museum der Hauptstadt Warschau. ${ }^{175}$

173 Die Ausstellung »Sybiracy - obywatele polscy - więźniowie i zesłańcy« (»Die nach Sibirien Deportierten - polnische Staatsangehörige - Gefangene und Deportierte«) wurde von Mitarbeitern der Abteilung Pomorska-Straße vorbereitet. Sie versammelte "zum ersten Mal in unserer Stadt Erinnerungsstücke von Polen, die in den Jahren 1939-1945 zur Katorga deportiert wurden «, umfasste aber in weiterer Perspektive auch die Deportationen im zaristischen Russland sowie die Rückkehr der Deportierten in den 1940erund 1950er-Jahren. Passowicz, Wacław: Kronika działalności Muzeum Historycznego Miasta Krakowa za rok 1990. In: Krzysztofory 18 (1991), 188-198, hier 188, 196. Siehe auch: Wystawa »Sybiracy«. Kraków kwiecień-czerwiec 1990. AMHK, teczka 123/17, OP-6411-57-90. Das Unabhängigkeitsmuseum in Warschau präsentierte 1992 anlässlich der in Zusammenarbeit mit der Organisation Karta veranstalteten »Woche des Gewissens« (Tydzień sumienia, 6.-12. April) eine gemeinsame Ausstellung unter dem Titel »Ocaleni z Gułagu« (Überlebende des Gulag), die Fotografien von Rückkehrern der 1950er-Jahre versammelte, sowie eine erste Schau der Erinnerungsstücke ehemaliger Deportierter, »Wystawa pamiątek zgromadzonych przez Związek Sybiraków« (Ausstellung von vom Verband der nach Sibirien Deportierten gesammelten Erinnerungsstücken). Stawarz, Andrzej: Działalność Muzeum Niepodległości w latach 1990-1995. In: Ders.: Muzeum Niepodległości, 3-17, hier 7; Pałaszewska, Mirosława/Żuchowska, Krystyna: Wystawy w Muzeum Niepodległości 1990-2005 [Die Ausstellungen im Unabhängigkeitsmuseum 1990-2005]. In: Niepodległość i Pamięć 23 (2006), 161-194, hier 165. Siehe auch das Interview mit dem Organisator der Schau »Überlebende des Gulag«, Tomasz Kizny: Wyrok. Z autorem wystawy, Tomaszem Kizny rozmawiała Zofia Broniek [Verurteilung. Mit dem Autor der Ausstellung, Tomasz Kizny, sprach Zofia Broniek]. In: Podkowieński Magazyn Kulturalny 4 (7) (1994), URL: http://free.art.pl/podkowa.magazyn/ index.htm (am 24.7.2012). Das Thema wurde auch in den folgenden Jahren vom MNW mithilfe von Wechselausstellungen verfolgt: In den Jahren 1996 bis 1997 wurde die Schau »Sybir 1940-1956« (Sibirien 1940-1956) präsentiert, von 2000 bis 2003 die Ausstellung »Sybiracy 1940-1956« (Die nach Sibirien Deportierten 1940-1956); beide wurden im X. Pavillon der Warschauer Zitadelle, einer Abteilung des MNW, gezeigt. Pałaszewska/Żuchowska: Wystawy w Muzeum Niepodległości, 180, 185, 193.

1741990 wurde die Schau »Proces szesnastu przywódców Polski Podziemnej« (Der Prozess der sechzehn Führer Untergrundpolens) gezeigt; zwei Jahre später die Ausstellung »Zbrodnie sowieckie na więźniach latem 1940 roku na Kresach Wschodnich II RP« (Sowjetische Verbrechen an Gefangenen im Sommer 1940 in den Ostgebieten der Zweiten Republik Polen). Vgl. Pałaszewska/Żuchowska: Wystawy w Muzeum Niepodległości, 161, 167.

175 Bis 2002 wurden in dem Museum keine Sonderausstellungen zu den Themen »Sybiracy» oder »Katyń« gezeigt. Siehe Pietrzak, Cecylia: Kalendarium Wystaw. 1972-1998 [Ausstellungschronik. 1972-1998]. In: Almanach Muzealny [Museumsalmanach]. Bd. 2. Hg.v. Muzeum Historyczne m.st. Warszawy. Warszawa 1999, 355-409; Pietrzak, Cecylia/ Wiśniewska, Jolanta / Rogulska, Barbara: Kalendarium wystaw 1999-2000 [Ausstellungs- 
Die meisten der genannten Sonderausstellungen wurden in enger Zusammenarbeit mit und oft auch auf Initiative von Interessenverbänden organisiert. Besonders engagiert waren hierbei die regionalen Sektionen der "KatyńFamilien" (Rodziny Katyńskie), die Angehörige der seit 1939/40 vermissten polnischen Offiziere und Polizisten versammeln, ${ }^{176}$ sowie des Vereins der nach Sibirien Deportierten " (Zwiazek Sybiraków) ${ }^{177}$ So entstand beispielsweise die Krakauer Ausstellung "Sie starben in Katyń" in enger Zusammenarbeit mit Katyń-Familien; ${ }^{178}$ in weiteren Städten, in denen die Schau gezeigt wurde, ergänzten die jeweiligen örtlichen Sektionen der Katyń-Familien diese Wanderausstellungen um lokale Kontexte und Erinnerungsstücke. ${ }^{179}$ Die ersten Schauen, die im Unabhängigkeitsmuseum in Warschau zum Thema "Sybiracy" präsentiert wurden, organisierte man in Kooperation mit der Nichtregierungsorganisation Karta und dem Verein der nach Sibirien Deportierten..$^{80}$ Die im MHK 1990 gezeigte Schau - von Mitarbeitern der Abteilung Pomorska-Straße vorbereitet - entstand ebenfalls in enger Kooperation mit

chronik 1999-2000]. In: Almanach Muzealny [Museumsalmanach]. Bd. 3. Hg.v. Muzeum Historyczne m.st. Warszawy. Warszawa 2001, 271-287; Pietrzak, Cecylia/Rogalska, Barbara/Wiśniewska, Jolanta: Kalendarium wystaw 2001-2002 [Ausstellungschronik 2001-2002]. In: Almanach Muzealny. Bd. 4. Hg. v. Muzeum Historyczne m. st. Warszawy. Warszawa 2003, 415-428. Eine mögliche Erklärung hierfür könnten die politischen Überzeugungen seines langjährigen Leiters, Janusz Durko, gewesen sein, der sich bis zu seiner Pensionierung 2003 auch einer Veränderung der Interpretation des Einmarsches der Roten Armee in Warschau als "Befreiung" widersetzte; dies bleibt jedoch eine Vermutung. Das Museum widmete sich Anfang der 1990er-Jahre dagegen anderen bislang tabuisierten oder kaum thematisierten Aspekten der Kriegsgeschichte. Ein Beispiel hierfür ist die Schau »Niemiecki ruch oporu 1933-1945« (Der deutsche Widerstand 1933-1945), die - organisiert vom deutschen »Institut für Auslandsbeziehungen« - 1990 im MHW gezeigt wurde. Mit der Präsentation dieser Schau erweiterte man das einseitige Bild der Deutschen. Pietrzak: Kalendarium Wystaw. 1972-1998, 388.

176 Die sich seit 1989 in verschiedenen Städten zusammenfindenden Gruppen schlossen sich 1992 unter einem gemeinsamen Dachverband zusammen, der »Föderation der KatyńFamilien« (Federacja Rodzin Katyńskich). Vgl. Historia Federacji Rodzin Katyńskich [Die Geschichte der Föderation der Katyń-Familien], URL: www.federacja-katyn. org.pl/federacja_his.php (am 23.7.2012). Siehe auch Przewoźnik/Adamska: Katyń, $423 \mathrm{f}$.

177 Der Verein war 1928 gegründet worden. Nach Unterbrechung seiner Tätigkeit während des Zweiten Weltkriegs und in der Volksrepublik Polen wurde er im Dezember 1988 offiziell wieder zugelassen. Vgl. Z życia Związku ... rok 1988/ 89 [Aus der Tätigkeit des Vereins ... das Jahr 1988/ 89], URL: www.zwiazeksybirakow.strefa.pl (am 24.7.2012).

178 Wystawa dla uczczenia: 50-lecia wybuchu II wojny 1939-1989 oraz 150-lecia wynalazku fotografii 1839-1989 [Information zur Ausstellung in Krakau]. AMMŁ, teczka 6/68, 1, 3.

179 So beispielsweise bei der Präsentation der Schau in Łódź. Budziarek, Marek: Zginęli w Katyniu [Faltblatt zur Ausstellung in Łódź]. AMMŁ, teczka 6/68, 3.

180 Dies waren die bereits erwähnten, anlässlich der »Woche des Gewissens« 1992 gezeigten Schauen »Überlebende des Gulag« und »Ausstellung von vom Verband der nach Sibirien Deportierten gesammelten Erinnerungsstücken«. Pałaszewska/Żuchowska: Wystawy w Muzeum Niepodległości, 165. 
der Krakauer Sektion der letztgenannten Organisation. ${ }^{181}$ Da die Museen bis 1989 zu diesen Tabuthemen nicht offiziell sammlerisch tätig werden konnten, waren diese Kooperationen essenziell. Mit ihrer Hilfe konnten Sammlungen zu den bislang verschwiegenen Themen aufgebaut und Dauerleihgaben angeworben werden, die die Grundlage neuer Dauerausstellungen oder der Ergänzung von bestehenden Präsentationen bildeten. So entstand etwa im MNW durch die Sammlungstätigkeit insbesondere im Kreis der ehemaligen Sybiracy 2005 eine Dauerausstellung mit dem Titel »Sybiracy 1940-1956«, die im X. Pavillon der Warschauer Zitadelle untergebracht wurde. ${ }^{182}$

Auf die Initiative der Katyń-Familien geht auch die Gründung eines eigenen Museums zurück, das den Massakern an polnischen Offizieren und Soldaten von 1940 gewidmet ist. Nach fast drei Jahren der Sammlung von Objekten und der Bemühungen der Föderation der Katyń-Familien um eine staatliche Unterstützung wurde am 29.Juni 1993 das "Katyń-Museum» (Muzeum Katyńskie) als Abteilung des »Museums der Polnischen Armee» (Muzeum Wojska Polskiego) in Warschau offiziell eröffnet. Eine Dauerausstellung unter dem Titel »Pamięć nie dała się zagładzić« (Die Erinnerung ließ sich nicht vernichten) wurde aufgebaut und in den folgenden Jahren sukzessive um neue Objekte aus laufenden Exhumierungsarbeiten an den Exekutionsstätten ergänzt. ${ }^{183}$ Wie der Titel bereits suggeriert, bestand das Hauptziel der Schau nicht allein in der Information über die Exekutionen, sondern zugleich in der Schaffung eines Gedenkortes, an dem die Toten gewürdigt werden. ${ }^{184}$

Von Beginn seiner Tätigkeit an litt das Museum unter erheblichen Finanzierungsproblemen. ${ }^{185}$ Die Initiatoren beklagten das geringe Interesse von-

181 Wystawa »Sybiracy«. Kraków kwiecień-czerwiec 1990. AMHK, teczka 123/17, OP6411-5790, 1.

182 Pałaszewska/Żuchowska: Wystawy w Muzeum Niepodległości, 193; Milewska-Młynnik, Anna: Wystawa »Sybir 1940-1956« [Die Ausstellung »Sibirien 1940-1956«]. In: Niepodległość i Pamięć 11 (1998), 255-257, hier 255 f.

183 Einen Überblick über den Aufbau und die Inhalte der Dauerausstellung, wie sie zum Beginn des 21. Jahrhunderts existierte, bieten zwei Publikationen: Łojek, Bożena u.a.: Muzeum Katyńskie w Warszawie [Das Katyń-Museum in Warschau]. Warszawa 2001, 145-170; Sawicki, Zdzisław (Red.): Muzeum Katyńskie - Oddział Muzeum Wojska Polskiego w Warszawie. Przewodnik [Das Katyń-Museum - Abteilung des Museums der Polnischen Armee in Warschau. Ausstellungsführer]. Warszawa 2004, 9-45.

184 Dies wurde im Ausstellungsführer auch explizit benannt. Sawicki: Muzeum Katyńskie, 8. Siehe auch Kosicki, Piotr H.: Les lieux de la mémoire polonaise de Katyn 1943-2010: d'une forêt à un musée. In: El Kenz, David/Nérard, François-Xavier (Hg.): Commémorer les victimes en Europe. XVIe-XXIe siècles. Seyssel 2011, 265-288, hier 280.

185 Die finanziellen Probleme des Museums verhinderten sowohl die Entwicklung der anvisierten eigenen breiten Forschungsaktivität als auch die regelmäßige Herausgabe von Publikationen. Łojek: Muzeum Katyńskie, 74. Eine umfangreiche Geschichte der Institution findet sich unter URL: www.muzeumkatynskie.pl/pl/23227/historia_muzeum_ katynskiego.html (am 8.1.2014). 
seiten der Regierung für die neue Institution. ${ }^{186}$ Aufgrund der ungünstigen Lage abseits des Zentrums von Warschau im ehemaligen Fort Sadyba sowie der geringen öffentlichen Präsenz des Museums blieben die Besucherzahlen sehr niedrig. ${ }^{187}$ Bis Ende der 2000er-Jahre fristete das Museum ein Nischendasein, bis es schließlich Anfang 2009 aufgrund erheblicher Baumängel im Fort geschlossen werden musste. Im selben Jahr hat sich jedoch eine Perspektive für die Institution aufgetan: Zum neuen Sitz des Museums wurde die Warschauer Zitadelle bestimmt, deren Kaponniere für das Museum umfassend umgebaut wurde. Zudem ist auf dem Gelände ein Gedenkareal entstanden. Die offizielle Eröffnung fand schließlich am 17. September 2015 statt, dem Jahrestag des sowjetischen Angriffs auf Polen im Jahr 1939. ${ }^{188}$

\section{Das museale Nebeneinander von Schweigen und Erinnern}

Diese regelrechte Eruption von Ausstellungen, die sich den polnisch-sowjetischen Beziehungen der Kriegs- und unmittelbaren Nachkriegszeit widmeten und sich schwerpunktmäßig auf die sowjetischen Verbrechen dieser Jahre konzentrierten, hatte ihre Vorläufer in den 1980er-Jahren. ${ }^{189}$ Bereits mit Entstehung der Gewerkschaft »Solidarność» (Solidarität) und während deren Auseinandersetzung mit der Regierung in den Jahren 1980 / 81 wurde ein Eingeständnis der sowjetischen Verantwortung für Kriegsverbrechen, darunter für die Morde in Katyń, gefordert. »Katyń« avancierte schließlich zu einem der bedeutendsten Themen der in den 1980er-Jahren immer stärker artikulierten Forderung nach der Beseitigung der sogenannten weißen Flecken der Geschichte. ${ }^{190}$ Die Massenmorde im Wald bei Smolensk waren in den Jahren des Staatssozialismus zum Symbol nicht nur für die Geschichtsverfälschungen seitens der UdSSR und der VRP geworden, ${ }^{191}$ sondern auch zur Metapher der verbrecherischen

186 Kosicki: Les lieux de la mémoire polonaise de Katyn, 280.

187 In den ersten sieben Jahren seines Bestehens zählte das Museum ca. 65.000 Besucher. Łojek: Muzeum Katyńskie, 137.

188 Bartoszewicz, Dariusz: Wstyd w Muzeum Katyńskim [Scham im Katyń-Museum]. In: Gazeta Wyborcza vom 7.1.2010, Online-Ausgabe, URL: http://warszawa.gazeta.pl/ warszawa/1,34889,7427197,Wstyd_w_Muzeum_Katynskim.html (am 20.5.2012); Michalak, Ada: Jutro otwarcie Muzeum Katyńskiego na Cytadeli [Morgen wird das KatyńMuseum in der Zitadelle eröffnet]. In: Rzeczpospolita vom 16.9.2015, Online-Ausgabe, URL: http://www.rp.pl/Historia/309169897-Jutro-otwarcie-Muzeum-Katynskiego-naCytadeli.html (am 20.11.2016).

189 Vorträge und Diskussionen in einem inoffiziellen, nichtöffentlichen Rahmen zu den Opfern des Stalinismus während und nach dem Krieg wurden bereits seit der zweiten Hälfte der 1970er-Jahre im Rahmen der von Oppositionsgruppen organisierten »fliegenden Universitäten« organisiert. In den Jahren 1980/81 konnten sie auch »offiziell oder halboffiziell« geführt werden. Ruchniewicz: Die Erinnerung an die Opfer, 35.

190 Ebd., 35; Grabski: Zarys historii historiografii, 242.

191 Ruchniewicz: Die Erinnerung an die Opfer, 35. 
sowjetischen Politik gegenüber Polen insgesamt, wie der Text in einem Begleitheft zur Ausstellung »Zginęli w Katyniu« in Łódź 1990 prägnant formuliert:

Sie starben nicht nur in Katyń, obwohl Katyń - bislang - der einzige bekannte Ort des Massenmordes ist. Damit ist er zu einem Symbol geworden. Einem Symbol für all das Leid, das polnischen Staatsbürgern durch das stalinistische System im sowjetischen Staat angetan wurde. ${ }^{192}$

Ende der 1980er-Jahre nahm selbst die polnische Regierung unter Einfluss von Perestroika (perestrojka / Umbau) und Glasnost (glasnost'/ Offenheit, Transparenz) in der UdSSR das Schlagwort der »weißen Flecken« auf. So berief man 1987 eine sowjetisch-polnische Historikerkommission zur Aufklärung der Morde in Katyń. ${ }^{193}$ Am 13. April 1990 schließlich gestand die sowjetische Regierung in einer Pressemitteilung offiziell die Verantwortung des NKVD für die Morde ein und bezeichnete diese als »eines der größten Verbrechen des Stalinismus ${ }^{194}$

In den staatlichen kulturhistorischen Museen fanden die immer stärker artikulierten Fragen nach sowjetischen Verbrechen und das Wissen darüber, insbesondere über die Massaker von 1940 in Katyń und anderen Orten, jedoch keinen Ausdruck. Bei politisch derart schwierigen Themen schwiegen die Institutionen bis zu Beginn des politischen Umbruchs 1989 und beteiligten sich (noch) nicht an der Vermittlung und Verbreitung der immer zahlreicher zur Verfügung stehenden Informationen. Ein Grund hierfür mag die immer noch drohende Zensur gewesen sein, auch wenn sie im Bereich historischer Schauen gerade in der zweiten Hälfte der 1980er-Jahre deutlich abnahm. ${ }^{195}$ Gleichwohl interessierten sich die Mitarbeiter der Museen offensichtlich für die Benennung und Aufarbeitung der Verbrechen der Sowjetunion (und der Vertreter des polnischen sozialistischen Staates), wie die Welle der Sonderausstellungen zu diesen Themen seit Ende 1989 zeigt.

Obwohl also - wie am Beispiel der Vielzahl der Sonderausstellungen ersichtlich - ein Bewusstsein für die notwendige Ergänzung und "Entlügung" (odkłamywanie) der historischen Narrative seitens der Museen vorhanden war, ging die Anpassung der Dauerausstellungen in der ersten Hälfte der

192 Budziarek, Marek: Zginęli w Katyniu [Begleitheft zur Ausstellung in Łódź]. AMMŁ, teczka $6 / 68,2$.

193 Sanford: Katyn and the Soviet Massacre, 215.

194 Przewoźnik/Adamska: Katyń, 450.

195 Gespräch mit Ryszard Iwanicki, Mitarbeiter des Martyrologiemuseums Radogoszcz, am 2. November 2010. Der Rückgang der Zensur war in der zweiten Hälfte der 1980er-Jahre ein allgemeines Phänomen in der VRP. Pawlicki, Aleksander: Sonderwege der Zensurpolitik in der Volksrepublik Polen. In: Bock, Ivo (Hg.): Scharf überwachte Kommunikation. Zensursysteme in Ost(mittel)europa (1960er-1980er Jahre). Berlin 2011, 209-361, hier 217; Ruchniewicz: Zeitgeschichte in Polen, 41. 
1990er-Jahre kaum voran. Dafür kann man zwei wesentliche Ursachen annehmen: zum einen waren diese organisatorischer und finanzieller Natur. Die untersuchten Institutionen unterlagen nach 1989 bis etwa Mitte des folgenden Jahrzehnts einem umfassenden rechtlichen und organisatorischen Transformationsprozess. ${ }^{196}$ Zudem war die finanzielle Situation der Museen äußerst angespannt ${ }^{197}$ - ein Problem, das Ende der 1980er- und in der ersten Hälfte der 1990er-Jahre die hohe Inflationsrate noch verschärfte. ${ }^{198}$ Die mit einem großen zeitlichen, personellen und materiellen Aufwand verbundene grundlegende Überarbeitung oder gar Neukonzeption von Dauerausstellungen wurde angesichts der schwierigen Lage der meisten Institutionen in den ersten Jahren der Systemtransformation daher kaum unternommen. Selbst für die Ergänzung bestehender Schauen um einzelne Themen waren oftmals weder der Raum noch die notwendigen Mittel vorhanden. Die 1990 und 1991 neu eröffneten Präsentationen waren dagegen bereits Ende der 1980er-Jahre vorbereitet worden. Die Mittel hierfür hatte man bereits in den Etats eingeplant bzw. aufgewendet; ihre Konzepte erfuhren nach Beginn des politischen Umbruchs 1989 nur geringe Korrekturen und Ergänzungen. Gerade im Fall von kleineren Museen mag ein weiterer Grund für das Fehlen wesentlicher Veränderungen der Ausstellungsnarrative die stärkere Fokussierung auf die lokale und regionale Geschichte gewesen sein, die eine Anpassung um die genannten Themenbereiche den Kuratoren als weniger dringlich erscheinen ließ. Zum anderen fehlten in diesem Zeitraum ausgearbeitete Synthesen oder Muster der neuen Interpretation der Rolle des ehemaligen »Großen Bruders« im Krieg, an die die Kuratoren sich hätten anlehnen können. Die Debatte um die Neubewertung der Sowjetunion in der Geschichte Polens der Jahre 1939 bis 1944/45, die eng verbunden war mit der Bewertung der Nachkriegsentwicklungen, hatte gerade erst begonnen bzw. war noch in vollem Gange. ${ }^{199}$

196 Folga-Januszewska: Muzea w Polsce (2009), 26f. Die strukturellen Entwicklungen der polnischen Museumslandschaft seit 1945 skizziert Kalinowski, Konstanty: Veränderungen in der Museumslandschaft Polens. Zmiany w krajobrazie muzeów w Polsce. In: Museumskunde 65/2 (2000), 56-68.

197 Die finanziellen Mittel der Institutionen waren gerade in der ersten Hälfte der 1990erJahre deutlich rückläufig. Folga-Januszewska: Muzea w Polsce (2009), 21.

198 Passowicz: Kronika działalności za rok 1990, 188; Kaliński, Janusz/Landau, Zbigniew: Gospodarka Polski w XX wieku [Die Wirtschaft Polens im 20. Jahrhundert]. Warszawa 1998, 362 f., 374 f.; Borodziej: Geschichte Polens, 385, 389.

199 Ruchniewicz: Zeitgeschichte in Polen, 42-49; Łukasiak-Mikłasz, Joanna (Hg.): Ofiary czy współwinni. Nazizm i sowietyzm w świadomości historycznej [Opfer oder Mitschuldige. Nazismus und Sowietismus im historischen Bewusstsein]. Warszawa 1997. Darin v.a.: Wóycicki, Kazimierz: Wstęp [Einleitung], 7-12; Paczkowski, Andrzej: Czy historycy dokonali »obrachunku« z PRL? [Haben die Historiker eine "Abrechnung" mit der VRP vorgenommen?], 13-29; Kersten, Krystyna: Czy można rozliczyć się z 
Die untersuchten historischen Museen unternahmen während dieser noch laufenden Diskussionen nicht den Versuch, eigene Interpretationen zu präsentieren, deren Akzeptanz noch nicht absehbar war.

Zusammenfassend lässt sich somit für diesen ersten Zeitraum unmittelbar nach Beginn der politischen Transformation festhalten, dass die Dauerausstellungen der Museen fast unverändert blieben, während in einer Vielzahl von Sonderausstellungen die Verbrechen des sowjetischen Regimes an Polen dargelegt wurden. Erstere arbeiteten weiterhin mit den Interpretationsangeboten der 1960er- bis 1980er-Jahre, die zwischen einer einseitigen Hervorhebung der positiven Rolle der Roten Armee als »Befreier« und der NichtThematisierung der Sowjetunion changierten. Die überwiegende Mehrzahl der Dauerausstellungen historischer Museen blieb somit fast ein Jahrzehnt lang hinter dem Diskussions- und Wissensstand am Ende der 1980er-Jahre zurück, der durch Veröffentlichungen neuer Dokumente ${ }^{200}$ und Publikationen des Exils bereits um grundlegende Informationen erweitert war. ${ }^{201}$

\subsection{Inklusion des »neuen« alten Feindbildes}

Deutlich mehr Platz räumte man der Darstellung der Sowjetunion und ihrer Rolle in den Jahren 1939 bis 1945 erst im Zuge umfassenderer Überarbeitungen bestehender Dauerausstellungen und der Neuschaffung von Präsentationen in den Jahren 1998 bis 2003 ein; lediglich im Historischen Museum der Stadt Lublin fand dies bereits 1995 statt. In fast allen neu eröffneten Präsentationen benannte man nun klar den Einmarsch der Sowjetunion auf polnisches Territorium im September 1939. Meist geschah dies in Form einer kartografischen Darstellung, die den Vormarsch deutscher und sowje-

historią PRL? [Kann man mit der Geschichte der VRP abrechnen?]. In: Borodziej, Włodzimierz (Hg.): Obrachunki z historią [Abrechnungen mit der Geschichte]. Warszawa 1997, 15-28.

200 Nicht nur war 1990 die sowjetische Verantwortung für die Massaker in Katyń offiziell geworden; seit 1986 erfolgte »[schrittweise] [d]ie Veröffentlichung des zuvor nur sehr unvollständig tabuisierten Dokuments«, d.h. des geheimen Zusatzprotokolls des Hitler-Stalin-Paktes, in dem die Aufteilung der Territorien Ostmitteleuropas zwischen dem nationalsozialistischen Deutschland und der UdSSR beschlossen worden war. Dessen Existenz wurde in der zweiten Hälfte der 1980er-Jahre somit einer breiteren polnischen Öffentlichkeit zugänglich, unter anderem auch durch Diskussionen, die in der Presse geführt wurden. Lipinsky, Jan: Das Geheime Zusatzprotokoll zum deutschsowjetischen Nichtangriffsvertrag vom 23. August 1939 und seine Entstehungs- und Rezeptionsgeschichte von 1939 bis 1999. Frankfurt am Main 2004, 495 f.

201 Ruchniewicz: Die Erinnerung an die Opfer, 35-37; Stobiecki, Rafał: Rok 1945 w polskiej debacie historycznej [Das Jahr 1945 in der polnischen Geschichtsdebatte]. In: Dzieje Najnowsze 37 / 4 (2005), 5-17, hier 10 f.; Górny: From the Splendid Past, $111 \mathrm{f}$. 
tischer Truppen auf polnisches Territorium im September $1939^{202}$ bzw. die Aufteilung der polnischen Gebiete zwischen der UdSSR und Deutschland skizzierte. ${ }^{203}$ In der Ausstellung des Gefängnismuseums Pawiak von 2001 schilderte man zudem die dem deutschen Angriff von 1939 vorausgegangenen politischen und diplomatischen Entwicklungen, namentlich den HitlerStalin-Pakt vom 23. August 1939 - in Polen als "Ribbentrop-Molotov-Pakt» bezeichnet - sowie den Deutsch-Sowjetischen Grenz- und Freundschaftsvertrag vom 28. September 1939, in dem der Grenzverlauf zwischen der UdSSR und dem Deutschen Reich endgültig festgelegt wurde. ${ }^{204}$ Die Schauen führten neben dem nationalsozialistischen Deutschland somit die Sowjetunion als zweiten Angreifer und Besatzer Polens als explizites Feindbild ein. Mit der Aufnahme dieses breiteren Kontextes des Kriegsbeginns gingen viele der musealen Narrative erstmals über den bis dato verfolgten lokalen und regionalen Rahmen der historischen Ereignisgeschichte hinaus und inkludierten Ereignisse von gesamtstaatlicher bzw. nationaler Bedeutung.

Die militärischen Hintergründe des Endes der deutschen Besatzung wurden dagegen in den neuen Ausstellungen - in Kontinuität der Praxis ihrer Vorgängerinnen - weiterhin meist nicht dargestellt. Die einzelnen Narrative endeten wie bislang mit Ereignissen von lokaler Bedeutung, so etwa im Fall der neu geschaffenen Präsentation des Historischen Museums der Stadt Łódź mit der Liquidierung des Ghettos Litzmannstadt oder im Fall der Schauen des Gefängnismuseums Pawiak und des Museums Radogoszcz mit der Zerstörung des Gefängnisses bzw. dem Massaker an den Häftlingen unmittelbar vor Abzug der Deutschen. Im Historischen Museum der Stadt Lublin bezeichnete man zwar den Einmarsch sowjetischer und polnischer Truppen 1944 weiterhin als »Befreiung «. ${ }^{205}$ Daneben wurde jedoch auch die ambivalente Situation der »Doppelherrschaft« im Juli 1944 in der Stadt präsentiert, während der sowohl die Vertreter der polnischen Exilregierung in London als auch das von der Sowjetunion gestützte kommunistische Polnische Komitee der Nationalen Befreiung die Repräsentation polnischer Staatlichkeit

202 Karte »Hauptangriffsrichtungen der deutschen und sowjetischen [sowiecka] Aggression«. MHK-Pomorska-Straße, Tafel 2; Karte »Der Septemberfeldzug des Jahres 1939«. MTNŁ-Radogoszcz, Sektion zum September 1939 (ohne Titel).

203 MNW-Pawiak, Sektion »Die Vierte Teilung Polens«.

204 Diese werden im Museum Pawiak mithilfe von Berichten in der westeuropäischen Presse sowie Karten illustriert, auf denen die jeweiligen Grenzen der Besatzungsgebiete eingezeichnet sind. MNW-Pawiak, Sektion »Die vierte Teilung Polens«. Auch im Ausstellungsführer zur Schau der Abteilung Pomorska-Straße des MHK - nicht jedoch in der Schau selbst - wird der Ribbentrop-Molotov-Pakt als Ursache des Angriffs auf Polen benannt. Salwiński: Wystawa stała, 37, 39.

205 So die Objektbeschriftung zu einer Fotografie: „Die Befreiung Lublins von der hitleristischen Besatzung. Defilee polnischer Soldaten, 1944«. MLL-Krakauer Tor, Sektion "Zweiter Weltkrieg". 
für sich beanspruchten. ${ }^{206}$ Die schwierige politische und militärische Situation nach Abzug der Deutschen, die Konkurrenz zwischen den mit der Londoner Exilregierung verbundenen Widerstandsgruppen und dem von der Sowjetunion gestützten kommunistischen Lager wurde somit erstmals museal präsentiert. Den Kampf um die Nachkriegsentwicklung in Polen und die entscheidende Rolle der UdSSR dabei stellte man hier bereits dar, ${ }^{207}$ während die meisten anderen Museen das schwierige Thema des Endes der deutschen Besatzung noch vermieden. Auch in dieser Schau wurde keine Bewertung der Folgen des Kriegsendes und der dominanten Rolle der UdSSR vorgenommen. Die Darstellung verwies die Besucher jedoch darauf, dass es zum Zeitpunkt des Einmarsches der Roten Armee verschiedene politische Kräfte und damit verbundene unterschiedliche Vorstellungen über die Zukunft Polens gab, die Richtung der politischen Nachkriegsentwicklung demnach nicht einseitig vorgezeichnet war.

Thematisch weiter ging in diesem Zeitraum allein die neue Ausstellung in der Pomorska-Straße in Krakau aus dem Jahr 1998. Wie in der Vorgängerausstellung wurden die Kämpfe der Roten Armee im Januar 1945 um die Stadt selbst zwar weiterhin ohne normative Zuschreibung präsentiert. ${ }^{208}$ Das museale Narrativ jedoch verlängerte man in die Nachkriegszeit: Aufgenommen wurde nun der "Zeitraum des Stalinismus « ${ }^{209}$, dessen Beginn auf den Tag des Endes der deutschen Besatzung der Stadt, den 18. Januar 1945, datiert wurde. Der folgende Ausstellungsabschnitt - „Gegen den Kommunismus« (Przeciw komunie) $-{ }^{210}$ fokussierte zum einen auf den Widerstand einzelner Partisaneneinheiten gegen die neue kommunistische Vorherrschaft und zum anderen auf das Vorgehen des »Woiwodschaftsamtes für Öffentliche Sicherheit" (Wojewódzki Urząd Bezpieczeństwa Publicznego, WUBP) gegen diese Gruppierungen. ${ }^{211}$ Diese Darstellung konzentrierte sich auf den innerpolnischen Kampf der Nachkriegszeit. Den Kontext dieser Auseinandersetzungen verortete man klar in einer abgrenzenden Gegenüberstellung der für ein

206 Präsentiert werden sowohl das Manifest des PKWN als auch die Erklärung des Delegierten der Polnischen Exilregierung in London im Bezirk Lublin Władysław Cholewa. Ebd.

207 Mehrere Fotografien vermitteln, dass die Nachkriegsentwicklung von Moskau aus gesteuert wurde: Eine davon zeigt die "Landung der Mitglieder des PKWN aus Moskau«, eine andere »Sowjetische Generäle auf einer Tribüne vor der Hauptpost in Lublin«. Objektbeschriftungen. Ebd.

208 Die entsprechende Ausstellungstafel bzw. der Themenabschnitt war neutral mit den Worten »Januar 1945« überschrieben. Präsentiert wurde neben einem Foto von »Sowjets" (Sowieci), d.h. sowjetischen Soldaten in Krakau, eine Karte, auf der der »Ablauf der Januaroffensive 1945 der Roten Armee« im Raum Krakau eingezeichnet war. Objektbeschriftung. MHK-Pomorska-Straße, Tafel 34.

209 MHK-Pomorska-Straße, Titel der Tafel 35.

210 MHK-Pomorska-Straße, Titel der Tafel 37.

211 MHK-Pomorska-Straße, Tafeln 37 bis 40. 
unabhängiges Polen kämpfenden Widerstandsgruppen einerseits und der "mit den Sowjets alliierten ${ }^{212}$ Kräfte andererseits. Die Sowjetunion wurde damit in erster Linie als Feind präsentiert: Zwar verdrängte die Rote Armee die Deutschen aus der Stadt und Region, ihre folgende Präsenz bzw. ihr Einfluss bedeuteten jedoch eine Fortsetzung der Besatzung, die den weiteren Kampf für die Unabhängigkeit des Landes erforderlich machte. Die Ambivalenz der Rolle der UdSSR im polnischen Kriegsnarrativ, die noch in der Vorgängerschau offenbar war, gab man hier auf; die Darstellung erfolgte nun in der rückblickenden Perspektive ihrer negativen Bewertung für die Nachkriegsentwicklung des Landes - der Etablierung der sozialistischen polnischen Regierung. In der Darstellung der mit der Sowjetunion verbundenen neuen politischen Kräfte des Landes als "Verräter « wurde diese negative Interpretation auf die dahinterstehende Macht übertragen. ${ }^{213}$

In allen untersuchten Präsentationen blieb das Feindbild der Sowjetunion dabei abstrakt. Die UdSSR oder der NKVD als ihr Repräsentant wurden zwar genannt. Konkrete Individuen, etwa einzelne (politische) Verantwortliche oder auch Einzeltaten machte man dagegen nicht kenntlich. Lediglich die Illustration der Kämpfe der Roten Armee gegen die Deutschen sowie der Verweis auf die Aktivitäten des NKVD vermittelten ein militärisches, mit Gewaltausübung konnotiertes Bild der Sowjetunion. Ihre negative Wahrnehmung, die Gefahr, die von ihr ausging, wurde dabei durch die Thematisierung der Massenerschießungen von Katyń sowie durch implizite Verweise auf die Deportationen von Polen in die UdSSR verstärkt. So fand sich in der Schau des MHK ein Propagandaplakat der deutschen Besatzungsmacht von 1944, das auf die Gefahr vonseiten der UdSSR verwies und auf die Mobilisierung von Polen gegen diesen "gemeinsamen Feind « zielte: Unter einem Totenkopf und einem roten Stern mit Hammer und Sichel prangte der Schriftzug "Etwa wieder Sibirien? Dein Vater starb in der sibirischen Katorga. Deinen Bruder ermordete man in Katyń. Denk an Dein Schicksal und das Deiner Familie!« In der Kurzbiografie von General August Emil Fieldorf, einem aus Krakau stammenden führenden Untergrundkämpfer, fand Erwähnung, dass er 1945 in die UdSSR deportiert worden war und erst 1947 ins Land zurückkehren konnte, wo er 1952 zum Tode verurteilt worden war. Nach 2003 wurde zudem ein Rahmen mit Fotografien der polnischen Soldatenfriedhöfe in Katyń, Mednoe

212 Mit dem Zusatz "Mit den Sowjets alliiert« (W sojuszu z sowjetami) war bereits zuvor die Darstellung der Aktivitäten der »Volksarmee« (Armia Ludowa, AL) und der »Volksgarde« (Gwardia Ludowa, GL) versehen. MHK-Pomorska-Straße, Tafel 30.

213 Im Themenabschnitt »Der Zeitraum des Stalinismus « präsentierte man unkommentiert ein Foto, auf dem der auf eine Hauswand gemalte Schriftzug »PPR [Polska Partia Robotnicza/»Polnische Arbeiterpartei«] = Verräter« zu lesen war. MHK-Pomorska-Straße, Tafel 36. 
und Charkov angebracht, zusammen mit Informationen über die aus dem Süden Polens stammenden Opfer der Massenmorde. ${ }^{214}$

Auch in fast allen bis 2003 neu gestalteten Ausstellungen der übrigen $\mathrm{Mu}-$ seen fügte man Verweise auf sowjetische Kriegsverbrechen ein, für die in allen Präsentationen stellvertretend das Thema »Katyń« stand. ${ }^{215}$ Ein Verweis auf die Massenerschießungen wurde beispielsweise in der Schau des Historischen Museums der Stadt Lublin integriert: In einer Vitrine zeigte man die Titelseite der Zeitung Nowy Głos Lubelski (Neue Lubliner Stimme) vom 17. April 1943, deren Leitartikel vom Fortschritt der Untersuchungen von Massengräbern polnischer Offiziere in der Nähe von Katyń berichtet. ${ }^{216}$ In ähnlicher Weise fand das Thema Einzug in die Dauerausstellung des Historischen $\mathrm{Mu}-$ seums der Stadt Łódź: In der Schau wurde ein Aufruf der Besatzungsorgane von 1943 gezeigt, der von den Exhumierungsarbeiten bei Smolensk unter Teilnahme polnischer Arbeiter und Delegierter aus Posen und Litzmannstadt berichtete. ${ }^{217}$ Die Schau des Museums Radogoszcz aus dem Jahr 2003 räumte den Massakern in Katyń, Mednoe und Charkov sogar umfangreich Platz ein. Ausführlich dargestellt wurden sowohl der Gesamtumfang des Verbrechens als auch die Zahl der aus der Region stammenden Opfer, Fotografien und Briefe einiger von ihnen sowie Objekte, die während der Exhumierungen in den Jahren 1991 bis 1997 gefunden wurden. ${ }^{218}$ Die Präsentation dreier Glas-

214 In den kurzen Begleittexten wurde der sowjetische Geheimdienst als Täter kurz genannt. Die Fotos in diesem Rahmen entstanden - so die in der Ausstellung zu lesende Angabe - im Jahr 2001. Im Ausstellungsführer von 2003 werden sie noch nicht erwähnt. Daher ist davon auszugehen, dass dieses Ausstellungselement erst nach 2003 in die Schau aufgenommen wurde.

215 Lediglich in der neuen Schau des Gefängnismuseums Pawiak von 2001 fehlten diese.

216 Dieser Hinweis auf den deutschen Fund der Massengräber polnischer Opfer des NKVD im Jahr 1943, der für Propagandazwecke in den besetzten polnischen Gebieten medial weit verbreitet worden war, ist jedoch nur für aufmerksame Besucher zu bemerken, die den Text des ausgestellten Blattes lesen. Die Objektbeschriftung verweist lediglich auf den Propagandazweck der Zeitung: " gadzinówka< [Propagandapresse] - deutsche Propagandazeitung in polnischer Sprache, die in den Jahren 1940-1944 auf dem Gebiet des Distrikts Lublin verbreitet wurde«. Vitrine 4. MLL-Krakauer Tor, Sektion »Zweiter Weltkrieg«. Diese Zeitung wird spätestens seit 1994 in der Schau gezeigt. Protokół odpowiedzialności. Wykaz eksponatów na wystawie »Historia miasta Lublina«. Unterschrift vom 22.9.1994. AMLL, Oddział Historii Miasta Lublina, ohne Signatur, [6]. Darüber hinaus wird bei der Kurzinformation zu General Mieczysław Smorawiński, dem Leiter der Verteidigung Lublins im September 1939, angegeben: »ermordet in Katyń.« Bei der Vorstellung des Delegierten der Londoner Exilregierung im Bezirk Lublin, Władysław Cholewa, sowie des Anführers der Heimatarmee im Bezirk Lublin, Kazimierz Tumidajski, wird erwähnt, dass sie zwischen 1944 und 1947 in mehreren Orten in der UdSSR interniert waren. MLL-Krakauer Tor, Sektion »Zweiter Weltkrieg«.

217 MMŁ, Sektion »Lodsch - Litzmannstadt«.

218 Gezeigt wurde daneben auch derselbe Aufruf wie in der Schau des MMŁ. MTNŁ-Radogoszcz, Sektion »In Gefangenschaft«. 
gefäße mit Erde von den drei Erschießungsstätten verstärkte noch die martyrologische Deutung des Verbrechens und die besondere Gewichtung des Ereignisses innerhalb des Ausstellungsnarrativs. ${ }^{219}$

Durch den Einbezug der Massaker in Katyń und anderen Orten in die Ausstellungsnarrative wurde das Feindbild des zweiten Besatzers Polens als verbrecherischer Macht, die internationale Konventionen der Kriegsführung gebrochen hatte, museal etabliert, auch wenn diese Ereignisse über die unmittelbare Geschichte der jeweiligen Region hinausgingen. Die für die Morde Verantwortlichen blieben jedoch weiterhin im Hintergrund. Lediglich im Museum Radogoszcz benannte man »die Entscheidung des Politbüros der VKP(B) [Vsesojuznaja kommunističeskaja partija (bol'ševikov)/ /Kommunistische Allunions-Partei (Bolschewiki)«] vom 5.3.1940« als Grundlage der Exekutionen. ${ }^{220}$ Unentschieden blieb ebenfalls die Bewertung der Rolle der Roten Armee und der Sowjetunion bei Kriegsende.

Es scheint, als sei in diesem Zeitraum trotz der Einführung der Sowjetunion als Aggressor in die musealen Erzählungen noch keine endgültige Interpretation dieses "neuen « Feindes gefunden worden. ${ }^{221}$ Während die Debatten in den 1990er-Jahren über die Bewertung der Volksrepublik und des Einflusses der UdSSR auf die innerpolnischen Entwicklungen der Jahre 1944 bis 1989 anhielten, die eng mit der Bewertung der Rolle Letzterer bei Kriegsende verbunden waren, ${ }^{222}$ zögerten die Kuratoren der Museen weiterhin, eine eindeutige Interpretation der Sowjetunion gerade in Bezug auf das Ende der deutschen Besatzung vorzunehmen. Zwar wurde die Tendenz hin zu ihrer negativen Gesamtbewertung offenbar. Als Feindbild, dessen Gestalt weder in wissenschaftlichen noch publizistischen Debatten abschließend definiert war, blieb die UdSSR in den Präsentationen jedoch im Hintergrund. Die wenigen Ausstellungselemente, die sich mit ihr befassten, entsprachen dem Informations- und Diskussionsstand vom Ende der 1980er- bzw. Anfang der 1990er-Jahre.

219 Ausführlicher hierzu siehe Teil 3, Kapitel 1.2.

220 Thementext. MTNŁ-Radogoszcz, Sektion »In Gefangenschaft«.

221 Die Sowjetunion als Feindbild war in dem Sinne neu, als sie bis 1989 in den Ausstellungen rein positiv präsentiert worden war. Da zugleich ihre Darstellung - wie eingangs erwähnt - auf das deutlich ältere Feindbild »der Russen« rekurriert, wird die Sowjetunion in ihrer musealen Präsentation in dieser Studie als »neues` altes Feindbild« bezeichnet.

222 Paczkowski: Czy historycy dokonali »obrachunku« z PRL; Stobiecki, Rafał: Die Zeitgeschichte in der Republik Polen seit 1989/1990. In: Nützenadel, Alexander/Schieder, Wolfgang (Hg.): Zeitgeschichte als Problem. Nationale Traditionen und Perspektiven der Forschung in Europa. Göttingen 2004, 329-346, hier 336-341; Górny: From the Splendid Past, 124-126; Ruchniewicz: Zeitgeschichte in Polen, 42-49. 


\subsection{Zwischen Dämonisierung und Neutralität - neue Ausprägungen des musealen Bildes der Sowjetunion, 2004-2010}

Mit der seit Beginn des Museumsbooms einsetzenden Pluralisierung musealer Geschichtsdeutungen haben sich in den untersuchten Dauerausstellungen zwei unterschiedliche Interpretationsmuster der Vergangenheit herauskristallisiert, die sich auch auf die Darstellung der Sowjetunion in den Jahren 1939 bis 1945 auswirken. Sie oszillieren zwischen zwei Polen: einerseits einer Rückbesinnung auf martyrologische Interpretationsmuster, die mit einer regelrechten Dämonisierung des Bildes der UdSSR einhergehen und stereotype Präsentationspraxen aus der Zeit der VRP in Bezug auf »die Hitleristen " aufgreifen. Der andere Pol wird markiert durch Schauen, die stereotype Geschichtsbilder zu hinterfragen und zu vermeiden suchen.

Zugleich wird in den Schauen, die seit 2004 entstanden sind, die inzwischen erfolgte Durchsetzung eines dominanten Diskurses zum Zweiten Weltkrieg sichtbar. Ein zentrales Beispiel hierfür betrifft die Darstellung des Kriegsanfangs. Die neu entstandenen Dauerausstellungen, die eine allgemeine Einordnung der Ereignisse des Weltkriegs in einen über die regionale Geschichte hinausgehenden, gesamtpolnischen Kontext vornehmen - dies betrifft sowohl die Schau des Museums des Warschauer Aufstands als auch diejenige in der Emaillewarenfabrik Oskar Schindlers in Krakau - inkludieren mittlerweile bei der Schilderung der Ereignisse des September 1939 selbstverständlich sowohl den deutschen Angriff am 1. September als auch den sowjetischen Einmarsch am 17. September. ${ }^{223}$ Die Sowjetunion wird damit als einer der zwei Angreifer und Besatzer Polens in die Schauen eingeführt, unabhängig davon, ob die Rote Armee in den jeweils thematisierten Städten und Regionen 1939 tatsächlich einmarschiert ist. Ihre Rollenzuschreibung als zwei-

223 In der Krakauer Schau erfolgt die Darstellung dieser Ereignisse im Themenraum "Kriegsausbruch« mithilfe zweier multimedialer Präsentationen, die die deutschen, sowjetischen und polnischen Truppenbewegungen auf polnischem Territorium sowie im südlichen Polen rund um Krakau im Jahr 1939 mithilfe von animierten Karten visualisieren. MHK-Schindler-Fabrik, Sektion 4: Kriegsausbruch. In der Schau des MPW erscheinen der 1. und 17. September in einer Zeitleiste, die die wesentlichen Ereignisse des Weltkriegs zu Beginn der Ausstellung zusammenfasst. Daneben wird in einer der ersten Sektionen der Ausstellung, die den Ereignissen in verschiedenen Regionen des besetzten Polens während des Kriegs gewidmet ist, ebenfalls eine Multimediapräsentation gezeigt, die wesentliche Ereignisse im Vorfeld und während des Kriegs im Überblick benennt. MPW, Sektion 6: Besatzung. Lediglich die Schau im Historischen Museum in Wrocław weicht von diesem Muster ab, da sie sich - wie bereits in Kapitel 3 der Einleitung beschrieben - auf die lokale und regionale Geschichte konzentriert und eine neue Perspektive auf die Stadtgeschichte zu entwerfen versucht, außerhalb des Kanons national-polnischer Geschichtserzählungen. 
ter Aggressor und negativer Akteur - im Sinne einer Zusammenarbeit mit dem nationalsozialistischen Deutschland - ist damit auch in den musealen Präsentationen inzwischen etabliert. Ein weiteres Element, das einen festen Platz in der Darstellung der Besatzungszeit einnimmt, ist die Referenz auf die Massenmorde des NKVD in Katyń und anderen Orten im Jahr 1940. Auch in der Dauerausstellung der Schindler-Fabrik findet sich dieses Thema; ${ }^{224}$ ebenso enthält die Schau des MPW einen Hinweis. ${ }^{225}$ Das Schlagwort "Katyń" hat sich somit auch museal zum zentralen Symbol sowjetischer Verbrechen an Polen während des Kriegs entwickelt und gehört zum Kanon der Darstellung des Zweiten Weltkriegs.

Deutliche Unterschiede zwischen einzelnen Schauen in der Präsentation von UdSSR und Roter Armee finden sich hingegen in ihrer allgemeinen Kontextualisierung im Ausstellungsnarrativ, vor allem mit Bezug auf das Kriegsende und seine Folgen, wie im Weiteren gezeigt wird.

\section{Die Inklusion der Sowjetunion in das national-martyrologische Geschichtsbild}

Den ersten der zwei genannten Pole der Darstellung repräsentiert die neue Dauerausstellung des Museums des Warschauer Aufstands. Das in den 1990erJahren in historischen Schauen bereits eingeführte negative Bild der Sowjetunion wird im MPW durch eine mit normativen Zuschreibungen arbeitende Symbolsprache und Rhetorik emotional aufgeladen und negativ verstärkt.

Auffällig ist zunächst die rein militärische Kontextualisierung der UdSSR als Besatzungsmacht und Kriegsgegner - sie erscheint in der Erzählung überwiegend über das Agieren der Roten Armee. Der Schwerpunkt der Darstellung liegt dabei auf der Betonung der Unrechtmäßigkeit ihres Handelns, das heißt ihrer Verstöße gegen internationales Recht sowie gegen geltende zwischenstaatliche Verträge. Dies vermittelt insbesondere ein stark wertender Sprachgebrauch. So wird beispielsweise der Angriff sowohl Deutschlands als

224 Bei der Schilderung des Alltags der Jahre 1943 wird die Entdeckung der Massengräber bei Katyń durch die Deutschen in einem Bereichstext dargestellt und deren propagandistische Verwendung durch die Besatzer zum Schüren antisowjetischer Stimmungen in der Bevölkerung klar benannt. Die Verantwortung des NKVD für die Massaker wird deutlich gemacht; eine ausführlichere Schilderung der deutsch-sowjetischen Beziehungen im Krieg findet jedoch nicht statt. MHK-Schindler-Fabrik, Sektion 15: Alltag, 1943, Abschnitt »Katyń».

225 Bei der Darstellung des Umgangs der zwei Besatzungsmächte mit der katholischen Kirche und ihrer Vertreter wird in einem Bereichstext darauf verwiesen: „Viele sterben in Katyń oder werden nach Osten deportiert«. Diese beiläufige Verwendung des Ortsnamens macht deutlich, dass die Ausstellungsmacher wie selbstverständlich davon ausgehen, dass den Besuchern die Bedeutung dieses Schlüsselbegriffs bekannt ist. Bereichstext: Die katholische Kirche in den Jahren des Zweiten Weltkriegs«. MPW, Sektion 6: Besatzung. 
auch der UdSSR auf Polen als »Überfall« (napaść) bezeichnet, während das Vorgehen japanischer Truppen in Pearl Harbour, das zum Kriegseintritt der USA führte, in neutralerer Ausdrucksweise als "Angriff« (atak) beschrieben wird. ${ }^{226}$ In der weiteren Präsentation zieht man eine Parallele zwischen den verbrecherischen Aktivitäten der beiden Okkupanten:

Am 17. September schließt sich die Sowjetunion Deutschland an und bricht damit die mit Polen getroffenen Verträge. [...] Von den ersten Tagen der beiden Besatzungen an häufen sich auf dem Gebiet Polens präzise geplante Exekutionen, Deportationen, Aussiedlungen, Verfolgungen. ${ }^{227}$

In diesem Aspekt unterscheidet sich die Darstellung der sowjetischen Handlungen kaum von jener der deutschen Besatzer, die als brutale, hinterhältige Akteure und unehrenhafte Militärs charakterisiert werden. Diese eindeutige Darstellung beider Feinde verstärkt noch die Opposition zu den polnischen "Soldaten", den als rechtmäßig und ehrenhaft agierend präsentierten Mitgliedern des polnischen Widerstands. ${ }^{228}$ Dies schafft eine umso deutlichere Abgrenzung zwischen der als Repräsentanten des »Guten« skizzierten eigenen Gemeinschaft der (widerständigen) polnischen Nation und den als Vertretern des »Bösen« schlechthin präsentierten zwei Besatzungsmächten.

Ein weiteres Charakteristikum ist die starke Personalisierung der Feinddarstellung, das heißt die Fokussierung auf führende politische und militärische Entscheidungsträger. ${ }^{229}$ Insbesondere wird die Person Iosif Stalins mit der UdSSR gleichgesetzt bzw. das Handeln ihrer Repräsentanten, wie der Roten Armee oder des NKVD, auf die explizite und unmittelbare Entscheidung und den Willen des politischen und militärischen Führers der Sowjetunion zurückgeführt, wie die folgenden Beispiele illustrieren:

226 MPW, Zeitleiste zu Beginn der Dauerausstellung, vor der Sektion 3: Der Aufstand nach 60 Jahren.

227 Thementext »Kriegsbeginn«. MPW, Sektion 6: Besatzung.

228 Zur Verwendung der Bezeichnung »Soldat« und ihrer Funktion in der historischen Konstruktion der Wir-Gemeinschaft der Polen im Krieg siehe Teil 3, Kapitel 2.2; vgl. auch Teil 1, Kapitel 1.3.

229 Unter einer personalisierten Darstellung wird »die Deutung und Darstellung historischer Sachverhalte an großen Persönlichkeiten und aus der Sicht großer Persönlichkeiten" verstanden. Bergmann, Klaus: Personalisierung, Personifizierung. In: Ders. u.a. (Hg.): Handbuch der Geschichtsdidaktik. 5., überarbeitete Aufl. Seelze-Velber 1997, 298-300, hier 298. Dem gegenüber steht eine Geschichtserzählung »von unten«, d.h. die Schilderung historischer Ereignisse anhand der Erfahrungen »einfacher, unbekannter Menschen«. Kaiser/Krankenhagen/Poehls: Europa ausstellen, 165 f., Zitat: 165. Ihren Ausdruck findet sie in der Darstellungsstragie der Personifizierung, unter der Klaus Bergmann »die Darstellung von Geschichte an `namenlosen den Personen und aus der Sicht dieser Personen [versteht], die immer gesellschaftliche Gruppierungen vertreten«. Bergmann: Personalisierung, Personifizierung, 299. 
Bis zum 10. September stellt Stalin den alliierten Flugzeugen die sowjetischen Landeplätze nicht zur Verfügung. ${ }^{230}$

Den für die Politik Stalins unbequemen Aufstand verurteilt seine Presse bereits am 13. August zur Niederlage. ${ }^{231}$

Nur an wenigen Stellen werden einzelne führende Generäle namentlich benannt; ${ }^{232}$ Vertreter niedrigerer militärischer Ränge oder einfache Soldaten präsentiert man dagegen nicht individuell. Das in der Ausstellung vermittelte Bild der Sowjetunion bleibt somit überwiegend anonym. Diese Darstellungsweise steht in scharfem Kontrast zur Präsentation der positiven Protagonisten der Erzählung, der polnischen Widerstandskämpfer und Aufständischen. Diese werden, soweit diese Informationen vorhanden sind, stets namentlich benannt; eine große Zahl von ihnen stellt man mit Biogrammen näher vor. ${ }^{233}$ Demgegenüber schafft die überwiegend auf Kollektivbezeichnungen und wenige anonyme Fotografien reduzierte, ansonsten auf die Person Stalins fokussierte Darstellungsweise der UdSSR eine deutliche Distanz zwischen den polnischen Helden und ihren Widersachern. »Die Sowjets (Sowieci) erscheinen somit als abstraktes Böses, dessen Repräsentant die Person ihres obersten Anführers ist. In der Charakterisierung Stalins findet die normative Zuspitzung der Erzählung auch ihren Höhepunkt: Vorgestellt wird der politische Anführer der Sowjetunion mit den Worten »Die sowjetische Inkarnation des Bösen - Stalin «. ${ }^{234}$ Im Biogramm zu seiner Person, das direkt unterhalb dieser Aussage präsentiert wird, erfolgt die unmittelbare und ausschließlich auf seine Person fokussierte Zuschreibung der politischen und militärischen Verantwortung im Zusammenhang mit den Ereignissen der sowjetischen Besatzung wie auch der Nachkriegsereignisse in Osteuropa:

[...] Am 17. September 1917 führt er die sowjetischen Truppen in Polen ein, wo er Massendeportationen und -exekutionen durchführt. [...] Den Satellitenstaaten zwingt er den Totalitarismus auf. [...] Der Stalinismus in den Jahren 1922-1953 bringt vielen Millionen Menschen den Tod. ${ }^{235}$

230 Bereichstext »Abwürfe für die Aufständischen«. MPW, Sektion 21: Abwürfe.

231 Bereichstext »Der Aufstand in der sowjetischen Presse«. MPW, Sektion 40: Die Großen Drei.

232 Dies betrifft etwa General Zygmunt Berling, den Führer der 1. Armee der Polnischen Armee in der Sowjetunion, sowie Marschall Konstantin Rokossovskij, der zum Zeitpunkt des Aufstands Befehlshaber der 1. Weißrussischen Front der Roten Armee war, die kurz vor Warschau stand. MPW, Sektion 29: Die Soldaten der Berling-Armee (Berlingowcy).

233 Siehe Teil 3, Kapitel 2.3.

234 Bildunterschrift unter einem Porträtfoto. MPW, Sektion 32: Treffen im Kreml. Siehe hierzu auch Heinemann: Emotionalisierungsstrategien, 233.

235 Biogramm »Józef Stalin«. MPW, Sektion 32: Treffen im Kreml. Hervorhebungen der Verfasserin. 
Auch in der übrigen Ausstellung finden sich ähnlich normative, eine emotionale Parteinahme der Besucher evozierende Aussagen und Ausdrucksweisen; so wird beispielsweise an anderer Stelle fast schon sarkastisch von »Väterchen Stalin « gesprochen. ${ }^{236}$

Dieser stark wertende Sprachgebrauch wird von einer suggestiven Symbolsprache unterstützt. Beispielhaft ist die Verwendung des Symbols von Hammer und Sichel. Eingeführt wird es zu Beginn des Rundgangs, bei der Darstellung des breiteren Kontextes des Angriffs Deutschlands und der Sowjetunion sowie der folgenden Besatzung. Auf einer großformatigen Karte ist die Aufteilung des polnischen Territoriums zwischen den beiden Aggressoren mit ihren bekanntesten Symbolen markiert: dem Hakenkreuz sowie Hammer und Sichel. ${ }^{237}$ Auch letzteres wird somit als eindeutig negatives Emblem in der musealen Erzählung markiert. Im weiteren Verlauf der Schau taucht dieses Zeichen an prominenter Stelle im Themenbereich "Das Lubliner Polen" auf, der der Entstehung und Durchsetzung des PKWN in den von der Sowjetunion ab Mitte 1944 besetzten polnischen Gebieten gewidmet ist. ${ }^{238}$

Eine über zwei Meter hohe, rot-leuchtende Skulptur in Form von Hammer und Sichel dominiert die Sektion (siehe Abb.22). Sie steht damit sinnbildlich für die Kontrolle der UdSSR über die entstehende sozialistische polnische Übergangsregierung in den Jahren 1944/45. Die negative bzw. abwertende Beurteilung dieser Ereignisse durch die Ausstellungsmacher zeigt sich auch in der weiteren Nutzung des Zeichens: So sind die Biogramme führender polnischer und sowjetischer Politiker, die diesen Prozess initiierten und durchführten, mit einem Stempel in roter Farbe signiert, der wiederum Hammer und Sichel zeigt (siehe Abb. 23). ${ }^{239}$ Sie werden damit als Unterstützer oder Vertreter der sowjetischen Besatzungsmacht gekennzeichnet und sprichwörtlich »abgestempelt«. Durch eine derartige Markierung mit einem in der Ausstellung eindeutig pejorativ konnotierten Symbol wird die negative Bewertung der Aktivitäten dieser Personen vorweggenommen, noch bevor die Besucher die Informationen zu den einzelnen Politikern und Militärs gelesen haben. Diese Wirkung verstärkt sich noch dadurch, dass die übrigen, in großer Zahl in der Schau verteilten Biogramme zu einzelnen Vertretern der Widerstandsbewegungen und des Untergrundstaates ohne eine ähnliche Markierung auskommen. Die Verwendung der roten Farbgebung, die die Sektion zum »Lubliner Polen « dominiert, ist generell auf die Schilderung der sozialistischen polnischen Regierung der Nachkriegszeit und der Sowjetunion beschränkt.

236 Die Überschrift zu einem Bereichstext lautete »Die Opfer der Politik Väterchen Stalins« (Ofiary polityki batiuszki Stalina). MPW, Sektion 29: Die Soldaten der Berling-Armee.

237 MPW, Sektion 6: Besatzung.

238 MPW, Sektion 28: Das Lubliner Polen.

239 Mit einem ebensolchen Stempel ist auch das bereits erwähnte Biogramm Stalins gekennzeichnet. 


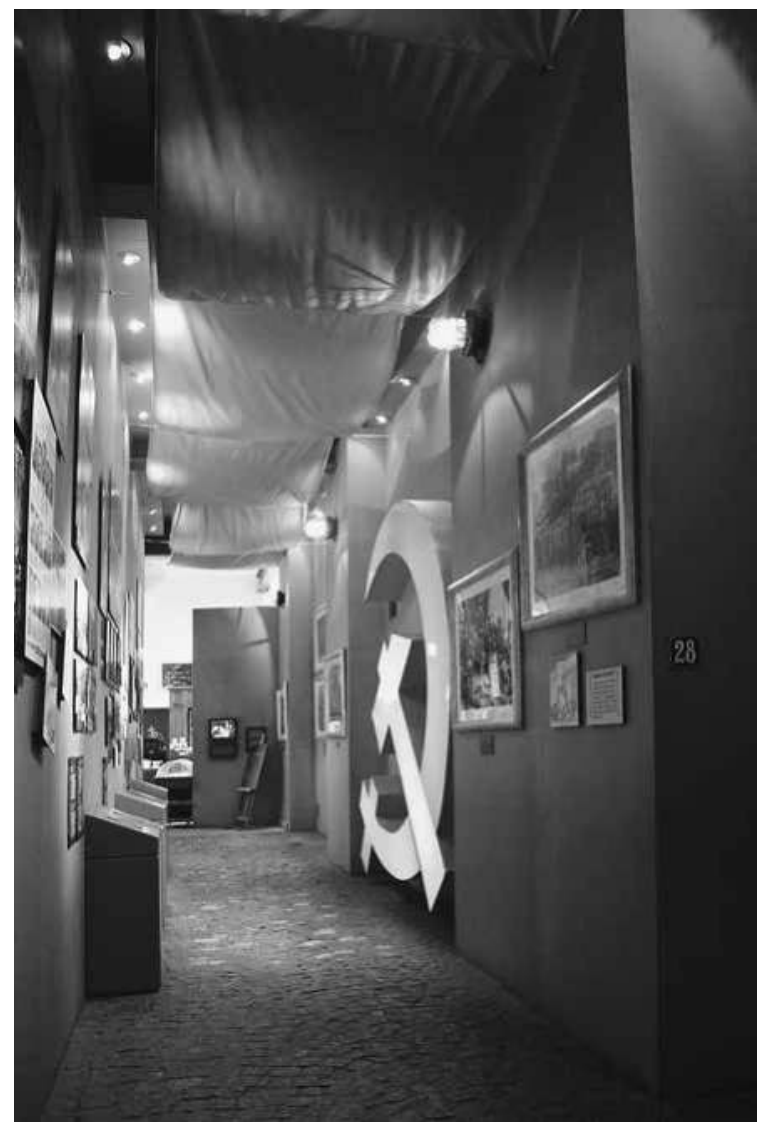

Abb. 22: MPW, Sektion »Das Lubliner Polen«.

So findet sie etwa Anwendung bei der Darstellung des Schauprozesses gegen führende Vertreter der polnischen Widerstandsbewegung in Moskau im Juni $1945 .{ }^{240}$ Eine stark vergrößerte Liste der Namen von verfolgten Widerstandskämpfern ist in roter Farbe gehalten ebenso wie ein Foto vom Prozess, das den Hintergrund der Ausstellungstafel bildet. In ihrem Zentrum prangt zudem ein roter Stern - Symbol sowohl für das kommunistische Regime im Nachkriegspolen als auch für die Dominanz der Sowjetunion im Land. ${ }^{241}$

Wie diese Beispiele bereits andeuten, ist die negative Darstellung der Rolle der Sowjetunion in diesem Museum eng verbunden mit der eindeutig nega-

240 MPW, Sektion 46: Die Aufständischen in der VRP.

241 Die Liste ist mit den Worten überschrieben: „Die Warschauer Aufständischen - Opfer des Stalinismus«. MPW, Sektion 46: Die Aufständischen in der VRP. 


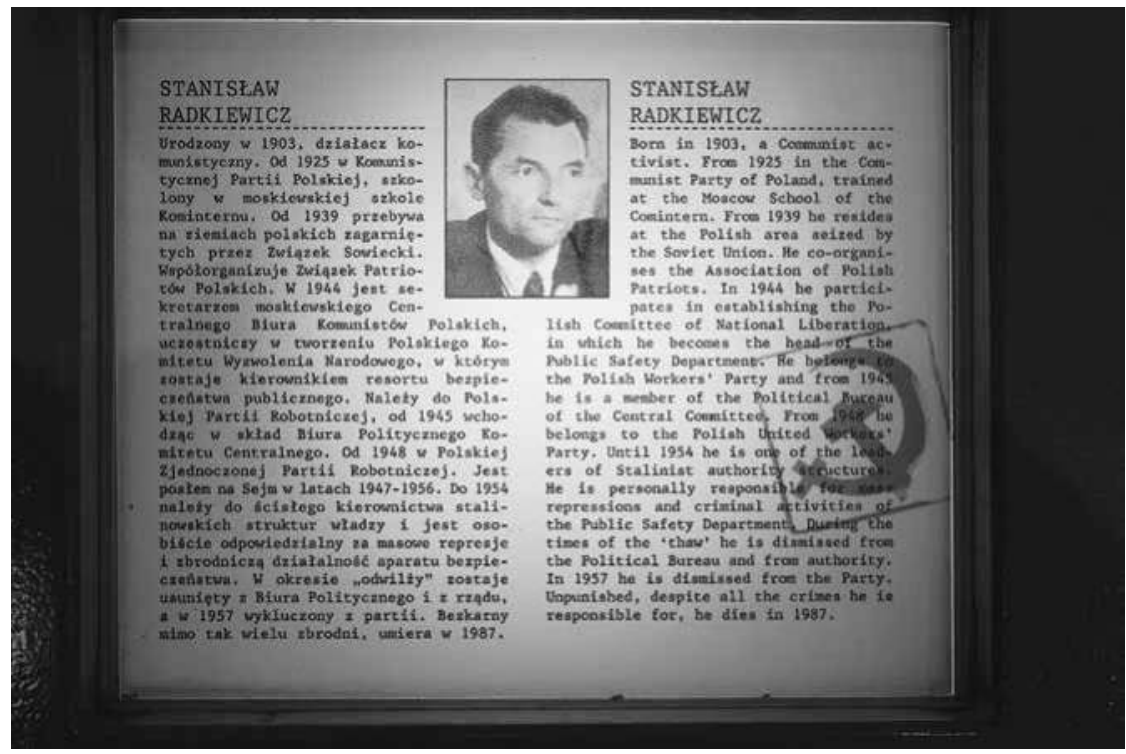

Abb. 23: MPW, Sektion »Das Lubliner Polen«, Biogramm von Stanisław Radkiewicz, der in den Jahren 1945 bis 1954 Minister für Öffentliche Sicherheit der VRP war.

tiv bewerteten politischen Nachkriegsentwicklung Polens, also der Etablierung der Volksrepublik unter sowjetischer Vorherrschaft. Dies zeigt sich etwa in der konsequenten Verwendung des Terminus "Befreiung" ausnahmslos in Anführungszeichen, welche die Zweifelhaftigkeit der Anwendbarkeit des Begriffs für das polnische Nachkriegsschicksal suggestiv vermittelt. ${ }^{242}$ In der Sektion zum »Lubliner Polen« wird diese Sichtweise offensiv und vielfältig transportiert: So schildert man etwa die Entstehung der Ämter für Öffentliche Sicherheit im neuen Polen unter dem aussagekräftigen Titel »Der Beginn des Kampfes mit der Freiheit«. An anderer Stelle findet sich eine Gegenüberbzw. Nebeneinanderstellung eines Aufrufs polnischer Anhänger der Sowjetunion einerseits, in der die Rote Armee als Befreier von der deutschen Unterdrückung bezeichnet und die Bevölkerung dazu angehalten wird, diese nach Kräften zu unterstützen, mit einer Karikatur eines lachenden Stalins andererseits, der sich als Befreier bezeichnet - während er einer gefesselten Frau, die symbolisch für das polnische Volk steht, eine Klinge an den Hals legt. ${ }^{243} \mathrm{Be}-$

242 Vgl. etwa die Bildunterschrift »Die >Befreier der Roten Armee fühlen sich auf polnischem Gebiet äußerst wohl.« MPW, Sektion 28: Das Lubliner Polen.

243 MPW, Sektion 28: Das Lubliner Polen. 
reits zu Beginn der Ausstellung spricht man zudem von einem »freien Polen" erst mit Bezug auf die Jahre nach 1989. ${ }^{244}$

Im Museum des Warschauer Aufstands erfolgt somit eine regelrechte Dämonisierung des Feindbildes der Sowjetunion: Die UdSSR erscheint als abstraktes Böses, ohne menschliche oder individuelle Züge. Diese Vermittlungs- und Interpretationspraxis erinnert deutlich an die Darstellung der »Hitleristen« in den Präsentationen aus den 1980er-Jahren. Dass dieser Wahrnehmung das ältere stereotype Feindbild »des Russen« zugrunde liegt, zeigt sich zudem in mehreren begrifflichen »Versprechern", die sich in der Schau finden. Während im Großteil der Dauerausstellung konsequent die Begriffe "Sowjetunion" (Związek Sowiecki) und "Sowjets" (Sowieci) verwendet werden, tauchen an einigen Stellen jedoch - offensichtlich synonym gebraucht die Bezeichnungen »Russland « und »Russen« auf. So ist beispielsweise ein Bereichstext, der dem Einmarsch der Roten Armee auf polnisches Territorium im September 1939 gewidmet ist, mit dem Titel »Der Einmarsch der Russen« (Wejście Rosjan) versehen. ${ }^{245}$ An anderer Stelle ist von "Lagern in den Tiefen Russlands« die Rede, die offensichtlich auf das Gulag-System in der UdSSR verweisen. ${ }^{246}$ Diese Freud'schen Versprecher bzw. Ungenauigkeiten in einer Schau, in der die Begriffswahl ansonsten sehr bewusst getroffen und umgesetzt ist, offenbaren die stereotypen Denkmuster und Vorstellungen der Ausstellungsverantwortlichen.

Anzumerken ist schließlich, dass in der ursprünglichen Fassung der Dauerausstellung - in der sie bis Juni 2007 existierte $-{ }^{247}$ das Feindbild Sowjetunion gegenüber dem der Deutschen sogar deutlich dominierte. Während die eigentlichen Besatzer und Gegner der Kämpfe im August und September 1944 in der Ausstellung weitgehend im Hintergrund blieben - direkt dargestellt wurden sie einzig in einem kleinen Themenraum,$-{ }^{248}$ werden die UdSSR und insbesondere der Einfluss ihres politischen und militärischen Führers Stalin vielfach und oft exponiert im Laufe des Rundgangs thematisiert. Erst mit der Inklusion einer eigenen Sektion zu den $»$ Deutschen in Warschau « erhielten die direkten Gegner der Aufständischen eine deutliche Präsenz im Ausstellungsnarrativ.

244 Bereichstext »Die Aufständischen in der VRP«. MPW, Sektion 3: Der Aufstand nach 60 Jahren.

245 MPW, Sektion 6: Die Besatzung.

246 Bereichstext »Die hinterhältigen `Waffenbrüder«. MPW, Sektion 28: Das Lubliner Polen.

247 Am 21. Juni 2007 wurde die Dauerausstellung um eine neue Sektion in der Halle B zu den »Deutschen in Warschau« erweitert. MPW, Sektion 56: Die Deutschen in Warschau.

248 MPW, Sektion 38: Die Deutschen. Siehe hierzu auch Teil 1, Kapitel 1.3. 
Alternative Perspektiven auf das Feindbild

Den mit starken normativen Deutungsmustern operierenden Schauen stehen Dauerausstellungen gegenüber, die versuchen, eindeutige Interpretationsvorgaben in Bezug auf die präsentierten Ereignisse in ihren Präsentationen zu vermeiden. $\mathrm{Zu}$ diesen gehören das Museum in der sogenannten SchindlerFabrik in Krakau sowie die Dauerausstellung des Historischen Museums in Wrocław. Die Perspektiven, die diese beiden Präsentationen verfolgen, unterscheiden sich jedoch voneinander.

In der Krakauer Ausstellung wird die Sowjetunion als Gegner und Angreifer Polens bereits bei der Thematisierung des Kriegsausbruchs benannt. In der weiteren Erzählung bleibt sie jedoch deutlich im Hintergrund. Einzig anlässlich der bereits erwähnten Schilderung der Entdeckung der Massengräber von Katyń wie auch der »Aktion `Gewittersturm« $(A k c j a » B u r z a \lll)^{249}$ skizziert man das Vorgehen der Roten Armee gegen polnische Soldaten und Vertreter der polnischen Untergrundorganisationen. ${ }^{250}$ Hierbei bleibt jedoch ein sachlicher Tonfall gewahrt; Massenexekutionen, Brutalität oder der Verrat der Bündnispartner finden keine wertende Beschreibung durch die Ausstellungsmacher. Der thematische Fokus liegt auf den Verteidigungsbemühungen der Deutschen in Krakau gegen die heranrückende sowjetische Armee. Zwar taucht in der Sektion, die den Kämpfen um Krakau gewidmet ist, an zwei Stellen der Begriff »Russen« auf, dies geschieht jedoch ausschließlich innerhalb zeitgenössischer Zitate: Eine Polin, »Halina Nelken, inhaftiert im KZ Płaszów« berichtet vom Ausbruch des Warschauer Aufstands und stellt fest: »Die Russen hielten an der Weichsel an [...]«. An anderer Stelle wird Hans Frank zitiert mit den Worten »Die Russen werden Krakau niemals bekommen. $\ll^{251}$ Diese Aussagen verweisen die Besucher somit darauf, dass in der Wahrnehmung der Zeitgenossen der geschilderten Ereignisse - sowohl von

249 Die Aktion »Gewittersturm« bezeichnet eine militärische Operation der Heimatarmee im Jahr 1944. Einzelne Städte und Regionen sollten mit dem Vormarsch alliierter Streitkräfte selbstständig oder in Zusammenarbeit mit sowjetischen Einheiten von den Deutschen befreit werden. Ziel war es, den polnischen Unabhängigkeitsanspruch in Bezug auf die Territorien des Landes in den Vorkriegsgrenzen geltend zu machen.

250 So wird im Bereichstext zur Aktion »Gewittersturm» benannt, dass die Zusammenarbeit des polnischen Untergrunds mit den sowjetischen Truppen nach dem Zurückdrängen der deutschen Einheiten an allen Orten mit der Verhaftung der polnischen Kräfte endete, die anschließend in die UdSSR deportiert wurden. Eine weitere Bewertung dieser Ereignisse oder aber einen sprachlichen und inhaltlichen Fokus auf das Schicksal der Deportierten finden die Besucher in der Schau hingegen nicht. MHKSchindler-Fabrik, Sektion 25: Die letzten Monate der Besatzung.

251 Beide Zitate sind in der Sektion jeweils an prominenter Stelle platziert und durch ihre Schriftgröße hervorgehoben. MHK-Schindler-Fabrik, Sektion 25: Die letzten Monate der Besatzung. 
Polen als auch Deutschen - die Rote Armee mit dem Angst- und Feindbild »der Russen" gleichgesetzt wurde. Die Autorenkommentare und -texte in der gesamten übrigen Ausstellung verwenden dagegen konsequent die Begriffe "Sowjetunion" (Zwiazek Sowiecki) und "sowjetische Armeen«/»Sowjets" (wojska sowieckie/Sowieci). Dass dieses Feindbild in der breiten Bevölkerung existierte bzw. die deutschen Besatzer versuchten, es zur Mobilisierung der Menschen für den Kampf gegen die Sowjetunion zu nutzen, wird den Besuchern zusätzlich vermittelt. Dies geschieht durch die Präsentation von antisowjetischen Plakaten der deutschen Besatzungsorgane in polnischer Sprache wie auch eines polnischsprachigen Flugblatts, das unter Verweis auf die Folgen des »Bolschewismus: [...] Massenmorde, allgemeines Elend [...]« zum freiwilligen Arbeitseinsatz beim Bau von Verteidigungsanlagen in Krakau aufruft. ${ }^{252}$ Das Feindbild Sowjetunion, das die Schau präsentiert, ist somit ein historisches; es bezieht sich auf die Wahrnehmung der Menschen und die Politik der Besatzungsorgane während der Jahre 1939 bis 1945. Eine wertende Einordnung, die dieses Feindbild perpetuieren würde, nehmen die Ausstellungsmacher hingegen nicht vor.

In der Darstellung des Endes der deutschen Besatzung wird dies noch einmal deutlich. Die chronologische Erzählung der Ausstellung endet mit dem Datum 18. Januar 1945, an dem »Einheiten der Roten Armee in Krakau ein[marschierten]. ${ }^{253}$ Auch in der Präsentation dieses Aspekts spiegelt sich das Bemühen der Kuratoren wider, vielfältige Perspektiven auf die historischen Ereignisse zuzulassen und die Erfahrungen der Bevölkerung zu porträtieren. So werden anhand von zwei Situationsberichten der AK vom 22. Januar 1945 die durchaus unterschiedlichen Reaktionen der Menschen auf dieses Ereignis deutlich:

Einzelne begrüßen Sowjets enthusiastisch. [...] Die Haltung der Bevölkerung ist all-

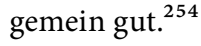

In Bezug auf die Soldaten der Berling-Armee zeigt die Bevölkerung keinen Enthusiasmus, und die Stimmung in der Bevölkerung ist sehr niedergeschlagen. ${ }^{255}$

Die Kuratoren der Schau vermeiden auch eine eindeutige Bewertung des Einmarsches der Roten Armee unter dem Gesichtspunkt seiner politischen Folgen für Krakau und Polen. In einem der kurzen Texte, die diesen themati-

252 MHK-Schindler-Fabrik, Sektion 22: Deutsche Propaganda, Sektion 25: Die letzten Monate der Besatzung.

253 So lautet der Text auf der letzten der Stempelkarten, die die Besucher im Laufe des Rundgangs sammeln können und die wesentliche Eckpunkte der Ausstellungserzählung markieren. MHK-Schindler-Fabrik, Sektion 26: Der Einmarsch der Roten Armee.

254 Ebd.

255 Ebd. 
schen Abschnitt begleiten, wird lediglich das »Ende der deutschen Besatzung « festgestellt und angefügt: "Krakau trat in einen neuen, ebenfalls schwierigen Abschnitt seiner Geschichte ein. ${ }^{256}$ Weder bezeichnet man den Einmarsch als »Befreiung" noch als Beginn einer neuen Besatzung. Die Ambivalenz der weiteren (politischen) Entwicklungen wird den Besuchern angedeutet, ohne eine normative Deutung dieser vorwegzunehmen oder gar zu oktroyieren. Dass die Nachkriegsereignisse in Polen in erheblichem Maße von der Sowjetunion beeinflusst wurden, suggeriert die Gestaltung dieses Abschnitts, der von einem überlebensgroßen Stalin-Porträt dominiert wird. ${ }^{257}$ Die unmittelbar daneben angebrachte, stilisierte Tür eines Eisenbahnwagons erinnert zugleich an die dem Ende der Besatzung folgenden Massenmigrationen, darunter die Deportationen von ehemaligen Kämpfern der AK in die Sowjetunion; ${ }^{258}$ eine Deutung, die verstärkt wird durch die rote Farbe, in der der inszenierte Wagon angestrichen ist.

Im Historischen Museum in Wrocław dagegen ist die Thematisierung der Sowjetunion beschränkt auf die Kämpfe um die Stadt bei Kriegsende, als die Rote Armee erstmals auf das Gebiet vordrang. ${ }^{259}$ Dargestellt wird die im Zuge des Heranrückens der Front erfolgte Erklärung der Stadt zur "Festung", der Einschluss der Stadt durch sowjetische Einheiten im Februar 1945 und die Kapitulationsverhandlungen zwischen der militärischen Stadtregierung und der Roten Armee. Diese rein militärischen Aspekte des Kriegsverlaufs werden überwiegend anhand von Militaria (Waffen, Uniformen, Stadtpläne) vermittelt. Die ausgestellten sowjetischen Propagandamaterialien ${ }^{260}$ sind allein an Soldaten der deutschen Armee adressiert. Die Opposition, die damit evoziert wird, besteht allein zwischen den deutschen Verteidigern der Stadt und dem sowjetischen Militär. Die militärische und weitgehend anonyme Darstellung der Roten Armee - namentlich genannt werden lediglich die ursprünglichen Besitzer oder Autoren gezeigter Objekte - entspricht dabei zwar einem Teil des Stereotyps »der Russen«. Ihr militärisches Vorgehen jedoch ist in diesem Teil der Schau ausschließlich auf die deutsche Stadt Breslau und deren Bewohner gerichtet. Gewalt und militärische Aggression in Bezug auf polnische Staatsbürger vonseiten der Sowjetunion werden dagegen nicht thema-

256 Ebd.

257 Wie im Ausstellungsführer erläutert wird, soll dieses an die Stalin-Porträts erinnern, die von Soldaten der Roten Armee in Krakau im Januar 1945 an verschiedenen Plätzen aufgestellt wurden. Marszałek/Bednarek: Fabryka Emalia, 39.

258 Eine solche Interpretation wird den Besuchern - unter gleichzeitigem Verweis auf die massenhafte Rückkehr von KZ-Insassen, Zwangsarbeitern und Flüchtlingen - auch im Ausstellungsführer vermittelt. Siehe ebd., $39 \mathrm{f}$.

259 MMW-MH, Saal 22.

260 Gezeigt werden eine Karikatur, die den deutschen Angriff auf die Sowjetunion 1941 mit der Niederlage des Ersten Weltkriegs in Verbindung setzt, sowie ein Flugblatt, das deutsche Soldaten zum Beenden der Kampfhandlungen auffordert. Ebd. 
tisiert. Weder gibt es Referenzen auf die Massaker in Katyń noch auf Deportationen polnischer Staatsbürger aus den zwischen 1939 und 1941 besetzten Gebieten in die UdSSR. Auch das Kriegsende stellt man in wertneutraler, faktenorientierter Weise dar: Zeitlicher Endpunkt der Erzählung im Raum 22 ist die Kapitulation der Stadt am 6. Mai 1945. Ein Verweis auf die Folgen dieses Ereignisses findet sich erst im nächsten Raum, der dem Thema »Breslau nach 1945 - Kriegsfolgen - Stalinismus « gewidmet ist. ${ }^{261}$ In Bezug auf Polen - den Staat wie die Nation - in den Jahren des Zweiten Weltkriegs wird die UdSSR damit nicht als Feind thematisiert. Hintergrund dieser Darstellungsweise ist der Versuch einer Konzentration auf die lokale Geschichte der Stadt, die bis zum Einmarsch der Roten Armee Teil des Deutschen Reiches war. Eine nationale polnische Meistererzählung ist nicht der bestimmende Referenzrahmen dieses thematischen Aspekts der Ausstellung - was jedoch nicht bedeutet, dass die Erzählung bei anderen thematischen Aspekten der Jahre 1939 bis 1945 nicht auf tradierte Geschichtsbilder Bezug nimmt. ${ }^{262}$

\section{Zusammenfassung}

Wie gezeigt wurde, zeichnet sich die museale Darstellung der deutschen Besatzer bis in die Gegenwart durch eine weitgehende Kontinuität von Deutungsmustern aus, die bereits in der Volksrepublik geprägt worden sind und auf älteren stereotypen Vorstellungen von »den Deutschen« basieren. Die einzige merkliche Wandlung, die das Feindbild erfahren hat, äußert sich im Wechsel der Begrifflichkeiten: Den volksrepublikanischen Ausdruck »die Hitleristen« löste sukzessive die nationale Bezeichnung »die Deutschen« ab. Die Darstellung des Feindes und damit auch die Gegenüberstellung von "Polen« und "Deutschen« erhielt hierdurch eine ethnisch-nationale Komponente. ${ }^{263}$

Die Sowjetunion als Feindbild konnte dagegen erst mit dem Systemwechsel von 1989 Ausdruck in musealen Darstellungen des Zweiten Weltkriegs finden. Zuvor wurde sie entweder ausschließlich positiv dargestellt, als Befreierin von der deutschen Besatzung, oder aber überhaupt nicht thematisiert. Trotz des Tabus, dem wesentliche Aspekte der polnisch-sowjetischen Beziehungen während des Kriegs unterlagen, war die Erinnerung an den sowjetischen Einmarsch und die Besatzung in der Gesellschaft jedoch prä-

261 Titel des Thementextes. MMW-MH, Saal 23. Im Thementext wird als wesentliche Folge des Einmarsches sowjetischer Truppen »die Übernahme der Stadt durch die polnische Verwaltung« genannt. Im Weiteren wird auch auf die »Abhängigkeit von der UdSRR« verwiesen. Ebd.

262 Siehe hierzu auch Teil 1, Kapitel 1.3 und Teil 3, Kapitel 1.3.

263 Bogumił/Wawrzyniak: Das Bild des "Deutschen«, 196. 
sent, wie die Welle der Sonderausstellungen zu den Themen "Katyń" und "Sybiracy« Anfang der 1990er-Jahre eindrücklich zeigt. In die Dauerausstellungen der meisten Museen hielt die UdSSR als Feindbild dagegen erst ab der zweiten Hälfte der 1990er-Jahre langsam Einzug. Symbolisch für ihre neue Rolle im Kriegsnarrativ als Angreifer und verbrecherische Besatzungsmacht stehen seit diesem Zeitraum die Darstellungen des 17. September 1939 sowie der Entdeckung der Massengräber polnischer Offiziere in Katyń im Jahr 1943. Während diese Aspekte dem Konsens der wissenschaftlichen und publizistischen Debatten seit Ende der 1980er- und Anfang der 1990er-Jahre entsprechen, wurde die Auseinandersetzung mit der Rolle der Sowjetunion bei Kriegsende, also in den Jahren 1944/45 - in Ermangelung eines solchen interpretatorischen Konsenses - in den Dauerausstellungen lange Zeit vermieden. Die ambivalente Rolle der UdSSR bei Kriegsende - als Ursache für das Ende der brutalen deutschen Besatzung einerseits, aber auch als Ursache für die Etablierung der sozialistischen Nachkriegsregierung andererseits erschwerte es offensichtlich den Ausstellungsverantwortlichen, angesichts der anhaltenden wissenschaftlichen und öffentlichen Debatten über dieses Thema eine eindeutige Verurteilung des Akteurs vorzunehmen, die für die Konstruktion eines klaren Feindbildes notwendig ist.

Die seit 2004 neu entstandenen Ausstellungen begegnen diesem Aspekt in unterschiedlicher Weise: Zum einen findet eine Dämonisierung der Sowjetunion statt, die eng mit einer eindeutig negativen Bewertung ihres Einflusses auf die polnische Nachkriegsentwicklung verbunden ist, also der Entstehung des sozialistischen Staates unter sowjetischer Dominanz. Andere Institutionen nehmen hingegen keine Bewertung des Einmarsches der Roten Armee unter dem Gesichtspunkt der Kriegsfolgen vor. Diese Unterschiede verweisen zum einen auf die deutliche Pluralisierung der Museumslandschaft mit Einsetzen des Museumsbooms. Zum anderen zeigen die unterschiedlichen Darstellungsweisen, dass sich in Bezug auf die Sowjetunion bei Kriegsende bis zum Jahr 2010 (noch) kein konsensuales Interpretationsmuster etabliert hatte. Spätestens seit Anfang der 2000er-Jahre wird die Sowjetunion in Bezug auf die Jahre 1944 / 45 zwar nicht mehr als "Befreierin« bezeichnet - in dieser Hinsicht sind die Meinungen eindeutig. Die Darstellung der polnischen Nachkriegsentwicklung und damit auch des Einmarsches sowjetischer Truppen bei Kriegsende als neue Besatzung ist jedoch keineswegs unumstritten. Die Aushandlungsprozesse zu diesem Thema, die mit einer grundsätzlichen Bewertung der Volksrepublik Polen einhergehen, dauern gegenwärtig noch an. ${ }^{264}$

264 Eine neue Kontextualisierung dieses Aspekts der Kriegsgeschichte offeriert das Museum des Zweiten Weltkriegs in Gdańsk, das in Kapitel 2 des Ausblicks näher vorgestellt wird. 
Während die Darstellung der Deutschen im Untersuchungszeitraum durchgängig hoch emotional blieb und bleibt - was vor dem Hintergrund des deutschen Besatzungsregimes und seiner Verbrechen gegen die Bevölkerung des besetzten Landes nicht überrascht -, dauerte es in den meisten Institutionen zehn bis fünfzehn Jahre (in einigen auch deutlich länger), bis eine Interpretation der Sowjetunion und ihrer Rolle im Krieg formuliert und in die Dauerausstellungen aufgenommen worden ist. Bis dahin blieb und bleibt sie zum Teil bis heute im übertragenen Sinne "farblos« - anonym, rein militärisch konnotiert und weitgehend abstrakt. Im Bereich ihrer permanenten Präsentationen wagten sich die Institutionen nicht mit einem Angebot eigener Geschichtsentwürfe vor. Neue Elemente fanden erst vor dem Hintergrund eines sich herauskristallisierenden gesellschaftlichen und wissenschaftlichen Konsenses Eingang in die Dauerausstellungen. Die museale Entwicklung dieses Feindbildes ist damit zugleich ein Beispiel dafür, wie zurückhaltend die meisten der untersuchten historischen Museen mit der Einführung neuer Inhalte und damit verbundener Interpretationen in ihre Ausstellungen sind.

Schließlich bleibt festzustellen, dass die Darstellung beider Feinde von stereotypen Mustern geprägt ist, die auf die älteren historischen Feindbilder »der Deutschen" respektive »der Russen" zurückgreifen. Elemente, die das einseitige Bild differenzieren und um ambivalente Aspekte erweitern würden etwa zivile Kontakte zwischen den Besatzern und der einheimischen Bevölkerung -, werden bislang kaum herangezogen. Das bislang einzige Beispiel in diese Richtung ist das Museum in der Krakauer Schindler-Fabrik. Eine wesentliche Ursache für die Persistenz schematischer Darstellungsweisen in Bezug auf die hier geschilderten Feindbilder kann in dem nur schwer fassbaren Ausmaß der von ihnen verübten Gräueltaten gesehen werden, die eine Anpassung etablierter Präsentationsweisen nicht als dringlich erscheinen lässt. Eine weitere, nicht zu vernachlässigende ist ihre Funktion für die Konstruktion des musealen Selbstbildes, also der Wir-Gemeinschaft der Protagonisten der Erzählungen - der (meist ethnisch-)polnischen Bevölkerung. Wie in Teil 3 eingehender dargestellt wird, ist auch das museale Bild der polnischen Bevölkerung im Krieg von zahlreichen etablierten Deutungsmustern gekennzeichnet. Erst eine klare Feinddarstellung bietet die deutliche Abgrenzungsfolie für eine ähnlich eindeutige Charakterisierung der eigenen Gemeinschaft bzw. Nation. Die Diversifizierung Ersterer hätte eine Differenzierung Letzterer zur Folge, da sie ambivalente Aspekte des Neben- und Miteinanders von Besatzern und Unterworfenen offenbart. Diese müssten zu einer Anpassung oder zumindest Erweiterung des bislang weitgehend homogenen (musealen) Selbstbildes polnischer Helden und Märtyrer führen. 


\title{
Teil 2 \\ Die Darstellung der Judenverfolgung - Abgrenzung nach innen
}

\begin{abstract}
Abgrenzungsstrategien, die bei der Konstruktion musealer Geschichts- und damit verbundener Selbstbilder eine wesentliche Rolle spielen, betreffen nicht allein die Darstellung von externen »Anderen« oder »Fremden«. Auch bei der Thematisierung religiöser, ethnischer und nationaler Minderheiten, die innerhalb des eigenen Staatsgebietes leben, kommen auf der Basis von spezifischen Hetero- wie Autostereotypen Prozesse der Inklusion und Exklusion zur Anwendung, die auf die Selbstbilder der Titularnation verweisen. Dieser Teil der Studie ist der musealen Darstellung des für polnische Geschichtsbilder wesentlichen internal other ${ }^{1}$ gewidmet: der jüdischen Bevölkerung des Landes. ${ }^{2}$

Die Wahrnehmung von Juden als "Fremde" und damit in Opposition zu Polen hat sich Ende des 19. Jahrhunderts mit der Verfestigung eines ethnisch und religiös definierten Verständnisses der polnischen Nation etabliert. ${ }^{3}$ In
\end{abstract}

1 Michlic: Poland's Threatening Other, 34.

2 Auf die zentrale Bedeutung von Juden als dem constitutive other polnischer nationaler Identitätsbildung weist u.a. Lech Nijakowski hin: Nijakowski, Lech M.: Pamięć o II wojnie światowej a relacje Polaków z innymi narodami [Die Erinnerung an den Zweiten Weltkrieg und die Beziehungen der Polen zu anderen Nationen]. In: Kwiatkowski, Piotr T. u. a.: Między codziennością a wielką historią. Druga wojna światowa w pamięci zbiorowej społeczeństwa polskiego [Zwischen Alltag und großer Geschichte. Der Zweite Weltkrieg in der kollektiven Erinnerung der polnischen Gesellschaft]. Gdańsk, Warszawa 2010, 239-286, hier 281. Als Juden werden in dieser Studie Personen bezeichnet, die während des Zweiten Weltkriegs von den Nationalsozialisten als solche kategorisiert und verfolgt wurden. In Bezug auf die Vorkriegszeit sind darunter auch diejenigen gefasst, die sich selbst als Juden betrachteten oder aber als solche von der Mehrheitsgesellschaft wahrgenommen wurden. Diese weite Definition bezieht sich somit auf die Kontexte der Entstehung jüdischer nationaler Selbstwahrnehmung und Identität in Ostmitteleuropa, die sowohl durch Entwicklungen innerhalb der jüdischen Gemeinden als auch eine zunehmende Abgrenzung vonseiten der Mehrheitsgesellschaft geprägt waren, somit durch ein Zusammenspiel aus »Fremdwahrnehmung und Selbstbestimmung«. Steffen, Katrin: Jüdische Polonität. Ethnizität und Nation im Spiegel der polnischsprachigen jüdischen Presse 1918-1939. Göttingen 2004, 19.

3 Steffen, Katrin: Formen der Erinnerung. Juden in Polens kollektivem Gedächtnis. In: Osteuropa 58/8-10 (2008), 367-386, hier 371; Janion, Maria: Do Europy - tak, ale razem z naszymi umarłymi [Nach Europa - ja, aber gemeinsam mit unseren Toten]. Warszawa 2000, 157 f. Siehe auch Porter, Brian: When Nationalism Began to Hate. Imganing Modern Politics in Nineteenth-Century Poland. New York, Oxford 2000, 176-182; Porter-Szücs, 
der Zwischenkriegszeit verbreiteten sich antisemitische Vorstellungen von einer »Bedrohung « Polens durch die jüdische Bevölkerung des Landes stark. ${ }^{4}$ Juden wurden als »innere Feinde« von einem großen Teil des politischen und gesellschaftlichen Spektrums aus der Staatsnation ausgeschlossen. ${ }^{5}$ Die antisemitischen Topoi ignorierten dabei weitgehend die große Bandbreite an Identitätsoptionen, die die als »Juden« bezeichneten Staatsbürger zu einer sehr heterogenen Gruppe machten. ${ }^{6}$ Gerade in Großstädten fanden innerhalb der Intelligenz und des Bürgertums Akkulturations- und - in geringerem Maße - Assimilationsbewegungen zur polnischen Mehrheitsgesellschaft statt, auch wenn diese nicht zu einem Massenphänomen wie in Westeuropa wurden. ${ }^{7}$ Die stereotypen Vorstellungen und Wahrnehmungsmuster von der »Andersartigkeit« der polnischen Juden $-{ }^{8}$ die nach 1945 große Wirkmäch-

Brian: Faith and Fatherland. Catholicism, Modernity, and Poland. Oxford, New York 2011, 272-289.

4 Steffen: Formen der Erinnerung, 372.

5 Die Etablierung der Vorstellung von Juden als dem »threatening other« der polnischen Nation macht Joanna Michlic im Zeitraum 1880 bis 1918 aus. In den 1890er-Jahren fand dieser Topos Eingang in die polnische Politik bzw. polnische politische Bewegungen. In der Zwischenkriegszeit wurde die Vorstellung eines grundsätzlichen Antagonismus zwischen Juden und Polen zum festen Bestandteil politischer Auseinandersetzungen in der Polnischen Republik, die seit den 1930er-Jahren zunehmend Einfluss auf den Alltag ausübten. So wurden beispielsweise Juden aus einigen Berufsverbänden ausgegrenzt und »Bank-Ghettos" (getta ławkowe) an Hochschulen geschaffen. Michlic: Poland's Threatening Other, 24-108, bes. 52-68, 73-76, 81 f., 88, 103 f., Zitat: 63. Siehe auch Steffen: Formen der Erinnerung, 371-373, Zitat: 371; Steinlauf, Michael C.: Pamięć nieprzyswojona. Polska pamięć Zagłady [Die nicht angenommene Erinnerung. Die polnische Erinnerung an den Holocaust]. Warszawa 2001, 32-34. Erstpublikation: Ders.: Bondage to the Dead. Poland and the Memory of the Holocaust. Syracuse, New York 1997.

6 Steffen: Jüdische Polonität, 12, 17-22. Die Hintergründe der großen Vielfalt an Identitätsoptionen von Juden in Ostmitteleuropa erläutert Hahn, Hans Henning: Zur Problematik jüdischer Identität in Ostmitteleuropa. Eine Einführung. In: Ders. / Stüben, Jens (Hg.): Jüdische Autoren in Ostmitteleuropa im 20. Jahrhundert. Frankfurt am Main 2000, 11-18, hier 15-17. Die starke politische Fraktionierung der polnischen Juden in der Zwischenkriegszeit schildert Weiss, Yfaat: Deutsche und polnische Juden vor dem Holocaust. Jüdische Identität zwischen Staatsbürgerschaft und Ethnizität. 1933-1940. München 2000, $225 \mathrm{f}$.

7 Żyndul, Jolanta: Z getta do asymilacji. Żydzi w poszukiwaniu tożsamości [Aus dem Ghetto in die Assimilation. Juden auf Identitätssuche]. In: Traba, Elżbieta/Traba, Robert (Hg.): Tematy żydowskie. Historia, literatura, edukacja [Jüdische Themen. Geschichte, Literatur, Erziehung]. Olsztyn 1999, 55-72, hier 56-58, 60, 69; Steinlauf: Pamięć nieprzyswojona, $20 \mathrm{f} ., 24,29$.

8 Die frühe Entstehung dieser Wahrnehmung vor dem Hintergrund der Akkulturationsund Assimilationsbewegungen anderer Minderheiten zeichnet Joanna Michlic bereits für den Zeitraum vor 1795 nach. Während der Teilungszeit vertiefte sie sich, mit einer gewissen Ausnahme für die in Preußen inkorporierten Gebiete, in denen Assimilationsbewegungen von Juden in die deutsche Mehrheitsgesellschaft relativ stark waren. Michlic: Poland's Threatening Other, $41 \mathrm{f}$., 49-52. Siehe auch Steffen: Jüdische Polonität, $25 \mathrm{f}$.; Steinlauf: Pamięć nieprzyswojona, $20 \mathrm{f}$. 
tigkeit behielten $-{ }^{9}$ blendeten dabei die jahrhundertelange Geschichte des $\mathrm{Zu}$ sammenlebens auf den polnischen Territorien aus, die durch vielfältige Kontakte und Beziehungen geprägt war. Auch wenn der Alltag meist eher von einem Neben- denn einem Miteinander polnischer und jüdischer Bewohner geprägt war, waren Juden bis kurz vor Ausbruch des Zweiten Weltkriegs ein fester Bestandteil des Lebens in polnischen Städten und Dörfern. ${ }^{10}$ Juden bildeten in vielen Regionen einen bedeutenden Anteil der Bevölkerung, ${ }^{11}$ so auch in den hier betrachteten Städten: In Warschau, Łódź und Lublin machten sie etwa ein Drittel der Gesamtbevölkerung aus, in Krakau ein Viertel. ${ }^{12}$ In Breslau war die jüdische Gemeinde vor 1939 deutlich zahlreicher als die polnische Minderheit. ${ }^{13}$ Der Zweite Weltkrieg und der Holocaust änderten die

9 So betont etwa Katrin Steffen die außerordentliche Bedeutung der Zwischenkriegszeit für die »Möglichkeiten der polnisch-jüdischen Verständigung«. Steffen: Formen der Erinnerung, 373.

10 Steinlauf: Pamięć nieprzyswojona, 17-19, 31; Steffen: Formen der Erinnerung, $369 \mathrm{f}$.

111931 lebten in der Polnischen Republik mehr als 3,1 Millionen Juden, die 9,8 Prozent der Bevölkerung ausmachten. Engelking-Boni, Barbara/Leociak, Jacek: Getto warszawskie. Przewodnik po nieistniejącym mieście [Das Warschauer Ghetto. Führer durch eine nichtexistente Stadt]. Warszawa 2001, 32.

12 Die größte Zahl jüdischer Einwohner hatte Warschau; 1938 waren es etwa 368.000, was 29,1 Prozent der Bewohner entsprach. Engelking-Boni/Leociak: Getto warszawskie, 34. Kurz vor dem Kriegsausbruch betrug der Anteil der jüdischen Bevölkerung in Lublin 32,5 Prozent. Radzik, Tadeusz: Lubelska dzielnica zamknięta [Der geschlossene Wohnbezirk von Lublin]. Lublin 1999, 11. In Łódź machten die etwa 230.000 Bewohner, die 1939 zur »jüdischen Nationalität« gezählt wurden, 33,8 Prozent der Gesamtbevölkerung der Stadt aus. Mroczka, Ludwik: Dynamika rozwoju i struktura społeczno-zawodowa głównych grup etnicznych w Łodzi w latach 1918-1939 [Entwicklungsdynamik und gesellschaftlich-berufliche Struktur der größten ethnischen Gruppen in Łódź in den Jahren 1918-1939]. In: Samuś, Paweł (Hg.): Polacy - Niemcy - Żydzi w Łodzi w XIX-XX w. Sąsiedzi dalecy i bliscy [Polen - Deutsche - Juden in Łódź im 19. und 20. Jahrhundert. Nahe und ferne Nachbarn]. Łódź 1997, 99-117, hier 101. 1931 lebten in Krakau 56.500 Personen, die sich bei der Volkszählung zum jüdischen Glauben bekannten (25,8 Prozent der Gesamtbevölkerung). Während der von den deutschen Besatzern befohlenen Registrierung aller Juden in Krakau und den angrenzenden Gemeinden im November 1939 wurden 68.482 Personen gezählt. Chwalba, Andrzej: Dzieje Krakowa [Die Geschichte Krakaus]. Bd. 5: Kraków w latach 1939-1945 [Krakau in den Jahren 19391945]. Kraków 2002, 95-162, hier 95; Adamczyk, Elżbieta: Społeczność Krakowa i jej życie [Die Krakauer Gesellschaft und ihr Leben]. In: Bieniarzówna, Janina/Małecki, Jan M. (Hg.): Dzieje Krakowa [Die Geschichte Krakaus]. Bd. 4: Kraków w latach 1918-1939 [Krakau in den Jahren 1918-1939]. Kraków 1997, 27-50, hier 30. Hierbei ist anzumerken, dass in allen Städten der Anteil der jüdischen Einwohner bis kurz vor Kriegsausbruch durch die zahlreiche Emigration bereits deutlich gesunken war. Siehe Engelking-Boni/ Leociak: Getto warszawskie, 33.

131938 lebten in Breslau - nach starker Emigration in den Vorjahren - noch etwa 10.000 Juden. Davies/Moorhouse: Breslau, 454. 1918 betrug die Zahl der polnischen Breslauer ca. 4.000 bis 5.000; laut Davies / Moorhouse fiel sie "auf einen statistisch unerheblichen Rest zwei Jahrzehnte später«. Ebd., 447. 
Bevölkerungszusammensetzung grundlegend: Die zuvor multiethnische Republik Polen wurde zu einem ethnisch weitgehend homogenen Staat. Neben der enormen Zahl der Holocaustopfer trugen auch die Massenmigrationen in den Jahren 1944 bis 1947 hierzu bei, darunter die Aussiedlung der deutschen Minderheit sowie der Bevölkerungsaustausch mit der Sowjetunion, zu dem auch die Umsiedlung von Ukrainern und Belarussen in die UdSSR gehörte. ${ }^{14}$ Die wenigen Juden, die den Holocaust in der Sowjetunion, in Verstecken oder in Lagern überlebt hatten, ${ }^{15}$ wanderten unmittelbar nach dem Krieg, in den Jahren 1956 bis 1960 und im Zuge der antisemitischen Kampagne von 1967 / 68 größtenteils aus. ${ }^{16}$

In der Geschichtspolitik und Historiografie der Volksrepublik wurden Juden als eigenständige Opfergruppe der nationalsozialistischen Besatzung vernachlässigt und spätestens seit Ende der 1960er-Jahre unter die polnischen Kriegsopfer subsumiert. ${ }^{17}$ Hierdurch blendete man die Singularität der Ver-

14 Borodziej: Geschichte Polens, 258-260.

15 Es wird geschätzt, dass etwa 50.000 bis 70.000 als Juden Verfolgte den Holocaust in den von Deutschen besetzten Gebieten überlebten. Etwa 180.000 kehrten nach dem Krieg aus der Sowjetunion nach Polen zurück. Żbikowski, Andrzej: Die Erinnerung an den Holocaust in Polen. In: Brumlik, Micha/Sauerland, Karol (Hg.): Umdeuten, verschweigen, erinnern. Die späte Aufarbeitung des Holocaust in Osteuropa. Frankfurt am Main 2010, 115-124, hier 115. Michael Steinlauf zitiert die Zahl von 244.000 Juden, die Ende der 1940er-Jahre in Polen offiziell registriert waren. In dieser Zahl fehlen diejenigen, die sich mit »arischen Papieren« versteckt hatten und nach dem Krieg entschieden, diese Identität beizubehalten. Steinlauf: Pamięć nieprzyswojona, $61 \mathrm{f}$.

16 Ursache für die große Zahl der Emigranten unmittelbar nach dem Krieg war, neben der von vielen empfundenen Unmöglichkeit eines Verbleibs in einem Land, das Friedhof der meisten Angehörigen und Freunde war, die negative Haltung der polnischen Mehrheitsbevölkerung den Holocaust-Überlebenden gegenüber. Diese entlud sich in physischer Gewalt, darunter in mehreren Pogromen (u.a. in Rzeszów, Krakau und Kielce). Cała, Alina: Kształtowanie się polskiej i żydowskiej wizji martyrologicznej po II wojnie światowej [Die Genese des polnischen und jüdischen Märtyrermythos nach dem Zweiten Weltkrieg]. In: Przegląd socjologiczny 49/2 (2000), 167-180, hier 168-170. Bereits bis 1951 sank die Zahl der in Polen offiziell als Juden Registrierten als Folge der großen Emigrationswelle auf weniger als 80.000. Zwischen 1956 und 1960 wanderten mehr als 40.000 Menschen aus; in den Jahren 1968 bis 1970 folgten weitere etwa 20.000. Steinlauf: Pamięć nieprzyswojona, 66, 84, 94. Teile der folgenden Ausführungen wurden publiziert in Heinemann, Monika: Die Musealisierung des Ghettos. Die Verfolgung von Juden während des Zweiten Weltkriegs in Warschauer Museen. In: François, Étienne u. a. (Hg.): Geschichtspolitik in Europa seit 1989. Deutschland, Frankreich und Polen im internationalen Vergleich. Göttingen 2013, 470-490.

17 Leociak, Jacek: Zraniona pamięć. Rocznice powstania w getcie warszawskim w prasie polskiej 1944-1989 [Verletzte Erinnerung. Die Jahrestage des Aufstands im Warschauer Ghetto in der polnischen Presse 1944-1989]. In: Michnik, Adam (Hg.): Przeciw antysemityzmowi. 1936-2009 [Gegen den Antisemitismus]. Bd. 3. Kraków 2010, 257-277, hier 267 f.; Zaremba, Marcin: Das organisierte Vergessen des Holocaust in der Ära Gierek: Kontinuität und Wandel. In: Wolff-Powęska, Anna / Forecki, Piotr (Hg.): Der Holocaust in der polnischen Erinnerungskultur. Frankfurt am Main u. a. 2012, 161-174, bes. 164, $167 \mathrm{f}$. 
nichtungsabsicht der Nationalsozialisten gegenüber der als jüdisch definierten Bevölkerung aus. Als Folge wurde auch die Frage nach den Verhaltensweisen von Polen gegenüber der Verfolgung und Ermordung ihrer jüdischen Mitbürger verdrängt. Exemplarisch für die Etablierung dieser Praxis ist der Umgang mit der Erinnerung an den Aufstand im Warschauer Ghetto von 1943. ${ }^{18}$ Dieses Ereignis, das international zur bekanntesten jüdischen Erhebung während des Kriegs avancierte, nahm auch in der Geschichtspolitik der VRP einen zentralen Platz ein. ${ }^{19}$ Bereits zum fünften Jahrestag des Aufstands 1948 wurde auf dem ehemaligen Ghettogelände ein Denkmal von Nathan Rapoport enthüllt, das in den kommenden Jahrzehnten zum zentralen Ort der jährlichen Gedenkfeierlichkeiten wurde. Dabei wurde seit den 1960er-Jahren die Tatsache, dass die Aufständischen Juden waren, immer mehr zurückgedrängt, sodass die Gedenkveranstaltungen zu »einem Alibi für das Vergessen, für den Ausschluss der Erinnerung an den Holocaust aus der Geschichte Polens $\aleph^{20}$ wurden. Als vermeintlicher Ausdruck des gemeinsamen polnischjüdischen Schicksals im Krieg ging der Aufstand schließlich als polnischer Widerstandsakt in das offizielle Geschichtsbild ein. ${ }^{21}$

18 Während der Liquidierung des Warschauer Ghettos brach am 19. April 1943 ein Aufstand aus, der erst am 16. Mai von deutschen Einheiten blutig niedergeschlagen werden konnte.

19 Die Entwicklung des Umgangs mit dem Warschauer Ghettoaufstand in der polnischen Historiografie und der offiziellen Gedenkpolitik der VRP beschreibt detailliert Renata Kobylarz. Kobylarz, Renata: Walka o pamięć. Polityczne aspekty obchodów rocznicy powstania w getcie warszawskim 1944-1989 [Der Kampf um die Erinnerung. Politische Aspekte der Gedenkfeiern zu den Jahrestagen des Warschauer Ghettoaufstandes 1944-1989]. Warszawa 2009.

20 Cała: Kształtowanie się polskiej i żydowskiej wizji martyrologicznej, 176.

21 Leociak: Zraniona pamięć, 267f., 274 f.; Zaremba, Marcin: Komunizm, legitymizacja, nacjonalizm. Nacjonalistyczna legitymizacja władzy komunistycznej w Polsce [Kommunismus, Legitimierung, Nationalismus. Die nationalistische Legitimierung der kommunistischen Herrschaft in Polen]. Warszawa 2001, 328-332; Kosmala, Beata: Der Aufstand im Warschauer Ghetto 1943 und der Warschauer Aufstand 1944 in der Geschichtspolitik der Volksrepublik. In: Brumlik, Micha/Sauerland, Karol (Hg.): Umdeuten, verschweigen, erinnern. Die späte Aufarbeitung des Holocaust in Osteuropa. Frankfurt am Main u.a. 2010, 179-202, hier 179, 182-184, 186. Siehe auch Michlic, Joanna Beata/Melchior, Małgorzata: The Memory of the Holocaust in Post-1989 Poland. Renewal - Its Accomplishments and Its Powerlessness. In: Himka, John-Paul/Michlic, Joanna Beata (Hg.): Bringung the Dark Past to Light. The Reception of the Holocaust in Postcommunist Europe. Lincoln, London 2013, 403-450, hier 413. Die Aufnahme des Ghettoaufstandes in den offiziellen Kanon der Gedenkveranstaltungen verfolgte zusätzlich das Ziel, die Erinnerung an den zweiten bedeutenden Aufstand in der Geschichte Warschaus während des Kriegs auszublenden: den Aufstand der polnischen Heimatarmee gegen die deutschen Besatzer 1944, den sogenannten Warschauer Aufstand. Dies hatte mehrere Gründe: Zunächst richtete sich der Aufstand von 1944 politisch gegen eine Vereinnahmung Polens in die Einflusssphäre der UdSSR. Die polnischen Widerstandskräfte wollten Warschau von den deutschen Besatzern befreien und damit den Anspruch der 
Vor diesem Hintergrund konzentrierte sich die Thematisierung der Beziehungen zwischen den einzelnen Bevölkerungsgruppen während der deutschen Besatzung jahrzehntelang allein auf die Betonung der polnischen Unterstützung für verfolgte Juden. ${ }^{22}$ Andere, insbesondere ambivalente und negative Phänomene der polnisch-jüdischen Kontakte während des Zweiten Weltkriegs waren tabuisiert und wurden auch vor dem Hintergrund der wiederholten Antisemitismus-Vorwürfe aus dem Ausland - die sich sowohl auf die Haltung von Polen während des Holocaust als auch auf die Vorgehensweisen der jeweiligen polnischen Regierungen der Nachkriegszeit bezogen ausgeblendet. ${ }^{23}$ In der gesellschaftlichen Wahrnehmung verschwand die Erinnerung an die jüdische Vergangenheit des Landes.

Nach ersten kleineren Initiativen in den 1970er-Jahren ${ }^{24}$ begann in der VRP schließlich in den 1980er-Jahren das Interesse an der Geschichte und Kultur der ehemaligen jüdischen Bewohner Polens zu wachsen. Öffentlichen Niederschlag fand dieses steigende Interesse in zahlreichen Publikationen, v.a. in Zeitschriften, die mit Kreisen der katholischen Intelligenz verbunden waren: Tygodnik Powszechny (Allgemeines Wochenblatt), Więź (Verbindung), Znak (Zeichen). Eine zentrale Bedeutung für die Debatten in diesen

Unabhängigkeit des polnischen Staates manifestieren. Zudem wurde die Erhebung von der Londoner Exilregierung und den mit ihr verbundenen Untergrundkräften, somit durch den politischen Gegner, organisiert. Schließlich war die Haltung der UdSSR während des Aufstandes umstritten: Während der zweimonatigen Kämpfe, in denen etwa 150.000 bis 180.000 Menschen starben - überwiegend Zivilisten -, versagte die Rote Armee, die kurz vor Warschau lag, den Aufständischen die Unterstützung. Zum Prozess der Ausgrenzung der Erinnerung an den Warschauer Aufstand in der VRP vgl. Borodziej, Włodzimierz: Der Warschauer Aufstand 1944. Frankfurt am Main 2004, $208-214$.

22 Die wenigen Arbeiten, die in der VRP erschienen und das Thema der Verfolgung und Ermordung von Juden behandelten, konzentrierten sich seit Ende der 1950er-Jahre auf den Aspekt der polnischen Hilfe für die Verfolgten. Die Entwicklung der Historiografie zum Thema polnischer Hilfe für verfolgte Juden stellt umfangreich Dariusz Libionka dar. Libionka, Dariusz: Polskie piśmiennictwo na temat zorganizowanej i indywidualnej pomocy Żydom (1945-2008) [Die polnische Literatur zum Thema der organisierten und individuellen Hilfe für Juden (1945-2008)]. In: Zagłada Żydów 4 (2008), 17-80, für den Zeitraum bis 1989 bes. 18-58. Siehe auch Aleksiun, Natalia: Historiografia na temat Zagłady i stosunków polsko-żydowskich w okresie drugiej wojny światowej [Die Historiografie zum Thema Holocaust und den polnisch-jüdischen Beziehungen während des Zweiten Weltkriegs]. In: Zagłada Żydów 1 (2005), 32-51, hier 41-44.

23 Kosmala: Der Aufstand im Warschauer Ghetto, 187 f.; Leociak: Zraniona pamięć, 270, 275; Michlic, Joanna B.: »Pamiętanie dla upamiętnienia«, "pamiętanie dla korzyści« i »pamiętanie, żeby zapomnieć«: różne modele pamięci o Żydach i Zagładzie w postkomunistycznej Polsce [»Erinnerung zum Gedenken«, »Erinnerung zum Nutzen« und »Erinnerung, um zu vergessen«: verschiedene Modelle der Erinnerung an Juden und den Holocaust im postkommunistischen Polen]. In: Kultura i Społeczeństwo 55/4 (2011), 225-245, hier 234.

24 Steinlauf: Pamięć nieprzyswojona, $112 \mathrm{f}$. 
Zirkeln erhielt etwa die Sonderausgabe der Krakauer Monatszeitschrift Znak aus Anlass des 40. Jahrestages des Warschauer Ghettoaufstandes. ${ }^{25}$ Im Zuge dieser Entwicklung setzte auch eine erste Auseinandersetzung mit den kritischen Aspekten der polnischen Augenzeugenschaft des Holocaust ein. Initiiert wurde sie in der zweiten Hälfte der 1980er-Jahre durch zwei Kontroversen zum Thema der polnisch-jüdischen Beziehungen während des Kriegs. Die erste entbrannte nach der Premiere von Claude Lanzmanns "Shoah« im April 1985 sowie der Ausstrahlung im Jahr 1986 einer auf polnische Aspekte zusammengekürzten Version des Films im polnischen Fernsehen. ${ }^{26}$ Die heftigen Reaktionen, die der Ausstrahlung folgten, waren sowohl in der offiziellen als auch der Untergrundpresse fast ausschließlich negativ: Der Film wurde als "antipolnisch" abgelehnt. Man warf ihm vor, unzulässig verallgemeinernde, die "polnische nationale Ehre und Moral« angreifende Anschuldigungen zu formulieren. Nur einzelne Autoren, wie etwa Jacek Kuron in einer Untergrundzeitschrift, zollten dem Werk Anerkennung und verwiesen auf den Unterschied zwischen dem Schicksal von Polen und Juden während der deutschen Besatzung. Nach Michael Steinlaufs Einschätzung hatte der Film trotz seiner verbreiteten Ablehnung eine grundlegende Wirkung: »[...] Behauptungen, wonach es während des Kriegs keinen Unterschied im Schicksal von Juden und Polen gegeben habe, verschwanden aus der öffentlichen Diskussion. ${ }^{27}$ Die zweite Kontroverse folgte kurz darauf: 1987 löste Jan Błońskis Essay "Biedni Polacy patrzą na getto " (Die armen Polen schauen auf das Ghetto) eine erste ausführlichere Debatte über die polnisch-jüdischen Beziehungen während der Besatzung aus. ${ }^{28}$ Der Autor postulierte eine moralische »Mitschuld durch Gleichgültigkeit« der polnischen Bevölkerung am Schicksal ihrer jüdischen Mitbürger und reflektierte kritisch insbesondere die polnische Haltung gegenüber Juden in der Zwischenkriegszeit. Auch hier waren die Reaktionen in der Presse überwiegend negativ. ${ }^{29}$ Der Text schaffte es jedoch, das Thema der polnisch-jüdischen Beziehungen der Jahre 1918 bis 1945 erstmals zu einem Gegenstand öffentlicher Diskussionen zu machen, auch

25 Znak 35/2-3 (1983). Eine detaillierte Analyse der Entwicklungen der 1980er-Jahre nimmt Michael Steinlauf vor. Steinlauf: Pamięć nieprzyswojona, 113-136.

26 Bikont, Anna: A on krzyczał: »Wszyscy jesteście kapo« [Und er schrie: »hr seid alle Kapos«]. In: Gazeta Wyborcza vom 4.10.1997.

27 Steinlauf: Pamięć nieprzyswojona, 127-129, Zitate: 129.

28 Błoński, Jan: Biedni Polacy patrzą na getto [Die armen Polen schauen auf das Ghetto]. In: Tygodnik Powszechny 2 (1987).

29 Die Argumentation Błońskis und die anschließende Debatte zeichnen nach KoźmińskaFrejlak, Ewa: Świadkowie zagłady - holocaust jako zbiorowe doświadczenie Polaków [Die Zeugen der Vernichtung - der Holocaust als kollektive Erfahrung der Polen]. In: Przegląd socjologiczny 49/2 (2000), 181-206, hier 189-205; Steinlauf: Pamięć nieprzyswojona, 129-132. 
wenn die Auseinandersetzungen weitgehend auf intellektuelle Kreise beschränkt blieben. ${ }^{30}$

Nach der durch diese Publikation ausgelösten Debatte verschwand das Thema jedoch in den 1990er-Jahren weitgehend aus der Öffentlichkeit. Die einzige Ausnahme bildete eine kurze, aber heftige Kontroverse, die wenige Monate vor dem 50. Jahrestag des Warschauer Aufstands um das polnischjüdische Verhältnis während der Kämpfe 1944 entbrannte. Ausgelöst wurde sie durch den Artikel »Polacy - Żydzi: Czarne karty powstania» (Polen - Juden: Die dunklen Seiten des Aufstands) von Michał Cichy in der Gazeta Wyborcza (Wahlzeitung), in dem der Autor die - dokumentierten - Ermordungen von etwa 60 Juden durch Aufständische darlegte. ${ }^{31}$ Die Reaktionen gerade vonseiten der Kombattantenverbände, aber auch einiger Historiker waren äußerst scharf und verurteilten die vermeintliche Verunglimpfung des Andenkens der Helden des Aufstands. Andere äußerten ihren Zuspruch für die Offenlegung der Taten, die zur umfassenden Auseinandersetzung mit dem polnischjüdischen Verhältnis im Krieg beitragen könne. ${ }^{32}$ Auch diese Diskussion hatte jedoch keine langfristigen Folgen für die öffentliche und gesellschaftliche Wahrnehmung des Themas.

Einen Wendepunkt in der innerpolnischen Beschäftigung mit negativen Haltungen und Handlungen von Polen gegenüber verfolgten Juden stellte dagegen die Publikation von Jan Tomasz Gross' Studie "Sąsiedzi« (Nachbarn) im Jahr 2000 dar. ${ }^{33}$ In dem Buch belegt der Autor die Verantwortung der

30 Michlic: »Pamiętanie dla upamiętnienia«, 229f. Siehe auch Dies.: Poland's Threatening Other, 274. An einer kritischen Aufarbeitung der schwierigen Aspekte der polnischjüdischen Beziehungen während der Besatzung war laut Antony Polonsky in den 1980erJahren auch nur eine Minderheit von Intellektuellen interessiert. Polonsky, Antony: Stosunki polsko-żydowskie od roku 1984. Refleksje uczestnika [Die polnisch-jüdischen Beziehungen seit 1984. Reflexionen eines Teilnehmers]. In: Baczkowski, Michał u.a. (Hg.): Widziane z zewnątrz [Von Außen betrachtet]. Warszawa 2011, 231-250, hier 239. Joanna Michlic attestiert in ähnlicher Weise, dass lediglich ein kleiner Teil der Wissenschaftler in den 1980er-Jahren Interesse an einer positiven Evaluation der polnischen Juden und ihres Beitrags zur polnischen Geschichte hatte. Michlic: "Pamiętanie dla upamiętnienia«, $229 \mathrm{f}$.

31 Cichy, Michał: Polacy - Żydzi: Czarne karty powstania [Polen - Juden: Die dunklen Seiten des Aufstands]. In: Gazeta Wyborcza vom 29./30.1.1994, 13. Ausführlich über diese Kontroverse: Krupa, Bartłomiej: Die Intensivierung der Holocaust-Diskussion. Der Streit um »Die dunklen Seiten des Aufstands« von Michał Cichy. In: Wolff-Powęska, Anna/ Forecki, Piotr (Hg.): Der Holocaust in der polnischen Erinnerungskultur. Frankfurt am Main u. a. 2012, 195-213. Siehe auch Steinlauf: Pamięć nieprzyswojona, 152-154. Eine deutsche Übersetzung des Artikels von Cichy ist erschienen als Cichy, Michał: Polen und Juden - schwarze Kapitel des Warschauer Aufstands. In: Engelking, Barbara/Hirsch, Helga (Hg.): Unbequeme Wahrheiten. Polen und sein Verhältnis zu den Juden. Frankfurt am Main 2008, 54-78.

32 Krupa: Die Intensivierung der Holocaust-Diskussion, 202-210.

33 Gross: Sąsiedzi. 
polnischen Einwohner der Kleinstadt Jedwabne für das 1941 verübte Pogrom an den jüdischen Bewohnern des Ortes, das bislang überwiegend den deutschen Besatzern zugeschrieben worden war. Die intensive publizistische und wissenschaftliche Debatte der Jahre 2000 bis 2002, die der Veröffentlichung des Buches folgte, unterschied sich von den vorangegangenen grundlegend: Erstmals wurden die diskutierten Thesen nicht überwiegend abgelehnt, sondern fanden auch breite Unterstützung. Zudem erreichte die Diskussion eine breite Öffentlichkeit. ${ }^{34}$ Hitzige Beiträge rief insbesondere die für den Großteil der Gesellschaft nur schwer zu akzeptierende Tatsache hervor, dass Polen nicht Deutsche - die Täter waren und dass diese Täter nicht zum "gesellschaftlichen Rand" gehörten. Letzterem waren bis dato vereinzelte negative Verhaltensweisen gegenüber Juden zugeschrieben wurden - wodurch sie zugleich aus der polnischen Gesellschaft ausgeschlossen werden konnten. ${ }^{35}$ Wie Dariusz Libionka festgestellt hat, hat erst mit der Debatte um Jedwabne eine wirkliche Akzentverschiebung in der Wahrnehmung des Holocaust in Polen stattgefunden; erst seit diesem Zeitpunkt wurde breit rezipiert, dass »der Holocaust inmitten der polnischen Gesellschaft stattgefunden hat $« .{ }^{36}$ Die Frage nach der Täterschaft an den Morden von Jedwabne bedeutete daher auch eine allgemeine Auseinandersetzung mit der Täterschaft von Polen während der Jahre 1939 bis $1945 .{ }^{37}$ Gross' Buch rüttelte somit an mehreren grundlegenden Mythen der polnischen Kriegserinnerung, in erster Linie dem »romanti-

34 Libionka, Dariusz: Debata wokół Jedwabnego [Die Jedwabne-Debatte]. In: Tych, Feliks / Adamczyk-Garbowska, Monika (Hg.): Następstwa zagłady Żydów. Polska 1944-2010 [Die Folgen der Vernichtung der Juden. Polen 1944-2010]. Lublin 2011, 733-773, hier 741. Die Diskussionen während des Höhepunktes der Debatte in den Jahren 2000 bis 2001 dokumentieren u.a. Jankowski, Robert: Jedwabne. Spór historyków wokół książki Jana T. Grossa »Sąsiedzi« [Jedwabne. Der Streit der Historiker über das Buch von Jan T. Gross »Nachbarn«]. Warszawa 2002; Polonsky, Antony/Michlic, Joanna B. (Hg.): The Neighbors Respond. The Controversy Over the Jedwabne Massacre in Poland. Princeton, N. J. u.a. 2004. Eine Auswahl der Erwiderungen von Gross auf die zahlreichen publizistischen Äußerungen versammelt Gross, Jan Tomasz: Wokół »Sąsiadów«. Polemiki i wyjaśnienia [Zu den »Nachbarn«. Polemiken und Erläuterungen]. Sejny 2003. Auch mehrere umfassende Analysen der Debatte sind inzwischen erschienen: Michlic, Joanna B.: Coming to Terms with the "Dark Past«. The Polish Debate About the Jedwabne Massacre. Jerusalem 2002; Kowitz, Stephanie: Jedwabne. Kollektives Gedächtnis und tabuisierte Vergangenheit. Berlin 2004. Das Buch enthält auch deutsche Übersetzungen zentraler Debattenbeiträge; Forecki, Piotr: Spór o Jedwabne. Analiza debaty publicznej [Der Streit um Jedwabne. Eine Analyse der öffentlichen Debatte]. Poznań 2008. Die Zahl von Artikeln zur Jedwabne-Debatte in Sammelbänden und Zeitschriften ist inzwischen kaum zu überblicken.

35 Libionka: Debata wokół Jedwabnego, 739.

36 Ebd., 745.

37 Krupa: Die Intensivierung der Holocaust-Diskussion, 199. 
schen Autostereotyp ${ }^{38}$ der Helden und Opfer, sowie an der Vorstellung, dass die Hilfsbereitschaft verfolgten Juden gegenüber ein verbreitetes Phänomen gewesen sei. ${ }^{39}$

Die Debatten rund um »Nachbarn« haben in einem Teil der polnischen Gesellschaft dazu geführt, dass sich das Wissen über die Ereignisse in Jedwabne und seiner Region und damit über negative Verhaltensweisen von Polen gegenüber Juden während des Kriegs verbreitete. Dieser Teil des gesellschaftlichen und politischen Spektrums befürwortete die Auseinandersetzung mit diesem schwierigen Aspekt der nationalen Vergangenheit und betrachtet sie als wichtig für die Formierung des nationalen Selbstbildes. ${ }^{40}$ Eine Folge dieses »kritischen Patriotismus" war der Boom, den die polnische Forschung zu den polnisch-jüdischen Beziehungen während des Kriegs und der unmittelbaren Nachkriegszeit erlebte. ${ }^{41}$ Die Positionen von Gross hatten jedoch auch erbitterte Gegner, und die Debatte um sein Buch trug letztlich mit zur Entstehung einer erinnerungskulturellen Gegenbewegung bei. Zusammen mit dem Streit um ein deutsches "Zentrum gegen Vertreibungen« bildete sie einen wesentlichen Hintergrund der Entstehung des Konzepts der »neuen Geschichtspolitik « in der polnischen politischen Rechten. ${ }^{42}$ Mit dem Schlagwort der

38 Libionka: Debata wokół Jedwabnego, 768. Siehe auch Kula, Marcin: Dyskusja o Jedwabnem czy o Polsce? [Diskussionen über Jedwabne oder Polen?]. In: Ders.: Uparta Sprawa. Żydowska? Polska? Ludzka? [Eine hartnäckige Sache. Jüdisch? Polnisch? Menschlich?]. Kraków 2004, 131-138, hier 136.

39 Michlic: Coming to Terms, 32; Dies. / Melchior: The Memory of the Holocaust, 423.

40 Steffen, Katrin: Ambivalenzen des affirmativen Patriotismus. Geschichtspolitik in Polen. In: Osteuropa 56/11-12 (2006), 219-233, hier 224; Michlic/Melchior: The Memory of the Holocaust, 224.

41 Zunächst wurden insbesondere die Ereignisse in Jedwabne und der Region intensiv untersucht, so auch vom »Institut für Nationales Gedenken« (Instytut Pamięci Narodowej, IPN). Die Ergebnisse von dessen Forschungen erschienen 2002: Machcewicz, Paweł (Hg.): Wokół Jedwabnego [Rund um Jedwabne]. 2 Bde. Warszawa 2002. Drei zentrale Beiträge dieser Bände sind auch auf Deutsch erschienen: Dmitrów, Edmund/Machcewicz, Paweł/Szarota, Tomasz: Der Beginn der Vernichtung. Zum Mord an den Juden in Jedwabne und Umgebung im Sommer 1941. Neue Forschungsergebnisse polnischer Historiker. Osnabrück 2004. 2003 wurde an der Polnischen Akademie der Wissenschaften in Warschau das "Zentrum der Erforschung des Holocaust « (Centrum Badań nad Zagłada Żydów) gegründet, das seit 2005 ein eigenes Jahrbuch herausgibt, Zagłada Żydów. Studia i Materiały (Die Vernichtung der Juden. Studien und Materialien), in dem zentrale Beiträge neuester Forschungen in erster Linie polnischer Wissenschaftler zum Holocaust auf polnischem Territorium und den polnisch-jüdischen Beziehungen während des Kriegs erscheinen. Das Zentrum publiziert in seiner Reihe zudem zentrale Publikationen aus diesem Themenbereich. Siehe seine Website, URL: www.holocaustresearch.pl (am 15.1.2014).

42 Steffen: Formen der Erinnerung, $381 \mathrm{f}$; Dies.: Ambivalenzen des affirmativen Patriotismus, 223 f.; Libionka: Debata wokół Jedwabnego, 769 f.; Wolff-Powęska, Anna: Polskie spory o historię i pamięć. Polityka historyczna [Polnische Diskussionen über Geschichte und Erinnerung. Geschichtspolitik]. In: Przegląd zachodni 1 (2007), 3-44, hier 34. 
"neuen Geschichtspolitik«, das in den Jahren der ersten PiS-Regierung 2005 bis 2007 seinen größten öffentlichen Einfluss erreichte, wurde die Durchsetzung eines affirmativen, apologetischen Geschichtsbildes propagiert. In diesem sollten die negativen Aspekte der polnischen Geschichte weitgehend ausgeklammert bleiben und der martyrologische Mythos der Polen als Helden und Opfer in den Vordergrund gestellt werden. ${ }^{43}$ Es handelte sich hierbei um eine "Verteidigungshaltung" gegen die als externen Angriff auf das »Paradigma der polnischen Unschuld « wahrgenommenen Positionen. ${ }^{44}$

Auch die folgenden zwei Publikationen von Gross - "Strach" (Angst) sowie "Złote Żniwa» (Goldene Ernte) aus den Jahren 2008 bzw. $2011{ }^{45}$ führten zu heftigen Debatten über polnischen Antisemitismus und polnische Schuld während und unmittelbar nach dem Holocaust. ${ }^{46}$ Gerade die Publikationen dieses Autors haben durch ihre Breitenwirkung über ein Fachpublikum hinaus dazu beigetragen, »die vielen Abstufungen von Mitwirkung an den Verbrechen der Deutschen und die Verstrickungen in Schuld« einem größeren Teil der polnischen Öffentlichkeit bekannt zu machen $-{ }^{47}$ wenn auch noch lange nicht von einer allgemeinen Akzeptanz oder einem breiten Wissen über diese Phänomene gesprochen werden kann. ${ }^{48}$

43 Zur Entwicklung der Debatte um die "neue Geschichtspolitik» siehe Steffen: Ambivalenzen des affirmativen Patriotismus; Wolff-Powęska: Polskie spory o historię i pamięć. Siehe auch Nijakowski: Polska polityka pamięci, 190-236.

44 Forecki, Piotr: Od »Shoah« do »Strachu«. Spory o polsko-żydowską przeszłość i pamięć w debatach publicznych [Von »Shoah« zu »Angst«. Die Auseinandersetzungen über die polnisch-jüdische Vergangenheit und Erinnerung in öffentlichen Debatten]. Poznań 2010, 299, 334-355.

45 Gross, Jan Tomasz: Strach. Antysemityzm w Polsce tuż po wojnie. Historia moralniej zapaści [Angst. Antisemitismus in Polen kurz nach dem Krieg. Die Geschichte einer moralischen Niederlage]. Kraków 2008 (die englische Ausgabe erschien bereits 2006); Gross, Jan Tomasz/Grudzińska-Gross, Irena: Złote żniwa. Rzecz o tym, co się działo na obrzeżach zagłady Żydów [Goldene Ernte. Was sich am Rande der Judenvernichtung ereignete]. Kraków 2011.

46 Die Entwicklung der innerpolnischen Auseinandersetzungen um das polnisch-jüdische Verhältnis im Krieg seit 1945 zeichnet anhand der zentralen Kontroversen Piotr Forecki nach: Forecki: Od »Shoah« do »Strachu«. Debattenbeiträge zu »Angst« versammelt Gądek, Mariusz (Hg.): Wokół Strachu. Dyskusja o książce Jana T. Grossa [Über »Angst«. Die Debatte über das Buch von Jan T. Gross]. Kraków 2008. Die Meinungen der Gegner von Gross versammelt Jankowski, Robert (Hg.): Cena »Strachu«. Gross w oczach historyków [Der Preis von »Angst«. Gross in den Augen von Historikern]. Warszawa 2008. Zur Diskussion im Jahr 2011: Lis, Daniel (Hg.): Wokół »Złotych żniw«. Debata o książce Jana Tomasza Grossa i Ireny Grudzińskiej-Gross [Über die »Goldene Ernte«. Die Diskussion über das Buch von Jan Tomasz Gross und Irena Grudzińska-Gross]. Kraków 2011.

47 Steffen: Formen der Erinnerung, 380.

48 Vgl. u.a. die soziologischen Analysen von Nijakowski: Pamięć o II wojnie światowej, 269-281; Ambrosewicz-Jacobs, Jolanta: Świadomość Holokaustu wśród młodzieży polskiej po zmianach systemowych 1989 roku [Die Wahrnehmung des Holocaust in der polnischen Jugend nach den Systemveränderungen des Jahres 1989]. In: Tych, Feliks/ 
Wie dieser kurze Überblick über die Entwicklung der polnischen Debatten zu den polnisch-jüdischen Beziehungen während des Kriegs deutlich macht, gehört dieses Thema zu denjenigen, die besonders polarisierende Diskussionen und starke Emotionen hervorrufen. ${ }^{49}$ Dies ist darauf zurückzuführen, dass dieser Aspekt implizit stets mit der ethisch konnotierten Frage nach der Rolle bzw. den Verhaltensweisen der ethnisch-polnischen Bevölkerung als Zeugen der Vernichtung ihrer jüdischen Mitbürger verbunden ist, also mit der »Frage, ob sie nicht mehr Hilfe hätten leisten können und wenn ja, warum sie das nicht getan haben ${ }^{50}{ }^{50}$ Die Debatten des ersten Jahrzehnts des 21. Jahrhunderts haben über diese zentrale moralische Frage hinaus eine weitere Komponente: Sie sind zugleich verbunden mit dem Ringen um die Anpassung oder aber die Bewahrung zentraler Elemente der polnischen Erinnerung an den Krieg. So bedeutet etwa die Auseinandersetzung mit der Vielfalt polnischjüdischer Kontakte, wozu auch negative Phänomene zählen, eine Abkehr von dem bislang dominierenden einseitig positiven Selbstbild, in dem der heldenhafte Kampf und das Martyrium der ethnischen Polen im Fokus steht. In einer übergreifenden Perspektive wird schließlich die Inklusion der Geschichte der jüdischen Bewohner Polens und ihres Schicksals während der Besatzungen in die polnische Erinnerung an den Krieg verhandelt. Gegenwärtig ist das Ergebnis dieser Aushandlungsprozesse noch offen - wie Joanna Michlic feststellt:

Wie die zweite Hälfte der ersten Dekade des 21. Jahrhunderts offenbart, [...] wurde noch kein allgemeiner gesellschaftlicher Konsens über die Rolle der polnisch-jüdischen Beziehungen in der Geschichte Polens und ihrer Bedeutung für die kollektive Erinnerung und Identität gefunden. ${ }^{51}$

Auch in der polnischen Historiografie ist die Inklusion des Holocaust bzw. der Erfahrungen der polnischen Juden in die (polnische) Geschichtserzählung der Jahre 1939 bis 1945 noch nicht erfolgt. ${ }^{52}$ Die Debatten um das pol-

Adamczyk-Garbowska, Monika (Hg.): Następstwa zagłady Żydów. Polska 1944-2010 [Die Folgen der Vernichtung der Juden. Polen 1944-2010]. Lublin 2011, 625-658, hier 632-639.

49 Koźmińska-Frejlak: Świadkowie zagłady, 182, 189.

50 Borodziej, Włodzimierz: Abschied von der Martyrologie in Polen? In: Sabrow, Martin/ Jessen, Ralph / Grosse Kracht, Klaus (Hg.): Zeitgeschichte als Streitgeschichte. Große Kontroversen seit 1945. München 2003, 288-305, hier 290.

51 Michlic: »Pamiętanie dla upamiętnienia«, 241.

52 Barbara Engelking-Boni stellte 2008 prägnant fest: »Der Holocaust ist immer noch nicht zu einem Teil der Geschichte Polens geworden«. Engelking-Boni, Barbara: Dolary skupuję, koty przechowuję [Kaufe Dollar, bringe Katzen unter]. In: Gazeta Wyborcza vom 18.2.2008, Online-Ausgabe, URL: http://wyborcza.pl/1,76842,4933898.html (am 16.12.2011). Ähnlich schätzt die gegenwärtige Situation in der polnischen Historiografie auch Andrzej Żbikowski ein. Siehe Potel, Jean-Yves: Koniec Niewinności. Polska wobec swojej żydowskiej przeszłości [Das Ende der Unschuld. Polen im Angesicht seiner jüdischen Vergangenheit]. Kraków 2010, $49 \mathrm{f}$. 
nisch-jüdische Verhältnis im Krieg beinhalten somit auch die Frage nach dem grundlegenden Zugang zur polnischen Geschichte: Ein in den vergangenen Jahrzehnten dominierendes exklusives ethnisches Nationskonzept, das nationale Zugehörigkeit auf der Basis von Abstammung und Religionszugehörigkeit definiert ${ }^{53}$ welche die polnischen Juden und auch den Holocaust aus der polnischen Geschichte ausschloss -, wird dabei zunehmend von einem integrativen staatsbürgerlichen Nationsverständnis herausgefordert. Dieses akzeptiert religiöse, kulturelle und ethnische Vielfalt und lässt sie als Bestandteile der nationalen Gemeinschaft und damit auch ihrer Geschichte zu. ${ }^{54}$

Im Folgenden wird untersucht, in welchem Maß die beschriebenen gesellschaftlichen Aushandlungsprozesse über die polnisch-jüdische Geschichte während der Besatzungszeit, sowie die in den vergangenen Jahrzehnten erbrachten wissenschaftlichen Erkenntnisse in die Dauerausstellungen der historischen Museen Eingang fanden. Zentral ist dabei die Frage, inwieweit die Geschichte der jüdischen Minderheit in das jeweilige lokale und regionale Geschichtsbild integriert oder ausgeschlossen wurde. Ebenso interessiert, ob bzw. in welcher Art und Weise der umkämpfte Aspekt der polnisch-jüdischen Beziehungen dargestellt wird. Gefragt werden soll dabei, inwiefern die Museen selbst zu den Initiatoren von Veränderungen gehörten, bzw. in welcher Weise sie auf externe erinnerungskulturelle und geschichtspolitische Entwicklungen reagierten. Schließlich geht es darum zu klären, ob das politische Umbruchjahr 1989 eine Zäsur auch für die museale Geschichtsdarstellung dieses Themenaspekts bedeutete. Überprüft werden soll nicht zuletzt, inwieweit der Prozess der »Rekonstruktion« und erste Anzeichen einer »Wiedergewinnung « der Erinnerung an die früheren jüdischen Einwohner, die Michael Steinlauf für die 1980er- respektive 1990er-Jahre postuliert, ${ }^{55}$ in die Tätigkeit der Institutionen öffentlicher Geschichtsvermittlung eingeflossen sind.

\section{Wandlungen von Marginalisierungsstrategien - museale Präsentationen der 1980er- und 1990er-Jahre}

Zunächst stehen die Wandlungen der musealen Präsentationen über den Systemwechsel von 1989 hinweg im Fokus. Die Dauerausstellungen, die Anfang der 1980er-Jahre und damit noch vor dem Boom der jüdischen Geschichte

53 Joanna Michlic fasst die damit verbundene »Vision von Polen« folgendermaßen zusammen: »[a vision] in which there is only room for a single culture and a single faith, ethnic Polish and Roman Catholic«. Michlic: Poland's Threatening Other, 3.

54 Ebd., 1-23.

55 Steinlauf: Pamięć nieprzyswojona, 113-136, 143-162. 
und Kultur unter polnischen Intellektuellen entstanden sind, dienen dabei als Ausgangspunkt für die Analyse der Präsentationen, die um das Wendejahr 1989 neu aufgelegt wurden sowie in der zweiten Hälfte der 1990er-Jahren neu entstanden sind.

\subsection{Die 1980er-Jahre - Marginalisierung durch Vereinnahmung}

Augenfällig in Bezug auf die Präsentationspraxis des jüdischen Schicksals in den 1980er-Jahren ist in erster Linie die Ähnlichkeit zwischen den Ausstellungen der verschiedenen Museen. Dies scheint zunächst bemerkenswert, da zwei der untersuchten Schauen - im Gefängnismuseum Pawiak und im Historischen Museum der Hauptstadt Warschau - bereits aus dem Jahr 1965 stammten. Die Präsentationen in Lublin (Abteilung "Unter der Uhr«) und Krakau (Abteilung Pomorska-Straße) wurden dagegen erst 1979 bzw. 1982 eröffnet. Trotz der eineinhalb bis zwei Jahrzehnte, die die Entstehung dieser Ausstellungen trennte, gleichen sich die Darstellungen des Themas in sämtlichen untersuchten Ausstellungen: In den meisten fanden sich nur vereinzelt wenige Hinweise auf die Judenverfolgung. Diese beschränkten sich zudem überwiegend auf die bloße Erwähnung der Existenz der jeweiligen Ghettos. ${ }^{56}$

Die Ausstellung von 1982 in der Pomorska-Straße in Krakau zeigte etwa vor allem Fotos vom Abtransport der Bewohner des Ghettos und damit seiner Liquidierung. ${ }^{57} 1990$ kamen Fotografien hinzu, die ihre vorangegangene Umsiedlung ins Ghetto sowie die Zwangsarbeit illustrierten. ${ }^{58}$ Das Schicksal der Deportierten - der Tod der überwiegenden Mehrheit von ihnen im Lager Płaszów oder in den Vernichtungslagern - wurde dabei lediglich angedeutet, mit Ausdrücken wie »die letzte Reise der Juden« (1982) oder "Aussiedlung"

56 Teile der folgenden Ausführungen wurden publiziert in Heinemann: Die »Emaillewarenfabrik Oskar Schindlers".

57 Gezeigt wurden ein Foto des Ghettogeländes nach der »Aussiedlungsaktion« sowie ein Foto des Abtransports seiner Bewohner. Daneben war eine Karte der Ghettos im Distrikt Krakau ausgestellt. Wroński, Tadeusz: Scenariusz wystawy Oddziału Muzeum Historycznego m. Krakowa przy ul. Wybickiego 2 (dawniej ul. Pomorska) pt. »Walka i męczeństwo Polaków w latach 1939-1945«. Kraków 26.5.1981. AMHK, PA-202 / 25 / 81, 4. Das Krakauer Ghetto wurde am 3. März 1941 geschaffen und im März 1943 liquidiert. Zur Geschichte des Krakauer Ghettos vgl. Chwalba, Andrzej: Kraków żydowski - Kroke [Das jüdische Krakau - Kroke]. In: Ders.: Dzieje Krakowa, Bd.5, 95-162; Zimmerer, Katarzyna: Zamordowany Świat. Losy Żydów w Krakowie 1939-1945 [Die vernichtete Welt. Das Schicksal der Juden in Krakau 1939-1945]. Kraków 2004.

58 Gąsiorowski, Teodor/Kuler, Andrzej/Natkaniec, Marek: Scenariusz wystawy »Kraków 1939-1945« (wersja V - zrealizowana). o. J. [1990]. AMHK, OP-6411-11-90, 7. 
(1990). ${ }^{59}$ In beiden Schauen beschränkte sich die Darstellung des Schicksals der Ghettobewohner insgesamt auf wenige Bilder und Objekte, während der Terror gegen die polnische Bevölkerung außerhalb des Ghettos verhältnismäßig umfangreich und differenziert geschildert wurde.$^{60}$ Explizite Darstellungen von Gewalt, wie beispielsweise Fotografien von Exekutionen oder Bekanntmachungen der Besatzungsorgane über verhängte und vollstreckte Todesurteile, bezogen sich ebenfalls fast ausschließlich auf die polnische Bevölkerung der Stadt und des Distrikts Krakau. Die wenigen präsentierten Abbildungen mit Bezug zum Ghetto und seinen Bewohnern waren dagegen frei von unmittelbarer Gewaltausübung. ${ }^{61}$ Das Ghetto und seine Einwohner erwähnte man somit zwar; ihr Leiden vor Ort und ihr weiteres Schicksal wurden jedoch in das übergeifende Thema des "Terrors" der Deutschen eingereiht und damit verallgemeinert. ${ }^{62}$ Der Schwerpunkt der Ausstellung lag auf der Schilderung des Leidens der polnischen Bevölkerung auf der sogenannten arischen Seite der Stadt.

Im Gefängnismuseum Pawiak in Warschau thematisierte man die jüdische Bevölkerung sogar noch sparsamer. In der gesamten Ausstellung verstreut wurde das Ghetto an einigen Stellen erwähnt, ohne jedoch die Umstände seiner Schaffung oder seiner Existenz zu schildern. Zu diesen wenigen sporadischen Hinweisen gehörte etwa die Anmerkung, dass Musiker aus dem Ghetto in das Gefängnis geholt wurden, oder der Verweis auf die Verschärfung der Kontrollen des polnischen Personals des Pawiak beim Betreten des Ghettos. ${ }^{63}$ Ebenso beiläufig wurde auf jüdische Insassen im Pawiak-Gefängnis

59 So die in den jeweiligen Bildunterschriften verwendeten Begriffe. Wroński: Scenariusz wystawy, 4; Gąsiorowski / Kuler/Natkaniec: Scenariusz wystawy, 7. Die Rahmendaten zur Existenz des Ghettos und damit seine zeitliche Einordnung in die Besatzung fehlte in beiden Schauen jedoch. Diese wurde erst 1998 in Form von Verweisen in kleineren Bereichstexten in die Ausstellung eingeführt.

60 Dargestellt wurden verschiedene gegen die polnische Bevölkerung gerichtete Aktionen und Zwangsmaßnahmen wie u. a. Straßenrazzien und Exekutionen von polnischen Zivilisten im Distrikt Krakau, die Foltermethoden während der Verhöre in der PomorskaStraße und dem gefürchteten Gefängnis Montelupich (1982) oder die »Sonderaktion Krakau" und das Arbeitslager "Liban« (1990). Wroński: Scenariusz wystawy, 3 f. und 8f.; Gąsiorowski/Kuler/Natkaniec: Scenariusz wystawy, 4-6. Zur Darstellung der polnischen Bevölkerung in den Ausstellungen siehe Teil 3.

61 Wroński: Scenariusz wystawy, 4; Gąsiorowski/Kuler/Natkaniec: Scenariusz wystawy, 7. Auch in der Schau von 1998 zeigte man ausschließlich Gewalttaten gegen die polnische Bevölkerung.

62 Die Schilderung des Ghettos war in den Ausstellungen von 1982 und 1990 jeweils dem Themenabschnitt »Der hitleristische Terrorapparat und seine verbrecherische Tätigkeit» zugeordnet. Wroński: Scenariusz wystawy, 2; Gąsiorowski/Kuler/Natkaniec: Scenariusz wystawy, 6 .

63 Scenopis stałej ekspozycji Muzeum Więzienia »Pawiak«. Warszawa 1987. AMNW, Scen. 72, 75, 78. Der Pawiak lag inmitten des Ghettogeländes. 
sowie jüdische Opfer von Massenexekutionen verwiesen: In Übersichten, die den »normalen« Tagesablauf im Pawiak schilderten, oder auf Exekutionslisten waren jüdische Häftlinge genannt. Man identifizierte sie durch gesonderte Bezeichnungen, durch Begriffe wie »Juden«, »jüdische Familien« oder "jüdische Häftlinge« (więźniowie Żydzi), womit sie zugleich von den übrigen »Frauen«, »Männern« und »Häftlingen« unterschieden wurden, die durch die sprachliche Herausstellung der »Juden « implizit als Vertreter polnischer Nationalität erschienen. ${ }^{64}$ Diese marginale Thematisierung behielt man im Pawiak nach der Umgestaltung der Präsentation im Jahr 1991 in fast identischer Form bei. Auch hier wurde die Ausgrenzung und Verfolgung der jüdischen Stadtbewohner nicht näher dargestellt; nur vereinzelt wurde auf das Ghetto verwiesen. ${ }^{65}$ Selbst den Ausbruch des Aufstands im Warschauer Ghetto 1943, ein im offiziellen Gedenkkalender der VRP fest verankertes Ereignis, streifte man in beiden Schauen lediglich, woran sich unmittelbar die Information über seine Niederschlagung anschloss. Im Anschluss wurden »die Ruinen des Ghettos « lediglich als Exekutionsorte von Häftlingen des Pawiak und von Warschauern erwähnt. ${ }^{66}$ Juden tauchten auch in den zahlreichen Auflistungen von Massenexekutionen, die sich in beiden Präsentationen fanden, insgesamt vergleichsweise selten auf; die Erschießungen, zu deren Opfern auch Juden zählten, waren zudem nicht visuell dargestellt.

In den Ausstellungen des MHK wie des Pawiak wurden somit zwar sowohl die polnische als auch die jüdische Bevölkerung als Opfer von Brutalität und Terror seitens der Deutschen präsentiert. Inhaltlich und visuell dominierten jedoch die Gräueltaten gegenüber ethnischen Polen beide Schauen. ${ }^{67}$ Jüdische

64 Derartige Bezeichnungen tauchen insbesondere bei der Auflistung von Opferzahlen einzelner Erschießungsaktionen auf, z. B. in der »Chronik der letzten Tage des Pawiak" und bei einer Liste von Massenexekutionen in den Ruinen des Ghettos. Scenopis stałej ekspozycji, 60-62, 70, 72 .

65 Bei der Schau von 1991 handelte es sich im Wesentlichen um eine leicht überarbeitete Variante der Vorgängerausstellung. Ein Großteil der Autorentexte wurde in z. T. leicht gekürzter Fassung übernommen. Gleiches trifft auf wesentliche Exponate und Dokumente zu. Vgl. Izdebska, Barbara: Pawiak 1939-1945. Ekspozycja stała. Scenopis. Warszawa 1991. AMNW, Scen. 79.

66 In beiden Ausstellungen wurde diese Information in lediglich einem, fast identischen Satz zusammengefasst: »Im April 1943 brach im Ghetto ein bewaffneter Aufstand aus. Nach seiner Niederlage wurden die Ruinen des Ghettos für die [hitleristischen - Ausstellung von 1990] Folterknechte zum günstigen Ort der Vernichtung tausender Häftlinge des Pawiak."Scenopis stałej ekspozycji, 69 f. (Thementext); Izdebska: Pawiak 1939-1945, 129.

67 In den Präsentationen des Pawiak-Museums ebenso wie der Abteilung Pomorska-Straße des MHK, die bis 1991 eröffnet wurden, zeigte man Fotos der ersten Massenexekutionen an Polen nach dem Einmarsch der Deutschen. Ähnliche Abbildungen unmittelbarer Gewaltausübung gegenüber Juden gab es hingegen nicht. Scenopis stałej ekspozycji, 55-57; Izdebska: Pawiak 1939-1945, 9 f.; Wroński: Scenariusz wystawy, 3 f.; Gąsiorowski/Kuler / Natkaniec: Scenariusz wystawy, $6 \mathrm{f}$. 
Opfer des deutschen Besatzungsterrors erschienen somit im Vergleich zur großen Zahl der polnischen Insassen des Pawiak-Gefängnisses sowie der Terroropfer im Distrikt Krakau als eine relativ kleine, untergeordnete Opfergruppe. Da ihre Erwähnung gerade im Pawiak-Museum derart marginal blieb, kann man vermuten, dass Besucher, die nicht explizit auf die Existenz der Ghettos hingewiesen wurden, dieses bei ihrem Rundgang übersehen konnten.

Auch auf die Motive für die Verfolgung und Ermordung der jüdischen Bevölkerung ging man in diesen Ausstellungen nur indirekt ein. Den einzigen Verweis auf die Ziele der deutschen Besatzungs- und Bevölkerungspolitik boten in den Schauen der Pomorska-Straße sowie des Pawiak von $1991 \mathrm{Zi}$ tate Adolf Hitlers mit dem Befehl, »ohne Gnade und Erbarmen alle Männer, Frauen und Kinder polnischer Rasse und Sprache zu töten «. ${ }^{68}$ Auch in der Ausstellung des Pawiak von 1965 wurde dieselbe Botschaft, wonach das Ziel der Deutschen die Vernichtung der polnischen Bevölkerung war, mehrfach mittels Autorentexten vermittelt: So präsentierte man etwa das Konzentrationslager Auschwitz als "neuen schrecklichen Ort der Vernichtung « für »Tausende Häftlinge des Pawiak«. ${ }^{69}$ Den Sitz der Sicherheitspolizei und des Sicherheitsdienstes für den Distrikt Warschau in der Szucha-Allee bezeichnete man als Ausgangspunkt für »Pläne der Terroraktionen, deren endgültiges Ziel die Ausrottung der polnischen Nation« gewesen sei. ${ }^{70}$ Die Verfolgung der jüdischen Einwohner des besetzten Polens erschien in dieser Kontextualisierung der Vernichtungsabsicht gegenüber der polnischen Gesamtbevölkerung untergeordnet. Die unterschiedlichen Dimensionen und Ziele der deutschen Besatzungspolitik in Bezug auf beide Bevölkerungsgruppen wurden damit verschleiert bzw. regelrecht umgekehrt: Durch die Marginalisierung jüdischer Opferdarstellung in den Präsentationen erschienen Polen als Haupt-

68 In den zwei Ausstellungen in der Pomorska-Straße unterschied sich der Wortlaut der Zitate nur minimal. In der Schau von 1982 war das folgende Zitat Adolf Hitlers mit dem Datum vom 20. August 1939 versehen: »Ich schicke meine Totenkopfverbände nach Osten mit dem Befehl, ohne Gnade und Erbarmen alle Männer, Frauen und Kinder polnischer Rasse und Sprache zu töten«. Wroński: Scenariusz wystawy, 2. In der Präsentation von 1990 wurde das fast wortgleiche Zitat Adolf Hitlers mit dem Datum vom 28. August 1939 angegeben: »Ich schicke meine Totenkopfverbände nach Osten mit dem Befehl, ohne Gnade alle Männer, Frauen und Kinder polnischer Rasse und Sprache zu töten.« Gąsiorowski/Kuler/Natkaniec: Scenariusz wystawy, 1. Auch im Pawiak wurde die Ausstellung mit einem Hitler-Zitat eröffnet. Dieses lautete hier: »Ich habe den Befehl erteilt und werde jeden erschießen lassen, der auch nur mit einem Wort zu kritisieren versucht, dass das Ziel des Kriegs nicht das Erreichen einer bestimmten Linie ist, sondern die physische Vernichtung des Gegners. Mit diesem Ziel habe ich zunächst nur im Osten meine Totenkopfverbände vorbereitet, mit dem Befehl, ohne Erbarmen, ohne Mitleid Frauen und Kinder polnischer Abstammung und polnischer Sprache zu töten." Dieses Zitat wurde auf den 22. August 1939 datiert. Izdebska: Pawiak 1939-1945, 9.

69 Scenopis stałej ekspozycji, 90.

70 Ebd., 67. 
opfer der Gewalt- und Vernichtungspolitik der Besatzungsmacht. Ausdruck fand diese Hierarchisierung von Opferzuschreibungen auch in der Vermeidung des Begriffs "Vernichtung" in Bezug auf die Verfolgung von Juden; verwendet wurde er, wie weiter oben bereits exemplarisch geschildert, ausschließlich bei der Darstellung der Zwangsmaßnahmen, die gegen die polnische Bevölkerung gerichtet waren.

Ein weiteres, damit eng verbundenes Charakteristikum der Darstellung dieses Themas ist bereits angeklungen: Zwar wurden in allen Ausstellungen, die in den 1980er-Jahren zu sehen waren, insgesamt wenige ethnische Zuschreibungen oder Begrifflichkeiten verwendet. Dort, wo sie jedoch auftauchten, dienten sie der Unterscheidung von »Polen« und »Nicht-Polen« bzw. »Polen« und »Juden«. In keiner der Ausstellungen wurde dabei der Begriff "Jude«/»jüdisch" als solcher problematisiert. Weder erläuterte man den Besuchern den rassistischen Hintergrund der nationalsozialistischen Zuschreibung »jüdisch «, ${ }^{71}$ noch thematisierte man die Wahrnehmung von ethnischen Unterschieden in der Zweiten Republik. Die Begriffe »Jude / »jüdisch"wurden in den Schauen ganz selbstverständlich gebraucht und weder reflektiert noch hinterfragt, womit sie eine »natürliche« oder scheinbar offensichtliche Differenzierung der Bevölkerung des besetzten Polens suggerierten. Den Besuchern wurde damit das Bild einer homogenen und klar zu differenzierenden Minderheit vermittelt, ohne auf die rassistischen Grundlagen der nationalsozialistischen Nationalitätenbegriffe einzugehen oder auf die Binnendifferenzierung der Gruppe der als Juden Verfolgten und der jüdischen Bevölkerung Polens hinzuweisen. Eine Historisierung der zeitgenössischen Wahrnehmung von Polen und Juden als verschiedene Nationalitäten, die in vollkommen getrennten Lebenswelten existierten, fand mithin nicht statt. Juden wurden als der polnischen Nation nicht Zugehörige aus der Wir-Gemeinschaft der Protagonisten der musealen Erzählungen weitgehend ausgeschlossen. Zugleich vereinnahmte man ihr Schicksal zur Stärkung des in den Ausstellungen gezeichneten Opferbildes, wobei ihre Thematisierung jedoch anonym und peripher blieb. So tauchten etwa »jüdische« Opfer von Massenerschießungen im Gefängnismuseum Pawiak ausschließlich in anonymen Opferlisten auf, in denen sie als abstrakte Zahlen - neben überwiegend polnischen Opfern - erschienen. Das Ghetto während seiner Existenz und dessen Bewohner waren zudem nicht visuell in den Ausstellungen präsent. ${ }^{72}$

71 Zur NS-Rassenpolitik siehe Friedländer, Saul: Das Dritte Reich und die Juden. Verfolgung und Vernichtung 1933-1945. Bonn 2007, Bd. 1: 162-191, v. a. 166-168; Bd. 2. Zur Situation in Polen direkt: Borodziej: Geschichte Polens, 201-210.

721991 wurde lediglich eine kartografische Darstellung in die Dauerausstellung aufgenommen in Form einer wandhohen Karte von Warschau und seiner Umgebung, in der u.a. auch die Grenzen des Ghettogeländes eingezeichnet waren. Izdebska: Pawiak 1939-1945, 9. 
Auch in der Pomorska-Straße in Krakau blieb die Darstellung der Ghettoinsassen weitgehend anonym. ${ }^{73}$

In anderen Schauen ging die Marginalisierung des jüdischen Schicksals noch weiter, indem die Verfolgung von Juden ganz unerwähnt blieb. So fand sich etwa im Martyrologiemuseum »Unter der Uhr« in Lublin weder ein Hinweis auf die Deportation von mehreren Tausend Juden aus den 1939 besetzten Gebieten nach Lublin noch eine Information über die zwei Ghettos, die im Stadtgebiet existiert hatten. ${ }^{74}$ Bis heute ist dieser Aspekt der Stadtgeschichte in der Ausstellung nicht vertreten. Zum Zeitpunkt der Recherchen im Jahr 2010 war eine seit der Eröffnung der Abteilung gezeigte Karte mit Exekutionsorten von Häftlingen des Lubliner Schlosses zwar um den Ort »Majdanek« ergänzt (der in der Ausstellungsversion von 1979 noch nicht vorhanden war). ${ }^{75}$ Auch wurden seit Anfang der 1990er-Jahre deutsche Konzentrationslager wie etwa Auschwitz-Birkenau oder Ravensbrück als Ziele der Deportationen von

Daneben waren in der Ausstellung zwei Fotos der »Ruinen des Warschauer Ghettos« zu sehen. Ebd., 130 (Bildunterschrift).

73 Ausnahmen stellten seit 1990 nur die wenigen namentlich genannten Mitglieder der »)üdischen Kampforganisation« (Żydowska Organizacja Bojowa, ŻOB) dar. Die Mitglieder der Organisation wurden jeweils mit einem Foto und dem Namen des/der Abgebildeten präsentiert. Gąsiorowski/Kuler/Natkaniec: Scenariusz wystawy, 12f. (Tafel 34). Auch in der Ausstellung von 1998 in der Pomorska-Straße fand sich diese Tafel wieder (mit vier weiteren Personen). In dieser Version der Schau wurden zusätzlich kurze Biogramme zu den einzelnen Personen hinzugefügt. MHK-Pomorska-Straße, Tafel 15.

74 In der Ausstellung gab es lediglich einen indirekten Hinweis auf die Präsenz einer jüdischen Gemeinde in der Stadt: So wurde in der 1979 eröffneten Schau die erste Massenexekution in Lublin am 23. Dezember 1939 geschildert, die - wie der Text auf der Ausstellungstafel informierte - auf dem alten jüdischen Friedhof (kirkut) stattfand und in der 10 Vertreter der Lubliner Intelligenz [erschossen wurden].» Auf das Schicksal der Mitglieder dieser Minderheit wurde jedoch an keiner Stelle weiter eingegangen. Siehe: Fotodokumentation der Museumseröffnung. AMLL, Kronika Klubu b. Więźniów Politycznych Zamku Lubelskiego i »Pod Zegarem« Nr. 3 (9/ 1978-8/ 1981), ohne Signatur, o. S. Zur Geschichte der jüdischen Bevölkerung der Stadt während der Besatzung: Radzik: Lubelska dzielnica zamknięta; Tomczyk, Józef: Rada Żydowska w Lublinie 1939-1942 organizacja, działalność i pozostałość aktowa [Der Judenrat in Lublin 1939-1942 - Organisation, Tätigkeit und Aktenbestände]. In: Radzik, Tadeusz (Hg.): Żydzi w Lublinie. Materiały do dziejów społeczności żydowskiej Lublina [Juden in Lublin. Materialien zur Geschichte der jüdischen Gemeinde Lublins]. Bd. 1. Lublin 1995, 245-255; Marszałek, Józef: Żydzi warszawscy w Lublinie i na Lubelszczyźnie w latach 1940-1944 [Warschauer Juden in Lublin und der Lubliner Region in den Jahren 1940-1944]. In: Radzik: Żydzi w Lublinie, 257-271. Zur Geschichte der Verfolgung der jüdischen Einwohner des Distrikts Lublin sowie der von hier ausgehenden »Aktion Reinhardt«: Musiał, Bogdan: Deutsche Zivilverwaltung und Judenverfolgung im Generalgouvernement. Eine Fallstudie zum Distrikt Lublin 1939-1944. Wiesbaden 1999; Libionka, Dariusz (Hg.): Akcja Reinhardt. Zagłada Żydów w Generalnym Gubernatorstwie [Die Aktion Reinhardt. Die Vernichtung der Juden im Generalgouvernement]. Warszawa 2004.

75 MLL-Unter der Uhr, Zelle 9; Fotodokumentation der Museumseröffnung. 
Häftlingen thematisiert. In beiden Fällen wurde und wird jedoch keinerlei Bezug zwischen diesen Orten und der Verfolgung von Juden und anderen Opfergruppen durch die deutschen Besatzer hergestellt. ${ }^{76}$

Trotz der in der offiziellen Geschichtspolitik des Landes propagierten übernationalen Rhetorik ${ }^{77}$ spiegelten die Dauerausstellungen der untersuchten Museen somit eine ethnisch-nationale Perspektive wider; der Fokus aller Präsentationen lag auf der Geschichte des ethnisch-polnischen Teils der Bevölkerung. Diese grundlegende Ausrichtung entsprach dem faktischen Nationalismus, dessen sich der sozialistische polnische Staat in dem Streben bediente, eine breite Unterstützung und Akzeptanz seitens der Bevölkerung zu erzielen. ${ }^{78}$ Die Ausstellungen perpetuierten dabei unreflektiert Kategorien nationaler und ethnischer Zugehörigkeit, die in der Zwischenkriegszeit tradiert worden waren, während des Kriegs in der Bevölkerung des besetzten Landes präsent und auch in der VRP wirkmächtig blieben. Juden wurden einerseits als »Fremde« in den Ausstellungen marginalisiert; ihre Erwähnung diente allein der Exemplifizierung des deutschen Besatzungsterrors. Andererseits zählte man die Opferzahlen der als Juden Verfolgten bei der Nennung der Gesamtverluste der jeweiligen Stadt, Region bzw. des Landes stets mit und vereinnahmte sie somit. ${ }^{79}$

Bei der in den Schauen angewandten "Opferarithmetik« ist auffällig, dass die gesonderte Nennung von Zahlen jüdischer Opfer bei Themen oder Orten (Konzentrations- und Vernichtungslagern) vermieden wurde, an denen sie die Mehrheit der Toten ausmachten. So erwähnte man etwa im PawiakMuseum die Nationalitäten der Gefangenen von Konzentrationslagern, in die Häftlinge des Gefängnisses deportiert worden waren, nur in den Fällen, in denen Polen die Mehrheit bildeten. So hieß es etwa über das Lager Ravensbrück: »Hier wurden Frauen 17 verschiedener Nationalitäten gefangen gehalten, von denen die Mehrzahl Polinnen waren. $\aleph^{80}$ Bei anderen Lagern, in denen andere Gruppen - in erster Linie Juden - die Mehrzahl der Todesopfer

76 Seit 1992 ist ein Ausstellungsteil dem Schicksal der nach Auschwitz-Birkenau deportierten Insassen des Gefängnisses gewidmet, die kollektiv als "politische Häftlinge polnischer Nationalität« identifiziert werden: Auf der gestreiften Häftlingskleidung, die in Zelle 10 ausgestellt wird, ist ein roter Wimpel mit einem »P« darin angebracht. Rote Wimpel als Symbole politischer Häftlinge, als welche Polen meist erfasst wurden, finden sich mehrfach in der gesamten Ausstellung. Eine Karte zeigt zusätzlich diejenigen Konzentrationslager, in die Häftlinge deportiert wurden. Es findet sich in dem Abschnitt jedoch kein Hinweis auf andere Opfergruppen, die in Auschwitz-Birkenau bzw. anderen Lagern gefangen gehalten und ermordet wurden. MLL-Unter der Uhr, Zelle 10.

77 Zaremba: Komunizm, legitymizacja, nacjonalizm, 399.

78 Ebd., 397-400.

79 Michlic/Melchior: The Memory of the Holocaust, 414.

80 Scenopis stałej ekspozycji, 93. Diese Aussage fand sich fast wortgleich auch in der Präsentation von 1991. Izdebska: Pawiak 1939-1945, 164. 
ausmachten, geschah dies dagegen nicht, so etwa bei der Darstellung von Auschwitz-Birkenau: »Oświęcim - das größte Konzentrationslager. Hier kamen 4 Millionen Menschen aus allen Ländern Europas um, darunter 2,5 Millionen polnische Staatsbürger. ${ }^{81}$ Bei der Herausstellung der Gesamtverluste des Landes während des Kriegs wurden die als Juden verfolgten Bürger des besetzten Polens in ähnlicher Weise mitgezählt:

Unter allen Ländern, die am Kampf gegen das hitleristische Deutschland teilnahmen, erlitt Polen die größten Verluste im Verhältnis zur Gesamtbevölkerungszahl. Über 6 Millionen verloren ihr Leben.

Allein in Konzentrationslagern, Gefängnissen und bei Massenexekutionen starben 3 Millionen 600 Tausend polnische Staatsbürger. ${ }^{82}$

Durch die ethnisch-neutrale Kategorie der "polnischen Staatsbürger« wurde die Zusammensetzung der Opferzahlen aus verschiedenen Gruppen Verfolgter verschleiert. Zugleich suggerierte die alleinige herausgehobene Erwähnung polnischer Insassen implizit, Polen seien die größte Opfergruppe der nationalsozialistischen Besatzungspolitik gewesen. Diese spezifische Präsentationsweise ist damit Ausdruck einer latenten Konkurrenz um den Status des primären Opfers, die sich auch in der Verwendung des Terminus "Vernichtung « widerspiegelte. Die Gleichsetzung von Konzentrationslagern mit überwiegend polnischem Leiden transportierte auch die Auswahl der präsentierten Exponate. So fanden sich in den Schauen ausschließlich Dokumente von Häftlingen polnischer Nationalität. ${ }^{83}$ Des Weiteren wurde in beiden Schauen ein gestreifter Häftlingsanzug präsentiert, auf dem ein roter Wimpel mit einem »P« darin aufgenäht war. Die Objektbeschriftung zu diesem Ausstellungsstück vermittelte auch unwissenden Besuchern die Bedeutung des Symbols: "Häftlingsanzug mit den Emblemen eines politischen Häftlings polnischer Nationalität. ${ }^{84}$

81 Scenopis stałej ekspozycji, 93. Interessanterweise entfiel dieser Text, der eine - durch Forschungen inzwischen korrigierte - stark überhöhte Opferzahl des Lagers enthielt, in der Ausstellungsversion von 1991.

82 Scenopis stałej ekspozycji, 56. Derselbe Text fand sich auch in der Ausstellung von 1991. Izdebska: Pawiak 1939-1945, 165. Die Hintergründe der Berechnungen und sukzessiven Verfestigung der polnischen Opferzahlen seit Kriegsende sowie deren Revision seit der Wende schildert ausführlich Gniazdowski, Mateusz: Bevölkerungsverluste durch Deutsche und Polen während des Zweiten Weltkrieges. Eine Geschichte der Forschungen und Schätzungen. In: Historie. Jahrbuch des Zentrums für Historische Forschung Berlin der Polnischen Akademie der Wissenschaften 1 (2008), 65-92, bes. $86 \mathrm{f}$.

83 Scenopis stałej ekspozycji, 90-95; Izdebska: Pawiak 1939-1945, 146-149, 151-154, 156-159, 161-165.

84 Scenopis stałej ekspozycji, 90; Izdebska: Pawiak 1939-1945, 154. Dieses Exponat findet sich bis heute in der Dauerausstellung des Museums. 
Mit dieser Einordnung des Schicksals der jüdischen Stadtbewohner folgten die Schauen beider Museen der historischen Meistererzählung der Volksrepublik, in der seit Ende der 1960er-Jahre die Unterdrückung und Ermordung der als Juden verfolgten Bevölkerung Vorkriegspolens in das nationalpolnische Martyrium des Kriegs vereinnahmt und damit letztlich verschwiegen wurde ${ }^{85}$ Das polnische Leiden und der polnische Widerstand während der Besatzungsjahre standen im Zentrum der Präsentationen; die Unterschiede der Verfolgungs- und Leidensgeschichte von Polen und Juden wurden somit verwischt. ${ }^{86}$ Andererseits muss erwähnt werden, dass gerade die Objektauswahl für die Museen sehr limitiert war. Die überwiegende Anzahl der Exponate stammte von ehemaligen Gefängnisinsassen, von denen die Mehrheit Polen waren bzw. als Polen Haft und Lager überlebt hatten - im Gegensatz zum Großteil der als Juden Deportierten. Allein dieser Sachverhalt reduzierte bereits den Kreis möglicher Objektspender oder -leihgeber. Zugleich kann jedoch darauf verwiesen werden, dass die Ausstellungsmacher die Einseitigkeit der vor diesem Hintergrund zustande gekommenen Objektauswahl nicht thematisierten, sondern, im Gegenteil, vielmehr durch die beschriebene Begriffswahl und Formulierungen den Fokus bewusst auf polnisches Leid lenkten, unter das andere Opfergruppen, in erster Linie Juden, stillschweigend subsumiert wurden.

Kennzeichnend für dieses Geschichtsbild war auch das weitgehende Fehlen von Verweisen auf jüdischen Widerstand in den meisten der genannten Ausstellungen. Wie bereits geschildert, fand sich in den Präsentationen des Pawiak zwar ein Hinweis auf den Ghettoaufstand im Jahr 1943; da man diesen jedoch bis auf seine bloße Benennung nicht weiter thematisierte, erschien er in der Erzählung als Randereignis. Da zudem der Auslöser des Aufstands der Beginn der endgültigen Liquidierung des Ghettos - sowie seine Ziele der Widerstand gegen die physische Vernichtung seiner Bewohner - nicht benannt wurden, erschien er als Teil des gesamtpolnischen Widerstands. In der Abteilung des MHK fehlte in den 1980er-Jahren sogar jeglicher Verweis auf jüdische Widerstandsgruppen. Die Ghettobewohner wurden dort allein als passive Opfer präsentiert - im Gegensatz zur polnischen Bevölkerung und den polnischen Untergrundbewegungen, denen etwa die Hälfte

85 Steinlauf: Pamięć nieprzyswojona, 79-107, bes. 85-87, 98-100; Zaremba: Das organisierte Vergessen 164, 167f.; Leociak: Zraniona pamięć, 267 f.; Kobylarz: Walka o pamięć, 176 f., 180, 221-246, 430 f.; Friedrich, Klaus-Peter: Erinnerungspolitische Legitimierung des Opferstatus: Zur Instrumentalisierung fragwürdiger Opferzahlen in Geschichtsbildern vom Zweiten Weltkrieg in Polen und Deutschland. In: Bingen, Dieter/Loew, Peter O./Wóycicki, Kazimierz (Hg.): Die Destruktion des Dialogs. Zur innenpolitischen Instrumentalisierung negativer Fremd- und Feindbilder. Polen, Tschechien, Deutschland und die Niederlande im Vergleich, 1900-2005. Wiesbaden 2007, 176-191, hier 178-180. 
der Ausstellungsfläche gewidmet war. ${ }^{87}$ Erst 1990 wurde eine Ausstellungstafel mit Informationen über die »)̈̈dische Kampforganisation« (Żydowska Organizacja Bojowa, ŻOB $)^{88}$ sowie deren Mitglieder in Krakau aufgenommen, womit Juden erstmals auch als Widerständige und aktive Kämpfer porträtiert wurden. ${ }^{89}$ Die entsprechende Ausstellungstafel war jedoch in der Sektion untergebracht, die den (polnischen) Widerstandsorganisationen und Untergrundbewegungen gewidmet war. ${ }^{90}$ Diese Zuordnung suggerierte eine Gemeinschaft von Polen und Juden im Widerstand und im Kampf gegen den gemeinsamen Feind - die deutschen Besatzer - und für ein gemeinsames Ziel - die Befreiung Polens. Auch mit der Einführung dieses neuen Elements in die Schau wurde den Besuchern somit, ähnlich wie im Gefängnismuseum Pawiak, weiterhin das Bild einer Schicksalsgemeinschaft von Polen und Juden während der Besatzung vermittelt, das die unterschiedlichen Verfolgungserfahrungen und Ziele der einzelnen Widerstandsgruppen außer Acht ließ.

Dieser Interpretations- und Darstellungsansatz war besonders prägnant im Stadtmuseum von Warschau. Zwar fanden sich in seiner Dauerausstellung immer wieder Verweise auf den "Judenwohnbezirk" und seine Insassen: So wurde die Schaffung des Ghettos erwähnt und seine Lage mittels eine Stadtplans verdeutlicht; ebenso zeigte man Objekte, die den schwierigen Alltag der Bewohner illustrierten. ${ }^{91}$ Auch der Ghettoaufstand wurde dargestellt, durch einen Plan des Ghettogeländes mit den darin vermerkten »Positionen

87 Zum Widerstands- bzw. Heldennarrativ in den Ausstellungen vgl. Teil 3, Kapitel 2.1.

88 Die ŻOB wurde am 28. Juli $1942 \mathrm{im}$ Warschauer Ghetto als Widerstandsbewegung gegen die deutschen Besatzer gegründet. Während der Liquidierung des Ghettos organisierte sie einen bewaffneten Aufstand, der vom 19. April bis zum 16. Mai 1943 andauerte. Eine lokale Abteilung der Organisation entstand im September 1942 in Krakau. Deren Mitglieder verübten in der Stadt mehrere Anschläge auf deutsche Einrichtungen und Offiziere sowie auf Informanten. Zimmerer: Zamordowany świat, 132, 142, 148, 158, $165 \mathrm{f}$.

89 Gąsiorowski/Kuler/Natkaniec: Scenariusz wystawy, $12 \mathrm{f}$.

90 Eingeleitet wurde diese Sektion von einer Ausstellungstafel mit einem Zitat General Władysław Sikorskis, der »alle Polen [aufruft], wo immer sie sich befinden, zum aufopferungsvollen und disziplinierten Militärdienst, zum weiteren unbeugsamen Kampf um unsere heiligen Rechte«. Darüber prangte exponiert das Zeichen des Kämpfenden Polen (Znak Polski Walczacej). Gąsiorowski/Kuler/Natkaniec: Scenariusz wystawy, 8. Ein Foto dieser Ausstellungstafel findet sich in Passowicz: Kronika działalności za rok 1990, 194. Das Zeichen des Kämpfenden Polens erinnert an einen Anker; es ist zusammengesetzt aus den Buchstaben P und W für »Polska Walcząca» (Kämpfendes Polen).

91 »In der dritten Vitrine wurden neben Fotografien aus dem Ghetto, Armbinden mit dem sechseckigen Stern und einer Lebensmittelkarte eine Zusammenstellung von Lebensmittelrationen in Kalorien untergebracht, die vielsagend auf die hohe Sterblichkeit der Ghettobevölkerung verweist [...].«Informator do ekspozycji: 1. „Warszawa w latach drugiej wojny światowej« (1939-1945) 2. »Warszawa - stolicą Polski Ludowej« (III piętro). AP, zespół 3195 / I (Muzeum Historyczne m. st. Warszawy), teczka 76, MHW-440, 45-57, hier 49. 
der Aufständischen und der Deutschen im April und Mai 1943« sowie Fotografien der Anführer der Erhebung. ${ }^{92}$ Bilder des zerstörten Ghettogebiets fanden sich schließlich im »Saal der Zerstörungen", der die Gesamtverluste der Hauptstadt während des Kriegs darstellte. ${ }^{93}$ Trotz dieser mehrfachen Verweise auf das Leiden im Ghetto und auch auf den Widerstand, ordnete man die Schilderung der jüdischen Bevölkerung jeweils dem übergreifenden Kontext des "Terrors während der Besatzung", des »Kampfes der polnischen Untergrundorganisationen in den Jahren 1940-1944 auf dem Gebiet Warschaus« und des »Kampfes der Warschauer Jugend « zu, durch ihre Unterbringung in den gleichnamigen Ausstellungssälen. ${ }^{94}$ Auch in dieser Schau wurde die Verfolgung von Juden somit dem übergreifenden Thema des Terrors der Besatzer gegen die polnische Bevölkerung untergeordnet. Im Unterschied zu den anderen, bereits beschriebenen - und kleineren - Ausstellungen, tauchten in dieser zwar bereits vor der politischen Wende von 1989 die Ghettoinsassen nicht nur als (passiv) Leidende, sondern auch als Widerständige auf. Bemerkenswert ist jedoch, dass die Kämpfer des Ghettoaufstandes von 1943 nicht mittels einer nationalen bzw. ethnischen Benennung als »uden « kenntlich gemacht, ${ }^{95}$ sondern neutrale Ausdrücke wie "Aufständische" und »ugend des kämpfenden Ghettos" zu ihrer Umschreibung verwendet

92 Ebd. Daneben wurden Ausschnitte aus dem sogenannten Stroop-Bericht gezeigt, in dem die Niederschlagung des Aufstands geschildert wird. Fotos jugendlicher Aufständischer fanden sich auch im folgenden Saal, der dem »Kampf der Warschauer Jugend gegen den Besatzer" gewidmet war. Ebd., 49-51.

93 Ebd., 53 f. In der begleitenden Broschüre zur Ausstellung werden bei der Aufzählung der Gesamtverluste Warschaus während des Kriegs die Opferzahlen unter der »jüdischen Bevölkerung« kurz genannt. Płoszajska: Muzeum Historyczne, 21.

94 So die Bezeichnung der Themen der einzelnen Ausstellungssäle im Manuskript des Ausstellungsführers. Informator do ekspozycji, 48-50.

95 Eine ethnische Zuordnung eines Teils der Stadtbewohner geschieht im Manuskripttext zum Themenabschnitt »Warschau in den Jahren des Zweiten Weltkriegs" nur ein einziges Mal: In der Beschreibung des zweiten Themensaales der Ausstellung, der dem Terror der Besatzer gewidmet ist, heißt es: »Im Moment des Einmarschs der hitleristischen Truppen hatte Warschau 1.300.000 Einwohner. Etwa 1/3 machten jüdische Einwohner aus.« Daran schließt sich unmittelbar die Information über die Schaffung des Ghettos und die Zahl der darin eingesperrten »Menschen« ein. Eine explizite Benennung der größten ethnischen Minderheit der Stadt erfolgt somit allein unter dem Gesichtspunkt ihrer Abgrenzung von der polnischen Mehrheitsbevölkerung. Informator do ekspozycji, 48. Im publizierten Ausstellungsführer wird die ethnische Zuschreibung »jüdische Bevölkerung« ausschließlich bei der Aufzählung der Bevölkerungsverluste der Stadt während der Besatzung verwandt. Płoszajska: Muzeum Historyczne, 21. In dem kurzen Text, der in diesem Begleitheft die Jahre der deutschen Besatzung beschreibt, fehlen ansonsten sämtliche Verweise auf jüdischen Widerstand bzw. den Ghettoaufstand. Demgegenüber wird der Warschauer Aufstand 1944 mit mehreren Sätzen erwähnt und auch eine Fotografie des Ausstellungssaales gezeigt, der der Erhebung gewidmet war. Ebd., 19-21, Fotografie: 20. 
wurden..${ }^{96}$ Hierdurch ordnete man die jüdischen Widerstandskämpfer wiederum den "polnischen Untergrundorganisationen in den Jahren 1940-1944« und dem »Kampf der Warschauer Jugend gegen den Besatzer « zu bzw. unter. ${ }^{97}$ Auch die Beschreibung des Ghettoalltags verwendete überwiegend ethnisch neutrale Begriffe, wie etwa »Ghettobevölkerung ${ }^{98}{ }^{98}$ Es fehlten jegliche Hinweise auf Unterschiede der Behandlung dieser beiden Bevölkerungsgruppen durch die Besatzer. Die Schau verleibte somit sowohl das Leiden der als Juden Verfolgten und im Ghetto Eingesperrten als auch den Kampf der Widerständigen unter ihnen einem polnischen Opfer- und Heldennarrativ ein; dass es sich um Erfahrungen handelte, die ein Großteil der ethnisch polnischen Bevölkerung nicht in gleicher Weise betraf bzw. teilte, war aus der musealen Erzählung nicht zu deduzieren.

Durch die Entkontextualisierung und die damit erzielte Verallgemeinerung des jüdischen Besatzungsschicksals verfolgte diese Ausstellung - ähnlich wie die bereits geschilderten Schauen - eine Strategie der Vereinnahmung und damit zugleich der Marginalisierung der größten ethnischen Minderheit der Stadt im musealen Narrativ. Dies zeigt insbesondere der Vergleich der Präsentationsweise der zwei für die Warschauer Geschichte der Jahre 1939 bis 1945 wesentlichen Aufstände, des Ghettoaufstands von 1943 und des Warschauer Aufstands von 1944. Während Ersterer, wie bereits beschrieben, in mehreren Verweisen in verschiedenen thematischen Räumen der Ausstellung auftauchte, dabei jedoch seiner Distinktion im Sinne der spezifischen Verfolgungsgeschichte seiner Teilnehmer beraubt wurde, war der Erhebung von 1944 ein eigener Ausstellungssaal gewidmet, in dem ausschließlich und detailliert die militärische Auseinandersetzung der (polnischen) Warschauer mit den deutschen Besatzern geschildert wurde. ${ }^{99}$ Er erhielt durch diese räumliche Hervorhebung besonderes Gewicht und Bedeutung innerhalb der musealen Erzählung.

Zwar bestand die in der Schau geschilderte primäre Opposition zwischen den »Deutschen" einerseits und den »Unseren«, das heißt »den polnischen Truppen ${ }^{100}$ andererseits, zu denen - dem offiziell staatsbürgerlichen Selbstverständnis der VRP entsprechend - durchaus auch jüdische Bürger gezählt werden konnten. In der Dauerausstellung des zentralen stadthistorischen Museums des Landes zeigte sich jedoch eine deutliche Hierarchisierung der beiden Aufstände und der damit thematisierten Bevölkerungsgruppen: Eine zentrale Rolle im musealen Narrativ nahm die polnische Erhebung von 1944

96 Informator do ekspozycji, 49, 51.

97 Ebd., 49-51.

98 Ebd., 49.

99 Ebd., 52 f.; Płoszajska: Muzeum Historyczne, $20 \mathrm{f}$.

100 Informator do ekspozycji, 46, 50. 
ein, ${ }^{101}$ während der Aufstand im Ghetto ethnisch entkontextualisiert als ein (polnischer) Widerstandsakt unter vielen erschien. Aus der Vereinnahmung der Besatzungserfahrungen der jüdischen Bevölkerung resultierte somit nicht allein die Marginalisierung ihrer Opfer, sondern auch die ihrer Helden. Die jüdischen Aufständischen wurden hier als polnische Kämpfer geehrt. ${ }^{102}$ Dort, wo »Juden« dagegen begrifflich gekennzeichnet waren, ignorierte man den Aufstand in den Präsentationen fast vollständig, wie im Pawiak-Museum und in der Krakauer Pomorska-Straße. Zugleich wurde mittels der beschriebenen Kontextualisierung die Spezifik der Verfolgung der Juden während der deutschen Besatzung als solche relativiert bzw. negiert. ${ }^{103}$

Unmittelbar verbunden mit dieser Marginalisierung des Schicksals der jüdischen Bevölkerung war, dass die Mehrzahl der Ausstellungen das Thema der Kontakte und gegenseitigen Wahrnehmungen von Polen und Juden ausblendete. Wenn dieser Aspekt überhaupt auftauchte, so wurde meist eine Zusammenarbeit im Widerstand gegen die deutschen Besatzer suggeriert, wie am Beispiel der Präsentationen im MHW und MHK (1990) bereits dargelegt. Die zweite Variante der Darstellung von Kontakten beider Bevölkerungsgruppen konzentrierte sich auf polnische Hilfe für verfolgte Juden. So fand sich etwa bei der Schilderung des Warschauer Aufstands von 1944 in der ersten Dauerausstellung des Pawiak-Museums ein Hinweis auf die Befreiung der sogenannten Gęsiówka (eines Außenlagers des Konzentrationslagers Majdanek in Warschau) durch die polnischen Aufständischen samt dem Hinweis, dass »Juden aus mehreren Ländern « befreit wurden. ${ }^{104}$ Der Verweis auf diese Episode

101 Die nationale Zuschreibung "polnisch« in Bezug auf die besetzte Stadt und ihre Bewohner taucht neben der Schilderung des Septemberfeldzugs von 1939 ausschließlich bei der Beschreibung des Warschauer Aufstands 1944 auf, wo von der "polnischen Seite« und "polnischen Verlusten" gesprochen wird. Ebd., 53. Die Ausdrücke »unsere Positionen", "polnische Armee« und »unsere Seite» werden bei der Schilderung militärischer Aktionen gegen die deutschen Angreifer und Besatzer verwendet, d.h. bei der Darstellung des Septembers 1939 sowie der Aktionen der (polnischen) Untergrundbewegungen. Ebd., $46 \mathrm{f}$.

102 Leociak: Zraniona pamięć, 275.

103 Ein Vorgehen, das sein Vorbild in der staatlichen Geschichtspolitik und dem offiziellen Diskurs hatte. Potel, Jean-Yves: Zbyt często powtarzane stereotypy [Allzu häufig wiederholte Stereotype]. In: Engelking, Barbara u.a. (Hg.): Zagłada Żydów. Pamięć narodowa a pisanie historii w Polsce i we Francji [Die Vernichtung der Juden. Nationale Erinnerung und Geschichtsschreibung in Polen und Frankreich]. Lublin 2006, 185-191, hier 188. Siehe auch Leociak: Zraniona pamięć, $265 \mathrm{f}$.

104 Scenopis stałej ekspozycji, 62. Dieses Ereignis während des Warschauer Aufstands, das in der Erinnerung an diese Erhebung nach dem Krieg einen festen Platz fand, beschreibt Szarota, Tomasz: Atak na Gęsiówkę 5 VIII 1944 r. [Der Angriff auf die Gęsiówka am 5. August 1944]. In: Ders.: Karuzela na placu Krasińskich. Studia i szkice z lat wojny i okupacji [Das Karusell auf dem Krasiński-Platz. Studien und Skizzen zu den Kriegsund Besatzungsjahren]. Warszawa 2007, 57-67. 
findet sich auch in den späteren Warschauer Ausstellungen immer wieder als prominentes Beispiel einer vermeintlich verbreiteten Hilfsbereitschaft der polnischen Bevölkerung. Im Drehbuch der Krakauer Pomorska-Straße von 1982 findet sich ebenfalls ein kleiner Hinweis auf polnische Hilfe: Eine Fotografie zeigte die Exekution eines Mitglieds des Bund (»Allgemeiner Jüdischer Arbeiterbund in Litauen, Polen und Russland«), Aleksander Hirschberg, und eines Mannes namens Kruk, der ihn in seinem Haus in Przemyśl versteckt hatte. ${ }^{105}$ Dieses Ausstellungselement fungierte somit als Beleg polnischer Hilfe für verfolgte Juden (bzw. jüdische Sozialisten) und damit als Unterpfand eines vermeintlich typischen Verhaltens der polnischen Bevölkerung. ${ }^{106}$ Die Tatsache, dass das Foto als konkreter Beleg eines solchen Falls nicht aus Krakau selbst stammt, ist dabei ein Indiz für die Seltenheit einer solchen Handlungsweise.

Die Bezüge auf polnisch-jüdische Kontakte während der Besatzung beschränkten sich somit weitgehend auf den Aspekt polnischer Hilfe und polnisch-jüdischer Waffenbrüderschaft im Kampf gegen den gemeinsamen Feind. Wie geschildert, handelte es sich bei diesen Beispielen jedoch um vereinzelte, nicht kontextualisierte Hinweise. Fand also bereits die Erwähnung der Existenz von Ghettos in den einzelnen Schauen nur marginal statt, so waren die Kontakte zwischen beiden Bevölkerungsgruppen in den Präsentationen fast vollständig ausgeblendet. Damit wurde zugleich das heikle Thema der polnischen Zeugenschaft der Verfolgung und Vernichtung der Juden weitgehend vermieden. Die Verengung der polnisch-jüdischen Beziehungen im Krieg auf ausschließlich positive Beispiele entsprach dem konsensualen zeitgenössischen und insbesondere offiziellen Geschichtsbild. Damit reagierte man auf latente oder direkte Vorwürfe eines polnischen Antisemitismus im Krieg, die der polnische Staat wie die polnische Öffentlichkeit gerade aus dem westlichen Ausland wahrnahmen und die im Zuge beispielsweise der Debatte über Lanzmanns »Shoah« starke Abwehrreaktionen seitens der polnischen Öffentlichkeit hervorriefen. ${ }^{107}$

105 Diese Informationen sind aus der Bildbeschreibung zu entnehmen. Wroński: Scenariusz wystawy, 3.

106 Vgl. Libionka: Polskie piśmiennictwo, 18-55; Leociak: Zraniona pamięć, bes. 268, 270, 275.

107 Steinlauf: Pamięć nieprzyswojona, 127-129; Wawrzyniak: ZBoWiD, 312. 


\subsection{Die zweite Hälfte der 1990er-Jahre - Marginalisierung durch Ausgrenzung}

Erst seit 1998 ist in einigen Präsentationen eine langsame Erweiterung dieser Darstellungspraxis erkennbar, so etwa in der 1998 neu eröffneten Schau in der Pomorska-Straße in Krakau. ${ }^{108}$ Zwar war diese Ausstellung - wie auch die von 1990 - eine nur an wenigen Stellen erweiterte und überarbeitete Fassung ihrer Vorgängerin. Dennoch gab es einige deutliche Akzentverschiebungen: Die Schilderung des jüdischen Widerstands - in Form einer Ausstellungstafel zur ŻOB - wurde nun dem Themenbereich der Verfolgung der jüdischen Bewohner Krakaus zugeordnet. Damit wurde der Zusammenhang zwischen den Widerstandsaktionen und der sukzessiven Ausgrenzung und Ermordung der Juden erkennbar. Eine weitere Neuerung der Schau bestand in der erstmaligen Darstellung der alltäglichen Schikanen gegen die jüdische Bevölkerung, die der Bildung des Ghettos vorausgegangen waren. ${ }^{109}$ Auch die rassistische Grundlage für die Ausgrenzung wurde nun erstmals thematisiert, mittels eines antisemitischen Plakats der Besatzungsorgane (in polnischer Sprache), das Juden als Ursache für ansteckende Krankheiten darstellte. ${ }^{110}$ Weitere Fotos zeigten dieses Plakat auf den Straßen Krakaus sowie ein Schild auf einer Straßenbahn, das »über die geltende Rassentrennung informierte ${ }^{111}$ Bei der Darstellung der Liquidierung des Ghettos wurde zudem nun erstmals das Ziel der Deportationen mit dem unmissverständlichen Begriff »Todeslager ${ }^{112}$ benannt und damit die Ermordung fast aller Bewohner des Ghettos explizit angesprochen.

Kennzeichnend für diese Schau, wie auch für andere ab Ende der 1990erJahre entstandene Dauerausstellungen, ${ }^{113}$ war darüber hinaus, dass das Ghetto bzw. die Verfolgung der jüdischen Einwohner der Stadt in einem eigenen Abschnitt und somit getrennt von der Erzählung über die polnischen Krakauer präsentiert wurde. Die Sektion, die dem »Schicksal der Juden« gewidmet war, ${ }^{114}$

108 Ein weiteres Beispiel ist die 1998 eröffnete historische Dauerausstellung des Historischen Museums der Stadt Łódź, die in Kapitel 3.1 dieses Teils analysiert wird.

109 So war in der Schau ein Foto zu sehen, das zeigte, wie deutsche Soldaten einem orthodoxen Juden die Schläfenlocken abschnitten. MHK-Pomorska-Straße, Tafel 11.

110 Der Text des Plakats lautete: "Juden - Läuse - Fleckfieber«. MHK-Pomorska-Straße, Tafel 12.

111 MHK-Pomorska-Straße, Tafel 11, Bildunterschrift. Das Foto zeigte ein Schild mit der Aufschrift »Für Juden - Für Nichtjuden«.

112 MHK-Pomorska-Straße, Tafel 13, Bildunterschrift.

113 Die Schauen, die in den Jahren 1998 bis 2003 entstanden sind, werden in den Kapiteln 2 und 3 dieses Teils näher analysiert.

114 So die Überschrift dieser Sektion. MHK-Pomorska-Straße, Tafel 11. Bereits in der Vorgängerversion von 1990 wurde ein einzelner Abschnitt mit demselben Titel eingeführt. Gąsiorowski/Kuler/Natkaniec: Scenariusz wystawy, 7. 
nahm jedoch einen deutlich kleineren Teil der Ausstellungsfläche bzw. -tafeln ein als die übrigen Elemente des übergreifenden Themas Besatzungsterror. Die Hauptprotagonisten der musealen Erzählung blieben weiterhin die polnischen Stadtbewohner. Das Ghetto und die darin Eingeschlossenen bildeten in diesem Narrativ nur eine Episode. Die Schau ist damit ein exemplarisches Beispiel für die auch in den 1990er-Jahren andauernde Marginalisierung des Schicksals der jüdischen Stadtbewohner in den Besatzungserzählungen. Diese fand nun jedoch nicht mehr durch eine Verallgemeinerung und eine daraus resultierende Vereinnahmung ihres Leidens in ein polnisches martyrologisches Narrativ statt, sondern durch die gesonderte Präsentation in einem eigenen thematischen Abschnitt. Im Vergleich zur Schilderung der Erfahrungen der polnischen Bevölkerung wurde das Schicksal der in den Ghettos Eingeschlossenen hier verharmlosend und nur sehr knapp dargestellt. Die als Juden Verfolgten grenzte man aus dem übergreifenden polnisch-nationalen Narrativ der Ausstellungen aus. Ihr Schicksal wurde als das einer "fremden" Gruppe nur peripher behandelt; ihre Thematisierung diente dabei weiterhin in erster Linie der Exemplifizierung der deutschen Verbrechen, die auf polnischem Territorium begangen wurden. Die marginale, oberflächliche und anonyme Darstellung verweist darauf, dass die Kuratoren die Erfahrungen der jüdischen Stadtbewohner nicht als Teil der polnischen Erfahrungen von Krieg und Besatzung angesehen haben; somit wurden sie nicht als Protagonisten der musealen Erzählungen und auch nicht als Teil der im Museum konstruierten Wir-Gemeinschaft betrachtet.

Ein besonders ausgeprägtes Beispiel dieser ausgrenzenden Präsentationspraxis findet sich wiederum in Lublin, konkret in der 1995 umgestalteten Dauerausstellung des Historischen Museums der Stadt Lublin. ${ }^{115}$ Der einzige Verweis auf jüdische Verfolgte ist hier in einem kurzen Text untergebracht, der einer Fotografie der Krematoriumsöfen des »Konzentrationslagers Majdanek $\aleph^{116}$ zugeordnet ist:

Das Konzentrationslager Majdanek wurde im September 1939 gebaut und war bestimmt für sowjetische Kriegsgefangene. Bald wurde es zum Arbeitslager für Juden, Straflager für Polen und Umsiedlungslager für die Bevölkerung der Region Zamość. Nach der Inbetriebnahme von Gaskammern im Jahr 1942 war es ein Vernichtungslager. $^{117}$

115 Der erste Teil der Dauerausstellung im Historischen Museum der Stadt Lublin von 1979 ist aus dem Quellenmaterial nicht rekonstruierbar, daher ist eine Angabe zu diesem Aspekt in dem Museum vor 1995 nicht möglich.

116 Protokół odpowiedzialności. Wykaz eksponatów na wystawie »Historia miasta Lublina«, 1995. AMLL, Oddział Muzeum Historii Miasta Lublina, ohne Signatur, [6].

117 MLL-Krakauer Tor, Sektion »Zweiter Weltkrieg«, Vitrine 2. 
Juden erscheinen in diesem kurzen Text als eine Opfergruppe unter vielen; die Gründe ihrer Ausgrenzung und Inhaftierung werden nicht genannt. Weitere Verweise auf die Verfolgung der jüdischen Bewohner der Stadt sowie der dorthin deportierten Juden aus anderen Regionen des besetzten Polen fehlen. Die Auflistung der verschiedenen Bestimmungen des Lagers suggeriert sogar eine Hierarchie der Opfer, in der Juden als Insassen eines »Arbeitslagers « als geringer repressiert erscheinen als die polnischen Inhaftierten des "Straflagers". Aus der unpersönlichen Formulierung des letzten Satzes hingegen ist nicht ersichtlich, welche Gruppen der Inhaftierten Hauptziele der direkten »Vernichtung " im Lager waren - die Ausdrucksweise suggeriert eher eine Gleichwertigkeit des Opferstatus der Insassen. Erst in Ausstellungsführern späterer Jahre - und nur in diesen, nicht in der Schau selbst - gibt es kurze Informationen über die beiden Lubliner Ghettos und das Schicksal ihrer Bewohner. Die Verfolgung und Ermordung eines Drittels der Stadtbevölkerung erscheint jedoch auch hier weiterhin lediglich als eine Episode der Besatzungsgeschichte. ${ }^{118}$

In den Dauerausstellungen der zwei der Stadtgeschichte gewidmeten $\mathrm{Mu}-$ seen Lublins spielt die Geschichte der jüdischen Einwohner bis in die Gegenwart fast keine Rolle; ${ }^{119}$ sie ist in den musealen Erzählungen nahezu vollständig abwesend. ${ }^{120}$ Die Narrationen beider Museen schreiben das tradierte heroische und martyrologische Geschichtsbild der Besatzung fort, das auf einem exklusiven ethnischen Nationsverständnis basiert, in dem ethnische und religiöse Minderheiten keinen Platz haben. ${ }^{121}$ Keines der beiden Museen hat die innerpolnischen erinnerungskulturellen Debatten der vergangenen zehn bis fünfzehn Jahre oder die Gedenkinitiativen vor Ort auch nur ansatzweise aufgenommen; zumindest schlugen sie sich in der Arbeit der jeweils zuständigen

118 Die Geschichte der jüdischen Bevölkerung der Stadt ist in den jüngsten Ausgaben des Ausstellungsführers lediglich am Rande thematisiert. Im Ausstellungsführer aus dem Jahr 2000 wird nur das größere der beiden Ghettos genannt sowie die Deportation seiner Bewohner in »Vernichtungslager«. Nebenbei wird erwähnt, dass auch Juden von Umsiedlungsaktionen der deutschen Behörden betroffen waren. Insgesamt nehmen diese Themen einen kleinen Absatz innerhalb der sieben, dem Zeitraum der Jahre 1939 bis 1944 gewidmeten Seiten ein. Chmielak/Jakimińska/Polańska: Historia Miasta Lublina, 60. Im Ausstellungsführer von 2008 wird neben der Existenz der zwei Ghettos auch die Umsiedlung von etwa 25.000 Juden aus den von den Deutschen besetzten Gebieten erwähnt. Daran schließt sich die Information über die Gründung des Konzentrationslagers Majdanek an mit einem Verweis auf seine geschätzte Gesamtopferzahl, ohne deren ethnische Zusammensetzung zu benennen. Auch diese Informationen sind lediglich in einem Absatz der insgesamt zehn, den Jahren 1939 bis 1944 gewidmeten Seiten zusammengefasst. Polańska/Jakimińska/Piwowarska: Lublin - historia miasta, 88-98, hier 92.

119 Zur Präsentationspraxis des Martyrologiemuseums "Unter der Uhr» nach 1989 siehe Teil 2, Kapitel 1.1.

120 Das Konzentrations- und spätere Vernichtungslager Majdanek lag während der Besatzung noch außerhalb der Stadtgrenze.

121 Diese Darstellung erfuhr bis zum Zeitpunkt der Recherche im Mai 2010 keine Änderung. 
Kuratoren nicht in einem gesteigerten Interesse an der Geschichte der jüdischen Stadtbewohner und ihrem Schicksal im Krieg nieder. Gerade vor dem Hintergrund, dass die Geschichte der jüdischen Bewohner und insbesondere ihre Auslöschung in verschiedenen Lubliner kulturellen Initiativen, deren Öffentlichkeitswirkung deutlich über die Stadt hinausreicht, in den vergangenen fast fünfzehn Jahren große Bedeutung gewonnen hat, ist die Persistenz dieser einseitigen, buchstäblich exklusiven Geschichtsperspektive bemerkenswert. ${ }^{122}$

Die verbreitete Ausgrenzung des jüdischen Schicksals in den musealen Erzählungen marginalisierte auch weitgehend die Kontakte zwischen Polen und Juden während der Besatzungszeit. Einzig in den Krakauer Ausstellungen waren in den 1990er-Jahren Berührungspunkte der verschiedenen Bevölkerungsgruppen der Stadt von einigen Fotografien zu deduzieren, welche das Ghetto und insbesondere dessen Liquidierung illustrierten. Diese waren 1990, in der Vorgängerversion der Ausstellung von 1998, noch mit anonymen Erläuterungen unterschrieben, die eine Zuordnung von einzelnen Akteursgruppen vermieden. ${ }^{123}$ In der Fassung von 1998 dagegen verwies man explizit auf einzelne Handelnde: So zeigte ein Foto einen »OD-Mann [Jüdischer Ordnungsdienst], der die Papiere eines Juden im Ghetto kontrolliert. « ${ }^{124}$ Auf zwei weiteren war »die blaue Polizei [zu sehen, die] die Umsiedlung der Juden [überwacht,] « sowie »ein deutscher Militärpolizist [, der] den Transport ins Todeslager [überwacht] « ${ }^{125}$ Erstmals legte man damit die Existenz einer Ghettopolizei wie auch der sich aus der polnischen Bevölkerung rekrutierenden sogenannten blauen Polizei offen. Polen und Juden waren somit bei Tätigkeiten erkennbar, in denen sie offizielle Funktionen im Rahmen des Besatzungsregimes übernahmen. ${ }^{126}$ Mit dem eindeutigen Hinweis darauf, wer den

122 Insbesondere die Kultureinrichtung»Burgtor - Theater NN" (Brama Grodzka-Teatr NN) hat in den vergangenen zwei Jahrzehnten durch vielfältige Gedenkinitiativen und Ausstellungsprojekte das Bewusstsein der Stadtbevölkerung für die jüdische Vergangenheit der Stadt in erheblichem Maße geprägt. Näheres dazu in Kapitel 5.

123 Beispielsweise »Kontrolle von Dokumenten« und »Verladung in den Zug«. Gąsiorowski/ Kuler/Natkaniec: Scenariusz wystawy, 7.

124 Bildunterschrift. MHK-Pomorska-Straße, Tafel 13. Auf dem Foto war deutlich ein Abzeichen in Form eines Davidsterns auf der Brust des OD-Mannes erkennbar, sodass er - bei entsprechendem Vorwissen und Aufmerksamkeit der Besucher - durchaus als "Jude« bzw. Vertreter der Ghettoinstitutionen erkennbar war.

125 Bildunterschriften. MHK-Pomorska-Straße, Tafel 13.

126 Die Fotografien der Schau von 1990 zeigten höchstwahrscheinlich dieselben Inhalte es handelte sich bei der Präsentation von 1998 um eine "renovierte« Fassung, in der die existierenden Fotos nicht entfernt wurden, sondern einige neue Materialien und Texte hinzugekommen sind. Jedoch setzte die Zuordnung der auf den Bildern zu sehenden Personen und ihrer Funktion einiges Vorwissen voraus. Es ist daher zu vermuten, dass die meisten Besucher an den Bildern vorbeigingen, ohne die in ihnen enthaltenen, über die Beschreibung der jeweiligen Bildunterschrift hinausgehenden Konnotationen und Inhalte wahrzunehmen. 
Massenmord an der jüdischen Bevölkerung direkt überwachte und zu verantworten hatte und wer allein Hilfsdienste während der Existenz des Ghettos leistete, wurde zugleich auf Abstufungen von Verantwortung und Schuld verwiesen. Zugleich ist dieser Fall exemplarisch für die museale Darstellung polnisch-jüdischer Kontakte seit den 1990er-Jahren: Wenn sie überhaupt erfolgte, so blieb sie auf die offizielle Ebene der Besatzungsorgane beschränkt. Hierdurch, ebenso wie durch die Präsentation des jüdischen Schicksals in einem eigenen thematischen Abschnitt, wurde der Eindruck vermittelt, dass die Lebenswelten der jüdischen und polnischen Bewohner der Stadt in den Jahren der deutschen Besatzung strikt voneinander getrennt gewesen waren und es keine Berührungspunkte zwischen ihnen gegeben hat. Dies unterstützte die durch die Ausstellung vermittelte Vorstellung, wonach das Schicksal von Juden nicht Teil der polnischen Geschichte sei, die im Vordergrund der gesamten Präsentation steht.

Die ersten öffentlichen bzw. publizistischen Debatten um das polnischjüdische Verhältnis während der Besatzung, die in der zweiten Hälfte der 1980er-Jahre stattfanden, fanden somit in den historischen Dauerausstellungen der 1990er-Jahre kaum Widerhall: Die meisten Ausstellungsmacher behielten auch nach 1989 weitgehend die etablierten Deutungsmuster bei; allein die Art der Marginalisierung des jüdischen Schicksals wandelte sich von einer vereinnahmenden zu einer ausgrenzenden Darstellung. Trotz der beschriebenen Marginalisierungsstrategien in Bezug auf die Erfahrungen der jüdischen Einwohner bleibt festzuhalten, dass die jüdische Bevölkerung des Landes die einzige Minderheit war, die in den untersuchten Ausstellungen bzw. in der Darstellung der Besatzungsgeschichte der einzelnen Städte bis Mitte der 1990er-Jahre überhaupt Erwähnung fand. Andere Minderheiten, die in den Orten lebten oder aber während der Besatzung dort hinkamen, wie etwa Ukrainer und Litauer, waren in den Präsentationen dagegen überhaupt nicht präsent. Deutsche porträtierte man ausschließlich als Aggressoren und Besatzer; die deutschen Minderheiten in einzelnen Städten, die dort bereits vor dem Krieg gelebt hatten, blieben unerwähnt. Die erste der betrachteten Ausstellungen, die sich auch der ethnischen Minderheiten in ihrer Stadtgeschichte annahm, war die 1998 eröffnete Dauerausstellung des Historischen Museums der Stadt Łódź, auf die in Kapitel 3.1 näher eingegangen wird.

Das gezeichnete Bild der weitgehenden Marginalisierung des jüdischen Schicksals in musealen Erzählungen kann vor dem Hintergrund des erwachenden Interesses an jüdischer Geschichte und Kultur in der letzten Dekade der VRP überraschen. Und tatsächlich bilden die Dauerausstellungen der hier untersuchten historischen Museen nicht das ganze Spektrum der Aktivitäten im polnischen Museumswesen in den 1980er- und 1990er-Jahren ab, wie im Folgenden aufgezeigt wird. 


\subsection{Exkurs: Das Bild der Verfolgung von Juden in der Alten Synagoge in Krakau sowie in Sonder- und Wechselausstellungen}

Das Historische Museum der Stadt Krakau richtete bereits Ende der 1970erJahre in der Alten Synagoge des Stadtteils Kazimierz eine eigene Abteilung zur jüdischen Geschichte und Kultur ein. ${ }^{127}$ Ihre erste Dauerausstellung mit dem Titel »Z dziejów i kultury Żydów w Krakowie« (Aus der Geschichte und Kultur der Juden in Krakau) wurde 1980 eröffnet. ${ }^{128}$ Laut dem Kurator der Schau, Eugeniusz Duda, stellte sie »die erste und bislang einzige judaistische Ausstellung dieser Art in Polen « dar. ${ }^{129}$ Neben umfangreichen Exponaten aus den Bereichen jüdischer Religion, Kultur und Alltag umfasste sie auch einen historischen Ausstellungsteil. Einer der zwei Räume dieses Abschnitts war dem »Martyrium der Krakauer Juden in den Jahren der hitleristischen Besatzung " gewidmet. ${ }^{130}$ Die Darstellung der jüdischen Erfahrungen der Besatzungszeit in dieser Schau ist vor dem Hintergrund der bisherigen Analysen in mehrfacher Hinsicht bemerkenswert. Zunächst einmal blieb die Präsentation nicht auf den Zeitraum der Existenz des Ghettos beschränkt. Die unmittelbar nach dem Einmarsch der deutschen Truppen beginnende Ausgrenzung und sukzessive Entrechtung der jüdischen Einwohner der Stadt wurde mit mehreren Beispielen illustriert. ${ }^{131}$ Auch die nationalsozialistische Rassenkategorie »Jude«, das heißt ihre Definition durch die Besatzungsorgane,

127 Pläne für ein »Museum der Geschichte der Krakauer Juden" gab es bereits in den 1950erJahren. Siehe: Zarys charakterystyki i zasad organizacyjnych przyszłego Muzeum Historii Żydów w Krakowie. 27.2.1956 [Abriss der Charakteristika und Organisationsprinzipien des zukünftigen Museums der Geschichte der Juden in Krakau. 27.2.1956]. In Auszügen abgedruckt in: Passowicz, Wacław: Kronika działalności Muzeum Historycznego m. Krakowa za rok 1987 [Chronik der Tätigkeiten des Historischen Museums der Stadt Krakau für das Jahr 1979]. In: Krzysztofory 15 (1988), 177-185, hier $177 \mathrm{f}$.

128 Passowicz, Wacław: Kronika działalności Muzeum Historycznego m. Krakowa za rok 1980 [Chronik der Tätigkeiten des Historischen Museums der Stadt Krakau für das Jahr 1980]. In: Krzysztofory 8 (1981), 137-142, hier $137 \mathrm{f}$.

129 Duda, Eugeniusz: Z dziejów i kultury Żydów w Krakowie. Przewodnik po wystawie stałej w Starej Synagodze [Aus der Geschichte und Kultur der Juden in Krakau. Führer durch die Dauerausstellung in der Alten Synagoge]. Kraków [1982], [3].

130 Ebd.

131 Dies geschah mittels zahlreicher Besatzungsverordnungen, die die Ausgrenzung der jüdischen Bevölkerung im Alltag veranschaulichten: die Kennzeichnung jüdischer Firmen, die Ausweispflicht von Juden, die Benutzung der Straßenbahn oder des PlantyParks. Wystawa stała: Z Dziejów i kultury Żydów w Krakowie. Spis eksponatów. Kraków 24.11.1980. AMHK, teczka »Muzeum Historyczne Miasta Krakowa. Oddział Stara Bożnica; Wystawy stałe 1979-1981«, ohne Signatur, [8]: Tafeln 1, 3, 4. Siehe auch Duda: Z dziejów i kultury Żydów, [23]. 
wurde explizit geschildert. ${ }^{132}$ Damit machte man deutlich, dass es sich bei dieser Kategorie um eine externe Zuschreibung, und nicht um eine objektive bzw. naturgegebene Charakteristik handelte. Dies ist umso beachtenswerter, als die Zuschreibung ethnischer und rassischer Kategorien durch die Besatzer (insbesondere der Kategorie "jüdisch«), bis in die Gegenwart in den meisten historischen Dauerausstellungen in Polen nicht problematisiert wird.

Zudem schilderte man in dieser Schau bereits zu einem frühen Zeitpunkt den Widerstand im Ghetto: Gezeigt wurde der Text des Eids der »Kampforganisation der Chaluc-Jugend " (Organizacja Bojowa Młodzieży Chalucowej). ${ }^{133}$ Den Abschluss der Schau bildete eine Installation aus großformatigen Fotografien zum Lager Płaszów. Darunter befand sich unter anderem ein Foto einer Exekution mehrerer Personen durch Erhängen sowie zwei Fotos von Deportationen; ${ }^{134}$ die grausamen Umstände im Lager sowie die weiteren Deportationen wurden hier vergleichweise umfangreich geschildert. Der Stacheldraht, der zur Installation gehörte, stammte aus Auschwitz $-{ }^{135}$ als Hinweis auf das Ziel bzw. Ende der Fahrt der Deportierten. Eine direkte Benennung des Massenmords an der großen Mehrheit der Ghettoinsassen blieb jedoch aus; ${ }^{136}$ dieser wurden allein durch die Gestaltung angedeutet. Im begleitenden Ausstellungsführer hingegen wurden die Deportations- und Exekutionswellen im Ghetto, in Płaszów sowie in der Krakauer Umgebung geschildert und auch das Ziel der Transporte explizit mit dem Begriff »Todeslager« benannt. ${ }^{137}$ Die relativ ausführliche Darstellung in der Schau und gerade die unmissverständliche Schilderung im Ausstellungsführer stellten einen Kontrast zur vorsichtigen und sehr knappen Präsentation der Judenverfolgung in der Pomorska-Straße dar. In der Alten Synagoge fand sich schließlich auch ein Hinweis zu polnisch-jüdischen Kontakten: In der Exponatliste der Schau wird ein Plakat der Besatzungsorgane vom Januar 1944 mit Namen von Erschossenen genannt, die höchstwahrscheinlich wegen Hilfsleistungen für Juden

132 Gleich die zweite Ausstellungstafel zeigt zwei offizielle Dokumente, die erläutern, wer nach den deutschen Bestimmungen als »Jude« zu klassifizieren war, darunter eine Verordnung der Besatzungsorgane vom 24. Juli 1940 »Über die Definition des Begriffs गJudeく im G. G.«. Wystawa stała: Z Dziejów i kultury Żydów w Krakowie. Spis eksponatów, [8].

133 Ebd., [10]. Diese Organisation gründete wenig später mit anderen Organisationen des jüdischen Widerstandes eine Krakauer Abteilung der ŻOB.

134 Eine Abbildung der Gesamtinstallation aus Fotografien und Stacheldraht ist im Ausstellungsführer abgedruckt. Duda: Z dziejów i kultury Żydów, [25]; Wystawa stała: Z Dziejów i kultury Żydów w Krakowie. Spis eksponatów, [11].

135 Wystawa stała: Z Dziejów i kultury Żydów w Krakowie. Spis eksponatów, [11].

136 Die Installation sowie ihre einzelnen Elemente waren nicht mit Objektbeschriftungen oder Erläuterungen versehen. Siehe Duda: Z dziejów i kultury Żydów, [25].

137 Ebd., [23]. 
zum Tode verurteilt worden waren. ${ }^{138}$ Dieses Exponat verweist wiederum auf den etablierten Topos vermeintlich verbreiteter polnischer Hilfe für verfolgte Juden. Im begleitenden Ausstellungsführer wurden jedoch auch Denunziationen und die Verfolgung sich versteckender Juden durch Polen angesprochen: »Auf der anderen Seite gehören jedoch zu den historischen Tatsachen auch Fälle niederträchtiger Zusammenarbeit der Einheimischen mit den Besatzungsorganen bei der Aufdeckung sich versteckender Juden. ${ }^{139}$ Dieser ergänzende Hinweis ist für den betrachteten Zeitraum außergewöhnlich.

Die in der Schau vermittelten Inhalte entsprachen somit weitgehend den interpretativen Topoi des offiziellen Geschichtsbildes der VRP. Die vergleichweise ausführliche Darstellung jüdischer Erfahrungen während des Kriegs ging in der Alten Synagoge jedoch weit über die übliche Präsentationsweise in Dauerausstellungen hinaus, die die gesamtstaatliche bzw. nationale Erfahrung des Kriegs und der Besatzung jeweils am Beispiel einer Stadt oder Region illustrierten. Aufmerksame Besucher konnten anhand des präsentierten Materials Juden als gesonderte Opfergruppe des NS-Terrors identifizieren und daraus einen Unterschied zur Verfolgung von ethnischen Polen ableiten. Die Ausstellung in der Alten Synagoge existierte jedoch seit den 1980er-Jahren parallel und weitgehend ohne Bezug zu der Darstellung des übergreifenden - polnischen - Besatzungsnarrativs, das in der Abteilung PomorskaStraße gezeigt wurde. ${ }^{140}$

138 Im begleitenden Ausstellungsführer wird das Verstecken von Juden außerhalb des Ghettos thematisiert und ausführlich die polnische Hilfe für Verfolgte. Die Aktivitäten des polnischen »Hilfsrates für Juden« (Rada Pomocy Żydom), der unter dem Kryptonym Żegota agierte, kommen allgemein sowie bezogen auf Krakau zur Sprache. Auch die spontane Hilfe Einzelner wird beschrieben, mit Verweis auf die Todesstrafe, die den Helfern für ihre Handlungen drohte. In diesem Zusammenhang werden Plakate erwähnt, die in der ganzen Stadt verteilt waren und auf denen »die Namen der Polen [verzeichnet waren], die ১für Juden erteilte Hilfsleistungen` erschossen worden sind«. Ebd., [23f.], Zitat: [23]. Die in der Exponatliste genannte »Bekanntmachung v. 29.1.1944 Liste der Erschossenen«, die also lange nach der Liquidierung des Ghettos verbreitet wurde, ist daher höchstwahrscheinlich ein Beispiel für ein solches Plakat, zumal die kleine Schau ansonsten keinerlei Bezüge zur Geschichte der restlichen Stadt und ihrer Bevölkerung während der Besatzung enthielt. Wystawa stała: Z Dziejów i kultury Żydów w Krakowie. Spis eksponatów, [10].

139 Duda: Z dziejów i kultury Żydów, [23].

140 Einen Raum, der dem »Martyrium« der jüdischen Krakauer während der Besatzung gewidmet war, gab es auch in der 1999 neu eröffneten Dauerausstellung in der Alten Synagoge. Es ist davon auszugehen, dass er im Zusammenhang mit der Eröffnung der neuen Abteilung des MHK in der Apotheke »Zum Adler« (2004) aus der Ausstellung entfernt wurde; im Ausstellungsführer von 2005 wird ein solcher Ausstellungsabschnitt nicht mehr genannt. Vgl. Scenariusz wystawy stałej w Oddziale Dzieje i Kultura Żydów. Kraków 1998. AMHK, OŻ-640 / 1 / 1998, 12; Duda, Eugeniusz: Stara Synagoga na Kazimierzu w Krakowie. Przewodnik [Die Alte Synagoge in Kazimierz in Krakau. Ausstellungsführer]. Kraków 2005. 
Neben dem Sonderfall dieser Dauerausstellung, die ausschließlich der Geschichte der jüdischen Krakauer gewidmet war, wurden in den 1980er-Jahren erste Sonderausstellungen gezeigt, die den jüdischen Anteil an der polnischen Geschichte vor allem aus kunst- und kulturhistorischer Perspektive beleuchteten. ${ }^{141}$ Eine der wohl prominentesten unter ihnen war die am 14. Juni 1989 im »Nationalmuseum in Krakau " (Muzeum Narodowe w Krakowie) eröffnete Schau "Żydzi - polscy« (Die - polnischen - Juden). ${ }^{142}$ Die Präsentation versammelte fast 1.500 Kunstwerke - Skulpturen, Grafiken, Kultgegenstände, in erster Linie jedoch Werke der Bildenden Kunst,$-{ }^{143}$ die die $»$ jahrhundertelange Anwesenheit der Juden in Polen ${ }^{144}$ in Erinnerung rufen und ihr kulturelles Erbe bewahren sollten:

Das Werk und die Traditionen, die von den polnischen Juden geschaffen wurden, gehören nicht mehr zu ihrem Erbe. Die verbliebenen wenigen Tausend können diesen Nachlass nicht stemmen. Die Erben müssen Andere sein. ${ }^{145}$

Die Ausstellung wurde zu einem enormen Besuchererfolg: Sie wurde viermal verlängert und schließlich ab Dezember 1989 in der Warschauer Galerie Zachęta gezeigt. ${ }^{146}$ Auch in Wrocław wurde im selben Jahr eine umfang-

$141 \mathrm{Zu}$ nennen sind hier etwa die Ausstellung »Kultura ocalona« (Die bewahrte Kultur), die 1983 im »Nationalmuseum Warschau« (Muzeum Narodowe w Warszawie) gezeigt wurde, sowie die Schau »Wystawa dzieł artystów żydowskich 1918-1939« (Ausstellung der Werke jüdischer Künstler 1918-1939), die 1987 im »Büro Künstlerischer Ausstellungen in Olsztyn« (Biuro Wystaw Artystycznych w Olsztynie) zu sehen war. Siehe die Kataloge beider Ausstellungen: Askanas, Barbara (Hg.): Kultura Ocalona. Katalog wystawy poświęconej kulturze Żydow polskich [Die bewahrte Kultur. Katalog einer der Kultur der polnischen Juden gewidmeten Ausstellung]. Warszawa 1983; Wystawa dzieł artystów żydowskich 1918-1939. Malarstwo, grafika, rysunek, rzeźba, metaloplastyka [Ausstellung der Werke jüdischer Künstler 1918-1939. Malerei, Zeichnen, Skulptur, Schmiedekunst]. Hg.v. Biuro Wystaw Artystycznych w Olsztynie und Żydowski Instytut Historyczny w Polsce. Olsztyn 1987.

142 Zając, Jolanta: Na inaugurację wielka wystawa »Żydzi polscy« [Zur Eröffnung die große Ausstellung »Die polnischen Juden«]. In: Trybuna Ludu vom 15.6.1989. Katalog zur Ausstellung: Wystawa Żydzi - polscy. Czerwiec-Sierpień 1989 [Ausstellung Die polnischen - Juden. Juni-August 1989]. Hg.v. Muzeum Narodowe w Krakowie. Kraków 1989. Siehe auch Adamczyk-Garbowska, Monika/Ruta, Magdalena: Od kultury żydowskiej do kultury o Żydach [Von der jüdischen Kultur zur Kultur über die Juden]. In: Tych, Feliks/Adamczyk-Garbowska, Monika (Hg.): Następstwa zagłady Żydów. Polska 1944-2010 [Die Folgen der Vernichtung der Juden. Polen 1944-2010]. Lublin 2011, 715-732, hier 726.

143 Zagórska, Bożena: W krakowskim Muzeum Narodowym Żydzi - polscy [Die - polnischen - Juden im Krakauer Nationalmuseum]. In: Trybuna Ludu vom 19./20.8.1989.

144 Zają: Na inaugurację wielka wystawa.

145 Wstęp [Einleitung]. In: Wystawa Żydzi - Polscy, 7-11, hier 7.

146 Po sukcesie w krakowskim muzeum: Wystawa »Żydzi polscy« także w Warszawie [Nach dem Erfolg im Krakauer Museum: Die Ausstellung "Die polnischen Juden« auch in Warschau]. In: Życie Warszawy vom 18./ 19.11.1989; Lisowski, Andrzej: »Żydzi Polscy» 
reiche Schau zur Geschichte der jüdischen Einwohner der Stadt präsentiert: "Wrocławscy Żydzi. 1850-1944" (Die Breslauer Juden. 1850-1944). ${ }^{147}$ Vorbereitet worden war sie von Maciej Łagiewski, einem Mitarbeiter des Architekturmuseums, der sich bereits seit 1983 schwerpunktmäßig mit der jüdischen Vergangenheit der Stadt befasste. ${ }^{148}$ Die Ausstellung erfuhr 1994 eine Neuauflage: Aus Anlass des 50. Jahrestages der Deportationen der letzten Juden aus der Stadt wurde sie - ergänzt um neue Exponate - zwischen dem 19. April und dem 30. August im Arsenal gezeigt, einer Abteilung des Historischen Museums der Stadt. ${ }^{149}$ Ziel der Ausstellung war laut Lagiewski, einen wenig bekannten Abschnitt der Stadtgeschichte zu präsentieren, »ohne Ideologie, Verschweigen und Verdrehungen, die so charakteristisch waren bei der Präsentation der Geschichte Schlesiens vor 1989 «. ${ }^{150}$ Diese beiden Ausstellungen sind prägnante Beispiele dafür, dass es in der polnischen Museumslandschaft durchaus bereits vor dem Systemwechsel Institutionen und Personen gab, die sich für die Aufarbeitung der sogenannten weißen Flecken der polnischen Geschichte auch im Bereich der jüdischen Vergangenheit des Landes interessierten und sich intensiv damit auseinandersetzten. So stützten sich die beiden genannten Schauen in Krakau und Wrocław auf Forschungen und Vorarbeiten aus den 1980er-Jahren. Möglichkeiten zur Realisierung umfangreicherer monothematischer Vorhaben ergaben sich jedoch zum Teil erst mit der politischen Liberalisierung im Verlauf des Jahres 1989.

Thematische Ausstellungen zur jüdischen Vergangenheit Polens und speziell zur Geschichte von Juden während des Zweiten Weltkriegs wurden im folgenden Jahrzehnt immer wieder organisiert, auch wenn gleichzeitig - wie bereits beschrieben - in den meisten Dauerausstellungen das Thema weiterhin nur marginal vertreten war. Zumeist waren runde Jahrestage des War-

w Krakowie [»Die polnischen Juden« in Krakau]. In: Tygodnik Polski vom 3.9.1989. Einer der fünf thematischen Abschnitte der Ausstellung war der »Endlösung" gewidmet, wie der Originaltitel des vierten Ausstellungsabschnitts lautete. Siehe: Wstęp [Einleitung]. In: Wystawa Żydzi - Polscy, 7-11, hier 11.

147 Die Ausstellung wurde vom 10. März bis zum 15. April 1989 im »Architekturmuseum« (Muzeum Architektury) präsentiert. In den Jahren 1990 bis 1992 wurde sie zudem in zehn deutschen Städten gezeigt. Łagiewski, Maciej: Wrocławscy Żydzi. 1850-1944 [Die Breslauer Juden. 1850-1944]. 2. erw. Aufl. Wrocław 1997, 6.

148 Łagiewski wurde 1991 zum Leiter des Historischen Museums von Wrocław ernannt, im Jahr 2000 zum Direktor des Stadtmuseums Wrocław.

149 Bei dieser Neuauflage standen finanzielle Mittel für die Publikation eines umfangreichen Albums zur Verfügung, das die Schau abbildet, aber in erster Linie Einblick in die Geschichte der jüdischen Bewohner der Stadt seit dem 18. Jahrhundert bis 1944 gibt. Dieses Album wurde 1997 und 2010 neu aufgelegt. Łagiewski, Maciej: Wrocławscy Żydzi. 1850-1944 [Die Breslauer Juden. 1850-1944]. Wrocław 1994; Bubnicki, Rafał: Wrocławscy Żydzi 1850-1944. Przypominanie historii [Die Breslauer Juden 1850-1944. Erinnern an die Geschichte]. In: Rzeczpospolita vom 21./ 22.5.1994.

150 Bubnicki: Wrocławscy Żydzi. 
schauer Ghettoaufstandes oder Jahrestage der Liquidierung der Ghettos der einzelnen Städte Anlass für solche Schauen. So verzeichnete man etwa 1993 eine hohe Anzahl von Sonderausstellungen zu Themen jüdischer Geschichte und Kultur in den Museen des Landes. Grund hierfür war das "Jahr der jüdischen Kultur« (Rok Kultury Żydowskiej) ${ }^{151}$, das anlässlich des 50. Jahrestages des Warschauer Ghettoaufstandes ausgerufen worden war. So porträtierte beispielsweise die Schau "Obecni wśród nas" (Anwesend unter uns) des Historischen Museums der Hauptstadt Warschau herausragende Vertreter der jüdischen Intelligenz, die sowohl an den polnischen Unabhängigkeitskämpfen teilgenommen als auch zur Entwicklung der polnischen Wirtschaft, Kunst und Kultur wesentlich beigetragen haben. ${ }^{152}$ Auch das Unabhängigkeitsmuseum in Warschau sowie die zwei Łódźer historischen Museen organisierten 1993 Sonderausstellungen zur jüdischen Vergangenheit. Im Gegensatz zur breiter gefassten Sonderausstellung im MHW konzentrierten sich diese Schauen jedoch auf die Besatzungszeit. ${ }^{153}$

Eine Sonderstellung, die in den 1990er-Jahren große Verbreitung erfuhr, war die Schau »I ciągle widzę ich twarze» (Und ich sehe noch immer ihre Gesichter), die nicht von einem Museum, sondern von der amerikanisch-polnisch-israelischen Stiftung "Shalom" (Fundacja Shalom) konzipiert wurde. Die Ausstellung zeigte Fotografien polnischer Juden aus der Kriegs-, aber auch der Vorkriegszeit. ${ }^{154}$ Die Fotos wurden auf einen Aufruf der Stiftung hin aus Polen und vielen anderen Ländern zusammengetragen, als oft einzige Erinnerungsstücke an Verwandte, Freunde oder Bekannte, die während des

151 Siehe Przybyła, Urszula: Okolicznościowe imprezy w kraju [Gedenkveranstaltungen im Land]. In: Słowo Żydowskie vom 4.6.1993, 6, 19, hier 19.

152 Głębocki, Wiesław/Karpowicz, Witold: Obecni wśród nas. Żydzi polscy w życiu politycznym, gospodarczym, społecznym, naukowym i kulturalnym Warszawy. Katalog wystawy [Anwesend unter uns. Polnische Juden im politischen, wirtschaftlichen, gesellschaftlichen, wissenschaftlichen und kulturellen Leben Warschaus. Ausstellungskatalog]. Warszawa 1993. Die Schau wurde vom 1. April bis zum 3. Oktober 1993 gezeigt. Pietrzak: Kalendarium wystaw. 1972-1998, 392.

153 Im MNW (zu dem der Pawiak gehört) wurde vom 5. Juli bis 1. August 1993 die Ausstellung »Polskie Państwo Podziemne wobec tragedii Żydów 1939-1945« (Der Polnische Untergrundstaat und die Tragödie der Juden 1939-1945) gezeigt. Pałaszewska, Mirosława/Kunert, Andrzej K.: Polskie Państwo Podziemne wobec tragedii Żydów 19391945 [Der Polnische Untergrundstaat und die Tragödie der Juden 1939-1945]. Warszawa 1993. Im Stadmuseum Łódź eröffnete man 1993 die vom »üdischen Museum Frankfurt" vorbereitete Ausstellung "Naszą jedyną drogą jest pracaর. Getto Łódzkie 19401944 r.« (»Unser einziger Weg ist Arbeit«. Das Ghetto in Łódź 1940-1944); im Museum Radogoszcz wurde im selben Jahr die Schau »Pieśń o zamordowanym żydowskim narodzie« (Lied über das ermordete jüdische Volk) gezeigt. Detaillierter werden die Ausstellungen dieser Museen in Kapitel 3.1 analysiert.

154 Eine Beschreibung der Inhalte und des Aufbaus der originalen Schau liefert Wiergowska, Dagmara: Klisze i pamięć [Klischees und Erinnerung]. In: Życie Warszawy vom 18.4.1996. AMMŁ, teczka 6/85, ohne Signatur. 
Holocaust umkamen. ${ }^{155}$ Nach ihrer Eröffnung 1996 wurde die Ausstellung in mehreren polnischen Städten, unter anderem auch 1997 im Historischen $\mathrm{Mu}$ seum der Stadt Łódź, und vor allem im Ausland gezeigt. ${ }^{156}$

Wie diese Beispiele zeigen, schlug sich das in den 1980er-Jahren in Intellektuellenkreisen erwachende Interesse an der Wiederentdeckung der Geschichte bzw. Erinnerung an die polnischen Juden durchaus im Ausstellungs- und Museumswesen nieder, wenn auch beschränkt auf den Sonderfall der Alten Synagoge in Krakau sowie zeitlich begrenzte Sonderausstellungen. Es umfasste jedoch noch kaum das Thema der Besatzungszeit. In den ständigen Präsentationen der historischen Museen zu den Jahren 1939 bis 1945 fanden die Debatten der 1980er-Jahre dagegen keinen Widerhall; das Interesse an der jüdischen Geschichte der eigenen Städte spiegelte sich nicht in der Darstellung der Besatzungszeit in den neuen Dauerausstellungen vom Anfang der 1990er-Jahre wider. Diese setzten die marginalisierende Art und Weise der Schilderung des jüdischen Schicksals ihrer Vorgängerinnen weitgehend identisch fort. Auch im Bereich der Wechselaustellungen gehörte das Schicksal der Juden während des Kriegs in dieser Dekade in den meisten $\mathrm{Mu}-$ seen weiterhin nicht zu den wesentlichen Themen der Ausstellungstätigkeit. Der Großteil der Sonderausstellungen mit Bezug zum Zweiten Weltkrieg befasste sich mit dem polnischen Widerstand oder dem Themenkomplex polnischer Martyrologie, etwa den Deportationen in Konzentrationslager und zur Zwangsarbeit. ${ }^{157}$ Jedoch bleibt zu konstatieren, dass in den 1990er-Jahren die Zahl von Sonderausstellung über die jüdische Vergangenheit des Landes allmählich zunahm. Außerdem fällt auf, dass das Interesse an »jüdischen Themen « in den Institutionen sehr unterschiedlich ausgeprägt war. Einzelne Museen nahmen ausschließlich zentrale Jahrestage zum Anlass für thematische Sonderausstellungen - Beispiel hierfür ist das Historische Museum der Hauptstadt Warschau; ${ }^{158}$ andere ignorierten das Thema weitgehend, und dies

155 Zur Entstehungsgeschichte der Schau siehe die Website der Stiftung: I ciągle widzę ich twarze [Und ich sehe noch immer ihre Gesichter], URL: www.shalom.org.pl/index. php?mid=4 (am 11.10.2013). Aus dem Fundus der zugesandten Fotos ist ein Katalog entstanden: Tencer, Gołda (Hg.): And I Still See Their Faces. Images of Polish Jews. Warszawa 1996.

156 Für eine Übersicht der Stationen der Schau siehe URL: www.shalom.org.pl/index.php? $\mathrm{mid}=11$ (am 11.10.2013). Im MHMŁ war sie zwischen dem 26. Mai und dem 10. August 1997 zu sehen. Einladungskarte zur Ausstellungseröffnung. AMMŁ, teczka 6/85, 1218M.

157 Siehe Teil 3, Kapitel 1.2 und 2.2.

158 Im Historischen Museum der Hauptstadt Warschau wurden monothematische Sonderausstellungen, die sich mit der jüdischen Vergangenheit des Landes befassten, ausschließlich in den Jahren 1983, 1993 und 2003 gezeigt. Zwischen diesen runden Jahrestagen des Warschauer Ghettoaufstandes war das Thema in der Ausstellungstätigkeit des Museums dagegen nicht präsent. Vgl. Pietrzak: Kalendarium wystaw. 1972-1998, bes. 375, 392; Pietrzak/Wiśniewska/Rogulska: Kalendarium wystaw 1999-2000; Pietrzak/ 
zum Teil bis in die Gegenwart, wie das Beispiel der zwei Abteilungen des Lubliner Museums in Lublin zeigt. ${ }^{159}$ Andererseits gab es auch historische $\mathrm{Mu}$ seen, die sich bereits früh intensiv mit der jüdischen Geschichte der eigenen Stadt auseinandersetzten, wie in Kapitel 3.1 am Beispiel von Łódź noch näher dargestellt wird. Die Sonder- und Wechselausstellungen der 1990er-Jahre weisen somit gerade beim Thema Judenverfolgung auf eine beginnende Ausdifferenzierung des historischen Ausstellungswesens in Bezug auf inhaltliche Schwerpunkte ebenso wie auf Deutungsangebote hin.

\subsection{Zwischenfazit}

Für die betrachteten Dauerausstellungen der 1980er- bis 1990er-Jahre lässt sich zusammenfassend festhalten, dass die Darstellung der Verfolgung der als jüdisch definierten Bevölkerung in dieser Phase kaum Veränderungen erfahren hat. Sie blieb sowohl vor als auch nach der Wende von 1989 ein untergeordneter Aspekt der präsentierten lokalen und regionalen Besatzungsgeschichte. Allein der Hintergrund bzw. die Strategie der Marginalisierung dieses Themas änderte sich in den 1990er-Jahren.

Bis Mitte des Jahrzehnts - dem Zeitraum also, in dem die Präsentationen, die in der VRP entstanden waren, weiterhin zu sehen und nur kosmetisch überarbeitet worden waren - wurde, dem Meisternarrativ der Volksrepublik folgend, das Schicksal der Juden unter das national-polnische Martyrium des Kriegs subsumiert, bis hin zu dem Extrem, dass es, wie in Lublin, vollständig ausgeblendet wurde. Die Entwicklung der Schauen des MHK seit 1990 verweist jedoch auf erste Veränderungen: Das Los der Krakauer Juden wurde erstmals als eigenständiger thematischer Aspekt der Besatzungsgeschichte

Rogalska / Wiśniewska: Kalendarium wystaw 2001-2002; Ciesielska, Marta (Hg.): Janusz Korczak. Warszawa jest moja i ja jestem jej [Wystawa z okazji 125-tej rocznicy urodzin Janusza Korczaka] [Janusz Korczak. Warschau ist mein und ich bin ihre. Ausstellung aus Anlass des 125. Geburtstages Janusz Korczaks]. Warszawa 2003; Ausstellungsarchiv auf der Website des Museums für die Jahre 2004, 2007 / 08 und 2009: URL: www.mhw.pl (am 28.4.2009 bzw. 2.7.2013).

159 In dem zur Verfügung stehenden Quellenmaterial des MLL konnten bis zum Jahr 2010 keine Sonderausstellungen nachgewiesen werden, die das Schicksal der jüdischen Bewohner Lublins, der Region oder des Landes ins Zentrum stellen. Nur in wenigen Ausstellungen räumte man dem jüdischen Schicksal während der Besatzung überhaupt Platz ein. Am umfangreichsten scheint dies noch in der 1993 eröffneten Schau »Okupacyjna codzienność Lublina 1939-1944« (Der Besatzungsalltag in Lublin 1939-1944) geschehen zu sein. In dessen Ausstellungsführer wird die Verfolgung und Ermordung der jüdischen Stadtbewohner auf einer knappen Seite geschildert. Oratowska, Barbara/ Polańska, Jolanta: Okupacyjna codzienność Lublina 1939-1944 [Der Besatzungsalltag in Lublin 1939-1944]. Lublin 1993, 7 f. 
herausgestellt. Als ein Verbrechen, das von »Fremden« (der deutschen Besatzungsmacht) an "Fremden" (einer als andere Nationalität wahrgenommenen Gruppe) begangen worden war, blieb das Leid der jüdischen Bevölkerung jedoch weiterhin ein untergeordneter Aspekt der Erzählung. Beide Darstellungspraxen zeigen, dass Juden nicht als Protagonisten der polnischen Geschichte, als Teil der lokalen, regionalen und nationalen Gemeinschaft angesehen wurden, die im Zentrum der Ausstellungsnarrative stand. In der musealen Präsentationspraxis der VRP - wie sie für die 1980er-Jahre exemplarisch rekonstruiert wurde - diente die Inklusion der jüdischen Bevölkerung als Staatsbürger des besetzten Landes dazu, ihr Leiden als mindestens gleichwertig, zumeist jedoch untergeordnet darzustellen. Die im MHK sich seit 1990 verändernde Darstellungsweise zeigt die auch in den 1990erJahren weiterhin verbreitete Wahrnehmung der Judenverfolgung als fremdes Element eines nationalen polnischen Geschichtsverständnisses, in dessen ethnischem Konzept der polnischen Nation Juden als »Andere« keinen Platz in der Wir-Gemeinschaft der Krakauer hatten. In diesem Sinne setzte sich die Marginalisierung der Verfolgung von Juden auch nach 1989 fort. Ihr Hintergrund war nun jedoch nicht mehr die in der sozialistischen VRP offiziell propagierte Einheit der Nation während der Besatzung und im Widerstand, ${ }^{160}$ sondern eine auf ethnischen Kategorien basierende Konzeption der polnischen Geschichte - die Vereinnahmung als polnische Kriegserfahrung wurde durch die Ausgrenzung aus dieser abgelöst. Wenn somit eine klare Hierarchie der Opferdarstellung erkennbar blieb, war die Etablierung eigener Themenabschnitte jedoch zugleich auch Zeichen der Anerkennung der Verfolgung von Juden als nennenswertes und - vor dem Hintergrund der in den meisten Museen sehr beschränkten Ausstellungsfläche - bedeutsames Element der Besatzungsereignisse.

Die in den 1980er-Jahren unter Intellektuellen beginnende Wiederentdeckung der jüdischen Vergangenheit des Landes hatte somit bis Ende der 1990er-Jahre keinen wesentlichen Einfluss auf die zentralen öffentlichen Geschichtsdarstellungen der historischen Museen. Der politische Umbruch des Jahres 1989 bedeutete in diesem Themenbereich auch keinen wesentlichen Bruch mit etablierten musealen Narrativen. Zwar gab es anlässlich des 50. Jahrestages des Warschauer Ghettoaufstandes eine Reihe von Sonderausstellungen. In den meisten Institutionen spielte die Verfolgung und Vernichtung der jüdischen Einwohner im Rahmen von Sonder- und Wechselausstellungen jedoch nur eine geringe Rolle: Thematische Ausstellungen hierzu waren selten. Der Aspekt gehörte offensichtlich nicht zu denjenigen, deren Aufarbeitung von den Kuratoren der meisten Museen als dringlich erachtet wurden - im 
Gegensatz etwa zu der in Kapitel 2 des ersten Teils thematisierten polnischsowjetischen Beziehungsgeschichte während und nach dem Krieg oder der Geschichte des polnischen Untergrundstaates und des nichtkommunistischen Widerstands, die in Kapitel 2.2 des dritten Teils analysiert werden. Mit diesem verbreiteten Desinteresse an der Geschichte jüdischer Besatzungserfahrungen unterschieden sich die Geschichtsmuseen des Landes kaum von den Interessenschwerpunkten der öffentlichen bzw. publizistischen Debatten und der wissenschaftlichen Forschung in diesem Jahrzehnt.

\section{Die Verfolgung von Juden als »fremde« Geschichte}

Die sich bereits in den Krakauer Ausstellungen der Jahre 1990 und 1998 zeigende Marginalisierung der Besatzungserfahrungen der jüdischen Bevölkerung durch Ausgrenzung bzw. Konzentration innerhalb eines untergeordneten Ausstellungsabschnitts charakterisierte auch die Dauerausstellungen vieler untersuchter Museen, die Ende der 1990er-Jahre bis Anfang des 21. Jahrhunderts entstanden sind. ${ }^{161}$ Auch Präsentationen, die seit Beginn des Museumsbooms, also seit 2004 grundlegend überarbeitet oder neu konzipiert wurden, führten diese Perspektive fort. Diese Kontinuität erstaunt zunächst angesichts der intensiven Diskussionen und Erkenntnisse, die mit der Jedwabne-Kontroverse in den Jahren 2000 bis 2002 initiiert wurden. Inwieweit Auswirkungen dieser für das Thema der polnisch-jüdischen Beziehungen während des Kriegs zentralen Debatte in den jüngsten Ausstellungen der historischen Museen von Warschau und Wrocław zu finden sind, ist Thema dieses Kapitels. Dabei wird insbesondere nach den grundlegenden Zugängen zur polnischen Geschichte gefragt, die die Schauen konstruieren.

\subsection{Die Warschauer Museumslandschaft am Anfang des 21. Jahrhunderts}

Eine der ersten Warschauer Präsentationen, die nach dem Systemwechsel von 1989 vollständig neu konzipiert wurde, war die im Juni 2001 eröffnete Dauerausstellung des Gefängnismuseums Pawiak. ${ }^{162}$ Ihre Vorbereitung hatte somit

161 Ausnahme hierbei war die Dauerausstellung des Stadtmuseums Łódź, die in Kapitel 3.1 analysiert wird.

162 Woltanowska, Magdalena: Nowa ekspozycja stała w Muzeum Więzienia »Pawiak« [Die neue Dauerausstellung im Gefängnismuseum »Pawiak«]. In: Niepodległość i Pamięć 18 (2002), 253-290, hier 254. 
noch vor dem Ausbruch der Jedwabne-Debatte begonnen und dauerte während der Diskussionen an. Die Eröffnung der Schau fand dann vor der Publikation der Ergebnisse neuer Forschungen zu den Ereignissen in Jedwabne und seiner Umgebung statt, die durch die Debatten um Gross' Buch angestoßen worden waren. ${ }^{163}$ Noch stärker als ihre Vorgängerin aus dem Jahr 1991 konzentriert sich die Ausstellung im großen Saal des Museums auf die Geschichte des Kriegs auf dem ganzen Gebiet des besetzten Polens und die deutsche Besatzung Warschaus zwischen 1939 und 1944. In diesem breiten thematischen Spektrum nehmen die über zweieinhalb Jahre währende Existenz des Warschauer Ghettos und seiner Zerstörung nur einen sehr kleinen Raum ein. ${ }^{164}$ Wenige Objekte und Fotografien dokumentieren die elenden Lebensbedingungen im Ghetto. Im Vordergrund stehen dabei das unschuldige Leiden, symbolisiert durch Fotos einer abgemagerten alten Frau und einer Kinderleiche, sowie die Brutalität der Besatzer, dargestellt mittels Fotografien der Demütigung orthodoxer Juden durch deutsche Soldaten. Fotos einer Kolonne von Ghettobewohnern auf dem Weg zur Deportation, von der Niederschlagung des Ghettoaufstands sowie der Gedenkstätte des ehemaligen Vernichtungslagers Treblinka illustrieren die Ermordung der Ghettobevölkerung. ${ }^{165}$ Im Gegensatz zu den vorangegangenen Präsentationen des Museums ist damit das Ghetto als eigenes Thema in der Erzählung der Warschauer Besatzungsgeschichte präsent; auch die Ermordung der Ghettoinsassen wird explizit thematisiert.

Kontakte zwischen der Bevölkerung der "arischen" Seite der Stadt und der des Ghettos werden jedoch nur an einer Stelle angedeutet: Ein Zitat des Schriftstellers Jarosław Iwaszkiewicz beschreibt seine Eindrücke beim Durchfahren des abgeriegelten Ghettogeländes mit einer Straßenbahn. Seine Beschreibung verweist vor allem darauf, wie fremd, andersartig und düster die Welt hinter der Ghettomauer aus dem Blickwinkel eines polnischen Bewohners der »arischen« Seite wirkte. Er erwähnt auch den Schmuggel ins Ghetto (hier durch einen polnischen Straßenbahnfahrer) sowie sporadische Nachrichten von Freunden, die in diesem leben und die ihm »wie aus einer anderen Welt geschrieben « erschienen. ${ }^{166}$ Dieser Bericht verweist zwar darauf, dass

163 V.a. Machcewicz: Wokół Jedwabnego. Teile der folgenden Ausführungen in Kapitel 2.1 und 2.2 wurden publiziert in Heinemann: Die Musealisierung des Ghettos.

164 Der Judenverfolgung sind eine hintere kleine Ecke des Ausstellungssaales gewidmet sowie zwei von insgesamt 32 Vitrinen.

165 Eines der Fotos zeigt die Deportation von Ghettobewohnern während der ersten großen Liquidierungsaktion im Juli 1942. Die Bildunterschrift lautet: „Verladen von Juden in Wagons und Verschickung in Todeslager - Warschauer Ghetto-Stawki-Straße, Juli-August 1942«. MNW-Pawiak, Sektion zum Ghetto (ohne Titel), Vitrine.

166 Zitat aus den Aufzeichnungen des Autors vom 23. Februar 1941. MNW-Pawiak, Sektion zum Ghetto, Vitrine. 
es Kontaktmöglichkeiten zwischen dem Ghetto und der Außenwelt gab; auch die Hilfe bzw. Zusammenarbeit mit Personen außerhalb des Ghettos wird beiläufig erwähnt. Die Entfremdung und Ausgrenzung der jüdischen Bevölkerung steht jedoch im Vordergrund der Schilderung. Ein Plan des Ghettos, der dieses in der städtischen Topografie verortet und auf dem die sich verändernden Ghettogrenzen markiert sind, legt den Schwerpunkt zusätzlich auf die Abtrennung dieses Gebiets von der restlichen Stadt. Auch eine Bekanntmachung der Besatzungsorgane, die das Ghetto als "verbotene Zone" bezeichnet, verstärkt den Eindruck einer strikten Separation der Bevölkerungen auf beiden Seiten der Mauern. Dass sich der Pawiak selbst inmitten dieses Sperrgebiets befand und dass sowohl Polen als auch Juden innerhalb seiner Mauern gefangen gehalten und exekutiert worden waren, wird nur am Rande erwähnt. ${ }^{167}$

Ein Fokus der gesamten Ausstellung liegt auf der Darstellung westlicher Reaktionen und Wahrnehmungen der Ereignisse im besetzten Polen; ${ }^{168}$ dieser Ansatz findet auch bei der Schilderung der Judenverfolgung Anwendung. Gezeigt werden konspirative Publikationen und Broschüren der Exilregierung in London, die im westlichen Ausland erschienen sind. Zu diesen gehört etwa die Broschüre von Natalia Zarembina »Obóz śmierci« (Todeslager) aus dem Jahr 1942, die als eine der ersten versuchte, die Öffentlichkeit über das Konzentrationslager Auschwitz zu informieren. ${ }^{169}$ Daneben wird das Titelblatt einer englischsprachigen Broschüre präsentiert, in der die an die Vereinten Nationen gerichtete Note der Londoner Exilregierung vom 10. Dezember 1942 mit Informationen über die Massenmorde an Juden im besetzten Polen abgedruckt ist. ${ }^{170}$ Diese Publikationen dokumentieren Versuche des polnischen Untergrunds und der Exilregierung, die westlichen Alliierten über die Verfolgung und Ermordung der Juden zu informieren und ein Eingreifen zu erzielen. Das Mitgefühl von Polen angesichts des Leidens im Ghetto und den Morden in den deutschen Lagern vermittelt das Gedicht Władysław Broniewskis »Żydom polskim. Pamięci Szmula Zygielbojma» (An die polni-

167 So ist ein Zeitzeugenbericht über die Exekution von 150 Juden im Pawiak im Mai 1943 in einer Vitrine ausgestellt, die der Verfolgung der Juden gewidmet ist. In einer weiteren kleinen Vitrine daneben werden Unterhosen eines Häftlings ausgestellt, die aus einem jüdischen rituellen Gebetsschal genäht worden sind. MNW-Pawiak, Sektion zum Ghetto.

168 Woltanowska: Nowa ekspozycja stała, 254.

169 Der Umschlag der englischsprachigen Ausgabe der Broschüre aus dem Jahr 1944 ist vergrößert und prominent platziert. Daneben werden Übersetzungen in andere Sprachen und Besprechungen der Broschüre in der polnischen Exilpresse präsentiert. MNWPawiak, Sektion zur Broschüre »Obóz śmierci« (ohne Titel).

170 Der Titel der Broschüre lautete »The Mass Extermination of Jews in German Occupied Poland $"$. 
schen Juden. In Erinnerung an Szmul Zygielbojm) aus dem Jahr $1943 .{ }^{171}$ Der Schwerpunkt der Darstellung liegt damit auf der Untätigkeit der westlichen Alliierten angesichts des Massenmordes und den dagegen gerichteten vergeblichen Aktivitäten der polnischen Exilregierung. ${ }^{172}$ Mit diesem impliziten Vorwurf des Versagens der Alliierten exkulpieren die Ausstellungsmacher damit indirekt die polnische und konkret die Warschauer Bevölkerung außerhalb der Ghettomauern. Zugleich begegnen sie so ausländischen Anschuldigungen, die seit Kriegsende immer wieder artikuliert wurden, wonach Polen überwiegend untätig geblieben seien angesichts der massiven Verfolgung ihrer jüdischen Nachbarn. Denn die Einstellungen und Handlungsoptionen der polnischen Bevölkerung vor Ort werden nur am Rande erwähnt. Dort, wo sie angedeutet sind - in Iwaszkiewiczs Bericht und dem Gedicht Broniewskis belegen sie ausschließlich positive Reaktionen, nämlich Mitgefühl und aktive Hilfe.

Die Ausstellung präsentiert den Pawiak insgesamt als Symbol des Martyriums der polnischen Warschauer während der Besatzung. ${ }^{173}$ Das Schicksal der im Ghetto eingesperrten und ermordeten Bevölkerung ist in diesem ethnisch-nationalen Narrativ ein externer Faktor; es fungiert als ein Beispiel unter vielen für den Terror der Besatzer sowie die Untätigkeit der westlichen Alliierten. Das Ghetto wird dabei aus der Perspektive der polnischen Bewohner geschildert. Stellvertretend für ihre Reaktionen auf diese Ereignisse stehen Mitgefühl, jedoch auch Entfremdung, wie sie Iwaszkiewicz ausdrückt, sowie die Belege für die Versuche der polnischen Exilregierung, die westlichen Alliierten über das Morden zu unterrichten. Nähere Kontakte zwischen Juden und Polen in Warschau während des Kriegs bleiben jedoch weit-

171 Zeitgenössische Gedichte, die auf die jeweiligen Ereignisse unmittelbar reagierten, sind wesentliche Gestaltungselemente dieser Ausstellung. Das hier genannte Gedicht wird nicht - wie andere (siehe Teil 3, Kapitel 1.2) - an herausragender Stelle, an den Wänden der Ausstellungshalle präsentiert, sondern ist in großformatiger Reproduktion auf einer Stellwand angebracht. Der Autor drückt Mitleid mit dem Massenmord an Frauen und Kindern aus sowie Anerkennung für den Widerstand in Form des Ghettoaufstandes in Warschau. Er beschwört dabei die Gemeinschaft der Polen und schildert den Ghettoaufstand als Fortsetzung des polnischen Widerstands, der im September 1939 begonnen hat. MNW-Pawiak, Sektion zum Ghetto.

172 Die Verzweiflung angesichts der Untätigkeit der Alliierten trotz der Informationen über das Morden im besetzten Polen wird mittels des Testaments bzw. des Abschiedsbriefs von Szmul Zygielbojm vermittelt, einem Mitglied des »Nationalrates der Republik Polen« (Rada Narodowa Rzeczpospolitej Polski) in London, in dem er den jüdischen Bund vertreten hat. Angesichts der voranschreitenden Niederschlagung des Warschauer Ghettoaufstandes verübte er am 12. Mai 1943 Selbstmord. Sein Tod sollte Protest gegen die Untätigkeit der Welt und Appell an die Alliierten sein, die letzten noch lebenden Juden in den von den Deutschen besetzten Territorien zu retten.

173 Siehe Teil 3, Kapitel 1.2. 
gehend unerwähnt; auch die Tätigkeit des »Hilfsrates für Juden«, der unter dem Kryptonym Żegota agierte, ${ }^{174}$ wird nicht thematisiert, ebensowenig die Aktivitäten des zitierten Jarosław Iwaszkiewicz selbst, der posthum für seine Hilfe für verfolgte Juden als »Gerechter unter den Völkern« ausgezeichnet worden ist. ${ }^{175}$

Eine ähnliche Perspektive präsentieren die zwei jüngsten Dauerausstellungen in Warschau, die sich dem Zeitraum des Weltkriegs widmen und die bereits deutlich nach dem Abklingen der Jedwabne-Debatte geplant und eröffnet wurden: die Präsentation des 2004 eröffneten Museums des Warschauer Aufstands und die Sektion zum Zweiten Weltkrieg im Historischen Museum der Hauptstadt Warschau, die in den Jahren 2006 bis 2009 grundlegend neu gestaltet wurde. Die in beiden Schauen vermittelten Interpretationen sowie die darin gewählten Schwerpunkte ähneln sich stark. So wird das Warschauer Ghetto in beiden Ausstellungen ebenfalls aus der Perspektive der polnischen Bewohner der »arischen Seite « präsentiert, als abgeschlossene und unzugängliche Welt. Im MHW wurde diese Interpretation durch die gestalterische Darstellung des Ghettos als ein abgetrennter Raum, eine Art Betonwürfel, vermittelt, in dem nur wenige schmale Schlitze einen Blick in die Welt im Inneren erlaubten (siehe Abb. 24). ${ }^{176}$ Die Besucher konnten durch sie nur undeutlich Fotos der katastrophalen Lebensbedingungen und insbesondere der Gewalt bei der Niederschlagung des Aufstands 1943 erkennen, die noch durch die rote Beleuchtung des Innenraums akzentuiert wurde. Im MPW wird das Ghetto vor dem Hintergrund einer Wand aus Ziegelsteinen thematisiert, auf der offizielle Bekanntmachungen der Besatzungsorgane plakatiert sind und die damit eine Assoziation mit der Ghettomauer hervorruft (siehe Abb. 25). ${ }^{177}$ Das Gestaltungselement der (Ghetto-)Mauer steht damit in beiden Ausstellungen symbolisch für die Vorstellung von einer vollständigen Abriegelung des Ghettos von der »arischen Seite« der Stadt. Schwerpunkt der Darstellung in beiden Museen sind sind die dramatischen Lebensbedingungen im Ghetto, die eine große Zahl an Todesopfern forderten, sowie die Ermordung der übrigen Bewohner in den Vernichtungslagern.

174 Der Hilfsrat für Juden (Rada Pomocy Żydom) wurde 1942 von der polnischen Exilregierung gegründet mit dem Ziel, Juden zu unterstützen, die sich vor der Verfolgung durch die deutschen Besatzer versteckten.

175 In der Schau findet sich nur ein einziger Hinweis auf die Existenz der Żegota: Im Biogramm von Prof. Jan Piekałkiewicz, das auf einer Milchglasplatte im Zentrum der Halle präsentiert wird, ist erwähnt, dass »er die Berufung des Hilfsrates für Juden `Żegotar gutgeheißen [hat]«. MNW-Pawiak.

176 Das Ghetto wurde im Themenraum »Der Polnische Untergrundstaat - Die Widerstandsbewegung in Warschau 1939-1944. Das Warschauer Ghetto « dargestellt. MHW, Saal 48.

177 MPW, Sektion 8: Ghetto. 


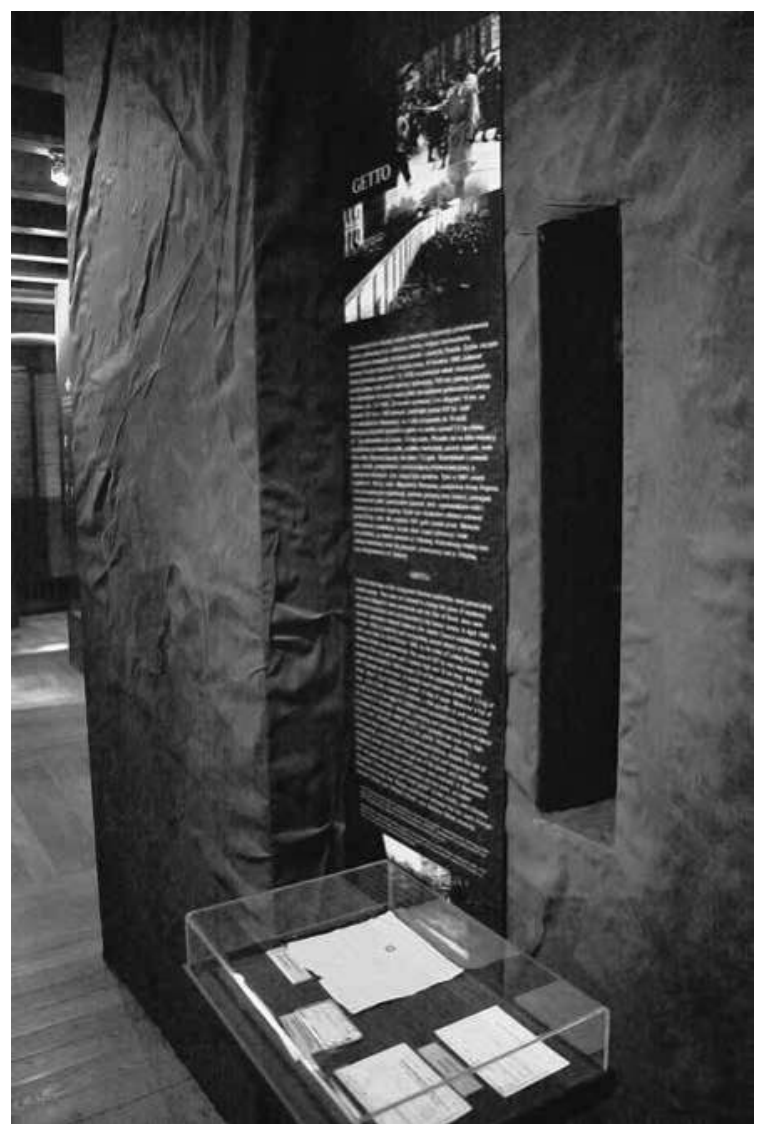

Abb. 24: MHW, Abschnitt „Das Warschauer Ghetto«.

Das Ghetto wird im MPW daneben auch in dem 2007 eröffneten Ausstellungsteil über »Die Deutschen in Warschau« thematisiert. ${ }^{178}$ Dort werden in erster Linie Fotografien von Exekutionen, Demütigungen orthodoxer Juden und der Niederschlagung des Aufstands gezeigt sowie Filmmaterial über das Leben im Ghetto, das aus deutschen Propagandaaufnahmen stammt. Auch im MHW handelte es sich bei den Fotografien, die den Themenbereich illustrierten und das Ghetto betrafen (bzw. überwiegend die Niederschlagung des Aufstandes), um deutsche Quellen. ${ }^{179}$ Der Blick hinter die Mauer erfolgt somit

178 MPW, Sektion 56: Die Deutschen in Warschau.

179 Beide Ausstellungen verwenden überwiegend Fotomaterial aus dem sogenannten StroopBericht, einer Dokumentation über die Niederschlagung des Ghettoaufstandes von 1943, die vom SS- und Polizeiführer Jürgen Stroop geleitet wurde. Vgl. Stroop, Jürgen: Es 


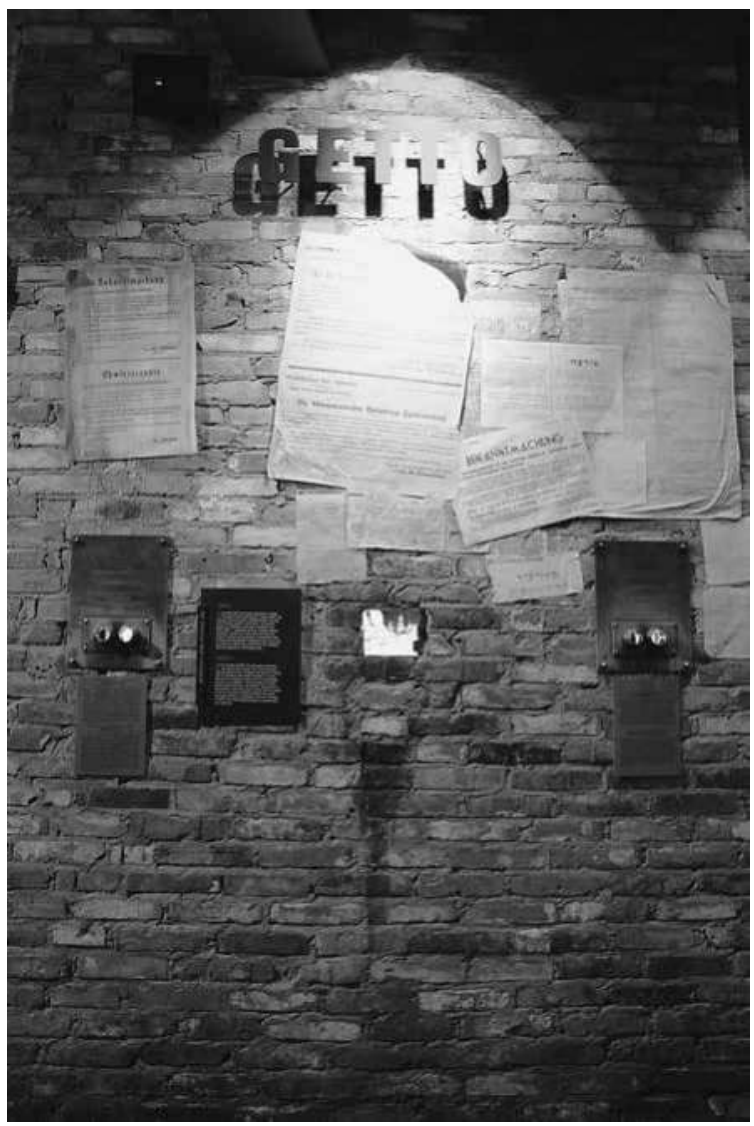

Abb. 25: MPW, Sektion »Ghetto«.

ausschließlich aus der Perspektive der Besatzer. Die Bewohner des Ghettos erscheinen dabei als anonyme, weitgehend homogene Masse. ${ }^{180}$

Das Thema der polnisch-jüdischen Kontakte ist durch die Betonung der strikten Trennung der Bevölkerungsgruppen per se vernachlässigt. Die einzige Erwähnung finden sie in Form von Verweisen auf polnische Hilfe für verfolgte Juden. So hieß es etwa im MHW:

gibt keinen jüdischen Wohnbezirk in Warschau mehr! (Stroop-Bericht). Hg.v. Andrzej Wirth. Neuwied u. a. 1960.

180 Die einzigen beiden Personen, die namentlich genannt werden und zu den verfolgten Juden gehörten, sind der Anführer des Ghettoaufstands Mordechaj Anielewicz sowie der letzte Führer der Erhebung Marek Edelman. Beide werden mit einem Biogramm kurz vorgestellt: Anielewicz in Sektion 7: Der Polnische Untergrundstaat, Edelman in Sektion 15: Die Kämpfe im August. 
Die Einwohner Warschaus, die im Untergrund agierende Heimatarmee und andere konspirative Organisationen halfen - trotz der drohenden Todesstrafe - den Ghettobewohnern: Es wurden Lebensmittel und Waffen geschmuggelt, man führte Menschen [aus dem Ghetto] heraus und versteckte sie auf der arischen Seite. Dank dieser Aktivitäten konnten über 20.000 Personen gerettet werden. ${ }^{181}$

\section{Im MPW erfolgt die Darstellung polnischer Hilfe in ähnlicher Weise:}

Hilfsleistungen für Juden bestrafen die Deutschen mit dem Tod. Dennoch gibt es mutige Polen, die sich bemühen, Juden zu retten, indem sie sie verstecken und sie mit Lebensmitteln versorgen. ${ }^{182}$

In beiden Schauen wird die Tätigkeit von Zivilisten erwähnt; der Schwerpunkt liegt jedoch auf der Darstellung der organisierten Hilfe des polnischen Untergrunds. Stellvertretend wird diese in beiden Präsentationen durch ein Ereignis während des Warschauer Aufstands 1944 dargestellt: der Befreiung der sogenannten Gęsiówka, eines Außenlagers des Konzentrationslagers Majdanek im Zentrum von Warschau an der Gęsia-Straße, während des Aufstands am 5. August $1944 .^{183}$ Im MPW wird dieses Ereignis an herausgehobener Stelle innerhalb des Rundgangs präsentiert, anlässlich des Themenaspekts »Juden im Warschauer Aufstand «. ${ }^{184}$ Dabei wird insbesondere darauf verwiesen, dass viele der befreiten Juden sowie derjenigen, die sich auf der »arischen Seite« versteckt gehalten hatten, an den Kämpfen 1944 teilgenommen haben. ${ }^{185}$ Auch im MHW wurde in den kurzen Biogrammen einzelner Anführer des Ghettoaufstandes darauf verwiesen, wer von ihnen am Aufstand 1944 teilgenommen hat. ${ }^{186}$

Dass es für Juden jedoch nicht ungefährlich war, sich 1944 gegenüber Einheiten der Aufständischen zu erkennen zu geben, wird in keiner der beiden

181 Thementext »Ghetto«. MHW, Saal 48.

182 Bereichstext »Alltag im Ghetto«. MPW, Sektion 8: Ghetto.

183 Im MHW wurde dieses Ereignis sowohl im zentralen Thementext zum Aufstand genannt als auch in einer Multimediapräsentation dargestellt, die die wichtigsten Ereignisse des Aufstands Tag für Tag auflistete. Thementext 1944 - Der Warschauer Aufstand «. MHW, Saal 50: »Der Warschauer Aufstand«. Auch in der Dauerausstellung des Pawiak-Museums findet sich ein Foto von befreiten Juden aus der Gęsiówka. MNWPawiak, Sektion »Warschauer Aufstand 1944«, Objekt 8. Den Kampf um das Lager beschreibt Szarota: Atak na Gęsiówkę.

184 Bereichstext »Juden im Warschauer Aufstand«. MPW, Sektion 15: Die Kämpfe im August.

185 »Dem Aufstand schließen sich Juden an, die sich vor der Vernichtung retten konnten und sich in Warschau versteckten." In dem Bereichstext folgen anschließend Aufzählungen jüdischer Einheiten und Kämpfer in der Heimatarmee und der kommunistischen »Volksarmee« (Armia Ludowa, AL). Ebd.

186 Diese Information erschien bei Icchak Cukierman, Cywia Lubetkin und Marek Edelman. MHW, Saal 48, Themenbereich »Der Aufstand im Ghetto«. 
Ausstellungen explizit benannt. ${ }^{187}$ Im MHW fand dieses Thema keinerlei Erwähnung. Im MPW erfordert es große Aufmerksamkeit der Besucher, um die in der Präsentation versteckten Hinweise zu bemerken und zu deuten. So endet etwa der Bereichstext über »Juden im Warschauer Aufstand« mit der abstrakten Information »In den Reihen der AK kämpfen auch Juden, die ihre Identität nicht offenbaren. ${ }^{188}$ Gründe für diese Zurückhaltung sind lediglich indirekt, aus der unmittelbar daneben ausgestrahlten Videoaufzeichnung eines Interviews mit Marek Edelman, einem der Anführer der Kämpfer während des Ghettoaufstandes und Teilnehmer des Warschauer Aufstands von 1944, zu entnehmen. ${ }^{189}$ Sein Bericht beginnt mit folgenden Worten:

Am ersten Tag, als der Aufstand ausbrach, ging natürlich Jurek nach draußen, denn er hatte einen Revolver. Er ging auf den Hof, und dort haben sie ihn angehalten, dort haben sie überprüft, ja wie denn, ein Zivilist mit einer Waffe und so weiter und so weiter. Ausweis, gefälschte Kennkarte und Jude - denn er war dazu noch dunkel[haarig] und sie haben ihn sofort auf dem Hof erschossen, nachts, diese Einheit, die diese ganze Pańska-Straße eingenommen hatte. Wer? Niemand weiß wer. Woher sollte man das wissen? Die Bewegungen der Aufständischen waren schließlich sehr intensiv. [...] Aber schon am zweiten Tag kam Kamiński und hat gesagt: [...] >Ihr seid noch da? Geht ihr zum Aufstand? ২ Ja, wir gehen, aber wo ... $<$ Er sagt: $>$ Nein, geht nicht, geht dorthin, wo man euch wird haben wollen. Nicht dorthin, wo es euch gefällt. [...] Sucht eine Gruppe, wo man euch wird haben wollen.< Aber wer hätte uns schon haben wollen ... Na ja, ganz egal. Leider waren die einzigen, die uns wirklich wollten, die AL, die kommunistische Volkarmee [...]. ${ }^{190}$

Seine Erlebnisse bei Aufstandsende beschreibt er an einer späteren Stelle:

Er [ein Oberleutnant, bei dessen Familie Edelman zu dem Zeitpunkt wohnte - d.Vf.] sagt: `Marek, wir gehen ins [Kriegsgefangenen-]Lager. Komm mit uns, du wirst hier sicher sein. Da sage ich: ^Aber garantierst du mir das? « Leider nein, denn ich weiß ja, wie die Soldaten sind. $>$ Also was? Kann ich gehen, und du wirst mich nicht verraten, sie werden mich nicht an die Deutschen verraten? > Nein, das garantiere ich nicht. Bleib in Warschau.< Nun, und so war es. ${ }^{191}$

187 Während des Warschauer Aufstands begingen polnische Aufständische mehrere Morde an Juden. Den Umfang solcher Auswüchse, ihren Hintergrund und die Überlieferung von Belegen schildern Engelking-Boni, Barbara/Libionka, Dariusz: Żydzi w powstańczej Warszawie [Juden im aufständischen Warschau]. Warszawa 2009, 159-193.

188 Bereichstext »Juden im Warschauer Aufstand». MPW, Sektion 15: Die Kämpfe im August. Vgl. Engelking-Boni/Libionka: Żydzi w powstańczej Warszawie, 81-97.

189 Der Zusammenschnitt des Interviews, der in der Ausstellung ausgestrahlt wird, enthält Berichte über die Erlebnisse von Edelman während des gesamten Aufstands, darunter auch über seine Begegnung mit ehemaligen Insassen der Gęsiówka. MPW, Sektion 15: Die Kämpfe im August.

190 MPW, Sektion 15: Die Kämpfe im August. Das Transkript des Interviews wurde von der Verfasserin verfasst.

191 Ebd. 
Diese Aussagen, wie das gesamte Interview, die ohne jeglichen begleitenden Kommentar ausgestrahlt werden, enthalten bemerkenswerte Hinweise auf die »dunklen Seiten des Aufstands ${ }^{192}$. Nicht nur berichtet Edelman von der Erschießung eines Bekannten durch Aufständische, unter anderem weil dieser Jude war, und von der Gefahr, die von den Aufständischen für sich versteckende Juden ausging. Er deutet auch an, dass für ihn polnische Mitaufständische in deutscher Kriegsgefangenschaft eine Gefahr bedeuteten, da die Wahrscheinlichkeit hoch war, dass sie ihn als Juden an die Deutschen verraten würden - eine Gefahr, die ihm durch einen polnischen Offizier als real bestätigt wurde.

Für die Einordnung dieser verstreuten Aussagen benötigen die Besucher jedoch ein gewisses Hintergrundwissen, da in der Ausstellung selbst kein weiterer Bezug auf ähnliche negative Phänomene bzw. Handlungsweisen vonseiten der Aufständischen genommen wird und auch Edelman diese nicht umfassend benennt und erläutert. ${ }^{193}$ Es ist auch unter Berücksichtigung der räumlichen und gestalterischen Gegebenheiten zweifelhaft, wie viele Besucher diese Elemente des Interviews wahrnehmen. So sind nicht alle Aussagen in der Videoaufzeichnung gut verständlich: Edelman spricht undeutlich, und die laute Geräuschkulisse der Ausstellung in diesem Bereich erschwert das Zuhören zusätzlich; um seine Worte zu verstehen, muss man sich direkt zu den Lautsprechern, die unterhalb des Bildschirms angebracht sind, hinunterbeugen. ${ }^{194}$ Bei diesem Video gibt es zudem - im Gegensatz zu vielen anderen im Laufe der Rundgangs - keine Sitzgelegenheiten; der Gang bzw. Bereich an dieser Stelle ist vergleichsweise eng; zahlreiche Besucher passieren ihn - Zuschauer, die die Aufzeichnung ansehen, stehen anderen also im Weg. Viele Besucher gehen daher an dem Video ganz vorbei oder sehen nur wenige Sekunden zu - während die Gesamtlänge der Aufzeichnung knapp acht Minuten beträgt. ${ }^{195}$

In der übrigen Ausstellung dominieren positive Darstellungen polnischer Verhaltensweisen gegenüber Juden; der Fokus liegt auf polnischer Hilfe für verfolgte Juden. In mehreren Biogrammen, insbesondere von Aufständischen, wird explizit auf deren Hilfsaktivitäten für Juden verwiesen sowie auf die

192 So lautete der Titel des Artikels von Michał Cichy, der eine erbitterte Kontroverse hervorrief. Siehe Cichy: Polacy - Żydzi.

193 Im Ausstellungskatalog ist das Thema der »Juden im Warschauer Aufstand« nicht enthalten; auch negative Verhaltensweisen von Aufständischen gegenüber Juden werden nicht erwähnt. Vgl. Dąbkowska-Cichocka: Przewodnik po Muzeum.

194 Das Interview ist mit englischen Untertiteln versehen, die es Ausländern ermöglichen sollen, den Inhalt zu erfassen. Polnischen Besuchern können diese ebenfalls hilfreich sein - solange diese die Sprache gut genug beherrschen, um die schnell wechselnden Zeilen in kurzer Zeit zu lesen.

195 Diese Beschreibungen beruhen auf den eigenen Beobachtungen der Verfasserin bei häufigen und jeweils längeren Aufenthalten in der Ausstellungssektion in den Jahren 2009 bis 2012. Die Länge der Aufzeichnung beträgt etwa 7 Minuten 49 Sekunden. 
Auszeichnung Einzelner mit der Medaille eines »Gerechten unter den Völkern «. ${ }^{196}$ Bei der Schilderung der Aktivitäten des Personals eines Krankenhauses im Stadtteil Wola wird unter anderem aufgelistet: "hier hilft man Juden, die aus dem Ghetto geflohen sind. ${ }^{197}$ Diese einseitig positive Darstellung wird nur mit einem einzigen Satz in der gesamten Ausstellung differenziert: »Leider gibt es auch solche, die Juden erpressen oder an Deutsche ausliefern. $"{ }^{198}$ Die Aussage suggeriert - gerade vor dem Hintergrund der in der übrigen Schau mehrfach erwähnten Hilfsleistungen -, negative Handlungen seien lediglich eine Randerscheinung während der Besatzung gewesen. Im MHW wurden sogar ausschließlich positive Haltungen von Polen gegenüber Juden erwähnt. ${ }^{199}$ Beide Museen perpetuieren somit weitgehend interpretative Topoi aus der Zeit der VRP, indem sie das Bild einer verbreiteten und allgemeinen Hilfe von Polen für Juden als Normalfall der polnisch-jüdischen Kontakte während der Besatzung zeichnen und auf den gemeinsamen Kampf gegen die Besatzer verweisen.

Auch wenn die Schilderungen der jüdischen Bevölkerung in den Museen auf das Ghetto konzentriert sind, wird doch in beiden die bereits mit dem Einmarsch deutscher Truppen beginnende Ausgrenzung und Stigmatisierung der Juden kurz erwähnt. ${ }^{200}$ So werden im MPW im Anfangsbereich des Ausstellungsrundgangs, der übergreifend dem deutschen und sowjetischen Besatzungsregime in Polen gewidmet ist, die Schaffung von Ghettos ab Oktober 1939 sowie die Morde in den Vernichtungslagern ab Dezember $1941 \mathrm{mit}$ zwei Sätzen benannt. ${ }^{201}$ In dieser Sektion finden sich auch einige Bekanntmachungen der Besatzungsorgane, die die jüdische Bevölkerung betreffen, unter anderem über das Verhängen der Todesstrafe bei »unbefugtem Verlassen des jüdischen Wohnbezirks «. ${ }^{202}$ Zudem wird in beiden Schauen das Ziel der deutschen Besatzer in Bezug auf die jüdische Bevölkerung unmissverständlich als »Vernichtung « benannt. ${ }^{203}$ Eine semantische Verharmlosung des

196 Im Biogramm Kardinal Adam Sapiehas, der während der Besatzung das faktische Oberhaupt der polnischen Katholiken im Generalgouvernement war, sowie Maximilian Kolbes wird auf ihre Unterstützung von Juden hingewiesen. MPW, Sektion 7: Der Polnische Untergrundstaat. Bei den Aufständischen Władysław Bartoszewski und Stefan Korboński wird erwähnt, dass sie als "Gerechte unter den Völkern« ausgezeichnet wurden. MPW, Sektion 46: Die Aufständischen in der VRP, Sektion 6: Besatzung.

197 Bereichstext »Das Krankenhaus von Wola«. MPW, Sektion 22: Das Krankenhaus der Aufständischen.

198 Bereichstext »Alltag im Ghetto«. MPW, Sektion 8: Ghetto.

199 Vgl. das weiter oben erwähnte Zitat.

200 Im MHW erfolgte dies im Thementext »Ghetto«. MHW, Saal 48.

201 Thementext »Kriegsanfang«. MPW, Sektion 6: Besatzung.

202 Zitat aus einem der Plakate. Ebd.

203 Im MHW stellte man die Deportation und Ermordung der Ghettobewohner im Bereichstext »Der Aufstand im Ghetto« dar. Auch hier wurden die unmissverständlichen 
jüdischen Schicksals, wie sie noch bis Mitte der 1990er-Jahre in den Dauerausstellungen anzutreffen war, findet somit nicht mehr statt. ${ }^{204}$

In den drei betrachteten Warschauer Ausstellungen ist das Thema der Verfolgung der jüdischen Stadtbewohner insgesamt weiterhin im musealen Narrativ marginalisiert. Zwar erfolgt die Darstellung ihres Schicksals insgesamt detaillierter - gerade in Bezug auf den präsentierten Materialumfang - als in den Schauen aus den 1980er- und von Anfang der 1990er-Jahre. Dem Thema wird jedoch weiterhin ein nur sehr kleiner Anteil der Ausstellungsfläche zugewiesen. Auch die Art und Weise der Verortung dieses Teils der Besatzungsgeschichte - die Verfolgung und Ermordung fast eines Drittels der Warschauer Vorkriegsbevölkerung - innerhalb der Erzählungen lässt sie als untergeordneten Aspekt der Kriegsereignisse erscheinen. Wie bereits dargelegt, ist dem Thema "Ghetto « in der Schau des Pawiak nur eine kleine Ecke der Ausstellungshalle gewidmet. Im MHW war es in einem Ausstellungssaal zusammen mit dem - weitaus ausführlicher und auch raumgreifender geschilderten - Thema "Die Widerstandsbewegung in Warschau 1939-1944" untergebracht. ${ }^{205}$ In den folgenden thematischen Sektionen, wie etwa der Schilderung des Alltags während der Besatzung oder des Warschauer Aufstandes, wurde die jüdische Bevölkerung der Stadt nicht mehr erwähnt. ${ }^{206}$

In der Präsentation des MPW, die sich insgesamt auf vier Etagen erstreckt, räumt man dem Ghetto nur an zwei Stellen Platz ein: auf einer Teilwand des Ausstellungsabschnitts »Die Deutschen in Warschau« - eine Zuordnung, die in erster Linie der Exemplifizierung der Brutalität und Unmenschlichkeit der Besatzer dient $-{ }^{207}$ sowie an der Wand aus Mauerwerk im ersten Teil der Ausstellung. ${ }^{208}$ Unmittelbar daneben, auf einer ähnlichen Grundfläche, wird das Thema "Terror « dargestellt (siehe Abb. 26). ${ }^{209}$ Der Schwerpunkt der Darstellung dieses Abschnitts liegt auf den Massenexekutionen von Polen. Diese werden nicht nur im Bereichstext dieser Sektion thematisiert, sondern insbesondere durch die an der Wand angebrachten Bekanntmachungen der

Begriffe »Ermordung« und »Vernichtung« verwendet. MHW, Saal 48. Im MPW findet sich in mehreren Kuratorentexten der Ausdruck »die zur Vernichtung verurteilten polnischen Juden«. So wird er in der Überschrift über einer Präsentation von Fotos der Niederschlagung des Ghettoaufstandes in der Sektion 8 (Ghetto) verwendet sowie im Thementext »Der Stadtbezirk hinter den Mauern«. MPW, Sektion 56: Die Deutschen in Warschau.

204 Die in beiden Schauen dennoch zu verzeichnende Konkurrenz um den Opferstatus wird in Teil 3, Kapitel 1.3 untersucht.

205 MHW, Saal 48. Dieser Saal war einer von insgesamt acht Räumen (und einem geräumigen Korridor), die dem Zeitraum der Jahre 1939 bis 1945 gewidmet waren.

206 Diese Themen wurden in den Sälen 49 bis 51 behandelt.

207 MPW, Sektion 56: Die Deutschen in Warschau.

208 MPW, Sektion 8: Ghetto.

209 MPW, Sektion 6: Besatzung. 


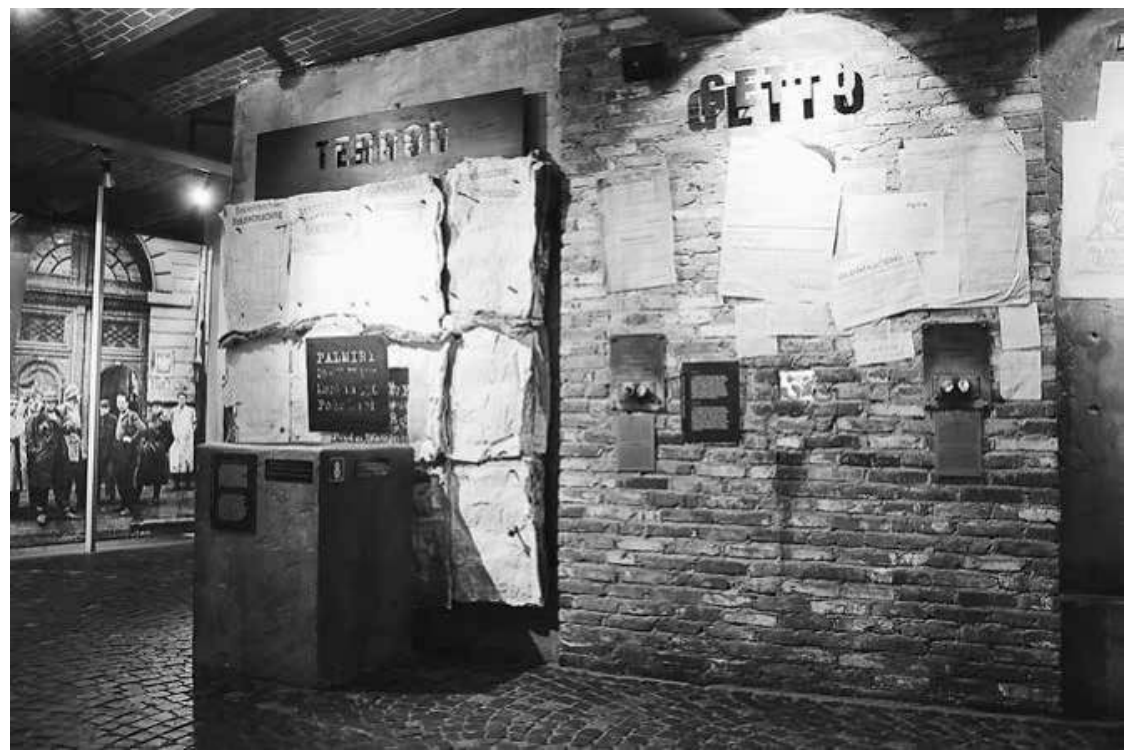

Abb. 26: MPW, Abschnitte »Terror« und »Ghetto«.

Besatzungsorgane illustriert, auf denen Namenslisten von zum Tode Verurteilten und Exekutierten abgedruckt sind. Stellvertretend für die Massenexekutionen steht auch der Begriff »Palmiry«, der prominent platziert ist: Der Name dieses Waldgebietes bei Warschau ist in der kollektiven Erinnerung gerade der Warschauer Bevölkerung mit den deutschen Massenerschießungen von Zivilisten, aber auch von bedeutenden Politikern und Kulturschaffenden assoziiert. Diese Deutung wird auch in der Schau unmissverständlich vermittelt, durch den Schriftzug "Palmiry/20-21.VI.1940 / Mord an 358 / Polen«. Die Plakate wiederum sind in großer Zahl übereinander geklebt, sodass sie dicke Bündel bilden, die eine hohe Zahl an Todesopfern suggerieren. ${ }^{210}$ Die wenigen, einzeln angebrachten Bekanntmachungen in der Sektion »Ghetto « unmittelbar daneben wirken demgegenüber deutlich weniger bedrohlich. Zusätzlich wird der erstgenannte Abschnitt rot angeleuchtet; die Papierstapel sind an den Rändern mit roter Farbe versehen, die angesichts des Themas eine unmittelbare Assoziation mit dem Blut der Opfer hervorruft, und auch der zentrale Schriftzug »Terror« ist blutrot beleuchtet - im Gegensatz zur Sektion »Ghetto «, die nicht mit einer ähnlich dramatischen Licht- und Farbregie versehen wurde. Die Gestaltung dieser zwei direkt nebeneinander positionierten Sektionen legt damit den Schwerpunkt auf die Gewalt an ethnischen 
Polen, wenn auch im Bereichstext zur Sektion »Ghetto « die deutlich höhere Zahl der dort Internierten von schätzungsweise 450.000 Menschen genannt wird. Diese Information muss jedoch aktiv rezipiert werden, wogegen die visuelle Botschaft der Sektion »Terror« eine entgegengesetzte Opferhierarchie suggestiv vermittelt. Zudem bleibt die Masse der im Ghetto Eingesperrten anonym, repräsentiert allein durch die abstrakte Opferzahl, während die Plakate der Sektion "Terror" die Namen konkreter Verurteilter nennen, wodurch der Eindruck entsteht, sämtliche (polnischen) Exekutierten seien namentlich aufgelistet und damit als Individuen repräsentiert. ${ }^{211}$ Dies übt eine deutlich stärkere affektive Wirkung aus als die zurückgenommene, abstrakte Präsentation des Ghettos und seiner Bewohner.

Ein thematischer Schwerpunkt der drei Dauerausstellungen liegt auf dem Warschauer Aufstand von 1944. Dieser wird als das zentrale Ereignis des Kriegs in der Stadtgeschichte jeweils ausführlich behandelt. Der Aufstand im Warschauer Ghetto ein Jahr zuvor erhält dagegen nur wenig Raum. So wird etwa im Pawiak-Museum die Jüdische Kampforganisation, die den Aufstand vorbereitete und mit durchführte, nur mittelbar über die Person eines ihrer Mitglieder, Michał Klepfisz, in die Schau eingebracht. ${ }^{212}$ Der Fokus der Darstellung liegt dabei auf der Niederlage der Aufständischen, die durch Fotos der Zerstörung des Ghettos und der Gefangennahme einzelner Personen symbolisiert werden. Im MHW stellte man den Aufstand in einem Thementext dar, in dem neben der ŻOB auch der »üdische Militärverband « (Żydowski Zwiazek Wojskowy, ŻZW) als zweite Widerstandsorganisation im Ghetto erwähnt wurde, die am Aufstand beteiligt war. ${ }^{213}$ Eingehender, mittels eines kurzen Textes und kurzen Biogrammen einzelner Anführer des Aufstands, wurde jedoch lediglich die ŻOB thematisiert. Ihr war allerdings hinsichtlich des Umfangs der einzelnen Texte insgesamt weniger Platz eingeräumt als der Żegota und damit der Hilfe des polnischen Untergrunds für sich versteckende Juden. Obwohl die Ausstellung des MPW wesentlich umfangreicher ist als die der beiden anderen Warschauer Museen, wird hier dem Aufstand den-

211 Diese Auffassung vertritt auch Bogumit: Miejsce pamięci versus symulacja przeszłości, 159. In der Sektion »Terror« werden zusätzlich in einer Multimediapräsentation Fotos von Exekutionen von Polen sowie Leichen, aber auch Abbildungen aus dem Ghetto gezeigt, die beide Bevölkerungsgruppen somit als dem Terror der Besatzer ausgesetzt illustrieren. Diese drastischen Bilder sind mit einem Warnhinweis versehen, sodass nicht jeder Besucher sie betrachten wird. Die an der Wand angebrachten Plakate hingegen verweisen ausschließlich auf nichtjüdische, polnische Opfer von Massenexekutionen, für die stellvertretend auch das prominent angebrachte Schlagwort »Palmiry« steht.

212 Gezeigt wird ein in New York veröffentlichter Nachruf auf Michał Klepfisz, ein Mitglied der ŻOB, der während des Aufstands starb und posthum den höchsten polnischen Orden »Virtuti Militari« 5. Klasse erhielt. MNW-Pawiak, Sektion zum Ghetto.

213 Thementext »Der Ghettoaufstand«. MHW, Saal 48. 
noch nicht mehr Platz eingeräumt: Der Anführer der Aufständischen, Mordechaj Anielewicz, wird mit einem Biogramm vorgestellt, und über die Ereignisse des Aufstands, darunter die Rolle des ŻOB und des ŻZW, berichtet ein kurzer Text. ${ }^{214}$ Zusätzlich sind Fotos von der Niederschlagung des Aufstandes zu sehen, die mit der Beschriftung versehen sind: "Die zur Vernichtung verurteilten polnischen Juden wählen einen würdigen Tod. ${ }^{215}$

Der Fokus liegt in all diesen Ausstellungen nicht auf dem Kampf der Aufständischen, den Vorbereitungen, Plänen, einzelnen Kampfhandlungen - wie dies etwa bei der Darstellung des Aufstands von 1944 der Fall ist -,, ${ }^{216}$ sondern auf der Gewalt, dem Leiden und der Zerstörung während seiner Niederschlagung. Im Begleittext der Schau des MPW ist zwar auch vom »heroischen Kampf « der Aufständischen die Rede; ${ }^{217}$ die präsentierten Exponate - überwiegend Fotos aus dem sogenannten Stroop-Bericht - lenken jedoch den Blick in erster Linie auf die Niederlage und das mit ihr einhergehende Elend und Sterben der Ghettobewohner. ${ }^{218}$ Nicht Helden oder »heroische Opfer « - also Märtyrer - ${ }^{219}$ stehen im Vordergrund der Erzählungen, sondern passive Opfer; Mitleid - weniger Bewunderung - wird mittels der Präsentationen beim Betrachter evoziert. ${ }^{220}$ Die im Pawiak ausgestellte Reproduktion des Gemäldes von Bronisław Wojciech Linke "El mole rachmim « ${ }^{21}$ fasst symbolisch diese Sichtweise auf das jüdische Schicksal während der Besatzung zusammen: Eine gebeugte Figur, in Trümmern stehend, in ein jüdisches Gebetstuch gehüllt, von mehreren Schüssen verletzt, schlägt die Arme in Trauer oder im Gebet über dem Kopf zusammen: ein Gebet in Erinnerung an die Toten.

214 MPW, Sektion 7: Der Polnische Untergrundstaat; Text»Umschlagplatz« [Originalschreibweise]. Sektion 8: Ghetto. Daneben gibt es im Zwischengeschoss ein Biogramm von Marek Edelman, in dem u.a. seine Rolle während des Ghettoaufstands kurz beschrieben wird. Sektion 15: Die Kämpfe im August, Themenabschnitt "Juden im Warschauer Aufstand «.

215 MPW, Sektion 8: Ghetto. Die Niederschlagung des Aufstands wird auch in der Sektion thematisiert, die den Deutschen in Warschau gewidmet ist: Erwähnt wird die »Liquidierung des Ghettos « mit einem Satz; Fotografien aus dem Stroop-Bericht illustrieren sie. Bereichstext »Der Stadtbezirk hinter den Mauern«. MPW, Sektion 56: Die Deutschen in Warschau, Themenabschnitt »Ghetto«.

216 Siehe Teil 3, Kapitel 2.3.

217 Text »Umschlagplatz«. MPW, Sektion 8: Ghetto.

218 Auch in den Präsentationen im Pawiak-Museum und im MHW werden überwiegend Fotografien aus dem Stroop-Bericht verwendet.

219 Assmann, Aleida: Der lange Schatten der Vergangenheit. Erinnerungskultur und Geschichtspolitik. Bonn 2007, 74.

220 Vgl. hierzu auch Bogumił/Wawrzyniak: Narracje zniszczenia, 12; Bogumit: The Enemy on Display, 91-94.

221 Der Titel verweist auf ein jüdisches Gebet zum Gedenken an Verstorbene, vor allem an Opfer antijüdischer Verfolgungen. Er lautet im Original »El mole rachamim«. Vgl. Rahe, Thomas: »Höre Israel«. Jüdische Religiösität in nationalsozialistischen Konzentrationslagern. Göttingen 1999, 223. 
Zugleich sind die Aufständischen und Mitglieder der jüdischen Widerstandsorganisationen fast die einzigen Juden, die in den drei Ausstellungen namentlich erwähnt werden. ${ }^{22}$ Sie sind diejenigen, die - wie es im MPW heißt - »einen würdigen Tod [wählen] « und im Kampf sterben. ${ }^{223}$ Diese Argumentation, wonach es beim Aufstand der im Ghetto Verbliebenen in erster Linie um »Würde« (godność) ging, gehörte bereits in der VRP zum etablierten Sprachgebrauch und diente, wie Jacek Leociak dargelegt hat, der Verneinung »dessen, was [...] das allgemein angenomme Ziel des Widerstandskampfes ist [...] [-] der Kampf ums Leben. ${ }^{224}$ Diese Perspektive, mit ihrem Fokus auf dem (hoffungslosen) Kampf um höhere Ideale und dem Tod als moralischen Triumph der Besiegten, rekurrierte auf tradierte Muster polnischer martyrologischer Geschichtserzählungen und Patriotismusvorstellungen. ${ }^{225}$ Eine solche Kontextualisierung ermöglichte letztlich die Vereinnahmung des Ghettoaufstands in ein national-polnisches Narrativ. ${ }^{226}$ Diese Interpretation sticht auch in den musealen Präsentationen vom Anfang des 21. Jahrhunderts hervor: Nur die Aufständischen haben sich demnach »würdig" verhalten, das heißt aktiv gekämpft, und verdienen daher eine namentliche Nennung. Die Anerkennung der "Ehrenhaftigkeit» der Angehörigen des Widerstands in den Schauen des MHW und MPW zeigt sich auch in der Verwendung der Bezeichnung "Soldaten " für sie, die ansonsten fast ausschließlich den Mitgliedern polnischer Untergrundorganisationen vorbehalten ist. ${ }^{227}$ Die derartige Herausstellung dieser Kämpfer markiert sie zugleich als Ausnahmen im Vergleich zu der anonymen, auf den ausgestellten Fotografien sichtbaren Mehrheit der Ghettoinsassen, die implizit als passiv und deren Tod somit als »unwürdig « erscheint. ${ }^{228}$ Diese Darstellung kontrastiert die in den Ghettos eingesperrte Bevölkerung zugleich mit dem heroisch-martyrologischen Bild der polnischen Bevölkerung, das alle drei Ausstellungen zeichnen: In diesem

222 Sowohl im MHW als auch im Pawiak wird zudem Janusz Korczak als herausragender Pädagoge und Autor kurz vorgestellt, jeweils mit einer Fotografie und einem knappen Biogramm. Erwähnt wird in beiden Ausstellungen, dass er freiwillig die jüdischen Kinder bei ihrer Deportation nach Treblinka begleitete, wo er ermordet wurde. MHW, Saal 48; MNW-Pawiak, Sektion zum Ghetto.

223 Fotoinstallation »Die zur Vernichtung verurteilten polnischen Juden wählen einen würdigen Tod«. MPW, Sektion 8: Ghetto.

224 Leociak: Zraniona pamięć, 263, 265f., Zitat: 265.

225 Siehe auch Janion, Maria: »Nie-Boska komedia« - skażone arcydzieło [Die »Nicht-göttliche Komödie«. Das verseuchte Meisterwerk]. In: Gazeta Wyborcza vom 29.3.2008, 32.

226 Leociak: Zraniona pamięć, 266, 268, 275.

227 Text »Umschlagplatz«. MPW, Sektion 8: Ghetto; Bereichstext »Der Aufstand im Ghetto«. MHW, Saal 48.

228 Vgl. Bogumił: Miejsce pamięci versus symulacja przeszłości, 159f. »Passivität« im Angesicht der eigenen Vernichtung wurde Juden bereits seit den 1960er-Jahren in der VRP immer wieder vorgeworfen. Michlic/Melchior: The Memory of the Holocaust, 417. 
fungieren die Mitglieder der Untergrundorganisationen als Repräsentanten einer vermeintlich allgemein verbreiteten patriotischen und kämpferischen Haltung der polnischen Gesamtbevölkerung. ${ }^{229}$

Diese Abgrenzung von der polnischen Bevölkerung als Hauptprotagonisten der Schauen erfolgt nicht zuletzt dadurch, dass der Blick der Ausstellungsbesucher auf das Ghetto derjenige der Bewohner der sogenannten arischen Seite der Stadt ist. Es handelt sich also um eine externe Perspektive, in der die als Juden Verfolgten als weitgehend homogene, anonyme Masse von "Fremden « innerhalb einer ethnisch-polnisch definierten nationalen Geschichte erscheinen. Diese Wahrnehmung als »fremdes" Element der Erzählung zeigte sich im MHW beispielsweise auch dadurch, dass der Ausdruck »arische Seite « im Ausstellungstext ohne Anführungszeichen auftauchte. Der zeitgenössische Ausdruck, der die nationalsozialistischen Rassenkategorien verwendet und den die Bevölkerung der besetzten Städte in den Jahren 1939 bis 1945 übernommen hatte, wurde hier nicht historisiert und reflektiert, sondern als vermeintlich objektive Tatsachenbeschreibung und damit in Abgrenzung zur nicht-»arischen«, jüdischen Bevölkerung verwendet. ${ }^{230}$ Das Schicksal der Eingeschlossenen fungierte in erster Linie als Beispiel für den Terror und die Unmenschlichkeit der Besatzer. Dieser deutlichen Unterscheidung zwischen den »Unseren« und den »Anderen« - Polen und Juden - wird auch dadurch Ausdruck verliehen, dass die nationalsozialistische Zuschreibung »ude «/»jüdisch" an keiner Stelle in den drei Präsentationen problematisiert oder hinterfragt wird. Ähnlich wie in den Ausstellungen aus der Vorwendezeit verwendet man auch in diesen Präsentationen die ethnisch-nationalen Zuschreibungen »polnisch" und »jüdisch « als scheinbar neutrale, eindeutige und gegebene Kriterien. Als Verbrechen, das von "Fremden " (den deutschen Besatzern) an "Fremden" auf polnischem Boden verübt wurde, bleibt das Schicksal der jüdischen Stadtbewohner in den Erzählungen dieser Museen nur ein Nebenschauplatz der Besatzungsgeschichte. ${ }^{231}$

Auch die zwei jüngsten Ausstellungen im MHW und MPW ingnorieren weitgehend die gerade in Bezug auf das Warschauer Ghetto umfangreichen neueren polnischen Forschungen zu Begegnungen zwischen Juden und NichtJuden während des Kriegs, die die Vielfalt der Verhaltensweisen polnischer Warschauer, darunter auch negative und ambivalente Ereignisse, umfassend dokumentieren und das tradierte Bild einer vermeintlich verbreiteten Hilfe durch Polen weitgehend relativiert und sogar widerlegt haben. ${ }^{232}$ Hier ist die

229 Vgl. Bogumit/Wawrzyniak: Narracje zniszczenia, 12 f. Siehe Teil 3, Kapitel 2.3.

230 Thementext »Ghetto«. MHW, Saal 48.

231 Diese Einschätzung teilen in Bezug auf die Schau des MHW auch Bogumił / Wawrzyniak: Narracje zniszczenia, 12.

232 Um nur einige prominente Beispiele zu nennen: Engelking, Barbara: „szanowny panie gistapo«. Donosy do władz niemieckich w Warszawie i okolicach w latach 1940-1941 
Entscheidung offensichtlich, Erkenntnisse, die nicht in das polnische Selbstbild der Helden und Märtyrer passen, zu vernachlässigen.

Die drei analysierten Präsentationen sind somit Beispiele eines konservativen Geschichtsbildes, das auf die Bewahrung eines positiven Selbstbildes der Wir-Gemeinschaft ethnischer Polen ausgerichtet ist. Vor diesem Hintergrund werden in der Darstellung der polnisch-jüdischen Beziehungen der Besatzungszeit Interpretationstopoi fortgeschrieben, die bereits in der VRP etabliert wurden. Insbesondere die zwei jüngeren Dauerausstellungen, jene des MPW und des MHW, repräsentieren damit Institutionen, die dem von den Vertretern der »neuen Geschichtspolitik« postulierten affirmativen Patriotismus in der Darstellung der polnischen Vergangenheit Ausdruck verleihen. Sie fokussieren in ihren jeweiligen historischen Darstellungen auf positive, den Nationalstolz unterstützende Aspekte der polnischen Geschichte und blenden deren negative Elemente bzw. solche, die das einheitliche Bild stören würden, weitgehend aus. ${ }^{233}$

Im Gegensatz zu dieser Präsentationspraxis der drei zuletzt betrachteten Museen stand jedoch eine Dauerausstellung in Warschau, die das Ghetto ins Zentrum der Aufmerksamkeit stellte. Inwieweit diese Schau sich auch in ihren Deutungsangeboten von den drei bekannteren Institutionen unterschied, wird im Folgenden analysiert.

[»sehr geehrter herr gistapo«. Denunziationen an deutsche Behörden in Warschau und seiner Umgebung in den Jahren 1940-1941]. Warszawa 2003; Grabowski, Jan: »Ja tego Zyda znam!« Szantażowanie Żydów w Warszawie, 1939-1943 [»Ich kenne diesen Juden!« Die Erpressung von Juden in Warschau, 1939-1943]. Warszawa 2004. Auch die Publikationen des Jüdischen Historischen Instituts, unter anderem in dessen Zeitschrift Biuletyn Żydowskiego Instytutu Historycznego (Bulletin des Jüdischen Historischen Instituts) - seit 2001 unter dem Namen Kwartalnik Historii Żydów (Vierteljahresheft der Geschichte der Juden) -, haben sich immer wieder mit diesem Thema befasst. Nur ein Beispiel ist Tych, Feliks: Świadkowie Shoah. Zagłada Żydów w polskich pamiętnikach i wspomnieniach [Zeugen der Shoah. Die Vernichtung der Juden in polnischen Tagebüchern und Memoiren]. In: Ders.: Długi cień zagłady. Szkice historyczne [Der lange Schatten der Vernichtung. Historische Skizzen]. Warszawa 1999, 9-54. Das bis heute zentrale Standardwerk über die Geschichte des Warschauer Ghettos wurde bereits 2001 publiziert: Engelking-Boni/Leociak: Getto warszawskie. Das Thema polnisch-jüdischer Beziehungen während der Besatzung wird darin zwar nicht umfassend besprochen; Verweise darauf und konkrete Beispiele finden sich jedoch immer wieder. Dieses Buch wurde im MHW bei der Konzeption der Sektion zum Ghetto nachweislich verwendet: Beim ausgestellten Stadtplan Warschaus mit den darin verzeichneten sich verändernden Ghettogrenzen wurde die Ausgabe des Werkes von Engelking-Boni und Leociak von 2001 als Quelle zitiert. Dennoch haben die Kuratoren die in derselben Publikation enthaltenen Hinweise auf die Vielfalt der Reaktionen der Warschauer Bevölkerung außerhalb des Ghettos auf das Leiden darin nicht aufgegriffen: In der bereits zuvor zitierten Passage des einleitenden Thementextes wurde ausschließlich auf polnische Hilfe verwiesen. Thementext »Ghetto «, MHW, Saal 48.

233 In Teil 3, Kapitel 2.3 und 3.2. wird dies eingehender dargelegt. 


\subsection{Ein Sonderfall? - Die Dauerausstellung des Jüdischen Historischen Instituts}

Die historische Dauerausstellung des Jüdischen Historischen Instituts, die bereits im Juni 2000 unter dem Titel »Getto Warszawskie. 15 listopada $1940-$ 16 maja 1943 r.« (Das Warschauer Ghetto. 15. November 1940 - 16. Mai 1943) eröffnet wurde und damit die älteste der untersuchten Warschauer Schauen aus diesem Zeitraum war, stellte gegenüber der im vorigen Abschnitt herausgearbeiteten Präsentationsweise bereits auf den ersten Blick einen deutlichen Kontrast dar: Sie war die einzige permanent der Öffentlichkeit zugängliche museale Präsentation der Stadt, die allein dem Warschauer Ghetto gewidmet war. In ihrer grundlegenden Herangehensweise an das Thema nahm sie zudem eine entgegengesetzte Perspektive ein: Die Besucher blickten nicht von außen, von der "arischen Seite " der Stadt, auf oder hinter die Mauern, wie dies bei den anderen Ausstellungen der Fall ist, sondern sie befanden sich inmitten der im Ghetto eingeschlossenen Menschen und erfuhren von der sukzessiven Entwicklung der Ereignisse aus ihrer Perspektive. Dies wurde insbesondere durch die Gestaltung vermittelt: Anstatt anonymen Menschenmassen begegnete man immer wieder einzelnen Personen und individuellen Sichtweisen und Einschätzungen - in Form von Fotografien sowie Zeitzeugenaussagen in Prosa und Gedichten. So bestand die überwiegende Anzahl der Kommentare, die die Exponate begleiteten, aus Ausschnitten aus Zeitzeugenberichten, darunter insbesondere des Tagebuchs des Leiters des Judenrates Adam Czerniaków sowie der Aufzeichnungen von Emanuel Ringelblum, dem Leiter des Untergrundarchivs des Warschauer Ghettos »Oneg Schabbat.$^{234}$ Diese individualisierte Erzählweise ist bei der Darstellung der Verfolgung der polnischen Juden Anfang der 2000er-Jahre in keinem anderen der untersuchten Museen zu finden.

Auch die Themenschwerpunkte der Schau unterschieden sich von denen der anderen Museen. Sie stellte nicht ausschließlich das Leiden und Sterben der Ghettobewohner dar, sondern konzentrierte sich auf das Leben und den Alltag dieses Teils der Stadt, wie ein Zitat illustriert: "Die Zeit verging, irgendwie lebte man hinter den Mauern des Ghettos. Wir haben uns etwas vorgemacht und hofften zu überleben ${ }^{235}{ }^{23}$ Diese Bemerkung - gleichzeitig das inoffizielle Leitmotiv der Ausstellung - ${ }^{236}$ war Ausgangspunkt für die Darstellung des Lebens im Ghetto aus vielfältigen Perspektiven: Ausführlich geschildert wurden unter anderem der überlebensnotwendige Schmuggel, die

234 Weitere Kommentare zu laufenden Entwicklungen im Ghetto stammten u. a. von Henryk Makower und dem Arzt Ludwik Hirszfeld.

235 Zitat von H. Makower. ŻIH, großer Ausstellungssaal.

236 Interview mit Magdalena Sieramska, der Kuratorin der Ausstellung, am 19. Mai 2010. 
Zwangsarbeit und Deportationen, das religiöse und kulturelle Leben seiner Bewohner oder die schwierige Lage der Kinder. Auch die Unterschiede in den Erfahrungen und Lebensbedingungen der verschiedenen gesellschaftlichen, sozialen und religiösen Gruppen, mit ihrer unterschiedlichen staatlichen und regionalen Herkunft sowie materiellen Bedingungen wurden problematisiert. Ebenso angesprochen wurden politische und Jugendgruppen wie etwa die sozialistisch-zionistische Gruppe »Hashomer Hatzair«.

Ähnlich wie in den anderen Ausstellungen war auch hier die Abgrenzung des Gebiets von der restlichen Stadt ein wesentliches Thema. Die Ghettomauer erschien dabei zum einen als Symbol der Trennung, als Verweis auf die physische Abriegelung des Gebietes vom restlichen Warschau. Im Gegensatz zu den übrigen Museen wurde die Mauer hier jedoch zugleich als Kontaktzone zur Außenwelt gezeigt. So schilderte man etwa ausführlich den Schmuggel von Gütern durch Löcher in der Mauer oder über diese hinweg - dies veranschaulichen nicht nur Zeitzeugenberichte und ein Gedicht, sondern auch großformatige Fotografien, die zeigten, auf welche verschiedenen Weisen die Mauer überwunden wurde. ${ }^{237}$ Auch die offiziellen Tore zum Ghetto tauchten immer wieder auf Abbildungen auf, als symbolhafte Orte des Ausschlusses wie gleichzeitig der Begegnung mit der "anderen« Seite. Als ein weiterer Ort der Kontakte zwischen Juden und Bewohnern der »arischen Seite« wurde das Gerichtsgebäude genannt:

'Als das Ghetto geschaffen wurde, wurden die Gerichte zum einzigen Verbindungsort zwischen rarischer und jüdischer Seite. Juden hatten Eintritt von der Leszna [Straße], Polen von der Ogrodowa [Straße].< H. Makower

Dies war einer der Wege, dem polnischen Untergrund Informationen über die Ereignisse im Ghetto zu übermitteln. ${ }^{238}$

Schließlich wurde die Kanalisation als Fluchtweg aus dem Ghetto für die überlebenden Aufständischen angeführt. Die städtische Kanalisation, die in den übrigen Ausstellungen allein mit den Kämpfen im Warschauer Aufstand 1944 assoziiert wird, ${ }^{239}$ diente hier als Symbol der Verbindung zwischen dem Ghettogelände und dem übrigen Stadtgebiet.

237 Mehrere Fotos zeigten die Schmuggler bei der Arbeit: beim Wurf eines Mehlsacks über die Mauer, beim Transport von Waren durch ein Loch, dem Klettern über die Mauer u. Ä. Der Schmuggel wurde auch aus der Perspektive der Kinder beschrieben, so z.B. durch einen Ausschnitt aus einem Gedicht von Henryka Łazowertówna mit dem Titel »Mały szmugler« (Kleiner Schmuggler). ŻIH, großer Ausstellungssaal.

238 Objektbeschriftung zu einem Foto des Gerichtsgebäudes in der Leszna-Straße. Ebd.

239 Ein wesentliches Element der Dauerausstellungen des MHW und des MPW ist jeweils ein Stadtplan Warschaus, in dem die Hauptverbindungsrouten der Aufständischen durch die Kanalisation zwischen den umkämpften Stadtgebieten verzeichnet sind. MHW, Saal 51; MPW, Sektion 25: Kanal. In die Schau des MPW sind darüber hinaus zwei Nachbil- 
Außer diesen Kontaktzonen wurden auch konkrete Situationen des Austauschs und der Zusammenarbeit geschildert. Auffällig war dabei die überwiegend wertfreie bis positive Darstellungsweise. So wurde zum Beispiel beim Thema Versorgung und Schmuggel deutlich, dass neben Deutschen auch Polen an der schwierigen Lage der Ghettobewohner verdienten - eine Information, die ausschließlich Zeitzeugenberichte vermittelten. So beschrieb etwa Ludwik Hirszfeld:

Die Zusammenarbeit [beim Schmuggel] findet harmonisch statt, die Aufteilung ist festgelegt entsprechend der Überlegenheit der jeweiligen Rasse: ein Jude erhält einen Teil, ein Pole zwei, ein Deutscher sieben. ${ }^{240}$

In diesem Kontext wies man auch auf Telefone als wesentliche Hilfsmittel der Schmuggler hin. ${ }^{241}$ An anderer Stelle zeigte ein Foto eine Kolonne von Juden, die auf dem Weg zur Zwangsarbeit über die Krakowskie Przedmieście gehen, eine der zentralen Straßen der Stadt. Auch wurden die Straßenbahnen gezeigt, die durch eine vom Ghettogelände abgetrennte Straße fahren. Amerksamen Besuchern wurde durch diese vielfach verstreuten Informationen deutlich, dass es Begegnungen beider Welten während des gesamten Zeitraums seiner Existenz gab, das Ghetto also keineswegs hermetisch von der umliegenden Stadt abgetrennt war. Dies wird auch in einem Dokumentarfilm immer wieder betont, der im Vorraum der Ausstellung gezeigt wurde und den insbesondere Gruppen zu Beginn ihres Rundgangs ansahen. ${ }^{24}$

Die Darstellung von direkten Kontakten zwischen Polen und Juden konzentrierte sich dagegen überwiegend auf den Austausch mit und die Unterstützung durch den polnischen Widerstand. Dieser wurde insbesondere beim Thema Widerstand im Ghetto und schließlich dem Ghettoaufstand mehrfach erwähnt. Die jüdischen Widerstandsgruppen innerhalb der Mauern,

dungen eines Abwasserkanals integriert (eine bequem zu durchlaufende Installation im Zwischengeschoss sowie eine schmale, enge und dunkle Version im Keller), durch die die Besucher gehen können. MPW, Sektion 25: Kanal, Sektion 55: Nachbau eines Kanals.

240 Objektbeschriftung eines Fotos. ŻIH, großer Ausstellungssaal.

241 Ein ausgestellter zeitgenössischer Telefonapparat war mit einem Zitat Emanuel Ringelblums versehen: »Mai 1941 - Zurzeit ist das Telefon das wichtigste Hilfsmittel beim Schmuggel.« Ebd.

242 Der Film »912 dni getta w Warszawie« (912 Tage des Ghettos in Warschau) wurde speziell für das ŻIH angefertigt und liegt in sieben Sprachversionen vor (Polnisch, Englisch, Hebräisch, Deutsch, Französisch, Spanisch und Russisch). Siehe: Wystawa o życiu, walce i zagładzie getta warszawskiego [Die Ausstellung zum Leben, Kampf und der Vernichtung des Warschauer Ghettos]. In: Tych/Bergmann/Hense: Żydowski Instytut Historyczny, 80-87, hier 80. Ein weiterer, nur wenige Minuten kurzer Dokumentarfilm über den Ghettoaufstand wurde in der Dauerausstellung im großen Saal ausgestrahlt. Siehe: The Warsaw Getto 1940-1943 [DVD]. Hg.v. Żydowski Instytut Historyczny. Warszawa 2001. 
vor allem die Jüdische Kampforganisation, sowie der Aufstand vom 19. April bis zum 16. Mai 1943 nahmen zudem einen wesentlichen Teil der Ausstellung ein. Neben dem Kampf und den ersten Erfolgen der Aufständischen (im Januar 1943 und am ersten Tag des April-Aufstands) und schließlich der Niederlage und Deportation der letzten im Ghetto Verbliebenen wurde in diesem Abschnitt auch ausführlich auf »Solidaritätsakte des Polnischen Untergrunds an den Mauern des Ghettos ${ }^{243}$ eingegangen, zu deren »Bezeugung « ein Zitat Jürgen Stroops angeführt wurde: »22.IV. - Ich muss darüber hinaus berichten, dass seit gestern ein Teil der an der Aktion beteiligten Truppen ständig von außerhalb des Ghettos beschossen wird, also von der arischen Seite «. ${ }^{244}$ Präsentiert wurden zudem Publikationen des polnischen Untergrunds, die vom Fortgang des »heldenhaften Kampfes « im Ghetto berichteten, ${ }^{245}$ sowie Personen, die Hilfsaktionen für die Kämpfenden leiteten oder aber die sich darum verdient gemacht haben, die Gräuel in den deutschen Ghettos, Konzentrations- und Vernichtungslagern publik zu machen, wie Jan Karski ${ }^{246}$ und Szmul Zygielbojm. ${ }^{247}$

Mittels dieser Exponate wurde deutlich, dass die polnische Untergrundpresse über die Zustände im Ghetto und die Deportationen berichtete - die Bevölkerung auf der "arischen Seite« also über Informationen zu den Repressionen im Ghetto und der Deportation seiner Bewohner in Vernichtungslager verfügte - und dass auch Anstrengungen von Vertretern der polnischen

243 So die Überschrift auf einem großformatigen Foto der brennenden Nalewki-Straße. ŻIH, großer Ausstellungssaal.

244 Zitat auf demselben Foto, unterhalb der Überschrift. Ebd.

245 Gezeigt wurden Kopien der Leitartikel im Biuletyn Informacyjny (Informationsbulletin) vom 29. April 1943 mit dem Titel»Ostatni akt wielkiej tragedii« (Der letzte Akt der großen Tragödie) sowie des Głos Warszawski (Warschauer Stimme) vom 23. April 1943 »Bohaterska walka ludności żydowskiej« (Der heldenhafte Kampf der jüdischen Bevölkerung). Ebd.

246 Jan Karski, dessen eigentlicher Name Jan Kozielewski lautete, war ein Kurier des polnischen Untergrundstaates. Er schmuggelte Informationen über die Verfolgung und Ermordung der Juden im besetzten Polen aus dem Land und übergab sie an die polnische Exilregierung in London. Ziel seines Berichts und seiner folgenden persönlichen Gespräche mit westlichen Politikern war es, die Alliierten zum Eingreifen zu bewegen. 1982 wurde er von Yad Vashem als »Gerechter unter den Völkern« ausgezeichnet.

247 Alle Personen wurden jeweils mit einem Porträtfoto sowie einer kurzen Information in Textform vorgestellt. $\mathrm{Zu}$ den Genannten, die aktiv an den Kämpfen beteiligt waren, gehörte u.a. Franciszek Bartoszek, »Anführer einer Kampfgruppe der GL [Gwardia Ludowa/Volksgarde], die am 20. April deutsche Stellungen an der Nowiniarska-Straße angegriffen hat.« Objektbeschriftung des Fotos. ŻIH, großer Ausstellungssaal. Daneben wurden auch zwei Hauptmänner der AK genannt, die jeweils eine Aktion leiteten, sowie ein Vertreter der regionalen Sektion der »Polnischen Arbeiterpartei« (Polska Partia Robotnicza), der für Hilfsaktionen für die Aufständischen im Ghetto verantwortlich war. Ebd. 
Exilregierung unternommen wurden, die Alliierten über die Lage der Juden im besetzten Polen zu informieren und ein aktives Eingreifen herbeizuführen. Zugleich ist jedoch auffällig, dass Wahrnehmungen des Aufstands wie der Ausgrenzung der jüdischen Stadtbewohner durch die polnische Zivilbevölkerung weder in diesem Abschnitt noch in den vorangegangenen geschildert wurden. Auch negative Verhaltensweisen von Polen gegenüber Juden, die sich auf der »arischen " Seite versteckten oder von dort Güter schmuggelten, oder Fälle von Erpressungen und Denunziationen, wurden nicht angesprochen.

Erst in der letzten Sektion, die als Epilog der Ausstellung fungierte, ging man auf die Haltung von vermeintlich »normalen« Bürgern gegenüber der Judenverfolgung ein. Unter dem großformatigen Titel »Die Gerechten unter den Völkern der Welt« wurden die Tätigkeit der Organisation Żegota, Fotos von Geretteten sowie von Personen präsentiert, die als »Gerechte unter den Völkern« ausgezeichnet wurden, da sie Juden versteckt oder ihnen anderweitig geholfen haben. Im Zentrum der Darstellung stand die moralisch vorbildliche Handlungsweise dieser Menschen. Die Hervorhebung bzw. Würdigung ihrer Taten wurde durch die Illustration der repressiven Maßnahmen der Besatzer gegenüber Polen, die Juden halfen, noch unterstützt. ${ }^{248}$ Dass es auch andere Verhaltensweisen gab, wurde mittels zweier Dokumente von polnischen Untergrundorganisationen angedeutet: Eines rief zur Unterstützung verfolgter Juden auf und warnte zugleich vor Strafen, die diejenigen erwarten, die Juden denunzieren oder erpressen; ein anderes informierte über die Vollstreckung eines Todesurteils an einem szmalcownik ${ }^{249} \cdot{ }^{250}$ Die randständige Darstellung dieser negativen Verhaltensweisen im Vergleich zur größeren Zahl der »Gerechten« und ihrer großflächigen Präsentation ließ diese jedoch insgesamt als Ausnahmen erscheinen. Der gleichzeitige Verweis

248 Dies erfolgte mittels zweier Bekanntmachungen der Besatzungsorgane: Eine aus Częstochowa informierte darüber, dass es verboten ist, geflüchteten Juden Hilfe zu leisten (indem ihnen Unterkunft gewährt oder sie mit Nahrungsmitteln versorgt werden), sowie darüber, dass bei Zuwiderhandlung die Todesstrafe verhängt wird. Die andere verkündete Todesurteile von mehreren Warschauern, die Juden beherbergt haben. ŻIH, Vorraum.

249 Als szmalcownik bezeichnete man während der Besatzung Personen, die Juden um Geld erpressten, welche sich außerhalb des Ghettos versteckten, und sie an die Deutschen denunzierten. Die Behörden des polnischen Untergrundsstaates verurteilten dieses Verhalten. Seit 1943 wurden Strafen gegen die Erpresser angedroht und zahlreiche Todesurteile von Untergrundgerichten erlassen und vollstreckt. Siehe Czajka, Michał: Szmalcownik. In: Kochanowski, Jerzy/Kosmala, Beata (Hg.): Deutschland, Polen und der Zweite Weltkrieg. Geschichte und Erinnerung. Potsdam, Warschau 2009, 327.

250 Reproduktionen eines Aufrufs des Hilfsrates für Juden »An das polnische Volk!« vom August 1943 und eines Berichts im Biuletyn Informacyjny vom 16. September 1943. ŻIH, Vorraum. 
auf das aktive Vorgehen des polnischen Untergrundstaates gegen diese Phänomene, den die Dokumente enthielten, unterstützte diesen Eindruck noch zusätzlich. Dennoch bleibt festzuhalten, dass diese Ausstellung - bis zur Eröffnung des Museums der Geschichte der Polnischen Juden im Oktober 2014 - die einzige ständige Warschauer Präsentation war, die zeigte, dass sich Juden auch auf der "arischen Seite « versteckt haben: So wurden nicht nur Personen vorgestellt, die Verstecke zur Verfügung stellten und Menschen retteten, sondern auch Fotos des Verstecks einer jüdischen Familie in der Kopernika-Straße $4 .{ }^{251}$

Die Schau im ŻIH bot somit als einzige der bis 2010 untersuchten Ausstellungen einen umfassenden Einblick in die Geschichte des Warschauer Ghettos aus der Binnenperspektive seiner Bewohner. Dies war ihr Alleinstellungsmerkmal in der musealen Landschaft der Stadt (bis Ende 2014). ${ }^{252}$ Dennoch lassen sich Ähnlichkeiten zwischen dieser Schau und den Präsentationen der anderen untersuchten Warschauer Museen feststellen: In Bezug auf die polnisch-jüdischen Beziehungen im Krieg konzentrierte sie sich, ähnlich wie die übrigen Institutionen, auf die Hilfe des polnischen Untergrunds sowie von Einzelpersonen, die schließlich in der herausgehobenen Darstellung der polnischen »Gerechten unter den Völkern« ihre Zuspitzung fand. Die Benennung und Entwicklung kritischer Themen - wie etwa die verbreitete Gleichgültigkeit der meisten polnischen Warschauer den verfolgten Juden gegenüber oder aber auch Denunziationen und Erpressungen - wurde noch Anfang des Jahres 2000, zum Zeitpunkt der Eröffnung dieser Präsentation, vermieden, auch wenn die Schau für aufmerksame Besucher zahlreiche Hinweise auf ambivalente Aspekte polnisch-jüdischer Kontakte enthielt. Dass auch im ŻIH die Begriffe "polnisch" und »jüdisch « nicht kontextualisiert und problematisiert wurden, stellt eine weitere Gemeinsamkeit dar. In der Ausstellung gab es zwar einen Hinweis darauf, dass die Zuschreibung »jüdisch « nicht unbedingt der Selbstwahrnehmung der Betroffenen entsprach: So wurde erwähnt, dass es Christen im Ghetto gab. ${ }^{253}$ Die rassistische Grundlage der Kategorisierung durch die Nationalsozialisten wurde jedoch nicht geschildert. Auch in dieser Schau wurde somit weitgehend unreflektiert ein ethnisches

251 Gezeigt wurden Fotos der Hausfassade, der Wohnung und des Geheimzimmers, in dem die Familie sich versteckt hielt. Ebd.

252 Eine solche Perspektive bietet auch die Holocaust-Sektion der Dauerausstellung des Museums der Geschichte der Polnischen Juden, die in Kapitel 1 des Ausblicks näher analysiert wird.

253 Gezeigt wurden Fotos der zwei katholischen Kirchen im Ghetto in der Leszno-Straße und der Grzybowska-Straße, die mit entsprechenden Textinformationen versehen waren, darunter dem Verweis, dass es im Ghetto »über 1.700 Christen« gab. ŻIH, großer Ausstellungssaal. 
Verständnis der Begriffe »Polen« und »Juden« als selbst- bzw. allgemeinverständlich vorausgesetzt.

Bemerkenswert war die Präsentation für die Warschauer Museumslandschaft allerdings noch unter einem weiteren Gesichtspunkt: Das in der Ausstellung versammelte Material zeigte eindrücklich, dass bereits vor der Jedwabne-Debatte und der durch sie angeregten polnischen Holocaust-Forschung Publikationen existierten, die andere als die in der VRP tradierten Blickwinkel auf das Ghetto und seine Bewohner ermöglichten. Gerade die Tagebücher und Aufzeichnungen von Zeitzeugen wie Emanuel Ringelblum und Adam Czerniaków, die einen unmittelbaren und umfassenden Einblick in den Ghettoalltag und die Wahrnehmung der Ereignisse durch die Bewohner bieten, waren bereits in der VRP erschienen. ${ }^{254}$ Auch die Autobiografien anderer Überlebender der Ghettos waren bereits lange veröffentlicht. ${ }^{255}$ Obwohl wenige Objekte aus den Ghettoruinen überdauerten - was ein Problem gerade für Ausstellungsmacher darstellt $-{ }^{256}$, zeigt das Beispiel dieser Dauerausstellung, dass eine umfassende Darstellung des Ghettos möglich war. Zudem war das Material des Ringelblum-Archivs im ŻIH für Historiker zugänglich. ${ }^{257}$

254 Ringelblum, Emanuel: Kronika getta warszawskiego: wrzesień 1939-styczeń 1943 [Chronik des Warschauer Ghettos: September 1939-Januar 1943]. Warszawa 1983; Czerniaków, Adam: Adama Czerniakowa dziennik getta warszawskiego. 6 IX 1939-23 VII 1942 [Das Tagebuch des Warschauer Ghettos von Adam Czerniaków. 6.9.1939-23.7.1942]. Bearb. von Marian Fuks. Warszawa 1983.

255 Hierzu gehörte etwa die Autobiografie des Arztes Ludwik Hirszfeld. Ders.: Historia jednego życia [Die Geschichte eines Lebens]. 2. Aufl. Warszawa 1957. Die erste Auflage des Buches erschien bereits zehn Jahre zuvor. In der Zeitschrift des ŻIH, dem Biuletyn Żydowskiego Instytutu Historycznego, wurden immer wieder polnische Übersetzungen aus Tagebüchern von Ghetto-Überlebenden publiziert. Siehe beispielsweise: Lewin, Abram: Dziennik z getta warszawskiego [Tagebuch aus dem Warschauer Ghetto]. In: Biuletyn ŻIH 19-20 (1956), 169-206; 21 (1957), 125-137; 22 (1957), 85-107; 23 (1957), 71-79; 24 (1957), 42-55; 25 (1958), 119-130. Zitiert nach Fuks, Marian: Adam Czerniaków i jego Dziennik [Adam Czerniaków und sein Tagebuch]. In: Czerniaków: Adama Czerniakowa dziennik, 9-44, hier 13f. Siehe auch Aleksiun: Historiografia na temat Zagłady, 37-41, $44-46$.

256 Dies war nach eigenen Worten auch für die Kuratorin der Dauerausstellung im ŻIH eine große Herausforderung. Aufgrund des weitgehenden Fehlens von dreidimensionalen Objekten konzentrierte sie sich daher auf existierende Fotografien sowie Dokumente aus dem Ringelblum-Archiv. Interview mit Magdalena Sieramska am 19. Mai 2010.

257 Ein großer Teil des Archivmaterials des ŻIH war Mitte der 1990er-Jahre bereits zugänglich, d.h. inventarisiert und durch Findbücher erschlossen, wie detailliert 1996 von Apolonia Umińska ausgeführt wurde: Umińska, Apolonia: Informacja o działalności Archiwum Żydowskiego Instytutu Historycznego [Informationen über die Tätigkeit des Archivs des Jüdischen Historischen Instituts]. In: Żbikowski, Andrzej (Hg.): Żydowski Instytut Historyczny. 50 lat działalności. Materiały z konferencji jubileuszowej [Das Jüdische Historische Institut - 50 Jahre Tätigkeit. Beiträge der Jubiläumskonferenz]. Warszawa 1996, 50-54. Eine Übersicht über den Bestand von Tagebüchern war 
Quellenmaterial, das eine differenziertere und auch ausführlichere Schilderung des Warschauer Ghettos ermöglicht hätte, war somit bereits seit langem - auch in den 1980er-Jahren - vorhanden. In den 1990er-Jahren wurde im ŻIH damit begonnen, das Material des Ringelblum-Archivs zu edieren; bis zum Jahr 2000 erschienen die ersten drei Bände. ${ }^{258}$ Der Zugang zu diesen Materialien wurde damit zunehmend einfacher. Scheinbar fehlte - und dies mindestens bis 2010, wenn man die knappe Darstellung des Ghettos im MHW berücksichtigt - ein grundlegendes Interesse für das Thema. Man kann daher davon ausgehen, dass die Judenverfolgung nach wie vor als »fremdes « Ereignis während der Besatzung wahrgenommen wird, dem weniger Relevanz zugesprochen wird als den polnischen Helden und Märtyrern. Deutlich hebt sich davon das ŻIH ab, dass das Ghetto aus einer Binnenperspektive darstellte, versteht es sich doch als Erbe und Bewahrer der jüdischen Geschichte der Stadt und des Landes.

\subsection{Eine lokale Geschichtsperspektive? - Das Historische Museum in Wroctaw}

Der Befund, dass das Schicksal der jüdischen Einwohner in der musealen Beschäftigung mit den Jahren 1939 bis 1944/ 45 eine Randstellung einnimmt, trifft für viele seit dem Jahr 2000 entstandenen Museen und Ausstellungen $\mathrm{zu}$, lässt sich aber selbst auf jüngste Institutionen ausweiten, die versuchen, neue Zugänge zur Stadtgeschichte zu entwickeln. Ein Beispiel hierfür ist die 2009 neu eröffnete Dauerausstellung des Historischen Museums in Wrocław. Erklärtes Ziel der Ausstellungsmacher war die Schaffung einer historischen Erzählung, die die wechselnden staatlichen Zugehörigkeiten der Stadt über

bereits publiziert: Dies. u. a. (Hg.): Inwentarz zbioru »Pamiętniki Żydów« 1939-1945 Archiwum Żydowskiego Instytutu Historycznego [Verzeichnis des Bestands »Tagebücher von Juden" 1939-1945 des Archivs des Jüdischen Historischen Instituts]. Warszawa 1994. Einen Überblick über die Bestände des Instituts gibt auch ein 2003 erschienenes Informationsheft: Tych/Bergmann/Hensel: Żydowski Instytut Historyczny.

258 Archiwum Ringelbluma: Konspiracyjne archiwum getta Warszawy [Das RingelblumArchiv: das geheime Archiv des Ghettos von Warschau]. Bd. 1: Listy o zagładzie [Briefe über die Vernichtung]. Hg.v. Feliks Tych. Bearb. von Ruta Sakowska. Warszawa 1997; Bd. 2: Dzieci - tajne nauczanie w getcie warszawskim [Kinder - der geheime Unterricht im Warschauer Ghetto]. Hg.v. Feliks Tych. Bearb. von Ruta Sakowska. Warszawa 2000; Bd. 3: Relacje z Kresów [Berichte aus den polnischen Ostgebieten]. Hg.v. Feliks Tych. Bearb. von Andrzej Żbikowski. Warszawa 2000. In den Jahren 2008 bis 2016 (Stand Mai 2017) sind die Bände 1 bis 17, 19 bis 20, 23 bis 24, 28 und 34 sowie der Inventarband erschienen. Siehe: Pełna edycja Archiwum Ringelbluma [Die vollständige Edition des Ringelbum-Archivs], URL: http://www.jhi.pl/projekty-naukowe/pelna-edycja-archiwumringelbuma (am 31.5.2017). 
die Jahrhunderte hinweg sowie ihre vielfältige Bevölkerungszusammensetzung berücksichtigt. Wie der Direktor des Stadtmuseums programmatisch zusammenfasst:

Das historische Bild der Breslauer umfasst Menschen verschiedener nationaler und religiöser Zugehörigkeit, die sich jedoch immer als Bürger einer Stadt, als Mitglieder der außergewöhnlichen hiesigen Gemeinschaft fühlten. ${ }^{259}$

Die Schau möchte also die lokale und regionale Vergangenheit in den Mittelpunkt stellen und sich weniger an einem nationalstaatlichen polnischen Geschichtskanon orientieren. Das Museum soll mit den Worten Lagiewskis ein Ort [...] der Kontemplation der Geschichte [...] unserer Heimat [mała ojczyzna] « sein. ${ }^{260}$ Doch inwieweit wurde dieser Anspruch in der Darstellung der Verfolgung jüdischer Breslauer umgesetzt?

Zunächst sind viele bemerkenswerte Elemente in der Ausstellung zu verzeichnen. Die Schau orientiert sich weniger an den traditionellen Eckdaten der polnischen Geschichte als vielmehr an jenen der Stadtgeschichte, sodass auch in Bezug auf die Kriegszeit die Erzählung nicht mit dem Jahr 1939 beginnt: Der Angriff auf Polen wird für die Geschichte des damals deutschen Breslau demnach nicht als zentrale Wegmarke gewertet. Der Ausstellungsraum, in dem die Kriegsjahre geschildert werden, umfasst stattdessen den Zeitraum 1933 bis 1945 und damit die NS-Herrschaft in Deutschland. ${ }^{261}$ Einer der in dem betreffenden Saal angebrachten "Meilensteine« der Stadtgeschichte ist neben diesen beiden Eckdaten das Jahr 1938. In diesem Jahr begann eine neue Etappe in der Verfolgung und Ausgrenzung der Juden aus dem öffentlichen Leben des Reiches, wofür symbolisch die sogenannte Kristallnacht ${ }^{262}$ vom 9./10. November 1938 steht; diese wird somit als wesentlicher Wendepunkt der städtischen Geschichte markiert. Die Pogrome erfahren in der Schau eine recht umfassende Behandlung: Neben einer Fotografie der brennenden Kuppel der Neuen Synagoge und einem propagandistischen Zeitungsbericht der Schlesischen Tageszeitung vom 11. November 1938 über die Ausschreitungen wird auch der von den Nationalsozialisten gewählte propagandistische Anlass der Exzesse dargestellt: das Attentat von Herschel

259 Łagiewski: Pałac z historią, 12.

260 Ebd., 13.

261 MMW-MH, Saal 22.

262 Der deutsche Begriff wird im Ausstellungskatalog in Anführungszeichen zitiert. Błaszkowski, Bartłomiej/Łagiewski, Maciej/Okólska, Halina: Sala 21. I wojna światowa - Republika Weimarska - Gmina żydowska [Saal 21. Erster Weltkrieg - Weimarer Republik - Jüdische Gemeinde]. In: Łagiewski, Maciej/Okólska, Halina/Oszczanowski, Piotr (Hg.): 1000 lat Wrocławia. Przewodnik po wystawie [1000 Jahre Wrocław. Führer durch die Ausstellung]. Wrocław 2009, 257-276, hier 275. 
Grynszpan auf einen deutschen Diplomaten in Paris. ${ }^{263}$ Beispielhaft für die zunehmende Ausgrenzung der jüdischen Stadtbewohner stehen Titelseiten der Verzeichnisse von »üdischen Geschäften in Breslau« und einem »Nur für Mitglieder der NSDAP« bestimmten »Verzeichnis der bekannten jüdischen Firmen in Breslau ${ }^{264}$ Eine Schwierigkeit bietet die Präsentationsweise dieses Themenbereiches jedoch: Die angeführten Quellen sind alle in deutscher Sprache verfasst. Hinweise zu ihnen bzw. dem durch sie geschilderten Kontext können Besucher, die die deutsche Sprache nicht beherrschen - also ein Großteil der polnischen Gäste -, nur über den Audioguide oder den Ausstellungsführer erhalten, denn diese Exponate sind nicht mit erläuternden Objektbeschriftungen oder Texten versehen. ${ }^{265}$ Es ist daher zu vermuten, dass Besucher, die ohne diese Hilfsmittel durch die Ausstellung gehen, die Inhalte dieses Abschnittes - und damit sämtliche Exponate, die die Ausgrenzung und Verfolgung der jüdischen Stadtbewohner vor 1939 betreffen - notgedrungen nicht zur Kenntnis nehmen. ${ }^{266}$

Wie die genannten Beispiele jedoch andeuten, spielt die Geschichte der jüdischen Einwohner der Stadt in der Dauerausstellung des Museums durchaus eine Rolle. Ihre Darstellung im 20. Jahrhundert findet allerdings schwerpunktmäßig im vorhergehenden Saal statt, unter dem Titel »Erster Weltkrieg - Weimarer Republik - Jüdische Gemeinde « ${ }^{267}$ In der Präsentation der unmittelbaren Kriegsjahre ist das Schicksal der jüdischen Breslauer, der größten Minderheit der Vorkriegsbevölkerung, jedoch marginalisiert. Gezeigt werden zwei Fotografien - ein durch Hakenkreuz-Schmierereien geschändeter jüdischer Friedhof und »die auf die Deportation wartenden Breslauer Juden (Herbst 1941) « ${ }^{268}$ - und Fragmente der zerstörten Gesetzestafeln einer städtischen Synagoge sowie eines der Abzeichen, die Juden in Deutschland seit September 1941 an ihrer Kleidung tragen mussten. Die mittels Exponaten knapp skizzierte Erzählung über die Verfolgung der jüdischen Breslauer endet da-

263 Präsentiert wird die Titelseite der Schlesischen Tageszeitung vom 8. November 1938 mit dem Aufmacher »üdischer Mordanschlag auf einen deutschen Diplomaten in Paris«. MMW-MH, Saal 22.

264 Die Zitate stammen jeweils aus den ausgestellten Reproduktionen dieser Quellen. Ebd.

265 Im Gegensatz zu anderen Objekten, die in den zentralen Vitrinen des Saales untergebracht sind sowie den übrigen Fotografien.

266 Dies war während der Recherchen auch die Beobachtung der Verfasserin.

267 Titel des Thementextes. MMW-MH, Saal 21. In diesem Saal werden insbesondere herausragende Persönlichkeiten aus Wissenschaft, Politik und Kunst, soziale Einrichtungen und die Religiosität der jüdischen Gemeinden Breslaus in der Zwischenkriegszeit präsentiert. Der Text im begleitenden Ausstellungsführer konzentriert sich auf die Geschichte der jüdischen Einwohner der Stadt vom 18. Jahrhundert bis zum Jahr 1944 12 von insgesamt 20 Seiten dieses Kapitels sind dieser Bevölkerungsgruppe gewidmet. Vgl. Błaszkowski/Lagiewski/Okólska: Sala 21, 265-276.

268 Objektbeschriftung. MMW-MH, Saal 22. 
mit im Jahr 1941. Themen wie Zwangsarbeit sowie Deportationen in Arbeits- und Konzentrationslager, Erfahrungen, die wesentlich zur Geschichte der Breslauer Juden ab 1940 zählten, werden ausschließlich am Beispiel der polnischen Bevölkerung der Stadt dargestellt, auch wenn jüdische Zwangsarbeiter bis 1944 in der Stadt eingesetzt worden waren. ${ }^{269}$ Das Schicksal der meisten deportierten jüdischen Breslauer - ihr Tod in den Konzentrationsund Vernichtungslagern -, das zugleich den wesentlichen Unterschied zwischen den polnischen und jüdischen Gefangenen ausmachte, ${ }^{270}$ wird innerhalb der Ausstellung nicht erwähnt. Diese Information bleibt auf den Ausstellungsführer sowie den Audioguide beschränkt, die jedoch von Besuchern zusätzlich erworben werden müssen. ${ }^{271}$ Zudem bleibt die jüdische Gemeinde der Stadt für den hier interessierenden Zeitraum vollständig anonym - im Gegensatz zu polnischen Zwangsarbeitern und einem polnischen Widerstandskämpfer, die jeweils individualisiert und namentlich in Erscheinung treten. ${ }^{272}$ Nicht zuletzt durch diese unpersönliche und weitgehend abstrakte Präsentationsweise bleibt das Schicksal der jüdischen Breslauer während des Kriegs in der Schau im Hintergrund.

269 Zur Darstellung von Polen in dieser Ausstellung siehe Teil 3, Kapitel 1.3. Polen stellten zwar während des Kriegs die größte Zahl der Zwangsarbeiter, die nach Breslau gebracht worden waren; die Zusammensetzung der verschiedenen Gruppen von Arbeitern war jedoch äußerst divers. Siehe Davies/Moorhouse: Breslau, $483 \mathrm{f}$. Zur Geschichte der jüdischen Stadtbewohner in den Jahren 1933-1945 vgl. Ziątkowski, Leszek: Die Geschichte der Juden in Breslau. Wrocław 2000, 103-112; Davies / Moorhouse: Breslau, 487-491.

270 Wie Michael Steinlauf prägnant zum Unterschied zwischen dem Schicksal von Polen und Juden auf dem besetzten polnischen Territorium festhält: »The difference is most simply illustrated in numbers: about two million Poles and three million Polish Jews died during the German occupation of Poland; these figures represent nearly 10 percent of the ethnically Polish population but almost 90 percent of the Jewish population of prewar Poland «. Steinlauf: Bondage to the Dead, 28.

271 Der Ausstellungsführer bedarf zudem eines aufmerksamen Lesers: Die Informationen über das Schicksal der jüdischen Gemeinden der Stadt in den Jahren 1933 bis 1945 sind umfangreich im Text zum Saal 21 geschildert. Im Text zum Ausstellungssaal 22 dagegen, der diesen Zeitraum direkt behandelt, finden sich nur sehr wenige Informationen mit Bezug auf die jüdischen Breslauer. Siehe Błaszkowski/Łagiewski/Okólska: Sala 21; Łagiewski, Maciej/Okólska, Halina/Błaszkowski, Bartłomiej/Smolak, Marzena: Sala 22. Dyktatura hitlerowska - II wojna światowa [Saal 22. Hitler-Diktatur - Zweiter Weltkrieg]. In: Łagiewski, Maciej/Okólska, Halina/Oszczanowski, Piotr (Hg.): 1000 lat Wrocławia. Przewodnik po wystawie [1000 Jahre Wrocław. Führer durch die Ausstellung]. Wrocław 2009, 277-286.

272 Gezeigt werden Ausweispapiere polnischer Zwangsarbeiter sowie ein Biogramm und ein Dokument, das die Vollstreckung des Todesurteils an Stanisław Peisert dokumentiert, einem Mitglied der »Nationalen Kampforganisation« (Narodowa Organizacja Bojowa, NOB). Peisert wurde für seine Widerstandstätigkeit zum Tod verurteilt. MMWMH, Saal 22. 
Auch wenn die jüdischen Stadtbewohner Breslaus in der musealen Erzählung zur ersten Hälfte der 20. Jahrhunderts durchaus prominent thematisiert werden, so fokussiert die Schau in Bezug auf die Darstellung der Kriegszeit auf ethnisch-polnische viktimologische - und in geringerem Maße auch martyrologische - Interpretationsmuster: Die Geschichte der jüdischen Bevölkerung ab 1939 ist weitestgehend marginalisiert; die Schilderung von Repressionen und Leid - und damit die Opferdarstellung - konzentriert sich auf die polnische Minderheit. Paradox wirkt hierbei insbesondere, wie stark die mittels Exponaten konstruierte Erzählung von der umfangreichen und vielseitigen Darstellung des dazugehörigen Ausstellungsführers divergiert. ${ }^{273}$

Gründe hierfür liegen im Bereich personeller Zuständigkeiten sowie des Konstruktionsprozesses der Ausstellung: Der Saal zu den Jahren der NS-Diktatur wurde im Wesentlichen von einem langjährigen Mitarbeiter des Museums konzipiert und zusammengestellt, Jerzy Zarawski, dessen Arbeitsschwerpunkt die Militärgeschichte des Zweiten Weltkriegs ist. ${ }^{274}$ Es ist anzunehmen, dass er jene Themen bevorzugte, in denen er selbst ausgewiesener Experte ist. ${ }^{275}$ Zugleich ist jedoch anzumerken, dass der Forschungs- und Arbeitsschwerpunkt des Direktors des Stadtmuseums, Maciej Lagiewski, im Bereich der jüdischen Geschichte Wrocławs liegt; das notwendige Fachwissen war im Museum also vorhanden. ${ }^{276}$ Mehr noch, die Darstellung der Geschichte

273 Um nur einen wesentlichen Punkt zu nennen: Während die von Objekten vermittelte Erzählung über das Schicksal der jüdischen Breslauer im Jahr 1941 endet, findet sich im Ausstellungsführer durchaus der Hinweis auf die Deportation der letzten Juden aus der Stadt im Herbst 1944. Błaszkowski/Łagiewski/Okólska: Sala 21, 276.

274 Jerzy Zarawski arbeitete bereits seit mehreren Jahrzehnten im Museum und war zum Zeitpunkt der Recherche Leiter des zum Stadtmuseum gehörenden »Militärhistorischen Museums« (Muzeum Militariów) im Arsenal. Interview mit Jerzy Zarawski am 31. März 2010. Siehe auch URL: www.muzeum.miejskie.wroclaw.pl/CMS/bip/kierownictwo.html (am 7.7.2013).

275 Im Interview berichtete Zarawski in Bezug auf die jüngste Umgestaltung des Ausstellungssaals 22, die er vorgenommen hatte, in erster Linie von der umfangreichen Ergänzung im Bereich Militaria, durch die eine gleichgewichtige Darstellung von Deutschen und Sowjets erreicht werden sollte. Interview mit Jerzy Zarawski am 31. März 2010.

276 Maciej Łagiewski war von 1983 bis 1990 Kustos am Architekturmuseum in Wrocław, wo er sich mit der Instandsetzung und Renovierung des Alten Jüdischen Friedhofs befasste. Dieser wurde 1988 als »Museum der Friedhofsarchitektur« (Muzeum Architektury Cmentarnej) unter der Leitung von Łagiewski zu einer Abteilung des Architekturmuseums. Gegenwärtig gehört er als eigenständige Abteilung, als »Museum der Friedhofskunst« (Muzeum Sztuki Cmentarnej), zum Stadtmuseum Wrocław. Okólska, Halina: Maciej Łagiewski - Dyrektor Muzeum Miejskiego Wrocławia [Maciej Łagiewski - Direktor des Stadtmuseums Wrocław]. In: Wrońska-Cupiat, Beata (Red.): »Nie ma jak w domu«. O Wrocławiu ... Dla dr. Macieja Łagiewskiego, dyrektora Muzeum Miejskiego Wrocławia w 50. rocznicę urodzin [»Am schönsten ist es Zuhause«. Über Wrocław ... Für Dr. Maciej Łagiewski, Direktor des Stadtmuseums Wrocław zum 50. Geburtstag]. 
der jüdischen Breslauer vom 18. Jahrhundert bis 1944 im Ausstellungsführer basiert auf Arbeiten des Direktors aus den 1980er- und frühen 1990er-Jahren: Der Text zu diesem Themenkomplex stammt, bis auf wenige stilistische Änderungen, vollständig aus einer früheren Publikation Łagiewskis. ${ }^{277}$ Fast alle Dokumente und Fotografien zur jüdischen Gemeinde der Stadt in diesem Ausstellungssaal finden sich ebenfalls bereits in dieser Publikation - einem Ausstellungskatalog - und waren daher mutmaßlich bereits in der Sonderausstellung »Wrocławscy Żydzi. 1850-1944« (Die Breslauer Juden. 1850-1944) 1994 oder deren erster Fassung aus dem Jahr 1989 zu sehen, aus der diese Publikation hervorging. ${ }^{278}$ Die einzelnen Sektionen dieses Ausstellungssaals wurden demnach von verschiedenen Personen erarbeitet: Łagiewski war für die »jüdische» Geschichte der 1930er-Jahre bis 1944 zuständig, während Zarawski den Großteil der Fläche des Raumes füllte, die der polnischen Kriegserfahrung sowie der »Festung Breslau" gewidmet ist. Aus dieser $\mathrm{Zu}$ sammenstellung einzelner Sektionen durch Personen mit unterschiedlichen fachlichen Interessensgebieten scheint das Ungleichgewicht in Bezug auf die Darstellung der Geschichte der polnischen und jüdischen Stadtbewohner vor bzw. nach $1939 \mathrm{zu}$ resultieren. Die Schwerpunktsetzung auf der polnischen Leidensgeschichte des Kriegs im Ausstellungsabschnitt zu den Jahren nach 1938, die mit einer weitgehenden Marginalisierung der Verfolgung der jüdischen Breslauer einhergeht, mag dabei zum einen ein Hinweis auf die unreflektierte Fortschreibung etablierter Interpretationsmuster eines der zentralen Ereignisse polnischer Geschichte sein. Zum anderen ist denkbar, dass in diesem Themenabschnitt, gerade weil er einen für das polnische historische Gedächtnis zentralen Zeitraum betrifft, bewusst auf Erwartungshaltungen des überwiegend polnischen Publikums eingegangen wurde.

Zusammenfassend bleibt demnach festzuhalten, dass in Bezug auf die Darstellung der Jahre 1939 bis 1945 und insbesondere des Schicksals einer wich-

Wrocław 2005, 8 f.; Stary Cmentarz Żydowski [Der alte jüdische Friedhof], URL: www. muzeum.miejskie.wroclaw.pl/CMS/muzeum_sztuki_cmentarnej/stary_cmentarz zydowski.html (am 19.7.2013). In dieser Zeit widmete sich Łagiewski der Erforschung der Geschichte der jüdischen Gemeinde der Stadt. Aus diesen Arbeiten sind zahlreiche Publikationen hervorgegangen: Łagiewski, Maciej: Stary Cmentarz Żydowski we Wrocławiu [Der Alte Jüdische Friedhof in Wrocław]. Wrocław 1986 (2. Aufl. 1995); deutsche Ausgabe: Ders.: Der alte jüdische Friedhof in Wrocław. Breslau. Bonn 1988; Ders.: Macewy mówią [Die Matzewen sprechen]. Wrocław 1991; deutsche Ausgabe: Ders.: Das Pantheon der Breslauer Juden. Der jüdische Friedhof an der Lohestraße in Breslau. Berlin 1999; Ders.: Wrocławscy Żydzi [1994] (2. Aufl. 1997; 3. Aufl. 2010); deutsche Ausgabe: Ders.: Breslauer Juden. 1850-1944. Wrocław 1996, 2011.

277 Lagiewski: Wrocławscy Żydzi [1997], 6-13. Das Buch, inklusive dem Text, erschien erstmals aus Anlass einer Sonderausstellung im Jahr 1994.

278 Die Sonderausstellung "Wrocławscy Żydzi. 1850-1944« wurde erstmals 1989 gezeigt und erlebte 1994 eine Neuauflage. Łagiewski: Wrocławscy Żydzi [1994], 6. 
tigen Bevölkerungsgruppe der Stadt, der jüdischen Gemeinde, auch in dieser Ausstellung etablierte narrative Hierarchien fortgesetzt werden. Präsentiert wird ein ethnisch-nationales Narrativ mit einem Schwerpunkt auf polnischem Leiden, das auch den Topos des polnischen Helden einschließt. Die jüdischen Breslauer sind in der Erzählung über den Zeitraum nach 1939 nachgeordnet. Und selbst die mit Abstand größte Bevölkerungsgruppe der Stadt, die deutsche Zivilbevölkerung, bleibt fast vollständig außen vor. ${ }^{279}$ Der Anspruch der Ausstellungsmacher, eine Geschichte der vielfältigen, multiethnischen städtischen Gemeinschaft umfassend zu schildern, wurde bei der Darstellung der Kriegsjahre somit nicht realisiert. Dem bereits in der VRP tradierten martyrologischen Geschichtsbild wurden nur wenige Neuerungen hinzugefügt - die sich ausschließlich auf die Jahre vor dem Kriegsausbruch beziehen, wie die Darstellung der »Reichskristallnacht« 1938 oder die Inhaftierung deutscher Oppositionspolitiker im KZ Dürrgoy 1933 -, ohne dieses jedoch im Wesentlichen zu verändern. Die Verfolgung der jüdischen Breslauer nach 1939 bleibt als eine Geschichte von »Fremden« innerhalb des polnischzentrierten Opfernarrativs peripher.

\subsection{Zwischenfazit}

Die Analysen dieses Kapitels zeigen zunächst eine markante Entwicklung innerhalb der musealen Darstellung der Judenverfolgung und -vernichtung: In allen untersuchten Dauerausstellungen, die seit Ende der 1990er-Jahre neu entstanden sind, war bzw. ist die Verfolgung der jüdischen Stadtbewohner ein fester Bestandteil der Narrative. Der Umfang der Präsentation dieses Themas - bezogen auf die Menge an Exponaten und zum Teil auch auf die Ausstellungsfläche - hat sich dabei im Vergleich zur jeweiligen Vorgängerausstellung meist erhöht. Nicht nur scheint demnach den Ausstellungsverantwortlichen nicht mehr möglich oder plausibel, das jüdische Schicksal bei der Schilderung der Besatzungszeit zu ignorieren. Zudem haben die Inhalte und Interpretationen, die in den Schauen vermittelt werden, erste Veränderungen erfahren. Insbesondere der Topos der Gleichwertigkeit der Verfolgung und Vernichtung von Polen und Juden ist aus den Schauen verschwunden. Zum Teil bleibt die Darstellung auch nicht mehr allein auf den Zeitraum der Existenz des jeweiligen Ghettos beschränkt, sondern bezieht die Politik der Besatzer seit September 1939 mit ein.

279 Lediglich ein unbeschriftetes Foto von den Straßen um den Marktplatz erlaubt einen Blick auf Alltagsszenen im Stadtzentrum. Deutsche werden ansonsten für die Jahre nach 1939 ausschließlich in militärischen Kontexten, als Soldaten oder Mitarbeiter in Konzentrationslagern, und damit dem tradierten stereotypen Feindbild entsprechend gezeigt. MMW-MH, Saal 22. Siehe hierzu auch Teil 1, Kapitel 1.3. 
Dennoch bleibt in allen untersuchten Ausstellungen das Schicksal der jüdischen Stadtbewohner gegenüber dem der polnischen Bürger des besetzten Landes unterrepräsentiert. Nur ein Bruchteil der Ausstellungsflächen ist dem Thema vorbehalten; der Schwerpunkt der Erzählungen liegt auf den Erfahrungen der polnischen Bewohner der sogenannten arischen Seite der Stadt. Zentrale Deutungsschemata sind dabei unverändert geblieben. Insbesondere die Vorstellung von einer vollständigen Trennung der Lebenswelten von Polen und Juden wird aufrechterhalten. Dies erfolgt in erster Linie durch die Beschränkung der Thematisierung der Judenverfolgung auf einen eigenen Ausstellungsabschnitt. Aber auch die ethnisch-nationalen Zuordnungen und Begriffe "polnisch « bzw. »jüdisch" - insbesondere in ihrer rassistischen Auffassung, die die deutschen Besatzer anwandten - werden nach wie vor nicht problematisiert. Allen vorgestellten Dauerausstellungen zu den Jahren 1939 bis 1945 liegt ein ethnisches Nationsverständnis zugrunde, das auf gemeinsame Abstammung, Kultur und Religion rekurriert. Davon abweichende individuelle Identitätsvorstellungen und Identifikationen haben in diesem einseitigen Schema keinen Raum. Juden werden daher nicht als Teil der polnischen Nation bzw. Gemeinschaft kontextualisiert. Die untersuchten Ausstellungen zeigen damit exemplarisch, dass jüdische Mitbürger in den Geschichtsbildern vieler polnischer Museen nach wie vor nur einen nachrangigen Platz einnehmen. Gerade bei der Schilderung der Kriegs- und Besatzungszeit wird das Schicksal von Juden als "fremdes « Leiden wahrgenommen und als solches marginalisiert. Die jüdische Bevölkerung des Landes und damit auch die Geschichte ihrer Verfolgung während der NS-Besatzung ist in diesen Museen nicht Teil der "eigenen ", "polnischen " Geschichte, daher spielt sie nur eine untergeordnete Rolle.

Eine Historisierung der Realitäten des Zusammenlebens von Polen und Juden in der Zwischenkriegszeit und deren Folgen für die Besatzungszeit findet somit in keiner der untersuchten Institutionen statt. Weder werden die sozio-kulturellen und religiösen Hintergründe des weitgehenden Nebeneinanders beider Bevölkerungsgruppen vor 1939 problematisiert, noch die Tatsache, dass Juden dennoch im Alltag der polnischen Bevölkerungsgruppe, im Bereich alltäglicher Begegnungen in der Öffentlichkeit, einen festen Platz einnahmen. Die Ausstellungen führen damit unreflektiert die zeitgenössische bzw. historische Fremdwahrnehmung von Polen und Juden fort. Vor diesem Hintergrund werden die Besatzungserfahrungen eines bedeutenden Anteils der Bevölkerungen aller in der Untersuchung betrachteten Städte als nur peripher relevant betrachtet. Dies ist umso bemerkenswerter, als in keiner der untersuchten Präsentationen eine ethnisch-nationale Definition polnischer bzw. lokaler Geschichte als Ausgangspunkt der jeweiligen Darstellung vorausgesetzt wird. Vielmehr postulieren alle Schauen ein territorial gefasstes Geschichtsverständnis. So lautete beispielsweise der Titel der Dauer- 
ausstellung des Historischen Museums der Hauptstadt Warschau »Siedem wieków Warszawy« (Sieben Jahrhunderte Warschau); die Präsentationen in der Krakauer Pomorska-Straße von 1990 und 1998 trugen den Titel »Kraków 1939-1945 « respektive »Kraków 1939-1956 «. ${ }^{280}$

Es überrascht daher kaum, dass die größte Leerstelle in den analysierten Schauen nach wie vor die polnisch-jüdischen Beziehungen während der Besatzung sind. Wenn sie überhaupt direkt angesprochen werden, dann in Form der einseitigen Betonung polnischer Hilfe oder Hilfsversuche. Selbst in den umfangreichen Dauerausstellungen des Museums des Warschauer Aufstands und des ŻIH werden bzw. wurden antijüdische Verhaltensweisen von Polen nur äußerst knapp erwähnt oder angedeutet. Dabei suggerieren die meisten Ausstellungen, dass die Ausnahmefälle der Hilfsleistungen ein verbreitetes gesellschaftliches Phänomen gewesen wären. Insbesondere die Ausstellungen, die deutlich nach dem Abklingen der Jedwabne-Kontroverse konzipiert worden sind, sind damit eindrückliche Beispiele dafür, dass die große Bedeutung, die das Thema der polnisch-jüdischen Kontakte in der publizistischen und wissenschaftlichen Öffentlichkeit erfahren hat, nicht gleichbedeutend mit dem Erreichen eines Konsenses bezüglich ihrer (auch kritischen) Darstellung ist. Ganz im Gegensatz hierzu repräsentieren gerade die Ausstellungen des MHW und des MPW die Perspektive der Gegner einer kritischen Auseinandersetzung mit der nationalen Vergangenheit. Diese Schauen beharren auf einseitigen, positiven nationalen Selbstbildern. ${ }^{281}$ Die Herausstellung polnischer Hilfe für verfolgte Juden wirkt hier als Gegenargument zu den negativen Phänomenen, die die Diskussionen der ersten Dekade der 2000er-Jahre ans Licht der Öffentlichkeit gebracht haben. ${ }^{282}$

\section{Der Entwurf einer multiethnischen Stadtgeschichte - Die Musealiserung des Ghettos Litzmannstadt}

Neben diesen Beispielen musealer Geschichtsbilder, die auf eine ethnischpolnische Wir-Gemeinschaft fokussieren, gibt es jedoch auch Museen, die einen anderen Blickwinkel wählten und sich um eine Rekontextualisierung der eigenen städtischen Geschichte aus einer multiethnischen und multikul-

280 Die ständigen Präsentationen des Pawiak von 1991 und 2001 in der großen Ausstellungshalle des Museums trugen und tragen den Titel »Pawiak 1939-1944«. Die Präsentation des Historischen Museums im Wrocław firmiert unter dem Titel »1000 lat Wrocławia« (1000 Jahre Wrocław).

281 Siehe hierzu auch die Analysen in Teil 3, Kapitel 1.3 und 2.3.

282 Michlic/Melchior: The Memory of the Holocaust, 435. 
turellen Perspektive bemühten. Ein besonders prägnantes Beispiel hierfür ist Łódź, in dem seit Mitte der 1990er-Jahre die Entstehung eines neuen städtischen Mythos zu beobachten ist, der eine solche Perspektive aufgreift und dezidiert popularisiert: »Der Mythos von Lodz als Stadt der vier Kulturen, mehr noch der vier Kulturen, Religionen, Völker: Polen, Deutsche, Juden, Russen ${ }^{283} \mathrm{Zu}$ diesem Prozess zählte von Beginn an ein stetig wachsendes Interesse für die Geschichte der früheren jüdischen Stadtbewohner, insbesondere deren Verfolgung in den Jahren 1939 bis 1945 und damit der Geschichte des Ghettos Litzmannstadt ${ }^{284}$.

Am Beispiel der zwei zentralen historischen Museen von Łódź, die sich mit der Besatzungszeit befassen, werden im Folgenden die verschiedenen Strategien der Inkorporation der jüdischen Łódźer in die musealen Geschichtsbilder und deren Veränderungen in den vergangenen Jahrzehnten nachvollzogen. Inwiefern resultierte daraus eine Integration dieser Bevölkerungsgruppe in die Wir-Gemeinschaft der Protagonisten der musealen Erzählungen? Interessant ist hierbei gerade die Frage, in welchem Maß man auch die polnisch-jüdischen Beziehungen während der Besatzung thematisiert, ob also die Wahrnehmungen und Begegnungsräume der verschiedenen Bevölkerungsgruppen untereinander angesprochen werden. Ziel ist nicht zuletzt, die Hintergründe für thematische Konjunkturen in einzelnen Institutionen herauszuarbeiten sowie die Frage zu beantworten, inwieweit die $\mathrm{Mu}-$ seen dem populären Mythos der »Stadt der vier Kulturen« folgen bzw. an seiner Konstruktion beteiligt waren und sind.

283 Indelak, Jacek: Die Stadt der vier Kulturen und andere Lodzer Mythen. In: Stadtbauwelt. Vierteljahreshefte der Bauwelt 48 (1997), 2716-2721, hier 2718. Wie Jacek Indelak prägnant festgestellt hat, geht mit dieser Besinnung auf den Anteil anderer Ethnien an der Stadtgeschichte auch eine gewisse »Verklärung der multikulturellen Vergangenheit der Stadt« als weitgehend konfliktfreies und positives Miteinander der Ethnien und Kulturen einher. Ebd., 2718.; Schuster, Frank M.: Die verborgene Stadt. Die Wiederentdeckung der polyethnischen Vergangenheit der Stadt Łódź. In: Convivium 16 (2008), 143-170, hier 153. Zur Kritik an dieser Romantisierung der multikulturellen Vergangenheit siehe auch Kossert, Andreas: >Promised Land? Urban Myth and the Shaping of Modernity in Industrial Cities: Manchester and Lodz. In: Emden, Christian/Keen, Catherine/ Midgley, David (Hg.): Imaging the City. Bd. 2: The Politics of Urban Space. Bern 2006, 169-192, hier $175 \mathrm{f}$.

284 Am 11. April 1940 wurde Łódź von den Besatzern in »Litzmannstadt« umbenannt, zu Ehren des deutschen Generals Karl Litzmann. 


\title{
3.1 Tradition versus Neuanfang - Musealisierungsstrategien bis 2003
}

\author{
Die Erinnerung an das Ghetto im Stadtbild bis Anfang \\ der 2000er-Jahre
}

Bis 1989 war die Erinnerung an das Ghetto ${ }^{285}$ und die ermordete jüdische Bevölkerung in Łódź so gut wie unsichtbar. Im öffentlichen Raum waren nach 1945 die materiellen Spuren der während des Kriegs umgekommenen jüdischen Einwohner der Stadt von der kommunistischen Regierung weitgehend beseitigt worden. ${ }^{286}$ So war beispielsweise der von den Nationalsozialisten zerstörte alte jüdische Friedhof Ende der 1940er-Jahre liquidiert worden; 1952 begann auf dem Gelände der Bau einer Wohnanlage - ohne die Gräber des ehemaligen Friedhofs vorher zu exhumieren. ${ }^{287}$ Das einzige vor 1989 errichtete Denkmal in Erinnerung an die Opfer des Ghettos entstand

285 Das Ghetto Litzmannstadt wurde im Februar 1940 geschaffen und bis zum 30. April 1940 von der umliegenden Stadt abgeriegelt. Es war das zweitgrößte Ghetto auf den von den Deutschen besetzten Gebieten (nach dem Warschauer) und existierte insgesamt am längsten, bis zum Sommer 1944. Insgesamt haben es während seiner Existenz etwa 200.000 Menschen durchlaufen, von denen über 45.000 bereits im Ghetto starben. Löw, Andrea: Juden im Getto Litzmannstadt. Lebensbedingungen, Selbstwahrnehmung, Verhalten. Göttingen 2006, 7. Zur Geschichte des Ghettos siehe auch Baranowski, Julian: The Łódź Ghetto 1940-1944. Łódzkie getto 1940-1944. Vademecum. 1. Aufl. Łódź 1999; Samuś, Paweł/Puś, Wiesław (Hg.): Fenomen getta łódzkiego. 1940-1944 [Das Phänomen des Ghettos von Łódź. 1940-1944]. Łódź 2006; Feuchert, Sascha/Leibfried, Erwin / Riecke, Jörn (Hg.): Die Chronik des Gettos Lodz/Litzmannstadt. 5 Bde. Göttingen 2007; Horwitz, Gordon J.: Ghettostadt. Łódź and the Making of a Nazi City. Cambridge Mass., London 2008.

286 Vgl. Gruszczyńska, Danuta K.: Przetrwali. 200 lat Gminy Żydowskiej w Łodzi [Sie haben überdauert. 200 Jahre der jüdischen Gemeinde in Łódź]. In: Kronika miasta Łodzi 3 (2006), 20-28, hier 27. Ebenso Romanowski, Gustaw/Strąkowski, Marek: Miejsca wymagają pamięci. Z Symchą Kellerem - przewodniczącym Gminy Wyznaniowej Żydowskiej - o sprawach duchowych i świeckich rozmawiają Gustaw Romanowski i Marek Strąkowski [Orte brauchen Erinnerung. Gustav Romanowski und Marek Strąkowski sprechen mit Symcha Keller, dem Vorsitzenden der Jüdischen Gemeinde, über geistige und weltliche Dinge]. In: Kronika miasta Łodzi 2 (2004), 13-20, hier 19.

287 Gruszczyńska: Przetrwali, 27. Erst 2003 erfuhren die Bewohner der Siedlung, dass sie auf Gräbern leben. Podolska, Joanna: Przekroczono wszelkie normy etyczne. Stary Cmentarz przy Wesołej [Es wurden alle ethischen Normen überschritten. Der alte Friedhof an der Wesoła-Straße]. In: Kronika miasta Łodzi 3-4 (2003), 97-99, hier 97. 1970 wiederum konnte die geplante Beseitigung der Massengräber von über 40.000 im Ghetto Verstorbener auf dem Neuen Jüdischen Friedhof an der Bracka-Straße nur durch massive internationale Proteste verhindert werden. Bevor jedoch die Liquidierung des sogenannten Ghettofeldes (Pole Gettowe) aufgehalten werden konnte, wurde auf einem Teil bereits die Fahrbahn der Zagajnikowa-Straße gebaut, die bis heute existiert. Romanowski/Strąkowski: Miejsca wymagają pamięci, 19; Gruszczyńska: Przetrwali, 27. 
1956 auf dem Gelände des Neuen Jüdischen Friedhofs und damit abseits der Öffentlichkeit, denn sichtbar war und ist es nur für Besucher. ${ }^{288}$ Die Erinnerung an das Ghetto und an die jüdischen Stadtbewohner, deren kulturelle und religiöse Einrichtungen verschwanden im Resultat fast vollständig aus dem Bewusstsein der Bevölkerung; ${ }^{289}$ dabei hatten Juden vor dem Krieg fast ein Drittel der Einwohner der Stadt ausgemacht, insgesamt etwa 230.000 bis 233.000 Menschen. ${ }^{290}$

Erst Anfang der 1990er-Jahre entstanden Initiativen, sich an die ehemaligen jüdischen Stadtbewohner zu erinnern. Im Jahr 1994, zum 50. Jahrestag der Liquidierung des Ghettos, organisierte die Stadtregierung umfangreiche Gedenkfeierlichkeiten, die diesem Jahrestag erstmals einen bedeutenden Rang in der städtischen Geschichtspolitik einräumten. ${ }^{291}$ Zur Erinnerung an die weitgehend ausgelöschte jüdische Gemeinde sollte auch das 1995 ent-

288 Wojalski, Mirosław Zbigniew: Cmentarz Żydowski w Łodzi [Der jüdische Friedhof in Łódź]. Łódź 2002, 52.

289 Michlic, Joanna B.: Łódź in the Post-Communist Era: In Search of a New Identity. In: Center for European Studies. Program on Eastern and Central Europe. Working Paper Series 65 (2008), 1-18, hier 7; Podolska, Joanna: The Memory of the Lodz Ghetto. In: Majewski, Tomasz/Zeigler-Janiszewska, Anna (Hg.): Memory of the Shoah. Cultural Representations and Commemorative Practices. Lodz 2010, 105-114, hier 105.

290 Es gibt unterschiedliche Angaben über die Bevölkerungszusammensetzung und -zahlen der Stadt bei Kriegsausbruch. Die Zahl von 233.000 Juden gibt u. a. Andrea Löw an: Löw: Juden im Getto Litzmannstadt, 55; ebenso Gruszczyńska: Przetrwali, 25. Polnische Publikationen sprechen dagegen oft von 230.000 Juden bei Kriegsbeginn. Siehe etwa Mroczka: Dynamika rozwoju i struktura społeczno-zawodowa, 101; Puś, Wiesław: Zmiany liczebności i struktury narodowościowej ludności Łodzi do roku 1939 [Veränderungen der Bevölkerungszahlen und -struktur von Łódź bis 1939]. In: Koter, Marek/Kulesza, Mariusz/Puś, Wiesław/Pytlas, Stefan: Wpływ wielonarodowego dziedzictwa kulturowego Łodzi na współczesne oblicze miasta [Der Einfluss des multinationalen kulturellen Erbes auf das heutige Stadtbild]. Łódź 2005, 9-39, hier 28.

291 An der zentralen Gedenkfeier nahmen neben den höchsten Vertretern der Stadt und der Woiwodschaft Łódź auch die obersten religiösen Führer der jüdischen Gemeinden Polens und Israels sowie die Botschafter Israels und der USA teil wie auch der Erzbischof Polens. Rubinstein, Renata: »... ma kto odmówić kadisz na ich grobach«. W rocznicę likwidacji getta łódzkiego [»... es gibt jemanden, der den Kaddisch über ihren Gräbern spricht«. Zum Jahrestag der Liquidierung des Łódźer Ghettos]. In: Słowo Żydowskie vom 23.9.1994, 6. Die vorangegangenen Initiativen zur Stärkung des polnisch-jüdischen Dialogs in der Stadt, insbesondere im Rahmen des »Jahres der jüdischen Kultur» (Rok Kultury Żydowskiej) 1993, sowie die Gedenkfeiern 1994 schildert Gumola, Mieczysław: Walka z niepamięcią. Ocalony honor miasta [Der Kampf gegen das Nichterinnern. Die gerettete Ehre der Stadt]. In: Romanowski, Gustaw/Strakowski, Marek/Sidor, Mateusz (Hg.): Żeby ten krzyk nie przeminął. Materiały z Obchodów 60. Rocznicy Zagłady Litzmannstadt Ghetto, 1944-2004 [Damit dieser Schrei nicht verhallt. Materialien der Gedenkfeiern zum 60. Jahrestag der Vernichtung des Ghettos Litzmannstadt, 1944-2004]. Łódź 2005, 59-64, hier 60-64. 
hüllte "Denkmal des Dekalogs" (Pomnik Dekalogu) beitragen. ${ }^{292}$ Die abstrakte Skulptur, die Moses mit den zwei Tafeln der Zehn Gebote zeigt, ist in ihrer beabsichtigten Referenz an die jahrhundertelange Anwesenheit von Juden auf polnischem Gebiet jedoch für die meisten Betrachter nur schwer zu erfassen. Das Denkmal, das am ursprünglichen Standort der ältesten Synagoge der Stadt errichtet wurde (die von den Deutschen 1939 gesprengt worden war), wird von der Bevölkerung nicht mit der jüdischen Stadtgeschichte assoziiert - es handelt sich damit um »[a]nother monument to oblivion. ॥ $^{293}$ Die geschichtspolitischen Initiativen der Stadtregierung in den 1990er-Jahren hinterließen keine dauerhaften Spuren im Bewusstsein der Einwohner. ${ }^{294}$ Bedeutete diese geringe Präsenz der Geschichte der jüdischen Bewohner im Stadtbild jedoch auch ihre Abwesenheit in den Geschichtsmuseen als Orten historischer Bildung?

Die Frage ist gerade vor dem Hintergrund interessant, dass seit Mitte der 1990er-Jahre die multiethnische Vergangenheit der Stadt verstärkt Interesse vonseiten der Wissenschaft ${ }^{295}$ sowie verschiedener Kulturinitiativen fand. Prominentestes Beispiel im Bereich kultureller Projekte ist das seit 2002 jährlich stattfindende "Festival des Dialogs der vier Kulturen" (Festiwal Dialogu Czterech Kultur), das diese Vergangenheit in Erinnerung rufen soll, insbesondere das Zusammenleben der vier größten Ethnien der Stadt - Polen, Deutsche, Russen und Juden. ${ }^{296}$ Das Festival romantisiert die multiethnische und

292 Das Denkmal wurde von der privaten Stiftung Karta $z$ Dziejów (Eine Seite aus der Geschichte) gestiftet, deren Ziel die Bewahrung der Erinnerung an die jahrhundertelange Anwesenheit von Juden auf polnischem Territorium ist. Die Stiftung bestimmte auch das Motiv der Skulptur, um das es im Stadtrat kontroverse Diskussionen gab. Siehe: Pomnik Dekalogu [Das Dekalog-Denkmal]. In: Kronika miasta Łodzi 1 (1996), 40 f.; Gumola, Mieczysław: Odczytane z kamienia - Pomnik Dekalogu [Aus dem Stein lesen Das Dekalog-Denkmal]. In: Kronika miasta Łodzi 2 (2004), 38-44; Gumola: Walka $\mathrm{z}$ niepamięcią, $59 \mathrm{f}$.

293 Die Form des Denkmals, die grundsätzlichen Normen jüdischer Erinnerung widerspricht (insbesondere dem Verbot figürlicher Repräsentation), kritisiert auch Piluk, Piotr: Lodz Bałuty. Memory of the Shoah in an Urban Landscape. In: Majewski, Tomasz/ Zeigler-Janiszewska, Anna (Hg.): Memory of the Shoah. Cultural Representations and Commemorative Practices. Lodz 2010, 99-104, hier 102f., Zitat: 103.

294 Neben dem Denkmal auf dem Jüdischen Friedhof und dem Denkmal des Dekalogs gab es bis Ende der 1990er-Jahre in der Stadt nur eine weitere Gedenkplatte auf dem ehemaligen Ghettogelände, die an jüdisches Schicksal der Jahre 1939 bis 1944 erinnerte. Piluk: Lodz Bałuty, 101; Podolska: The Memory of the Lodz Ghetto, 105.

295 Einen stringenten Überblick über die Entwicklung des fachwissenschaftlichen Interesses an der nichtpolnischen Vergangenheit der Stadt und Region bietet Schuster: Die verborgene Stadt, bes. 150-157.

296 Das Festival hat seinen Ursprung in einer privaten Initiative und wird seit 2008 von städtischen Institutionen organisiert. Siehe: O festiwalu [Über das Festival], URL: www.4kultury.pl/pl/ (am 16.12.2013); Uchwała rady miasta Łodzi nr XXIII/ 0485/07 w sprawie utworzenia instytucji kultury pod nazwą »Miasto Dialogu« w Lodzi i nadania 
multikulturelle Vergangenheit von Łódź, indem es die Erfolge der städtischen Vielvölkergemeinschaft hervorhebt, vor allem die rasante gesellschaftliche und industrielle Entwicklung im 19. Jahrhundert. Ambivalente und konfliktgeprägte Aspekte des Zusammenlebens der verschiedenen ethnischen und sozialen Gruppen werden dagegen vernachlässigt. ${ }^{297}$

\section{Das Stadtmuseum Łódź}

Eine Institution, in der die jüdische Geschichte der Stadt bereits seit den 1980er-Jahren eine gewichtige Rolle spielte, ist das Historische Museum der Stadt Łódź (Muzeum Historii Miasta Łodzi, MHMŁ), das 2010 in Stadtmuseum Łódź (Muzeum Miasta Łodzi, MMŁ) umbenannt wurde. Bereits in der ersten Hälfte der 1980er-Jahre lässt sich die verhältnismäßig intensive Darstellung des Ghettos Litzmannstadt in einer Sonderausstellung des $\mathrm{Mu}$ seums verzeichnen, die unter dem Titel »Łódź w planach eksterminacyjnych okupanta hitlerowskiego 1939-1945 r.« (Łódź in den Vernichtungsplänen des hitleristischen Besatzers 1939-1945) von April bis Mai 1985 gezeigt wurde. In der begleitenden Ausstellungsbroschüre erfolgte zwar die - geschichtspolitisch gebotene und in Ausstellungen anderer Museen aus dieser Dekade bereits beobachtete - Einordnung der "Vernichtung [eksterminacja] des jüdischen Volkes" als einer der ersten Schritte hin zu einer "Vernichtung [eksterminacja] der polnischen Nation", womit das Schicksal beider Bevölkerungsgruppen gleichgestellt wurde. ${ }^{298} \mathrm{Im}$ Rahmen der Schau behandelte man die jüdische Bevölkerung der Stadt und ihre Verfolgung jedoch relativ umfassend, zum einen in einer eigenen thematischen Sektion, zum anderen durch die Illustrierung der Verfolgung auch in anderen Themenabschnitten. ${ }^{299}$

jej statutu [Beschluss des Stadtrates von Łódź Nr. XXIII / 0485/ 07 über die Gründung einer Kultureinrichtung mit dem Namen »Stadt des Dialogs« in Łódź und die Verabschiedung ihrer Satzung]. 27.12.2007, URL: http://bip.uml.lodz.pl/index.php?str=83\& $\mathrm{id}=20992(\mathrm{am} \mathrm{16} .12 .2013)$.

297 Michlic: Łódź in the Post-communist Era, $11 \mathrm{f}$. Die Hintergründe und Realitäten, die diese romantisierte Version der Vergangenheit verschweigt, schildert pointiert Eser, Ingo: Lodz - Blick(e) auf eine Stadtgeschichte. In: Dyroff, Stefan/Radziszewska, Krystyna/Röskau-Rydel, Isabel (Hg.): Lodz jenseits von »Fabriken, Wildwest und Provinz«. Kulturwissenschaftliche Studien über die Deutschen in und aus den polnischen Gebieten. München 2009, 31-55, bes. 46. Allgemeiner auch Strobel, Georg W.: Łódź: wielonarodowa polis w Polsce [Łódź: multinationale Polis in Polen]. In: Kobylińska, Ewa/ Lawaty, Andreas/Stephan, Rüdiger (Hg.): Polacy i Niemcy. 100 kluczowych pojęć [Polen und Deutsche. 100 Schlüsselbegriffe]. Warszawa 1996, 431-436.

298 [Budziarek, Marek]: Łódź w planach eksterminacyjnych okupanta hitlerowskiego 19391945 [Broschüre]. Łódź 1985. AMMŁ, teczka 6/60, Dz. Historii, o.S.

299 Eine der sechs Sektionen der Schau war explizit dem Ghetto gewidmet. [Budziarek, Marek]: Scenariusz wystawy "Łódź w planach eksterminacyjnych okupanta hitlerowskiego 1939-1945 r.«. Łódź 1985. AMMŁ, teczka 6/ 60, Dz. Historii, 1-4, hier 1 f. Auch in 
Diese Ausstellung mit ihrem vergleichsweise umfangreichen Material zum Ghetto ist damit ein Beispiel dafür, dass es auch bereits vor 1989 möglich war, die Geschichte der jüdischen Stadtbewohner als wesentliches Element der Besatzungsgeschichte zu präsentieren - sofern Interesse seitens der $\mathrm{Mu}$ seumsmitarbeiter vorhanden war. Auch die Zensur hatte hiergegen offenbar keine Einwände, ${ }^{300}$ was sich vermutlich darauf zurückführen lässt, dass die übergreifende geschichtspolitische Kontextualisierung weiterhin dem offiziellen Geschichtsbild entsprach. Aufmerksame Besucher konnten dennoch aus dem Umfang der präsentierten Exponate eine andere (als die in Textform postulierte gleichwertige) Gewichtung von Opfer- und Leidenshierarchien ableiten.

1989 wurde aus Anlass des 50. Jahrestages des Kriegsausbruchs eine weitere Sonderausstellung gezeigt, die der Besatzungszeit gewidmet war: »Łódź Lodsch - Litzmannstadt. Łódź w okresie okupacji hitlerowskiej« (Łódź Lodsch - Litzmannstadt. Łódź während der hitleristischen Besatzung). ${ }^{301}$ Auch in dieser Schau wurde dem Ghetto Litzmannstadt bei der Schilderung des Besatzungsalltags umfangreich Platz eingeräumt. Dem Ghetto war in der thematisch gegliederten Schau einer von neun Abschnitten (mit dem Titel "Litzmannstadt Getto«) gewidmet. Bemerkenswert ist, dass im Hinblick auf die Anzahl der präsentierten Exponate dies die mit Abstand umfangreichste Sektion war: 49 Objektpunkte werden im Drehbuch angegeben, während die übrigen Abschnitte zwischen acht und 22 Angaben umfassen. Schwerpunkt der Darstellung war dabei der Alltag der im Ghetto Eingesperrten, nicht allein ihre Internierung und ihr Abtransport, wie dies bei den Schauen anderer Museen aus den 1980er-Jahren der Fall war. ${ }^{302}$ Heraus ragt des Weiteren, dass die Verfolgten in dieser Schau wie auch in der Ausstellung von 1985 mittels dem Begriff »Juden« ( $\dot{Z} y d z i)$ eindeutig als Opfergruppe identifiziert und nicht durch ethnisch bzw. national neutrale Begriffe in das polnische Opfernarrativ

anderen Sektionen tauchten Verweise auf die jüdische Bevölkerung auf: So wurden etwa Fotos der Zerstörung zweier Synagogen in der Sektion »Kultur" gezeigt; das Foto der Verhöhnung eines Rabbis fand sich im Abschnitt "Geistliche«. Ebd., 2-4.

300 Das Drehbuch der Ausstellung ist mit einem Stempel des »Bezirksamtes zur Kontrolle von Publikationen und Schauspielen in Łódź« (Okręgowy Urząd Kontroli Publikacji $i$ Widowisk w Łodzi) versehen, mit der die Zustimmung zur »Verbreitung«, d. h. der Präsentation der Schau erteilt wurde. Ebd., 1.

301 Jabłoński, Cezary/Budziarek, Marek: "Łódź Lodsch Litzmannstadt«. Scenariusz wystawy czasowej. Lódź 1989. AMMŁ, teczka 6/67, Dz. Historii, 5-17, hier 7.

302 Ebd., 5-17, bes. 11; Teksty do wystawy »Łódź w latach okupacji 1939-1945«. Łódź 1989. AMMŁ, teczka 6/ 67, Dz. Historii, 18-23, hier 20 f. Es ist möglich, dass ein Teil des Materials nicht in der Schau gezeigt worden ist. Nichtsdestoweniger verweist eine Auflistung der Objekte in einer Begleitbroschüre zur Ausstellung darauf, dass die Sektion »Litzmannstadt-Getto" weiterhin eine der umfangreichsten der Schau war. AMMŁ, teczka 6/67, Dz. Historii, [16]. 
vereinnahmt wurden, wie dies in anderen untersuchten Präsentationen der 1980er-Jahre geschah. ${ }^{303}$

In der ersten Hälfte der 1990er-Jahre erhielt die Geschichte des Ghettos in der Ausstellungstätigkeit des Museums eine noch prominentere Rolle. 1993 wurde, nach mehrjährigen Bemühungen, die Ausstellung des Frankfurter Jüdischen Museums »Naszą jedyną drogą jest pracar. Getto łódzkie 1940-1944 r." (»Unser einziger Weg ist Arbeit«. Das Ghetto in Łódź 1940-1944) gezeigt. ${ }^{304}$ Besonders an dieser Ausstellung war die Präsentation farbiger Diapositive, die das Leben im Ghetto illustrierten. Die Aufnahmen stammten von dem Österreicher Walter Genewein, der in der Ghettoverwaltung tätig gewesen war. Auf seinen Bildern sind »kein Hunger, Gewalt und Morde« zu sehen, sie wurden daher in der Schau mit Fotos kontrastiert, die von jüdischen Ghettofotografen stammten und »Tod und Erniedrigung « unmittelbar zeigten. ${ }^{305}$ Ab August 1994 - dem 50. Jahrestag der Liquidierung des Ghettos - präsentierte man die Schau dann als Dauerleihgabe in den Räumlichkeiten des Museums am Platz der Freiheit (Plac Wolności). ${ }^{306}$ Damit war die Geschichte der jüdischen Bewohner während der deutschen Besatzung mit einer eigenen, umfangreichen und permanent zugänglichen Exposition im Stadtmuseum vertreten. Dies stellte eine Ausnahmesituation in der damaligen polnischen Museumsland-

303 Teksty do wystawy »Łódź w latach okupacji 1939-1945«, 20-22. Vgl. Kapitel 1.1 in diesem Teil.

304 Die Ausstellung wurde erstmals 1990 im Jüdischen Museum Frankfurt gezeigt. Sie wurde zur Sensation durch die Präsentation von farbigen Diapositiven, die der Österreicher Walter Genewein im Auftrag des Leiters der Ghettoverwaltung angefertigt hatte und die erst 1987 in einem Antiquariat aufgetaucht waren. Das Łódźer Museum hat sich über zwei Jahre darum bemüht, sie auch in der Stadt zu zeigen, die Schauplatz der in der Ausstellung dargestellten Ereignisse gewesen war. Gezeigt wurde die Schau im Hauptgebäude des Museums. Budziarek, Marek: Naszą jedyną drogą jest praca [Unser einziger Weg ist Arbeit]. In: Gazeta Łódzka vom 16. / 17.1.1993. AMMŁ, teczka 6/ 74, Dz. Historii, o. S.

305 AT: Getto łódzkie w fotografii [Das Łódźer Ghetto in der Fotografie]. In: Nowy Świat z Piotrkowskiej vom 20.1.1993. AMMŁ, teczka 6/74, Dz. Historii, o.S. Die SchwarzWeiß-Fotografien, die neben Geneweins Aufnahmen zu sehen waren, zeigten u.a. Verhungerte, Exekutierte oder Erfrorene, wie die Objektbeschriftungen der Fotografien und Dokumente offenbaren. »Our only way is work«. The Łódź Ghetto 1940-1944 [Begleitheft zur Ausstellung]. Hg.v. The Museum of History of the City of Łódź. Łódź 2002, passim, bes. 61, 77. Siehe auch: »Unser einziger Weg ist Arbeit«. Das Ghetto in Łódź 1940-1944 [Einladung zur Ausstellungseröffnung]. Jüdisches Museum Frankfurt am Main, 1990. AMMŁ, teczka 6/74, Dz. Historii, o.S.

306 Budziarek, Marek: Holocaust in colored pictures. In: »Our only way is work«, 3-5, hier 5. Es ist unklar, wie lange die Ausstellung am Platz der Freiheit bestand, vermutlich etwa bis 2002/03. Gespräche mit Mitarbeitern des Stadtmuseums (Tomasz Kochelski - Bibliotheksleiter, Arkadiusz Podmajstrzy - Aufsicht in der Ausstellung "Unser einziger Weg ist Arbeit« am Platz der Freiheit) am 4. und 9. März 2010. 
schaft dar. ${ }^{307}$ Die Ausstellung fand später weitere Verwendung und wurde 2004 und 2009 nochmals in der Stadt präsentiert. ${ }^{308}$ In den Räumlichkeiten des MHMŁ wurde 1997 auch die bereits erwähnte, namhafte Ausstellung "I ciągle widzę ich twarze« (Und ich sehe noch immer ihre Gesichter) gezeigt. ${ }^{309}$

Bereits diese Sonderausstellungen belegen das große Interesse im Historischen Museum der Stadt an der Geschichte der jüdischen Bewohner. Gerade die Akquise so prominenter Präsentationen wie "Unser einziger Weg ist Arbeit« und »I ciągle widzę ich twarze« erforderte seitens des Museums große Anstrengungen. Diese starke Präsenz der Geschichte der jüdischen Einwohner in der Ausstellungstätigkeit des Museums lässt sich wesentlich auf das persönliche wissenschaftliche Interesse eines Mitarbeiters der Geschichtsabteilung zurückführen, Marek Budziarek. ${ }^{310}$ Er arbeitete seit 1984 im MHML und wirkte wesentlich an der Erarbeitung aller bereits genannten Sonderausstellungen mit. ${ }^{311}$ Budziarek traf mit seinem Interesse an der Geschichte des

307 Neben dem ŻIH in Warschau gab es in den untersuchten Städten nur ein einziges Museum, das bereits früher eine Dauerausstellung präsentierte, die das Schicksal der jüdischen Bevölkerung während der deutschen Besatzung thematisierte: die Abteilung des Historischen Museums der Stadt Krakau in der Alten Synagoge (1980). Siehe Kapitel 1.3 in diesem Teil.

3082004 wurde die Ausstellung im Zusammenhang mit den Gedenkfeierlichkeiten zum 60. Jahrestag der Liquidierung des Ghettos erneut im Hauptgebäude des Stadtmuseums gezeigt. Kronika Obchodów [Chronik der Gedenkfeierlichkeiten]. In: Romanowski, Gustaw/Strąkowski, Marek/Sidor, Mateusz (Hg.): Żeby ten krzyk nie przeminął. Materiały z Obchodów 60. Rocznicy Zagłady Litzmannstadt Ghetto, 1944-2004 [Damit dieser Schrei nicht verhallt. Materialien der Gedenkfeiern zum 60. Jahrestag der Vernichtung des Ghettos Litzmannstadt, 1944-2004]. Łódź 2005, 103-122, hier 119. Von April bis August 2009 war sie in der Abteilung "Station Radegast« (Stacja Radegast) des Museums der Unabhängigkeitstraditionen zu sehen. Interview mit Anna Kulazińska, Leiterin der Abteilung Station Radegast, am 10. März 2010.

309 Die Ausstellung wurde vom 26. Mai bis 10. August gezeigt. Einladungskarte zur Ausstellungseröffnung im MHMŁ. AMMŁ, teczka 6/85, Dz. Historii, Inv.-Nr. 121811.

310 So die Einschätzung von Mitarbeitern des Museums. Gespräch mit Tomasz Kochelski, Bibliotheksleiter, am 4. März 2010. Budziarek hat sich bis zu seinem Tod 2006 vielfach mit dem Thema befasst und dazu publiziert, darunter in Monografien und Sammelbänden zur Stadtgeschichte, aber auch in Zeitschriften und Zeitungen, wie etwa Tygiel Kultury (Kultureller Schmelztiegel), Kronika Miasta Łodzi (Chronik der Stadt Łódź) und Gazeta Wyborcza. Siehe u.a.: Budziarek, Marek (Hg.): Judaica łódzkie w zbiorach muzealnych i zasobach archiwalnych [Łódźer Judaica in Museums- und Archivbeständen]. Łódź 1994; Ders.: Łódź - Lodsch - Litzmannstadt. Wycinki z życia mieszkańców okupowanego miasta [Łódź - Lodsch - Litzmannstadt. Ausschnitte aus dem Leben der Bewohner einer besetzten Stadt]. 2. Aufl. Łódź 2004 (Erstauflage 2001); Ders.: Łódź. Miasto czterech kultur [Łódź. Stadt der vier Kulturen]. Łódź 2004.

311 Warzecha, Małgorzata: Kustosz znaczy obrońca. Marek Budziarek (1951-2006) [Der Kustos als Verteidiger. Marek Budziarek (1951-2006)]. In: Kronika miasta Łodzi 1 (2006), 193-196, hier 194. So wirkte er an den Sonderausstellungen von 1985 und 1989 mit: [Budziarek]: Łódź w planach eksterminacyjnych okupanta; Jabłoński / Budzia- 
Ghettos auf die Zustimmung und Unterstützung der Museumsleitung, wie die prominente und dauerhafte Präsentation etwa der Schau »Unser einziger Weg ist Arbeit« illustriert. Hier zeigt sich beispielhaft die große Bedeutung individueller Interessen und des Engagements einzelner Kuratoren, die für die Einführung bestimmter Themen auch in Museen ein wesentlicher Faktor sind. Im vorliegenden Beispiel traf das Interesse des zuständigen wissenschaftlichen Mitarbeiters auf den dezidierten Anspruch der Museumsleitung seit der Wende, die Geschichte der »multireligiösen, multinationalen, multikulturellen Stadt« zu zeigen, der seinen Ausdruck schließlich in der neuen historischen Dauerausstellung »Łódźer Triade« fand. ${ }^{312}$ Auch an der Erarbeitung dieser Präsentation war Budziarek als einer von zwei Autoren des Drehbuchs wesentlich beteiligt. ${ }^{313}$

Diese neue Dauerausstellung wurde 1998 unter dem Titel »Triada łódzka. Trzy wielkie społeczności. Polacy - Niemcy - Żydzi« (Łódźer Triade. Drei große Gemeinschaften. Polen - Deutsche - Juden) eröffnet. Wie bereits der Titel verrät, spielte in dieser Exposition, die die Stadtgeschichte bis zum Jahr 1945 umfasste, gerade auch die Geschichte der jüdischen Bewohner eine herausragende Rolle. Diese Gewichtung erstreckte sich auch auf die letzte thematische Sektion der Schau, »Lodsch - Litzmannstadt«, die der Besatzungszeit 1939 bis 1945 gewidmet war. Etwa die Hälfte der Ausstellungsfläche in diesem Bereich nahm das Ghetto Litzmannstadt als »Vorhof der Vernichtung " (Przedsionek zagłady) ${ }^{314}$ ein. Im derart betitelten Bereichstext wurden detailliert und mit deutlicher Wortwahl die einzelnen

rek: »Łódź Lodsch Litzmannstadt«. Scenariusz wystawy czasowej. Darüber hinaus bemühte er sich um die Präsentation der Schau »Unser einziger Weg ist Arbeit« in Łódź und wurde der zuständige Kurator für die Präsentation im MHMŁ. Romanowski, Gustaw: W Łodzi: Getto - kolor i mrok [In Łódź: Das Ghetto - Farbe und Dunkelheit]. In: Rzeczpospolita i kultura vom 19.1.1993. AMMŁ, teczka 6/74, Dz. Historii, o. S.

312 Laurentowicz, Małgorzata/Budziarek, Marek: »Wielka triada łódzka» (wystawa stała w Muzeum Historii Miasta Łodzi). Łódź, 20.6.1997 [Drehbuch]. AMMŁ, teczka 6/89, 23-29, hier 23. Vorarbeiten für diese neue Schau waren die früheren Sonderausstellungen, darunter die 1989 gezeigte Präsentation »Łódź - Lodsch - Litzmannstadt. Łódź während der hitleristischen Besatzung«. Czubaczyński: Pałac - Muzeum [1995], [44]; Projekt scenariusza wystawy okolicznościowej z okazji 50-lecia wybuchu drugiej wojny światowej. AMMŁ, teczka 6/67, Dz. Historii, 1-4, hier 1.

313 Die zweite Autorin war Małgorzata Laurentowicz-Granas. MMŁ, Informationstafel in der Ausstellung. Ebenso betreute Budziarek die Erstellung des »Arbeitszimmer[s] von Prof. Jan Karski«, auf das im Folgenden noch eingegangen wird. Budziarek, Marek: Gabinet Prof. Jana Karskiego [Das Arbeitszimmer von Prof. Jan Karski] [Ausstellungskatalog]. Łódź 1999, 2. Er baute zudem Kooperationen mit dem United States Holocaust Memorial Museum sowie Yad Vashem auf. Warzecha: Kustosz znaczy obrońca, 194.

314 Titel des Bereichstextes. MMŁ, Sektion »Lodsch - Litzmannstadt«. Die Texte und Bildunterschriften der Ausstellungen finden sich auch im begleitenden Katalog: Laurentowicz/Budziarek: Triada, zur Sektion »Lodsch - Litzmannstadt«: 53-60. 
Etappen der "vollständigen rassischen Segregation" geschildert: von den ersten Bestimmungen zur Kennzeichnung jüdischer Geschäfte, über die Gründung des Ghettos, die »mittelbare Vernichtung der jüdischen Bevölkerung" durch die dramatischen Lebensbedingungen und die Zwangsarbeit bis zur »direkten Vernichtung" im Vernichtungslager Chełmno nad Nerem (Kulmhof am Ner) und anderen Lagern. ${ }^{315}$ Veranschaulicht wurden diese Ereignisse nicht nur über Alltagsgegenstände, Schmuck, Geld und Bekanntmachungen aus dem Ghetto, sondern auch durch namentliche und mit Fotografien versehene Ghetto-Arbeitskarten. Mittels dieser Objekte traten den Besuchern konkrete Menschen entgegen; die abstrakte Schilderung der Grausamkeiten, des Lebens und Sterbens im Ghetto wurde gerade durch die bildliche Sichtbarmachung einzelner Inhaftierter sprichwörtlich lebendig, was einen empathischen Zugang zu ihrem Schicksal beförderte. Daneben fanden sich von den NS-Behörden herausgegebene Postkarten aus dem Ghetto, die explizit mit dem Begriff "Propaganda" versehen waren. ${ }^{316}$ Deren verharmlosende Darstellung des Lebens in dem abgetrennten Stadtgebiet - weder waren direkte Gewalt oder Zwangsarbeit noch Hunger oder Tod zu sehen wurde korrigiert durch die bereits erwähnte umfangreiche Darstellung im Bereichstext.

Überraschend wirkte vor dem Hintergrund dieser detaillierten und - in Bezug auf die Lagerorganisation und die langsame Tötung seiner Insassen - vergleichsweise differenzierten Darstellung die Schilderung der NSBesatzungspolitik im Thementext dieser Ausstellungssektion - »Lodsch Litzmannstadt«. Zwar wurde dort beschrieben, dass das Warthegau zu einem »Versuchsgelände der vielschichtigen Nationalitätenpolitik des hitleristischen Apparats « wurde. ${ }^{317}$ Die Kontextualisierung der Verfolgung von Juden und Polen erfolgte jedoch entlang etablierter narrativer Muster der VRP: Das Vorgehen der Besatzer in Bezug auf Polen und Juden wurde jeweils mit dem Begriff »Vernichtung" gefasst und weitgehend gleichgestellt:

Łódź [...] nahm in den Vernichtungsplänen des hitleristischen Besatzers eine besondere Rolle ein. Es wurde zum Versuchsgelände der vielschichtigen Nationalitätenpolitik des hitleristischen Apparats. Eben hier wurde das am längsten funktionierende Ghetto Europas geschaffen, durch das ca. 200.000 Menschen gingen (von denen aufgrund der dort herrschenden Bedingungen ca. 46.500 im Ghetto selbst starben). [...]

315 Bereichstext »Der Vorhof der Vernichtung«. MMŁ, Sektion »Lodsch - Litzmannstadt«. Siehe auch Laurentowicz/Budziarek: Triada, $59 \mathrm{f}$.

316 Die dazugehörige Bildunterschrift lautete: "Propagandapostkarten aus dem Ghetto Łódź, 1940-1944«. MMŁ, Sektion »Lodsch - Litzmannstadt«. Siehe auch Laurentowicz/ Budziarek: Triada, 55.

317 Thementext »Lodsch - Litzmannstadt«. MMŁ, Sektion »Lodsch - Litzmannstadt». Siehe auch Laurentowicz/Budziarek: Triada, 54. 
die polnische Bevölkerung wurde einer breit angelegten Vernichtungsaktion unterzogen (maximale Ausbeutung von Arbeitskraft, Raub von Eigentum, massenhafte Verhaftungen, Exekutionen, Deportationen in Konzentrationslager, Aussiedlung ins Generalgouvernement, Zwangsverschickung zur Arbeit ins Reich). ${ }^{318}$

Dieser Rückgriff auf interpretatorische Leitlinien der sozialistischen Zeit überrascht umso mehr, als dies das einzige Element der Dauerausstellung war, in der diese Rhetorik verwendet wurde. Im Text, der die Eröffnung der Schau begleitete und ihr Konzept zusammenfasste, machte man dagegen den Unterschied im Besatzungsschicksal von Polen und Juden kenntlich; mit dem Begriff »Vernichtung« wurde dort allein das Vorgehen der Nationalsozialisten gegenüber Juden bezeichnet:

Genau hier hat die hitleristische Besatzungsmacht spezielle Haftanstalten geschaffen, aber vor allem eines der größten und am längsten existierenden Ghettos in Europa für die jüdische Bevölkerung. [...] Die Vernichtungspolitik der hitleristischen Besatzungsmacht führte zur vollständigen Vernichtung des jüdischen Volkes. ${ }^{319}$

Wie ein Textvergleich zeigt, resultierte diese Inkonsistenz aus der Verwertung früherer Publikationen: Der Thementext »Lodsch - Litzmannstadt« war eine gekürzte Version der Broschüre zur Sonderausstellung »€ódź in den Vernichtungsplänen des hitleristischen Besatzers 1939-1945 « von 1985. ${ }^{320}$ Dass der Text eine tendenziöse Aussage vermittelte, scheint nicht beachtet oder aufgefallen zu sein.

Bemerkenswert sind des Weiteren zwei Aspekte: Zunächst fällt auf, dass auch in dieser Ausstellung die Begriffe "jüdisches Volk» (nacja żydowska) und »uden« sowie »Polen« und »Deutsche« selbstverständlich verwendet wurden. Gerade mit Bezug auf die deutsche Besatzung und deren Nationalitätenpolitik wurde die rassistische Zuschreibung »Jude«/»jüdisch« nicht problematisiert, sondern als vermeintlich objektive Kategorie verwendet. Und dies, obwohl in den vorherigen Sektionen der Schau das Neben- und Miteinander verschiedener Religionen und Ethnien in der Stadt - darunter auch ihr oft erzwungener Charakter - sowie verschiedene Akkulturations- und Assimilationsprozesse innerhalb der Stadtbevölkerung gerade im 19. Jahrhun-

318 Siehe auch ebenda.

319 Budziarek, Marek: Triada łódzka. Trzy wielkie społeczności. Polacy - Niemcy - Żydzi (zamiast przewodnika). In: Triada łódzka. »Łódzkie sentymenty«. Portrety Łodzian i ich rodzin. Muzeum Historii Miasta Łodzi 6.12.1998 [Broschüre zur Ausstellungseröffnung]. AMMŁ, teczka 6/89, [o.S.]. Der Text wurde - bis auf wenige stilistische Anpassungen - auch als Einleitung im Katalog zur Ausstellung abgedruckt: Wstęp [Einleitung]. In: Laurentowicz/Budziarek: Triada, $3 \mathrm{f}$.

320 [Budziarek]: Łódź w planach eksterminacyjnych okupanta. 
dert ausführlich zur Sprache kam. ${ }^{321}$ Die hierdurch angedeutete Ambivalenz von Identitätsempfindungen und -zuschreibungen wurde bei der Darstellung der Jahre 1939 bis 1945 dagegen aufgegeben: Dieser Sektion lag eine grundlegende Unterscheidung der städtischen Gesellschaft entlang scheinbar klarer ethnisch-nationaler Kriterien zugrunde. Der zweite Punkt, der ins Auge sticht, ist die vollkommene Absenz polnisch-jüdischer Kontakte und gegenseitiger Wahrnehmungen während der Besatzung. Weder in den Themenund Bereichstexten, noch unter den präsentierten Objekten fand sich hierauf ein Hinweis. Das Schicksal der jüdischen wie der polnischen Stadtbewohner wurde buchstäblich nebeneinander, und damit auch voneinander unabhängig, präsentiert - sowohl inhaltlich als auch räumlich: Der Ausstellungssaal, in dem diese Sektion untergebracht war, wurde durch einen Gewölbebogen in zwei etwa gleich große Raumabschnitte geteilt. Die Darstellung der Erfahrungen der polnischen und jüdischen Bevölkerung in den Jahren 1939 bis 1945 erfolgte rechts bzw. links von dieser sinnbildlichen Trennlinie.

Dennoch verfolgte diese Dauerausstellung nicht dieselbe ethnisch-nationale Perspektive, die die meisten anderen historischen Schauen bis in die Gegenwart charakterisiert: Die verschiedenen Ethnien, die die Stadt bewohnten, wurden als konstitutive Elemente der städtischen Gemeinschaft betrachtet, was sich auch in dem umfangreichen Platz zeigt, den die Verfolgung der jüdischen Bevölkerung bei der Schilderung der Jahre 1939 bis 1945 erhielt. »Juden « wurden zwar als eigene ethnische Gruppe betrachtet, sie waren jedoch im Gegenteil zu den deutschen Besatzern - keine »Fremden «, sondern Teil der Wir-Gemeinschaft, die in dieser musealen Erzählung konstruiert wurde. Die Ausstellung präsentierte somit ein staatsbürgerliches Identitätskonzept, in dem verschiedene Religionen und Ethnien Platz fanden. Eine solche Perspektivierung städtischer Geschichte, das heißt die Loslösung von einer rein polnischen, ethnisch-zentrierten Betrachtungsweise, war Ende der 1990er-Jahre einzigartig in der polnischen Museumslandschaft. ${ }^{322}$

321 Laurentowicz/Budziarek: Triada, Abschnitte: »Ein religiöses und nationales Phänomen«, 10-12; »Die Großen dieser Stadt«, 26-28; »Religiöse Koexistenz«, $44 \mathrm{f}$. In der Ausstellung wurden nicht nur verschiedene ethnische Gruppen thematisiert - Polen, Deutsche, Juden, Russen -, sondern auch religiöse Gemeinschaften, die in der Stadt vertreten waren, darunter orthodoxe Christen und verschiedene protestantische Glaubensrichtungen.

322 Wobei jedoch anzumerken ist, dass dieser multireligiöse und multikulturelle Blick auf die Vergangenheit mit einer gewissen Romantisierung derselben einhergeht. Zwar wurden ambivalente Aspekte des oft erzwungenen Nebeneinanders der Kulturen bis 1939 in der Ausstellung erwähnt; Schwerpunkt der Darstellung waren jedoch die Erfolge der Stadt im Bereich ihrer wirtschaftlichen und kulturellen Entwicklung. Diese Einschätzung teilt auch Andreas Kossert, der auf den Ausstellungskatalog der Schau verweist bei seiner Kritik der Idealisierung der städtischen Vergangenheit seit den 1990er-Jahren. Kossert: >Promised Land, $176 \mathrm{f}$. 
Das Ghetto im Martyrologiemuseum Radogoszcz

Das Martyrologiemuseum Radogoszcz dagegen, das spezialisiert ist auf die Geschichte der deutschen Besatzung, unterschied sich bis Anfang der 2000erJahre nicht wesentlich von anderen musealen Institutionen Polens und deren Umgang mit der jüdischen Vergangenheit der eigenen Stadt und Region. In den zahlreichen Sonder- und Wechselausstellungen, die seine Mitarbeiter in den letzten drei Jahrzehnten für das Museum der Unabhängigkeitstraditionen $\mathrm{zu}$ diesem Themenbereich vorbereiteten, spielte die Verfolgungsgeschichte der jüdischen Stadtbewohner nur eine untergeordnete Rolle. Bis zur Eröffnung der neuen Dauerausstellung 2003 fanden lediglich zwei kleinere Ausstellungen $\mathrm{zu}$ diesem Themenkreis statt. ${ }^{323}$ In einigen anderen Sonderausstellungen wurden das Ghetto und die Ermordung seiner Insassen erwähnt, wobei sich diese Verweise jedoch auf wenige Objekte und einzelne Sätze beschränkten. ${ }^{324}$ Auch in der 1990 überarbeiteten und ergänzten

323 "Nieznane zdjęcie z łódzkiego getta« (Die unbekannte Fotografie aus dem Łódźer Ghetto). Siehe: Einladungskarte zur Ausstellungseröffnung am 18.4.1988. AMTNŁ, Oddział Martyrologii Radogoszcz, ohne Signatur. »Pieśń o zamordowanym żydowskim narodzie« (Lied vom ermordeten jüdischen Volk, gezeigt 1993). Vgl. Źródlak: Bibliografia radogoska, 115 .

324 So fand sich etwa in der Sonderausstellung "Wojna i dziecko« (Der Krieg und das Kind) von 1986 das ikonische Bild des kleinen Jungen aus dem Warschauer Ghetto. [Muzeum Historii Ruchu Rewolucyjnego w Łodzi Oddział Radogoszcz]: Wojna i dziecko [Flyer zur Ausstellung]. Łódź 1986. AMTNŁ, Oddział Martyrologii Radogoszcz, ohne Signatur. Ebenso beiläufig wurden die Vernichtungspläne gegenüber der jüdischen Bevölkerung in den folgenden Schauen erwähnt: "Pamięć i przebaczenie. W 50 rocznicę wyzwolenia hitlerowskich więzień i obozów koncentracyjnych« (Erinnerung und Vergebung. Zum 50. Jahrestag der Befreiung der hitleristischen Gefängnisse und Konzentrationslager, gezeigt 1995). Rukowiecki, Andrzej/Siemiński, Henryk: Pamięć i przebaczenie. W 50 rocznicę wyzwolenia hitlerowskich więzień i obozów koncentracyjnych [Erinnerung und Vergebung. Zum 50. Jahrestag der Befreiung der hitleristischen Gefängnisse und Konzentrationslager] [Ausstellungskatalog]. Łódź 1995; »Kwiaty Wojny« (Blumen des Kriegs, April 1995). Kwiaty Wojny [Blumen des Kriegs] [Ausstellungskatalog]. Hg.v. Muzeum Tradycji Niepodległościowych w Łodzi. April 1996. "Wolność krzyżami się mierzy`. Śladami miejsc walki i męczeństwa w wojewódstwie łódzkim 1939-1945« (»Freiheit wird mit Kreuzen gemessen«. Auf den Spuren der Orte des Kampfes und des Martyriums in der Łódźer Woiwodschaft 1939-1945, April 1997). Wróbel, Grzegorz J./Iwanicki, Ryszard/Janaszek, Grażyna: Scenariusz wystawy pt. »Wolność krzyżami się mierzy«. Śladami miejsc walki i męczeństwa w województwie m. łódzkim 1939-1945«. Łódź, April 1997. AMTNŁ, Oddział Martyrologii Radogoszcz, ohne Signatur. »A jednak tak byłoく. Dzień powszedni okupowanej Łodzi« (»So war es eben«. Der Alltag im besetzten Łódź, 1998). Rukowiecki, Andrzej/Pińkowska, Jadwiga/Źródlak, Wojciech: »A jednak tak było«. Dzień powszedni okupowanej Łodzi. Scenariusz wystawy. Łódź 1.9.1998-Februar 1999. AMTNŁ, Oddział Martyrologii Radogoszcz, ohne Signatur. 
Dauerausstellung »Łódź w okresie wojny i okupacji« (Łódź in der Kriegs- und Besatzungszeit) war das Thema nur sehr marginal vertreten. ${ }^{325}$

Mehr Raum erhielt die Verfolgung der jüdischen Stadtbewohner erst in der neuen Dauerausstellung von 2003, in der dem Ghetto Litzmannstadt eine eigene Sektion gewidmet war. Die Darstellung konzentrierte sich - ähnlich wie in den meisten der bereits besprochenen Ausstellungen aus dieser Zeit auf den Zeitraum der Existenz des Ghettos. Lediglich sehr knapp erwähnte man die der Ghettogründung vorausgehenden Schikanen, indem die Vorschriften präsentiert wurden, eine Armbinde und später einen gelben Stern an der Kleidung zu tragen. ${ }^{326}$ Betont wurde insbesondere die »Isolierung [des Ghettos] vom Rest der Stadt $«{ }^{327}$ So illustrierte eine der insgesamt zehn dem Thema gewidmeten Tafeln ${ }^{328}$ mittels großformatiger Fotografien die Zerstörung von Häusern entlang dreier Straßen, die in unmittelbarer Nähe zur Ghettogrenze lagen, die die Besatzer als »sanitäre Schutzzone« um das Ghetto bezeichneten. ${ }^{329}$ Die folgende Tafel zeigte Fotografien der bewachten

325 Laut Ryszard Iwanicki, einem wissenschaftlichen Mitarbeiter der Abteilung Radogoszcz, wurde das Ghetto auf nur einer Ausstellungstafel kurz dargestellt, wobei der Schwerpunkt auf den Massenmorden im Lager Kulmhof am Ner lag. Das Drehbuch der Dauerausstellung von 1990 stand der Verfasserin nicht zur Verfügung, sodass keine detaillierteren Angaben gemacht werden können. Iwanickis Aussagen zufolge war die Geschichte des Ghettos eines der Themen, die in der Neufassung der Schau 2003 die größte Ausweitung erfahren haben. Interview mit Ryszard Iwanicki am 2. November 2010.

326 Dieser Zwang zur äußeren Kennzeichnung wurde mittels zweier Bekanntmachungen vermittelt, die über die entsprechenden Bestimmungen informierten. MTNŁ-Radogoszcz, Sektion »Litzmannstadt - Ghetto«, Tafel 2, 4 [Die hier angewandte Nummerierung der Tafeln beziehen sich ausschließlich auf die Elemente dieses Themenabschnitts]. Ausführlicher erfolgte die Darstellung der Ereignisse vor der Schaffung und Schließung des Ghettos in dem zwei Jahre später erschienenen Ausstellungsführer: Przewodnik po ekspozycji stałej. Łódź i Ziemia Łódzka w okresie wojny i okupacji 1939-1945 [Führer durch die Dauerausstellung. Łódź und das Łódźer Gebiet während des Kriegs und der Besatzung 1939-1945]. In: Iwanicki/Janaszek/Rukowiecki: Martyrologium Łódzkie, 25-65, hier $41 \mathrm{f}$.

327 MTNŁ-Radogoszcz, Sektion »Litzmannstadt - Ghetto«, Tafel 1, Zitat aus dem Thementext »Litzmannstadt - Ghetto«.

$328 \mathrm{Zu}$ dieser thematischen Sektion werden alle Tafeln gezählt, die unter der Überschrift »Litzmannstadt - Ghetto« in der Ausstellung präsentiert wurden. Fünf der Tafeln befanden sich in einer langen Vitrine, in der weitere Objekte zum Thema untergebracht waren. Das Thema des »Jugendverwahrlagers« für polnische Kinder und Jugendliche eines Lagers, das 1942 auf dem Ghettogelände, aber von diesem abgetrennt errichtet wurde - wird hier nicht mit hinzugezählt, da es durch eine eigene Themenüberschrift eingeleitet wurde und damit eine eigenständige Sektion innerhalb der Schau darstellte.

329 MTNŁ-Radogoszcz, Sektion »Litzmannstadt - Ghetto«, Tafel 3, Zitat aus dem Bereichstext (der Ausdruck »sanitarna strefa ochronna» ist im Text in Anführungszeichen gesetzt). 
Übergänge über Straßen, die durch das Ghettogelände verliefen, aber von seinem Territorium ausgenommen waren, darunter die ikonischen Bilder zweier Holzbrücken über die Zgierska-Straße ${ }^{330}$ als Symbole der Trennung des Ghettogeländes von der übrigen Stadt.. ${ }^{331}$ Angesichts dieser deutlichen Hervorhebung der Isolation überrascht es kaum, dass in der Schau Kontakte zwischen den Bewohnern beider Stadtgebiete nicht thematisiert wurden. Die einzigen Berührungspunkte, die in dieser Hinsicht erkennbar waren, bildeten die auf den Fotos abgebildeten deutschen (uniformierten) Sicherheitskräfte, die das Ghetto bewachen. Diese Personen waren die einzigen, die im Rahmen der in der Ausstellung präsentierten Erzählung unmittelbaren »Kontakt« mit der Ghettobevölkerung hatten - als Unterdrücker und Verursacher des Leidens.

Litzmannstadt war tatsächlich eines der am schärfsten bewachten Ghettos auf polnischem besetztem Gebiet. In der Forschungsliteratur wird immer wieder auf die besonderen Schwierigkeiten der Kontaktaufnahme zwischen dem Ghetto und der Widerstandsbewegung in der Stadt verwiesen, die auf den besonders hohen Anteil an deutschen und volksdeutschen Bewohnern im gesamten Stadtgebiet zurückgeführt wird. ${ }^{332}$ Dies bedeutet jedoch nicht, dass die Stadtbevölkerung und die im Ghetto Gefangengehaltenen keinerlei Kommunikationsmöglichkeiten hatten oder diese nicht nutzten. Wie Dorota Siepracka festgestellt hat:

Die Archivrecherchen zeigen, dass diese [polnisch-jüdischen] Beziehungen nicht nur existierten, sondern - für ein derart hervorragend bewachtes Ghetto - überraschend zahlreich und vielfältig waren. Daraus folgt, dass das Łódźer Ghetto, obwohl es eines der am strengsten bewachten Ghettos in den besetzten Gebieten war, mit Sicherheit nicht hermetisch isoliert war. ${ }^{333}$

330 Ebd., Tafel 5, bes. Foto 5, 6.

331 Dass diese Fotografien die Isolation des Ghettogeländes illustrieren sollten, wird im begleitenden Ausstellungsführer betont: Przewodnik po ekspozycji stałej, 45.

332 Die Etablierung des Bildes eines hermetisch abgeriegelten Ghetto Litzmannstadt in der Forschungsliteratur zeichnet Dorota Siepracka nach. Siepracka, Dorota: Stosunki polsko-żydowskie w czasie okupacji hitlerowskiej. Stan badań i perspektywy badawcze [Polnisch-jüdische Beziehungen während der Besatzung. Forschungsstand und Forschungsperspektiven]. In: Samuś/Puś: Fenomen getta łódzkiego, 335-345, hier 335338. Siehe auch Siepracka, Dorota: Stosunki polsko-żydowskie w Łodzi podczas okupacji niemieckiej [Die polnisch-jüdischen Beziehungen in Łódź während der deutschen Besatzung]. In: Żbikowski, Andrzej (Hg.): Polacy i Żydzi pod okupacją niemiecką, 1939-1945. Studia i materiały [Polen und Juden während der deutschen Besatzung, 1939-1945. Studien und Materialien]. Warszawa 2006, 691-735, hier 697.

333 Siepracka: Stosunki polsko-żydowskie w Łodzi, 735. Auch Andrea Löw verweist darauf, dass man im Fall des Ghettos Litzmannstadt nicht von einem vollständigen Fehlen von Kontakten mit der Außenwelt sprechen kann. Löw: Juden im Getto Litzmannstadt, 507. 
Die bedeutendste Form von Verbindungen mit der Außenwelt, insbesondere mit Polen außerhalb des Ghettos, war - wie in allen »Judenwohnbezirken« der Schmuggel von Waren. ${ }^{334}$ Daneben arbeiteten einige wenige Polen in der deutschen Ghettoverwaltung oder belieferten das Ghetto auf offiziellem Weg mit Gütern, was von einigen zum Austausch oder Schmuggel genutzt wurde. ${ }^{335}$ Umgekehrt gab es auch einige Arbeitskommandos aus Ghettobewohnern, die außerhalb des Lagers in der Stadt und der umliegenden Region arbeiteten und dadurch Kontakt- und nicht zuletzt Möglichkeiten der zusätzlichen Versorgung hatten. ${ }^{336} \mathrm{Zu}$ diesen wenigen, aber dennoch existierenden Beziehungen zwischen Bewohnern des Ghettos und denen der sogenannten arischen Seite der Stadt fanden sich jedoch in der Ausstellung keinerlei Hinweise. Zwar wurden Arbeitseinsätze außerhalb des Ghettos angesprochen. ${ }^{337}$ Diese erschienen jedoch ausschließlich im Zusammenhang mit der Illustrierung des Ghettoalltags, insbesondere der Zwangsarbeit. Dass es dennoch Kontakte mit der Außenwelt gab, konnten aufmerksame Besucher lediglich aufgrund eines indirekten Hinweises deduzieren: In der Schau fand sich eine Anordnung des Vorsitzenden des Judenrates, Mordechaj Chaim Rumkowski, die Gespräche am oder über den Ghettozaun hinweg strengstens untersagt. ${ }^{338}$ Dieses Objekt ist ein anschauliches Beispiel für die Mehrdeutigkeit zeitgenössischer Quellen und damit auch von Museumsexponaten: Die Anordnung kann sowohl als Ausdruck der strikten Separation des Ghettos gesehen werden (selbst kurze Wortwechsel wurden unterbunden) als auch als Zeichen des Bestehens von Verbindungen zur Außenwelt (Menschen kamen dennoch an die Ghettogrenze, um sich auszutauschen oder Waren zu schmuggeln). ${ }^{339}$ Vor dem Hintergrund der in der Schau betonten Isolation haben die meisten Besucher das Exponat ver-

334 Siepracka: Stosunki polsko-żydowskie w Łodzi, 718; Horwitz: Ghettostadt, 68, 102.

335 Siepracka: Stosunki polsko-żydowskie w Łodzi, 715, 717; Löw: Juden im Getto Litzmannstadt, 507.

336 Diese Gruppen waren jedoch zahlenmäßig sehr gering. Siepracka: Stosunki polskożydowskie w Łodzi, 722.

337 »Bekanntmachung 166«. MTNŁ-Radogoszcz, Sektion »Litzmannstadt - Ghetto«, Tafel 6.

338 »Bekanntmachung Nr. 70«. Ebd., Tafel 4. Als eben dies - als Hinweis auf offensichtlich existierende Kontakte mit Menschen außerhalb des Ghettos - wertet auch Dorota Siepracka dieses Dokument in ihrer Analyse der deutsch-polnischen Beziehungen während der Besatzung. Siepracka: Stosunki polsko-żydowskie w Łodzi, 707. Auch in der begleitenden Ausstellungsbroschüre werden Kontakte mit der (polnischen) Welt außerhalb des Ghettos nicht thematisiert. Betont wird dagegen die »Isolierung der Ghettobewohner«, die die verschiedenen Tafeln der Ausstellung illustrieren. Vgl. Przewodnik po ekspozycji stałej, $41-48$, bes. $45,47$.

339 Wie Andrea Löw zudem zu Recht hinweist: »Auch wird deutlich, dass eine Darstellung, die nur anhand offizieller Quellen versucht, die Geschichte des Ghettos zu rekonstruieren, viele Details übersehen muss. So zeigen beispielsweise Verbote keineswegs, dass es bestimmte Phänomene in der Folge nicht mehr gegeben hat.« Löw: Juden im Getto Litzmannstadt, 507. 
mutlich in der erstgenannten Lesart wahrgenommen. Damit erschienen die Lebenswelten beider Bevölkerungsgruppen insgesamt als strikt voneinander getrennt, wozu nicht zuletzt beitrug, dass die Schilderung des Ghettos und der als Juden Verfolgten weitgehend auf einen Ausstellungsabschnitt beschränkt und damit von der übrigen Erzählung getrennt blieb. ${ }^{340}$

Der Alltag der Eingeschlossenen, insbesondere die allgemeine Zwangsarbeit, wurde daneben relativ ausführlich geschildert. Hierfür hatten die Ausstellungsverantwortlichen umfangreiches und auch bis dato selten verwendetes Quellenmaterial zusammengetragen. So zeigte man etwa Ausschnitte aus der Ghetto-Chronik. ${ }^{341}$ Auch zahlreiches ikonografisches Material wurde verwendet. Allerdings blieb der Kontext der gezeigten Fotografien dabei jedoch vollständig ausgeblendet. Die Besucher erfuhren nicht, wer die Autoren der einzelnen Fotos waren, aus welcher Perspektive und mit welchem Ziel die Aufnahmen entstanden sind, da Quellenangaben zu den verwendeten Fotografien bzw. Hinweise zu ihren Entstehungsumständen fehlten. So präsentierte man in der Ausstellung einige der farbigen Diapositive von Walter Genewein, die durch die bereits erwähnte Frankfurter Ausstellung 1993 erstmals nach Łódź kamen. ${ }^{342}$ Beschrieben waren die Fotos mit dem abstrakten Kom-

340 Juden und Kontexte ihrer Verfolgung wurden nur kurz und beiläufig an drei Stellen in der restlichen, umfangreichen Ausstellung erwähnt. In einem Bereichstext schilderte man die Veränderungen der Bevölkerungszusammensetzung anhand der Bevölkerungsstatistik für die Jahre 1939 und 1944: 1944 wurden nur noch Polen und Deutsche erwähnt, "Juden" und »andere Nationalitäten" gab es nicht mehr. Beim Themenabschnitt zur Verfolgung der katholischen Kirche zeigte man u. a. das Foto einer in ein Depot umfunktionierten katholischen Kirche, in der »Bettwäsche, die Juden geraubt wurde«, gesammelt wurde. Beim Thema »Germanisierung« wurde im Thementext erwähnt, dass Polen und Juden ausgesiedelt wurden. MTN $€-$ Radogoszcz, Sektion $»$ Es gibt kein Łódź mehr, nur noch Litzmannstadt«", Tafel 3, Bereichstext; Sektion »Wir Deutschen sind hier als Herren hergekommen, die Polen sollen uns dienen«", Tafel 3, Foto 2, Bildunterschrift; Sektion "Germanisierung«, Thementext.

341 Gezeigt wurde jeweils eine Seite aus dem Biuletyn Kroniki Codziennej (Tageschronik) vom 4. und 7. März 1941 (in polnischer Sprache). MTNŁ-Radogoszcz, Sektion »Litzmannstadt - Ghetto«, Tafel 7, 8. Im Archiv des Ältesten der Juden des Ghettos Litzmannstadt wurde in den Jahren 1940 bis 1944 eine Chronik der Ereignisse und des Lebens im Ghetto erstellt, zu der neben den Ausgaben der »Tageschronik« umfangreiches Fotomaterial gehörte. Zur Geschichte der Chronik siehe Feuchert, Sascha: Die GhettoChronik: Entstehung und Überlieferung. Eine Projektskizze. In: Ders. / Leibfried, Erwin/ Riecke, Jörn (Hg.): Die Chronik des Gettos Lodz/Litzmannstadt. Supplemente und Anhang. Göttingen 2009, 167-190.

342 MTNŁ-Radogoszcz, Sektion »Litzmannstadt - Ghetto«, Tafel 7, 8. Die Fotografien hatten keine Quellenangaben. Sie finden sich jedoch im Bestand der Genewein-Fotos, die im Archiv von Yad Vashem einsehbar sind. Vgl. Yad Vashem Photo Archive, Bestand "Color photographs taken in the Lodz Ghetto by a German photographer«, URL: http:// collections.yadvashem.org/photosarchive/en-us/6464349-container.html (am 18.10.2013), item 61, 80, 143, 144, 146, 254, 262, 276. 
mentar "Szenen aus dem Alltag im Łódźer Ghetto ${ }^{343}$ und suggerierten damit eine scheinbar objektive Dokumentation zeitgenössischer Ereignisse. Auf den Fotos sind jedoch weder direkte Gewalt, qualvoller Hunger, Erniedrigungen noch Tod zu sehen; sie wirken vergleichsweise harmlos. Geneweins Absicht war es, das effiziente Funktionieren des Lagers zu zeigen, insbesondere die Produktivität der diversen Betriebe innerhalb des Zwangsarbeitssystems. Hierbei handelt es sich, wie es in der Einladung zur Eröffnung der Frankfurter Schau prägnant hieß, um »eine einzigartige Dokumentation, deren Lücken freilich für sich sprechen. ${ }^{344}$ Um deren verharmlosende Perspektive aufzuzeigen und zugleich zu korrigieren, wurden den Bildern in der Ausstellung des Frankfurter Jüdischen Museums daher auch (im Geheimen aufgenommene) Aufnahmen zweier jüdischer Fotografen des Ghettos gegenübergestellt, die eine andere Perspektive auf die Ghettobevölkerung und ihren Alltag einbrachten und insbesondere das Leiden der Bewohner explizit zeigten. ${ }^{345}$ Eine solche Gegenüberstellung fand in der Ausstellung des Museums Radogoszcz hingegen nicht statt. Zwar fanden sich neben den Fotografien Geneweins auch solche anderer Fotografen. Die Bilder, die für die Schau ausgewählt wurden, waren jedoch frei von explizit negativen oder auch überraschenden Motiven: Weder sah man auf ihnen Gewalt oder Hunger, Momente des Familienlebens, noch das Sterben im Ghetto. ${ }^{346}$ Sie wirkten ähnlich

343 MTNŁ-Radogoszcz, Sektion »Litzmannstadt - Ghetto«, Tafel 7, Bildunterschrift. Auf Tafel 8 wurden noch zwei weitere Fotografien von Genewein gezeigt, die laut den Bildunterschriften $»$ Funktionäre des Ordnungsdienstes, also [der] jüdische[n] Polizei des Łódźer Ghettos« zeigten sowie »Funktionäre der Feuerwehr im Ghetto«. Ebd., Tafel 8, Foto 4, 5 .

344 »Unser einziger Weg ist Arbeit«. Das Ghetto in Łódź 1940-1944 [Einladung zur Ausstellungseröffnung]. Jüdisches Museum Frankfurt am Main, 1990. AMMŁ, teczka 6/74, Dz. Historii, o. S. Siehe auch Loose, Ingo: »Das Gesicht des Gettos«. Photographien und Photographen im Ghetto Litzmannstadt 1940-1944. In: Das Gesicht des Gettos. Bilder jüdischer Photographen aus dem Getto Litzmannstadt 1940-1944. The Face of the Ghetto. Pictures Taken by Jewish Photographers in the Litzmannstadt Ghetto 1940-1944 [Ausstellungskatalog]. Hg.v. der Stiftung Topographie des Terrors. Berlin 2010, 25-37, hier 27.

345 AT: Getto łódzkie w fotografii [Das Łódźer Ghetto in der Fotografie]. In: Nowy Świat z Piotrkowskiej vom 20.1.1993. AMMŁ, teczka 6/74, Dz. Historii, o. S. Die Schwarz-WeißFotografien, die neben Geneweins Aufnahmen zu sehen waren, zeigten unter anderem Verhungerte, Exekutierte oder Erfrorene, wie die Objektbeschriftungen der Bilder und Dokumente offenbaren. Siehe: »Our only way is work«, passim, bes. 61, 77. Siehe auch: "Unser einziger Weg ist Arbeit«. Das Ghetto in Łódź 1940-1944 [Einladung zur Ausstellungseröffnung]. Jüdisches Museum Frankfurt am Main, 1990. AMMŁ, teczka 6/74, Dz. Historii, o.S.

346 Die jüdischen Fotografen fertigten zum einen Auftragsfotografien für die deutsche Ghettoverwaltung an; zum anderen dokumentierten sie heimlich die Zustände im Ghetto und das Alltagsleben seiner Bewohner, darunter auch Hungertote, Einrichtungen der Selbstverwaltung wie Krankenhäuser oder Suppenküchen, religiöse Feste, 
"neutral« wie die Bilder Geneweins und fokussierten auf die Zwangsarbeit der Insassen. Dass es sich dabei ebenso wie bei Genewein auch um Auftragsarbeiten handeln konnte und daher bewusst bestimmte Motive ausgewählt, aber auch vermieden worden sind ${ }^{347}$ war für den Betrachter nicht ersichtlich. Die von den Ausstellungsverantwortlichen vorgenommene Auswahl an Fotografien perpetuierte damit unreflektiert die Perspektive der Besatzer. Die Besucher sahen dadurch unwillkürlich die Insassen des Ghettos mit deren Augen bzw. aus einem meist für Propagandazwecke gewählten Blickwinkel ohne darauf hingewiesen zu werden, da einordnende Kommentare fehlten. Grund für diese Bildauswahl war höchstwahrscheinlich nicht das Bestreben, drastische Darstellungen zu vermeiden. Denn in der zweiten Dauerausstellung des Museums, die der Geschichte des Gefängnisses Radegast während der Besatzung gewidmet ist, finden sich großformatige Nahaufnahmen der Leichen der (polnischen) Opfer des Massakers an den Gefängnisinsassen am 17./ 18. Januar $1945 .{ }^{348}$ Vielmehr kann diese zurückgenommene Illustrierung des Ghettos als Ausdruck der Persistenz einer latenten Opferkonkurrenz interpretiert werden, in der jüdisches Leiden nicht eindrücklicher als polnisches erscheinen sollte.

Auffällig ist schließlich, dass auch in dieser Schau die rassistische Grundlage der Zuschreibung »Jude«/»jüdisch« durch die Besatzer nicht erwähnt wurde. Die Begriffe gebrauchte man vielmehr als vermeintlich neutrale ethnische Kategorien und suggerierte damit eine homogene Gruppe Verfolgter.

aber auch fröhliche Alltagsmomente wie spielende Kinder und Familienfeiern. Loose: "Das Gesicht des Gettos«, 34. Vgl. auch Publikationen der Aufnahmen dieser Fotografen: Grossman, Mendel: With a Camera in the Ghetto. Tel-Aviv 1970; Baranowski: The Łódź Ghetto 1940-1944; Ross, Henryk: Łódź Ghetto Album. Photographs by Henryk Ross. Selected by Martin Parr and Timothy Prus. Foreword by Robert Jan van Pelt. Text by Thomas Weber. London 2004; Baranowski, Julian/Nowinowski, Sławomir M. (Hg.): Getto Łódzkie. Litzmannstadt Ghetto. 1940-1944. Łódź 2009; Das Gesicht des Gettos. Bilder jüdischer Photographen aus dem Getto Litzmannstadt 1940-1944. The Face of the Ghetto. Pictures Taken by Jewish Photographers in the Litzmannstadt Ghetto 1940-1944 [Ausstellungskatalog]. Hg.v. der Stiftung Topographie des Terrors. Berlin 2010.

347 »Die Ablichtungen von Mendel Grosman, Henryk Ross und anderen Photographen wurden zumindest innerhalb der nationalsozialistischen Stadtverwaltung verwendet, vielleicht sogar innerhalb der nationalsozialistischen Ämter- und Parteihierarchie des Warthegaus. Als offizielle Auftragsbilder sollten sie die Produktivität und Bedeutung des Ghettos für die deutsche Kriegswirtschaft herausstreichen.«Loose: »Das Gesicht des Gettos«, 33 .

348 Die Schau mit dem Titel »Śmierć nie straszna, lecz powolne konanie« (Nicht der Tod ist schrecklich, sondern das langsame Sterben) wird in ihrer aktuellen Form seit 2007 im Museum Radogoszcz gezeigt. Bereits in ihrer Vorgängerversion (und höchstwahrscheinlich auch in deren Vorläufern vor 1989) waren Abbildungen der Opfer des Massakers vom Januar 1945 enthalten. Vgl. Radogoszcz 1939-1945. In: Iwanicki/Janaszek/ Rukowiecki: Martyrologium Łódzkie, 66-80, hier 73. 
In Übereinstimmung mit diesem zugrunde gelegten oder vorausgesetzten ethnischen Nationsverständnis wurde auch die Deportation von "Juden aus Österreich, Tschechien, Luxemburg und Deutschland" sowie aus dem Warthegau erwähnt, ohne die individuelle Identität der Betroffenen zu hinterfragen oder zu thematisieren, obwohl es sich bei den Deportierten aus Westeuropa zum großen Teil um assimilierte Juden oder Personen handelte, die keinen Kontakt mehr zum jüdischen Glauben und Kultur hatten. ${ }^{349}$ Ebenso unreflektiert erfolgt die Bezeichnung der etwa 5.000 innerhalb des Ghettos internierten "Zigeuner« (Cyganie). ${ }^{350}$ Der Begriff wurde ohne Anführungszeichen, ebenfalls als scheinbar objektive ethnische Bezeichnung herangezogen - ohne seine pejorative Konnotation oder die in der betroffenen Bevölkerungsgruppe verwendete Selbstbezeichnung (Roma/Romowie) zu beachten. Zugleich bleibt jedoch festzuhalten, dass diese Schau als erste der untersuchten überhaupt die Verfolgung anderer Minderheiten neben Juden thematisierte. Die gesamte Dauerausstellung konzentrierte sich insgesamt weiterhin auf die Erfahrungen und die Verfolgung der polnischen Stadtbewohner. Der Zuwachs an Informationsmaterial und Raum in der Schau (im Vergleich zur Vorgängerausstellung) ist jedoch ein Hinweis darauf, dass dem Ghetto als Teil der Stadtgeschichte seitens der Kuratoren nun mehr Bedeutung beigemessen wurde.

Auch wenn diese Schau erst fünf Jahre nach der historischen Dauerausstellung des stadthistorischen Museums eröffnet wurde, wiesen beide Ausstellungen in Bezug auf die Darstellung der Jahre 1939 bis 1945 erstaunliche Parallelen auf - die sich in erster Linie in ihren Leerstellen zeigten. Das Ghetto und das Schicksal der darin Gefangengehaltenen wurden in beiden Museen geschildert. Die Hintergründe der rassistisch motivierten Verfolgung durch die Besatzer blieben jedoch ebenso unerwähnt wie Kontakte zwischen der Bevölkerung außerhalb und innerhalb des Ghettos. Beide Institutionen präsentierten somit ihren Besuchern das Bild zweier homogener Ethnien, die sich

349 Zitat aus dem Thementext »Litzmannstadt - Ghetto«. MTNŁ-Radogoszcz, Sektion »Litzmannstadt - Ghetto«, Tafel 1. Mentalitäts- und kulturelle Unterschiede, nicht zuletzt die Sprachbarriere (die Deportierten aus Westeuropa sprachen meist weder Jiddisch noch Polnisch) erschwerten die Integration dieser Gruppe in die Ghettogesellschaft, die sich zu diesem Zeitpunkt überwiegend aus polnischen Juden zusammensetzte. Löw: Juden im Getto Litzmannstadt, 224, 231-262, bes. 234, 240, 246, 253-255, 261; Radziszewska, Krystyna: Żydzi zachodnioeuropejscy w getcie łódzkim w świetle dzienników i wspomnień z getta [Westeuropäische Juden im Łódźer Ghetto im Spiegel von Tagebüchern und Erinnerungen aus dem Ghetto]. In: Samuś/Puś: Fenomen getta łódzkiego, 309-325, hier 319-322. Siehe auch Radziszewska, Krystyna: Die Darstellung des deutschen Anteils an der Stadtgeschichte in den Museen der Stadt Łódź. In: Dyroff/Krzoska: Geschichtsbilder, 161-172, hier 141-147.

350 Dem »Zigeunerlager« war die letzte der zehn Tafeln in dieser Sektion gewidmet. MTNŁRadogoszcz, Sektion »Litzmannstadt - Ghetto«. 
klar voneinander unterschieden und während der Besatzung keine gemeinsamen Berührungspunkte hatten, und damit - auch räumlich - weitgehend getrennte Geschichten. Während in Bezug auf den ersten Aspekt - die unterstellte Selbstverständlichkeit der Zuschreibung "jüdisch " - beide Ausstellungen den Schauen anderer Museen, auch jüngeren Datums, glichen, zeichnete sie beim zweiten Aspekt jedoch eine Besonderheit aus: Die Hilfe von Polen für verfolgte Juden - die einzige Art von Kontakten zwischen den Bevölkerungsgruppen, die in anderen Museen Erwähnung findet - wurde in den Łódźer Präsentationen weder betont noch erwähnt. ${ }^{351}$ Implizit vermittelten beide die

351 Der einzige Verweis auf dieses Themenspektrum im MMŁ fand sich außerhalb der historischen Ausstellung in einem anderen Teil der übergreifenden Dauerausstellung des Museums, zu dem diese Schau gehörte: In einem der prächtigen Wohnräume des ehemaligen Palastes, der Sitz des Museums ist, wurde 1999 innerhalb des »Pantheons der Großen Łódźer" (Panteon Wielkich Łodzian) ein Raum zum Gedenken an Jan Karski eingerichtet, das »Arbeitszimmer von Prof. Jan Karski« (Gabinet Prof. Jana Karskiego). Karski, der in Łódź geboren und aufgewachsen ist, wird dort als Symbolfigur der polnischen Holocaust-Erinnerung präsentiert - als der erste Emissär des polnischen Untergrundstaates, der Informationen über die Verfolgung und Ermordung der Juden im besetzten Polen in den Westen überbrachte und versuchte, die Alliierten zum Eingreifen zu bewegen. Czubaczyński, Ryszard (Hg.): Pałac - Muzeum. Muzeum Historii Miasta Łodzi. Informator - przewodnik [Palast - Museum. Das Historische Museum der Stadt Łódź. Informationsbroschüre - Ausstellungsführer]. Łódź 2003, 170; Wystawa stała "Z dziejów Łodzi. Historia - Kultura - Codzienność« - Panteon wielkich łodzian [Dauerausstellung »Aus der Geschichte Łódźs. Geschichte - Kultur - Alltag« - Das Pantheon der großen Łódźer], URL: www.muzeum-lodz.pl/pl/muzeum/wystawy/wystawastala-z-dziejow-lodzi?start=1 (am 24.7.2013). Siehe auch Budziarek: Gabinet Prof. Jana Karskiego. Der einzige implizite Verweis im MMŁ auf polnisch-jüdische Kontakte während der Besatzung bezieht sich somit auf die heroischen - wenn auch tragischen, da gescheiterten - Taten eines »Gerechten unter den Völkern«, der während der Besatzung jedoch nicht in seiner Heimatstadt agierte. 2011 wurde ein weiterer Saal zu Ehren Marek Edelmans und seiner Frau Alina Margolis eröffnet. Edelman, der letzte Anführer des Warschauer Ghettoaufstandes, praktizierte nach dem Krieg als Arzt in Łódź. Im Jahr 2000 wurde ihm die Ehrenbürgerwürde der Stadt verliehen. In dem Saal wird auch das Warschauer Ghetto kurz illustriert, in dem Edelman während des Kriegs gefangen gehalten wurde. Siehe: Marek Edelman i Alina Margolis - Życie jest najważniejsze ... [Marek Edelman und Alina Margoli. Das Leben ist das Wichtigste ...] In: Wystawa stała "Z dziejów Łodzi. Historia - Kultura - Codzienność « - Panteon wielkich łodzian [Dauerausstellung »Aus der Geschichte Łódźs. Geschichte - Kultur - Alltag« - Das Pantheon der großen Łódźer]. www.muzeum-lodz.pl/pl/muzeum/wystawy/wystawa-stala-z-dziejowlodzi?start=1 (am 4.8.2013); Pawłowska, Anna: Gabinet Marka Edelmana w Muzeum Miasta Łodzi [Das Arbeitszimmer Marek Edelmans im Stadtmuseum Łódź]. In: Dziennik Łódzki vom 3.10.2011, Online-Ausgabe, URL: www.dzienniklodzki.pl/artykul/457 680,gabinet-marka-edelmana-w-muzeum-miasta-lodzi,id,t.html (am 4.3.2013). Siehe auch Pawlak, Monika: Marek Edelman: dowódca powstania w getcie wybrał Łódź [Marek Edelman: Der Anführer des Ghettoaufstandes wählte Łódź]. In: Dziennik Łódzki vom 17.9.2010, Online-Ausgabe, URL: www.dzienniklodzki.pl/artykul/308829, marek-edelman-dowodca-powstania-w-getcie-wybral-lodz,id,t.html (am 4.8.2013). 
Botschaft von der hermetischen Abriegelung des Ghettogeländes von der übrigen Stadt, durch die Kontakte oder gar Hilfeleistungen im besetzten Łódź noch schwieriger und seltener waren als in anderen Regionen. Diese Darstellung entsprach weitgehend dem Forschungsstand zum Entstehungszeitpunkt beider Schauen. ${ }^{352}$ Durch das Auslassen der Kontakte zwischen der "arischen Seite " und den Ghettobewohnern wurde aber zugleich der ambivalente Aspekt der Gleichgültigkeit oder gar antisemitische Einstellungen der polnischen Bevölkerung ausgeklammert. Dieser Blickwinkel auf die polnisch-jüdischen Beziehungen während der Besatzung ist in Łódź - und nicht nur dort - bis heute ${ }^{353}$ nicht in den permanenten Präsentationen der städtischen historischen Museen vertreten, obwohl die historiografische Aufarbeitung dieses Sachverhalts mittlerweile vorangeschritten ist. ${ }^{354}$

Trotz dieser Ähnlichkeiten unterschieden sich die zwei Dauerausstellungen jedoch in einem zentralen Punkt grundsätzlich: Im Gegensatz zu dem staatsbürgerlichen Konzept der Erzählung des MMŁ, wo dem Ghetto und seinen Insassen dieselbe Bedeutung beigemessen wurde wie den Erfahrungen der polnischen Stadtbewohner und sie als gleichberechtigte Protagonisten der musealen Erzählung in Erscheinung traten, lag der Präsentation

352 Vgl. Siepracka: Stosunki polsko-żydowskie w czasie okupacji hitlerowskiej.

353 Im September 2011 wurde eine neue Dauerausstellung zu den Jahren der deutschen Besatzung im Museum Radogoszcz eröffnet. Bei dieser handelt es sich weitgehend um eine gestalterisch modernisierte Fassung der Vorgängerpräsentation, die sich nur in wenigen Aspekten von der Schau von 2003 unterscheidet. In Bezug auf die jüdische Bevölkerung wurde eine zusätzliche Tafel aufgenommen, in der Gewaltakte gegen jüdische Bewohner der Stadt und deren Kulturgüter vor der Schaffung des Ghettos aufgelistet werden; die übrigen Sektionen gleichen sich weitgehend. Ausstellungsbesuch am 28. März 2012.

354 Siehe beispielsweise Löw: Juden im Getto Litzmannstadt; Siepracka: Stosunki polskożydowskie w Łodzi; Dies.: Stosunki polsko-żydowskie w czasie okupacji hitlerowskiej. In einem gemeinsamen Projekt der Universitäten Gießen und Łódź wurde die Chronik des Ghettos Litzmannstadt vollständig ediert und in einer deutschen und polnischen Parallelausgabe 2007 publiziert. Deutsche Ausgabe: Feuchert/Leibfried/Riecke: Die Chronik des Gettos. Ein Großteil der Bestände der Ghetto-Chronik befindet sich bereits seit Ende der 1960er-Jahre im »Staatsarchiv in Łódź« (Archiwum Państwowe w Łodzi). Feuchert: Die Ghetto-Chronik, 187; Sobiczewski, Bernard: Źródła do dziejów getta łódzkiego w zasobie Archiwum Państwowego w Łodzi [Quellenmaterial zur Geschichte des Łódźer Ghettos im Bestand des Staatsarchivs in Łódź]. In: Samuś/Puś: Fenomen getta łódzkiego, 401-405. Die Arbeit an einer ersten Edition der Chronik begann in den 1960er-Jahren. Nur die ersten zwei Bände wurden jedoch publiziert, bevor das Projekt im Zuge der Ereignisse von 1968 abgebrochen wurde. Kronika getta łódzkiego/1: Styczeń 1941-maj 1942 [Die Chronik des Łódźer Ghettos. Bd. 1: Januar 1941-Mai 1942]. Hg.v. Danuta Dąbrowska und Lucjan Dobroszycki. Łódź 1965; Kronika getta łódzkiego/2: Czerwiec-grudzień 1942 [Die Chronik des Łódźer Ghettos. Bd.2: Juni-Dezember 1942]. Hg.v. Danuta Dąbrowska und Lucjan Dobroszycki. Łódź 1966; Waingertner, Przemysław: Problematyka getta łódzkiego w źródłach drukowanych i literaturze naukowej [Das Thema des Łódźer Ghettos in gedruckten Quellen und in der Forschungsliteratur]. In: Samuś/Puś: Fenomen getta łódzkiego, 389-399, hier 390. 
im Museum Radogoszcz ein exklusives ethnisches Nationsverständnis zugrunde. Die Schau konzentrierte sich auf das Besatzungsschicksal und die Erfahrungen der ethnisch-polnischen Bewohner der Stadt und Region. Juden bzw. die Geschichte des Ghettos wurden nur als Nebenschauplatz der nationalsozialistischen Gräueltaten thematisiert. Die Tatsache, dass das Ghetto jedoch mittlerweile einen größeren Platz in der musealen Erzählung einnahm, verweist auf übergreifende erinnerungskulturelle Veränderungsprozesse: Die Geschichte des zweitgrößten Ghettos auf polnischem Territorium konnte 2003 durch die Kuratoren nicht mehr vernachlässigt oder marginalisiert werden. Beigetragen haben hierzu wohl in erster Linie das gestiegene Interesse an der jüdischen Geschichte der Stadt in Łódź selbst, in ihrer Kultur- und Wissenschaftslandschaft, aber auch die landesweiten Debatten über das polnischjüdische Verhältnis während der Besatzung, die im Zuge der Jedwabne-Debatte breitere Aufmerksamkeit fanden und die Wahrnehmung des Holocaust als Teil der Besatzungsgeschichte auf polnischem Territorium gestärkt haben. Dennoch blieben im Museum Radogoszcz Juden weiterhin als "Fremde» aus der Wir-Gemeinschaft der Protagonisten der Regionalgeschichte ausgeschlossen. Die Schilderung ihres Schicksals erfolgte allein im thematischen Kontext der Grausamkeit der Besatzer. Externe Entwickungen haben jedoch in den vergangenen Jahren dazu geführt, dass auch im Museum der Unabhängigkeitstraditionen das Ghetto Litzmannstadt inzwischen eine bedeutende Rolle spielt, wie im folgenden Exkurs geschildert wird.

\subsection{Exkurs: »Mit den Opfern schreien«}

Wie gezeigt wurde, fand die Geschichte des Ghettos in der musealen Landschaft von Łódź Anfang des 21. Jahrhunderts Beachtung, und insbesondere im Stadtmuseum spielte sie seit den 1990er-Jahren eine bedeutende Rolle. Dennoch blieb die jüdische Vergangenheit in der kollektiven Erinnerung und Wahrnehmung der Einwohner so gut wie unbekannt: „Even residents of Bałuty ${ }^{355}$, strolling down the same streets and living in the same buildings, were not aware of what the Litzmannstadt Ghetto used to be. ${ }^{356}$

Ein Umbruch in dieser öffentlichen Wahrnehmung erfolgte jedoch 2004, im Zusammenhang mit dem 60. Jahrestag der Liquidierung des Ghettos Litzmannstadt. ${ }^{357}$ Dieser Jahrestag wurde vom Stadtpräsidenten Jerzy Kropiwnicki zu einem Ereignis von zentraler Bedeutung für die städtische Erinnerungs-

355 Das Ghetto wurde im Stadtviertel Bałuty errichtet, das diesen Namen bis heute trägt.

356 Podolska: The Memory of the Lodz Ghetto, 105.

357 Der Jahrestag der Liquidierung des Ghettos Litzmannstadt wird am 29. August begangen, dem Tag, an dem 1944 die letzten Deportationen aus dem Ghetto stattfanden. 
kultur erhoben. Im Jahr 2003 initiierte er umfangreiche Feierlichkeiten, deren Höhepunkt die Gedenkzeremonien zwischen dem 27. und dem 30. August 2004 bildeten. In Zusammenarbeit mit der Jüdischen Gemeinde der Stadt sowie zahlreichen Organisationen aus dem Bereich der Kulturvermittlung wurden darüber hinaus über den Zeitraum von insgesamt einem Jahr hinweg vielfältige Veranstaltungen organisiert. ${ }^{358}$ Programmatisches Ziel dieser Initiative war es, die Erinnerung an das Ghetto und die mit ihm verbundenen Ereignisse in das Gedächtnis der Stadt und seiner heutigen Bewohner zurückzuholen, diese Erinnerung also für »die amputierte Geschichte der Stadt ${ }^{359}$ mit Michael Steinlauf gesprochen - »wiederzugewinnen«. Die Einwohner Łódźs sollten Kropiwnicki zufolge ihre Verantwortung als »Zeugen des Verbrechens" wahrnehmen und des Schicksals ihrer Landsleute gedenken. ${ }^{360} \mathrm{Zu}$ diesem Zweck initiierte die Stadtregierung auch zwei städtebauliche Projekte, die die Erinnerung an das Ghetto Litzmannstadt auf Dauer in der Topografie der Stadt verankern sollten.

Das erste war der Denkmalkomplex der »Station Radegast ${ }^{361}$, der am Ort der gleichnamigen früheren Bahnstation am Rande des Ghettogeländes entstanden ist. Ab 1942 fanden von diesem Bahnhof aus die Deportationen der Ghettobewohner in Konzentrations- und Vernichtungslager statt. Der neue Gedenkort wurde 2009 offiziell als »Abteilung Station Radegast« (Oddzial Stacja Radegast) Bestandteil des Museums der Unabhängigkeitstraditionen. ${ }^{362}$

358 Die Eröffnung des Gedenkjahres fand am 2. Oktober 2003 mit einem Konzert von Andrzej Krauze sowie der Eröffnung der Sonderausstellung "Dzieci z łódzkiego getta" (Die Kinder aus dem Łódźer Ghetto) statt. Seinen Abschluss bildete eine wissenschaftliche Konferenz zur Geschichte des Ghettos Litzmannstadt, die von der Universität Łódź und den Regionalabteilungen des IPN sowie des Staatsarchivs vom 11. bis 12. Oktober 2004 organisiert wurde. Andrzejewska-Psarska, Małgorzata (Hg.): Upamiętnienie Żydów Łódzkich 2003-2005. Raport z działań upamiętniających żydowskie dziedzictwo Łodzi [Das Gedenken an die Łódźer Juden 2003-2005. Bericht über die Aktivitäten im Zusammenhang mit dem Gedenken an das jüdische Erbe von Łódź]. Łódź [2005], 29.

359 Nach einem Zitat aus der Gazeta Wyborcza. Zitiert nach: Andrzejewska-Psarska: Upamiętnienie Żydów Łódzkich, 41.

360 Kropiwnicki, Jerzy: Rola świadka - rzecz o obchodach 60. rocznicy likwidacji Litzmannstadt Ghetto w Łodzi [Die Rolle des Zeugen - Zu den Gedenkfeierlichkeiten des 60. Jahrestages der Liquidierung des Ghettos in Łódź]. In: Kronika miasta Łodzi 2 (2004), 5-9, hier $8 \mathrm{f}$.

361 Der vollständige Name des Gedenkortes lautet »Station Radegast - Denkmal für die Vernichtung des Ghettos Litzmannstadt« (Stacja Radegast - Pomnik Zagłady Litzmannstadt Getto).

362 Der Bau des Komplexes dauerte von 2004 bis 2005. Die offizielle Übernahme des Grundstücks durch das MTNŁ wurde dagegen erst 2009 vollzogen; seit September 2009 ist das Areal eine Abteilung des MTNŁ. Gespräch mit Anna Kulazińska, Leiterin der Abteilung Station Radegast, am 10. März 2010. Die folgenden Ausführungen basieren auf dem Besuch der Gedenkstätte durch die Verfasserin am 3. März 2010. Eine Unterabteilung der Station Radegast ist die Abteilung »Schmiede der Roma« (Kuźnia Romów). 
Teil des Komplexes ist ein 140 Meter langer Tunnel aus Beton, der »Tunnel der Deportierten« (Tunel Deportowanych), in den eine Ausstellung integriert ist, die über wesentliche Ereignisse der Jahre 1939 bis 1945 im besetzten Łódź informiert: An einer Seite des Tunnels wurden großformatige Jahreszahlen angebracht, denen jeweils kurze Texte mit Informationen zu zentralen Ereignissen der Ghetto- und der Stadtgeschichte im Zeitraum 1939 bis 1945 beigefügt sind (siehe Abb. 27). ${ }^{363}$ Bestandteil der Schau ist eine Präsentation von Transportlisten sowie wenigen zeitgenössischen Fotografien, die die einmarschierenden deutschen Truppen sowie Kinder und Jugendliche bei der Zwangsarbeit im Ghetto zeigen. Auch einige Objekte - Knöpfe und Scheren, die bei Ausgrabungen im ehemaligen Vernichtungslager Kulmhof am Ner gefunden wurden, einem der Zielorte der Deportationen - werden präsentiert. ${ }^{364}$

Zum Komplex der Gedenkstätte gehören des Weiteren das Stationsgebäude sowie unmittelbar davorliegende Gleisstücke, die zusammen die einzigen originalen Überreste des historischen Ortes darstellen. Auf den Gleisen wurde eine zeitgenössische Lokomotive mit drei Güterwagons aufgestellt, die an jene erinnern sollen, mit denen die Ghettobewohner deportiert wurden (siehe Abb. 28). Die Fenster der Wagons sind mit Stacheldraht verkleidet; in einen von ihnen kann man eintreten. Am Ende der Bahnrampe, in der Richtung, in die die Lokomotive ausgerichtet ist und damit auf das Ziel ihrer Fahrt verweisend, wurden symbolische Grabsteine aufgestellt, die in ihrer Form an jüdische Grabmale erinnern. Sie tragen jeweils die Namen der Zielorte der Deportationen und entsprechen in ihrer Größe ungefähr der Zahl der dorthin jeweils aus dem Ghetto deportierten und ermordeten Menschen. Der Architekt

In dem Gebäude einer früheren Schmiede - von der Größe einer Garage -, die sich auf dem Gelände des Roma-Lagers befindet, das kurzzeitig innerhalb des Ghettos bestand, wird die Geschichte der dort inhaftierten und ermordeten Menschen geschildert. Die dortige Dauerausstellung wurde 2009 eröffnet. Vgl. I skrzypce przestały grać ... Obóz cygański 1941-1942 [Und die Geigen hörten auf zu spielen ... Das Zigeunerlager 1941-1942] [Ausstellungsführer]. Hg.v. Muzeum Tradycji Niepodległościowych w Łodzi. Łódź 2009. Die Ausstellung ist nur nach vorheriger Anmeldung zugänglich.

363 Siemiński, Henryk (Hg.): Stacja Radegast. Litzmannstadt Getto 1940-1944. Łódź 2005, 1. Die Texte der Ausstellung im »Tunnel der Deportierten« sind abgedruckt in einer Broschüre: Stacja Radegast. Pomnik zagłady Litzmannstadt Getto [Station Radegast. Denkmal der Vernichtung des Ghettos Litzmannstadt]. Łódź o. J. [2005].

364 Bielecki, Czesław: Radegast. In: Ders.: Więcej niż architektura. Pochwała eklektyzmu [Mehr als Architektur. Ein Lob dem Eklektizismus]. Olszanica 2005, 50-63, hier 60. Kopien sämtlicher erhaltener Transportlisten sind darüber hinaus im Stationsgebäude ausgelegt, das restauriert und zu einem Ausstellungsraum ausgebaut wurde. In diesem wurden bislang Wechselausstellungen zur Geschichte des Ghettos gezeigt. 2010 war die Schaffung einer multimedialen Dauerausstellung in dem Gebäude für die Zukunft geplant, die umfangreicher als die minimalistische Schau im Tunnel die Geschichte des Ortes und des Ghettos Litzmannstadt illustrieren soll. Gespräch mit Anna Kulazińska, Leiterin der Abteilung Station Radegast, am 10. März 2010. 


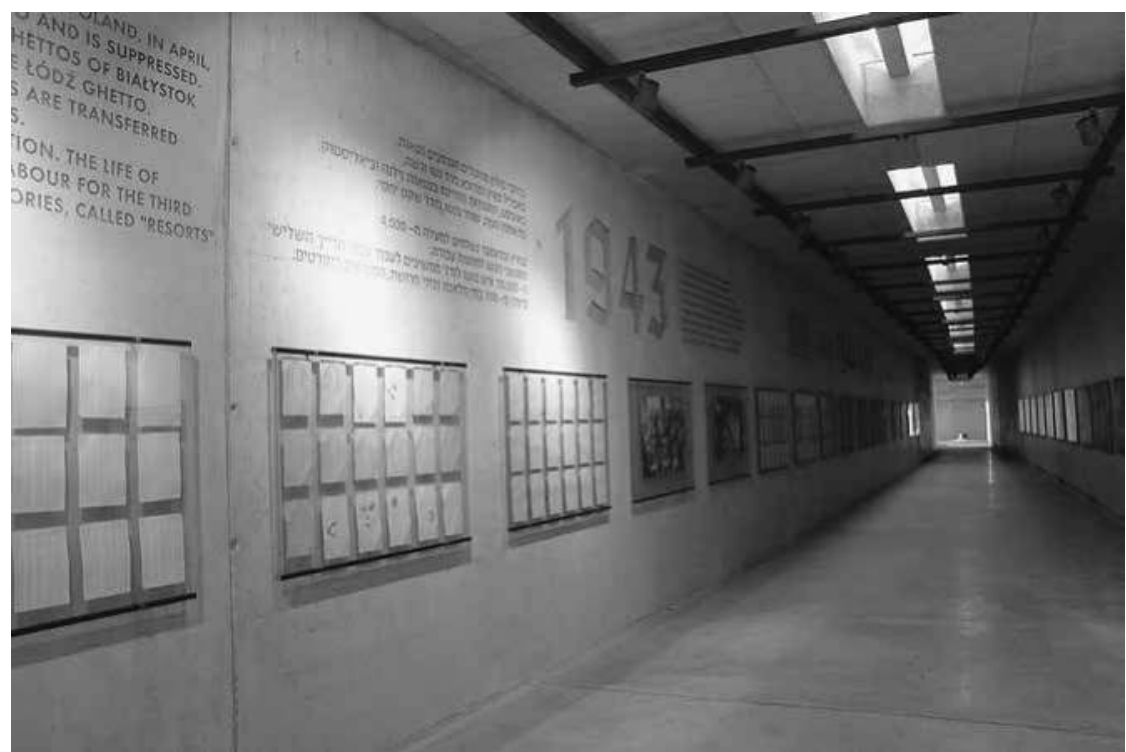

Abb. 27: Station Radegast, die Ausstellung im »Tunnel der Deportierten«.

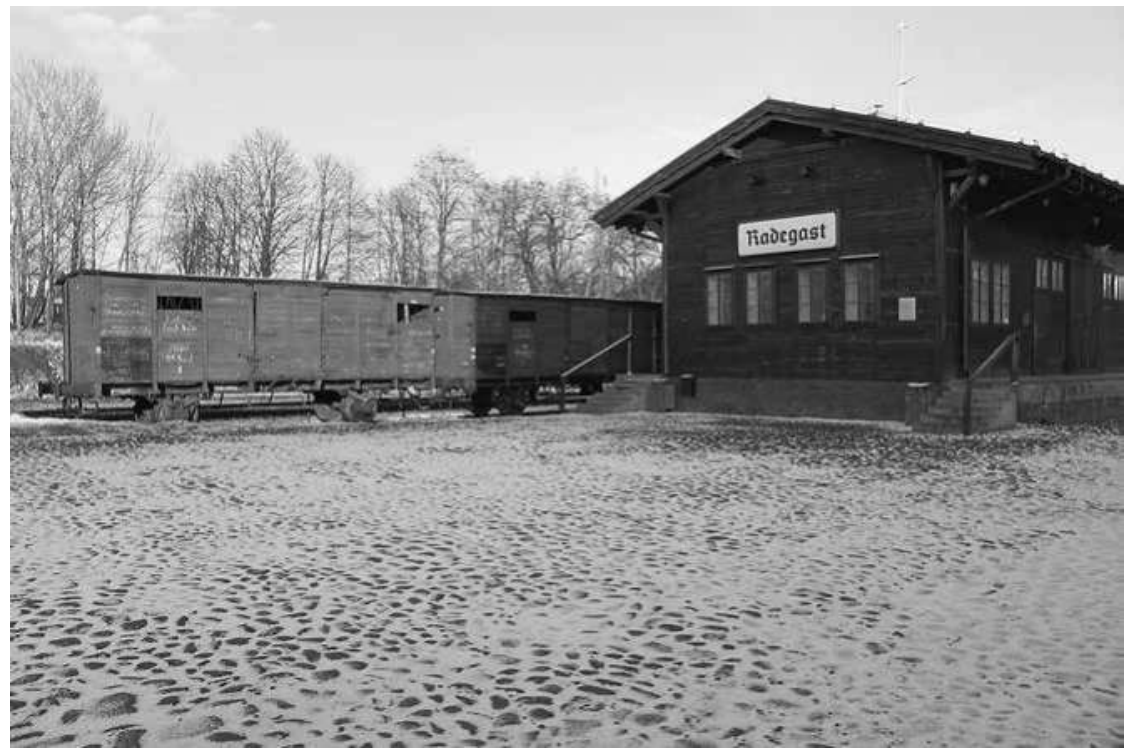

Abb. 28: Station Radegast, das erhaltene Stationsgebäude. 
des Denkmals Czesław Bielecki begreift sie auch als symbolische Massengräber (siehe Abb. 29). Die Bahngleise enden auf der anderen Seite im Tunnel der Deportierten. Dieser wiederum mündet in eine Halle, in deren Mitte ein Grablicht, eine ewige Flamme, aufgestellt ist und auf deren Wänden die Namen der Orte stehen, aus denen Menschen in das Ghetto deportiert worden sind (daher der Name »Halle der Städte« / Hall Miast). Die Halle bildet das Podest eines hohen, nach oben offenen Turms, der wie ein Schornstein wirkt und daher bei vielen Besuchern die Assoziation mit einem Krematorium hervorruft - was auch vom Architekten durchaus beabsichtigt wurde (siehe Abb. 30). Die Museumsmitarbeiter sehen dieses Objekt kritisch, da es zweideutig ist und viele Besucher von dem Turm fälschlicherweise darauf schließen, im Ghetto Litzmannstadt habe es ein Krematorium gegeben. Der Turm hat die Form einer abgebrochenen Säule - ein Symbol, das sich auch auf jüdischen Grabmalen wiederfindet und für einen frühzeitigen und unerwarteten Tod steht. Er fungiert damit als Symbol des Gedenkens an die Toten, woher auch seine Bezeichnung als »Säule der Erinnerung “ (Kolumna Pamięci) rührt. Die Botschaft der Anlage, gleichsam die Lehre der historischen Ereignisse, derer mit ihr gedacht wird, ist in dem biblischen Gebot »Du sollst nicht töten « zusammengefasst, das über dem Eingang bzw. Ausgang der Halle der Städte angebracht ist. ${ }^{365}$

Die Ausstellung im Tunnel der Deportierten wie auch die übrigen Elemente des Areals fokussieren auf zwei Akteursperspektiven: Im Zentrum stehen die Opfer der NS-Vernichtungspolitik, also die jüdischen Ghettoinsassen, deren Perspektive die Besucher im Laufe ihres Rundgangs einnehmen und mit denen sie sich identifizieren sollen. ${ }^{366}$ Als weitere Akteure tauchen mit den deutschen Besatzern die Täter auf. Dies geschieht nicht allein über den kurzen historischen Abriss im Tunnel der Deportierten und die wenigen dort untergebrachten Fotografien, sondern auch durch die Architektur und die gestalterischen Elemente der Anlage: So sind die übergroßen Jahreszahlen 1939 bis 1945, die an der Außen- und Innenwand des Tunnels angebracht sind, in gebrochener Schrift gestaltet, den, wie der Architekt schreibt, »von den Deutschen bevorzugten Schwabacher Lettern «. ${ }^{367}$ Diese Type fungiert - und das nicht allein in Polen - als Chiffre insbesondere für das nationalsozialistische Deutschland. Ebenso ist der Name auf dem Bahnhofsgebäude und in der

365 Bielecki: Radegast; Stacja Radegast - Pomnik zagłady łódzkiego getta [Station Radegast - Denkmal der Vernichtung des Łódźer Ghettos]. In: Dom i Miasto. Stacja Radegast [Haus und Stadt. Die Station Radegast], URL: http://dim.com.pl/index.php?option=com content\&view=article\&id=85\&Itemid= 95\&lang=pl (am 5.5.2011); Gespräch mit Agnieszka Marchewa, einer Mitarbeiterin der Abteilung Station Radegast, am 10. März 2010.

366 Bielecki: Radegast, 52, 56, 59; Kompleks pomników upamiętniających Litzmannstadt Getto w Łodzi [Der Denkmalkomplex zur Erinnerung an das Ghetto Litzmannstadt in Łódź]. In: Andrzejewska-Psarska: Upamiętnienie Żydów Łódzkich, 44-47, hier 45.

367 Bielecki: Radegast, 63. 


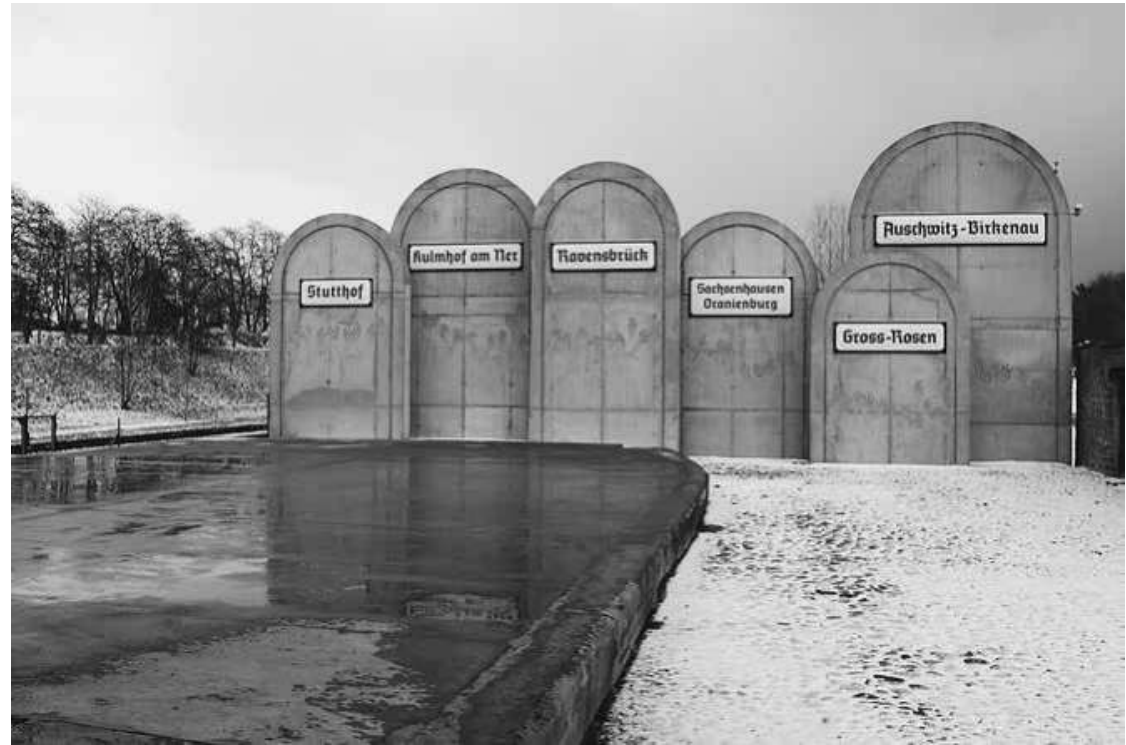

Abb. 29: Station Radegast, symbolische Grabsteine am Ende des Bahnsteigs.

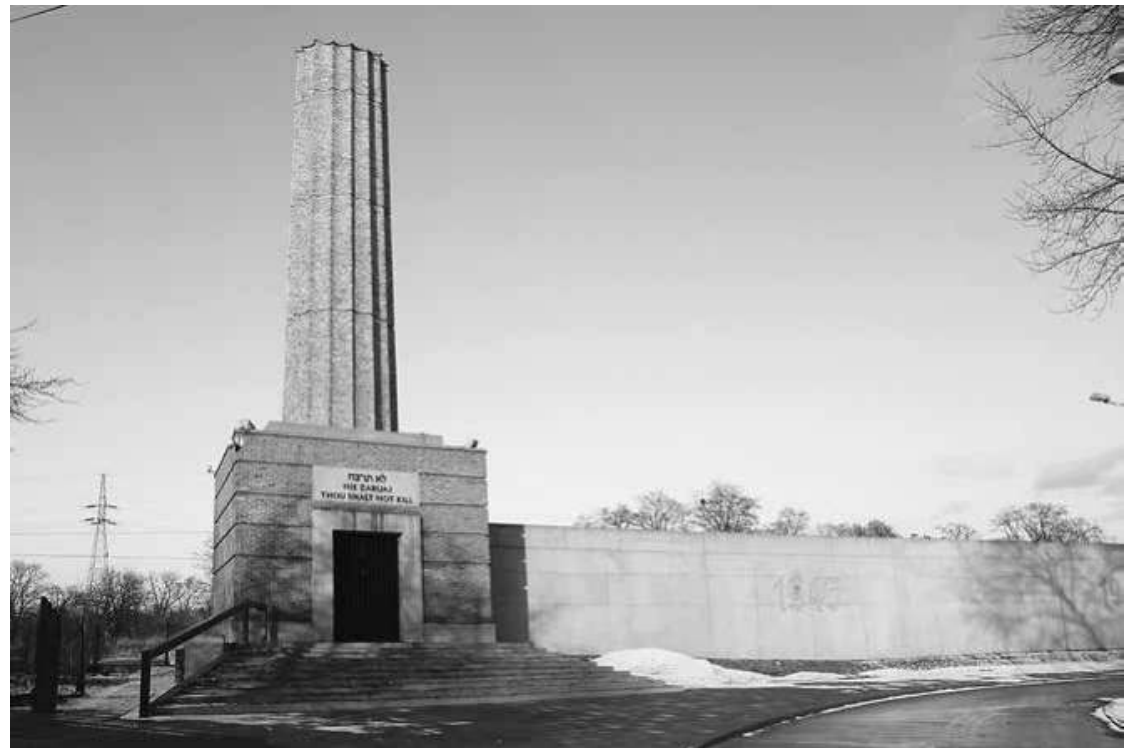

Abb. 30: Station Radegast, die »Halle der Städte« mit der »Säule der Erinnerung«. 
offiziellen Bezeichnung des Denkmalkomplexes auf Deutsch geschrieben "Station Radegast « - womit die Verantwortung für das Leiden und den Massenmord unterstrichen wird. ${ }^{368}$ Auch die Strenge und Rohheit der Materialien des Tunnels der Deportierten können als Verweis auf die Brutalität und Mitleidlosigkeit der deutschen Besatzer gelesen werden. ${ }^{369}$

Eine dritte Perspektive oder Rolle ist in diesem Denkmalkomplex jedoch abwesend: Die polnische Bevölkerung der Stadt, also der Großteil der nichtdeutschen Einwohner, die außerhalb des Ghettos lebten, werden museal und architektonisch nicht thematisiert. Unerwähnt bleiben Elemente aus dem Alltag dieser Bevölkerungsgruppe oder ihre Wahrnehmung des riesigen Ghettos innerhalb der Stadt. Der Gedenkkomplex und seine Ausstellung schaffen somit weder inhaltlich noch symbolisch einen Bezug zur Stadt Łódź bzw. Litzmannstadt während der Besatzung. Vielmehr handelt es sich um ein Mahnmal, das auf die Stätten des organisierten Massenmords verweist - gerade in der Ausstellung im Tunnel werden in erster Linie die diversen Transport- und Deportationswellen aufgezählt -, nicht aber auf die Ereignisse und das Leiden vor Ort, innerhalb des Ghettos. ${ }^{370}$ Der inhaltliche Bezug zur Stadt und ihrer Geschichte während des Kriegs und der Besatzung ist somit weitgehend ausgespart - betont wird die »Isolation « »vom Rest der Stadt «. ${ }^{371}$

Dieser Umstand ist gerade deshalb bemerkenswert, da die Rolle der polnischen Einwohner als Zeugen des Verbrechens von offiziellen Vertretern der Stadt zum Hauptgrund für die Notwendigkeit des Gedenkens erklärt wurde. Insbesondere Jerzy Kropiwnicki, der sich als treibenden Kraft für die Realisierung eines Gedenkortes an der Station Radegast einsetzte, ${ }^{372}$ stellte den

368 Vgl. auch: Memoriał Radegast [Die Gedenkstätte Radegast], URL: www.ghetto.lodz.pl/ index.php/pl/miejsca-pamieci/stacja-radegast (am 30.12.2010).

369 So hat sie insbesondere Bielecki interpretiert: »Die Materialien des Denkmals sind primitiv, roh, brutal: Beton, Abbruchziegel, korrodierter Profilstahl. Die gesamte Installation soll das Ausmaß und das Handwerk der Vernichtung zeigen. Es soll daran erinnern, wie wenig es braucht, um zehntausende Menschen umzubringen.« Bielecki: Radegast, 63.

370 Bei der Jahreszahl 1942 wird allgemein geschildert: „Das Ghetto verwandelt sich in ein riesiges Arbeitslager.» Bei der Jahreszahl 1945 werden zusammenfassend die Todesursachen der Inhaftierten genannt: »Einige wurden brutal ermordet, der Großteil ist verhungert oder durch Krankheiten umgekommen.« MTNŁ-Station Radegast, Tunnel der Deportierten.

371 Bei der Schilderung der Schaffung des Ghettos 1940 wird abschließend festgestellt: »Über 160.000 Juden werden gefangen gesetzt und vom Rest der Stadt isoliert.« MTNŁStation Radegast, Tunnel der Deportierten, Text zur Jahreszahl 1940.

372 Bemühungen zur Umwandlung des Stationsgeländes in einen Ort der Erinnerung an das Ghetto gab es bereits zuvor vonseiten privater Initiativen. Die Realisierung dieser Pläne ermöglichte jedoch erst das Engagement Kropiwnickis. Die Entwicklungen, die zu diesem Engagement führten, beschreiben Jean-Yves Potel und Joanna Podolska: Potel, Jean-Yves: Dworzec. Stacja Łódź-Radegast - Graffiti - Świadkowie likwidacji getta [Der Bahnhof. Die Station Łódź-Radegast - Graffities - Die Zeugen der Liquidierung des 
Aspekt der polnischen Zeugenschaft in den Mittelpunkt seiner Argumentation für die Feierlichkeiten:

Ich bin unveränderlich der Meinung, dass die polnischen Einwohner Łódźs, die von der hitleristischen Todesmaschinerie schließlich auch nicht umgangen wurden, das Recht und die moralische Pflicht haben, der Welt die Tatsache der Vernichtung eines Drittels des lebenden Gewebes dieser Stadt in Erinnerung zu rufen. [...] Daran muss man erinnern: sich bewusst machen, wer der Täter, wer das Opfer und wer der Zeuge des Verbrechens war. [...] Der Zeuge [...] steht vor einer moralischen Herausforderung. Wenn es darum geht, mit dem Verbrechen abzurechnen, können wir nicht mit dem Henker zusammen schweigen; wir müssen zusammen mit dem Opfer schreien. Schweigen ist in einem solchen Moment moralisch nicht akzeptabel. Ich bin zu dem Schluss gekommen, dass der sechzigste Jahrestag der Vernichtung der jüdischen Gemeinschaft in Łódź unserem kollektiven Bewusstsein das Gefühl der Besonderheit dieses Ereignisses aus der schlimmen Geschichte des 20. Jahrhunderts zurückbringen sollte. ${ }^{373}$

Der von Kropwinicki geprägte Ausdruck »Mit den Opfern schreien« wurde zum inoffiziellen Motto der Gedenkfeiern 2004. ${ }^{374}$ Auffällig ist jedoch, dass die Argumentation des Stadtpräsidenten vollständig auf die Gegenwart bezogen war. Es ging ihm darum, sich heute, in der Gegenwart, zu den Opfern zu bekennen, sie als Teil der Geschichte der Stadt und als ehemalige Mitbürger zu ehren und die Erinnerung an sie im kollektiven Gedächtnis zu verankern. Er ging dagegen in keiner seiner medialen Äußerungen auf die Vergangenheit, auf die Rolle und die Haltung der damaligen Zeugen der Vernichtung ein. Die eindeutigen Rollenzuschreibungen, die Kropiwnicki nannte, spiegeln sich im Gedenkkomplex der Station Radegast wider: Juden waren die Opfer, Deutsche die Täter; die heutige Generation der nachgeborenen Zeugen erinnert mit dem Gedenkort öffentlich an das Verbrechen und ehrt diejenigen, die ihm zum Opfer gefallen sind - sie »schreit mit den Opfern « ${ }^{375}$

Ghettos]. In: Ders.: Koniec Niewinności, 143-158, hier 145-152; Podolska: The Memory of the Lodz Ghetto, 106-108.

373 Kropiwnicki: Rola świadka - rzecz o obchodach 60. rocznicy, $8 \mathrm{f}$.

374 Das Motiv wurde auch in den folgenden Jahren anlässlich der Gedenkfeiern zum Jahrestag der Liquidierung des Ghettos immer wieder von ihm verwendet, u. a. 2009: Obchody 65. Rocznicy likwidacji łódzkiego getta: »Musimy krzyczeć głośno« [Die Gedenkfeiern zum 65. Jahrestag der Liquidierung des Ghettos von Łódź: „Wir müssen laut schreien«]. In: Gazeta Wyborcza vom 27.8.2009, Online-Ausgabe, URL: www.wiadomosci.gazeta. pl/Wiadomosci/2029020,80291,6970988.html?sms_code $=($ am 30.12.2010 $)$.

375 An den Mauern, die das Gelände der Gedenkstätte einzäunen, brachte man mehrere Gedenkplaketten und -tafeln an, die das Gedenken der Stadt Łódź, aber auch der Herkunftsstädte der Deportierten dokumentieren: Eine Tafel erinnert an die Einweihung des Areals 2004; eine andere dokumentiert das »ehrende Gedenken« der Stadt Łódź an seine früheren Bewohner; weitere gedenken der in das Ghetto deportierten Juden aus Berlin, Luxemburg und Wien sowie der aus Österreich deportierten Roma und Sinti. MTNŁ-Station Radegast. 
Das Thema der zeitgenössischen Zeugen und ihrer Haltungen zum Verbrechen wird erst im zweiten Gedenkkomplex aufgegriffen, der ebenfalls zum Jahrestag 2004 initiiert wurde - dem »Park der Überlebenden" (Park Ocalatych). ${ }^{376}$ Überlebende des Ghettos Litzmannstadt, die seit $2004 \mathrm{zu}$ Gedenkfeiern angereist sind, haben darin Bäume gepflanzt, als »Symbol des Sieges des Lebens über den Tod « ${ }^{377}$ und als Sinnbild der Unsterblichkeit der Erinnerung an die Opfer des Ghettos und an die Überlebenden. ${ }^{378}$ Darin sind zwei 2009 eingeweihte Denkmale eingeschlossen: Auf dem »Hügel der Erinnerung" (Kopiec Pamięci) steht eine Bank mit einer Skulptur von Jan Karski; am anderen Ende des Parks befindet sich das monumentale »Denkmal der Polen, die von 1939 bis 1945 Juden retteten« (Pomnik Polaków Ratujacych Żydów 1939-1945). Es besteht aus Wänden mit den Namen aller Polen, die mit der Medaille der »Gerechten unter den Völkern« ausgezeichnet wurden, angeordnet in Form eines Davidsterns. ${ }^{379}$ Diese beiden Bauwerke dominieren das Parkgelände, da sie buchstäblich aus ihm herausragen. Daneben wurde ebenfalls 2009 ein weiteres, kleines Denkmal zur Erinnerung an die Organisation Żegota aufgestellt. ${ }^{380}$

376 Die Idee zu diesem Ensemble stammte von einer Überlebenden des Ghettos, Halina Elczewska. Sie wurde von Kropiwnicki aufgegriffen und um die Denkmale zu Ehren von Jan Karski und die polnischen »Gerechten unter den Völkern« ergänzt. Der Park mit einer Fläche von 8,5 Hektar, der an der Grenze des ehemaligen Ghettogeländes liegt, wurde 2004 eröffnet. Podolska, Joanna/ Gnacikowska, Wioletta: Park Ocalałych powstał wczoraj w Łodzi. In: Gazeta Wyborcza vom 30.8.2004, zitiert nach URL: www.ghetto. lodz.pl/index.php/pl/napisali-o-nas/2004/192-park-ocalalych-powstal-wczoraj-w-lodzi (am 30.12.2010).

377 Ebd.

378 Vgl. Park Symbol [Der Park als Symbol], URL: www.ghetto.lodz.pl/index.php/pl/parkocalalych/historia (am 30.2.2010). Vorbild dieser Idee ist die »Allee der Gerechten« in Yad Vashem. Siehe: Park Ocalałych. In: Romanowski, Gustaw/Strakowski, Marek/Sidor, Mateusz (Hg.): Żeby ten krzyk nie przeminął. Materiały z Obchodów 60. Rocznicy Zagłady Litzmannstadt Ghetto, 1944-2004 [Damit dieser Schrei nicht verhallt. Materialien der Gedenkfeiern zum 60. Jahrestag der Vernichtung des Ghettos Litzmannstadt, 1944-2004]. Łódź 2005, 133 f., hier 133. Die Ausführungen zu den Elementen und der Gestaltung des Geländes basieren auf dem Besuch der Verfasserin am 10. März 2010.

379 An der offenen Seite des Denkmals befindet sich eine Stele mit einem Adler darauf, dem Symbol des polnischen Staates. An der Stele sind zwei Zitate angebracht: aus dem Talmud der Satz »Wer ein Leben rettet, rettet die ganze Welt« und aus dem Neuen Testament "Liebe deinen Nächsten wie dich selbst.« Das Denkmal hebt mittels der Verbindung jüdischer und christlicher sowie polnisch-nationaler Symbolik somit auch die Gemeinsamkeit der Erinnerung und des Schicksals beider Völker hervor. Beide Denkmale wurden 2009 eingeweiht; geplant waren sie jedoch von Anfang an. So wurde der Grundstein für das Denkmal der polnischen »Gerechten« bereits 2003 gesetzt. Andrzejewska-Psarska: Upamiętnienie Żydów Łódzkich, unpaginierte S. 5 nach S. 56.

380 Auf dem quaderförmigen Obelisken wird allgemein und ohne Bezug zur Stadt Łódź die Tätigkeit des Hilfsrates für Juden Żegota skizziert, mit dem Verweis auf die Auszeichnung seiner Mitglieder durch Yad Vashem als »Gerechte unter den Völkern«. 
Mit der Ehrung Jan Karskis, der polnischen »Gerechten« sowie der Mitglieder des Hilfsrates für Juden steht in dem Parkareal nicht die Ehrung der Überlebenden und der Toten des Ghettos im Vordergrund, sondern in erster Linie die positive Rolle von Polen als Helfer und Retter. Die schwierige Frage nach den vielfältigen Verhaltensweisen der Zeitgenossen angesichts der Verfolgung jüdischer Mitbürger wird einseitig zugespitzt: Die ambivalente Figur des Zeugen, der passiver Zuschauer, Täter, Kollaborateur oder Helfer der Verfolgten sein konnte, ${ }^{381}$ wird auf eine eindeutig positive moralische Haltung verengt. Stellvertretend für das polnisch-jüdische Verhältnis im Krieg werden die moralisch herausragenden Handlungen der Helfer im Stadtbild verankert. Der Zeuge wird mit dem Retter gleichgesetzt - die Ausnahme damit implizit zur Regel erklärt. ${ }^{382}$ Bemerkenswert ist zudem, dass diese Denkmäler, im Gegensatz zu dem Arrangement der Bäume der Überlebenden, eine nationale, nicht eine lokale Perspektive präsentieren: So werden sämtliche Polen geehrt, die als »Gerechte« ausgezeichnet wurden. Auch der geborene Łódźer Karski, der während der Besatzungszeit selbst keinen Bezug zu seiner Heimatstadt hatte, wird als übergreifendes Symbol für die Versuche des polnischen Untergrunds geehrt, der Welt vom nationalsozialistischen Massenmord zu berichten. Mit der Herausstellung der gegenwärtigen Symbolfiguren des polnischen Holocaust-Diskurses wird somit zugleich die heikle und ambivalente Frage der Vielgestaltigkeit der polnisch-jüdischen Beziehungen während der Besatzung, gerade in Łódź selbst, ausgeklammert. ${ }^{383}$ Auf ähnliche Weise ausgespart wird dieser kritische Themenkomplex auch in der Gedenkstätte Station Radegast mittels des Verweises auf die bekannte Chiffre von der strikten Isolation des Ghettos Litzmannstadt, wie es insbesondere in der integrierten Ausstellung der Fall ist.

\subsection{Zwischenfazit}

Das Ghetto Litzmannstadt war spätestens seit 2003 in den Dauerausstellungen beider stadthistorischer Museen Łódźs deutlich vertreten. Vor dem Hintergrund der Präsentationen anderer in dieser Arbeit untersuchten Museen

381 Vgl. Hilberg, Raul: Täter, Opfer, Zuschauer. Die Vernichtung der Juden 1933-1945. Frankfurt am Main 1999.

382 Leociak, Jacek: Dyskurs o pomocy [Der Diskurs über die Hilfe]. In: Zagłada Żydów 4 (2008), 7-13, hier 13.

383 Wie Jacek Leociak prägnant feststellt: »Die polnische Erinnerung schwelgt im hellen Licht der Gerechten, ohne die dunklen Zeichen der Verbrechen an sich heranzulassen.» Ebd., 12. Gerade angesichts der nur wenigen Belege über Łódźer Helfer wird die Verortung des Denkmals der polnischen Gerechten in dieser Stadt daher auch kritisch gesehen. Siehe etwa Podolska: The Memory of the Lodz Ghetto, $113 \mathrm{f}$. 
ist insbesondere das frühe Interesse an der Geschichte der jüdischen Einwohner im Stadtmuseum bemerkenswert: Bereits seit 1998 stellte man Juden in der historischen Dauerausstellung gleichberechtigt neben Polen (und den deutschen Łódźern) als Teil der städtischen Vergangenheit dar und propagierte damit offensiv das historische Bild eines multikulturellen und multiethnischen Łódź $^{384}$ Sogar schon früher, seit 1989, spielt das Museum mit seinen vielfältigen Sonderausstellungen eine zentrale Rolle bei der Wiederentdeckung der jüdischen Vergangenheit der Stadt, auch in der Zeit der Besatzung. Im Gegensatz dazu hat das Museum Radogoszcz erst in Reaktion auf die deutliche Hinwendung zur jüdischen Geschichte in der städtischen Erinnerungskultur und Geschichtspolitik Anfang der 2000er-Jahre dem Ghetto Litzmannstadt in seiner Dauerausstellung etwas mehr Platz eingeräumt.

Die Bedeutung, die dem Schicksal der Juden innerhalb der Besatzungsgeschichte zugeschrieben wurde, unterscheidet sich folglich in beiden Institutionen grundlegend: Während im Stadtmuseum Juden als eine der größten Bevölkerungsgruppen prominent innerhalb der musealen Erzählung in Erscheinung traten, blieben das Ghetto und seine Bewohner im Museum Radogoszcz randständige Themen. Hintergrund dieser Darstellungspraxis ist das den Schauen zugrundeliegende diametral unterschiedliche Verständnis der städtischen Wir-Gemeinschaft, die sie jeweils konstruierten: Im staatsbürgerlichen Konzept des MMŁ war die jüdische Bevölkerung gleichberechtigter Protagonist neben der polnischen - und für den Zeitraum vor 1939 auch der deutschen. Der Präsentation im Museum Radogoszcz lag und liegt dagegen ein exklusives ethnisches Nationsverständnis zugrunde, in dem allein die polnischen Łódźer im Zentrum der Aufmerksamkeit stehen. Eine wesentliche Gemeinsamkeit kennzeichnete dennoch die Darstellungen beider Museen: Die Besatzungserfahrungen von Polen und der als Juden Verfolgten wurden jeweils nebeneinander und ohne Bezug zueinander geschildert. Das schwierige Thema der polnisch-jüdischen Beziehungen und gegenseitigen Wahrnehmungen blieb unerwähnt.

Diese Leerstelle wurde auch in den städtischen Gedenkinitiativen seit 2003 und den seither entstandenen memorialen Projekten nicht gefüllt. Zwar gelang es mithilfe verschiedener Initiativen und Veranstaltungen seit 2003, die Erinnerung an das Ghetto in der Stadttopografie sowie zunehmend im Bewusstsein der Bewohner zu verankern. ${ }^{385}$ Durch diese Initiativen konnte auch

384 Die russische Minderheit der Stadt wird in den Teilen der Ausstellung, die den Zeitraum vor 1939 betrachten, ebenfalls geschildert und damit Bezug genommen auf den Topos vom »Łódź der vier Kulturen«. Vgl. Laurentowicz/Budziarek: Triada, 10-12, bes. 11.

385 Michlic: Łódź in the Post-Communist Era, 15; Podolska: The Memory of the Lodz Ghetto, 105 f., 113. 
das negative Image Łódźs als einer der antisemitischsten Städte Polens bekämpft werden. ${ }^{386}$ In Bezug auf das polnisch-jüdische Verhältnis ist jedoch ein einseitiger Fokus auf die polnischen "Gerechten unter den Völkern" gesetzt, die quasi stellvertretend für die moralische Haltung der (heutigen) polnischen Łódźer stehen. Kritische und ambivalente Aspekte der jüngsten Vergangenheit, die die eindeutigen historischen Rollenzuschreibungen gerade für die Besatzungszeit diversifizieren könnten, werden sowohl in den Ausstellungen als auch in den Memorialkomplexen ausgeblendet - angesichts neuer Forschungsergebnisse und zugänglichen Quellenmaterials kann man sogar sagen: tabuisiert. Joanna Michlic und Małgorzata Melchior folgend sind die Łódźer Gedenkorte, gerade der »Park der Überlebenden" mit seinen Denkmälern, Beispiele für die Schwierigkeiten eines Teils des sich im Zuge der Jedwabne-Kontroverse herauskristallisierenden »Selbstverteidigungslagers«, die neuen Erkenntnisse mit dem emotional behafteten Selbstbild der Helden und Märtyrer in Einklang zu bringen:

Even among the adherents of a mild approach, who accepted parts of Gross's proposition about the direct participation of Poles in the Jedwabne massacre and recognized the Holocaust as an event in its own right, there was apparent discomfort with integrating the dark past as a part of Polish national history and identity. They still found it hard to accept the image of Poles also as villains, and instead preferred to turn to narratives of Polish solidarity with its Jewish citizens during the Holocaust or to the more general positive representations of Poles in World War II. ${ }^{387}$

Die einseitige Hervorhebung der polnischen "Gerechten unter den Völkern", wie sie im Park der Überlebenden stattfindet - unter vollständiger Ausblendung anderer Haltungen, etwa der während des Kriegs überwiegenden Gleichgültigkeit und Passivität der Polen dem Schicksal ihrer jüdischen Nachbarn gegenüber -, kann damit als eine Ausprägung des Konzepts eines »affir-

386 Dieses Negativimage der Stadt im In- und Ausland, das als nachteilig für die Stadtentwicklung und gerade den Tourismus angesehen wurde, war ein nicht unwesentlicher Grund für die Initiative der Stadtregierung zur Herausstellung des Jahrestages 2004. Lupiński, Piotr: Krzyczeć z ofiarą. Rozmowa z Jerzem Kropiwnickim [Mit dem Opfer schreien. Ein Gespräch mit Jerzy Kropiwnicki]. In: Gazeta Wyborcza vom 24.4.2004, zitiert nach URL: www.ghetto.lodz.pl/index.php/pl/napisali-o-nas/2004/86-krzycze-z-ofiarrozmowa-z-jerzym-kropiwnickim (am 30.12.2010). Siehe auch Romanowski/Strakowski: Miejsca wymagają pamięci, 20. Zu dieser Reputation trugen insbesondere die verbreiteten antisemitischen Schmierereien im gesamten Stadtgebiet bei. Potel: Dworzec, 148; Michlic: Łódź in the Post-Communist Era, 16. Letztendlich waren die Bemühungen um die Etablierung eines neuen, positiven Stadtimages als offener, multikultureller und toleranter Stadt damit auch Überlegungen der Stadtentwicklung geschuldet. Potel: Dworzec, 149.

387 Michlic/Melchior: The Memory of the Holocaust, 424. 
mativen Patriotismus« gedeutet werden, wie er von den Vertretern der sogenannten neuen Geschichtspolitik propagiert wird. ${ }^{388}$

Die Dauerausstellung des Stadtmuseums sowie die vorgestellten Gedenkinitiativen konstruieren und unterstützen letztlich das seit Mitte der 1990erJahre aufgebaute Geschichtsbild von Łódź als der "Stadt der vier Kulturen", in der den jüdischen Stadtbewohnern und dem Ghetto in der Besatzungsgeschichte eine wesentliche Bedeutung zugewiesen wird. Ein kritisches Hinterfragen der beschworenen Łódźer Koexistenz verschiedener Religionen und Ethnien, gerade in Bezug auf die Zeit der deutschen Okkupation, ist dabei nicht Teil dieses romantisierten Mythos; weder im MMŁ noch in den Gedenkkomplexen finden sich hierzu Ansätze. Eine ständige Präsentation städtischer Geschichte, die noch einen Schritt weitergeht und sich auch der ambivalenten und kritischen Aspekte der Kriegs- und Besatzungszeit annimmt, entstand schließlich über zehn Jahre nach der Schau des MMŁ in Krakau, wie im Folgenden geschildert wird.

\section{Eine integrative Stadtgeschichte - Die »Emaillewarenfabrik Oskar Schindlers»}

Wie in den vorangegangenen Analysen bereits deutlich geworden ist, gehören die polnisch-jüdischen Kontakte und gegenseitigen Wahrnehmungen nach wie vor zu den schwierigsten Themen der (nicht nur) musealen Aufbereitung der Besatzungszeit. Die Tatsache, dass die Ausgrenzung, Entrechtung, Ghettoisierung und schließlich der Abtransport der jüdischen Einwohner in Konzentrations- und Vernichtungslager vor den Augen der polnischen Bevölkerung geschah, Polen also ungewollt zu Augenzeugen der ersten Phase des Holocaust ${ }^{389}$ wurden, ist in der Erinnerungskultur des Landes bis heute ein heikles Thema. Bei diesem schwingt die ethisch konnotierte Frage mit, wie die Bewohner der sogenannten arischen Seite auf die Verfolgung ihrer jüdischen Mitbürger reagierten, ob sie zu Hilfsleistungen bereit waren, die Verfolgung gar unterstützten oder zu ihrem eigenen Vorteil ausnutzten. Wie bereits geschildert, wurde diesem Komplex - und dem in seinem Zusammenhang auftauchenden impliziten Vorwurf eines verbreiteten polnischen Antisemitismus - jahrzehntelang mit der einseitig positiven Hervorhebung pol-

388 Wolff-Powęska: Polskie spory o historię i pamięć, 24-33; Nijakowski: Polska polityka pamięci, 201-204.

389 Marszałek, Magdalena: Holocaust. Die Tragödie der Nachbarn. In: Hahn, Hans Henning/ Traba, Robert (Hg.): Deutsch-Polnische Erinnerungsorte. Bd. 2: Geteilt/Gemeinsam. Paderborn 2014, 641-660, hier 641. 
nischer Hilfe für verfolgte Juden begegnet. ${ }^{390}$ Heute stehen die tradierten Geschichtsbilder der Besatzungszeit, die wesentlich mit moralischen Konnotationen operieren, vor der Herausforderung, das sich durch neue Forschungen herauskristallisierende Bild einer weitgehend gleichgültigen polnischen Bevölkerung mit dem vertrauten Bild der Helden und Märtyrer zu vereinen bzw. letzteres zu revidieren. Wie in Kapitel 2 gezeigt, dominiert jedoch in den Anfang des neuen Jahrhunderts eröffneten Ausstellungen weiterhin eine ausschließlich positive Schilderung der Verhaltensweisen von Polen gegenüber verfolgten Juden. Diese ist verbunden mit einer weitgehenden Marginalisierung der Judenverfolgung in den musealen Narrativen, die in der Wahrnehmung von Juden als »Fremde« in einer ethnisch-polnisch definierten Stadt- und Landesgeschichte begründet ist.

Auch wenn diese Geschichtsperspektive im polnischen historischen $\mathrm{Mu}-$ seumswesen nach wie vor dominiert, so gibt es doch erste Beispiele neuer Geschichtsentwürfe, die das Spektrum dessen erweitern, was als »eigene« lokale, regionale und letztendlich auch nationale Geschichte gewertet wird. Die erste Institution innerhalb des Untersuchungszeitraumes dieser Studie, die einen solchen Perspektivwechsel vornahm, war das Stadtmuseum Łódź, das in seiner 1998 eröffneten historischen Dauerausstellung die polnischen, jüdischen und deutschen Łódźer als konstitutive Elemente der Stadtgeschichte in den Fokus stellte und damit eine multiethnische Konzeption dieser Vergangenheit etablierte. Wie gezeigt wurde, setzte jedoch auch diese Ausstellung in Bezug auf die Jahre 1939 bis 1945 zum Teil etablierte Interpretationsmuster fort. Eine grundsätzliche Neukonzeption städtischer Besatzungsgeschichte unternahm erst die 2010 eröffnete neue Dauerausstellung des Historischen Museums der Stadt Krakau in der ehemaligen Emaillewarenfabrik Oskar Schindlers. Ihr Alleinstellungsmerkmal innerhalb der polnischen Museumslandschaft liegt bis heute darin begründet, dass in ihr die Erfahrungen von Polen und Juden miteinander verflochten und immer wieder in Bezug zueinander geschildert werden. Insbesondere die gegenseitigen Wahrnehmungen und Kontakte der polnischen und jüdischen Bevölkerung werden differenziert im Verlauf der gesamten Schau thematisiert. Damit ist diese Präsentation auch die erste der untersuchten - und höchstwahrscheinlich die erste in Polen überhaupt -, die den Aspekt der polnischen Augenzeugenschaft des Holocaust aufgreift und die Ambivalenz und Vielgestaltigkeit dessen illustriert, was der Begriff der »(Augen-)Zeugenschaft« im Alltag umfasste.

390 Szurek, Jean-Charles: Między historią a pamięcią: polski świadek Zagłady [Zwischen Geschichte und Erinnerung: Der polnische Zeuge des Holocaust]. In: Engelking, Barbara, u. a. (Hg.): Zagłada Żydów. Pamięć narodowa a pisanie historii w Polsce i we Francji [Die Vernichtung der Juden. Nationale Erinnerung und Geschichtsschreibung in Polen und Frankreich]. Lublin 2006, 174-184, hier 175; Leociak: Zraniona pamięć, 268 f. 


\subsection{Die neue Wir-Gemeinschaft der Krakauer}

Die erste Besonderheit, die beim Betreten der Dauerausstellung in der Schindler-Fabrik ${ }^{391}$ auffällt, ist die für polnische historische Ausstellungen immer noch ungewöhnliche Konzeption der Wir-Gemeinschaft, die im Zentrum der Erzählung steht: Nicht allein Polen, sondern auch Juden werden als integraler Bestandteil der Bevölkerung Krakaus und somit der Protagonisten der musealen Narration eingeführt. So begegnet den Besuchern bereits an den Wänden im ersten Raum der Schau, einem inszenierten Fotoatelier der Zwischenkriegszeit, das Bild eines kleinen Jungen mit Schläfenlocken neben dem Porträt eines Paares in polnischer Volkstracht. ${ }^{392}$ Vom Schicksal der jüdischen Einwohner erfährt man nicht mehr, wie noch in den Vorgängerausstellungen des Museums, aus einer externen, polnischen Perspektive, sondern die Besucher verfolgen die Ereignisse von Beginn an aus dem Blickwinkel sowohl der polnischen als auch der jüdischen Krakauer. Die Schilderung der Entwicklungen geschieht dabei meist übergreifend und nicht auf eine Ethnie beschränkt. So werden etwa bei der Darstellung der Beschränkungen, die nach dem Einmarsch der Deutschen den Alltag der Stadtbewohner prägten, die spezifischen Situationen aller Bevölkerungsgruppen in der Stadt geschildert, wobei gerade die Unterschiede in ihrer Behandlung deutlich benannt werden. ${ }^{393}$ Auch die Ziele und Motive der Besatzer für die repressiven Maßnahmen gegen die jüdische Bevölkerung werden klar angesprochen:

Vom ersten Tag der Besatzung an wandten die deutschen Behörden immer restriktivere Verfügungen gegenüber der jüdischen Bevölkerung des GG [Generalgouvernement] an. Der nazistischen Ideologie entsprechend, zielten sie auf die Ausgrenzung der Juden (Anordnung zur Kennzeichnung von Läden und Firmen sowie des Tragens von Armbinden mit einem Davidstern), ihre ökonomische Ausbeutung und auch ihre sukzessive Herabsetzung in der gesellschaftlichen Hierarchie. ${ }^{394}$

Immer wieder werden zudem die alltäglichen Berührungspunkte der Lebenswelten verschiedener Ethnien illustriert. So an einer Fotowand, die dem Alltag der Jahre 1940 bis 1941 gewidmet ist. Gezeigt werden dort verschiedene Straßenszenen: Die Kutschfahrt eines deutschen Paares auf dem Marktplatz, Ju-

391 Teile der folgenden Analysen wurden publiziert in Heinemann: Die »Emaillewarenfabrik Oskar Schindlers".

392 MHK-Schindler-Fabrik, Sektion 1: Der Fotograf.

393 So z.B. bei der Thematisierung der schwierigen Versorgungslage, etwa der Lebensmittelzuweisungen für »Deutsche, Ukrainer, Polen und Juden. Erstere bekamen die höchsten Zuteilungen, Letztere die geringsten, und manchmal gar keine.« Thementext »Alltag«. MHK-Schindler-Fabrik, Sektion 9: Alltag, 1940-1941.

394 MHK-Schindler-Fabrik, Sektion 5: Öffentlicher Raum I. 
den bei der Zwangsarbeit (an weißen Armbinden erkennbar) sowie Passanten, deren Nationalität nicht ersichtlich ist, unter denen höchstwahrscheinlich auch ethnische Polen sind. Wie die in den Bildunterschriften genannten Straßennamen offenbaren, zeigen die beschriebenen Fotografien allesamt Ereignisse aus der Altstadt, einem relativ kleinen Stadtviertel. ${ }^{395}$ In der nächsten Sektion der Ausstellung, dem »Bahnhof«, sehen die Besucher nebeneinander Abbildungen von Polen, die zur Zwangsarbeit nach Deutschland geschickt werden, Juden, die in den Jahren 1940 bis 1941 aus Krakau in die umliegenden Städte ausgesiedelt werden, sowie deutsche Offiziere, die den Fahrplan studieren. Durch die Illustrierung dieser Begegnungsräume und Verflechtungen der Geschichten der einzelnen Krakauer Bevölkerungsgruppen wird deutlich, dass deren Erfahrungswelten keineswegs hermetisch voneinander getrennt waren, wie dies noch in früheren Ausstellungen auch im MHK suggeriert worden war. ${ }^{396}$ Erst wenn der Ausstellungsrundgang zur Errichtung des Ghettos und seiner Abriegelung durch eine Mauer im Jahr 1941 gelangt, trennen sich die Narrative auch räumlich.

Dennoch verfolgen die Besucher die Entwicklung der historischen Ereignisse weiterhin auch aus den unterschiedlichen Perspektiven beider Bevölkerungsgruppen ${ }^{397}$ Die Ausstellungsmacher möchten damit den Besuchern ermöglichen, sich in die präsentierten Situationen hineinzuversetzen, und ihnen das Gefühl geben, Teilnehmer der historischen Ereignisse zu sein, deren Entwicklung sie durch die Schau hindurch verfolgen. Dies wird in erster Linie durch die Ausstellungsgestaltung erreicht: Ganze Räume und Raumzüge sind so inszeniert, dass sie die Ausstellungsbesucher in imaginierte Orte und Situationen in der Vergangenheit hineinversetzen. Exemplarisch stehen hierfür die dem Ghetto und seiner Liquidierung gewidmeten Sektionen der Schau. Zunächst treten die Besucher scheinbar selbst in den »Judenwohnbezirk « ${ }^{398}$ ein. Die beklemmende Enge des Ganges, in dem sie sich wiederfinden und der zu beiden Seiten von einer nachgebildeten Ghettomauer begrenzt wird, vermittelt den Betrachtern physisch die klaustrophobische Enge dieses abgesperrten Stadtgebiets. Das Gefühl der Ausweglosigkeit der Situation wird noch durch die Dunkelheit in diesem Raum verstärkt sowie durch

395 MHK-Schindler-Fabrik, Sektion 9: Alltag, 1940-1941.

396 Siehe Kapitel 1.

397 So betreten die Besucher im weiteren Verlauf des Rundgangs etwa ein Friseurgeschäft, in dem sie aus den Gesprächen der (polnischen) Kunden von den Ereignissen in der Stadt im Sommer 1944 erfahren, v. a. vom Anschlag auf General Wilhelm Koppe. Im Keller desselben inszenierten Gebäudes treten sie in das enge Versteck von Juden ein, die sich auf der sogenannten arischen Seite verstecken. MHK-Schindler-Fabrik, Sektion 23: Friseur, Sektion 24: Keller.

398 So die Bezeichnung auf einem zu Beginn der Sektion angebrachten originalen Schild. MHK-Schindler-Fabrik, Sektion 14: Ghetto. 


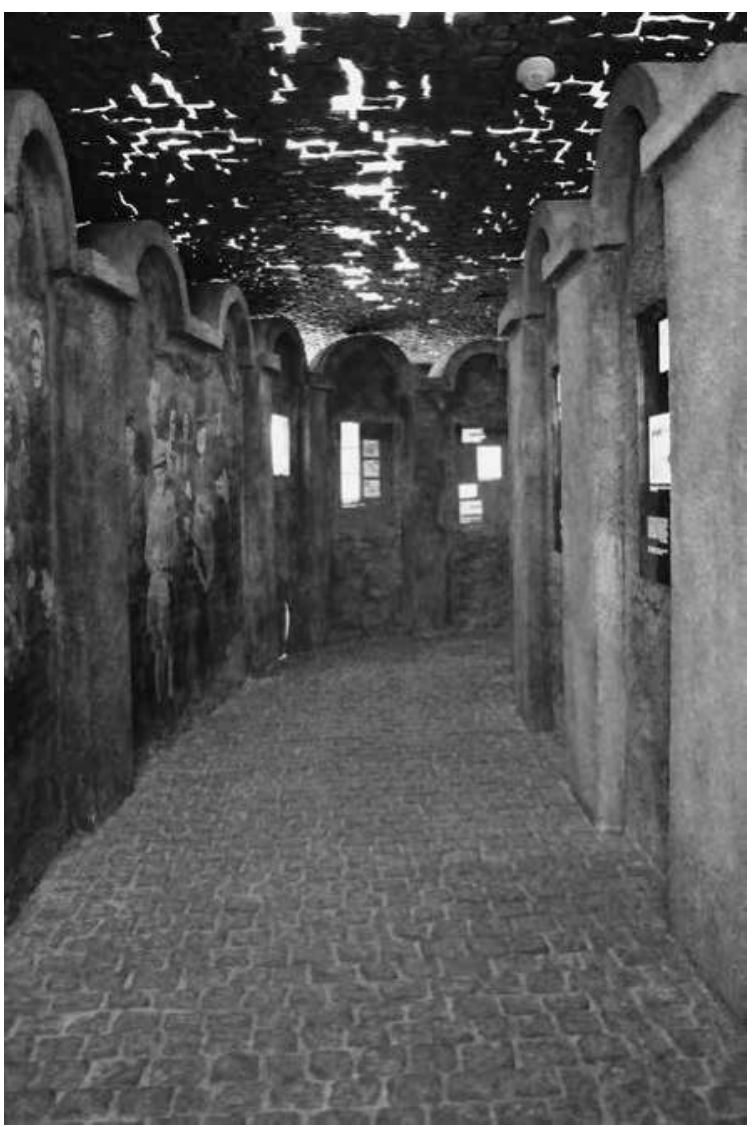

Abb. 31: Schindler-Fabrik, Sektion »Ghetto«.

die Pflastersteine, die nicht nur den Boden bedecken, sondern scheinbar auch die Decke bzw. den Himmel und dadurch das Gefühl hervorrufen, lebendig begraben zu sein (siehe Abb. 31). In eine der Ausstellungswände ist ein Spiegel integriert; unversehens erblicken die Besucher sich selbst zwischen lebensgroßen Fotografien von Ghettobewohnern und sehen sich damit als Teilnehmer der Ereignisse, von denen sie im Laufe des Rundgangs erfahren (siehe Abb. 32). Unvermittelt betreten die Besucher dann überfüllte Wohnräume im Ghetto - sie laufen mitten durch ein mit Möbeln zugestelltes Zimmer, in dem weiße Plastiken an die Menschen erinnern, die in der Enge leben mussten (siehe Abb. 33) -, bevor sie wieder in den engen, dunklen Gang eintreten. Beim Durchschreiten des Zimmers hören sie Gesprächsfetzen von Bewohnern, die sich über Alltagsprobleme wie Lebensmittelpreise unterhalten und Gerüchte austauschen. 


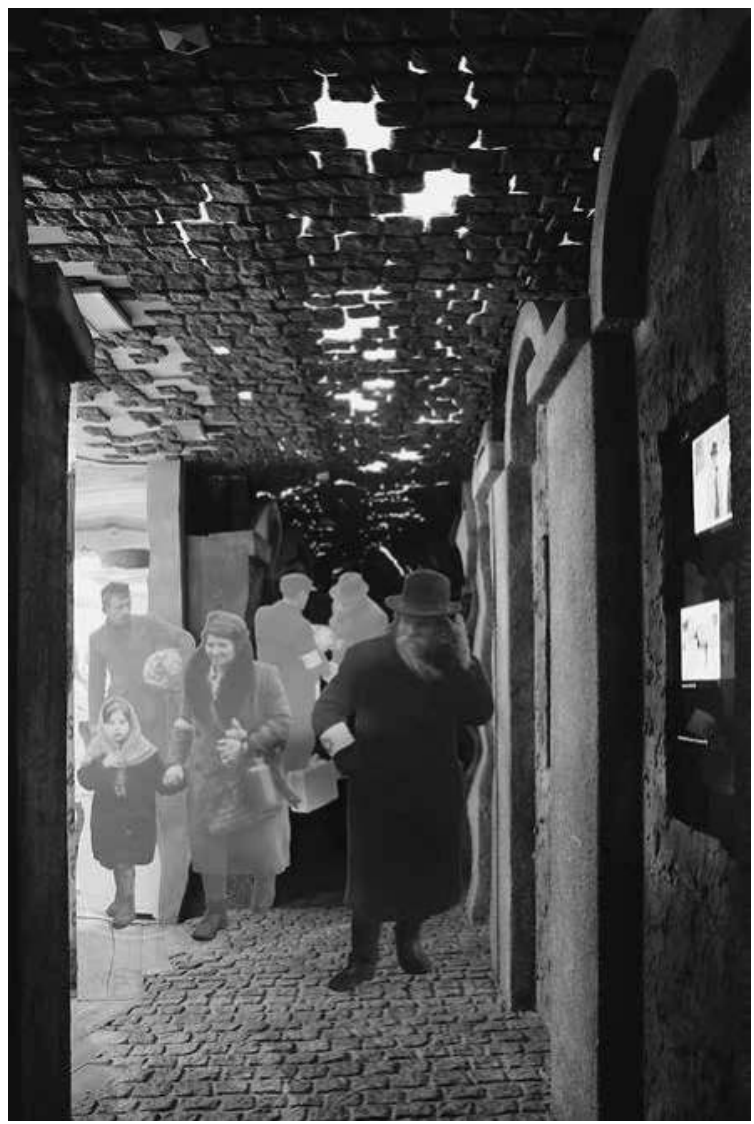

Abb. 32: Schindler-Fabrik, Spiegelwand in der Sektion "Ghetto«.

Die Liquidierung des Ghettos zwei Jahre später wird in einem ähnlich gestalteten schmalen schwarzen Gang erzählt, der von einer Seite wiederum von der Ghettomauer begrenzt wird. ${ }^{399}$ Am Ende des langen Ganges deutet die rote Einfärbung einer auf Raumhöhe vergrößerten Fotografie die Brutalität und Gewalt der Deportationen an, welche die entlang des Ganges angebrachten kleinen sepiafarbenen Fotografien der Kolonnen von Menschen nur zum Teil wiedergeben. Am Ende des Ganges trifft man auf einen Haufen aus Möbelstücken und Matratzen, die für das zurückgelassene Hab und Gut der Deportierten und damit auch sinnbildlich für deren Abwesenheit stehen. Im Hintergrund sind furchteinflößendes Hundegebell sowie die bedrohlichen 


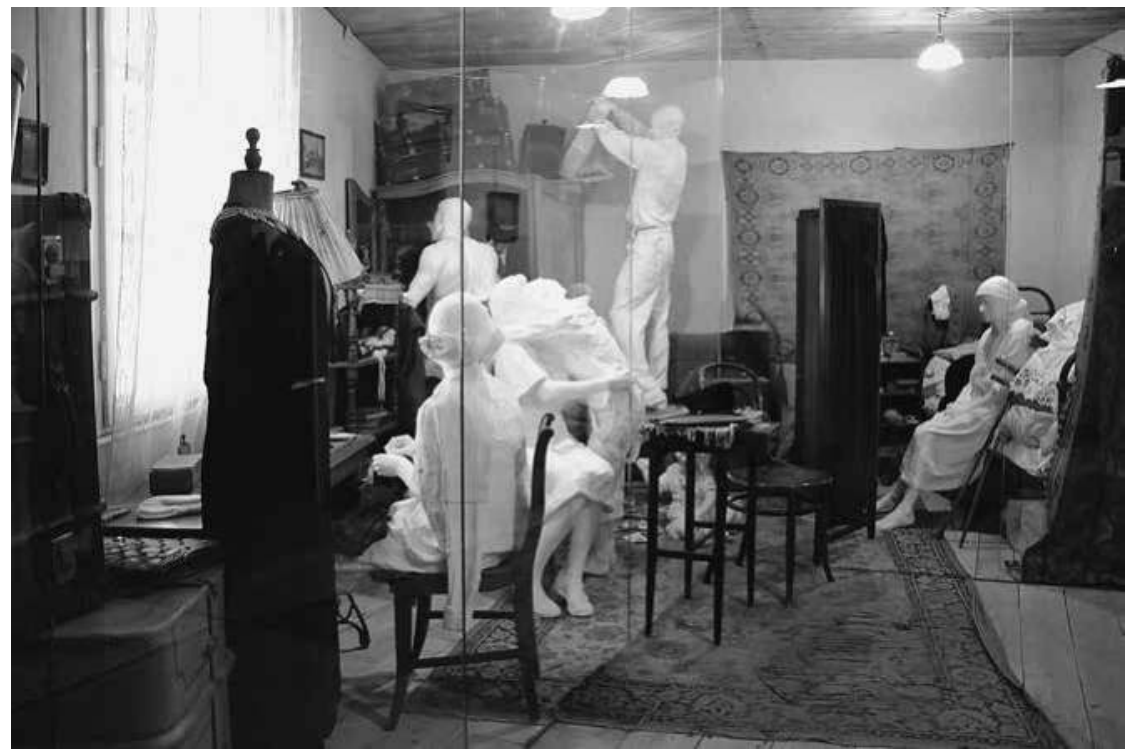

Abb. 33: Schindler-Fabrik, inszeniertes Zimmer in der Sektion »Ghetto«.

deutschen Rufe »Schneller, schneller! Raus!« zu hören. Im nächsten Moment betritt man bereits den Steinbruch des Konzentrationslagers Płaszów. ${ }^{400}$ Als würden sie sich innerhalb eines Bühnenbildes bewegen, erlaufen die Besucher somit die einzelnen Stationen der Deportation. ${ }^{401}$

In die Erfahrungswelt der Ghettoinsassen einzutauchen, wird darüber hinaus durch eine Vielzahl von Zeitzeugenberichten ermöglicht, die die Erlebnisse und Gefühle individueller Bewohner im Angesicht von Angst und Terror widerspiegeln. Anzumerken ist hierbei, dass die meisten der gezeigten Zeugnisse von Überlebenden nach Kriegsende verfasst wurden. Sie geben somit keine unmittelbaren Eindrücke aus der jeweils thematisierten Zeit wieder, sondern enthalten Einschätzungen, die erst mehrere Jahre nach den Ereignissen verschriftlicht wurden. Dieser Kontext ist den Besuchern jedoch nicht

400 MHK-Schindler-Fabrik, Sektion 21: Das Lager Płaszów. An diesem Punkt endet die imaginierte Teilnahme der Besucher an den Ereignissen.

401 Die deutlichen Anleihen an Theaterkulissen lassen sich auf den beruflichen Hintergrund der Ausstellungsgestalter zurückführen: Łukasz Czuj ist Theaterregisseur, Michał Urban ist Szenograf; beide haben mehrere Jahre an Theatern gewirkt. Siehe: Opis projektu: Fabryka Schindlera, nowy oddział Muzeum Historycznego Miasta Krakowa. Przy ulicy Lipowej na krakowskim Zabłociu. [o. J.]. AMHK, ohne Signatur, 3; Interview mit Monika Bednarek, Leiterin der Abteilungen in der Schindler-Fabrik und der Pomorska-Straße des MHK, am 16. März 2010. Siehe auch Ziębińska-Witek: Historia w Muzeach, 197-199. 
ersichtlich: Präsentiert werden die Zeitzeugenberichte auf scheinbar handschriftlich verfassten Zetteln, die eine direkte Überlieferung aus der beschriebenen Zeit suggerieren, zumal das in den Autorenunterschriften angegebene Alter der Protagonisten dem Zeitpunkt entspricht, zu dem die beschriebene Situation erlebt worden ist - der jedoch nicht zwangsläufig dem Zeitpunkt entsprach, zu dem die Niederschrift des Berichts erfolgte. ${ }^{402}$ Die Berichte zeigen ein großes Spektrum persönlicher Einstellungen und Reaktionen auf die Verfolgung. Gerade mithilfe dieser Quellen werden überkommene, schablonenhafte Topoi der Besatzungsjahre diversifiziert und um neue, bislang in historischen Ausstellungen kaum erwähnte Aspekte bereichert. So schildert der Arzt Julian Aleksandrowicz das Nebeneinander von Lebensdurst und Verzweiflung im Ghetto:

Was für Kontraste! In den einen Wohnungen des Ghettos - Gebete, Weinen und Jammern der Verwaisten, und direkt hinter der Wand - Musik, Wodka, Ausschweifungen ohne irgendwelche Hemmungen. In ein paar Stunden sind wir an der Reihes, denken die Teilnehmer. `Die OD-Männer [Jüdischer Ordnungsdienst] werden uns auf den `Optimar-Platz schleppen. Sollen sie uns wenigstens vom Alkohol betäubt rausschleppen, mit dem Gefühl befriedigter Gelüste. Was können wir schon mit unseren bloßen Händen ausrichten? ${ }^{403}$

An anderer Stelle werden auch fröhliche Momente des Ghettolebens geschildert, die bislang gerade bei dieser Thematik in keinem polnischen Museum erwähnt wurden:

Die Jugend organisiert Tanzabende, ich höre, wie mein Bruder abends zurückkommt und belustigt den Eltern erzählt, bei wem sie sich dieses mal amüsiert haben und wie lustig es war. Der einzige grüne Ort sind die Krzemionki, die eigentlich fast komplett zertrampelt sind, aber doch grün. Es wimmelt dort von Menschen, Frauen sitzen zusammen, bessern etwas aus, stopfen etwas, na und tratschen. Die Männer politisieren, die Jugend flirtet miteinander. ${ }^{404}$

Auch die gezeigten Fotografien spiegeln die Diversität des Alltags im Ghetto wieder: Es finden sich sowohl Bilder von Armut und Hunger, aber auch vom religiösen Leben von Orthodoxen und Fotografien junger, lachender Paare

402 Siehe etwa das Zeugnis von »Roma Liebling (Ligocka), 5 Jahre« in Sektion 14: Ghetto. Diese Irreführung der Besucher, die eine Unterscheidung von originalen und "produzierten« Exponaten und Kopien verhindert, wurde bereits mehrfach kritisiert: LinkLenczowska, Magdalena: Śmierć w nowych dekoracjach [Der Tod im neuem Gewand]. In: Herito 1 (2010), 104-117, hier 116; Bogumit: Miejsce pamięci versus symulacja przeszłości, 155.

403 MHK-Schindler-Fabrik, Sektion 14: Ghetto.

404 »Stella Müller (Madej), 8 Jahre«. Ebd. 
im einzigen parkähnlichen Gelände des Ghettos. ${ }^{405}$ Wie diese Beispiele verdeutlichen, stehen in dieser Ausstellung auch bei der Darstellung des Schicksals der jüdischen Stadtbewohner nicht mehr die herausragenden bzw. vereinzelten Schicksale der Widerständigen im Vordergrund - auch wenn diese in der Schau enthalten sind. ${ }^{406}$ Der Fokus liegt auf dem Alltag der »normalen« Menschen und damit auch auf dem Leben - nicht allein dem Sterben im Ghetto.

Ein weiteres herausragendes Merkmal der Ausstellung ist der Umfang, den die polnisch-jüdischen Begegnungsräume und Kontakte während der Besatzung einnehmen, wobei die Besonderheit ihrer Darstellung darin liegt, auch ambivalente und negative Aspekte offen darzustellen. Zugleich verdeutlichen die vielfältigen und in der ganzen Schau verstreuten Referenzen zu diesem Teil des Alltags den Besuchern immer wieder, dass die Lebenswelten der Stadtbewohner zu keinem Zeitpunkt vollständig voneinander getrennt waren. So werden in der Sektion »Ghetto « die Arbeitseinsätze außerhalb des Ghettogeländes und der Schmuggel von Lebensmitteln illustriert. ${ }^{407}$ Aber auch die Wahrnehmung der Welt und der Menschen außerhalb der Mauern durch die Insassen wird immer wieder in Zeitzeugenberichten thematisiert:

Bis zu diesem Jahr hatte ich noch Vertrauen zu den Polen, jetzt habe ich auch das nicht mehr. Heute war ich auf den Krzemionki, wo ich an Maurern vorbeigegangen bin, und sie haben Kalk genommen und mich damit überschüttet. Danach hatte ich in den Haaren, auf dem Kleid, auf dem Kopf, auf den Händen, auf den Beinen überall Kalk, der brannte. Und die Maurer lachten. Es ist sehr schlimm, Jude zu sein. ${ }^{408}$

Hier gleich hinter der Mauer, hinter dem Tor ist eine andere Welt. Diese Welt ist auch vom Krieg gebrochen, aber doch auf ihre Weise frei. Dort gehen die Kinder zur Schule, Erwachsene arbeiten, gehen auf hellen Straßen oder in den Planty spazieren, sehen sich Schaufenster an, hören den Hejnał [Trompetensignal] vom Turm der Marienkirche. ${ }^{409}$

Beispielhaft für kritische Themen, die die Schau ausführlich darstellt, ist auch der Abschnitt »Juden auf der arischen Seite«, der das Verstecken außerhalb

$405 \mathrm{Ebd}$

406 Es werden sowohl der polnische Apotheker Tadeusz Pankiewicz und seine Mitarbeiterinnen vorgestellt, die der Ghettobevölkerung halfen, als auch die Mitglieder der ŻOB im Ghetto. Ebd.

407 So zeigt man u.a. ein Foto von jüdischen Arbeitskräften bei der Barbakane. An anderer Stelle berichtet Maniusia Weinfeld vom Schmuggel von Milch, Käse und Eiern von außerhalb des Ghettos. Ebd.

408 »Renia [Nachname nicht lesbar], 14 Jahre. « Nach diesem negativen Bericht folgt unmittelbar ein Verweis auf Hilfe seitens der Bevölkerung außerhalb des Ghettos: Roma Liebling (Ligocka) berichtet von einem Jungen, der ihr aus der Straßenbahn, die durch das Ghettogelände fuhr, mehrere Brote zugeworfen hat - eine streng verbotene Tat. Ebd.

409 »Halina Nelken, 17 Jahre.« Ebd. 
des Ghettos und die damit verbundenen Gefahren und Probleme thematisiert. Hier werden die Umstände geschildert, die das Überleben im überwiegend polnischen Umfeld begünstigten, wie Aussehen oder Kenntnis der polnischen Sprache sowie religiöser und kultureller Normen der christlich geprägten Umgebung. Daneben werden die Aktivitäten des Hilfsrates für Juden ${ }^{410}$ sowie jene Strafen angesprochen, die Polen riskierten, wenn sie Juden halfen. Ein Schwerpunkt der Präsentation liegt jedoch auf der Gefahr, die von polnischen, volksdeutschen und jüdischen Erpressern und Informanten ausging. Auch an dieser Stelle setzten die Ausstellungsmacher wieder Zeitzeugenberichte ein, die individuelle Erfahrungen mit szmalcowniki und die Frustration angesichts des weitgehenden Fehlens polnischer Hilfsbereitschaft dokumentieren:

Wenn einige Polen uns nicht hätten sehen wollen - uns, also die Juden, die sich bereits irgendwie auf der arischen Seite eingerichtet hatten -, wie viel mehr hätten die Besatzung überlebt. ${ }^{411}$

Erstmals erhalten Besucher hierdurch die Möglichkeit, etwas aus der Binnenperspektive über die Umstände zu erfahren, in denen Juden in Verstecken auf der "arischen Seite« lebten und überlebten, welche Erfahrungen sie dort gemacht haben.

Ein weiterer Aspekt fällt jedoch gleichwohl ins Auge: Auch in dieser Schau thematisiert man die Frage der ethnischen Zugehörigkeit bzw. ihrer Definition sowie die Existenz verschiedener Identitätsentwürfe nicht. Die Termini "polnisch" und »jüdisch" werden nicht reflektiert, sondern als objektive Unterscheidungskategorien beibehalten. Dementsprechend findet die willkürliche, rassistische Grundlage der nationalsozialistischen Kategorisierung verschiedener »Rassen« auch keine Erwähnung.

\subsection{Die »Gerechten« als Pointe der Erzählung}

Den Kulminationspunkt der präsentierten Vielfalt an menschlichen Verhaltensweisen stellen in den Planungen der Ausstellungsmacher die letzten Räume der Schau dar, die als "Saal der Entscheidungen" (Sala Wyborów) bezeichnet werden. ${ }^{412}$ Zugleich erfährt gerade das Thema der polnisch-jüdischen Beziehungen hier seine Zuspitzung. Die Rauminstallation ist als Epilog der musea-

410 Die Krakauer Sektion der Żegota wurde am 12. März 1943 gegründet.

411 Schriftliches Zitat von Mieczysław Mariański. MHK-Schindler-Fabrik, Sektion 20: Die Liquidierung des Ghettos, Abschnitt »Juden auf der arischen Seite«.

412 MHK-Schindler-Fabrik, Sektion 27: Saal der Entscheidungen; Czuj, Łukasz/Urban, Michał: Opis koncepcji aranżacji wystawy stałej »Kraków - czas okupacji (1939-45)«. Kraków o. J. [2008/09]. AMHK, ohne Signatur, 2; Marszałek/Bednarek: Fabryka Emalia, 40 . 
len Erzählung gedacht, als Ort der Reflexion über das Gesehene. ${ }^{413}$ Die zwei Säle ${ }^{414}$ sind äußerst schlicht gestaltet. Der erste, ein runder, hell erleuchteter, schmuckloser Saal, ruft die Assoziation eines Tempels hervor und suggeriert somit einen Ort der Kontemplation. An seinen hellen Wänden sind einzelne Berichte angebracht, die von Hilfeleistungen für Verfolgte handeln. An den Säulen, die in die Wände eingelassen sind, sind Beispiele für das Unterlassen von Unterstützung oder egoistisches Verhalten zu lesen (siehe Abb. 34). Erwähnt werden in beiden Fällen sowohl Taten von großer Tragweite, wie das Überlassen von Taufurkunden oder die Abweisung eines sich auf dem Hof versteckenden jüdischen Kindes, aber auch vermeintlich geringfügige Handlungen. So findet sich etwa ein Bericht über einen Mann, der Jugendliche vertrieb, die Zwangsarbeiter beim Schneeschippen auslachten und bewarfen, und den Gepeinigten Tee anbot; oder die Aussage einer Frau, die es bei einer zufälligen Begegnung vermied, eine ehemalige Klassenkameradin zu grüßen, die sie mit einer Davidstern-Armbinde antraf. Die Besucher stehen somit einem breiten Spektrum von Handlungsweisen gegenüber, die nicht immer eindeutig zu bewerten sind, zumal die Gestaltung des Raumes nicht sofort eine eindeutige Zuschreibung offensichtlich werden lässt, da alle Texte in verschiedenen Schriftgrößen und -arten auf einem gleichmäßig grau-weißen Hintergrund abgedruckt sind.

Im darauffolgenden, abgedunkelten Raum werden Zeitzeugenberichte ähnlicher Aussage in Form zweier digitaler Bücher zusammengefasst. Das eine, in Weiß gehaltene Buch trägt den Titel »Die Gerechten " (Sprawiedliwi) - eine Anspielung auf den Titel »Gerechte unter den Völkern«. In ihm sind Berichte versammelt, die das ehrenhafte, mutige, mitfühlende Handel $n^{415}$ von Bewohnern der Stadt und Region während der Besatzung beschreiben, die zumeist als »Gerechte unter den Völkern« ausgezeichnet wurden. Ebenfalls darin enthalten ist eine Liste aller Bewohner Krakaus und seiner Umgebung, denen der Titel verliehen wurde. Das zweite »Buch«, mit der Aufschrift »Informanten«

413 Bednarek, Monika: Kraków - czas okupacji 1939-1945. Zarys koncepcji wystawy [Kraków - Die Besatzungszeit 1939-1945. Abriss des Konzepts der Ausstellung]. In: Dies. u. a. (Hg.): Kraków - czas okupacji 1939-1945 [Kraków - Die Besatzungszeit 1939-1945]. Kraków 2010, 36-55, hier 43, 55.

414 Den beiden Räumen vorangestellt ist ein dunkler, schmaler Gang, dessen Boden sich bewegt. Er stellt einen Übergang zwischen dem Ende der Besatzungszeit und damit dem Ende der präsentierten historischen Ereignisse und dem Epilog der Schau dar. Die Ausstellungsmacher bezeichnen ihn als "Symbol des Grauens und der Grausamkeit des Kriegs«. Marszałek/Bednarek: Fabryka Emalia, 40.

415 Die genannten Attribute dienen als Zwischenüberschriften des »Buches«, sie beschreiben Motive und Bewertungen der Handlungen Einzelner: „Liebe«, »Uneigennützigkeit«, »Mitgefühl«, »Mut«, »Solidarität«, »Anstand«, »Widerstand«, »Humanitä «, »Zusammenarbeit», »Würde«, »Wertschätzung«, »Glaube«, »Freundschaft«. MHK-SchindlerFabrik, Sektion 27: Saal der Entscheidungen. 


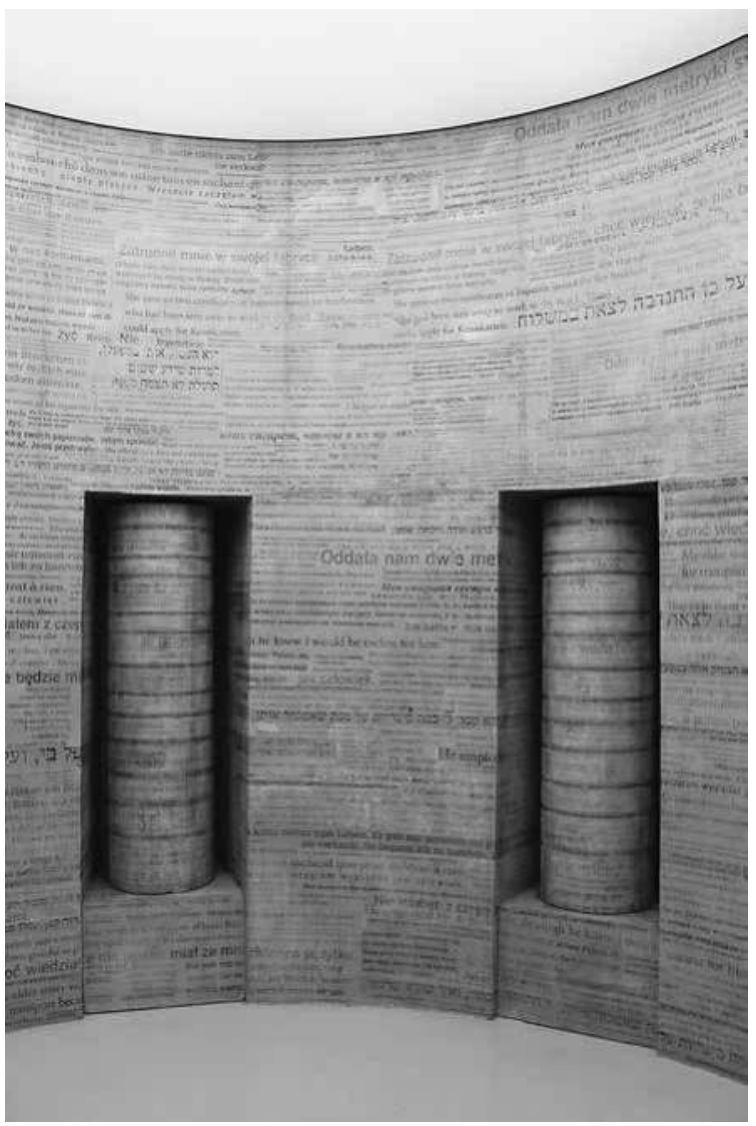

Abb. 34: Schindler-Fabrik, "Saal der Entscheidungen«, erster Teil.

(Konfidenci), ist schwarz gestaltet - darin sind Aussagen versammelt, die von moralisch verwerflichem Handeln wie Denunziationen und Erpressungen berichten (siehe Abb. 35). Die vielfältigen Verhaltensweisen von Krakauern während der Besatzung werden mit dieser Präsentationsweise in einen strikt normativen Rahmen eingeordnet; es erfolgt eine rigorose Zweiteilung in Gut und Böse, in die die Besucher ihre Überlegungen unwillkürlich einordnen müssen. Das Anliegen der Ausstellungsverantwortlichen ist es, mittels »dieser $\mathrm{Zu}$ sammenstellung von Haltungen zur Reflexion anzuregen sowie zum Versuch der Beantwortung der Frage: Wie hätte ich mich in einer solchen Situation verhalten ${ }^{416}{ }^{41}$ Es stellt sich jedoch die Frage, wer bei einer derart strikten ethi- 


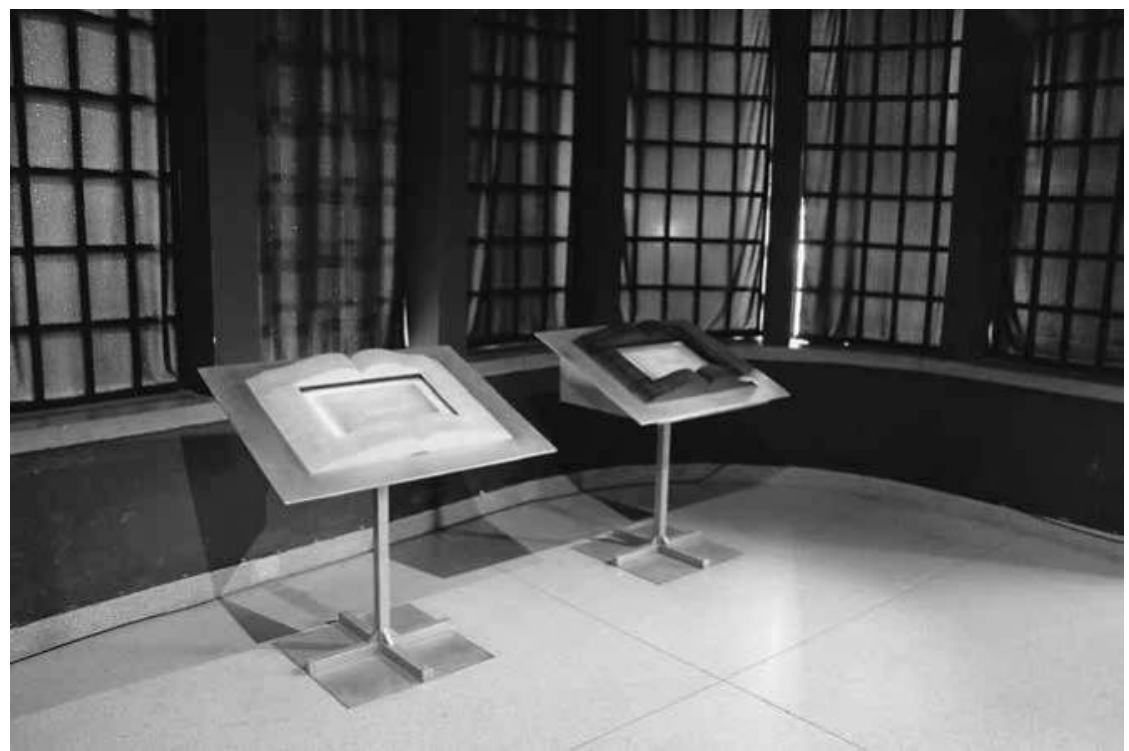

Abb. 35: Schindler-Fabrik, »Saal der Entscheidungen«, zweiter Teil.

schen Vorgabe sich selbst eingestehen wird, dass sie oder er zu den »Verbrechern $\aleph^{417}$ gehört hätte? Diese Installation konterkariert somit paradoxerweise die bis dahin dominierende multiperspektivische Erzählweise der Ausstellung, in der immer wieder ambivalentes Handeln gezeigt wird, das nicht unbedingt eindeutige Einteilungen in Schwarz und Weiß erlaubt, sondern die vielen Graustufen des Besatzungsalltags offenbart. Den Besuchern wird letztlich im »Saal der Entscheidungen« die Bewertung der historischen Ereignisse innerhalb eines universellen moralischen Kanons vorgegeben. Diese normative Bevormundung ist auch einer der bislang größten Kritikpunkte der Schau. ${ }^{418}$

Die herausgehobene Würdigung der »Gerechten« war bereits in den ersten Konzeptionen der Schau vorgesehen. ${ }^{419}$ Als Endpunkt des Rundgangs war

417 In der Einleitung der Präsentation »Informanten« ist eine Bekanntmachung der »Bezirksleitung des Zivilkampfes in Krakau" (Okregowe Kierownictwo Walki Cywilnej w Krakowie) zu lesen, in der es heißt: »Ein Verbrechen ist ein Verbrechen immer und überall, sogar während des Kriegs [...].« MHK-Schindler-Fabrik, Sektion 27: Saal der Entscheidungen.

418 Link-Lenczowska: Śmierć w nowych dekoracjach, 113 f.; Bogumił: Miejsce pamięci versus symulacja przeszłości, 165.

419 Bednarek, Monika/Gawron, Edyta/Jeżowski, Grzegorz/Sabor, Agnieszka/Zbroja, Barbara/Zimmerer, Katarzyna: Wstępna koncepcja muzeum w fabryce Naczyń Emaliowanych Oskara Schindlera przy ul. Lipowej 4 w Krakowie. Muzeum Historyczne Miasta Krakowa 19.10.2007. AMHK, OP-640/ 19/07, 11. 
ursprünglich ein »Saal der Gerechten« (Sala Sprawiedliwych) vorgesehen, als Ort, »an dem die Einstellungen gerade der jungen Besucher entwickelt werden sollen ${ }^{420}$ Gezeigt werden sollten hier »Beispiele der Haltungen der Bewohner Krakaus im Angesicht von Gefahr und Krieg«, mit dem Schwerpunkt auf Menschen, die als "Gerechte unter den Völkern« ausgezeichnet worden waren. Daneben wollte man die Namen aller Polen präsentieren, denen von Yad Vashem dieser Titel verliehen worden war. ${ }^{421}$ Diese ursprüngliche Planung stieß im Programmrat der Ausstellung auf erhebliche Skepsis. Kritik an der Idee und der durch sie suggerierten einseitigen Betonung polnischer Hilfe, die zudem mit der Ehrung aller polnischen »Gerechten« den regionalen Rahmen der geplanten Ausstellung verlassen hätte, äußerten insbesondere der Leiter des Archivs von Yad Vashem Haim Gertner sowie Lili Haber vom »Verein der Krakauer in Israel« (Związek Krakowian w Izraelu). Im Zuge der Debatten wurde der Vorschlag von Gertner zu einer Veränderung der Konzeption dieser Sektion hin zu einem "Saal der Entscheidungen« aufgenommen, in dem die Besucher Beispiele konkreter Einzelpersonen zu sehen bekämen und über die »Wahlmöglichkeiten, Dilemmata» reflektieren könnten, vor denen sie standen. ${ }^{422}$ Die Darstellung der »Gerechten « wurde infolge dieser Überlegungen etwas zurückgenommen; insbesondere verzichtete man auf die Nennung aller mit diesem Titel ausgezeichneter Polen. Dennoch dominieren auch in dieser Form noch die Symbolfiguren der »Gerechten unter den Völkern « die Darstellung der moralisch einwandfreien Haltungen im weißen "Buch «. ${ }^{423}$

Die Installation folgt mit ihrem besonderen Gewicht auf den von Yad Vashem geehrten Helfern dem Schwerpunkt des aktuellen Holocaust-Gedächtnisses in Polen - der Fokussierung auf die polnischen "Gerechten unter den Völkern «. ${ }^{424}$ Der Titel der »Gerechten« ist dabei in den vergangenen zwei Jahrzehnten in Polen zu einem spezifischen »Gütesiegel « avanciert, das die Unterstützung von Juden seitens der polnischen Bevölkerung auch international bestätigt. ${ }^{425}$ Es scheint, dass die Anerkennung polnischer Gleichgültigkeit und

420 Bednarek, Monika/Gawron, Edyta/Jeżowski, Grzegorz/Sabor, Agnieszka/Zbroja, Barbara/Zimmerer, Katarzyna: Wystawa stała: Kraków - czas okupacji (1939-45). Koncepcja scenariusza. Februar 2008. AMHK, OP-520-12/08, 18.

421 Ebd.

422 Bednarek, Monika: II posiedzenie rady programowej Muzeum Pamięci. Fabryka Oskara Schindlera. 18. März 2008. AMHK, OP-520-1/ 08, 3-5.

423 Die überwiegende Anzahl der in der Präsentation enthaltenen Berichte über positive Taten bezieht sich auf Handlungen von Personen, die von Yad Vashem ausgezeichnet wurden. MHK-Schindler-Fabrik, Sektion 27: Saal der Entscheidungen.

424 Leociak: Dyskurs o pomocy, 12.

425 Die öffentliche Herausstellung der »Gerechten« und damit die Nutzung des Titels von Yad Vashem in der polnischen Erinnerungskultur erfolgt erst seit dem Systemwechsel von 1989. Zuvor wurden die Auszeichnungen durch die Institution eines Landes, »mit dem die Beziehungen [...] angespannt waren« sowie die Übergabe der Medaillen 
Schuld während des Holocaust, die nach den intensiven Debatten der 2000erJahre erfolgte und die gerade in der besprochenen Ausstellung sichtbar ist, durch die Herausstellung der großen Zahl der polnischen bzw. Krakauer Gerechten aufgewogen werden soll. Die Betonung polnischer Hilfe für verfolgte Juden und die damit einhergehende Überzeugung, dass diese weiter verbreitet gewesen war, als es in den Debatten der letzten Jahre und gerade im Ausland dargestellt wurde, stellt eine der wesentlichen Kontinuitäten des in der Volksrepublik tradierten martyrologischen polnischen Geschichtsbildes dar. ${ }^{426}$

Im vorliegenden Beispiel mag gerade die Lokalisierung der Ausstellung in der ehemaligen Schindler-Fabrik ein wesentlicher Grund für den Wunsch gewesen sein, die polnischen »Gerechten « hervorzuheben: Das Gebäude der ehemaligen Emaillewarenfabrik wird spätestens seit dem 1993 erschienenen Film »Schindler's List« in erster Linie mit der Person des deutschen Unternehmers Oskar Schindler und seiner außerordentlichen Rettungsaktion in Verbindung gebracht, mithin mit der Person des "guten Deutschen«. Die Taten polnischer Staatsbürger, die Juden halfen - etwa Tadeusz Pankiewicz, dem in unmittelbarer Nähe ein Museum gewidmet ist,$-{ }^{427}$ sind dagegen im Ausland weitestgehend unbekannt. Das Wissen um ihre Verdienste und ihre vergleichsweise hohe Anzahl angesichts des Einzelfalls Schindler wird somit unter Nutzung der Anziehungskraft seines Namens einer größeren, gerade auch internationalen Öffentlichkeit vermittelt. ${ }^{428}$ Zugleich ist eine gewisse Arith-

in Polen weitgehend abseits der öffentlichen Aufmerksamkeit vollzogen. Libionka: Polskie piśmiennictwo, $30 \mathrm{f}$. Die Institutionalisierung des Gedenkens an die »Gerechten« seit der politischen Wende von 1989 schildert Koźmińska-Frejlak, Ewa: Wdzięczność i zapomnienie. Polacy i Żydzi wobec Sprawiedliwych (1944-2007) [Dankbarkeit und Vergessen. Das Verhältnis von Polen und Juden gegenüber den Gerechten (1944-2007)]. In: Tych, Feliks / Adamczyk-Garbowska, Monika (Hg.): Następstwa zagłady Żydów. Polska 1944-2010 [Die Folgen der Vernichtung der Juden. Polen 1944-2010]. Lublin 2011, 813852 , hier $830-834$.

426 Leociak: Dyskurs o pomocy, 9.

427 Der polnische Apotheker Tadeusz Pankiewicz erhielt während der Besatzung als einziger Pole die Genehmigung, sein Geschäft, das innerhalb der Ghettogrenzen lag, weiterzuführen. Er und seine Mitarbeiterinnen unterstützten die Ghettobewohner. Pankiewicz wurde 1983 für seine Taten als »Gerechter unter den Völkern« ausgezeichnet. Seine ehemalige Apotheke »Zum Adler» (Apteka»Pod Orłem») ist seit 2003 eine Abteilung des MHK.

428 Ausländische Touristen machen den Großteil der Besucher der Abteilung aus. So befanden sich beispielsweise unter den 199.684 Besuchern im Jahr 2011 139.681 Ausländer, was einem Anteil von knapp 70 Prozent aller Besucher entspricht. Frekwencja roczna 2011 r. AMHK, ohne Signatur, 2. Diese Situation war von den Ausstellungsverantwortlichen bereits in der Planungsphase der Abteilung antizipiert worden. Demzufolge spielte die Berücksichtigung ausländischer Museumsbesucher, deren (fehlender) Kenntnisse der polnischen Geschichte sowie ihres spezifischen Wissens über den historischen Ort der Fabrik Oskar Schindlers bei den Planungen auch eine Rolle. Interview mit Monika Bednarek, Leiterin der Abteilungen in der Schindler-Fabrik und der PomorskaStraße des MHK, am 16. März 2010. 
metik des Heldentums zu beobachten: Während Schindler als deutscher Einzelfall präsentiert wird, erscheinen die als »Gerechte unter den Völkern« ausgezeichneten Bewohner Krakaus und der Region als Unterpfand einer breiteren Hilfs- und Risikobereitschaft der polnischen Krakauer und damit der zweiten Opfer der Besatzung. Es scheint, als wollten die Ausstellungsverantwortlichen mit diesem Abschluss der Schau der Gefahr einer einseitigen Fokussierung der Besucherwahrnehmung auf Oskar Schindler begegnen.

Die Idee, am authentischen Ort der ehemaligen Fabrik Oskar Schindlers die polnischen »Gerechten « zu ehren, bestand bereits seit Längerem. Das touristische Interesse an dem Gebäude geht auf das Jahr 1993 zurück, in dem Steven Spielbergs Film »Schindler's List« (USA) in die Kinos kam. Der Film basierte auf dem 1982 veröffentlichten Buch von Thomas Keneally »Schindler's Ark «. ${ }^{429}$ Jedoch erst mit dem großen Erfolg der Spielfilmfassung begannen Touristen, in Krakau nach den Spuren der Geschichte Oskar Schindlers und der von ihm Geretteten zu suchen. ${ }^{430}$ Das steigende Interesse an der jüdischen Vergangenheit der Stadt, das sich auch in der starken Zunahme der Touristenzahlen zeigte, fand seinen Niederschlag schließlich auch in den Plänen der Stadt zur Revitalisierung einzelner Stadtbezirke, darunter Podgórze, dem Ortsteil, in dem das Ghetto und die Fabrik Schindlers bestanden hatten. ${ }^{431}$

429 Keneally, Thomas: Schindler's Ark. London 1982. In den USA wurde das Buch unter dem Titel veröffentlicht, der später auch für den Film übernommen wurde: Keneally, Thomas: Schindler's List. New York 1982.

430 Der Film wurde größtenteils im früheren jüdischen Viertel Krakaus Kazimierz gedreht, in dem allerdings nicht das Ghetto errichtet worden war. Touristenführer nahmen jedoch bald auch den Originalschauplatz der Handlung im Viertel Podgórze in ihre Stadtführungen auf, und Touristen kamen zum Gelände der ehemaligen Fabrik Schindlers - obwohl die Besichtungsmöglichkeiten bis Mitte der 2000er-Jahre noch an deren Tor endeten. Sabor, Agnieszka: Lipowa 4. W dawnej »Emalii« powstało muzeum opowiadające o Krakowie w latach 1939-45 [Lipowa 4. In der ehemaligen »Emaille« ist ein Museum entstanden, das von Krakau in den Jahren 1939-45 erzählt]. In: Tygodnik Powszechny, Online-Ausgabe vom 31.8.2010, URL: http://tygodnik.onet.pl/33,0,51887, artykul.html (am 10.5.2011); Gruber, Ruth Ellen: Virtually Jewish. Reinventing Jewish Culture in Europe. Berkeley u. a. 2002, 127-130.

431 Strategia Promocji Krakowa na lata 2008-2012 [Strategie der Vermarktung Krakaus für die Jahre 2008-2012], 61, URL: http://www.bip.krakow.pl/_inc/rada/uchwaly/show_pdf. php?id=38334 (am 5.1.2014); Salwiński, Jacek: Wokół Lipowej [Rund um die LipowaStraße]. Kraków 2011, 23 f. Siehe auch Meroń, Katarzyna: Dziedzictwo żydowskie Podgórza w działaniach samorządu terytorialnego [Das jüdische Erbe von Podgórze in den Aktivitäten der Gemeindeselbstverwaltung]. Kraków: Uniwersytet Jagielloński, 2009. Unveröffentlichte Magisterarbeit, $48 \mathrm{f}$. Im Zuge der Revitalisierungspläne wurde auch der Platz der Ghettohelden (Plac Bohaterów Getta) in der Nähe der Fabrik, von dem aus die Deportationen stattfanden, zu einem Gedenkort umgestaltet. Dieser ist inzwischen sowohl bei den Bewohnern von Podgórze als auch bei Besuchern der Stadt sehr beliebt und hat zur Aufwertung dieses Stadtbezirks beigetragen. Siehe Potel, Jean-Yves: Krzesła [Stühle]. In: Ders.: Koniec Niewinności, 127-142, hier 131-134; Wiśniewski, 
Konkrete Überlegungen zur Nutzung des Areals der ehemaligen Fabrik wurden ab dem Jahr 2005 diskutiert, als das Gelände in den Besitz der Stadt überging. ${ }^{432} \mathrm{Zu}$ den meistdebattierten Vorschlägen gehörten ein Museum der polnischen »Gerechten unter den Völkern«, ein Museum Oskar Schindlers und ein Museum der Krakauer Sektion der Żegota. ${ }^{433}$ Die Stadt entschloss sich jedoch für einen anderen Weg und übertrug das Verwaltungsgebäude der ehemaligen Fabrik dem stadthistorischen Museum, das darin seine langjährigen Pläne zur Etablierung einer umfassenden Dauerausstellung zur Geschichte Krakaus während des Zweiten Weltkriegs realisierte. ${ }^{434}$

In seiner Außendarstellung nutzt die neue Abteilung des MHK offensiv die Popularität und Wiedererkennbarkeit der "Marke« Schindler: Ihr offizieller Name lautet "Emaillewarenfabrik Oskar Schindlers« (Fabryka Emalia Oskara Schindlera); im alltäglichen Gebrauch des Museums (so etwa auf seinen Internetseiten), in Presseberichten und Touristenführern hat sich die kürzere Bezeichnung "Schindler-Fabrik« (Fabryka Schindlera) anstelle des sperrigen Titels der Dauerausstellung etabliert. ${ }^{435}$ Touristen von außerhalb Kra-

Michał: Zabłocie - modelowa rewitalizacja? [Zabłocie - beispielhafte Revitalisierung?]. In: Herito 4 (2011), 58-77, hier 73 f.; Murzyn-Kupisz, Monika: Przywracanie pamięci czy masowa konsumpcja? Dylematy odkrywania żydowskiego dziedzictwa kulturowego krakowskiego Kazimierza [Wiederherstellung der Erinnerung oder Massenkonsum? Dilemmata der Wiederentdeckung des jüdischen Kulturerbes im Krakauer Kazimierz]. In: Dies. / Purchla, Jacek (Hg.): Przywracanie pamięci. Rewitalizacja zabytkowych dzielnic żydowskich w miastach Europy Środkowej [Wiederherstellung der Erinnerung. Die Revitalisierung historischer jüdischer Stadteile in mitteleuropäischen Städten]. Kraków 2008, 363-398, hier 396; Meroń: Dziedzictwo żydowskie Podgórza, 53-56.

432 Bednarek: Kraków - czas okupacji 1939-1945. Zarys koncepcji wystawy, 36; Sabor: Lipowa 4.

433 Sabor: Lipowa 4; Szostkiewicz, Adam: Żydzi Schindlera patrzą nam w oczy [Die Juden Schindlers blicken uns in die Augen]. In: Polityka vom 16.6.2011, Online-Ausgabe, URL: www.polityka.pl/historia/1516534,1,zydzi-schindlera-patrza-nam-w-oczy.read (am 21.6.2011); Kursa, Magdalena: Zabłocie: Arka z naczyń emaliowanych [Zabłocie: Eine Arche aus Emaillewaren]. In: Gazeta Wyborcza Kraków vom 27.2.2009, Online-Ausgabe, URL:http://krakow.gazeta.pl/krakow/1,35798,6324647,Zablocie__Arka_z_naczyn_ emaliowanych.html (am 6.1.2014). Siehe auch Meroń: Dziedzictwo żydowskie Podgórza, 69.

434 Ein erstes Nutzungskonzept des Gebäudes wurde im MHK im Jahr 2007 erarbeitet. Passowicz, Wacław: Kronika działalności Muzeum Historycznego Miasta Krakowa w 2007 roku [Chronik der Tätigkeiten des Historischen Museums der Stadt Krakau im Jahr 2007]. In: Krzysztofory 26 (2008), 247-283, hier 251. Auf dem direkt an das Museum angrenzenden Gelände der ehemaligen Fabrikhallen entstand das »Museum für Moderne Kunst in Krakau" (Muzeum Sztuki Wspótczesnej w Krakowie).

435 Der Titel der Schau lautet »Kraków - czas okupacji 1939-1945« (Krakau - Die Besatzungszeit 1939-1945). Kritik an der fehlenden Eingängigkeit dieser Bezeichnung äußerte u. a. Romanowski, Rafał: Nazwy, których turysta nie zrozumie i nie powtórzy [Titel, die kein Tourist wird verstehen oder wiederholen können]. In: Gazeta Wyborcza Kraków 
kaus und insbesondere Ausländer besuchen das Museum daher oft mit der Erwartungshaltung, eine Schau über Schindler und die von ihm geretteten Juden zu sehen und sind (manchmal auch negativ) überrascht, eine stadthistorische Ausstellung anzutreffen, in der dieses Thema nur eine relativ kleine Fläche einnimmt. ${ }^{436}$

\subsection{Zwischenfazit}

In der Dauerausstellung der Schindler-Fabrik wird die jüdische Bevölkerung Krakaus als selbstverständlicher Bestandteil der lokalen und auch nationalen Gemeinschaft begriffen; der Schau liegt damit ein integratives staatsbürgerliches Verständnis der polnischen Nation zugrunde. Diese grundlegende Ausrichtung als multiethnische Stadtgeschichte ist mit derjenigen der historischen Dauerausstellung des Stadtmuseums Łódź vergleichbar. Die Krakauer Präsentation entwickelt den Ansatz jedoch weiter: Die städtische Gemeinschaft der polnischen und jüdischen Krakauer und deren Erfahrungen werden miteinander verflochten dargestellt; immer wieder werden Bezüge und Beziehungen zwischen den zwei Bevölkerungsgruppen hergestellt. Die Besucher betrachten die Ereignisse aus einer Binnenperspektive nicht nur der polnischen, sondern auch der jüdischen Stadtbewohner. Dabei werden die Wahrnehmungen und Handlungen der Protagonisten in ihrer ganzen Vielfalt gezeigt, wozu auch ambivalente und negative Verhaltensweisen gehören, insbesondere bei der Darstellung der polnisch-jüdischen Kontakte während der Besatzung. Diese Dauerausstellung ist damit die erste des Landes, die das tabuisierte Thema der polnischen Augenzeugenschaft des Holocaust und insbesondere das Thema der polnisch-jüdischen Beziehungen in vielfältigen Facetten aufgreift und damit Forschungserkenntnisse sowie Debatten der letzten zwanzig Jahre über die jüdische Vergangenheit der Stadt (und des Landes) konsequent umsetzt.

Vor dem Hintergrund der städtischen Kultur- und Wissenschaftslandschaft scheint es vielleicht weniger überraschend, dass eine derart innovative Konzeption einer musealen Besatzungsgeschichte gerade in Krakau erstmals verwirklicht wurde. Krakau bzw. Krakauer Intellektuelle und Institutionen gehörten zu den Initiatoren der Wiederentdeckung der jüdischen Vergangenheit

vom 4.8.2010, Online-Ausgabe, URL: http://krakow.gazeta.pl/krakow/1,35798,8211142, Nazwy__ktorych_turysta_nie_zrozumie_i_nie_powtorzy.html (am 5.1.2013). Siehe auch Link-Lenczowska: Śmierć w nowych dekoracjach, 108.

436 Szostkiewicz: Żydzi Schindlera patrzą nam w oczy; Kursa, Magdalena: Multimedialny labirynt u Schindlera [Ein multimediales Labyrinth bei Schindler]. In: Gazeta Wyborcza Kraków vom 13.3.2009, Online-Ausgabe, URL: http://krakow.gazeta.pl/krakow/ 1,35798,6385910,Multimedialny_labirynt_u_Schindlera.html (am 5.1.2014). 
des Landes. ${ }^{437}$ Das Interesse an der jüdischen Geschichte hat hier bereits früh institutionalisierte Formen angenommen, sowohl im Bereich der Wissenschaft als auch der Kultur. ${ }^{438}$ Auch im Bereich der musealen Präsentation jüdischer Geschichte und Kultur nimmt die Stadt, genauer ihr Historisches Museum, eine tragende Rolle ein: 1980 eröffnete in der restaurierten Alten Synagoge von Kazimierz mit der Dauerausstellung "Aus der Geschichte und Kultur der Juden in Krakau ( $Z$ dziejów i kultury Żydów w Krakowie) die erste umfassende Schau in Polen zu diesem Thema, in der ein Raum auch explizit dem Schicksal der jüdischen Gemeinde in den Jahren 1939 bis 1945 gewidmet war. ${ }^{439}$

Bis zur Eröffnung der Schindler-Fabrik wurden jedoch die Kriegs- und Besatzungserfahrungen der polnischen und jüdischen Krakauer im MHK weitgehend getrennt voneinander präsentiert, in der Abteilung Pomorska-Straße und der Alten Synagoge bzw. seit 2004 in der neuen Abteilung des Museums in der ehemaligen Apotheke »Zum Adler« (Apteka »Pod Orłem«). ${ }^{440}$ In letz-

437 Nur ein zentrales Beispiel ist die Sonderausgabe der Krakauer Monatszeitschrift Znak aus Anlass des 40. Jahrestages des Warschauer Ghettoaufstandes: Znak 35/2-3 (1983). Ein weiteres ist der für die innerpolnische Debatte so wichtige Beitrag von Jan Błoński, der 1987 im ebenfalls in Krakau erscheinenden Tygodnik Powszechny abgedruckt wurde. Błoński: Biedni Polacy patrzą na getto.

438 Seit 1988 findet im Krakauer Stadtteil Kazimierz das »Festival der jüdischen Kultur» (Festiwal Kultury Żydowskiej) statt. Gruber: Virtually Jewish, 45f. Siehe auch Potel, Jean-Yves: Zapomniana wyspa [Die vergessene Insel]. In: Ders.: Koniec Niewinności, 109-126. Anfang der 1990er-Jahre entstand die »Stiftung Judaica« (Fundacja Judaica), aus der das »Zentrum für Jüdische Kultur« (Centrum Kultury Żydowskiej) hervorging, das diverse Veranstaltungen zur jüdischen, aber auch der Geschichte und Kultur anderer ethnischer Minderheiten initiiert. Siehe die Website der Institution, URL: www. judaica.pl (am 7.1.2013); Potel, Jean-Yves: Królewska tolerancja [Königliche Toleranz]. In: Ders.: Koniec Niewinności, 93-107, hier 105; Murzyn-Kupisz: Przywracanie pamięci czy masowa konsumpcja, $372 \mathrm{f}$. Bereits 1986 wurde an der Jagiellonen-Universität eine Abteilung zur Erforschung der jüdischen Geschichte und Kultur (Międzywydziałowy Zakład Historii i Kultury Żydów w Polsce) eingerichtet, die im Jahr 2000 in einen Lehrstuhl für Judaistik umgewandelt wurde und bis heute besteht. URL: www.judaistyka. uj.edu.pl/de/instytut/historia (am 7.1.2014). Siehe auch Potel: Królewska tolerancja, 104f. Seit 1996 gibt es an der Universität darüber hinaus eine eigene Arbeitsgruppe, die sich der Erforschung des Holocaust widmet. 2008 entstand daraus das »Zentrum der Erforschung des Holocaust an der Jagiellonen-Universität« (Centrum Badań Holokaustu Uniwersytetu Jagiellońskiego). URL: www.holocaust.uj.edu.pl/de/centrum (am 7.1.2014).

439 Duda: Z dziejów i kultury Żydów, [3], [23-25]; Passowicz: Kronika działalności za rok 1980, 137 f. Siehe Kapitel 1.3.

440 In der Alten Synagoge konzentrierte man sich in den letzten Jahren auf die Geschichte und Kultur der jüdischen Gemeinde vor 1939; die Darstellung der Geschichte der Jahre 1939 bis 1945 war nicht mehr Bestandteil der Schau. Vermutlich wurde diese Veränderung im Zusammenhang mit der Gründung der neuen Abteilung in der Apotheke »Zum Adler« vorgenommen, deren neue Dauerausstellung 2004 eröffnet wurde. (In der überarbeiteten Dauerausstellung von 1999 war die Vernichtung der Krakauer Juden noch Bestandteil der Präsentation; 2005 jedoch fehlte dieses Thema. Vgl. Scenariusz wystawy 
terer war bereits 1983 aus privater Initiative ein Museum in Erinnerung an die Taten Tadeusz Pankiewiczs geschaffen worden. Dieses wurde vom MHK übernommen und 2004 mit einer neuen Dauerausstellung wiedereröffnet, die die Geschichte der jüdischen Gemeinde während der Besatzung schilderte. ${ }^{441}$ Mit der neuen Schau in der Schindler-Fabrik verfolgte das MHK das Ziel, die bis dato räumlich und weitgehend auch inhaltlich getrennten musealen Erzählungen in einer gemeinsamen, integrativen Darstellung zusammenzuführen. ${ }^{442}$ Bei der Realisierung dieses Vorhabens nutzten die Museumsmitarbeiter besonders stark die in Krakau vorhandene fachliche Expertise: Vorbild des grundsätzlichen Zugangs zur multiethnischen Stadtgeschichte der Besatzung war die grundlegende Publikation Andrzej Chwalbas, eines Historikers an der Jagiellonen-Universität, der zugleich Leiter des Programmrats der Schau wurde und die Entwicklung des Ausstellungskonzepts begleitete. ${ }^{443}$ Als Ko-Autoren des Drehbuchs wurden Krakauer Intellektuelle eingeladen, deren Fachgebiet die jüdische Geschichte der Stadt ist. ${ }^{44}$

stałej w Oddziale Dzieje i Kultura Żydów. Kraków 1998. AMHK, OŻ-640/1/1998, 12; Duda: Stara Synagoga na Kazimierzu [2005].)

441 Passowicz, Wacław: Kronika działalności Muzeum Historycznego Miasta Krakowa 2003-2004 [Chronik der Tätigkeiten des Historischen Museums der Stadt Krakau 2003-2004]. In: Krzysztofory 24 (2006), 165-197, hier 168; Pióro, Anna: Apteka pod Orłem. Przewodnik [Apotheke zum Adler. Ausstellungsführer]. Kraków 2009, 13 f.

442 Interview mit Monika Bednarek, Leiterin der Abteilungen in der Schindler-Fabrik und der Pomorska-Straße des MHK, am 16. März 2010. Die Dauerausstellungen der Abteilungen Pomorska-Straße und Apotheke »Zum Adler« wurden in den Jahren 2011 bzw. 2013 neu konzipiert und konzentrieren sich nun auf einzelne Aspekte der Besatzungsgeschichte: den deutschen und sowjetischen Terror gegenüber der Krakauer Bevölkerung in den Jahren 1939 bis 1956 respektive die Person Pankiewiczs, und seiner Hilfe für die Ghettoinsassen. Ziel des Museums war es, dass sich die drei Abteilungen, die zu einem »Pfad der Erinnerung" (trasa pamięci) verbunden wurden, inhaltlich ergänzen. Vgl. Trasa pamięci [Pfad der Erinnerung], URL: www.mhk.pl/trasa-pamieci (am 7.1.2014); Trasa Pamięci [Pfad der Erinnerung] [Broschüre]. Hg.v. Muzeum Historyczne Miasta Krakowa. Kraków o. J.

443 Chwalba: Dzieje Krakowa. Bd.5. Neuauflage als Einzelpublikation: Ders.: Okupacyjny Kraków w latach 1939-1945 [Das besetzte Krakau in den Jahren 1939-1945]. Kraków 2011; Bogumit: Miejsce pamięci versus symulacja przeszłości, 162; Bednarek, Monika: II posiedzenie rady programowej Muzeum Pamięci. Fabryka Oskara Schindlera. 18. März 2008. AMHK, OP-520-1/ 08, 1.

444 Diese waren Edyta Gawron, Historikerin an der Krakauer Jagiellonen-Universität, die Kunsthistorikerin Barbara Zbroja und die Autorin und Journalistin Katarzyna Zimmerer, die bereits zuvor ein gemeinsames Ausstellungsprojekt kuratiert hatten: »Świat przed katastrofą. Żydzi krakowscy w dwudziestoleciu międzywojennym« (Die Welt vor der Katastrophe. Die Krakauer Juden in der Zwischenkriegszeit), Ausstellung vom 25. Juni bis 28. Oktober $2007 \mathrm{im}$ "Internationalen Kulturzentrum in Krakau« (Międzynarodowe Centrum Kultury w Krakowie). Zimmerer hat zudem eine Geschichte der jüdischen Krakauer während der Besatzung publiziert: Zimmerer: Zamordowany Świat. 
Die große Bedeutung, die der Geschichte der jüdischen Stadtbewohner und damit zwangsläufig auch ihrer Ermordung - in der Ausstellung der Schindler-Fabrik eingeräumt wird, führt dazu, dass das Museum in Polen hin und wieder, entgegen seiner stadthistorischen Ausrichtung, als Holocaust-Museum wahrgenommen wird. ${ }^{445}$ Ursache hierfür ist zum einen die Verbindung des Museums mit der Person Oskar Schindlers, die durch seine Lokalisation am authentischen Ort, aber auch seine Namensgebung erzeugt wird, wodurch die tragischen Ereignisse des Holocaust ins Zentrum gerückt scheinen. Hierzu trägt nicht zuletzt die Installation »Saal der Entscheidungen « bei, die die "Gerechten unter den Völkern« in den Vordergrund stellt und den letzten Eindruck der Museumsbesucher vor Verlassen der Ausstellung prägt. Zum anderen verweist die Wahrnehmung der Institution als Holocaust-Museum auf die aktuelle Ausnahmeposition ihrer Konzeption in der polnischen historischen Museumslandschaft. Die meisten Museen, gerade stadthistorische Institutionen, vermeiden nach wie vor, die Verfolgung und Ermordung der jüdischen Bevölkerung ihrer Stadt und Region - die oft einen erheblichen Prozentsatz ausmachte - als wichtigen Bestandteil der Lokalgeschichte in ihre Ausstellungsnarrative zu integrieren, ihr mehr als nur die Rolle einer Fußnote einzuräumen. Hintergrund ist die immer noch verbreitete Persistenz einer ethnisch-nationalen Konzeption polnischer Geschichte, gerade in Bezug auf die Jahre des Zweiten Weltkriegs. ${ }^{446}$ Die neue Dauerausstellung des MHK nimmt daher eine Vorreiterfunktion bei der Musealisierung der polnisch-jüdischen Geschichte ein, gerade weil sie die traditionelle Trennung der Besatzungsgeschichten beider Bevölkerungsgruppen überwindet und zu einer gemeinsamen Erzählung zusammenführt.

\section{Zusammenfassung und Ausblick}

Die Wahrnehmung von Juden als »Andere« und »Fremde«, die bereits vor dem Krieg in der polnischen Gesellschaft und Politik verbreitet war und in der faktisch ethnisch-national orientierten Geschichtspolitik der VRP überdauerte, liegt auch dem Großteil der hier untersuchten historischen Dauerausstellungen bis in die Gegenwart zugrunde. Die Verfolgung und Vernichtung der jüdischen Bevölkerung wird in diesen nicht als Teil der polnischen (Besatzungs-)Erfahrungen verstanden, da die polnischen Juden nicht Teil der Wir-Gemeinschaft sind, die in den Schauen konstruiert und präsentiert

445 Vor diesem Hintergrund hat Anna Ziębińska-Witek die Schau als eines der zentralen Fallbeispiele ihrer Studie gewählt. Ziębińska-Witek: Historia w Muzeach, 193-200.

446 Siehe Kapitel 2 in diesem Teil und Teil 3. 
wird. Diese basiert in den meisten Museen weiterhin auf einem exklusiven ethnischen Verständnis der Nation, das - wie im folgenden Teil dargelegt zudem auch meist religiös definiert wird. Als Tragödie eines »fremden" Volkes auf polnischem Territorium bleibt die Besatzungserfahrung der jüdischen Warschauer, Lubliner oder Breslauer in den musealen Erzählungen marginalisiert - ohne, dass die historische Fremdwahrnehmung von Polen und Juden von den Ausstellungsmachern reflektiert und in den Präsentationen historisiert wird.

Die Darstellungspraxis der VRP, in der das jüdische Schicksal weitgehend unter das polnische Martyrium des Kriegs vereinnahmt wurde, ist im Zuge der Neufassung von Schauen seit den 1990er-Jahren einer Marginalisierung durch Ausgrenzung der Verfolgung von Juden aus dem Gesamtnarrativ gewichen. Die verbreitete Darstellung des Ghettos in einem einzelnen thematischen Abschnitt dient dabei weiterhin in erster Linie der Exemplifizierung des deutschen Besatzungsterrors und bleibt von der Schilderung der Erlebnisse der polnischen Bevölkerung sowohl inhaltlich als auch räumlich getrennt. Zugleich erfuhr seit Ende der 1990er-Jahre die Behandlung dieses Themas in allen neu entstandenen oder überarbeiteten Schauen eine merkliche Ausweitung; die Zahl der Exponate und die Ausstellungsfläche, die der Judenverfolgung gewidmet ist, nimmt merklich zu. Dieser quantitative Zuwachs ging jedoch nur in wenigen Museen mit einer Veränderung etablierter Interpretationstopoi einher. 1998 eröffnete die erste Dauerausstellung aus dem Kreis der untersuchten Museen, die eine Neukonzeption der städtischen Geschichte unternahm: Das Stadtmuseum Łódź präsentierte die jüdischen Stadtbewohner erstmals gleichrangig neben den polnischen und - in Bezug auf die Zeit vor 1939 - deutschen Łódźern, wenn auch die Erfahrungen beider Bevölkerungsgruppen während des Kriegs nach wie vor strikt voneinander getrennt dargestellt wurden. Erst mehr als zehn Jahre später entwickelt ein weiteres Museum diese multiethnische Sicht auf die Geschichte seiner Stadt und Region wesentlich fort: Das Museum in der ehemaligen Emaillewarenfabrik Oskar Schindlers in Krakau aus dem Jahr 2010 entwirft eine miteinander verflochtene Darstellung der Besatzungserfahrungen der polnischen und jüdischen Krakauer, die auch den ambivalenten Themenkomplex der Kontakte beider Bevölkerungsgruppen prominent aufnimmt. Diese zwei Präsentationen sind mit ihrer Integration der jüdischen Bewohner in das städtische Geschichtsbild und die damit konstruierte lokale und nationale Gemeinschaft jedoch - innerhalb des Untersuchungszeitraums - noch deutliche Ausnahmen im Bereich der städtischen Geschichtsmuseen. Der Großteil aktueller Dauerausstellungen, die seit der Jahrhundertwende entstanden sind, betrachtet den Holocaust und dessen erste Phase, die in den Städten selbst stattfand, als fremdes Element einer als ethnisch-polnisch kontextualisierten Stadt- und im weiteren Sinne auch Landesgeschichte. 
In Bezug auf die inhaltliche Darstellung der Judenverfolgung unterscheiden sich die Präsentationen der Museen am deutlichsten beim Umgang mit schwierigen Themen; insbesondere der Komplex der polnisch-jüdischen Beziehungen in den Jahren 1939 bis 1945 ist bis in die Gegenwart mit vielen Tabus versehen. Bis Anfang der 2000er-Jahre war das Thema in allen untersuchten Schauen nur äußerst marginal vertreten. Die wenigen Verweise bezogen sich in den bis Mitte der 1990er-Jahre eröffneten Präsentationen auf den gemeinsamen Kampf von Polen und Juden gegen die deutschen Feinde, in einigen Fällen auch auf polnische Hilfe gegenüber verfolgten Juden. Seit der Jedwabne-Kontroverse der Jahre 2000 bis 2002, während der die Neufassung der Dauerausstellungen vieler Institutionen begann, zeichnen sich zwei grundlegende Varianten der Handhabung ab: In einigen Institutionen werden die polnisch-jüdischen Kontakte auf die einseitige Herausstellung polnischer Hilfe verkürzt. In diesen Schauen fehlen meist jegliche Verweise auf andere als positive Verhaltensweisen von Polen gegenüber verfolgten Juden. Als deren Garanten fungieren insbesondere in jüngeren Präsentationen diejenigen Polen, die als "Gerechte unter den Völkern« ausgezeichnet wurden. In anderen Ausstellungen wird das Thema polnisch-jüdischer Beziehungen nach wie vor gänzlich verschwiegen. Beide Darstellungsvarianten finden sich insbesondere in Präsentationen, die ein konservatives, heroisch-martyrologisches Bild der polnischen Geschichte der Jahre 1939 bis 1945 konstruieren. Deren Autoren stehen neueren Forschungserkenntnissen über die polnischjüdischen Beziehungen während des Holocaust weitgehend ablehnend oder kritisch gegenüber - in dem Sinne, als sie diese nicht in das etablierte positive Geschichtsbild der polnischen Helden und Opfer bzw. Märtyrer zu integrieren suchen. Lediglich die Dauerausstellung des Jüdischen Historischen Instituts präsentierte alltägliche Kontakte zwischen den Menschen auf beiden Seiten der Mauer eingehender. In den untersuchten stadthistorischen und martyrologischen Museen jedoch entstand bis 2010 erst eine Dauerausstellung, die dieses Tabuthema aufgenommen hat und aus vielfältigen Perspektiven differenziert und offen darstellt: die Dauerausstellung des MHK in der Schindler-Fabrik.

Wie anhand der Sonderausstellungen einzelner Institutionen oder am Beispiel des Historischen Museums der Stadt Krakau mit seiner Abteilung Alte Synagoge aufgezeigt wurde, gehörten einzelne Museen in den 1980er- bis Mitte der 1990er-Jahren zu den Initiatoren und zentralen Akteuren der Wiederentdeckung der jüdischen Vergangenheiten ihrer Städte. Auch das Schicksal von Juden während der Besatzung wurde im Zuge dessen in Sonderausstellungen prominent dargestellt. Eindrückliche Beispiele hierfür sind die Sonderausstellungen im Stadtmuseum Łódź und im Architekturmuseum von Wrocław. In diesen Institutionen war es das Interesse einzelner Mitarbeiter neben der Unterstützung seitens der Museumsleitung -, das die Entwicklung 
neuer Erzählungen bzw. Perspektiven auf diese bis dato weitgehend vergessenen oder vernachlässigten Aspekte der Stadthistorie voranbrachte. Beide Museen verdeutlichen zugleich, dass das grundsätzliche Interesse an der jüdischen Vergangenheit der Städte bis heute nicht zwingend auch mit einer musealen Auseinandersetzung über deren ambivalente Aspekte einherging und -geht: Sowohl in den frühen Sonderausstellungen als auch in den Dauerausstellungen, die aus dem Material der ersteren schöpften und in denen die Geschichte der jüdischen Einwohner prominent vertreten war bzw. ist, wurden und werden kritische Themen, etwa die polnisch-jüdischen Kontakte während des Kriegs und die gegenseitige Wahrnehmung dieser Bevölkerungsgruppen, nicht angesprochen. Gerade in Bezug auf die Jahre 1939 bis 1945 scheuen sich offenbar viele Museen gegenwärtig noch immer, Themen wie Denunziationen und Erpressungen einzuführen, die das tradierte einseitige Selbstbild der polnischen Helden und Märtyrer revidieren oder differenzieren würden.

Zugleich muss darauf hingewiesen werden, dass die untersuchten kommunalen Museen keineswegs das gesamte Spektrum der musealen Wahrnehmung und Darstellung des Themas in den vergangenen zwei Dekaden umfassen. Warschau und Lublin sind hierfür besonders aussagekräftige Beispiele. Während etwa die etablierten historischen Museen Lublins das Schicksal der jüdischen Bevölkerung ihrer Stadt bis in die Gegenwart fast vollständig ausblenden, existiert seit den 1990er-Jahren eine Kulturinstitution, die sich intensiv darum bemüht, die jüdische Geschichte Lublins in das Bewusstsein seiner Bewohner zurückzuholen: das "Burgtor - Theater NN« (Brama Grodzka - Teatr NN $)^{447}$. Diese Institution folgt einem diametral anderen Ge-

447 Das »Theater NN« (Teatr NN) wurde 1990 gegründet und war seit 1991 Teil des »Lubliner Kulturzentrums" (Lubelskie Centrum Kultury). 1998 wurde das Burgtor - Theater NN eine eigenständige kommunale Kultureinrichtung. Seit 1997 führt es diverse museale, künstlerische und kulturelle Projekte und Veranstaltungen durch, die mit der Erinnerung an den Holocaust und die polnisch-jüdische Vergangenheit der Stadt verbunden sind. Aus mehreren dieser Projekte sind historische Ausstellungen hervorgegangen, einschließlich der aktuellen Dauerausstellung von 2009. Zur Geschichte der Institution: Historia Ośrodka. 1990-1992 [Die Geschichte der Einrichtung. 1990-1992], URL: http://tnn.pl/k_15_m_453.html (am 5.3.2012); Historia Ośrodka. 1992-1998 [Die Geschichte der Einrichtung. 1992-1998], URL: http://tnn.pl/k_16_m_453.html (am 5.3. 2012); Historia Ośrodka. 1998-2001 [Die Geschichte der Einrichtung. 1998-2001], URL: http://tnn.pl/k_17_m_453.html (am 5.3.2012); Historia Ośrodka. 2001-2005 [Die Geschichte der Einrichtung. 2001-2005], URL: http://tnn.pl/k_18_m_453.html (am 5.3. 2012); Historia Ośrodka »Brama Grodzka - Teatr NN« [Die Geschichte der Einrichtung »Burgtor - Theater NN"], URL: http://teatrnn.pl/kalendarium/node/1453/historia ośrodka_brama_grodzka_teatr_nn (am 7.2.2014). Ein Überblick über die Tätigkeiten im Bereich der Geschichtsvermittlung findet sich in Pietrasiewicz, Tomasz: Ośrodek "Brama Grodzka - Teatr NN" 1990-2010: Artystyczne i animatorskie działania w przestrzeni miasta związane z pamięcią [Institut »Burgtor - Theater NN" 1990-2010: Künstlerische und Bildungsaktivitäten im städtischen Raum, die mit Erinnerung verbunden sind]. Bd. 2. Lublin 2010, 5-116. 
schichtsbild, als es in den Abteilungen des Lubliner Museums gezeigt wird: »Die Geschichte der Lubliner Juden ist schließlich ein integraler Teil der Geschichte Lublins «, ${ }^{448}$ so der konzetionelle Grundtenor. Im Burgtor, das der Einrichtung zugleich ihren Namen gegeben hat, wird seit 1999 eine Dauerausstellung präsentiert, in der das polnisch-jüdische Lublin der Vorkriegszeit im Zentrum steht; seit 2008 enthält sie auch eine Sektion zum Holocaust. 2011 eröffnete schließlich eine überarbeitete Fassung dieser Ausstellung unter dem Titel »Lublin. Pamięć miejsca « (Lublin. Die Erinnerung des Ortes). ${ }^{449}$ Die Präsentation ist ebenso wie ihre Vorgängerin nicht in erster Linie auf die Aufzählung historischer Fakten konzentriert, sondern versammelt $\mathrm{Ob}$ jekte und Materialien, die den Besuchern den Alltag der verlorenen polnischjüdischen Vergangenheit der Stadt nahebringen. Hierzu gehören etwa Zeitzeugenberichte zu »Straßen«, »Orten«, »Geräuschen und Gerüchen« sowie »Geschmäckern« des Lublin der Zwischenkriegszeit. ${ }^{450}$ Die Vernichtung der jüdischen Stadtbewohner wird ausschließlich mittels künstlerischer Installationen vermittelt. ${ }^{451}$ Etwa ein Drittel des Ausstellungsabschnitts zum Holo-

448 Pietrasiewicz, Tomasz: Wstęp [Einleitung]. In: Ders.: Brama Grodzka. Kręgi Pamięci [Das Burgtor. Kreise der Erinnerungen]. Lublin 2008, [1].

449 Wystawa »Lublin. Pamięć Miejsca« [Die Ausstellung "Lublin. Die Erinnerung des Ortes«], URL: http://teatrnn.pl/kalendarium/node/1366/wystawa_lublin_pamięć_miejsca (am 29.2.2012). Die aktuelle Dauerausstellung basiert auf früheren Ausstellungen des Instituts; die erste wurde 1998 gezeigt: »Wielka Księga Miasta. Lublin w Fotografii do 1939 roku« (Das große Buch der Stadt. Lublin in Fotografien bis zum Jahr 1939). 1999 wurde die erste Dauerausstellung in der Brama Grodzka eröffnet - „Portret Miejsca« (Ortsporträt). Sie stellte das polnisch-jüdische Lublin der Zwischenkriegszeit anhand von Fotografien, Zeitzeugenberichten, filmischen und literarischen Porträts vor. 2008 wurde die Schau um eine Sektion zur Vernichtung der jüdischen Bevölkerung ergänzt, die aus einem Projekt des Theater NN hervorgegangen ist - »Pamięć Sprawiedliwych - Pamięć Światła (Die Erinnerung an die Gerechten - die Erinnerung an das Licht). Siehe: Wielka Księga Miasta. Lublin w fotografii do 1939 roku [Das große Buch der Stadt. Lublin in Fotografien bis zum 1939], URL: www.tnn.pl/k_29_m_3.html (am 29.2.2012); Wystawa »Portret Miejsca» [Die Ausstellung »Ortsporträt»], URL: www. teatrnn.pl/kalendarium/node/1026/wystawa_portret_miejsca (am 29.2.2012); Wystawa "Pamięć Sprawiedliwych - Pamięć Światła» [Die Ausstellung »Die Erinnerung an die Gerechten - die Erinnerung an das Licht«], URL: www.teatrnn.pl/kalendarium/ node/1028/wystawa_„pamięć_sprawiedliwych_-_pamięć_światła“ (am 29.2.2012).

450 So lauten die thematischen Überschriften zu einzelnen Zeitzeugenberichten, die man in einer Installation im ersten Raum der Ausstellung anhören kann. Diese und die folgenden Ausführungen zu den Inhalten der Ausstellung basieren auf dem Besuch der Schau durch die Verfasserin am 23. März 2012.

451 In einer der Installationen finden sich auch farbige Diapositive, die die Bewohner des Ghettos im Jahr 1941 zeigen. Die Aufnahmen wurden von einem deutschen Soldaten 1941 angefertigt. Eine detaillierte Beschreibung der Holocaust-Sektion findet sich unter: Wystawa »Pamięć Sprawiedliwych - Pamięć Światła«, URL: http://teatrnn.pl/kalendarium/ node/1028/wystawa_„pamięć_sprawiedliwych_-_pamięć_światła“ (am 29.2.2012). 
caust ist der Präsentation von Zeitzeugenberichten gewidmet, die die Hilfe von Menschen aus der Region für verfolgte Juden dokumentieren, daher auch ihr Name: "Lichter in der Dunkelheit - Die Gerechten unter den Völkern" (Światła w Ciemności - Sprawiedliwi wśród Narodów Świata). ${ }^{452}$ Auch in dieser Institution stehen die »Gerechten« damit am Ende des Ausstellungsnarrativs und schaffen einen positiven Ausblick aus der tragischen Geschichte des Holocaust. Zugleich kann man vermuten, dass der Rekurs auf die "noch immer wenig bekannten« Fälle polnischer Hilfe den Besuchern die Akzeptanz und Inklusion dieses schwierigen Kapitels der regionalen Vergangenheit in ihr Geschichtsbild erleichtern soll. ${ }^{453}$

Analog zur Situation in Lublin findet sich auch in Warschau, dessen historische Museen die Besatzungszeit zumeist entlang nationalkonservativer Interpretationsmuster darstellen, mit dem $»$ Haus der Begegnungen mit der Geschichte (Dom Spotkań $z$ Historia, DSH) eine Kulturinstitution, die alternative Geschichtsbilder offeriert. Das prominenteste Beispiel seiner Aktivitäten war die umfangreiche Ausstellung »Oblicza totalitaryzmu« (Gesichter des Totalitarismus), mit der die Einrichtung eröffnet wurde. Die Schau war ursprünglich als Dauerausstellung für die neugeschaffene Institution gedacht; sie wurde 2005 bis 2006 und nochmals 2009 jeweils über einen längeren Zeit-

452 Ebd.

453 Pietrasiewicz, Tomasz: Wstęp. Einleitung. Introduction. In: Dąbrowska, Anna (Red.): Światła w ciemności. Sprawiedliwi Wśród Narodów Świata. Relacje/Lichter in der Finsternis. Gerechte unter den Völkern. Berichte/Lights in the Darkness. The Righteous Among the Nations. Testimonies. Lublin 2008, 3 f. Das wesentliche Ziel des gleichnamigen Projekts, aus dem die Publikation hervorgegangen ist, war es, das Wissen um Fälle polnischer Hilfe in der Bevölkerung der Woiwodschaft Lublin zu verbreitern und diese Taten als positive Elemente der polnischen Vergangenheit zu präsentieren. Dies geschah vor dem Hintergrund der immer noch gerade im ländlichen Raum verbreiteten Ablehnung von Personen, die während des Kriegs Juden geholfen haben. Insbesondere sollte den "Gerechten« die Angst vor dem Öffentlichmachen ihrer Taten genommen werden. Mit den Worten Tomasz Pietrasiewiczs: »[Die Geschichten der Gerechten] werden oft von den Gerechten selbst und ihren Familien nicht als Grund zum Stolz angesehen, sondern als etwas, über das man besser nicht spricht. [...] Wir möchten dies ändern und hoffen, dass unser Projekt hierzu beitragen wird.« Ebd. Siehe auch die Einschätzung von Dariusz Libionka zum selben Thema: Libionka, Dariusz: Sprawiedliwi - jako wyzwanie. Die Gerechten als Herausforderung. The Righteous as a Challenge. In: Ebd., 11-16. Das Burgtor - Theater NN hat darüber hinaus Unterrichtsmaterialien erarbeitet, mit denen die Geschichten von polnischen Helfern und insbesondere die ambivalente Haltung ihrer Umgebung zu diesen Taten, aber auch zur Verfolgung der Juden differenziert behandelt werden können: Baum-Gruszowska, Marzena/ Majuk, Dominika (Red.): Światła w ciemności. Sprawiedliwi Wśród Narodów Świata: relacje historii mówionej w działaniach edukacyjnych [Lichter in der Dunkelheit Die Gerechten unter den Völkern. Zeitzeugenberichte in Bildungsaktivitäten]. Lublin 2009. 
raum in den Räumlichkeiten des DSH gezeigt. ${ }^{454}$ Die Ausstellung präsentierte die Entstehung des totalitären Deutschen Reiches und der Sowjetunion, die gesellschaftlichen und politischen Entwicklungen in der Zweiten Polnischen Republik, den Zweiten Weltkrieg sowie die sowjetische Dominanz in Ostmitteleuropa nach Kriegsende bis zur politischen Wende 1989. Der Fokus lag auf der Geschichte Polens, die als Beispiel für die Zusammenarbeit der zwei totalitären Regime und deren Methoden im 20. Jahrhundert diente. Der Schwerpunkt der Erzählung betraf die Jahre 1939 bis 1945, wobei dem Holocaust an Juden sowie Sinti und Roma die größte Fläche eingeräumt wurde. ${ }^{455}$ Die Präsentation im DSH, gerade auch in dieser Sektion, schilderte ausführlich und differenziert die Reaktionen der autochtonen, größtenteils polnischen Bevölkerung auf die Entrechtung, Enteignung, Demütigung und Morde, schließlich die Deportationen der jüdischen Bevölkerung. Der Antisemitismus und die zunehmende Brutalisierung der Gesellschaft, die Übernahme jüdischen Eigentums, Angst vor Repressionen, die die Denunziation von Juden beförderte - all diese ambivalenten und kritischen Aspekte der polnisch-jüdischen Beziehungen während des Holocaust problematisierte man hier offen. ${ }^{456} \mathrm{Da}$ bei wurden immer wieder gerade konträre Sichtweisen miteinander kontras-

454 Die erste Fassung war zwischen dem 17. September 2005 und der zweiten Septemberhälfte 2006 zu sehen. Die zweite, gestalterisch überarbeitete Version wurde vom 28. September 2009 bis zum 17. Januar 2010 gezeigt. Auskunft von Ewa Mazur, Mitarbeiterin der Ausstellungsabteilung des DSH, per E-Mail vom 30. September 2010; Oblicza totalitaryzmu [Gesichter des Totalitarismus], URL: www.dsh.waw.pl/pl/3_78 (am 18.9.2010); Wystawa »Oblicza totalitaryzmu« [Ausstellung »Gesichter des Totalitarismus«]. In: Gazeta Wyborcza vom 9.12.2012, Online-Ausgabe, URL: http://wiadomosci.gazeta.pl/ kraj/2029020,34309,3058906.html?sms_code $=($ am 24.9.2010 $)$. Die Ausstellung wurde von der Nichtregierungsorganisation Karta entwickelt, aus der auch die Idee für das DSH hervorging. Seit 2006 ist das DSH eine eigenständige kommunale Kulturinstitution der Stadt Warschau, die sich auf die Vermittlung der Geschichte der Stadt, Polens und Ostmitteleuropas im 20. Jahrhundert für ein breites Publikum spezialisiert. Zu seinen zentralen Aktivitäten gehört die Organisation von historischen Ausstellungen. Interview mit Katarzyna Madon-Mitzner, der stellvertretenden Direktorin des DSH und Leiterin der Mediathek, am 25. Mai 2010. Siehe auch: Misja [Mission], URL: http://dsh.waw. $\mathrm{pl} / \mathrm{pl} / \mathrm{misja} / 10$ (am 8.2.2014).

455 Den Jahren 1939 bis 1945 waren elf von insgesamt 18 thematischen Sektionen der Ausstellung gewidmet. Der Holocaust umfasste zehn Ausstellungstafeln; acht Tafeln waren dem Thema »Vertreibungen 1939-49« gewidmet, dessen Schwerpunkt auf dem polnisch-ukrainischen Konflikt in Wolhynien lag. Diese wie auch die weiteren Aussagen zu Inhalten und Elementen der Ausstellung beziehen sich auf die zweite Version der Schau, die von der Verfasserin am 30. Oktober 2009 besucht wurde, sowie auf die digitalen Versionen der Ausstellungstafeln, die der Verfasserin vom DSH zur Verfügung gestellt wurden.

456 Die Präsentation dieser Inhalte erfolgte dabei fast ausschließich über Zeitzeugnisse Zeitzeugenberichte, Fotografien und historische Dokumente. Jede thematische Sektion wurde lediglich von einem Kuratorentext eingeleitet. 
tiert, um die verschiedenen Perspektiven (politische Entscheidungen und deren Auswirkungen auf die Zivilbevölkerung, die Haltungen von Helfern verfolgter Juden und passiven Zuschauern ihres Leids) der Ereignisse deutlich zu machen. Man verwies etwa auf die Hilfe seitens »vieler Personen« für verfolgte Juden sowie auf deren Gegenstück, die "polnischen und ukrainischen sszmalcowniki«; zugleich wurde auch festgestellt: »Der Großteil der polnischen Gesellschaft blieb während des Holocaust passiv.« ${ }^{457}$

Diese zwei exemplarischen Fälle verdeutlichen, dass die Unterschiede in der Darstellung der Besatzungsgeschichte und insbesondere der Verfolgung der jüdischen Einwohner des Landes nicht nur zwischen den verschiedenen Städten des Landes bestanden - und immer noch bestehen -, sondern dass sie auch innerhalb der Städte selbst zu finden sind. ${ }^{458}$ Die Ausdifferenzierung der musealen Erzählungen, die seit der zweiten Hälfte der 1990er-Jahre, verstärkt aber seit Beginn des Museumsbooms 2004, in Polen zu beobachten ist, macht zugleich deutlich, dass gegenwärtig kein Konsens bezüglich der Wahrnehmung der polnischen Juden in der polnischen Geschichte existiert. Gerade bei der Behandlung des für das polnische historische Selbstbild zentralen Zeitraums des Zweiten Weltkriegs ist die Frage der Wahrnehmung und Darstellung der Verfolgung und Vernichtung der jüdischen Bewohner des Landes nach wie vor umstritten. Die diametral unterschiedlichen Präsentationsweisen der Lubliner Ausstellungszentren, der zwei Abteilungen des Lubliner Museums sowie des Burgtor - Theaters NN, sind hier nur ein besonders markantes Beispiel für das Nebeneinander konkurrierender Geschichtsbilder auf engem Raum.

Die merkliche Ausweitung der Darstellung des jüdischen Schicksals während des Kriegs, die in vielen Institutionen im gleichen Zeitraum zu beobachten ist, weist zugleich auf externe erinnerungskulturelle Einflüsse hin, insbesondere auf die Wirkung des internationalen Holocaust-Diskurses. ${ }^{459}$

457 Einleitender Thementext zur Sektion »Holocaust «.

458 Ein weiterer wichtiger Akteur im Bereich der Geschichtsvermittlung mittels historischer Ausstellungen ist das »Büro für Öffentliche Bildung" (Biuro Edukacji Publicznej) des IPN, das neben der Zentrale in Warschau Abteilungen in elf Woiwodschaften des Landes unterhält. Im Juni 2016 wurde das Büro aufgeteilt in ein »Büro für Nationale Bildung" (Biuro Edukacji Narodowej), in dessen Rahmen die Ausstellungstätigkeit des IPN fortgesetzt wird, sowie ein »Büro für Historische Forschung» (Biuro Badań Historycznych).

459 Levy, Daniel/Sznaider, Natan: Erinnerung im globalen Zeitalter: Der Holocaust. Frankfurt am Main 2001, 210-214. Zu den Einflüssen der internationalen Holocaust-Gedenkkultur auf die osteuropäischen Staaten, gerade im Rahmen ihres NATO- und EU-Beitritts, siehe Kroh, Jens: Das erweiterte Europa auf dem Weg zu einem gemeinsamen Gedächtnis? Die Stockholmer »Holocaust-Konferenz« und ihre Bedeutung für die europäische Erinnerung. In: Frölich, Margrit/Jureit, Ulrike/Schneider, Christian (Hg.): Das Unbehagen an der Erinnerung - Wandlungsprozesse im Gedenken an den Holocaust. Frankfurt am Main 2012, 201-216. 
Obwohl die Verfolgung und Vernichtung der polnischen Juden in den meisten Museen noch marginalisiert bleibt, wird dem Thema mittlerweile meist mehr Platz eingeräumt, als dies noch Anfang der 1990er-Jahre der Fall war. Auch Fragen der Stadtentwicklung spielen für diesen Bedeutungszuwachs der Holocaust-Erinnerung in polnischen Städten eine zentrale Rolle. Die Wiederentdeckung ihrer jüdischen Vergangenheit hat die Entwicklung einzelner Städte und ihrer Bezirke wesentlich befördert. Zentral ist hierbei die $\mathrm{Zu}$ nahme der Anzahl ausländischer Touristen in Polen seit den 1990er-Jahren, gerade in den Großstädten. Das prominenteste Beispiel ist Krakau, dessen früheres jüdisches Viertel Kazimierz sich zu einem kulturellen Zentrum und Touristenmagneten entwickelt hat. ${ }^{460}$ Auch für die Revitalisierung des nahegelegenen Bezirks Podgórze wird dessen jüdische Geschichte genutzt: $\mathrm{Mu}$ seen und Gedenkorte zur Erinnerung an das Krakauer Ghetto sowie das Konzentrationslager Płaszów wurden zu prominenten Touristenzielen ausgebaut oder neu errichtet. Ausländische Besucher der Stadt, insbesondere aus westlichen Staaten und Israel, sind eine Hauptzielgruppe dieser Aktivitäten. ${ }^{461}$ Die Schaffung prominenter Gedenkorte des Holocaust zielt nicht zuletzt oft darauf ab, ein positives Stadtimage zu kreieren. So war auch die Etablierung des Gedenkortes an das Ghetto Litzmannstadt in Łódź mit der Überlegung verbunden, das Negativimage der Stadt als antisemitischster des Landes oder gar Europas zu bekämpfen und Łódź unter anderem für jüdische Touristen attraktiv zu machen, die die Stadt bislang weitgehend gemieden hatten. ${ }^{462}$

Die von Michael Steinlauf aufgeworfene Frage nach einer "Wiedergewinnung" der Erinnerung an die jüdischen Stadtbewohner seit der Wende von 1989 kann somit übergreifend bejaht werden - in dem Sinne, dass die Geschichte der Ghettos und ihrer Bewohner in die meisten musealen Erzählungen der untersuchten Städte mittlerweile als eigenes Thema Einzug gehalten hat. Wie deutlich geworden ist, unterscheidet sich die Verortung dieser Ereignisse innerhalb der Narrative jedoch gegenwärtig sehr stark. Die Frage, die demnach aktuell in der polnischen historischen Museumslandschaft als nur einem Element eines größeren erinnerungskulturellen Selbstverständigungsprozesses - verhandelt wird, ist die nach der Zuordnung dieser Er-

460 Murzyn, Monika A.: Kazimierz. Środkowoeuropejskie doświadczenie rewitalizacji [Kazimierz. Eine mitteleuropäische Erfahrung der Revitalisierung]. Kraków 2006, u. a. 267-294, 305-343. Siehe auch Gruber: Virtually Jewish, $107 \mathrm{f}$.

461 Seit den 1990er-Jahren bilden Ausländer einen bedeutenden Teil der Besucher in den Abteilungen Alte Synagoge und Apotheke "Zum Adler« des MHK. In der Apotheke machten sie beispielsweise 2010 knapp 90 Prozent der Besucher aus, in der Alten Synagoge 53 Prozent. Auch die Schindler-Fabrik wird in erster Linie von Ausländern besucht; 2010 machten sie ca. 60 Prozent, 2011 knapp 70 Prozent aller Besucher dort aus. Siehe: Frekwencja roczna 2010 r. AMHK, ohne Signatur, 2 f.; Frekwencja roczna 2011 r. AMHK, ohne Signatur, 2.

462 Siehe Kapitel 3.3. 
eignisse: Bleiben sie zukünftig weiterhin als externes, fremdes Schicksal auf polnischem Boden marginalisiert oder setzt sich die in den Stadtmuseen von Łódź und Krakau etablierte Integration der ehemaligen jüdischen Einwohner in die historische Wir-Gemeinschaft als gleichberechtigte Elemente durch? ${ }^{463}$ Dieser Aspekt ist unmittelbar verknüpft mit der Entwicklung des historischen polnischen Selbstbildes, wie es die Ausstellungen konstruieren. Denn die Inkorporation jüdischer Erfahrungen und Wahrnehmungen der Kriegsjahre als gleichrangige Elemente in ein städtisches und im weiteren Sinne auch staatliches bzw. staatsbürgerlich-nationales Geschichtsbild erfordert die Auseinandersetzung mit den polnisch-jüdischen Beziehungen während der Besatzungen. Das tradierte einseitige und eindeutige polnische Selbstbild der heroischen Widerstandskämpfer und unschuldig für das Vaterland Leidenden wird dabei durch das stetig wachsende Wissen bzw. die Forschungsergebnisse der vergangenen zehn Jahre zu ambivalenten und negativen Verhaltensweisen von Polen gegenüber verfolgten Juden herausgefordert. 



\section{Teil 3 \\ Das polnische museale Selbstbild}

Nachdem in den beiden vorangegangenen Teilen untersucht wurde, in welcher Art und Weise sich die Ausstellungsnarrative in Bezug auf die Kontextualisierung innerer und äußerer Fremd- und Feindbilder entwickelt haben, soll nun die museale Konstruktion der Wir-Gemeinschaft der Polen während der Besatzung im Fokus stehen. Diese kreiste jahrzehntelang um die zentralen Topoi der Helden und Märtyrer. In den untersuchten Dauerausstellungen der 1980er-Jahre fanden sich diese zentralen Interpretationselemente bereits prägnant in den Titeln der einzelnen Präsentationen und Museumsabteilungen. So stand etwa die Dauerausstellung der Abteilung Pomorska-Straße des MHK unter der Überschrift »Walka i męczeństwo Polaków w latach 19391945 (Der Kampf und das Martyrium der Polen in den Jahren 1939-1945). ${ }^{1}$ Das Museum »Unter der Uhr« in Lublin ebenso wie das Museum Radogoszcz trugen die Schlagworte Martyrium und Widerstandskampf ebenfalls bereits in ihrem Namen: Martyrologiemuseum »Unter der Uhr« (Muzeum Martyrologii »Pod Zegarem«) bzw. Museum des Martyriums und des Kampfes in Radogoszcz (Muzeum Martyrologii i Walki w Radogoszczu). ${ }^{2}$ In diesen zwei zentralen Rollen wurde das Schicksal der polnischen Bevölkerung während der Kriegs- und Besatzungsjahre auch in der Schau selbst gefasst: die Rolle der aktiven (Widerstands-)Kämpfer - der Helden - auf der einen Seite und die der Leidenden für das Vaterland - der Märtyrer - auf der anderen. Ähnliche Beschreibungen von Inhalten und Botschaften fanden sich auch in den übrigen untersuchten Museen, die in den 1980er-Jahren besichtigt werden konnten. Besonders herausgehoben waren sie in den Institutionen, die in vormaligen Gefängnissen der Gestapo und anderer deutscher Besatzungsorgane, mithin an authentischen Orten deutscher Verbrechen, untergebracht waren. So wurde etwa das Museum Radogoszcz als »Museum des Martyriums und des Kampfes« bezeichnet, als »Ort des Gedenkens an das Märtyrertum der polnischen Nation in den Jahren der hitleristischen Besatzung «. ${ }^{3}$ Eine Gedenk-

1 Wroński, Tadeusz: Scenariusz wystawy Oddziału Muzeum Historycznego m. Krakowa przy ul. Wybickiego 2 (dawniej ul. Pomorska) pt. »Walka i męczeństwo Polaków w latach 1939-1945«. Kraków 26.5.1981. AMHK, PA-202/25/81, 1.

2 Kowalski: Muzeum Martyrologii; Heinrich/Szczepaniak: Muzeum Martyrologii i Walki, 95.

3 Heinrich/Szczepaniak: Muzeum Martyrologii i Walki, 95. 
tafel direkt neben dem Eingang des Museums "Unter der Uhr« in Lublin erinnert bis heute an die "polnischen Patrioten, die [...] mit ihrem heldenhaften Tod und Leiden Zeugnis ablegten für die Liebe zum Vaterland und den ungebrochenen Willen zur Standhaftigkeit . $^{4}$ Und auch am sogenannten Schlesischen Haus in Krakau, in dessen Kellern sich Folterzellen der Gestapo befanden, wurde eine Gedenktafel angebracht, die das Leiden der Insassen unter das Motto stellt »Dulce et decorum est pro patria mori.$^{5}$

Diese Orte, an denen Menschen unter grausamen Bedingungen gefangen gehalten, gefoltert und ermordet wurden und die Ausgangspunkte für Deportationen in Konzentrations- und Vernichtungslager waren, nahmen von Beginn ihrer Musealisierung an eine Doppelfunktion ein: Sie fungierten als Gedenk- wie auch Informationsorte, was sich auch in ihrer Bezeichnung als "martyrologische« Einrichtungen bzw. Museen widerspiegelte. ${ }^{6}$ Dem entsprach auch die architektonische Ausgestaltung der Institutionen: Das Areal des Gefängnismuseums Pawiak ebenso wie des Museums Radogoszcz wurden als "Denkmal-Mausoleum " (pomnik-mauzoleum) ausgebaut, in denen die historischen Dauerausstellungen zwar einen wesentlichen, aber nur einen von mehreren Bestandteilen der Museums- bzw. Gedenkstättenkomplexe bildeten. ${ }^{7}$ In den kleineren Institutionen, in denen größere Umbauten und die

4 Die Tafel wurde 1979 enthüllt, anlässlich der Eröffnung des Museums. Siehe: Skarżyński, Janusz: Muzeum w Domu pod Zegarem. In: Za wolność i lud vom 1.12.1979. AMLL, Kronika Klubu b. Więźniów Politycznych Zamku Lubelskiego i »Pod Zegarem« Nr. 3 (9/1978-8/1981), ohne Signatur, o.S.

5 Die Gedenktafel wurde am 17. Januar 1975 enthüllt. Gąsiorowski: »Dom Śląski«, 82.

6 Der Terminus "martyrologisches Museum« (muzeum martyrologii, muzeum martyrologiczne) ist in Polen in der Nachkriegszeit aufgekommen und wird, wie Tomasz Kranz festgestellt hat, bis heute weitgehend unreflektiert verwendet, d.h. ohne eine nähere Auseinandersetzung mit dem Komplex von Bedeutungen, die darunter im allgemeinen, aber auch wissenschaftlichen Sprachgebrauch subsumiert werden. Die Durchsetzung des Begriffs ist laut Kranz »Ausdruck der allgemeinen Betrachtung und Interpretation in Polen der Geschichte durch das Prisma der `nationalen Martyrologie«. Die Bezeichnung umfasst Orte, an denen während des Zweiten Weltkriegs von den deutschen Besatzern Verbrechen verübt wurden. Ihnen wird eine kommemorative ebenso wie edukative Funktion zugesprochen. Dazu zählen in erster Linie die ehemaligen Konzentrations- und Vernichtungslager, aber auch andere Inhaftierungs- und Folterstätten, wie etwa die Gefängnisse Radogoszcz und Pawiak. Kranz, Tomasz: Muzea-miejsca pamięci w wymiarze społeczno-politycznym [Museen-Gedenkorte in politisch-gesellschaftlicher Dimension]. In: Przeszłość i Pamięć 3 (1998), 6-12, bes. 6 f., Zitat: 6. Siehe auch Ders.: Die NS-Hinterlassenschaft und die historisch-politische Bildung heute. In: Ders. (Hg.): Die Verbrechen des Nationalsozialismus im Geschichtsbewußtsein und in der historischen Bildung in Deutschland und Polen. Lublin 1998, 157-169, hier 164; Bednarek: Pamięć zbiorowa, 230-232.

7 Heinrich/Szczepaniak: Muzeum Martyrologii i Walki, 96. Das Pawiak-Museum wurde ursprünglich als kurhan (Grabhügel) eröffnet; spätestens seit den 1990er-Jahren wird es als »Mausoleum« bezeichnet. Scenopis stałej ekspozycji Muzeum Więzienia "Pawiak«. Warszawa 1987. AMNW, Scen. 72, 1; Izdebska: Muzeum Więzienia »Pawiak«, 252. 
Schaffung von Denkmalarrangements nicht möglich waren, da sie sich in größeren und bereits anderweitig genutzten Gebäuden befanden, wurden die bereits erwähnten Gedenktafeln angebracht. Als Orte des Leidens und Todes oder des letzten bekannten Aufenthaltsortes von Angehörigen der lokalen Bevölkerung waren diese Stätten seit Kriegsende zu Orten der privaten und später auch institutionalisierten Erinnerung und Kommemoration geworden. Exemplarisch steht dafür das Areal des ehemaligen Pawiak-Gefängnisses: Neben dem neugebauten Museumsgebäude, einem Denkmal und dem symbolisch arrangierten ehemaligen Gefängnishof gehörte zu den wesentlichen Elementen des 1965 eröffneten Komplexes der einzige Baum auf dem Gelände, der die Zerstörung überstanden hatte. Dieser war bereits kurz nach Kriegsende zu einem symbolischen Friedhof für viele Menschen geworden, deren Angehörige zuletzt dort lebend gesehen worden waren; ihre Familien brachten daran Todesanzeigen und Grabtafeln an. In dieser Funktion wurde der Baum schließlich selbst zu einem Symbol des Ortes, als »Zeuge der deutschen Verbrechen, die man nicht vergessen kann, ebenso wie des Leidens und des Heldentums der Gefangenen ${ }^{8}$. Als er Mitte der 1980er-Jahre abstarb und schließlich Anfang des neuen Jahrhunderts abgetragen werden musste, ersetzte man ihn durch eine originalgetreue Skulptur. ${ }^{9}$ Ein zentrales Element des »Mausoleums « Radogoszcz dagegen ist ein Sarkophag aus schwarzem Granit, der inmitten der Ruine des abgebrannten Gefängnisgebäudes, auf einem "symbolischen Grab in Form eines kleinen Grabhügels« aufgestellt worden war und den Opfern des Massakers vom 18. Januar 1945 gewidmet ist. ${ }^{10}$ In der Eingangshalle des Ausstellungsgebäudes waren zudem Urnen mit der Asche von in Konzentrationslagern Ermordeten aufgestellt; den akustischen Hintergrund dieses Raums wie der daran anschließenden Dauerausstellung bildete Trauermusik. ${ }^{11}$ Asche von KZ-Opfern fand sich auch im Pawiak-Museum: Im rekonstruierten Zellentrakt des ehemaligen Hauptgebäudes stellte man in der

8 So die Darstellung in einem Themenraum, der der Geschichte des Baums gewidmet ist. MNW-Pawiak, Themenraum »Das Denkmal des Baumes«. Siehe auch Izdebska: Muzeum Więzienia »Pawiak«, 265-267.

9 Der Baum starb 1984 ab, wurde jedoch weiterhin konserviert. Erst als er drohte umzustürzen, wurde er 2004 entfernt und 2005 durch einen Bronzeabguss ersetzt. Die Enthüllung der Skulptur erfolgte durch den Warschauer Stadtpräsidenten Lech Kaczyński und den Marschall der Woiwodschaft Masowien. Woltanowska, Magdalena: Pomnik Drzewa Pawiackiego [Das Denkmal des Pawiak-Baums]. In: Niepodległość i Pamięć 22 (2006), 259-266, bes. 259-262; Izdebska: Muzeum Więzienia »Pawiak«, 265-267. Gegenwärtig ist der Geschichte des Baums und seines Denkmals ein eigener Ausstellungssaal gewidmet.

10 Heinrich/Szczepaniak: Muzeum Martyrologii i Walki, 97 (Zitat); Teren Mauzoleum Radogoskiego [das Areal des Mausoleums Radogoszcz]. In: Iwanicki/Janaszek/Rukowiecki: Martyrologium Łódzkie, 12-20, hier 15-17.

11 Heinrich/Szczepaniak: Muzeum Martyrologii i Walki, 98. 
sogenannten Todeszelle Urnen mit Asche von Opfern der Lager Sachsenhausen und Majdanek auf. ${ }^{12}$ Diese finden sich dort bis heute. Der Raum bildet einen symbolischen Ort der Kommemoration, der regelmäßig von ehemaligen Häftlingen und deren Angehörigen besucht wird; Zeichen der lebendigen Erinnerung sind die frischen Blumen, die dort bis heute regelmäßig aufgestellt werden. ${ }^{13}$ Die symbolische Bedeutung dieser Orte unterstrichen auch die offiziellen Gedenkzeremonien, die in den martyrologischen Museen zu zentralen Daten stattfanden, so etwa zu den Jahrestagen der Befreiung einzelner Städte, dem 9. Mai und den Jahrestagen der letzten Massaker vor Ort. ${ }^{14}$ Das ganze Jahr über, insbesondere jedoch an Allerheiligen, werden bis heute auf dem Gelände der Museen, an einzelnen Denkmälern und Gedenktafeln Blumen niedergelegt und Grablichter angezündet. ${ }^{15}$ Auch in neu geschaffenen Institutionen, die speziell der Geschichte der Kriegs- und Besatzungsjahre gewidmet sind und sich nicht immer an authentischen Orten von Verbrechen befinden, werden teilweise kommemorative Elemente integriert, wie in Kapitel 1.3 und 2.3 am Beispiel des Museums des Warschauer Aufstands noch eingehender geschildert wird.

Im Folgenden wird der Frage nachgegangen, inwiefern sich das traditionelle Deutungsmuster der Helden und Märtyrer, das sich in den beschriebenen Entstehungskontexten einzelner Schauen und Museumsareale sowie den dort zu beobachtenden sozialen Praktiken manifestiert, in den drei Jahrzehnten des Untersuchungszeitraums gewandelt hat. Ein besonderes Augenmerk soll hierbei insbesondere auf dem Zusammenspiel zwischen der Entwicklung polnischer Auto- und der bereits untersuchten Heterostereotype liegen. In diesem Kontext interessiert weiter, inwieweit neue Selbst- bzw. Gemeinschaftsbilder von Polen Eingang in die historischen Ausstellungen finden. Nicht zuletzt stellt sich schließlich die Frage, welche Leerstellen in den Erzählungen festzustellen sind. Mittels dieser Analysen sollen zwei zentrale Thesen der jüngeren Erinnerungskulturforschung überprüft werden: Zum einen geht

12 Eine Tafel informierte darüber, dass die Insassen der Todeszellen von diesen aus zu den Exekutionen geführt wurden. Scenopis stałej ekspozycji, 112. Das Arrangement dieses Raumes und seine Gedenkfunktion werden bis heute bewahrt. Auf der Texttafel wurde lediglich der Begriff »hitleristisch« durch »deutsch» ersetzt.

13 Interview mit Joanna Gierczyńska, der Leiterin des Gefängnismuseums Pawiak, am 9. Juli 2009.

14 Die Gedenkveranstaltungen in Radogoszcz seit Kriegsende skizzieren Heinrich/Szczepaniak: Muzeum Martyrologii i Walki, 96, 107. Zum Gefängnismuseum Pawiak: Domańska, Regina: Muzeum Więzienia »Pawiak« [Das Gefängnismuseum »Pawiak»]. In: Muzea Walki 1 (1968), 88-97, hier 90.

15 Heinrich/Szczepaniak: Muzeum Martyrologii i Walki, 102. Dies bestätigen auch die Beobachtungen der Verfasserin während der Recherchen und der zahlreichen Aufenthalte vor Ort in den Jahren 2009 bis 2012. 
es um die Annahme einer zunehmenden geschichtspolitischen und erinnerungskulturellen Konzentration auf die passiven Opfer von Gewalt, die europaweit und damit auch in den Ländern des ehemaligen Ostblocks zu erkennen sei. ${ }^{16}$ Zum anderen soll untersucht werden, inwieweit sich die in den museum studies verbreitete These des sich seit den 1970er-Jahren in Westeuropa herausbildenden Primats der Alltagsgeschichte, das heißt der Konzentration auf die Geschichte und die individuelle Erfahrungen sogenannter einfacher Menschen, und deren Auswirkungen seit den 1980er-Jahren auf die museale Inszenierung von Krieg und Besatzung auf das polnische Beispiel übertragen lässt. ${ }^{17}$

\section{Opferbilder}

Zentral bei der Untersuchung der musealen Konstruktion von Opferbildern ist die Frage, wie die zwei Pole des ambivalenten Opferbegriffs gewichtet sind und welchen Veränderungen sie unterliegen. Zum einen unterscheidet man Opfer, die selbstbestimmt für etwas, meist ein höheres Gut wie etwa die Nation oder das Vaterland, leiden oder gar ihr Leben geben; sie werden mit dem lateinischen Terminus sacrificium gefasst. Dieses Verständnis liegt dem Begriff des Märtyrers zugrunde, der als heroisches Opfer kontextualisiert wird und oft eine sakrale Komponente enthält, die dem religiösen Ursprung des Wortes zuzuschreiben ist. Von diesem wird der Typus des passiv Leidenden unterschieden, die sogenannte victima, die synonym für das unschuldige Leiden bzw. das Opfer von Verbrechen steht. Diese zwei Pole des Opferbegriffs markieren auch eine grundsätzliche Unterscheidung zwischen Subjekten historischer Ereignisse einerseits, den sich selbstbestimmt Opfernden und damit aktiv Handelnden, und den "passive[n] und wehrlose[n] Objekten von

16 Sabrow, Martin: Die postheroische Gedächtnisgesellschaft. Bauformen des historischen Erzählens in der Gegenwart. In: François, Etienne u. a. (Hg.): Geschichtspolitik in Europa seit 1989. Deutschland, Frankreich und Polen im internationalen Vergleich. Göttingen 2013, 311-322, hier 314f.; Kaiser/Krankenhagen/Poehls: Europa ausstellen, 76 f.; Piskorski, Jan M.: Od kultu herosów do adoracji ofiar. Przemiany w kulturze pamięci [Vom Kult der Heroen zur Verehrung der Opfer. Veränderungen der Erinnerungskultur]. In: Więź 53/2-3 (2010), 5-20, hier 13. Kritisch setzt sich mit dieser Entwicklung auseinander Lagrou, Pieter: Europa als Ort gemeinsamer Erinnerungen? Opferstatus, Identität und Emanzipation von der Vergangenheit. In: François, Etienne u. a. (Hg.): Geschichtspolitik in Europa seit 1989. Deutschland, Frankreich und Polen im internationalen Vergleich. Göttingen 2013, 298-308, bes. 300 f., 308.

17 Thiemeyer: Fortsetzung des Krieges, $118 \mathrm{f}$., 126f, $145 \mathrm{f}$; Kaiser/Krankenhagen/Poehls: Europa ausstellen, $165 \mathrm{f}$., $228 \mathrm{f}$. 
Gewalt" andererseits. ${ }^{18}$ Für die Entwicklung des Opfergedächtnisses und nicht zuletzt für dessen (auch museale) Darstellung ist diese Unterscheidung zentral, da sie stark an normative Wertungen von »würdigem» oder »sinnlosem « Leiden gebunden ist. Weder die deutsche noch die polnische Sprache kennen eine ähnliche begriffliche Trennung des Opferbegriffs wie sie im Lateinischen, aber etwa auch im Englischen (victim versus sacrifice) vorgenommen wird. Im Polnischen gibt es, ähnlich wie im Deutschen, neben dem übergreifenden Terminus ofiara (Opfer), der beide Bedeutungspole umfasst, allein die direkte Präzisierung męczennik (Märtyrer) bzw. martyrologia (Martyrium) und męczeństwo (Martyrium / Märtyrertum).

Anhand der Analyse der Opferdarstellungen wird in diesem Abschnitt der Frage nachgegangen, inwieweit im Fall polnischer musealer Geschichtsdarstellungen eine "passive Wendung ${ }^{19}{ }^{19}$ konstatiert werden kann. Ist also eine Subjektivierung der passiven Opfer festzustellen; werden die unschuldig Leidenden in den musealen Narrativen zu Akteuren der historischen Ereignisse, oder bleiben sie deren passive Objekte (20 $^{20}$ Welche Formen der Sinnstiftung für das geschilderte Leiden und Sterben und darauf basierende Hierarchien von Opfergruppen sind auszumachen? Der Themenkomplex umfasst schließlich auch Fragen nach der Entwicklung von Opferkonkurrenzen, also danach, inwieweit andere Gruppen Verfolgter Eingang in die Erzählungen oder gar in die konstruierten Wir-Gemeinschaften finden.

\subsection{Die 1980er-Jahre - martyrologische Sinnstiftung}

Wie die einleitenden Ausführungen illustrieren, waren gerade die martyrologischen Museen und Abteilungen einzelner Institutionen bereits in den Anfängen ihrer Musealisierung Orte der Trauer und des Gedenkens an die Opfer des Besatzungsterrors. Dementsprechend nahm die Schilderung der Leiden der Inhaftierten in ihren Dauerausstellungen von Beginn an großen Raum ein. Verhör- bzw. Foltermethoden illustrierte man mit Fotografien oder Zeichnungen, die von ehemaligen Häftlingen oder nach ihren Berichten angefertigt worden waren; schriftliche Zeugnisse - in Form von Erfahrungsberichten, die nach dem Krieg verfasst wurden, oder Kassibern, die an Freunde und Ver-

18 Assmann: Der lange Schatten der Vergangenheit, 72-74, Zitat: 73; Münkler, Herfried/ Fischer, Karsten: »Nothing to kill or die for ...« Überlegungen zur politischen Theorie des Opfers. In: Leviathan 28/3 (2000), 343-362, hier 345 f. Siehe auch Schulze Wessel, Martin: Einleitung. In: Franzen, K. Erik/Schulze Wessel, Martin (Hg.): Opfernarrative. Konkurrenzen und Deutungskämpfe in Deutschland und im östlichen Europa nach dem Zweiten Weltkrieg. München 2012, 1-8, hier $1 \mathrm{f}$.

19 Münkler/Fischer: »Nothing to kill or die for ...«, 348 .

20 Schulze Wessel: Einleitung, 2. 
wandte außerhalb der Gefängnismauern geschmuggelt worden waren - gaben Einblicke in die Erlebnisse Einzelner. ${ }^{21}$ Ebenso wurden in einigen Präsentationen großformatige Fotos von Opfern der Massenexekutionen vor Ort gezeigt. ${ }^{22}$ Im Pawiak-Museum konnten sich die Besucher auch Audioaufnahmen von eingesprochenen Kassibern anhören. ${ }^{23}$ Diese Elemente prägten die affektive Rezeption der historischen Ereignisse entscheidend. ${ }^{24}$ Die ausführliche Schilderung der grausamen Methoden der Besatzer war jedoch nicht auf die martyrologischen Museen beschränkt. Auch im Historischen $\mathrm{Mu}-$ seum der Hauptstadt Warschau wurde das Schicksal der in der Szucha-Allee ${ }^{25}$

21 Im Museum »Unter der Uhr« in Lublin wurden sowohl zahlreiche Zeitzeugenberichte als auch eine Fotografie gezeigt, auf der ein ehemaliger Insasse Foltermethoden nachstellte. Ebenso wurden Schlagstöcke und Ketten gezeigt, die die Wärter verwendeten. MLLUnter der Uhr, Zelle 7. Siehe auch die Fotodokumentation der 1979 eröffneten Schau in: AMLL, Kronika Klubu b. Więźniów Politycznych Zamku Lubelskiego i »Pod Zegarem» Nr. 3 (9/1978-8/ 1981), ohne Signatur, o. S. In der Abteilung Pomorska-Straße des MHK war den »Untersuchungsmethoden der Gestapo« die Sektion 2.a der Dauerausstellung gewidmet. Darin präsentiert wurden Zeichnungen eines ehemaligen Häftlings, die Foltermethoden illustrierten. In einer Vitrine waren Folterwerkzeuge untergebracht, darunter Peitschen, Schlagstöcke, Handschellen sowie eine Gasmaske. Ebenso zu sehen waren - teilweise handschriftlich verfasste - Erinnerungen ehemaliger Inhaftierter sowie Kassiber. Wroński: Scenariusz wystawy, 7-9. In der Ausstellung des Gefängnismuseums Pawiak fanden sich zahlreiche Berichte ehemaliger Insassen ebenso wie Kassiber. Scenopis stałej ekspozycji, 59f., 66, 69, 84-86. Im Museum Radogoszcz präsentierte man neben den Folterwerkzeugen und Berichten ehemaliger Insassen auch Zeugenaussagen aus dem Prozess gegen den deutschen Kommandanten des Gefängnisses. Heinrich/Szczepaniak: Muzeum Martyrologii i Walki, 100.

22 So im Museum »Unter der Uhr« in Lublin, dessen Ausstellung mit Fotografien der Leichen des letzten Massakers der Deutschen auf dem Lubliner Schloss am 22. Juli 1944 endete. Ausstellungstafel »Der Mord auf dem Schloss 22. VII. 1944«. MLL-Unter der Uhr, Zelle 10. Im Museum Radogoszcz wurden ebenfalls die Opfer des von den Deutschen bei ihrem Abzug am 18. Januar 1945 verübten Massenmordes auf vergrößerten Fotografien präsentiert. Heinrich/Szczepaniak: Muzeum Martyrologii i Walki, 100.

23 Diese Aufnahmen standen in mehreren Sprachen zur Verfügung. Domańska: Muzeum Więzienia »Pawiak«, 89. Bis in die Gegenwart gehören Einspielungen von Kassibern zum Rundgang aller organisierten Besuchergruppen.

24 Die besonders starke Wirkung dieser Ausstellungssektionen wird für die Dauerausstellung des Museums Radogoszcz geschildert. Siehe Heinrich/Szczepaniak: Muzeum Martyrologii i Walki, 100. In einem Bericht zur Tätigkeit des Pawiak-Museums wird darauf verwiesen, dass der Saal, in dem die Audioaufnahmen von Kassibern angehört werden, für viele gerade junge Besucher der eindrücklichste des Ausstellungsrundgangs ist. Domańska: Muzeum Więzienia »Pawiak«, 88 f., 91.

25 An der Szucha-Allee 25 in Warschau war während der deutschen Besatzung der Sitz des Kommandanten der Sicherheitspolizei und des SS-Sicherheitsdienstes des Distrikts Warschau untergebracht. Daneben befand sich dort ein Untersuchungsgefängnis der Gestapo, in dessen Verhörräumen Häftlinge u.a. des Pawiak-Gefängnisses gefoltert wurden. 
und im Pawiak Gefolterten und Ermordeten mit ähnlichen Materialien veranschaulicht. ${ }^{26}$

Neben den Geschehnissen an den konkreten Ausstellungsorten bzw. früheren Inhaftierungsstätten stellte der Besatzungsterror in der jeweiligen Stadt und Region einen weiteren thematischen Schwerpunkt dar. Fotos zeigten die Opfer von Massenexekutionen, die deutsche Einheiten bei Kriegsausbruch verübten, und Gefangene von Straßenrazzien; die berüchtigten »Bekanntmachungen" (obwieszczenia) der Besatzungsorgane illustrierten die massenweise verhängten und öffentlich verkündeten Todesurteile. ${ }^{27}$ In diesem Rahmen wurde auch auf jüdische (Todes-)Opfer bzw. das Schicksal der Ghettoinsassen verwiesen. ${ }^{28}$ Gerade die gezeigten anonymen fotografischen Darstellungen von Razzien und Exekutionen lenkten den Blick auf zufällige, damit auch wehrlose und unschuldige Opfer der Besatzer. Diese erschienen in den Sektionen, die dem »Besatzungsterror" gewidmet waren, damit in erster Linie als Objekte der Gewalt der Deutschen.

Die Konzentration auf dieses von den Besatzern verursachte Leiden erfüllte mehrere Funktionen. Vordergründig diente diese Darstellungspraxis der Dokumentation der Grausamkeit und Unmenschlichkeit der »Hitleristen«, mithin gewissermaßen der Beweisführung für die vor Ort verübten Verbrechen und damit auch der Anklage der Verantwortlichen. Diese Funktion wurde von den Mitarbeitern einzelner Institutionen auch explizit benannt.

26 Ausgestellt wurden die Fotokopie eines Kassibers aus dem Pawiak-Gefängnis sowie Folterwerkzeuge, die bei den Verhören in der Szucha-Allee eingesetzt wurden. Informator do ekspozycji: 1. »Warszawa w latach drugiej wojny światowej« (1939-1945) 2. »Warszawa - stolicą Polski Ludowej« (III piętro). AP, zespół 3195/I (Muzeum Historyczne m. st. Warszawy), teczka 76, MHW-440, 45-57, hier 48.

27 Wroński: Scenariusz wystawy, $3 \mathrm{f}$.; Informator do ekspozycji, $48 \mathrm{f}$. Im Pawiak-Museum fand sich gleich im ersten Abschnitt der Sektion zum Zweiten Weltkrieg ein Bekanntmachungsplakat der ersten Opfer öffentlicher Exekutionen in Warschau. Ebenso enthielt die Schau zahlreiche Listen, die die Opfer der Massenexekutionen an verschiedenen Tagen summarisch aufführten, darunter von Massakern in Palmiry und in den Ruinen des zerstörten Ghettogeländes. Scenopis stałej ekspozycji, 53, 70-72. Im Lubliner Museum »Unter der Uhr« fanden sich wenigstens drei Bekanntmachungen im Zellengang sowie in Zelle 6. In Zelle 9 stellte man die Orte von Exekutionen innerhalb der Stadt wie im Distrikt Lublin kartografisch dar; die einzige öffentliche Exekution war mittels eines Zeitungsartikels und Zeugenberichten illustriert. MLL-Unter der Uhr, Zelle 6, 9. Auch im Museum Radogoszcz gehörten die Bekanntmachungen der Besatzungsorgane über zum Tode Verurteilte und Exekutierte zu zentralen Elementen der Illustration der Besatzungspolitik. Siehe die Schilderungen zum ersten Saal der Schau in Heinrich/Szczepaniak: Muzeum Martyrologii i Walki, 98.

28 In der Abteilung Pomorska-Straße des MHK, im MHW ebenso wie im Museum Radogoszcz waren die knappen Darstellungen der Verfolgung und Segregation der jüdischen Bevölkerung in den Sektionen mit den programmatischen Titeln »Besatzungsterror« untergebracht. Wroński: Scenariusz wystawy, 4; Informator do ekspozycji, 48 f.; Heinrich/ Szczepaniak: Muzeum Martyrologii i Walki, 100. Detailliert hierzu siehe Teil 2, Kapitel 1. 
Regina Domańska, die erste Leiterin des Gefängnismuseums Pawiak und selbst eine ehemalige Pawiak-Insassin, äußerte sich zur Sammlung von Informationen über das ehemalige deutsche Wachpersonal folgendermaßen: »[Es] erschien [...] notwendig, ihre Namen und möglichst vollständige Daten zu erfassen. Vielleicht trägt dieses Material wenigstens in kleinem Maße dazu bei, Beweise ihrer Verbrechen zusammenzutragen. ${ }^{29}$ Ein Zeitungsbericht zur Eröffnung des Museums »Unter der Uhr« in Lublin legt nahe, dass dieses Anliegen vom Publikum durchaus wahrgenommen wurde. Der Autor schreibt: »Dokumente, Fotokopien, Fotos ... Jedes Exponat klagt die hitleristischen Verbrecher an. ${ }^{30}$ Insbesondere die Namenslisten von Wärtern und Befehlshabern der einzelnen Inhaftierungs- und Folterstätten, die in allen untersuchten martyrologischen Abteilungen aus diesem Zeitraum zu finden waren, vermittelten das Bestreben nach einer Beweisführung und zugleich der Anklage von Schuldigen. Unter der unmissverständlichen Überschrift »Folterknechte« (oprawcy) waren jeweils die Verantwortlichen einzeln aufgeführt, teilweise auch mit ihrem militärischen Rang und einer kurzen Information über ihre Verurteilung während des Kriegs (durch Gerichte des Untergrundstaates) oder danach. ${ }^{31}$ Die buchstäblich dokumentarische Funktion der Schauen spiegelt die zentrale Rolle wider, die die Museen bei ihrer Gründung, aber auch in den folgenden Jahrzehnten einnahmen: Ihre Mitarbeiter mussten einen Großteil der historischen Ereignisse an den jeweiligen Orten (Exekutionen, Deportationen, Lebensbedingungen der Häftlinge etc.) erst rekonstruieren. Dank ihrer Forschungsarbeit wurden nicht nur Zeugenberichte gesammelt, sondern es sind auch Materialsammlungen von Insassen, Deportierten sowie dem deutschen Personal entstanden. ${ }^{32}$

29 Domańska: Muzeum Więzienia »Pawiak«, 93; Izdebska: Muzeum Więzienia »Pawiak«, 259. Der Gesamtkomplex des Museums Radogoszcz wurde insgesamt als »Zeugnis des Verbrechens des Völkermords« (dokument zbrodni ludobójstwa) bezeichnet. Heinrich/ Szczepaniak: Muzeum Martyrologii i Walki, 95.

30 Skarżyński: Muzeum w Domu pod Zegarem.

31 So im Lubliner Museum »Unter der Uhr« und in der Abteilung Pomorska-Straße in Krakau sowie im Pawiak-Museum in Warschau, wo eine Liste der »Folterknechte der Gestapo« sowie der Kommandanten des Gefängnisses und ihrer Stellvertreter präsentiert wurde. MLL-Unter der Uhr, Zelle 10; Wroński: Scenariusz wystawy, 9 f.; Scenopis stałej ekspozycji, 63-65.

32 In diesem Zusammenhang arbeiteten die einzelnen Museen eng mit den Vereinigungen der früheren Häftlinge zusammen, die Erfahrungsberichte, Namen, aber auch Dokumente und Objekte für die Ausstellungen zur Verfügung stellten. Domańska, Regina: Problematyka badań nad dziejami Pawiaka w okresie okupacji [Die Problematik der Erforschung der Geschichte des Pawiak während der Besatzungszeit]. In: Muzeum Historii Polskiego Ruchu Rewolucyjnego w Warszawie, 58-65; Dies.: Muzeum Więzienia "Pawiak«, 91-96; Salwiński, Jacek: Ulica Pomorska 2. Oddział Muzeum Historycznego Miasta Krakowa. Dorobek, potrzeby, perspektywy [Pomorska-Straße 2. Abteilung des 
Die Betonung des massenhaften Charakters der Verfolgung und der Todesopfer diente zugleich als Beleg für die in den Schauen postulierte Vernichtungsabsicht der "Hitleristen " gegenüber der polnischen Nation. ${ }^{33}$ Besonders eindrücklich zeigt dies das Beispiel der Dauerausstellung im Pawiak-Museum, in der die symbolische Opferzahl von sechs Millionen polnischer Staatsbürger als Beleg dafür herangezogen wurde, dass »von allen Ländern, die am Krieg mit Hitler-Deutschland teilnahmen, [...] Polen die größten Verluste in Bezug auf seine Gesamtbevölkerungszahl erlitten [hat] «. ${ }^{34}$ In dieser Argumentation vereinnahmte man die jüdischen Opfer stillschweigend unter die Gesamtbevölkerung. Bei der näheren Darstellung gerade von Konzentrationslagern wiederum wandte man eine solche Auswahl und Präsentationsweisen von Fakten an, dass der Eindruck entstand, ethnische Polen hätten die größte Opfergruppe des Besatzungsterrors ausgemacht. ${ }^{35}$ Die Betonung der Grausamkeit auf der einen und des unmenschlichen Leidens auf der anderen Seite unterstrich zudem die klare Abgrenzung zwischen der eigenen Wir-Gemeinschaft und den Besatzern in eindeutigen normativen Kategorien von "gut« und »böse«.

Das Leiden der polnischen Nation wurde jedoch in allen Schauen nicht in erster Linie im Rahmen von victima kontextualisiert; "passive und wehrlose Objekt[e] von Gewalt « ${ }^{36}$ waren in allen Schauen zwar präsent, bildeten jedoch lediglich den anonymen Hintergrund der Erzählung. Auf die Unschuld und Wehrlosigkeit der Opfer des Besatzungsterrors wurde etwa im Pawiak-Museum hingewiesen: Auf den präsentierten Listen von Massenexekutionen und Deportationen in KZs benannte man jeweils die Zahl der Frauen und Kinder unter den Opfern einzeln und betonte sie damit. ${ }^{37}$ Auch in einem präsentierten Gedichtfragment waren »Frauen, Jungen, Kinder ... « als Leidtragende der Gewaltexzesse hervorgehoben. ${ }^{38}$ Und tatsächlich ist davon auszugehen, dass viele der auf den namenlosen Fotografien, Zeichnungen und Exekutionslisten Aufgeführten Zivilisten waren. ${ }^{39}$ Die diversen Verhaftungsgründe und Aktivitäten der Gefängnisinsassen wie der übrigen Todesopfer wurden jedoch in den übergreifenden Kontext einer postulierten allgemeinen

Historischen Museums der Stadt Krakau. Schaffen, Bedürfnisse, Perspektiven]. In: Sowiniec 19 (2001), 137-148, hier 137f., 141-145; Heinrich/Szczepaniak: Muzeum Martyrologii i Walki, $96 \mathrm{f}$., 104.

33 Siehe hierzu Teil 1, Kapitel 1.1.

34 Scenopis stałej ekspozycji, 56.

$35 \mathrm{Zu}$ der in den Schauen angewandten »Opferarithmetik« siehe Teil 2, Kapitel 1.1.

36 Assmann: Der lange Schatten der Vergangenheit, 73.

37 Scenopis stałej ekspozycji, 55, 57, 70-72, $90 \mathrm{f}$.

38 Ebd., 73.

39 Im Pawiak wurde etwa auf einer Liste von Exekutionen explizit darauf verwiesen, dass neben Häftlingen des Pawiak im Juli 1943 u. a. auch »über 300 internierte jüdische Familien« sowie "ca. 400 auf der Straße gefangengenommene Personen« in den Ruinen des Ghettos erschossen wurden. Scenopis stałej ekspozycji, $70 \mathrm{f}$. 
Widerständigkeit der Nation eingeschrieben. Dies geschah zum einen durch die Auswahl der namentlich vorgestellten Individuen. Von den Häftlingen des Pawiak-Gefängnisses etwa, die auf der Rückwand des Ausstellungssaals mit Fotografien und kurzen Biogrammen porträtiert waren, gehörten drei Viertel Untergrundgruppierungen an. ${ }^{40}$ Auch im MHW, in der PomorskaStraße in Krakau und im Łódźer Museum Radogoszcz waren es in erster Linie die Anführer einzelner Widerstandsgruppen der Stadt und Region, die in der Schau namentlich und mit Fotografien individuell herausgestellt wurden. ${ }^{41}$ Ihre derart hervorgehobene Darstellung markierte sie zugleich als vermeintliche Repräsentanten einer breiteren Mehrheit der Bevölkerung. Hierbei sei angemerkt, dass in den Untersuchungsgefängnissen der Besatzer zahlreiche Mitglieder von Untergrundgruppen gefangen gehalten und verhört wurden. Daneben fanden sich jedoch auch viele auf bloßen Verdacht oder aufgrund zufälliger Umstände inhaftierte Zivilisten. Die heterogene Zusammensetzung der Häftlinge wie der übrigen Opfer des »hitleristischen« Terrors wurde in den Schauen dennoch suggestiv zu einer insgesamt widerständigen Gemeinschaft zusammengefasst.

Im Pawiak-Gefängnis wurde diese Deutung den Besuchern auf mehreren Ebenen vermittelt. Unmissverständlich hieß es im einleitenden Thementext der dem Widerstand gewidmeten Sektion:

Die Häftlinge, die in ihrer überwältigenden Mehrheit aus den Reihen der gegen den Besatzer Kämpfenden gerissen waren, blieben Teil der kämpfenden Nation. Die Bestialität des Feindes erregte Furcht, spornte jedoch auch zum Kampf an. [...] [D]er Kampf der Häftlinge des Pawiak dauerte ununterbrochen an. [...] Dieser Kampf ließ hoffen. $^{42}$

Daneben fanden sich in der Dauerausstellung zahlreiche Gedichte, die ähnliche Sichtweisen offenbarten. Grafisch hervorgehoben war beispielsweise ein Ausschnitt aus einem Poem Władysław Broniewskis. Die Opfer der ersten öffentlichen Exekution von Pawiak-Häftlingen werden dort als Kämpfer für die »Freiheit [...], das Volk, unser Brot - und die Unabhängige [gemeint ist Polen - d. Vf.] « bezeichnet, als Vorreiter, denen »Millionen von uns« folgten. ${ }^{43}$ Auch die in allen Schauen präsentierten Bekanntmachungen suggerierten eine allgemeine Resistenz der Bevölkerung: Die Plakate - die in ihrer polnischen Sprachversion gezeigt und damit von den Besuchern gelesen

40 Ebd., 95-109.

41 Informator do ekspozycji, 49-52; Wroński: Scenariusz wystawy, 4f.; Heinrich/Szczepaniak: Muzeum Martyrologii i Walki, 101.

42 Thementext »Kampf und Hoffnung«. Scenopis stałej ekspozycji, 80.

43 Der Abschnitt stammt aus Broniewskis Gedicht »Pięćdziesięciu» (Die Fünfzig). Ebd., 58. Weitere Gedichte ähnlicher Aussage: ebd., 89, 94. 
werden konnten $-{ }^{44}$ benannten jeweils Angriffe auf Vertreter der Besatzungsmacht als Gründe für die Exekution von Verurteilten und die Androhung weiterer Opfer, sollten sich ähnliche Ereignisse wiederholen. Zudem war bei zahlreichen Personen als Grund für die Verurteilung die "Zugehörigkeit zu verbotenen Organisationen ${ }^{45}$ genannt - eine Anklage, die freilich die Perspektive der Besatzungsjustiz wiedergibt und nicht zwingend den Aktivitäten der konkreten Personen entsprechen musste. Das Leiden unter dem Terror der Besatzer wurde somit martyrologisch umgedeutet; ihm wurde Sinn verliehen als Leiden im Rahmen des Kampfes für ein höheres Gut: das Vaterland. Im Pawiak wurde diese Deutung expressiv mittels einer Häftlingsinschrift zusammengefasst, die aus einer Zelle in der Szucha-Allee stammte: »Es ist leicht, von Polen zu sprechen / schwieriger, für sie zu arbeiten / noch schwieriger zu sterben, / und am schwersten, für sie zu leiden. $\aleph^{46}$ Die Opfer der Besatzungsgewalt - unabhängig davon, ob sie tatsächlich widerständig agiert hatten - wurden somit nicht als victimae, sondern sacrificia kontextualisiert, als heroische Opfer. Durch die Suggestion, das ganze Volk habe für die Freiheit Polens gekämpft und gelitten, verknüpfte man somit die Rollen der Opfer, die als Märtyrer präsentiert wurden, und der Helden unmittelbar miteinander. ${ }^{47}$

Eine Ausnahme von dieser Darstellungspraxis bildeten in den meisten der untersuchten Schauen jedoch die jüdischen Opfer. Sofern sie überhaupt erwähnt wurden, porträtierte man sie als passive Opfer der Willkür und Grausamkeit der Deutschen, wobei die visuelle wie kognitive Thematisierung ihres Leidens deutlich geringer im Umfang und weniger explizit war, damit auch weniger eindrücklich und affektiv. ${ }^{48}$ Die randständige Darstellung suggerierte ein scheinbar geringeres Ausmaß ihrer Verfolgung, sodass der Fokus des Besatzungsterrors auf die ethnisch-polnische Bevölkerung gerichtet erschien. Allein in der Ausstellung des Historischen Museums der Hauptstadt Warschau wurde auch auf jüdischen Wiederstand - die »Jugend des kämpfen-

44 Die »Bekanntmachungen« über Exekutionen und Geiselnahmen seitens der Besatzer wurden jeweils in zwei Sprachvarianten publiziert. In den untersuchten Ausstellungen finden sich zum Teil auch die deutschsprachigen Plakate, überwiegend jedoch deren polnischsprachige Pendants. So etwa im Lubliner Museum »Unter der Uhr« (Zelle 6, Zellengang), und im MHW in Saal 47. Siehe auch Wroński: Scenariusz wystawy, 3.

45 MLL-Unter der Uhr, Zelle 6, Zellengang.

46 (Im Polnischen ist »Polen« weiblich.) Scenopis stałej ekspozycji, 69.

47 Exemplarisch hierfür ist die Darstellung der Untergrundaktivitäten der polnischen Wärter im Pawiak-Gefängnis. In einem Begleittext wird betont: »Die Mehrzahl der polnischen Gefängniswärter erfüllte eine bedeutsame Rolle in der konspirativen Arbeit. [...] Hier die Namen derjenigen, die den Häftlingen halfen und durch die Hände der hitleristischen Folterknechte umkamen oder nach dem Krieg starben [...].« Ebd., $82 \mathrm{f}$.

48 Siehe Teil 2, Kapitel 1.1. 
den Ghettos« -, mithin den Aufstand von 1943 eingegangen. ${ }^{49}$ Wie bereits in Kapitel 1.1 des zweiten Teils herausgearbeitet, blieben jedoch der spezifische Hintergrund der Verfolgung der jüdischen Bevölkerung und somit auch die Motive und Ziele jüdischer Widerstandskämpfer unerwähnt; sie wurden hierdurch letztlich als Teil der polnischen Widerstandsbewegung präsentiert.

Im Unterschied zu den ethnisch-polnischen Gefängnisinsassen, Verhafteten oder Exekutionsopfern blieben die verfolgten Juden zudem weitgehend anonym. Demgegenüber zeichnete die Präsentation der Opfer des Besatzungsterrors in den martyrologischen Institutionen eine starke Individualisierung aus. Im Pawiak-Museum, im Museum »Unter der Uhr« in Lublin, im Museum Radogoszcz in Łódź ebenso wie in der Krakauer Pomorska-Straße fanden sich Namenslisten von Inhaftierten, zum Teil mit fotografischen Porträts. ${ }^{50}$ Diese waren Ausdruck der zweiten Seite des dokumentarischen Charakters dieser Einrichtungen: Es sollten nicht nur die Verbrecher angeklagt, sondern auch deren Opfern bzw. »dem Kampf der Gefangenen« gedacht werden. ${ }^{51}$ Die sukzessive vervollständigten Namenslisten waren sowohl Dokumente der Verbrechen als auch Belege individuellen Martyriums; als solche stellten sie zugleich kommemorative Elemente der Ausstellungen dar. Diese

49 Dargestellt wurden auch der Verlauf der Kämpfe und die Anführer der Aufständischen. Informator do ekspozycji, 49, 51, Zitat: 51. Das Schicksal des Ghettos und seiner Einwohner, darunter auch der Aufstand von 1943, wurden außer in diesem Museum in einer Dauerausstellung im Jüdischen Historischen Institut umfangreicher geschildert. Diese Präsentation stellte seit den 1970er-Jahren die sukzessive Verfolgung und Ermordung der jüdischen Bevölkerung des besetzten Landes dar, mit einem Schwerpunkt auf dem Aufstand im Warschauer Ghetto im Jahr 1943. Głębocki/Mórawski: Nowy kształt Muzeum Żydowskiego Instytutu Historycznego, 71, 73-76. Die Rekonstruktion dieser Präsentationen ist aufgrund fehlender Dokumentationen bzw. Quellen nicht möglich.

50 Im MHK waren diese unter der Überschrift "Von ihnen gab es Tausende« aufgeführt. Wroński: Scenariusz wystawy, $7 \mathrm{f}$. Im Pawiak-Museum präsentierte man Originaldokumente, die Namenslisten von Insassen zeigten. Fotografien einzelner Inhaftierter, jeweils mit kurzen Biogrammen, nahmen die Rückwand des Ausstellungssaals ein. Scenopis wystawy stałej, 55, 67-69, 95-109. Der Gefängnisgang im Museum »Unter der Uhr« in Lublin war gesäumt von Porträts ehemaliger Insassen. Im Museum Radogoszcz wurden Fotos der Inhaftierten zusammen mit Bildern ihrer Familien und Freunde gezeigt, die sie zum Zeitpunkt ihrer Verhaftung bei sich getragen hatten. Heinrich/Szczepaniak: Muzeum Martyrologii i Walki, $100 \mathrm{f}$.

51 Domańska: Problematyka badań nad dziejami Pawiaka, 59. Die Anklage der Verbrechen und Täter sowie »die Würdigung der Opfer« beschreibt Volkhard Knigge als wesentliche Charakteristika der ersten Ausstellungen in Gedenkstätten in ehemaligen Konzentrationslagern ebenso wie Museen. Wie die Ausführungen der vorliegenden Studie zeigen, waren diese Vermittlungsziele auch im östlichen Europa verbreitet und stellten damit eine wesentliche Gemeinsamkeit der Musealisierung insbesondere der Orte von deutschen Besatzungsverbrechen dar. Knigge, Volkhard: Gedenkstätten und Museen. In: Ders./Frei, Norbert (Hg.): Verbrechen erinnern. Die Auseinandersetzung mit Holocaust und Völkermord. Bonn 2005, 398-409, hier 401, 403. 
Funktion war nicht zuletzt eng verbunden mit der zum Entstehungszeitpunkt der einzelnen Ausstellungen noch großen Zahl von Überlebenden und Angehörigen von Ermordeten sowie der engen Zusammenarbeit ehemaliger Insassen mit den einzelnen Institutionen. ${ }^{52}$

Abschließend sticht noch ein weiterer Aspekt der Opferdarstellung dieses Zeitraums ins Auge: Zwar griff man in der sprachlichen Kontextualisierung des Leidens während der Besatzung auf religiöse Semantiken zurück. So ist vielfach vom »Martyrium« bzw. »Märtyrertum« (martyrologia, męczeństwo) die Rede, nicht zuletzt in der Benennung der jeweiligen Institutionen und ihrer Dauerausstellungen. $\mathrm{Zu}$ den individuellen Gedenkriten an den Denkmälern und Gedenktafeln der Museumsareale gehörten zudem die Niederlegung von Blumen und das Anzünden von Grablichtern - soziale Praktiken, die jenen auf einem Friedhof entsprechen..$^{53}$ Hierdurch wurden die Museen bzw. Gedenkstätten zusätzlich sakralisiert. Denn diese verbreiteten kommemorativen Rituale verwiesen wiederum auf die sinnbildliche Präsenz der Toten, wie sie von den Angehörigen an den Orten des Todes bzw. Leidens ihrer Freunde und Familienmitglieder wahrgenommen wurde. Die Museumsverantwortlichen stellten diese auch faktisch her, indem sie Urnen mit der Asche Verstorbener innerhalb der Areale unterbrachten. In den Schauen selbst verwendete man hingegen keine religiöse Symbolik; auch Verweise auf religiöse Themen, etwa die Religiosität der Gefängnisinsassen, gab es nur ver-

52 Die Museumsmitarbeiter gerade der sogenannten martyrologischen Einrichtungen waren bei der Erforschung der Geschichte der einzelnen Institutionen sowie der Sammlung von Objekten auf die Kooperation mit ehemaligen Insassen angewiesen, wie eingangs bereits geschildert wurde. So arbeiteten beispielsweise Vertreter des Pawiak-Museums seit der Gründung ihrer Institution eng mit dem »Klub der ehemaligen Politischen Häftlinge des Pawiak« (Klub byłych Więźniów Politycznych Pawiaka) zusammen. Im Museumsgebäude trafen sich die ehemaligen Häftlinge regelmäßig; diese Treffen werden bis in die Gegenwart organisiert. Gerade in den ersten Jahren der Museumstätigkeit wirkten ehemalige Häftlinge auch als Museumsführer. Domańska: Muzeum Więzienia „Pawiak«, 89, 96; Interview mit Joanna Gierczyńska, der Leiterin des Gefängnismuseums Pawiak, am 9. Juli 2009. Siehe auch: Klub byłych Więźniów Politycznych Pawiaka [Der Klub der ehemaligen Politischen Häftlinge des Pawiak], URL: www.muzeumniepodleglosci.pl/pawiak/o-muzeum/klub-bylych-wiezniow-politycznych-pawiaka/ (am 25.7.2014). Diese enge Zusammenarbeit mit ehemaligen Insassen, von denen zudem oft erst die Initiative zur Musealisierung der Orte von NS-Verbrechen ausging, war gängige Praxis in allen martyrologischen Einrichtungen - nicht nur in Polen, sondern auch in ähnlichen Institutionen in anderen Ländern. Knigge: Gedenkstätten und $\mathrm{Mu}-$ seen, 401.

53 Exemplarisch für das Museum Radogoszcz: Heinrich/Szczepaniak: Muzeum Martyrologii i Walki, 97, 102. Für den Pawiak: Balcerzak, Janina: W XX-lecie powstania Muzeum Historii Polskiego Ruchu Rewolucyjnego [Zum 20. Jahrestag der Entstehung des Museums der Geschichte der Polnischen Revolutionären Bewegung]. In: Muzeum Historii Polskiego Ruchu Rewolucyjnego w Warszawie, 8-15, hier $9 \mathrm{f}$. 
einzelt. Meist beschränkte sich dies auf die Ausstellung eines einzelnen Rosenkranzes, der von Insassen während der Haft angefertigt worden war. ${ }^{54}$

Lediglich im Gefängnismuseum Pawiak war dieser Themenaspekt gewichtiger vertreten: In der Sektion zum Schicksal der Häftlinge in den Konzentrations- und Vernichtungslagern war ein umfangreicherer Abschnitt Pater Maximilian Kolbe gewidmet, der im Pawiak inhaftiert war und von dort nach Auschwitz deportiert wurde. Im ausführlichen Biogramm seiner Person wird darauf verwiesen, dass Kolbe

während seines Aufenthaltes im Gefängnis [...] Mithäftlingen religiösen Trost [spendete] und [ihnen] Mut [machte], womit er ihren Willen zum Kampf und Überleben weckte. [...] Am 14. Juli 1944 starb er den Märtyrertod im Bunker in Block 11; er gab freiwillig sein Leben für die Rettung eines Häftlings, der Frau und Kinder hatte. ${ }^{55}$

Als einer der bekanntesten Insassen des Pawiak und zugleich als polnische Symbolfigur konnte der katholische Ordensmann Kolbe, der »Märtyrer Oświęcims « ${ }^{56}$, durch die Verweise auf seine Unterstützung der Widerständigen und seinen eigenen Märtyrertod stringent in die Opferdarstellung der Schau integriert werden. Seine Religion und sein religiöses Amt blieben dabei weitgehend im Hintergrund. ${ }^{57}$ Als katholischer Märtyrer von Auschwitz unterstützte seine herausgehobene Darstellung jedoch die suggestive Verbindung des größten Konzentrations- und Vernichtungslagers mit einer ethnisch-polnischen Opfergeschichte, die implizit religiös, nämlich christlich konnotiert war. ${ }^{58}$ Mithilfe seiner Person konnte ein dominanter polnischer Opferstatus betont werden. Indirekt wurde hierdurch zugleich die weitaus hö-

54 Wroński: Scenariusz wystawy, 8; Scenopis stałej ekspozycji, 80. Im Historischen Museum der Stadt Lublin wurden seit 1987 mehrere solcher Objekte in einer der Vitrinen gezeigt: Das Leiden der Häftlinge des Lubliner Schlosses wurde u. a. durch zwei handgefertigte Rosenkränze sowie zwei Heiligenbilder, die Häftlinge bei sich gehabt hatten, illustriert. Diese vier Objekte finden sich auch in der 1995 eröffneten neuen Dauerausstellung. Siehe: Protokół odpowiedzialności. Wykaz eksponatów na wystawie »Historia miasta Lublina«. 14. August 1987. AMLL, Oddział Muzeum Historii Miasta Lublina, ohne Signatur.

55 Scenopis stałej ekspozycji, 92.

56 Ebd.

57 Auch die politischen Kontexte der Aktivitäten Pater Kolbes vor Kriegsausbruch, insbesondere die antisemitischen Aspekte seiner verlegerischen Tätigkeit, blieben - und bleiben in dem Museum bis heute - gänzlich unerwähnt. Zu den Inhalten der von Kolbe herausgegebenen Zeitschriften siehe Caumanns, Ute/Niendorf, Mathias: Von Kolbe bis Kielce. Ein Heiliger, seine Presse und die Geschichte eines Pogroms. In: Bömelburg, Hans-Jürgen/Eschment, Beate (Hg.): „Der Fremde im Dorf«. Überlegungen zum Eigenen und zum Fremden in der Geschichte. Rex Rexheuser zum 65. Geburtstag. Lüneburg 1998, 169-194.

58 Die Darstellung Kolbes war in der Sektion zum KZ Auschwitz untergebracht. Scenopis stałej ekspozycji, 90-93. 
here Opferzahl jüdischer Lagerinsassen und Deportierter verschwiegen. Auch dieses Element ist damit ein Beispiel für die in dieser Schau - ebenso wie in den übrigen Präsentationen des Jahrzehnts - zu beobachtende Opferkonkurrenz. Wie am Beispiel der Darstellung von Opferzahlen bereits ausgeführt wurde, äußerte sich diese Konkurrenz in erster Linie in der vereinnahmenden und damit zugleich marginalisierenden Darstellung der als Juden Verfolgten, die stillschweigend zu den polnischen Kriegsopfern gezählt wurden, ohne den spezifischen Kontext und das Ausmaß ihrer Verfolgung zu thematisieren. ${ }^{59}$

\subsection{Die 1990er-Jahre bis 2003}

Die ersten Veränderungen in den Opferdarstellungen, die nach dem Umbruch des Jahres 1989 zu beobachten waren, betrafen die Inklusion religiöser Symboliken und Themen in die Dauerausstellungen. Die Religiosität der Verfolgten ebenso wie die Rolle und das Schicksal von Geistlichen während der Besatzung wurden nun zu einem wichtigen Topos in den Darstellungen. Die erste Schau, die den Aspekt gesondert herausgriff, war die 1991 eröffnete Dauerausstellung des Gefängnismuseums Pawiak. Der Glaube der Inhaftierten wurde hier als einziges Thema neu in die überarbeitete Schau aufgenommen. Zahlreiche Exponate illustrierten das vor den Wärtern geheim gehaltene religiöse Leben; gezeigt wurden nun zahlreiche handgeschriebene Gebete, selbstgefertigte Rosenkränze, Heiligenbilder und eine Bibel. ${ }^{60}$ Auch in der Gestaltung der Schau integrierte man religiöse Symbolik: Auf den Wänden des Ausstellungssaales, die ebenso wie die Decke schwarz gestrichen waren, wurden großformatig die Namen einzelner Exekutionsorte und Konzentrationslager angebracht, in die die Insassen deportiert worden waren. Die einzelnen Ortsnamen waren jeweils durch mehrere Kreuze voneinander getrennt. ${ }^{61}$ Diese verwiesen zum einen durch ihre Assoziation mit Grabmalen auf das mit den konkreten Ortsnamen verbundene Schicksal vieler Gefängnisinsassen. Zum anderen markierten sie als religiöse Symbole die Zugehörigkeit der Insassen - und im weiteren Sinne auch der Protagonisten der in der Schau gezeichneten Wir-Gemeinschaft - zur christlichen Glaubensgemeinschaft. Hierdurch wurden wiederum andere Verfolgtengruppen, insbesondere die jüdische Bevölkerung, hintangestellt.

In den wenigsten Schauen war in den 1990er-Jahren religiöse, konkret christliche Symbolik derart prominent vertreten wie im Pawiak. In den meis-

59 Siehe hierzu auch Teil 2, Kapitel 1.1.

60 Izdebska, Barbara: Pawiak 1939-1945. Ekspozycja stała. Scenopis. Warszawa 1991. AMNW, Scen. 79, 127-129, 136f., Zitat: Bildunterschrift S. 129.

61 Ebd., 184. Siehe auch eine Fotografie des Ausstellungssaales in Izdebska: Muzeum Więzienia »Pawiak«, 274. 
ten Präsentationen blieb das Thema Religion und Glaube eines unter vielen. Auffällig ist jedoch, dass religiöse Objekte, die in der Gefangenschaft angefertigt oder bewahrt wurden, nach 1989 in alle Präsentationen verstärkt Einzug hielten. ${ }^{62}$ Auch religiöse Repräsentanten und deren Rolle während der Besatzung traten nun sukzessive in den Vordergrund, so in den Schauen des MHK in der Pomorska-Straße von 1990 und 1998 etwa Erzbischof Adam Sapieha. ${ }^{63}$

Besonders auffällig geschah dies schließlich in den Anfang der 2000erJahre neu konzipierten Dauerausstellungen des Gefängnismuseums Pawiak und des Martyrologiemuseums Radogoszcz in Łódź. In der Präsentation des Museums Radogoszcz von 2003 gehörte zur Schilderung der repressiven Besatzungspolitik auch das Vorgehen gegenüber der katholischen Kirche. ${ }^{64}$ Herausgehoben wurde insbesondere an die in verschiedenen Konzentrationslagern umgekommenen Geistlichen aus Łódź erinnert: Auf einer großformatigen Tafel waren sie namentlich aufgeführt, jeweils mit kurzen Angaben über ihre Vorkriegstätigkeit und die Umstände ihres Todes. In derselben Sektion mit dem Titel »In den Konzentrationslagern« fanden sich zudem Objekte, die das Thema zusätzlich mit einer sakralen Aura versahen: eine Urne sowie drei kleine Glasgefäße, gefüllt mit »Erde von Orten, die mit dem Blut ermordeter Häftlinge von Konzentrationslagern geheiligt wurde«, wie die be-

62 Im Museum »Unter der Uhr« in Lublin wurden nach 1989 in die Vitrinen Objekte aufgenommen, die von den Insassen des Gefängnisses auf dem Schloss angefertigt worden waren, darunter ein Rosenkranz aus Brot. MLL-Unter der Uhr, Zelle 8, Vitrine. Auch in der Abteilung Pomorska-Straße des MHK erhöhte sich in den 1990 und 1998 neueröffneten Dauerausstellungen die Zahl der präsentierten Objekte, die auf die Religiosität der Insassen der deutschen Gefängnisse verwiesen. Gąsiorowski, Teodor/Kuler, Andrzej/ Natkaniec, Marek: Scenariusz wystawy »Kraków 1939-1945« (wersja V - zrealizowana). o. J. [1990]. AMHK, OP-6411-11-90, 5f.; MHK-Pomorska-Straße, Objekte 117, 118, 120, 124. Im Historischen Museum von Lublin wurden auch nach 1989 weiterhin zwei handgefertigte Rosenkränze sowie zwei Heiligenbilder von Insassen des Lubliner Schlosses präsentiert; auf dem einen findet sich ein selbstverfasstes Gebet.

631990 wurde er erstmals als einer von vier Vertretern des »Bürgerlichen Hilfskomittees« (Obywatelski Komitet Pomocy) mit einem Foto in der Schau aufgeführt. Gąsiorowski/ Kuler/Natkaniec: Scenariusz wystawy, 3. In der überarbeiteten Fassung von 1998 präsentierte man ihn hervorgehoben, mit einem großformatigen Porträt einzeln auf einer Tafel, als faktischen Anführer der polnischen katholischen Kirche während der Besatzung und ihren Vertreter in Verhandlungen mit den Besatzern. MHK-Pomorska-Straße, Tafel 5.

64 Auf einer Ausstellungstafel wurde die sukzessive Einschränkung der Religionsausübung der polnischen Bevölkerung geschildert, die Verfolgung von Priestern und ihre Deportation in Konzentrationslager ebenso wie die Beschlagnahmung von Kircheneigentum. Fotografien zeigten die Verbrennung von Devotionalien und die Verwendung eines Kirchenraums als Lager für Güter, die der jüdischen Bevölkerung geraubt worden waren. MTNŁ-Radogoszcz, Sektion »Wir Deutschen sind hier als Herren hergekommen, die Polen sollen uns dienen««, Tafel 3. 
gleitende Objektbeschriftung erläuterte. Diese Einordnung kennzeichnete die Objekte unmissverständlich als Reliquien, mithin als Elemente des Gedenkens. ${ }^{65}$ Auch in der vorangegangenen Sektion fanden sich bereits drei ähnliche Gefäße mit »Erde aus den Begräbnisstätten in Katyń, Charkov und Mednoe ${ }^{66}$, den Massengräbern polnischer Soldaten und Offiziere, die während des Kriegs vom NKVD ermordet worden waren. Ihre Unterbringung in der Ausstellung schuf eine symbolische Verbindung zu den Toten und den Stätten ihres gewaltsamen Todes und damit eine sinnbildliche Präsenz der Ermordeten. ${ }^{67}$ Damit fungierten sie als Beleg der Verbrechen, die in beiden Sektionen geschildert waren. Diese Vermittlungsabsicht kann auch bei einem weiteren Objekt der Schau angenommen werden, einem Glasbehälter mit Kieselerde, die mit Cyklon B angereichert ist, das - wie die begleitende Objektbeschriftung erläutert - "zum Vergasen von Häftlingen verwendet wurde«. Bemerkenswert ist, dass dieses Objekt in der Sektion "In den Konzentrationslagern" gezeigt wurde, die ausschließlich dem Schicksal polnischer Insassen der Lager gewidmet war. Der Tod der meisten Ghettoinsassen in den Lagern Kulmhof und Auschwitz wurde getrennt davon in der Sektion zum Ghetto Litzmannstadt behandelt. Dadurch konnte bei den Besuchern der Eindruck entstehen, der Tod in der Gaskammer sei das Schicksal der Mehrzahl der polnischen KZ-Insassen gewesen. Die stark emotionalisierenden Objekte wie die Gefäße mit Erde von den Ermordungsstätten bewirkten daneben jedoch in erster Linie, dass diese beiden (polnischen) Opfergruppen - die in die Lager Deportierten und die Opfer des NKVD - innerhalb der Ausstellung besonders hervorgehoben wurden. Der Verweis auf das "Blut ermordeter Häftlinge", welches die Erde "geheiligt" habe, fasste ihr Schicksal in einen säkularsakralen, martyrologischen Kontext: als Opfer für das Vaterland. Die textuelle Kontextualisierung der Leidenserfahrungen erfolgte dabei in einer ähnlich religiösen Rhetorik wie bereits vor 1989.

Während in der allgemeinen Gestaltung dieser Schau religiöse Symbolik sonst keine weitere Rolle spielte, nimmt sie in der Ausstellung des Pawiak, die 2001 eröffnet wurde und bis heute zu sehen ist, eine tragende interpretative Funktion ein. Buchstäblich augenfällig sind in erster Linie die zeitgenössischen Gedichte, die großformatig an den Seitenwänden der Ausstel-

65 Thiemeyer: Fortsetzung des Krieges, 152; Knigge: Gedenkstätten und Museen, 400 f. Die Erde stammte aus den Konzentrationslagern Dachau, Buchenwald, Groß-Rosen sowie Ravensbrück.

66 MTNŁ-Radogoszcz, Sektion »In Gefangenschaft«, Objektbeschriftung.

67 Analog beschreibt Sandra Petermann den Umgang mit der Erde von den Schlachtfeldern des Ersten Weltkriegs in Frankreich. Petermann, Sandra: Rituale machen Räume. Zum kollektiven Gedenken der Schlacht von Verdun und der Landung in der Normandie. Bielefeld 2007, 181. 


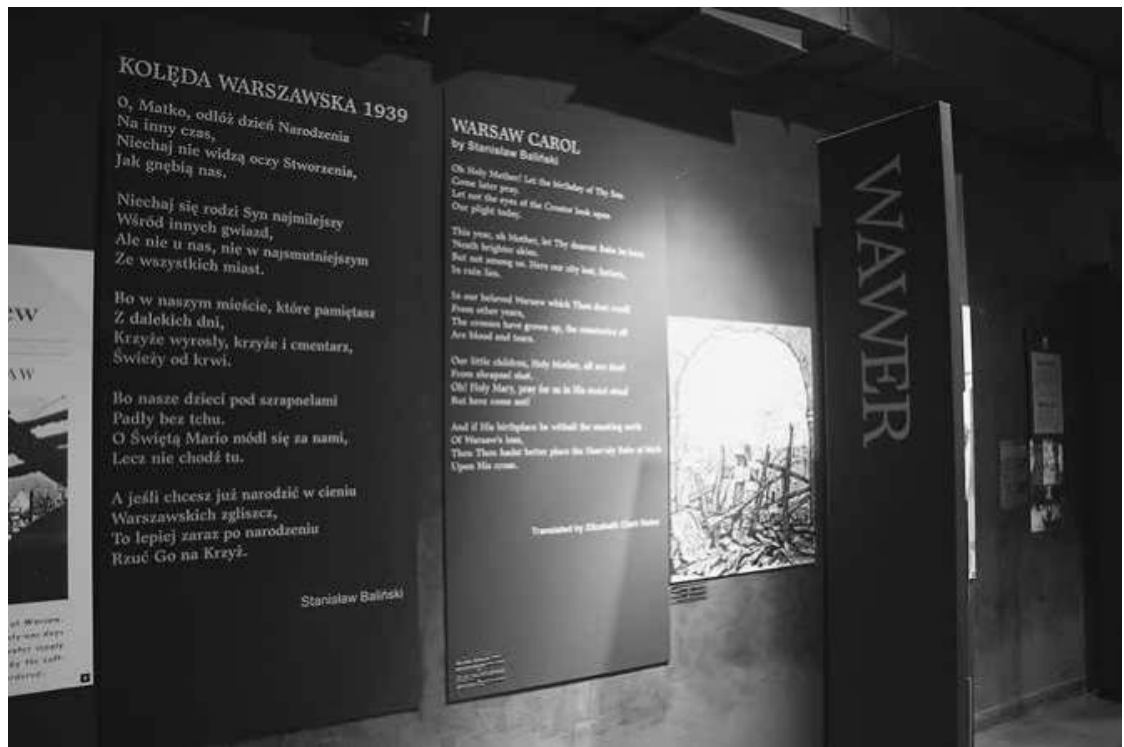

Abb. 36: Gefängnismuseum Pawiak, das Gedicht »Warschauer Weihnachtslied 1939« im ersten Teil des Ausstellungsrundgangs.

lungshalle angebracht sind. ${ }^{68}$ Sie stechen sowohl durch ihre Schriftgröße heraus - die Gedichte nehmen fast die gesamte Raumhöhe ein - als auch durch ihre markante Farbgebung: Da die Hallenwände ebenso wie die Tafeln, auf denen die Gedichte abgedruckt wurden, dunkelgrau bis schwarz gestrichen sind, tritt die weiße Farbe der Schriftzeilen umso deutlicher hervor (siehe Abb. 36). Auch inhaltlich setzen die Gedichte markante Akzente. Sie sind jeweils thematischen Sektionen der Ausstellung zugeordnet - im ersten Teil beispielsweise dem Widerstand gegen den deutschen Angriff im September 1939, der folgenden Niederlage sowie der Darstellung des Terrorregimes der Besatzer - und kommentieren die dargestellten Ereignisse auf eindringliche und emotionale Art. Ein Großteil von ihnen rekurriert auf christliche Motive und Ausdrucksformen. So verweist das erste Gedicht, das den Besuchern in der Ausstellung begegnet, "Święty Boże« (Heiliger Gott) von Kazimierz Wierzyński, ${ }^{69}$ mit den Zeilen »Heiliger Gott, / Heiliger Starker, / Heili-

68 Teile der folgenden Ausführungen wurden bereits publiziert in Heinemann: Emotionalisierungsstrategien.

69 Das Gedicht wurde in der Warschauer Gazeta Polska (Polnische Zeitung) am 30. August 1939 veröffentlicht. Die Informationen zum Erscheinungsort und -datum der einzelnen Gedichte werden jeweils in der Ausstellung selbst angegeben. 
ger Unsterblicher ${ }^{70}$ auf die in der Karfreitagsliturgie der katholischen Kirche verwendete Trishagion-Akklamation. In der Version von Wierzyński wird der Segen Gottes für den gerechten Kampf der polnischen Armee um die Heimat, ihr nationales Erbe und ihre Zukunft erbeten. In der "Kolęda Warszawska 1939« (Warschauer Weihnachtslied 1939) von Stanisław Baliński, die als nächstes folgt, ${ }^{71}$ wird die Mutter (Gottes) gebeten, den Tag der Geburt ihres Sohnes auf eine andere Zeit und an einen anderen Ort als das geschundene Warschau zu verlegen, in dem zahllose Gräber die Niederlage im Kampf gegen die deutschen Aggressoren markieren. Die Bezeichnung des Gedichts im Titel als kolęda (Weihnachtslied) erlaubt nicht nur die zeitliche Einordnung der beschriebenen Ereignisse, sondern verweist auch auf eine der ältesten polnischen religiösen Liedformen. ${ }^{72}$ Ebenso stellt das "Stabat Mater" von Józef Wittlin, das im Themenbereich des deutschen Besatzungsregimes $\mathrm{zu}$ finden ist, einen Rückgriff auf christliches Liedgut dar. ${ }^{73}$ Die ersten Worte des Gedichts lauten: „Es stand die schmerzensreiche Mutter" - eine Übersetzung des lateinischen Titels des katholischen Hymnus "Stabat Mater Dolorosa", in dem die Leiden Marias beim Tod Jesu am Kreuz geschildert werden. ${ }^{74}$ In den Versen Wittlins trauert eine einfache polnische Frau um ihren von Deutschen erhängten Sohn. In der letzten Strophe des Gedichts wird mit den Worten »Stabat Mater, Mater nostra, Polonia« die leidende Frau, die eine »Krone aus Dornen« trägt, mit dem besetzten Polen gleichgesetzt. Das Symbol der Dornenkrone verweist noch einmal mehr auf das Martyrium, das das Land durchleben muss. ${ }^{75}$ Die Leiden des polnischen Volkes unter der deutschen Besatzung werden durch dieses Bild mit den Leiden Christi gleichgesetzt, dem Leiden um der Erlösung willen. ${ }^{76}$ Die Deutung der Besatzungszeit wird mit diesen Elementen um eine tief religiöse und zugleich eschatologische Sinngebung ergänzt. Sie knüpft damit an das im 19. Jahrhundert geprägte

70 Der Wortlaut der Übersetzung wurde entnommen aus: Trishagion. In: Brockhaus-Enzyklopädie in 30 Bänden. Bd. 27. 21. Aufl. Leipzig u. a. 2001, 760.

71 Das Gedicht erschien am 17. März 1940 in den Wiadomości Polskie (Polnische Nachrichten) in Paris.

72 Der Begriff kolęda bezeichnet ein religiöses Lied, dessen Inhalt mit dem Fest der Geburt Jesu Christi verbunden ist. Die Ursprünge dieses Liedguts in Polen reichen bis ins 15. Jahrhundert zurück. Vgl. Kolęda. In: Wielka Encyklopedia Polski [Große Enzyklopädie Polens]. Bd. 2. Kraków 1999, 42.

73 Das Gedicht wurde im Tygodniowy Przegląd Literacki Koła Pisarzy z Polski (Wöchentliche Review des Kreises der Schriftsteller aus Polen) am 1. Oktober 1940 in New York veröffentlicht.

74 Stabat Mater. In: Brockhaus-Enzyklopädie in 30 Bänden. Bd. 26. 21. Aufl. Leipzig u.a. 2001, 92. Hieraus stammt auch die deutsche Übersetzung.

75 Vgl. Christliche Symbole. In: Bauer, Wolfgang/Dümotz, Irmtraud/Golowin, Sergius: Lexikon der Symbole. 20. Aufl. Wiesbaden 2004, 206.

76 Ebd., 201-206. 
"martyrologisch-mesjanistische " polnische Selbstbild an. ${ }^{77}$ Die Steigerung dieser religiös-martyrologischen Motive zu einer national-patriotischen Sinnstiftung erfolgt schließlich im »Dekalog Polaka» (Dekalog des Polen) von Zofia Kossak-Szczucka. ${ }^{78}$ In Anlehnung an die Form des biblischen Dekalogs werden darin die Zehn Gebote für das Verhalten aller Polen während der Besatzung formuliert. Die Aufzählung schließt mit den Worten: »Du wirst Polen mit der ersten nach Gott gegebenen Liebe ehren. / Du wirst Es mehr lieben, als dich selbst." Dieser Katalog von »Ehrvorschriften« ist ein flammender patriotischer Aufruf zu Widerstand und Kampf um die Freiheit des Landes unter unbedingter Selbstaufopferung.

Auch das Gedicht »Hymn więzienny« (Gefängnis-Hymne) bekräftigt schließlich die martyrologische Lesart der Opfer und Leiden unter den Häftlingen des Pawiak-Gefängnisses und ordnet sie in einen national-patriotischen Deutungshorizont ein. Verfasst wurde es von der im Widerstand aktiven Dichterin Józefa Radzymińska während ihrer Haft im Pawiak 1941. Es leitet den Themenbereich »Leben der Häftlinge« ein und ist ein Aufruf zum Durchhalten, um sowohl der Haft als auch der Folter zu widerstehen. Die Leiden der Insassen werden darin als »heilige Qualen« bezeichnet und mit den Worten »Der Stolz [wielkość] der Nation sind wir!« in den nationalen Unabhängigkeitskampf eingebunden. Als Ausgangspunkt für die Darstellung des Gefängnisalltags wird mit diesem Gedicht ein patriotisches Widerstandsmanifest gewählt. Ähnlich wie in den früheren Dauerausstellungen des Museums wird hier zugleich suggeriert, alle oder zumindest der Großteil der Häftlinge seien ähnlich kämpferisch gesonnen gewesen. Das »bloße« Leiden und der individuelle Überlebenswille, unabhängig von patriotischen Überlegungen, finden hier keine Erwähnung. Lediglich im folgenden Gedicht mit dem Titel »Aleja Szucha« (Szucha-Allee) wird das Grauen der gewalttätigen Verhöre eindrücklich geschildert. ${ }^{79}$ Auch hier steht jedoch das kämpferische Widerstehen gegen die Folter im Vordergrund: Der Protagonist des Gedichts betet für alle Inhaftierten darum, dass sie den Willen aufbringen mögen, Informationen, die andere in Gefahr bringen könnten, zu verschweigen und hofft auf eingeschmuggeltes Gift, das alleine sie erlösen könne. Wiederum wird hiermit

77 Janion: Do Europy, 22 f., Zitat: 23. Siehe auch Traba, Robert: Der Opferdiskurs als zentraler identitätsstiftender Faktor der polnischen Meistererzählung. In: Bingen, Dieter/Loew, Peter O. (Hg.): Polen. Jubiläen und Debatten. Beiträge zur Erinnerungskultur. Wiesbaden 2012, 27-36, hier $31 \mathrm{f}$.

78 Das Gedicht wurde im Dezember 1940 veröffentlicht.

79 Das Gedicht »Aleja Szucha (zamiast życzeń świątecznych)« (Szucha-Allee (anstelle von Feiertagsgrüßen)) wurde anonym verfasst und lediglich mit dem Pseudonym »Janek« unterschrieben. Es erschien erstmals im April 1944 in der Warschauer Untergrundzeitschrift Głos Polski (Polnische Stimme). 
suggeriert, die Leidenden - und mithin implizit alle Verfolgten und Inhaftierten - seien im Widerstand aktiv gewesen.

Die Gedichte wurden von den Ausstellungsverantwortlichen als Zeugnisse ausgesucht, die in unmittelbarer zeitlicher Nähe und in Reaktion auf die in der Ausstellung jeweils thematisierten Ereignisse entstanden sind. ${ }^{80}$ Als Quellen stellen sie damit zeitgenössische Rezeptionen der Ereignisse dar. Durch ihre prominente Darstellungsweise in der Ausstellung, die ohne jede Kontextualisierung erfolgt, wirken sie jedoch wie unmittelbare Kommentare der Kuratoren zu den jeweils thematisierten Geschehnissen. Die Gedichte transportieren eindrücklich die Verzweiflung, das Leiden und die Trauer angesichts des Terrors und der Zerstörung, zugleich vermitteln sie aber auch einen entschlossenen Willen zum Widerstand. Damit bilden sie einen stark emotionalisierenden Hintergrund für den gesamten Ausstellungsrundgang. Ihre Auswahl ist dabei sehr bewusst getroffen und konzentriert sich, wie beschrieben, auf Verse, die mit christlichen Topoi operieren, darunter insbesondere katholischen Symboliken. Die hierdurch suggestiv gezeichnete Wir-Gemeinschaft der Gefängnisinsassen, der Bewohner des besetzten Warschaus wie auch des gesamten Landes aktualisiert damit das tradierte Autostereotyp des »Polen-Katholiken " (Polak-katolik), einem ethnischen Verständnis polnischer Nationszugehörigkeit, für das auch die Religionszugehörigkeit zentral ist. ${ }^{81}$

In diesem traditionellen Selbstbild, das der Schau zugrunde liegt, spielt die Widerständigkeit und die damit einhergehende martyrologische Opferdarstellung eine tragende Rolle. Verbunden ist sie insbesondere mit dem Interpretationsmuster polnischer Geschichte als kontinuierlicher Freiheitskampf, das in der Romantik zum dominanten historischen Deutungsschema avanciert ist. ${ }^{82}$ Suggestiv zusammengefasst wird diese grundlegende Sichtweise der Schau gleich beim Betreten der großen Ausstellungshalle, die den Jahren 1939 bis 1944 gewidmet ist: Über dem Titel der Ausstellung (»Pawiak 1939-1944«) finden sich Gedichtzeilen, die durch ihre herausgehobene Positionierung als Leitmotiv erkannt und von den Besuchern interpretiert werden können: »Let them only just remember this thing about us: / That we all

80 Hierauf verweisen die kleinformatigen Objektbeschriftungen, die bei jedem Gedicht dessen ursprünglichen Publikationsort und -datum nennen. Auch die englischen Übersetzungen der Gedichte, die abgesehen von zwei Ausnahmen jeweils unmittelbar neben der polnischen Fassung zu finden sind, sind zeitgenössischen, im Ausland erschienenen Zeitungen und Zeitschriften (meist des polnischen Exils) entnommen, was ebenfalls in den Objektbeschriftungen vermerkt ist. Die derart herausgehoben präsentierten Gedichte wurden mehrheitlich nicht von Insassen des Gefängnisses publiziert. Einige der Poeme Letzterer sind jedoch in kleinerem Format in den Vitrinen der Ausstellung gezeigt.

81 Janion: Do Europy, 157 f.; Porter-Szücs: Faith and Fatherland, 328-359.

82 Ebd., 22-25; Traba: Der Opferdiskurs, 29, 31. Vgl. auch Porter: When Nationalism Began to Hate. 
fell in battle so that freedom might live. ${ }^{83}$ Mit diesen beiden Elementen wird die grundlegende Deutung, die dem Ort im Rahmen der Ausstellung zugewiesen wird, bereits festgelegt: der Pawiak als Symbol der polnischen Opferbereitschaft und des heldenhaften Kampfes gegen die deutsche Besatzung. Denn die Insassen - von denen nicht wenige bei Exekutionen und in Konzentrationslagern umkamen - sollen als Menschen erinnert werden, die »für die Freiheit gefallen sind «, eine Wortwahl, die den Tod im aktiven Kampf impliziert. Unabhängig von den realen Umständen ihrer Verhaftung und Ermordung wird das Schicksal der Häftlinge somit im nationalen Unabhängigkeitskampf verortet, wodurch ihrem Leiden Sinn verliehen wird.

Ein weiteres Ausstellungselement bindet diese Deutung schließlich in eine längere historische Perspektive ein: Unterhalb der Tafel mit dem Ausstellungstitel befindet sich eine Vitrine mit verschiedenen Objekten, die an die polnischen Unabhängigkeitsbestrebungen seit dem 19. Jahrhundert und die in den Jahren 1863 bis 1944 (dem Zeitraum der Existenz des Gefängnisses) für ihre Aktivitäten im Freiheitskampf verfolgten Gefangenen des Pawiak erinnern. Unter den Exponaten befinden sich beispielsweise Porträts gefallener Teilnehmer des Januaraufstands 1863, eine Gedenkmedaille für den Aufstand von 1905 sowie Rosenkränze, die im Gefängnis in den Jahren 1939 bis 1944 gefertigt worden sind. Dieser in der Ausstellung präsentierte Zeitraum wird hierdurch gleich zu Beginn der Erzählung symbolisch an den Topos des polnischen nationalpatriotischen Unabhängigkeitskampfes des 19. und 20. Jahrhunderts angebunden.

Die christlich-martyrologische Deutung der Leiden vor Ort transportieren schließlich auch die in der Hallenmitte herausgehoben auf Glasplatten aufgebrachten Porträts von Inhaftierten. Als exemplarische Stellvertreter für das Schicksal der Gefangenen während der Besatzungszeit - so der explizite Verweis in den Begleitbüchern zur Ausstellung $-^{84}$ finden sich unter den fünf derart herausgestellten Personen zwei christliche Geistliche: Pater Maximilian Kolbe und Edmund Bursche, ein Pastor und Theologe der EvangelischAugsburgischen Kirche. In den umfangreichen Biogrammen, die die Fotografien aller Protagonisten begleiten, werden ihre patriotische Einstellung und

83 Diese Zeilen stammen aus dem Gedicht »Testament poległych" (Das Testament der Gefallenen) von Ryszard Kiersnowski, das am 31. Oktober 1942 erstmals in der in London erscheinenden polnischen Exilzeitschrift Polska Walcząca (Kämpfendes Polen) publiziert wurde. Gegenüber dem Eingang ist nur die polnische Fassung der Verse angebracht; deren englische Übersetzung, die hier zitiert wird, sowie das polnische Original des Gedichts, aus dem sie stammen, werden im weiteren Verlauf der Ausstellung an exponierter Stelle präsentiert.

84 Pawiak 1835-1944. Przewodnik po ekspozycji stałej. The Guidebook to the Permanent Display. Hg.v. Muzeum Niepodległości w Warszawie. Warszawa 2006, 26f.; Pawiak 1835-1944. Museumsführer, 34, 37. 
das daraus resultierende Martyrium unterstrichen. Zu Bursche etwa wird die Anekdote zitiert, wonach er auf die Anschuldigung Heinrich Himmlers hin, er habe sein (deutsches) Vaterland verraten, geantwortet habe: "Ich habe mein Vaterland [Polen - d.Vf.] niemals verraten und werde es niemals verraten.« Bei der Darstellung Kolbes erfährt man nicht nur von seinem Märtyrertod im KZ Auschwitz, sondern auch davon, dass er vor seiner Verhaftung polnische und jüdische Zwangsumgesiedelte betreut hatte. ${ }^{85}$ Beide wurden somit offensichtlich als Persönlichkeiten ausgewählt, die sich durch ihr Verhalten während des Kriegs ausgezeichnet haben. Ihr Leiden für Polen bzw. für ihre Landsleute markiert sie - vor dem Hintergrund der religiösen Funktionen, die sie einnahmen -, als Märtyrer in religiöser wie säkularer, das heißt patriotischer Dimension. Ihre Opferbereitschaft für das Vaterland ebenso wie der aktive Widerstandskampf der übrigen drei Porträtierten ${ }^{86}$ erscheinen zugleich als stellvertretend für die gesamte Häftlingsgemeinschaft. Das PawiakGefängnis wird hierdurch, in Kontinuität der Vorgängerausstellungen, als Symbol des Märtyrertums und des Kampfeswillens, mithin des Patriotismus der Häftlinge während der Besatzung charakterisiert. ${ }^{87}$

Auch in der Präsentationsweise dieser Ausstellungselemente wird auf sakrale Gestaltungsmotive zurückgegriffen. Die Biografien sind auf milchigweißen Glaswänden platziert, die in der Hallenmitte frei stehen (siehe Abb. 37). Auf jeder Glaswand ist eine Fotografie der jeweiligen Person abgebildet; sie scheinen in Lebensgröße vor den Besuchern zu stehen. Da die Wände relativ hoch sind, blicken die Besucher zudem - gerade, wenn sie die Informationen zum Lebenslauf der einzelnen Persönlichkeiten lesen möchten - zu den »Helden des Pawiak $\aleph^{88}$ buchstäblich auf. Bereits hierdurch wird deutlich, dass die ausgewählten Individuen als Vorbilder inszeniert werden. Die Glasscheiben sind zudem jeweils einzeln von oben mit Halogenlampen angestrahlt; die abgebildeten Personen scheinen zu leuchten und erinnern damit an Inszenierungen von Heiligenbildern. Über jedem der Texte prangt ein Kreuz sowie einem Grabspruch gleich - das Motto der Ausstellung. Diese gestalterischen Elemente bewirken, dass die Glaswände an Grabmale erinnern. Alle der Protagonisten kamen tatsächlich während der Besatzung gewaltsam ums Leben.

85 Interessanterweise wird in dieser Neufassung der Schau die Gründung des Rycerz Niepokalanej (Ritter der Unbefleckten) wie des Mały Dziennik (Kleine Tageszeitung) durch Kolbe erwähnt, deren antisemitische Ausrichtung jedoch nicht.

86 Siehe Kapitel 2.2 in diesem Teil.

87 Unmissverständlich wird dies auch auf einer Ausstellungstafel zusammengefasst, die sich rechts vom Eingang der Ausstellungshalle befindet und die Schau symbolisch beschließt. Dort heißt es: »[...] der Pawiak [ist] ein Symbol des Martyriums der Warschauer Bevölkerung und Symbol der Vernichtung [zagłada] der Elite der polnischen Nation während der deutschen Besatzung, aber auch Symbol des Widerstands und des Kampfes gegen die mit Gewalt aufgezwungene fremde Macht.«

88 Pawiak 1835-1944. Museumsführer, 34. 


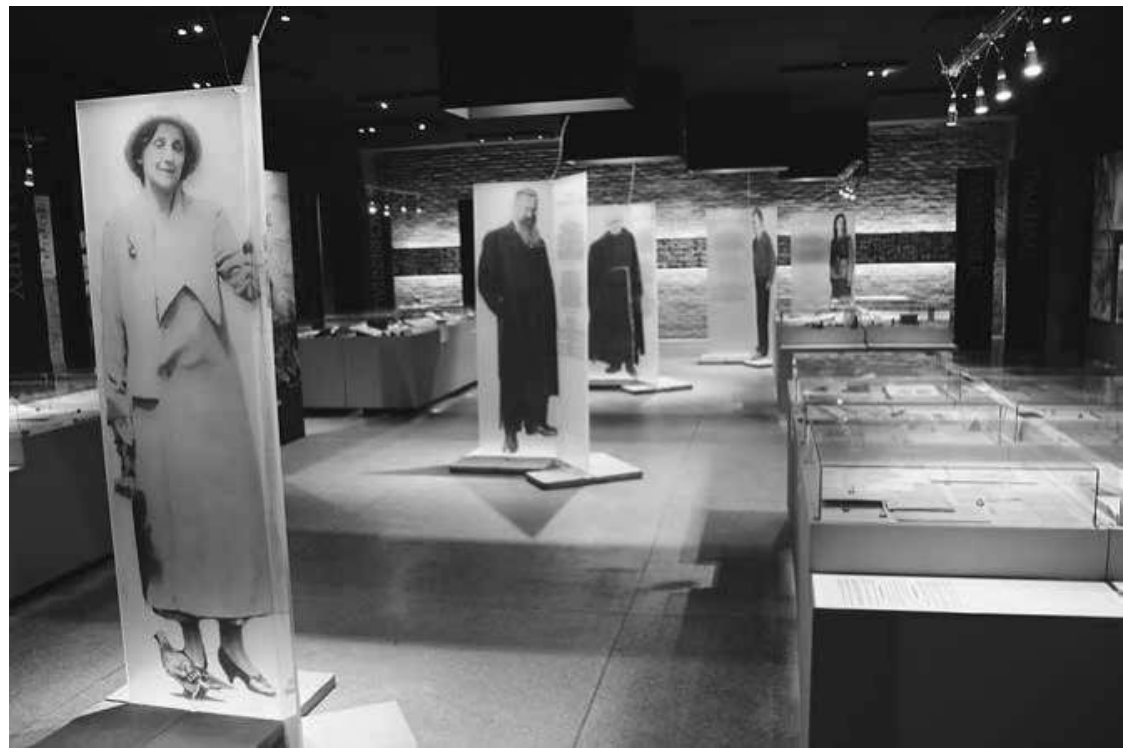

Abb. 37: Gefängnismuseum Pawiak, fünf Persönlichkeiten »begegnen« den Besuchern in der Mitte des Ausstellungssaals.

Noch bevor die Besucher die Informationen zu den einzelnen Individuen jedoch lesen können, wird durch diese Elemente bereits vorgegeben, dass es sich um Menschen handelt, die das Leitmotiv der Schau lebten und dafür starben, sie daher als Helden und Märtyrer zu erinnern sind. Die Gestaltung der Objektträger verleiht den fünf Einzelpersonen somit eine sakrale, Ehrfurcht gebietende Aura.

Neben der Aufnahme religiöser Themen und Symboliken in die Schauen ist eine weitere wesentliche Veränderung der Opferdarstellungen bis Anfang der 2000er-Jahre zu konstatieren: die Inklusion der Opfer der sowjetischen Besatzung sowie der Verfolgung des antikommunistischen Widerstands in der Nachkriegszeit. Diese war unmittelbar verbunden mit der sukzessiven Integration des Feindbildes der Sowjetunion in die Ausstellungen..$^{89}$ Die mit diesem Feindbild verbundene Opferdarstellung kreist um die zwei Topoi »Katyń" und »Sybiracy«, also die Ermordung polnischer Offiziere und Soldaten durch den NKVD im Jahr 1940 bzw. die Deportation von Polen in sowjetische Lager. Insbesondere das Thema Katyń wurde bis Anfang der Nullerjahre in allen neu eröffneten Präsentationen integriert. Zum Teil geschah dies nur durch kleine Hinweise, wie etwa im Historischen Museum der Stadt Lublin. 
In dessen Dauerausstellung von 1995 wurde das Thema fast beiläufig untergebracht: Der Leitartikel einer Ausgabe des Nowy Głos Lubelski (Neue Lubliner Stimme) vom 17. April 1943 berichtet von den Untersuchungen der Massengräber polnischer Offiziere in der Nähe von Katyń. Dieser Hinweis auf den Fund der Massengräber im Jahr 1943 durch deutsche Einheiten und dessen propagandistische Verwendung in der Presse des Generalgouvernements setzt jedoch aufmerksame Besucher voraus: Den brisanten Inhalt bemerkt nur, wer den Text der in der Vitrine ausgestellten Titelseite auch tatsächlich liest, denn die Objektbeschriftung verweist lediglich auf den Propagandahintergrund der von den Besatzungsorganen in polnischer Sprache herausgegebenen Zeitung. ${ }^{90}$ Daneben findet sich noch ein weiterer peripherer Hinweis: Bei den kurzen biografischen Angaben zu General Mieczysław Smorawiński, des Anführers der Verteidigung Lublins im September 1939, wird angegeben: »ermordet in Katyń.» Im Stadtmuseum Łódź fand sich ein Plakat der Besatzungsorgane von 1943, das von den Exhumierungsarbeiten bei Smolensk unter Teilnahme polnischer Arbeiter und Delegierter aus Posen und Litzmannstadt berichtete. Umfangreicher fand das Thema seit der Jahrhundertwende in den Dauerausstellungen Eingang: In der Pomorska-Straße in Krakau, wo bereits seit 1998 ein Plakat deutscher Besatzungsorgane die propagandistische Ausnutzung des sowjetischen Verbrechens an Polen illustrierte, ${ }^{91}$ wurden nach 2003 Fotografien der polnischen Soldatenfriedhöfe in Katyń, Mednoe und Charkov hinzugefügt, zusammen mit Informationen über die Zahlen der aus dem Süden Polens stammenden Opfer der Massenmorde. ${ }^{92}$

Besonders umfangreich herausgestellt wurde das Thema jedoch in der Schau mit der insgesamt auch größten Ausstellungsfläche, im Martyrologiemuseum Radogoszcz. Den Massenmorden widmete man hier eine eigene Sektion, in der sowohl Propagandamaterial der Deutschen aus dem Jahr 1943 gezeigt wurde als auch Fotografien und Objekte, die während der Exhumierungsarbeiten in Katyń und Mednoe im Jahr 1994 gefunden worden waren. Präsentiert wurden daneben zahlreiche Fotografien und Dokumente von Łódźer Bürgern, die bei den Exekutionen umgekommen waren. Die herausragende Bedeutung, die die Kuratoren dem Thema zumaßen, zeigte sich, wie bereits erläutert, insbesondere anhand der präsentierten Reliquien in Form von Erde, die von den Begräbnisstätten in Katyń, Mednoe und

90 Die Objektbeschriftung lautet: "gadzinówka< [Propagandapresse] - deutsche Propagandazeitung in polnischer Sprache, die in den Jahren 1940-1944 auf dem Gebiet des Distrikts Lublin verbreitet wurde». Vitrine 4. MLL-Krakauer Tor, Sektion »Zweiter Weltkrieg«.

91 MHK-Pomorska-Straße, Tafel 33.

92 Die Fotos entstanden - so die in der Ausstellung zu lesende Angabe - im Jahr 2001. Im Ausstellungsführer von 2003 werden sie noch nicht erwähnt. Daher ist davon auszugehen, dass dieses Ausstellungselement erst nach 2003 in die Schau aufgenommen wurde. 
Charkov stammte. Bemerkenswert war bei dieser Präsentation jedoch auch die Verortung der Sektion: Man ordnete sie dergestalt ein, dass vom Schicksal polnischer Kriegsgefangener in deutschen Lagern, über die sowjetischen Verbrechen an Kriegsgefangenen - beides unter dem Sektionstitel »In Gefangenschaft« -, zum Schicksal polnischer Insassen deutscher Konzentrationslager übergeleitet wurde. Der Kriegsgefangenschaft in deutschen Lagern und den sowjetischen Exekutionen war dabei in etwa gleich viel Platz eingeräumt; zunächst wurde somit die vergleichsweise gute Behandlung der polnischen Kriegsgefangenen durch die Deutschen den Massakern des NKVD gegenübergestellt. ${ }^{93}$ Erst im Anschluss an die Katyń-Sektion, bei der Darstellung der deutschen Konzentrationslager, kam die Brutalität des zweiten Besatzers zur Sprache. ${ }^{94}$ Auch die Sowjetunion wurde somit als Feindbild in der Schau gekennzeichnet, die in ihrer regionalen Ausrichtung eigentlich auf Łódź und seine Umgebung und damit auf die in das Deutsche Reich eingegliederten Gebiete konzentriert war. Das Arrangement dieser Sektionen, mit den darin platzierten reliquienartigen Objekten, zog letztlich suggestiv ein Gleichheitszeichen zwischen den verbrecherischen Charakteren beider Regime - ein Ausdruck des sich nach der Wende von 1989 in der polnischen Geschichtsschreibung und öffentlichen Debatte behauptenden Totalitarismus-Paradigmas, das in Bezug auf die Kriegsjahre »quasi axiomatisch vorausgesetzt« wird. ${ }^{95}$

Die Deportationen polnischer Soldaten und Zivilisten in die Sowjetunion waren demgegenüber bis Anfang der Nullerjahre in den übrigen Schauen nur in spärlichen Andeutungen vertreten. Ein Grund hierfür lag in der regionalen Ausrichtung der meisten Dauerausstellungen; die untersuchten Städte waren bis 1944 nicht von der Roten Armee besetzt worden, daher waren sie von den ersten Deportationswellen bis ins Jahr 1941 auch nicht betroffen. Eine

93 Die Präsentation der Gefangenschaft polnischer Soldaten und Offiziere in deutschen Kriegsgefangenenlagern ist weitgehend frei von direkter Gewaltdarstellung. Die ausgestellten Zeichnungen von Insassen und Fotografien zeigen sorgfältig arrangierte Gruppenaufnahmen sowie Sport- und Kulturveranstaltungen, die die Häftlinge organisierten. MTNŁ-Radogoszcz, Sektion »In Gefangenschaft«.

94 Insgesamt nahm dieser Abschnitt etwas mehr Raum ein als die zwei unter dem Titel »In Gefangenschaft« subsumierten Themen. MTNŁ-Radogoszcz, Sektion »In den Konzentrationslagern «.

95 Hofmann, Andreas R.: Realsozialismus und Totalitarismus. Polnische Variationen über ein europäisches Thema. In: Inter Finitimos 5 (2007), 9-26, hier 14f., 21-23, Zitat: 14. In Bezug auf die Bewertung der Volksrepublik als "totalitäres System « hält die Debatte dagegen an. Vgl. Hoenig, Bianca: Chancen und Grenzen eines Paradigmas. Die Totalitarismustheorie in Anwendung auf den ostmitteleuropäischen Staatssozialismus. In: Bohemia 49/2 (2009), 431-444. Siehe auch den Themenschwerpunkt »Im Brennpunkt: Was die Volksrepublik Polen ein totalitärer Staat? « der Zeitschrift Inter Finitimos 5 (2007). Stobiecki: Die Zeitgeschichte, 337-339. 
weitere Ursache ist darin zu sehen, dass die Nachkriegszeit bzw. die Ereignisse nach der Befreiung einzelner Regionen durch sowjetische Truppen seit 1944 in den wenigsten Schauen thematisiert wurden. Einige knappe Hinweise fanden sich dennoch, so in der Dauerausstellung des Historischen Museums der Stadt Lublin aus dem Jahr 1995: Bei zwei führenden Vertretern des Untergrunds, Władysław Cholewa und Kazimierz Tumidajski, wird erwähnt, dass sie zwischen 1944 und 1947 in mehreren Orten in der UdSSR interniert waren. ${ }^{96}$ Auch in der Schau in der Krakauer Pomorska-Straße von 1998 fand sich in einem kurzen Biogramm zu General August Emil Fieldorf ein Hinweis auf seine Deportation in die Sowjetunion im Jahr 1945 und die Gefangenschaft in mehreren Lagern zwischen 1945 und 1947. Eingebettet war die Darstellung seiner Person in den breiteren Kontext der Nachkriegszeit, die in der Schau unter dem Titel »Gegen die Kommune [den Kommunismus - d.Vf.]« (Przeciw komunie) firmierte. ${ }^{97}$ Diese Sektion widmete sich der Verfolgung des antikommunistischen Widerstands seit 1945. Herausgestellt wurden hier mehrere Beispiele von Kämpfern aus der Region, die vom NKVD und später von Einheiten des Ministeriums für Öffentliche Sicherheit der Volksrepublik Polen verfolgt, das heißt inhaftiert und zum Teil zum Tode verurteilt wurden. ${ }^{98}$ Die Widerstandskämpfer wurden dabei klar von den Repräsentanten des neuen sozialistischen Staates abgegrenzt: Überwiegend bezeichnete man sie als »Soldaten" (żotnierze) des "für die Unabhängigkeit kämpfenden Untergrunds" (podziemie niepodległościowe). ${ }^{99} \mathrm{Ihr}$ Leiden rückte damit in den martyrologischen Kontext des Kampfes für das Vaterland. Diese Ausstellung sowie diejenige im Lubliner Stadtmuseum von 1995 waren jedoch bis 2003 die einzigen, die den Partisanenkampf der Nachkriegsjahre bzw. die Verfolgung von Widerstandskämpfern nach dem Einmarsch der Roten Armee thematisierten.

Wie damit deutlich wird, konzentrierten sich die meisten der Ausstellungen, die nach der politischen Wende von 1989 geschaffen wurden, bei der Schilderung der Opfer des Besatzungsterrors wie ihre jeweiligen Vorgängerfassungen aus den Jahren der VRP auf Personen, die aufgrund ihrer Kampfbzw. Widerstandsaktivitäten verfolgt wurden und umgekommen sind. Menschen, die sich während des Kriegs und der Besatzung ausgezeichnet haben, ragten somit weiterhin auch innerhalb der Präsentationen heraus. Sie waren

96 Władysław Cholewa war der Delegierte der Londoner Exilregierung im Bezirk Lublin, Kazimierz Tumidajski der Anführer der Heimatarmee in diesem Bezirk.

97 MHK-Pomorska-Straße, Tafeln 37-40.

98 Es fanden sich sowohl Fotografien einzelner Einheiten als auch Dokumente der Schauprozesse. MHK-Pomorska-Straße, Tafeln 37-39. In diesem Zusammenhang wurde auch das Internierungsgefängnis des WUBP am Invalidenplatz - in der Nähe des Museumsgebäudes - thematisiert. Gezeigt wurde u. a. eine Tür aus diesem Arrest. Ebd., Objekt 329, Tafel 40.

99 Siehe die Bildunterschriften und Biogramme auf den Tafeln 37 und 38. 
es, die individuell porträtiert wurden, meist nicht nur über eine reine Namensnennung, sondern auch mit Fotografien und kurzen Biogrammen. In der Krakauer Pomorska-Straße gehörten dazu etwa neben den führenden Mitgliedern diverser Widerstandsgruppen auch die »[E]rmordete[n] Mitglieder des Magistrats «. ${ }^{100}$ Die Mehrheit der unter dieser Überschrift aufgeführten Personen war im Zusammenhang mit Widerstandsaktivitäten verhaftet worden, wie die Biogramme unterhalb der Fotografien kenntlich machten. ${ }^{101}$ Im Łódźer Museum Radogoszcz fanden sich in der Schau verteilt zahlreiche Listen von exekutierten oder in KZs umgekommenen Mitgliedern einzelner Untergrundeinheiten. ${ }^{102}$ Selbst auf der äußerst begrenzten Ausstellungsfläche im Stadtmuseum Łódź waren es Widerstandskämpfer, deren Schicksal individuell, anhand konkreter Ereignisse geschildert wurde. ${ }^{103}$ Insofern folgten die Schauen, die nach der Wende entstanden waren, weitgehend tradierten Interpretationsmustern. Verändert hatte sich lediglich der politische Fokus der Darstellung: Unter den herausgestellten inhaftierten und umgekommenen Widerstandskämpfern dominierten nun Vertreter der größten Untergrundorganisation während des Kriegs, der Heimatarmee, und mit ihr alliierter Gruppen. ${ }^{104}$ Die Mitglieder kommunistischer Gruppierungen traten demgegenüber in den Hintergrund, negativ bewertet wurden sie aber nicht.

Zivile Opfer blieben demgegenüber weitgehend anonym, wenngleich sich im Vergleich zu den Schauen von vor 1989 bei ihrer Darstellung bereits Änderungen abzeichneten: In einigen Präsentationen fanden nun auch Verfolgte namentliche Erwähnung, die nicht im Zusammenhang mit wider-

100 MHK-Pomorska-Straße, Titel der Tafel 21.

101 Bei den übrigen Personen handelte es sich um Reservisten der Armee oder leitende Angestellte der Zivilverwaltung, die im Rahmen konzertierter Aktionen gegen die polnische Intelligenz verhaftet worden waren.

102 Bei der Darstellung des organisierten Widerstands fanden sich mehrere Namenslisten und Tafeln mit Porträtfotografien ermordeter Widerständler. Sie nahmen insgesamt etwa die Hälfte der dem Widerstand gewidmeten Ausstellungsfläche ein. In der Sektion zu den deutschen Konzentrationslagern war eine Liste der in den Lagern umgekommenen Mitgliedern der Untergrundpfadfinderorganisation »Graue Reihen« (Szare Szeregi) aus der Region zu sehen. MTNŁ-Radogoszcz, Sektion »Wir werden siegen«.

103 Im Bereichstext wurde etwa die Exekution von Widerständlern geschildert, die entflohenen Kriegsgefangenen geholfen hatten. Unmittelbar daneben fand sich das Plakat der Besatzungsorgane, das ihr Todesurteil und dessen Vollstreckung verkündete. Die im Bereichstext thematisierte Exekution mehrerer Polen aufgrund einer Anklage der Sabotage war zusätzlich mit einem Gemälde illustriert. Abschnitt »Untergrundbewegung «. MMŁ, Sektion »Lodsch - Litzmannstadt«.

104 Beispielhaft kann hier die flächenmäßig sehr kleine Schau des Łódźer Stadtmuseums herangezogen werden: Bei der Schilderung der »Untergrundbewegung - so der Titel des entsprechenden Bereichstextes - waren die exekutierten AK-Mitglieder die einzigen Vertreter des Untergrunds, die namentlich genannt wurden. Ebd. Zur Darstellung des Widerstands in den Ausstellungen siehe auch Kapitel 2 in diesem Teil. 
ständigem Verhalten gelitten hatten. So porträtierte man in der Krakauer Pomorska-Straße und im Museum Radogoszcz in Łódź Menschen, die noch im Jahr 1939 im Zusammenhang mit dem Vorgehen der Besatzer gegen die polnische Intelligenz in Konzentrationslager deportiert oder exekutiert worden waren. ${ }^{105}$ Darüber hinaus wurden auch die Repressalien der Besatzer gegen die breite Bevölkerung thematisiert, vor allem die Deportationen in Konzentrationslager und zur Zwangsarbeit sowie die Exekutionen Inhaftierter, diese jedoch überwiegend in allgemeiner Form. Am umfangreichsten geschah dies in der Ausstellung des Museums Radogoszcz von 2003: Zahlreiche Plakate der Besatzungsorgane veranschaulichten die Namen und vermeintlichen "Verbrechen « von Polen, die durch Sondergerichte zum Tode verurteilt worden waren; Fotos, der Bericht polnischer Untergrundeinheiten sowie eine Namensliste von Opfern illustrierten die Massenexekutionen in der Region. Unmittelbar daneben fand das Leiden der in den Gefängnissen der Stadt Inhaftierten Ausdruck; gezeigt wurden hier unter anderem Namenslisten aus den Evidenzbüchern einzelner Einrichtungen. ${ }^{106}$ Der Umfang der Darstellung von Personen, die individuell von den Gewaltmaßnahmen der Besatzer betroffen waren, stellte bis ins Jahr 2003 jedoch eine Ausnahme unter den untersuchten Institutionen dar. Meist fanden die Namen Einzelner lediglich in zwei Zusammenhängen Eingang in die Schauen: Durch die Bekanntmachun-

105 Unter der deutschsprachigen Überschrift "Sonderaktion Krakau« wurden diejenigen am 6. November 1939 verhafteten und ins KZ Sachsenhausen deportierten Professoren und Hochschulmitarbeiter aufgeführt (jeweils mit einem Foto und einem kurzen Biogramm), die während der Haft umkamen. MHK-Pomorska-Straße, Tafel 17. In der Dauerausstellung des Museums Radogoszcz hingen Porträtfotos sowie eine Liste der zwischen dem 9. und dem 11. November 1939 verhafteten und exekutierten Vertreter der Łódźer Intelligenz. MTNŁ-Radogoszcz, Sektion »In der Gewalt der Wehrmacht«. Im Gefängnismuseum Pawiak porträtierte man namhafte Opfer der Massenexekutionen in Palmiry: einen Spitzensportler sowie zwei führende Politiker der Zwischenkriegszeit. MNW-Pawiak, Sektion »Palmiry«.

106 Im weiteren Verlauf der Schau schilderte man die Bemühungen der Besatzer um eine Germanisierung der Region, die durch die Aussiedlung von Polen und Juden sowie die Germanisierung polnischer Kinder erreicht werden sollte. Auch der Verschickung zur Zwangsarbeit ins Deutsche Reich sowie in das Internierungslager für Kinder und Jugendliche räumte man umfangreich Platz ein. Dabei traten den Besuchern zahlreiche Betroffene durch Fotografien und persönliche Dokumente individuell gegenüber. Hierbei sei angemerkt, dass die gezeigten Materialien zum überwiegenden Teil von den Besatzern angefertigt worden waren. Die Besucher betrachteten daher diese Personen unbewusst aus deren Perspektive, so etwa im Fall der Fotografien von Kindern, die der Germanisierungspolitik unterworfen worden waren. Die Opfer wurden hierdurch ein weiteres Mal viktimisiert, denn es ist davon auszugehen, dass die derart in der Schau gezeigten Personen nicht nach ihrem Einverständnis zur öffentlichen Darstellung gefragt worden sind. Dieser - in ethischer wie fachlicher Hinsicht - unreflektierte Umgang mit Quellenmaterial kennzeichnet einen Großteil historischer Ausstellungen bis heute (und dies nicht nur in Polen). 
gen der Besatzer über Exekutionen - auf den Plakaten waren die Namen und "Vergehen" der zum Tode Verurteilten angegeben. ${ }^{107}$ Daneben waren es Dokumente von Personen, die in Konzentrationslager oder zur Zwangsarbeit deportiert worden waren, durch die einzelne Zivilisten in den Erzählungen in Erscheinung traten. ${ }^{108}$ Näheres zu ihrem Leben vor der Festnahme und ihrem weiteren Schicksal erfuhren die Besucher jedoch nicht, im Gegensatz zur gängigen Praxis der Darstellung von Untergrundaktivisten. Fotografien oder die Auflistung von Straßenrazzien und Exekutionen, die sich in den meisten Schauen fanden, blieben dagegen überwiegend anonym. ${ }^{109}$ Die passiv unter der Gewalt der Besatzer Leidenden blieben somit innerhalb der musealen Erzählungen reine Objekte der historischen Ereignisse; als Akteure traten sie hingegen nicht in Erscheinung.

Auffällig ist insgesamt, dass die physische Verfolgung im Zentrum der Darstellungen des Alltags und der Besatzungspolitik stand. Die individuellen Beispiele und Schicksale, die den Besuchern begegneten, zeigten fast ausschließlich Personen, die inhaftiert, gefoltert, ermordet oder in Konzentrationslager deportiert worden waren. Es waren demnach die Erfahrungen des kleineren Teils der Bevölkerung, die die musealen Erzählungen prägten. Dabei lag der Schwerpunkt nicht auf den zivilen, zufälligen Opfern der willkürlichen Straßenrazzien und Massenexekutionen, sondern auf der Ausnahmeerscheinung der Mitglieder des Widerstands. Zwar waren die victimae in den Schauen aus diesem Zeitraum somit präsent und dies im Vergleich zu den Ausstellungen von vor 1989 in merklich ausgeweiteter Form. Eindringlicher jedoch wurde die Gruppe der heroischen Opfer, der sacrificiae, präsentiert. Sie waren es - und sind es teilweise bis heute -, die während des Rundgangs visuell und inhaltlich herausragten, denn gerade ihre individualisierte, affektive Präsentation machte ihre Darstellung besonders eindrücklich. Im

107 MHK-Pomorska-Straße, Tafel 20. Im Łódźer Museum Radogoszcz sowie im Stadtmuseum Łódź waren es Bekanntmachungen der Urteile des Sondergerichts Litzmannstadt, die in dieser Form gezeigt wurden.

108 Im Stadtmuseum von Łódź ebenso wie im Museum Radogoszcz gehörten zu diesen Objekten Briefe von in KZs Internierten. In der Schau des Warschauer Pawiak-Museums von 2001 fanden sich neben zahlreichen Briefen von KZ-Insassen an ihre Familien sowie Mitteilungen aus den Konzentrationslagern über den Tod von Insassen auch Deportationslisten, auf denen die Namen der in verschiedene KZs Deportierten verzeichnet waren. Daneben stellte man auch Hefte einzelner KZ-Insassen mit Gedichten oder selbst komponierter Musik aus. Auch im Lubliner Stadtmuseum fanden sich Briefe und Dokumente von im KZ Majdanek sowie auf dem Lubliner Schloss inhaftierten Personen.

109 Siehe etwa MHK-Pomorska-Straße, Tafel 18-19. Im Pawiak-Museum werden unter dem Titel »Massenexekutionen« Fotografien erhängter und erschossener Menschen gezeigt sowie eine Liste der Massenexekutionen von Pawiak-Häftlingen in den Ruinen des Ghettos, in der jedoch die Opfer lediglich durch summarische Zahlenangaben repräsentiert waren. Ebenso zeigt man Berichte, die in Publikationen des Untergrunds über die Exekutionen erschienen. MNW-Pawiak, Vitrinen passim. 
Vordergrund der Opferdarstellung stand somit weiterhin ein martyrologisches Narrativ: Leiden als Teil des Kampfes für die Unabhängigkeit des Vaterlandes. Innerhalb der Opferdarstellung ist somit eine Hierarchisierung sichtbar: "Verdienstvolle« Opfer, solche also, die sich durch aktiven Kampf und Widerstand hervorgetan haben und infolge dessen gelitten hatten - die Soldaten des September 1939 ebenso wie die Mitglieder diverser Untergrundorganisationen -, standen im Vordergrund. Ihr Kampf und auch ihr Tod wurden als ehrenhaft hervorgehoben. Der "graue Alltag" jenseits unmittelbaren physischen Leidens und Sterbens, jenseits also des heroischen Einsatzes des eigenen Lebens für das Vaterland, ebenso wie das Leiden passiver, da zufälliger Opfer, blieben im Hintergrund der Darstellungen und wurden weitgehend allgemein und anonym skizziert. ${ }^{110}$

Für diese Darstellungspraxis kann man mehrere pragmatische Gründe anführen: Die Opfer unter den Widerstandskämpfern waren zumeist besser dokumentiert als diejenigen unter der Zivilbevölkerung. Die diversen Untergrundorganisationen registrierten ihre Mitglieder nicht nur, sondern verfolgten auch deren Schicksal im Falle einer Verhaftung. Demgegenüber waren die Namen und das weitere Los verhafteter und deportierter oder exekutierter Zivilisten meist nur ihren Familien und Freunden bekannt; Informationen und Unterlagen befanden sich überwiegend in Privateigentum und waren damit verstreut. Der Fokus der Ausstellungen auf die von den Besatzern Verfolgten ist darüber hinaus Ausdruck der dokumentarischen sowie der Gedenkfunktion vieler Einrichtungen. Nicht nur bezeugen die Einzelschicksale und die Listen von Exekutionsopfern die Verbrechen der deutschen Besatzer. Viele der untersuchten Museen, insbesondere wenn sie an authentischen Orten von Besatzungsverbrechen untergebracht sind, verstehen sich bis heute zugleich als Gedenkstätten. Gerade die Namenslisten umgekommener Untergrundkämpfer oder Vertreter der lokalen Intelligenz dienen daher auch der Bewahrung der Erinnerung an diese Personen und ihrer Ehrung.

Durch diese Präsentationspraxis legten die Ausstellungen der Jahre 1990 bis 2003 zugleich nahe, dass die geschilderten Schicksale - der Kämpfer wie der Opfer - repräsentativ für die Gesamtheit der Besatzungserfahrungen der ethnisch-polnischen Bevölkerung gewesen seien. Gerade die in den meisten Schauen zu beobachtende Konzentration auf den Widerstand und das Schicksal seiner inhaftierten Mitglieder perpetuierte somit das tradierte martyrologische Selbstbild der Kriegsjahre. Weiterhin konnte bei Besuchern der Eindruck entstehen, Widerständigkeit, Gefangenschaft, Folter und Exekutionen seien zentrale, nahezu allgemeine Besatzungserfahrungen innerhalb der polnischen Bevölkerung gewesen. Unterstützt wurde diese unterschwellig ver-

110 Detaillierter zur Entwicklung der Alltagsdarstellung während des Kriegs und der Besatzung siehe Kapitel 3.1 in diesem Teil. 
mittelte Botschaft noch durch die Eindeutigkeit der Darstellung: Bis 2003 gibt es in den Schauen kaum Hinweise auf zweifelhafte oder negative Verhaltensweisen innerhalb des Widerstands oder der breiten Bevölkerung. Nur in wenigen Ausstellungen fanden sich vereinzelte Hinweise etwa auf die Existenz von Spionen und Denunzianten, die die Untergrundorganisationen unterwanderten und immer wieder die Zerschlagung und Inhaftierung ganzer Gruppen herbeiführten. ${ }^{11}$ Analog zur einseitigen, schematischen Darstellung der Besatzer erfolgte auch die Konstruktion der eigenen, polnischen Wir-Gemeinschaft weiterhin entlang eindeutiger, etablierter Topoi.

Aus dieser Wir-Gemeinschaft blieb die jüdische Bevölkerung nach wie vor ausgeschlossen, wenn auch der Schilderung ihrer Verfolgung bis Anfang der Nullerjahre in den Ausstellungen deutlich mehr Platz eingeräumt wurde. Wie bereits in Teil 2 dargelegt, veränderte sich jedoch die Verortung dieser Opfergruppe innerhalb der musealen Narrative. Von der stillschweigenden Vereinnahmung, die noch die Präsentation der 1980er-Jahre prägte, wechselten die Schauen zu einer vom polnischen Besatzungsschicksal weitgehend losgelösten Schilderung. Dem »Ghetto « wurde nun in vielen Schauen eine eigene Sektion eingeräumt und damit die Unterschiede des jüdischen Verfolgungsschicksals angedeutet. Zwar blieb die Verfolgung und Ermordung eines Viertels bis eines Drittels der Einwohner der untersuchten Städte in den Ausstellungen marginalisiert, die Bezugnahme zwischen den Schicksalen beider Bevölkerungsgruppen änderte sich jedoch merklich. Insbesondere wurde nun in den Schauen eine Vernichtungsabsicht der Deutschen nicht mehr primär oder gar ausschließlich bezogen auf die ethnisch-polnische Bevölkerung postuliert. In diesem Zusammenhang trat in den ab Mitte der 1990er-Jahren neu entstehenden Präsentationen eine vereinnahmende "Opferarithmetik « deutlich in den Hintergrund. Zugleich ist bei der Darstellung dieser Bevölkerungsgruppe eine ähnliche ethische Hierarchisierung von Tod und Leiden zu beobachten, wie sie auch bei der Darstellung der polnischen Stadtbewohner auffiel. Es waren die Mitglieder des jüdischen Widerstands bzw. ihr Kampf und folgender Tod, die detaillierter porträtiert wurden. So findet sich beispielsweise in der Ausstellung des Gefängnismuseums Pawiak von 2001 ein prominent platziertes Gedicht, das die mutigen jüdischen Kämpfer des Warschauer Ghettoaufstandes von 1943 preist. ${ }^{112}$ Daneben werden einzelne herausragende Persönlichkeiten der jüdischen Gemeinschaft thematisiert, die ihr Leben für andere opferten. Im Pawiak-Museum sind es Janusz Korczak sowie Szmul Zygielbojm, die als Märtyrer individuell porträtiert werden. Ersterer begleitete

111 Näher zu den Leerstellen der Ausstellungsnarrative siehe Kapitel 3.2 in diesem Teil.

112 Das Gedicht »Żydom polskim. Pamięci Szmula Zygielbojma» (Den polnischen Juden. Im Gedenken an Szmul Zygielbojm) wurde in der Zeitschrift $W$ drodze (Auf dem Weg) in Jerusalem am 16. Juni 1943 publiziert. 
freiwillig die Kinder des von ihm geleiteten Waisenhauses in den Tod. Zygielbojm beging Selbstmord als Akt des öffentlichen Protests gegen die Untätigkeit der Alliierten angesichts der Verfolgung und Ermordung der Juden im besetzten Polen. ${ }^{113}$ In der Krakauer Pomorska-Straße waren es ausschließlich die ermordeten Mitglieder der ŻOB, die jeweils mit einem Foto und einem kurzen Biogramm einzeln porträtiert wurden. ${ }^{114}$ Die übrige Gruppe der als Juden Verfolgten, die passiven Opfer der NS-Verfolgung, blieben dagegen als anonyme und abstrakte Objekte der Verfolgung marginalisiert.

\subsection{Der Museumsboom - Diversifizierung des Märtyrertopos}

Wie gezeigt werden konnte, hatte die heroische Opfererzählung bis Anfang der 2000er-Jahre also keineswegs ausgedient. Das viktimologische Narrativ erfuhr zwar mit Beginn der 1990er-Jahre eine Aufwertung, dennoch blieb die martyrologische Interpretationspraxis im Vordergrund der meisten Präsentationen. Vor diesem Hintergrund wird nun danach gefragt, inwieweit die Ausdifferenzierung der musealen Narrationen seit Beginn des Museumsbooms auch in diesem zentralen Element des polnischen Autostereotyps ihren Niederschlag fand. Ist tatsächlich auch im Fall der öffentlichen Geschichtskonstruktion und -vermittlung in polnischen Museen eine "Wende im Opfergedächtnis $\aleph^{115} \mathrm{zu}$ verzeichnen?

\section{Dominanz des Märtyrertopos}

Entgegen diesem vor allem in der westlichen Geschichtswissenschaft verbreiteten erinnerungskulturellen Postulat zeichnet sich ein Großteil der untersuchten Dauerausstellungen, die seit 2004 in Polen neu eröffnet oder grundlegend überarbeitet worden sind, durch eine deutliche Akzentuierung des seit der Romantik tradierten martyrologischen Vergangenheitsbildes aus. Dieses besteht aus einem ausgeprägten Helden- und damit unmittelbar verbundenen Märtyrertopos. Das herausragendste Beispiel dieses Geschichtsbildes ist das Museum des Warschauer Aufstands.

In seiner Dauerausstellung ist die Darstellung von Leiden und Tod von einem heroischen Opfernarrativ dominiert, denn geschildert werden diese

113 Korczak wird mit einem großformatigen Foto, einem kurzen Biogramm sowie einem Personalbogen von 1940 präsentiert. Daneben wird das Testament Szmul Zygielbojms in polnischer und englischer Sprache gezeigt sowie ein Bericht aus der New Yorker Zeitschrift The Polish Review vom 19. Juli 1944 über einen Kämpfer des Ghettoaufstandes, Michal Klepfisz.

114 MHK-Pomorska-Straße, Tafel 15.

115 Assmann: Der lange Schatten der Vergangenheit, 76. 
Themen in erster Linie im Kontext des Kampfes der Aufständischen gegen die Besatzer und für die Freiheit des Vaterlandes. Ausdruck dessen sind etwa die verstreut in der Schau auftauchenden halbhohen, schwarzen Blöcke. ${ }^{116}$ Auf ihnen werden einzelne Teilnehmer des Aufstands vorgestellt. In ihrer Gestaltung sind sie an Grabmale angelehnt: Am oberen Ende des Blocks erscheint jeweils der Name und das während des Kriegs verwendete Pseudonym; darunter sind kleine ovale Porträtfotografien angebracht. Darüber befindet sich der »Anker» (kotwica), eines der bekanntesten Symbole des polnischen Widerstands während des Kriegs, ${ }^{117}$ schräg liegend vor einem Palmzweig. Das Zeichen des »Kämpfenden Polen« erscheint dabei anstelle des Kreuzes, das auf einem Großteil christlicher Grabmale zusammen mit einem Palmwedel $\mathrm{zu}$ finden ist, dem Symbol des Sieges und der Überwindung des Todes. ${ }^{118}$ Noch bevor die Besucher also an die Objekte herantreten, wird ihnen bereits assoziativ vermittelt, dass darauf der gefallenen Teilnehmer des Aufstands, mithin seiner Märtyrer gedacht wird. Der vergleichsweise niedrige militärische Rang der vorgestellten Aufständischen (keiner gehörte zum Führungsstab der AK) deutet darauf hin, dass die Ausstellungsmacher »durchschnittliche« Teilnehmer der Kämpfe als repräsentative Individuen präsentieren wollten. ${ }^{119}$ Die Biogramme zeigen jedoch allesamt Personen, die sich während der Kämpfe in herausragender Weise hervorgetan haben, zumeist Führungspersönlichkeiten waren (wenn auch auf niedriger militärischer Ebene) und während des Aufstands umgekommen sind. So werden auf einem der Steine im Zwischengeschoss das Leben und die Verdienste von Krzysztof Kamil Baczyński vorgestellt, einem der bekanntesten polnischen Dichter des Zweiten Weltkriegs. Ein anderer ist der Zugführerin Ewa Matuszewska gewidmet, die ein Feldlazarett organisiert hat und mit Verletzten zurückblieb, nachdem sich die Kämpfer aus der Region zurückgezogen hatten; »sie stirbt, erschossen

116 Teile der folgenden Ausführungen wurden bereits publiziert in Heinemann: Emotionalisierungsstrategien.

117 Das Zeichen der kotwica ist zusammengesetzt aus den Buchstaben P (der den oberen Teil des »Ankers« bildet) und W, die für Polska Walczaca (Kämpfendes Polen) stehen. Das Symbol wurde im Rahmen eines Wettbewerbs der Heimatarmee unter zahlreichen Vorschlägen ausgewählt und erstmals in einer Sabotageaktion im März 1942 auf Mauern, Straßenlaternen und Ähnlichem in Warschau verbreitet. Seit Kriegsende wird es als Synonym für den polnischen Widerstand verstanden und verwendet. Vgl. Szarota, Tomasz: V - jak zwycięstwo. Symbole, znaki i demonstracje patriotyczne walczącej Europy 1939-1945 [V - wie Sieg. Symbole, Zeichen und patriotische Manifestationen des kämpfenden Europas 1939-1945]. Warszawa 1994, 32 f.

118 Vgl. Palme. In: Seibert, Jutta: Lexikon christlicher Kunst. Themen, Gestalten, Symbole. Freiburg u. a. 1980, $243 \mathrm{f}$.

119 Wie einer der Mitbegründer des Museums, Paweł Kowal, explizit formuliert hat: „[Die Ausstellung] zeigt normale Menschen, solche wie jeden von uns.« Kowal: Jak budowaliśmy Muzeum, 8. 
von Deutschen, mit einer Bandage in der Hand. $\varkappa^{120}$ Bei den individuell vorgestellten Protagonisten, die stellvertretend für die Teilnehmer an den Kämpfen stehen, handelt es sich somit ausnahmslos um verdiente Aufständische, die bei den Besuchern Bewunderung hervorrufen sollen und damit zugleich als Identifikationsfiguren inszeniert werden.

Verfolgung und Tod der Widerstandskämpfer werden jedoch nicht allein mit Bezug auf die zwei Monate der Kämpfe geschildert. Auch der Verfolgung von ehemaligen Widerständlern - insbesondere der Mitglieder der Heimatarmee - in der Volksrepublik ebenso wie ihrer Internierung in deutschen Kriegsgefangenenlagern unmittelbar nach der Kapitulation der Aufständischen wird umfangreich Platz eingeräumt. ${ }^{121}$ Bemerkenswerterweise findet hier eine Symbolik Verwendung, die in Westeuropa ausschließlich mit dem Holocaust verbunden wird: Die Schilderung der Deportation der Warschauer Bevölkerung und der Aufständischen wird gestalterisch vermittelt durch Koffer und Eisenbahnschienen (siehe Abb. 38). ${ }^{122}$ Das Schicksal ehemaliger Kämpfer in der Nachkriegszeit bildet bereits den Einstieg in die Ausstellungserzählung: Der erste Bereichstext, auf den die Besucher beim Betreten der Ausstellung treffen, ist den »Aufständischen in der VRP« gewidmet und schildert schwerpunktmäßig ihre Verfolgung und Ächtung in der neuen polnischen sozialistischen Republik. ${ }^{123}$ Am Ende des Rundgangs wird der Prozess gegen 16 führende Vertreter des polnischen Untergrundstaates in Moskau im Jahr 1945 geschildert. ${ }^{124}$

Für die Darstellung der Verluste und Todesopfer unter den Kämpfenden finden in der Ausstellung wie im Museumskomplex zahlreiche religiöse Elemente und Symboliken Verwendung: Die Sektion, die den Ereignissen der Aktion "Gewittersturm " gewidmet ist, dominiert ein großes, verwittertes hölzernes Kreuz. Die begleitende Objektbeschriftung informiert darüber, dass dieses auf dem Grab eines im April 1944 in Wolhynien gefallenen Soldaten aufgestellt und zusammen mit seinen sterblichen Überresten 1989 nach Warschau überführt wurde. ${ }^{125}$ Das Kreuz sticht durch seine Größe ebenso wie seine Platzierung besonders hervor. Es ist damit eines der zentralen Objekte, die die Besucher visuell wahrnehmen, sobald sie sich der Sektion nähern. Suggestiv wird somit auch in diesem Themenbereich bereits durch gestalterische Elemente die martyrologische Interpretation der Ereignisse

120 Zitat aus dem Biogramm ihrer Person. MPW, Sektion 36: Die Kämpfe im September.

121 MPW, Sektion 45: Weihnachten im Lager.

122 MPW, Sektion 43: Exodus.

123 Titel des Bereichstextes. MPW, Sektion 3: Der Aufstand nach 60 Jahren. (Die ersten beiden Sektionen umfassen in der Zählung des Ausstellungsführers die Garderobe und den Eingangsbereich.)

124 MPW, Sektion 46: Die Aufständischen in der VRP.

125 MPW, Sektion 9: Aktion »Gewittersturm«. 


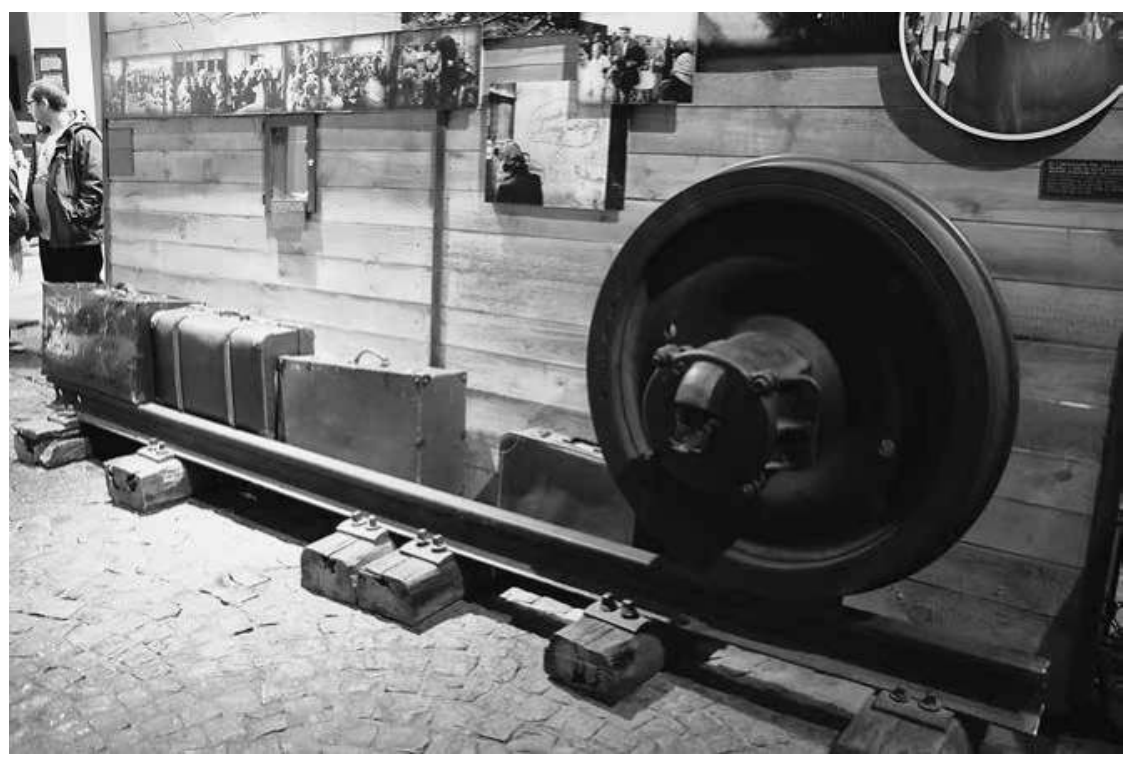

Abb. 38: MPW, Sektion »Exodus«.

des Jahres 1944 in den östlichen Gebieten des besetzten Polens vermittelt es geht um den heldenhaften, jedoch verlustreichen Kampf für die Unabhängigkeit des Landes. Auch inhaltlich gibt es zahlreiche Verweise auf Religiosität und Religionsvertreter, die während des Aufstands aktiv waren. Als zum Alltag während der Kämpfe gehörendes Element werden etwa die Gottesdienste und Kapellen in Hinterhöfen und Kellern thematisiert. Stellvertretend für diesen Teil des "Alltags« stellt man Priester namentlich und mit Fotografien vor, die einzelne Verbände der Aufständischen betreuten. ${ }^{126}$ Besonders herausgehoben wird der Priester Józef Stanek, der Aufständischen wie Zivilisten während der Kämpfe aufopferungsvoll geholfen habe. ${ }^{127}$ Betont wird

126 MPW, Sektion 18: Religiöses Leben.

127 MPW, Sektion 30: 108 Selige. Die gesamte Sektion, die ihrer Bezeichnung nach 108 selig gesprochenen polnischen Geistlichen gewidmet ist, die während des Zweiten Weltkriegs den Märtyrertod starben, wird allein von der Person und dem Schicksal Staneks dominiert. Ein großformatiges Gemälde mit seinem Porträt steht im Mittelpunkt der Sektion; sein Schicksal während des Aufstands, vor allem zwei Zeugnisse seiner Märtyrertat, werden umfangreich gezeigt. Die übrigen Priester erscheinen ausschließlich in Form ihres Namens im Hintergrund der Wand. In der Nähe werden in einer Vitrine lebensgroß das Ornat und die Stola eines weiteren Priesters ausgestellt, der eine Einheit der Aufständischen betreute und »in den ersten Tagen des Aufstands mit der Waffe in der Hand kämpfte«. MPW, Sektion 36: Die Kämpfe im September. Objektbeschriftung. 
insbesondere, dass er die Möglichkeit eines sicheren Entkommens auf das andere Weichselufer für einen Schwerverletzten aufgab, dem er seinen Platz im Schlauchboot überließ. Im September 1944 wurde er von deutschen Truppen gefasst und ermordet. Im Jahr 1999 sprach ihn der polnische Papst Johannes Paul II. zusammen mit 107 weiteren polnischen Geistlichen als Märtyrer selig. Diese besondere Schilderung seines Schicksals hat einen weiteren Hintergrund: Stanek ist seit 2004 Schutzpatron der Kapelle, die in das Museumsgebäude integriert ist und die auch von der Dauerausstellung aus betreten werden kann. In ihrem Altar wurden im Jahr 2004 Reliquien des Priesters beigesetzt. In der Kapelle - die von den Museumsverantwortlichen als Bestandteil der Dauerausstellung verstanden wird - finden jeden Sonntag sowie an besonderen Feier- und Gedenktagen Gottesdienste statt. ${ }^{128}$ Auch unter den wenigen individuell porträtierten Zivilisten finden sich Geistliche, die die stark religiös konnotierte Opferdarstellung der Schau verstärken: Eine der ersten Sektionen, in der das deutsche Besatzungsregime bis ins Jahr 1944 vorgestellt wird, behandelt etwa das Leben und Sterben Maximilian Kolbes und Edith Steins, ${ }^{129}$ zweier christlicher Symbolfiguren, die von der katholischen Kirche als Märtyrer anerkannt und heiliggesprochen wurden. Wie diese Schilderungen verdeutlichen, fügen zahlreiche Elemente der Ausstellungs- und Museumsgestaltung ebenso wie die in der Schau gesetzten inhaltlichen Akzente dem ethnisch-nationalen Antagonismus, der der Erzählung zugrunde liegt, eine starke religiöse Komponente hinzu. Diese unterstützt die martyrologische Deutung der Todesopfer unter den Aufständischen und implizit der gesamten polnischen Bevölkerung. Letztlich wird hierdurch das traditionelle Autostereotyp des »Polen-Katholiken« (Polak-katolik) fortgeschrieben, das seit Anfang der 1990er-Jahre sukzessive in vielen historischen Schauen reüssiert.

Das Gros der zivilen, meist passiven Opfer der Kämpfe und Besatzungsgewalt bleibt dagegen weitgehend im Hintergrund. Nur an wenigen Stellen wird das Schicksal der Zivilbevölkerung direkt thematisiert. Dort wo dies geschieht, dient die Schilderung ihrer Leiden in erster Linie der Illustration der unmenschlichen Grausamkeit der Deutschen. Das prägnanteste Beispiel hierfür ist die Installation, die die Massaker an ca. 40.000 Bewohnern der Stadteile Wola und Ochota thematisiert, die zwischen dem 5. und dem 7. August 1944 durch SS-Einheiten verübt worden waren. In einem insze-

128 Kowal: Jak budowaliśmy Muzeum, 8. Siehe auch Dąbkowska-Cichocka: Przewodnik po Muzeum, $220 \mathrm{f}$. Für religiöse Zeremonien im Rahmen von Gedenkfeierlichkeiten steht schließlich im Park, der das Museumsgebäude umgibt, auch ein Altar zu Verfügung.

129 Das Leben der "Heiligen Teresia Benedicta vom Kreuz« wird in einem gleichnamigen Bereichstext geschildert. MPW, Sektion 6: Besatzung. Auf der gegenüberliegenden Wand findet sich ein Biogramm des "Heiligen Rajmund Maria Kolbes (Pater Maksymilian)«. MPW, Sektion 7: Polnischer Untergrundstaat. 
nierten Zelt sind Protokolle der Exhumierungen von Opfern dieser Gräueltaten ausgelegt. ${ }^{130}$ In ihrer zurückgenommenen Gestaltung ist diese Sektion, die massenhafte Gewalt schildert, durchaus eindrücklich: Das Innere des Zeltes aus grauem Wollstoff ist vollkommen schmucklos. In dem dunklen, leeren Raum ist lediglich der lange Tisch beleuchtet, auf dem die Protokolle einzelner Opfer ausliegen. Die auf den ersten Blick individualisierte Darstellung präsentiert die zivilen Opfer dennoch weitgehend abstrakt: Die Protokolle bieten Einblick einzig in die grausamen Todesumstände Einzelner; weitere Informationen zu ihrer Person und ihrem Leben fehlen hingegen. Den Besuchern begegnen diese Menschen somit lediglich in der Rolle von Beweisstücken der deutschen Verbrechen. Sie sind Objekte der geschilderten historischen Ereignisse. Konsequenterweise ist diese Sektion auch dem übergreifenden thematischen Bereich "Die Deutschen im Aufstand « zugeordnet. ${ }^{131}$

Auch in der kurz darauf folgenden Sektion »Das Krankenhaus der Aufständischen« stellt die Schilderung der Arbeit von Ärzten und Pflegepersonal in erster Linie den Hintergrund dar, um die Grausamkeit der deutschen Truppen hervorzuheben. ${ }^{132} \mathrm{Im}$ Bereichstext "Gefährlicher Dienst" etwa wird unterstrichen: "Die Deutschen und ihre Kollaborationseinheiten respektieren keinerlei Konventionen. Die Liste der Morde an Sanitäterinnen der AK ist lang.« Zum »Schicksal von Zivilisten ${ }^{133}$ heißt es:

Während des Aufstands verüben die Deutschen massenhafte Verbrechen an der Zivilbevölkerung. [...] Sie töten ohne Rücksicht auf Alter und Geschlecht. Sie bringen kleine Kinder und schwangere Frauen um. Viele Menschen verbrennen sie bei lebendigem Leibe. Verletzte töten sie mit Kopfschüssen. $[\ldots]^{134}$

In der Mitte der Sektion befinden sich - abgeschirmt von den Augen kleinerer Kinder und von Besuchern, die dramatische Bilder meiden möchten - vier Bildschirme, auf denen drastische Fotografien und Filmaufnahmen von Ermordeten gezeigt werden, darunter Nahaufnahmen verstümmelter Leichen. Als unschuldige und wehrlose, jedoch weitgehend anonyme victimae tauchen Zvilisten bei der Schilderung von Tod und Leiden also durchaus auf. Namentlich vorgestellt werden in dieser Sektion - so wie im Großteil der übri-

130 MPW, Sektion 20: Der Völkermord in Wola.

131 An der Rückseite des Zeltes finden sich die Biogramme der Anführer der Einheiten, die die Massaker verübt hatten, Heinrich Reinefarth und Oskar Dirlewanger. Alle Bereichstexte der Dauerausstellung sind mit Themenüberschriften versehen, die hochkant am Rand des jeweiligen Textes angebracht sind. Neben dem genannten Titel gehören dazu u. a. auch »Alltag«, »Unterstützung der Aufständischen« und Im Ausland«. Diese Überschriften stellen thematische Zusammenhänge über die nummerierten Sektionen hinweg her.

132 MPW, Sektion 22: Das Krankenhaus der Aufständischen.

133 Titel des Bereichstextes. Ebd.

134 Bereichstext »Schicksal von Zivilisten«. Ebd. 
gen Schau - jedoch ausschließlich die Personen, die sich durch ihre selbstlose Arbeit hervorgetan haben, also Ärzte und Sanitäterinnen, die zudem überwiegend dem Widerstand angehörten. Herausgehoben werden insbesondere diejenigen unter ihnen, die aufgrund ihrer Arbeit ums Leben gekommen sind. So heißt es etwa zum Porträt einer jungen Frau:

Wanda Gromulska `Teresa‘, Sanitäterin im Bataillon `Golskiı, kommt am 3. August in der Gegend der Technischen Hochschule Warschau ums Leben, als sie zu einem Verletzten rennt. Posthum ausgezeichnet mit der Tapferkeitsmedaille.

Es sind somit auch hier die aktiven, heroischen Opfer, die Märtyrer im Kampf gegen die Besatzer, die durch ihre individualisierte Darstellung in den Vordergrund der musealen Erzählung treten und so die zahlenmäßig größere Gruppe der victimae in den Hintergrund treten lassen. ${ }^{135}$

Eine symbolische Zuspitzung erfährt das martyrologische Narrativ der Ausstellung in einer Installation, auf die die Besucher kurz vor dem Ende des Rundgangs treffen: ${ }^{136}$ In einer quadratischen Fläche, die von nachgebildeten Mauerresten begrenzt wird, sind drei symbolische Gräber in das Straßenpflaster eingelassen (siehe Abb. 39). Unvermittelt finden sich die Besucher somit in einem provisorischen Friedhof inmitten zerstörter Häuser wieder. An den Mauerwänden finden sich Fotografien von einhundert gefallenen Aufständischen, die meist junge, darunter auch viele lachende Gesichter zeigen. In die Wände eingelassen sind verglaste Hohlräume, in denen - Reliquien gleich - Objekte ausgestellt sind, die den Toten gehörten. So finden sich etwa die »[i]n einem Glas aufbewahrten Reste der blutverschmierten und angebrannten Dokumente von Franciszek Świątkowki, der in einer Massenexekution in den Ruinen des Großen Theaters am 8. August 1944 ermordet wurde«, wie die dazugehörige Objektbeschriftung informiert. Ein schlichtes Holzkreuz ist mit dem Hinweis versehen:

Der Buchenwald-Häftling Jan Zabłotniak verliert im Aufstand seine Kinder, die Zwillinge Bożena und Stanisław - Soldaten des >Parasok [ [SChirm`, Name einer Aufständischeneinheit - d. Vf.]. Er verschließt seinen Schmerz in den Armen des Kreuzes. ${ }^{137}$

Immer wieder finden sich an den Objekten und inszenierten "Gräbern« auch Grablichter und Blumen, als handele es sich um eine reale Ruhestätte von Toten des Aufstands. Durch einen Begleittext wird auf den Mut und die Opfer-

135 Die Schätzungen der Todesopfer des Warschauer Aufstands reichen von 150.000 bis 180.000 Personen. Etwa 90 Prozent davon waren Zivilisten. Borodziej: Geschichte Polens, 250.

136 MPW, Sektion 37: Gedenkort. Teile der folgenden Ausführungen zur Installation »Gedenkort" wurden bereits publiziert in Heinemann: Emotionalisierungsstrategien.

137 Objektbeschriftung. MPW, Sektion 37: Gedenkort. 


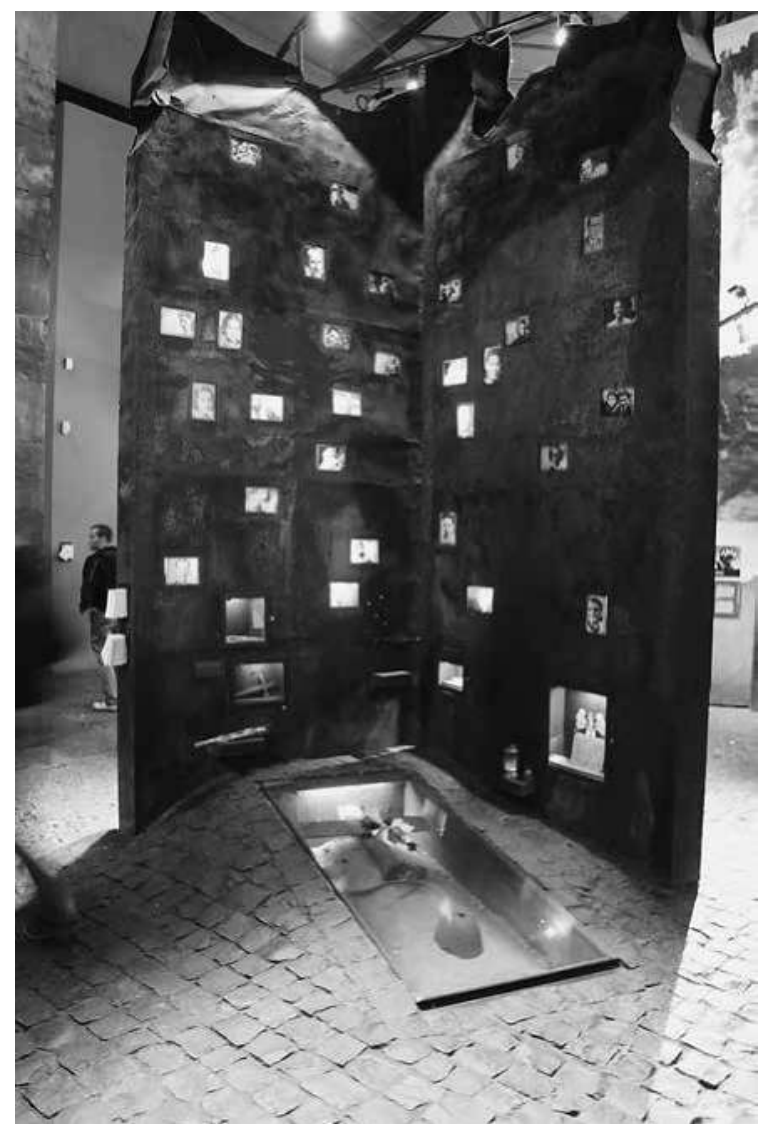

Abb. 39: MPW, Sektion »Gedenkort«.

bereitschaft der Aufständischen, der »jungen Patrioten « hingewiesen. ${ }^{138}$ Die Gesamtinstallation ist für die Besucher damit deutlich als Ort identifizierbar, an dem des Märtyrertodes der jungen Aufständischen gedacht werden soll. Als »Gedenkort« (miejsce pamięci) ist sie auch explizit im Ausstellungsführer vermerkt. ${ }^{139}$

Das Arrangement wirkt innerhalb des Rundgangs wie eine Zäsur, denn es spricht kulturell tief verankerte Codes an. Es unterbricht die Ausstellungserzählung und fordert ähnlich wie ein Friedhof, an den es erinnern soll, zum Innehalten und stillen Gedenken im Angesicht der (hier vermeintlichen) Ge-

138 Bereichstext $»$ Die außergewöhnliche Jugend besonderer Tage«. MPW, Sektion 37: Gedenkort. Vgl. auch Dąbkowska-Cichocka: Przewodnik po Muzeum, 174.

139 Siehe auch Dąbkowska-Cichocka: Przewodnik po Muzeum, 172-175. 
genwart der Toten auf, welche ein kritisches Hinterfragen der Taten dieser Gefallenen oder der Umstände ihres Todes verbietet. Wie Robert Traba zum traditionellen polnischen Totengedenken ausführt:

Die Erinnerung an die Verstorbenen sollte nicht nur >ewig`sein, wie es oft auf den Gräbern gefallener Helden verkündet wird, es reicht nicht aus, nur `Gutes zu sagen oder gar nichts zu sagen (aut bene, aut nihil), wie ein altrömischer Sinnspruch fordert. \Im Polnischen` sollte die Erinnerung an die Verstorbenen diese ehren. Der Tod, besonders der tragische Tod, eröffnet einen Weg zur Heiligkeit. ${ }^{140}$

Ein Hinweis auf diese unterschwellig transportierte aber auch von den Besuchern (unbewusst) rezipierte Botschaft ist das $\mathrm{zu}$ beobachtende Verhalten in diesem Ausstellungssegment: Die Besucher bemühen sich, nicht auf die Glassscheiben über den vermeintlichen Gräbern zu treten und verharren meist andachtsvoll in der Mitte der Fläche, in respektvollem Abstand zu den "Mauerwänden « mit den darin untergebrachten Memorabilia. ${ }^{141}$

Zusammenfassend lässt sich festhalten, dass die Auswahl und Zusammenstellung der gezeigten Fakten, Personen und Ereignisse eine normative Hierarchie zwischen einzelnen Opfergruppen etabliert. Es wird zwischen dem "ehrenhaften«, da sinnbehafteten Tod im aktiven Kampf und Widerstand sowie dem Sterben ohnmächtig Leidender unterschieden: ${ }^{142}$ Die inhaftierten, verletzten und umgekommenen Soldaten der polnischen Armee und der diversen Untergrundgruppierungen, allen voran der Heimatarmee, werden als Märtyrer für das Vaterland herausgehoben geehrt. Die weitaus zahlreicheren Zivilisten im umkämpften Warschau, die bei Massakern und während der Kampfhandlungen, jedoch ohne eigene aktive Beteiligung am Widerstand ums Leben kamen, bleiben im Hintergrund. Sie erscheinen nicht als Protagonisten der Erzählung, sondern lediglich als Objekte der durch die Besatzer ausgeübten Gewalt. Zwar werden sie unterschwellig in das martyrologische Gesamtnarrativ eingeschlossen, mittels dessen die Schau eine ungebrochene Zusammenarbeit und Unterstützung der Aufständischen durch die Warschauer Bevölkerung suggeriert. ${ }^{143}$ Aus dem Pantheon des martyrologischen Gedenkens, den das Museum konstruiert, bleiben sie jedoch ausgeschlossen. So sind die kommemorativen Elemente der Schau - die "Grabsteine«, der Gedenkort, sowie das im Weiteren noch zu analysierende Monument - den Aufständischen und ihrem Andenken vorbehalten.

140 Traba: Der Opferdiskurs, 28.

141 Diese Beobachtung hat sich bei zahlreichen Besuchen der Verfasserin in dem Museum in den Jahren 2009 bis 2014 wiederholt bestätigt.

142 Exemplarisch Assmann: Der lange Schatten der Vergangenheit, $74 \mathrm{f}$.

143 Zur spezifischen Darstellung des Alltags der Besatzung und damit auch der Kontextualisierung der Zivilbevölkerung siehe Kapitel 3.1. 
Auch das übrige Museumsareal bildet diese Hierarchie ab: ${ }^{144}$ Der sogenannte »Park der Freiheit" (Park Wolności), der das Museumsgebäude umgibt, wurde als Gedenkort für den Aufstand von 1944 arrangiert. Sein zentrales Element ist die 156 Meter lange "Mauer der Erinnerung» (Mur Pamięci), auf der die Namen der Teilnehmer der Kämpfe von 1944 zusammengetragen und sukzessive ergänzt werden. Daneben finden sich im Park auch mehrere kleine Denkmale, die verschiedenen Gruppen von Kämpfern gewidmet sind. ${ }^{145}$ Die memorialen Elemente des Areals, insbesondere jedoch die zentrale Mauer der Erinnerung, ${ }^{146}$ stellen somit die aktiven Kämpfer, die Aufständischen in den Mittelpunkt des ehrenvollen Andenkens. Die überwiegende Mehrheit der in der Stadt eingeschlossenen Bevölkerung, die Zivilisten, blieben hier dagegen lange Zeit unerwähnt. Erst 2010 wurde im Park ein kleines Denkmal enthüllt, das explizit der während der Kämpfe ermordeten und nach der Kapitulation deportierten Zivilbevölkerung gewidmet ist. Initiiert worden war es jedoch nicht vom Museum, sondern von ehemaligen Aufständischen. ${ }^{147}$ Bemerkenswert ist, dass die Würdigung ziviler Opfer auch hier unter der Prämisse einer martyrologischen Kontextualisierung erfolgt, denn abschließend heißt es in der Denkmalinschrift: »Zur Erinnerung an die Zivilbevölkerung von Warschau, die aufopferungsvoll die Soldaten im Kampf um Freiheit und Ehre des polnischen Volkes unterstützt hat.. ${ }^{148}$

Diese normative Rangfolge wird auch bei der Darstellung des Schicksals der in den Ghettos Eingesperrten angewendet. Individuell in Erscheinung treten und umfangreicher thematisiert werden allein die jüdischen Wider-

144 Teile der folgenden Ausführungen wurden bereits publiziert in Heinemann, Monika: Das Museum des Warschauer Aufstands. In: Zeitgeschichte-online, Juli 2014, URL: www.zeitgeschichte-online.de/geschichtskultur/das-museum-des-warschauer-aufstands (am 24.1.2015).

$145 \mathrm{Zu}$ den Gewürdigten zählen die Sanitäter, Anwälte und Georgier im Aufstand, die kämpfenden Polinnen und die Filmschaffenden, die in der Propagandaabteilung der AK Filmchroniken der laufenden Ereignisse erstellten. Ihnen sind Denkmale in Form kleiner Obelisken gewidmet, die alle von (externen) Organisationen oder Privatpersonen gestiftet wurden.

146 Wie Paweł Kowal feststellt, wird die »Mauer der Erinnerung « zusammen mit der Kapelle als Bestandteil der Dauerausstellung betrachtet. Ziel der Museumsverantwortlichen ist es darüber hinaus, dass die Besucher - in erster Linie die Warschauer - zum Museumskomplex eine persönliche Beziehung aufbauen, ihn als Ort des Gedenkens an verstorbene Familienmitglieder auffassen. Sie möchten ihre Institution als "persönlichen, familiären - einen Warschauer Pantheon" verstanden wissen. Im Ausstellungsführer heißt es weiter programmatisch: "Das Elektrizitätswerk ist zu einer Art patriotischem Tempel geworden.« Kowal: Jak budowaliśmy Muzeum, $8 \mathrm{f}$.

147 Urzykowski, Tomasz: Nowy pomnik: Powstańcy przepraszają warszawiaków [Ein neues Denkmal: Die Aufständischen bitten die Warschauer um Verzeihung]. In: Gazeta Wyborcza vom 3.10.2010, Online Ausgabe, URL: http://wyborcza.pl/2029020,75248,8458419. html (am 4.10.2010).

148 Deutsche Inschrift im Original auf dem Denkmal. 
standskämpfer - diejenigen des Warschauer Ghettoaufstands von 1943 sowie die wenigen, die in Verstecken oder in Gefangenschaft überlebt und im Aufstand 1944 gekämpft haben. ${ }^{149}$ Explizit verbalisiert wird ihre Abgrenzung von den übrigen, passiv gebliebenen Ghettobewohnern in der Beschriftung einer Fotopräsentation: »Die zur Vernichtung verurteilten polnischen Juden wählen einen würdevollen Tod «. ${ }^{150}$ Diese Aussage führt direkt die Argumentation der Jahre der Volksrepublik fort. ${ }^{151}$ Auch die bereits vor 1989 (im MHW) zu beobachtende Abgrenzung der jüdischen von den polnischen Warschauer Aufständischen wird hiermit unterschwellig vermittelt: Während die Polen 1944 (und auch bereits zuvor) für die Unabhängigkeit, das Vaterland, mithin die Zukunft gekämpft hätten, gehe es beim Ghettoaufstand allein um eine Zeichensetzung und die Wahl der eigenen Todesumstände.

Neben dieser übergreifenden Hierarchie von Leidens- und Todesarten ist in der Ausstellung auch eine ethnisch-nationale Konkurrenz um den Opferstatus festzustellen, die sich exemplarisch in der Verortung und Gestaltung des Ausstellungsabschnitts »Ghetto « spiegelt. Unmittelbar neben diesem wird der »Terror« der Besatzer gegen die polnische Bevölkerung geschildert. ${ }^{152}$ Dieser Abschnitt ist visuell eindringlich gestaltet: Zahlreiche Bekanntmachungen der Besatzungsorgane mit Listen von zum Tode Verurteilten, in dicken Schichten übereinander plakatiert und damit die enorme Zahl der Opfer unterstreichend, bilden den Hintergrund für die Schilderung der von den Besatzern im Raum Warschau durchgeführten Massenexekutionen (siehe Abb. 40). Diese Darstellungsweise nimmt assoziativ Bezug auf das in Polen bis heute weithin bekannte Zitat Hans Franks vom Februar 1940:

In Prag waren z. B. große rote Plakate angeschlagen, auf denen zu lesen war, daß heute 7 Tschechen erschossen worden sind. Da sagte ich mir: wenn ich für je sieben erschossene Polen ein Plakat aushängen lassen wollte, dann würden die Wälder Polens nicht ausreichen, das Papier herzustellen für solche Plakate. ${ }^{153}$

Stellvertretend für das Grauen steht der Name »Palmiry«, einem Dorf bei Warschau, in dessen Nähe mehrere Hundert Vertreter der polnischen Inteli-

149 Mordechaj Anielewicz und Marek Edelman werden jeweils mit einem kurzen Biogramm und einem Foto vorgestellt; Edelman kommt sogar selbst zu Wort, in Form einer Videoaufzeichnung eines Interviews (auf dieses wird näher in Kapitel 3.1 eingegangen). MPW, Sektion 7: Polnischer Untergrundstaat; Sektion 15: Die Kämpfe im August. In Sektion 15 ist ein Abschnitt explizit dem Kampf der »Juden im Warschauer Aufstand» gewidmet.

150 MPW, Sektion 8: Ghetto.

151 Leociak: Zraniona pamięć, 263.

152 MPW, Sektion 8: Ghetto, Sektion 6: Besatzung. Siehe hierzu auch Teil 2, Kapitel 2.1.

153 Präg, Werner/Jacobmeyer, Wolfgang (Hg.): Das Diensttagebuch des deutschen Generalgouverneurs in Polen 1939-1945. Stuttgart 1975, 104. Zitiert nach Borodziej: Der Warschauer Aufstand, 27. 


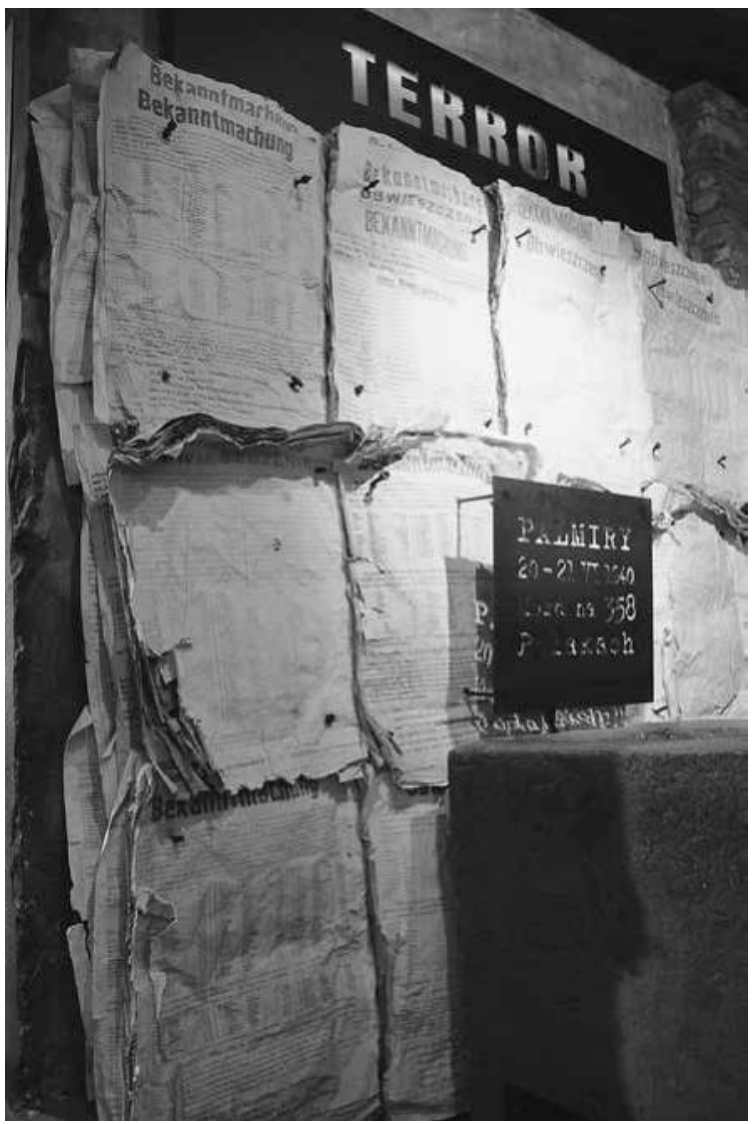

Abb. 40: MPW, Abschnitt »Terror«.

genz erschossen wurden. Die Buchstaben des Begriffs »Terror« leuchten rot; die Ränder der Plakate sind gleichfalls rot bemalt und rufen hierdurch Assoziationen mit dem Blut der Opfer hervor. ${ }^{154}$ Das Leben und Sterben im Ghetto

154 Hier findet sich zudem ein für Kinder abgeschirmter Bildschirm mit drastischen Aufnahmen von Leichen und Exekutionen. Einige Aufnahmen zeigen auch das Leiden im Warschauer Ghetto. Diese sieht man jedoch nur, wenn man sich die gesamte, relativ lange Präsentation grausamster Aufnahmen ansieht. Die Bekanntmachungen der deutschen Besatzer an der Wand darüber hingegen nennen ausschließlich polnische Opfer von Verurteilungen und Exekutionen. Insbesondere der Begriff "Palmiry« ist bei polnischen Besuchern allein mit polnischem Leid konnotiert. In der Sektion 6 werden darüber hinaus auch das Pawiak-Gefängnis und die Verhörzellen der Gestapo in der Szucha-Allee in Warschau als Orte der Inhaftierung und Folter thematisiert. Die Darstellung bleibt jedoch allgemein und anonym. MPW, Sektion 6: Besatzung. 
unmittelbar daneben wird hingegen auf einer Ziegelwand geschildert - einer Bezugnahme auf die Ghettomauer -, die mit warmem Licht beleuchtet ist und auf der einzelne Plakate mit Bekanntmachungen verteilt sind (siehe Abb. 25). Hierdurch wirkt die Sektion deutlich harmloser, wenn auch die in den jeweiligen Bereichstexten genannten Opferzahlen von ca.450.000 Ghettobewohnern und mehreren Tausend exekutierten Polen eine entgegengesetzte Gewichtung des Ausmaßes der Verfolgung kognitiv kenntlich machen. Die Gestaltungsweise beider Abschnitte legt jedoch implizit den Schwerpunkt auf die Gewalt an ethnischen Polen, denn die Zahlen der Verfolgten rezipiert nur, wer die Texte in beiden Sektionen auch liest.

Deutlicher noch zeigt sich die parallele Kontextualisierung polnischen und jüdischen Leidens in der Sektion zu den Massenmorden in Wola. Die Massaker werden dort als »Völkermord« (ludobójstwo) beschrieben: Mit diesem Begriff ist die Sektion im Ausstellungsflyer bezeichnet; im Bereichstext der Schau ist von der »Vernichtung « (eksterminacja) der Bevölkerung des Stadtteils die Rede. ${ }^{155}$ Unmissverständlich erfolgt die Einordnung der Ereignisse schließlich im Ausstellungsführer:

Die Massenexekutionen in Wola und Ochota stellen in ihrer Summe einen Akt des Völkermords an der Zivilbevölkerung Warschaus dar, eines der größten deutschen Verbrechen, die während des Zweiten Weltkriegs verübt wurden. ${ }^{156}$

Hier wird eine Argumentations- bzw. Darstellungsweise angewandt, die in den Ausstellungen der Vorwendezeit zu beobachten, aber in den 1990er-Jahren verschwunden war: Die massenhaften Tötungen von Polen und Juden werden gleichermaßen als »Völkermord « und »Vernichtung« dargestellt. Durch die zudem im Vergleich zur Schilderung des Themenbereichs »Ghetto« gestalterisch besonders eindrucksvolle Darstellung des Leidens der polnischen $\mathrm{Zi}$ vilbevölkerung, für die die genannten Sektionen beispielhaft sind, steht im Endeffekt das ethnisch-polnische viktimologische Narrativ deutlich im Vordergrund der Wahrnehmung des Leidens unter der Besatzung.

Die gleiche implizite Rangfolge der Opferdarstellung fand sich auch in den 2006 bis 2009 neu gestalteten Sälen zum Zweiten Weltkrieg des Historischen Museums der Hauptstadt Warschau. Während das Heldentum und die Opferbereitschaft der verschiedenen Widerstandsgruppen - vor allem derjenigen, die sich der Londoner Exilregierung unterstellten - die Erzählung dominierten, ${ }^{157}$ wurde in den weniger zahlreichen viktimologischen Elemen-

155 Bereichstext »Das Blutbad von Wola« (Rzeź Woli). MPW, Sektion 20: Der Völkermord in Wola.

156 Dąbkowska-Cichocka: Przewodnik po Muzeum, 125.

157 Von den insgesamt sieben Sälen, die dem Zeitraum 1939 bis 1945 gewidmet waren (der Einmarsch sowjetischer Truppen in Warschau 1945 war nur äußerst knapp im achten Saal untergebracht, der zentral die Entwicklung der Stadt zwischen 1945 und 1990 
ten der Schau eine Hierarchisierung deutlich, die durch verschiedene Darstellungsmittel das Leiden der ethnisch-polnischen Zivilbevölkerung in den Vordergrund stellte. So war dem Schicksal der als Juden Verfolgten lediglich ein kleiner Abschnitt in einem Ausstellungssaal gewidmet, dessen größerer Teil den »Polnischen Untergrundstaat" (Polskie Państwo Podziemne, PPP) und die diversen Aktionen des Widerstands in Warschau vorstellte. ${ }^{158}$ Während die Lebensbedingungen und das Sterben der im Ghetto eingesperrten Bevölkerung anonym und abstrakt geschildert wurden, waren es auch hier die Anführer des jüdischen Widerstands, die bei der Schilderung des Ghettoaufstands 1943 individuell in Erscheinung traten und dadurch hevorgehoben wurden. ${ }^{159}$ Neben diesen fand einzig die Person des bekannten Märtyrers Janusz Korczak eine individuelle Erwähnung. Im weiteren Verlauf des Rundgangs fanden sich dagegen nur dort einzelne Hinweise auf jüdische Opfer, wo es um die Schilderung der Gesamtverluste der Stadt im Krieg ging - eine großformatige Tafel nannte zentrale Zahlen der Kriegsverluste: »Ungefähr 650.000 Einwohner Warschaus verloren ihr Leben. $85 \%$ der Stadt wurden zerstört. Über 500.000 Warschauer wurden vertrieben. ${ }^{160}$ Ein erläuternder Text im selben Raum spezifizierte vier Etappen der Zerstörung der Stadt; eine davon war der "Aufstand im Ghetto, 19.4.-16.5.1943« ${ }^{161}$ Dass ein Großteil der bis zu 460.000 Menschen, die zeitgleich im Ghetto lebten, ${ }^{162}$ bereits 1942 in Vernichtungslager deportiert worden oder im Ghetto umgekommen war, wurde hier ignoriert. Einzig das heroische Aufbegehren gegen die Besatzer erhielt hier den Status, erinnerungswürdig zu sein. Analog folgte unmittelbar darauf der Hinweis auf den Aufstand von 1944. Ohne dies zu benennen,

behandelte), wurden die Kämpfe im September 1939, die Widerstandsbewegung und der Warschauer Aufstand 1944 in insgesamt vier Räumen dargestellt. MHW, Saal 46, $48,50,51$.

158 MHW, Saal 48: „Der Polnische Untergrundstaat - Die Widerstandsbewegung in Warschau 1939-1944. Das Warschauer Ghetto 1949-1943«. Zum Vergleich: Dem »hitleristischen Terror in Warschau 1939-1944«, d.h. dem gewaltsamen Vorgehen gegen die ethnisch-polnische Bevölkerung, war ein eigener Themensaal gewidmet. Ein weiterer behandelte die Deportation der Warschauer Bevölkerung nach der Niederschlagung des Aufstands 1944. MHW, Saal 47 (Zitat: Titel des Saals), Saal 52. Zur Darstellung des Ghettos in dieser Schau siehe Teil 2, Kapitel 2.1.

159 Daneben wurden namentlich die führenden (polnischen) Mitglieder der Żegota aufgeführt. MHW, Saal 48.

160 MHW, Tafel im Gang zwischen den Sälen 51 und 52.

161 Ebd., Bereichstext »Bilanz der Zerstörungen und der Bevölkerungsverluste Warschaus 1939-1945«.

162 Schätzungen zufolge erreichte die Bevölkerungszahl im Ghetto im März 1941 ihren Höchststand von ca. 460.000 Personen. Deutsche zeitgenössische Angaben gehen in diesem Zeitraum sogar von bis zu 490.000 Ghettoinsassen aus. Engelking-Boni/Leociak: Getto warszawskie, 65-68, hier 66. 
wurde zugleich die Zahl der ermordeten Ghettobewohner zu den Gesamtverlusten der Stadt hinzugezählt, wodurch diese noch drastischer erschienen. Diese Opferarithmetik erinnerte wiederum an die Jahre der VRP.

Im Zentrum der Gesamterzählung dieser Ausstellung standen die Soldaten im September-Krieg 1939 und die Mitglieder des Untergrunds, die als Helden und Märtyrer für das Vaterland porträtiert wurden. Diese heroischen Opfer nahmen einen Großteil der Schilderung polnischen Leidens und Sterbens während der Jahre 1939 bis 1945 ein. Den Höhepunkt der heroisch-martyrologischen Interpretation stellten die zwei Räume dar, die dem Warschauer Aufstand 1944 gewidmet waren. ${ }^{163}$ So wie bereits die Schilderung des Widerstands der Jahre 1939 bis 1944, war auch dieser Teil der Ausstellung durch eine starke Individualisierung gekennzeichnet: Konkrete Aufständische traten durch die zahlreichen präsentierten Objekte individuell in Erscheinung, bei denen größtenteils der frühere Besitzer genannt und seine bzw. ihre Aufstandsgeschichte berichtet wurde. ${ }^{164}$

Zivile Opfer blieben in den zwei Räumen dagegen weitgehend im Hintergrund. Thematisiert wurden sie erst umfangreich im letzten Saal der Sektion, der der "Vernichtung Warschaus" gewidmet war. ${ }^{165}$ Unter diesem Titel wurden sowohl die Massaker in den Stadtteilen Wola und Ochota während des Aufstands 1944 als auch die der Kapitulation folgende Deportation der Aufständischen und der verbliebenen Zivilbevölkerung geschildert. Zahlreiche Fotografien zeigten hier die zivilen Opfer deutscher Verbrechen. Im Gegensatz zur Schilderung des Widerstands blieben diese jedoch größtenteils anonym. Nur wenige wurden namentlich benannt; dabei handelte es sich um Personen, die sich während dieser schwierigen Phase besonders ausgezeichnet hatten, konkret um Menschen, die die Rettung polnischer Kulturgüter vor der Zerstörung geleitet hatten. ${ }^{166}$ Die übrigen Fotografien zeigten Kolonnen deportierter Zivilisten wie Aufständischer, darunter Menschenmassen, die auf einem Bahnhof oder im Durchgangslager Pruszków warten. In der Gestaltung dieser Sektion wurden zahlreiche sakrale Symboliken verwendet: In der Mitte des weitgehend dunklen Raumes, flach über dem Boden schwebend, befand sich eine großformatige Karte der zerstörten Stadt mit

163 MHW, Saal 50, 51.

164 Im Saal 51 wurden beispielsweise Grabtafeln von den provisorischen Gräbern zweier gefallener Aufständischer gezeigt. In einer Vitrine daneben fanden sich Medaillons mit religiösen Motiven, Dokumente, aber auch eine weiß-rote Armbinde von Aufständischen, die während der Kämpfe umkamen, wie die jeweils ausführlichen Objektbeschriftungen informierten.

165 MHW, Saal 52: „Die Vernichtung Warschaus - Die Vertreibung der Bevölkerung durch die deutschen Nazis. 1. August 1944-17. Januar 1945«.

166 Die Professoren Stanisław Lorentz, Jan Zachwatowicz und Wacław Borowy wurden als Organisatoren dieser sogenannten Pruszkower Aktion mit Porträtfotos vorgestellt. 


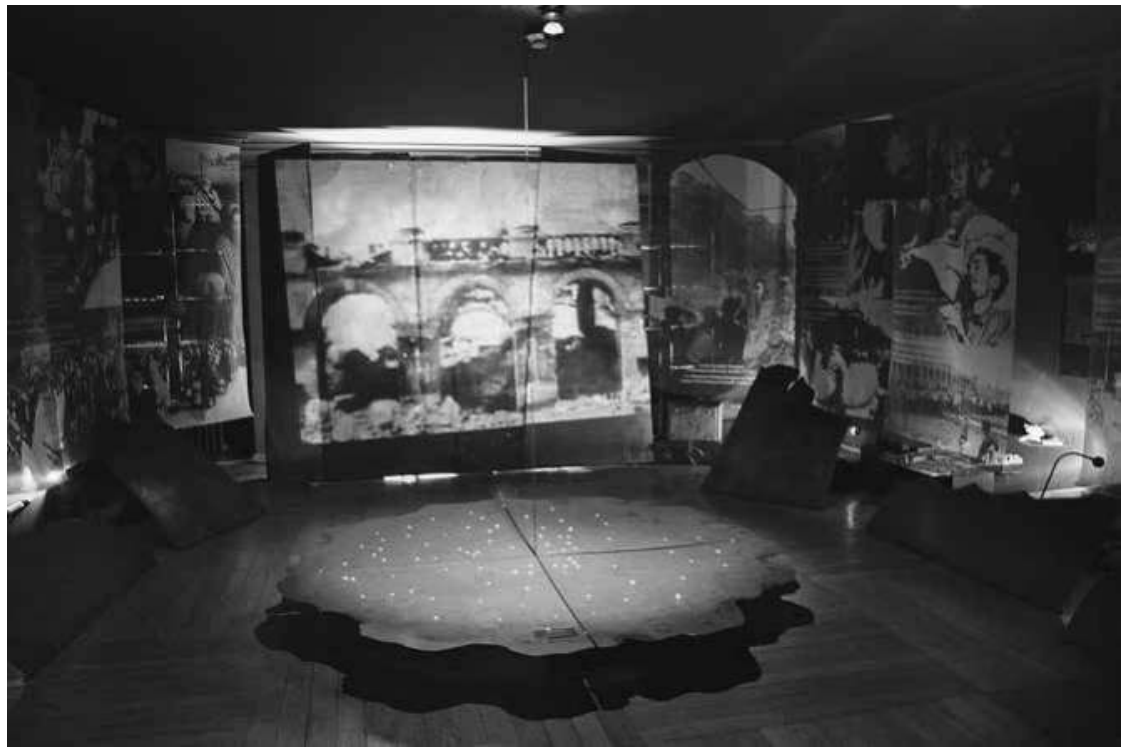

Abb. 41: MHW, Saal „Die Vernichtung Warschaus - Die Vertreibung der Bevölkerung durch die deutschen Nazis. 1. August 1944-17. Januar 1945«.

einzelnen leuchtenden Punkten (siehe Abb.41). Die Installation erinnerte an Grablichter, die traditionell auf polnischen Friedhöfen aufgestellt werden eine Assoziation, die auch bewusst von den Ausstellungsverantwortlichen anvisiert wurde. ${ }^{167}$ An der Stirnseite des Saales wurden Fotografien der zerstörten Stadt gezeigt. Den akustischen Hintergrund bildete das »Polnische Requiem« Krzysztof Pendereckis. Diese christliche Trauersymbolik wurde noch durch eine weitere Installation unterstützt: In regelmäßigen Abständen wurde der Raum verdunkelt, und es leuchteten nahe der Decke nacheinander die Nahaufnahmen dreier ungenannter Personen auf, zweier Frauen und eines Mannes. ${ }^{168}$ Ihre erschöpften Gesichter, die im Dunkeln leuchteten, zudem die Haltung der einen Frau, die wie im Gebet versunken zu sein schien, erinnerten an christliche Märtyrerinszenierungen.

Erstmals wurde in diesem Museum dem Leiden der Zivilbevölkerung bei Kriegsende Platz in diesem Ausmaß eingeräumt. Die Darstellung unterstrich jedoch in erster Linie die Grausamkeit der Besatzer, die auch in mehreren

167 Interview mit Joanna Maldis, Kuratorin der Sektion zum Zweiten Weltkrieg, am 30. Juni 2009.

168 Die vergrößerten Aufnahmen waren zeitgenössischen Fotografien der Aussiedlung der Warschauer Bevölkerung in dem Raum entnommen. 
Bereichstexten der Sektion betont wurde. ${ }^{169}$ In der spezifischen Gestaltung und Präsentationsweise, insbesondere in der verwendeten sakralen Symbolik, wurde das Leiden der Zivilbevölkerung letztlich als Opfer für das Vaterland kontextualisiert: als Opfer für die Unabhängigkeit Polens und damit als spiritueller Sieg. ${ }^{170}$ Deutlich wurde hiermit die Einordnung ihres Leidens in das übergeordnete martyrologische Narrativ der Kriegs- und Besatzungszeit.

Auch die Dauerausstellung im Martyrologiemuseum »Unter der Uhr« in Lublin zeichnet sich bis in die Gegenwart durch die martyrologische Interpretation der Leiden während der Besatzung aus. Seit 2009 hat sie ihr thematisches Spektrum und insbesondere ihre martyrologische Interpretation der Besatzungszeit in die Nachkriegszeit erweitert: Präsentiert wird seitdem auch das Schicksal von Mitgliedern zahlreicher nichtkommunistischer Untergrundgruppierungen, allen voran der AK, und Kämpfern des antikommunistischen Widerstands der Nachkriegszeit, die zwischen 1944 und 1954 auf dem Lubliner Schloss gefangengehalten und exekutiert bzw. vom NKVD und der Justiz des sozialistischen Nachkriegspolens verfolgt und zum Tode verurteilt worden waren. ${ }^{171}$ Wie auch dieses Beispiel dokumentiert, hat das heroische Opfernarrativ im polnischen historischen Museumswesen der Gegenwart keineswegs ausgedient. Seine Umsetzung in der genannten Schau ist sogar in dem Sinne besonders, als hier konkrete Ziele und Aktivitäten der widerständigen Gruppierungen gar nicht mehr thematisiert werden, sondern allein die Verfolgung ihrer Mitglieder.

Die angeführten drei Institutionen und ihre Dauerausstellung sind somit Ausdruck der Bewahrung und zugleich einer neuen Forcierung des tradierten polnischen Selbstbildes der Helden und Märtyrer. Die Lubliner Schau und die Präsentation des MPW verweisen zudem auf die deutliche Abgrenzung, die inzwischen oft zur VRP vorgenommen wird: Als Märtyrer des legitimen Widerstands werden diejenigen hervorgehoben, die für eine alternative, nichtkommunistische Staatlichkeit während der Besatzung und auch nach Kriegsende gekämpft hatten; dem sozialistischen polnischen Nachkriegsstaat wird damit die Legitimität verweigert. ${ }^{172}$

169 So schilderte gleich der erste Text, den man beim Betreten des Raumes las, die Massenexekutionen deutscher Truppen an der Warschauer Zivilbevölkerung seit dem Beginn des Aufstands. Im Weiteren wurden die dramatischen Lebensbedingungen im Durchgangslager Pruszków sowie die planmäßige Zerstörung der Stadt nach der Deportation der Bevölkerung geschildert. MHW, Saal 52.

170 Eine ähnliche Interpretation der Raumgestaltung nehmen auch die Autoren der folgenden Studie vor: Bogumit: The Enemy on Display, $90 \mathrm{f}$.

171 MLL-Unter der Uhr; die benannte Sektion, die den Zeitraum der Jahre 1944 bis 1954 umfasst, verteilt sich über die Zelle 4, den kurzen Gang links vom Eingang sowie den hinteren Gang des Zellentraktes des Museums.

172 Näheres hierzu in Kapitel 2.3 in diesem Teil. 
Am anderen Ende des Spektrums aktueller musealer Geschichtsperspektiven kann man jedoch auch eine langsame Abwendung vom martyrologischen Opfertopos beobachten. Eine solche Veränderung ist bei den untersuchten Dauerausstellungen erstmals bei der 2009 eröffneten Präsentation des Historischen Museums in Wrocław wahrzunehmen. Im Zentrum der Schilderung des Schicksals der Stadtbevölkerung nach 1939 stehen hier polnische Zwangsarbeiter und KZ-Häftlinge, für die zahlreiche Objekte stehen. ${ }^{173}$ Gezeigt werden persönliche Dokumente von polnischen Zwangsarbeitern ebenso wie ein Aufnäher mit dem Buchstaben »P« (für »Pole»), der von ihnen zwangsweise auf der Kleidung getragen werden musste. Umfangreichere Exponate behandeln die KZ-Insassen: $\mathrm{Zu}$ sehen sind unter anderem zwei originale gestreifte Häftlingsanzüge - jeweils mit einem roten Wimpel und dem Buchstaben » $\mathrm{P} «$ darin, das Zeichen, mit dem sogenannte politische Häftlinge als Polen in den Lagern gekennzeichnet wurden - sowie geschnitzte Figuren von KZ-Insassen. Letztere sind besonders eindrücklich, da die verzerrten Gesichter den Schmerz und die Folter affektiv vermitteln. ${ }^{174}$ Daneben finden sich einige Objekte aus dem KZ Groß-Rosen, darunter ein Schlagstock und eine Peitsche. Zwar tragen alle Figuren von Insassen ebenfalls den Wimpel polnischer politischer Häftlinge auf der Kleidung. Gründe für die Inhaftierung in den Lagern, die dem expressiv illustrierten Leiden Sinn verliehen haben könnten, werden jedoch nicht thematisiert. Die Holzfiguren vermitteln auch keinerlei heroische Haltungen; weder ist Entschlossenheit noch Widerstandswille den verzerrten Gesichtern und gebeugten Figuren zu entnehmen (siehe Abb. 42). Die diskriminierende Ausgrenzung, Ausbeutung und Folter der Zwangsarbeiter und KZ-Insassen, mithin die Leidensschilderung steht im Zentrum der Präsentation.

Des Weiteren weisen zwei Fotografien darauf hin, dass im ersten Konzentrationslager der Region, dem Lager Breslau-Dürrgoy (polnisch: Tarnogaj), bereits 1933 (deutsche) Vertreter der politischen Opposition interniert wurden. ${ }^{175}$ Die Objekte, mithilfe derer die später hinzugekommenen Lager und deren Insassen in den folgenden Jahren geschildert werden, thematisieren jedoch ausschließlich polnische Häftlinge. Auch die Dokumente der Zwangsarbeiter stammen allein von Polen. Diese auf das polnische Schicksal konzentrierte Darstellung hat zunächst augenfällige Ursachen: Die deutsche Stadt Breslau hatte zwar vor dem Jahr 1939 nur eine sehr geringe polnische Bevöl-

173 MMW-MH, Saal 22.

174 Flankiert werden sie von einem Kapo (dessen grüner Wimpel ihn als »Berufsverbrecher« identifiziert) und zwei Wachleuten. Ebd.

175 Zwei großformatige Fotografien zeigen drei führende Sozialdemokraten, die $1933 \mathrm{im}$ Lager interniert wurden: Hermann Lüdemann, Paul Löbe und Karl Mache. Ebd. 


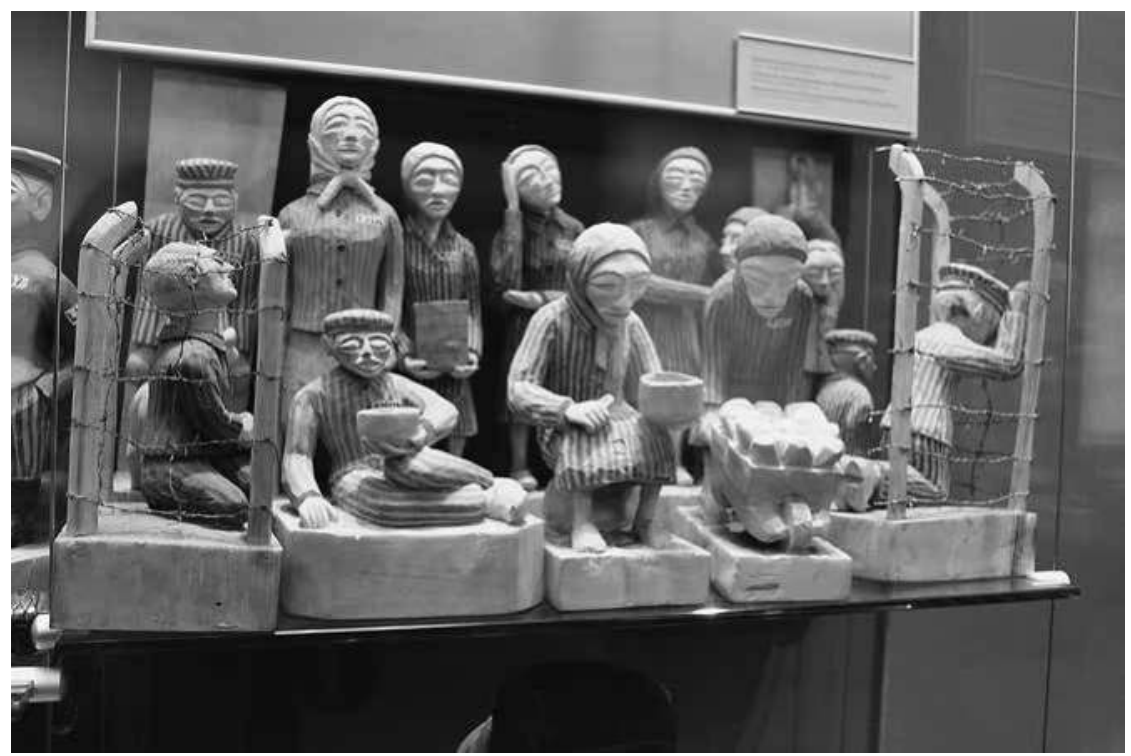

Abb. 42: Historisches Museum in Wroctaw, Exponat im Saal »Die hitleristische Diktatur - Der Zweite Weltkrieg".

kerungszahl. ${ }^{176}$ Im Laufe des Kriegs kamen jedoch Zehntausende Polen als Zwangsarbeiter in die Stadt oder wurden in naheliegenden Konzentrationslagern interniert. ${ }^{177}$ Bemerkenswert ist, dass in der musealen Präsentation vollkommen vernachlässigt wird, dass neben Polen auch Menschen aus zahlreichen weiteren Ländern in den Lagern inhaftiert waren. ${ }^{178}$ Wie Norman Davies und Roger Moorhouse schildern:

Die einheimischen Breslauer hatten das Gefühl, von Tschechen, Polen, Ukrainern, Franzosen und Sowjets überschwemmt zu werden. Nach wie vor sehr groß war der Anteil jüdischer Arbeiter in den Sklavenbrigaden aus den Lagern. ${ }^{179}$

Auch das Schicksal der jüdischen Stadtbewohner nach 1938 wird in der Schau jedoch nur am Rande thematisiert; den einzigen Hinweis darauf bietet ein Foto, das »[d]ie auf die Deportation wartenden Breslauer Juden (Herbst

1761918 betrug die Zahl der polnischen Breslauer ca. 4.000 bis 5.000, laut Davies / Moorhouse fiel sie "auf einen statistisch unerheblichen Rest zwei Jahrzehnte später«. Davies / Moorhouse: Breslau, 447.

177 Ebd., 484.

178 Diese Tatsache wird nur im Ausstellungsführer geschildert, den man jedoch zusätzlich erwerben muss. Siehe Łagiewski/Okólska/Błaszkowski/Smolak: Sala 22.

179 Davies/Moorhouse: Breslau, 483. 
1941) ${ }^{180}$ zeigt. Weder ihre Ermordung in den Vernichtungslagern noch die Zwangsarbeit in der Stadt, aber auch in den Konzentrationslagern der Region werden erwähnt. Diese Information bleibt auf den Ausstellungsführer beschränkt. ${ }^{181}$ In der Opferdarstellung dieser Sektion der Dauerausstellung dominiert somit eine ethnisch-polnische Leidensgeschichte, in der andere Opfergruppen - in erster Linie die jüdische Bevölkerung der Stadt - marginalisiert werden. Ein Charakteristikum ist zudem eine fast ausschließlich viktimologische Darstellung, denn die Leiden der KZ-Insassen wie der Zwangsarbeiter werden nicht in einen größeren Erklärungszusammenhang gestellt; sie dienen in erster Linie der Exemplifizierung der Grausamkeit der Deutschen.

Es sind jedoch nicht allein die victimae, die hier in Erscheinung treten. Ein Arrangement mehrerer Objekte schildert die Geschichte von Stanisław Peisert, der während des Kriegs Mitglied der »Nationalen Kampforganisation« (Narodowa Organizacja Bojowa, NOB) war und für seine Untergrundaktivitäten verhaftet und zum Tode verurteilt wurde. Die Exekution fand in einem Breslauer Gefängnis statt. Wie sein Biogramm informiert, lebte Peisert in Poznań, wo er in Untergrundaktivitäten involviert war; dort verhaftete und verurteilte man ihn schließlich. ${ }^{182}$ Stellvertretend für die polnische Widerstandsbewegung in der Region stehen somit nicht deren Aktivitäten, etwa konkrete Aktionen, sondern die Hinrichtung eines Widerständlers. Nicht der Topos des aktiv Kämpfenden, mithin des Helden, steht in diesem Arrangement im Vordergrund, sondern der des Märtyrers, des Leidenden für das Vaterland. Das polnische Selbstbild, das in dieser Sektion gezeichnet wird, ist damit in zweifacher Hinsicht opferorientiert. Eindeutig im Vordergrund stehen die wehrlosen und leidenden Inhaftierten in den Konzentrationslagern sowie die Zwangsarbeiter. Offensichtlich war es den Ausstellungsverantwortlichen jedoch wichtig, neben diesem dominanten viktimologischen Motiv auch die tradierte romantische Figur des im Kampf für das Vaterland Gefallenen

180 Deutsche Objektbeschriftung im Original. MMW-MH, Saal 22.

181 Die Schilderung des Schicksals der jüdischen Stadtbewohner erfolgt im Wesentlichen im Kapitel zum vorangehenden Ausstellungssaal, der dem Ersten Weltkrieg und der Zwischenkriegszeit gewidmet ist; im Text zum Saal 22 finden sich nur kleinere Hinweise. Siehe Błaszkowski / Łagiewski/Okólska: Sala 21, bes. 272-276; Łagiewski/Okólska/ Błaszkowski/Smolak: Sala 22.

182 Auf einer Ausstellungstafel finden sich ein Porträt Peiserts in der Uniform der Aufständischen des Großpolnischen Aufstands von 1918/19 sowie ein Biogramm. Die übrigen zwei Exponate, mithin die Hälfte der seiner Person gewidmeten Objekte, illustrieren die Hinrichtung Peiserts: Gezeigt werden ein Schriftzeugnis, das die Enthauptung dokumentiert (inklusive polnischer Übersetzung), sowie die Guillotine aus dem Gefängnis, in dem die Hinrichtung stattfand. Eine umfassendere Schilderung der Aktivitäten der Breslauer Untergrundgruppen erfolgt wiederum erst im Ausstellungsführer. Łagiewski/ Okólska/Błaszkowski/Smolak: Sala 22, 282. 
aufzunehmen. Dass hierfür ein Beispiel aus einer anderen Metropole gewählt werden musste, statt auf ein lokales zurückgreifen zu können, verweist bereits auf die verhältnismäßig geringe Bedeutung des Widerstands in der Region. Der Märtyrertopos ist damit auch in dieser Schau vertreten, er ist jedoch in den Hintergrund getreten. Die Präsentation dieser Sektion ist zudem ein Beispiel dafür, wie traditionelle Interpretationsschemata der polnischen Erfahrungen der Jahre 1939 bis 1945 auf die Geschichte einer in diesem Zeitraum größtenteils von Deutschen bewohnten Stadt übertragen werden.

Wesentlich prägnanter erfolgt die Abkehr von etablierten Darstellungspraxen in der Dauerausstellung des MHK von 2010 in der sogenannten Schindler-Fabrik. In dieser stehen nicht mehr die Ausnahmeerscheinungen der ethnisch-polnischen Helden und Märtyrer im Mittelpunkt der Erzählung über den Zweiten Weltkrieg, sondern der Alltag der polnischen und jüdischen Stadtbewohner in den Jahren 1939 bis $1945 .{ }^{183}$ Physisches Leiden und Sterben, sowie der Widerstand und damit verbundene Verfolgung, nehmen hier einen deutlich geringeren Anteil der Ausstellungsfläche ein, als dies noch in den Vorgängerpräsentationen zur Kriegszeit in der Pomorska-Straße üblich war. Auffällig ist zudem, dass die stark normative Aufladung der Leidensschilderung, die für die soeben geschilderten Dauerausstellungen zu konstatieren ist, in dieser Präsentation weitgehend fehlt. Es wird weder wertend zwischen dem Tod von Zivilisten und Mitgliedern von Untergrundgruppierungen unterschieden, noch eine Hierarchisierung jüdischer und polnischer Verfolgung angewendet. Die Besucher verfolgen die Ereignisse des Besatzungsalltags, darunter auch die verschiedenen Formen der Repressionen, aus der Binnenperspektive sowohl der ethnisch-polnischen als auch der jüdischen Krakauer, der Perspektive sogenannter gewöhnlicher Menschen und der weitaus weniger zahlreichen Vertreter des polnischen und jüdischen Untergrunds. So begegnen sie etwa zu Beginn der Besatzung deutschen Soldaten, die religiöse Juden auf der Straße schikanieren und demütigen, mit Armbinden gekennzeichneten Juden bei der Zwangsarbeit und erfahren von den Beschlagnahmungen jüdischer und polnischer Geschäfte und Wohnungen. ${ }^{184}$ Kurz darauf werden sie scheinbar zu teilnehmenden Beobachtern der "Sonderaktion Krakau«: In einem inszenierten Lesesaal hören sie die (deutschsprachige) Ansprache des Gestapo-Offiziers Bruno Müller, bevor sie - wie im November 1939

183 Zur Darstellung des Besatzungsalltags in dieser Ausstellung siehe Kapitel 3.1.

184 Thementext, Fotografien. MHK-Schindler-Fabrik, Sektion 5: Öffentlicher Raum I. Ein Foto von Wehrmachtssoldaten zeigt beispielsweise lachende uniformierte Deutsche, die jüdischen Männern die Schläfenlocken abschneiden. Hinweise in Textform, aber auch mittels Fotografien verweisen im Verlauf des gesamten Rundgangs immer wieder auf die verschiedenen deutschen Repressionen. So zeigen Fotos in der Sektion "Bahnhof" etwa ins Umland ausgesiedelte Juden sowie Polen, die zur Zwangsarbeit ins Deutsche Reich deportiert werden. MHK-Schindler-Fabrik, Sektion 10: Bahnhof. 
die Professoren und Mitarbeiter der Krakauer Hochschulen - auf einen Lastwagen treffen, um schließlich von ihrer Deportation in die Konzentrationslager Sachsenhausen und Dachau zu erfahren. ${ }^{185}$

Auch von den brutalsten Verbrechen an der polnischen und jüdischen Bevölkerung wird gleichermaßen aus einer Binnenperspektive berichtet: So betritt man in der Sektion »Terror inszenierte Zellen des Gefängnisses in der Montelupich-Straße, in dem vor allem Mitglieder des polnischen Untergrunds und politisch engagierte Personen gefangengehalten und exekutiert wurden. ${ }^{186}$ Später läuft man durch das Ghetto, folgt den Bewohnern während ihrer Deportation und im Lager Płaszów. ${ }^{187}$ Auch hier geht es darum, die Verbrechen der Besatzer kenntlich zu machen. So wurde die Sektion »Terror« etwa unmittelbar an die Darstellung des Lebens der Deutschen in der Hauptstadt des Generalgouvernements angeschlossen, ${ }^{188}$ wodurch die scheinbar heile Welt der politischen, der Jugend- und Kulturveranstaltungen mit dem repressiven Antlitz des NS-Besatzungssystems direkt kontrastiert wird. Zugleich bleiben jedoch die Menschen, die Opfer der deutschen Grausamkeit und Brutalität wurden, immer Subjekte, das heißt aktive Protagonisten der historischen Ereignisse: Dort wo es möglich ist, also entsprechende Quellen vorhanden sind, treten direkt betroffene Individuen namentlich auf, und konkrete Personen erzählen mit ihren eigenen Worten von dem Erlittenen; wiederum stammen die Zeitzeugenberichte sowohl von polnischen als auch von jüdischen Betroffenen. ${ }^{189}$

Auffällig ist zudem, dass die individuell Porträtierten nicht zwingend während des Kriegs umkamen; auch Personen, die die Repressalien überlebten, tauchen als Verfolgte in der Schau auf. Exemplarisch hierfür ist die Sektion zur »Sonderaktion Krakau«: In der Vorgängerpräsentation in der Pomorska-

185 Nach dem Durchschreiten des dunklen Hörsaales treffen die Besucher auf die geöffnete Rückseite eines LKW; wenige Schritte weiter finden sich die "Schutzhaft«-Karten der Inhaftierten, private Familienfotos sowie Dokumente aus den Konzentrationslagern. MHK-Schindler-Fabrik, Sektion 6: Sonderaktion Krakau.

186 Hierüber berichtet der entsprechende Bereichstext. MHK-Schindler-Fabrik, Sektion 8: Terror.

187 MHK-Schindler-Fabrik, Sektion 14: Ghetto, Sektion 20: Die Liquidierung des Ghettos, Sektion 21: Das Lager Płaszów. Siehe hierzu auch Teil 2, Kapitel 4.

188 MHK-Schindler-Fabrik, Sektion 7: Generalgouvernement, Sektion 8: Terror.

189 In der Sektion »Terror« finden sich Filmmitschnitte von Interviews mit Zeitzeugen der Verfolgung. Einzelne Inhaftierte werden auch mit Fotografien, biografischen Informationen und persönlichen Dokumenten vorgestellt. MHK-Schindler-Fabrik, Sektion 8: Terror. Ein großer Teil der Texte in der Sektion »Ghetto« stammt aus (schriftlichen) Berichten von Zeitzeugen. Hierzu gehören etwa Roman Polański und Roma Ligocka. Auch die Bedingungen des Überlebens außerhalb des Ghettogeländes ebenso wie die Liquidierung des Ghettos schildern primär Zeugenberichte. Dazu gehören auch die Beobachtungen des einzigen Polen im Ghetto, des Apothekers Tadeusz Pankiewicz. MHKSchindler-Fabrik, Sektion 14: Ghetto, Sektion 20: Die Liquidierung des Ghettos. 
Straße von 1998 wurden allein diejenigen Hochschulmitarbeiter mit Porträtfotos und kurzen Angaben zur Person vorgestellt, die in der Gefangenschaft starben. ${ }^{190}$ Auch in den im vorherigen Abschnitt geschilderten Ausstellungen werden primär Protagonisten präsentiert bzw. innerhalb der Erzählung herausgehoben, die während der Jahre 1939 bis 1945 umkamen. In der Schindler-Fabrik treffen die Besucher dagegen nun auch auf zahlreiche Überlebende der Lager, die nach der Entlassung aus der Haft nach Krakau zurückkehrten. Diese Präsentationsweise zeigt beispielhaft den bemerkenswerten Perspektivwechsel, den die Schau vollzieht: Nicht mehr das Gedenken an die von den Besatzern Ermordeten, sondern die historische Information steht im Vordergrund. Vorgestellt werden daher nicht mehr ausschließlich die Getöteten, sondern auch die größere Zahl der Überlebenden findet Beachtung. Hierdurch wird schließlich das Ausmaß der Verfolgung deutlich - und nicht zuletzt der Unterschied zwischen dem Schicksal polnischer und jüdischer Inhaftierter markiert.

Wie im folgenden Abschnitt noch gezeigt werden wird, ist das polnische Selbstbild der aktiven Widerständler auch in dieser Ausstellung deutlich präsent. Die Verfolgung von Zivilisten und Widerständlern wird jedoch nicht zugunsten letzterer gewichtet. Vielmehr werden die Etappen und Formen der Repressionen in ihrem jeweiligen zeitlichen und inhaltlichen Kontext geschildert. Bei der Darstellung der Situation in Krakau während der Aktion "Gewittersturm" und des Warschauer Aufstands im Jahr 1944 werden etwa auch die Auswirkungen auf Krakau geschildert, die die breite Bevölkerung trafen - so die massiven Straßenrazzien am 6. August, während der 6.000 bis 8.000 Personen inhaftiert wurden. ${ }^{191}$ In einem inszenierten Kellerversteck von Juden beobachten die Besucher wie aus dem Fenster eine dieser Razzien. ${ }^{192}$ Eine martyrologische Deutung der Verfolgung von Polen, etwa durch religiöse Symboliken und Termini, findet ebenfalls nicht statt. Religion wird nur in dem Sinne thematisiert, als konkrete Aktivitäten von Vertretern der katholischen Geistlichkeit in Krakau zur Sprache kommen. ${ }^{193}$

190 MHK-Pomorska-Straße, Tafel 17.

191 Bereichstext »6.VIII. 1944, Sonntag«. MHK-Schindler-Fabrik, Sektion 25: Die letzten Monate der Besatzung.

192 Es handelt sich dabei um Filmaufnahmen, die am 6. August 1944 geheim angefertigt worden waren. MHK-Schindler-Fabrik, Sektion 24: Keller.

193 Herausgehoben präsentiert werden zwei Symbolfiguren aus Krakau, Adam Stefan Sapieha, der als Erzbischof während der Besatzung die katholische Kirche Krakaus führte, sowie der junge Student Karol Wojtyła, der 1978 zum Papst gewählt wurde und die Besatzungszeit ebenfalls in Krakau erlebte. Neben diesen zwei zentralen, auch international bekannten Persönlichkeiten schildert ein Bereichstext die allgemeine Situation der polnischen katholischen Kirche während des Kriegs, darunter die Hilfsleistungen für Bedürftige und Verfolgte ebenso wie die Repressionen gegen einzelne Klöster und Geistliche. MHK-Schindler-Fabrik, Sektion 18: Öffentlicher Raum II. 
Die Abkehr von einseitigen martyrologischen Interpretationsmustern resultiert aus dem spezifischen Ansatz dieser Ausstellung: Die ethnisch-polnische Bevölkerung, aber auch die als Juden Verfolgten, werden hier nicht allein als Helden und Opfer gezeigt. Die Schau bemüht sich vielmehr um das Aufzeigen der Komplexität des Alltags der Jahre 1939 bis 1945, der unterschiedlichen Verhaltensweisen von Menschen angesichts der schwierigen Realität von Krieg und Besatzung. Daher gibt es auch immer wieder Verweise auf negative Verhaltensweisen, etwa auf die Tätigkeit polnischer (und jüdischer) Spitzel, Erpresser oder Kriegsgewinnler. ${ }^{194}$ Diese Differenzierung, die die Darstellung der Protagonisten der musealen Erzählung erfährt, schließt ihre einseitige Heroisierung oder Viktimisierung aus. Zusammenfassend lässt sich für diese Präsentation somit festhalten, dass sie als eine der ersten in Polen eine deutliche Abkehr vom bislang dominierenden Märtyrertopos vollzieht. Zivile und mithin meist zufällige, wehrlose und passiv unter der Gewalt von Krieg und Besatzern Leidende stehen gleichberechtigt neben den Getöteten und Inhaftierten unter den Kämpfern der Armee und der Untergrundgruppierungen. Bei der Schilderung des Schicksals der jüdischen Krakauer ist dieser Perspektivwechsel am augenfälligsten. Während in den Vorgängerpräsentationen allein die Widerstandskämpfer der ŻOB individuell auftraten, sind es nun sogenannte gewöhnliche Menschen abseits der aktiven Resistenz, die die museale Schilderung prägen. Insgesamt bildet die Opferdarstellung jedoch keinen Schwerpunkt der musealen Erzählung; der Alltag der Zivilbevölkerung, das Leben und Überleben während der Besatzung stehen in ihrem Fokus, nicht in erster Linie das Leiden und Sterben.

\subsection{Zwischenfazit}

Wie die Analysen dieses Abschnitts zeigen, kann man für die historischen Dauerausstellungen, die bis 2010 neu entstanden sind, nicht pauschal von einem passive turn ${ }^{195}$ sprechen. Es wäre jedoch auch falsch zu behaupten, bis zur Wende von 1989 seien ausschließlich heroische Opfer in den musealen Darstellungen der Kriegs- und Besatzungszeit vertreten gewesen. Zivile, das heißt wehrlose Opfer des Terrors der »Hitleristen« waren auch in den untersuchten Präsentationen der 1980er-Jahre Bestandteile der Narrationen. Da sie jedoch als reine Objekte der Gewalt und somit abstrakt und anonym in Erscheinung traten, blieben sie im Hintergrund. Primäres Ziel ihrer Darstellung war es, die Unmenschlichkeit der deutschen Besatzer hervorzuheben, was eine umso prägnantere Abgrenzung der eigenen Wir-Gemeinschaft zu

194 Ausführlicher hierzu in Kapitel 3.

195 Münkler/Fischer: »Nothing to kill or die for ...«, 348. 
diesem Feindbild ermöglichte. Prominent präsentiert wurden dagegen die Helden und damit auch Märtyrer des aktiven Widerstandskampfes. Sie waren die Protagonisten der musealen Erzählungen und wurden zugleich als Repräsentanten der unterdrückten Nation dargestellt. Letztlich schufen die Schauen das Bild einer universell widerständigen Gemeinschaft, in der innerhalb eines übergeordneten martyrologischen Narrativs auch den Leiden der passiven Opfer indirekt Sinn verliehen wurde.

Seit den 1990er-Jahren räumte man den zivilen Opfern der Repressionen mehr Platz ein. Im Hinblick auf den Umfang ihrer Darstellung traten sie zunehmend neben die Märtyrer der Widerstandserzählungen. In ihrer interpretatorischen Schwerpunktsetzung waren jedoch die bis Anfang der 2000er-Jahre geschaffenen und sind auch mehrheitlich die seit 2004 eröffneten Ausstellungen nach wie vor von einem martyrologischen Opferbild geprägt, das wesentliche Interpretationsschemata der Volksrepublik perpetuiert. Nicht das traumatische Gedächtnis an unschuldige und wehrlose Leidende stand und steht im Vordergrund, sondern ihre sinnstiftende Einbindung in ein übergreifendes nationales Helden- und Märtyrernarrativ. Dieses wird unterschwellig durch die Konzentration der individualisierten Darstellungen auf die Soldaten der polnischen Armee und die Mitglieder des Widerstands, damit auch auf ihre Leiden in Gefangenschaft, unter Folter oder bei Exekutionen vermittelt.

Veränderungen fanden sich hingegen im Bereich der verwendeten Symbolik sowie durch die Hinzunahme einzelner bislang tabuisierter thematischer Topoi. Mit Beginn der 1990er-Jahre ist eine verstärkte Verwendung sakraler Symboliken zu verzeichnen ebenso wie die Thematisierung von Religion und Glaubensausübung der unterdrückten ethnisch-polnischen Bevölkerung. Das martyrologische, auf einem ethnischen Verständnis der polnischen Nation basierende Opferbild, das die meisten Schauen zeichneten, wurde hierdurch um eine christliche Komponente ergänzt. Daneben fügte man den präsentierten Leidensformen eine neue Richtung hinzu. Mit der Hinzunahme der Sowjetunion als zuvor tabuisiertem zweiten Angreifer und Besatzer Polens hielt ein zentraler Topos der polnischen Erinnerung an die sowjetischen Verbrechen der Kriegsjahre Einzug in die musealen Erzählungen: Die Massenmorde an polnischen Offizieren und Soldaten in Katyń und anderen Orten der Sowjetunion im Jahr 1940 standen nun stellvertretend für die polnischen Leiden unter diesem »neuen« alten Feind. Eng damit verbunden findet auch die Verfolgung des nichtkommunistischen Widerstands der Kriegsjahre wie des antikommunistischen Untergrunds der Nachkriegszeit durch die neuen staatssozialistischen polnischen Regierungsorgane zunehmend Erwähnung. Die polnischen Kommunisten der Nachkriegsregierung werden hierdurch klar aus der Wir-Gemeinschaft der Helden und Märtyrer ausgeschlossen. Diese Neuerungen bzw. Veränderungen hatten und 
haben jedoch keinen Einfluss auf die dominierenden Interpretationsschemata der Schauen. Ganz im Gegenteil stützen sie das etablierte martyrologische Selbstbild.

Schließlich lässt sich konstatieren, dass die Ausstellungen bis in die Gegenwart eine deutliche Hierarchie der Opfer vermitteln. Die aktiven Widerständler, die im Rahmen ihres Kampfes gegen die Besatzer litten oder den Tod fanden, werden herausragend porträtiert. Die zufälligen, zivilen, meist passiven Opfer bleiben demgegenüber abstrakt, in Form anonymer Fotografien und summarischer Opferzahlen. Diese Präsentationsweise etabliert eine normative Hierarchie des Leidens, die sich auch bei der Schilderung der Verfolgung der jüdischen Einwohner findet. Zusätzlich ist bei der Kontextualisierung dieses Themas in den 1980er-Jahren wie in vielen gegenwärtig zu besichtigenden Präsentationen eine unterschwellige gruppenspezifische Hierarchisierung des Opferstatus festzustellen. Das Schicksal der jüdischen Einwohner war und bleibt im Vergleich zur Schilderung des Leids ethnischer Polen in vielen Schauen marginalisiert. Wenn überhaupt, sind es die jüdischen Widerstandskämpfer, etwa die Aufständischen des Warschauer Ghettoaufstandes von 1943, die als einzige Vertreter dieser Gruppe von Verfolgten individuell genannt und vorgestellt werden. Sie sind es, die als "würdige«, da aktiv widerständige und in dem Sinne heroische Opfer eine eigenständige Erwähnung finden. Die übrige Masse der Ghettobewohner bleibt demgegenüber namens- und gesichtslos. Ausnahmen stellen im Untersuchungszeitraum einzig die Dauerausstellungen des Stadtmuseums von Łódź und der Krakauer Schindler-Fabrik dar. Diese präsentieren nicht nur polnische und jüdische Stadtbewohner als gleichberechtigte Protagonisten der historischen Ereignisse, sie stellen auch das Leben und Leiden von Zivilisten unter ihnen erstmals in den Vordergrund.

Abschließend lässt sich somit festhalten, dass trotz neuer Themen und Symboliken ebenso wie neuer Präsentations- und Gestaltungsmöglichkeiten, sich die musealen Opferdarstellungen bis in die Gegenwart durch eine bemerkenswerte Kontinuität auszeichnen. Der zentrale Topos einer moralisch überlegenen, ethnisch-polnischen widerständigen Gemeinschaft wurde einzig um eine religiöse, nämlich christliche Komponente erweitert. Eine Differenzierung und Erweiterung, gar Infragestellung dieser einseitigen Perspektive findet dagegen erst langsam statt. Nur eine einzige der untersuchten Ausstellungen stellt die Topoi der sacrificia und victimae in den Hintergrund und fokussiert stattdessen auf die Alltagserfahrungen der zivilen Bevölkerungsmehrheit. 


\section{Heldenbilder}

Die Betonung der zentralen Rolle des eigenen Widerstands gegen das NSRegime und dessen Heroisierung hat sich in den europäischen Staaten (mit Ausnahme der BRD) in den ersten Jahrzehnten nach Kriegsende als dominantes Selbstbild der eigenen Nation und zentrales Narrativ der Kriegs- und Besatzungszeit etabliert - und zwar auf beiden Seiten des Eisernen Vorhangs. In diesem heroischen Kriegsbild stand das Heldengedenken im Vordergrund, auch wenn die Massen der (zivilen) Kriegsopfer berücksichtigt wurden. ${ }^{196}$ In Polen rekurrierte dieses Deutungsschema stark auf tradierte romantische martyrologische Geschichtsbilder. ${ }^{197}$ Wie im vorangegangenen Abschnitt bereits deutlich wurde, ist eine Ablösung dieses heroischen durch ein viktimologisches Opfernarrativ in den untersuchten polnischen Geschichtsausstellungen bis 2010 größtenteils nicht zu verzeichnen. Thema der folgenden Ausführungen ist nun, inwieweit der gleichwohl stattfindende Bedeutungszuwachs passiver Opfer in den musealen Erzählungen, das mit Beginn der 1990er-Jahre neu hinzukommende Feindbild der Sowjetunion - und damit verbunden auch der polnischen kommunistischen Nachkriegsregierung -, sowie das sich transformierende Fremdbild der jüdischen Verfolgten Auswirkungen auf das Autostereotyp der heldenhaften Kämpfer hatte. Zu fragen ist hierbei nicht zuletzt nach dem sich wandelnden Verständnis widerständigen Verhaltens, das die Schauen transportieren.

\subsection{Die Musealisierung des Widerstands in den 1980er-Jahren}

Den Ausgangspunkt für die Analysen bilden auch hier wiederum die Präsentationspraxen, die sich in den 1980er-Jahren in den Museen manifestierten. Zwei zentrale Eckpunkte kennzeichneten übergreifend die Widerstandsdarstellungen in den Dauerausstellungen: erstens die Hervorhebung der vermeintlich bedeutenden Rolle der kommunistischen Widerstandsbewegungen im Kampf gegen die deutschen Besatzer und zweitens die Charakterisierung der Resistenz als kollektive Anstrengung der gesamten Bevölkerung des okkupierten Landes. Beide narrative Elemente waren dabei eng miteinander verknüpft.

196 François, Etienne: Meistererzählungen und Dammbrüche. Die Erinnerung an den Zweiten Weltkrieg zwischen Nationalisierung und Universalisierung. In: Flacke, Monika (Hg.): Mythen der Nationen. 1945 - Arena der Erinnerungen. Bd. 1. Mainz 2004, 13-28, hier $15-17$, bes. 16 .

197 Traba: Der Opferdiskurs, 33. 
Zunächst zum ersten Punkt: Bei der Nennung konkreter Organisationen konzentrierten sich alle untersuchten Schauen in den 1980er-Jahren stark auf Einheiten des kommunistischen Widerstands, in erster Linie die »Volksgarde (Gwardia Ludowa, GL) und deren Nachfolgeorganisation »Volksarmee» (Armia Ludowa, AL) sowie ihre politische Führung, die »Polnische Arbeiterpartei« (Polska Partia Robotnicza, PPR). In den meisten der Ausstellungen machten diese Gruppen etwa die Hälfte der thematisierten Widerstandsorganisationen aus. So etwa im Gefängnismuseum Pawiak, in dem einzelne Organisationen mittels kurzer Biogramme von inhaftierten Mitgliedern und Sympathisanten einzelner Gruppen in die Präsentation eingebracht wurden. ${ }^{198}$

Bemerkenswert ist jedoch zugleich, dass die Darstellungen aller untersuchten Ausstellungen in diesem Jahrzehnt sich nicht allein auf den kommunistischen und allgemein linken Widerstand beschränkten. Neben diesem figurierten prominent Organisationen, die mit der Exilregierung in London verbunden waren und politisch in einem Konkurrenzverhältnis zu den kommunistischen Gruppen standen. ${ }^{199} \mathrm{Zu}$ den thematisierten Organisationen gehörten vor allem die Heimatarmee und ihr Vorgänger, der "Verband für den Bewaffneten Kampf« (Związek Walki Zbrojnej, ZWZ), ${ }^{200}$ sowie die »Bauern-

198 Das Ende der Dauerausstellung des Pawiak-Museums bildete eine Ziegelwand, auf der überwiegend ermordete und umgekommene Insassen des Gefängnisses mit einem Foto und einem kurzen Biogramm präsentiert wurden. Von den 56 Personen gehörten mit 22 fast die Hälfte kommunistischen Untergrundorganisationen an oder arbeiteten mit ihnen zusammen. Dazu zählten die PPR, GL und AL, aber auch der kommunistische »Verband Kampf der Jungen" (Związek Walki Młodych, ZWM) und die linke »Polnische Volksunabhängigkeitsaktion«(Polska Ludowa Akcja Niepodległościowa, PLAN). Zum Vergleich: 21 der Vorgestellten gehörten Organisationen an, die mit der Londoner Exilregierung verbunden waren, darunter dem »Verband für den Bewaffneten Kampf« (Zwiazek Walki Zbrojnej, ZWZ), der AK, den »Grauen Reihen« (Szare Szeregi), der »Polnischen Sozialistischen Partei« (Polska Partia Socjalistyczna, PPS) und der Bauernpartei. Siehe: Scenopis stałej ekspozycji, 95-109.

199 Zur Zusammensetzung und den unterschiedlichen politischen Zielen innerhalb des polnischen Widerstands siehe Borodziej, Włodzimierz: Terror und Politik. Die deutsche Polizei und die polnische Widerstandsbewegung im Generalgouvernement 1939-1944. Mainz 1999, 6-10; Mazur, Grzegorz: Der Widerstand im Generalgouvernement 1939-1945. In: Młynarczyk, Jacek Andrzej (Hg.): Polen unter deutscher und sowjetischer Besatzung 1939-1945. Osnabrück 2009, 405-425.

200 Die Heimatarmee war die größte der polnischen Widerstandsorganisationen während des Zweiten Weltkriegs. Unterschiedliche Schätzungen gehen davon aus, dass sie zum Höhepunkt ihrer Tätigkeit ca. 250.000 bis 350.000 Soldaten umfasste; der Großteil von ihnen war jedoch unbewaffnet. Gegründet wurde sie als "Dienst für Polens Sieg" (Stużba Zwycięstwu Polski, SZP) im Herbst 1939; auf Befehl der Exilregierung wurde diese Organisation um die Jahreswende 1939/40 in den Verband für den Bewaffneten Kampf (ZWZ) umgewandelt. Dieser größten Organisation des mit der Exilregierung verbundenen Lagers schlossen sich sukzessive zahlreiche der versprengten Untergrundgruppierungen des besetzten Landes an. Im Februar 1942 wurde der ZWZ in Heimatarmee umbenannt. Mazur: Der Widerstand im Generalgouvernement, 408, 410; 
bataillone« (Bataliony Chłopskie, BCh) ${ }^{201}$. Zum Teil nahmen die Verweise auf diese Gruppen ähnlich viel Raum ein wie die Darstellungen des kommunistischen Widerstands, so etwa in den Dauerausstellungen des Historischen Museums der Hauptstadt Warschau oder in der Abteilung Pomorska-Straße des MHK in Krakau. ${ }^{202}$ In den musealen Widerstandserzählungen waren die kommunistischen Organisationen in diesen beiden Ausstellungen zwar bedeutend, standen jedoch etwa auf gleicher Stufe mit Einheiten, die anderen politischen Richtungen nahestanden. So stellte man beispielsweise in der zentralen Ausstellung des stadthistorischen Museums der Hauptstadt den Widerstand gegen die Besatzer als gemeinsame Anstrengung von $\mathrm{AK}$ und $\mathrm{AL}$ dar, wie der Text eines Ausstellungsführers dokumentiert:

Die Soldaten der Heimatarmee und der Volksarmee antworteten mit Kugeln auf den Terror der Besatzer, die Straßenrazzien, öffentlichen Exekutionen, auf den Abtransport von Gefangenen in Konzentrationslager oder zur Arbeit nach Deutschland. ${ }^{203}$

Die Reihenfolge der Nennung beider Gruppierungen kann zudem als Hinweis auf deren anteilige Bedeutung im Widerstand gesehen werden. Ein eindeutiges Primat kommunistischer Widerstandsgruppen wurde somit in den Ausstellungen der 1980er-Jahre nicht proklamiert.

Borodziej: Terror und Politik, 6f. Umfassend zur Entstehung und dem Aufbau der AK: Mazur, Grzegorz: Der »Bund für den bewaffneten Kampf - Heimatarmee« und seine Gliederung. In: Chiari, Bernhard (Hg.): Die polnische Heimatarmee. Geschichte und Mythos der Armin Krajowa seit dem Zweiten Weltkrieg. München 2003, 111-149. Siehe auch Borodziej, Włodzimierz u. a.: Polska Podziemna 1939-1945 [Polen im Untergrund 1939-1945]. Warszawa 1991, 82-86, 94-112.

201 Die Bauernbataillone waren die bewaffnete Widerstandsorganisation der »Volkspartei« (Stronnictwo Ludowe, SL), die der Exilregierung und damit dem Untergrundstaat angehörte. Sie wurden im August 1940 gegründet und entwickelten sich zu einer der größten Widerstandsgruppen im GG; ihre Truppenstärke wird auf 100.000 bis 150.000 Personen geschätzt. Im Sommer 1944 schloss sich ein Teil der BCh der Heimatarmee an. Mazur: Der »Bund für den bewaffneten Kampf - Heimatarmee«, 115 f. Vgl. Borodziej: Polska Podziemna, 113-117.

202 In der Präsentation des MHW wurden u. a. zentrale Aktionen der Pfadfinderorganisation im Untergrund Graue Reihen und der Heimatarmee dargestellt, darunter der Anschlag der AK auf Franz Kutschera, den Leiter der SS und der Polizei im Distrikt Warschau, sowie die »Aktion beim Arsenal«, bei der Häftlinge eines Gefängnistransports befreit wurden. Informator do ekspozycji, $50 \mathrm{f}$. Im MHK wurden analog zur Präsentation eines "Organisationsschema[s] des Krakauer Bezirks der GL-AL« zusammen mit Fotografien und Abzeichen von Einheiten der GL und AL sowie einiger ihrer Untergrundpublikationen auch Organisationsschemata der Krakauer Bezirke der AK und der BCh gezeigt, ebenfalls mit Fotografien einzelner Einheiten sowie mit Dokumenten und Objekten, darunter Kopien von Einsatzbefehlen, Abzeichen und Untergrundpresseerzeugnissen. Wroński: Scenariusz wystawy, 4-6, Zitat: 4.

203 Płoszajska: Muzeum Historyczne, 20. 
Ein wesentlicher Unterschied ist jedoch zwischen der Darstellung kommunistischer und konkurrierender Untergrundorganisationen festzustellen: Bei der Thematisierung der ZWZ-AK und der Einheiten, die der Bauernpartei nahestanden, ging man meist nicht auf individuelle, führende Vertreter dieser Organisationen ein - im Gegensatz zur Darstellung des kommunistischen Widerstands. Auch ihre Beziehungen zur Londoner Exilregierung blieben in allen Schauen unerwähnt; nur in wenigen fand sich überhaupt ein Hinweis auf deren Existenz. Am deutlichsten war noch der Hinweis im Pawiak-Museum. Dort wurde unter den einzeln vorgestellten Häftlingen auch Jan Piekałkiewicz aufgeführt, der als »herausragender Funktionär der Bauernpartei« und "[i]n den Jahren 1942/43 Delegierter der Exilregierung im Lande" vorgestellt wurde - die einzige Erwähnung dieser Regierung und ihrer Repräsentanz im besetzten Polen in der gesamten Präsentation. ${ }^{204}$ In der Schau des MHK stellte man in einer Vitrine das »Siegel des Bezirksvertreters der Regierung [im Lande]« aus - ohne jedoch dessen Tätigkeit und die dahinterstehenden politischen Strukturen zu thematisieren. Es entsteht dadurch der Eindruck, das Siegel sei ein in die Ausstellung "eingeschmuggelter" bzw. für interessierte und wissende Besucher versteckter Hinweis auf diesen in der offiziellen Geschichtspolitik lange tabuisierten und später verurteilten Teil der polnischen Kriegsereignisse gewesen. ${ }^{205}$ Diese Vermutung stützt sich zusätzlich darauf, dass das besagte Exponat im Drehbuch nicht aufgeführt ist, dagegen aber in allen Inventarlisten der Ausstellungsexponate der folgenden Jahre auftaucht. ${ }^{206}$ Organisationen und einzelne Einheiten des nichtkommunistischen Untergrunds kontextualisierte man somit als (Mit-)Kämpfer gegen die Besatzer und für die Freiheit des Landes. Die auf den Fotografien zu sehenden Repräsentanten der »unteren Ebene« dieser Gruppen, die einfachen Widerstandskämpfer, wurden als positiver Teil der Resistenz anerkannt. Ihre Führungsstruktur im Rahmen des Untergrundstaates und dessen Londoner Zentrale blieben jedoch - bis auf die erwähnten marginalen Hinweise, die allein Besucher mit Vorwissen deuten konnten - unerwähnt. Dem offiziellen Geschichtsbild der VRP folgend wurde somit den einfachen Widerstandskämpfern ein Heldenstatus eingeräumt und ihnen damit die Aufnahme in das nationale Heldenkollektiv ermöglicht. Diese integrative Geschichtsperspektive, die in erster Linie der Legitimierung des bestehenden Herrschafts-

204 Scenopis stałej ekspozycji, 105.

205 Borodziej: Terror und Politik, 10-12, 15.

206 Rozmieszczenie eksponatów na wystawie przy ul Pomorskiej. AMHK, OWM-1/47/82, 1; Rozmieszczenie eksponatów na wystawie stałej »Walka i męczeństwo Polaków w latach 1939-1945« przy ul. Pomorskiej 2 od dnia 16 I 1984. AMHK, OWM-6400-1 / 84, 2; Rozmieszczenie eksponatów na wystawie stałej »Walka i męczeństwo Polaków w latach 1939-1945« przy ul. Pomorskiej 2 od dnia 3 I 1985 roku. AMHK, OWM-6400-1 / 85, 3. 
systems und der Stabilisierung der Gesellschaft diente, etablierte sich bereits in den späten 1950er-Jahren. Joanna Wawrzyniak bezeichnet sie als "Mythos der Einheit der Widerstandsbewegung «. ${ }^{207}$ Die im offiziellen Geschichtsbild negativ bewertete »bürgerliche« Exilregierung blieb dagegen aus diesem Heldenkollektiv exkludiert.

Insgesamt ist festzustellen, dass in den stadthistorischen Museen die umfangreichste und detaillierteste Betrachtung des organisierten Widerstands, darunter insbesondere kommunistischer Organisationen, im Vergleich zu den lokalen martyrologischen Museen zu beobachten war. Besonders auffällig ist dies beim Historischen Museum der Hauptstadt Warschau. Dort wurden prominent die Entstehung und die führenden Köpfe der PPR, der GL und des "Landesnationalrats" (Krajowa Rada Narodowa) behandelt ebenso wie ihre bekanntesten Widerstandsaktionen. ${ }^{208}$ Bei der Schilderung des »Kampfes der Warschauer Jugend " nahmen die Aktionen und der Aufbau der kommunistischen Gruppen etwa die Hälfte der Ausstellungsfläche ein. ${ }^{209}$ Die Betonung der wichtigen Rolle von linken Organisationen bzw. Arbeiterbewegungen setzte hier bereits beim September 1939 an: Im Ausstellungssaal zum deutschen Angriff präsentierte man einen umfangreichen Kalender, der die Verteidigung der Stadt im September 1939 dokumentierte. Eröffnet wurde er mit den Fotografien zweier Personen, die als zentral bei der Organisation der Verteidigung dargestellt wurden:

[...] Mieczysław Niedziałkowski, der Chefredakteur der Zeitung ’Robotnikı [Arbeiter] und Hauptorganisator der Arbeiterbataillone zur Verteidigung Warschaus, sowie Stefan Starzyński - der damalige Präsident Warschaus, der am 8.9.39 zum Zivilkommissar beim Oberkommando der Verteidigung der Hauptstadt ernannt wurde. ${ }^{210}$

207 Wawrzyniak: ZBoWiD, 171-244, bes. 244. Die Vorläufer dieser Vision in der Propaganda der PPR noch in den Kriegsjahren zeichnet Marcin Zaremba nach: Zaremba: Komunizm, legitymizacja, nacjonalizm, 121-134, bes. 128-131.

208 Der Widerstand, seine Protagonisten und Aktionen wurden im Saal 58 sowie in den Sälen 59 und 60 thematisiert. Letztere waren explizit dem »Kampf der Warschauer Jugend» gewidmet. In den drei Sälen nehmen Vertreter und Aktivitäten kommunistischer Gruppen etwa die Hälfte der Ausstellungsfläche ein. Informator do ekspozycji, $49 \mathrm{f}$., Zitat: 50. Siehe auch Płoszajska: Muzeum Historyczne, 20. Der Umfang, der einzelnen Themen eingeräumt wurde, kann nur auf Basis des zur Verfügung stehenden ausführlichen Manuskripts eines Ausstellungsführers geschätzt werden (Informator do ekspozycji), da das Drehbuch der Schau nicht erhalten ist.

209 Präsentiert wurden Materialien zu den Gruppen Spartakus, ZWM, „Verband der Unabhängigen Sozialistischen Jugend« (Związek Niezależnej Młodzieży Socjalistycznej, ZNMS) und der »Arbeiterpartei der Polnischen Sozialisten« (Robotnicza Partia Polskich Socjalistów, RPPS). Informator do ekspozycji, $51 \mathrm{f}$.

210 Informator do ekspozycji, 47. 
Die sozialistischen Arbeiterbrigaden wurden somit auf eine Stufe mit der Symbolfigur des Warschauer Widerstands gegen die deutsche Aggression im September 1939 gestellt, dem Stadtpräsidenten Starzyński.

Auch in den Lubliner Museen ist eine ähnlich starke Konzentration auf den kommunistischen Widerstand zu beobachten, wobei diese Schauen in ihrer Hervorhebung noch einen Schritt weitergehen. Im Historischen Museum der Stadt Lublin nahm die Schilderung des Widerstands gegen die »Hitleristen« eine herausragende Rolle ein: Diesem Thema war als einzigem in der Sektion zum Zweiten Weltkrieg eine eigene großformatige Texttafel gewidmet, womit der Widerstandsaspekt besonders herausgestellt erschien. Der Inhalt der Tafel kann als exemplarisch für die Präsentationsweise des Widerstands in der VRP in diesem Jahrzehnt gelesen werden. Unter dem Titel »Die Widerstandsbewegung in Lublin in den Jahren 1939-1944« fanden sich folgende Informationen:

Ab Herbst 1939 fanden in Lublin die Untergrundorganisationen der Widerstandsbewegung ihren Sitz: das Kommando der Verteidiger Polens ZWZ ebenso wie Organisationen der linken Bewegung. Ab 1942 wurde das städtische Komitee der PPR berufen und eine Abteilung der GL unter Leitung von R. Postowicz `Murzyn`gegründet. Durch die Stadt führten Schmuggeltrassen von [Untergrund-]Publikationen und Menschen. Hier befanden sich zahlreiche Kontaktpunkte der regionalen Lubliner Organisationen der PPR, GL und AL. Die Lubliner Verschwörer hatten einen ausgebauten Nachrichtendienst in den Polizeiorganen des Besatzers, in der Eisenbahn und in den städtischen Behörden. ${ }^{211}$

Erwähnt wurden sowohl der Vorläufer der Heimatarmee als auch kommunistische Gruppierungen. Die Erstnennung des ZWZ konnte von Besuchern sogar als Hinweis auf seine anteilig größere Bedeutung gewertet werden. Näher ausgeführt wurden jedoch die Aktivitäten des kommunistischen Lagers, wodurch dessen Bedeutung suggestiv erhöht wurde. Im Museum »Unter der Uhr« sollte der politische Hintergrund der Verfolgung und Inhaftierung durch die ausgestellten Dokumente nahegebracht werden, die das Schicksal namentlich genannter Verurteilter illustrierten. Bis auf eine Ausnahme waren auf den für die Schau ausgewählten Plakaten und Deportationslisten ausschließlich Mitgliedschaften in kommunistischen Organisationen als Verhaftungsgründe direkt benannt; lediglich eines der Plakate bezichtigte Mitglieder des ZWZ eines Angriffs auf Deutsche. ${ }^{212}$ Durch diese spezifische Objektaus-

211 Wystawa: Historia miasta Lublina. Otwarcie - 18.VII.1979 r. AMLL, ohne Signatur.

212 In der Ausstellung wurden u. a. vier sogenannte Todesplakate gezeigt, mit denen die Besatzungsmacht Vergeltungsmaßnahmen für Angriffe auf ihre Angehörigen verkündete. Eines dieser Plakate nennt als Ursache der deutschen Vergeltungsmaßnahmen einen Angriff von Kommunisten. Auf diesem und zwei weiteren werden explizit Angehörige kommunistischer Organisationen mit besonderen Strafen bedroht, sollten Kommunis- 
wahl, ebenso wie durch die umfangreichen Verweise auf kommunistische Organisationen und Führungsfiguren in der Schau des Stadtmuseums, vermittelte man den Eindruck, die polnischen Kommunisten wären eine zentrale Kraft im Widerstand gewesen und könnten damit schließlich auch einen entscheidenden Anteil am Sieg über die deutschen Besatzer für sich beanspruchen. Tatsächlich war ihre militärische Bedeutung verhältnismäßig gering. ${ }^{213}$ Wie Włodzimierz Borodziej feststellt: »das Übergewicht des regierungstreuen Widerstands war erdrückend «. ${ }^{214}$

Hierbei muss für alle untersuchten musealen Erzählungen betont werden, dass eine Dominanz kommunistischer Widerstandsbewegungen lediglich durch die Ausstellungspraxis suggeriert wurde. In keiner der Ausstellungen wurde explizit festgestellt oder behauptet, Kommunisten hätten die führende Rolle im polnischen Untergrund gespielt. In diesem Sinne wichen die Schauen auf sachlicher Ebene nicht von den Fakten ab. Durch die geschilderten Kontextualisierungen entstand bei den Besuchern jedoch mit hoher Wahrscheinlichkeit der Eindruck einer solchen Hierarchie. Mittels dieser Darstellungsweise konnte die führende Rolle der polnischen Kommunisten in der Nachkriegsentwicklung des Landes als logische Folge des linken, in erster Linie kommunistischen Kampfes gegen die Besatzer reklamiert und legitimiert werden.

Diese Legitimierungsstrategien wurden in denjenigen Ausstellungen, die das Kriegsende thematisierten, konsequent bis in die Darstellung der Nachkriegszeit weitergeführt. So folgte im Historischen Museum der Stadt Lublin

ten weitere Angriffe verüben. Neben diesen sind die Verurteilungsgründe von Angehörigen anderer Untergrundgruppierungen meist lediglich als »Mitgliedschaft in einer verbotenen Organisation « benannt, so auch in einem ausgestellten Zeitungsartikel, der die Verurteilten der einzigen öffentlichen Exekution in Lublin namentlich aufführt. Ein einziges Plakat nennt einen Angriff des ZWZ bzw. PZP (Polski Związek Powstańczy/ "Polnischer Aufständischen-Verband« - einer der Decknamen der Heimatarmee) als Anlass für die Exekution von Mitgliedern dieser Organisation. Schließlich findet sich im Abschnitt, der der Deportation von Häftlingen in Konzentrationslager gewidmet ist, eine Namensliste, auf der explizit der Verfolgungsgrund der Deportierten vermerkt ist: ihre Mitgliedschaft in der PPR. MLL-Unter der Uhr, linker und rechter Zellengang, Zelle 6, 9, 10.

213 Die Aktivitäten kommunistischer Untergrundgruppen auf dem besetzten polnischen Territorium setzten erst relativ spät ein, da die GL als militärischer Arm der PPR erst 1942 gegründet wurde. Im Januar 1944 wurde sie in Volksarmee umbenannt. Die Einheiten der GL-AL gehörten zahlenmäßig zu den kleineren Untergrundorganisationen. Von nur einigen hundert Personen im Jahr 1942 sollen sie erst im April 1944 auf etwa 14.000 und schließlich im Juli 1944 auf 34.000 Mann angewachsen sein. Am größten war ihre Bedeutung noch im Bezirk Lublin, wo sie zusammen mit sowjetischen Partisanen zu einer Konkurrenz für den mit der Londoner Exilregierung verbundenen Widerstand wurde. Mazur: Der Widerstand im Generalgouvernement, $422 \mathrm{f}$. Siehe auch Borodziej: Geschichte Polens, $215 \mathrm{f}$.

214 Borodziej: Geschichte Polens, 216. 
unmittelbar auf die Darstellung des - in der Ausstellung überwiegend kommunistischen - Widerstands die »Befreiung Lublins«, die mithilfe von Fotografien polnischer und sowjetischer Soldaten der Roten Armee sowie dem Manifest des Polnischen Komitees der Nationalen Befreiung illustriert wurde, woran sich wiederum scheinbar folgerichtig der Abschnitt »Lublin, die Hauptstadt des PKWN« anschloss. ${ }^{215}$ Ähnlich wurde auch im Stadtmuseum von Warschau eine direkte Verbindung zwischen dem gemeinsamen Kampf polnischer und sowjetischer Truppen und der Befreiung des Landes sowie der Etablierung der sozialistischen Übergangsregierung gezogen: Den Abschluss der Sektion zum Zweiten Weltkrieg bildete eine Tafel, die die "Januaroffensive der 1. Weißrussischen Front der Sowjetischen Armee [darstellte], im Zuge derer Warschau befreit wurde «. ${ }^{216}$ Die Karte zeigte schematisch den Frontverlauf, wobei farblich zwischen Einheiten der »sowjetischen Armee« und »Einheiten der 1. Armee der Polnischen Armee« unterschieden wurde. Explizit wurde zudem darauf hingewiesen, dass es polnische Truppenverbände waren, die Warschau befreiten. ${ }^{217}$ Unmittelbar auf diese Tafel folgte auch hier das Manifest des PKWN, das den Beginn der sozialistischen Nachkriegsentwicklung des Landes markierte. Die musealen Erzählungen vom bedeutenden kommunistischen Widerstand während der deutschen Besatzung endeten somit mit der Betonung des gemeinsamen Kampfes von Polen und Rotarmisten bei der Befreiung des Landes. Zu beachten ist weiterhin, dass bei der Darstellung von Polen in Armeen außerhalb des besetzten Landes allein auf die Zusammenarbeit in sowjetischen Truppenverbänden eingegangen wurde die polnischen Auslandsstreitkräfte im Westen fanden dagegen keinerlei Erwähnung. Die polnischen Kommunisten und die UdSSR wurden somit zu Befreiern des Landes stilisiert und aus dieser Logik ergab sich folgerichtig ihr Führungsanspruch in der politischen Nachkriegsentwicklung des Landes. In dieser Präsentationsweise spiegelt sich die fortbestehende Wirkung des »Mythos des Sieges über den Faschismus « (Joanna Wawrzyniak), der sich bereits in den ersten Jahren der VRP etablierte und zur prägenden Erzählung über den Regierungsbeginn der Polnischen Arbeiterpartei wurde. ${ }^{218}$

215 Die Zitate entsprechen den Überschriften der jeweiligen Ausstellungstafeln. Wystawa: Historia miasta Lublina. Zur Darstellung der Befreiung der Stadt in dieser Ausstellung siehe auch Teil 1, Kapitel 2.1.

216 Untertitel der Ausstellungstafel. MHW, Saal 53.

217 In der Erläuterung auf der Karte hieß es: »[...] Die 1. Weißrussische Front setzt sich zusammen aus: der 47. und 61. Sowjetischen Armee, der 2. Gardepanzerarmee sowie der 1. Armee der Polnischen Armee, die Warschau befreite." Ebd.

218 Wawrzyniak: ZBoWiD, 105-170, bes. 168-170. Seit der zweiten Hälfte der 1950er-Jahre trat das Argumentationsmuster des »Sieges über den Faschismus« in den Hintergrund, blieb jedoch bis zuletzt Teil des argumentativen Arsenals der volksrepulikanischen Geschichtspolitik. Ebd., 171, 308. Siehe auch Wawrzyniak, Joanna: On the Making of Second World War Myths. War Veterans, Victims and the Communist State in Poland, 
Die politischen Konflikte zwischen den einzelnen Organisationen des Untergrunds, allen voran zwischen den in der ZWZ-AK versammelten Gruppierungen und der PPR, wurden in den Ausstellungen ebenfalls verschwiegen. ${ }^{219}$ Auch die Differenzen hinsichtlich der politischen Ausrichtung des Landes nach dem Krieg und schließlich der bewaffnete Kampf einzelner Gruppen gegen die neue sozialistische Regierung in der Nachkriegszeit blieben unerwähnt. Durch die Auslassung dieser Themen entstand in den Ausstellungen der Eindruck einer scheinbar geschlossenen Zusammenarbeit der verschiedenen Widerstandsgruppen gegen den gemeinsamen Feind. Nicht zuletzt konnte hierdurch das Bild gezeichnet werden, alle Gruppen, ebenso wie die breite Bevölkerung, hätten sich bei Kriegsende geschlossen hinter die neue Regierung gestellt. Sinnbildlich wurde diese Sichtweise insbesondere im Lubliner Stadtmuseum vermittelt: Auf der letzten Ausstellungstafel »Lublin, die Hauptstadt des PKWN « fand sich eine großformatige Fotografie von Menschenmassen bei einer Demonstration zur Unterstützung des PKWN. ${ }^{220}$

Das zweite zentrale Merkmal der musealen Heldendarstellung dieses Jahrzehnts betraf die Suggestion einer allgemeinen Widerstandstätigkeit. Der aktive Kampf gegen die Besatzer wurde als vermeintlich verbreitete Haltung der gesamten Bevölkerung ausgelegt. Im Pawiak-Museum hieß es etwa:

Die Häftlinge, die in ihrer überwältigenden Mehrheit aus den Reihen der gegen den Besatzer Kämpfenden gerissen waren, blieben Teil der kämpfenden Nation. [...] der Kampf der Häftlinge des Pawiak dauerte ununterbrochen an. ${ }^{21}$

Der entfesselte, offene Terror des Besatzers erstickte nicht den Willen zum Kampf. [...] Das ganze kämpfende Warschau erinnerte sich an die Menschen hinter Gittern. Als Vergeltung für die Verbrechen antwortete die Hauptstadt mit Kampfhandlungen. ${ }^{222}$

Die »Nation« bzw. die mit ihr synonym gesetzte Bevölkerung innerhalb wie außerhalb der Gefängnismauern wurde hier als Kollektiv von Widerstandskämpfern präsentiert. Die verschiedenen politischen Orientierungen der ein-

1945-1969. In: Stegmann, Natali (Hg.): Die Weltkriege als symbolische Bezugspunkte: Polen, die Tschechoslowakei und Deutschland nach dem Ersten und Zweiten Weltkrieg. Prag 2009, 189-208, hier 207.

219 Den Konflikt zwischen PPR und AK schildern Borodziej: Terror und Politik, 8-10; Marszalec, Janusz: Der Polnische Untergrundstaat und die polnischen Kommunisten. In: Böhler, Jochen/Lehnstaedt, Stephan (Hg.): Gewalt und Alltag im besetzten Polen 19391945. Osnabrück 2012, 449-476. Zum langwierigen Vereinigungsprozess innerhalb des polnischen Untergrunds und den weiterbestehenden Konflikten der größten Lager siehe Mazur: Der »Bund für den bewaffneten Kampf - Heimatarmee«, 112-121; Borodziej: Geschichte Polens, 210-216.

220 Wystawa: Historia miasta Lublina.

221 Thementext »Kampf und Hoffnung«. Scenopis stałej ekspozycji, 80.

222 Ebd., 88. 
zelnen Untergrundorganisationen blieben dabei weitgehend im Hintergrund; einzig an den am Ende des Ausstellungssaals präsentierten Biogrammen einzelner Insassen ließen sich diese ablesen. ${ }^{223}$ In der übrigen Schau fanden die unterschiedlichen politischen Ziele und daraus resultierenden Konflikte zwischen einzelnen Gruppen keinen Ausdruck. Der vermeintlich allgemeine Kampf gegen die »Hitleristen« wurde zum zentralen Interpretationstopos. Nicht nur konnten hierdurch Organisationen, die den linken Gruppierungen kritisch gegenüberstanden, in ein gemeinsames Widerstandsnarrativ integriert werden. ${ }^{24}$ Auch symbolträchtige Elemente der lokalen Besatzungsgeschichte, so zum Beispiel weithin bekannte Widerstandsaktionen, konnten hervorgehoben und wertgeschätzt werden, ohne in den Vordergrund stellen zu müssen oder auch nur zu erwähnen, dass sie nicht von kommunistischen Widerständlern, sondern konkurrierenden Gruppierungen verübt wurden. So waren etwa für die Warschauer Geschichte der Jahre 1939 bis 1944 zentrale Widerstandsakte - der Anschlag auf Franz Bürkle, den Stellvertreter des Pawiak-Kommandanten, sowie die »Aktion beim Arsenal« - in der Ausstellung dargestellt. $^{225}$ Die ausführenden Organisationen - Heimatarmee und »Graue Reihen « (Szare Szeregi) - erwähnte man hingegen nicht. Beide Aktionen wurden vielmehr als konkrete Beispiele der abstrakten Feststellung angeführt, wonach »als Vergeltung für die Verbrechen [...] die Hauptstadt mit Kampfhandlungen [antwortete] «. ${ }^{226}$ Ein weiteres Beispiel ist die Darstellung des gefängnisinternen Widerstandsnetzes im Pawiak, dem überwiegend Mitglieder der ZWZ-AK angehörten. ${ }^{27}$ Die Aktivitäten dieser Zellen schilderte man in der Ausstellung ausführlich, wobei immer wieder der Heldenmut der Protagonisten hervorgehoben wurde. In einem Ausstellungstext hieß es beispielsweise: »Der Großteil der polnischen Gefängnisfunktionäre erfüllte eine bedeutsame Rolle in der konspirativen Arbeit. Unter Lebensgefahr über-

223 Ebd., 95-109.

224 Joanna Wawrzyniak hat hierfür den Ausdruck des »Mythos der Einheit des Widerstands« geprägt. Wawrzyniak: ZboWiD, 171-244.

225 In der Ausstellung fanden sich jeweils Situationspläne beider Widerstandsakte. Scenopis stałej ekspozycji, 88. In der »Aktion beim Arsenal« am 26. März 1943 befreiten Mitglieder der Grauen Reihen einen der ihren, Jan Bytnar, sowie weitere Häftlinge eines Gefängnistransports der Gestapo, der von der Szucha-Allee auf dem Weg zum PawiakGefängnis war. Die Aktion wurde bereits während des Kriegs in der Untergrundpresse und in dem Roman »Kamienie nach szaniec« (Steine auf der Schanze) von Aleksander Kamiński beschrieben. Das Buch wurde nach dem Krieg zur Pflichtlektüre in Schulen, wodurch die Erinnerung an diese Tat in das kollektive Gedächtnis mehrerer Generationen von Polen eingegangen ist.

226 Der zitierte Abschnitt gehörte zu einem Text, der beiden Situationsskizzen vorangestellt war. Scenopis stałej ekspozycji, 88 .

227 Woltanowska, Magdalena: Wystawa »Pawiak 1835-1944«. »Pawiak 1835-1944«. An Exhibition. In: Pawiak 1835-1944. The Guidebook, 19-93, hier 37. 
mittelten sie Kassiber, Untergrundpresse, Lebensmittel, Medizin. « $^{228}$ In der gesamten Schau fand sich jedoch kein einziger Hinweis auf den organisationellen Hintergrund der Aktivisten. ${ }^{229}$

Wenngleich diese Sichtweise nicht in allen Ausstellungen derart deutlich formuliert war, lag sie doch allen untersuchten Schauen in diesem Jahrzehnt zugrunde. Denn neben der Opferdarstellung, die in erster Linie der Illustrierung der Grausamkeit und Unmenschlichkeit der deutschen Besatzer diente, figurierten Polen in den musealen Erzählungen immer als Widerstandskämpfer. So wurde etwa die polnische Bevölkerung in der Ausstellung der Krakauer Pomorska-Straße ausschließlich in der Rolle von Opfern deutscher Gewaltmaßnahmen und Mitgliedern von Widerstandsorganisationen porträtiert. ${ }^{230}$ Andere Rollenbilder oder Aspekte der Besatzungserfahrungen waren bis 1989 in den Ausstellungen nicht zu finden, wie in Kapitel 3 noch näher geschildert wird. Festzustellen ist darüber hinaus, dass in der Darstellung polnischer Kriegs- und Besatzungserfahrungen die Widerstands- und damit Heldendarstellung anteilig in den meisten Ausstellungen den größeren Teil der Ausstellungsfläche und somit auch der musealen Erzählung einnahm. Die heroischen Kämpfer waren es zudem, die mittels Fotografien, kurzen Biogrammen oder Organisationsschemata ihrer Formationen individuell in Erscheinungen traten, während die zivilen Opfer deutscher Massenexekutionen größtenteils namenlos blieben. ${ }^{231}$ Auch hierdurch erschienen erstere im Resultat als Repräsentanten der Gesamtbevölkerung. Zugleich wurden sie durch ihre individualisierte und damit herausgehobene Präsentationsweise auch als Vorbilder bzw. Identifikationsfiguren für die Museumsbesucher inszeniert.

\subsection{Die Evolution des Heldenbildes nach 1989}

Die zu Beginn der 1990er-Jahre neu eröffneten Dauerausstellungen zeigten zunächst nur wenige Veränderungen dieses etablierten Geschichtsbildes. Erste vorsichtige Neuerungen, gewissermaßen Vorboten der künftigen Interpretationswandlungen des Heldenbildes, waren dennoch zu verzeichnen. In der 1991 eröffneten, leicht überarbeiteten Fassung der Dauerausstellung des

228 Scenopis stałej ekspozycji, $82 \mathrm{f}$.

229 Siehe ebd., 82-85.

230 Wroński: Scenariusz wystawy, 3-10.

231 Von den Häftlingen des Pawiak-Gefängnisses etwa, die auf der Rückwand des Ausstellungssaals mit Fotografien und kurzen Biogrammen porträtiert waren, gehörten drei Viertel Untergrundgruppierungen an. Scenopis stałej ekspozycji, 95-109; Informator do ekspozycji, 49-52; Wroński: Scenariusz wystawy, 4f.; Heinrich/Szczepaniak: Muzeum Martyrologii i Walki, 101. 
Pawiak-Museums zeigten sich diese überwiegend in Detailaspekten. So entfernte man den Hinweis auf Warschau als "Zentrum des revolutionären Proletariats « aus dem einleitenden Ausstellungstext; ${ }^{232}$ in der Darstellung der Widerständigkeit der Gefängnisinsassen wurde insgesamt die emphatische Ausdrucksweise zurückgenommen. Etwa bezeichnete man nun die gegenseitige Hilfe der Häftlinge untereinander nicht mehr als »Kampf « gegen das Besatzungsregime, sondern konzentrierte sich auf die psychologische Wirkung dieser verbotenen Aktivitäten, womit diese gewissermaßen in einen zivilen oder zumindest nichtmilitärischen Kontext überführt wurden: ${ }^{233}$

In den grausamen Umständen von Terror und Gewalt war die gegenseitige Hilfe eine Angelegenheit von großer Bedeutung. [...] Ein gutes Wort, eine Nachricht von Verwandten, ein Lied und ein Witz, die Atmosphäre gegenseitigen Wohlwollens - all das gab Hoffnung zum Durchhalten und seelischen Halt. ${ }^{234}$

Die Häftlinge suchten der tragischen Realität zu entkommen und schrieben trotz der Verbote der [Gefängnis-]Leitung heimlich Gedichte, fertigten kleine Gegenstände und Schmuckstücke an, zeichneten. ${ }^{235}$

In der Schau der Abteilung Pomorska-Straße des MHK in Krakau von 1990 waren bereits weitergehende Änderungen gerade im Bereich der Darstellung des Widerstands zu vermerken. So wurde eine Tafel zur »Delegatur der Regierung [im Lande] « (Delegatura Rzadu) neu aufgenommen und damit die Existenz der Exilregierung in London und deren Wirken im polnischen Widerstand erstmals explizit thematisiert. ${ }^{236}$ Unmittelbar darauf folgte eine weitere Neuerung in Form einer Tafel zum "Geheimen Unterricht« (Tajne Nauczanie). ${ }^{237}$ Dieser wurde durch die Unterbringung im Ausstellungsabschnitt, der explizit dem Widerstand gegen das Regime gewidmet war, somit als Teil der aktiven Resistenz der Nation kontextualisiert. Bemerkenswert war ferner die

232 Scenopis stałej ekspozycji, 53; Izdebska: Pawiak 1939-1945, 10.

233 In der Vorgängerversion der Ausstellung hieß es noch über die Häftlinge: »Darüber hinaus hielt ununterbrochen der Kampf darum an, trotz der Bestialität des Feindes sich gegenseitig den Rücken zu stärken, die Gefolterten, Kranken, Gebrochenen zu versorgen, den Glauben an den endgültigen Sieg über den Hitlerismus zu verbreiten. Dieser Kampf brachte Hoffnung.« Scenopis stałej ekspozycji, 80.

234 Izdebska: Pawiak 1939-1945, 132. Dieser Text fand sich auch in der Vorgängerversion der Schau. Dort war er jedoch dem übergreifenden Interpretationsschema des »Kampfes« der Häftlinge im Gefängnis zugeordnet, der in der Fassung von 1991 entfernt wurde. Allein durch die Entfernung einzelner Aussagen wurde somit ein veränderter Kontext der Beschreibungen des Häftlingsalltags geschaffen. Vgl. Scenopis stałej ekspozycji, 82.

235 Izdebska: Pawiak 1939-1945, 133.

236 Titel der Tafel 25. Gasiorowski/Kuler/Natkaniec: Scenariusz wystawy, 10.

237 Titel der Tafel 26. Ebd. 
Ausweitung der Schilderung der Aktivitäten der Heimatarmee: Man fügte zwei Tafeln ein, die zwei zentralen Widerstandsaktionen von AK-Einheiten gewidmet waren: der »Aktion Koppe« und »Aktion Krüger ${ }^{238}$ Die Heimatarmee wurde hierdurch deutlich in den Vordergrund der Widerstandsdarstellung gerückt; ihr waren vier eigene Ausstellungstafeln der Sektion gewidmet, während den übrigen Gruppierungen maximal zwei Tafeln eingeräumt wurden. Damit wurde erstmals die zahlenmäßige Bedeutung der ZWZ-AK als größter Untergrundorganisation der Region berücksichtigt und vermittelt. ${ }^{239}$ Auch erweiterte man die Widerstandserzählung um weitere Organisationen: So wurden die Sozialisten und die rechten Nationaldemokraten erstmals in der Schau erwähnt. ${ }^{240}$ Neu hinzu kam ebenso eine Tafel zur Jüdischen Kampforganisation (ŻOB), wenn auch ihre Darstellung noch losgelöst vom spezifischen Verfolgungskontext ihrer Mitglieder sowie ihrer Widerstandsziele erfolgte. $^{241}$

Trotz dieser spürbaren Anpassungen kann von einer umfangreichen »Dekommunisierung « der Besatzungserzählungen nicht gesprochen werden. Die linken Widerstandsgruppierungen, allen voran die Volksgarde und die Volksarmee, blieben zu diesem Zeitpunkt wichtige Bestandteile der Widerstandserzählungen. Im MHK wurde 1990 sogar eine neue Tafel aufgenommen, auf der die politische Führung dieser Gruppen, die Polnische Arbeiterpartei, eigens dargestellt war. ${ }^{242}$ Eine Bewertung oder eher Umwertung dieser Organisationen, etwa unter dem Gesichtspunkt ihres Einflusses auf die Nachkriegsentwicklung des Landes, fand jedoch nicht statt.

Auffällig ist eine weitere Entwicklung: Den Verteidigungskämpfen der polnischen Armee im September 1939 wurde nun zum Teil Platz im Ausstellungsnarrativ eingeräumt. Im MHK beispielsweise thematisierte man erstmals die Armee »Krakau« mit ihrem Anführer General Antoni Szylling. Dar-

238 Tafel 32: »Aktion Krüger - 20. April 1943« und Tafel 33:»Aktion Koppe - 11. Juli 1944«. Ebd., $11 \mathrm{f}$. Mit den Schlagworten werden die Anschläge auf die SS- und Polizeiführer im GG Friedrich Wilhelm Krüger und Wilhelm Koppe bezeichnet, die AK-Einheiten in Krakau ausführten; beide schlugen fehl.

239 Chwalba: Dzieje Krakowa, Bd. 5, 278-298. Vgl. auch Jeżowski, Grzegorz: Polskie Państwo Podziemne [Der Polnische Untergrundstaat]. In: Bednarek, Monika u. a. (Hg.): Kraków czas okupacji 1939-1945 [Kraków - Die Besatzungszeit 1939-1945]. Kraków 2010, 362-391, hier 363, 371-373.

240 Beiden Gruppierungen war jeweils eine Tafel gewidmet. Tafel 27: PPS-WRN (Polska Partia Socjalistyczna - Wolność, Równość, Niezawisłość/»Polnische Sozialistische Partei Freiheit, Gleichheit, Unabhängigkeit«); Tafel: 29: Nationaldemokraten (Narodowcy). Ebd., $10 \mathrm{f}$. Auch im MHW erweiterte man im Zuge der Umgestaltung einiger Teile der Dauerausstellung in den Jahren 1990/91 die Darstellung des Widerstands. ŻmudaLiszewska: Muzeum Historyczne, 61.

241 Vgl. Teil 2, Kapitel 1.1.

242 Tafel 35: PPR. Präsentiert waren darauf die Parteisekretäre der regionalen Parteistrukturen. Gąsiorowski/Kuler/Natkaniec: Scenariusz wystawy, 13. 
gestellt wurden auch die allgemeine Mobilmachung, Truppenbewegungen bei Kriegsausbruch sowie polnische Armeeeinheiten im Feld. ${ }^{243}$ Die legitime Verteidigung Polens durch die Armee - und damit implizit den Einsatz der Vorkriegsregierung zum Zeitpunkt des Kriegsausbruchs - stellte diese Ausstellung somit erstmals heraus. Innerhalb der untersuchten Dauerausstellungen thematisierten vor 1989 nur wenige überhaupt den September-Feldzug. Hierzu gehörte das MHW, das die Kriegsereignisse auch auf das gesamte polnische Staatsgebiet bezogen darstellte - jedoch unter Auslassung des Einmarsches der Roten Armee ab dem 17. September 1939. ${ }^{244}$ Im Zuge der Umgestaltung dieses Themensaals in den Jahren 1990/91 wurde nun auch der Angriff der Sowjetunion erstmals explizit benannt und dargestellt. ${ }^{245}$ Bereits in diesen frühen, nur leicht angepassten Ausstellungen, die kurz nach der Wende eröffnet wurden, zeigten sich damit bereits zentrale Entwicklungsmomente des musealen Heldennarrativs der kommenden Jahre. Eine deutliche Ausprägung erreichte dieses schon in den Schauen, die bis 2003 eröffnet wurden und damit im Rahmen der erstmaligen umfassenden Um- oder Neugestaltung historischer Dauerausstellungen nach 1989. Auffällig war dabei, wie stark sich das in den unterschiedlichen musealen Erzählungen vermittelte Bild polnischer Kämpfer ähnelte.

In allen seit der zweiten Hälfte der 1990er-Jahre eröffneten Ausstellungen nahm die militärische Verteidigung der jeweiligen Stadt und Region im September 1939 nun eine zentrale Stelle ein. Die polnischen Streitkräfte wurden somit in das Heldennarrativ miteinbezogen: Nicht allein der deutsche Angriff und dessen Ergebnis, die Besetzung des Landes, wurden geschildert, wie es noch vor 1989 üblich war. Die führenden Organisatoren der militärischen Verteidigung der Regionen wurden nun zu herausragenden Protagonisten; auch die Repräsentanten der zivilen Stadtverwaltungen und ihr Einsatz

243 Den Ereignissen vom 31. August 1939 (der allgemeinen Mobilmachung) bis zur Besetzung Krakaus durch deutsche Truppen waren die ersten fünf Tafeln und zwei Vitrinen der Ausstellung gewidmet. Die Präsentation umfasste ein Plakat, das über die Mobilmachung informierte, Skizzen militärischer Lagepläne, Fotografien von Armeeeinheiten sowie Militaria. Ebd., $1 \mathrm{f}$. In der Schau des Gefängnismuseums Pawiak wurde dieser Themenaspekt 1991 noch nicht aufgenommen. Wie bereits dargestellt, handelte es sich bei dieser Ausstellung um eine lediglich wenig umgestaltete Version der Vorgängerpräsentation, die nur minimale inhaltliche Anpassungen erfahren hatte. Vgl. Izdebska: Pawiak 1939-1945.

244 Dem Zeitraum 1. bis 28. September 1939 war der erste Saal der Sektion zum Zweiten Weltkrieg, Saal 56, gewidmet. Siehe: Informator do ekspozycji, 46-48. Daneben fanden sich die militärischen Ereignisse des Septembers 1939 einzig im Museum Radogoszcz. Heinrich/Szczepaniak: Muzeum Martyrologii i Walki, 98.

245 Erwähnung fand die Besetzung der östlichen Gebiete Polens durch die Rote Armee im einleitenden Text des Saals; zudem wurde sie kartografisch dargestellt. MHW, Saal 46. Zur Darstellung des Kriegsanfangs vor und nach 1989 siehe Teil 1, Kapitel 2.1. 
während des Angriffs erhielten zunehmend Platz. Diese Personen waren als Vertreter der in der Geschichtspolitik der VRP negativ bewerteten Vorkriegsregierung vor 1989 noch weitgehend ignoriert worden. ${ }^{246}$ In den neuen Präsentationen fungierten sie nun als Symbolfiguren der legitimen Verteidigung des Landes gegen die illegitime Aggression der Deutschen und zunehmend auch der Sowjetunion. ${ }^{247}$ In der 2001 eröffneten neuen Dauerausstellung des Gefängnismuseums Pawiak in Warschau etwa wird der Kriegsausbruch am Beispiel des Angriffs auf den polnischen Stützpunkt auf der Westerplatte am 1. September 1939 ausführlich geschildert, eines Ereignisses, das in der polnischen kollektiven Kriegserinnerung von hoher Symbolkraft ist. ${ }^{248}$

Als exemplarisch für die inzwischen große Bedeutung des Kriegsbeginns und der polnischen Armee in den musealen Erzählungen kann die Dauerausstellung des Museums Radogoszcz aus dem Jahr 2003 gelten, in der das Thema verhältnismäßig großen Raum einnahm. ${ }^{249}$ Die Darstellung setzte dabei noch vor dem 1. September 1939 an, mit der zunehmenden Kriegsgefahr seit Ende der 1930er-Jahre, im Angesicht derer umfangreiche Werbekampagnen für Kriegsanleihen zur Ausrüstung des Militärs stattfanden, was anhand des Łódźer Beispiels geschildert wurde. ${ }^{250}$ Den eigentlichen Kriegsausbruch illus-

246 Die Ausnahme bildete hier das MHW, dessen Schilderung des September 1939 an zentraler Stelle sowohl den Stadtpräsidenten Warschaus Stefan Starzyński und den Organisator der Arbeiterbataillone zur Verteidigung der Stadt Mieczysław Niedziałkowski nannte als auch den militärischen Befehlshaber der Verteidigung der Stadt General Walerian Czuma und den Anführer der Armee »Warschau« Juliusz Rómmel. Informator do ekspozycji, $46 \mathrm{f}$.

247 In der räumlich sehr begrenzten Dauerausstellung des Historischen Museums der Stadt Lublin ist eine ganze Ausstellungstafel den führenden Vertretern der Stadtverwaltung und des Militärs, die die Verteidigung Lublins organisiert hatten, gewidmet, auf der sie mit Fotografien und knappen Biogrammen dargestellt werden. Die Angaben zu jeder Person sind jeweils mit goldenen Rahmen versehen, wodurch sie als positive und zugleich herausragende Protagonisten der Kriegsereignisse "geadelt» werden. MLL-Krakauer Tor, Sektion "Zweiter Weltkrieg".

248 Präsentiert werden seitenlange Berichte über den deutschen Angriff auf die Westerplatte mit großformatigen Fotografien und Zeichnungen in zwei englischen und einer amerikanischen Zeitschrift. MNW-Pawiak, Sektion »Die vierte Teilung Polens«.

249 Die erste Sektion zu Kriegsgefahr und Kriegsbeginn, d.h. den Zeitraum bis zum Einmarsch der deutschen Truppen in die Stadt, umfasste fast ein Fünftel der Ausstellung; ihr waren 16 von 86 Ausstellungstafeln gewidmet. MTNŁ-Radogoszcz, Sektion »Im Angesicht der Bedrohung", Sektion zum September 1939 (ohne Titel). Hier muss darauf hingewiesen werden, dass die vergleichsweise materialreiche Darstellung des Kriegsanfangs in dieser Schau aufgrund der großen Ausstellungsfläche möglich war. In kleineren Ausstellungen, die zwischen 1995 und 2003 eröffnet wurden, ist jedoch anteilig ein ähnliches Verhältnis bei der Schilderung des Kriegsbeginns und der polnischen Kämpfe gegen die Aggressoren im September 1939 zu beobachten.

250 Präsentiert wurden Plakate, die einzelne Kundgebungen für Sammelaktionen in der Stadt ankündigen, sowie Titelseiten der Zeitschrift Łódźw Ilustracjach (Łódź in Bildern), die solche Aktionen und die Übergabe angekaufter Ausrüstung an einzelne Armee- 
trierte man mittels eines Plakats der Allgemeinen Mobilmachung sowie des Textes der Ansprache des Präsidenten, Ignacy Mościcki, in der er den deutschen Angriff und damit den Kriegsausbruch verkündete. Ebenso fanden sich Plakate, die die Bevölkerung zum Zusammenhalt und zum Kampf gegen den Aggressor aufrufen. ${ }^{251}$ Diese Objekte sind seit der zweiten Hälfte der 1990erJahre zu ikonischen Elementen der musealen Darstellung des Themas avanciert und finden sich in den meisten Schauen zu diesem Themenbereich wieder. ${ }^{252}$ Die Kämpfe im September schließlich wurden anhand der Zusammensetzung einzelner polnischer Armeeeinheiten und ihrer Führungskräfte aus der Region Łódź geschildert - schriftlich, grafisch und mittels Fotografien - ebenso wie mittels einzelner zentraler Schlachten. ${ }^{253}$ Auffällig war hier die personalisierte Form der Präsentation: Die militärischen und politischen Anführer standen im Vordergrund. Sie waren diejenigen, die namentlich und oft auch mit Porträtaufnahmen in Erscheinung traten. Einzelschicksale von Soldaten unterer Ränge verschwanden dagegen hinter summarischen Angaben von Truppenstärke und Opferzahlen ebenso wie hinter anonymen Gruppenaufnahmen. ${ }^{254}$

Diese Darstellungsweise unterscheidet sich bemerkenswert von derjenigen des anderen zentralen historischen Museums der Stadt, des Stadtmuseums Łódź. In dessen 1998 neueröffneter Dauerausstellung fanden die Ereignisse des September 1939 keinerlei Erwähnung. ${ }^{255}$ Ganz im Einklang mit

einheiten in der Stadt dokumentierten. MTNŁ-Radogoszcz, Sektion »Im Angesicht der Bedrohung".

251 Der Text auf den Plakaten lautete "Zu den Waffen! Geschlossen und vereint besiegen wir den Feind!« (Do broni! Zwarci i zjednoczeni zwycieżymy wroga!) und »Untersteh dich!« (Wara!). Ebd.

252 Das Plakat der Allgemeinen Mobilmachung fand sich prominent in der Schau der Pomorska-Straße von 1998 und ist im Pawiak-Museum bis heute zu sehen. MHKPomorska-Straße, Tafel 1. In der Präsentation des Pawiak-Museums von 2001 wird das Titelblatt des Kurier Warszawski (Warschauer Kurier) vom 1. September 1939 gezeigt, in dem die Ansprache des Präsidenten abgedruckt ist. Daneben werden die gleichen Plakate wie im Museum Radogoszcz prominent ausgestellt. Die gleichen Elemente finden sich auch in den jüngsten, umfangreichen Präsentationen des MPW und der SchindlerFabrik in Krakau. MPW, Sektion 6: Besatzung; MHK-Schindler-Fabrik, Sektion 3: Wartesaal, Sektion 4: Kriegsausbruch.

253 Hierzu gehören die Kämpfe an der Mokra (1. September 1939), an der Bzura (9. bis 20. September 1939) und um die Festung Modlin (10. bis 29. September 1939). MTNŁRadogoszcz, Sektion zum September 1939 (ohne Titel).

254 Im Museum Radogoszcz wurden die Zahlen der Bataillone, Regimenter und weiterer Einheiten der deutschen und polnischen Armeen jeweils aufgeführt; in ähnlicher Weise wurden die Todesopfer und Verletzten aufgezählt. Ebd. In analoger Weise erfolgte die Darstellung der Zusammensetzung und Einsätze der Armee »Krakau« in der Schau der Abteilung Pomorska-Straße im MHK. MHK-Pomorska-Straße, Tafel 3.

255 Mittels eines Plakats wurde lediglich die Berufung des Bürgerkomitees nach Abzug der polnischen Truppen eingeführt. Abschnitt »Lodsch - Litzmannstadt«. MMŁ, Sektion »Lodsch - Litzmannstadt«. 
der Präsentationspraxis der Volksrepublik setzte die Erzählung vom Zweiten Weltkrieg mit dem Ergebnis des September-Feldzugs ein - in diesem Fall der Inkorporation des Großteils der Region in das Deutsche Reich im Oktober 1939. ${ }^{256}$ Weder der sowjetische Angriff auf Polen, die militärischen Auseinandersetzungen mit den deutschen Truppen in der Region noch die involvierten polnischen Streitkräfte fanden Erwähnung. Eine mögliche Begründung für die Auslassung dieser Elemente ist die äußerst kleine Ausstellungsfläche, die eine starke Konzentration auf lokale Themen und Ereignisse notwendig machte. Trotzdem ist der fehlende Verweis auf die Verteidigung der Stadt Anfang September im Vergleich mit den anderen Präsentationen aus diesem Zeitraum auffällig. ${ }^{257}$ Eine weitere Überlegung drängt sich hier daher auf: Wie bereits in Kapitel 3.1 des zweiten Teils geschildert, wurden für diesen Abschnitt der Dauerausstellung Materialien aus einer Sonderausstellung von 1985 wiederverwendet. Der einleitende Thementext der Sektion mit dem Titel »Lodsch - Litzmannstadt« war eine gekürzte Fassung einer Broschüre zur Sonderausstellung »Łódź w planach eksterminacyjnych okupanta hitlerowskiego 1939-1945 r.« (Łódź in den Vernichtungsplänen des hitleristischen Besatzers 1939-1945. ${ }^{258}$ Mehr noch gab es hier eine personelle Kontinuität: Der für die Ausstellung von 1998 zuständige Kurator hatte bereits an der Ausstellung 1985 mitgearbeitet und den besagten Text verfasst. Eine Perspektiverweiterung unter stärkerer Berücksichtigung der militärischen Ereignisse im September 1939 fand hier nicht statt, die Erzählung zu den Jahren 1939 bis 1945 setzte wie zuvor mit dem Ergebnis der Kämpfe, also dem Beginn der deutschen Besatzung ein.

In einem anderen thematischen Bereich passte sich die Schau jedoch den nach 1989 veränderten Argumentationsmöglichkeiten an: Bei der Darstellung des Widerstands standen die Heimatarmee und ihre Vorgängerorganisationen, der »Dienst für Polens Sieg« (Służba Zwycięstwu Polski, SZP) und der »Verband für den Bewaffneten Kampf« (ZWZ), klar im Vordergrund. ${ }^{259}$

256 Mit dieser Information setzte der Thementext »Lodsch - Litzmannstadt« ein. Ebd.

257 So ist etwa auch die Ausstellungsfläche in der Dauerausstellung des Historischen Museums der Stadt Lublin sehr begrenzt. Dennoch wurde hier 1995 den Kämpfen im September verhältnismäßig viel Platz eingeräumt.

258 [Budziarek, Marek]: Łódź w planach eksterminacyjnych okupanta hitlerowskiego 19391945 [Broschüre]. Łódź 1985. AMMŁ, teczka 6/60, Dz. Historii, o.S.

259 Das Thema »Untergrundbewegung« (Konspiracja) nahm in der Ausstellung des Łódźer Stadtmuseums von 1998 den kleinsten Abschnitt ein. Dies entsprach durchaus den eingeschränkten Handlungsspielräumen der Untergrundbewegungen in der von Deutschen und Volksdeutschen stark kontrollierten Stadt. Die Sektion umfasste einen längeren Bereichstext sowie ein Plakat und ein Gemälde, die Todesurteile bzw. die Exekution von enttarnten Widerstandskämpfern illustrierten. Abschnitt »Untergrundbewegung«. MMŁ, Sektion »Lodsch - Litzmannstadt«. 
Die Existenz eines linken Untergrunds wurde zwar erwähnt, jedoch auf dessen deutlich geringere Bedeutung im Vergleich zur AK hingewiesen. ${ }^{260}$ Auch in anderen Ausstellungen wurde und wird auf einzelne kommunistische Gruppierungen Bezug genommen; diese spielen jedoch - ebenso wie weitere, außerhalb der AK stehende Organisationen - in allen eine untergeordnete Rolle. ${ }^{261}$ Dies entspricht auch der anteilig geringen Bedeutung des kommunistischen Widerstands in den ins Deutsche Reich eingegliederten Gebieten sowie im Generalgouvernement. ${ }^{262}$ Am meisten Platz wurde anderen Gruppierungen als der AK noch in der Pomorska-Straße in Krakau eingeräumt. Sowohl die »Sozialistische Partei Polens - Freiheit, Gleichheit, Unabhängigkeit« (Polska Partia Socjalistyczna - Wolność, Równość, Niezawisłość, PPSWRN), die Bauernbataillone, die rechten »Nationalen Streitkräfte (Narodowe Sity Zbrojne, NSZ) als auch die Volksgarde bzw. spätere Volksarmee wurden dort mit ihren führenden Vertretern und Grafiken ihrer jeweiligen regionalen Organisationsstruktur präsentiert. ${ }^{263}$

Den Gegenpol bildet die Präsentation des Lubliner Historischen Museums von 1995: Linke und kommunistische Widerstandsgruppen werden dort nun gar nicht mehr erwähnt. Einzig die AK tritt als Akteur in Erscheinung und

260 Bereichstext »Untergrundbewegung«, Abschnitt »Untergrundbewegung«. Ebd.

261 Im Martyrologiemuseum Radogoszcz wurden in erster Linie die AK und mit ihr kooperierende Gruppen, v.a. die Grauen Reihen und der »Eidechsenverband« (Związek Jaszczurczy), an herausragender Stelle thematisiert; in einer Vitrine schilderte man auch kurz die Tätigkeit der »Polnischen Kampforganisation `Freiheit« (später »Polnische Bewaffnete Organisation«; Polska Organizacja Bojowa »Wolność»bzw. Polska Organizacja Zbrojna). Neben Informationen zur Entstehung der einzelnen Gruppen und einer Auswahl der von ihnen verbreiteten Untergrundpublikationen lag ein Schwerpunkt der Darstellung auf der Vorstellung der jeweiligen Anführer mittels einer Fotografie und kurzen Informationen zu ihrer Widerstandstätigkeit während der Besatzung. Einen weiteren Fokus bildete die namentliche Aufführung identifizierter Opfer von Massenexekutionen und in Konzentrationslager verschickter Mitglieder dieser Organisationen. Die Tätigkeit der BCh und GL-AL in der Region erwähnte man in zwei Vitrinen über einzelne Objekte. MTNŁ-Radogoszcz, Sektion »Wir werden siegen«. Im Gefängnismuseum Pawiak wird der aktive Widerstand gegen die Deutschen in erster Linie über zentrale Aktionen der AK illustriert, allen voran die Aktion beim Arsenal, den Anschlag auf den stellvertretenden Kommandanten des Pawiak Franz Bürkl und den Anschlag auf Franz Kutschera, SS- und Polizeiführer im Distrikt Warschau. MNWPawiak, Sektionen »Aktion beim Arsenal«, »Anschläge auf die Henker des Pawiak«.

262 Mazur: Der Widerstand im Generalgouvernement, 423.

263 Jeder dieser Gruppierungen war eine Ausstellungstafel gewidmet, und zwar sowohl in der Präsentation von 1990 als auch in ihrer überarbeiteten Fassung von 1998. Gasiorowski / Kuler/Natkaniec: Scenariusz wystawy, 10 f., 13 f.; MHK-Pomorska-Straße, Tafel 27-30. Die SZP-ZWZ-AK erhielt zwei Tafeln. Zudem wurden die zwei bekanntesten Aktionen von AK-Einheiten in Krakau, die »Aktion Krüger« und »Aktion Koppe« auf je einer Tafel vorgestellt. Gąsiorowski/Kuler/Natkaniec: Scenariusz wystawy, $11 \mathrm{f}$.; MHK-Pomorska-Straße, Tafel 25, 26. 
zwar bei der Schilderung der politischen Situation beim Abzug der deutschen Truppen: Unter dem Stichwort »Juli $1944 «^{264}$ werden zunächst Władysław Cholewa, der Delegierte der Exilregierung im Bezirk Lublin, und Kazimierz Tumidajski, der Anführer der AK im Bezirk Lublin, vorgestellt, mit jeweils einem von ihnen unterzeichneten zentralen Dokument, in dem der Führungsanspruch der Londoner Exilregierung und ihrer Vertreter im Land bekräftigt wird. ${ }^{265}$ Direkt im Anschluss finden sich Fotos der »Ankunft der Mitglieder des PKWN aus Moskau ${ }^{266}$ sowie das Manifest des PKWN. Damit wird den Besuchern die Uneindeutigkeit der Lage und nicht zuletzt der politischen Optionen bei Abzug der deutschen Truppen im Sommer 1944 vermittelt. $^{267}$ Zudem erfolgt hier indirekt, durch den Hinweis auf ihre »Ankunft [...] aus Moskau«, die Markierung des PKWN als »Import« aus der Sowjetunion und damit als abhängig von dieser Macht. Die Schau vollzieht damit eine deutliche Abkehr von der teleologischen Erzählung ihrer Vorgängerin, in der der gemeinsame Kampf von polnischen und sowjetischen Staatsbürgern in der Roten Armee scheinbar folgerichtig in die sozialistische Nachkriegsentwicklung Polens unter dem Stichwort »Lublin als Hauptstadt des PKWN ${ }^{268}$ mündete. Zugleich ist sie die einzige Präsentation dieses Zeitraums, in der die Konkurrenz und der Konflikt zwischen diesen zwei zentralen Akteuren des polnischen Untergrunds (der Londoner Exilregierung und der AK auf der einen und der polnischen Kommunisten, die von der UdSSR protegiert wurden, auf der anderen Seite) um die politische Zukunft des Landes dargestellt werden.

In den anderen untersuchten Präsentationen fanden sich keinerlei Hinweise auf Konflikte innerhalb des Widerstands. Im Gegensatz dazu wurde durch die reine Aufzählung und Nebeneinanderstellung der einzelnen Gruppierungen, wie sie etwa in der Pomorska-Straße in Krakau erfolgte, oder die Betonung der Zusammenarbeit einzelner Gruppen im Museum Radogoszcz eher der Eindruck eines verbreiteten Zusammenhalts sowie einer Zusammenarbeit innerhalb des Untergrunds suggeriert. Dass die einzelnen Gruppen zu-

264 Titel der Ausstellungstafel, die diese Sektion einleitet. MLL-Krakauer Tor, Sektion "Zweiter Weltkrieg".

265 Es handelt sich dabei um den »letzte[n] Befehl von Oberst Kazimierz Tumidajski« sowie einer »Amtlichen Bekanntmachung« Cholewas. Die Zitate stammen aus den Überschriften beider Dokumente. Ebd.

266 Objektbeschriftung zu einer Fotografie. Ebd., Vitrine 5.

267 Dies wird insbesondere auf der letzten Ausstellungstafel deutlich, auf der neben Fotografien einer Militärparade polnischer Armeeeinheiten (im Rahmen der sowjetischen Streitkräfte) auch die Abbildung von »Soldaten der AK im Juli 1944 vor dem Gebäude der Delegatur der [Londoner Exil-]Regierung« in Lublin zu sehen ist. Ebd. Zur Darstellung des Endes der deutschen Besatzung in dieser Ausstellung siehe auch Teil 1, Kapitel 1.2.

268 Titel der Ausstellungstafel. Wystawa: Historia miasta Lublina. 
einander auch in einem politischen Konkurrenzverhältnis standen, wurde mit der Ausnahme des Historischen Museums der Stadt Lublin - in keiner der Ausstellungen thematisiert. Insgesamt erschien der bewaffnete Widerstand gegen die Deutschen in den meisten Schauen somit als geschlossene Bewegung, die sich aus zwar vielfältigen, aber gemeinsam agierenden Gruppen zusammensetzte - eine bemerkenswerte Kontinuität der Darstellungspraxis, wie sie in den 1980er-Jahren zu beobachten war.

Eng verknüpft mit der nun dominierenden Position der AK in den Widerstandserzählungen war auch die Inklusion der Londoner Exilregierung und des unter ihrer Führung stehenden "Polnischen Untergrundstaates ${ }^{269}$ in die musealen Narrative. Galt in den Ausstellungen vor 1989 noch klar der kommunistische Widerstand und das mit ihm verbundene PKWN als legitime Vertretung polnischer Staatlichkeit während der Besatzung, ging diese Position in den Präsentationen der 1990er-Jahre nun eindeutig an die Exilregierung im Westen über. In allen Präsentationen sticht dabei die Betonung der Legitimität eben dieser Regierung und ihrer Vertreter in den besetzten Territorien hervor. Im Stadtmuseum von Łódź war etwa vom »bewaffnete[n] Łódźer Untergrund, der die legale polnische Regierung in der Emigration anerkannte die Rede. ${ }^{270}$ In der Pomorska-Straße in Krakau setzte die Widerstandserzählung sogar beim »Untergrundstaat« (Państwo Podziemne) an. ${ }^{271}$ Direkt neben dessen Darstellung war großformatig das Symbol des »Kämpfenden Polens« (Polska Walcząca), der berühmte Anker, platziert. ${ }^{272}$ Damit erschien die folgende Vorstellung der einzelnen Widerstandsorganisationen der übergreifenden Struktur des Untergrundstaates zugeordnet. Der Verweis auf den Untergrundstaat fungierte damit innerhalb des Widerstandsnarrativs als Element, das eine vermeintliche Einheit der Untergrundgruppierungen und damit implizit der gesamten Nation - im Kampf gegen die Besatzer ver-

269 Der Ausdruck »Polnischer Untergrundstaat« (Polskie Państwo Podziemne, PPP), der gegenwärtig in der Wissenschaft, aber auch der breiten Publizistik etabliert ist, fand in der polnischen Historiografie erst seit den 1980er-Jahren verstärkt Verwendung. Mazur: Der Widerstand im Generalgouvernement, 405.

270 Bereichstext »Untergrundbewegung«. MMŁ, Sektion »Lodsch - Litzmannstadt«. Im Museum Radogoszcz in Łódź wurde die herausragende Bedeutung der Exilregierung durch den großformatig abgebildeten Eid der Heimatarmee vermittelt, in dem unter anderem »dem Präsidenten der Republik und den Befehlen des Obersten Führers sowie des von ihm bestimmten Anführers der Heimatarmee« Gehorsam geschworen wurde. MTNŁ-Radogoszcz, Sektion »Wie werden siegen«.

271 Titel der Ausstellungstafel. MHK-Pomorska-Straße, Tafel 22.

272 MHK-Pomorska-Straße, Tafel 23. Auch in der Schau von 1990 leitete das Zeichen des Kämpfenden Polens die Sektion zum Widerstand ein, zusammen mit einem Zitat von General Władysław Sikorski, dem Premierminister der Londoner Exilregierung, in dem er "alle Polen, wo auch immer sie sich befinden« zum Kampf für Polens Freiheit aufrief. Gąsiorowski/Kuler/Natkaniec: Scenariusz wystawy, 8. 
mittelte. Als dessen Repräsentanten erhielten der Delegierte im Lande bzw. die Delegierten einzelner Bezirke eine herausgehobene Position. ${ }^{273} \mathrm{Im}$ Gefängnismuseum Pawiak wird die Person des im Gefängnis inhaftierten Delegierten der Regierung im Lande Jan Piekałkiewicz - der bis dato lediglich als einer unter vielen Inhaftierten vorkam - nun auch buchstäblich herausragend präsentiert, auf einer der in der Mitte der Ausstellungshalle positionierten fünf Glaswände, auf denen zentrale Protagonisten der musealen Erzählung mit einem umfassenden Biogramm und lebensgroßen Fotografien porträtiert werden. Dem Phänomen des Untergrundstaates ist daneben eine eigene Sektion der Ausstellung gewidmet, in der insbesondere auch sein Aufbau, mit der Londoner Exilregierung an seiner Spitze, dargestellt ist. ${ }^{274}$

Die Umwertung des legitimen Repräsentations- und Führungsanspruchs während der Besatzung, das heißt die Abkehr vom PKWN hin zur Exilregierung im Westen, spiegelte sich auch in der im Laufe der 1990er-Jahren erfolgenden Anpassung der verwendeten Termini: Zunehmend bezeichnete man die Mitglieder des Untergrunds, vor allem die Kämpfer der AK-Einheiten und mit ihr verbündete Gruppierungen, explizit als »Soldaten«. Der Begriff markierte sie als Vertreter einer legalen Staatlichkeit und damit Repräsentanten der im September 1939 zerschlagenen polnischen Armee. Hierdurch wurde zugleich ihr Bezug zur Exilregierung unterstrichen, als legitimer und völkerrechtlich anerkannter, mithin legaler Repräsentanz des besetzten Landes und Oberbefehlshabers ihres Militärs. Die Widerstandskämpfer, die nach militärischem Vorbild organisiert waren, wurden somit in den Schauen als reguläre Armee im Untergrund präsentiert, mit der Londoner Exilregierung als ihrer politischen Führung. ${ }^{275}$ Zwar wurde die Bezeichnung in den 1980erJahren bereits teilweise in den musealen Erzählungen eingesetzt - so etwa im Historischen Museum der Hauptstadt Warschau -, doch lag dort der wesentliche Akzent noch auf dem Kampf der »Partisanen« und damit irregulären und nicht mit Erkennungszeichen versehenen Einheiten. ${ }^{276}$ Der Begriff dominierte in der sozialistischen Geschichtspolitik in Anlehnung an den Mythos des sowjetischen Partisanenkampfes und folglich auch der Entstehungsgeschichte des polnischen kommunistischen Untergrunds während

273 Im MHK etwa wurden der Delegierte für den Bezirk Krakau sowie Führungsfiguren des Untergrundstaates in Krakau präsentiert, zusammen mit einem Diagramm der Organisationsstruktur der Regierungsdelegatur. MHK-Pomorska-Straße, Tafel 22.

274 Gezeigt wird ein Schema des Aufbaus von "Poland's Underground State«, das in der New Yorker The Polish Review im Juli 1944 erschienen ist. MNW-Pawiak, Sektion »Polnischer Untergrundstaat«.

275 Dies entsprach auch dem zeitgenössischen Selbstverständnis der ZWZ-AK. Borodziej: Geschichte Polens, 214.

276 Barth, Boris: »Partisan« und »Partisanenkrieg« in Theorie und Geschichte. Zur historischen Dimension der Entstaatlichung von Kriegen. In: Militärgeschichtliche Zeitschrift 64/ 1 (2005), 69-100, hier 69-71, 91. 
des Kriegs. ${ }^{277}$ Der zunehmende Verzicht auf diesen Terminus nach der Wende von 1989 kann daher in erster Linie als Abkehr von volksrepublikanischen Geschichtsdeutungen und den durch sie legitimierten Machtansprüchen der polnischen Kommunisten gewertet werden. Diese Betonung der Legitimität des bewaffneten Kampfes, den die Bezeichnung »Soldaten « für die Mitglieder des Untergrunds transportierte, diente daneben auch der deutlichen Abgrenzung der polnischen Widerstandskämpfer von ihren Feinden. Während erstere als militärische Kräfte einer international anerkannten Exilregierung als ehrenhafte Soldaten porträtiert wurden, sprach man den deutschen (und zunehmend auch sowjetischen) Besatzern diese Ehrenhaftigkeit und Legitimität der Gewaltanwendung ab, was implizit durch die Art und Weise ihrer Bezeichnung und Kontextualisierung vermittelt wurde. ${ }^{278}$

In denjenigen neuen Ausstellungen nach 1989, in denen die Wortwahl der "Partisanen" weiterhin Anwendung fand, scheint dies in erster Linie mit personellen Kontinuitäten auf Seiten der zuständigen Kuratoren verbunden gewesen zu sein, so etwa in den zwei Łódźer Institutionen. ${ }^{279}$ Die Mitarbeiter griffen hier - höchstwahrscheinlich weitgehend unreflektiert - auf vertraute und lang etablierte Sprachpraxen zurück. Dennoch wurde auch in diesen Institutionen, so etwa im Museum Radogoszcz, der Führungsanspruch der mit der Exilregierung verbundenen Kräfte und ihre militärische Organisation, die sie als legitime Repräsentanten der polnischen (Vorkriegs-)Armee im besetzten Land markierte, offensiv vermittelt: An herausragender Stelle zeigte man in der Łódźer Schau den Eid der Soldaten der Heimatarmee, mit dem »der Republik Polen, [...] dem Präsidenten der Republik und den Befehlen des Oberbefehlshabers sowie des durch ihn bestimmten Anführers der Heimatarmee die Treue geschworen wurde. ${ }^{280}$ Die Sektion zum Widerstand begleiteten zudem großformatige Fotografien, die allesamt einheitlich uniformierte Untergrundeinheiten zeigten. Bei den umfangreichen Listen exekutierter Mitglieder der Gruppierungen wurden die Einzelpersonen fast aus-

277 Vgl. etwa Wawrzyniak: ZBoWiD, 257-262.

278 Siehe auch Teil 1, Kapitel 1.

279 Im Stadtmuseum Łódź sprach man bei der Darstellung des Widerstands im Bereichstext "Untergrundbewegung« zu gleichen Teilen sowohl von »Partisaneneinheiten«, der »Untergrundbewegung " (konspiracja) als auch "Soldaten dieser Untergrundarmee«. Der zuständige Kurator der Sektion, Marek Budziarek, hatte für die Dauerausstellung auf eigene Arbeiten im Rahmen einer Sonderausstellung aus dem Jahr 1985 zurückgegriffen, wie bereits in Teil 2, Kapitel 3.1 aufgezeigt wurde. In der Schau des Museums Radogoszcz dominierte zwar der Begriff »Soldaten«; immer wieder war bei der Darstellung des Widerstands jedoch auch die Rede von »Partisanen«. Auch an dieser Präsentation haben maßgeblich Mitarbeiter mitgewirkt, die bereits seit Jahrzehnten im Museum arbeiten, darunter Ryszard Iwanicki. Interview mit Ryszard Iwanicki, Mitarbeiter der Abteilung Radogoszcz des MTNŁ, am 2. November 2010.

280 MTNŁ-Radogoszcz, Sektion »Wir werden siegen«. 
schließlich als "Soldaten" und "Offiziere« vorgestellt; Wert legte man auch auf die Nennung ihres jeweiligen militärischen Ranges innerhalb der Untergrundarmee - ${ }^{281}$ eine Praxis, die die Widerstandsdarstellungen bis in die Gegenwart prägt.

Im Gegenzug wurde nun die politische Führung des kommunistischen Widerstands kaum mehr erwähnt. In der Krakauer Pomorska-Straße entfernte man für die Präsentation von 1998 die Ausstellungstafel zur PPR, die 1990 noch neu hinzugekommen war. In den übrigen Präsentationen dieses Zeitraums wurde bzw. wird die PPR wenn überhaupt, dann beiläufig in Biogrammen einzelner Widerstandskämpfer genannt; umfassender geschildert wurden lediglich die Aktivitäten ihres militärischen Arms, der GL-AL. Wie bereits erwähnt, entspricht die marginale Betrachtung des kommunistischen Widerstands in den Dauerausstellungen seiner tatsächlich geringen militärischen Bedeutung. Eine Bewertung des Bündnisses der PPR und ihrer militärischen Formationen mit der Sowjetunion fand jedoch bis 2003 so gut wie nicht statt. Einzig in der Ausstellung der Pomorska-Straße von 1998 war eine erste negative Einschätzung des kommunistischen Widerstands im Lichte seiner positiven Einstellung der UdSSR gegenüber zu verzeichnen. In der Überschrift der ihr gewidmeten Ausstellungstafel wurde die GL-AL mit dem Hinweis versehen »Im Bündnis mit den Sowjets «. ${ }^{282}$ Verbunden war die in dieser Aussage enthaltene negative Zuschreibung mit der in der Präsentation zu beobachtenden negativen Bewertung der Kriegsfolgen und damit auch der Rolle der UdSSR. Die Erzählung wurde - als einzige der im Untersuchungszeitraum entstandenen Schauen - in die Nachkriegszeit erweitert. Thematisiert wurde der Zeitraum 1945 bis 1956 dabei allein unter dem Gesichtspunkt des Kampfes und der Verfolgung des antikommunistischen Untergrunds durch den WUBP. ${ }^{283}$ Vor dem Hintergrund der eindeutig negativen Beurteilung der sozialistischen Nachkriegsregierung und ihres Bündnispartners Sowjetunion wurden somit auch die polnischen kommunistischen Widerstandsgruppen der Besatzungszeit abgewertet. Für den hier analysierten Zeitraum der musealen Entwicklung war diese normative Bewertung und damit auch Ausgrenzung eines Teils der Untergrundbewegungen jedoch noch eine Ausnahme. In den übrigen betrachteten Schauen wurden kommunistische und auch rechte Widerstandsorganisationen (die nicht oder kaum mit der AK zusammenarbeiteten) nicht normativ dargestellt. Sie erschienen als Teil des unmissverständlich positiv konnotierten Widerstands- und damit Heldenkollektivs.

281 Ebd.

282 MHK-Pomorska-Straße, Tafel 30.

283 Siehe hierzu auch Teil 1, Kapitel 2.2. 
Die polnischen Selbstbilder, die die in den Jahren 1990 bis 2003 eröffneten Dauerausstellungen zeichneten, verdichten sich symbolisch in den in der Präsentation des Pawiak-Museums platzierten lebensgroßen Fotografien von Gefängnisinsassen. ${ }^{284}$ Neben den bereits genannten zwei christlichen Märtyrerfiguren (Maximilan Kolbe und Edmund Bursche) ${ }^{285}$ sowie Jan Piekałkiewicz, dem Delegierten der Regierung im Lande, finden sich dort zwei Mitglieder von Widerstandsgruppen: Vorgestellt werden die polnische Parlamentsabgeordnete und Senatorin Halina Jaroszewiczowa, die während der Besatzung in der SZP-ZWZ aktiv war, sowie ein Unterleutnant der polnischen Gefängniswache des Pawiak, Ludwika Uzarówna-Krysiakowa, die Mitglied der gefängnisinternen Zelle des polnischen Untergrunds war. ${ }^{286}$ Das Tableau der präsentierten Persönlichkeiten skizziert somit Märtyrer und Widerstandskämpfer, die sich der Führung der Londoner Exilregierung unterstellten, als vorbildhafte Vertreter der in den Jahren 1939 bis 1944 im Pawiak Inhaftierten. Bemerkenswert ist, dass unter diesen fünf Vorbildfiguren nun herausragend auch zwei Frauen porträtiert werden, womit stereotype Vorstellungen von Kampf und Widerstand als männlicher Domäne herausgefordert werden. Der in allen Biogrammen geschilderte Patriotismus, Mut und die Opferbereitschaft für das Vaterland wird zugleich suggestiv auf alle Häftlinge übertragen. Da die Ausstellung starke Bezüge zur gesamtpolnischen Geschichte dieses Zeitraums herstellt und Hinweise auf weniger heldenhaftes und martyrologisches Verhalten von Polen in den Jahren 1939 bis 1945 fehlen, stehen die fünf Protagonisten implizit auch stellvertretend für die gesamte polnische Gesellschaft der Besatzungszeit. Zwar wird in dieser wie in den übrigen untersuchten Dauerausstellungen dieser Jahre - im Unterschied zu den Vorgängerpräsentationen - eine allgemeine Widerständigkeit der Bevölkerung nicht mehr explizit postuliert. Durch die Konzentration der musealen Erzählungen auf Kämpfer und Märtyrer als beispielhafte, zugleich aber auch herausragende und damit vorbildhafte Vertreter ihrer Nation wurde und wird eine solche Deutung dennoch unterschwellig vermittelt.

284 Teile der folgenden Ausführungen wurden bereits publiziert in Heinemann: Emotionalisierungsstrategien.

285 Siehe Teil 3, Kapitel 1.2.

286 Seit 1942 war sie zudem die Hauptverbindungsperson dieser Zelle zur Vertretung der polnischen Exilregierung und hat in dieser Funktion nicht nur Informationen aus dem Gefängnis über die darin verübten Verbrechen an die Außenwelt weitergeleitet, sondern auch vielfältig die Häftlinge unterstützt. Diese Informationen sind ihrem Biogramm zu entnehmen. 


\subsection{Der Heldentopos im Museumsboom}

Die soeben skizzierten Charakteristika der Kampf- und Widerstandsdarstellungen der 1990er- und beginnenden 2000er-Jahre haben grundsätzlich bis zum Ende des Untersuchungszeitraums im Jahr 2010 Gültigkeit. Eine Veränderung ist mit Beginn des Museumsbooms allein in der Relation dieses Heldennarrativs zu anderen Elementen des polnischen Selbstbildes im Krieg zu verzeichnen. Diese Entwicklung fügt sich in die seit 2004 zu beobachtende Zweiteilung der aktuellen polnischen Museumslandschaft ein. Auf der einen Seite erfolgt eine Überhöhung des Heldenbilds durch eine einseitige Heroisierung des Widerstands und der polnischen Streitkräfte an den verschiedenen Fronten des Kriegs, der alle anderen Aspekte polnischer Besatzungserfahrungen zu- bzw. untergeordnet werden. Die Umsetzung dieser Position wird im Folgenden anhand der Musealisierung des Warschauer Aufstands von 1944 exemplarisch analysiert. Auf der anderen Seite werden Armee und Widerstand zu gleichberechtigten Elementen der Besatzungsgeschichte, das heißt sie treten von ihrer früheren dominanten Position an die Seite der Opfer- wie der Alltagsdarstellungen. Die Ausnahmeerscheinungen der aktiv Kämpfenden werden dabei nicht vernachlässigt; sie bleiben ein wesentliches Element der polnischen Besatzungserfahrung. Das Hauptaugenmerk der Ausstellungsmacher verlagert sich bei diesen Präsentationen jedoch deutlich auf den Alltag der sogenannten gewöhnlichen Menschen, also der passiven Bevölkerungsmehrheit. Zugleich versucht man in diesen Schauen, stereotype Interpretationstopoi zu hinterfragen und die historischen Ereignisse aus vielfältigen Perspektiven zu betrachten. Inwieweit dies in Bezug auf das tradierte Selbstbildnis der Helden und Opfer gelingt, wird in den nachfolgenden Ausführungen untersucht.

Exemplarisch für diesen zweiten Pol des aktuellen musealen Erzählspektrums ist die Dauerausstellung »Krakau - Die Besatzungszeit 1939-1945 « des MHK in der ehemaligen Emaillewarenfabrik Oskar Schindlers. Diese Präsentation ist weder von einem Opfer- noch von einem Heldennarrativ dominiert. Vielmehr stehen die Alltagserfahrungen der Mehrheitsbevölkerung abseits der unmittelbaren Gewalterfahrung oder dem aktiven Kampf im Vordergrund, wie eingehender in Kapitel 3 dargelegt wird. Die Kämpfe im September 1939 ebenso wie die Aktivitäten des Untergrunds bleiben jedoch auch hier wichtige Bestandteile der Erzählung. Den ersten wesentlichen Wendepunkt des Ausstellungsnarrativs stellen der Kriegsausbruch und die vorangegangene Mobilmachung dar, denen eigene Themenräume gewidmet sind. ${ }^{287}$

287 Die allgemeine Mobilmachung im August wird in einem arrangierten Bahnhofswartesaal geschildert. MHK-Schindler-Fabrik, Sektion 3: Wartesaal. Unmittelbar darauf folgen der Kriegsausbruch und die Kämpfe um die Stadt. MHK-Schindler-Fabrik, Sektion 4: Kriegsausbruch. 
Besonders ausführlich geschildert werden die September-Ereignisse. Zwei auffällig platzierte Multimediapräsentationen stellen neben den Kampfhandlungen in und um Krakau auch den Frontverlauf auf polnischem Territorium sowie die Einsätze der Armee »Krakau« dar. In diesen wird die Aggression sowohl vonseiten Deutschlands als auch kurz darauf der UdSSR hervorgehoben. Bereits an dieser Stelle wird jedoch auch die grundlegende Interpretation der weiteren Aktivitäten im polnischen Untergrund eingeführt:

Die polnische Führung hat trotz der Niederlage keine Kapitulationserklärung unterzeichnet und war entschlossen, den Kampf außerhalb des Territoriums des Landes weiterzuführen [...]. Der internierte Präsident Ignacy Mościcki ernannte seinen Stellvertreter, Władysław Raczkiewicz, der sich in Frankreich aufhielt. Dort wurde auch die neue Regierung der RP [Rzeczpospolita Polska/Republik Polen] formiert. [...] Auf diese Weise blieb die Kontinuität der Staatsgewalt erhalten. ${ }^{288}$

Mit der Betonung der Kontinuität der polnischen Regierung im Exil wird ihre Legitimität als alleinige und international anerkannte Vertreterin polnischer Interessen kenntlich gemacht. Daran unmittelbar angeschlossen ist die Einführung des Widerstands auf dem besetzten polnischen Territorium: »Noch während die Kampfhandlungen im September 1939 andauerten, formierten sich in ganz Polen spontan geheime Organisationen, die sich den Kampf für die Unabhängigkeit zum Ziel setzten. ${ }^{289}$ Im Folgenden geht es um die Entstehung des ZWZ, mit dem expliziten Verweis, dass diese Organisation auf Basis eines »Befehls des Oberbefehlshabers in Paris « geschaffen wurde, aus der 1942 die Heimatarmee hervorging. ${ }^{290}$ Diese Darstellung macht eine unmittelbare Verbindung zwischen der Exilregierung und der größten Widerstandsbewegung kenntlich. Hierdurch wiederum hebt man zugleich auch die Legitimität der Aktivitäten der AK hervor. Auffällig ist dabei, dass diese die einzige Organisation ist, die derart herausragend präsentiert wird. Die SZP-ZWZ-AK wird somit von Beginn der Besatzung an als Hauptvertreterin des polnischen Widerstandskampfes eingeführt; ${ }^{291}$ andere Gruppen tauchen erst wesentlich später auf und bleiben auch dann deutlich im Hintergrund.

Der prominenten Schilderung der Exilregierung im Kontext der September-Ereignisse folgend liegt ein deutlicher Schwerpunkt der Widerstands-

288 Ausschnitt aus dem Bereichstext (ohne Überschrift). MHK-Schindler-Fabrik, Sektion 4: Kriegsausbruch.

289 Ebd.

290 Ebd.

291 Als eine der ersten Gruppen, die im Untergrund entstand, wird im Bereichstext die Krakauer »Organisation Weißer Adler« (Organizacja Orła Białego) genannt. »[E]ine Woche später, in Warschau, und später in anderen Städten des besetzten Landes, [entstand] der Dienst für Polens Sieg (SZP).« Aus dieser ging später der ZWZ und schließlich die AK hervor. Ebd. 
darstellung auf dem polnischen Untergrundstaat. Dieser wird an mehreren Stellen thematisiert. Verschiedene Aspekte seiner Existenz und die Tätigkeiten von Widerstandsgruppen sind dabei immer wieder in den Rahmen der Alltagsdarstellung integriert. Hierzu gehören etwa Hinweise auf die beständige und bereits zu einem frühen Zeitpunkt der Besatzung einsetzende Verbreitung von (verbotenen) Informationen durch "verschiedene konspirative Gruppen ${ }^{292}$ oder auch das geheime Schulwesen ${ }^{293}$. An diversen Punkten der Ausstellung zu findende Bekanntmachungen der Besatzungsorgane über inhaftierte und exekutierte Personen nennen als Verhaftungsgründe oft Anschläge von Untergrundgruppierungen auf Deutsche, Sabotageakte oder die Mitgliedschaft in Widerstandsorganisationen. ${ }^{294}$ In zwei Sektionen ist dem Phänomen des Untergrundstaates zudem umfangreich Platz eingeräumt: $\mathrm{Zu}$ nächst wird unter dem übergreifenden Thema »Alltag 1943« der »Polnische Untergrundstaat ${ }^{295}$ in einer eigenen Untersektion vorgestellt. Hier wird die Vielfalt der unter diesem Schirm organisierten Aktivitäten aufgefächert, deren militärische, politische und auch zivile Elemente. Die Besucher treffen auf unterschiedliche Formationen und Repräsentanten des organisierten Widerstands. Fotos zeigen die Vereidigung von Mitgliedern der Grauen Reihen, Porträts junger "Soldaten der AK-Einheit >Blitz« mit Maschinengewehren und Munition und unmittelbar daneben eine Porträtfotografie dreier gutaussehender junger Frauen, die frisiert, geschminkt, zivil gekleidet in die Kamera lächeln - und als »Soldaten« der »Nationalen Militärorganisation« (Narodowa Organizacja Wojskowa) namentlich vorgestellt werden. ${ }^{296}$ Gerade die letztgenannte Fotografie spielt damit auch mit stereotypen Vorstellungen über die Rollenverteilung zwischen den Geschlechtern. Frauen werden hier explizit neben Männern gleichberechtigt als "Soldaten«, mithin als aktiv Kämpfende erwähnt. Es fällt auf, dass der Terminus »Soldaten« hier für alle Mitglie-

292 In Sektion 5 schildert ein Bereichstext die beginnende Diskriminierung der Bevölkerung durch die Besatzer. Abschließend wird erwähnt, dass nicht alle Krakauer ihre Radios den Besatzungsvorschriften entsprechend abgegeben hatten und Informationen aus abgehörten Radioberichten in Untergrundbulletins publiziert wurden. MHK-SchindlerFabrik, Sektion 5: Öffentlicher Raum I.

293 Dieser Aspekt illegaler Aktivitäten wird in Sektion 9 eingeführt. Der Thementext schildert die Initiative Krakauer Pädagogen und Hochschulangehöriger bei der Organisation geheimen Unterrichts unmittelbar nach Einführung der restriktiven Bildungspolitik der Besatzer. Erwähnt wird zudem, dass das System »im Herbst 1940 in die Struktur des Polnischen Untergrundstaates eingeschrieben [wurde]«. Gezeigt wird auch das Foto einer Prüfungsbestätigung im Rahmen des geheimen Schulunterrichts. MHK-Schindler-Fabrik, Sektion 9: Alltag, 1940-1941.

294 Solche Plakate finden sich etwa in Sektion 8 (Terror) und Sektion 15 (Alltag, 1943, im Abschnitt »Alltag«).

295 Titel des Abschnitts. MHK-Schindler-Fabrik, Sektion 15: Alltag, 1943.

296 Die Zitate sind den jeweiligen Objektbeschriftungen entnommen. Ebd. 
der der genannten Untergrundgruppen verwendet wird - eine Wortwahl, die bei der Darstellung des Widerstands in der gesamten Ausstellung konsequent Anwendung findet. Hierdurch wird eine prägnante Opposition zu den Besatzern markiert: Während die deutsche Okkupation in Krakau als illegitim und verbrecherisch charakterisiert wird, was unter anderem auch durch die Vermeidung des Begriffs "Soldat « in Bezug auf deutsche Einheiten transportiert wird, ${ }^{297}$ stehen die "Soldaten « der verschiedenen polnischen Untergrundeinheiten aufseiten der gerechten Sache, der legitimen Verteidigung des Vaterlandes.

Neben den militärischen werden auch die politischen und zivilen Elemente des Untergrundstaates thematisiert. Zum einen stellt man seine führenden Repräsentanten in der Region vor. ${ }^{298}$ Daneben werden Beispiele seiner Tätigkeit im besetzten Land präsentiert, darunter Aufrufe an die polnische Bevölkerung zum Widerstand, an Deutsche adressiertes Propagandamaterial, der Stundenplan einer Gruppe des geheimen Schulunterrichts sowie antideutsche Karikaturen. Die gezeigten Dokumente, Abbildungen und Karikaturen verweisen nicht nur auf die Vielfalt der unterschiedlichen Aktivitäten, die unter der Schirmherrschaft des PPP subsumiert waren. Es wird auch deutlich, dass seine Strukturen von verschiedenen politischen Parteien getragen wurden. Auffällig ist zugleich, dass - dem Titel des Abschnitts entsprechend - alle hier erwähnten Organisationen mit der AK kooperierten oder zu Unterstützern der Exilregierung zählten. Politische und militärische Gruppierungen, die diese nicht anerkannten oder sich ihren Befehlen nicht unterstellten, wie die NSZ der rechten Nationaldemokraten oder auch kommunistische Gruppierungen, wie die Kampforganisationen der PPR, die GL und AL, werden hier hingegen nicht erwähnt. An einer Stelle wird zudem der politische Konflikt zwischen den mit der Exilregierung kooperierenden Gruppen und diesen Formationen thematisiert: Gezeigt wird ein Aufruf, adressiert an die »Jugend Polens! «, in dem unter anderem "vor dem kommunistischen und äußersten rechten Untergrund gewarnt wird « - wie in der Objektbeschriftung noch einmal explizit hingewiesen wird. Die Bedeutung dieser Gruppen war in der Region Krakau tatsächlich verhältnismäßig gering. ${ }^{299}$ Ihre marginale Behandlung kontrastiert allerdings mit der früheren Präsentationspraxis in der Pomorska-Straße, in der linken und rechten Gruppierungen verhältnismäßig

297 Siehe Teil 1, Kapitel 1.3.

298 Vorgestellt werden Jan Jakóbiec, der Bezirksdelegierte der Regierung im Lande für den Bezirk Krakau, und Władysław Sikorski, der Premierminister der Exilregierung sowie Oberster Befehlshaber der polnischen Streitkräfte. Prominent präsentiert wird auch der Anführer der AK für den Bezirk Krakau, Józef Spychalski. Abschnitt »Der Polnische Untergrundstaat«. MHK-Schindler-Fabrik, Sektion 15: Alltag, 1943.

299 Siehe die umfangreiche Darstellung des Widerstands in Krakau im begleitenden Ausstellungskatalog: Jeżowski: Polskie Państwo Podziemne, 371, 373, 391. 
viel Platz eingeräumt war. Der einzige, allgemein formulierte Hinweis auf diese Organisationen findet sich in der zweiten Sektion, die dem Thema »Polnischer Untergrundstaat" gewidmet ist. ${ }^{300}$ Im Vordergrund steht in diesem Abschnitt das geheime Pressewesen. Der einleitende Bereichstext erwähnt: »Auch Organisationen, die außerhalb der Strukturen des Polnischen Untergrundstaates verblieben, besaßen eigene Pressetitel und Druckereien. « ${ }^{301}$ Unter den auf den Wänden des Themenraumes angebrachten Zeitungsseiten finden sich auch Titel linker Gruppierungen, wie die Brygada (Brigade). Die NSZ ebenso wie die $\mathrm{BCh}$ werden daneben in einer Multimediapräsentation thematisiert, die relativ versteckt in der hintersten Ecke dieser Sektion zu finden ist. Die GL-AL findet hingegen auch hier keine Erwähnung; peripher taucht sie lediglich bei der Schilderung des Widerstands im Ghetto auf. ${ }^{302}$

Innerhalb der Ausstellungserzählung nimmt diese Sektion eine prägende Funktion ein. Sie ist als Wohnung inszeniert. Die Besucher treten ein in den Flur einer vermeintlich gewöhnlichen, bürgerlichen Wohnung einer polnischen Familie. Von dort gelangt man in ein Wohnzimmer und in die Küche. Schnell wird klar, dass diese Räume von Widerstandskämpfern bewohnt werden. Im Flur steht eine Schreibmachine; die Wand hinter ihr ist mit Seiten aus Untergrundzeitungen beklebt; auch aus der Schublade des Küchentisches quellen Zeitungen; in einem angrenzenden Raum trifft man auf eine Druckerpresse und weitere Untergrundpublikationen; ein vergrößertes Foto an der hinteren Wand erweckt den Eindruck, zwei Männer würden gerade an einer neuen Publikation arbeiten (siehe Abb. 43 bis 45). Man trifft hier jedoch nicht nur auf eine konspirative Redaktion und Druckerei, sondern auch auf versteckte Waffen - in der doppelten Rückwand des Küchenschrankes.

Diese Inszenierung bietet einen Einblick in vermeintlich private Räumlichkeiten von polnischen Krakauern - analog zu denen jüdischer Stadtbewohner, die die Besucher bereits passiert haben. ${ }^{303}$ Beide Installationen stellen damit markante Einschnitte im Ausstellungsnarrativ dar; der öffentliche Raum der Krakauer Straßen und Plätze, durch die man während der ganzen Schau geht, wird verlassen, und man erhält Eintritt in die intime Umgebung privater Wohnungen der zwei Hauptprotagonisten der musealen Erzählung - der

300 MHK-Schindler-Fabrik, Sektion 19: Polnischer Untergrundstaat.

301 Bereichstext »Untergrunddruckerei $\ll$. Ebd.

302 Der kommunistische Widerstand wird in der Multimediapräsentation erwähnt, die in der Sektion "Ghetto « untergebracht ist. Unter dem Stichwort "Widerstandsbewegung" wird dort die Etablierung von Widerstandsgruppen im Ghetto geschildert. Dabei wird die Zusammenarbeit mit der PPR - als einziger Partei des polnischen Untergrunds - benannt, dank derer die Widerständler in den Besitz von Waffen und Sprengstoffen kamen. Anschließend erwähnt man die von einzelnen Gruppen durchgeführten größeren Aktionen; die meisten von ihnen fanden außerhalb des Ghettogeländes statt. MHKSchindler-Fabrik, Sektion 14: Ghetto.

303 Ebd. 


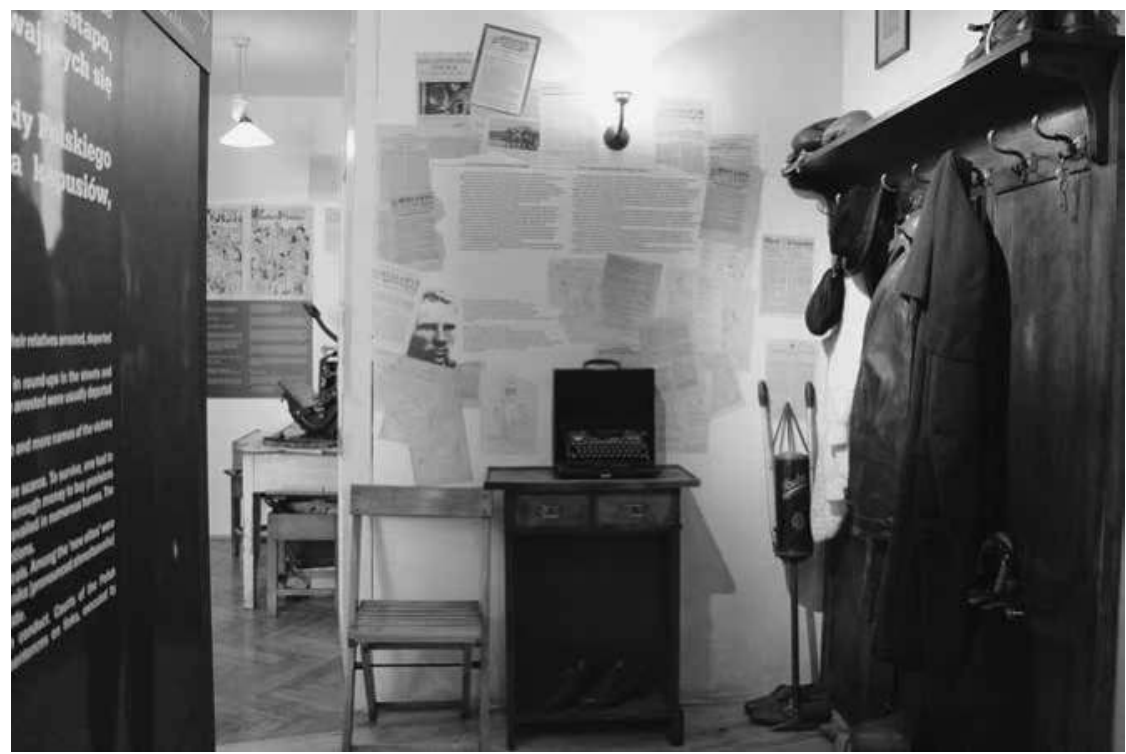

Abb. 43: Schindler-Fabrik, inszenierter Flur in der Sektion »Polnischer Untergrundstaat».

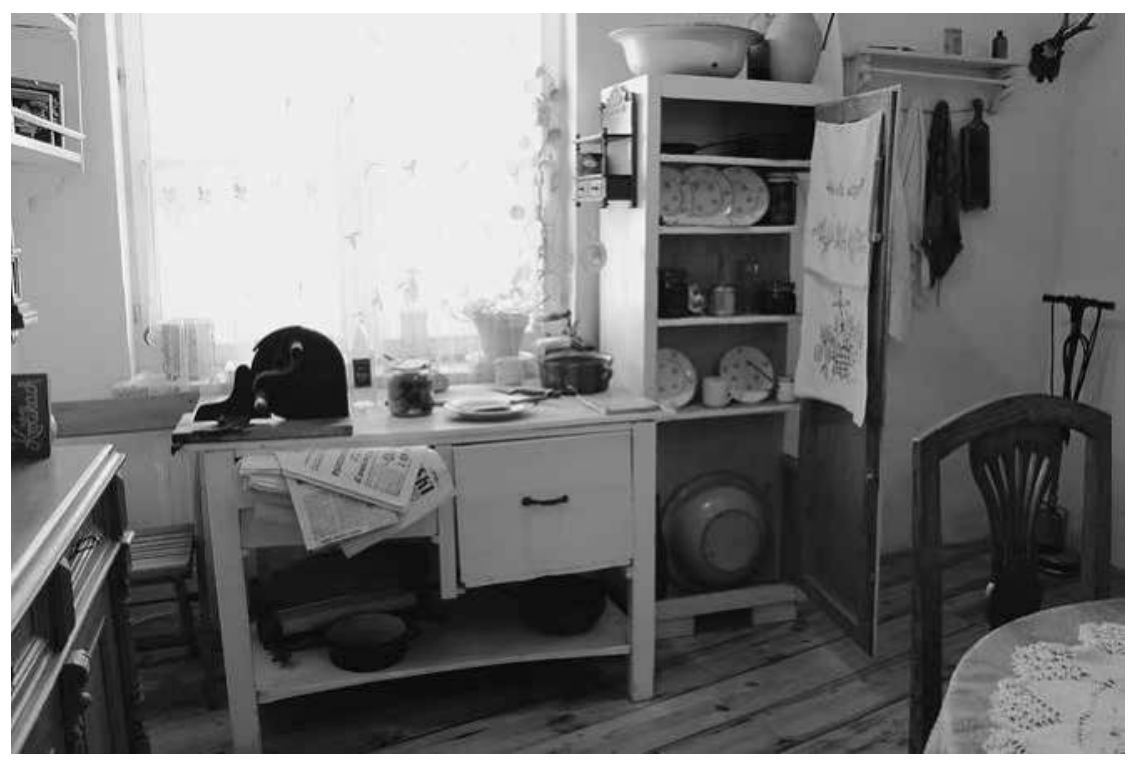

Abb. 44: Schindler-Fabrik, Küche in der Sektion »Polnischer Untergrundstaat«. 


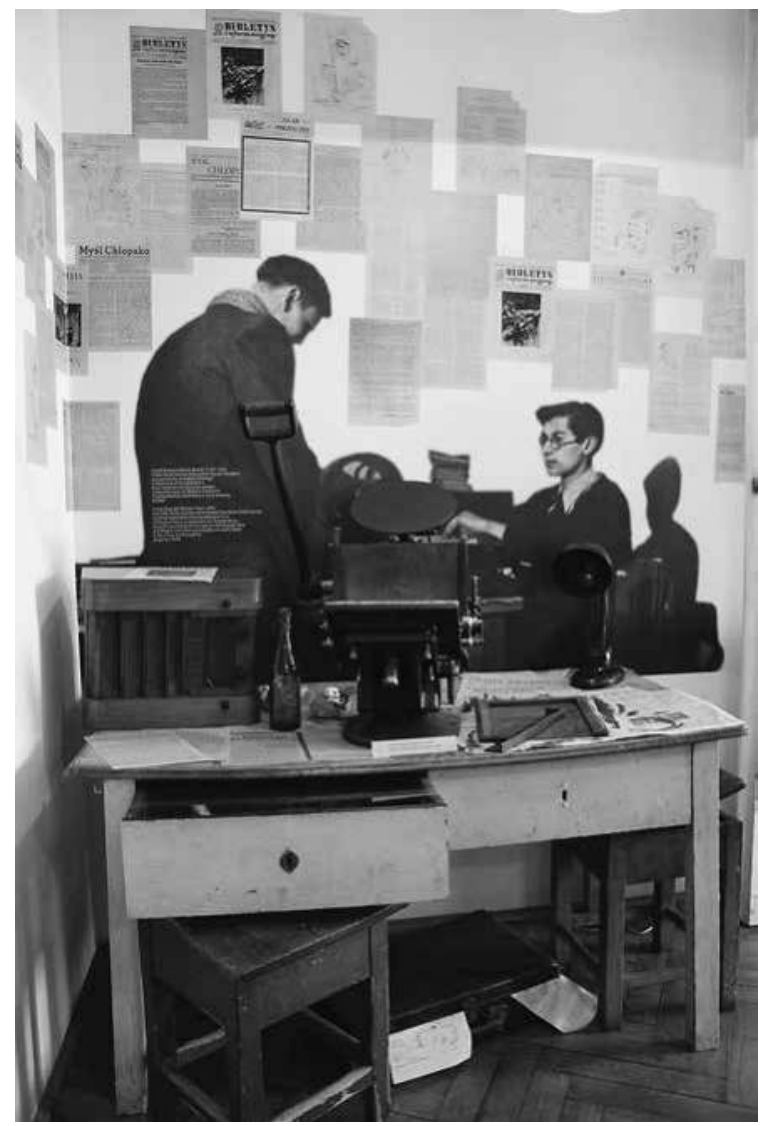

Abb. 45: Schindler-Fabrik, konspirative Druckerei in der Sektion »Polnischer Untergrundstaat«.

jüdischen und polnischen Stadtbewohner. Insbesondere die zweite Installation markiert jedoch suggestiv auch einen deutlichen Unterschied zwischen den beiden Gruppen: Die Ghettobewohner treffen die Besucher in Mitleid erweckender Enge und Unsicherheit an, noch dazu in sehr intimen Situationen - eine Frau etwa wäscht sich gerade (siehe Abb.46). Die zusammengepferchte jüdische Bevölkerung erscheint somit im zentralen, da äußerst einprägsamen Element der Sektion in erster Linie als Leidende, als passive Opfer. Polen hingegen werden in der privaten Umgebung ihrer Wohnung als aktive Widerständige, mithin als Helden porträtiert. ${ }^{304}$

304 Wie bereits in Teil 2, Kapitel 4 geschildert, stellt man in der Sektion »Ghetto « ebenfalls Widerstandsgruppen von Ghettobewohnern dar, in einer Multimediapräsentation so- 


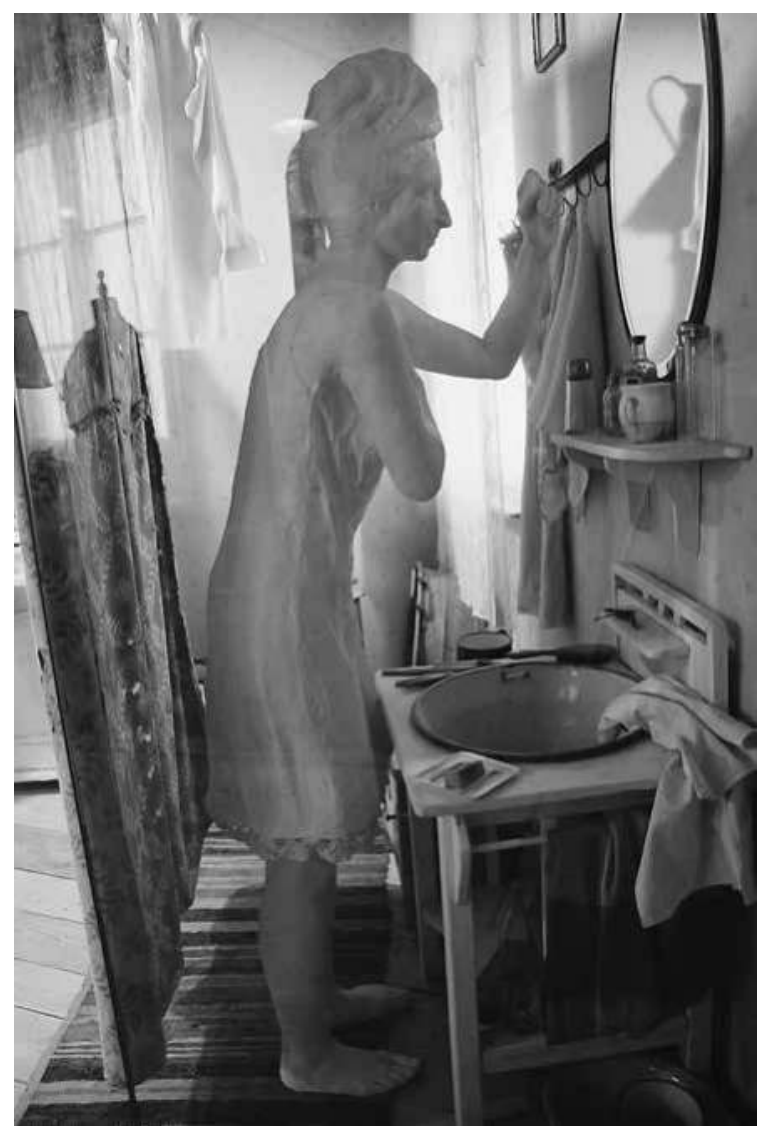

Abb. 46: Schindler-Fabrik, arrangierte Szene in der Sektion »Ghetto«.

Das Anliegen der Ausstellungsmacher war es, den Besuchern einen Einblick in die historischen Ereignisse aus der Perspektive der (damaligen) Einwohner Krakaus zu ermöglichen; Ziel war es, eine »emotionale Geschichte der Stadt « zu präsentieren. ${ }^{305}$ Es ist daher davon auszugehen, dass durch die inszenierte Ghettowohnung bei den Besuchern Empathie geweckt werden sollte mit den Leidtragenden dieser unmenschlichen Bedingungen. Bemerkens-

wie mittels Fotografien und Zeitzeugenberichten. Den prägenden Eindruck der Sektion liefern jedoch wohl eher nicht die kleinen Fotografien und kurzen Texte zur ŻOB, sondern die affektiven und eindrücklichen Inszenierungen einer imaginierten Ghettowohnung. Ebd.

$305 C z u j$, Łukasz/Urban, Michał: Opis koncepcji aranżacji wystawy stałej »Kraków - czas okupacji (1939-45)«. Kraków o. J. [2008/09]. AMHK, ohne Signatur, 2-4, Zitat: 2. 
wert erscheint jedoch, dass bei der Inszenierung der privaten Umgebung von Polen nicht etwa analog zum Ghetto eine repräsentative Darstellung gewählt wurde, sondern die Ausnahmeerscheinung der aktiv Widerstand Leistenden. Trotz des im europäischen Vergleich großen Ausmaßes der Untergrundaktivitäten im besetzten Polen bleibt festzuhalten, dass insgesamt nur ein kleiner Teil der Bevölkerung im Widerstand aktiv war. ${ }^{306}$ Zwar ist nachvollziehbar, dass die Ausstellungsmacher nach interessanten Möglichkeiten gesucht haben, das Thema des Untergrundstaates mit mehr als nur der sogenannten Flachware (zweidimensionalen Objekten wie Dokumenten und Presseerzeugnissen) sinnlich erfahrbar zu machen. Gerade die im Rahmen des Ausstellungsrundgangs markante Installation einer vermeintlich privaten Umgebung betont jedoch nicht nur das darin vermittelte Thema; sie beansprucht auch eine gewisse Allgemeingültigkeit desselben, hier also der großen Verbreitung der Widerstandstätigkeit innerhalb der polnischen Bevölkerung.

Die Darstellung des Widerstands, des organisierten wie des zivilen, ist somit dominiert von der Exilregierung und dem von ihr geleiteten Untergrundstaat samt seiner Militärorganisation, der Heimatarmee. Die AK und kleinere Organisationen, die sich der Londoner Führung unterstellten, stehen stellvertretend für die gesamte, als legitim gekennzeichnete Resistenz während der Besatzung. Zwar wird auf die Vielfalt der existierenden Organisationen hingewiesen; der dominante Eindruck, der sich während des Rundgangs verdichtet - insbesondere durch die suggestiv inszenierte Wohnung -, ist jedoch der einer Gleichsetzung des Freiheitskampfes mit der AK und dem Untergrundstaat. Andere politische Optionen erscheinen lediglich am Rande. Bemerkenswert daran ist, dass der kommunistische Widerstand im Land und auch die beginnende Etablierung des von der Sowjetunion eingesetzten PKWN auf den von der Roten Armee befreiten Gebieten in der Erzählung weitgehend unerwähnt bleiben. Selbst in einer der letzten Sektionen der Schau, in der die Ereignisse des »Sommers 1944« geschildert werden, das heißt der Beginn der Aktion »Gewittersturm « und die Vorbereitungen der Deutschen zur Verteidigung Krakaus angesichts der nahende Ostfront, wird die Opposition zwischen der Exilregierung und des PKWN nicht erwähnt. ${ }^{307}$ Und dies, obwohl

306 Die Personenstärke des gesamten Bezirks Krakau der ZWZ-AK - der weit über die Stadt hinausging und die größte räumliche Ausdehnung aller Bezirke der AK hatte - wird zu ihrem Höhepunkt Mitte 1944 auf 90.000 Personen geschätzt. Mazur: Der »Bund für den bewaffneten Kampf - Heimatarmee«, 136. Siehe auch Jeżowski: Polskie Państwo Podziemne, 135, 137. Die Schätzungen der Bevölkerungszahlen für die Stadt Krakau während des Kriegs variieren stark. Nach »deutschen Angaben« hatte Krakau Anfang 1943 über 280.000 Einwohner, darunter waren knapp 252.000 Polen. Vgl. Chwalba: Okupacyjny Kraków, 36 f.

307 Ein einleitender Text, das erste Element dieser Sektion, auf das die Besucher treffen, schildert unter dem großformatigen Titel »Sommer 44 « die Situation in der Stadt im Juli dieses Jahres. MHK-Schindler-Fabrik, Sektion 25: Die letzten Monate der Besatzung. 
die regionale Reichweite und die Zielsetzung der Aktion "Gewittersturm» klar benannt werden, womit bereits der lokale Fokus der übrigen Ausstellung erweitert wird. Zur Sprache kommen nicht nur die Kämpfe von AKEinheiten bei Vilnius (Wilno) und Lviv (Lwów), sondern auch explizit deren Hintergründe:

Ziel der militärischen Operation `Gewittersturm`war es, der sowjetischen Führung klarzumachen, dass auf den Territorien Polens in den Grenzen von 1939, die von der deutschen Besatzung befreit worden waren, Polen die Hausherren sind, die die Führung der Exilregierung in London anerkennen. ${ }^{308}$

Die politische Gegnerschaft zwischen den Repräsentanten der Exilregierung und der UdSSR und die folgenden militärischen Ereignisse, darunter die Gefangennahme von AK-Einheiten nach der gemeinsamen Befreiung einzelner Gebiete, werden benannt. ${ }^{309}$ Dass es parallel zu den geschilderten Ereignissen Entwicklungen in den befreiten Gebieten gab, die den Zielen der Exilregierung zuwiderliefen, also die Etablierung des PKWN, bleibt hingegen unerwähnt. Die Darstellung konzentriert sich auf den Teil des Widerstands, der die Führung der Londoner Exilregierung anerkannt hat und mithin als einzig legitimer Repräsentant des polnischen Untergrunds kontextualisiert wird. Auch wenn die polnischen Kommunisten in dieser Schau somit kein einziges Mal herausgehoben thematisiert werden, so müssen sie als Verbündete der Sowjetunion implizit als illegitim erscheinen.

Es bleibt demnach festzuhalten, dass der bewaffnete Kampf bei Kriegsausbruch und im Angesicht des nahenden Kriegsendes sowie der Widerstand während der Besatzung ein prägnantes Element auch dieser Ausstellung und des in ihr präsentierten Selbstbildes der polnischen Bevölkerung im Krieg bleiben. Die Darstellung des Widerstands konzentriert sich dabei auf diejenigen Gruppierungen, die in der AK aufgegangen sind oder mit ihr zusammenarbeiteten, sowie auf die Londoner Exilregierung, die als einzig legitime politische Vertretung des okkupierten Landes in den Vordergrund rückt. Der Widerstand, in ziviler und militärischer Form, ist jedoch zugleich überwiegend ethnisch-polnisch konnotiert. Jüdische Untergrundgruppierungen wirken demgegenüber als Randerscheinung: In der Sektion »Ghetto« werden ihre Aktivitäten vor allem innerhalb einer Multimediapräsentation geschildert; allein ein Zeitzeugenbericht, der sich im Laufe des Rundgangs findet, gibt einen Eindruck vom Kampfeswillen der Widerständler. ${ }^{310}$ Die größte Aktion der Krakauer Sektion der ŻOB, der Anschlag auf das deutsche Café »Cyganeria« - der in Zusammenarbeit mit polnischen Kommunisten durch-

308 Thementext »Aktion `Gewittersturm«. Ebd.

309 Ebd.

310 MHK-Schindler-Fabrik, Sektion 14: Ghetto. 
geführt wurde -, wird im Ausstellungsrundgang allein mit einem kleinen Kalenderblatt erwähnt. ${ }^{311}$ Ihre umfangreichere Darstellung ist in der bereits erwähnten Multimediapräsentation in der Sektion »Ghetto untergebracht. Damit bleibt sie zugleich faktisch dem Großteil der Besucher verborgen, da angesichts der Länge des Rundgangs und der Masse der präsentierten Materialien wie der sinnlichen Eindrücke durch ständig wechselnde Szenografien kaum ein Besucher die Präsentation intensiv studiert. Auch hier ist ein Vergleich zur Darstellungspraxis der Aktionen polnischer Gruppen augenfällig: Zentrale Anschläge, wie die Aktion Krüger und die Aktion Koppe, sind mit wandfüllenden Comics prominent in den Ausstellungsrundgang integriert. ${ }^{312}$ Trotz dieser markanten Unterschiede in der Präsentationsweise des jüdischen und polnischen Widerstands wird die Schilderung polnischer Besatzungserfahrungen in dieser Schau nicht mehr vom Widerstandsnarrativ dominiert. In der Art und Weise der Inszenierung der Wohnung polnischer Untergrundaktivisten scheint jedoch die Suggestion einer vermeintlich allgemein verbreiteten widerständigen Haltung in der breiten (ethnisch-polnischen) Bevölkerung hervor.

Diese positive Voreingenommenheit gegenüber dem organisierten Widerstand zeigt sich auch bei der Thematisierung von negativen Verhaltensweisen. Zwar entsteht hier ingesamt ein differenzierteres Bild, da die Existenz auch von polnischen Spitzeln im Widerstand wie in der breiten Bevölkerung immer wieder genannt wird. Zugleich wird betont, dass der polnische Untergrundstaat gegen diese aktiv vorging. ${ }^{313}$ Im Vergleich mit anderen Ausstellungen aus diesem Zeitraum ist die wiederholte Erwähnung der Existenz von heimischen Denunzianten bemerkenswert. In Bezug auf den organisierten Widerstand geht die Darstellung dieses Aspekts jedoch nicht über einzelne Verweise hinaus, wie in Kapitel 3.2 vertieft wird. Gerade die weitreichenden Folgen der Unterwanderung des Untergrunds durch Personen, die mit den deutschen Behörden kooperierten, werden in der Schau kaum erwähnt. So erfahren die Besucher erst im umfangreichen Ausstellungskatalog von der Zerschlagung ganzer Krakauer Einheiten infolge der Spitzelaktivitäten. ${ }^{314}$ Die Schilderung des Spitzel- und Denunziantenwesens konzentriert sich dagegen

311 Kalenderblatt zum 22. Dezember 1942. MHK-Schindler-Fabrik, Sektion 18: Öffentlicher Raum II.

312 MHK-Schindler-Fabrik, Sektion 19: Polnischer Untergrundstaat, Sektion 23: Friseur.

313 Urteile der Untergrundgerichtshöfe gegen Spitzel und szmalcowniki ebenso wie die verhängten Todesstrafen werden etwa bei der Schilderung des Versteckens von Juden außerhalb des Ghettos (Sektion 20: Liquidierung des Ghettos) oder der ökonomischen Bereicherung von Einzelnen trotz des verbreiteten Mangels (Sektion 18: Öffentlicher Raum II) geschildert.

314 Siehe Jeżowski: Polskie Państwo Podziemne. 
auf ihre dramatischen Konsequenzen für Juden, die sich außerhalb des Ghettos versteckten. ${ }^{315}$

\section{Der Mythos des Warschauer Aufstands 1944}

Der zweite Pol musealer Darstellung von Verteidigungskrieg und Widerstand, der einen deutlichen Kontrast zu der soeben geschilderten Präsentation in der Schindler-Fabrik bildet, lässt sich prägnant am Beispiel der $\mathrm{Mu}$ sealisierung des Warschauer Aufstandes von 1944 darlegen. Dieses Ereignis, das ursprünglich fast ausschließlich in der lokalen Warschauer Erinnerungskultur verankert war, ${ }^{316}$ wird seit Mitte der 2000er-Jahre zunehmend auch überregional erinnert. Es ist inzwischen zum zentralen polnischen Widerstandsakt während der Besatzung avanciert und steht stellvertretend für den Freiheitskampf der Jahre 1939 bis 1945. Zunehmend wird er auch als Ausgangspunkt einer möglichen alternativen Entwicklung der Polnischen Republik nach Kriegsende zelebriert, als Nukleus eines von der Sowjetunion unabhängigen, demokratischen Polens. Die über Jahrzehnte andauernde Debatte über den Sinn des Aufstands und die Verantwortung der politischen und militärischen Führung für die Entscheidung zu seinem Beginn wie auch für die enormen Opfer, die die Erhebung kostete, treten dabei weitgehend in den Hintergrund. Die Chiffre »1944« repräsentiert mittlerweile die undifferenziert heroische, national-patriotische Erinnerung an die Jahre der deutschen und sowjetischen Besatzungen. ${ }^{317}$ Eine zentrale Rolle bei der Etablierung dieser Deutung spielte das 2004 eröffnete Museum des Warschauer Aufstands. Daher soll im Folgenden das in seiner Dauerausstellung konstruierte Heldenbild umfassend analysiert werden. Zentrale Topoi und Symbole, die in diesem Museum verwendet werden, finden sich jedoch auch bereits in früheren Schauen, auf die ebenfalls eingegangen wird. Die Wirkung der durch das MPW lancierten Aufstandserzählung wird schließlich in neueren Präsentationen nachvollzogen.

315 MHK-Schindler-Fabrik, Sektion 20: Liquidierung des Ghettos, Thementext in Sektion 18: Öffentlicher Raum II.

316 Markiewicz, Tomasz: Der Kampf um die Erinnerung. Denkmäler der Heimatarmee in Warschau seit 1945. In: Chiari, Bernhard (Hg.): Die polnische Heimatarmee. Geschichte und Mythos der Armia Krajowa seit dem Zweiten Weltkrieg. München 2003, 753-775.

317 Garsztecki, Stefan: Warschauer Aufstand und Zweiter Weltkrieg. Polnische Gedächtnispolitik zwischen nationaler Kanonbildung und europäischen Ansätzen. In: Loew, Peter O./Prunitsch, Christian (Hg.): Polen. Jubiläen und Debatten. Beiträge zur Erinnerungskultur. Wiesbaden 2012, 136-156, hier 140, 147; Krzymianowska, Justyna: Der Warschauer Aufstand zwischen Tabuisierung und Heroisierung. In: Schmid, Harald/ Krzymianowska, Justyna (Hg.): Politische Erinnerung. Geschichte und kollektive Identität. Würzburg 2007, 211-222, hier 219 f. 
Im Zentrum des MPW stehen die Aufständischen, zelebriert als Helden und Märtyrer ${ }^{318}$; ihnen sind das Museum und die Dauerausstellung gewidmet. Dies wird gleich beim Betreten der Schau deutlich. Denn die Erzählung beginnt nicht etwa mit den historischen Ereignissen des Weltkriegs und des Aufstandes selbst, sondern setzt - gewissermaßen als Prolog - mit dessen Nachgeschichte an, konkret mit dem Schicksal der Aufständischen in der VRP. Die ersten einleitenden Texte schildern die Verfolgung der ehemaligen AK-Kämpfer durch »die Kommunisten« in den Jahren des Stalinismus und die einseitige Erinnerung an das Ereignis nach $1956 .{ }^{319}$ Zugleich wird deutlich gemacht, dass die angemessene Anerkennung ihrer Leistungen erst nach 1989 möglich wurde: »Erst das freie Polen, für das sie [die Aufständischen d.Vf.] im Warschauer Aufstand gekämpft haben, wird ihnen Ehre erweisen $[\ldots] .{ }^{320}$ Diesem Anspruch folgend wird den ehemaligen Aufständischen auch gleich zu Beginn buchstäblich das Wort überlassen: Die erste raumgreifende Installation, auf die die Besucher treffen, sind arrangierte Telefonzellen (siehe Abb. 47). Über jedem der dort aufgestellten fünf Telefone hängt das Porträt und kurze Biogramm eines Kombattanten; neben den Telefonen befinden sich Fragen über die individuellen Erfahrungen eines jeden von ihnen. Durch das Drücken eines Knopfes neben der jeweiligen Frage können sich die Besucher die Schilderung des Zeitzeugen anhören. Die ersten Informationen, die die Besucher über den Aufstand erhalten, stammen also unmittelbar von Teilnehmern der Kämpfe - aus der retrospektiven Sichtweise der ersten Häfte der Nullerjahre - und geben einen Einblick in deren individuelle Perspektiven. Zugleich erfahren die ehemaligen Aufständischen durch diesen Einstieg in die museale Erzählung eine herausgehobene Würdigung. Bereits hier wird der Anspruch der Museumsverantwortlichen deutlich, das Museum als »Ehrerbietung " an die ehemaligen Kämpfer verstanden zu wissen. ${ }^{321}$

318 Näheres zum Märtyrerbild dieser Schau in Kapitel 1.3 dieses Teils.

319 Thementext "Erinnerung und Geschichte«, Bereichstext »Die Aufständischen in der VRP«. MPW, Sektion 3: Der Aufstand nach 60 Jahren.

320 Bereichstext "Die Aufständischen in der VRP«. Ebd.

321 Ołdakowski, Jan/Kowal, Paweł: Podstawowe założenia programowe i organizacyjne Muzeum Powstania Warszawskiego w Warszawie ul. Przyokopowa 28. Warszawa 2003. AMPW, ohne Signatur, 5 f., 8. Dies wird auch von den Museumsverantwortlichen immer wieder betont. Vgl. Ukielski, Paweł: Nowoczesna placówka edukacji patriotycznej [Eine moderne Einrichtung der patriotischen Erziehung]. In: Pamięć dla przyszłości. Konferencja poświęcona problemom współczesnej edukacji patriotycznej. Muzeum Powstania Warszawskiego 29 października 2005 [Erinnerung für die Zukunft. Eine Konferenz $\mathrm{zu}$ den Problemen der gegenwärtigen patriotischen Erziehung. Museum des Warschauer Aufstands 29. Oktober 2005]. Hg.v. Muzeum Powstania Warszawskiego. Warszawa 2006, 21-29, hier 21; Ołdakowski, Jan: Jedyne takie muzeum - Muzeum Powstania Warszawkiego [Ein einzigartiges Museum - das Museum des Warschauer Aufstands]. In: Rottermund, Andrzej/Soltan, Andrzej/Wrede, Marek (Hg.): 200 lat muzealnictwa warszawskiego. Dzieje i perspektywy. Materiały z sesji naukowej. Zamek Królewski w 


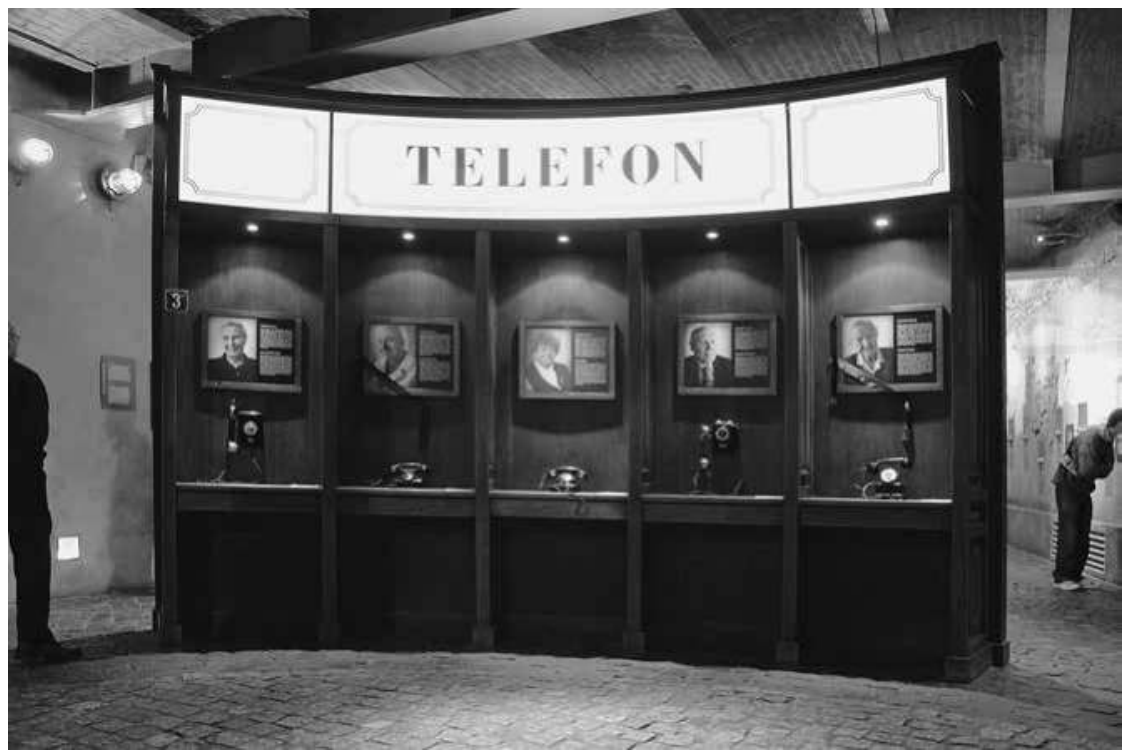

Abb. 47: MPW, Sektion »Der Aufstand nach 60 Jahren«.

Diese wird auch im weiteren Verlauf der Schau immer wieder vermittelt. Unmittelbar nach der beschriebenen Sektion treffen die Besucher auf eine weitere Installation, einen metallenen Quader. ${ }^{322}$ Seine Oberfläche ist mit den Daten der 63 Tage des Aufstandes sowie mit dem bekannten Anker als Zeichen des »Kämpfenden Polens«, versehen (siehe Abb. 48 und 49). ${ }^{323}$ Aus

Warszawie. 16-17 listopada 2005 roku [200 Jahre des Warschauer Museumswesens. Geschichte und Perspektiven. Materialien der wissenschaftlichen Konferenz. Königsschloss in Warschau. 16.-17. November 2005]. Warszawa 2006, 425-430, hier 426.

322 MPW, Sektion 5: Monument. Teile der folgenden Ausführungen wurden bereits publiziert in Heinemann: Emotionalisierungsstrategien.

323 Das Museum des Warschauer Aufstands verwendet dieses Symbol zentral in seiner Außendarstellung (auf der Internetseite, den Publikationen, Souvenirs und Werbemitteln). Prominent ist insbesondere seine Verwendung im Logo des Museums, das aus dem Anker und dem Namen der Institution besteht. Buchstäblich herausragend ist die kotwica auch am Museumsgebäude angebracht, nämlich dem Aussichtsturm, und fungiert damit als ein weithin sichtbares Emblem der Institution. Durch diesen Einsatz des während des Kriegs in großen Teilen des besetzten Landes verwendeten Zeichens wird es unmittelbar mit dem Warschauer Aufstand verknüpft und zu einem spezifischen Symbol der Ereignisse von 1944 uminterpretiert. Selbst wenn dies nicht die Absicht der Museumsverantwortlichen ist, so muss doch davon ausgegangen werden, dass es in der öffentlichen Wahrnehmung insbesondere in Warschau inzwischen als solches geprägt ist. Dazu trägt auch die mögliche Verwechslung der ursprünglichen Bedeutung der beiden Buchstaben P und W für Polska Walcząca (Kämpfendes Polen) mit dem Begriff Powstanie Warszawskie (Warschauer Aufstand) bei. 
seinem Inneren, durch inszenierte »Einschusslöcher «, sind Lieder der Aufständischen, Gebete, Geräusche von Schusswechseln und insbesondere ein vermeintlicher Herzschlag zu hören.

An seiner Schmalseite ist eine Tafel angebracht, die über die Aussage der Installation informiert:

\section{MONUMENT.}

Das `Herz‘ des Museums schlägt für diejenigen, die gekämpft haben, die umgekommen sind - und für diejenigen, die überlebt haben. Es ist ein Symbol unserer Erinnerung und Ausdruck der Ehrerbietung für den Warschauer Aufstand und seine Teilnehmer. Im Monument wurden die Geräusche des aufständischen Warschaus eingeschlossen [...], die uns in die Atmosphäre dieser Tage hineinziehen. ${ }^{324}$

Spätestens diese Beschreibung identifiziert das Objekt unmissverständlich als Denkmal. Zugleich wird durch seine Widmung eine grundlegende Deutung des Aufstands etabliert. Dies geschieht, noch bevor die Besucher etwas von den Ereignissen der Erhebung erfahren haben. Denn die Installation ist in einem der ersten Ausstellungsabschnitte untergebracht, in dem der übergreifende Kontext des deutschen und sowjetischen Angriffs 1939 und des deutschen Besatzungsregimes im besetzten Polen dargestellt wird. ${ }^{325}$ Dem Aufstand wird jedoch bereits ein Denkmal gesetzt und damit eine grundlegende normative Interpretation vorweggenommen: Dass es sich um ein herausragendes, »denkmalwürdiges« Ereignis handele, dem die Besucher - die implizit zur angesprochenen Wir-Gemeinschaft gezählt werden - Ehre erweisen sollen. Das Monument reicht vom Erdgeschoss bis ins erste Stockwerk. Es ist daher ständiger Begleiter der Ausstellungsbesucher; es ist nicht nur von verschiedenen Punkten der Ausstellungsräumlichkeiten immer wieder zu sehen, auch der vermeintliche Herzschlag, der aus seinem Inneren dringt, ist in einem großen Teil der Ausstellung wahrnehmbar. Die Besucher werden daher immer wieder an die Bedeutung der Ereignisse erinnert, von denen sie im Laufe ihres Rundgangs durch die Ausstellung erfahren und deren Deutung ihnen bereits zu Beginn mit auf den Weg gegeben wurde. Es handelt sich bei dieser Installation damit um ein projektives Element der Ausstellungskommunikation, das den Besuchern konkrete Interpretationen vorgibt. ${ }^{326}$ Diesem

324 MPW, Sektion 5: Monument.

325 Die Sektion 6: Besatzung, befindet sich direkt gegenüber dem Monument.

326 Mit der Integration von künstlerischen Arrangements in Ausstellungsflächen können laut Christopher Marshall sowohl projektive als auch reflexive Räume (projective space versus reflective space) innerhalb des Ausstellungsrundgangs geschaffen werden, d.h. (Be-)Deutungen können vorgegeben oder aber Freiraum für eigene Assoziationen der Besucher geboten werden. Die Wirkung von Installationen hängt dabei zum einen von ihrer konkreten gestalterischen Form, aber auch entscheidend von ihrer Platzierung und Kontextualisierung innerhalb des Ausstellungsnarrativs ab. Marshall: When Worlds Collide, 170, 182. 


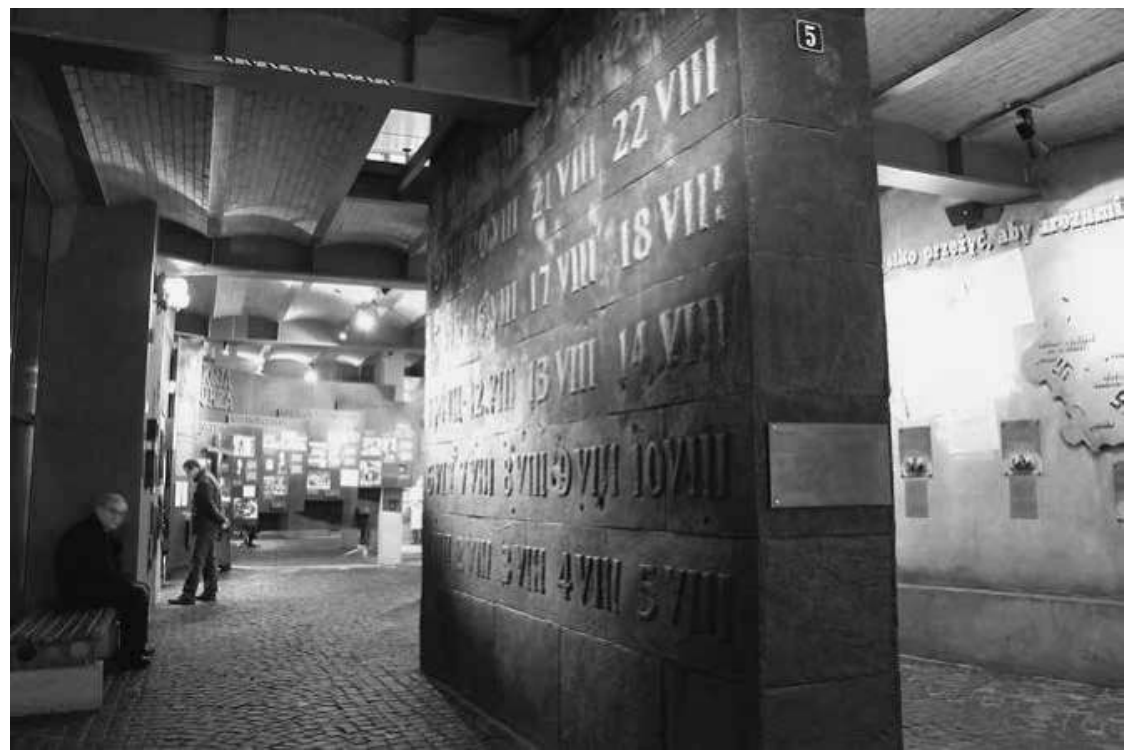

Abb. 48: MPW, das »Monument« im Erdgeschoss.

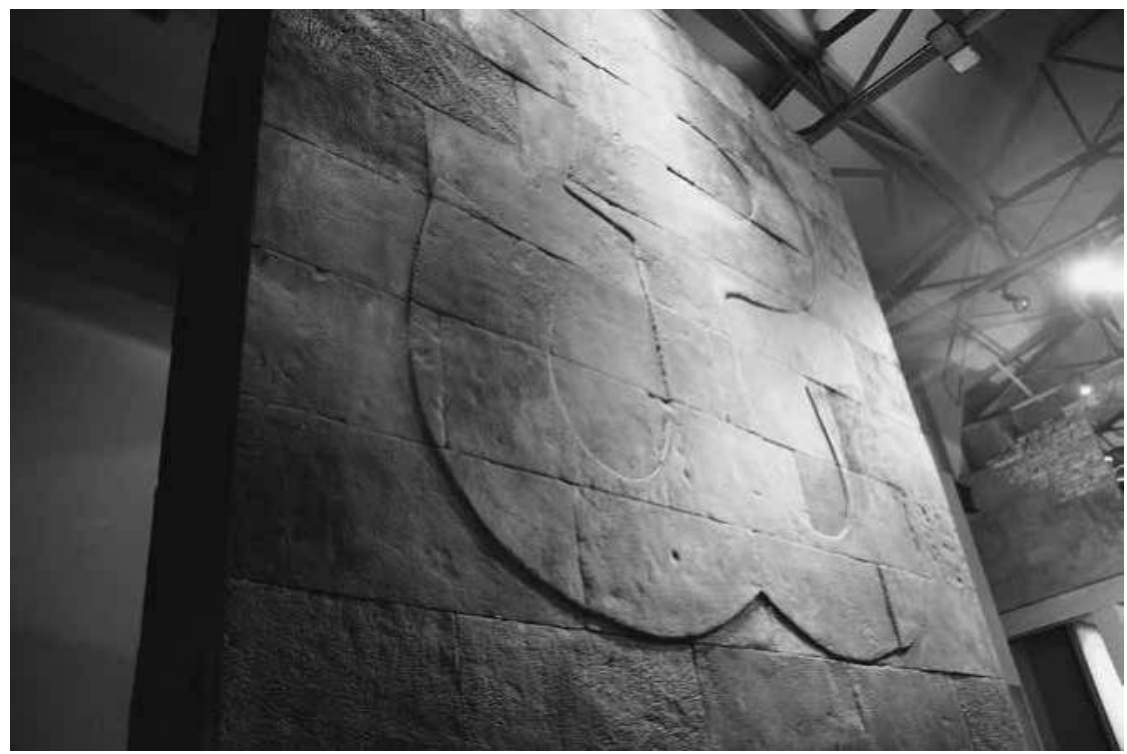

Abb. 49: MPW, das »Monument« in der ersten Etage. 
einleitenden Element der Schau folgend wird auch die übrige Aufstandserzählung dominiert von einem einseitig positiven und heroisierenden Blick auf die Kämpfe und ihre polnischen Protagonisten, die Aufständischen.

Expliziter Anspruch der Ausstellungsmacher war es, »echte Menschen « zu zeigen, "normale Menschen, solche wie jeder von uns «. ${ }^{327}$ Im Laufe des Rundgangs trifft man tatsächlich auf eine große Zahl von Individuen, Akteuren der Besatzungsgeschichte und insbesondere des polnischen Widerstands, darunter sowohl solche, die seit 1939 / 40 aktiv waren, als auch Kämpfer im Aufstand 1944. Bei diesen mit Fotografien und Biogrammen vorgestellten Personen, die über die ganze Schau verteilt in Schubladen und auf inszenierten Grabsteinen $^{328} \mathrm{zu}$ finden sind, handelt es sich jedoch immer um führende oder anderweitig herausragende Vertreter des Untergrunds und der Aufständischen. So werden etwa bei der Schilderung des Verlaufs der Aktion "Gewittersturm « allein die Anführer einzelner regionaler Einheiten der AK erwähnt. ${ }^{329}$ Auch im Verlauf der detaillierten Darstellung des Aufstands selbst werden sogenannte gewöhnliche Menschen, gerade einfache Zivilisten, namentlich nicht erwähnt. Diese bilden lediglich den Hintergrund der großflächig verteilten Fotografien und allgemeinen Schilderungen, beispielsweise in der Sektion $»$ Die Stunde $\mathrm{W} \ll$, die dem Ausbruch des Aufstands gewidmet ist, oder bei der Thematisierung der Versorgungslage. ${ }^{330}$ Alle der einzeln porträtierten Aufständischen sind dagegen Führungsfiguren, wenn auch oft mit niedrigem militärischen Rang, und haben sich während der Kämpfe ausgezeichnet. So wird etwa der Tod eines Mitglieds der Grauen Reihen porträtiert, des 16-jährigen Zbigniew Banaś, der als Meldegänger und Briefträger der Feldpost der Aufständischen agierte. Bei seiner Vorstellung wird betont, dass er »die Briefe der Feldpost an die entferntesten Abschnitte der Front [zustellt]. Für seinen Mut wird er posthum mit dem Tapferkeitsorden [Krzyż Waleczny] ausgezeichnet. ${ }^{331}$ Bei den dergestalt präsentierten »einfachen « Personen, die repräsentativ für »uns alle« stehen sollen - Polen in der Vergangenheit,

327 Kowal: Jak budowaliśmy Muzeum, 8.

$328 \mathrm{Zu}$ den »Grabsteinen« als Elementen der martyrologischen Ausstellungserzählung siehe Kapitel 1.3.

329 Darunter sind u.a. Jan W. Kiwerski, dessen AK-Einheiten im Bezirk Wolhynien die Aktion »Gewittersturm« initiierten, und Kazimierz Tumidajski, der Anführer des Bezirks Lublin der AK war. MPW, Sektion 9: Aktion »Gewittersturm».

330 MPW, Sektion 11: Die Stunde »W«, Sektion 17: Nahrung und Wasser. Die Bildunterschriften der meisten Fotografien verweisen auf deren geografische Position oder die Art der zu sehenden Aktivitäten. Die abgebildeten Personen bleiben dagegen überwiegend anonym; ihre Identifizierung erfolgt, wenn überhaupt, allgemein über die Zugehörigkeit zu einer Aufstandseinheit. Detaillierter wird auf die spezifische Schilderung des Alltags in diesem Museum in Kapitel 3.1 eingegangen.

331 Bereichstext »Zbyszek, genannt Banane«. MPW, Sektion 36: Die Kämpfe im September. 
aber auch in der Gegenwart - handelt es sich also weitgehend um politische, militärische und religiöse Führungs- und Symbolfiguren. Sie stellen zugleich Vorbilder dar in einem Heldennarrativ, das den Intentionen der Ausstellungsmacher zufolge auf die Ausbildung eines unkritischen, heroisierenden Patriotismus zielt. ${ }^{32}$ Die Besucher sollen sich mit diesen Personen identifizieren. Aus ihrer Perspektive heraus werden die sich entwickelnden historischen Ereignisse betrachtet.

Die Wahrnehmungen und Eindrücke der unteren Ränge der Aufständischen finden sich lediglich in Videozusammenschnitten von Interviews mit ehemaligen Kombattanten wieder. ${ }^{333}$ Diese Interviews wurden während der Entstehung des Museums geführt und spiegeln damit die gegenwärtige Perspektive der Protagonisten wider, fast sechzig Jahren nach dem Ereignis, und somit Einschätzungen, die unter dem Einfluss der Debatten, Berichterstattung und Literatur sowie eigener Reflexionen mehrerer Dekaden geformt worden sind. Auffällig ist zudem, dass für die Präsentationen Ausschnitte ausgewählt wurden, die nicht nur das Thema des entsprechenden Abschnittes behandeln, in dem sie untergebracht sind, sondern auch die dort vermittelte übergreifende Interpretation der Ausstellungsmacher stützen. ${ }^{334}$ So berichten in der Videopräsentation zum Untergrundstaat Mitglieder verschiedener Einheiten, wie sie Kontakt zum Untergrund aufgenommen haben und wie sie, oft Dank der Hilfe von Fremden, der Verhaftung durch deutsche Einheiten während ihrer konspirativen Arbeit entgingen. ${ }^{335}$ Zwischen den einzelnen Berichten wird der "Eid der Soldaten der AK" rezitiert, unterbrochen von Aufnahmen von Straßenrazzien, Exekutionen, dem Elend und massenhaften Sterben im Ghetto, die eindringlich die Notwendigkeit dieser Aktivitäten begründen. Berichte über Informanten in den Reihen der Widerständler oder über missglückte Aktionen fehlen dagegen. Der Mut und die Opferbereitschaft der jungen Kämpfer stehen im Vordergrund. An späterer Stelle berichten ehemalige Aufständische in einer Präsentation zum Aufstandsbeginn von ihrem Enthusiasmus bei Ausbruch der Kämpfe und der Unterstützung

332 Ołdakowski/Kowal: Podstawowe założenia programowe i organizacyjne, 6, 8.

333 So schildern ehemalige Kombattanten etwa die »Freude der ersten Tage«. Videopräsentation. MPW, Sektion 13: Die Freude der Aufständischen, Zitat: Titel des Bereichstextes. Weitere Videopräsentationen, die Zeitzeugeninterviews verwenden, sind in den Sektionen 6 (Besatzung), 7 (Polnischer Untergrundstaat) und 36 (Die Kämpfe im September) untergebracht.

334 Eine Ausnahme stellt die Videoaufzeichnung eines Interviews mit Marek Edelman dar, der durchaus kritische Aspekte der Aufstandsgeschichte berichtet. Dies ist jedoch zugleich die einzige Präsentation, die derart platziert worden ist, dass sie nur wenige Besucher tatsächlich ansehen. MPW, Sektion 15: Die Kämpfe im August. Näher hierzu siehe Teil 2, Kapitel 2.1.

335 MPW, Sektion 7: Polnischer Untergrundstaat. 
ihrer Angehörigen. Ein älterer Mann erzählt, wie seine Eltern zwar besorgt um ihren 15-jährigen Sohn gewesen seien, letztendlich habe sein Vater ihn aber ziehen lassen und ihm mit auf den Weg gegeben »Geh, mein Sohn, aber lass dich nicht blöd [auf blöde Art und Weise - d. Vf.] umbringen ${ }^{336}$ - ein Appell für einen würdigen, sinnhaften Tod. Anderweitige Reaktionen auf den Aufstandsausbruch, wie Unsicherheit, Angst und Ablehnung, finden sich hier nicht. Allein besorgte und dennoch unterstützende Eltern werden erwähnt. Eine ältere Frau äußert schließlich überzeugt, an die (nicht sichtbaren) Interviewer gerichtet, deren Platz in der Ausstellung die Besucher einnehmen: "Und ich denke, ihr jungen Leute, damals in Warschau, ihr wärt mit Sicherheit genauso engagiert gewesen und hättet gearbeitet wie wir. ${ }^{337}$ Diese Präsentation konstruiert somit eine Verbindung und ein Gemeinschaftsgefühl zwischen den Kämpfern von 1944 und den heutigen Museumsbesuchern. Damit wird eine heldenhafte und für ihr Land opferbereite, in diesem Verständnis patriotische Wir-Gemeinschaft etabliert. Dass dies ein Anliegen der Ausstellungsmacher ist, zeigt bereits die Platzierung dieser Videopräsentation: Sie nimmt eine ganze Wand im Zentrum der Ausstellungssektion ein. Davor gibt es eine große freie Fläche, in der sowohl Gruppen als auch zahlreiche individuelle Besucher stehen und die Präsentation ansehen und anhören können. Direkt vor der Präsentation ist eine Sitzgelegenheit installiert. Allein diese Verortung innerhalb des Rundgangs stellt sicher, dass ein Großteil der Besucher die emphatischen und emotionalen Schilderungen der Euphorie des Aufstandsbeginns rezipieren, die wiederum das heroische Grundnarrativ der Schau stützen.

Dieses Gefühl der Teilhabe, das hier vermittelt wird, unterstützen noch weitere gestalterische Mittel, unter anderem mehrere Installationen, die innerhalb des Rundgangs verteilt sind. So betritt man auf dem Zwischengeschoss scheinbar einen der Kanalisationskanäle, die die Aufständischen benutzten, um die von Deutschen besetzten Stadtteile unbemerkt zu passieren (siehe Abb. 50). ${ }^{338}$ Dieser ist breit, sodass mehrere Besucher bequem auch nebeneinander hindurchgehen können. Dennoch hat man versucht, den Kanal den Erfahrungen der Aufständischen nachzuempfinden: So sind darin etwa Schriftzüge an den Mauerwänden angebracht, die die geografische Orientierung erleichtern sollten oder an einem Kanalisationsausgang vor Deutschen an der Oberfläche warnen. Hier findet sich auch ein scheinbar vergittertes Kanalende, das in seiner Stilistik deutlich auf den Film Andrzej Wajdas »Kanał« (Der Kanal; VRP, 1956) rekurriert. Im Gegensatz zur Schlussszene des Films, in dem die einzigen zwei überlebenden Aufständischen an einem

336 Aussage von Kazimierz Głowacki. MPW, Sektion 13: Die Freude der Aufständischen.

337 Aussage von Maria Urbaniec-Downarowicz. Ebd.

338 MPW, Sektion 25: Kanal. 


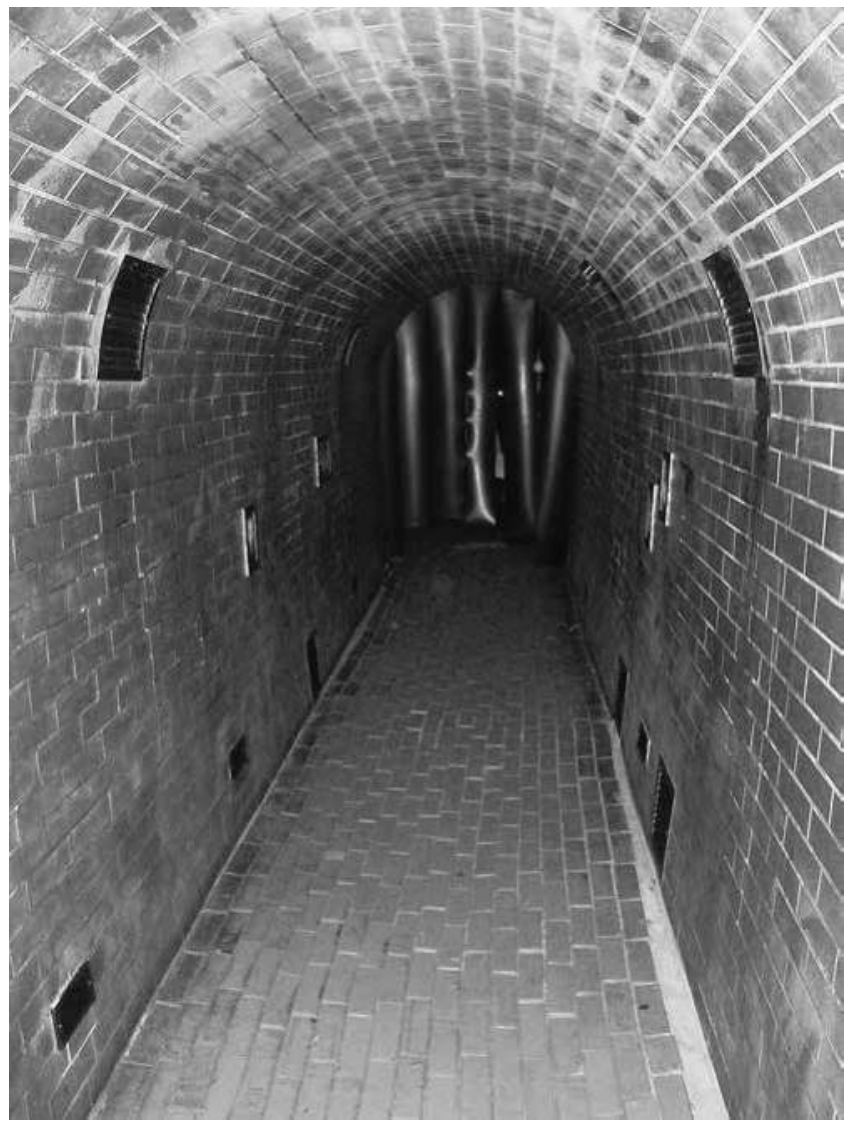

Abb. 50: MPW, Sektion »Kanal«.

verschlossenen Gitter ankommen (und damit ihrem Todesurteil begegnen), wird im Museum ein positiver Ausblick angeboten: Als Zeichen der Hoffnung sind mehrere Gitterstäbe durchbrochen. Im Keller des Museums findet sich schließlich ein in originalen Abmessungen nachgebauter Kanalisationskanal. ${ }^{339}$ Durch diesen können sich die Besucher zwängen und selbst die Dunkelheit und Enge erfahren, ${ }^{340}$ die die Aufständischen ertragen mussten - ein beliebter Spaß gerade bei Schülergruppen, auch wenn die suggerierte Authentizität selbstverständlich illusorisch ist; man bedenke allein die realen Bedingungen

339 MPW, Sektion 55: Nachbau eines Kanals.

340 Das vermeintliche »Nacherleben« der Erfahrungen der Aufständischen wird im Ausstellungsführer auch explizit als Ziel dieser Installation genannt. Dąbkowska-Cichocka: Przewodnik po Muzeum, 208. 
eines Abwasserkanals und vergleiche diese mit dem sauberen, warmen und sicheren Nachbau im Museum. An anderer Stelle können die Besucher eine der Waffen der Aufständischen bzw. ihre Nachbildung berühren und sogar den Auslöser betätigen. ${ }^{341}$

Diese inszenatorischen Mittel tragen wesentlich zu der starken Emotionalisierung der gesamten Ausstellungserzählung bei. ${ }^{342}$ Einen wesentlichen Einfluss hierauf hat nicht zuletzt die in der Schau verwendete Sprache. Nicht nur sind alle Texte im Präsenz formuliert, wodurch die Besucher die Entwicklung der Ereignisse scheinbar unmittelbar verfolgen. Wie bereits in den Kapiteln 1.3 und 2.3 des ersten Teils geschildert wurde, sind die von den Kuratoren verfassten Ausstellungstexte stark normativ aufgeladen. Während die Darstellungen der Kriegsgegner und Besatzer durch abwertende, sarkastische und ihre Verbrechen eindeutig verurteilende Formulierungen begleitet sind, erfolgt in der Präsentation der Aufständischen das genaue Gegenteil: Hier wird der Mut und das Heldentum der Protagonisten unterstrichen. Dies geschieht durch die Wortwahl, so etwa bei der Schilderung des Sanitätsdienstes: »Der Dienst in der Sanitätspatrouille erfordert Opferbereitschaft und Mut « ${ }^{343}$ oder im Biogramm von Kardinal Adam Stefan Sapieha, in dem es heißt: »[w]ürdevoll repräsentiert er die Nation in Gesprächen mit der deutschen Führung « ${ }^{344}$. Auch die verwendete Terminologie trägt zur deutlichen Abgrenzung der negativ und positiv bewerteten Protagonisten der Ausstellungserzählung bei. So ist die Bezeichnung "Soldat« in der gesamten Ausstellung fast ausschließlich den Aufständischen vorbehalten, wodurch die Legitimität, Legalität und nicht zuletzt Ehrbarkeit ihres Kampfes für die Unabhängigkeit des Vaterlandes unterstrichen wird. Auffällig ist, dass der Begriff "Soldat" für Männer und Frauen verwendet wird, womit das ursprünglich rein männliche Heldennarrativ um weibliche Protagonisten erweitert wird. ${ }^{345}$ Die besondere Würdigung der Aufständischen zeigt sich noch in einem weiteren Detail: In sämtlichen Ausstellungstexten werden sowohl der Begriff "Warschauer Aufstand « als auch »Aufständische(r) « groß geschrieben, was im Polnischen unüblich ist - und somit bereits rein sprachlich den Aufstand als herausragendes Ereignis markiert. ${ }^{346}$

341 MPW, Sektion 15: Die Kämpfe im August.

$342 \mathrm{Zu}$ den emotionalisierenden Elementen des MPW siehe auch Heinemann: Emotionalisierungsstrategien, 226-236.

343 Objektbeschriftung. MPW, Sektion 22: Das Krankenhaus der Aufständischen.

344 MPW, Sektion 7: Polnischer Untergrundstaat.

345 Zu einer Sanitäterin wird beispielsweise berichtet: „Sie stirbt, erschossen nach den Worten >Ich bin Soldat der Heimatarmee.« Objekttext. MPW, Sektion 22: Das Krankenhaus der Aufständischen.

346 Diese spezifische Schreibweise verwendet das Museum auch auf seiner Website, in eigenen Publikationen und der Öffentlichkeitsdarstellung. 
Es sind jedoch nicht allein die Aufständischen des polnischen Untergrunds, die exponiert als Kämpfer für die Unabhängigkeit des Landes präsentiert werden. Auch die polnischen Soldaten der sogenannten BerlingArmee $^{347}$ ebenso wie die polnischen Soldaten in den Armeen der westlichen Alliierten ${ }^{348}$ finden sich prominent porträtiert. Bei der Schilderung der alliierten Hilfsflüge wird etwa mehrfach der militärische wie zivile Beitrag von Polen erwähnt. ${ }^{349}$ Hierdurch wird nicht nur ihr Einsatz gewürdigt, sondern insbesondere betont, dass Polen an allen Fronten für die Unabhängigkeit des Landes gekämpft und versucht haben, dem Aufstand zum Erfolg zu verhelfen.

Wie bereits festgestellt wurde, ist die Wir-Gemeinschaft der Polen, die in diesem Museum präsentiert wird, eng definiert. Exemplarisch im Bereich der Widerstandserzählung steht dafür die Darstellung der dritten Akteursgruppe im Warschauer Aufstand aufseiten der AK, nämlich der Ausländer. Diesen ist eine eigene, kleine Sektion gewidmet. ${ }^{350}$ In deren einleitendem Bereichstext wird die grundlegende Abgrenzung der polnischen zu anderen ethnischen Gruppen pointiert getroffen. Es heißt dort: »Im Warschauer Aufstand kämpfen neben Polen freiwillig Vertreter vieler Nationalitäten. Die größte Gruppe sind Juden." Durch die pauschale Zuordnung aller Juden, die im Aufstand kämpften, zu den »Ausländern« (an den Kämpfen nahmen etwa ungarische Juden teil, die aus der Gęsiówka befreit worden waren), werden implizit auch die überlebenden Warschauer und damit die polnischen Juden en gros aus der ethnisch-national konnotierten Wir-Gemeinschaft ausgeschlossen.

Ein weiteres Kennzeichen der Präsentation - und damit ihrer Heldendarstellung - liegt in der deutlichen Kontrastierung von "Gut« und »Böse«, die auch im Arrangement der Ausstellungsräume transportiert wird. Die Sektionen, die sich mit den deutschen Besatzern und dem Einfluss der Sowjetunion auf die polnische Nachkriegsentwicklung befassen, schaffen bereits durch ihre Gestaltung eine Distanz zwischen den Besuchern und den geschil-

347 MPW, Sektion 29: Die Soldaten der Berling-Armee. Hierbei handelte es sich um polnische Streitkräfte, die auf Befehl der sowjetischen Führung in der UdSSR seit 1943 aufgebaut wurden. Zusammengesetzt waren sie aus polnischen Staatsbürgern, die aus den ostpolnischen Gebieten in die Sowjetunion deportiert worden waren. Oberbefehlshaber der Armee wurde General Zygmunt Berling.

348 MPW, Sektion 21: Abwürfe.

349 So etwa im Bereichstext "Allierte Flieger über Warschau«, in dem die polnischen Flieger besonders hervorgehoben werden. Auch in Objektbeschriftungen wird auf den Einsatz von Polen an vorderster Front hingewiesen: $»[\ldots]$ Als erste fliegen über Warschau Polen aus dem 1586. Geschwader für Besondere Aufgaben. [...]«In einem Zeitungsbericht aus der Londoner Zeitschrift Wicher wolności (Sturm der Freiheit) aus dem Jahr 1984 wird über die in den Abwürfen enthalten Hilfslieferungen berichtet: »[...] Den Malteserinnen zittern die Hände, als sie Blut für Transfusionen herausnehmen. Polnische Etiketten. Das Blut polnischer Blutspender aus dem polnischen Krankenhaus in Edinburgh.« Ebd.

350 MPW, Sektion 39: Ausländer im Aufstand. 
derten Ereignissen und Personen: Wie in Kapitel 1.3 des ersten Teils erläutert, strahlen die Räume, in denen »die Deutschen" thematisiert werden, durch die Verwendung kühlen Neonlichts, grober Materialien wie Beton und Metall und schließlich einer Geräuschkulisse, die von marschierenden Soldaten, Schüssen und gebrüllten Befehlen dominiert ist, bereits eine kühle, rohe und mit Gewalt assoziierte Atmosphäre aus. Die Sektion zum "Lubliner Polen" wiederum ist vollständig in leuchtendem Rot gehalten - einer Farbe, die sowohl mit der kommunistischen Sowjetunion als auch mit Blut und damit Gewalt verbunden wird und die in der Schau ansonsten nur bei der Darstellung der Rolle Stalins und der UdSSR sowie der Verfolgung der Aufständischen nach Kriegsende großflächig verwendet wird. ${ }^{351}$ Die übrige Ausstellungsfläche, die den Großteil der Schau ausmacht, ist dagegen deutlich freundlicher gestaltet. Es wird warmes Licht verwendet, das inszenierte Mauerwerk ist in Brauntönen gehalten, das Kopfsteinplaster auf dem Boden, das an das Straßenpflaster der okkupierten Stadt erinnern soll, wird für die meisten der Besucher vertraut wirken. Trotz des geschilderten Leids und der Kämpfe ist die Darstellung des Aufstands selbst somit dominiert von einer vergleichsweise freundlichen Atmosphäre. Dies ist insofern nachvollziehbar, als den Besuchern, die einen sehr langen Ausstellungsparcours bewältigen müssen, der Aufenthalt möglichst angenehm gemacht werden soll. Zugleich unterstützt diese Gestaltungsweise jedoch auch das in den entsprechenden Sektionen vermittelte Bild der jeweiligen Protagonisten. Eine deutliche Trennung zwischen »Uns«, der polnischen Wir-Gemeinschaft, und den eindeutig negativ charakterisierten Feinden wird somit auf mehreren Kommunikationsebenen vermittelt.

Eine Trennungslinie verläuft jedoch nicht allein gegenüber äußeren »Fremden« bzw. Feinden. Gleichzeitig wird auch eine Unterscheidung innerhalb der eigenen Wir-Gemeinschaft zwischen "guten" und »bösen« Polen vollzogen. Wie bereits erwähnt, werden die Aufständischen von 1944 in der gesamten Ausstellung weitgehend mit der Heimatarmee gleichgesetzt, zu der auch die Pfadfinder der Grauen Reihen gezählt werden. Andere Gruppen, die ebenfalls im Aufstand kämpften, erwähnt man lediglich an wenigen Stellen. ${ }^{352} \mathrm{Zu}$ ihnen gehört der NSZ, der die zweitgrößte Truppenstärke nach der AK im Aufstand ausmachte und mit ihr zusammenarbeitete. ${ }^{353}$ Ebenfalls vorgestellt werden die Soldaten der Berling-Armee, das heißt diejenigen Polen, die aufseiten

351 So in Sektion 46 (Die Aufständischen in der VRP) oder in Sektion 32 (Treffen im Kreml). Bei letzterem ist das großformatige Zitat Iosif Stalins - seine Absage an eine Hilfe für die Aufständischen - in rot gehalten. Siehe hierzu auch Teil 1, Kapitel 2.3.

352 Die Zusammensetzung der Aufständischen wird in einem kurzen Bereichstext geschildert. Bereichstext »Kräftevergleich«. MPW, Sektion 11: Die Stunde »W«.

353 Ein Informationstext erwähnt den NSZ kurz; daneben werden zwei der Anführer dieser Truppen vorgestellt. Bereichstext »Der NSZ auf den Barikaden«. MPW, Sektion 36: Die Kämpfe im September. 
der Sowjetunion kämpften: Sie werden jedoch nicht für ihre Zusammenarbeit mit dem Feind verurteilt. Vielmehr exkulpiert man sie explizit aufgrund ihres Kampfes für die Befreiung Polens ebenso wie durch den Hinweis, dass »für viele Polen [...] die Armee von der Oka die einzige Chance auf eine Rückkehr ins Land [ist] «. ${ }^{354}$ So wird unter dem Titel »Die Opfer der Politik Väterchen Stalins« (Ofiary polityki batiuszki Stalina) ${ }^{355}$ der Versuch der Soldaten der Polnischen Armee, vom Stadtteil Praga aus in den umkämpften Warschauer Vierteln zu landen, folgendermaßen erläutert:

[...] Sie [die polnischen Soldaten - d.Vf.] glauben, sie würden den Aufständischen zu Hilfe kommen - in Wirklichkeit, unvorbereitet für den Kampf in der Stadt, erleiden sie schwere Verluste. Die Landung endet mit einer Niederlage. Nur Stalin ist zufrieden - er kann die Beschuldigungen einer Vernachlässigung der Hilfe für den Aufstand abweisen. ${ }^{356}$

Als Kämpfer für die gerechte nationale Sache, die von der Sowjetunion lediglich benutzt wurden, porträtiert man sie als Teil der nationalen Heldengemeinschaft. Ihr Anführer, General Zygmunt Berling, wird jedoch kurz darauf als ein Vertreter der mit der Sowjetunion zusammenarbeitenden neuen Führung des Landes negativ markiert. ${ }^{357}$

Eine ähnliche Argumentation verwendet die knappe Präsentation der Einheiten der kommunistischen Volksarmee, die im Aufstand kämpften. Bei ihrer Darstellung unterstreicht man gleich zu Beginn, dass diese kleine Formation von etwa 300 Personen "trotz des Widerstands eines Teils der führenden Parteifunktionäre der PPR « am Aufstand teilnahm. ${ }^{358}$ Auch werden diese Mitglieder der AL ebenfalls als »Soldaten « bezeichnet. Zwar ist aus den in unmittelbarer Nähe gezeigten Titelseiten von Untergrundzeitschriften der PPR-AL zu entnehmen, dass diese die Zusammenarbeit mit der Roten Armee und der Sowjetunion unterstützten. Als Mitkämpfer im Aufstand erscheinen jedoch diese kommunistischen Widerständler als gleichwertige Kämpfer für das Vaterland. ${ }^{359}$ Interessanterweise wiederholt sich hier eine Argumentationsweise, die unter

354 Objektbeschriftung. MPW, Sektion 28: Das Lubliner Polen.

355 Titel des Bereichstextes. MPW, Sektion 29: Die Soldaten der Berling-Armee.

356 Bereichstext: »Die Opfer der Politik Väterchen Stalins«. Ebd.

357 Das Biogramm Berlings ist mit einem roten Stempel in der Form von Hammer und Sichel versehen. MPW, Sektion 28: Das Lubliner Polen.

358 Bereichstext »Die Volksarmee im Aufstand«. MPW, Zwischengeschoss, ohne Sektion.

359 An anderer Stelle wird die AL noch im Zusammenhang mit der Befreiung der sogenannten Gęsiówka genannt, eines Außenlagers des Konzentrationslagers Majdanek in der Gęsia-Straße in Warschau, in dem Juden inhaftiert waren. In diesem Abschnitt wird erwähnt, dass die meisten Juden, die sich in Warschau bis 1944 versteckt gehalten hatten, beim Ausbruch des Aufstands der AL beitraten. Auch Marek Edelman berichtet in dem an dieser Stelle ausgestrahlten Interview, dass er in die AL ging (siehe Teil 2, Kapitel 2.1.). Bereichstext »Juden im Warschauer Aufstand«. MPW, Sektion 15: Die Kämpfe im August. 
umgekehrten Vorzeichen in der VRP auf die Mitglieder der Heimatarmee und die Warschauer Aufständischen angewandt wurde: ${ }^{360}$ Es erfolgt eine Unterscheidung zwischen einer verbrecherischen bzw. landesverräterischen Führung und den einfachen Soldaten. Hier sind es nun die Mitglieder der unteren Reihen der AL (zuvor bereits der Berling-Armee), die aufgrund ihrer Teilnahme am Kampf um Warschau in den Pantheon der Helden aufgenommen werden. Ihre Anführer, allen voran die politische Führung der PPR, werden jedoch für ihre Zusammenarbeit mit dem Feind Sowjetunion aus ebendieser Gemeinschaft ausgeschlossen.

Ähnlich verhält es sich auch mit den Repräsentanten der neuen kommunistischen Übergangsregierung in den von der Roten Armee befreiten Gebieten, denen die Sektion "Das Lubliner Polen" gewidmet ist. ${ }^{361}$ Diese werden pauschal unter der Kollektivbezeichnung "die Kommunisten« (komuniści) gefasst; nur wenige führende Vertreter des neuen Regimes werden namentlich genannt und mittels Biogrammen vorgestellt. ${ }^{362}$ Als politische Alliierte der in der Ausstellung ausschließlich negativ bewerteten UdSSR werden diese jedoch buchstäblich abgestempelt: Auf ihre Biogramme samt Porträtfotografien wurde jeweils das Symbol von Hammer und Sichel in Form eines roten Stempels abgedruckt - eine Form der Markierung, die bei den übrigen in der Ausstellung verteilten Biogrammen nicht angewendet wird. Nachdrücklich betonen auch die verwendeten Begriffe die Distanz zwischen »den Kommunisten" und der übrigen polnischen Bevölkerung: In den begleitenden Ausstellungstexten, selbst in Objektbeschriftungen, werden Ausdrücke wie "Volksherrschaft / Volksregierung " (władza ludowa) ausnahmslos in Anführungszeichen gebraucht und den "polnischen Soldaten und Zivilisten « gegenübergestellt, die ohne diese Zeichen der Distanzierung auskommen. ${ }^{363}$ Eine Hervorhebung erhält auch die Tatsache, dass das PKWN und die neuen polnischen Anführer in den befreiten Regionen von außen, nämlich der UdSSR bzw. Stalin, eingesetzt und ihm unterstellt, demnach also nicht unabhängig waren:

[...] Am 21. Juli berufen die polnischen Kommunisten, auf Anweisung Stalins hin, in Moskau das Polnische Komitee der Nationalen Befreiung, das unter der vollständigen Kontrolle der sowjetischen Führung steht. [... $]^{364}$

360 Borodziej: Der Warschauer Aufstand, 208-213.

361 MPW, Sektion 28: Das Lubliner Polen.

362 Einzeln vorgestellt werden u. a. Jerzy Borejsza, der an der Spitze des Zensursystems der VRP stand, und General Zygmunt Berling, der Anführer der polnischen Armee in der Sowjetunion. Ebd.

363 Objektbeschriftung. Ebd. Prägnant zeigt dies auch die Objektbeschriftung zu der Fotografie einer Massendemonstration: »Die Kommunisten brauchen die `Unterstützung des Volkes - eine Demonstration `der Freude` über die Transformation des PKWN in die Übergangsregierung organisieren sie in Lublin schon am nächsten Tag.« Ebd.

364 Thementext »Lubliner Polen««. Ebd. 
An anderer Stelle wird Bolesław Bierut, der erste Präsident der Volksrepublik Polen, als »Stalins Mann«" vorgestellt. ${ }^{365}$ Dies markiert die polnischen Kommunisten indirekt als »fremde " Macht, was sie aus der Gemeinschaft der übrigen Polen, dem »für die Unabhängigkeit kämpfenden Untergrund«, ausschließt. ${ }^{366}$ Zugleich wird ihnen dadurch auch die Legitimität als Vertreter polnischer Interessen abgesprochen. Während der mit der AK verbundene Untergrund positiv erscheint, da er die Führung der Londoner Exilregierung und des von ihr geleiteten Untergrundstaates akzeptiert, die bereits zu Beginn der Schau als legitime Führung des besetzten Landes eingeführt wurde, ${ }^{367}$ werden »die Kommunisten« als Marionetten Stalins porträtiert. Dies vermittelt äußerst plakativ eine stark vergrößerte Karikatur: Darauf ist Stalin zu sehen, der einer mit einer Mechanik bestückten Puppe, die er von hinten aufzieht und die mit dem Schriftzug »Komitee der Nationalen Befreiung« versehen ist, ein »Memorandum der polnischen Regierung « reicht. Mit Blick auf die Marionette äußert er: "Ich mische mich nicht in polnische innere Angelegenheiten ein - soll er das für mich erledigen!«. Die Unterzeile lautet: »Verabschiedung nach Lublin«. Die Karikatur überlappt ein großformatiges Plakat, auf dem die Repräsentanten des PKWN vorgestellt wurden; unmittelbar daneben wird die Publikation und Verbreitung des sogenannten Manifests des PKWN geschildert. Sie ist somit als Anspielung erkennbar auf die Gründung des PKWN und die Absprache bzw. Vorgabe seiner »Regierungserklärung «, des Manifests, durch Moskau. Diese Zeichnung ist jedoch mit keinerlei Objektbeschriftung oder anderen Hinweisen versehen, die auf ihren Entstehungsort und Publikationszeitpunkt verweisen würden. Daher wirkt sie in der Präsentation wie ein direkter Kommentar der Ausstellungsmacher.

Immer wieder wird schließlich der Verrat polnischer Interesse an die Sowjetunion durch die polnischen Kommunisten betont. So heißt es etwa zur Festlegung der neuen Ostgrenze des Landes:

[...] Während der Gespräche mit Stalin akzeptieren die polnischen Kommunisten die sowjetischen Forderungen in vollem Umfang. Sie versuchen nicht, um die Zugehörigkeit der östlichen Gebiete zu Polen zu kämpfen. [... $]^{368}$

Zusätzlich desavouierend wirken Verweise auf die Ähnlichkeit der Methoden der Kommunisten und der deutschen Besatzer:

Brutale Revisionen gehören während der fünf Jahre der Besatzung zum polnischen Alltag - nach der `Befreiung « werden diese reibungslos durch die Soldaten des Korpus

365 Objektbeschriftung zu einem großformatigen Porträt Bieruts. Ebd.

366 Thementext »Lubliner Polen««; Bereichstext »Die Anfänge des Kampfes gegen die Freiheit«. Ebd.

367 MPW, Sektion 7: Polnischer Untergrundstaat.

368 Bereichstext »Das PKWN und die östliche Grenze«. MPW, Sektion 28: das Lubliner Polen. 
der Inneren Sicherheit [Korpus Bezpieczeństwa Wewnętrznego; Formation des polnischen Ministeriums für Öffentliche Sicherheit] durchgeführt. ${ }^{369}$

Die `Volksregierung verwandelt nach dem Vorbild der Deutschen das Lubliner Schloss in ein schweres Gefängnis um. In Exekutionen sterben wieder polnische Soldaten und Zivilisten. ${ }^{370}$

Auch in anderen Sektionen der Ausstellung, die sich auf das Polen der Nachkriegszeit beziehen, steht der Begriff »Kommunisten« in eindeutiger Opposition zur polnischen Wir-Gemeinschaft, die die Ausstellung konstruiert. Exemplarisch geschieht dies gleich zu Beginn der Schau, die mit dem Schicksal der Aufständischen nach dem Krieg eröffnet. Erwähnt wird dort, dass einige der ehemaligen Kämpfer »sogar durch die Kommunisten ermordet [wurden] «. ${ }^{371}$ Der einleitende Thementext stellt sodann »die Kommunisten « direkt den AK-Kämpfern und ehemaligen Aufständischen gegenüber. Die Illegitimität des sozialistischen Nachkriegspolens, die den Besuchern durch diese Gegenüberstellung vermittelt wird, zeigt sich nicht zuletzt darin, dass als das »freie Polen« explizit dasjenige bezeichnet wird, das nach »dem Fall des Kommunismus 1989 « entstand. ${ }^{372}$

Zusammenfassend lässt sich für das Museum des Warschauer Aufstands festhalten, dass in diesem das Heldennarrativ des Widerstandskampfes das Bild der polnischen Wir-Gemeinschaft dominiert. Dieser Kampf ist sowohl gegen äußere Feinde gerichtet, unmittelbar gegen die deutschen Besatzer und politisch gegen die UdSSR - die im Vergleich zu den Deutschen sogar deutlich in den Vordergrund tritt - als auch gegen deren Unterstützer im Inneren, die polnischen Kommunisten. Die Gemeinschaft der Polen, die in diesem Museum konstruiert wird, ist eine einheitlich kämpferische, antikommunistische und ehrbare in ihren Zielen wie ihren Verhaltensweisen. Ihre Darstellung ist damit durch starke moralische Imperative charakterisiert. ${ }^{373}$ Die am Aufstand aktiv teilnehmende kleine Gruppe der AL erscheint als Ausnahme, die den Ausschluss der übrigen polnischen Kommunisten aus der Gemeinschaft der Polen noch unterstreicht.

Weniger heroische, ambivalente oder gar negative Ereignisse während des Aufstands finden sich im Laufe des Rundgangs dagegen so gut wir gar nicht. ${ }^{374}$

369 Objektbeschriftung. Ebd.

370 Objektbeschriftung. Ebd. Hervorhebung durch die Verfasserin.

371 Bereichstext »Die Aufständischen in der VRP«. MPW, Sektion 3: Der Aufstand nach 60 Jahren.

372 Thementext »Erinnerung und Geschichte«; Bereichstext »Die Aufständischen in der VRP«. Ebd.

373 Mit dieser Darstellungsweise vermittelt die Schau den von Vertretern der PiS propagierten »romantischen Heldenkult«. Nijakowski: Polska polityka pamięci, 220.

$374 \mathrm{Zu}$ der spezifischen Präsentationsweise des Alltags während des Aufstand sowie der Leerstellen der Erzählung des MPW siehe Kapitel 3. 
Besonders auffällig erscheint die vollständige Ausklammerung der Debatte, die die Auseinandersetzung mit dem Warschauer Aufstand jahrzehntelang geprägt hat: der Diskussion um die Frage nach dem Sinn der Kämpfe und ihrer immensen Opfer. ${ }^{375}$ In der gesamten Ausstellung finden sich allein Positionen, die die Aufstandsentscheidung unterstützen. Auf die erste treffen die Besucher, noch bevor sie die Präsentation selbst betreten haben: Über deren Eingangstür ist das Motto der Schau angebracht (siehe Abb. 51): »Wir wollten frei sein und diese Freiheit uns allein verdanken. ${ }^{376}$ In der ersten Sektion wird dann das Video eines Interviews mit Jan Nowak-Jeziorański ausgestrahlt. ${ }^{377}$ Nowak-Jeziorański schildert dort wortreich und emotional seine Überzeugung, »dass das ausbrechen musste!« Diese Worte müssen für polnische Besucher umso eindrücklicher wirken, als der berühmte Kurier, der Informationen zwischen der Exilregierung und der Führung des Untergrundstaates im besetzten Land transportiert hatte, in der Dritten Republik zu einer Symbolfigur avanciert ist, einem Repräsentanten des Freiheitskampfes. Kurz darauf trifft man auf eine ähnlich eindeutige, die Aufstandsentscheidung unterstützende Aussage: »Man musste das alles erlebt haben, um zu verstehen, dass Warschau nicht nicht kämpfen konnte. « ${ }^{378}$ Dieser Satz überspannt großformatig die gesamte Länge des Ausstellungsabschnitts, in dem der Kriegsausbruch und die Besatzungen geschildert werden (siehe Abb. 52). Wie diese Beispiele zeigen, finden sich schon im ersten Teil der Ausstellung mehrere explizite und in ihrer Wertung übereinstimmende Antworten auf die jahrzehntelang diskutierte Frage nach dem Sinn des Aufstands und der Verantwortung seiner politischen und militärischen Führer. Dennoch wird die Sinnfrage in der Schau selbst kein einziges Mal direkt formuliert. Allein ein vereinzelter Hinweis macht deutlich, dass die Entscheidung für den Aufstandsbeginn nicht unumstritten war. Im Thementext »Vor der Stunde >W« heißt es: »Trotz zahlreicher Zweifel und Widerstände vonseiten des RJN [Rada Jedności Narodowej/ Rat der Nationalen Einheit] fällt am 31. Juli die Entscheidung zum Auslösen des Aufstands $« .{ }^{379}$ Bevor die Besucher

375 Den Verlauf der Debatte, die eng verknüpft war mit der Bewertung der Heimatarmee, zeichnen nach Dmitrów, Edmund/Kułak, Jerzy: Der polnische "Historikerstreit« zur Armia Krajowa. In: Chiari, Bernhard (Hg.): Die polnische Heimatarmee. Geschichte und Mythos der Armia Krajowa seit dem Zweiten Weltkrieg. München 2003, 807-846, hier 832-836; Borodziej: Der Warschauer Aufstand, 208-218. Am Beispiel der Manifestationen der Erinnerung an die AK und den Aufstand 1944 schildert die Auseinandersetzungen Markiewicz: Der Kampf um die Erinnerung, 753-775.

376 Das Zitat stammt vom Vizepremier der polnischen Exilregierung und Delegierten der Regierung im Lande Jan Stanisław Jankowski. MPW, Sektion 2: Eingangsbereich.

377 MPW, Sektion 3: Der Aufstand nach 60 Jahren.

378 Diese Worte stammen von Kazimierz Iranek-Osmecki, einem der Führer der Heimatarmee. MPW, Sektion 6: Besatzung.

379 MPW, Sektion 10: Vor der Stunde »W«. 


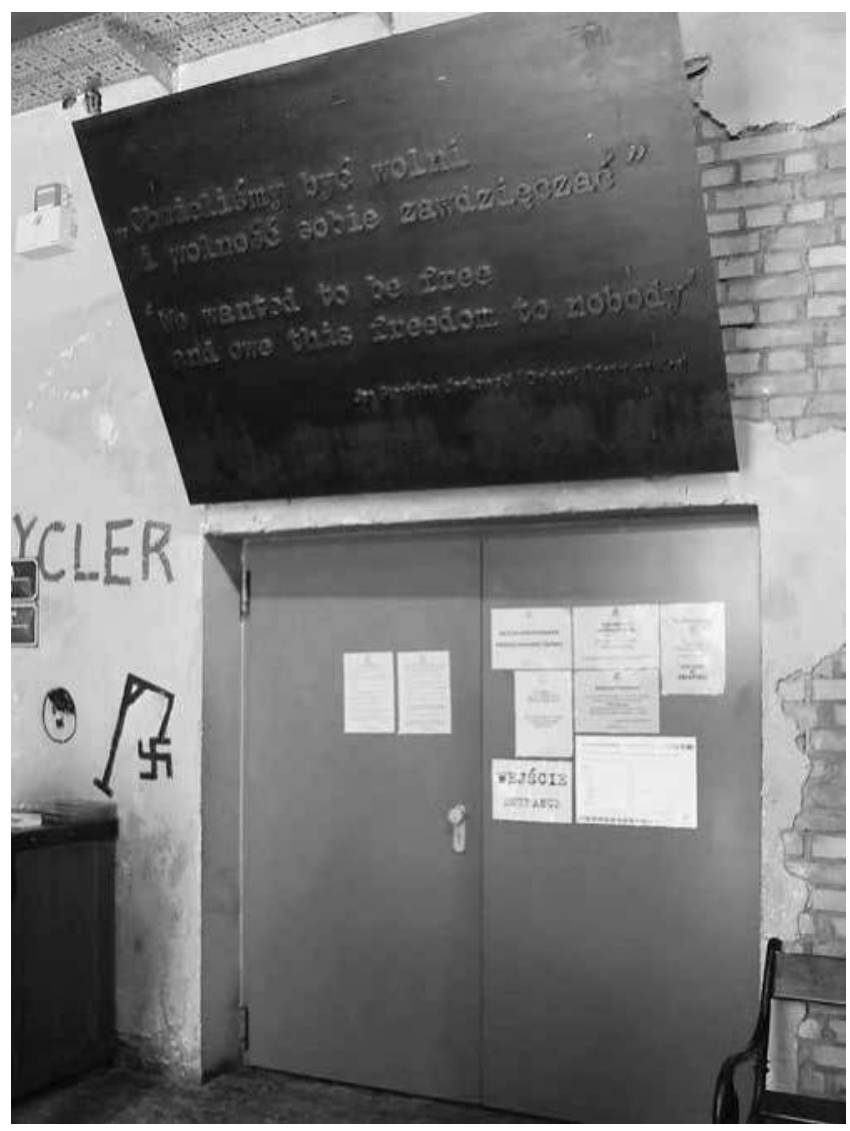

Abb.51: MPW, Eingangsbereich des Museums.

jedoch an diesen Punkt der Ausstellung gelangen und die Möglichkeit haben, diese vereinzelte Information zu entdecken, wurden ihnen die Notwendigkeit und Unausweichlichkeit des Aufstands bereits mehrfach durch die beschriebenen Ausstellungselemente deutlich gemacht.

Die Vermeidung einer Auseinandersetzung mit der Debatte um den Aufstand ist auch einer der größten Kritikpunkte an der Dauerausstellung seit ihrer Eröffnung. ${ }^{380}$ Die Museumsleitung ist sich dieser durchaus bewusst und gab bislang als Erklärung an, dass die intellektuelle Debatte museal nur

380 So etwa bei Traba, Robert: Kicz patriotyczny [Patriotischer Kitsch]. In: Gazeta Wyborcza vom 6.1.2006, Online-Ausgabe, URL: www.wyborcza.pl (am 29.5.2011); Ostolski: Przestrzeń muzeum, 83; Krzymianowska: Der Warschauer Aufstand, 222; Garsztecki: Warschauer Aufstand, 136-156, hier 148. 


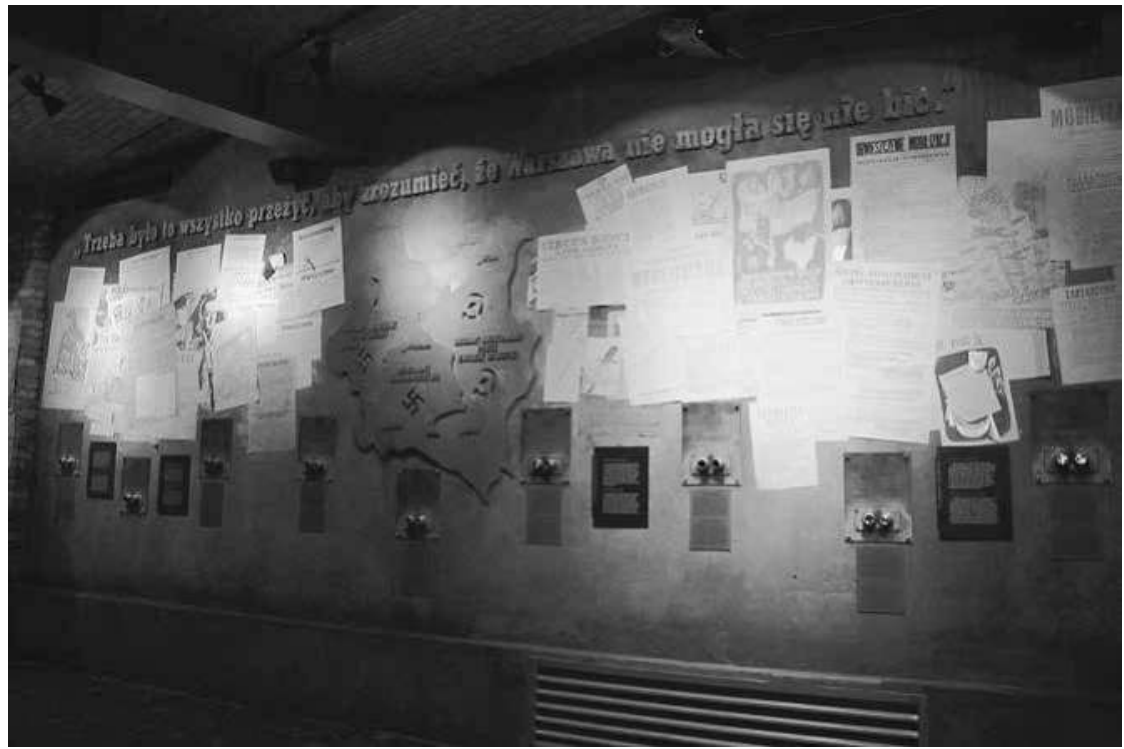

Abb. 52: MPW, Sektion »Besatzung».

schwer abzubilden sei. ${ }^{381}$ Angesichts der zahlreichen Argumente für den Aufstand, die in der Schau untergebracht worden sind, erscheint diese Argumentation jedoch wenig plausibel. Auch zeigt ein zeitgenössisches Beispiel aus Warschau, dass es sehr wohl Möglichkeiten gab und gibt, das schwierige Thema auch im Medium Ausstellung anzubringen. Im Haus der Begegnung mit der Geschichte (Dom Spotkań z Historia) wurde in den Jahren 2005 / 06 und 2009 / 10 die Ausstellung »Oblicza totalitaryzmu « (Gesichter des Totalitarismus) gezeigt. ${ }^{382}$ In dieser war dem Warschauer Aufstand von 1944 eine eigene Sektion gewidmet. Verschiedene Aussagen und Bewertungen der Aufstandsfrage fanden sich dort nebeneinander gestellt; diese illustrierten äußerst gegensätzliche Einschätzungen: Direkt hinter dem Befehl Tadeusz Komorowskis vom 1. August 1944, der den Aufstand initiierte, ist die Reaktion General Władysław Anders' hierzu angeführt: »Ich persönlich halte die Entscheidung des Oberbefehlshabers der Heimatarmee für ein Unglück. « ${ }^{383}$ Durch diese Kontrastierung von Positionen wurde den Besuchern vermittelt,

381 Interview mit Paweł Ukielski, dem stellvertretenden Direktor des Museums für inhaltliche Fragen, am 8. Juli 2009. Siehe auch: W poszukiwaniu formuły nowoczesnego muzeum. Dyskusja [Auf der Suche nach der Formel für das moderne Museum. Diskussion]. In: Borussia 47 (2010), 123-134, hier 132.

382 Siehe auch Teil 2, Kapitel 5.

383 Deutsche Übersetzung auf der Ausstellungstafel. DSH, Sektion 15: Der Warschauer Aufstand 1944. 
dass die Frage der Aufstandsentscheidung für die Zeitgenossen keineswegs einfach oder klar war.

Mitte 2011 wurde der Ausstellung schließlich eine neue, abschließende Sektion unter dem Titel »Die Erinnerung an den Aufstand (Pamięć Powstania) hinzugefügt. ${ }^{384}$ Auch in dieser steht jedoch die Apologie im Vordergrund: Denn die Kuratorentexte auf den zwei zentralen Wänden der Sektion erwähnen zwar, dass es Debatten um den Aufstand gab und gibt, unterstreichen jedoch in erster Linie die verfälschende Darstellung der Ereignisse und deren Instrumentalisierung in der VRP, ohne auf konkrete Kritikpunkte einzugehen. Als Kronzeuge für die Rechtmäßigkeit des Aufstands sowie der Aufstandserinnerung wird der frühere amerikanische Präsident Ronald Reagan herangezogen. Das folgende Zitat aus einer Proklamation zum 40. Jahrestag des Aufstandsbeginns überschreibt großformatig die Sektion: »It is right that we pay tribute to those who sacrificed all for independence and freedom." Dass der Aufstand auch kritisch bewertet wurde, erfährt man erst, wenn man sich in die präsentierten Quellen vertieft, die in einer Multimediapräsentation und in Form von Audioaufzeichnungen von Zeitzeugeninterviews vermittelt werden. Dies erfordert jedoch einen erheblichen Zeitaufwand, da die präsentierten Ausschnitte aus Publikationen der vergangenen siebzig Jahre ebenso wie die Interviewmitschnitte äußerst umfangreich sind und ein Eindruck von den bestehenden Dissonanzen über die Bewertung des Ereignisses erst durch die Rezeption mehrerer Beiträge entsteht. Es ist kaum wahrscheinlich, dass viele Besucher am Ende des langen, an verschiedensten Sinnenseindrücken und Informationen reichen Rundgangs noch Aufnahmekapazität für eine genauere Auseinandersetzung mit dem Thema und den präsentierten Materialien haben. Daher ist davon auszugehen, dass auch hier der allgemeine Eindruck der Besucher durch den großformatigen, den Aufstand bekräftigenden Text der zentralen Ausstellungswand geprägt werden wird. Der begleitende Bereichstext zu den Zeitzeugeninterviews gibt zudem deren Deutung größtenteils bereits vor:

"[...] Offen parteiisch und unrechtmäßig [krzywdzacy] sind die Stimmen der Kommunisten. Ein Beispiel ist die Stimme Wanda Odolskas, einer führenden Propagandistin des Polnischen Radios. Die Aufständischen selbst wiederum vertreten größtenteils die Ansicht, dass der Ausbruch des Aufstands notwendig war und bereuen nicht ihre Entscheidung, sich den Kämpfen angeschlossen zu haben. ${ }^{385}$

Die eindimensionale Heroisierung der Kämpfe vom August und September 1944, wie sie im Museum des Warschauer Aufstands erfolgt, führt dazu, dass

384 Auskunft des MPW, E-Mail vom 30. Mai 2017.

385 Bereichstext »Stimmen über den Aufstand«. MPW, Sektion »Die Erinnerung an den Aufstand«. 
der verlorene Kampf gegen die deutschen - und politisch auch die sowjetischen - Besatzer letztlich in einen moralischen Sieg umgedeutet wird. Wie Justyna Krzymianowska prägnant zusammenfasst: »[D]er Besucher könnte das Museum verlassen, ohne zu merken, dass der Aufstand blutig niedergeschlagen wurde und die jungen Soldaten [...] den Aufstand nicht überlebt haben. $\aleph^{386}$ Dies wird nicht nur von Mitarbeitern anderer Museen als Kritikpunkt an der Monumentalisierung und Heroisierung der historischen Ereignisse in dieser Schau angeführt. ${ }^{387}$ Eine solche Erfahrung machen auch die Pädagogen des Museums in ihrer Arbeit mit Jugendlichen immer wieder. Der Leiter der museumspädagogischen Abteilung des MPW hat etwa im Interview im Rahmen dieser Untersuchung darauf hingewiesen, dass gerade jugendliche Museumsbesucher von der begeisternden Ausstellungserzählung oft darauf schließen, der Aufstand sei in erster Linie ein Riesenspaß gewesen. Diesem Eindruck muss immer wieder in der Nachbereitung des Ausstellungsbesuchs im Rahmen der Unterrichtseinheiten, die seine Abteilung für Schülergruppen organisiert, entgegengewirkt werden. ${ }^{388}$ Denn der Schwerpunkt der musealen Darstellung liegt auf den Kämpfen, nicht der Niederlage und ihren Folgen. ${ }^{389}$

Der Aufstand von 1944 ist in Warschau seit Jahrzehnten ein wesentliches Element der lokalen Erinnerungskultur, das trotz der Bemühungen der sozialistischen Machthaber nicht verdrängt werden konnte. Ausdruck dieser Erinnerung, die wesentlich von der lokalen Bevölkerung getragen wurde, waren Gedenkzeremonien auf Friedhöfen, die sukzessive Anbringung von Gedenktafeln sowie wiederholte Initiativen für ein Aufstandsdenkmal. ${ }^{390} \mathrm{Im}$ Zuge der politischen Liberalisierung, die 1956 einsetzte, konnte der Aufstand zunehmend auch öffentlich erwähnt und seiner gedacht werden. Um seine Inklusion in das Geschichtsbild der VRP zu ermöglichen, wurde jedoch eine strikte Unterscheidung zwischen dem »Londoner Lager« - das heißt der Führung der Heimatarmee und der Londoner Exilregierung, deren Politik als unverantwortlich und verbrecherisch gebrandmarkt wurde - und den hel-

386 Krzymianowska: Der Warschauer Aufstand, 222.

387 Dieser Eindruck wurde von Mitarbeitern verschiedener historischer Museen der Verfasserin gegenüber geschildert. Die Kritik an den im MPW vermittelten Sichtweisen wird von ihnen jedoch meist ausschließlich in privaten Gesprächen artikuliert.

388 Interview mit Karol Mazur am 25. Juni 2009.

389 Von den 51 inhaltlichen Sektionen der Schau (entsprechend der Zählung des Museumsflyers von 2009) sind dem Ende der Kämpfe, d.h. der Kapitulation, der anschließenden Deportation der Aufständischen und der Zivilbevölkerung sowie der Zerstörung der Stadt allein fünf gewidmet: MPW, Sektion 41: Der Tod der Stadt, 42: Kapitulation, 43: Exodus, 44: Die Warschauer Robinsons (Robinsonowie), 45: Weihnachten im Lager.

390 Markiewicz: Der Kampf um die Erinnerung. Das erste Denkmal, das explizit dem Warschauer Aufstand bzw. seinen jüngsten Teilnehmern gewidmet war - das »Denkmal des Kleinen Aufständischen « (Pomnik Małego Powstańca) -, wurde schließlich im Oktober 1983 enthüllt. Ebd., $771 \mathrm{f}$. 
denhaft kämpfenden einfachen Aufständischen sowie der Warschauer Bevölkerung beibehalten, die bereits kurz nach Kriegsende eingeführt worden war. 1968 wurde die Erhebung schließlich endgültig zu einem »Volksaufstand « umgedeutet. ${ }^{391}$ Wesentliche Aspekte der historischen Ereignisse blieben dabei jedoch unerwähnt; so wurde das politische Ziel der Kämpfe - die Unabhängigkeit des Landes -, das gegen die UdSSR gerichtet war, und insbesondere die Rolle der Roten Armee weitgehend verschwiegen. ${ }^{392}$

Die zwiespältige und dennoch präsente Aufstandserinnerung an die Warschauer Kämpfe von 1944 spiegelte sich auch in der lokalen Museumslandschaft wider. Im zentralen stadthistorischen Museum war die Erhebung seit 1958 in der Dauerausstellung mit einem eigenen Themenraum präsent. ${ }^{393}$ Dieser wurde auch in der überarbeiteten Fassung von 1965 beibehalten, die in den 1980er-Jahren zu besichtigen war. ${ }^{394}$ Mit dieser prominenten Platzierung hob man den Aufstand von 1944 in der musealen Erzählung deutlich hervor. Diese Aufwertung wird im Vergleich zur Darstellung des Ghettoaufstands von 1943 in derselben Schau besonders offenkundig: Letzterer spielte in der offiziellen Geschichtspolitik des Landes eine weitaus bedeutendere Rolle, trat im stadthistorischen Museum jedoch klar hinter den Warschauer Aufstand zurück. ${ }^{395}$ Wahrscheinlich ist diese vergleichweise starke Gewichtung des Warschauer Aufstands der Lebendigkeit der Erinnerung in der lokalen Gemeinschaft geschuldet. Das MHW organisierte in den vergangenen Jahrzehnten auch zahlreiche Sonderausstellungen zu dem Thema, insbesondere zu den Jahrestagen des Aufstandsbeginns 1984, 1994 und 2004. Die erste Schau wurde 1969 eröffnet; weitere folgten erst 1979 und $1981 .{ }^{396}$ Seit der Wende hat kein anderes Thema der Geschichte des Zweiten Weltkriegs in dieser Institution eine derart große Aufmerksamkeit erfahren ${ }^{397}$ Dies ist maßgeblich

391 Borodziej: Der Warschauer Aufstand, 210-212.

392 Wie Edmund Dmitrów und Jerzy Kułak zusammenfassen, vertraten Historiker in der VRP zunächst die These, wonach »Stalin den Aufstand unterstützen wollte, die Hauptkommandantur dieses Angebot aber ablehnte. Danach hielt sich lange die Meinung, Stalin hätte aus rein militärischen Gründen nicht helfen können.« Dmitrów / Kułak: Der polnische »Historikerstreit«, 834.

393 Żurawski, Władysław: Ekspozycja w Muzeum Historycznym m. st. Warszawy p.t. »Warszawa w walce w latach 1939-1945«. AP, zespół 3195/I (Muzeum Historyczne m. st. Warszawy), teczka 74, MHW-440, 143-148, hier $143 \mathrm{f}$., $146 \mathrm{f}$.

394 Saal 61. Siehe: Informator do ekspozycji, $52 \mathrm{f}$.

395 Siehe hierzu auch Teil 2, Kapitel 1.1.

396 Soltan: Muzeum Historyczne, 36. Entgegen der Behauptung Sołtans wurde die zweite Sonderausstellung zum Aufstand bereits 1979 eröffnet. Pietrzak: Kalendarium Wystaw. 1972-1998, 368.

397 Vgl. Pietrzak: Kalendarium Wystaw. 1972-1998; Dies./Wiśniewska/Rogalska: Kalendarium wystaw 1999-2000; Pietrzak/Rogalska/ Wiśniewska: Kalendarium wystaw 20012002; Ausstellungsarchiv auf der Website des Museums für die Jahre 2004, 2007/08 und 2009: URL: www.mhw.pl (am 28.4.2009 bzw. 2.7.2013). 
auf die Gründung des Museums des Warschauer Aufstands als Abteilung des MHW im Jahr 1983 zurückzuführen. Seine Mitarbeiter befassten sich seitdem mit dem Aufbau einer Sammlung von historischen Objekten; auf diesen basierten die in den 1990er-Jahren erarbeiteten Schauen wesentlich. ${ }^{398}$

In den Dauerausstellungen des anderen Warschauer Museums, das sich zentral mit den Ereignissen des Kriegs und der Besatzung befasst, dem Gefängnismuseum Pawiak, erhielt der Aufstand hingegen bis zur Eröffnung der Dauerausstellung von 2001 nur mit wenigen peripheren Hinweisen Aufmerksamkeit. ${ }^{399}$ Erst in dieser Dauerausstellung, der ersten, die nach dem Systemwechsel grundlegend neu erarbeitet worden war, räumte man der Erhebung umfangreich Platz ein. Betont wird in der neuen Sektion in erster Linie der unbedingte Kampfeswille der Aufständischen - repräsentiert durch ein emotionales Gedicht, das mit den Worten endet »Wir fordern - Munition!!! «. ${ }^{400}$ Zudem stehen die internationale Unterstützung durch die westlichen Alliierten, vertreten durch Winston Churchill, sowie die moralische Authorität Papst Pius XII. im Zentrum dieses Themenkomplexes. ${ }^{401}$ Zentrale Erfolge der Aufständischen, denen in der gegenwärtigen Erinnerung große Bedeutung eingeräumt wird, werden mittels Fotografien präsentiert: Darunter befindet sich ein Bild der Befreiung von Juden aus dem Lager in der Gęsia-Straße, der sogenannten Gęsiówka. Zwei Fotografien zeigen die Gefangennahme deutscher Soldaten. Diese verweisen implizit auf den Unterschied zum Vorgehen des Feindes: Die Deutschen werden interniert, nicht erschossen oder misshandelt, wie dies seitens deutscher Truppen geschah. Unterschwellig wird damit die Ehrbarkeit der Soldaten der Untergrundarmee im Kampf betont. Ein weiteres Foto zeigt schließlich den Abzug der Aufständischen in geschlossenen, militärischen Formationen in die Kriegsgefangenschaft nach der Kapitulation. Es sind somit die Aufständischen, die aktiven Kämpfer, die die Schilderung der zwei Monate der Kämpfe dominieren. Die Zivilbevölkerung oder Erfahrungen jenseits he-

398 Vgl. die Angaben zu den Organisatoren der einzelnen Sonderausstellungen in Pietrzak: Kalendarium Wystaw. 1972-1998.

399 In der Ausstellung aus dem Jahr 1965 benannte man nur kurz den Ausbruch der Kämpfe. Deren Ende bzw. die Niederlage der Aufständischen, in deren Folge auch das Museumsgebäude von den Deutschen gesprengt wurde, thematisierte man dagegen nicht. Scenopis stałej ekspozycji, 62. In der Präsentation von 1990 tauchte der Aufstand sogar nur in wenigen Objektbeschriftungen auf. Izdebska: Pawiak 1939-1945, 37, 52. Ohne den Aufstandskontext zu erwähnen, endeten beide Schauen mit dem Hinweis auf die Zerstörung des Gebäudes durch deutsche Einheiten.

400 Es handelt sich dabei um das Gedicht »Apel Warszawy« (Der Appell von Warschau) von Zbigniew Jasiński. MNW-Pawiak, Sektion »Der Warschauer Aufstand«.

401 Gezeigt werden der Text einer Ansprache Winston Churchills vor dem Unterhaus des britischen Parlaments vom 5. Oktober 1944, in der er den »heroischen Verteidigern Warschaus « Anerkennung zollt, sowie ein Brief Papst Pius XII. an den polnischen Präsidenten im Exil Władysław Raczkiewicz vom 31. August 1944, in dem er sein Mitgefühl für die Leidenden und Kämpfenden in Warschau ausdrückt. Ebd. 
roischer Kämpfe werden vollständig ausgeklammert. Dies steht im Einklang mit der übergreifenden Widerstandsschilderung dieser Schau, die sich auf die Helden und Märtyrer konzentriert, wie bereits in Kapitel 2.2 herausgearbeitet.

In den untersuchten Museen anderer Regionen und ihren Dauerausstellungen finden sich bis 2004 dagegen kaum Verweise auf die Ereignisse in Warschau 1944 und deren größeren Kontext, die Aktion "Gewittersturm«. Lediglich im Museum Radogoszcz wurde seit $2003^{402}$ der Einsatz der Lódźer regionalen Einheiten der AK im Sommer 1944 geschildert. Auch im Rahmen von Sonderausstellungen spielte das Thema bis Mitte der Nullerjahre in den meisten der betrachteten Museen keine Rolle; es wurden keine eigenen Präsentationen hierzu erarbeitet. ${ }^{403}$ Einzig das Historische Museum der Hauptstadt Warschau zeigte seine Schauen in Form von Wanderausstellungen in vielen Regionen, womit es den Aufstand auch außerhalb der Hauptstadt popularisierte. ${ }^{404}$ Erst 1994, anlässlich des 50. Jahrestags der Erhebung, fanden eigene Sonderausstellungen auch in anderen Museen statt, so im Warschauer Unabhängigkeitsmuseum und im Museum der Unabhängigkeitstraditionen

402 Da die Drehbücher der Vorgängerausstellungen dieses Museums nicht zur Verfügung standen, ist es nicht möglich, eine Aussage darüber zu treffen, ob die Aktion »Gewittersturm « und die Kämpfe in der besetzten Hauptstadt bereits früher dort thematisiert wurden.

403 Die erste monothematische Sonderausstellung zum Warschauer Aufstand im Museum der Unabhängigkeitstraditionen in Łódź bzw. seinem Vorgänger, dem Museum der Geschichte der Revolutionsbewegung in Łódź, zeigte man 1983 in dessen Abteilung Radogoszcz. Die Schau »Warszawa walczy« (Warschau kämpft) wurde in der Hauptstadt vorbereitet. Siehe Iwanicki, Ryszard: Związek Walki Zbrojnej-Armia Krajowa, 1939-1945 (Z działalności edukacyjnej Muzeum Tradycji Niepodległościowych w Łodzi) [Der Verband für den Bewaffneten Kampf-Heimatarmee, 1939-1945 (Aus der Bildungstätigkeit des Museums der Unabhängigkeitstraditionen in Łódź)]. In: Armia Krajowa. W 65. Rocznicę nadania siłom zbrojnym w kraju nazwy "Armia Krajowa« (Jednodniówka) [Die Heimatarmee. Zum 65. Jahrestag der Benennung der Streitkräfte im Lande als »Heimatarmee" (Sonderausgabe)]. Hg.v. Muzeum Tradycji Niepodległościowych w Łodzi. 12. Februar 2007, 8.

$404 \mathrm{Zu}$ den Sonderausstellungen, die eine große Verbreitung fanden, gehörten die 1981 in Łódź erstmals gezeigte Präsentation »Sylwester Kris-Braun, fotoreporter Powstania Warszawskiego" (Sylwester Kris-Braun. Fotoreporter des Warschauer Aufstands). Sie wurde 1982 in Wrocław, Belgrad und Zagreb, 1984 in Warschau, Przasnysz und Sandomierz, 1985 in Ostrołęka sowie 1986 in Puławy gezeigt. Pietrzak: Kalendarium Wystaw. 1972-1998, 372 f., 377, 379, 381. Eine weitere Ausstellung, die große regionale Verbreitung fand, war »Losy ludności po Powstaniu Warszawskim 1944« (Das Schicksal der Bevölkerung nach dem Warschauer Aufstand von 1944), die 1984 zum 40. Jahrestag des Ausbruchs des Aufstands organisiert worden war. Sie wurde 1985 in Legionowo, Sandomierz und Puławy gezeigt sowie 1987 in Katowice und 1989 in Maków Mazowiecki. Ebd., 377f., 383, 385. Daneben erarbeiteten die Mitarbeiter des MHW weitere kleinere Schauen zum Aufstand von 1944, die ebenfalls in verschiedenen Regionen des Landes gezeigt wurden. Zum Jahrestag 1994 organisierte man mehrere thematische Schauen, die im In- und Ausland präsentiert wurden. Siehe ebd., 394-396. 
in Łódź. ${ }^{405}$ Auch 2004, zum 60. Jahrestag des Aufstands und der Aktion »Gewittersturm « - die nicht zuletzt durch die medienwirksame Eröffnung des Museums des Warschauer Aufstands große Aufmerksamkeit erhielten -, würdigten zahlreiche Institutionen das Ereignis mit eigenen Präsentationen. ${ }^{406}$

Die steigende Wahrnehmung und Bedeutung des Aufstands, die seit der Eröffnung des MPW zu verzeichnen sind, haben ihren Niederschlag auch in Dauerausstellungen gefunden, die seit diesem Zeitraum neu entstanden sind oder grundlegend überarbeitet wurden. So wurde in den 2006 bis 2009 neu gestalteten Sektionen zum Zweiten Weltkrieg des Historischen Museums der Hauptstadt Warschau der Aufstand deutlich aufgewertet: Den Kämpfen waren nun zwei ganze Räume gewidmet; ${ }^{407}$ dazu kam ein dritter Raum, der wie in den Vorgängerfassungen - die Zerstörung der Stadt behandelte. ${ }^{408}$ Hier wurden jedoch nicht mehr allein abstrakt die Zerstörung der Bausubstanz und die übergreifenden Kriegsverluste aufgeführt wie noch zuvor. Die De-

405 Im Unabhängigkeitsmuseum in Warschau, zu dem das Gefängnismuseum Pawiak gehört, wurden 1994 zwei thematische Sonderausstellungen präsentiert: »Kobiety w Powstaniu Warszawskim« (Frauen im Warschauer Aufstand) sowie "Generał BórKomorowski i jego żołnierze w akcji ‘Burza« (General Bór-Komorowski und seine Soldaten in der Aktion »Gewittersturm«). Siehe: Kobiety w Powstaniu Warszawskim [Frauen im Warschauer Aufstand] [Ausstellungskatalog]. Hg.v. Muzeum Niepodległości. Warszawa, August-September 1994; Andrysewicz, Bogusław u. a.: Generał BórKomorowski i jego żołnierze w akcji »Burza«. Scenariusz. Warszawa Juli 1994. AMNW, Scen. 91; Bałuk, Stefan: Generał Bór Komorowski i jego żołnierze w akcji »Burza«. Scenariusz wystawy. Warszawa 1994. AMNW, [ohne Signatur]. Vgl. auch Pałaszewska, Mirosława: Wystawy w Muzeum Niepodległości poświęcone II wojnie światowej [Ausstellungen zum Zweiten Weltkrieg im Unabhängigkeitsmuseum]. In: Niepodległość i Pamięć 18 (2002), 219-239, hier 230-234. Im Hauptgebäude des MTNŁ war von August 1994 bis Februar 1995 die Schau »Warszawa. 1 VIII 1944. W 50. rocznicę Powstania Warszawskiego « (Warschau. 1.8.1944. Zum 50. Jahrestag des Warschauer Aufstands) zu sehen. Iwanicki: Związek Walki Zbrojnej-Armia Krajowa, 8.

406 Im Historischen Museum der Stadt Krakau wurde 2004 eine Ausstellung zusammen mit der regionalen Sektion des IPN organisiert: die Schau »Burza. Armia Krajowa w 1944 r.» (Gewittersturm. Die Heimatarmee im Jahr 1944; 1.8.-2.10.2004). Siehe: Einladung zur Ausstellungseröffnung. AMHK, teczka 385/7, OP-6410 A (Oddział»Ulica Pomorska«). Im MNW in Warschau zeigte man im selben Jahr vom 29. Juli bis 3. Oktober die Präsentation »Czterdziesty czwarty. W 60. rocznicę Powstania Warszawskiego (Vierundvierzig. Zum 60. Jahrestag des Warschauer Aufstands). Siehe: Oleszczuk, Anna: Czterdziesty czwarty. W 60. Rocznicę Powstania Warszawskiego [Begleitheft zur Ausstellung]. Warszawa 2004. AMNW, Sign. 31040. Auch im Museum der Unabhängigkeitstraditionen in Łódź organisierte man im August desselben Jahres eine Sonderausstellung. Siehe Czernielewski, Konrad: Powstanie Warszawskie 1944. W 60 rocznicę wybuchu [Der Warschauer Aufstand 1944. Zum 60. Jahrestag des Ausbruchs] [Begleitheft zur Ausstellung]. Łódź August 2004.

407 MHW, Saal 50, 51: »Der Warschauer Aufstand«.

408 MHW, Saal 52: „Die Vernichtung Warschaus - Die Vertreibung der Bevölkerung durch die deutschen Nazis. 1. August 1944-17. Januar 1945«. 
portationen der Zivilbevölkerung und der Aufständischen, mithin die direkten Folgen des Aufstands, dominierten nun diese Ausstellungssektion. ${ }^{409}$ In den Räumen, die die zwei Monate der Kämpfe im Jahr 1944 darstellten, standen dagegen die militärischen Aspekte der Ereignisse im Zentrum. Umfassend und detailliert beschrieb ein ausführlicher Thementext den Verlauf der Kampfhandlungen; eine Karte unmittelbar daneben stellte die umkämpften Stadtareale dar und listete die Fronteinheiten auf. Im Anschluss wurden die Presse der Aufständischen, Kommunikationswege, die Bewaffnung und Uniformen, die Feldpost und die Religiosität während der Auseinandersetzungen behandelt. Auch in dieser Präsentation standen die Aufständischen im Vordergrund; ihr heldenhafter Kampf und heroischer Tod prägten die Darstellung. Dies geschah in erster Linie über die Informationen zu einzelnen präsentierten Objekten; angegeben wurde jeweils, wem sie gehörten, und teilweise auch, unter welchen Umständen sie aufbewahrt wurden. Bei allen derart Porträtierten handelte es sich um Kämpfer der AK. Das Leben und Leiden der Zivilbevölkerung spielte hier kaum eine Rolle. Periphere Hinweise auf ihre Situation boten die Inhalte der wenigen ausgestellten Feldpostbriefe sowie einige anonyme Fotografien. Erst im folgenden Themensaal zur Zerstörung der Stadt standen Zivilisten im Vordergrund; dort wurden auch die Massaker an polnischen Stadtbewohnern während des Aufstands thematisiert. Bei der unmittelbaren Schilderung der Erhebung selbst ging es jedoch einzig um die Aufständischen. Ihre einseitige heroische und martyrologische Darstellung wies eine weitere Gemeinsamkeit mit den bereits geschilderten Präsentationen auf: Wie auch im Pawiak-Museum und im MPW wurden in dieser Schau die Auseinandersetzungen um den Entschluss zum Aufstand nicht betrachtet. ${ }^{410}$

Der Einfluss der wachsenden Bedeutung der Erinnerung an den Warschauer Aufstand zeigt sich selbst in der Dauerausstellung der SchindlerFabrik in Krakau. Obwohl die Schau einen regionalgeschichtlichen Schwerpunkt hat, nimmt hier die Aktion "Gewittersturm» einen erheblichen Umfang bei der Darstellung der letzten Kriegsmonate ein. ${ }^{411}$ Dabei wird auch vielfältig auf die Kämpfe in Warschau vom August und September 1944 und deren Auswirkungen in der Region Krakau verwiesen. Berichtet wird etwa

409 Zur Darstellung dieses Themenraumes siehe auch Kapitel 1.3 in diesem Teil.

410 Auch in einer anderen Sektion stand der organisierte Widerstand im Zentrum: Der Großteil des Themensaals 48 war dem Polnischen Untergrundstaat sowie den diversen Aktionen der Widerständler im Stadtgebiet von Warschau gewidmet. Der Schwerpunkt der Schilderungen lag auf den Operationen der Heimatarmee und mit ihr verbündeter Gruppen. MHW, Saal 48: »Der Polnische Untergrundstaat - die Widerstandsbewegung in Warschau 1939-1944. Das Warschauer Ghetto 1940-1943«.

411 Dem Abschnitt »Aktion >Gewittersturm« ist knapp die Hälfte der Sektion 25 (Die letzten Monate der Besatzung) gewidmet. 
von den Maßnahmen der deutschen Behörden, die den Ausbruch von Kämpfen in Krakau verhindern sollten: so etwa eine groß angelegte Straßenrazzia, die am 6. August 1944 im Zusammenhang mit dem Ausbruch der Kämpfe in Warschau durchgeführt wurde. Gezeigt werden auch deutsche Propagandapublikationen, in denen den Krakauern zur Abschreckung das Ausmaß der Leiden ihrer Warschauer Landsleute mit großformatigen Fotografien vor Augen geführt werden sollte. ${ }^{412}$ Dem gegenübergestellt sind Materialien, die den Durchhalte- und Kampfeswillen der AK dokumentieren: Angeführt wird der Befehl des Oberbefehlshabers der AK vom August, wonach alle Einheiten der Untergrundarmee der Hauptstadt zu Hilfe kommen sollten, ebenso eine Ansprache des Delegierten der Regierung im Lande für den Bezirk Krakau, der vor Provokationen seitens der Deutschen warnt. Schließlich wird auch die Aussiedlung eines Teils der Warschauer Bevölkerung in die Region Krakau nach der Niederschlagung des Aufstands sowie ihre Betreuung durch die lokale Sektion des »Hauptfürsorgerats« (Rada Główna Opiekuńcza, RGO) illustriert. Zwar schildert man in dieser Schau auch den breiteren regionalen Rahmen der Aktion »Gewittersturm« sowie ihre politische Zielsetzung; die Darstellung ist jedoch klar dominiert von Verweisen auf die Kämpfe in Warschau selbst. Diese Schau belegt damit exemplarisch die inzwischen etablierte überregionale Bedeutung der Aufstandserinnerung. Dabei ist zu betonen, dass in diesem Museum eine Bewertung der Kämpfe in der Hauptstadt nicht stattfindet; diese werden weder in einen heroischen noch martyrologischen Kontext gestellt. Vielmehr werden die zeitgenössische Wahrnehmung des Aufstands über die Hauptstadt hinaus sowie dessen Auswirkungen auf die Besatzungspolitik der Deutschen außerhalb Warschaus geschildert. Als unmittelbar Betroffene der Ereignisse stehen auch hier - wie im Großteil dieser Schau - Zivilisten im Vordergrund: als Verhaftete, Ermordete und Ausgesiedelte aus Warschau. Die Entscheidungen zur Vorbereitung der Aktion »Gewittersturm« wie zur Ausrufung des Warschauer Aufstands werden nicht kommentiert, sondern lediglich als Tatsachen benannt. Begründet wird hingegen die Entscheidung der Führung des Krakauer Untergrunds, in der Stadt selbst auf einen Aufstand zu verzichten. Die genannten Ursachen - »vernichtende Übermacht der Deutschen und der Stopp der sowjetischen Offensive « $-{ }^{413}$, zusammen mit dem Aufruf des Delegierten, durchzuhalten und sich nicht provozieren zu lassen, vermitteln eher den Eindruck einer sachlichen, verant-

$412 \mathrm{Zu}$ sehen sind eine polnischsprachige Zeitungsseite mit dem Titel »Die Tragödie Warschaus« sowie die deutschsprachige Ausgabe des Goniec Krakowski (Krakauer Bote), in dem eine Ansprache des Generalgouverneurs »in Sachen der Hilfsaktion für Warschau« abgedruckt ist - auf der Ausgabe befindet sich eine von der AK angebrachte Aufschrift: "Die Verbrecher vergießen Krokodilstränen«. MHK-Schindler-Fabrik, Sektion 25: Die letzten Monate der Besatzung.

413 Abschnitt »Aktion `Gewittersturm« «, Textabschnitt »Juli 1944«. Ebd. 
wortungsvollen Beurteilung der Lage seitens der Untergrundführung. Das hier gezeigte Bemühen, aussichtslose Kämpfe und hohe Opferzahlen seitens des Untergrundstaates und der AK zu vermeiden, steht damit im deutlichen Kontrast zur einseitigen Heroisierung eines Kampfes um jeden Preis, wie sie in den Warschauer Museen erfolgt.

\subsection{Zwischenfazit}

Wie gezeigt wurde, erfuhren die musealen Darstellungen der heroischen Kämpfer und Widerständler in den drei Jahrzehnten des Untersuchungszeitraums zwar Wandlungen, weisen jedoch zugleich bis in die Gegenwart bemerkenswerte Kontinuitäten auf. Die wohl deutlichste Veränderung betraf die politische Ausrichtung des Widerstands. Während in den Präsentationen der 1980er-Jahre Kommunisten und Heimatarmee oft als weitgehend gleichberechtigte militärische Vertreter porträtiert wurden und eine führende politische Rolle der kommunistischen Gruppierungen im Untergrund suggestiv vermittelt wurde, löste die Heimatarmee als größte Widerstandsorganisation die Kommunisten in den 1990er-Jahren klar ab. Sie trat in den Vordergrund aller Präsentationen. Damit einher ging die Inklusion der Londoner Exilregierung in die Schauen, die nun die Rolle der legitimen politischen Vertretung polnischer Interessen erhielt. Diese Wandlung der den Kommunisten und ihrer bewaffneten Organisationen eingeräumten Bedeutung ging jedoch meist nicht mit einer veränderten Bewertung ihrer Aktivitäten einher, was etwa die Nachkriegsentwicklung des Landes betrifft. Einzig in der Präsentation des Historischen Museums der Stadt Krakau aus dem Jahr 1998 findet diesbezüglich eine negative Umwertung statt. Diese ist verbunden mit der Erweiterung des thematischen Spektrums der Schau in die Nachkriegszeit, konkret um die Verfolgung des nichtkommunistischen Widerstands im Stalinismus. In den übrigen Präsentationen traten kommunistische Gruppierungen bei der Schilderung des Widerstands lediglich in den Hintergrund und wurden zu randständigen Akteuren, was ihrer anteilig geringen Bedeutung im Untergrund entsprach. Sie blieben jedoch als Teil der aktiven Resistenz Bestandteil des Helden-Pantheons. Erst mit dem Beginn des Museumsbooms setzt sich eine deutliche Umwertung von Teilen des polnischen Untergrunds durch. In der Schau des Museums des Warschauer Aufstands werden die Kommunisten des PKWN als mit der Sowjetunion alliierte politische Kräfte aus der Wir-Gemeinschaft der heldenhaften Polen ausgeschlossen. Bemerkenswerterweise bleiben die im Aufstand 1944 kämpfenden Einheiten der Volksarmee ebenso wie die polnischen Streitkräfte in der Sowjetunion dennoch als Teil der kämpfenden Nation Bestandteile des Heldenkollektivs. Lediglich ihre politische Führung wird als Verräterin an den nationalen In- 
teressen betrachtet und als solche verurteilt - eine Argumentation, die mit umgekehrten politischen Vorzeichen bereits in der VRP angewandt wurde.

Ein weiteres Merkmal der Schauen, die seit 1990 entstanden sind, bleibt der Ausschluss der jüdischen Widerstandskämpfer aus dem ethnisch-national konnotierten Heldennarrativ. Dies ist selbst in der Präsentation zu verzeichnen, die als einzige im Untersuchungszeitraum die jüdische Bevölkerung mit ins Zentrum der Darstellung der Jahre 1939 bis 1945 stellt: die Dauerausstellung des MHK in der Schindler-Fabrik. Während Juden im Besatzungsalltag und auch bei der Opferdarstellung dort gleichberechtigt mit den polnischen Krakauern thematisiert werden, bleibt der Aspekt »Widerstand « weitgehend auf die polnische Stadtbevölkerung konzentriert. In den Ausstellungen, die seit der Wende von 1989 eröffnet wurden, hat sich jedoch das Verständnis dessen, was unter »Widerstand « zu fassen ist, deutlich erweitert. Waren es vor 1989 primär die aktiv Kämpfenden und im Untergrund Tätigen, beginnt in den 1990er-Jahren die Erweiterung um zivile Aspekte widerständigen Verhaltens. Insbesondere das Untergrundschulwesen wird als Element des Untergrundstaates in fast allen neuen Präsentationen erstmals als resistentes Verhalten dargestellt. Auch die Untergrundpublikationen, Presseerzeugnisse wie dichterische Werke, finden verstärkt Eingang in die Schauen ebenso die Tätigkeit karitativer Organisationen.

Insgesamt ist festzustellen, dass in den meisten musealen Präsentationen, die seit der Wende von 1989 neu konzipiert oder umfassend überarbeitet wurden, der Kampf gegen die zwei Aggressoren bei Kriegsausbruch ebenso wie der ethnisch-polnische Widerstand während der Besatzung Schlüsselelemente der Schilderung waren und nach wie vor sind. Innerhalb der untersuchten Institutionen gab es nur zwei, in deren Dauerausstellungen nicht die Mitglieder der polnischen Armee und Untergrundorganisationen die zentralen Protagonisten polnischer Kriegs- und Besatzungserfahrungen darstellten - die Dauerausstellung des Łódźer Stadtmuseums von 1998 und die des MHK von 2010. In einigen der jüngsten Ausstellungen ist sogar eine verstärkte Konzentration auf den Widerstand zu beobachten, die mit einer einseitigen und stark normativen Hervorhebung seiner Verdienste einhergeht. Die Widerstandskämpfer, allen voran die AK, stehen in diesen Präsentationen weitgehend stellvertretend für die gesamte polnische Bevölkerung, die hierdurch indirekt $\mathrm{zu}$ einer vermeintlich allgemeinen widerständigen Gemeinschaft verklärt wird. Paradoxerweise wird hierdurch wiederum ein zentraler Topos der volksrepublikanischen Geschichtspolitik fortgeführt. Präsentationen wie die des MPW und des MHW in Warschau vollziehen damit zugleich eine regelrechte Monumentalisierung der Heimatarmee und insbesondere des Warschauer Aufstands von 1944. Wie der enorme Besuchererfolg des MPW nahelegt, kommt dieses Geschichtsbild den Einstellungen und Präferenzen eines großen Teils der polnischen Besucher entgegen. Ein weiteres gemeinsames 
Merkmal der Mehrheit der untersuchten Präsentationen bleibt zudem die Auslassung ambivalenter und negativer Aspekte der Geschichte des Widerstands. Die politische Konkurrenz zwischen einzelnen Organisationen, die Existenz von Informanten innerhalb der Gruppen ebenso wie negative Verhaltensweisen von Mitgliedern des Widerstands werden bis in die Gegenwart kaum erwähnt. Das polnische Selbstbild der heldenhaften Widerstandskämpfer und Märtyrer für das Vaterland ist somit über die politische Wende von 1989 hinweg von einer bemerkenswerten Kontinuität geprägt. Allein die Ablösung der als legitim porträtierten politischen Führung der Kommunisten durch die Exilregierung im Westen markiert eine deutliche Wende.

\section{Der Besatzungsalltag}

Neben diesen zwei dominanten Topoi des polnischen Selbstbildes der Kriegszeit hat im Untersuchungszeitraum ein weiteres Element Eingang in die musealen Erzählungen der Jahre 1939 bis 1944/45 gefunden: Der Besatzungsalltag findet zunehmend Beachtung, womit das Leben von Zivilisten auch abseits unmittelbarer Gewalterfahrungen und widerständigen Verhaltens thematisiert wird. Wie dieser Prozess verlief, wird im Folgenden analysiert. Dabei wird zum einen danach gefragt, welche Rollenbilder und damit Bedeutungen Zivilisten in den Erzählungen zugewiesen werden. Zum anderen ist von Interesse, welche Grenzen oder Tabus bei der Darstellung der polnischen Wir-Gemeinschaft im Krieg - und damit einhergehend der Fremd- und Feindbilder - bis heute festzustellen sind.

\subsection{Die »Entdeckung« der Zivilbevölkerung}

Wie bereits aus den Darstellungen der beiden vorangegangenen Abschnitte deutlich wurde, war das Leben und Überleben während des Kriegs und der Besatzung lange Zeit kein Thema der musealen Darstellungen der Jahre 1939 bis $1944 / 45$. So konzentrierten sich die Dauerausstellungen der untersuchten Museen, die in den 1980er-Jahren zu besichtigen waren, auf das durch die Grausamkeit der Besatzer verursachte Leiden und Sterben einerseits und den Widerstand gegen die »Hitleristen « andererseits. Die gezeigten Objekte und Fotografien umfassten fast ausschließlich diese Themen. ${ }^{414}$ Der Alltag der

414 In der Krakauer Pomorska-Straße beispielsweise waren die einzigen Objekte, die nicht unmittelbar Verfolgung und Gewaltanwendung darstellten, Plakate der Besatzungsorgane, die die zwangsweise Abgabe von Waffen und Radioapparaten sowie die Einfüh- 
breiten Bevölkerung jenseits dieser Extremsituationen wurde dagegen nicht behandelt. Zivilisten spielten lediglich als Opfer willkürlicher Massenerschießungen sowie als widerständige Gemeinschaft - etwa das "ganze kämpfende Warschau ${ }^{415}$ - eine untergeordnete Rolle; sie blieben jedoch als abstrakte und weitgehend gesichtslose Masse immer im Hintergrund. ${ }^{416}$ Hierdurch erschienen sie - so die Besucher ihr marginales Auftreten überhaupt registrierten - nicht als Protagonisten der historischen Ereignisse, sondern lediglich als deren Objekte. Folglich erfuhren die Besucher von den Geschehnissen der Kriegsjahre auch nicht aus deren Perspektive; die Märtyrer und Helden dominierten die musealen Erzählungen. ${ }^{417}$ Der einzige »Alltag«, der geschildert wurde, betraf den der Insassen der deutschen Gefängnisse und damit wiederum die heroischen Opfer. ${ }^{418}$

Erst im Laufe der 1990er-Jahre begannen Ausstellungsmacher, auch zivile Aspekte der Besatzungsereignisse in die Schauen zu integrieren. Besonders prominent geschah dies im Krakauer Stadtmuseum bzw. in dessen Abteilung in der Pomorska-Straße. Dort wurde unter dem Titel »Aus der Geschichte der hitleristischen Besatzung « dem städtischen Alltag in den Jahren 1939 bis 1945 in der Schau von 1990 eine eigene kleine Sektion eingeräumt. ${ }^{419}$ Hier präsentierte man nun nicht mehr allein Verordnungen der Besatzungsorgane, sondern stellte auch die lokale Zivilverwaltung und die Tätigkeit des karitativen Hauptfürsorgerates vor; mit mehreren Fotos wurde auch der Baudienst illustriert, zu dem Polen zwangsweise eingezogen wurden. ${ }^{420}$ Weitere Fotografien zeigten vermeintlich alltägliche Situationen, darunter Menschen, die an einer Bank anstehen, oder einen Leser des von den Besatzungsorganen für die polnische Bevölkerung herausgegebenen Goniec Krakowski (Krakauer Bote). Die Provenienz der Fotografien und damit auch ihr spezifischer Blickwinkel -

rung einer Sperrstunde anordneten - für deren Nichtbeachtung wiederum schwere Strafen angedroht wurden. Vgl. Wroński: Scenariusz wystawy, 2-4, genannte Objekte: $2 \mathrm{f}$.

415 Scenopis stałej ekspozycji, 88.

416 In der Dauerausstellung des Historischen Museums der Hauptstadt Warschau etwa trat die Zivilbevölkerung allein in den Verlusten des September 1939 und des Warschauer Aufstands 1944 sowie bei der Nennung der im Ghetto Eingesperrten direkt in Erscheinung. Nur bei der Schilderung des Lebens der Ghettobevölkerung wurden auch Lebensmittelkarten und eine Aufstellung der (niedrigen) Kalorienwerte einzelner Lebensmittelrationen gezeigt, die die hohe Sterblichkeit im Ghetto begründeten. Informator do ekspozycji, 48 f., 53.

417 So fanden sich etwa in den Ausstellungen des Warschauer Pawiak-Museums, des Museums »Unter der Uhr« in Lublin ebenso wie der Krakauer Pomorska-Straße Zeitzeugenberichte und Kassiber, die die Verhör- bzw. Foltermethoden der Gestapo sowie die schwierigen Lebensbedingungen der Insassen schilderten. MLL-Unter der Uhr, Zelle 7; Scenopis stałej ekspozycji, 59f., 66, 69, 84-86; Wroński: Scenariusz wystawy, 8.

418 MLL-Unter der Uhr, Zelle 8; Scenopis stałej ekspozycji, 58-60, 74-78.

419 Gąsiorowski/Kuler/Natkaniec: Scenariusz wystawy, 2-4.

420 Ausstellungstafeln 7-9. Ebd., 3. 
höchstwahrscheinlich handelte es sich um deutsche Propagandaaufnahmen wurden dabei nicht genannt. Des Weiteren wurden mehrere Ausweispapiere von Polen sowie Bezugskarten für verschiedene Güter ausgestellt. ${ }^{421}$ Im stadthistorischen Museum von Warschau fand im Themensaal, der den Ereignissen des Septembers 1939 gewidmet war und der Anfang der 1990er-Jahre überarbeitet wurde, nun der Alltag der Bevölkerung während der Kämpfe um die Stadt ebenfalls Erwähnung. ${ }^{422}$ Fotografien zeigten lange Schlangen vor Geschäften, Plakate der Allgemeinen Mobilmachung an Litfaßsäulen und Häuserwänden ebenso wie Flüchtlinge aus dem Westen des Landes, die nach Warschau strömten. Auf anderen waren Zivilisten zu sehen, die an den Befestigungsanlagen der Stadt mitarbeiteten. Bereichstexte wiesen auf die sich verschlechternden Lebensbedingungen der Menschen hin - den zunehmenden Mangel an Lebensmitteln und die Probleme bei der Strom- und Wasserversorgung, die schließlich vollständig zusammenbrach. Gezeigt wurde zudem ein zeitgenössischer Bericht über die "Stimmungen und die Situation der Bevölkerung Warschaus «. ${ }^{423}$ Die Kämpfe bei Kriegsausbruch thematisierte man somit erstmals auch in ihren Auswirkungen auf das Leben der Mehrheit der Stadtbewohner.

Auch im Warschauer Pawiak-Museum bemühte man sich, in der Dauerausstellung von 1991 den Besuchern »die Atmosphäre im besetzten Warschau « ${ }^{424}$ nahezubringen. Hierzu diente eine Audiospur, die während des Rundgangs im Hintergrund abgespielt wurde und inszenierte Alltagsgeräusche der Jahre 1939 bis 1944 in die Schau einbrachte: unter anderem die Rufe eines Zeitungsverkäufers, das Läuten einer Straßenbahn, die Ausrufe deutscher Polizisten und das Klappern von Pferdehufen. ${ }^{425}$ Daneben fanden sich im Ausstellungssaal zwei Litfaßsäulen, die mit Verordnungen und Bekanntmachungen der Besatzungsorgane - darunter solche über Exekutionen -, aber auch mit polnischer und deutscher Werbung für Cafés, Alltagsprodukte und Theater- und Musikaufführungen beklebt waren. ${ }^{426}$ Im Raum standen zudem zwei inszenierte Straßensperren mit Stacheldraht. In ihrer Umgebung wurden Fotografien gezeigt, die ebenfalls einen Eindruck vom Besatzungsalltag Warschaus geben sollten. $\mathrm{Zu}$ sehen waren darauf etwa deutsche Wachposten, Rikschas, eine Straßenkapelle sowie Szenen des Straßenhandels und von Razzien. ${ }^{427}$

421 Vitrine C, Ausstellungstafel 12. Ebd., 4.

422 MHW, Saal 46: „Die Verteidigung Warschaus im September 1939«.

423 Der Bericht mit Datum vom 17. September 1939 war vom Stadtpräsidenten Stefan Starzyński verfasst worden, der zum Zivilkommissar beim Oberkommando der Verteidigung Warschaus ernannt worden war.

424 Izdebska: Pawiak 1939-1945, 184; Izdebska: Muzeum Więzienia »Pawiak«, 264.

425 Izdebska: Pawiak 1939-1945.

426 Ebd., 175-181.

427 Ebd., 42-44, $144 \mathrm{f}$. 
In diesen Schauen hielt das zivile Leben somit nun auch außerhalb einer rein viktimologischen Darstellung des Leidens, verursacht durch die unmittelbare Gewaltanwendung der Besatzer, als Hintergrund der Erzählung Einzug. Einzelne Protagonisten traten hierbei zunächst noch kaum in Erscheinung. Dort, wo dies geschah, wie in der Pomorska-Straße des MHK, waren es allein leitende Vertreter der Administration und karitativer Einrichtungen, mithin politische und gesellschaftliche Führungspersönlichkeiten, die individuell vorgestellt wurden. Das Alltagsleben der Durchschnittsbevölkerung wurde zunächst primär in Gestalt einzelner, meist anonymer Objekte illustriert, etwa Lebensmittelmarken und Fotografien von Straßenszenen. Dokumente und Ausweispapiere blieben, so sie denn zu entziffern waren, die einzigen Hinweise auf Individuen. ${ }^{428}$ Zivilisten waren somit bis Ende der 1990er-Jahre weiterhin nur selten die Protagonisten der musealen Erzählungen. Ein allgemeiner Eindruck vom Alltag wurde zwar in die Präsentationen integriert, blieb jedoch von nachrangiger Bedeutung gegenüber dem dominierenden Märtyrer- und Heldennarrativ.

In anderen Präsentationen, die in diesem Zeitraum entstanden, spielt der Alltag der Zivilbevölkerung dagegen bis heute weiterhin so gut wie keine Rolle, so in den Schauen des Historischen Museums von Lublin (1995) und des Pawiak-Museums in Warschau (2001). In Lublin etwa werden lediglich jene die Zivilbevölkerung betreffende Verteidigungsmaßnahmen im September 1939 umfangreicher thematisiert; auch die zivilen Anführer der Stadtverteidigung werden vorgestellt. ${ }^{429}$ Das Leben der Menschen unter deutscher Besatzung wird dagegen allein durch zwei Plakate mit Verordnungen angedeutet. ${ }^{430}$ Die Erzählung geht von der Verteidigung im September 1939 über die Etablierung der Inhaftierungs- und Tötungsstätten im Lubliner Schloss und im Lager Majdanek direkt zu den militärischen und politischen Ereignissen des Sommers 1944 über. Das Leben der Bevölkerung zwischen diesen Eckdaten findet keine Beachtung. Zu berücksichtigen bleibt bei dieser Schau jedoch die extrem begrenzte Ausstellungsfläche, die eine äußerst kompakte

428 So wurde der Alltag der Bevölkerung des besetzten Łódź im Stadtmuseum in erster Linie anhand von Marken für einzelne Lebensmittel, Fahrkarten, Werbegegenständen von Brauereien sowie verschiedenen Ausweispapieren (Kennkarten, Ausweisen der Deutschen Volksliste, einem Arbeitsbuch) illustriert. MMŁ, Sektion»Lodsch - Litzmannstadt«.

$429 \mathrm{Zu}$ sehen sind Zeitungsberichte und Anschläge, die die Maßnahmen zur Verteidung der Stadt bekannt geben, sowie eine Armbinde und Spangen der zivilen Luftverteidigung. Fotos dokumentieren die Zerstörungen in der Stadt im September. Daneben werden der Vizepräsident der Stadt und der Woiwode der Region Lublin jeweils mit einer Fotografie und kurzen Angaben zu ihrer Person vorgestellt. MLL-Krakauer Tor, Sektion »Zweiter Weltkrieg".

430 Diese betreffen die Verhängung einer nächtlichen Ausgangssperre für die nichtdeutsche Bevölkerung sowie Anweisungen zur Kennzeichnung von Straßen und Häusern im Distrikt Lublin. Ebd. 
Schilderung der Jahre 1939 bis 1944 erzwingt. Angesichts dieser Umstände wurde von den Ausstellungsverantwortlichen der zivile Alltag der Besatzung offensichtlich als nachrangig eingestuft.

Überraschender ist hingegen die marginale Stellung des Alltags in der Dauerausstellung des Gefängnismuseums Pawiak in Warschau. Diese umfasst thematisch die Ereignisse der Jahre 1939 bis 1944 sowohl im Gefängnis selbst und in der Stadt als auch allgemeiner auf dem Territorium des besetzten Landes (mit einem Schwerpunkt auf den Gebieten, die Teil des Generalgouvernements wurden). In Kontinuität der Darstellungspraxis von vor 1989 sind in dieser Präsentation Zivilisten jedoch weiterhin allein als Opfer deutscher Grausamkeit präsent, etwa der Bombenangriffe und Massenexekutionen im September 1939, sowie als Insassen des Gefängnisses. ${ }^{431}$ Der Alltag des Großteils der Bevölkerung außerhalb der Gefängnismauern und Tötungsstätten wird nur kurz und auch dann nur allgemein angesprochen: Mehrere Tabellen zeigen die Kalorienzahl verschiedener Lebensmittelrationen der (polnischen und jüdischen) Bevölkerung des GG im Vergleich mit anderen europäischen Ländern sowie die Entwicklung der Kalorienrationen der Warschauer Einwohner in den Jahren 1938 bis 1943 - eine Illustration des Hungers in der Stadt und im besetzten Land. ${ }^{432}$ Ebenso stehen die Fotografien einer ausgemergelten Frau und einer Kinderleiche stellvertretend für die katastrophalen Lebensbedingungen im Warschauer Ghetto. ${ }^{433}$ Bis auf diese wenigen Hinweise bleibt das Leben der zivilen Stadtbewohner in der Schau jedoch unberücksichtigt. Die einzigen Zivilisten, die namentlich in Erscheinung treten, sind die Opfer der Massenexekutionen in Palmiry bei Warschau. Stellvertretend für letztere werden drei prominente Persönlichkeiten vorgestellt: ein berühmter Sportler sowie zwei hochrangige Politiker der Zwischenkriegszeit. ${ }^{434}$ Diese wenigen Bezüge auf alltägliche oder zivile Kontexte der Kriegs- und Besatzungszeit wurden in dieser Schau somit in den zentralen martyrologischen Interpretationstopos eingefügt.

Jedoch gab es im Untersuchungszeitraum selbst in Warschau deutliche Abweichungen von diesem Muster, wie dies das Beispiel der im Jahr 2000 eröffneten Dauerausstellung im Jüdischen Historischen Institut zeigt, die ein

431 Umfangreich wird das Massaker in Wawer geschildert. Für die Grausamkeit der Deutschen bei Kriegsausbruch steht symbolisch das bekannte Foto Julien Bryans von einem verzweifelten polnischen Mädchen, das über die Leiche ihrer bei einem Bombenangriff getöteten Schwester gebeugt ist. MNW-Pawiak, Sektionen »September« und »Wawer«.

432 MNW-Pawiak, Sektion zur Besatzungspolitik (ohne Titel).

433 MNW-Pawiak, Sektion zum Warschauer Ghetto (ohne Titel).

434 Präsentiert werden mittels großformatiger Fotografien Janusz Kusociński, Leichtathlet und Olympiasieger, Maciej Rataj, Präsident des Sejm, sowie Mieczysław Niedziałkowski, ein führender Politiker der polnischen Sozialisten und im Untergrund Vorsitzender des »Hauptrates für Nationale Verteidigung (Rada Główna Obrony Narodowej). MNWPawiak, Sektion »Palmiry«. 
gegenteiliges Konzept verfolgte: Ihr Schwerpunkt lag gerade auf der Schilderung des Alltags der Bewohner des Warschauer Ghettos. ${ }^{435}$ Soziale, kulturelle, religiöse und politische Aspekte ebenso wie die Anstrengungen der täglichen Nahrungsmittelversorgung wurden hier umfangreich dargestellt. In diesem umfassenden Ansatz war die Schau zum Zeitpunkt ihrer Entstehung herausragend in der Schilderung nicht nur des jüdischen Schicksals im Krieg, sondern auch im thematischen Umfang der Besatzungserzählung: Der Alltag und das Leben der Mehrheit der Bevölkerung - hier der im Ghetto Eingesperrten - standen im Fokus, nicht die Ausnahmeerscheinungen der Widerstandskämpfer. Auch wenn die übrigen untersuchten Präsentationen nicht derart weit in der Schilderung der Erfahrungen sogenannter normaler Menschen gingen, so ist doch bis Anfang der 2000er-Jahre in der Mehrzahl von ihnen eine spürbare Ausweitung der Alltagsdarstellung zu verzeichnen, die umso prägnanter erfolgte, je später die Ausstellungen überarbeitet oder neu konzipiert wurden. Beispiele hierfür finden sich in Łódź und Krakau. Die 1998 eröffnete Dauerausstellung in der Pomorska-Straße des MHK, deren Alltagsdarstellung größtenteils aus der Version von 1990 übernommen worden war, ergänzte man um weiteres ikonografisches Material; dieses bezog sich in erster Linie auf den Besatzungsalltag. Hinzu kamen etwa Fotografien und Dokumente, die die zunehmende Diskriminierung der jüdischen Bevölkerung bereits vor der Schaffung des Ghettos illustrierten. ${ }^{436}$ Andere Ausstellungstafeln erweiterte man um Fotografien, die Aspekte des polnischen Alltags zeigten, beispielsweise eine Durchsuchung von Passanten oder Menschenmassen, die amtliche Bekanntmachungen auf dem Alten Markt anhören. ${ }^{437}$ Nach 2003 kamen weitere Fotografien hinzu, die die Präsenz deutscher Soldaten im Stadtraum und die Tätigkeit des »Patronat« illustrierten, einer karitativen Organisation, die sich um Inhaftierte und deren Familien kümmerte. ${ }^{438}$ Auch in der Schau des Museums Radogoszcz in

$435 \mathrm{Zu}$ den Inhalten und Darstellungspraxen in dieser Schau siehe ausführlich Teil 2, Kapitel 2.2.

436 Gezeigt wurde u.a. ein Foto der Demütigung eines orthodoxen Judens, dem deutsche Soldaten die Schläfenlocken abschneiden, ein Foto einer Straßenbahn mit dem Hinweis auf die Unterteilung des Wagons »Für Juden / Für Nichtjuden« sowie die Fotografie eines Propagandaplakats in einem Hauseingang, das vor der vermeintlichen Gesundheitsgefahr warnt, die von Juden ausgehe. Der Text des Plakats, das auf einer Ausstellungstafel gegenüber noch einmal im Original gezeigt wurde, lautet (übersetzt): "Juden Flöhe - Fleckfieber«. MHK-Pomorska-Straße, Tafel 11, 12.

437 MHK-Pomorska-Straße, Tafel 18.

438 Diese Elemente sind weder im Drehbuch der Schau von 1997 noch im begleitenden Ausstellungsführer von 2003 erwähnt, daher müssen sie nach diesem Zeitpunkt in die Schau aufgenommen worden sein. Vgl. Scenariusz zmodyfikowanej wystawy »Kraków 1939-1956« przy ul. Pomorskiej 2. o. J. [1997]. AMHK, OP-640-24-97; Salwiński: Wystawa stała. 
Łódź, die 2003 eröffnet wurde, war dem Besatzungsalltag verhältnismäßig viel Platz eingeräumt. Besonders auffällig wirkten die großformatigen Reproduktionen von Fotografien, die durchgängig in der ganzen Schau oberhalb der Ausstellungstafeln angebracht waren. Viele von ihnen zeigten alltägliche Szenen des Stadtlebens, darunter solche friedlicher Straßenzüge. ${ }^{439}$ Die Auswirkungen der Besatzungsbestimmungen wurden am Beispiel etwa des öffentlichen Nahverkehrs, der Kirchenpolitik, der Währungsreform oder der Eingemeindung umliegender Ortschaften in das Stadtgebiet ausgeführt. In Vitrinen fanden sich neben diversen polnischen, deutschen und volksdeutschen Ausweispapieren sowie Bezugskarten für Lebensmittel auch alltägliche Konsumartikel wie die Verpackungen von Schokolade und Waschpulver. ${ }^{440}$ Hier wurde sogar der Versuch unternommen, mittels einzelner Zitate eine individuelle Perspektive auf die Wahrnehmung der Stadt durch Polen zu eröffnen. ${ }^{441}$ Verhältnismäßig umfangreich wurde schließlich auch das Leben im Ghetto Litzmannstadt geschildert. ${ }^{442}$

Wie diese Beispiele illustrieren, entwickelte sich seit Beginn der 1990erJahre der Alltag unter der Besatzung in vielen Präsentationen zu einem eigenständigen Thema. Er wurde jedoch bis Anfang der 2000er-Jahre in den Schauen, die ein Gesamtbild ihrer jeweiligen Stadtgeschichte der Jahre 1939 bis 1944/ 45 zeichneten, nicht zu einem Schwerpunkt der Darstellung. Die Ausstellungsfläche, die dem Thema gewidmet wurde, blieb gering im Vergleich zu den etablierten Topoi der Besatzungsnarrative. Aspekte des zivilen Lebens blieben zudem weitgehend abstrakt und bildeten meist lediglich einen illustrativen Hintergrund. Konkrete Individuen und Erfahrungen waren kaum präsent; dort wo einzelne Protagonisten in Erscheinung traten, handelte es sich um Führungspersönlichkeiten des politischen oder gesell-

439 Es fanden sich aber auch Bilder aus dem Ghetto, dem sogenannten Jugendverwahrlager und Kriegsgefangenenlagern. Die Fotografien waren thematisch den entsprechenden Sektionen der Schau zugeordnet und bildeten ihren ikonografischen Hintergrund. MTNŁ-Radogoszcz, Sektion »Litzmannstadt - Ghetto«, Sektion »Polen - Jugendverwahrlager der Sicherheitspolizei in Lizmannstadt [sic!]«, Sektion »In Gefangenschaft«. In der Sektion zum Alltag der besetzten Stadt fand sich zudem auch eine Tafel mit (deutschen) Postkarten und dementsprechend repräsentativen Fotomotiven des Stadtzentrums. Ebd., Sektion »Es gibt kein Łódź mehr, nur noch Litzmannstadt«.

440 Ebd., Sektion zum Leben in »Litzmannstadt» (ohne Titel).

441 In der Ausstellung fanden sich zwei Zitate aus Ryszard Małeckis Buch »Pod herbem Wandalów« (Unter dem Wappen der Vandalen); eines beschreibt emotional die drastischen Einschränkungen durch die Besatzungsbestimmungen; das andere schildert das Gefühl der Alienation, das polnische Łódźer beim Betreten des von Deutschen dominierten Stadtzentrums fühlen mussten. Siehe auch Teil 1, Kapitel 1.2.

442 MTNŁ-Radogoszcz, Sektion »Litzmannstadt - Ghetto«. Die Darstellung, insbesondere die in dieser Sektion gezeigten Fotografien, waren jedoch weitgehend frei von Gewalt oder Elend und wirkten damit, gerade im Vergleich zur Darstellung des gegen die polnische Bevölkerung gerichteten Terrors, vergleichweise harmlos. Siehe hierzu Teil 2, Kapitel 3.1. 
schaftlichen Lebens. Insgesamt blieben die Kämpfe im September 1939 und der Widerstand gegen die deutschen Besatzer sowie das Leiden der von ihnen unmittelbar Verfolgten weiterhin im Zentrum der Erzählungen und perpetuierten damit ein polnisches Selbstbild der Helden und Märtyrer. Die verhältnismäßig geringe Bedeutung, die dem Besatzungsalltag in den Museen zugewiesen wurde, spiegelte sich auch darin wider, dass nur wenige der untersuchten Institutionen bis 2010 hierzu einzelne thematische Sonderschauen organisierten. $^{443}$

Zwei Aspekte sind bei der skizzierten Entwicklung des Themas noch anzuführen: Zum einen umfasste die Einführung und sukzessive Erweiterung des Alltags in den musealen Erzählungen nicht nur die Schilderung des Lebens der ethnisch-polnischen Bevölkerung, vielmehr wurde sie auch auf die Darstellung der verfolgten und in den Ghettos eingesperrten jüdischen Einwohner ausgeweitet - wenn auch mit der Einschränkung, dass deren Schicksal innerhalb der meisten Narrative weiterhin marginalisiert blieb. ${ }^{44}$ Zum anderen war die Schilderung alltagsbezogener Aspekte nicht zwingend losgelöst von den dominierenden Interpretationstopoi. Im Pawiak-Museum etwa

443 Im Hauptgebäude des Lubliner Museums in Lublin wurde am 22. September 1993 eine Sonderausstellung mit dem Titel »Okupacyjna codzienność Lublina 1939-1944« (Der Besatzungsalltag in Lublin 1939-1944) gezeigt, die von der Leiterin der Abteilung »Unter der Uhr« kuratiert worden war. Siehe Oratowska / Polańska: Okupacyjna codzienność Lublina; Komunikat o działalności Stowarzyszenia w okresie od 15 czerwca 1993 r. do 1 grudnia 1993 r., S. 3. In: AMLL, Kronika Stowarzyszenia b. Więźniów Politycznych Zamku Lubelskiego i »Pod Zegarem« Nr. 19 (12 / 1993-11 / 1996), ohne Signatur. Im Museum Radogoszcz in Łódź wurde bis 2010 lediglich eine Sonderausstellung zu der Thematik gezeigt: im Jahr 1998 die Schau »`A jednak tak byłoく. Dzień powszedni okupowanej Łodzi« (»Und doch war es so«. Der Alltag des besetzten Łódź), die am 1. September eröffnet wurde. Rukowiecki, Andrzej/Pińkowska, Jadwiga/Źródlak, Wojciech: »A jednak tak było «. Dzień powszedni okupowanej Łodzi. Scenariusz wystawy. Łódź 1.9.1998Februar 1999. AMTNŁ, ohne Signatur; Einladungskarte zur Ausstellungseröffnung am 1. September 1998. AMTNŁ, ohne Signatur. In den folgenden Jahren gab es zwei weitere Sonderausstellungen, die den Alltag unmittelbar nach der Befreiung im Jahr 1945 schilderten: im Jahr 2000 die Präsentation »Rok 1945 - życie codzienne w Łodzi« (Das Jahr 1945 - der Alltag in Łódź) und 2005 die Schau »Wolna Łódź. 19 I 1945 r. W 60. rocznicę zakończenia okupacji hitlerowskiej w Łodzi« (Das freie Łódź. 19. Januar 1945. Zum 60. Jahrestag des Endes der hitleristischen Besatzung in Łódź). Źródlak: Bibliografia radogoska, 136, 150; Wolna Łódź. 19 I 1945 r. W 60. rocznicę zakończenia okupacji hitlerowskiej w Łodzi [Ausstellungsdrehbuch]. Łódź o. J. AMTNŁ, ohne Signatur. Das Museum der Unabhängigkeitstraditionen erarbeitete 1995 im Auftrag des »Polnischen Instituts « (Instytut Polski) in Budapest eine Schau mit dem Titel »59 miesięcy. O życiu Polaków pod okupacją niemiecką i sowiecką w czasie II wojny światowej« (59 Monate. Das Leben der Polen unter deutscher und sowjetischer Besatzung während des Zweiten Weltkriegs). Inwiefern hierbei jedoch ein Schwerpunkt der Darstellung auch außerhalb unmittelbarer Opfer- und Heldendarstellungen gelegt wurde, lässt sich nicht sagen. Pałaszewska/Żuchowska: Wystawy w Muzeum Niepodległości, 175.

444 Siehe Teil 2, Kapitel 1.2 und 2.1. 
sind die wenigen Hinweise auf die Lebensbedingungen der breiten Bevölkerung innerhalb und außerhalb des Ghettos unmittelbar in die viktimologische Darstellung des Besatzungsterrors eingebunden, womit vor allem die Unmenschlichkeit und Grausamkeit der Deutschen unterstrichen wird. Weniger geht es darum zu zeigen, wie die Menschen unter den schwierigen Bedingungen (über-)lebten und ihren Alltag bestritten.

\section{Heroisierung des Alltags}

Das Beispiel des Pawiak kündigt bereits eine Tendenz an, die sich wenig später mit dem beginnenden Museumsboom noch stärker ausprägt: Zwar sind die Lebensbedingungen der breiten Bevölkerung spätestens seit 2004 ein fester Bestandteil musealer Erzählungen über die Jahre 1939 bis 1944/45. Ihre Kontextualisierung bleibt jedoch oftmals innerhalb des klassischen Interpretationsrahmens der Helden und Märtyrer verankert; die Schilderung eines Besatzungsalltags dient in diesen Schauen somit einzig dazu, das martyrologische und heroische Selbstbild zu untermauern.

Auch in diesem Bereich ist die Dauerausstellung des Museums des Warschauer Aufstands das prominenteste Beispiel. Im ersten Moment könnte man den Eindruck erhalten, einzelnen Aspekten des Lebens während der Kämpfe im August und September 1944 werde hier umfassend Raum gegeben. So sind den Reaktionen der Warschauer auf den Ausbruch der Erhebung, der Versorgungslage und der Betreuung der Verwundeten während der folgenden zwei Monate, der Kultur und Religiosität in der umkämpften Stadt jeweils eigene Sektionen gewidmet. Obwohl die Ausstellungsverantwortlichen nach eigener Aussage den Alltag »der ganzen Warschauer Bevölkerung in jenen Tagen« schildern wollten ${ }^{445}$ bleibt sie bei näherer Analyse jedoch fast gänzlich im Hintergrund. Beispiel hierfür sind die in der Ausstellung verteilten Bildschirme mit Videomitschnitten von Zeitzeugeninterviews, die ausschließlich ehemalige Aufständische zu Wort kommen lassen. Aus ihrer Perspektive werden der Verlauf der Ereignisse und einzelne Aspekte der Kämpfe geschildert, so auch die »Euphorie $\aleph^{446}$ der Menschen am 1. August 1944. Es sind die Aufständischen, ihre Erfahrungen und Erinnerungen, die hierdurch stellvertretend für die Warschauer und im weiteren Sinne auch die Gesamtbevölkerung des besetzten Landes stehen. ${ }^{447}$ Exemplifiziert wird diese Perspektive in der Benennung und Umsetzung des thematischen Abschnitts, der dem Beginn der Kämpfe gewidmet ist: Während die Bereichstexte allgemein berich-

445 Ołdakowski/Kowal: Podstawowe założenia programowe i organizacyjne, 9.

446 So lautete die Wortwahl von Eugenia Gugała-Stolarska, Pseudonym »Werka«, in der Videopräsentation der Sektion 13: Die Freude der Aufständischen.

447 Siehe hierzu auch Kapitel 2.3 in diesem Teil. 
ten »Die Bevölkerung Warschaus nimmt den Ausbruch des Aufstands mit Enthusiasmus auf ${ }^{448}$ und ${ }^{4}$ Warschau fühlt sich am 1. August [1944] frei ${ }^{449}$, verweist der Titel der Sektion - »Die Freude der Aufständischen « - präziser auf die Perspektive derjenigen, die hier ihre Eindrücke tatsächlich schildern.

Im weiteren Verlauf der Schau wird die Zivilbevölkerung fast ausschließlich an solchen Stellen erwähnt, an denen eine uneingeschränkte Unterstützung der Kämpfenden vermittelt werden soll. So etwa bei der Schilderung des Beistands von Künstlern und Priestern. Ein Ausstellungstext berichtet von der Schenkung von Wertgegenständen an die Aufständischen durch eine berühmte Künstlerin. ${ }^{450}$ In dieser Sektion, ebenso wie im benachbarten $\mathrm{Ab}$ schnitt zum religiösen Leben während der Kämpfe, sind es dennoch nicht die Handlungen von zivilen Akteuren, auf die in erster Linie verwiesen wird. In beiden Sektionen sind es Künstler respektive Priester, die in den Reihen der Aufständischen kämpften, welche mittels Porträtfotografien und kurzen Informationstexten individuell benannt und damit hervorgehoben werden. ${ }^{451}$ Über die Ansichten und Lebensbedingungen der Zivilbevölkerung wird dagegen überwiegend abstrakt berichtet; auf Fotografien bilden sie lediglich einen illustrativen Hintergrund. Mittels dieser Präsentationsweise erweckt die Schau den Eindruck einer verschworenen Gemeinschaft zwischen Aufständischen und Zivilisten, ein Topos, der bereits vor 1989 die museale Darstellung der Besatzungszeit prägte (wenn er auch in allgemeinerer Weise auf den Widerstand bezogen war). ${ }^{452}$ Es scheint zudem, als sei die Haltung der Bevölkerung bis zum Ende der Kämpfe unverändert positiv geblieben. Dabei schlug die Stimmung der Zivilbevölkerung angesichts der sich zunehmend verschlechternden Versorgungs- und Sicherheitslage bald um, was in der Ausstellung jedoch unerwähnt bleibt. ${ }^{453}$ Ganz im Gegenteil hierzu wird während des Rundgangs immer wieder der Einfallsreichtum der Warschauer - vertreten durch die Aufständischen - bei der Überwindung militärischer und all-

448 Bereichstext »Die Freude der ersten Tage«. MPW, Sektion 13: Die Freude der Aufständischen.

449 Bereichstext »Der freie Staat $«$. Ebd.

450 Bereichstext »Die wertvolle Hilfe der Künstlerin«. MPW, Sektion 19: Kulturleben.

451 Präsentiert werden u.a. einer der berühmtesten polnischen Schriftsteller der Besatzungszeit, Krzysztof Kamil Baczyński, und Zbigniew Jasiński, dessen bekannte Gedichte die Radiostation der Aufständischen »Blitz« (Błyskawica) verbreitete. MPW, Sektion 19: Kulturleben. In der Sektion 18 (Religiöses Leben) werden zahlreiche Priester namentlich und mit Porträtfotografien vorgestellt; alle von ihnen waren während der Kämpfe einzelnen Einheiten der Aufständischen zugeteilt. Auch das Foto einer Hochzeit zeigt ein Paar, das an den Kämpfen aktiv teilnahm.

452 Ein Teil der folgenden Ausführungen wurde bereits publiziert in Heinemann: Das Museum des Warschauer Aufstands.

453 Die Erfahrungen und Stimmungen in der Zivilbevölkerung während der Kämpfe schildert u. a. Borodziej: Der Warschauer Aufstand, 188-204. 
täglicher Probleme hervorgehoben. Beispielhaft ist die Sektion, die sich der Versorgungslage während der Kämpfe widmet: ${ }^{454}$ Während die Ausstellungstexte von Entbehrungen und Hunger berichten, sind auf den zahlreichen großformatigen Fotografien, die diesen Ausstellungsteil dominieren, ausnahmslos Personen zu sehen, die Speisen zubereiten, essen oder aber Lebensmittel und Wasser transportieren - meist Aufständische, die an ihren Armbinden zu erkennen sind; viele von ihnen lächeln in die Kamera. Selbst die Beschriftungen der präsentierten Objekte benennen deren Funktion bei der Zubereitung von improvisierten Speisen. Das sorgfältig zusammengestellte visuelle und gegenständliche Narrativ widerspricht somit dem kognitiven. Insgesamt bleibt der Eindruck haften, dass die Probleme weitgehend erfolgreich bewältigt wurden. Das Leiden der Menschen unter Nahrungs- und Wassermangel wird dagegen ausgespart. Die Gesamterzählung vermittelt damit paradoxerweise einen optimistischen Eindruck von der Alltagssituation in der umkämpften Stadt. Das Arrangement dieser Sektion ist damit ein prägnantes Beispiel für Monika Flackes Feststellung: »Bilder bilden nicht die Wirklichkeit ab, sie stellen eine $>$ Wirklichkeit $<$ her ${ }^{455}$ Suggestiv, optimistisch und damit ansprechend wirken gerade die zahllosen Bilder, die von Fotografen der AK während des Aufstands angefertigt worden waren. ${ }^{456}$ Fröhliche, junge und gutaussehende Menschen begegnen darin den Besuchern während des gesamten Rundgangs und prägen hierdurch eine fast zwangsläufig positive, parteiische Sichtweise der Besucher auf die Protagonisten der Erzählung (siehe Abb. 53). Wiederum sind es jedoch die Aufständischen, die derart in Erscheinung treten und das gezeigte visuelle Material dominieren.

Der einzige Moment, an dem Zivilisten tatsächlich im Zentrum der Aufmerksamkeit stehen, ist die Schilderung der Massaker an mehrehren Tausend Bewohnern der Stadtteile Wola und Ochota, die in den ersten Tagen des Aufstands von SS-Einheiten verübt wurden. ${ }^{457}$ Wie in Kapitel 1.3 gezeigt wurde, sind die Opfer dieser Verbrechen in der entsprechenden Sektion jedoch nicht die Protagonisten der Ereignisse, sondern vielmehr deren Objekte; ihr Schicksal bezeugt in erster Linie die unmenschliche Grausamkeit der Besatzer. Dort, wo Individuen mit ihren konkreten Erfahrungen und Handlungen in Er-

454 MPW, Sektion 17: Nahrung und Wasser.

455 Flacke, Monika: Erinnerungen. In: Dies. (Hg.): Mythen der Nationen. 1945 - Arena der Erinnerungen. Bd. 1. Mainz 2004, 7-12, hier 10. Siehe hierzu auch Bredekamp, Horst: Bildakte als Zeugnis und Urteil. In: Flacke, Monika (Hg.): Mythen der Nationen. 1945 Arena der Erinnerungen. Bd. 1. Mainz 2004, 29-66, hier $29 \mathrm{f}$.

456 Die Heimatarmee unterhielt eine eigene Propagandaabteilung, deren Aufgabe u.a. die fotografische und filmische Dokumentation der Kämpfe 1944 war. Eine kurze Erwähnung findet die Abteilung auch in der Ausstellung. Siehe: Bereichstext »Das Büro für Information und Propaganda«. MPW, Sektion 36: Die Kämpfe im September.

457 MPW, Sektion 20: Der Völkermord in Wola. 


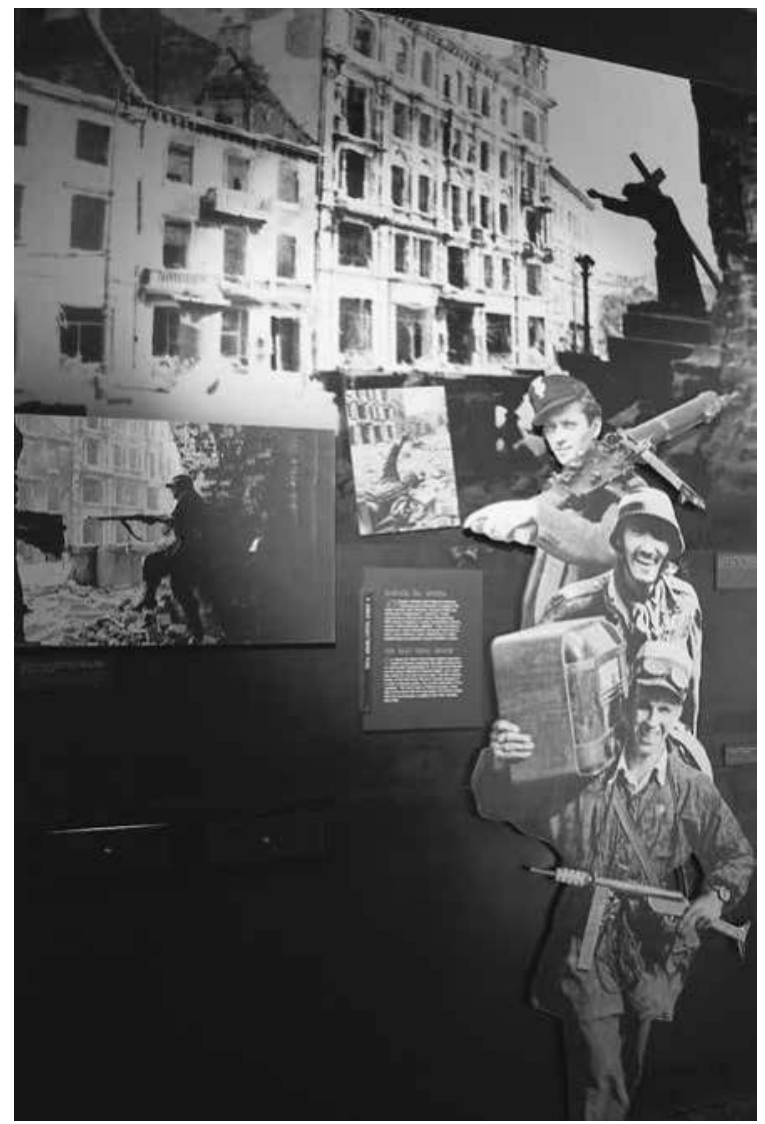

Abb. 53: MPW, Sektion »Die Kämpfe im August«.

scheinung treten, handelt es sich dagegen fast ausschließlich um Mitglieder der Untergrund- und Widerstandsorganisationen. Sie stehen stellvertretend für die Warschauer Gesamtbevölkerung.

Wie aus diesen Analysen deutlich wird, werden im MPW Zivilisten und Elemente des Alltagslebens der aufständischen Stadt erstens weitgehend im Hintergrund und zweitens einzig in solcher Form kontextualisiert, dass sie das einseitig heroische Interpretationsschema der Schau stützen. ${ }^{458}$ Raum für

458 Dieselbe Darstellungsweise wird auch zu Beginn der Ausstellung in Bezug auf die Schilderung der Kämpfe von 1939 und das deutsche Besatzungsregime im Generalgouvernement angewandt: Die Zivilbevölkerung wird als scheinbar homogene Einheit thematisiert, etwa in ihrer "massenhaften« Beteiligung an der Verteidigung Warschaus im September 1939. MPW, Sektion 6: Besatzung, Bereichstext "Die Bevölkerung in der Verteidigung Warschaus«. 
davon abweichende Handlungen und ambivalente, sich wandelnde Haltungen oder auch reinen Überlebenswillen gibt es dagegen nicht, wie im folgenden Abschnitt noch erläutert wird. ${ }^{459}$

Zwar ist das Museum des Warschauer Aufstands das exponierteste Beispiel dieser Darstellungspraxis; es ist jedoch nicht die einzige der untersuchten Institutionen, die bis 2010 eine derartige Interpretation vornimmt. Ganz ähnlich verfuhr auch das Warschauer stadthistorische Museum bei der Schilderung des Alltags der besetzten Stadt. In den zwischen 2006 und 2009 überarbeiteten Sektionen der Schau wurde ein Saal den verschiedenen Aspekten des Lebens der Jahre 1939 bis 1944 gewidmet. ${ }^{460}$ Mehrere wandhohe Tableaus mit Fotografien illustrierten den öffentlichen Nahverkehr der Besatzungsjahre, die überfüllten Straßenbahnen und zahlreichen Rikschas, Straßenszenen mit deutschen Uniformierten, aber auch zivilen Spaziergängern ebenso wie den ärmlichen Straßenhandel im Unterschied zu einem üppig bestückten Lebensmittelgeschäft »Nur für Deutsche $« .{ }^{461}$ Der begleitende Thementext schilderte die erschwerten Lebensbedingungen der Bevölkerung, darunter den lebensnotwendigen Schwarzmarkt und Schmuggel von Gütern. Abschließend wurde auf den spezifischen Humor der Warschauer eingegangen, die verbreiteten politischen Witze und unter Lebensgefahr in der Öffentlichkeit gesungenen patriotischen Lieder. Das Fazit der Ausstellungsverantwortlichen lautete: »All diese Handlungen unterstützten die Polen in ihrem Patriotismus und der Widerstandshaltung gegen den Besatzer. ${ }^{462}$ Die zunächst sachliche - wenn auch rein auf die ethnisch-polnische Bevölkerung bezogene Darstellung der veränderten Lebenssituation und der Reaktion der Menschen darauf wurde letztlich einseitig auf eine allgemeine Widerstandshaltung zugespitzt.

Deutlicher geschah dies noch bei den beiden übrigen Themenabschnitten des Saals, die das Untergrundpublikationswesen und das geheime Schulwesen darstellten. Die dort namentlich vorgestellten Schriftsteller, darunter bekannte Persönlichkeiten wie Krzysztof Kamil Baczyński und Tadeusz Borowski, publizierten nicht nur in Untergrundverlagen, sondern stellten zudem prototypische Beispiele polnischer Helden und Märtyrer dar: Der Großteil der Genannten war im Widerstand aktiv, die übrigen wurden von den Besatzern verfolgt, das heißt exekutiert oder in Konzentrationslager deportiert. Stellvertretend für das geheime Kulturleben der Stadt standen hiermit wiede-

459 Dies stellt auch Adam Ostolski fest. Siehe Ostolski: Przestrzeń muzeum, 82.

$460 \mathrm{MHW}$, Saal 49. In der unmittelbar an diesen Raum anschließenden Sektion zum Aufstand 1944 blieb die Zivilbevölkerung und ihre Perspektive der zweimonatigen Kämpfe dagegen weitgehend außen vor. Siehe Kapitel 2.3.

461 Abschnitte »Der Alltag des besetzten Warschau (1939-1944)« und »Verkehr und Handel«. MHW, Saal 49.

462 Thementext »Der Alltag des besetzten Warschau (1939-1944)«. Ebd. 
rum Ausnahmeerscheinungen, die als Vorbilder fungierten: „Während der Besatzung debütierte eine ganze neue Generation von Dichtern, die sich im Überlebenskampf der Nation engagierten «. ${ }^{463}$ Ähnlich erfolgte die Darstellung des Schulwesens während der Besatzung: Wie der Titel des Abschnitts "Das geheime Bildungswesen" - bereits deutlich machte, stand der im Untergrund organisierte Schul- und Hochschulunterricht im Vordergrund. Die Aufstellung der Zahlen der während des Kriegs unterrichteten Schulkinder und Studenten sowie der erlangten Abiture, Hochschulabschlüsse, Doktorgrade und Habilitationen wirkte dabei als Beleg für den erfolgreichen Widerstand - diesmal im intellektuellen Bereich - gegen die Besatzungspolitik. Insgesamt vermittelte der Saal damit eine heroische Interpretation des Alltags der polnischen Warschauer in den Jahren 1939 bis 1944. Diese erschienen wie auch vor der Wende von 1989 - als geschlossene Gemeinschaft, geeint im Widerstand gegen die Deutschen. Hierauf verwies nicht zuletzt die Rückwand des Raums, die auf ihrer gesamten Breite und Höhe mit Parolen und Losungen bedruckt war, die Widerstandsgruppen auf den Wänden und Litfaßsäulen der Stadt verbreiteten. Hinweise auf ambivalente Aspekte des Lebens und Überlebens der Zivilbevölkerung, etwa die starke Zunahme von Denunziationen und Kriminalität, ${ }^{464}$ fehlten hingegen gänzlich.

Einen anderen Fall stellt die Dauerausstellung des Historischen Museums von Wrocław dar. In deren Sektion zum Zweiten Weltkrieg ist der Alltag der Jahre 1939 bis 1945 so gut wie nicht präsent. Ethnische Polen werden fast ausschließlich als Zwangsarbeiter und Insassen von Konzentrationslagern thematisiert; daneben wird ein Repräsentant des verfolgten polnischen Widerstands in den ins Deutsche Reich eingegliederten Gebieten hervorgehoben. ${ }^{465}$ Da Polen in die mehrheitlich deutsche Stadt nach 1939 in erster Linie als Zwangsarbeiter gebracht wurden, ist der Fokus auf diese Themen wenig verwunderlich. Überraschend ist vielmehr, dass der Alltag der Mehrheitsbevölkerung - also der Deutschen - überhaupt nicht betrachtet wird. Für die Jahre des Kriegs ist sie allein durch militärische Vertreter repräsentiert. ${ }^{466}$ Damit setzt auch diese Schau in Bezug auf die Jahre 1939 bis 1945 das tradierte polnische Selbstbild der Helden und Opfer fort, wenn auch hier das Leiden im Vordergrund steht. In diesem spielen Alltagserfahrungen mit ihren abivalenten und profanen, mithin wenig heroischen Komponenten, keine Rolle.

463 Ebd., Bereichstext »Untergrundliteratur - Verlagstätigkeit«.

464 Borodziej: Geschichte Polens, 221 f., 225. Siehe hierzu auch Kapitel 3.2.

465 Siehe Kapitel 1.3.

466 Siehe auch Teil 1, Kapitel 1.3. 
»Normalisierung» des Alltags

Eine gegenläufige Tendenz zu diesen in tradierten Rollenbildern verhafteten Präsentationen zeichnet sich in der Abteilung des Historischen Museums der Stadt Krakau in der ehemaligen Emaillewarenfabrik Oskar Schindlers ab. Ihre Dauerausstellung präsentiert eine diametral entgegengesetzte Perspektive auf die Kriegs- und Besatzungsjahre der Stadt. Ausgangspunkt der Erzählung sind die Erfahrungen der Mehrheitsbevölkerung, also der "gewöhnlichen" Menschen mit ihren alltäglichen Problemen und Erlebnissen. Bemerkenswert ist hierbei, dass sowohl die polnische als auch die jüdische Bevölkerung gleichermaßen in die Wir-Gemeinschaft der Krakauer eingeschlossen werden. Dieser integrative Ansatz stellt im Untersuchungszeitraum ein Unikat im polnischen historischen Museumswesen dar. Aus der Perspektive beider Bevölkerungsgruppen verfolgen die Besucher die Entwicklung der Ereignisse. Ermöglicht wird dies durch eine Vielzahl von Zeitzeugenberichten; aber auch die Gestaltung einzelner Sektionen und inszenatorische Eingriffe führen die Besucher in den Alltag und die Perspektive der »durchschnittlichen« Krakauer ein. ${ }^{467}$

Charakteristisch für diese Präsentation ist, dass einzelne Ereignisse und Themenbereiche zunächst meist aus einer Perspektive "von unten«, das heißt durch die Wahrnehmungen und Meinungen der Bewohner der Stadt eingeführt werden. So leiten beispielsweise geflüsterte Gespräche in einem inszenierten Hauseingang die Schilderung der Besetzung Krakaus durch deutsche Truppen im September 1939 ein. ${ }^{468}$ Hier werden die polnischen Flüchtlinge und Ausgesiedelten aus Schlesien und Pommerellen angesprochen, deren Unterbringung große Schwierigkeiten bereitete, Überfälle auf jüdische Läden, der Mangel bestimmter Lebensmittel; man hört Gerüchte von hungernden polnischen Insassen der Kriegsgefangenenlager, aber auch freudige Berichte über den Besuch einer Theaterpremiere oder eines Kinofilms. Dazwischen

467 Im Folgenden wird schwerpunktmäßig auf die polnische Bevölkerung bzw. die Bewohner außerhalb des Ghettos eingegangen, da die Darstellung der jüdischen Bevölkerung, u. a. ihrer Alltagserfahrungen der Jahre seit 1939, bereits umfangreich in Teil 2, Kapitel 4 geschildert wurde.

468 MHK-Schindler-Fabrik, Sektion 4: Kriegsausbruch. In ähnlicher Weise erfahren die Besucher von den Ängsten, Befürchtungen und Alltagsproblemen der im Ghetto eingesperrten Menschen. Im weiteren Verlauf des Rundgangs laufen sie durch ein überfülltes Zimmer im Ghetto. Den Hintergrund dieser Inszenierung bilden Tonaufnahmen von arrangierten Gesprächen der Bewohner über ihre Alltagssorgen. MHK-Schindler-Fabrik, Sektion 14: Ghetto. Auch die Darstellung des Lebens der deutschen Besatzer in der Stadt wird eingeleitet mit einem (schriftlichen) Kommentar einer polnischen Zeitzeugin: Karolina Lanckorońska schildert ihre Wahrnehmung der Absperrung des Wawels und damit seine "Abwesenheit" im Stadtleben als ein Symbol des Verlusts der polnischen Unabhängigkeit. MHK-Schindler-Fabrik, Sektion 7: Generalgouvernement. 
finden sich immer wieder überraschende Wahrnehmungen dieser Zeit. Eine weibliche Stimme äußert empört: »Es ist eine Schande, dass unsere Regierung es zu einer solch erbärmlichen Niederlage hat kommen lassen, dass sie nichts vorhergesehen hat, dass sie der Nation und der Gesellschaft etwas vorgemacht hat." Eine andere sagt überzeugt: »Es gibt keinen Grund, Angst zu haben. Die Deutschen sind doch kultivierte Menschen.« Solch kritische Positionen gegenüber der eigenen politischen Führung, ebenso wie anfänglich optimistische Haltungen den Besatzern gegenüber, mithin Perspektiven, die dem tradierten Selbst- und Feindbild entgegenstehen, stellen ein absolutes Novum in den musealen Präsentationen dar. Die distanzierte und kritische Haltung vieler Stadtbewohner zur polnischen Vorkriegsregierung wird auch im folgenden Saal deutlich, dessen übergreifendes Motto wiederum ein Zitat bildet: »Was ist von den hochtrabenden, starken Worten geblieben ...». Diese Zeile überspannt großformatig die zentrale Wand der Sektion; in vollständiger Fassung lautet das Zitat:

Was ist von den hochtrabenden, starken Worten über unsere Macht, über den berühmten Knopf am Mantel, geblieben? Der Abgrund zwischen demjenigen, mit dem man uns über Jahre gefüttert hat, und dem Moment der blitzartigen Niederlage [ist] gewaltig ... ${ }^{469}$

Die Aussage knüpft an eine von der Presse der Zwischenkriegszeit häufig wiederholte Losung des Marschalls Edward Rydz (Pseudonym »Śmigły«) an, mit der er die absolute Verteidigungsbereitschaft Polens gegen äußere Gegner proklamiert hatte: "nicht einmal einen Knopf werden wir abgeben ${ }^{470}{ }^{40}$ Sie dokumentiert eindrücklich die Überraschung und Enttäuschung der polnischen Bevölkerung angesichts der erschreckend schnellen Niederlage.

Im weiteren Verlauf des Rundgangs treffen die Besucher immer wieder auf divergierende und teils sogar konträre Positionen, die die Vielfalt der Wahrnehmungen und der »Graustufen« des Alltags offenbaren. Diese Vielfalt gründet sich auf der starken sozial- und gesellschaftsgeschichtlichen Ausrichtung der Präsentation. Im arrangierten »öffentlichen Raum« (plac miejski) der Stadt etwa - so der Titel gleich zweier Sektionen - begegnen die Besucher buchstäblich einzelnen Krakauern, in Form lebensgroßer Fotografien. ${ }^{41}$ Darunter findet sich eine fröhliche Gruppe von Frauen; wie man er-

469 Das Zitat, das in kleinerer Schriftgröße die Präsentation auf dieser Wand einleitet, stammt von Julian Waga. MHK-Schindler-Fabrik, Sektion 5: Öffentlicher Raum I.

470 Das Originalzitat, auf das Waga anspielt, stammt aus einer Rede von Śmigły-Rydz im Jahr 1935 auf einem Kongress des »Verbands Polnischer Legionäre» (Związek Legionistów Polskich), auf dem er sich derart mit Bezug auf Begehrlichkeiten äußerer Mächte gegenüber Polen geäußert hatte. Auf diesen Kontext weist hin Bogumit: Miejsce pamięci versus symulacja przeszłości, 163.

471 MHK-Schindler-Fabrik, Sektion 18: Öffentlicher Raum II. 
fährt, handelt es sich um Ehefrauen polnischer Offiziere, über die berichtet wird, dass diese unter dem Zwang der veränderten Lebensbedingungen der Besatzungsjahre »unabhängig und selbstständig geworden« seien. ${ }^{42}$ Ein Foto zweier Männer mit weißen Armbinden ist mit der Information versehen, dass Juden bis Juli 1941 zum Teil noch Geschäfte und Werkstätten außerhalb des Ghettos besaßen und erst ab Juli 1941 in der Stadt nur noch als Zwangsarbeiter in Erscheinung traten. Beim Bild eines älteren Paares, das von einem (polnischen) Polizisten abgeführt wird, erfährt man vom verbreiteten Schmuggel von Lebensmitteln aus den Dörfern in die Stadt, der aufgrund der zahlreichen Denunzianten sowie der unberechenbaren und korrupten deutschen und polnischen Polizisten sehr gefährlich war. Über einem weiteren Foto einer Gruppe von Passanten wird zusammengefasst:

Krakau, das von den Kriegshandlungen nicht zerstört wurde, machte den Eindruck einer dem Anschein nach normalen Stadt. Menschen kümmerten sich um ihre Angelegenheiten - sie arbeiteten, besuchten Konzerte, Kinos und Theater, beteten in den Kirchen, trafen sich in Cafés, veranstalteten in ihren Wohnungen Gesellschaften. ${ }^{473}$

Bereits in einem früheren Abschnitt des Rundgangs sind die Besucher auf Fotografien einer polnischen Osterfeier mit einem reich gedeckten Tisch getroffen, gut angezogenen Menschen in einem voll besetzten Café, einer lachenden jungen Frau, die in einem Geschäft mit gebrauchter Kleidung einen Hut anprobiert; direkt daneben finden sich ein Plakat, das eine Silvesterfeier für die deutschen Stadtbewohner ankündigt, oder das Foto einer Gartenanlage für Deutsche, aber auch Plakate, die die Exekution inhaftierter Polen verkünden. ${ }^{474}$ Diese Arrangements und Installationen vermitteln den Besuchern eindrücklich die Diversität der Besatzungsrealität - das Nebeneinander von verhältnismäßiger Normalität und Ausgrenzung, Armut und relativem Wohlstand, gegenseitiger Unterstützung, aber auch Verfolgung sowie Denunziationen. Sie verweisen zudem immer wieder auf die öffentlichen Begegnungsräume der drei großen Bevölkerungsgruppen der Stadt - Polen, Juden und Deutschen.

Eine weitere Besonderheit der Vermittlungspraxis dieser Schau ist bereits angeklungen: Berichte von Zeitzeugen, in geschriebener wie audiovisueller Form, werden zahlreich im Verlauf des gesamten Ausstellungsrundgangs eingesetzt. Sie offenbaren individuelle und damit auch subjektive Sichtweisen der polnischen und jüdischen Protagonisten der historischen Ereignisse und bieten immer wieder auch überraschende Einsichten in den Alltag der Menschen. Nicht zuletzt verweisen gerade die Berichte von Augenzeugen auch auf

472 So lautet das Fazit des kurzen Begleittextes zu dem Foto. Ebd.

473 Ebd.

474 MHK-Schindler-Fabrik, Sektion 15: Alltag, 1943. 
viele ambivalente und negative Erscheinungen des polnischen und jüdischen Alltags, ${ }^{475}$ wie im Folgenden noch näher geschildert wird.

Wie diese Ausführungen verdeutlichen, rekrutieren sich die Protagonisten dieser Erzählung wesentlich aus der breiten Masse der Stadtbewohner. Nicht mehr die Ausnahmeerscheinungen der aktiv Widerständigen und unmittelbar Verfolgten stehen hier im Vordergrund, auch wenn sie in diesem breiten Fächer ebenfalls thematisiert werden, sondern die Erfahrungen der durchschnittlichen Krakauer. Ihr Alltag wird zudem differenziert präsentiert, aus einer größtenteils sozial- und gesellschaftsgeschichtlichen Perspektive. Die Ausstellung zeichnet dabei kein schematisches Bild einer in ihren Ansichten und Verhaltensweisen vermeintlich homogenen Wir-Gemeinschaft, sondern bemüht sich, ein breites Tableau menschlicher Verhaltensweisen während der Besatzung offenzulegen. Dadurch erfährt insbesondere das tradierte Selbstbild der ethnisch-polnischen Bevölkerung im Krieg eine deutliche Diversifizierung.

\subsection{Leerstellen des Besatzungsalltags}

In den vorangegangenen Kapiteln wurde bereits mehrfach auf Leerstellen innerhalb der Ausstellungsnarrative hingewiesen, die Einfluss auf die Konstruktion der dargebotenen Interpretationen haben. Diese ausgelassenen oder tabuisierten Themen haben für die Schaffung der musealen Kriegserzählungen eine prägende Bedeutung, denn letztlich bestimmen sie wesentlich die Grenzen des polnischen Selbstbildes im Zweiten Weltkrieg, das vermittelt wird. An dieser Stelle soll näher betrachtet werden, welche Aspekte der Kriegs- und Besatzungsrealität in den musealen Präsentationen der untersuchten drei Jahrzehnte und teilweise bis heute nicht thematisiert werden. Dargelegt werden sollen zudem die Hintergründe und Darstellungslogiken, die für die Vermeidung bestimmter Themen ausgemacht werden können.

Übergreifend ist festzustellen, dass in erster Linie Aspekte tabuisiert wurden bzw. werden, die aus der jeweiligen Perspektive des Entstehungszeitraums einzelner Schauen negativ bewertet wurden und vor allem Begegnungen mit und Reaktionen auf inner- sowie außerstaatliche »Andere « im Alltag umfassten. $\mathrm{Zu}$ diesem Themenspektrum zählen Formen der Interaktion mit Vertretern der Besatzungsmacht, etwa im Bereich des Schmuggels von Waren, der Korruption oder der Arbeit von Polen in einzelnen exekutiven Institutionen der Besatzer, wie der Polizei. ${ }^{476}$ Auch die Reaktionen und Verhaltensweisen

475 Siehe hierzu auch Teil 2, Kapitel 4.

476 Den Alltag der Menschen während der Jahre 1939 bis 1945 und dessen vielfältige Formen der Begegnung und Interaktion auch mit den Besatzern schildert etwa Borodziej: Geschichte Polens, 191-234. Erste Darstellungen des Alltags der »Kowalskis«, also der durchschnittlichen polnischen Bevölkerung in den Jahren der Besatzung, fanden sich 
von Polen im Angesicht der Verfolgung der jüdischen Einwohner des Landes, die außerhalb des engen Spektrums von Mitgefühl oder Unterstützung für die Verfolgten lagen, blieben weitgehend unbeachtet, wie ausführlich bereits in Teil 2 dargelegt worden ist. Nicht zuletzt ist es schließlich die jeweilige Binnenperspektive, also die Erfahrungen und Wahrnehmungen sowohl unter den Deutschen auf polnischem Territorium - der Feinde, als auch innerhalb der konkurrierenden Opfergruppe der jüdischen Bevölkerung, die mindestens bis Mitte der 2000er-Jahre nicht thematisiert werden. Ein zweiter Schwerpunkt der zu konstatierenden Leerstellen lag und liegt bei ambivalent oder negativ bewerteten Verhaltensweisen innerhalb der ethnisch-polnischen Bevölkerung, also bei Negativerfahrungen mit den Mitgliedern der eigenen Wir-Gemeinschaft. Hierzu zählen in erster Linie Denunziationen von Polen durch Polen sowie die Spitzeltätigkeit für die Besatzer ${ }^{477}$ - der Übergang solcher Verhaltensweisen zur Kooperation oder mindestens Interaktion mit den Besatzern ist dabei fließend - und die gestiegene Kriminalität und Gewaltbereitschaft. ${ }^{478}$ Der Aspekt der Passivität von großen Teilen der Bevölkerung, ${ }^{479}$ die Konzentration auf das eigene Überleben und den eigenen Alltag, mithin die Abwesenheit widerständigen Verhaltens, kann schließlich als ein weiteres charakteristisches Element der Besatzungsjahre genannt werden, das bis in die Gegenwart kaum Erwähnung in den musealen Erzählungen findet.

Da der Alltag der Menschen außerhalb der Extremerfahrungen unmittelbarer Verfolgung oder Involvierung in Widerstandshandlungen in den Schauen, die in den 1980er-Jahren zu besichtigen waren, unerwähnt blieb, wurden damit auch negative Phänomene der innerpolnischen Besatzungsrealität ausgeblendet. Lediglich im Pawiak-Museum konnten aufmerksame Besucher einen vereinzelten, peripheren Verweis auf die Existenz von Informanten (konfidenci) entdecken: Im Thementext "Kampf und Hoffnung « wurde als eines der Ziele des Widerstandskampfes der Gefängnisinsassen die »Warnung vor Informanten « genannt. ${ }^{480}$ Auch nach 1989 traten ähnliche Andeutungen nur sporadisch auf. Im Stadtmuseum von Łódź wurde beispielsweise nur in-

auch bereits bei Szarota, Tomasz: Okupowanej Warszawy dzień powszedni. Studium historyczne [Der Alltag des besetzten Warschaus. Eine historische Studie]. 2. erw. Aufl. Warszawa 1978 (Erstauflage 1973).

477 Borodziej: Terror und Politik, 136-161.

478 Deren negative Folgen im Alltag der Menschen im Generalgouvernement beschreibt Gross, Jan Tomasz: Polish Society Under German Occupation. The Generalgouvernement, 1939-1944. Princeton, New Yersey 1979, 160-167.

479 Majewski, Piotr: Konzept und Organisation des »zivilen Kampfes«. In: Chiari, Bernhard (Hg.): Die polnische Heimatarmee. Geschichte und Mythos der Armia Krajowa seit dem Zweiten Weltkrieg. München 2003, 303-323, hier 323.

480 Weiter wurde auf Spitzel und die Gefahr, die von ihnen für die Untergrundbewegung innerhalb und außerhalb des Gefängnisses ausging, jedoch nicht eingegangen. Scenopis stałej ekspozycji, 80 . 
direkt auf Informanten der deutschen Behörden in den Reihen der Untergrundbewegungen hingewiesen: "Überdies überwachte die örtliche Gestapo ständig die Reihen des Łódźer Untergrunds und führte ununterbrochen Verhaftungen durch, womit sie die Untergrundarbeit wesentlich störte. ${ }^{481}$ In der weitaus umfangreicheren Schau des Museums Radogoszcz von 2003 waren Hinweise auf diese Situation noch wesentlich spärlicher: Lediglich in einem von zahlreichen Fallbeispielen individueller Verfolgung - dem Schicksal der Familie Ajnenkiel, Mitgliedern der SZP-ZWZ-AK, die in ein Konzentrationslager deportiert worden waren - erschien ein Hinweis, dass ihre Verhaftung auf die Tätigkeit eines Spitzels zurückzuführen war. ${ }^{482}$ Interessierte Leser der ausgestellten Quellenmaterialien, konkret der Untergrundpresse, konnten zudem in einer Publikation der Armia Ludowa eine Mitteilung über die »Liquidierung « von 18 »Spitzeln« (szpicle) finden ${ }^{483}$ Auch in der Schau des PawiakMuseums von 2001 war der einzige Hinweis auf ähnliche Verhaltensweisen in einem zeitgenössischen Zeitungsausschnitt enthalten. ${ }^{484}$ In den übrigen Schauen fanden sich keinerlei Verweise auf anderes als heroisches und ehrenhaftes Verhalten der polnischen Bevölkerung. ${ }^{45}$

Selbst in Präsentationen, die seit 2004 neu geschaffen wurden, finden sich meist allenfalls marginale Hinweise auf negative oder ambivalente Aspekte des Besatzungsalltags. In der umfangreichen Dauerausstellung des Museums des Warschauer Aufstands sind an nur wenigen Stellen Hinweise auf unrühmliche Verhaltensweisen der polnischen Aufständischen und der Zivilbevölkerung enthalten. ${ }^{486}$ So findet sich in der Sektion, die dem Abwurf von Hilfslieferungen durch die westlichen Alliierten gewidmet ist, ein "Appell an die Einwohner Warschaus« des Kommandanten des Warschauer Bezirks der AK, Antoni Chruściel. Darin wird von der Plünderung unbewachter

481 Bereichstext »Untergrundbewegung«. MMŁ, Sektion »Lodsch - Litzmannstadt«.

482 Objektbeschriftung zu mehreren Fotos der Familienmitglieder. MTNŁ-Radogoszcz, Sektion »In den Konzentrationslagern".

483 Die Publikation datiert vom 15. März 1944. MTNŁ-Radogoszcz, Sektion »Wir werden siegen«.

484 Die Ausgabe der Untergrundzeitung Biuletyn Informacyjny (Informationsbulletin) vom 15. April 1943 zählt als Ergebnisse einer Aktion vom 26. März zu den »Verlusten des Feindes« unter anderem »2 zivile Agenten, 2 blaue Polizisten« auf. MNW-Pawiak, Sektion »Aktion beim Arsenal«.

485 Dies trifft auf die Dauerausstellungen in der Krakauer Pomorska-Straße von 1990 und 1998 sowie diejenige im Gefängnismuseum Pawiak von $1991 \mathrm{zu}$.

486 Zwei davon wurden bereits in Teil 2, Kapitel 2.1 thematisiert: Bei der Darstellung des Ghettos erfolgt in einem Bereichstext der Hinweis: »Leider gibt es auch solche, die Juden erpressen oder an Deutsche ausliefern."Bereichstext "Alltag im Ghetto«. MPW, Sektion 8: Ghetto. In einem Interviewmitschnitt berichtet Marek Edelman über den Mord einer Aufständischen-Einheit an einem Juden sowie vom Antisemitismus, der unter den Kämpfern verbreitet war und auch für ihn selbst eine reale Gefahr darstellte. MPW, Sektion 15: Die Kämpfe im August. 
Hilfsgüter durch Zivilisten berichtet und angekündigt, dass dieses Verhalten durch Standgerichte mit Todesurteilen bestraft werden würde. ${ }^{487}$ Die Platzierung dieser Information erfolgt jedoch dergestalt, dass ein Großteil der Besucher sie vermutlich nicht rezipieren wird: Das Plakat ist nur eines unter mehreren Quellen und zahlreichen Kuratorentexten in dieser Sektion. Zudem müssen die Besucher den Text aufmerksam und vollständig lesen, um auf den genannten Hinweis zu stoßen. Es sind jedoch nicht allein die negativen Handlungen, die in dieser Präsentation fehlen. Auch im allgemeineren Sinne "unheroisches" Verhalten bleibt ausgespart, so etwa die mit dem Andauern der Kämpfe abnehmende Unterstützung der Zivilbevölkerung für die Aufständischen, die zum Ende hin in Verzweiflung und den Wunsch nach Kapitulation umschlug. ${ }^{488}$ Eine breitere Schilderung der Einstellungen und Erfahrungen der Aufständischen selbst findet ebenfalls nicht statt. Angst und Verzweiflung angesichts der Übermacht des Gegners und der Ungewissheit ob des Schicksals von Angehörigen und Freunden bleiben unerwähnt. Die als vorbildhaft dargestellte Vorgehensweise der Kämpfer wird lediglich an einer versteckten Stelle nuanciert: In der bereits geschilderten Videoaufzeichnung eines Interviews mit Marek Edelman findet sich der einzige Hinweis auf den unter den Aufständischen verbreiteten Antisemitismus und gewaltsame Übergriffe gegen Juden; die Platzierung des Bildschirms im Rundgang führt jedoch dazu, dass kaum ein Besucher den brisanten Inhalt seiner Ausführungen rezipiert. ${ }^{489}$

In der Sektion zum Alltag der Stadt im Warschauer stadthistorischen Museum waren die Besucher sogar gänzlich auf eigene Deduktionen der präsentierten Symbolik angewiesen, um auf die Existenz von Verhaltensweisen polnischer Stadtbewohner zu schließen, die von den (zeitgenössischen) Verfassern verurteilt oder zumindest abgelehnt wurden: So war auf der Rückwand des Ausstellungssaales, der dem Alltag der Jahre 1939 bis 1944 gewidmet ist, mehrfach die Losung "Nur Schweine sitzen im Kino" (Tylko świnie siedza w kinie) angebracht, die die polnische Bevölkerung zum Boykott deutscher Kinotheater aufrief. ${ }^{490}$ Dass diese Losung eine Reaktion auf die fortgesetzten Kinobesuche durch Polen war, ist eine Schlussfolgerung, die höchst-

487 MPW, Sektion 21: Abwürfe.

488 Borodziej: Der Warschauer Aufstand, 191-195, 199, 202.

489 Siehe Teil 2, Kapitel 2.1.

490 Ein Zeitungsausschnitt, der ohne jegliche einordnende Information zum Erscheinungsorgan und -datum gezeigt wurde, enthielt einen beiläufigen Artikel über einen Säureangriff auf eine Frau in einer Warschauer Straßenbahn. Abschnitt »Der Alltag des besetzten Warschaus (1939-1944)«. MHW, Saal 49. Auch im MPW werden Karikaturen gezeigt, die auf vom Untergrund verurteilte Handlungen hinweisen, etwa das Lesen des deutschen Propagandablattes Nowy Kurier Warszawski (Neuer Warschauer Kurier) und Verhältnisse polnischer Frauen mit Deutschen. MPW, Sektion 56: Die Deutschen in Warschau. 
wahrscheinlich nur wenige Besucher trafen, zumal in den Texten und Bildmaterialien der übrigen Schau keinerlei Hinweise auf anderes als moralisch einwandfreies Verhalten der Stadtbevölkerung enthalten waren. ${ }^{491}$

Auffällig bei den untersuchten Schauen ist die äußerst marginale Thematisierung von als nichtpatriotisch oder unmoralisch gewertetem Verhalten ebenso wie die Platzierung der entsprechenden Hinweise darauf. Viele der Verweise auf die Existenz solcher Phänomene wurden nur beiläufig und damit wohl größtenteils zufällig in den Schauen untergebracht. Denn die genannten Kontexte finden sich oft in Materialien und Texten, die vordergründig anderen Themen gewidmet sind. Exemplarisch kann hier auf die Dauerausstellung des Pawiak-Museums von 2001 verwiesen werden: Primäres Thema eines dort präsentierten Zeitungsartikels ist eine erfolgreiche Aktion des Widerstands; seine Unterbringung in der Schau dient also der Hervorhebung der Effektivität der Helden des Untergrunds. Eher beiläufig bzw. zufällig sind in der folgenden Aufzählung unter den »Verlusten des Feindes« auch 2 zivile Agenten, 2 blaue Polizisten« aufgeführt. ${ }^{492}$ Die Museumsbesucher müssten also nicht nur alle Kuratorentexte, sondern auch alle präsentierten zeitgenössischen Materialien aufmerksam studieren, um darauf zu stoßen, dass die in den Schauen postulierte Wir-Gemeinschaft der Polen sich in den Jahren 1939 bis 1944/ 45 nicht ausschließlich helden- und märtyrerhaft verhalten hat. Denunziationen, das Erpressen von Juden oder persönliche Bereicherung wurden und werden somit weiterhin als randständiges und damit zugleich vernachlässigbares Verhalten behandelt. ${ }^{493}$ Das Problem des szmalcownictwo, die Erpressung von Juden, die sich außerhalb der Ghettos versteckten, wird als Problem der Besatzungsjahre sogar erst in den allerjüngsten Schauen überhaupt erwähnt - konkret und detailliert in der Krakauer Schindler-Fabrik, wie im Folgenden noch geschildert wird; mittels eines ab-

491 Wie Piotr Majewski anhand von Berichten der Untergrundpresse nachweist, scheiterten die Aufrufe zum Boykott von Kinos »vollständig«. Zur Begründung führt er an: »Das ergab sich vor allem aus dem begrenzten Zugang zu anderen Formen von Unterhaltung, zumal das illegale Kulturschaffen in seinem Wesen elitär war. Die Masse der Menschen hatte keine große Auswahl hinsichtlich ihrer Freizeitgestaltung." Majewski: Konzept und Organisation des »zivilen Kampfes«, 312.

492 Ausgabe des Biuletyn Informacyjny vom 15. April 1943. MNW-Pawiak, Sektion »Aktion beim Arsenal«.

493 In Bezug auf das Thema wirtschaftlicher Zusammenarbeit entspricht dies weitgehend dem aktuellen Forschungsstand, denn wie Jerzy Borejsza feststellt: »Die wirtschaftliche Kollaboration vieler polnischer Staatsbürger verschiedener Nationalitäten ist bisher praktisch noch nicht erforscht.« Borejsza, Jerzy W.: Einige Anmerkungen zum Gebrauch des Begriffs Kollaboration in der heutigen polnischen Sprache. In: Tauber, Joachim (Hg.): »Kollaboration« in Nordosteuropa. Erscheinungsformen und Deutungen im 20. Jahrhundert. Wiesbaden 2006, 305-313, hier 307. 
strakten Hinweises im Museum des Warschauer Aufstands. ${ }^{494}$ Dies mag vor dem Hintergrund durchaus vorhandener neuerer Forschungsergebnisse, etwa der Arbeiten von Barbara Engelking und Jan Grabowski, gerade bei Ausstellungen jüngeren Datums überraschen. ${ }^{495}$ Die Suggestion der lediglich marginalen Bedeutung solch moralisch verwerflichen Verhaltens markiert die Schuldigen als Ausnahme, die gewissermaßen die Regel der vorbildlich agierenden Polen bestätigen.

Erwähnenswert erscheint in den musealen Darstellungen auch die Art und Weise des Umgangs mit der durchaus umstrittenen und während der Besatzung in der Bevölkerung äußerst negativ bewerteten polnischen Polizei im Generalgouvernement, die wegen der Farbe ihrer Uniformen »blaue Polizei« (policja granatowa) genannt wurde. ${ }^{496}$ Hinweise auf Vertreter dieser Formation und ihre Handlungen, die gegen andere Polen gerichtet waren, ebenso wie Verweise auf Anschläge auf polnische Polizisten finden sich in mehreren Ausstellungen, so auch in Schauen, die vor 1989 entstanden sind. In der Dauerausstellung des Pawiak-Museums, die in den 1980er-Jahren existierte, wurden Vertreter der blauen Polizei zwei Mal beiläufig erwähnt: zunächst bei der Schilderung einer Flucht aus dem Pawiak; von den Entkommenen wurden zwei Personen durch einen namentlich genannten »Zugführer der blauen Polizei« den Wachtmeistern des Pawiak wieder übergeben. ${ }^{497}$ In derselben "Chronik der normalen Tage des Pawiak« wird erwähnt, dass in der Leichenhalle des Gefängnisses die Überreste eines »Agenten der Ermittlungsbehörde der blauen Polizei« eingeliefert wurden. ${ }^{498}$ In der 1979 eröffneten Schau des

494 In einem Text zum »Alltag im Ghetto « wird erwähnt: »Leider gibt es auch solche, die Juden erpressen oder den Deutschen übergeben«. MPW, Sektion 6: Ghetto. Zur Darstellung der Verfolgung der jüdischen Bevölkerung und des polnisch-jüdischen Verhältnisses während der Besatzung in diesem Museum siehe auch Teil 2, Kapitel 2.1.

495 Engelking: »szanowny panie gistapo«; Grabowski, Jan: Szmalcownicy warszawscy, 1939-1942 [Warschauer szmalcowniki, 1939-1942]. In: Zeszyty Historyczne 143 (2003), 85-117; Ders.: »Ja tego Zyda znam!«.

496 Die erste umfassende Studie, die sich mit der polnischen Polizei im GG befasste, erschien bereits 1990: Hempel, Adam: Pogrobowcy klęski. Rzecz o policji "granatowej« w Generalnym Gubernatorstwie 1939-1945 [Die Totengräber der Niederlage. Zur »blauen" Polizei im Generalgouvernement 1939-1945]. Warszawa 1990. Polen wurden in den Polizeidienst lediglich im Generalgouvernement zugelassen; in den von den Deutschen ab 1941 okkupierten Ostgebieten des Landes, in denen sie eine Minderheit bildeten, waren jedoch lediglich 10 bis 15 Prozent der »blauen Polizisten« Polen. In den ins Deutsche Reich eingegliederten Gebieten wurden Polen aus administrativen Aufgaben und insbesondere der Polizei weitgehend verdrängt. Ebd., 35 f.; Dean, Martin: Polen in der einheimischen Hilfspolizei. Ein Aspekt der Besatzungsrealität in den deutsch besetzten ostpolnischen Gebieten. In: Chiari, Bernhard (Hg.): Die polnische Heimatarmee. Geschichte und Mythos der Armia Krajowa seit dem Zweiten Weltkrieg. München 2003, 355-368, hier 356-359, 363, 368.

497 Scenopis stałej ekspozycji, 75.

498 Ebd., 78. 
Museums »Unter der Uhr« in Lublin findet sich eine Bekanntmachung der Besatzungsorgane, die über die Exekution mehrerer Personen berichtet. Als Anlass der Vergeltungsmaßnahme wird unter anderem ein Angriff auf »zwei polnische Beamte der Polizei« genannt. ${ }^{499}$ Primäres Anliegen der Präsentation der genannten Materialien und der damit verbundenen Informationen war es jeweils, die Brutalität und Grausamkeit des Besatzungsterrors zu illustrieren. Beiläufig und höchstwahrscheinlich von den Kuratoren unbeachtet, wiesen diese Ausstellungselemente jedoch zugleich darauf hin, dass der polnische Widerstand gegen Vertreter dieser Organisation gewaltsam vorging, was den Schluss zulassen konnte, dass es einen Anlass hierfür gegeben haben musste. Voraussetzung einer solchen Folgerung war jedoch, dass die Besucher sich diese Frage bzw. diesem Sachverhalt selbst stellten, denn er wurde, wie bereits erwähnt, in keiner der Ausstellungen direkt thematisiert.

Offener kenntlich gemacht finden sich Vertreter der polnischen Polizei allein in den Schauen des Historischen Museums der Stadt Krakau. Bemerkenswert ist die Evolution ihrer Darstellung im Zeitraum 1990 bis 2010: In der Dauerausstellung der Abteilung Pomorska-Straße von 1998 fanden sich zwei Fotografien, auf denen Vertreter der blauen Polizei zu sehen waren und als solche auch benannt wurden: Ein Foto zeigte einen Polizisten, der den Verkehr regelt. ${ }^{500}$ Ein paar Abschnitte weiter trafen die Besucher auf eine Abbildung, die »die blaue Polizei [zeigte, die] die Umsiedlung der Juden [überwacht]«, wie die begleitende Objektbeschriftung vermittelte. ${ }^{501}$ Zwar verlangte diese Darstellung den Besuchern Vorwissen darüber ab, dass die »blaue Polizei« in der Stadt größtenteils aus ethnischen Polen bestand. Dennoch war damit der Hinweis auf die Arbeit von Polen in exekutiven Funktionen der Besatzungsmacht erkennbar. Dieselben zwei Fotografien fanden sich höchstwahrscheinlich bereits in der Vorgängervariante der Schau von 1990, dort jedoch ohne den expliziten Hinweis auf die Protagonisten, die auf den Fotografien zu sehen waren, und somit auch ohne den Verweis auf eine Form polnischer Mitarbeit bei der Ausgrenzung und Verfolgung der jüdischen Stadtbewohner. ${ }^{502}$ Diese Schlussfolgerungen konnten nur Besucher mit einem breiteren Wissen über die Besatzungszeit direkt aus der Fotografie selbst ziehen. Interessant

499 MLL-Unter der Uhr, Zelle 6.

500 Die begleitende Bildunterschrift lautete: »Die blaue Hilfspolizei regelt den Straßenverkehr am Hauptbahnhof . MHK-Pomorska-Straße, Tafel 9.

501 MHK-Pomorska-Straße, Tafel 13.

502 Die Objektbeschriftungen in dieser Schau waren weitgehend abstrakt formuliert. Die Fotografien, die denselben Themenbereichen wie in der Version von 1998 zugeordnet waren, hatten entsprechend die Beschriftung: »Ein Polizist, der den Straßenverkehr regelt« und »Die Sammlung vor der Aussiedlung«. Gasiorowski/Kuler/Natkaniec: Scenariusz wystawy, 4, 7. Da die Schau von 1998 lediglich eine Erweiterung der Fassung von 1990 darstellte, in der die bestehenden Ausstellungstafeln weitgehend erhalten blieben, ist sehr wahrscheinlich, dass es sich in beiden Schauen um dieselben Abbildungen handelte. 
ist die Positionierung der Abbildungen in den Ausstellungen und damit die Kontextualisierung der Tätigkeit und mittelbar auch der Verantwortung polnischer Polizisten bei der Judenverfolgung: Eingebettet war sie in die Schilderung der Aktivitäten des jüdischen Ordnungsdienstes und deutscher Militärpolizisten. Auf einer Tafel der Präsentation von 1998, die die Existenz und Auflösung des Ghettos thematisierte, fanden sich mehrere Fotografien, die nacheinander folgende Situationen zeigten: ein Mitglied des jüdischen Ordnungsdienstes, der die Dokumente eines Juden prüft (ersterer war neben seiner Uniform deutlich durch einen Aufnäher in Form eines Davidsterns erkennbar); einen Vertreter der blauen Polizei, der die »Umsiedlung der Juden überwacht «, sowie einen »deutschen Militärpolizisten«, der den »Transport in das Todeslager [überwacht] «. ${ }^{503}$ Hierdurch war eine Hierarchie der Mitarbeit und Schuld bei der Verfolgung der jüdischen Bevölkerung erkennbar: Unmittelbare Verantwortung an ihrer Ermordung tragen die Deutschen, während einzelne Polen und Juden lediglich Hilfsdienste bzw. Aufsichtsfunktionen übernahmen.

Die Handlungsweisen der polnischen und auch jüdischen Sicherheitsdienste und deren negative Auswirkungen auf die ihnen jeweils unterstellten Bevölkerungsgruppen werden genauer erst in der 2010 eröffneten Schau in der Schindler-Fabrik thematisiert. Einerseits treten hier polnische Polizisten weiterhin auch als »harmlose« Hüter der Straßenverkehrsordnung in Erscheinung. ${ }^{504}$ Daneben erscheinen sie jedoch auch als korrupte Mitarbeiter der Deutschen bei der Verfolgung von Schmugglern: Eine lebensgroße Fotografie zeigt einen blauen Polizisten, der einen Mann mit einem Korb unter dem Arm abführt. Die dazugehörige Information benennt den größeren Kontext dieser Situation:

Die Dörfer, in denen man illegal Lebensmittel kaufte, waren voller Denunzianten. Deutsche und polnische Polizisten kontrollierten Bahnhöfe und durchsuchten die Passagiere der Züge. Das Ergebnis der Durchsuchungen war unvorhersehbar manchmal requirierten die Polizisten die gesamte Ware, manchmal ließen sie sich mit einer entsprechenden Geldsumme bestechen. Viel zu oft jedoch führten sie die Schmuggler zum Polizeiposten ab - wenn man sie von dort zur Zwangsarbeit ins Reich schickte, konnten sie von Glück sprechen. Für Schmuggel drohte das Konzentrationslager. ${ }^{505}$

503 Objektbeschriftungen. MHK-Pomorska-Straße, Tafel 13. Die abstrakten Bildunterschriften in der Schau von 1990 verweisen wiederum auf dieselben Fotografien.

504 Eine Fotografie zeigt - samt der hier unmissverständlichen Erläuterung in der Bildunterschrift - einen "polnische[n] Polizist[en] (blauer), der einen Strafzettel für ordnungswidriges Überqueren der Straße ausstellt.« Eine andere zeigt einen "polnischen Polizisten« beim Regeln des Straßenverkehrs. Objektbeschriftungen. MHK-SchindlerFabrik, Sektion 9: Alltag, 1940-1941.

505 MHK-Schindler-Fabrik, Sektion 18: Öffentlicher Raum II. 
Dass das Vorgehen der polnischen Polizei gegen die eigene Bevölkerung hier überhaupt angesprochen wird, ist innerhalb des Untersuchungszeitraums ein absolutes Novum. Die Teilnahme polnischer Polizisten an der Bekämpfung des Schmuggels und die damit verbundene verbreitete Korruption wird somit zwar erwähnt; ihre extrem negative Wahrnehmung durch die Bevölkerung, also die Angst und der regelrechte Hass den Vertretern dieser Organisation gegenüber, bleibt jedoch unerwähnt. ${ }^{506}$ Vergleichsweise kritischer und auch direkter erfolgt demgegenüber bemerkenswerterweise die Charakterisierung des jüdischen OD und seine Perzeption, die mittels eines Zeitzeugenberichts transportiert wird:

Die OD-Männer hatten eine sehr schlechte Reputation. `Sie waren es, die die Juden aus ihren Wohnungen holten und sie dabei mit Schreien, oft auch Schlägen zur Aussiedlung trieben. Sie waren es, die auf der Grundlage von Namenslisten [...] die Zellen ihres Gefängnisses füllten.` - erinnert sich Aleksander Bieberstein. [... ${ }^{507}$

Eine weitere Auseinandersetzung mit dem Phänomen der polnischen Hilfspolizei im GG findet in der Schau nicht statt. Umfangreicher wird dagegen das verbreitete Spitzel- und Denunziantenwesen geschildert, sowohl unter der polnischen wie der jüdischen Bevölkerung. Hinweise auf »einheimische Spitzel« und die Gefahr, die von ihnen beispielsweise für das geheime Schulwesen und Juden ausging, die das Ghetto verlassen wollten und sich auf der "arischen « Seite der Stadt versteckten, finden sich in mehreren Kuratorentexten:

Unter den sneuen Eliten befanden sich Informanten der Gestapo, Denunzianten und szmalcowniki, die Juden erpressten, die sich auf der arischen Seite versteckten. ${ }^{508}$

Die Besatzung begünstigte die Demoralisierung. Ethische Normen, die vor dem Krieg galten, wurden gelockert. Für einen Liter Wodka, ein Kilo Zucker, 500 Zloty wurden Juden von polnischen und jüdischen Informanten denunziert. Für einige wurde die Erpressung der sich Versteckenden zu einer einträglichen Beschäftigung. ${ }^{509}$

Die negativen Auswirkungen der heimischen Informanten auf die Aktivitäten des Widerstands bleiben dagegen weitgehend unbeachtet. Eindrücklicher werden die Folgen in Bezug auf Juden geschildert, die versuchten, aus dem

506 Hempel: Pogrobowcy klęski, 345-357.

507 MHK-Schindler-Fabrik, Sektion 14: Ghetto.

508 Thementext (ohne Titel). MHK-Schindler-Fabrik, Sektion 15: Alltag, 1943. Kursivsetzung des originalen Begriffs von der Verfasserin.

509 MHK-Schindler-Fabrik, Sektion 20: Die Liquidierung des Ghettos, Abschnitt: »Juden auf der arischen Seite«. Im Thementext »Alltag« hieß es abschließend zur Schilderung des Untergrundschulwesens: »Man fürchtete nicht nur die Gestapo, sondern auch einheimische Spitzel.« MHK-Schindler-Fabrik, Sektion 9: Alltag, 1940-1941. 
Ghetto zu fliehen. Dies geschieht schwerpunktmäßig mittels schriftlicher Zeitzeugenberichte:

Es war so einfach zu sagen - flieht vor der Aussiedlung! Aber wie sollte man den Stacheldraht überwinden, der von der Polizei umstellt war? Wie den ersten Schritt machen auf der freien Straße? Wenn sie die Armbinde sehen - Kugel in den Kopf. Sie ablegen? Wenn sie bemerken, wie sich diese weiße, symbolische Binde vom Arm schiebt, übergeben sie einen direkt in die Hände der Polizei. Selbst wenn man sich im kleinsten Tor versteckt, irgendjemand wird immer bemerken, dass du als Jude in die Einfahrt reingegangen bist und herausgekommen bist als - wer? Na wer? [... $]^{510}$

Auch die ökonomische Bereicherung Einzelner während der Besatzung wird direkt benannt. ${ }^{511}$ Der verbreitete Schmuggel von Waren und die dabei auch stattfindenden Interaktionen mit Deutschen werden dagegen als notwendiges Mittel zum Überleben kontextualisiert und damit als positives Beispiel des Einfallsreichtums der Bevölkerung. ${ }^{512}$ Wie Tomasz Szarota prägnant feststellte, entspricht diese positive Wahrnehmung des Schwarzmarktes dem polnischen Autostereotyp in der Erinnerung an die Kriegsjahre. ${ }^{513}$ Diese Sichtweise prägt auch die Darstellung anderer Museen. Im MPW wird sie etwa in der Überschrift zu einer Fotopräsentation deutlich: "»... wer Handel treibt, der lebt ...< - die Polen finden sich im Alltag zurecht ${ }^{5 .}{ }^{514}$ In der Schilderung des Handels als Alltagsphänomen im MHW dominierten Fotografien von Vorortzügen und Privatleuten beim Kleinhandel. Im Thementext der Sektion hieß es: »[...] vor dem Hunger bewahrten [...] der illegale Handel und Schmuggel von Gütern, die mit der Kleinbahn, den sog. ciuchcie, aus den hauptstädtischen Vororten transportiert wurden. ${ }^{515}$ Bei den Darstellungen beider Museen fehlen allerdings jegliche Hinweise auf deutsche Akteure im Schwarzmarkthandel, die umfangreiche Korruption oder die Gefahr durch einheimische Spitzel und Revisionen durch nichtdeutsche Akteure,

510 MHK-Schindler-Fabrik, Sektion 14: Ghetto. Zahlreiche Zeitzeugenberichte beschreiben den Schrecken des verbreiteten Spitzelwesens auch im Abschnitt »Juden auf der arischen Seite« in Sektion 20: Die Liquidierung des Ghettos.

511 In einem Thementext heißt es: „Es gab auch solche, die durch krumme Geschäfte für sich ein Vermögen anhäuften.« Thementext (ohne Titel). MHK-Schindler-Fabrik, Sektion 15: Alltag, 1943.

512 MHK-Schindler-Fabrik, Sektion 9: Alltag, 1940-1941.

513 Szarota, Tomasz: Polski autostereotyp w konfrontacji z doświadczeniami lat wojny i okupacji [Das polnische Autostereotyp in der Gegenüberstellung mit den Erfahrungen der Kriegs- und Besatzungsjahre]. In: Ders.: Karuzela na placu Krasińskich. Studia i szkice z lat wojny i okupacji [Das Karussell auf dem Krasiński-Platz. Studien und Skizzen zu den Kriegs- und Besatzungsjahren]. Warszawa 2007, 419-437, hier 425.

514 MPW, Sektion 6: Besatzung.

515 Thementext »Der Alltag des besetzten Warschaus (1939-1944)«. MHW, Saal 49. 
mithin die »Graubereiche«, die mit dieser notwendigen Überlebensstrategie einhergingen.

Zusammenfassend lässt sich für die untersuchten Präsentationen der drei Jahrzehnte festhalten, dass es zwar einzelne Verweise auf die Existenz negativ bewerteten Handelns - sowohl aus zeitgenössischer ${ }^{516}$ als auch aus der Perspektive des jeweiligen Entstehungszeitraums der Schauen - gab, jedoch die damit angedeuteten Verhaltensweisen ebenso wie die dahinterstehenden Kontexte nicht problematisiert oder auch nur benannt wurden. Mit Ausnahme der Dauerausstellung des MHK von 2010 waren somit polnische Verhaltensweisen und Akteure, die außerhalb des engen Spektrums heldenund märtyrerhaften Handelns lagen, in den präsentierten Ausstellungen tabuisiert - und sind es überwiegend bis in die Gegenwart.

Welche Gründe können für diese Präsentationspraxen angeführt werden? Allgemein ist festzustellen, dass die Thematisierung von moralisch zweifelhaftem oder verwerflichem Verhalten der eigenen Landsleute während der Besatzungsjahre, insbesondere, wenn sie den Aspekt einer Interaktion oder sogar Zusammenarbeit mit den Besatzern beinhaltet, an den Grundfesten des polnischen Autostereotyps der Kriegsjahre rüttelt. ${ }^{517}$ Das Schlagwort der »Kollaboration" schwebt damit gleichsam im Raum, das in Polen emotional hoch aufgeladen ist und eine extrem pejorative Konnotation hat; im verbreiteten Verständnis von Historikern wie der Öffentlichkeit impliziert es eine Nähe zu »nationalem Verrat.$^{518}$ Die polnische Selbstwahrnehmung der Kriegsjahre ist bis in die Gegenwart geprägt vom Stolz auf den »fehlenden Quisling«, darauf also, dass es in Polen kein Kollaborationsregime

516 Die von den Institutionen des Untergrundstaates negativ bewerteten Handlungsweisen der Bevölkerung - sowie die Versuche, dagegen vorzugehen - stellt umfassend dar Majewski: Konzept und Organisation des »zivilen Kampfes«, 303-323. Siehe auch Młynarczyk, Jacek Andrzej: Zwischen Kollaboration und Verrat. Zum Problem der Kollaboration im Generalgouvernement 1939-1945. In: Ders. (Hg.): Polen unter deutscher und sowjetischer Besatzung 1939-1945. Osnabrück 2009, 345-383.

517 Kwiatkowski, Piotr T.: II wojna światowa jako doświadczenie narodowe [Der Zweite Weltkrieg als nationale Erfahrung]. In: Ders. u.a.: Między codziennością a wielką historią. Druga wojna światowa w pamięci zbiorowej społeczeństwa polskiego [Zwischen Alltag und großer Geschichte. Der Zweite Weltkrieg in der kollektiven Erinnerung der polnischen Gesellschaft]. Gdańsk, Warszawa 2010, 133-199, bes. 143-152; Szarota, Tomasz: Kolaboracja z okupantem niemieckim i sowieckim w oczach Polaków - wówczas, wczoraj i dziś [Die Kollaboration mit dem deutschen und sowjetischen Besatzer aus polnischer Sicht - damals, gestern, heute]. In: Ders.: Karuzela na placu Krasińskich, 71-92, hier 85; Ders.: Polski autostereotyp, 425.

518 Borejsza: Einige Anmerkungen zum Gebrauch des Begriffs Kollaboration, 306; Madaj$c z y k$, Piotr: Bedeutung und Nutzen des Begriffs »Kollaboration« für Forschungen über die Zeitgeschichte Polens. In: Tauber, Joachim (Hg.): »Kollaboration« in Nordosteuropa. Erscheinungsformen und Deutungen im 20. Jahrhundert. Wiesbaden 2006, 314-323, hier 314 . 
gab. ${ }^{519}$ Durch diese Engführung des Verständnisses von Kollaboration auf Formen der direkten politischen Zusammenarbeit blieben lange Zeit andere Arten der Kooperation, etwa in wirtschaftlichen oder sozialen Bereichen, unbeachtet. ${ }^{520}$

Phänomene wie das verbreitete Denunziantentum wurden auch in der polnischen Forschung lange als marginales Verhalten gesellschaftlicher Randgruppen dargestellt; eine Sichtweise, die jüngere Forschungen jedoch klar widerlegen. Jan Grabowski stellte etwa in Bezug auf Warschau fest:

Entgegen oft wiederholten Meinungen war das Phänomen des szmalcownictwo keine marginale Verhaltensweise, sondern wurde zu einer Einkommensquelle für Tausende Menschen. Viele Warschauer wurden unmittelbare (und oft passive) Zeugen der Erpressungen, und die ganze Gesellschaft war sich der Hetzjagd auf sich versteckende Juden bewusst. ${ }^{521}$

Karol Sauerland fasste in Bezug auf die polnisch-jüdischen Kontakte der Besatzungsjahre prägnant zusammen:

[...] Polen [waren] nicht nur Zuschauer [...], sondern es [gab] unter ihnen auch Erpresser, Plünderer, Denunzianten [...], man [kann] nicht nur von Einzelnen am Rande der Gesellschaft sprechen [...]. Wenn sie am Rand der Gesellschaft agierten, muss dieser recht breit gewesen sein. ${ }^{522}$

Man kann daher davon ausgehen, dass bei der Vermeidung der skizzierten Themen durch die Museumskuratoren, ähnlich wie bei Fachhistorikern, we-

519 Borodziej, Włodzimierz: Zur Debatte um Kollaboration in Polen im Zweiten Weltkrieg. In: Tauber, Joachim (Hg.): Kollaboration« in Nordosteuropa. Erscheinungsformen und Deutungen im 20. Jahrhundert. Wiesbaden 2006, 342-352, hier 344, 346. Dass das Fehlen eines Kollaborationsregimes in erster Linie darauf zurückzuführen ist, dass es vonseiten der deutschen Besatzer kein Interesse an einem solchen gab und damit auch keine politischen Kollaborationsangebote an die polnischen Eliten, wird bei dieser Argumentation oft vernachlässigt. Siehe auch Szarota, Tomasz: Kolaboranci w kraju bez Quislinga [Kollaborateure im Land ohne Quisling]. In: Ders.: Karuzela na placu Krasińskich, 107-115, hier $109 \mathrm{f}$.

520 Borodziej: Zur Debatte um Kollaboration, 343 f.; Szarota, Tomasz: Kolaboranci pod pręgierzem [Kollaborateure am Pranger]. In: Ders.: Karuzela na placu Krasińskich, 93-106, hier 93; Röger, Maren: Verdrängter Besatzungsalltag: Intime Kontakte zwischen Deutschen und Polen 1939-1945 und ihre Nachgeschichte. In: Historie. Jahrbuch des Zentrums für Historische Forschung Berlin der Polnischen Akademie der Wissenschaften 7 (2013/2014), 170-181, hier 170 f., 180.

521 Grabowski: »Ja tego Zyda znam!«, 8. Kursivsetzung des originalen Begriffs von der Verfasserin.

522 Sauerland, Karol: Die polnische Gesellschaft in der deutschen Besatzungszeit aus jüdischer Sicht. In: Löw, Andrea/Robusch, Kerstin/Walter, Stefanie (Hg.): Deutsche Juden - Polen. Geschichte einer wechselvollen Beziehung im 20. Jahrhundert. Festschrift für Hubert Schneider. Frankfurt am Main, New York 2004, 137-156, hier 155. 
niger sachliche Überlegungen eine Rolle spielten als emotional-ideologische. Diese sind auch nach 1989 deutlich präsent:

Jenes eigentümliche Gefühl, dass man die nationale Ehre der Polen verteidigen und deswegen die unschönen Ereignisse nicht allzu plastisch darstellen sollte, verbindet paradoxerweise nicht wenige Ideologen und Historiker aus der Zeit der Volksrepublik mit denen der Dritten Republik nach 1989. ${ }^{523}$

Dieses Diktum Jerzy Borejszas lässt sich auch auf weite Teile der polnischen historischen Museumslandschaft übertragen. Prägnanteste Vertreter dieser Einstellung sind die Verantwortlichen der Dauerausstellung des Museums des Warschauer Aufstands. Sein Direktor Jan Ołdakowski bezeichnet es als "Museum des nationalen Stolzes«, was seiner Ansicht nach Hintergrund für den enormen Besuchererfolg der Institution ist: "Die Polen wollen die Geschichte ihrer eigenen Nation erfahren, sie wollen gemeinsam ihren Stolz [auf diese Geschichte - d. Vf.] zeigen. ${ }^{524}$ Die »dunklen« oder auch nur »grauen« Seiten dieser Geschichte würden das einseitige und eindeutige Selbstbild stören, das die Präsentation des Museums wie auch die meisten Schauen der übrigen untersuchten Institutionen konstruieren. Vor diesem Hintergrund überrascht wenig, dass der Begriff »Kollaboration« in den meisten Ausstellungen auch keine Verwendung findet. In der einzigen Präsentation, in der er auftaucht - im Museum des Warschauer Aufstands -, ist er den Feinden zugeordnet, nämlich den mit den Deutschen zusammenarbeitenden Kollaborationseinheiten anderer Nationalitäten, etwa der Russischen Volksbefreiungsarmee. ${ }^{525}$ Hierdurch wird auch die weitere Konnotation des Terminus deutlich: »Kollaboration« scheint weitgehend mit »Täterschaft» und »Schuld»

523 Borejsza: Einige Anmerkungen zum Gebrauch des Begriffs Kollaboration, 307.

524 Ołdakowski, Jan: Muzeum historycznego niepokoju [Ein Museum der historischen Unruhe]. In: Cichocka, Lena u.a. (Hg.): Polityka historyczna. Historycy - politycy prasa [Geschichtspolitik. Historiker - Politiker - Presse]. Warszawa 2005, 250-253, hier 251.

525 Auch diese Praxis steht im Einklang mit dem gegenwärtigen innerpolnischen Diskussionsstand zu diesem Thema. Borodziej: Zur Debatte um Kollaboration, 344. Hier nur einige Beispiele für Hinweise auf feindliche Kollaborationseinheiten in der Schau: Im Bereichstext »Gefährlicher Dienst« ist von den »Deutschen und ihren Kollaborationseinheiten« die Rede. Sektion 22: Das Krankenhaus der Aufständischen. In einem Bereichstext zur Bodenreform des PKWN wird erwähnt, dass in diesem Zusammenhang die Konfiszierung der Ländereien von »Deutschen, Kollaborateuren und Personen, die sich dem Armeedienst entzogen«, veranlasst wurde. Darauf, wer als »Kollaborateur« angesehen wurde, wird jedoch nicht weiter eingegangen. Sektion 28: Das Lubliner Polen. Vielfache Hinweise auf die deutschen Kollaborationseinheiten finden sich auch in der Sektion "Die Deutschen in Warschau" (Sektion 56). In einem Objekttext heißt es dort etwa: "Bestandteil der Kampfgruppe >Reinefarth sind Kollaborationseinheiten, zusammengesetzt aus Russen, Ukrainern, Aserbaidschanern und Turkmenen.« 
an Besatzungsverbrechen assoziiert zu werden. Diese Position ist in der breiten gesellschaftlichen Geschichtswahrnehmung und, wie in der vorliegenden Studie gezeigt wurde, auch Geschichtsvermittlung allein für die Feindbilder reserviert, was eine Auseinandersetzung mit Straftaten und Verfehlungen, die von eigenen Staatsangehörigen verübt wurden, zusätzlich erschwert.

Die Leerstellen ermöglichen es somit, in den musealen Erzählungen eine klare Abgrenzung zwischen »Gut» und »Böse« zu erhalten: Das Verschweigen jeglicher Momente ambivalent oder negativ bewerteter Formen der Interaktionen zwischen der eigenen Wir-Gemeinschaft und den Feinden ebenso wie den »inneren Fremden«, den verfolgten Juden, trägt zur Bewahrung der tradierten Topoi der ethnisch-polnischen, makellosen Helden und Opfer bzw. Märtyrer bei. Diese Vorstellungen sind stark normativ geprägt und oft von einem "moralischen Überlegenheitsgefühl ${ }^{526}$ begleitet, das keine Differenzierung duldet. Dort, wo eine Diversifizierung dieser Darstellungen durch die Berücksichtigung bislang verschwiegener Alltagserscheinungen der Besatzungszeit unternommen wird - wie im geschilderten Beispiel der Krakauer Schindler-Fabrik -, wird zwangsläufig das einseitige Bild der polnischen Gemeinschaft im Krieg hinterfragt. Auch die Marginalisierung der konkurrierenden Opfergruppe der Juden ist dann kaum mehr möglich. Wie jedoch die Beispiele in diesem Teil der Studie gezeigt haben, fällt die Abkehr von dem eindeutigen und unproblematischen Selbstbild der polnischen Wir-Gemeinschaft im Krieg nach wie vor schwer.

\section{Zusammenfassung}

Wie gezeigt wurde, kreisen die in den Dauerausstellungen der untersuchten drei Jahrzehnte präsentierten polnischen Selbstbilder um die zentralen Topoi der Helden und Opfer. Im Bereich der Opferdarstellung steht dabei die martyrologische Deutung des durch die Besatzer erlittenen Leids im Vordergrund, die eine sinnstiftende Einbindung in das nationale Heldenkollektiv ermöglicht. Gleichwohl ist festzustellen, dass auch vor der Wende von 1989 die passiven Opfer der deutschen Gewaltherrschaft in allen untersuchten Schauen präsent waren. Als Zeugnisse der unmenschlichen Grausamkeit der Besatzer blieben sie jedoch, abstrakt und weitgehend anonym dargestellt, im Hintergrund der musealen Erzählungen, gleichsam Objekte der historischen Er-

526 Friedrich, Klaus-Peter: Zusammenarbeit und Mittäterschaft in Polen 1939-1945. In: Dieckmann, Christoph/Quinkert, Babette/Tönsmeyer, Tatjana (Hg.): Kooperation und Verbrechen. Formen der »Kollaboration« im östlichen Europa 1939-1945. Göttingen 2003, 113-150, hier 114 . 
eignisse und nicht deren selbstbestimmt agierende Subjekte. Die zentralen Protagonisten der Ausstellungserzählungen waren die heldenhaften Widerstandskämpfer und - damit unmittelbar verbunden - die Inhaftierten, Gefolterten, Deportierten und Exekutierten unter ihnen, die als Märtyrer für das Vaterland präsentiert wurden. Der Schilderung des Leids von Zivilisten, mithin von passiven Opfern der Besatzungswillkür, wurde erst in den 1990er-Jahren spürbar mehr Platz eingeräumt. In keiner der untersuchten Ausstellungen, die bis 2010 entstanden sind, wurde jedoch das heroische von einem viktimologischen Opfernarrativ abgelöst. Vielmehr trat letzteres an die Seite der Helden- und Märtyrerdarstellungen, die - um die Soldaten der polnischen Armee im September 1939 erweitert - nach wie vor den Schwerpunkt eines Großteils der Erzählungen bilden. Eine passive Wende ist in den musealen Geschichtsdarstellungen des Zweiten Weltkriegs in Polen bis 2010 somit nicht zu konstatieren. Das ethnisch-national gefasste, martyrologische Selbstbild wurde vielmehr in zahlreichen Ausstellungen nach 1989 durch die Inklusion christlicher Symboliken um eine stark religiöse Komponente erweitert.

Eine Veränderung des in den Schauen gezeichneten Heldenbildes ist nach 1989 allein in Bezug auf seine politische Ausrichtung zu verzeichnen. Während in den Ausstellungen vor 1989 eine zentrale politische Rolle der kommunistischen Widerstandsgruppen suggeriert wurde, die die Legitimität der sozialistischen Nachkriegsregierung des Landes begründete, wurde mit Beginn der 1990er-Jahre die AK als zentrale und größte Untergrundorganisation klar in den Vordergrund gestellt. Hierbei ist anzumerken, dass diese in den Schauen, die in den 1980er-Jahren zu besichtigen waren, bereits eine oft gleichberechtigte Darstellung neben den kommunistischen Gruppierungen erfahren hatte. In den 1990er-Jahren lösten nun jedoch die polnische Exilregierung und die von ihr geleiteten Strukturen des Untergrundstaates die vorherige Fokussierung auf die kommunistische Übergangsregierung, das PKWN und die UdSSR als Bündnispartner eindeutig ab. Die seit den 1990erJahren neu entstandenen Präsentationen unterstreichen nun die Legitimität der Londoner Führung als einziger rechtmäßiger politischer Vertretung des besetzten Landes. Eine Umwertung bzw. Abwertung kommunistischer Widerstandsgruppierungen ging mit dieser Entwicklung meist nicht einher. Lediglich in einzelnen Präsentationen ist eine solche zu verzeichnen: Dies betrifft Dauerausstellungen, deren zeitlicher Rahmen in die Nachkriegszeit erweitert wurde. ${ }^{527}$ In diesen stellte man nun auch die Verfolgung der mit der Exilregierung verbundenen Gruppierungen seit 1944 / 45 dar und verurteilte die Vorgehensweise sowjetischer Einheiten und der sozialistischen polnischen

527 So in der Präsentation des MHK in der Pomorska-Straße von 1998 sowie in der Schau des MPW. 
Regierung gegen diese Gruppen als Verrat. Bemerkenswert ist, dass gerade in dem Museum, in dem die Verurteilung dieser Praktiken wie insgesamt der VRP am stärksten ausgeprägt ist - im Museum des Warschauer Aufstands - lediglich die politische Führung der polnischen Kommunisten aus der Wir-Gemeinschaft ausgeschlossen wird. Die Einheiten der Volksarmee, die im Aufstand 1944 kämpften, ebenso wie die polnischen Soldaten in den sowjetischen Streitkräften, bleiben hingegen Teil des nationalen HeldenPantheons.

Diese auf Helden und Märtyrer konzentrierte Darstellung erweiterte sich in den 1990er-Jahren zudem um einen weiteren Aspekt der Besatzungsjahre: Der Alltag der breiten Masse der Bevölkerung wurde sukzessive in die Erzählungen integriert. Zunächst beschränkte sich seine Thematisierung auf weitgehend illustrative Hintergrunddarstellungen. In den meisten Schauen, die seit Mitte der 1990er-Jahren neu entstanden sind oder grundlegend überarbeitet wurden, blieb das Thema noch nachrangig und wurde eher abstrakt, mittels anonymer Objekte und Fotografien oder Zeichnungen porträtiert. Dort wo Akteure, etwa von zivilen Verwaltungsstrukturen oder karitativen Einrichtungen, in Erscheinung traten, handelte es sich ausschließlich um leitende Funktionsträger. Der Alltag der breiten Bevölkerung abseits aktiver Untergrundtätigkeit und unmittelbarer Verfolgung, gerade auch mit seinen ambivalenten Elementen, fand in den Schauen dagegen noch kaum Raum. Zentrale Protagonisten der musealen Erzählungen blieben die Kämpfer und die unmittelbar unter der Besatzungsgewalt Leidenden. Durch die Konzentration der Darstellungen auf diese Akteure wurden sie - und werden weitgehend bis heute - suggestiv als Repräsentanten der breiten Massen der Bevölkerung in den Jahren 1939 bis 1945 kontextualisiert. Unterschwellig wirkt darin der bereits vor 1989 etablierte Topos der allgemein widerständigen nationalen Gemeinschaft während der Besatzung bis in die Gegenwart fort. ${ }^{528}$ Auch die Verhaltensweisen der polnischen Bevölkerung in den Jahren 1939 bis 1944/ 45 wurden und werden nach wie vor überwiegend innerhalb der schematischen und moralisch eindeutigen Topoi der makellosen Helden und Opfer dargestellt. Ambivalente Aspekte oder gar von den Zeitgenossen verurteilte Verhaltensweisen der Besatzungsjahre blieben dagegen außen vor. Phänomene wie die »Plage des Denunziantentums « ${ }^{529}$, das Erpressen von sich versteckenden Juden oder die Interaktion und zum Teil sogar Zusammenarbeit mit den Besatzern, beispielsweise beim illegalen Handel oder in der blauen Polizei, bleiben bis in die Gegenwart weitgehend unerwähnt. Dort, wo sich einzelne Hinweise finden, werden sie meist nicht kontextualisiert und er-

528 Besonders prägnante Beispiele hierfür sind die Dauerausstellungen des Warschauer stadthistorischen Museums und des Museums des Warschauer Aufstands.

529 Borodziej: Geschichte Polens, 221. 
scheinen daher - wenn sie vom Rezipienten überhaupt bemerkt werden - als marginales und damit vernachlässigbares Verhalten einer Minderheit.

Das somit weiterhin dominante Helden- und Opfernarrativ ist weitgehend bezogen auf eine ethnisch-national definierte polnische Wir-Gemeinschaft. Das Schicksal der jüdischen Bevölkerung des Landes wird bislang nur in wenigen Ausstellungen inklusiv dargestellt, als gleichberechtigter Teil der lokalen Geschichte. ${ }^{530}$ In ihrer Kontextualisierung ist im Großteil der musealen Narrative eine deutliche Hierarchie des Leidens erkennbar. Als konkurrierende Opfergruppe bleiben die als Juden Verfolgten im Vergleich zur Schilderung des Leids polnischer Opfer zweitrangig. Namentlich genannt und individuell proträtiert werden aus dieser Gruppe zudem allein Helden- und Märtyrerfiguren, somit Personen, die sich für andere bzw. ein höheres Ziel opferten. Während jedoch die polnischen Widerständigen als Kämpfer für ihre Nation und das Vaterland klar im Vordergrund stehen, werden die jüdischen Untergrundkämpfer und Aufständischen von 1943 in erster Linie als Personen dargestellt, die einen »würdigen" Tod wählen - womit implizit die Masse der passiven Ghettobewohner als sinnlos Leidende markiert wird.

Die Analysen in diesem Teil zeigen somit, dass das polnische Selbstbild der Kriegs- und Besatzungszeit, das die Ausstellungen der untersuchten drei Jahrzehnte zeichnen, von einer starken Kontinuität geprägt ist: Zentrale Interpretationselemente wie das der allgemein widerständigen Gemeinschaft im Krieg, die sich moralisch einwandfrei verhalten hat, werden bis in die Gegenwart tradiert. Es wird offensichtlich versucht, das romantische Interpretationsmuster der Helden und, damit unmittelbar verbunden, der Märtyrer zu bewahren. Dies unterstreicht auch die Beobachtung, dass bis in die Gegenwart in den meisten Präsentationen ambivalente oder gar negative polnische Verhaltensweisen der Jahre 1939 bis 1944/45 nicht oder nur in wenigen Andeutungen enthalten sind. Auch die Erfahrungen der passiven Bevölkerungsmehrheit abseits aktiver Widerstandstätigkeit und unmittelbarer, physischer Verfolgung bleiben weitgehend tabuisiert.

Erst eine Dauerausstellung differenziert dieses etablierte Geschichtsbild. Die Präsentation in der Krakauer Schindler-Fabrik erweitert nicht nur die Definition der Wir-Gemeinschaft der Krakauer um die jüdischen Einwohner der Stadt und Region. Hier treten die unmittelbaren Helden- und Opferfiguren in den Hintergrund - auch wenn sie Bestandteile der Erzählung bleiben. Im Vordergrund stehen stattdessen die "gewöhnlichen « Krakauer Bürger und mit ihnen der Alltag der breiten Massen der polnischen und jüdischen Stadtbewohner; die Vielfalt und Diversität ihrer Verhaltensweisen und Einstellungen kommt hier zum Ausdruck. Damit treten erstmals die Ambivalen-

530 Dies war bei den untersuchten Präsentationen nur in der Ausstellung des MMŁ von 1998 sowie des MHK in der Schindler-Fabrik der Fall. 
zen und Graustufen, aber auch die eindeutig negativ bewerteten Akteure der Besatzungsjahre unmittelbar in Erscheinung. In den übrigen Dauerausstellungen tabuisierte oder weitgehend marginalisierte Erscheinungen wie Konflikte zwischen verschiedenen Widerstandsorganisationen, die ökonomische Bereicherung Einzelner, das verbreitete Spitzelwesen und die Teilnahme der blauen Polizei am Vorgehen gegen Schmuggler werden explizit geschildert. Auch der Antisemitismus in der polnischen Bevölkerung ist Thema. Hierdurch wird zwangsläufig das traditionelle polnische Selbstbild dekonstruiert - ein Vorgehen, das im Untersuchungszeitraum eine Ausnahme darstellt.

Der Abschied von dem vertrauten und einfachen, da in seinen Wertungen eindeutigen Selbstbild, seine Erweiterung um bislang tabuisierte Aspekte und damit seine Differenzierung fallen schwer, wie die ungebrochene Betonung des heroischen Topos in einigen jüngeren Ausstellungen zeigt. Allen voran das Museum des Warschauer Aufstands hat zu einer regelrechten Renaissance des heroischen polnischen Selbstbildes beigetragen. Insgesamt zeigen die Beispiele des MPW und der Schindler-Fabrik jedoch, dass eine Ausdifferenzierung musealer Geschichtsbilder und damit verbundener historischer Selbstbilder in den Präsentationen beginnt. Polnische Identitätsentwürfe werden - am Beispiel dieses zentralen historischen Zeitraums - zunehmend verhandelt.

Anhand der Entwicklung des musealen Selbstbildes der polnischen WirGemeinschaft in den untersuchten drei Jahrzehnten lassen sich zudem zentrale Entwicklungen der musealen Vermittlungspraxen beobachten: Bis zum Beginn des Museumsbooms ist die Schilderung der Kriegs- und Besatzungszeit geprägt von einer Personalisierung, das heißt führende Vertreter des Untergrunds und der administrativen Behörden - ebenso wie der Besatzungsmacht - prägen die historischen Darstellungen. In Bezug auf die martyrologischen Museen an authentischen Orten von Verbrechen der Jahre 1939 bis 1944 / 45 muss jedoch hinzugefügt werden, dass in ihrem Fall von Beginn an auch Elemente der Personifizierung zu verzeichnen sind. Gerade die Schilderungen der Leiden der Gefangenen erfolgte in diesen Institutionen mittels zahlreicher Zeugnisse einfacher Inhaftierter: Folterpraktiken oder der Hunger im Gefängnis wurden mittels Kassibern und Zeugenberichten ehemaliger Insassen eindrücklich geschildert. Listen der inhaftierten, deportierten und exekutierten Insassen sollten die Namen aller versammeln, die vor Ort gelitten hatten. Als Orte der Dokumentation wie auch der Kommemoration wurde in diesen Museen von Beginn ihrer Tätigkeit an (so im Gefängnismuseum Pawiak bereits ab 1965) die Geschichte sowohl »von oben« als auch »von unten« erzählt - eine Strategie, die etwa Thomas Thiemeyer als anfänglich auf westeuropäische Museen beschränktes Phänomen skizziert. ${ }^{531}$ In 
den stadthistorischen Museen hingegen, deren Präsentationen nicht an solch emotional aufgeladenen Orten untergebracht waren, fanden sogenannte einfache Menschen als Protagonisten der Besatzungszeit erst mit dem Museumsboom Eingang in die Präsentationen. Diese Strategie der personifizierten Geschichtsvermittlung wird dabei für diametral verschiedene Interpretationen der Vergangenheit verwendet. Im Museum des Warschauer Aufstands etwa sind durchaus Aufständische niedrigen militärischen Ranges vertreten, wie Sanitäterinnen und Priester. Dennoch unterlag ihre Auswahl offensichtlich besonderen Kriterien, denn bei allen in der Dauerausstellung individuell Porträtierten handelt es sich um verdiente Persönlichkeiten, die sich in militärischer, ethischer oder anderer Weise besonders hervorgetan haben. Diese spezifischen »einfachen" Aufständischen werden als Repräsentanten nicht nur der übrigen Widerstandskämpfer, sondern auch der breiteren Bevölkerung der Stadt und des besetzten Landes präsentiert. Sie fungieren damit gleichsam als Belege der vorbildlichen Handlungsweise der Aufständischen und werden zugleich als Vorbilder für die Besucher inszeniert. In der Dauerausstellung des MHK im Schindler-Museum von 2010 kommen demgegenüber "gewöhnliche« Krakauer zu Wort. Einfache Menschen, fernab konspirativer Tätigkeiten, illustrieren den Alltag der breiten Massen der polnischen und jüdischen Krakauer. Im Gegensatz zum MPW werden hier jedoch individuelle und subjektive Schilderungen präsentiert, die auch kontrastierende Wahrnehmungen des Besatzungsalltags offerieren. Sie bieten Einblick gerade auch in die Graustufen und die negativen Erscheinungen der Jahre 1939 bis 1945. Mit diesem zu ihrem Entstehungszeitraum für das polnische Museumswesen einmaligen Blickwinkel ist diese Schau zugleich die einzige der untersuchten, die ihren Schwerpunkt tatsächlich auf die Alltagserfahrungen der Bevölkerungsmehrheit und mithin eine Geschichte »von unten« legt. Die Orientierung der neuen Kulturgeschichte auf die Populär- sowie die Alltagskultur ${ }^{532}$ setzt diese Schau damit als einzige der betrachteten Ausstellungen konsequent um. 



\section{Ausblick: Neue Impulse für die Musealisierung des Zweiten Weltkriegs}

In jüngster Zeit sind in Polen neue umfangreiche Museumsprojekte realisiert worden, die versprechen, wegweisende Impulse im Rahmen der erinnerungskulturellen Verhandlungsprozesse über die polnische Vergangenheit, insbesondere des Zweiten Weltkriegs, zu geben. Ebenso werden sie maßgeblich zu einer weiteren Auseinandersetzung im polnischen historischen Museumswesen um die Zielsetzungen, Formen und Strategien musealer Geschichtsvermittlung beitragen. Zwei der ambitioniertesten Institutionen werden im Folgenden näher betrachtet: das »Museum der Geschichte der Polnischen Juden« (Muzeum Historii Żydów Polskich, MHŻP) in Warschau sowie das "Museum des Zweiten Weltkriegs" (Muzeum II Wojny Światowej, MIIWŚ) in Gdańsk. Während die Dauerausstellung des MHŻP bereits am 28. Oktober 2014 eröffnet wurde, ${ }^{1}$ sind die Arbeiten an der ständigen Präsentation des MIIWŚ erst in jüngster Zeit beendet worden; die Schau wurde am 23. März 2017 offiziell für das Publikum geöfnet. Zugleich ist gegenwärtig noch nicht absehbar, wie lange die Präsentation in dieser, vom Gründungsteam des Museums geplanten und verantworteten Gestalt erhalten bleiben wird, nachdem dessen Direktion Anfang April 2017 ausgetauscht worden ist. ${ }^{2}$

Die Schaffung beider Institutionen war mit einem erheblichen finanziellen Aufwand verbunden. ${ }^{3}$ Ihre Ausstellungsflächen sind die bislang umfang-

1 Wystawa stała [Die Dauerausstellung], URL: www.polin.pl/pl/wystawa-stala (am 10.2.2015). Das Museumsgebäude ist bereits seit April 2013 für die Öffentlichkeit zugänglich; bis zur Eröffnung der Dauerausstellung wurden darin mehrere Sonderausstellungen und verschiedene kulturelle Veranstaltungen organisiert. Vgl. URL: www.polin.pl/pl/calendar (am 22.3.2015). Die kulturellen Aktivitäten der Institution haben jedoch bereits deutlich vor der Eröffnung seines Gebäudes begonnen. In den Jahren 2006 bis 2009 war auf dem Gelände des zukünftigen Museums ein Zelt aufgestellt, in dem zahlreiche Veranstaltungen der Warschauer Bevölkerung jüdische Geschichte und Kultur sowie die Pläne für die zukünftige Institution nahebrachten. Siehe hierzu die Jahresberichte des Museums: Biuletyn Muzeum Historii Żydów Polskich (Winter 2006), 6-8, (Herbst 2007), 16f., (Sommer 2008), $12 \mathrm{f}$. Vgl. auch die virtuelle Fassung der Sonderausstellung des Museums "Jak zrobić Muzeum? / »How to make a museum « unter URL: www.google.com/cultural institute/exhibit/how-to-make-a-museum/wR7xiggx (am 22.3.2015).

2 Näher hierzu in Kapitel 2.

3 Der Bau des Museumsgebäudes des MHŻP hat rund 320 Millionen PLN gekostet; für die Dauerausstellung wurden etwa 145 Millionen PLN von internationalen Spendern auf- 
reichsten innerhalb der historischen Museen des Landes: Die ständige Präsention des MHŻP umfasst mehr als 4.000 Quadratmeter, die des MIIWŚ fast 5.000 Quadratmeter. ${ }^{4}$ Diesem großzügigen Rahmen entspricht auch der umfassende Anspruch, den die Dauerausstellungen vermitteln: Beide entwerfen Narrative, die über einen lokalen oder regionalen Rahmen hinausgehen und das gesamte polnische historische Staatsgebiet umfassen, was einzigartig im polnischen historischen Museumswesen ist. Im Fall des Museums in Gdańsk nimmt die Erzählung sogar Bezug auf sämtliche Territorien, die vom Zweiten Weltkrieg erfasst worden sind. Die Schauen präsentieren somit in ihrem jeweiligen thematischen Rahmen erstmals übergreifende, gesamtpolnische Erzählungen.

Im Folgenden werden beide Dauerausstellungen analysiert, und zwar im Hinblick auf die jeweils spezifischen und vor dem Hintergrund der aktuellen musealen Präsentationspraxis der Jahre 1939 bis 1944 / 45 neuen Perspektiven, die die Schauen entwerfen. Da eine detaillierte Analyse der außerordentlich umfangreichen Präsentationen den Rahmen der vorliegenden Studie sprengen würde, konzentrieren sich die Ausführungen darauf, die grundlegenden Ausrichtungen dieser jüngsten Expositionen herauszuarbeiten. Insbesondere wird danach gefragt, welche inhaltlichen und interpretativen Neuerungen sie in die museale Darstellung des Weltkriegs und der damit unmittelbar verbundenen polnischen Selbst- und Fremdbilder einbringen. Daneben wird auch auf Innovationen im Bereich musealer Arbeits- und Vermittlungspraxen eingegangen. Dieser Abschnitt gibt somit einen Einblick in die neuesten musealen Auseinandersetzungen mit dem Zeitraum des Zweiten Weltkriegs in Polen.

gebracht. Siehe: Muzeum [Das Museum], URL: www.szih.org.pl/pl/Muzeum-POLIN.html (am 22.3.2015); Muzeum Historii Żydów Polskich to nowoczesne centrum edukacji i kultury [Das Museum der Geschichte der Polnischen Juden ist ein modernes Bildungs- und Kulturzentrum]. In: Gazeta Wyborcza vom 19.10.2010, Online-Ausgabe, URL: http://wia domosci.gazeta.pl/wiadomosci/1,114877,16827900,Muzeum_Historii_Zydow_Polskich_ to_nowoczesne_centrum.html (am 29.10.2014.) Für den Bau des MIIWŚ und die Realisierung seiner Dauerausstellung wurden insgesmt fast 450 Millionen PLN aus dem Staatshaushalt aufgebracht. Siehe: Muzeum II Wojny Światowej otwarte [Das Museum des Zweiten Weltkriegs ist eröffnet]. 23.3.2017, URL: www.tvn24.pl/pomorze,42/gdanskmuzeum-ii-wojny-swiatowej-otwarte,725769.html (am 20.5.2017).

4 Wystawa stała [Die Dauerausstellung], URL: www.polin.pl/pl/wystawa-stala (am 10.2.2015); Informacje o wystawie głównej [Informationen über die Dauerausstellung], URL: www. muzeum1939.pl/pl/wystawy/wystawa_glowna/informacje_o_wystawie (am 20.5.2017). 


\section{Das Museum der Geschichte der Polnischen Juden}

Die erste der hier betrachteten Dauerausstellungen wurde zwar erst vor wenigen Jahren eröffnet, die Geschichte des Projekts ist jedoch bereits deutlich älter. ${ }^{5}$ Die Initiative zur Schaffung eines Museums, das der Geschichte der Juden auf polnischem Boden gewidmet sein sollte, datiert aus dem Jahr 1993; die Idee stammt von der damaligen Direktorin des »Vereins Jüdisches Historisches Institut« (Stowarzyszenie Żydowski Instytut Historyczny) Grażyna Pawlak. 1997 übertrug die Stadt Warschau dem Verein das Grundstück, auf dem das zukünftige Museum errichtet werden sollte. Im Jahr 2005 unterzeichneten schließlich die Stadt Warschau, das Ministerium für Kultur und Nationales Erbe sowie der Verein Jüdisches Historisches Institut die Gründungsurkunde des Museums. Die Institution stellt damit die erste Einrichtung Polens in gemeinsamer privater und öffentlicher Trägerschaft dar. Während die Stadt Warschau und das Ministerium den Neubau des Museumsgebäudes finanzierten sowie den Großteil der laufenden Unterhaltskosten tragen, lag die Schaffung und Finanzierung der Dauerausstellung in der Verantwortung des Vereins, der hierfür Spendengelder im In- und Ausland einwarb.

Anliegen der Initiatoren des Projekts war es, einen Ort zu schaffen, der die jahrhundertelange gemeinsame und miteinander verflochtene Geschichte von Polen und Juden zeigt. In diesem Sinne sollen »die Juden« nicht als fremdes Element polnischer Historie porträtiert werden, sondern als deren integraler Bestandteil. ${ }^{6}$ Daher auch der bewusst gewählte Ausdruck "polnische Juden" (polscy Żydzi) im Namen des Museums - und nicht etwa "Juden in Polen« (Żydzi w Polsce). Das übergreifende Anliegen der Museums- wie Ausstellungsverantwortlichen ist es somit, die Geschichte der Juden, die auf polnischem Territorium lebten, in das polnische Verständnis der Vergangenheit des Landes zu integrieren. Der Fokus der Institution sollte zudem nicht ausschließlich oder in erster Linie auf dem Holocaust liegen. In den Worten von Jerzy Halbersztadt, dem Gründungsdirektor des MHŻP, war es das Ziel, ein »Museum des Lebens $\aleph^{7}$ zu schaffen, in dem der Holocaust, der wesent-

5 Einen Überblick über die Entstehungsgeschichte des Projekts bietet Wóycicka, Zofia: 1000 Jahre im Museum. Die Geschichte der polnischen Juden. In: Osteuropa 58/8-10 (2008), 409-417, $411 \mathrm{f}$. Die folgenden Ausführungen zur Entstehungsgeschichte des Museums beziehen sich auf diese Publikation.

6 Kirshenblatt-Gimblett, Barbara: Theater of History. In: Dies. / Polonsky, Antony (Hg.): Polin. 1000 Year History of Polish Jews [Ausstellungskatalog]. Warsaw 2014, 19-35, hier 32.

7 Podgórska, Joanna: Muzeum Życia. Rozmowa z Jerzym Halbersztadtem, dyrektorem powstającego Muzeum Historii Żydów Polskich [Museum des Lebens. Ein Gespräch mit Jerzy Halbersztadt, dem Direktor des entstehenden Museums der Geschichte der Polnischen Juden]. In: Polityka vom 4.11.2009, Online-Ausgabe, URL: www.polityka.pl/ tygodnikpolityka/historia/222399,1,muzeum-zycia.read (am 22.3.2015). 
lich auf besetztem polnischen Territorium stattfand, zwar einen umfangreichen Platz erhält, aber nicht als teleologisches Ziel und zugleich Ende der Geschichte von Polen und Juden erscheint. ${ }^{8}$ Daher wird die museale Erzählung auch in die Nachkriegszeit fortgeführt, über die Jahre der Volksrepublik und den demokratischen Wandel des Jahres 1989 hinweg. ${ }^{9}$ Der Vernichtung des Großteils der polnischen Juden ebenso wie der folgenden Emigration weiter Teile der Überlebenden wird hier zwar prominent Platz eingeräumt, zugleich wird jedoch deutlich, dass der Holocaust nicht das Ende jüdischen Lebens in Polen war und dass eine Neu- bzw. Wiederentdeckung der jüdischen Vergangenheit des Landes in der polnischen Gegenwart eine maßgebliche Rolle spielt. ${ }^{10}$ Die Ausstellungsverantwortlichen zielen mit ihrem Museum und dessen zentralem Element, seiner Dauerausstellung, somit auf eine fundamentale Veränderung polnischer Geschichtswahrnehmungen und historischer Selbstbilder ebenso wie auf einen neuen Blick auf das polnisch-jüdische Erbe in der Gegenwart. ${ }^{11}$

Wie bereits angedeutet, umfasst die Dauerausstellung tausend Jahre der "Geschichte der Juden auf den historischen Gebieten der Republik Polen «. ${ }^{12}$ Sie ist in acht sogenannte Galerien gegliedert, die von der Ankunft der Juden auf historischem polnischen Territorium bis in die Gegenwart reichen. ${ }^{13}$ Eine davon ist dem Holocaust (Zagłada) ${ }^{14}$ gewidmet und damit der Verfolgung und dem Massenmord an den polnischen und europäischen Juden während des Zweiten Weltkriegs.

Der Übergang von Friedens- zu Kriegszeiten und damit der Beginn der Galerie wird bereits gestalterisch als Wendepunkt markiert: ${ }^{15}$ Von der hell be-

8 Siehe auch Kirshenblatt-Gimblett: Theater of History, 30, 32.

9 Den Ereignissen seit der sukzessiven Befreiung des Landes von den deutschen Truppen beginnend im Jahr 1944 bis in die Gegenwart, ist die achte und damit letzte Galerie der Dauerausstellung gewidmet.

10 Wie es in der Beschreibung der Sektion heißt: "Der Besucher, der den letzten Teil der Dauerausstellung verlässt, wird in die Diskussionen über die Identität und Erinnerung an die Vergangenheit und die Gegenwart der polnischen Juden gezogen." Siehe: Wystawa stała. Powojnie (1944 do dziś) [Die Dauerausstellung. Die Nachkriegszeit (1944 bis heute)], URL: www.polin.pl/pl/wystawy-wystawa-glowna-galerie/powojnie (am 11.2.015).

11 Vgl. Kirshenblatt-Gimblett: Theater of History, 19.

12 Statut [Satzung], URL: www.polin.pl/pl/statut (am 22.3.2015).

13 Eine Übersicht über den Aufbau der Schau findet sich auf der Website des Museums: Wystawa stała [Die Dauerausstellung], URL: www.polin.pl/pl/wystawa-stala (am 11.2.2015).

14 So lautet auch der Titel der Galerie. Inhaltlich verantwortlich für das Konzept dieser Sektion waren die zwei renommierten polnischen Holocaust-Forscher Barbara Engelking und Jacek Leociak.

15 Die folgenden Ausführungen zu den Inhalten der Schau basieren auf den Besuchen der Verfasserin am 26. und 28. August 2014. 
leuchteten Straße der Zwischenkriegszeit treten die Besucher in einen dunklen Gang, in dem sie vom Kriegsausbruch am 1. September 1939, das heißt dem deutschen und wenig später auch sowjetischen Angriff auf Polen erfahren. ${ }^{16}$ Hier finden sich zentrale Elemente des musealen polnischen Kriegsnarrativs wie die Verkündung der Mobilmachung durch den Staatspräsidenten Ignacy Mościcki im August 1939 oder ein Plakat, das für den Kauf von Kriegsanleihen wirbt. Unmittelbar daneben angebracht ist ein Plakat, auf dem der "Verein der jüdischen Teilnehmer der Kämpfe um die Unabhängigkeit Polens" (Związek Żydów Uczestników Walk o Niepodległość Polski) »die jüdischen Bürger« zur "gemeinsamen Anstrengung für die Stärkung der militärischen Schlagkraft des Staates", das heißt den Ankauf von Kriegsanleihen aufruft. ${ }^{17}$ Auf der gegenüberliegenden Wand des Gangs steht ein großformatiges Zitat des Arbeiters Baruch Goror: „Es lebe unser geliebtes Vaterland Polen und seine Verbündeten!« Im Weiteren wird das Schicksal eines jüdischen Soldaten der polnischen Armee, Samuel Przedborski, geschildert. Ein kleiner Bereichstext nennt dazu die Zahl von 150.000 jüdischen Soldaten in der polnischen Armee, die im September 1939 kämpften. Die jüdischen Einwohner des Landes werden auf diese Weise als patriotische Staatsbürger markiert, die die Republik als ihre Heimat ansahen und in deren Verteidigung gegen äußere Aggressoren sie emotional, ökonomisch und militärisch involviert waren - ebenso, wie dies auf die ethnisch-polnische Bevölkerung des Landes zutraf. Bereits hier wird deutlich, dass die Erfahrungen und Handlungen von Juden als Teil der übergreifenden Geschichte des polnischen Staates, in diesem Sinne der polnischen Geschichte - hier des Weltkriegs - präsentiert werden.

Dies setzt sich auch in der daran anschließenden Sektion fort, die der Etablierung des deutschen und sowjetischen Besatzungsregimes gewidmet ist. Einen Schwerpunkt der Darstellung bilden hier die Verbrechen der Besatzer gegen die lokale Bevölkerung. Genannt werden die in den polnischen historischen Narrativen der Besatzungszeit fest verankerten ersten Gräueltaten der Deutschen: die Sonderaktion Krakau und das Massaker von Wawer, die stellvertretend stehen für das Vorgehen gegen die polnische Elite einerseits und die exzessive Gewaltanwendung gegenüber Zivilisten andererseits. In dieser Aufzählung aufgeführt wird jedoch auch eine Massenexekution an jüdischen Einwohnern Warschaus, die als Vergeltung für die Ermordung eines polnischen Polizisten ausgeführt wurde. ${ }^{18}$ Nicht nur wird durch diese Zusam-

16 Die Angriffsrichtungen der Armeen beider Länder werden auf einer großformatigen Karte gezeigt.

17 Text des Plakates.

18 Bereichstext. Wie dort angegeben ist, fanden alle diese Ereignisse im Zeitraum November bis Dezember 1939 statt. 
menstellung deutlich, dass sowohl Polen als auch Juden von Beginn der Besatzung an Opfer der deutschen Gewalt wurden; zugleich wird bereits auf Unterschiede in ihrer Behandlung verwiesen, denn es waren Juden - nicht Polen -, die für den Mord an einem polnischen Polizisten hingerichtet wurden.

Die Schilderung des sowjetischen Vorgehens gegen die Bevölkerung der östlichen Gebiete des besetzten Polen zeigt wiederum exemplarisch das Bestreben der Ausstellungsverantwortlichen, stereotype Vorstellungen durch die Kontrastierung mit historischen Fakten zu hinterfragen, gleichzeitig aber auch ihre Existenz zu thematisieren. Den Schwerpunkt des Abschnitts bilden die Deportationen in den Osten. Ein Zeitzeugenzitat berichtet, wie die jüdische Bevölkerung anfangs zwar die Sowjets den Deutschen vorzog, die Repressalien ersterer sie aber bald eines besseren belehrten. ${ }^{19}$ Daran anschließend findet sich der Hinweis, wonach bis Juni 1941 über 320.00 »polnische Staatsbürger" deportiert worden sind, unter denen sich ca. 80.000 Juden befanden. ${ }^{20}$ Diese großformatig präsentierten Informationen zielen offensichtlich auf das immer noch verbreitete Stereotyp der Żydokomuna, das heißt der Vorstellung von einer breiten Unterstützung der sowjetischen Besatzer in der kollektiven Erinnerung "die Kommunisten « - durch die jüdischen Einwohner des Landes, die zudem implizit davon ausgeht, allein Polen hätten unter der sowjetischen Herrschaft und den mit ihr kollaborierenden Juden gelitten. Dass diese Vorstellung (auch) eine zeitgenössische war, vermittelt ein Zitat Jan Karskis:

Allgemein ist man der Meinung, dass die Juden Polen und die Polen verraten haben, dass sie im Prinzip Kommunisten sind, dass sie zu den Bolschewiken mit wehenden Fahnen übergegangen sind ... Die Polen warten auf den Moment, wenn sie sich an den Juden werden rächen können. ${ }^{21}$

Die Gegenüberstellung dieses Zitats mit den historischen Zahlen der Verfolgten macht somit deutlich, dass sowohl Polen als auch Juden Ziele der Repressionen beider Aggressoren und Besatzer waren.

Im Weiteren konzentriert sich die Darstellung auf die deutsche Okkupation und die zunehmende Trennung beider Bevölkerungsgruppen durch die Besatzungsverordnungen, die schließlich in der Schaffung von Ghettos mündete. Das Leben und Leiden in diesen "Judenwohnbezirken" wird daran anschließend am Beispiel des Warschauer Ghettos intensiv beleuchtet. Die Erzählung gelangt schließlich zur großen Deportationswelle vom Sommer 1942 und dem Aufstand 1943, der während der Liquidierung des restlichen

19 Dies vermittelt ein Zitat aus dem Tagebuch von Baruch Milch, das den großformatigen Bereichstext eröffnet.

20 Bereichstext unter dem Sektionstitel »17. September 1939«.

21 Zitat aus einem Bericht Karskis vom Februar 1940. 
Ghettos ausbrach. Die starke Konzentration auf Warschau gerade in dieser Galerie ist verbunden mit der Verortung des Museums selbst: Es befindet sich auf dem Territorium des ehemaligen Ghettogeländes; direkt gegenüber seinem Eingang steht das Denkmal des Warschauer Ghettoaufstandes.

Der Warschauer Fokus zeigt sich auch in einem weiteren zentralen Vermittlungselement der Schau: Die Narration wird getragen von Zeitzeugenberichten - in den genannten Sektionen von Menschen, die in Warschau lebten oder im dortigen Ghetto eingesperrt wurden. Ausschnitte aus ihren überlieferten Zeugnissen sind großformatig im gesamten Rundgang platziert. Berichte von Augenzeugen stellen auch die Audiokommentare in den zahlreichen Foto- und Videopräsentationen, die detallierter in einzelne Themenbereiche einführen. ${ }^{22}$ Diese Selbstzeugnisse schildern eindringlich die Erfahrungen und individuellen Wahrnehmungen der Ereignisse durch die unmittelbar Betroffenen. Sie vermitteln die Emotionen ebenso wie die Diversität der zeitgenössischen Perspektiven und Meinungen. Hierdurch werden Besucher immer wieder gezwungen, auch tradierte historische Einschätzungen zu hinterfragen bzw. sich eine eigene Meinung zu bilden. Beispielhaft hierfür ist die Schilderung der Reaktionen auf den Selbstmord des Vorsitzenden des Judenrates des Warschauer Ghettos, Adam Czerniaków. ${ }^{23}$ Aufgeführt werden mehrere Äußerungen, unter anderem eine von Emanuel Ringelblum, dem Leiter von Oneg Schabbat: »Der Selbstmord Czerniakóws - zu spät. Ein Beweis der Schwäche. Er hätte zum Widerstand aufrufen sollen. Ein schwacher Mensch.« Ein weiteres bezeichnet ihn dagegen als »erstes Opfer der Aussiedlungsverfügung ${ }^{24}{ }^{24}$ Der Ingenieur Henryk Bryskier wiederum berichtet: »Einige hielten diese Tat für Heldentum, andere für Feigheit; es gab jedoch auch solche, die diesen Selbstmord als dummen Akt der Gerechtigkeit für nationalen Verrat betrachteten.« Diese Äußerungen zeigen ein ganzes Spektrum unterschiedlicher Meinungen und Einschätzungen der Per-

22 So finden sich etwa im Abschnitt, der dem Leben im Warschauer Ghetto gewidmet ist, mehrere Präsentationen: Eine erörtert die Arbeit der diversen sozialen Einrichtungen; eine weitere schildert die Zwangsarbeit im Ghetto; die dritte schließlich stellt die jüdische Polizei im Ghetto vor. Die Ankunft deutscher Truppen und die Etablierung ihres Besatzungsregimes ebenso wie die Erfahrungen der nach Sibirien Deportierten, die zuvor präsentiert wurden, werden ebenfalls durch Zeitzeugen geschildert und kommentiert. Lediglich in einer Präsentation wird auf anderes Quellenmaterial zurückgegriffen: Die deutschen Repressionen gegen die polnische Bevölkerung und die Tätigkeit des polnischen Untergrundstaates, die Thema einer Präsentation in der »arischen Straße« sind, werden mitteils eingesprochener Ausschnitte aus der Untergrundzeitschrift Biuletyn Informacyjny geschildert.

23 Adam Czerniaków beging Selbstmord am Tag nach dem Beginn der großen Deportationswelle aus dem Warschauer Ghetto, am 23. Juli 1942. Zuvor hatte er sich geweigert, die Bekanntmachung der Besatzungsorgane zur Aussiedlung zu unterschreiben.

24 Zitat von Chaim A. Kaplan vom 26. Juli 1942. 
son Czerniakóws und seines Selbstmordes auf. Eine eindeutige Bewertung wird den Besuchern jedoch nicht präsentiert. An anderer Stelle wiederum geht man auf das breite Spektrum polnischer Wahrnehmungen und Haltungen gegenüber der Judenverfolgung ein, konkret illustriert durch einzelne Reaktionen polnischer Warschauer, die außerhalb des Ghettos lebten. Ein Kommentar aus einem Gespräch in der Bahn - »Die Deutschen werden Polen von den Juden säubern ${ }^{25}$ - wird mit der folgenden Beschreibung kontrastiert: »Das Ghetto brennt ... ständige Explosionen, und die Leute gehen in Ruhe ... niemand wendet im Angesicht der Schüsse und Explosionen auch nur die Augen $\mathrm{ab} \ll^{26}$.

Wie diese Beispiele andeuten, dienen die umfangreichen Zitate aus Egodokumenten und Zeitzeugenberichten nicht allein als vereinzelte Kommentare zu den geschilderten historischen Ereignissen. In dieser Schau nehmen sie eine zentrale Rolle bei der Konstruktion der musealen Erzählung ein. Nur wenige zusätzliche Kuratorentexte liefern ergänzende Informationen und Kontexte; diese sind zudem fast alle in deutlich kleinerer Schriftgröße und am Rande der zentralen visuellen und kognitiven Elemente der jeweiligen Abschnitte platziert. Um der Erzählung zu folgen, ist es nicht zwingend notwendig, diese Bereichstexte zu lesen. Die wenigen Kuratorentexte sind zudem weitgehend neutral formuliert; emotionale und subjektive Einschätzungen finden sich allein in den zeitgenössischen Quellen. In dieser Ausstellung sind es somit nicht mehr - wie bislang im historischen Museumswesen üblich die Einschätzungen und Äußerungen der anonym verbleibenden Kuratoren, die die Narration leiten, sondern die Protagonisten der historischen Ereignisse selbst. ${ }^{27}$ Ihre Aussagen und Berichte bilden die oberste Informationsebene der Schau. Selbst Besucher, die relativ zügig oder oberflächlich durch die Galerie gehen und nur hin und wieder einzelne Texte rezipieren, werden somit von den historischen Ereignissen durch die unmittelbar Betroffenen bzw. Teilnehmenden erfahren.

Auffällig ist zudem die Auswahl und Zuordnung der präsentierten Selbstzeugnisse: Die Berichte stammen aus dem jeweils geschilderten Zeitraum.

25 Zur Provenienz dieser Aussage heißt es in der Schau: »erinnerte sich in ihrem Tagebuch Waleria Nachurska an Worte, die sie in einem Zug gehört hatte«.

26 Zitat aus einem Brief Alicja Iwańskas an Jan Gralewski.

27 Diese zentrale Prämisse der Ausstellungskommunikation hat Barbara KirshenblattGimblett, die Leiterin des Teams von Wissenschaftlern, die die Schau inhaltlich erarbeitet haben, auch in ihrem programmatischen Text zum Konzept der Dauerausstellung betont: Kirshenblatt-Gimblett: Theater of History, 32. Eine gekürzte Fassung des Textes wurde zur Eröffnung der Dauerausstellung auch im Tygodnik Powszechny publiziert: Kirshenblatt-Gimblett, Barbara: Teatr historii: 12 zasad [Das Theater der Geschichte: 12 Prinzipien]. In: Tygodnik Powszechny 44 (2014), Online-Ausgabe, URL: http://tygodnik. onet.pl/historia/teatr-historii-12-zasad/h14m8 (am 20.3.2015). 
Sie geben daher die zeitgenössische Perspektive der Protagonisten, also auch ihren jeweiligen Informationsstand wieder. ${ }^{28}$ Die Darstellung der historischen Ereignisse erfolgt somit nicht aus einer ex post-Perspektive, in Kenntnis der späteren Folgen einzelner Entscheidungen und Entwicklungen. Hierdurch wird die Ungewissheit und Unentschiedenheit der Geschehnisse den Besuchern offengelegt. Ein prägnantes Beispiel findet sich im Abschnitt, der der großen Aussiedlungsaktion aus dem Warschauer Ghetto im Sommer 1942 vorangeht: Ein großformatiges Zitat berichtet von Gerüchten, die im Ghetto zu kursieren begannen, über die Aussiedlung von Juden aus Lublin und anderen Städten in den Osten; "von den Ausgesiedelten ist jede Spur verschwunden. ${ }^{29}$ Es ist hier (noch) nicht die Rede von den Massenmorden in den Vernichtungslagern, da die Ghettobewohner selbst von ihrem Schicksal bzw. dem Hintergrund der Pläne der Besatzer nichts wussten. Die Besucher verfolgen somit unmittelbar die Angst und Unsicherheit der Ghettobewohner über das, was nun kommen wird. Eine solche Präsentationsweise verzichtet bewusst auf Einschätzungen, die im Nachgang der Geschehnisse, das heißt erst mit dem Abstand mehrerer Jahre oder gar Jahrzehnte etwa in Autobiografien und Zeitzeugeninterviews von Überlebenden verfasst bzw. aufgezeichnet worden sind. Mit dieser Darstellungsweise wird zugleich auf eine nachträgliche sinnstiftende Einordnung in übergreifende Interpretationsmuster jüdischer bzw. polnisch-jüdischer Geschichte verzichtet. ${ }^{30}$ Auch in dieser sehr bewussten Selektion der Quellen stellt die Schau eine Neuerung im polnischen historischen Ausstellungswesen dar.

Bemerkenswert ist schließlich noch ein weiterer Punkt: Es sind nicht allein die als Juden Verfolgten, denen buchstäblich das Wort überlassen wird - auch wenn sie aus naheliegenden Gründen im Vordergrund der Narration stehen. Wie bereits erwähnt, finden sich ebenfalls Zeugnisse ethnisch-polnischer Staatsbürger, die Einblick geben in ihre Haltungen und Wahrnehmungen während der Jahre 1939 bis 1945. Schließlich sind es auch die deutschen Besatzer selbst, die ihre Ziele ebenso wie deren Umsetzung schildern. Um nur ein Beispiel herauszugreifen: Den Prozess der Selektion und Ermordung von Juden in Auschwitz II-Birkenau beschreibt der Leiter des Vernichtungslagers

28 Gerade für die Verantwortlichen der Holocaust-Galerie war diese Perspektive von Beginn an zentral. Leociak, Jacek: Jak opowiedzieć/pokazać Zagładę w muzeum? [Wie kann man den Holocaust im Museum erzählen / zeigen?]. In: Nieroba, Elżbieta (Hg.): Targowisko przeszłości. Społeczne konsekwencje popkulturowych sposobów opowiadania o świecie minionym [Der Marktplatz der Vergangenheit. Gesellschaftliche Folgen popkultureller Erzählstrategien über die vergangene Welt]. Warszawa 2011, 105-117, hier 110. Vgl. auch Heinemann: Die Musealisierung des Ghettos, 484-488, bes. 486.

29 Zitat aus dem Tagebuch Stanisław Sznapmans, eines Polizisten im Warschauer Ghetto.

30 Vgl. Leociak: Jak opowiedzieć/ pokazać Zagładę, 111. 
Rudolf Höß - die Texte stammen aus seiner Autobiografie, die er 1947 in Haft verfasst hatte. ${ }^{31}$

Dieses Beispiel verweist auf eine weitere Spezifik der Präsentationspraxis dieser Schau: den reflektierten Umgang mit dem zur Verfügung stehenden Quellenmaterial und der Offenlegung von dessen Entstehungsgeschichte. Die in der Ausstellung untergebrachten Zitate sind alle mit Angaben über ihren Entstehungszeitpunkt, den Autor und den Kontext der Niederschrift (etwa Tagebuch, Brief, wiedergegebenes Gespräch) versehen. Ebenso sind an allen verwendeteten Abbildungen - unabhängig davon, ob es sich um kleine Porträtaufnahmen oder wandfüllend vergrößerte Aufnahmen handelt - Angaben zu ihrem Motiv und ihrer Provenienz vorhanden. Hierdurch erhalten die Besucher meist auch Einblick in den Entstehungskontext der Quellen und die damit verbundene spezifische Perspektive des Autors, Fotografen oder auch ihres Auftraggebers. Zudem erfährt der Entstehungsprozess zentraler Quellen oder Dokumentensammlungen immer wieder umfassende Beachtung, wofür die Autobiografie von Rudolf Höß nur ein Beispiel ist. So werden etwa zuvor bereits die Arbeitsweise, Ziele und gesammelten Materialien des Untergrundarchivs des Warschauer Ghettos Oneg Schabbat geschildert ebenso wie seine Überlieferung. ${ }^{32}$ Im Laufe des Rundgangs finden sich dann immer wieder Zitate aus Berichten, bei denen explizit darauf hingewiesen wird, dass sie für Oneg Schabbat angefertigt wurden. Ebenso gezeigt werden die deutschen Propagandakompanien, die Film- und Fotoaufnahmen im Ghetto anfertigten: ${ }^{33}$ Wandfüllend im Rundgang untergebracht ist beispielsweise eine Fotografie, die die Aufnahmearbeiten eines deutschen Filmteams in einem Ghettobetrieb zeigt. Dem sogenannten Stroop-Bericht ist ein eigener Themenabschnitt gewidmet, in dem ausführlich die Entstehung und Zielsetzung des Berichts und der berühmten Fotografien, die er enthält, erläutert wer-

31 Dieser Entstehungskontext wird explizit in der Schau erläutert. Daneben eröffnet ein Ausschnitt aus dem Einsatzgruppenbefehl Reinhard Heydrichs vom 2. Juli 1941 die Sektion »Unternehmen Barbarossa«. Teile des Protokolls der Wannsee-Konferenz vom 20. Januar 1942 geben Einblick in die Planungen der Umsetzung des Massenmords an den europäischen Juden. Die Massaker an Juden und Polen in Ponary zwischen 1941 und 1944 werden von Berichten teilnehmender oder anwesender Deutscher begleitet.

32 Bei der Schilderung des Warschauer Ghettos ist dem Untergrundarchiv ein eigener Teilabschnitt gewidmet. In der Sektion, die später die Aussiedlungsaktion 1942 darstellt, findet sich eine Installation, die das Vergraben des ersten Teils des Archivs illustriert: Mehrere Kartons sind in einer Öffnung im Boden auf Sand platziert. Seine Wiederentdeckung nach dem Krieg ist eines der ersten Themen, die zu Beginn der folgenden Galerie »Nachkriegszeit« (Powojnie) erwähnt werden.

33 Es war den Verantwortlichen der Galerie nach eigenen Worten ein besonderes Anliegen, den Besuchern deutlich zu machen, dass ein Großteil der überlieferten Fotografien von den Tätern angefertigt wurde und sie eine weitere Form der Erniedrigung ihrer Opfer darstellten. Leociak: Jak opowiedzieć/pokazać Zagładę, 111. 
den. Festgehalten wird hier auch explizit: »Der Bildbericht [deutscher Begriff im Original - d.Vf.] zeigt nicht die Kämpfe, sondern die brutale Pazifizierung des Aufstands." In den zuvor untersuchten Warschauer Ausstellungen waren und sind die Fotografien aus dem Stroop-Bericht meist mit der ungenauen Angabe "Der Aufstand im Warschauer Ghetto $1943 «^{34}$ versehen. Weder wird der Autor der Aufnahmen benannt, noch ihr spezifischer Blickwinkel thematisiert - die Niederschlagung der Kämpfe und Inhaftierung von Aufständischen und Zivilisten, gesehen mit den Augen der Feinde. Der so gestaltete Einsatz der Fotografien trägt zur Abgrenzung der jüdischen von den polnischen Aufständischen bei. Während die Bilder aus dem Stroop-Bericht nämlich primär Mitleid beim Betrachter hervorrufen, zeigen etwa die Fotografien der Aufständischen von 1944, die von der eigenen Propagandaabteilung der AK angefertigt wurden, gelöste, lachende und siegesgewisse Kämpfer, die in vielen Schauen als Sinnbilder des Heldentums präsentiert werden.

Beachtenswert ist vor diesem Hintergrund auch die Darstellung der Massaker von Paneriai (Ponary) zwischen 1941 und 1944. Dies ist der einzige Abschnitt der Holocaust-Galerie, in der Abbildungen von Exekutionen und Leichen gezeigt werden. Sie sind jedoch hier nicht prominent im Vordergrund platziert, sondern bleiben im Hintergrund, um den Besuchern die Möglichkeit zu geben, selbst zu entscheiden, ob sie die grausamen Szenen betrachten möchten. Die Texte und Fotografien dieser Sektion sind auf Blechen reproduziert, die sich in Form zweier "Bänder« durch zahlreiche Baumstämme winden. Auf dem unteren Band, das in einer Höhe angebracht ist, die der durchschnittlichen Sichthöhe der meisten Besucher entsprechen dürfte, wird der Verlauf der Exekutionen geschildert, und zwar wesentlich mittels schriftlicher Berichte von Augenzeugen. Erst auf dem hinteren Band sind die grausamen Fotografien der Exekutionen untergebracht. Dieses Band ist oberhalb des ersten und zudem hinter diesem zurückgesetzt angebracht; es befindet sich damit in größerer Höhe und Entfernung von den Betrachtern. Die Fotografien sind zudem kleinformatig. Die Besucher müssen also bewusst näher herantreten und ihre gewohnte Sichtachse verlassen, um die Aufnahmen zu betrachten. Schnell wird zudem deutlich, dass die Fotos nicht zur bloßen Exemplifizierung der Grausamkeit der Mörder gezeigt werden. Vielmehr nutzt man sie als Beispiele, anhand derer der Entstehungskontext und die Überlieferung dieser und ähnlicher Bilder in ihrer Rolle als Dokumente und Beweise der Verbrechen thematisiert werden. In den Texten, die zwischen den Fotos untergebracht sind, erfahren die Besucher etwa davon, dass deutsche Soldaten privat und trotz der Verbote seitens ihrer Vorgesetzten Aufnahmen von Massakern und der Erniedrigung der lokalen Bevölkerung anfertigten, die in Alben aufbewahrt oder als Postkarten in die Heimat verschickt

34 Objektbeschriftung in der aktuellen Dauerausstellung des Gefängnismuseums Pawiak. 
wurden..$^{35}$ Unmittelbar daneben findet sich ein Zitat aus einem Brief von Otto Wöhler, dem Generalstabschef der Heeresgruppe Mitte, vom 22. Juli 1941:

Es ist selbstverständlich für jedes normale menschliche Wesen, dass man diese abstoBenden Exzesse nicht fotografieren oder sie in Briefen an die Heimat erwähnen wird. Die Anfertigung und Verbreitung dieser Art von Fotografien und Berichten über solche Vorkommnisse wird als Untergrabung der Moral und Disziplin der Streitkräfte gewertet und streng bestraft werden.

Es wird somit deutlich, dass die Praxis dieser Aufnahmen nicht gestattet oder generell befürwortet wurde. Der Ausdruck »diese abstoßenden Exzesse« verweist zudem darauf, dass die Massaker auch innerhalb des deutschen Militärs nicht allein positiv gewertet wurden - ein Hinweis auf die Diversität von Ansichten selbst unter den Tätern.

Wie bereits erwähnt, bildet diese Sektion mit den grausamen Bildern von Exekutionen und ihren Opfern eine Ausnahme in der Galerie. Im restlichen Rundgang wurden keine Fotos verwendet, die die Opfer der NS-Verbrechen in entmenschlichter Weise zeigen. ${ }^{36}$ So finden sich etwa im Abschnitt, der dem Leben im Warschauer Ghetto gewidmet ist, keine Fotos, die grausam ausgemergelte Personen zeigen, Kinder, die vollkommen entkräftet auf der Straße betteln, oder Leichen von Verhungerten - Motive, die bislang im (nicht nur polnischen) historischen Museumswesen gängige Praxis sind. Lediglich ein Bild zeigt einen Toten auf einem Bürgersteig liegend; dessen Gesicht ist jedoch mit einem Tuch bedeckt, einem letzten Zeichen von Pietät. Auch in diesem Fall ist die Aufnahme Ausgangspunkt für die Schilderung größerer Kontexte - hier der Umstände, die dazu führten, dass hungernde Familien ihre Toten nicht meldeten, sondern sie auf den Straßen ablegten. ${ }^{37}$ Auch in der Sektion, die den Massenmord in den Vernichtungslagern schildert, wird weitgehend auf ikonische »Bilder des Grauens $^{38}$ verzichtet. Weder werden Leichenberge noch bis auf die Knochen ausgezehrte Menschen gezeigt. Auf den nur wenigen Fotografien, die in diesem Abschnitt überhaupt präsentiert werden, sind Deportierte bei oder kurz nach ihrer Ankunft im Lager zu sehen, in ihrer privaten Kleidung und (noch) ungeschoren. ${ }^{39}$ Ein weiteres Bild zeigt

35 Diese Informationen werden in einem Bereichstext geschildert.

36 Dies trifft auf die an den Ausstellungswänden untergebrachten Abbildungen ebenso zu wie auf die zahlreichen Multimediapräsentationen.

37 Die Hintergründe - das Weiternutzen der Lebensmittelkarten durch die hungernden Familien, fehlende finanzielle Mittel für die Beerdigung - werden in der Objektbeschriftung zu dieser Abbildung genannt.

38 Liss, Andrea: Trespassing Through Shadows. Memory, Photography, and the Holocaust. Minneapolis, London 1998, 5.

39 Auch hier wird wiederum die Provenienz der Fotografien offengelegt. Geschildert wird die Geschichte von Lilly Jacob, die im Arbeitslager Dora-Mittelbau ein Fotoalbum fand, das Bilder ungarischer Juden auf der Rampe in Auschwitz-Birkenau enthielt. Auf diesen 
Häftlinge, die die Habseligkeiten der Deportierten sortieren. Die einzigen Aufnahmen, die den Tod zeigen, finden sich am Ende des Raumes: Auf Stelen werden die vier Fotografien gezeigt, die ein Mitglied des Sonderkommandos in Auschwitz angefertigt hat und die aus dem Lager geschmuggelt worden sind. Die kleinformatigen Bilder stehen so als einzigartige Dokumente des Verbrechens an exponierter Stelle, als Ausnahme, denn gemacht wurden sie von einem der Betroffenen, nicht von den Tätern. ${ }^{40}$

In dieser Quellenauswahl und ihrer Präsentationspraxis wird der Anspruch der Ausstellungsverantwortlichen deutlich, eine zweifache Viktimisierung der Verfolgten und Ermordeten zu vermeiden, die sie auch in der Überlieferung - gerade in der hauptsächlich von den Tätern stammenden visuellen als entmenschlichte Objekte des Massenmordes erscheinen lassen würde. ${ }^{41}$ Die als Juden Verfolgten erscheinen in dieser Schau stets als Subjekte der historischen Ereignisse, ${ }^{42}$ als Individuen, deren Würde auch in der musealen Schilderung ihres Leidens gewahrt wird. Dieser reflektierte und ethische Umgang mit historischem Quellenmaterial ist bislang im polnischen historischen Ausstellungswesen, das sich mit dem Zeitraum 1939 bis 1945 befasst, einzigartig. Großformatige Aufnahmen von Opfern deutscher Gräueltaten während des Kriegs gehörten bereits in der Volksrepublik zur gängigen musealen Darstellung der Besatzungszeit. Bis in die Gegenwart sind Fotos etwa von Leichen, meist erhängten und erschossenen Personen, etablierte Elemente historischer Ausstellungen. Sie finden sich prominent und offensichtlich unhinterfragt, zudem in meist rein illustrativer Verwendung, in konzeptionell innovativen ebenso wie traditionellen musealen Erzählungen, so beispielsweise in der Krakauer Schindler-Fabrik und im Museum Radogoszcz. ${ }^{43}$

erkannte sie sich selbst und ihre Familie wieder. Die Autorenschaft der Fotos und die weitere Überlieferung des Albums werden ebenfalls dargestellt.

40 Ihre Geschichte wird in einem kleinen Bereichstext geschildert.

41 Leociak: Jak opowiedzieć/ pokazać Zagładę, $110 \mathrm{f}$. Liss: Trespassing, 4.

42 Vgl. Kirshenblatt-Gimblett: Theater of History, 32.

43 In der Krakauer Schau sind Fotos von Exekutionen an einer Wand entlang des Ganges der Sektion »Terror untergebracht. Weder werden die Besucher vor den drastischen Fotografien gewarnt, noch können sie selbst entscheiden, ob sie sie betrachten möchten, da die Bilder alle offen und in einer bequemen Sichthöhe untergebracht sind. Um die Sektion zu durchqueren, muss man zudem an allen von ihnen vorbeilaufen. MHK-Schindler-Fabrik, Sektion 8: Terror. Im Łódźer Museum Radogoszcz finden sich in einer zweiten Dauerausstellung, die allein der Geschichte des Gefängnisses während des Kriegs gewidmet ist, zahlreiche großformatige Fotografien, die das Gelände unmittelbar nach dem Massaker durch deutsche Truppen am 17. / 18. Januar 1945 zeigen. Prominent zu sehen sind insbesondere die Berge verbrannter Leichen der Opfer. Auch im Lubliner Museum »Unter der Uhr« bilden Großaufnahmen der Toten des Massakers auf dem Lubliner Schloss am 22. Juli 1944 bis in die Gegenwart den Abschluss der Schilderung der Jahre 1939 bis 1945. MLL-Unter der Uhr, Zelle 10. 
Ein weiteres Alleinstellungsmerkmal der Ausstellung ist die Präsentation bzw. Auseinandersetzung mit umstrittenen und schwierigen Themen des Holocaust. So wird etwa die jüdische Polizei im Ghetto (deren offizielle Bezeichnung »Ordnungsdienst« [OD] lautete), ihre Arbeitsweise und Wahrnehmung durch die Bewohner, umfangreich und vielfältig geschildert. ${ }^{44}$ Zur Sprache kommt die verbreitete Korruption unter ihren Mitgliedern ebenso wie die Zusammenarbeit von Teilen mit den Deutschen - unter dem unmissverständlichen Begriff »Kollaboration $"$ gefasst. ${ }^{45}$ Gleichzeitig benennt die Schau auch die negativen Auswirkungen ihrer Gründung auf die Ghettobevölkerung: »In letzter Zeit hat sich die Plage des Denunziantentums verbreitet. Leszno 13 [Adresse der jüdischen Polizei - d.Vf.] hat einfach die Dämme geöffnet, hat den schlechten Trieben freien Lauf gelassen. ${ }^{46}$ Schließlich schildert man umfassend ihre Mitwirkung an der großen Aussiedlungsaktion im Sommer 1942. ${ }^{47}$ Deutlich wird hier die Verachtung und der Hass, den die übrigen Ghettobewohner ihnen für ihre Taten entgegenbrachten. Dargestellt werden jedoch auch die Motive der Polizisten für ihre Mitwirkung.

Ein weiteres Thema, das im Laufe des Rundgangs wiederholt behandelt wird, sind die polnisch-jüdischen Beziehungen während der Besatzungen, darunter insbesondere der Antisemitismus. Angesprochen werden sowohl das zeitgenössische Stereotyp der Żydokomuna als auch positive Beurteilungen des deutschen Vorgehens gegen die jüdische Bevölkerung des Landes. Daneben weist man die Besucher jedoch auch darauf hin, dass die ausgrenzenden Bestimmungen der Besatzer die Entfremdung und Segregation der beiden Bevölkerungsgruppen beförderten und nicht zuletzt auch zum Ziel hatten. ${ }^{48}$ Die Folgen dieser Bemühungen und Vorurteile werden im weiteren Verlauf der Erzählung umfangreich ersichtlich: Nicht nur wird klar benannt und anhand vieler Zeitzeugenberichte umfassend geschildert, dass Hilfsleistungen von Polen für verfolgte Juden eine Ausnahme waren. Auch die unter der polnischen Bevölkerung dominierende Gleichgültigkeit gegenüber dem Schicksal ihrer jüdischen Landsleute ist Gegenstand der Darstellung. ${ }^{49}$ Dies

44 In der Präsentation, die der Polizei im Abschnitt zum Leben im Warschauer Ghetto gewidmet ist, wird auch der Wandel ihrer Wahrnehmung skizziert: von einer anfänglich positiven Rezeption durch die Ghettobewohner hin zu Angst und Feindseligkeit.

45 Siehe Bereichstext im Abschnitt zur Jüdischen Polizei (Sektion, die dem Leben im Warschauer Ghetto gewidmet ist).

46 Zitat von Emanuel Ringelblum vom 17. April 1941.

47 Mehrere Zeitzeugenberichte - auch der eines Mitglieds des Ordnungsdienstes selbst schildern das brutale Vorgehen der Deutschen und ihrer Hilfstruppen, darunter des OD.

48 Der sukzessiven Einführung immer neuer diskriminierender Bestimmungen der Besatzer ist ein eigener Themenraum gewidmet. In diesem wird ausführlich auf die Formen der »Separierung der Juden vom Rest der Gesellschaft« eingegangen.

49 In einem Bereichstext auf der sogenannten arischen Straße (Näheres zu diesem Raumarrangement im Folgenden) heißt es dazu: »Die Haltungen der Polen im Angesicht der 
widerlegt somit klar die in der polnischen historischen Erinnerung bis in die Gegenwart häufig vorgebrachte These von der verbreiteten Hilfsbereitschaft Juden gegenüber; dagegen wird die anteilige Bedeutung einzelner Verhaltensweisen und ihrer Folgen offenbar. Den verschiedenen Formen und Erfahrungen des Versteckens ebenso wie der Unterstützungsleistungen, die Juden erfuhren, ist ein eigener umfassender Abschnitt gewidmet. Die dort präsentierten Berichte geben einen Einblick in altruistische wie auch rein ökonomische Hintergründe von Hilfsleistungen; sie illustrieren Verrat und Grausamkeit seitens der Helfer ebenso wie die ständig präsente Gefahr, die von der mehrheitlich polnischen Umgebung für die sich Versteckenden und ihre Helfer ausging. ${ }^{50}$ Eine Bewertung verschiedener Verhaltensweisen durch die $\mathrm{Ku}-$ ratoren bleibt auch hier aus.

Schließlich illustriert man auch die Pogrome, die während des Kriegs von Einheimischen an Juden begangen wurden. Geschildert werden ausführlich die Vorkommnisse in Jedwabne und Lemberg (Lwów, Lviv) im Juni und Juli 1941, wobei jeweils die unmittelbare Täterschaft - im ersten Fall polnischer Einwohner, im zweiten der ukrainischen Stadtbevölkerung - klar benannt wird. Skizziert werden zudem die Hintergründe der Übergriffe: das Machtvakuum und Chaos nach Beginn des deutschen Angriffs auf die Sowjetunion, feindselige Einstellungen und Kollaborationsanschuldigungen der jüdischen Bevölkerung gegenüber sowie das Gewährenlassen vonseiten der Deutschen. Auch die unmittelbar daran anschließende Darstellung der Massaker von Ponary benennt klar, dass zu den Tätern neben Deutschen wesentlich litauische Hilfseinheiten zählten. Den Besuchern wird somit deutlich, dass auch Teile der lokalen Bevölkerungen der besetzten Gebiete gewaltsam gegen jüdische Mitbürger vorgingen und damit selbst zu Tätern wurden. Die nebeneinandergestellte Schilderung polnischer, ukrainischer und litauischer Gräueltaten vermeidet jedoch zugleich eine auf die polnische Bevölkerung zugespitzte Darstellung, die wie ein globaler, allein auf Polen konzentrierter

Tragödie der Juden waren unterschiedlich. Nur wenige entschieden sich dafür, ihr Leben zu riskieren und Juden zu retten. Viele, beschäftigt mit den Beschwerlichkeiten des Besatzungsalltags, interessierten sich nicht für ihr Schicksal. Es kam auch vor, dass Polen Juden an die Deutschen verrieten oder sie selbst ermordeten. Der Aufstand im Warschauer Ghetto rief verschiedene Reaktionen auf der arischen Seite hervor. Einige hatten Mitleid mit den Juden, bewunderten ihr Heldentum, die Mehrheit jedoch blieb demgegenüber gleichgültig. Andere äußerten antisemitische Kommentare.» Dieser Text in kleiner Schriftgröße ist als weiterführende Erläuterung unter dem bereits erwähnten großformatigen Zitat von Alicja Iwańska angebracht, das diesen Inhalt aus individueller Perspektive und sehr pointiert vermittelt: »Das Ghetto brennt ... ständige Explosionen, und die Leute gehen in Ruhe ... niemand wendet im Angesicht der Schüsse und Explosionen auch nur die Augen $\mathrm{ab}$ «.

50 Der organisierten Hilfe für versteckte Juden sowie den Formen des Versteckens sind zwei Räume im Anschluss an die "arische Straße» gewidmet. 
Antisemitismus-Vorwurf erscheinen könnte. Vielmehr wird das Verhältnis des Phänomens kenntlich gemacht, denn »die große Mehrheit der >Pogromer [...] innerhalb des alten Staatsgebiets [wurden] von Nichtpolen in Gang gesetzt.$^{51}$ Auffällig ist zudem, dass die Darstellung frei von emotionaler Parteinahme oder Anklagen seitens der Kuratoren ist. Die Ereignisse werden vielmehr von Augenzeugen geschildert. ${ }^{52}$ Die Verbrechen an Juden - vor allem ihre Ermordung - von anderen als deutschen Tätern sind bislang in der Schilderung des Zweiten Weltkriegs in Polen weitgehend tabusiert, wie bereits in den vorangegangenen Teilen dargelegt worden ist. Die Dauerausstellung des MHŻP unternimmt somit auch in diesem Themenbereich einen zentralen Schritt hin zu einer Veränderung etablierter Geschichtsbilder.

Abschließend noch ein paar Worte zum grundlegenden Gestaltungskonzept der Ausstellung und der hier betrachteten Galerie: Wie bereits erläutert, war es das Ziel der Ausstellungsverantwortlichen, die Besucher die allmähliche Entwicklung der historischen Ereignisse nachvollziehen zu lassen und dies aus der jeweils aktuellen Perspektive der Protagonisten der musealen Erzählung. Die Betrachter folgen ihren Erlebnissen primär anhand der zahlreichen zeitgenössischen Berichte und Zitate. Zugleich bleibt durch die Gestaltung der einzelnen Abschnitte der Schau jedoch immer ein gewisser Abstand zu den geschilderten Ereignissen gewahrt. Denn zu keinem Zeitpunkt erweckt das Arrangement den Eindruck, die Betrachter sollten sich selbst als unmittelbare Teilnehmer der präsentierten Geschehnisse sehen. Es gibt keine vermeintlichen (Re-)Konstruktionen historischer Begebenheiten, Situationen oder Örtlichkeiten in Inszenierungen, wie dies etwa die Präsentationen der Schindler-Fabrik und des Museums des Warschauer Aufstands unternehmen. Vielmehr werden die thematisierten Kontexte lediglich symbolisch arrangiert, ohne die Assoziation einer vermeintlich realistischen Darstellung zu erwecken..$^{53}$

So erfahren die Besucher beispielsweise vom Leben im Warschauer Ghetto in einer Folge kleiner, verwinkelter Raumeinheiten. Sie vermitteln sinnbildlich die räumliche Enge und Begrenztheit des Ghettogeländes. Aus diesen Räumen tritt man an eine Treppe, die man hinaufsteigen muss. An deren Wänden berichten Zitate, wie die Brücke über die Chłodna-Straße wahr-

51 Borodziej: Geschichte Polens, 197.

52 Den Ablauf der Ereignisse in Jedwabne beschreibt ein Bericht Szmul Wasersteins; ihre Erlebnisse in Lemberg schildert Rózia Bassechez-Wagnerowa.

53 Jana Scholze unterscheidet in diesem Sinne die Begriffe »Szenografie« und »Inszenierung " voneinander. Während in ihrer Definition erstere eine »)̈̈bersetzungく der intendierten Inhalte« umfasst, »[folgt] die szenische Gestaltung des Ausstellungskontextes [...] einem mehr oder weniger dezidierten Anspruch auf eine naturalistische Rekonstruktion oder Konstruktion des Darzustellenden.« Scholze: Medium Ausstellung, 226, 201. 
genommen wurde, die die zwei Hälften des Warschauer Ghettos miteinander verband. Oben angekommen, blicken die Besucher durch eine Glasscheibe auf eine Raumflucht, über deren Boden Schienen verlaufen; an eine Wand sind großformatige Fotografien von Straßenszenen projiziert. Zitate neben der Glasscheibe dokumentieren die Perspektive der Ghettobewohner, die auf der Brücke sehnsuchtsvoll auf die "arische Seite« der Stadt blickten, deren Leben ihnen normal und weitgehend friedlich erschien. Im weiteren Verlauf des Rundgangs treten die Museumsbesucher schließlich selbst auf diese "Straße« - und sehen hinauf zur Brücke, deren Abbildung lebensgroß auf einer Wand angebracht ist. Im oberen Teil der Wand befindet sich die Glassscheibe, durch die sie bereits zuvor geschaut haben. Hier erfahren sie nun aus einer polnischen Perspektive von den Repressionen der deutschen Besatzer gegen die polnische Bevölkerung, der Wahrnehmung des Ghettoaufstands, aber auch von der Existenz des Untergrundstaates und vom Warschauer Aufstand 1944. Vermittelt wird dies mittels Dokumenten, Zitaten und einer Multimediapräsentation, die allesamt von der »Brücke« aus nicht zu sehen waren. Zugleich wird auch hier ein Einblick in jüdische Perspektiven des »arischen Warschau " geboten - dieses Mal aus der Perspektive von Juden, die versuchten, aus dem Ghetto zu fliehen: Beim Betreten der »Straße« treffen die Besucher auf einen Bericht Basia Temkin-Bermanowas, die von ihrer Begegnung mit szmalcowniki bei ihrer Flucht berichtet.

Dieses Arrangement von Räumen, Gestaltungselementen und schließlich Quellen erlaubt es den Besuchern, vielfältige Perspektiven der historischen Ereignisse und ihrer Protagonisten nachzuvollziehen. Dennoch verlassen sie den musealen Rahmen der Erzählung niemals: Die Wände und Böden der Ausstellungsräume sind in schlichten Materialien verarbeitet. Die Treppe, der man sinnbildlich auf die Brücke über die Chłodna-Straße folgt, ist mit warmem Licht beleuchtet und mit Parkett versehen, die Wände links und rechts sind hellgrau gestrichen. Die Schienen auf der symbolischen Straße schließlich verlaufen nicht über Pflastersteine oder Asphalt, sondern auf einer einfarbigen, glatten Fläche. Die Oberflächen einer der letzten Sektionen dieser Galerie schließlich, die den Vernichtungslagern gewidmet ist - ihre Wände, der Boden sowie die Decke - bestehen aus rostglänzendem, scheinbar korrodiertem Metall. Die Schritte der Besucher auf den Bodenplatten erzeugen ein metallenes Echo. Hierdurch wird eine Assoziation mit dem industriell geplanten und durchgeführten Massenmord erzeugt. Das Arrangement lässt jedoch nicht den Gedanken aufkommen, man würde selbst diese Stätten betreten. Auch in seiner Geräusch- und Lichtkulisse ist der Rundgang weit entfernt von dem überwältigenden, alle Sinne kontinuierlich beanspruchenden Gestaltungsarrangement der multimedialen, mit umfangreichen Inszenierungen arbeitenden Ausstellungen, die während der ersten Jahre des Museumsbooms entstanden sind. Gerade in der Holocaust-Sektion sind es fast ausschließlich 
die Stimmen eingesprochener Selbstzeugnisse und Berichte, die zu hören sind und durch die die Protagonisten der historischen Erzählung auch immer wieder selbst zu Wort kommen.

Wie diese Ausführungen und Beispiele zeigen, haben die Ausstellungsverantwortlichen die gegenwärtig zur Verfügung stehenden gestalterischen, technischen und multimedialen Ausdrucksmittel äußerst reflektiert eingesetzt und sich in der Holocaust-Galerie für eine eher zurückhaltende Szenografie entschieden. Auch hierin hebt sich die Schau deutlich vom aktuellen Mainstream des polnischen historischen Ausstellungswesens ab, in dem umfangreiche und möglichst realistische Inszenierungen dominieren. Der reflektierte und ethische Umgang mit den historischen Quellenmaterialien, ebenso wie die in dieser Galerie realisierte Multiperspektivität, haben das Potenzial, für die zukünftige Entwicklung der - nicht nur polnischen - musealen Präsentationspraxis des Zweiten Weltkriegs und des Holocaust entscheidende Impulse zu liefern.

\section{Das Museum des Zweiten Weltkriegs}

Die ständige Präsentation des Museums des Zweiten Weltkriegs wurde im Frühjahr 2017, am 23. März eröffnet. ${ }^{54}$ Abgeschlossen war ihre Planungsphase zwar bereits 2014, das heißt die Inhalte - Exponate, Ausstellungstexte, multimediale Präsentationen - und deren Arrangement waren zu diesem Zeitpunkt detailliert ausgearbeitet. ${ }^{55}$ Die physische Realisierung verzögerte sich jedoch aufgrund von technischen Problemen beim Bau des Museumsgebäudes. 2016 schien die Eröffnung der Schau gänzlich gefährdet: Am 15. April des Jahres verkündete der Minister für Kultur und Nationales Erbe Piotr Gliński von der Regierungspartei PiS - ohne vorherige Konsultation der betroffenen Institutionen - die Absicht, das Museum des Zweiten Weltkriegs mit dem erst

54 Vom 28. bis zum 29. Januar 2017 war die zu diesem Zeitpunkt noch nicht ganz fertiggestellte Schau bereits für Besucher geöffnet worden. Dni otwarte Muzeum II Wojny Światowej [Tage der offenen Tür im Museum des Zweiten Weltkriegs], URL: www. muzeum1939.pl/pl/aktualnosci/act/news-info/type/month/y/2017/m/1\#article-cab7dfbb e73d9e12a8a63ea602951378 (am 20.5.2017). Bereits zuvor, am 23. Januar 2017, war die Ausstellung einem Fachpublikum präsentiert und von internationalen und nationalen Museumsexperten und Fachwissenschaftlern diskutiert worden. Siehe: Dyskusja po prezentacji wystawy głównej z udziałem muzealników [Diskussion im Anschluss an die Präsentation der Dauerausstellung unter Teilnahme von Museumsfachleuten], URL: www.muzeum1939.pl/pl/aktualnosci/act/news-info/type/month/y/2017/m/1\#article-1c7 9554cb2f8541728cca66701fb6ab6 (am 20.5.2017).

55 Interview mit Piotr M. Majewski, dem stellvertretenden Direktor des MIIWŚ, am 29. August 2014. 
kurz zuvor gegründeten »Museum der Westerplatte und des Kriegs 1939« (Muzeum Westerplatte i Wojny 1939) zu vereinen. ${ }^{56}$ Hintergrund war die anhaltende Kritik am Konzept des MIIWŚ seitens der PiS. Eine Zusammenlegung der beiden Museen hätte den Wechsel seiner Direktion und die Veränderung der Dauerausstellung ermöglicht. Der Parteivorsitzende Jarosław Kaczyński hatte die Umgestaltung der geplanten Schau bereits im Juni 2013 als Ziel einer zukünftigen PiS-Regierung formuliert; er wolle sie dergestalt ändern, dass sie »den polnischen Standpunkt « wiedergebe - ohne freilich zu spezifizieren, was genau dies beinhalten sollte. ${ }^{57}$ Gegen die Entscheidung des Ministers gingen der Direktor des Museums und der "Beauftragte für Bürgerrechte« (Rzecznik Praw Obywatelskich) gerichtlich vor. In der dadurch gewonnenen Zeit gelang es dem Team, die Präsentation fertigzustellen und zu eröffnen. Letztlich ermöglichte jedoch das Urteil des Obersten Verwaltungsgerichts vom 5. April 2017 die Umsetzung der Vereinigung beider Museen. ${ }^{58}$ Bereits am folgenden Tag setzte der Minister einen kommissarischen Direktor für das neu geschaffene "Museum des Zweiten Weltkriegs in Gdańsk" (Muzeum II Wojny Światowej w Gdańsku) ein, der Gründungsdirektor des MIIWŚ Paweł Machcewicz und seine beiden Stellvertreter wurden ihrer Positionen enthoben. ${ }^{59}$ Das Schicksal der Ausstellung ist seit diesem Zeitpunkt ungewiss. Zum Zeitpunkt der Fertigstellung dieser Publikation (Mai 2017) ist sie für Besucher in ihrer originalen Fassung zugänglich. In medialen Äußerungen hat der neue Direktor jedoch bereits angekündigt, in die Schau ein-

56 Obwieszczenie Ministra Kultury i Dziedzictwa Narodowego z dnia 15 kwietnia 2016 r. o zamiarze i przyczynach połączenia państwowych instytucji kultury Muzeum II Wojny Światowej w Gdańsku oraz Muzeum Westerplatte i Wojny 1939 [Bekanntmachung des Ministers für Kultur und Nationales Erbe vom 15. April 2016 über die Absicht und Gründe für den Zusammenschluss der staatlichen Kulturinstitutionen Museum des Zweiten Weltkriegs in Gdańsk und Museum der Westerplatte und des Kriegs 1939]. In: Dziennik Urzędowy Ministra Kultury i Dziedzictwa Narodowego vom 15.4.2016, Pos. 18.

57 Vgl. die Reaktion der Direktion des Museums hierauf: Oświadczenie dyrektora Muzeum w związku z wypowiedzią Jarosława Kaczyńskiego wygłoszoną podczas kongresu Prawa i Sprawiedliwości w dn. 29 czerwca 2013 r. [Erklärung des Museumsdirektors im Zusammenhang mit der Äußerung Jarosław Kaczyńskis auf dem Kongress der Partei Recht und Gerechtigkeit am 29. Juni 2013]. 30.6.2013, URL: www.muzeum1939.pl/pl/aktualnosci (am 14.5.2017).

58 Postanowienie Naczelnego Sądu Administracyjnego z dnia 5 kwietnia 2017 r. Sygn. akt II OZ 299/ 17 [Beschluss des Obersten Verwaltungsgericht vom 5. April 2017. Aktenzeichen II OZ 299/ 17], URL: www.muzeum1939.pl/object.php/act/sho/oid/cef0998b2ed5 afa916d431f58bf1898d (am 5.4.2017).

59 Dr Karol Nawrocki został nominowany na p.o. dyrektora nowo utworzonego Muzeum II Wojny Światowej w Gdańsku [Dr. Karol Nawrocki wurde zum kommissarischen Direktor des neu geschaffenen Museums des Zweiten Weltkriegs in Gdańsk ernannt], URL: www.muzeum1939.pl/pl/aktualnosci/act/news-info/type/month/y/2017/m/04\#article-1 cc1f2e043f3deada8218bd17977797d (am 6.4.2017). 
greifen und Veränderungen an den präsentierten Perspektiven vornehmen zu wollen. ${ }^{60}$

Die Ausstellung ist gegenwärtig die größte historische Schau des Landes; in diesem Ausblick ist es daher unmöglich, sie vollständig zu erfassen. Vor dem Hintergrund der vorangegangenen Analysen konzentrieren sich die folgenden Ausführungen daher auf herausragende Aspekte ihrer Erzählung ebenso wie der angewandten Vermittlungs- und Darstellungsstrategien. ${ }^{61}$

Zunächst ist festzuhalten, dass der bereits im ersten Museumskonzept aus dem Jahr 2008 präsentierte Anspruch, ein möglichst breites Bild des Kriegs in seinem territorialen Umfang zu präsentieren, ${ }^{62}$ realisiert worden ist. Die Narration geht weit über das besetzte Polen hinaus und umfasst den gesamten europäischen Raum. Es werden immer wieder auch Ausblicke auf Vorkommnisse außerhalb Europas gegeben, so auf den Krieg im Atlantik, die Ereignisse in Nordafrika und die Expansions- und Besatzungspolitik des japanischen Kaiserreichs. ${ }^{63}$ Geschehnisse außerhalb Polens gehen dabei nicht allein in wenigen Hinweisen oder Exkursen in die Erzählung ein, sondern sind konstitutiver Bestandteil der übergreifenden Narration und begegnen den Besuchern während des gesamten Rundgangs. Polnische Erfahrungen der Jahre 1939 bis 1945 bilden dabei zwar die grundlegenden und auch die zahlreichsten Fallbeispiele, sie werden jedoch in grenzüberschreitende Ereignisse und Erfahrungen dieses Zeitraums - mit einem deutlichen Schwerpunkt auf Europa - eingeordnet. Auch in ihrem zeitlichen Rahmen ist die Erzählung übergreifend: Sie reicht vom Ausbruch des Ersten Weltkriegs bis in die Gegenwart. ${ }^{64}$ Damit

60 Nowy dyrektor Muzeum II Wojny Światowej: zmienię wystawę. Były dyrektor: więcej pokory [Der neue Direktor des Museums des Zweiten Weltkriegs: ich werde die Ausstellung verändern. Der frühere Direktor: Mehr Demut]. 13.5.2017, URL: www.tvn24.pl/ pomorze,42/nowy-dyrektor-muzeum-ii-wojny-swiatowej-chce-zmienic-wystawe, 739462.html (am 14.5.2017). Einen Überblick über die Auseinandersetzung um das Museum und seine Dauerausstellung bietet Logemann, Daniel: Streit um das Museum des Zweiten Weltkriegs in Gdańsk. Wie soll man "polnische Geschichte« zeigen? In: Zeitgeschichte-online, April 2017, URL: www.zeitgeschichte-online.de/geschichtskultur/ streit-um-das-museum-des-zweiten-weltkriegs-gdansk (am 26.5.2017).

61 Die Analysen beziehen sich auf den Ausstellungsbesuch am 7. und 8. April 2017.

62 Machcewicz, Paweł/Majewski, Piotr M.: Muzeum II Wojny Światowej. Zarys koncepcji programowej [Das Museum des Zweiten Weltkriegs. Abriss des Programmkonzepts]. In: Przegląd polityczny 91-92 (2008), 46-51, hier 47.

63 Siehe u.a. Sektion 5: Eine neue Art von Krieg, darin v.a. Thementext »Eine neue Art von Krieg", Bereichstext "Deutsche und japanische Eroberungen", Bereichstext und Abschnitt $»$ Der Krieg auf dem Meer«. Die Nummerierung der einzelnen Ausstellungssektionen bezieht sich auf den Katalog der Schau: Wnuk, Rafał u. a.: Muzeum II Wojny Światowej. Katalog wystawy głównej [Das Museum des Zweiten Weltkriegs. Katalog der Dauerausstellung]. Gdańsk 2016, $2 \mathrm{f}$.

64 Vgl. die erste und die letzte Sektion der Schau: Sektion A: Auf dem Weg zum Europa von Versailles, Sektion 18: Vom Krieg zur Freiheit. Geschildert werden etwa die Kriegsverbrecherprozesse, deren jüngster gegen John Demjaniuk Eingang in die Schau gefunden 
werden zum einen die Ereignisse geschildert, die den Vorlauf des Zweiten Weltkriegs bildeten, darunter v. a. die Etablierung des Stalinismus in der Sowjetunion, des Faschismus in Italien, des Nationalsozialismus in Deutschland und des japanischen Imperialismus - gefasst unter dem übergreifenden Topos des "Totalitarismus.$^{65}$ Zum anderen geht es aber auch um die langjährigen Folgen des Kriegs, auf die im Weiteren noch eingegangen wird. Das Museum bietet damit nicht nur in Polen, sondern auch europaweit erstmals eine länder- und nationsübergreifende Erzählung des Zweiten Weltkriegs an. Darin verwoben ist eine umfassende Darstellung der polnischen Kriegs- und Besatzungserfahrungen. Parallel dazu inkorporiert die Schau jedoch Perspektiven weiterer, schwerpunktmäßig europäischer Länder und Nationen in eine gemeinsame Erzählung. Hierdurch hat diese das Potenzial, anschlussfähig und damit nicht zuletzt verständlich auch für ausländische Besucher und deren jeweilige nationale Kriegsnarrative und Erinnerungstopoi zu sein.

$\mathrm{Zu}$ den zentralen Ansätzen der Ausstellungserzählung gehört weiterhin die deutliche Abkehr von einem Fokus auf militärische Ereignisse und primär bewaffnete Widerstandsakte. Es sind nicht mehr wie noch in älteren Schauen weitgehend abstrakte Darstellungen von Armeebewegungen, Schlachten, militärischen und politischen Anführern sowie Anschlägen von Untergrundgruppierungen, die die Erzählung leiten. ${ }^{66}$ Vielmehr ist diese gerichtet auf eine zivile und Alltagsperspektive, wobei letztere auch die Erfahrungen einfacher Soldaten umfasst. Der Alltag des Kriegs und der Besatzungen in seinen vielfältigen Facetten, mithin die Erlebnisse und Perspektiven der breiten Masse der Gesellschaften, stehen in der gesamten Schau im Zentrum. So wird etwa der deutsche Angriff auf Polen im September 1939 schwerpunktmäßig anhand seiner Auswirkungen auf Zivilisten sowie gefangene Soldaten geschildert. Mit großformatigen Fotografien werden die Fliegerangriffe auf polnische Ortschaften sowie die Erschießungen von einfachen Bewohnern und Kriegsgefangenen dargestellt. ${ }^{67}$ Auch Repressionen gegen die ortsansässige Bevölkerung sind eindrücklich illustriert, so zeigt ein Bild etwa zwei ältere jüdische Männer, die von deutschen Soldaten dazu gezwungen werden, sich gegenseitig die Bärte abzuschneiden. ${ }^{68}$ Die Verteidigung Warschaus wird

hat. Siehe Sektion 16: Nach dem Krieg, Abschnitt»Der Triumph der Gerechtigkeit«. Die Videpräsentation, welche die Schau beschließt und die - ohne einordnende Kommentare eines Erzählers - versucht, die Besucher assoziativ zu erreichen, enthält u. a. Aufnahmen der europäischen Flüchtlingskrise der letzten Jahre. Sektion 18.

65 Vgl. Sektion 1: Die Geburt und Expansion der Totalitarismen.

66 Informationen über militärische Ereignisse sind in die Schau integriert, jedoch in einer untergeordneten Vermittlungsebene. So wird etwa der Großteil der militärischen Auseinandersetzungen in Multimediapräsentationen, auf kleineren Tastbildschirmen präsentiert. Vgl. exemplarisch Sektion 5: Eine neue Art von Krieg.

67 Sektion 3: Krieg also!, Abschnitte »Deutsche Verbrechen in Polen«, »Vernichtungskrieg«.

68 Ebd., Abschnitt »Deutsche Verbrechen in Polen«. 
mittels Fotografien geschildert, die mehrheitlich das Leiden der eingekesselten Bevölkerung, symbolisiert von Frauen und Kindern, zeigen. Stellvertretend für diese stehen die großformatigen Fotos eines kleinen Jungen, der inmitten von Häuserschutt sitzt, sowie eines verzweifelten Mädchens, das über der Leiche ihrer von deutschen Fliegern erschossenen Schwester kniet. ${ }^{69}$ Der Fokus auf übergreifende Erfahrungen der Gesellschaften verschiedener Staaten in den Jahren 1939 bis 1945 spiegelt sich auch in der Verortung der Sektion "Kriegs- und Besatzungsalltag" auf der zentralen Achse der Ausstellung, entlang zweier Raumfluchten, die die Besucher während ihres Rundgangs durch die Ausstellungssektionen immer wieder kreuzen, wodurch sie auch außerhalb der einzelnen Themenräume wiederholt mit dieser Perspektive konfrontiert werden. ${ }^{70}$ Die von den Ausstellungsautoren dem Thema beigemessene zentrale Bedeutung wird nicht zuletzt gleich zu Beginn unterstrichen, wenn von der "größten Front des Zweiten Weltkriegs " gesprochen wird. ${ }^{71}$

Selbst die Sektion, die ihrem Titel nach dem militärischen Vormarsch der deutschen Truppen in den Jahren 1940 bis 1942 gewidmet ist ${ }^{72}$ thematisiert schwerpunktmäßig Alltagserfahrungen dieser Jahre - diesmal derjenigen von Soldaten. So wird etwa auf ihre Verpflegung und Ausrüstung, den Umgang mit der Langeweile zwischen den Kampfhandlungen, Erfahrungen von Verwundung und Kriegsgefangenschaft eingegangen. An der Darstellung dieser Aspekte zeigt sich zugleich exemplarisch eine weitere narrative Strategie der Ausstellung: Die Behandlung der genannten Themen erfolgt armee- und länderübergreifend, und das sowohl anhand von Beispielen aus den besetzten und alliierten als auch der mit dem nationalsozialistischen Deutschland verbündeten Staaten. So werden die Uniformierung und Ausrüstung der Soldaten oder die ihnen zur Verfügung stehende Presse mit Objekten und Materialien der polnischen, britischen und amerikanischen, dazwischen aber auch der deutschen, japanischen und sowjetischen Streitkräfte präsentiert. Hörstationen geben Einblicke in Feldpostbriefe und damit individuelle Wahrnehmungen polnischer und deutscher Soldaten. In ähnlicher Weise umfasst die spätere Schilderung der zivilen Erfahrungen des Bombenkriegs

69 Bei der letztgenannten Fotografie handelt es sich um Kazimiera Mika, die über ihrer toten Schwester Anna kniet. Dieses Bild, aufgenommen vom amerikanischen Fotografen Julien Bryan, wurde durch die Publikation auf dem Cover des Life-Magazins zu einer der international bekanntesten Abbildungen der Belagerung Warschaus. Ebd., Abschnitt »Die belagerte Stadt«.

70 Sektion B: Kriegs- und Besatzungsalltag. Dargestellt werden hier u.a. die Rationierung von Lebensmitteln, der Schwarzmarkt, der Einfluss des Kriegs und der Besatzungen auf den öffentlichen Nahverkehr oder die Bekleidung und Mode.

71 Untertitel des Thementextes »Der Alltag während des Kriegs und der Besatzung«. Ebd.

72 Siehe Thementext »Eine neue Art von Krieg. Die deutschen Siege 1940-1942«. Sektion 5: Eine neue Art von Krieg. 
unter anderem britische, französische und deutsche Beispiele. ${ }^{73}$ Diese Darstellungsweise unterstreicht einerseits die Gemeinsamkeit von Erfahrungen der Kriegsjahre über Ländergrenzen hinweg. Aufgezeigt werden durch die Gegenüberstellung mehrerer Länderbeispiele jedoch andererseits ebenso die Unterschiede in den Besatzungserfahrungen einzelner Staaten und Nationalitäten. Deutlich wird so etwa die unterschiedliche Härte der Besatzungsregime in West- und Osteuropa ${ }^{74}$

Auch in der Darstellung des Widerstands gegen die Besatzer werden die geschilderten grundlegenden narrativen Ansätze deutlich. Auffällig ist vor allem, dass der zivile Widerstand gleichberechtigt neben dem organisierten und militärischen präsentiert wird. ${ }^{75}$ Unterschiedliche Formen widerständigen Verhaltens werden dadurch anerkannt, was wiederum ermöglicht, dass Besucher aus Ländern, die von anderen Kriegserfahrungen als der polnischen geprägt sind, sich in der Erzählung und ihre jeweiligen nationalen Topoi im europäischen Erfahrungsspektrum wiederfinden. Vor dem Hintergrund der beschriebenen Ausprägungen von Widerstand - konzentriert jedoch allein auf die Besatzungen in Europa - werden gleichermaßen Unterschiede kenntlich gemacht. Insbesondere das einzigartige Phänomen des Polnischen Untergrundstaates wird hervorgehoben, dessen Aktivitäten - unter anderem der Presse, dem Untergrundgerichtswesen und dem geheimen Schulunterricht der größte Abschnitt dieser Sektion gewidmet ist. ${ }^{76}$

Des Weiteren finden sich in der umfassenden Schau immer wieder einer breiten, nicht nur polnischen Öffentlichkeit bislang weniger bekannte Informationen, die für viele Besucher mit Sicherheit überraschende Perspektiven eröffnen. Hierzu zählt etwa die Darstellung von Leid aufseiten der Gesellschaften der Angreiferstaaten. Exemplarisch sei hier die umfangreiche Schilderung des Schicksals sowjetischer Kriegsgefangener in deutscher Haft genannt. ${ }^{77}$ Sie dominiert den Themenraum, der den Verbrechen an Kriegsgefangenen gewidmet ist. Ein raumfüllend ausgestrahlter Videofilm zeigt in drastischen Aufnahmen die elenden Lebensbedingungen und das Massensterben sowjetischer Inhaftierter in deutschen Kriegsgefangenenlagern.

73 Sektion 6: Krieg ohne Gnade, Abschnitt "Leben unter Bomben".

74 Vgl. etwa die Bereichstexte »Die Besatzung in Westeuropa«, »Sanfte Besatzung« und »Die Besatzung in Osteuropa und auf dem Balkan«. Sektion 7: Besatzung und Kollaboration.

75 Beiden Aspekten sind jeweils eigene Abschnitte gewidmet. Siehe Sektion 11: Widerstand, Abschnitte »Die zivile Widerstandsbewegung in Europa« und »Partisanenkrieg und Untergrundkampf« (Partyzantka i walka podziemna).

76 Sektion 11: Widerstand, Abschnitt »Polnischer Untergrundstaat «.

77 Sektion 6: Krieg ohne Gnade, Abschnitt „Verbrechen an Kriegsgefangenen«. Ein weiteres Thema, das in dieses Spektrum fällt, ist etwa die Schilderung des Leidens der deutschen Zivilbevölkerung bei der Evakuierung und Flucht aus den Ostgebieten. Sektion 15: Das Ende des Kriegs, Abschnitt »Der Fall des tausendjährigen Reiches«. 
Kontrastiert werden diese Szenen mit den Bestimmungen des 1929 in Genf verabschiedeten internationalen Abkommens über die Behandlung von Kriegsgefangenen, die großformatig an der nebenliegenden Wand zu lesen sind und im klaren Widerspruch stehen zu der im Film geschilderten Praxis. Im einleitenden Text wird auch auf die Relation der Opferzahlen in Bezug auf andere Inhaftierte eingegangen:

Millionen Soldaten aus allen kämpfenden Armeen gerieten in Gefangenschaft. Sie wurden dort unterschiedlich behandelt. [...] Das schlimmste Los traf die sowjetischen Gefangenen in deutscher Gefangenschaft. Von 5,7 Mio. starben aufgrund von Hunger, Krankheiten, Entkräftung, unmenschlicher Lebensbedingungen sowie geplanter Vernichtung 3,3 Mio. [... $]^{78}$

Sowjetische Kriegsgefangene in deutscher Haft werden hierdurch als zweitgrößte Opfergruppe des Kriegs markiert. In der öffentlichen Wahrnehmung des Kriegs in vielen Staaten, auch in Polen, ist dies eine bisher kaum rezipierte Information. Gleich im Anschluss wird die Hungerkatastrophe im belagerten Leningrad ausführlich geschildert. ${ }^{79}$ Eine solche Perspektive, in der sowjetische Zivilisten und Soldaten als Opfer von Gewalt thematisiert werden, wird gerade für polnische und ostmitteleuropäische Museumsbesucher neu sein, denen bis dato in musealen Narrativen die Sowjetunion ausschließlich als Aggressor und Besatzungsmacht begegnet. Hierbei ist jedoch anzumerken, dass dies angesichts des bisherigen Fokus der meisten historischen Dauerausstellungen in den Ländern der Region auf eine rein nationalstaatliche bzw. regionale Kriegserfahrung kaum überrascht.

Wie die geschilderten Beispiele illustrieren, differenziert die Schau somit die in polnischen musealen Kriegs- und Besatzungsdarstellungen bislang dominierenden abstrakten Feindbilder deutlich. Deutsche und "Sowjets« kommen nicht mehr in allein militärischer Funktion und weitgehend entmenschlicht vor. Ohne die Verantwortung für den Kriegsausbruch und Gräueltaten zu mindern, werden die Gesellschaften der Angreiferstaaten als Subjekte porträtiert, deren Leben und Alltag ebenfalls vom Krieg beeinflusst wurde. An verschiedenen Stellen wird zudem deutlich gemacht, dass sich die Regime auch gegen Teile der eigenen Bevölkerungen richteten. So finden der »Große Terror " und die Hungerkatastrophe in der Sowjetunion der 1930er-Jahre Erwähnung. ${ }^{80}$ In Bezug auf die Entwicklung in Deutschland seit der Macht-

78 Bereichstext »Verbrechen an Kriegsgefangenen«. Sektion 6: Krieg ohne Gnade, Abschnitt "Verbrechen an Kriegsgefangenen«. Auch die in dem Raum gezeigten Objekte schildern die Lebensbedingungen sowjetischer Kriegsgefangener.

79 Sektion 6: Krieg ohne Gnade, Abschnitt »872 Tage Belagerung«.

80 Sektion 1: Die Geburt und Expansion der Totalitarismen, Abschnitt "Die Sowjetunion« (Związek Radziecki). 
übernahme der Nationalsozialisten werden der Zwangscharakter der geschaffenen staatlichen Organisationen, die zunehmende Ausgrenzung und Verfolgung der jüdischen Bevölkerung in den 1930er-Jahren, die Inhaftierung von politischen Gegnern sowie das Vorgehen gegen Behinderte veranschaulicht. ${ }^{81}$ Zugleich verweisen gerade die zahlreichen, in verschiedenen Sektionen der Ausstellung untergebrachten Zeitzeugenberichte - sowohl solche von Deutschen als auch von Bewohnern der besetzten Staaten - auf die bewusste Teilnahme an und Unterstützung der Besatzungspolitik und der damit einhergehenden Verbrechen durch die breite Mehrheit der deutschen Soldaten, Polizisten und weiteren Angehörigen der Besatzungsmacht. ${ }^{82}$ Immer wieder gibt es zudem deutliche Hinweise darauf, dass die deutsche Zivilbevölkerung von den Verbrechen wusste oder davon profitierte, so etwa im Fall der Millionen Zwangsarbeiter im Deutschen Reich. ${ }^{83}$ Auch hierdurch wird die bislang überwiegend abstrakte Darstellung »der Deutschen" erweitert, denn kenntlich wird, dass es sich nicht um Verbrechen einer anonymen Macht oder kleinen Führungsriege handelte, sondern um Unrecht, das eine breite, auch zivile Unterstützer- und Mitwisserbasis hatte. Ein prominentes, da großformatig platziertes Beispiel hierfür ist eine Fotografie im ersten Abschnitt der Holocaust-Sektion, die die Exekution von Juden im ukrainischen Ivangorod zeigt. $^{84}$ Die begleitende Objektbeschriftung erläutert, dass das Bild mit seiner unmittelbaren Darstellung von Tätern und Opfern von einem Deutschen an seine Familie geschickt wurde - diese damit also wusste, worin die »Aufgabe « des Absenders an der Ostfront bestand.

Eine weitere neue Perspektive dürfte für die meisten Besucher - vor allem für diejenigen aus westlichen Staaten, allerdings durchaus auch für solche aus Ostmitteleuropa und nicht zuletzt Polen - die Kontextualisierung des Jahres 1945 darstellen. Das »Ende des Kriegs«, wie es in neutraler Form heißt, steht dabei zunächst für das »Ende der Kampfhandlungen ${ }^{85}{ }^{85}$ Zugleich wird eine der Folgen dieses Ereignisses und damit dessen Ambivalenz kenntlich gemacht: »Polen und das ganze Ostmitteleuropa gingen von der deutschen Besatzung gegen ihren Willen in den Machtbereich der Sowjetunion über. ${ }^{86}$ Ein paar Schritte weiter erfolgt eine weitere Einordnung dieser Ereignisse: „Vollkommener Sieg, nicht eindeutige Befreiung. Für Ostmitteleuropa war das Kriegs-

81 Ebd., Abschnitt »Der Nationalsozialismus in Deutschland «.

82 Beispiele hierfür sind die zahlreichen schriftlichen Zeitzeugenberichte in der HolocaustSektion (Sektion 9), ebenso wie Hörstationen, an denen Gespräche deutscher Soldaten untereinander (Ebd., »Dialog zweier Wehrmacht-Soldaten«) oder aber Ausschnitte aus Briefen an ihre Familien angehört werden können (Sektion 5: Eine neue Art von Krieg).

83 Sektion 8: Terror, Abschnitt "Zwangsarbeit«.

84 Sektion 9: Holocaust.

85 Titel und Untertitel des Thementextes der Sektion 15: Das Ende des Kriegs.

86 Thementext »Das Ende des Kriegs«. Ebd. 
ende der Beginn einer neuen Unterdrückung ${ }^{87}{ }^{87}$ Der Begriff "Befreiung $"$ (wyzwolenie) findet damit zwar für das Ende der deutschen Besatzung Anwendung, jedoch mit einer Einschränkung. Denn die folgende Entstehung der sozialistischen Staaten im östlichen Europa schildert man als »Unterdrückung « und »Abhängigkeit von der Sowjetunion ${ }^{88}{ }^{88}$ womit die fehlenden Einflussmöglichkeiten der Gesellschaften auf die Wahl des politischen Systems kenntlich gemacht werden. Zugleich wird jedoch ein klarer qualitativer Unterschied zwischen dem deutschen (und auch dem früheren sowjetischen) Besatzungsregime der Jahre 1939 bis 1945 (bzw. 1939 bis 1941) und den folgenden Entwicklungen markiert. Denn der Begriff »Besatzung wird allein für die Ereignisse bis 1945, jedoch nicht für die folgende Sowjetisierung der Region verwendet. Mit diesen Einordnungen setzt man den Begriff »Befreiung « für die Schilderung des Kriegsendes ein - was in anderen jüngeren polnischen Ausstellungen vermieden wird - und weist gleichzeitig auf dessen Ambivalenz im ostmitteleuropäischen Kontext hin. Dagegen bleibt der Terminus »Freiheit« (wolność) den Ereignissen des Jahres 1989 und damit dem Zusammenbruch der sozialistischen Regime in Ostmitteleuropa vorbehalten, die hierdurch als endgültige Überwindung der (negativen) Kriegsfolgen markiert werden. ${ }^{89}$

Dieses Thema illustriert zugleich, dass es den Ausstellungsmachern ein wesentliches Anliegen war, die spezifischen Kriegs- und Besatzungserfahrungen Polens und in breiterer Perspektive Ostmitteleuropas in ein als dominant wahrgenommenes westliches Narrativ der Jahre 1939 bis 1945 einzuschreiben. ${ }^{90}$ Sichtbar wird dies auch in der Hervorhebung weiterer Themen innerhalb der Ausstellungserzählung. So wird insbesondere die Allianz zwischen dem nationalsozialistischen Deutschland und der UdSSR immer wieder betont. Dementsprechend nimmt die Darstellung des Hitler-Stalin-Pakts eine exponierte Stellung als zentrale Etappe auf dem Weg in den Krieg ein. Thematisiert wird er in einem schmalen Gang, auf dessen Längsseiten sich Hakenkreuzflaggen mit Fahnen der UdSSR wandhoch gegenüberstehen; eine monumentale und zugleich erdrückende Szenografie. Die Bedeutung der

87 Bereichstext "Vollkommener Sieg, nicht eindeutige Befreiung«. Ebd.

88 Ebd. Siehe auch Thementext »Auf beiden Seiten des Eisernen Vorhangs«. Sektion 17: Auf beiden Seiten des Eisernen Vorhangs.

89 Thementext „Vom Krieg zur Freiheit«. Sektion 18: Vom Krieg zur Freiheit. Im selben Thementext wird der Beginn des »Falls des Kommunismus« mit der Entstehung der Gewerkschaft Solidarność (Solidarität) in Gdańsk verbunden, der acht Jahre später die »unblutige Befreiung von der kommunistischen Herrschaft» folgte, welche den Weg frei machte für den Fall der Berliner Mauer. Ebd.

90 Machcewicz, Paweł: Muzeum zamiast zasieków [Museum statt Stacheldrahtverhaue]. In: Gazeta Wyborcza vom 8.11.2007, Online-Ausgabe, URL: www.wyborcza.pl (am 6.4.2011). Ders.: Po co nam Muzeum II Wojny Światowej? [Wofür brauchen wir das Museum des Zweiten Weltkriegs?]. In: Wnuk: Muzeum II Wojny Światowej, 7-13, hier 8. 
Übereinkunft wird dementsprechend explizit benannt: »Die Verschwörung Hitlers und Stalins/Die Teilung Mittel- und Osteuropas «. ${ }^{91}$ Bei der Schilderung des Kriegsanfangs liegt ein inhaltlicher Schwerpunkt auf dem sowjetischen Einmarsch auf polnisches Territorium am 17. September 1939 und der folgenden »Teilung Polens« zwischen Deutschland und der UdSSR. ${ }^{22}$ Die Sowjetunion wird damit explizit als Aggressor und Besatzungsmacht gekennzeichnet. Die folgende Darstellung der Besatzungsregime beider Staaten, der die größte Sektion der Schau unter dem Titel »Terror« gewidmet ist, unterstreicht zudem immer wieder die Parallelität der von ihnen ausgeübten Repressionen. ${ }^{93}$ Besonders eindrücklich vermittelt diese zentrale Perspektive ${ }^{94}$ eine Inszenierung: Einleitend zur Schilderung der Massenmorde von Katyń und zugleich anschließend an die Darstellung der Verfolgung polnischer Eliten durch die deutschen Besatzer wird das doppelte Verfolgungsschicksal zweier polnischer Familien gezeigt. Anhand eines Objekts aus dem Besitz jeder Familie erfährt man von der Ermordung Angehöriger sowohl in Katyń als auch im Generalgouvernement. ${ }^{95}$

Wichtig war den Ausstellungsmachern darüber hinaus ein weiterer Punkt, der bislang in westlichen Kriegsdarstellungen wenig beachtet und in der Schau entsprechend intensiv dargestellt wird: das unmittelbar mit dem Septemberfeldzug einsetzende brutale deutsche Vorgehen gegen die polnische und jüdische Zivilbevölkerung sowie Armeeangehörige. Wie bereits geschildert, zeigen zahlreiche großformatige Fotografien mit teilweise drastischem Inhalt die Brutalität der deutschen Truppen im September 1939. Damit soll die in der westlichen Historiografie lange existierende Vorstellung widerlegt werden, der "Vernichtungskrieg" (wojna na wyniszczenie) - so auch die explizite Benennung in der Schau für die Ereignisse von 1939 - habe erst mit dem deutschen Angriff auf die Sowjetunion knapp zwei Jahre später begonnen. ${ }^{96}$

91 Titel und Untertitel des Thementextes. Sektion 2: Frieden um jeden Preis?

92 Sektion 3: Krieg also!, Abschnitte »Aggression aus dem Osten« und »Die Teilung Polens«.

93 So folgt auf die Schilderung des deutschen Vorgehens gegen polnische Eliten im Jahr 1939 und im Rahmen der sogenannten AB-Aktion (Außerordentliche Befriedungsaktion) 1940 die Darstellung der Massenexekutionen polnischer Kriegsgefangener durch den NKVD im Jahr 1940 in Katyń und weiteren Orten. Sektion 8: Terror, Abschnitte »Der deutsche Besatzungsterror« und »Das Verbrechen von Katyń«.

94 Die Ähnlichkeit des Vorgehens der zwei Besatzungsmächte und ihrer Verbündeten wird auch in der folgenden Darstellung der Umsiedlungen und Deportationen in beiden Besatzungsgebieten unterstrichen. Sektion 8: Terror, Abschnitt »Umsiedlungen, Deportationen, Vertreibungen«.

95 Sektion 8: Terror, Abschnitt »Das Verbrechen von Katyń«.

96 Sektion 3: Krieg also!, Abschnitt „Vernichtungskrieg«. Vgl. Logemann, Daniel: Die entstehende Dauerausstellung des Museums des Zweiten Weltkrieges in Danzig. In: Inter Finitimos 10 (2012), 126-133, hier $127 \mathrm{f}$.; Machcewicz: Po co nam Muzeum, 8; Böhler, Jochen: Auftakt zum Vernichtungskrieg. Die Wehrmacht in Polen 1939. Bonn 2006. 
Die Ausstellung in ihrer Gesamtheit vermittelt die grundlegende Aussage, wonach der Zweite Weltkrieg eine Katastrophe für alle davon erfassten Staaten und Nationen darstellte. Diese Botschaft wird gleich beim Betreten der Schau formuliert: Der erste zentrale Text, auf den die Besucher treffen, bezeichnet die Jahre zwischen 1939 und 1945 als "größte Katastrophe in der Geschichte der Menschheit«. ${ }^{97}$ Wie bereits dargestellt, konzentriert sich die weitere Schilderung der Kämpfe und Besatzungen in erster Linie auf deren negative Auswirkungen für die Zivilbevölkerung, aber auch einfache Soldaten. Konsequent werden daher die Kriegsereignisse unter dem übergreifenden Thema »Der Schrecken des Kriegs « zusammengefasst. ${ }^{98}$ Exemplarisch für die damit verbundene Erzählweise ist die spezifische Kontextualisierung des größten Aufstands der Besatzungszeit, des Warschauer Aufstands von 1944. ${ }^{99}$ Diese erfolgt wesentlich mittels zweier Videopräsentationen. ${ }^{100}$ Die erste, auf einem vergleichsweise kleinen Bildschirm untergebrachte, enthält eine Chronologie der Ereignisse. Bemerkenswert ist, dass die Schilderung eingebettet ist in eine ganze Reihe von Aufständen gegen die deutschen Besatzer, die bei Kriegsende in verschiedenen europäischen Ländern ausbrachen: den Aufstand in Paris im August 1944, den Slowakischen Nationalaufstand 1944 sowie den Prager Aufstand Anfang Mai 1945. Diese werden alle in ähnlicher Weise dargestellt, jeweils mit Fotografien und knappen Informationen über die Entwicklung der Ereignisse. Eröffnet wird die Reihe von der Erhebung im Warschauer Ghetto 1943, der damit in die Reihe der großen

97 Titel des Thementextes. Sektion A: Auf dem Weg zum Europa von Versailles.

98 Die Ausstellungserzählung ist in drei übergreifende Kapitel gegliedert: I. Der Weg zum Krieg, II. Der Schrecken des Kriegs und III. Der lange Schatten des Kriegs. Vgl. Wnuk: Muzeum II Wojny Światowej, 3.

99 Sektion 11: Widerstand, Abschnitt "Der Warschauer Aufstand».

100 Beim Betreten dieses - von der Ausstellungsfläche her eher kleinen - Abschnitts treffen die Besucher zunächst auf eine wandhohe Vitrine mit zahlreichen Objekten. Diese sind lediglich mit Nummern versehen. Näheres über sie erfährt man erst in einer Multimediapräsentation, die durch einen Tastbildschirm vor der Vitrine zugänglich ist. Enthalten sind darin umfangreiche Materialien, darunter zahlreiche schriftliche Erfahrungsberichte von Zeitzeugen, zu verschiedenen Aspekten der 63 Tage der Kämpfe, wie dem Schicksal der Zivilisten während und nach dem Ende des Aufstands oder der medizinischen Versorgung der Aufständischen. Die Präsentation ist deutlich umfassender als die übrigen in der Schau zu findenden Medienbildschirme dieser Art. Erreicht werden durch sie jedoch höchstwahrscheinlich nur wenige Besucher. Während des Besuchs der Verfasserin in der Schau gingen die meisten Besucher an der Vitrine und dem dazugehörigen Multimediabildschirm recht schnell vorbei, wenn letzterer nicht frei war. Aufgrund des Umfangs der darin enthaltenen Materialien verbrachten Besucher, die an den Bildschirm herantraten, eine längere Zeit davor. Der Großteil der Besucher hielt daher erst bei der zweiten der gezeigten Videopräsentationen an, die im Folgenden noch geschildert wird. 
europäischen und polnischen Aufstände eingeordnet wird. Als größtem bewaffneten Widerstandsakt gegen die deutsche Besatzung nimmt der Warschauer Aufstand ein Jahr später zwar den größten Teil der Präsentation ein; die Gegenüberstellung mit anderen Erhebungen bietet den Besuchern jedoch eine weitere Ebene der Einordnung der Kämpfe. So endet die Darstellung jeweils mit einer Aufzählung der Opferzahlen sowie der Nennung der »Folge» bzw. des Ergebnisses - so der Befreiung der Stadt bzw. dem Sieg der Aufständischen in Paris und Prag, bei den übrigen dagegen der »Niederlage« und ihrer Auswirkungen. Genannt werden hier die »endgültige Vernichtung des Ghettos und der jüdischen Gemeinschaft Warschaus«, die »blutige Pazifizierung der Slowakei« und die »Zerstörung der Millionenstadt «. ${ }^{101}$ Eine weitergehende Bewertung oder Deutung der verlustreichen Kämpfe findet hier nicht statt.

Diese faktografische - allerdings auch sehr zeitintensive und daher kaum von Besuchern vollständig wahrgenommene $-{ }^{102}$ Schilderung wird ergänzt durch einen im folgenden Raum gezeigten Film. In diesem werden Fotografien der einzelnen Aufstände mit eingesprochenen Zitaten von Teilnehmern der Ereignisse zusammengestellt. Die Aussagen sind sehr emotional und vermitteln damit eindrücklich die individuellen Wahrnehmungen und Gefühle der Aufstandsteilnehmer und weiterer Zeitzeugen. So wird berichtet von der Unruhe in Warschau nach Ausbruch des Ghettoaufstandes, aber auch von der unwirklichen Situation, dass »nur ein paar Straßenbahnhaltestellen« vom Töten im Ghetto entfernt Menschen »trinken, essen, Musik spielt, ein Mann singt«; zitiert wird die Wahrnehmung Icchak Cukiermans vom einsamen Kampf des jüdischen Untergrunds, abgeschnitten vom übrigen allgemeinen Widerstand des Landes; später berichtet Marek Edelmann vom Gefühl der Befriedigung angesichts der Angst der Deutschen vor den Kämpfenden im Ghetto. ${ }^{103}$ Die Motive der jüdischen Widerstandskämpfer werden hierdurch kenntlich gemacht, ebenso wie die Reaktionen der polnischen Bevölkerung außerhalb der Mauer - ihre überwiegende Gleichgültigkeit dem Schicksal der letzten im Ghetto verbliebenen Menschen gegenüber. Die Schil-

101 Die Zitate stammen aus der Präsentation im ersten Saal des Abschnitts. Sektion 11: Widerstand, Abschnitt "Der Warschauer Aufstand .

102 Die ausschließlich visuelle Präsentation, die aus einem Zusammenschnitt von Textabschnitten und Fotografien besteht, dauert insgesamt etwas über 24 Minuten; ein Umfang, der selbst für einen Ausstellungsrundgang von geplanten drei Stunden (diesen Umfang veranschlagt das Museum), enorm ist. Beim Besuch der Verfasserin konnte keine Person beobachtet werden, die sich annähernd diese Zeit zum Betrachten der Präsentation nahm. Regulamin zwiedzania [Besuchsregeln], URL: www.muzeum1939.pl/ pl/zaplanuj_wizyte/regulamin_zwiedzania (am 6.5.2017).

103 Die Zitate wurden dem Film entnommen. Sektion 11: Widerstand, Abschnitt »Der Warschauer Aufstand». 
derung der Ereignisse ein Jahr später wiederum beginnt mit der Euphorie der ersten Tage nach dem Ausbruch der Kämpfe in Warschau, dem folgenden Elend der Zivilisten und den Massenexekutionen durch die Deutschen. Das Zitat einer Kämpferin berichtet schließlich von der Wut der Menschen auf die Aufständischen, die sie für ihr Unglück verantwortlich machten - ein bis dato in der musealen Darstellung des Warschauer Aufstands kaum erwähnter Umstand.

Der Filmabschnitt zum Warschauer Aufstand endet mit dem Zitat „Wir wollten frei sein und diese Freiheit uns allein verdanken«. Dasselbe Zitat findet sich auch im Museum des Warschauer Aufstands; dort fungiert es als übergreifendes Motto der Schau, als Element positiver Sinnstiftung und zugleich vorwegnehmende Begründung der Unausweichlichkeit der Erhebung. ${ }^{104}$ Hier jedoch wird seine Lesart ins Gegenteil gekehrt. Als Schlusspunkt einer affektiven Schilderung vor allem des Leidens und Sterbens der Warschauer Bevölkerung im Aufstand, geäußert vor dem Hintergrund einer Schuttwüste, wirkt die Äußerung wie ein Rechtfertigungsversuch, der angesichts des geschilderten Elends hohl, im besten Falle ambivalent klingen muss. Der Film, der die Fläche der gesamten Längsseite des Raumes einnimmt, und sein emotionaler Inhalt erreichen deutlich mehr Besucher als die vorangegangene kleinformatige Videopräsentation der Chronologie der Ereignisse. ${ }^{105}$ Die verwendeten Zitate spiegeln zwar auch die Motive und Ziele der Widerstandskämpfer. Es ist jedoch nicht der Mut und die Opferbereitschaft von Helden und Märtyrern, die hier im Fokus stehen, sondern die Wahrnehmungen und vor allem das Leiden von Zivilisten. Eine positive Sinngebung der hohen Opferzahlen gerade des Warschauer Aufstandes findet hier nicht statt, womit die Schau eine alternative Sichtweise der bislang dominierenden musealen Erzählung der Ereignisse von 1944 offeriert. Das Museum des Warschauer Aufstandes etablierte seit seiner Eröffnung die inzwischen verbreitete Deutung der brutal niedergeschlagenen Erhebung als moralischer Sieg der Aufständischen. Dementgegen erscheint der Kampf von 1944 in dieser Schau ähnlich vergeblich wie der von 1943; beide werden unmissverständlich als Niederlage porträtiert.

Wie das Beispiel dieses Themenabschnitts verdeutlicht, positioniert sich das MIIWŚ mit seiner auf die Gräuel und die Leiden der Jahre 1939 bis 1945 konzentrierten Erzählung als Antikriegsmuseum. Krieg und Besatzung werden in ihren dramatischen Auswirkungen auf alle involvierten Gesellschaften

104 Vgl. Teil 3, Kapitel 2.3.

105 Dies hat neben seinem Inhalt auch mit der Gestaltung des Raumes zu tun. Die Videopräsentation wird großformatig ausgestrahlt, sie ist damit von allen Punkten des Raumes gut zu sehen. Zudem gibt es Sitzgelegenheiten, die zusätzlich zum Verweilen und Ausruhen einladen. 
als grundsätzlich negativ dargestellt. Prägnant wird diese Botschaft in dem explizit an Kinder adressierten Ausstellungsteil heruntergebrochen:

Der Krieg ist kein Abenteuer. Er lässt Kinder leiden, die durch ihn oft ihre Eltern und nahe Verwandte verlieren und manchmal selbst zu Opfern werden. Er nimmt ihnen immer die unbeschwerte Kindheit. Der Zweite Weltkrieg war in dieser Hinsicht besonders grausam, denn zum Hauptziel wurden in ihm nicht Soldaten, sondern wehrlose Zivilisten. [...] Wir wünschen Euch, dass ihr wirklich niemals den Schrecken des Kriegs kennenlernt. ${ }^{106}$

Eine interpretative Einordnung des Zeitraums seitens der Ausstellungsautoren findet sich im ersten übergreifenden Thementext, auf den die Besucher direkt beim Betreten der Ausstellung treffen. Hier wird eine universelle Deutung des Zweiten Weltkriegs vermittelt, die seine Bedeutung für die Gegenwart und damit die Aktualität der Auseinandersetzung mit den damaligen Ereignissen begründen soll:

[...] In Zeiten der Verachtung für Menschenleben erfordete Anstand oftmals Heldentum, für Widerstand zahlte man den höchsten Preis. Der Alltag wurde zum Kampf ums Überleben und zum Raum dramatischer Entscheidungen. [...] Diese Erfahrung bleibt bis heute aktuell, sie betrifft die wichtigsten Entscheidungen, vor denen die Menschheit und jeder einzelne von uns auch heute steht. So wie damals, bleiben auch heute Freiheit, Würde, Leben, in deren Verteidigung Millionen Menschen in den Jahren 1939-1945 Opfer brachten, universelle Werte. ${ }^{107}$

An keinem Punkt des Ausstellungsrundgangs werden jedoch die dargestellten Personen und Ereignisse in den Kontext von Helden- oder Märtyrertum gestellt, der eine nachträgliche teleologische Sinnstiftung der Jahre 1939 bis 1945 evozieren könnte.

Mit Blick auf die präsentierten polnischen Kriegs- und Besatzungserfahrungen sind einige grundlegende inhaltliche Kontextualisierungen erwähnenswert. So stellen die Ausstellungsautoren Polen ins »Zentrum der Ereignisse $«,{ }^{108}$ und dies nicht nur als Region, anhand derer die Geschichte der Jahre 1939 bis 1945 wesentlich geschildert wird. Deutlich wird das Anliegen, Polen als das Land im europäischen und internationalen Kriegsgedächtnis zu verankern, in dem einerseits der Krieg am 1. September 1939 begann. Betont wird andererseits, dass hier - konkret vor Ort, in Gdańsk - die Überwindung einer seiner wesentlichen Folgen, nämlich die Teilung Europas ent-

106 Thementext »Zeitreise«. Sektion C: Zeitreise - Eine Ausstellung für Kinder.

107 Thementext »Die größte Katastrophe in der Geschichte der Menschheit«. Sektion A: Auf dem Weg zum Europa von Versailles.

108 So lautet auch die Darstellung im ersten übergreifenden Thementext der Ausstellung. Thementext »Die größte Katastrophe in der Geschichte der Menschheit«. Sektion A: Auf dem Weg zum Europa von Versailles. 
lang des Eisernen Vorhangs, mit der Gründung der Gewerkschaft Solidarność (Solidarität) 1980 und dem Sieg ihrer Mitglieder in den ersten halbfreien Wahlen des Landes am 4. Juni 1989 initiiert wurde. ${ }^{109}$

Weiterhin bemerkenswert ist die Definition der polnischen Wir-Gemeinschaft, wie sie die Ausstellung zeichnet. Diese wird staatsbürgerlich-inklusiv gefasst; die jüdische Bevölkerung wie auch weitere ethnische Minderheiten der Zweiten Republik werden als Teil der polnischen staatlichen Gemeinschaft thematisiert. ${ }^{110}$ Aus dieser Perspektive ist die Verfolgung der jüdischen Bewohner des Landes Teil der eigenen, hier polnischen Geschichte der Jahre 1939 bis 1945, was sich auch in der Darstellung spiegelt. So sind die Erfahrungen der jüdischen Bevölkerung des besetzten Polens und die gegen sie gerichteten repressiven Maßnahmen kontinuierliche Bestandteile der Ausstellungserzählung. Die Verortung des Holocaust in einem eigenen Themenabschnitt markiert zugleich die Spezifik und damit auch den Unterschied zwischen der Verfolgung von Juden und Nichtjuden durch die Nationalsozialisten. ${ }^{111}$

Zugleich fällt auf, dass die polnische Wir-Gemeinschaft während des Kriegs nicht als vermeintlich uniform in ihren Einstellungen und Verhaltensweisen erscheint. Immer wieder gibt es Verweise auf Verhalten, das aus ethischer Perspektive negativ bewertet werden kann. Hierzu zählen etwa »Verrat«, Tratsch und die verbreiteten Denunziationen, die als eine der größten Gefahren für den polnischen Untergrund geschildert werden. ${ }^{12}$ Auch die Tätigkeit der sogenannten blauen Polizei wird beim Thema Kollaboration erwähnt; ${ }^{113}$ ein Gegenstand, der in früheren wie den meisten gegenwärtigen historischen Ausstellungen des Landes noch gemieden wird. Das von den polnischen Einwohnern der Kleinstadt Jedwabne verübte Massaker an ihren jüdischen Nachbarn - das in der Öffentlichkeit mittlerweile bekannteste von polnischen Tätern verübte Pogrom - wird in einer Reihe von Pogromen geschildert, die auf

109 Vgl. Thementext »Vom Krieg zur Freiheit«. Sektion 18: Vom Krieg zur Freiheit. Auch im Vorwort des Ausstellungskatalogs begründet der Gründungsdirektor die Wahl der Stadt als Standort des Museums mit diesem Kontext. Machcewicz: Po co nam Muzeum, $10 \mathrm{f}$.

110 Vermittelt wird dies etwa mit Bezug auf die Zwischenkriegszeit im Arrangement des inszenierten Schaufensters eines Buchladens, in dem polnische, deutsche, ukrainische, belarussische und hebräische Fibeln ausliegen. Zugleich stellen einzelne Kuratorentexte auch die Nationalitätenkonflikte innerhalb des Staates dar. Sektion 1: Die Geburt und Expansion der Totalitarismen, Abschnitt »Das wiedergeborene Polen«.

111 Sektion 8 der Ausstellung ist dem deutschen und sowjetischen »Terror « (so ihr Titel) in den besetzten Territorien gewidmet; die folgende Sektion 9 behandelt den Holocaust.

112 »Denunziation von Władysław Bartoszewski (Kopie)« sowie Thema »Denunziantentum im besetzten Polen« in der Multimediapräsentation »Verschiedene Gesichter der Kollaboration«. Sektion 7: Besatzung und Kollaboration; Bereichstext »Konspiration«. Sektion 11: Widerstand.

113 Ihr ist ein eigener thematischer Abschnitt in der Multimediapräsentation »Verschiedene Gesichter der Kollaboration« gewidmet. Sektion 7: Besatzung und Kollaboration. 
den 1941 von den Deutschen besetzten Territorien stattfanden. Auch wenn sich also bisherige Tabuthemen der polnischen Besatzungserinnerung in dieser Schau finden, ist dennoch eine gewisse Zurückhaltung beim Kenntlichmachen der anteiligen Bedeutung einzelner Verhaltensweisen spürbar. So heißt es zu den Beziehungen zwischen Polen und Juden während des Holocaust:

Die Aktion `Reinhardt fand vor den Augen der Polen statt. Die Deutschen verboten unter Androhung der Todesstrafe Hilfsleistungen für Juden. Viele Polen waren ihrem Schicksal gegenüber gleichgültig, einige versuchten sogar Profit aus der schwierigen Situation ihrer Mitbürger zu ziehen - sie erpressten sie, verrieten sie an die Deutschen, stahlen ihr Eigentum und töteten sogar Flüchtlinge aus den Ghettos und den Transporten in die Lager. Andere halfen Juden, indem sie sie mit Lebensmitteln und Dokumenten versorgten oder sie versteckten. Über 6,6 Tsd. von ihnen wurden dafür nach dem Krieg durch Israel mit der Medaille Gerechter unter den Völkern geehrt. ${ }^{114}$

Diese ausführliche Darstellung der Haltungen von Polen der Verfolgung ihrer jüdischen Mitbürger gegenüber ist vor dem Hintergrund der gegenwärtigen Präsentationspraxis in polnischen historischen Museen bemerkenswert. Dennoch geht aus diesen Schilderungen kaum hervor, dass im besetzten Polen - und nicht nur dort - die überwiegende Mehrzahl der Bevölkerung zu den Gleichgültigen zählte. Vielmehr suggeriert die Wortwahl (»viele«, »andere«), Gleichgültigkeit, Mitgefühl und Hilfe seitens der »Zeugen« seien weitgehend gleich verbreitete Handlungsweisen gewesen, während allein Fälle von Denunziationen und Täterschaft als selten (»einige«) markiert werden. Dieser Eindruck verstärkt sich noch dadurch, dass unter den präsentierten polnischen Beispielen in der Holocaust-Sektion aktive Hilfsleistungen und »Mitgefühl « ${ }^{115}$ dominieren. Mehrere Zeugnisse dokumentieren etwa die Hilfsaktivitäten von Tadeusz Pankiewicz und seinen Mitarbeiterinnen in ihrer Apotheke im Krakauer Ghetto oder von Bauern, die erfolgreich jüdische Nachbarn bis zum Kriegsende versteckten. ${ }^{116}$ Auch die vergeblichen Versuche Jan Karskis, die westlichen Alliierten über das deutsche Vorgehen gegen Juden $\mathrm{zu}$ unterrichten, werden illustriert. ${ }^{117}$ Neben diesen zahlreichen Beispielen für Hilfsleistungen taucht als Sinnbild negativer polnischer Ver-

114 Bereichstext »Polen und Juden«. Sektion 9: Holocaust.

115 Als Beispiel eines mitfühlenden Beobachters - mit dem expliziten Titel »Mitgefühl« versehen - wird der polnische Arzt Zygmunt Klukowski vorgestellt, dessen Tagebucheinträge einen Einblick in den Alltag der Besatzung geben, darunter auch in die Verfolgung der Juden seiner Heimatstadt. Bereichstext »Mitgefühl«, ebd.

116 Geschildert wird auch das Schicksal von Rozalia Reinisch aus Lviv, die Dank der Hilfe einer polnischen Familie überlebte. Ebd.

117 Ebd. Zudem wird bei der Schilderung des Polnischen Untergrundstaates die Tätigkeit des Hilfsrates für Juden illustriert; zentrales Beispiel ist hier sein Mitglied Irena Sendler, die 2.500 Kinder aus dem Warschauer Ghetto rettete. Sektion 11: Widerstand, Abschnitt »Polnischer Untergrundstaat«. 
haltensweisen außer dem Pogrom in Jedwabne, das die aktive Täterschaft illustriert, noch ein Eintrag »Aus dem Tagebuch eines anonymen Polen« auf, der als exemplarischer Fall verbreiteter antisemitischer (aber passiver) Haltungen präsentiert wird. ${ }^{118}$ Durch diese Auswahl von Fallbeispielen sind es die Ausnahmen der aktiven Helfer und mitfühlenden Nachbarn, die die museale Schilderung polnischer Haltungen während des Holocaust prägen. $\mathrm{Zu}$ dem werden überwiegend Aktivitäten illustriert, die wirkungsvoll oder sogar erfolgreich waren, womit sie wiederum Ausnahmen innerhalb der Einzelfälle aktiver Hilfe darstellen. Die Darstellung sowohl ambivalenter und negativer als auch gleichgültiger Haltungen bleibt demgegenüber im Hintergrund.

Schließlich soll noch auf die übergreifenden Darstellungs- und Vermittlungsweisen eingegangen werden, die in dieser Ausstellung hervorstechen. Zunächst ist anzumerken, dass die Schau stark auf eine exponatbasierte Vermittlung setzt. Angesichts der vergleichsweise jungen Geschichte des Hauses ist es bemerkenswert, dass es den Mitarbeitern gelungen ist, in kurzer Zeit eine vergleichsweise große Sammlung an originalen Objekten aufzubauen. In ihrem Einsatz in der Schau werden die Artefakte überwiegend mit allgemeineren Informationen versehen, die deutlich über ihre Benennung und eine bloße Quellenangabe (Archiv, Museum, Leihgeber oder Schenkungen) hinausgehen. Die Objekte leiten damit die Erzählung wesentlich, denn das Konkrete wird zur Exemplifizierung größerer Zusammenhänge eingesetzt, wodurch die Informationsvermittlung eine weitere Tiefe erhält. ${ }^{119}$ Dabei wird zum Teil auch auf verschiedene Ebenen der Lesarten bzw. Deutung einzelner Materialien eingegangen. Beispielsweise kommt bei der Schilderung der Zwangsarbeit in Deutschland eine Zeichnung aus dem Amstettner Anzeiger von 1943 zum Einsatz, die den »richtigen« Umgang mit Zwangsarbeitern illustrieren sollte. Die Objektbeschriftung erläutert:

[...] Die Zeitung warnte deutsche Familien davor, Mahlzeiten gemeinsam mit polnischen Zwangsarbeitern an einem Tisch einzunehmen, was davon zeugt, dass es zu solchen Situationen gelegentlich kam. ${ }^{120}$

Den Besuchern wird damit kenntlich gemacht, dass die (hier visuelle) Darstellung oder das Aussprechen von Verboten nicht zwingend mit deren Einhalten gleichzusetzen ist.

118 Der Eintrag stammt vom 27. Oktober 1942. Sektion 9: Holocaust, Zitat: Objektbeschriftung.

119 So wird etwa am Beispiel eines Handbuchs für die Kaninchenzucht erläutert, dass während des Kriegs in ganz Europa Kleinzuchten von Tieren populär wurden, die Quelle für ansonsten schwer erhältliches und teures Fleisch waren. Sektion B: Kriegs- und Besatzungsalltag, Abschnitt »Der Krieg aus Küchenperspektive«.

120 Sektion 8: Terror, Abschnitt »Zwangsarbeit«. 
Wie bereits dargelegt, konzentriert sich die Vermittlung auf eine Perspektive "von unten «; die Erfahrungen und Wahrnehmungen sogenannter gewöhnlicher Menschen dominieren die Erzählung und ermöglichen das emotionale Einfühlen der Besucher in die geschilderten Ereignisse. Damit verbunden ist der Einsatz zahlreicher Selbstzeugnisse in der gesamten Schau. Dazu zählen schriftlich überlieferte Dokumente und Aussagen unmittelbar aus den Kriegsjahren, wie etwa das Tagebuch und die Briefe der polnischen Zwangsarbeiterin Halina Fedorowicz, ${ }^{121}$ ebenso wie nach dem Krieg entstandene oder veröffentlichte Erinnerungen. ${ }^{122}$ Besonders zahlreich finden sich während des Rundgangs Videomitschnitte von Zeitzeugeninterviews. Der Großteil von ihnen wurde erst in den vergangenen Jahren für das $\mathrm{Mu}$ seum aufgezeichnet. ${ }^{123}$ Zeitgenössische Perspektiven und Wahrnehmungen mischen sich somit mit Erzählungen, die aus dem Abstand, der Reflexion und der sich verändernden Rückschau mehrerer Jahrzehnte entstanden sind, ohne dass jedoch diese Spezifik bzw. der unterschiedliche Hintergrund für die Besucher kenntlich gemacht und eingeordnet wird. Die Videomitschnitte werden kommentarlos als Quellen, gleichberechtigt neben Materialien aus den Jahren 1939 bis 1945 präsentiert. Dieses Darstellungs- bzw. Perspektivproblem findet sich in vielen aktuellen Ausstellungen, so etwa in der Krakauer Schindler-Fabrik oder im Museum des Warschauer Aufstands.

$\mathrm{Zu}$ den gängigen Charakteristika musealer Schauen der jüngeren Zeit, auch in Polen, gehört ferner die Integration kommemorativer oder reflexiver Installationen in den Rundgang. ${ }^{124}$ Die Dauerausstellung des MIIWŚ weist zwei Elemente dieser Art auf. Auf die erste treffen die Besucher bei der Schilderung des Besatzungsterrors. Den Massakern an polnischen Offizieren in Katyń und weiteren Orten ist ein Raum gewidmet, den zahlreiche schmale Vitrinen dominieren, die unter anderem Knöpfe, Orden oder Rangabzeichen von Uniformen enthalten. ${ }^{125}$ Objektbeschriftungen zu den einzelnen Vitrinen gibt es, im Unterschied zur Handhabung im Rest der Schau, nicht. Allein eine Tafel fasst zusammen, dass es sich um »Objekte [handelt], die polnischen Staatsangehörigen gehörten, die vom NKVD in Katyń und Bykovnja erschos-

121 Diese finden sich großformatig platziert in der Sektion 8: Terror, Abschnitt »Zwangsarbeit«.

122 Darunter Zitate aus dem Tagebuch von Zygmunt Klukowski in der Sektion 9: Holocaust.

123 So auch ein Interview mit dem polnischen Filmemacher Andrzej Wajda. Interview mit Piotr M. Majewski am 29. August 2014.

124 Heinemann, Monika: Muzeum historyczne jako fabryka pamięci - polski boom muzealny z perspektywy nowej muzeologii [Das historische Museum als Erinnerungsfabrik - Der polnische Museumsboom aus der Perspektive der Neuen Museologie]. In: Řezník, Miloš u. a. (Hg.): Historia w kulturze ponowoczesnej. Koncepcje - metody - perspektywy badawcze [Geschichte in der Spätmoderne. Konzepte - Methoden - Forschungsperspektiven]. Kraków 2017 (i.E.).

125 Sektion 8: Terror, Abschnitt »Das Verbrechen von Katyń«. 
sen worden sind $« .{ }^{126}$ Die Vitrinen werden alle einzeln von oben beleuchtet, wodurch sie besonders hervorgehoben erscheinen; eine Inszenierung, die an die Präsentation von wertvollen Gegenständen wie Kunstschätzen erinnert. An einer Seitenwand sind großformatig Zeilen aus Zbigniew Herberts Gedicht »Guziki« (Knöpfe) angebracht. In diesem werden die Knöpfe »der Mäntel und Uniformen« als Grabmale der Toten von Katyń bezeichnet, die als einzige "Zeugen des Verbrechens « überdauert haben. ${ }^{127}$ Dieses Arrangement nimmt nicht primär eine informative Funktion ein, sondern spricht in erster Linie die Emotionen der Besucher an. Ebenso ist es bei dem im angrenzenden Raum ausgestrahlten Film über »die Erinnerung an Katyń « ${ }^{128}$ : Kinder ermordeter polnischer Offiziere, darunter der international bekannte Regisseur Andrzej Wajda, erzählen von der Bedeutung, die die Erinnerung an ihre Väter im Leben ihrer Familie spielte. In diesem Ausstellungsabschnitt geht es somit nicht schwerpunktmäßig um die Erzählung der Ereignisgeschichte; hierzu gibt es lediglich im einleitenden Text eine kurze Skizze. Vielmehr wird für die Ermordeten und ihre Familien innerhalb des musealen Rahmens ein Ort des Gedenkens geschaffen. Durch diesen erfährt der Topos »Katyń« und damit der Mord an Vertretern der polnischen Elite durch den NKVD eine besondere Hervorhebung im Ausstellungsrundgang, die wiederum die Rolle der Sowjetunion als Aggressor und verbrecherischer Macht während des Kriegs unterstreicht.

Ein weiterer Ort, der nicht Informationen vermittelt, sondern zur individuellen Reflexion anregen soll, findet sich in der Holocaust-Sektion. Ihren Abschluss bildet ein Raum, in dem eine Installation aus raumhohen Glaswänden mit Porträtfotografien mehrerer hundert Personen untergebracht ist. Die Aufnahmen stammen alle aus der Vorkriegszeit und zeigen »Menschen wie wir« (Ludzie tacy jak my), wie der Titel der erläuternden Texttafel lautet. Dort heißt es weiter:

Während des Zweiten Weltkriegs wurden fast 6 Mio. Juden ermordet. Hinter dieser schwer vorstellbaren Zahl verbergen sich individuelle Personen mit ihren eigenen Gesichtern, Gefühlen, Schicksalen, die brutal und unerwartet unterbrochen wurden. Die hier untergebrachten Fotografien stammen aus unterschiedlichen Quellen. Sie zeigen Holocaustopfer aus vielen Ländern, normale Menschen wie wir selbst. ${ }^{129}$

Mit dieser Einordnung wie in der folgenden Installation wird der Versuch unternommen, die Distanz zwischen den Besuchern und den zuvor geschil-

126 Inschrift der Tafel. Ebd.

127 Zitate aus den in der Schau gezeigten Zeilen des Gedichts. An einer Wand des Raums werden zudem Briefe, Fotografien und einzelne Besitztümer von Personen gezeigt, die in Katyń und anderen Orten 1940 erschossen worden sind.

128 Titel des Films.

129 Bereichstext »Menschen wie wir». Sektion 9: Holocaust. 
derten historischen Ereignissen und ihren Protagonisten aufseiten der Opfer zu verringern. Auch hier werden die als Juden Verfolgten zudem nicht als »Fremde« kontextualisiert, sondern als Teil der in der Ausstellung geschilderten Wir-Gemeinschaft der Verfolgten, in die sich die Besucher einfühlen sollen.

Abschließend muss noch auf einen wesentlichen Kritikpunkt der Ausstellung eingegangen werden: Grundsätzlich problematisch erscheint der Einsatz von Bildquellen, die Gräueltaten und das Leiden von Menschen explizit zeigen. Wie bereits mehrfach erwähnt, finden sich im Verlauf des gesamten Rundgangs zahlreiche Fotografien und Filmaufnahmen, die in drastischer, da unmittelbarer Weise Erniedrigungen, das Leiden und Sterben von Menschen darstellen. Oftmals werden sie großformatig reproduziert bzw. ausgestrahlt. ${ }^{130}$ Probleme wirft ihr Einsatz gleich in mehrfacher Hinsicht auf. Zunächst werden die auf den Bildquellen verewigten Personen durch die wiederholte öffentliche Zurschaustellung ihrer Qualen zu Objekten des Kriegsund Besatzungsterrors reduziert; ihre Leiden werden gewissermaßen wiederholt bzw. erneuert, ohne dass sie in ihrer Würde und Individualität als Subjekte berücksichtigt werden. ${ }^{131}$ Die ethisch konnotierte Frage nach der zweifachen Viktimisierung der dargestellten Opfer durch den Einsatz dieser Bilder scheint in der Ausstellungsvorbereitung unbeachtet geblieben zu sein. Die überwiegende Anzahl der gezeigten grausamen Fotografien und Filmaufnahmen wurde zudem von Tätern aufgenommen, deren Blickwinkel der $\mathrm{Mu}$ seumsbesucher damit ungewollt und oft unwissend einnimmt. ${ }^{132}$ Denn überwiegend bleibt die Thematisierung des Entstehungskontexts der Materialien aus, womit auch die Motive ihrer Autoren sowie deren spezifische Perspektive

130 Um nur zwei Beispiele zu nennen: Beim Betreten des Themenraums, in dem der Winterkrieg 1940 geschildert wird, treffen die Besucher auf eine Fotografie der Leiche eines erfrorenen sowjetischen Soldaten; diese nimmt die gesamte Breite und Höhe der hinteren Wand des Raumes ein, direkt gegenüber dem Eingang. Sektion 4: Winterkrieg. Der Film, in dem das Schicksal sowjetischer Soldaten in deutscher Kriegsgefangenschaft geschildert wird, enthält Szenen, die u. a. Berge nackter Leichen zeigen. Seine Projektion nimmt die gesamte Fläche einer Wand des Themenraums ein. Sektion 6: Krieg ohne Gnade, Anschnitt »Verbrechen an Kriegsgefangenen«.

131 Williams: Memorial Museums, 57, 73.

132 Im Hinblick auf Fotografien der in Ghettos eingesperrten Menschen erläutert die spezifischen Perspektiven der existierenden Aufnahmen Loose: „Das Gesicht des Gettos«. Am Beispiel der Fotografien aus dem Stroop-Bericht schildert diesen Zusammenhang Hamann, Christoph: Der Junge aus dem Warschauer Ghetto. Der Stroop-Bericht und die globalisierte Ikonografie des Holocaust. In: Paul, Gerhard (Hg.): Das Jahrhundert der Bilder. Bd. 1: 1900 bis 1949. Bonn 2009, 614-623, hier 617. Zum Einsatz und der Wirkung von Täter-Fotografien in KZ-Gedenkstätten siehe Weigel, Phillip: Schrecken erzieht nicht: Zum Einsatz von Fotografien in den Ausstellungen polnischer ShoahGedenkstätten. In: Ganzenmüller, Jörg/Utz, Raphael (Hg.): Orte der Shoah in Polen. Gedenkstätten zwischen Mahnmal und Museum. Köln u. a. 2016, 49-65, hier 53-55. 
für den Betrachter nicht kenntlich werden. Eine Ausnahme stellt die Holocaust-Sektion dar. In dieser werden die Entstehungszusammenhänge einzelner Fotografien wie die dadurch vermittelten Perspektiven der - Raul Hilberg entlehnten - Trias der Täter, Opfer sowie Zeugen umfangreich thematisiert. Die Kontextualisierung etwa der farbigen Aufnahmen Walter Geneweins aus dem Ghetto Litzmannstadt mit ihrem spezifischen Blickwinkel erfolgt für die Besucher in einer begleitenden Bildbeschreibung in folgender Weise:

Der Deutsche [sic] Walter Genewein, Leiter der Finanzabteilung des Łódźer Ghettos, machte von dessen Bewohnern farbige Fotografien. Sie spiegeln die enorme Distanz zwischen Genewein und den Juden wieder - dem Täter und den Opfern. Die Fotografierten hatten Angst vor Genewein, sie beobachteten seine Bewegungen, vermieden nahen Kontakt.

Kontrastiert werden die Bilder mit Aufnahmen von Mendel Grossman, zu denen erläutert wird:

Mendel Grossman (1913-1945) war ein offizieller jüdischer Fotograf im Ghetto, er machte jedoch auch viele Fotos, die er versteckte. Die Juden, die im Ghetto arbeiteten, vertrauten Grossman, daher sind seine Fotografien, vor allem die Nahaufnahmen, ein warmes und mit Traurigkeit erfülltes Zeugnis der tragischen Situation der Ghettobewohner. ${ }^{133}$

Ähnlich umfassende Erläuterungen, die immer wieder neben dem Entstehungskontext auch die Überlieferung der Aufnahmen thematisieren, finden sich bei den meisten Fotografien dieser Sektion. In den übrigen Teilen der Ausstellung werden solche Einordnungen, die den spezifischen Blickwinkel von Bildern offenlegen, nur an wenigen Stellen unternommen. ${ }^{134}$

Auch ist fraglich, wie weit die mögliche Wirkung der "Bilder des Grauens" auf die Besucher von den Ausstellungsautoren reflektiert worden ist. So gibt es an keinem Punkt des Rundgangs Warnungen ob der drastischen Darstellungen, auf die man gleich trifft. Somit haben die Besucher auch keine Möglichkeit selbst zu entscheiden, ob sie die emotional aufwühlenden Bilder betrachten oder darauf verzichten möchten. Dass die unerwartete Begegnung mit drastischen Darstellungen von Elend und Tod bei vielen Besuchern eher

133 Beide Zitate stammen aus der Objektbeschriftung der jeweiligen Abbildungen. Die ausgestellten Aufnahmen Grossmans zeigen verschiedene Werkstätten im Ghetto.

134 Dies geschieht vor allem im Zusammenhang mit der Vorstellung einzelner Fotografen bzw. Autoren gezeigter Fotografien. So werden bei der Schilderung der Zwangsarbeit im Deutschen Reich Fotografien des Tschechen Zdeněk Tmej gezeigt; bei der Schilderung des Partisanenwiderstands erfährt man etwas über die Person und Bilder des Fotografen und AK-Mitglieds Edward Buczek sowie des sowjetischen Kriegsberichterstatters Michail Trachman. Sektion 8: Terror, Abschnitt »Zwangsarbeit«; Sektion 11: Widerstand, Abschnitt »Partisanenkrieg und Untergrundkampf«. 
Abwehr denn die Bereitschaft zur Einfühlung in das Schicksal der Dargestellten zur Folge haben kann, ${ }^{135}$ der exzessive Einsatz solcher Bilder somit die Auseinandersetzung mit den geschilderten Ereignissen eher behindert denn fördert, scheint dabei vernachlässigt worden zu sein. ${ }^{136}$ Dies ist umso kritischer zu betrachten, als der Ausstellungsbesuch bereits für Kinder ab zwölf Jahren empfohlen wird. ${ }^{137}$ Insgesamt entsteht der Eindruck, dass die dramatischen Bilder als vermeintlich dokumentarische Belege bzw. Beweise der dargestellten Verbrechen eingesetzt und als notwendig erachtet wurden. ${ }^{138}$ Dass es jedoch durchaus möglich ist, auf solch problematische Quellen zu verzichten und dennoch die Dramatik und Grausamkeit der historischen Geschehnisse eindrücklich zu vermitteln, zeigt das Beispiel der Holocaust-Galerie im Museum der Geschichte der Polnischen Juden.

Zusammenfassend lässt sich festhalten, dass die Dauerausstellung des MIIWŚ, wie sie im April 2017 zu besichtigen war, ein europäisches Panorama der Kriegs- und Besatzungsjahre 1939 bis 1945 zeichnet, in dessen Zentrum die Ereignisse auf dem besetzten polnischen Territorium stehen. Zugleich findet hier der passive turn seinen Niederschlag, der in westlichen Kriegsnarrativen bereits seit längerem konstatiert worden ist: Der bewaffnete Kampf und Widerstand treten entschieden in den Hintergrund der Erzählung während in erster Linie das Leiden und Leben von sogenannten gewöhnlichen Menschen Aufmerksamkeit erfahren. Mit ihrem dezidierten Fokus auf den Erfahrungen der Zivilbevölkerung sowie auf der Alltagsgeschichte des Kriegs, damit auf den Wahrnehmungen und dem Erleben einer Mehrheit der polnischen wie weiterer europäischer Gesellschaften, bietet die Schau somit

135 Hamann: Der Junge aus dem Warschauer Ghetto, 619. Liss: Trespassing, 4-6.

136 Mögliche negative Auswirkungen von drastischen Gewaltbildern auf Besucher wurden laut dem Gründungsdirektor bei der Auswahl von Fotomaterial für die Ausstellung in Betracht gezogen. Um zu verhindern, dass die Besucher gleichgültig auf die zahlreichen Abbildungen reagieren, habe man sich bewusst dafür entschieden, überwiegend solche Fotografien zu verwenden, auf denen die Opfer identifiziert werden, man einige Informationen über ihr Leben auffinden und für Besucher bereitstellen konnte. Vgl. Machcewicz, Paweł: Representing Violence and Death in the Museum of the Second World War in Gdańsk. In: Przegląd historyczny 57 / 1 (2016), 53-62, hier 54-57. Bei dieser Argumentation wird nicht nur nicht auf das Problem der wiederholten Viktimisierung der auf den Abbildungen zu sehenden Opfer eingegangen, sondern auch vernachlässigt, dass eine große Anzahl drastischer Bilder dennoch zentraler Bestandteil der Ausstellungserzählung ist und buchstäblich abschreckende Wirkung auf die Besucher entfalten kann.

137 Regulamin zwiedzania [Besuchsregeln], URL: www.muzeum1939.pl/pl/zaplanuj_wizyte/ regulamin_zwiedzania (am 6.5.2017).

138 Weigel: Schrecken erzieht nicht, $51 \mathrm{f}$. Siehe auch Maischein, Hannah: „Sekundäre Augenzeugen" der Shoah? Zur fotografischen Kommunikation in Erinnerungsdiskursen. In: Heinemann, Monika u.a. (Hg.): Medien zwischen Fiction-Making und Realitätsanspruch - Konstruktionen historischer Erinnerungen. München 2011, 3-23, hier 3. 
einen innerhalb des polnischen historischen Museumswesens neuen narrativen Zugang zu den Jahren 1939 bis 1944 / 45 an. Eine zentrale Bedeutung wird die Präsentation damit in erster Linie für ihr polnisches Publikum haben, das bislang überwiegend mit musealen Narrationen des Zweiten Weltkriegs konfrontiert ist, die in strikten nationalen Kontexten verhaftet bleiben, in denen der Krieg als Auseinandersetzung zweier Aggressoren mit Polen erscheint, die in heroisch-martyrologische Sinngebungen eingebettet ist. Durch die Einbindung und das wiederholte In-Beziehung-Setzen der Erfahrungen und Ereignisse in verschiedenen Regionen Europas ist wiederum für Besucher aus westlichen Staaten zu erwarten, dass die Schau nachvollziehbar und anschlussfähig an ihnen bekannte, eigene nationale Narrationen sein wird.

\section{Fazit}

Wie deutlich geworden ist, erweitern die Dauerausstellungen beider Museen tradierte polnische Geschichtsperspektiven des Zweiten Weltkriegs auf je eigene Weise. Im MHŻP wird die jüdische Bevölkerung des Landes als integraler Bestandteil der polnischen Geschichte präsentiert und damit eine bislang als "fremd" wahrgenommene Minderheit in einer übergreifenden Erzählung der polnischen Vergangenheit verortet. Nicht nur bedeutet dies die Abkehr von einem ethnisch-national definierten polnischen Selbstbild. Das Museum mit seiner core exhibition ist auch das erste des Landes, das eine Gesamtnarration polnischer Geschichte von ihren Anfängen bis in die Gegenwart, unter Berücksichtigung aller historischen polnischen Gebiete präsentiert. Es ist damit das erste Museum der Geschichte Polens ${ }^{139}$, was auch die Eindrücke der Besucher bestätigen. So formulierte der Journalist Roman Pawłowski prägnant:

139 Bereits 2006 wurde von der nationalkonservativen Regierung unter Führung der PiS das »Museum der Geschichte Polens« (Muzeum Historii Polski) gegründet. Nach dem Regierungswechsel 2007 war die Realisierung dieser Institution, d.h. der Neubau eines Museumsgebäudes und die Fertigstellung einer Dauerausstellung, jedoch lange Jahre ungewiss. Am 21. Juli 2015 wurde schließlich ein langjähriger Finanzierungsplan für die Fertigstellung des Museums seitens der Regierung der »Bürgerplattform» (Platforma Obywatelska, PO) beschlossen. Dieser plant die Eröffnung der Dauerausstellung im November 2019. Siehe: Uchwała Nr 118 / 2015 Rady Ministrów z dnia 21 lipca 2015 r. w sprawie ustanowienia programu wieloletniego »Budowa Muzeum Historii Polski w Warszawie« [Beschluss Nr. 118/2015 des Ministerrats zur Aufstellung des mehrjährigen Plans »Bau des Museums der Geschichte Polens in Warschau«], URL: http://bip.mkidn.gov.pl/ pages/legislacja/programy-wieloletnie/uchwala-nr-118.2015-rady-ministrow-z-dnia-21lipca-2015-r.-w-sprawie-ustanowienia-programu-wieloletniego-budowa-muzeum-his torii-polski-w-warszawie.php (am 25.5.2017). 
Diese Ausstellung ist ein Spiegel, in dem wir uns selbst betrachten. Die Erzählung über die Geschichte der polnischen Juden ist gleichzeitig das erste Museum der Geschichte Polens. Dies ist der beste Beweis für ihre These - das integrale Zusammenleben über Tausend Jahre hinweg. ${ }^{140}$

Das Museum in Gdańsk ermöglicht ebenfalls einen Blick über den eigenen, nationalen Tellerrand hinaus, hier in Bezug auf eine territoriale, grenzüberschreitende Perspektive. Seine Dauerausstellung ist die erste Präsentation des Landes, in der der Weltkrieg in seinem buchstäblich globalen Ausmaß geschildert wird. Sie hat damit das Potenzial, die bisherige nationale Fokussierung in Verhältnis zu setzen zu anderen Kriegs- und Leidensnarrationen, sowie die übergreifenden Gemeinsamkeiten vieler Kriegs- und Besatzungserfahrungen, gerade im Bereich der Alltagserfahrungen, einem polnischen Publikum vor Augen zu führen. Ihrem ausländischen, vor allem westlichen Publikum bietet die Schau wiederum erstmals eine Narration an, in der zentrale Topoi der ostmitteleuropäischen Besatzungserfahrungen in vertraute Kriegserzählungen anschlussfähig integriert und letztere damit wesentlich erweitert werden.

Beide Museen fordern somit ihre Besucher heraus, in dem sie sie mit bislang vielfach unbekannten Kontexten, Perspektiven und vielfältigen historischen Wahrnehmungen konfrontieren. Damit schaffen sie die Möglichkeit für eine grundlegendere Öffnung und Neubewertung bisheriger Geschichtsbilder, die das Potenzial bietet, gerade das polnische historische Selbstbild in seiner Bezugnahme auf innere und äußere »Andere« oder »Fremde« zu verändern.

140 Pawłowski, Roman: Otwiera się interaktywne Muzeum Historii Żydów Polskich. Czyli pierwsze muzeum historii Polski [Das interaktive Museum der Geschichte der Polnischen Juden wird eröffnet. Also das erste Museum der Geschichte Polens]. In: Gazeta Wyborcza vom 27.10.2014, Online-Ausgabe, URL: www.wyborcza.pl/1,75475,16869612, Otwiera_sie_interaktywne_Muzeum_Historii_Zydow_Polskich_.html (am 25.3.2015). 



\section{Schlussbetrachtungen}

(Geschichts-)Museen sind in Polen das erinnerungskulturelle Medium der Stunde. In keinem anderen Land des östlichen Europa ist eine derartige Fülle an musealen Neugründungen und Neukonzeptionen historischer Schauen zu beobachten. Dieser Boom hält seit nun fast anderthalb Jahrzehnten an und ein Ende ist gegenwärtig nicht in Sicht. Was sowohl in der breiten wie in einer Fachöffentlichkeit als Erneuerung des polnischen Museumswesens wahrgenommen wird, ist dabei eine komplexe Entwicklung, die neben der Implementierung neuer Methoden und Techniken der Ausstellungsgestaltung und musealen Vermittlung vor allem ein heftiges Ringen um die inhaltliche Gestalt der polnischen Vergangenheit einschließt. Polnische historische Selbstbilder und die ihnen zugrunde liegenden Fremd- und Feindbilder werden aktuell neu verhandelt; Positionen der Bewahrung stehen dabei Ambitionen ihrer Veränderung gegenüber. Kristallisationspunkt dieser Auseinandersetzungen sind die Jahre des Zweiten Weltkriegs, anhand deren Interpretation und Darstellung Fragen lokaler, regionaler wie nationaler historischer Identität debattiert werden.

Vor dem Hintergrund dieser Aktualität des Themas fragte die vorliegende Studie nach den Wandlungen und Kontinuitäten polnischer Selbstbilder, die historische Museen in fünf Großstädten des Landes über einen Zeitraum von drei Jahrzehnten hinweg (re-)präsentieren und konstruieren. Ziel war es, die Entwicklung der musealen Darstellung des Zweiten Weltkriegs seit den 1980er-Jahren nachzuvollziehen und ihre Zäsuren zu identifizieren. Nicht zuletzt wurde nach der Rolle der Museen als erinnerungskulturelle Akteure gefragt: Inwieweit berücksichtigen sie neue wissenschaftliche Erkenntnisse und öffentliche Debatten zu den Ereignissen der Jahre 1939 bis 1945 in Neukonzeptionen ihrer Schauen und inwiefern werden sie selbst zu Initiatoren der Vermittlung veränderter Geschichtsbilder?

Wie die Analysen gezeigt haben, verlief die Entwicklung der musealen Geschichtsbilder des Zweiten Weltkriegs in Polen entlang anderer Einschnitte als die politische Transformation des Landes. Der Systemwechsel von 1989 hatte gerade auf die Dauerausstellungen der Museen kaum Einfluss. Erste veränderte Interpretationen der Kriegsgeschichte äußerten sich zunächst allein in Sonderausstellungen, die einzelne bisherige Tabuthemen einer breiten Öffentlichkeit präsentierten - allen voran die Massenmorde an polnischen Soldaten und Offizieren durch den NKVD 1940 sowie die Deportationen von Polen in die Sowjetunion in den folgenden Jahren. Deutliche Wandlungen er- 
fährt die polnische Museumslandschaft erst seit Mitte der 2000er-Jahre mit dem einsetzenden Museumsboom. Wie gezeigt wurde, verläuft die Entwicklung dabei nicht nur in eine Richtung: Ein Fortschreiben tradierter Interpretationstopoi und die Entwicklung neuer Perspektiven sind parallel zu beobachten.

$\mathrm{Zu}$ den wesentlichen Elementen der Kriegs- und Besatzungsnarrative, die bis zum Ende des Untersuchungszeitraums im Jahr 2010 durch eine starke Kontinuität gekennzeichnet waren, gehörte insbesondere das Feindbild der Deutschen, das weitgehend unverändert bis heute besteht. In seiner Darstellung steht seit den 1990er-Jahren zunehmend ein nationaler Antagonismus im Vordergrund. Hinzugekommen in die musealen Erzählungen ist in den 1990er-Jahren die Sowjetunion als zweiter Aggressor. Beide Besatzer werden bis heute weitgehend schematisch und entmenschlicht gezeichnet, basierend auf älteren stereotypen Vorstellungen von »den Deutschen « respektive »den Russen«. Auch das polnische Selbstbild im Krieg erfuhr in den meisten historischen Museen bis ins Jahr 2010 kaum Veränderungen. Dominant ist ein heroisches und martyrologisches Narrativ. Nur allmählich erhalten seit Ende der 1990er-Jahre auch die zivilen, passiven Opfer der Besatzungsgewalt stärkere Aufmerksamkeit. Eine Ablösung des martyrologischen Opfergedächtnisses durch ein primär viktimologisches ist jedoch für die musealen Erzählungen nicht zu konstatieren; vielmehr treten beide Narrationen weitgehend gleichberechtigt nebeneinander. Prägnanter ist die Veränderung der Gewichtung der einzelnen Fraktionen des polnischen Widerstands. Die Heimatarmee und die Londoner Exilregierung als legitime Vertreterin polnischer Staatlichkeit sind ins Zentrum der neueren Darstellungen gerückt, während kommunistische Gruppierungen in den Hintergrund getreten sind, ihrer anteiligen Bedeutung am Widerstand entsprechend. Die Charakterisierung der Widerständler als nationale Helden im gerechten Kampf für die Unabhängigkeit des Landes folgt jedoch weiterhin den interpretativen Mustern, die bereits in der VRP geprägt worden sind.

In Bezug auf innerstaatliche Fremdbilder - in erster Linie die Opfergruppe der als Juden Verfolgten - bestimmt eine ethnisch-nationale Perspektive den Großteil der untersuchten Schauen aus den 1980er-Jahren bis hin zu solchen, die erst vor wenigen Jahren eröffnet wurden. Die jüdischen Staatsbürger des besetzten Landes bleiben aus der in den Ausstellungen konstruierten ethnisch-polnischen Wir-Gemeinschaft ausgeschlossen. Seit Ende der 1990erJahre nimmt der Umfang der Schilderungen der jüdischen Besatzungserfahrungen in den untersuchten Institutionen zwar stetig zu; kontextualisiert werden sie jedoch bis in die Gegenwart meist als Schicksal einer fremden Ethnie auf polnischem Boden, die Opfer von fremden Tätern geworden ist, was Hintergrund ihrer randständigen Schilderung ist. Eine Veränderung erfuhr allein die Strategie der Marginalisierung: Die in der VRP dominante Verein- 
nahmung des jüdischen Schicksals unter das gesamtpolnische wurde nach 1989 von einer ausgrenzenden Präsentationsweise abgelöst, in der die Verfolgung und Ermordung von 25 bis 30 Prozent der Vorkriegsbevölkerung fast aller untersuchten Städte jeweils in einer kleinen Sektion zum Thema "Ghetto« untergebracht wurde. Deutlich wird in der Präsentationspraxis selbst jüngster Ausstellungen eine unterschwellige Opferhierarchie, in der polnisches Leiden wesentlich eindrücklicher als jüdisches geschildert und damit in den Vordergrund gerückt wird. Die klare Abgrenzung entlang ethnisch-nationaler Kategorien wird zudem durch die markante Zunahme religiöser Symboliken und Inhalte in den Schauen seit den 1990er-Jahren verstärkt, die das im 19. Jahrhundert tradierte nationale Selbstbild des »Polen-Katholiken« perpetuieren.

Neben dieser nach wie vor dominanten Darstellungsweise entwickelten einzelne Museen jedoch auch neue Ansätze musealer Stadtgeschichten, die von einer strikten ethnisch-polnischen Narration Abstand nahmen. Vorreiter war unter den untersuchten Institutionen das Stadtmuseum Łódź, das bereits 1998 eine historische Dauerausstellung eröffnete, in der neben Polen auch die im lokalen Kontext zwei größten Minderheiten - Juden und Deutsche - als zentrale Elemente der städtischen Vergangenheit präsentiert und in der die Geschichte der jüdischen Bevölkerung während des Zweiten Weltkriegs gleichberechtigt Platz neben der polnischen eingeräumt wurde. Weiterentwickelt wurde dieses multiethnische Konzept einer Stadtgeschichte durch das Historische Museum der Stadt Krakau, das in seiner 2010 neu eröffneten Abteilung in der sogenannten Schindler-Fabrik erstmals eine Erzählung präsentiert, in der die jüdische Bevölkerung der Stadt nicht nur in die WirGemeinschaft der Krakauer integriert wird, sondern auch die vielfältigen Beziehungen zwischen den verschiedenen Bevölkerungsgruppen der Stadt in den Jahren 1939 bis 1945 offen dargestellt und ihre gegenseitigen Wahrnehmungen und Interaktionen - positive, ambivalente sowie negative - thematisiert werden. In ein gesamtpolnisches Narrativ überführt diese Perspektive schließlich das Museum der Geschichte der Polnischen Juden, das die jüdische Bevölkerung der historischen polnischen Territorien als integralen und gleichberechtigten Bestandteil der polnischen Geschichte in ihrer Gesamtheit schildert. In seiner Holocaust-Galerie setzt es zudem Maßstäbe in Bezug auf Methoden und Ethik der musealen Vermittlung der Kriegs- und Besatzungszeit.

Auch das Museum des Zweiten Weltkriegs bringt eine grundsätzlich neue Perspektive in die Darstellung der Jahre 1939 bis 1945 ein, die im zweifachen Sinne über die Landesgrenzen hinausweist. Zum einen schildert es den Weltkrieg in seinem globalen Ausmaß - mit einem Schwerpunkt auf Ereignissen in Europa - und geht damit über den bis dato strikt nationalen Kontext polnischer musealer Weltkriegsdarstellungen hinaus. Hierdurch setzt es die etablierten Erinnerungstopoi in Beziehung zu Ereignissen und Erfahrungen 
anderer Nationen und Staaten. Mit diesem Ansatz macht es zum anderen seine Erzählung zum polnischen Kriegsschicksal für ausländische, vor allem europäische Besucher verständlich und anschlussfähig. Zudem steht hier erstmals in Polen ein viktimologisches Narrativ im Vordergrund; eine heroisch-martyrologische Sinnstiftung oder gar teleologische Zuspitzung findet sich in diesem Museum dagegen nicht.

Anhand der untersuchten Dauerausstellungen wird deutlich, dass die historische Museumslandschaft Polens seit mehreren Jahren ein Experimentierfeld ist, auf dem unterschiedliche Vergangenheitsnarrative und damit verbundene Identitätsbilder entworfen werden. Neukonzeptionen, die traditionelle Interpretationsmuster infragestellen oder sogar ablösen, stehen dabei Institutionen und Schauen gegenüber, die diese Deutungen zu bewahren suchen. Die Qualität bzw. »Modernität« der eingesetzten Gestaltungs- und Vermittlungstechniken ist dabei kein Gradmesser für die Innovativität der präsentierten Erzählungen. Mithilfe umfangreicher Szenografien und Inszenierungen, multimedialer Installationen oder personifizierter Narrationen bemühten sich etwa Institutionen wie das Museum des Warschauer Aufstands oder auch das stadthistorische Museum Warschaus, die Erinnerung an die Jahre 1939 bis $1945 \mathrm{zu}$ remythologisieren, indem sie einseitige und eindeutige Visionen einer Vergangenheit unter heroischen und martyrologischen Vorzeichen präsentieren; ambivalente Aspekte oder Schattenseiten polnischer Verhaltensweisen während der Besatzungen werden darin weitgehend ignoriert. Vernachlässigt werden hier somit jüngere wissenschaftliche Erkenntnisse auch solche, die zu prominenten öffentlichen Debatten geführt haben -, während andere Museen diese in multiperspektivischen Arrangements umsetzen. Letztere fordern die Besucher heraus, da sie keine eindeutigen Sichtweisen offerieren, sondern im Gegenteil vielfältige und ungewohnte Perspektiven auf die eigene Vergangenheit eröffnen und dabei auch vor schwierigen Themen nicht zurückschrecken. Das Historische Museum in Wrocław wiederum ist ein Beispiel für den Versuch eines innovativen Ausstellungskonzepts, das darum bemüht ist, traditionelle nationalgeschichtliche Perspektiven zu verlassen, und gleichzeitig in der Schilderung des für die polnische nationale Erinnerung zentralen Zeitraums des Zweiten Weltkriegs genau solche weitgehend perpetuiert.

Wie in der Studie weiterhin herausgearbeitet werden konnte, ging die Pluralisierung musealer polnischer Geschichtsbilder der Jahre 1939 bis 1945, die die untersuchten Dauerausstellungen aus drei Jahrzehnten abbilden, nicht vom Zentrum des Landes, also der Hauptstadt aus, sondern vielmehr von den Regionen, in denen sich historische Museen zunehmend um eine Neu- oder Wiederentdeckung gerade der multiethnischen Vergangenheiten ihrer Städte bemühen. Besonders eindrückliche Beispiele hierfür sind zwei der betrachteten 
Institutionen: das Stadtmuseum Łódź sowie das Historische Museum der Stadt Krakau. Beide Museen spielten in ihren Städten bereits seit den 1980errespektive den 1970er-Jahren eine zentrale Rolle bei der Wiederentdeckung insbesondere ihrer jüdischen Vergangenheit. Sie sind Beispiele dafür, wie historische Museen mit ihren Dauerausstellungen $\mathrm{zu}$ wichtigen Akteuren der Veränderung etablierter Geschichtsbilder in ihren jeweiligen lokalen und regionalen Kontexten avancieren. Damit sind sie zugleich Ausdruck wie aktive Protagonisten des seit den 1990er-Jahren zunehmenden Interesses für die eigene, regionale Geschichte in den einzelnen Teilen des Landes und der sich daraus entwickelnden »regionale[n] partikulare[n] Gedächtnisse «. ${ }^{1}$ Die Analysen haben ebenso aufgezeigt, wie zentral das individuelle Interesse und Engagement einzelner Kuratoren für die Aufnahme und zum Teil auch Etablierung neuer Themen in den Museen waren, insbesondere am Ende der 1980er- und in der ersten Hälfte der 1990er-Jahre. In der territorialen Breite des Untersuchungsfeldes wurde zudem sichtbar, dass es meist die stadthistorischen Museen sind, in denen alternative Konzepte musealer Erzählungen entwickelt werden, während die sogenannten martyrologischen Einrichtungen - ihrer gleichzeitigen Funktion als Gedenkorte entsprechend - von starker Kontinuität geprägt sind und ihre tradierten Narrative der ethnischpolnischen Helden und Märtyrer bislang kaum erweitert haben.

Die Analysen zeigen des Weiteren, wie sehr sich das Agieren der Museen in den untersuchten drei Jahrzehnten gewandelt hat. In den 1980er-Jahren folgten die historischen Museen in ihren Dauerausstellungen im Großen und Ganzen dem etablierten master narrative der VRP. Einige Kuratoren nutzten die wenigen Spielräume, die es erlaubten - bei einem entsprechend aufmerksamen Publikum - als verfälschend wahrgenommene Deutungen zu vermeiden oder auch zu ergänzen. Hierzu gehörte insbesondere die Auslassung einer direkten Thematisierung des Kriegsendes, durch die die Darstellung der Rolle der Sowjetunion als »Befreierin« umgangen wurde. Auch gelang es zum Teil, mithilfe einzelner Ausstellungsstücke auf die Londoner Exilregierung und die mit ihr verbundenen Strukturen des Untergrundstaates im besetzten Land hinzuweisen. Größere Veränderungen etablierter Erzählungen fanden jedoch selbst im Angesicht der im Laufe der 1980er-Jahre nachlassenden Zensur kaum statt. Auch nach dem politischen Wandel von 1989 blieben die Dauerausstellungen bis in die zweite Hälfte der 1990er-Jahre weitgehend

1 Kraft, Claudia: Die Debatte über polnisches Nationalbewusstsein und polnische Erinnerungskultur heute. In: Faulenbach, Bernd/Jelich, Franz-Joseph (Hg.): „Transformation« der Erinnerungskulturen in Europa nach 1989. Essen 2006, 93-112, hier 112. Siehe auch Traba, Robert: Regionalismus in Polen. Die Quellen des Phänomens und sein neues Gesicht nach 1989. In: Ther, Phillipp/Sundhaussen, Holm (Hg.): Regionale Bewegungen und Regionalismen in europäischen Zwischenräumen seit der Mitte des 19. Jahrhunderts. Marburg 2003, 275-283. 
unverändert. Die Kuratoren wagten es nicht, mit eigenen Interpretationen der Kriegs- und Besatzungsgeschichte an die Öffentlichkeit zu treten. Die finanziell sehr angespannte Situation aller Kulturinstitutionen in diesem Zeitraum kann hierfür als eine, aber nicht als ausschlaggebende Ursache gelten. So wurden weitgehend unstrittige Themen, die bereits in den 1980er-Jahren zunehmende Aufmerksamkeit im Publikationsweg des "Zweiten Umlaufs" und teilweise selbst in offiziellen Verlautbarungen erfahren haben, durchaus im Rahmen von Sonderausstellungen offensiv thematisiert - das prominenteste Beispiel ist hier das Thema »Katyń«. Vielmehr kann konstatiert werden, dass es die verantwortlichen Museumsmitarbeiter in diesem Zeitraum weitgehend vermieden, in den erinnerungskulturellen und geschichtswissenschaftlichen Debatten, deren Ausgang noch kaum abzusehen war, Partei zu ergreifen. Ein Großteil der Museen präsentierte sich daher in den 1990er-Jahren gerade mit ihren Dauerausstellungen als weitgehend konservative Institutionen, die abwarteten, bis sich ein neuer Konsens historischer Erzählungen des Weltkriegs und der unmittelbaren Nachkriegszeit herauskristallisiert. Erst seit Beginn des Museumsbooms 2004 treten die Museen zunehmend offensiv mit eigenen Interpretationen an die Öffentlichkeit und verstehen sich immer mehr als aktive Teilnehmer am Prozess der Verhandlung und Prägung historischer Geschichtsbilder.

Dies ist verbunden mit einer deutlichen Veränderung ihres Selbstverständnisses als Institutionen der historischen Bildung und ihrer damit verbundenen Vermittlungsziele. So verstehen sich gerade die historischen Museen nicht mehr allein als Orte der Sammlung und Bewahrung von Zeugnissen der Vergangenheit; es genügt auch nicht mehr, diese im Rahmen von Dauer- und Wechselausstellungen zu präsentieren, um ihrem institutionellen Auftrag nachzukommen. Vielmehr sehen sich gerade neu geschaffene Einrichtungen in der Rolle eines Akteurs, der im Bereich der historischen Bildung mit eigenen Initiativen das Publikum zu erreichen sucht, um zentrale Themen und Geschichtsperspektiven zu vermitteln, die auch in den Ausstellungen präsentiert werden. Dabei werden die Museen immer mehr zu Orten, die eine breite kulturelle Tätigkeit in ihrer Stadt und Region entfalten. Eine Vorreiterrolle in dieser Entwicklung nahm das Museum des Warschauer Aufstands ein. Seine Eröffnung 2004 ging einher mit einer breiten Medienpräsenz und einer Vielfalt an Kulturangeboten, die sich stetig erweitert hat und bisher so verschiedene Veranstaltungen wie wissenschaftliche Konferenzen, Sommerschulen für Studenten, Rockkonzerte und Filmnächte umfasste. ${ }^{2}$ Das Museum profiliert sich damit als Ort geschichtspolitischer, aber auch gesellschaftlicher Diskussionen, als kultureller Veranstaltungsort und als Bildungsinstitution,

2 Für eine Übersicht der kulturellen und Bildungsangebote des Museums siehe seine Website, URL: www.1944.pl (am 2.4.2015). 
die in ihrer thematischen Spannbreite über das eigentliche Thema der Dauerausstellung hinausgeht und allgemeiner auf die jüngste Geschichte, aber auch Gegenwart der Stadt - weniger des Aufstands - gerichtet ist. Auch das damals noch im Entstehen befindliche Museum der Geschichte der Polnischen Juden begann bereits im Jahr 2006, lange vor der Existenz eines eigenen Gebäudes, mit einer an die Warschauer Bevölkerung gerichteten vielfältigen kulturellen Tätigkeit. ${ }^{3}$ Andere Museen, etwa das Historische Museum der Stadt Krakau, folgen diesen Beispielen und entwickeln eine ähnlich umfangreiche und öffentlich präsente Aktivität, durch die sie ihre eigenen Themen und Geschichtsbilder auch einer Öffentlichkeit nahebringen, die sich bislang wenig an Museen oder historischen Schauen interessiert zeigte. ${ }^{4}$ Die Auswirkungen dieser vielfältigen Aktivitäten, die weit über den Rahmen der Ausstellungstätigkeit hinausgehen, auf die lokalen und regionalen Erinnerungskulturen, aber auch ihre überregionale Bedeutung, sind ein lohnendes Thema für weitere Forschungen.

Zusammenfassend ist festzustellen, dass in Polen gegenwärtig verschiedene museale Interpretationsangebote bezüglich dessen, was als Teil der eigenen, regionalen und nationalen Geschichte angesehen werden soll, nebeneinander existieren, ohne dass sich eine deutungsvorgebende Institution oder Ausstellung herauskristallisiert. Im Bereich der publikumswirksamen Ausstellungsgestaltung ist nach wie vor die Schau des Museums des Warschauer Aufstands mit ihren umfangreichen Szenografien und Inszenierungen ein zentraler Referenzpunkt des polnischen historischen Museumswesens. Was jedoch die vermittelten Inhalte und Deutungen betrifft, gehen die musealen Erzählungen sehr unterschiedliche Wege. Insbesondere die ethnisch-nationale Meistererzählung, deren zentrale Vermittlungsinstanzen in der VRP noch die hauptstädtischen Museen waren, wird immer häufiger aufgebrochen.

Die geschilderten Veränderungsprozesse der polnischen Museumslandschaft sind in vollem Gange. Neue Impulse setzten insbesondere die jüngsten musealen Großprojekte wie das Museum der Geschichte der Polnischen Juden und das Museum des Zweiten Weltkriegs. Viele der dargestellten Entwicklungen sind bisher noch auf die großen, finanziell gut ausgestatteten Institutionen in regionalen Zentren konzentriert. Daneben bestehen ältere Institutionen und Dauerausstelllungen (teilweise sogar noch aus den Jahren vor der Wende von 1989) weiterhin fort. Gerade Museen in kleineren Städten ha-

3 Realisiert wurde diese im sogenannten Ohel (hebräisch: Zelt), einer Installation die an ein Zelt erinnerte. Siehe: Biuletyn Muzeum Historii Żydów Polskich (Winter 2006), 24; Historia: od Idei, przez OHEL do Muzeum POLIN [Geschichte: Von der Idee, über das Ohel zum Museum Polin], URL: http://www.polin.pl/pl/historia-od-idei-przez-ohel-domuzeum-polin (am 26.5.2017).

4 Für einen Überblick über die Aktivitäten des MHK in diesem Bereich siehe seine Website: Aktualności [Aktuelles], URL: www.mhk.pl/aktualnosci (am 2.4.2015). 
ben kaum die finanziellen und personellen Ressourcen für eine vollständige Neukonzeption und -gestaltung ihrer historischen Schauen. Dennoch nehmen auch diese Institutionen den Wandel von Geschichtsperspektiven und Präsentationsmethoden wahr; oftmals sind Neugestaltungen für die Zukunft bereits avisiert. ${ }^{5}$

Neben den historischen Museen, die Gegenstand dieser Untersuchung waren, sind innerhalb des letzten Jahrzehnts zahlreiche neue Akteure im polnischen historischen Ausstellungswesen hinzugekommen. Hierzu gehören Kulturinstitutionen, die zu wichtigen Zentren historischer Bildung in ihrer jeweiligen Stadt und Region geworden sind und selbst historische Schauen organisieren, ohne dass sie sich als Museen verstehen. Diese Einrichtungen unterscheiden sich von den klassischen Museen in erster Linie dadurch, dass sie keine eigene Sammlung historischer Artefakte besitzen und auch nicht intendieren, eine solche aufzubauen. Nur selten zeigen sie außerdem ständige Präsentationen; meist handelt es sich um Wechselausstellungen, die wenige Wochen oder Monate gezeigt werden. $\mathrm{Zu}$ diesen Institutionen zählen etwa das Haus der Begegnung mit der Geschichte in Warschau und das Lubliner Burgtor - Theater NN. Wie am letztgenannten Beispiel gezeigt wurde, stellen diese Einrichtungen inzwischen wichtige Ergänzungen der historischen Ausstellungslandschaft dar, vor allem durch die Auseinandersetzung mit Elementen der städtischen, regionalen aber auch staatlichen Geschichte - in diesem Fall der jüdischen Vergangenheit Lublins -, die von den etablierten Museen vor Ort bislang vernachlässigt werden. Neben diesen aus städtischen Haushalten finanzierten Institutionen sind in jüngster Zeit zudem auch private $\mathrm{Mu}$ seen entstanden wie das ")üdische Museum Galizien« (Żydowskie Muzeum Galicja) in Krakau. Ein weiterer Akteur im Bereich historischer Ausstellungstätigkeit ist das »Institut für Nationales Gedenken« (Instytut Pamięci Narodowej, IPN), dessen »Büro für Öffentliche Bildung« (Biuro Edukacji Publicznej) bzw. »Büro für Nationale Bildung" (Biuro Edukacji Narodowej) ${ }^{6}$ inzwischen $\mathrm{zu}$ einem bedeutenden Produzenten historischer Schauen geworden ist. Das

5 So plant etwa das Historische Museum der Stadt Lublin eine Veränderung seiner Dauerausstellung. Der Beginn der Umbauarbeiten ist für Ende 2017 anvisiert. Auskunft des Museums, E-Mail vom 31. Oktober 2016.

6 Im Juni 2016 wurde das Büro für Öffentliche Bildung aufgeteilt in ein Büro für Nationale Bildung, in dessen Rahmen die Ausstellungstätigkeit des IPN fortgesetzt wird, sowie ein »Büro für Historische Forschung « (Biuro Badań Historycznych). Zur Tätigkeit des Büros siehe die Website des IPN: Biuro Edukacji Publicznej [Das Büro für Öffentliche Bildung], URL: www.ipn.gov.pl/o-ipn/struktura/bep (am 17.4.2015); Działalność edukacyjna Instytutu Pamięci Narodowej [Die Bildungstätigkeit des Instituts für Nationales Gedenken], URL: http://ipn.gov.pl/pl/edukacja-1 (am 26.5.2017). Eine Übersicht über die bisherigen Ausstellungen findet sich unter: Wystawy [Ausstellungen], URL: https://ipn.gov.pl/ pl/edukacja-1/wystawy (am 26.5.2017). 
Institut hat mit seinen Dependencen in elf regionalen Zentren ein landesweites Wirkungsfeld. Es erreicht selbst kleine Ortschaften und Kulturhäuser, da seine Präsentationen in Form von Wanderausstellungen verfügbar sind und diese auch kostenfrei verliehen werden. ${ }^{7}$

Diese Akteure sind bislang noch kaum Gegenstand erinnerungskultureller Forschungen im Zusammenhang mit dem Medium Ausstellung. So stellt beispielsweise das interpretative Spektrum der Schauen des IPN, die sich thematisch auf die Geschichte des Zweiten Weltkriegs und der Volksrepublik Polen konzentrieren, ein lohnendes Forschungsfeld im Bereich des historischen Ausstellungswesens dar. Als Akteur staatlicher Geschichtspolitik, der unmittelbar von Veränderungen politischer Machtverhältnisse auf Regierungsebene beeinflusst wird, agiert das IPN unter anderen Prämissen als die zumeist kommunal finanzierten Museen, die in dieser Studie im Zentrum standen und deren Handlungs- und Wirkungsrahmen seit der Wende von 1989 von einer städtischen Erinnerungskultur geprägt ist. Ausgehend von den hier erarbeiteten Analysen ließe sich nach der gegenseitigen Wahrnehmung, der Zusammenarbeit und dem Einfluss der einzelnen Akteure aufeinander fragen, ebenso wie nach ihrer überregionalen Wirkung. Die vorliegende Arbeit bietet schließlich - zusammen mit anderen Forschungsarbeiten, die in den letzten Jahren die musealen Landschaften einzelner Länder in einer größeren regionalen Breite untersuchen $-{ }^{8}$ einen Ausgangspunkt für transnationale Vergleichsstudien. ${ }^{9}$ Untersuchungen in einem gesamteuropäischen Rahmen, über die Grenzen des früheren Eisernen Vorhangs hinweg, können bislang postulierte Ähnlichkeiten innerhalb des westlichen respektive östlichen Europa infrage stellen, ebenso wie die meist vorausgesetzte zwingende Differenz zwischen diesen Regionen.

7 Gespräch mit Paweł Kowalski und Artur Ossowski, Mitarbeitern des »Abteilungsbüros für Öffentliche Bildung« (Oddziałowe Biuro Edukacji Publicznej) des IPN in Łódź, am 2. März 2010.

8 Beispiele hierfür sind etwa die Dissertation von Ekaterina Makhotina und die Forschungen von Ekaterina Keding zu den Museums- und Gedenkstättenlandschaften von Litauen respektive Belarus. Makhotina: Erinnerungen an den Krieg; Keding: Sieghafter Durchbruch.

9 Bislang gibt es erst eine Studie, die eine solche Perspektive unternimmt, und zwar bezogen auf die museal konstruierten Europavorstellungen in mehreren europäischen Ländern: Kaiser/Krankenhagen/Poehls: Europa ausstellen. 



\section{Dank}

Bei der vorliegenden Studie handelt es sich um die leicht überarbeitete und aktualisierte Fassung meiner Dissertation, die im Juli 2015 an der LudwigMaximilians-Universität München angenommen wurde. Sie ist mit der Unterstützung vieler Personen und Institutionen entstanden. Zunächst möchte ich meinem Doktorvater Martin Schulze Wessel danken, der mich als wissenschaftliche Mitarbeiterin in das internationale Forschungsprojekt »Musealisierung der Erinnerung. Zweiter Weltkrieg und nationalsozialistische Besatzung in Museen, Gedenkstätten und Denkmälern im östlichen Europa« am Collegium Carolinum in München aufgenommen und während der Arbeit an dem Thema kontinuierlich gefördert hat. Viele Kooperationspartner des von der VolkswagenStiftung großzügig finanzierten Projekts haben die Studie mit methodischen Anregungen und ihren eigenen Forschungsperspektiven bereichert, allen voran Volkhard Knigge, Etienne François und Peter Haslinger. Włodzimierz Borodziej sei für die stets aufgeschlossenen und konstruktiven Beratungen im Verlauf der Forschungen gedankt.

Mein herzlicher Dank gilt weiterhin dem Deutschen Polen-Institut Darmstadt, dessen Halbjahresstipendium es mir ermöglicht hat, intensiv in der anregenden Atmosphäre des Instituts zu arbeiten. Von der Expertise seiner Mitarbeiter wie von seinen umfangreichen Beständen habe ich gleichermaßen profitiert. Den Kolleginnen und Kollegen im Collegium Carolinum bin ich für die langjährige kollegiale Unterstützung während der Arbeit an diesem Thema sowie in meinen verschiedenen Aufgabenbereichen am Institut verbunden. Danken möchte ich auch den Mitarbeiterinnen und Mitarbeitern der polnischen Museen, Kulturinstitutionen und Archive, die bereit waren, ihr Wissen mit mir zu teilen und immer wieder verborgene Quellenschätze aufgetan haben. Sehr bereichernd waren auch die zahlreichen Gespräche mit $\mathrm{Zu}$ zanna Bogumił und Piotr M. Majewski während meiner Forschungsreisen, deren Fachwissen und Kenntnis insbesondere der Warschauer Kultur- und Museumslandschaft mich vielfach inspiriert haben. Ulrike Lunow sei für die intensive Lektüre des Manuskripts und die ebenso enthusiastischen wie konstruktiven Diskussionen, Arpine Maniero und Anna Bischof für die vielfältigen Debatten während des Schreibprozesses sowie Stephanie Weiss für ihr gründliches Lektorat herzlich gedankt.

Mein besonderer Dank gilt Martin Schulze Wessel und Ulf Brunnbauer für die Aufnahme der Arbeit in die Reihe »Schnittstellen. Studien zum östlichen und südöstlichen Europa«. Die Graduiertenschule für Ost- und Südosteuropa- 
studien der Ludwig-Maximilians-Universität München und der Universität Regensburg sowie der Schroubek Fonds Östliches Europa haben die Drucklegung großzügig unterstützt.

Abschließend möchte ich der während der Arbeit an diesem Buch wichtigsten Person danken, Sebastian Lehnert.

Leipzig, Juni 2017 


\section{Abkürzungsverzeichnis}

AK

AL

AMHK

AMLL

AMME

AMMW

AMNW

AMPW

AMTNE

AP

$\mathrm{BCh}$

BRD

DDR

DSH

Gestapo

GG

GL

IPN

$\mathrm{KZ}$

MIIWŚ

$\mathrm{MH}$

MHK

MHMŁ

MHW

MHŻP

MLL

MME

MMW

Armia Krajowa (Heimatarmee)

Armia Ludowa (Volksarmee)

Archiwum Muzeum Historycznego Miasta Krakowa (Archiv des Historischen Museums der Stadt Krakau)

Archiwum Muzeum Lubelskiego w Lublinie (Archiv des Lubliner Museums in Lublin) Archiwum Muzeum Miasta Łodzi (Archiv des Stadtmuseums Łódź) Archiwum Muzeum Miejskiego Wrocławia (Archiv des Stadtmuseums Wrocław)

Archiwum Muzeum Niepodległości w Warszawie (Archiv des Unabhängigkeitsmuseums in Warschau)

Archiwum Muzeum Powstania Warszawskiego (Archiv des Museums des Warschauer Aufstands)

Archiwum Muzeum Tradycji Niepodległościowych $w$ Łodzi (Archiv des Museums der Unabhängigkeitstraditionen in Łódź)

Archiwum Państwowe (Staatsarchiv)

Bataliony Chłopskie (Bauernbataillone)

Bundesrepublik Deutschland

Deutsche Demokratische Republik

Dom Spotkań z Historia (Haus der Begegnung mit der Geschichte)

Geheime Staatspolizei

Generalgouvernement

Gwardia Ludowa (Volksgarde)

Instytut Pamięci Narodowej (Institut für Nationales Gedenken)

Konzentrationslager

Muzeum II Wojny Światowej (Museum des Zweiten Weltkrieges)

Muzeum Historyczne we Wrocławiu (Historisches Museum in Wrocław)

Muzeum Historyczne Miasta Krakowa (Historisches Museum der Stadt Krakau)

Muzeum Historii Miasta Łodzi (Historisches Museum der Stadt Łódź)

Muzeum Historyczne m. st. Warszawy (Historisches Museum der Hauptstadt Warschau)

Muzeum Historii Żydów Polskich (Museum der Geschichte

der Polnischen Juden)

Muzeum Lubelskie w Lublinie (Lubliner Museum in Lublin)

Muzeum Miasta Łodzi (Stadtmuseum Łódź)

Muzeum Miejskie Wrocławia (Stadtmuseum Wrocław) 
MNW Muzeum Niepodległości w Warszawie (Unabhängigkeitsmuseum in Warschau)

MPW Muzeum Powstania Warszawskiego (Museum des Warschauer Aufstands)

MTNE Muzeum Tradycji Niepodległościowych w Łodzi (Museum der Unabhängigkeitstraditionen in Łódź)

NKVD Narodnyj komissariat vnutrennich del (Volkskommissariat des Inneren)

NS Nationalsozialismus

NSDAP Nationalsozialistische Deutsche Arbeiterpartei

NSZ Narodowe Siły Zbrojne (Nationale Streitkräfte)

OD Jüdischer Ordnungsdienst

o. J. ohne Jahresangabe

o.S. ohne Seitenangabe

PiS Prawo i Sprawiedliwość (Recht und Gerechtigkeit)

PKWN Polski Komitet Wyzwolenia Narodowego (Polnisches Komitee der Nationalen Befreiung)

PPP Polskie Państwo Podziemne (Polnischer Untergrundstaat)

PPR Polska Partia Robotnicza (Polnische Arbeiterpartei)

RONA Russkaja Osvoboditel'naja Narodnaja Armija (Russische Volksbefreiungsarmee)

Scen. Scenariusz ([Ausstellungs-]Drehbuch)

SS Schutzstaffel

SZP Stu̇̇ba Zwycięstwu Polski (Dienst für Polens Sieg)

UdSSR Union der Sozialistischen Sowjetrepubliken

USA United States of America

VRP Volksrepublik Polen

WUBP Wojewódzki Urząd Bezpieczeństwa Publicznego (Woiwodschaftsamt für Öffentliche Sicherheit)

ŻIH Żydowski Instytut Historyczny (Jüdisches Historisches Institut)

ŻOB Żydowska Organizacja Bojowa (Jüdische Kampforganisation)

ZWM Związek Walki Młodych (Verband Kampf der Jungen)

ZWZ Związek Walki Zbrojnej (Verband für den Bewaffneten Kampf)

ŻZW Żydowski Związek Wojskowy (Jüdischer Militärverband) 


\section{Quellen- und Literaturverzeichnis}

\section{Archivbestände}

Archiv des Historischen Museums der Stadt Krakau (AMHK)

- Bestand der Abteilung »Pomorska-Straße»

- Bestand der Abteilung "Geschichte und Kultur der Krakauer Juden« bzw. »Alte Synagoge«

- Bestand der Abteilung »Emaillewarenfabrik Oskar Schindlers»

Archiv des Lubliner Museums in Lublin (AMML)

- Bestand der Abteilung "Krakauer Tor»

- Bestand der Abteilung »Unter der Uhr«

Archiv des Museums der Unabhängigkeitstraditionen (AMTNŁ)

- Bestand der historischen Abteilung

Archiv des Museums des Warschauer Aufstands (AMPW)

Archiv des Stadtmuseums Łódź (AMMŁ)

- Bestand der historischen Abteilung

Archiv des Stadtmuseums Wrocław (AMMW)

- Bestand der historischen Abteilung

- Pressearchiv

Archiv des Unabhängigkeitsmuseums in Warschau (AMNW)

- Bestände des Gefängnismuseums Pawiak

Staatsarchiv (AP)

- Bestand des Historischen Museums der Hauptstadt Warschau (bis 1989): zespół 3195 / 0 Muzeum Historyczne m. st. Warszawy

Herder-Institut

- Zeitungsausschnittssammlung

Yad Vashem Photo Archive

- Bestand »Color photographs taken in the Lodz Ghetto by a German photographer«, URL: http://collections.yadvashem.org/photosarchive/en-us/6464349-container.html (am 18.10.2013) 


\section{Gedruckte Quellen}

1000 lat Wrocławia. Historia i sztuka w Pałacu Królewskim [Begleitheft zur Ausstellung]. Hg.v. Muzeum Miejskie Wrocławia. Wrocław o. J. [2009/2010].

Andrzejewska-Psarska, Małgorzata (Hg.): Upamiętnienie Żydów Łódzkich 20032005. Raport z działań upamiętniających żydowskie dziedzictwo Łodzi [Das Gedenken an die Łódźer Juden 2003-2005. Bericht über die Aktivitäten im Zusammenhang mit dem Gedenken an das jüdische Erbe von Łódź]. Łódź [2005].

Archiwum Ringelbluma: Konspiracyjne archiwum getta Warszawy [Das Ringelblum-Archiv: das geheime Archiv des Ghettos von Warschau]. Bd. 1: Listy o zagładzie [Briefe über die Vernichtung]. Hg.v. Feliks Tych. Bearb. von Ruta Sakowska. Warszawa 1997; Bd. 2: Dzieci - tajne nauczanie w getcie warszawskim [Kinder der geheime Unterricht im Warschauer Ghetto]. Hg.v. Feliks Tych. Bearb. von Ruta Sakowska. Warszawa 2000; Bd. 3: Relacje z Kresów [Berichte aus den polnischen Ostgebieten]. Hg.v. Feliks Tych. Bearb. von Andrzej Żbikowski. Warszawa 2000.

Askanas, Barbara (Hg.): Kultura Ocalona. Katalog wystawy poświęconej kulturze Żydow polskich [Die bewahrte Kultur. Katalog einer der Kultur der polnischen Juden gewidmeten Ausstellung]. Warszawa 1983.

Balcerzak, Janina: W XX-lecie powstania Muzeum Historii Polskiego Ruchu Rewolucyjnego [Zum 20. Jahrestag der Entstehung des Museums der Geschichte der Polnischen Revolutionären Bewegung]. In: Muzeum Historii Polskiego Ruchu Rewolucyjnego w Warszawie 1957-1977 [Das Museum der Geschichte der Polnischen Revolutionären Bewegung in Warschau 1957-1977]. Hg.v. Muzeum Historii Polskiego Ruchu Rewolucyjnego w Warszawie. Warszawa 1977, 8-15.

Baum-Gruszowska, Marzena/Majuk, Dominika (Red.): Światła w ciemności. Sprawiedliwi Wśród Narodów Świata: relacje historii mówionej w działaniach edukacyjnych [Lichter in der Dunkelheit - Die Gerechten unter den Völkern. Zeitzeugenberichte in Bildungsaktivitäten]. Lublin 2009.

Bednarek, Monika: Pamięć zbiorowa - muzeum - miejsce pamięci [Kollektive Erinnerung - Museum - Gedenkort]. In: Krzysztofory 25 (2007), 227-236.

Bednarek, Monika: Kraków - czas okupacji 1939-1945. Zarys koncepcji wystawy [Kraków - Die Besatzungszeit 1939-1945. Abriss des Konzepts der Ausstellung]. In: Dies. et al. (Hg.): Kraków - czas okupacji 1939-1945 [Kraków - Die Besatzungszeit 1939-1945]. Kraków 2010, 36-55.

Bednarek, Monika: Die Dauerausstellung »Krakau - Besatzungszeit 1939-1945« in der ehemaligen Emaillewarenfabrik Oskar Schindlers. In: Inter Finitimos 10 (2012), 100-108.

Bednarek, Monika et al. (Hg.): Kraków - czas okupacji 1939-1945 [Kraków - Die Besatzungszeit 1939-1945]. Kraków 2010.

Bednarek, Monika/Salwiński, Jacek: Pomorska. Przewodnik po miejscu pamięci narodowej i oddziale Muzeum Historycznego Miasta Krakowa [Pomorska. Führer durch den Ort der nationalen Erinnerung und die Abteilung des Historischen $\mathrm{Mu}-$ seums der Stadt Krakau]. Kraków 2003. 
Bergmann, Eleonora (Hg.): Jewish Historical Institute. The First Fifty Years. 1947-1997. Warsaw 1996.

Bielecki, Czesław: Radegast. In: Ders. (Hg.): Więcej niż architektura. Pochwała eklektyzmu [Mehr als Architektur. Ein Lob dem Eklektizismus]. Olszanica 2005, 50-63.

Biuletyn Muzeum Historii Żydów Polskich (Winter 2006), (Herbst 2007), (Sommer 2008).

Błaszkowski, Bartłomiej/Lagiewski, Maciej/Okólska, Halina: Sala 21. I wojna światowa - Republika Weimarska - Gmina żydowska" [Saal 21. Erster Weltkrieg Weimarer Republik - Jüdische Gemeinde]. In: Łagiewski, Maciej/Okólska, Halina / Oszczanowski, Piotr (Hg.): 1000 lat Wrocławia. Przewodnik po wystawie [1000 Jahre Wrocław. Führer durch die Ausstellung]. Wrocław 2009, 257-276.

Borak, Elżbieta: Muzeum »Pod Zegarem« [Das Museum »Unter der Uhr«]. In: Muzea Walki 14 (1981), 90-92.

Budziarek, Marek (Hg.): Judaica łódzkie w zbiorach muzealnych i zasobach archiwalnych [Łódźer Judaica in Museums- und Archivbeständen]. Łódź 1994.

Budziarek, Marek: Gabinet Prof. Jana Karskiego [Das Arbeitszimmer von Prof. Jan Karski] [Ausstellungskatalog]. Łódź 1999.

Budziarek, Marek: Łódź. Miasto czterech kultur [Łódź. Stadt der vier Kulturen]. Łódź 2004.

Budziarek, Marek: Łódź - Lodsch - Litzmannstadt. Wycinki z życia mieszkańców okupowanego miasta [Łódź - Lodsch - Litzmannstadt. Ausschnitte aus dem Leben der Bewohner einer besetzten Stadt]. 2. Aufl. Łódź 2004 (Erstauflage 2001).

Chmielak, Jadwiga/Jakimińska, Grażyna/Polańska, Magdalena: Historia Miasta Lublina. Informator do wystawy stałej w Muzeum Historii Miasta Lublina [Die Geschichte der Stadt Lublin. Führer zur Dauerausstellung im Historischen Museum der Stadt Lublin]. Lublin 2000.

Ciepłowski, Stanisław/Kasprowicz, Grażyna: Dorobek wydawniczy Muzeum Historycznego m.st. Warszawy za lata 1948-2000 [Die Veröffentlichungen des Historischen Museums der Hauptstadt Warschau in den Jahren 1948-2000]. In: Almanach Muzealny [Museumsalmanach]. Bd.3. Hg.v. Muzeum Historyczne m.st. Warszawy. Warszawa 2001, 323-353.

Ciesielska, Marta (Hg.): Janusz Korczak. Warszawa jest moja i ja jestem jej. Wystawa z okazji 125-tej rocznicy urodzin Janusza Korczaka [Janusz Korczak. Warschau ist mein und ich bin ihre. Ausstellung aus Anlass des 125. Geburtstages Janusz Korczaks]. Warszawa 2003.

Czerniaków, Adam: Adama Czerniakowa dziennik getta warszawskiego. 6 IX 1939-23 VII 1942 [Das Tagebuch des Warschauer Ghettos von Adam Czerniaków. 6.9.193923.7.1942]. Bearb. von Marian Fuks. Warszawa 1983.

Czernielewski, Konrad: Powstanie Warszawskie 1944. W 60 rocznicę wybuchu [Der Warschauer Aufstand 1944. Zum 60. Jahrestag des Ausbruchs] [Begleitheft zur Ausstellung]. Łódź August 2004.

Czubaczyński, Ryszard (Hg.): Pałac - Muzeum. Muzeum Historii Miasta Łodzi. Informator - przewodnik [Palast - Museum. Das Historische Museum der Stadt Łódź. Führer durch das Museum]. Łódź 1995.

Czubaczyński, Ryszard (Hg.): Pałac - Muzeum. Muzeum Historii Miasta Łodzi. In- 
formator - przewodnik [Palast - Museum. Das Historische Museum der Stadt Łódź. Führer durch das Museum]. Łódź 2003.

Dąbkowska-Cichocka, Lena et al. (Hg.): Przewodnik po Muzeum Powstania Warszawskiego [Führer durch das Museum des Warschauer Aufstands]. 3., ergänzte Aufl. Warszawa 2010.

Dąbrowska, Anna (Hg.): Światła w ciemności. Sprawiedliwi Wśród Narodów Świata. Relacje/Lichter in der Finsternis. Gerechte Unter Den Völkern. Berichte/Lights in the Darkness. The Righteous Among the Nations. Testimonies. Lublin 2008.

Domańska, Regina: Muzeum Więzienia »Pawiak« [Das Gefängnismuseum »Pawiak«]. In: Muzea Walki 1 (1968), 88-97.

Domańska, Regina: Problematyka badań nad dziejami Pawiaka w okresie okupacji [Die Problematik der Erforschung der Geschichte des Pawiak während der Besatzungszeit]. In: Muzeum Historii Polskiego Ruchu Rewolucyjnego w Warszawie 1957-1977 [Das Museum der Geschichte der Polnischen Rewolutionären Bewegung in Warschau 1957-1977]. Hg.v. Muzeum Historii Polskiego Ruchu Rewolucyjnego $w$ Warszawie. Warszawa 1977, 58-65.

Duda, Eugeniusz: Stara Synagoga na Kazimierzu w Krakowie. Przewodnik [Die Alte Synagoge in Kazimierz in Krakau. Ausstellungsführer]. Kraków 2005.

Duda, Eugeniusz: Stara Synagoga na Kazimierzu w Krakowie. Przewodnik [Die Alte Synagoge in Kazimierz in Krakau. Ausstellungsführer]. Kraków 2007.

Duda, Eugeniusz: Z dziejów i kultury Żydów w Krakowie. Przewodnik po wystawie stałej w Starej Synagodze [Aus der Geschichte und Kultur der Juden in Krakau. Führer durch die Dauerausstellung in der Alten Synagoge]. Kraków [1982].

Durko, Janusz (Hg.): Muzeum Historyczne Warszawy [Das Historische Museum von Warschau]. Warszawa 1973.

Durko, Janusz: Muzeum Warszawy i jego współtwórcy w mojej pamięci. 1951-2003 [Das Museum Warschaus und seine Mitgründer - meine Erinnerungen. 1951-2003]. Warszawa 2008.

Feuchert, Sascha/Leibfried, Erwin/Riecke, Jörn (Hg.): Die Chronik des Gettos Lodz/ Litzmannstadt. 5 Bde. Göttingen 2007.

Gąsiorowski, Teodor: »Dom Śląski« przy ul. Pomorskiej 2 w Krakowie [Das »Schlesische Haus in der Pomorska-Straße 2 in Krakau]. In: Krzysztofory 17 (1990), 82-84.

Gauda, Alfred/Nasalski, Zygmunt: Muzeum Okręgowe w Lublinie. Informator [Das Bezirksmuseum in Lublin. Museumsführer]. Lulin 1981.

Głębocki, Wiesław/Karpowicz, Witold: Obecni wśród nas. Żydzi polscy w życiu politycznym, gospodarczym, społecznym, naukowym i kulturalnym Warszawy. Katalog wystawy [Anwesend unter uns. Polnische Juden im politischen, wirtschaftlichen, gesellschaftlichen, wissenschaftlichen und kulturellen Leben Warschaus. Ausstellungskatalog]. Warszawa 1993.

Głębocki, Wiesław/Mórawski, Karol: Nowy kształt Muzeum Żydowskiego Instytutu Historycznego w Warszawie [Die neue Gestalt des Museums des Jüdischen Historischen Instituts in Warschau]. In: Muzea Walki 10 (1977), 71-76.

Głowacka, Maria/Lechowicz, Małgorzata: Więzienie przy Długiej (Gdańska) w Łodzi 1885-1953. Wystawa stała [Das Gefängnis an der Długa- (Gdańska-)Straße in Łódź 1885-1953. Dauerausstellung]. Lódź o. J. [2009]. 
Grossman, Mendel: With a Camera in the Ghetto. Tel-Aviv 1970.

Gumola, Mieczysław: Walka z niepamięcią. Ocalony honor miasta [Der Kampf gegen das Nichterinnern. Die gerettete Ehre der Stadt]. In: Romanowski, Gustaw/ Strąkowski, Marek/Sidor, Mateusz (Hg.): Żeby ten krzyk nie przeminął. Materiały z Obchodów 60. Rocznicy Zagłady Litzmannstadt Ghetto, 1944-2004 [Damit dieser Schrei nicht verhallt. Materialien der Gedenkfeiern zum 60. Jahrestag der Vernichtung des Ghettos Litzmannstadt, 1944-2004]. Łódź 2005, 59-64

Heinrich, Maria/Szczepaniak, Jacek: Muzeum Martyrologii i Walki w Radogoszczu [Das Museum des Martyriums und des Kampfes in Radogoszcz]. In: Muzea Walki 15 (1982), 95-108.

Hirszfeld, Ludwik: Historia jednego życia [Die Geschichte eines Lebens]. 2. Aufl. Warszawa 1957.

I skrzypce przestały grać ... Obóz cygański 1941-1942 [Und die Geigen hörten auf zu spielen ... Das Zigeunerlager 1941-1942]. Hg.v. Muzeum Tradycji Niepodległościowych $w$ Łodzi. Łódź 2009.

Iwanicki, Ryszard: Związek Walki Zbrojnej-Armia Krajowa, 1939-1945 (Z działalności edukacyjnej Muzeum Tradycji Niepodległościowych w Łodzi) [Der Verband für den Bewaffneten Kampf-Heimatarmee, 1939-1945 (Aus der Bildungstätigkeit des Museums der Unabhängigkeitstraditionen in Łódź)]. In: Armia Krajowa. W 65. Rocznicę nadania siłom zbrojnym w kraju nazwy »Armia Krajowa« (Jednodniówka) [Die Heimatarmee. Zum 65. Jahrestag der Benennung der Streitkräfte im Lande als "Heimatarmee" (Sonderausgabe)]. Hg.v. Muzeum Tradycji Niepodległościowych w Łodzi. 12. Februar 2007, 8.

Iwanicki, Ryszard/Janaszek, Grażyna/Rukowiecki, Andrzej: Martyrologium Łódzkie. Przewodnik po Radogoszczu i Miejscach Pamięci Narodowej [Łódźer Martyrologium. Führer durch Radogoszcz und die Orte nationaler Erinnerung]. Łódź 2005.

Izdebska, Barbara: Pawiak 1939-1944 [Ausstellungsführer]. Warszawa 1994.

Izdebska, Barbara: Muzeum Więzienia "Pawiak« - historia i teraźniejszość [Das Gefängnismuseum »Pawiak» - Geschichte und Gegenwart]. In: Niepodległość i Pamięć 2 / 3 (4) (1995), 247-275.

Jakimińska, Grażyna: Brama Krakowska. Historia [Das Krakauer Tor. Geschichte]. Lublin 1995.

Jakimińska, Grażyna/Nasalski, Zygmunt: 100 lat Muzeum Lubelskiego [100 Jahre des Lubliner Museums]. In: Studia i Materiały Lubelskie 15 (2008), 9-52.

Jeżowski, Grzegorz: Polskie Państwo Podziemne [Der Polnische Untergrundstaat]. In: Bednarek, Monika et al. (Hg.): Kraków - czas okupacji 1939-1945 [Kraków - Die Besatzungszeit 1939-1945]. Kraków 2010, 362-391.

Jodłowiec-Dziedzic, Anna: Apteka w getcie krakowskim [Die Apotheke im Krakauer Ghetto]. Kraków 2004.

Jodłowiec-Dziedzic, Anna: Zagłada Żydów Krakowskich 1939-1945 [Die Vernichtung der Krakauer Juden 1939-1945]. Kraków o. J. [2004].

Kirshenblatt-Gimblett, Barbara: Theater of History. In: Dies. / Polonsky, Antony (Hg.): Polin. 1000 Year History of Polish Jews [Ausstellungskatalog]. Warsaw 2014, 19-35.

Kobiety w Powstaniu Warszawskim [Frauen im Warschauer Aufstand] [Ausstellungskatalog]. Hg.v. Muzeum Niepodległości. Warszawa, August-September 1994. 
Kowal, Paweł: Jak budowaliśmy Muzeum [Wie wir das Museums geschaffen haben]. In: Dąbkowska-Cichocka, Lena et al. (Hg.): Przewodnik po Muzeum Powstania Warszawskiego [Führer durch das Museum des Warschauer Aufstands]. 3., ergänzte Aufl. Warszawa 2010, 7-11.

Kowalski, Zdzisław: Muzeum Martyrologii »Pod Zegarem« [Martyrologiemuseum »Unter der Uhr«] [Ausstellungsführer]. Lublin 1986.

Kronika getta łódzkiego / 1: Styczeń 1941-maj 1942 [Die Chronik des Łódźer Ghettos. Bd. 1: Januar 1941-Mai 1942]. Hg.v. Danuta Dąbrowska und Lucjan Dobroszycki. Łódź 1965.

Kronika getta łódzkiego/2: Czerwiec-grudzień 1942 [Die Chronik des Łódźer Ghettos. Bd. 2: Juni-Dezember 1942]. Hg.v. Danuta Dąbrowska und Lucjan Dobroszycki. Łódź 1966.

Kropiwnicki, Jerzy: Rola świadka - rzecz o obchodach 60. rocznicy likwidacji Litzmannstadt Ghetto w Łodzi [Die Rolle des Zeugen - Zu den Gedenkfeierlichkeiten des 60. Jahrestages der Liquidierung des Ghettos in Łódź]. In: Kronika miasta Łodzi 2 (2004), 5-9.

Kwiaty Wojny [Blumen des Kriegs] [Ausstellungskatalog]. Hg.v. Muzeum Tradycji Niepodległościowych w Łodzi. April 1996.

Łagiewski, Maciej: Stary Cmentarz Żydowski we Wrocławiu [Der Alte Jüdische Friedhof in Wrocław]. Wrocław 1986 (2. Aufl. 1995).

Łagiewski, Maciej: Der alte jüdische Friedhof in Wrocław, Breslau. Bonn 1988.

Łagiewski, Maciej: Macewy mówią [Die Matzewen sprechen]. Wrocław, Warszawa, Kraków 1991.

Łagiewski, Maciej: Wrocławscy Żydzi. 1850-1944 [Die Breslauer Juden. 1850-1944]. 1. Aufl. Wrocław 1994.

Łagiewski, Maciej: Breslauer Juden. 1850-1944. Wrocław 1996 (2. Aufl. 2011).

Łagiewski, Maciej: Wrocławscy Żydzi. 1850-1944 [Die Breslauer Juden. 1850-1944]. 2. erw. Aufl. Wrocław 1997.

Łagiewski, Maciej: Das Pantheon der Breslauer Juden. Der jüdische Friedhof an der Lohestraße in Breslau. Bonn 1999.

Łagiewski, Maciej: Pałac z historią - historia w pałacu [Ein Palast mit Geschichte - Geschichte im Palast]. In: Ders./Okólska, Halina/Oszczanowski, Piotr (Hg.): 1000 lat Wrocławia. Przewodnik po wystawie [1000 Jahre Wrocław. Führer durch die Ausstellung]. Wrocław 2009, 9-15.

Łagiewski, Maciej/Okólska, Halina/Błaszkowski, Bartłomiej/Smolak, Marzena: Sala 22. Dyktatura hitlerowska - II wojna światowa [Saal 22. Hitler-Diktatur - Zweiter Weltkrieg]. In: Łagiewski, Maciej/Okólska, Halina/Oszczanowski, Piotr (Hg.): 1000 lat Wrocławia. Przewodnik po wystawie [1000 Jahre Wrocław. Führer durch die Ausstellung]. Wrocław 2009, 277-286.

Łagiewski, Maciej/Okólska, Halina/Oszczanowski, Piotr (Hg.): 1000 lat Wrocławia. Przewodnik po wystawie [1000 Jahre Wrocław. Führer durch die Ausstellung]. Wrocław 2009.

Łagiewski, Maciej/Okólska, Halina/Oszczanowski, Piotr (Hg.): 1000 Jahre Breslau. Führer durch die Ausstellung. 2., veränderte und erweiterte Aufl. Breslau 2011.

Laurentowicz, Małgorzata / Budziarek, Marek (Red.): Triada. Trzy wielkie społeczności. 
Polacy - Niemcy - Żydzi [Triade. Drei große Gemeinschaften. Polen - Deutsche Juden] [Katalog zur Dauerausstellung]. Łódź 2001.

Leociak, Jacek: Jak opowiedzieć/ pokazać Zagładę w muzeum? [Wie kann man den Holocaust im Museum erzählen / zeigen?]. In: Nieroba, Elżbieta (Hg.): Targowisko przeszłości. Społeczne konsekwencje popkulturowych sposobów opowiadania o świecie minionym [Der Marktplatz der Vergangenheit. Gesellschaftliche Folgen popkultureller Erzählstrategien über die vergangene Welt]. Warszawa 2011, 105-117.

Logemann, Daniel: Die entstehende Dauerausstellung des Museums des Zweiten Weltkrieges in Danzig. In: Inter Finitimos 10 (2012), 126-133.

Łojek, Bożena et al.: Muzeum Katyńskie w Warszawie [Das Katyń-Museum in Warschau]. Warszawa 2001.

Machcewicz, Paweł: Das Museum des Zweiten Weltkrieges in Danzig. In: Troebst, Stefan/Wolf, Johanna (Hg.): Erinnern an den Zweiten Weltkrieg. Mahnmale und Museen in Mittel- und Osteuropa. Leipzig 2011, 163-174.

Machcewicz, Paweł: »Museum statt Stacheldrahtverhaue«. Das Museum des Zweiten Weltkriegs in Danzig. In: Borodziej, Włodzimierz/Puttkamer, Joachim Von (Hg.): Europa und sein Osten. Geschichtskulturelle Herausforderungen. München 2012, 81-103.

Machcewicz, Paweł: Representing Violence and Death in the Museum of the Second World War in Gdańsk. In: Przegląd historyczny 57 / 1 (2016), 53-62.

Machcewicz, Paweł: Po co nam Muzeum II Wojny Światwej? [Wofür brauchen wir das Museum des Zweiten Weltkriegs?]. In: Wnuk, Rafał et al. (Hg.): Muzeum II Wojny Światowej. Katalog wystawy głównej [Das Museum des Zweiten Weltkrieges. Katalog der Dauerausstellung]. Gdańsk 2016, 7-13.

Machcewicz, Paweł/Majewski, Piotr M.: Muzeum II Wojny Światowej. Zarys koncepcji programowej [Das Museum des Zweiten Weltkriegs. Abriss des Programmkonzepts]. In: Przegląd polityczny 91-92 (2008), 46-51.

Madałowa, Krystyna: Stowarzyszenie byłych Więźniów Politycznych Zamku Lubelskiego i »Pod Zegarem« 1969-2002. Działalność - Wspomnienia [Der Verein der ehemaligen politischen Häftlinge des Lubliner Schlosses und »Unter der Uhr« 1969-2002. Tätigkeit - Erinnerungen]. Lublin 2002.

Maliszewska, Izabella/Maliszewski, Stanisław: Kalendarium zmagań o Muzeum Powstania Warszawskiego [Chronik des Ringens um das Museum des Warschauer Aufstands]. In: Almanach Muzealny [Museumsalmanach]. Bd.4. Hg.v. Muzeum Historyczne m. st. Warszawy. Warszawa 2003, 333-342.

Marszałek, Anna/Bednarek, Monika: Fabryka Emalia Oskara Schindlera. Przewodnik [Die Emaillewarenfabrik Oskar Schindlers. Ausstellungsführer]. Kraków 2010.

Marszałek, Anna/Bembenek, Mariusz: Wokół placu Inwalidów [Rund um den Invalidenplatz]. Kraków 2009.

Meller, Beata: History, Ideology and Politics in the Historical Museum of Warsaw. In: Museum International 47 / 3 (1995), 22-27.

Milewska-Młynnik, Anna: Wystawa »Sybir 1940-1956« [Die Ausstellung »Sibirien 1940-1956«]. In: Niepodległość i Pamięć 11 (1998), 255-257.

Muzeum Historii Polskiego Ruchu Rewolucyjnego w Warszawie 1957-1977 [Das 
Museum der Geschichte der Polnischen Revolutionären Bewegung in Warschau 1957-1977]. Hg. v. Muzeum Historii Polskiego Ruchu Rewolucyjnego w Warszawie. Warszawa 1977.

Muzeum Historyczne m.st. Warszawy. Informator [Das Historische Museum der Hauptstadt Warschau. Ausstellungsführer]. Hg.v. Muzeum Historyczne m. st. Warszawy. Warszawa o. J. [2006].

Muzeum Powstania Warszawskiego. Plan. Warsaw Rising Museum. Map. Hg. v. Muzeum Powstania Warszawskiego. Warszawa o. J. [2009].

Obwieszczenie Ministra Kultury i Dziedzictwa Narodowego z dnia 15 kwietnia 2016 r. o zamiarze i przyczynach połączenia państwowych instytucji kultury Muzeum II Wojny Światowej w Gdańsku oraz Muzeum Westerplatte i Wojny 1939 [Bekanntmachung des Ministers für Kultur und Nationales Erbe vom 15. April 2016 über die Absicht und Gründe für den Zusammenschluss der staatlichen Kulturinstitutionen Museum des Zweiten Weltkriegs in Gdańsk und Museum der Westerplatte und des Kriegs 1939]. In: Dziennik Urzędowy Ministra Kultury i Dziedzictwa Narodowego vom 15. April 2016, Pos. 18.

Okólska, Halina: Sala 23. Wrocław po 1945 - następstwa wojny - stalinizm [Saal 23. Wrocław nach 1945 - Kriegsfolgen - Stalinismus]. In: Eagiewski, Maciej/ Okólska, Halina/Oszczanowski, Piotr (Hg.): 1000 lat Wrocławia. Przewodnik po wystawie [1000 Jahre Wrocław. Führer durch die Ausstellung]. Wrocław 2009, 287-294.

Ołdakowski, Jan: Muzeum historycznego niepokoju [Ein Museum der historischen Unruhe]. In: Cichocka, Lena et al. (Hg.): Polityka historyczna. Historycy - politycy - prasa [Geschichtspolitik. Historiker - Politiker - Presse]. Warszawa 2005, 250-253.

Ołdakowski, Jan: Jedyne takie muzeum - Muzeum Powstania Warszawkiego [Ein einzigartiges Museum - das Museum des Warschauer Aufstands]. In: Rottermund, Andrzej/Sołtan, Andrzej/Wrede, Marek (Hg.): 200 lat muzealnictwa warszawskiego. Dzieje i perspektywy. Materiały z sesji naukowej. Zamek Królewski w Warszawie. 16-17 listopada 2005 roku [200 Jahre des Warschauer Museumswesens. Geschichte und Perspektiven. Materialien der wissenschaftlichen Konferenz. Königsschloss in Warschau. 16.-17. November 2005]. Warszawa 2006, 425-430.

Oratowska, Barbara: Więźniowie Zamku Lubelskiego straceni w latach 1944-1954 [Die in den Jahren 1944-1954 erschossenen Häftlinge des Lubliner Schlosses] [Ausstellungsführer]. Lublin 2008.

Oratowska, Barbara / Polańska, Jolanta: Okupacyjna codzienność Lublina 1939-1944

[Der Besatzungsalltag in Lublin 1939-1944] [Ausstellungsführer]. Lublin 1993.

Oświadczenie dyrektora Muzeum w związku z wypowiedzią Jarosława Kaczyńskiego wygłoszoną podczas kongresu Prawa i Sprawiedliwości w dn. 29 czerwca 2013 r. [Erklärung des Museumsdirektors im Zusammenhang mit der Äußerung Jarosław Kaczyńskis auf dem Kongress der Partei Recht und Gerechtigkeit am 29. Juni 2013]. 30.6.2013, URL: www.muzeum1939.pl/pl/aktualnosci (am 14.5.2017).

„Our only way is work«. The Łódź Ghetto 1940-1944 [Begleitheft zur Ausstellung].

Hg. v. The Museum of History of the City of Łódź. Łódź 2002.

Pałaszewska, Mirosława: Wystawy w Muzeum Niepodległości poświęcone II wojnie 
światowej [Ausstellungen zum Zweiten Weltkrieg im Unabhängigkeitsmuseum]. In: Niepodległość i Pamięć 18 (2002), 219-239.

Pałaszewska, Mirosława/Kunert, Andrzej K.: Polskie Państwo Podziemne wobec tragedii Żydów 1939-1945 [Der Polnische Untergrundstaat und die Tragödie der Juden 1939-1945] [Ausstellungsführer]. Warszawa 1993.

Pałaszewska, Mirosława/Żuchowska, Krystyna: Wystawy w Muzeum Niepodległości 1990-2005 [Die Ausstellungen im Unabhängigkeitsmuseum 1990-2005]. In: Niepodległość i Pamięć 23 (2006), 161-194.

Passowicz, Wacław: Kronika działalności Muzeum Historycznego m. Krakowa za rok 1979 [Chronik der Tätigkeiten des Historischen Museums der Stadt Krakau für das Jahr 1979]. In: Krzysztofory 7 (1980), 104-108.

Passowicz, Wacław: Kronika działalności Muzeum Historycznego m. Krakowa za rok 1980 [Chronik der Tätigkeiten des Historischen Museums der Stadt Krakau für das Jahr 1980]. In: Krzysztofory 8 (1981), 137-142.

Passowicz, Wacław: Kronika działalności Muzeum Historycznego m. Krakowa za rok 1987 [Chronik der Tätigkeiten des Historischen Museums der Stadt Krakau für das Jahr 1987]. In: Krzysztofory 15 (1988), 177-185.

Passowicz, Wacław: Kronika działalności Muzeum Historycznego m. Krakowa za rok 1989 [Chronik der Tätigkeiten des Historischen Museums der Stadt Krakau für das Jahr 1989]. In: Krzysztofory 17 (1990), 116-123.

Passowicz, Wacław: Kronika działalności Muzeum Historycznego Miasta Krakowa za rok 1990 [Chronik der Tätigkeiten des Historischen Museums der Stadt Krakau für das Jahr 1990]. In: Krzysztofory 18 (1991), 188-198.

Passowicz, Wacław: Kronika działalności Muzeum Historycznego Miasta Krakowa 2003-2004 [Chronik der Tätigkeiten des Historischen Museums der Stadt Krakau 2003-2004]. In: Krzysztofory 24 (2006), 165-197.

Passowicz, Wacław: Kronika działalności Muzeum Historycznego Miasta Krakowa w 2007 roku [Chronik der Tätigkeiten des Historischen Museums der Stadt Krakau im Jahr 2007]. In: Krzysztofory 26 (2008), 247-283.

Passowicz, Wacław: Kronika działalności Muzeum Historycznego Miasta Krakowa w 2008 roku [Chronik der Tätigkeiten des Historischen Museums der Stadt Krakau im Jahr 2008]. In: Krzysztofory 27 (2009), 331-361.

Pawiak 1835-1944. Przewodnik po ekspozycji stałej. Museumsführer durch die ständige Ausstellung. Hg.v. Muzeum Niepodległości w Warszawie. Warszawa 2004.

Pawiak 1835-1944. Przewodnik po ekspozycji stałej. The Guidebook to the Permanent Display. Hg.v. Muzeum Niepodległości w Warszawie. Warszawa 2006.

Pawlak, Grażyna S.: Prace nad powołaniem Muzeum Historii Żydów Polskich [Die Arbeiten zur Berufung des Museums der Geschichte der Polnischen Juden]. In: Żbikowski, Andrzej (Hg.): Żydowski Instytut Historyczny. 50 lat działalności. Materiały z konferencji jubileuszowej [Das Jüdische Historische Institut - 50 Jahre Tätigkeit. Beiträge der Jubiläumskonferenz]. Warszawa 1996, 105-111.

Pietrasiewicz, Tomasz: Brama Grodzka. Kręgi Pamięci [Das Burgtor. Kreise der Erinnerungen]. Lublin 2008.

Pietrasiewicz, Tomasz: Ośrodek»Brama Grodzka - Teatr NN« 1990-2010: Artystyczne i animatorskie działania w przestrzeni miasta związane z pamięcią [Institut »Burg- 
tor - Theater NN« 1990-2010: Künstlerische und Bildungsaktivitäten im städtischen Raum, die mit Erinnerung verbunden sind]. Bd. 2. Lublin 2010.

Pietrasiewicz, Tomasz: Teatr NN 1990-2010 [Theater NN 1990-2010]. Bd. 1. Lublin 2010.

Pietrzak, Cecylia: Kalendarium wystaw. 1972-1998 [Ausstellungschronik. 1972-1998]. In: Almanach Muzealny [Museumsalmanach]. Bd.2. Hg. v. Muzeum Historyczne m.st. Warszawy. Warszawa 1999, 355-409.

Pietrzak, Cecylia/Rogalska, Barbara/Wiśniewska, Jolanta: Kalendarium wystaw 2001-2002 [Ausstellungschronik 2001-2002]. In: Almanach Muzealny [Museumsalmanach]. Bd.4. Hg.v. Muzeum Historyczne m. st. Warszawy. Warszawa 2003, 415-428.

Pietrzak, Cecylia/Wiśniewska, Jolanta/Rogalska, Barbara: Kalendarium wystaw 1999-2000 [Ausstellungschronik 1999-2000]. In: Almanach Muzealny [Museumsalmanach]. Bd.3. Hg.v. Muzeum Historyczne m.st. Warszawy. Warszawa 2001, 271-287.

Pióro, Anna: Apteka pod Orłem. Przewodnik [Apotheke zum Adler. Ausstellungsführer]. Kraków 2009.

Płoszajska, Maria (Red.): Muzeum Historyczne m.st. Warszawy [Das Historische Museum der Hauptstadt Warschau]. Warszawa [198-].

Polańska, Magdalena/Jakimińska, Grażyna/Piwowarska, Magdalena: Lublin - historia miasta. Informator do wystawy stałej w Muzeum Historii Miasta Lublina [Die Geschichte der Stadt Lublin. Führer zur Dauerausstellung im Historischen Museum der Stadt Lublin]. Lublin 2008.

Postanowienie Naczelnego Sądu Administracyjnego z dnia 5 kwietnia 2017 r. Sygn. akt II OZ 299/ 17 [Beschluss des Obersten Verwaltungsgericht vom 5. April 2017. Aktenzeichen II OZ 299/17], URL: www.muzeum1939.pl/object.php/act/sho/oid/ cef0998b2ed5afa916d431f58bf1898d (am 5.4.2017).

Ringelblum, Emanuel: Kronika getta warszawskiego: wrzesień 1939-styczeń 1943 [Chronik des Warschauer Ghettos: September 1939-Januar 1943]. Warszawa 1983.

Romanowski, Gustaw/Strąkowski, Marek/Sidor, Mateusz (Hg.): Żeby ten krzyk nie przeminął. Materiały z Obchodów 60. Rocznicy Zagłady Litzmannstadt Ghetto, 1944-2004 [Damit dieser Schrei nicht verhallt. Materialien der Gedenkfeiern zum 60. Jahrestag der Vernichtung des Ghettos Litzmannstadt, 1944-2004]. Łódź 2005.

Ross, Henryk: Łódź Ghetto Album. Photographs by Henryk Ross. Selected by Martin Parr and Timothy Prus. Foreword by Robert Jan van Pelt. Text by Thomas Weber. London 2004.

Rostworowski, Marek (Hg.): Polaków portret własny [Das Selbstbildnis der Polen]. Bd. 1: Ilustracje [Illustrationen]. Warszawa 1983.

Rostworowski, Marek (Hg.): Polaków portret własny [Das Selbstbildnis der Polen]. Bd. 2: opisanie ilustracji [Beschreibung der Illustrationen]. Warsaw 1986.

Rukowiecki, Andrzej/Siemiński, Henryk: Pamięć i przebaczenie. W 50 rocznicę wyzwolenia hitlerowskich więzień i obozów koncentracyjnych [Erinnerung und Vergebung. Zum 50. Jahrestag der Befreiung der hitleristischen Gefängnisse und Konzentrationslager] [Ausstellungskatalog]. Łódź 1995.

Sala 1. Kamienie Milowe Wrocławia [Saal 1. Die Meilensteine Wrocławs]. In: Ła- 
giewski, Maciej/Okólska, Halina/Oszczanowski, Piotr (Hg.): 1000 lat Wrocławia. Przewodnik po wystawie [1000 Jahre Wrocław. Führer durch die Ausstellung]. Wrocław 2009, $16 \mathrm{f}$.

Salwiński, Jacek: Ulica Pomorska 2. Oddział Muzeum Historycznego Miasta Krakowa. Dorobek, potrzeby, perspektywy [Pomorska-Straße 2. Abteilung des Historischen Museums der Stadt Krakau. Schaffen, Bedürfnisse, Perspektiven]. In: Sowiniec 19 (2001), 137-148.

Salwiński, Jacek: Dom Śląski. Pomorska 2, Królewska 1 - historia gmachu [Das Schlesische Haus. Pomorska-Straße 2, Królewska-Straße 1 - die Geschichte des Gebäudes]. In: Bednarek, Monika/Salwiński, Jacek (Hg.): Pomorska. Przewodnik po miejscu pamięci narodowej i oddziale Muzeum Historycznego Miasta Krakowa [Pomorska. Führer durch den Ort nationaler Erinnerung und die Abteilung des Historischen Museums der Stadt Krakau]. Kraków 2003, 7-18.

Salwiński, Jacek: Wystawa stała »Kraków 1939-1956« [Die Dauerausstellung »Krakau 1939-1956«]. In: Bednarek, Monika/Salwiński, Jacek (Hg.): Pomorska. Przewodnik po miejscu pamięci narodowej i oddziale Muzeum Historycznego Miasta Krakowa [Pomorska. Führer durch den Ort nationaler Erinnerung und die Abteilung des Historischen Museums der Stadt Krakau]. Kraków 2003, 37-79.

Salwiński, Jacek: Kronika działalności Muzeum Historycznego Miasta Krakowa w 2009 roku [Chronik der Tätigkeiten des Historischen Museums der Stadt Krakau im Jahr 2009]. In: Krzysztofory 28 / 2 (2010), 237-260.

Salwiński, Jacek: Wokół Lipowej [Rund um die Lipowa-Straße]. Kraków 2011.

Salwiński, Jacek: Kronika działalności Muzeum Historycznego Miasta Krakowa w 2011 roku [Chronik der Tätigkeiten des Historischen Museums der Stadt Krakau im Jahr 2011]. In: Krzysztofory 30 (2012), 297-318.

Sawicki, Zdzisław (Red.): Muzeum Katyńskie - Oddział Muzeum Wojska Polskiego w Warszawie. Przewodnik [Das Katyń-Museum - Abteilung des Museums der Polnischen Armee in Warschau. Ausstellungsführer]. Warszawa 2004.

Siemiński, Henryk (Hg.): Stacja Radegast. Litzmannstadt Getto 1940-1944 [Station Radegast. Das Ghetto Litzmannstadt 1940-1944]. Łódź 2005.

Sieramska, Magdalena: Muzeum Żydowskiego Instytutu Historycznego - Zbiory i działalność [Das Museum des Jüdischen Historischen Instituts - Sammlungen und Tätigkeit]. In: Żbikowski, Andrzej (Hg.): Żydowski Instytut Historyczny. 50 lat działalności. Materiały z konferencji jubileuszowej [Das Jüdische Historische Institut - 50 Jahre Tätigkeit. Beiträge der Jubiläumskonferenz]. Warszawa 1996, 55-61.

Sil, Jan: Kronika Muzeum Lubelskiego za lata 1988-1995 [Chronik des Lubliner Museums für die Jahre 1988-1995]. In: Studia i Materiały Lubelskie 14 (1997), 229-248.

Sołtan, Andrzej: Muzeum Historyczne m.st. Warszawy i jego wkład w rozwój varsavianistyki [Das Historische Museum der Hauptstadt Warschau und sein Beitrag in die Entwicklung der Varsavianistik]. In: Rottermund, Andrzej/Sołtan, Andrzej/ Wrede, Marek (Hg.): 200 lat muzealnictwa warszawskiego. Dzieje i perspektywy. Materiały z sesji naukowej. Zamek Królewski w Warszawie. 16-17 listopada 2005 roku [200 Jahre des Warschauer Museumswesens. Geschichte und Perspektiven. 
Materialien der wissenschaftlichen Konferenz. Königsschloss in Warschau. 16.-17. November 2005]. Warszawa 2006, 79-101.

Soltan, Andrzej: Muzeum Historyczne m. st. Warszawy 1936-2006 [Das Historische Museum der Hauptstadt Warschau 1936-2006]. In: Almanach Muzealny [Museumsalmanach]. Bd.5. Hg.v. Muzeum Historyczne m. st. Warszawy. Warszawa 2007, 7-54.

Stacja Radegast. Pomnik zagłady Litzmannstadt Getto [Station Radegast. Denkmal der Vernichtung des Ghettos Litzmannstadt] [Flyer]. Łódź o. J. [2005].

Stawarz, Andrzej (Hg.): Muzeum Niepodległości 1990-1995. Działalność i zbiory [Das Unabhängigkeitsmuseum 1990-1995. Tätigkeit und Sammlungen]. Warszawa 1995.

Stowarzyszenie Żydowski Instytut Historyczny: Raport merytoryczny. Wystawa główna Muzeum Historii Żydów Polskich (1995-2012). 2. Aufl. Hg. v. Stowarzyszenie Żydowski Instytut Historyczny. Warszawa Juni 2012.

Strategia Promocji Krakowa na lata 2008-2012 [Strategie der Vermarktung Krakaus für die Jahre 2008-2012], URL: www.bip.krakow.pl/_insc/rada/uchwaly/show_pdf. php?id=38334 (am 5.1.2014).

Strobin, Marian: Muzeum Historii Ruchu Rewolucyjnego w Łodzi. Założenia i kształt stałej ekspozycji [Das Museum der Geschichte der Revolutionsbewegung in Łódź. Konzept und Gestalt der Dauerausstellung]. In: Muzea Walki 5 (1972), 112-122.

Świat przed katastrofą. Żydzi krakowscy w dwudziestoleciu międzywojennym. A World Before a Catastrophe. Krakow's Jews Between the Wars. Hg.v. Międzynarodowe Centrum Kultury. Kraków 2007.

Tańska, Irena (Hg.): Wystawa Sybiracy 1940-1956. Informator [Die Ausstellung Die nach Sibirien Deportierten 1940-1956. Ausstellungsführer]. Warszawa 2000.

Tencer, Gołda (Hg.): And I Still See Their Faces. Images of Polish Jews. Warszawa 1996.

The Warsaw Getto 1940-1943 [DVD]. Hg. v. Żydowski Instytut Historyczny. Warszawa 2001.

Trasa Pamięci [Pfad der Erinnerung] [Broschüre]. Hg. v. Muzeum Historyczne Miasta Krakowa. Kraków o. J.

Tych, Feliks / Bergmann, Eleonora/Hensel, Jürgen (Hg.): Żydowski Instytut Historyczny. Przewodnik [Führer durch das Jüdische Historische Institut]. Warszawa 2003.

Uchwała Nr 118/2015 Rady Ministrów z dnia 21 lipca 2015 r. w sprawie ustanowienia programu wieloletniego »Budowa Muzeum Historii Polski w Warszawie« [Beschluss Nr. 118/2015 des Ministerrats zur Aufstellung des mehrjährigen Plans »Bau des Museums der Geschichte Polens in Warschau«], URL: http://bip.mkidn. gov.pl/pages/legislacja/programy-wieloletnie/uchwala-nr-118.2015-rady-ministrowz-dnia-21-lipca-2015-r.-w-sprawie-ustanowienia-programu-wieloletniego-budowamuzeum-historii-polski-w-warszawie.php (am 25.5.2017).

Uchwała rady miasta Łodzi nrXXIII/0485/07 w sprawie utworzenia instytucji kultury pod nazwą »Miasto Dialogu“ w Łodzi i nadania jej statutu [Beschluss des Stadtrates von Łódź Nr. XXIII / 0485 / 07 über die Gründung einer Kultureinrichtung mit dem Namen »Stadt des Dialogs« in Łódź und die Verabschiedung ihrer Satzung]. 27.12.2007, URL: http://bip.uml.lodz.pl/index.php?str=83\&id=20992 (am 16.12.2013). 
Uchwała w sprawie ustanowienia programu wieloletniego »Budowa Muzeum II wojny Światowej w Gdańsku«, przedłożona przez ministra kultury i dziedzictwa narodowego. 4 stycznia $2011 \mathrm{r}$ [Beschluss über die Schaffung eines mehrjährigen Plans »Bau des Museums des Zweiten Weltkriegs«, vorgelegt vom Minister für Kultur und Nationales Erbe. 4. Januar 2011], URL: www.premier.gov.pl (am 12.4.2011).

Ukielski, Paweł: Nowoczesna placówka edukacji patriotycznej [Eine moderne Einrichtung der patriotischen Erziehung]. In: Pamięć dla przyszłości. Konferencja poświęcona problemom współczesnej edukacji patriotycznej. Muzeum Powstania Warszawskiego 29 października 2005 [Erinnerung für die Zukunft. Eine Konferenz zu den Problemen der gegenwärtigen patriotischen Erziehung. Museum des Warschauer Aufstands 29. Oktober 2005]. Hg.v. Muzeum Powstania Warszawskiego. Warszawa 2006, 21-29.

Ukielski, Paweł: Das »Museum des Warschauer Aufstandes« als Erinnerungsort. In: Weber, Matthias et al. (Hg.): Erinnerungsorte in Ostmitteleuropa. Erfahrungen der Vergangenheit und Perspektiven. München 2011, 209-218.

Umińska, Apolonia: Informacja o działalności Archiwum Żydowskiego Instytutu Historycznego [Informationen über die Tätigkeit des Archivs des Jüdischen Historischen Instituts]. In: Żbikowski, Andrzej (Hg.): Żydowski Instytut Historyczny. 50 lat działalności. Materiały z konferencji jubileuszowej [Das Jüdische Historische Institut - 50 Jahre Tätigkeit. Beiträge der Jubiläumskonferenz]. Warszawa 1996, 50-54.

Umińska, Apolonia et al. (Hg.): Inwentarz zbioru »Pamiętniki Żydów« 1939-1945 Archiwum Żydowskiego Instytutu Historycznego [Verzeichnis des Bestands »Tagebücher von Juden« 1939-1945 des Archivs des Jüdischen Historischen Instituts]. Warszawa 1994.

Wnuk, Rafał et al.: Muzeum II Wojny Światowej. Katalog wystawy głównej [Das Museum des Zweiten Weltkrieges. Katalog der Dauerausstellung]. Gdańsk 2016.

Wojak, Sławomir: Trzydzieści lat krakowskiego muzealnictwa (1945-1975) [Dreißig Jahre Krakauer Museumswesen (1945-1975)]. In: Krzysztofory 2 (1975), 11-32.

Woltanowska, Magdalena: Nowa ekspozycja stała w Muzeum Więzienia »Pawiak» [Die neue Dauerausstellung im Gefängnismuseum »Pawiak«]. In: Niepodległość i Pamięć 18 (2002), 253-290.

Woltanowska, Magdalena: Pomnik Drzewa Pawiackiego [Das Denkmal des PawiakBaums]. In: Niepodległość i Pamięć 22 (2006), 259-266.

Wóycicka, Zofia: 1000 Jahre im Museum. Die Geschichte der polnischen Juden. In: Osteuropa 58 / 8-10 (2008), 409-417.

Wrońska-Cupiał, Beata (Hg.): »Nie ma jak w domu«. O Wrocławiu ... Dla dr. Macieja Łagiewskiego, dyrektora Muzeum Miejskiego Wrocławia w 50. rocznicę urodzin [»Am schönsten ist es Zuhause«. Über Wrocław ... Für Dr. Maciej Łagiewski, Direktor des Stadtmuseums Wrocław zum 50. Geburtstag]. Wrocław 2005.

Wystawa dzieł artystów żydowskich 1918-1939. Malarstwo, grafika, rysunek, rzeźba, metaloplastyka [Ausstellung der Werke jüdischer Künstler 1918-1939. Malerei, Zeichnen, Skulptur, Schmiedekunst]. Hg. v. Biuro Wystaw Artystycznych w Olsztynie und Żydowski Instytut Historyczny w Polsce. Olsztyn 1997. 
Wystawa Żydzi - Polscy. Czerwiec-Sierpień 1989 [Ausstellung Die - polnischen Juden. Juni-August 1989]. Hg.v. Muzeum Narodowe w Krakowie. Kraków 1989.

Z dziejów i kultury Krakowa w Krzysztoforach. Przewodnik po wystawie stałej [Aus der Geschichte und Kultur im Krzysztofory-Palast. Führer durch die Dauerausstellung]. Hg. v. Muzeum Historyczne m. Krakowa. Kraków [1986].

Żmuda-Liszewska, Krystyna: Muzeum Historyczne m. st. Warszawy 1936-1996 [Das Historische Museum der Hauptstadt Warschau 1936-1996]. Warszawa 1996.

Źródlak, Wojciech: Bibliografia radogoska [Radegaster Bibliografie], bibliografia radogoska_nwe_2010-03-04.pdf, Stand: 10.2.2010, URL: www.muzeumtradycji.pl (am 4.3.2010).

\section{Interviews}

Interview mit Monika Bednarek, Leiterin der Abteilungen Pomorska-Straße und Emaillewarenfabrik Oskar Schindlers des Historischen Museums der Stadt Krakau, am 16. März 2010.

Interview mit Joanna Gierczyńska, Leiterin des Gefängnismuseums Pawiak, am 9. Juli 2009.

Interview mit Ryszard Iwanicki, Mitarbeiter des Martyrologiemuseums Radogoszcz, am 2. November 2010.

Interview mit Anna Kulazińska, Leiterin der Abteilung Station Radegast des Museums der Unabhängigkeitstraditionen, am 10. März 2010.

Interview mit Maciej Łagiewski, Direktor des Stadtmuseums Wrocław, am 27. April 2011.

Interview mit Jacek Leociak, verantwortlicher Kurator der Sektion »Holocaust« der Dauerausstellung des Museums der Geschichte der Polnischen Juden, am 12. Juli 2011.

Interview mit Katarzyna Madoń-Mitzner, stellvertretende Direktorin des Hauses der Begegnung mit der Geschichte und Leiterin der Mediathek, am 25. Mai 2010.

Interview mit Piotr M. Majewski, stellvertretender Direktor des Museums des Zweiten Weltkrieges, am 29. August 2014.

Interview mit Joanna Maldis, Kuratorin der Sektion zum Zweiten Weltkrieg des Historischen Museums der Hauptstadt Warschau, am 30. Juni 2009.

Interview mit Stanisław Maliszewski, Mitarbeiter des Historischen Museums der Hauptstadt Warschau, zuständig für die Geschichte des Warschauer Aufstands 1944, am 24. Juni 2009.

Interview mit Karol Mazur, Leiter der museumspädagogischen Abteilung des Museums des Warschauer Aufstands, am 25. Juni 2009.

Interview mit Halina Okólska, Leiterin des Historischen Museums in Wrocław, am 29. März 2010.

Interview mit Barbara Oratowska, Leiterin der Abteilung »Unter der Uhr« des Lubliner Museums in Lublin, am 11. Mai 2010. 
Interview mit Tomasz Pietrasiewicz, Leiter des Burgtores - Theaters NN in Lublin, am 22. März 2012.

Interview mit Joanna Podolska, Leiterin des Marek-Edelman-Zentrums des Dialogs (Centrum Dialogu im. Marka Edelmana) in Łódź, am 28. März 2012.

Interview mit Magdalena Sieramska, Kuratorin der Dauerausstellung von 2001 des Jüdischen Historischen Instituts, am 19. Mai 2010.

Interview mit Paweł Ukielski, stellvertretender Direktor für inhaltliche Fragen des Museums des Warschauer Aufstands, am 8. Juli 2009.

Interview mit Jerzy Zarawski, Leiter der Abteilung Arsenal des Stadtmuseums Wrocław, am 31. März 2010.

\section{Presse}

AT: Getto łódzkie w fotografii [Das Łódźer Ghetto in der Fotografie]. In: Nowy Świat z Piotrkowskiej vom 20.1.1993.

Bartoszewicz, Dariusz: Wstyd w Muzeum Katyńskim [Scham im Katyń-Museum]. In: Gazeta Wyborcza vom 7.1.2010, Online-Ausgabe, URL: http://warszawa.gazeta.pl/ warszawa/1,34889,7427197,Wstyd_w_Muzeum_Katynskim.html (am 20.5.2012).

Bikont, Anna: A on krzyczał: „Wszyscy jesteście kapo« [Und er schrie: »Ihr seid alle Kapos«]. In: Gazeta Wyborcza vom 4. Oktober 1997.

Błoński, Jan: Biedni Polacy patrzą na getto [Die armen Polen schauen auf das Ghetto]. In: Tygodnik Powszechny 2 (1987).

Bubnicki, Rafał: Wrocławscy Żydzi 1850-1944. Przypominanie historii [Die Breslauer Juden 1850-1944. Erinnern an die Geschichte]. In: Rzeczpospolita vom 21./22.5.1994.

Budziarek, Marek: Naszą jedyną drogą jest praca [Unser einziger Weg ist Arbeit]. In: Gazeta Łódzka vom 16./ 17.1.1993.

Cichy, Michał: Polacy - Żydzi: Czarne karty powstania [Polen - Juden: Die dunklen Seiten des Aufstands]. In: Gazeta Wyborcza vom 29./30.1.1994, 13.

Engelking-Boni, Barbara: Dolary skupuję, koty przechowuję [Kaufe Dollar, bringe Katzen unter]. In: Gazeta Wyborcza vom 18.2.2008, Online-Ausgabe, URL: http:// wyborcza.pl/1,76842,4933898.html (am 16.12.2011).

Janion, Maria: »Nie-Boska komedia« - skażone arcydzieło [Die »Nicht-göttliche Komödie«. Das verseuchte Meisterwerk]. In: Gazeta Wyborcza vom 29.3.2008, 32.

Kirshenblatt-Gimblett, Barbara: Teatr historii: 12 zasad [Das Theater der Geschichte: 12 Prinzipien]. In: Tygodnik Powszechny 44 (2014), Online-Ausgabe, URL: http:// tygodnik.onet.pl/historia/teatr-historii-12-zasad/h14m8 (am 20.3.2015).

Kursa, Magdalena: Zabłocie: Arka z naczyń emaliowanych [Zabłocie: Eine Arche aus Emaillewaren]. In: Gazeta Wyborcza Kraków vom 27.2.2009, Online-Ausgabe, URL: http://krakow.gazeta.pl/krakow/1,35798,6324647,Zablocie__Arka_z_ naczyn_emaliowanych.html (am 6.1.2014).

Kursa, Magdalena: Multimedialny labirynt u Schindlera [Ein multimediales Laby- 
rinth bei Schindler]. In: Gazeta Wyborcza Kraków vom 13.3.2009, Online-Ausgabe, URL: http://krakow.gazeta.pl/krakow/1,35798,6385910,Multimedialny_labirynt_ u_Schindlera.html (am 5.1.2014).

Link-Lenczowska, Magdalena: Śmierć w nowych dekoracjach [Der Tod im neuen Gewand]. In: Herito 1 (2010), 104-117.

Lisowski, Andrzej: "Żydzi Polscy« w Krakowie [»Die polnischen Juden« in Krakau]. In: Tygodnik Polski Nr. 36 vom 3.9.1989.

Lupiński, Piotr: Krzyczeć z ofiarą. Rozmowa z Jerzem Kropiwnickim [Mit dem Opfer schreien. Ein Gespräch mit Jerzy Kropiwnicki]. In: Gazeta Wyborcza vom 24.4. 2004, Online Ausgabe, URL:www.ghetto.lodz.pl/index.php/pl/napisali-o-nas/2004/ 86-krzycze-z-ofiar-rozmowa-z-jerzym-kropiwnickim (am 30.12.2010).

Machcewicz, Paweł: Muzeum zamiast zasieków [Museum statt Stacheldrahtverhaue]. In: Gazeta Wyborcza vom 8.11.2007, Online-Ausgabe, URL: www.wyborcza.pl (am 6.4.2011).

Michalak, Ada: Jutro otwarcie Muzeum Katyńskiego na Cytadeli [Morgen wird das Katyń-Museum in der Zitadelle eröffnet]. In: Rzeczpospolita vom 16.9.2015, Online-Ausgabe, URL: www.rp.pl/Historia/309169897-Jutro-otwarcie-MuzeumKatynskiego-na-Cytadeli.html (am 20.11.2016).

Muzeum Historii Żydów Polskich to nowoczesne centrum edukacji i kultury [Das Museum der Geschichte der Polnischen Juden ist ein modernes Bildungs- und Kulturzentrum]. In: Gazeta Wyborcza vom 19.10.2010, Online-Ausgabe, URL: www.wiadomosci.gazeta.pl/wiadomosci/1,114877,16827900,Muzeum_Historii_ Zydow_Polskich_to_nowoczesne_centrum.html (am 29.10.2014).

Obchody 65. Rocznicy likwidacji łódzkiego getta: »Musimy krzyczeć głośno« [Die Gedenkfeiern zum 65. Jahrestag der Liquidierung des Ghettos von Łódź: „Wir müssen laut schreien«]. In: Gazeta Wyborcza vom 27.8.2009, Online-Ausgabe, URL: www.wiadomosci.gazeta.pl/Wiadomosci/2029020,80291,6970988.html?sms_ code $=($ am 30.12.2010) .

Pawlak, Monika: Marek Edelman: dowódca powstania w getcie wybrał Łódź [Marek Edelman: Der Anführer des Ghettoaufstandes wählte Łódź]. In: Dziennik Łódzki vom 17.9.2010, Online-Ausgabe, URL: www.dzienniklodzki.pl/artykul/308829, marek-edelman-dowodca-powstania-w-getcie-wybral-lodz,id,t.html (am 4.8.2013).

Pawłowska, Anna: Gabinet Marka Edelmana w Muzeum Miasta Łodzi [Das Arbeitszimmer Marek Edelmans im Stadtmuseum Łódź]. In: Dziennik Łódzki vom 3.10.2011, Online-Ausgabe, URL: www.dziennik lodzki.pl/artykul/457680,gabinetmarka-edelmana-w-muzeum-miasta-lodzi,id,t.html (am 4.3.2013).

Pawłowski, Roman: Otwiera się interaktywne Muzeum Historii Żydów Polskich. Czyli pierwsze muzeum historii Polski [Das interaktive Museum der Geschichte der Polnischen Juden wird eröffnet. Also das erste Museum der Geschichte Polens]. In: Gazeta Wyborcza vom 27.10.2014, Online-Ausgabe, URL: www.wyborcza.pl/1, 75475,16869612,Otwiera_sie_interaktywne_Muzeum_Historii_Zydow_Polskich_. html (am 25.3.2015).

Po sukcesie w krakowskim muzeum: Wystawa »Żydzi polscy« także w Warszawie [Nach dem Erfolg im Krakauer Museum: Die Ausstellung »Die polnischen Juden« auch in Warschau]. In: Życie Warszawy vom 18./ 19.11.1989. 
Podgórska, Joanna: Muzeum Życia. Rozmowa z Jerzym Halbersztadtem, dyrektorem powstającego Muzeum Historii Żydów Polskich [Museum des Lebens. Ein Gespräch mit Jerzy Halbersztadt, dem Direktor des entstehenden Museums der Geschichte der Polnischen Juden]. In: Polityka vom 4.11.2009, Online-Ausgabe, URL: www.polityka.pl/tygodnikpolityka/historia/222399,1,muzeum-zycia.read (am 22.3.2015).

Podolska, Joanna: Nie lubię, jak ktoś obraża innych. Kolorowa Tolerancja w Łodzi [Ich mag es nicht, wenn jemand andere beleidigt. Bunte Toleranz in Łódź]. In: Tygiel Kultury (2000), URL: www.tygielkultury.eu/7_9_2000/aktual/8ram.htm (am 26.8.2011).

Podolska, Joanna/Gnacikowska, Wioletta: Park Ocalałych powstał wczoraj w Łodzi. In: Gazeta Wyborcza vom 30.8.2004, zitiert nach URL: www.ghetto.lodz.pl/ index.php/pl/napisali-o-nas/2004/192-park-ocalalych-powstal-wczoraj-w-lodzi (am 30.12.2010).

Przybyła, Urszula: Okolicznościowe imprezy w kraju [Gedenkveranstaltungen im Land]. In: Słowo Żydowskie vom 4.6.1993, 6, 19.

Przybyła, Urszula/Zawistowska, Władysława: Obecni wśród nas [Anwesend unter uns]. In: Słowo Żydowskie vom 4.6.1993, 16, 19.

Romanowski, Gustaw: W Łodzi: Getto - kolor i mrok [In Łódź: Das Ghetto - Farbe und Dunkelheit]. In: Rzeczpospolita i kultura vom 19.1.1993.

Romanowski, Rafał: Nazwy, których turysta nie zrozumie i nie powtórzy [Titel, die kein Tourist wird verstehen oder wiederholen können]. In: Gazeta Wyborcza Kraków vom 4.8.2010, Online-Ausgabe, URL: http://krakow.gazeta.pl/krakow/1,35798,8211 142,Nazwy__ktorych_turysta_nie_zrozumie_i_nie_powtorzy.html (am 5.1.2013).

Rubinstein, Renata: »... ma kto odmówić kadisz na ich grobach«. W rocznicę likwidacji getta łódzkiego [»... es gibt jemanden, der den Kaddisch über ihren Gräbern spricht«. Zum Jahrestag der Liquidierung des Łódźer Ghettos]. In: Słowo Żydowskie 19 (71) vom 23.9.1994, 6.

Sabor, Agnieszka: Lipowa 4. W dawnej »Emalii« powstało muzeum opowiadające o Krakowie w latach 1939-45 [Lipowa 4. In der ehemaligen "Emaille« ist ein $\mathrm{Mu}-$ seum entstanden, das von Krakau in den Jahren 1939-45 erzählt]. In: Tygodnik Powszechny, Online-Ausgabe vom 31.8.2010, URL: http://tygodnik.onet.pl/ 33,0,51887,artykul.html (am 10.5.2011).

Skarżyński, Janusz: Muzeum w Domu pod Zegarem [Das Museum im Haus unter der Uhr]. In: Za wolność i lud vom 1.12.1979.

Szostkiewicz, Adam: Żydzi Schindlera patrzą nam w oczy [Die Juden Schindlers blicken uns in die Augen]. In: Polityka vom 16.6.2011, Online-Ausgabe, URL: www.polityka.pl/historia/1516534,1,zydzi-schindlera-patrza-nam-w-oczy.read (am 21.6.2011).

Traba, Robert: Kicz patriotyczny [Patriotischer Kitsch]. In: Gazeta Wyborcza vom 6.1.2006, Online-Ausgabe, URL: www.wyborcza.pl (am 29.5.2011).

Urzykowski, Tomasz: Nowy pomnik: Powstańcy przepraszają warszawiaków [Ein neues Denkmal: Die Aufständischen bitten die Warschauer um Verzeihung]. In: Gazeta Wyborcza vom 3.10.2010, Online-Ausgabe, URL: http://wyborcza.pl/ 2029020,75248,8458419.html (am 4.10.2010). 
Wiergowska, Dagmara: Klisze i pamięć [Klischees und Erinnerung]. In: Życie Warszawy vom 18.4.1996.

Wyrok. Z autorem wystawy, Tomaszem Kizny rozmawiała Zofia Broniek [Verurteilung. Mit dem Autor der Ausstellung, Tomasz Kizny, sprach Zofia Broniek]. In: Podkowieński Magazyn Kulturalny 4 (7) (1994), Online-Ausgabe, URL: http://free. art.pl/podkowa.magazyn/index.htm (am 24.7.2012).

Wystawa »Oblicza totalitaryzmu« [Ausstellung »Gesichter des Totalitarismus«]. In: Gazeta Wyborcza vom 9.12.2012, Online-Ausgabe, URL: http://wiadomosci.gazeta. pl/kraj/2029020,34309,3058906.html?sms_code= (am 24.9.2010).

Zagórska, Bożena: W krakowskim Muzeum Narodowym Żydzi - polscy [Die - polnischen - Juden im Krakauer Nationalmuseum]. In: Trybuna Ludu vom 19./ 20.8.1989.

Zając, Jolanta: Na inaugurację wielka wystawa "Żydzi polscy« [Zur Eröffnung die große Ausstellung »Die polnischen Juden«]. In: Trybuna Ludu vom 15.6.1989.

\section{Literatur}

Adamczyk, Elżbieta: Społeczność Krakowa i jej życie [Die Krakauer Gesellschaft und ihr Leben]. In: Bieniarzówna, Janina/Małecki, Jan M. (Hg.): Dzieje Krakowa [Die Geschichte Krakaus]. Bd.4: Kraków w latach 1918-1939 [Krakau in den Jahren 1918-1939]. Kraków 1997, 27-50.

Adamczyk-Garbowska, Monika / Ruta, Magdalena: Od kultury żydowskiej do kultury o Żydach [Von der jüdischen Kultur zur Kultur über die Juden]. In: Tych, Feliks / Adamczyk-Garbowska, Monika (Hg.): Następstwa zagłady Żydów. Polska 1944-2010 [Die Folgen der Vernichtung der Juden. Polen 1944-2010]. Lublin 2011, 715-732.

Aleksiun, Natalia: Historiografia na temat Zagłady i stosunków polsko-żydowskich w okresie drugiej wojny światowej [Die Historiografie zum Thema Holocaust und den polnisch-jüdischen Beziehungen während des Zweiten Weltkriegs]. In: Zagłada Żydów 1 (2005), 32-51.

Ambrosewicz-Jacobs, Jolanta: Świadomość Holokaustu wśród młodzieży polskiej po zmianach systemowych 1989 roku [Die Wahrnehmung des Holocaust in der polnischen Jugend nach den Systemveränderungen des Jahres 1989]. In: Tych, Feliks/ Adamczyk-Garbowska, Monika (Hg.): Następstwa zagłady Żydów. Polska 1944-2010 [Die Folgen der Vernichtung der Juden. Polen 1944-2010]. Lublin 2011, 625-658.

Anderson, Benedict: Imagined Communities. Reflections on the Origin and Spread of Nationalism. London, New York 2006 (Erstauflage 1983).

Assmann, Aleida: Der lange Schatten der Vergangenheit. Erinnerungskultur und Geschichtspolitik. Bonn 2007.

Assmann, Aleida/Assmann, Jan: Das Gestern im Heute. Medien und soziales Gedächtnis. In: Merten, Klaus/Schmidt, Siegfried J./Weischenberg, Siegfried (Hg.): Die Wirklichkeit der Medien. Eine Einführung in die Kommunikationswissenschaft. Opladen 1994, 114-140.

Assmann, Jan: Das kulturelle Gedächtnis. Schrift, Erinnerung und politische Identität in frühen Hochkulturen. München 1992. 
Baranowski, Julian: The Łódź Ghetto 1940-1944. Łódzkie getto 1940-1944. Vademecum. 1. Aufl. Łódź 1999.

Baranowski, Julian: Zigeunerlager in Litzmannstadt 1941-1942. The Gypsy Camp in Łódź / Obóz cygański w Łodzi 1941-1942. Łódź 2003.

Baranowski, Julian/Nowinowski, Sławomir M. (Hg.): Getto Łódzkie. Litzmannstadt Ghetto. 1940-1944. Łódź 2009.

Barth, Boris: »Partisan« und »Partisanenkrieg» in Theorie und Geschichte. Zur historischen Dimension der Entstaatlichung von Kriegen. In: Militärgeschichtliche Zeitschrift 64/ 1 (2005), 69-100.

Bauer, Wolfgang/Dümotz, Irmtraud/Golowin, Sergius: Lexikon der Symbole. 20. überarb. Aufl. Wiesbaden 2004.

Baur, Joachim: Die Musealisierung der Migration. Einwanderungsmuseen und die Inszenierung der multikulturellen Nation. Bielefeld 2009.

Baur, Joachim (Hg.): Museumsanalyse. Methoden und Konturen eines neuen Forschungsfeldes. Bielefeld 2010.

Beier-De Haan, Rosmarie: Erinnerte Geschichte - Inszenierte Geschichte. Ausstellungen und Museen in der Zweiten Moderne. Frankfurt am Main 2005.

Beil, Christine: »Musealisierte Gewalt«. Einige Gedanken über Präsentationsweisen von Krieg und Gewalt in Ausstellungen. In: Museumskunde 68 / 1 (2003), 7-17.

Beil, Christine: Der ausgestellte Krieg. Präsentationen des Ersten Weltkriegs 1914-1939. Tübingen 2004.

Berghold, Josef: Feindbilder aus der Sicht der politischen Psychologie. In: Bingen, Dieter/Loew, Peter O./Wóycicki, Kazimierz (Hg.): Die Destruktion des Dialogs. Zur innenpolitischen Instrumentalisierung negativer Fremd- und Feindbilder. Polen, Tschechien, Deutschland und die Niederlande im Vergleich, 1900-2005. Wiesbaden 2007, 15-22.

Bergmann, Klaus: Personalisierung, Personifizierung. In: Bergmann, Klaus et al. (Hg.): Handbuch der Geschichtsdidaktik. Seelze-Velber 1997, 298-300.

Błoński, Jan: Biedni Polacy patrzą na getto [Die armen Polen schauen auf das Ghetto]. 2. Aufl. Kraków 2008.

Blume, Rebekka: Das lettische Okkupationsmuseum. Das Geschichtsbild des Museums im Kontext der Diskussionen über die Okkupationszeit in der lettischen Öffentlichkeit. Bremen Juli 2007.

Bogumit, Zuzanna: Miejsce pamięci versus symulacja przeszłości - druga wojna światowa na wystawach historycznych [Gedenkort versus Simulation der Vergangenheit - Der Zweite Weltkrieg in historischen Ausstellungen]. In: Kultura i Społeczeństwo 55 / 4 (2011), 149-170.

Bogumit, Zuzanna: Pamięć Gułagu [Die Erinnerung an den Gulag]. Kraków 2012. Bogumit, Zuzanna et al.: The Enemy on Display, The Second World War in Eastern European Museums. New York 2015.

Bogumit, Zuzanna/Wawrzyniak, Joanna: Das Bild des »Deutschen«. Die Darstellung der NS-Besatzung in ausgewählten Warschauer Museen. In: Bingen, Dieter/Loew, Peter Oliver/Popp, Dietmar (Hg.): Visuelle Erinnerungskulturen und Geschichtskonstruktionen in Deutschland und Polen seit 1939. Warszawa 2009, 189-204.

Bogumił, Zuzanna/Wawrzyniak, Joanna: Narracje zniszczenia. Trauma wojenna 
w muzeach miejskich Petersburga, Warszawy i Drezna [Narrative der Zerstörung. Das Trauma des Kriegs in den Stadtmuseen St. Petersburgs, Warschaus und Dresdens]. In: Kultura i Społeczeństwo 54 / 4 (2010), 3-21.

Böhler, Jochen: Auftakt zum Vernichtungskrieg. Die Wehrmacht in Polen 1939. Bonn 2006.

Bömelburg, Hans-Jürgen: Die Erinnerung an die deutsche Besatzung während des Zweiten Weltkriegs in Polen - Transformationen und Kontinuitäten der polnischen Erinnerungskultur 1980-2005. In: Faulenbach, Bernd/Jelich, Franz-Josef (Hg.): »Transformationen« der Erinnerungskulturen in Europa nach 1989. Essen 2006, 55-78.

Borejsza, Jerzy W.: Einige Anmerkungen zum Gebrauch des Begriffs Kollaboration in der heutigen polnischen Sprache. In: Tauber, Joachim (Hg.): «ollaboration« in Nordosteuropa. Erscheinungsformen und Deutungen im 20. Jahrhundert. Wiesbaden 2006, 305-313.

Borodziej, Włodzimierz: Erinnerung an den Zweiten Weltkrieg - 50 Jahre später. In: Kobylińska, Ewa/Lawaty, Andreas (Hg.): Erinnern, vergessen, verdrängen. Polnische und deutsche Erfahrungen. Wiesbaden 1998, 66-77.

Borodziej, Włodzimierz: Terror und Politik. Die deutsche Polizei und die polnische Widerstandsbewegung im Generalgouvernement 1939-1944. Mainz 1999.

Borodziej, Włodzimierz: Abschied von der Martyrologie in Polen? In: Sabrow, Martin/Jessen, Ralph/Grosse Kracht, Klaus (Hg.): Zeitgeschichte als Streitgeschichte. Große Kontroversen seit 1945. München 2003, 288-305.

Borodziej, Włodzimierz: Der Warschauer Aufstand 1944. Frankfurt am Main 2004.

Borodziej, Włodzimierz: Zur Debatte um Kollaboration in Polen im Zweiten Weltkrieg. In: Tauber, Joachim (Hg.): »Kollaboration« in Nordosteuropa. Erscheinungsformen und Deutungen im 20. Jahrhundert. Wiesbaden 2006, 342-352.

Borodziej, Włodzimierz: Geschichte Polens im 20. Jahrhundert. München 2010.

Borodziej, Włodzimierz: Der Zweite Weltkrieg in der Geschichtspolitik Polens seit 1989. In: Troebst, Stefan/ Wolf, Johanna (Hg.): Erinnern an den Zweiten Weltkrieg. Mahnmale und Museen in Mittel- und Osteuropa. Leipzig 2011, 145-150.

Borodziej, Włodzimierz: Geschichtspolitik und »Konkurrenz der Opfer«. In: François, Etienne et al. (Hg.): Geschichtspolitik in Europa seit 1989. Deutschland, Frankreich und Polen im internationalen Vergleich. Göttingen 2013, 159-168.

Borodziej, Włodzimierz et al.: Polska Podziemna 1939-1945 [Polen im Untergrund 1939-1945]. Warszawa 1991.

Borodziej, Włodzimierz/Hajnicz, Artur (Hg.): Kompleks Wypędzenia [Der Komplex der Vertreibung]. Kraków 1998.

Borodziej, Włodzimierz/Lemberg, Hans (Hg.): Niemcy w Polsce 1945-1950. Wybór dokumentów [Die Deutschen in Polen 1945-1950. Eine Auswahl von Dokumenten]. 4 Bde. Warszawa 2000-2001.

Borodziej, Włodzimierz/Lemberg, Hans (Hg.): >Unsere Heimat ist uns ein fremdes Land geworden ... Die Deutschen östlich von Oder und Neiße 1945-1950. Dokumente aus polnischen Archiven. 4 Bde. Marburg 2000-2004.

Borodziej, Włodzimierz/Ziemer, Klaus (Hg.): Deutsch-polnische Beziehungen 1939 1945 - 1949. Eine Einführung. Osnabrück 2000. 
Bown, Hilary/Fuhrmann, Karolina/Milewicz, Maciej: Geschichtspolitik und lokale Identität in Breslau seit 1989. In: Ther, Phillipp / Królik, Tomasz/Henke, Lutz (Hg.): Das polnische Breslau als europäische Metropole. Erinnerung und Geschichtspolitik aus dem Blickwinkel der Oral History. Polski Wrocław jaki metropolia europejska. Pamięć i polityka historyczna z punktu widzenia oral history. Wrocław 2005, 42-52.

Boysen, Jens: Militär- und Kriegsmuseen in Deutschland und Polen. In: Inter Finitimos 10 (2012), 36-53.

Bredekamp, Horst: Bildakte als Zeugnis und Urteil. In: Flacke, Monika (Hg.): Mythen der Nationen. 1945 - Arena der Erinnerungen. Bd. 1. Mainz 2004, 29-66.

Bussenius, Daniel: Von der Hauptstadtposse zur Erfolgsgeschichte. Die Entstehung des Jüdischen Museums Berlin 1971-2001. Göttingen 2014.

Cała, Alina: Przenikanie się i wzajemne oddziaływanie. Żydzi i ich otoczenie [Gegenseitige Durchdringung und Beeinflussung. Juden und ihre Umgebung]. In: Traba, Elżbieta/Traba, Robert (Hg.): Tematy żydowskie. Historia, literatura, edukacja [Jüdische Themen. Geschichte, Literatur, Erziehung]. Olsztyn 1999, 45-54.

Cała, Alina: Kształtowanie się polskiej i żydowskiej wizji martyrologicznej po II wojnie światowej [Die Genese des polnischen und jüdischen Märtyrermythos nach dem Zweiten Weltkrieg]. In: Przegląd socjologiczny 49/ 2 (2000), 167-180.

Caumanns, Ute/Niendorf, Mathias: Von Kolbe bis Kielce. Ein Heiliger, seine Presse und die Geschichte eines Pogroms. In: Bömelburg, Hans-Jürgen / Eschment, Beate (Hg.): »Der Fremde im Dorf«. Überlegungen zum Eigenen und zum Fremden in der Geschichte. Rex Rexheuser zum 65. Geburtstag. Lüneburg 1998, 169-194.

Cemka, Franciszek: Zustand, Struktur und Finanzierung der Museen in Polen nach der Reform der Selbstverwaltung. Stan, struktura i finansowanie muzeów w Polsce po reformie samorządowej. In: Museumskunde 65 / 2 (2000), 24-36.

Chojecka, Ewa: Trzy modele kulturowej pamięci: Kraków, Katowice, Wrocław [Drei Modelle kultureller Erinnerung: Krakau, Katowice, Wrocław]. In: Herito 2 (2011), 78-87.

Chwalba, Andrzej: Dzieje Krakowa [Die Geschichte Krakaus]. Bd. 5: Kraków w latach 1939-1945 [Krakau in den Jahren 1939-1945]. Kraków 2002.

Chwalba, Andrzej: Dzieje Krakowa [Die Geschichte Krakaus]. Bd. 6: Kraków w latach 1945-1989 [Krakau in den Jahren 1945-1989]. Kraków 2004.

Chwalba, Andrzej: Okupacyjny Kraków w latach 1939-1945 [Das besetzte Krakau in den Jahren 1939-1945]. Kraków 2011.

Cichy, Michał: Polen und Juden - schwarze Kapitel des Warschauer Aufstands. In: Engelking, Barbara/Hirsch, Helga (Hg.): Unbequeme Wahrheiten. Polen und sein Verhältnis zu den Juden. Frankfurt am Main 2008, 54-78.

Cornelißen, Christoph: Was heißt Erinnerungskultur? Begriff - Methoden - Perspektiven. In: Geschichte in Wissenschaft und Unterricht 54 (2003), 548-563.

Davies, Norman/Moorhouse, Roger: Breslau - Die Blume Europas. Die Geschichte einer mitteleuropäischen Stadt. München 2002.

Dawid, Evelyn/Schlesinger, Robert: Texte in Museen und Ausstellungen. Ein Praxisleitfaden. Bielefeld 2002.

Dean, Martin: Polen in der einheimischen Hilfspolizei. Ein Aspekt der Besatzungs- 
realität in den deutsch besetzten ostpolnischen Gebieten. In: Chiari, Bernhard (Hg.): Die polnische Heimatarmee. Geschichte und Mythos der Armia Krajowa seit dem Zweiten Weltkrieg. München 2003, 355-368.

Deme, Katalin: Jüdische Museen in Ostmitteleuropa. Kontinuitäten - Brüche - Neuanfänge: Prag, Budapest, Bratislava (1993-2012). Göttingen 2016.

Dmitrów, Edmund: Die Polen: Zum Wandel historischer Selbst- und Fremdbilder einer Opfernation seit dem Zweiten Weltkrieg. In: Buschmann, Nikolaus/Langewiesche, Dieter (Hg.): Der Krieg in den Gründungsmythen europäischer Nationen und der USA. Frankfurt, New York 2003, 331-350.

Dmitrów, Edmund: Zum Wandel der Gedenktage anlässlich des Warschauer Aufstands von 1945 bis heute. In: Jaworski, Rudolf/Kusber, Jan (Hg.): Erinnern mit Hindernissen. Osteuropäische Gedenktage und Jubiläen im 20. und zu Beginn des 21. Jahrhunderts. Münster 2011, 167-178.

Dmitrów, Edmund/Kułak, Jerzy: Der polnische »Historikerstreit« zur Armia Krajowa. In: Chiari, Bernhard (Hg.): Die polnische Heimatarmee. Geschichte und Mythos der Armia Krajowa seit dem Zweiten Weltkrieg. München 2003, 807-846.

Dmitrów, Edmund/Machcewicz, Paweł/Szarota, Tomasz: Der Beginn der Vernichtung. Zum Mord an den Juden in Jedwabne und Umgebung im Sommer 1941. Neue Forschungsergebnisse polnischer Historiker. Osnabrück 2004.

Doroszewski, Jerzy/Radzik, Tadeusz (Hg.): Z dziejów społeczności żydowskiej na Lubelszczyźnie w latach 1918-1939 [Aus der Geschichte der jüdischen Gemeinde in der Lubliner Region in den Jahren 1918-1939]. Lublin 1991.

Dyroff, Stefan/Krzoska, Markus (Hg.): Geschichtsbilder und ihre museale Präsentation. Ausgewählte Beiträge zur Geschichte der Deutschen in Polen in Vergangenheit und Gegenwart. München 2008.

Dyroff, Stefan/Radziszewska, Krystyna/Röskau-Rydel, Isabel: Lodz jenseits von »Fabriken, Wildwest und Provinz«. Kulturwissenschaftliche Studien über die Deutschen in und aus den polnischen Gebieten. München 2009.

Ebenfeld, Stefan: Geschichte nach Plan? Die Instrumentalisierung der Geschichtswissenschaft in der DDR am Beispiel des Museums für Deutsche Geschichte in Berlin (1950 bis 1955). Marburg 2001.

Engelhardt, Isabelle: A Topography of Memory. Representations of the Holocaust at Dachau and Buchenwald in Comparison with Auschwitz, Yad Vashem and Washington, DC. Bruxelles u.a. 2002.

Engelking, Barbara: »szanowny panie gistapo«. Donosy do władz niemieckich w Warszawie i okolicach w latach 1940-1941 [»sehr geehrter herr gistapo«. Denunziationen an deutsche Behörden in Warschau und seiner Umgebung in den Jahren 1940-1941]. Warszawa 2003.

Engelking-Boni, Barbara / Leociak, Jacek: Getto warszawskie. Przewodnik po nieistniejącym mieście [Das Warschauer Ghetto. Führer durch eine nichtexistente Stadt]. Warszawa 2001.

Engelking-Boni, Barbara/Libionka, Dariusz: Żydzi w powstańczej Warszawie [Juden im aufständischen Warschau]. Warszawa 2009.

Eser, Ingo: Lodz - Blick(e) auf eine Stadtgeschichte. In: Dyroff, Stefan/Radziszewska, Krystyna/Röskau-Rydel, Isabel (Hg.): Lodz jenseits von »Fabriken, Wildwest und 
Provinz«. Kulturwissenschaftliche Studien über die Deutschen in und aus den polnischen Gebieten. München 2009, 31-55.

Fabiszak, Małgorzata/Owsiński, Marcin (Hg.): Obóz - muzeum. Trauma we współczesnym wystawiennictwie [Lager - Museum. Traumata im gegenwärtigen Ausstellungswesen]. Kraków 2013.

Faulenbach, Bernd/Jelich, Franz-Joseph (Hg.): »Asymmetrisch verflochtene Parallelgeschichte?« Die Geschichte der Bundesrepublik und der DDR in Ausstellungen, Museen und Gedenkstätten. Essen 2005.

Fedorowicz, Agnieszka: Współczesne formy upamiętniania wiedzy o martyrologii Polaków dystryktu lubelskiego w świetle działalności Muzeum Martyrologii »Pod Zegarem« [Aktuelle Formen der Vermittlung des Wissens über das Martyrium der Polen im Distrikt Lublin am Beispiel der Tätigkeiten des Martyrologiemuseums »Unter der Uhr«]. In: Konferencja »Od Westerplatte do Norymbergi. II wojna światowa we współczesnej historiografii, muzealnictwie i edukacji« w Muzeum Stutthof (2-5 września 2009 r.) [Konferenz »Von der Westerplatte nach Nürnberg. Der Zweite Weltkrieg in Geschichtswissenschaft, Museumswesen und Bildung der Gegenwart«im Museum Stutthof (2.-5. September 2009)]. Hg.v. Muzeum Stutthof. Sztutowo 2009, 328-333.

Feuchert, Sascha: Die Ghetto-Chronik: Entstehung und Überlieferung. Eine Projektskizze. In: Ders./Leibfried, Erwin/Riecke, Jörn (Hg.): Die Chronik des Gettos Lodz/ Litzmannstadt. Supplemente und Anhang. Göttingen 2009, 167-190.

Filipkowski, Piotr: Das Zentrum KARTA - Konzept und Formen historischer Bildung. In: Knigge, Volkhard/Mählert, Ulrich (Hg.): Der Kommunismus im Museum. Formen der Auseinandersetzung in Deutschland und Ostmitteleuropa. Köln u.a. 2005, 147-159.

Filipkowski, Piotr: Historia mówiona i wojna: doświadczenie obozu koncentracyjnego w perspektywie narracji biograficznych [Oral history und Krieg: Die Erfahrung des Konzentrationslagers in der Perspektive biografischer Narrationen]. Wrocław 2010.

Fischer, Peter et al.: Museen und Ausstellungen. Inter Finitimos 10 (2012).

Flacke, Monika: Erinnerungen. In: Dies. (Hg.): Mythen der Nationen. 1945 - Arena der Erinnerungen. Bd. 1. Mainz 2004, 7-12.

Flacke, Monika: Geschichtsausstellungen. Zum `Elend der Illustration‘. In: Helas, Philine et al. (Hg.): Bild / Geschichte. Festschrift für Horst Bredekamp. Berlin 2007, 481-490.

Flierl, Thomas/Müller, Elfriede (Hg.): Osteuropa - Schlachtfeld der Erinnerungen. Berlin 2010.

Folga-Januszewska, Dorota: Muzea w Polsce 1989-2008 [Museen in Polen 1989-2008]. In: Muzealnictwo 50 (2009), 18-46.

Folga-Januszewska, Dorota: Muzea w Polsce 1989-2008. Stan, zachodzące zmiany i kierunki rozwoju muzeów w Europie oraz rekomendacje dla muzeów polskich [Museen in Polen 1989-2008. Aktuelle Situation, stattfindende Veränderungen und Entwicklungsrichtungen von Museen in Europa sowie Empfehlungen für polnische Museen]. Warszawa Dezember 2008.

Forecki, Piotr: Spór o Jedwabne. Analiza debaty publicznej [Der Streit um Jedwabne. Eine Analyse der öffentlichen Debatte]. Poznań 2008. 
Forecki, Piotr: Od »Shoah« do »Strachu«. Spory o polsko-żydowską przeszłość i pamięć w debatach publicznych [Von »Shoah« zu »Angst«. Die Auseinandersetzungen über die polnisch-jüdische Vergangenheit und Erinnerung in öffentlichen Debatten]. Poznań 2010.

François, Etienne: Meistererzählungen und Dammbrüche. Die Erinnerung an den Zweiten Weltkrieg zwischen Nationalisierung und Universalisierung. In: Flacke, Monika (Hg.): Mythen der Nationen. 1945 - Arena der Erinnerungen. Bd. 1. Mainz 2004, 13-28.

François, Etienne et al. (Hg.): Geschichtspolitik in Europa seit 1989. Deutschland, Frankreich und Polen im internationalen Vergleich. Göttingen 2013.

Franzke, Jürgen: Sakral oder schockierend - Die Darstellung historischer Wirklichkeit im Museum. In: Rüsen, Jörn/Ernst, Wolfgang/Grütter, Heinrich Theodor (Hg.): Geschichte sehen. Beiträge zur Ästhetik historischer Museen. Pfaffenweiler 1988, 69-81.

Friedländer, Saul: Das Dritte Reich und die Juden. Verfolgung und Vernichtung 1933-1945. 2 Bde. Bonn 2007.

Friedrich, Klaus-Peter: Zusammenarbeit und Mittäterschaft in Polen 1939-1945. In: Dieckmann, Christoph / Quinkert, Babette/Tönsmeyer, Tatjana (Hg.): Kooperation und Verbrechen. Formen der »Kollaboration« im östlichen Europa 1939-1945. Göttingen 2003, 113-150.

Friedrich, Klaus-Peter: Erinnerungspolitische Legitimierung des Opferstatus: Zur Instrumentalisierung fragwürdiger Opferzahlen in Geschichtsbildern vom Zweiten Weltkrieg in Polen und Deutschland. In: Bingen, Dieter/Loew, Peter O./Wóycicki, Kazimierz (Hg.): Die Destruktion des Dialogs. Zur innenpolitischen Instrumentalisierung negativer Fremd- und Feindbilder. Polen, Tschechien, Deutschland und die Niederlande im Vergleich, 1900-2005. Wiesbaden 2007, 176-191.

Gądek, Mariusz (Hg.): Wokół Strachu. Dyskusja o książce Jana T. Grossa [Über »Angst«. Die Debatte über das Buch von Jan T. Gross]. Kraków 2008.

Ganzenmüller, Jörg/Utz, Raphael (Hg.): Orte der Shoah in Polen. Gedenkstätten zwischen Mahnmal und Museum. Köln u. a. 2016.

Ganzer, Christian: Musealisierung des Kriegsbeginns. Geschichtsbilder in der Dauerausstellung des »Museums der Verteidigung der Brester Festung«. In: Makhotina, Ekaterina et al. (Hg.): Krieg im Museum. Präsentationen des Zweiten Weltkriegs in Museen und Gedenkstätten des östichen Europa. Göttingen 2015, 83-109.

Garsztecki, Stefan: Warschauer Aufstand und Zweiter Weltkrieg. Polnische Gedächtnispolitik zwischen nationaler Kanonbildung und europäischen Ansätzen. In: Loew, Peter O./Prunitsch, Christian (Hg.): Polen. Jubiläen und Debatten. Beiträge zur Erinnerungskultur. Wiesbaden 2012, 136-156.

Gasowski, Tomasz: The Second Republic and its Jewish Citizens. In: Kapralski, Sławomir (Hg.): The Jews in Poland. Bd. 2. Cracow 1999, 125-136.

Geertz, Clifford: Dichte Beschreibung. Bemerkungen zu einer deutenden Theorie von Kultur. In: Ders. (Hg.): Dichte Beschreibung. Beiträge zum Verstehen kultureller Systeme. Frankfurt am Main 1987, 7-43.

Głowiński, Michał: Język jako bariera [Die Sprache als Barriere]. In: MagdziakMiszewska, Agnieszka/Zuchniak, Monika/Kowal, Paweł (Hg.): Polacy i Rosjanie. 
100 kluczowych pojęć [Polen und Russen. 100 Schlüsselbegriffe]. Warszawa 2002, $11-20$.

Gniazdowski, Mateusz: Bevölkerungsverluste durch Deutsche und Polen während des Zweiten Weltkrieges. Eine Geschichte der Forschungen und Schätzungen. In: Historie. Jahrbuch des Zentrums für Historische Forschung Berlin der Polnischen Akademie der Wissenschaften 1 (2008), 65-92.

Goldmann, Barbara: Muzea polskie, ich liczby i region działania w XIX i XX wieku [Polnische Museen, ihre Zahl und Tätigkeitsfelder im 19. und 20. Jahrhundert]. In: Muzealnictwo 43 (2001), 87-98.

Górny, Maciej: From the Splendid Past into the Unknown Future: Historical Studies in Poland after 1989. In: Antohi, Sorin/Trencsénye, Balász/Apor, Péter (Hg.): Narratives Unbound. Historical Studies in Post-Communist Eastern Europe. Budapest, New York 2007, 101-172.

Grabowski, Jan: Szmalcownicy warszawscy, 1939-1942 [Warschauer szmalcowniki, 1939-1942]. In: Zeszyty Historyczne 143 (2003), 85-117.

Grabowski, Jan: »Ja tego Zyda znam!« Szantażowanie Żydów w Warszawie, 1939-1943 [»Ich kenne diesen Juden!« Die Erpressung von Juden in Warschau, 1939-1943]. Warszawa 2004.

Grabski, Andrzej F.: Zarys historii historiografii polskiej [Abriss der Geschichte der polnischen Historiografie]. Poznań 2000.

Gross, Jan Tomasz: Polish Society Under German Occupation. The Generalgouvernement, 1939-1944. Princeton, New Yersey 1979.

Gross, Jan Tomasz: Sąsiedzi. Historia zagłady żydowskiego miasteczka [Nachbarn. Die Geschichte der Vernichtung eines jüdischen Städtchens]. 2. Aufl. Sejny 2000.

Gross, Jan Tomasz: Wokół »Sąsiadów«. Polemiki i wyjaśnienia [Zu den »Nachbarn«. Polemiken und Erläuterungen]. Sejny 2003.

Gross, Jan Tomasz: Upiorna dekada. Eseje o stereotypach na temat Żydów, Polaków, Niemców, komunistów i kolaboracji 1939-1948 [Die schreckliche Dekade. Essays zu Stereotypen über Juden, Polen, Deutsche, Kommunisten und die Kollaboration 1939-1945.]. Neue, korrigierte und erweiterte Aufl. Kraków 2007.

Gross, Jan Tomasz: Strach. Antysemityzm w Polsce tuż po wojnie. Historia moralniej zapaści [Angst. Antisemitismus in Polen kurz nach dem Krieg. Die Geschichte einer moralischen Niederlage]. Kraków 2008.

Gross, Jan Tomasz/Grudzińska-Gross, Irena: Złote żniwa. Rzecz o tym, co się działo na obrzeżach zagłady Żydów [Goldene Ernte. Was sich am Rande der Judenvernichtung ereignete]. Kraków 2011.

Gruber, Ruth Ellen: Virtually Jewish. Reinventing Jewish Culture in Europe. Berkeley u.a. 2002.

Gruszczyńska, Danuta K.: Przetrwali. 200 lat Gminy Żydowskiej w Łodzi [Sie haben überdauert. 200 Jahre der jüdischen Gemeinde in Łódź]. In: Kronika miasta Łodzi 3 (2006), 20-28.

Grütter, Heinrich Theodor: Zur Theorie historischer Museen und Ausstellungen. In: Blanke, Horst Walter/Jaeger, Friedrich/Sandkühler, Thomas (Hg.): Dimensionen der Historik. Geschichtstheorie, Wissenschaftsgeschichte und Geschichtskultur heute. Jörn Rüsen zum 60. Geburtstag. Köln u. a. 1998, 179-193. 
Gumola, Mieczysław: Odczytane z kamienia - Pomnik Dekalogu [Aus dem Stein lesen - Das Dekalog-Denkmal]. In: Kronika miasta Łodzi 2 (2004), 38-44.

Gutman, Israel (Hg.): Encyclopedia of the Holocaust. New York, London 1990.

Hahn, Hans Henning: Stereotypen in der Geschichte und Geschichte im Stereotyp. In: Ders. (Hg.): Historische Stereotypenforschung. Methodische Überlegungen und empirische Befunde. Oldenburg 1995, 190-204.

Hahn, Hans Henning: Zur Problematik jüdischer Identität in Ostmitteleuropa. Eine Einführung. In: Ders. / Stüben, Jens (Hg.): Jüdische Autoren in Ostmitteleuropa im 20. Jahrhundert. Frankfurt am Main 2000, 11-18.

Hahn, Hans Henning/Hahn, Eva: Nationale Stereotypen. Plädoyer für eine historische Stereotypenforschung. In: Hahn, Hans Henning (Hg.): Stereotyp, Identität und Geschichte. Die Funktion von Stereotypen in gesellschaftlichen Diskursen. Frankfurt am Main u. a. 2002, 17-56.

Hahn, Hans Henning / Traba, Robert (Hg.): Deutsch-Polnische Erinnerungsorte / Polsko-niemieckie miejsca pamięci. 9 Bde. Paderborn und Warszawa 2012-2015.

Hajduk, Jadwiga: Die publizistische Kontroverse um das »Zentrum gegen Vertreibungen«. Der Opfer-Täter-Diskurs in der deutschen und polnischen Presse (1999-2006). Łódź 2010.

Hamann, Christoph: Der Junge aus dem Warschauer Ghetto. Der Stroop-Bericht und die globalisierte Ikonografie des Holocaust. In: Paul, Gerhard (Hg.): Das Jahrhundert der Bilder. Bd. 1: 1900 bis 1949. Bonn 2009, 614-623.

Hansen, Marc: Die Toten der Schlacht im Großen Krieg und das Museum - Eine vergleichende Analyse der Darstellungspraxis deutscher und britischer Militärmuseen. In: Clauss, Martin (Hg.): Sterben im Krieg von der Antike bis zur Gegenwart. Paderborn 2017 (i. E.).

Hartwich, Mateusz: Rezension »1000 lat Wrocławia - 1000 Jahre Breslau«. In: H-Sozu-Kult, 20.6.2009, URL: http://hsozkult.geschichte.hu-berlin.de/rezensionen/id= 116\&type=rezausstellungen (am 21.6.2013).

$\mathrm{Ha}$, Matthias: Gestaltetes Gedenken. Yad Vashem, das US-Holocaust-MemorialMuseum und die Stiftung Topographie des Terrors. Frankfurt am Main, New York 2002.

Heinemann, Monika: Emotionalisierungsstrategien in historischen Ausstellungen am Beispiel ausgewählter Warschauer Museen. In: Dies. et al. (Hg.): Medien zwischen Fiction-Making und Realitätsanspruch - Konstruktionen historischer Erinnerungen. München 2011, 213-236.

Heinemann, Monika: Die Musealisierung des Ghettos. Die Verfolgung von Juden während des Zweiten Weltkriegs in Warschauer Museen. In: François, Étienne et al. (Hg.): Geschichtspolitik in Europa seit 1989. Deutschland, Frankreich und Polen im internationalen Vergleich. Göttingen 2013, 470-490.

Heinemann, Monika: Das Museum des Warschauer Aufstands. In: Zeitgeschichte-online, Juli 2014, URL: www.zeitgeschichte-online.de/geschichtskultur/das-museumdes-warschauer-aufstands (am 11.4.2015).

Heinemann, Monika: Die »Emaillewarenfabrik Oskar Schindlers« - Die neue Dauerausstellung vor dem Hintergrund der Musealisierung des Zweiten Weltkrieges seit den Achtzigerjahren. In: Makhotina, Ekaterina et al. (Hg.): Krieg im Museum. Prä- 
sentationen des Zweiten Weltkriegs in Museen und Gedenkstätten des östlichen Europa. Göttingen 2015, 255-284.

Heinemann, Monika: Muzeum historyczne jako fabryka pamięci - polski boom muzealny z perspektywy nowej muzeologii [Das historische Museum als Erinnerungsfabrik - Der polnische Museumsboom aus der Perspektive der Neuen $\mathrm{Mu}$ seologie]. In: Ǩezník, Miloš et al. (Hg.): Historia w kulturze ponowoczesnej. Koncepcje - metody - perspektywy badawcze [Geschichte in der Spätmoderne. Konzepte - Methoden - Forschungsperspektiven]. Kraków 2017 (i. E.).

Heinemann, Monika et al. (Hg.): Medien zwischen Fiction-Making und Realitätsanspruch - Konstruktionen historischer Erinnerungen. München 2011.

Hempel, Adam: Pogrobowcy klęski. Rzecz o policji "granatowej« w Generalnym Gubernatorstwie 1939-1945 [Die Totengräber der Niederlage. Zur »blauen« Polizei im Generalgouvernement 1939-1945]. Warszawa 1990.

Herget, Beate/Pleitner, Berit (Hg.): Heimat im Museum? Museale Konzeptionen zu Heimat und Erinnerungskultur in Deutschland und Polen. München 2008.

Hilberg, Raul: Täter, Opfer, Zuschauer. Die Vernichtung der Juden 1933-1945. Frankfurt am Main 1999.

Hinz, Hans-Martin (Hg.): Der Krieg und seine Museen. Frankfurt am Main, New York 1997.

Hoenig, Bianca: Chancen und Grenzen eines Paradigmas. Die Totalitarismustheorie in Anwendung auf den ostmitteleuropäischen Staatssozialismus. In: Bohemia 49/2 (2009), 431-444.

Hoffmann, Detlef: Drei Jahrzehnte Museumsentwicklung in der Bundesrepublik Trends, Strukturen, Perspektiven. In: Vom Elfenbeinturm zur Fußgängerzone. Drei Jahrzehnte deutsche Museumsentwicklung. Versuch einer Bilanz und Standortbestimmung. Hg.v. Landschaftsverband Rheinland. Opladen 1996, 13-23.

Hofmann, Andreas R.: Realsozialismus und Totalitarismus. Polnische Variationen über ein europäisches Thema. In: Inter Finitimos 5 (2007), 9-26.

Holtschneider, K. Hannah: The Holocaust and Representation of Jews. History and Identity in the Museum. London, New York 2011.

Hooper-Greenhill, Eilean: Studying Visitors. In: Macdonald, Sharon (Hg.): A Companion to Museum Studies. Malden, MA u. a. 2006, 362-376.

Horwitz, Gordon J.: Ghettostadt. Łódź and the Making of a Nazi City. Cambridge Mass., London 2008.

Huener, Jonathan: Auschwitz, Poland, and the Politics of Commemoration. 1945-1979. Athens 2003.

Indelak, Jacek: Die Stadt der vier Kulturen und andere Lodzer Mythen. In: Stadtbauwelt. Vierteljahreshefte der Bauwelt 48 (1997), 2716-2721.

International Council of Museums: ICOM Statues. Vienna 2007.

Jagodzińska, Katarzyna: Muzealna nadprodukcja? [Museale Überproduktion?]. In: Muzealnictwo 52 (2011), 215-225.

Jagodzińska, Katarzyna: Historyczne mury dla nowych muzeów. Muzealna moda na początku XXI wieku [Historische Mauern für neue Museen. Die museale Mode am Anfang des 21. Jahrhunderts]. In: Kultura i Społeczeństwo 55/ 4 (2011), 171-190. 
Janion, Maria: Do Europy - tak, ale razem z naszymi umarłymi [Nach Europa - ja, aber gemeinsam mit unseren Toten]. Warszawa 2000.

Jankowski, Robert: Jedwabne. Spór historyków wokół książki Jana T. Grossa »Sąsiedzi« [Jedwabne. Der Streit der Historiker über das Buch von Jan T. Gross »Nachbarn«]. Warszawa 2002.

Jankowski, Robert (Hg.): Cena »Strachu«. Gross w oczach historyków [Der Preis von "Angst«. Gross in den Augen von Historikern]. Warszawa 2008.

Jarausch, Konrad H./Sabrow, Martin: »Meistererzählung « - Zur Karriere eines Begriffs. In: Dies. (Hg.): Die historische Meistererzählung. Deutungslinien der deutschen Nationalgeschichte nach 1945. Göttingen 2002, 9-32.

Jong, Steffi De: Bewegte Objekte. Zur Musealisierung des Zeitzeugen. In: Schmidt, Sibylle / Krämer, Sybille / Voges, Ramon (Hg.): Politik der Zeugenschaft. Zur Kritik einer Wissenspraxis. Bielefeld 2011, 243-264.

Kaiser, Brigitte: Inszenierung und Erlebnis in kulturhistorischen Ausstellungen. Museale Kommunikation in kunstpädagogischer Perspektive. Bielefeld 2006.

Kaiser, Wolfram/Krankenhagen, Stefan/Poehls, Kerstin: Europa ausstellen. Das Museum als Praxisfeld der Europäisierung. Köln u. a. 2012.

Kalinowski, Konstanty: Die polnische Museumslandschaft. In: Schmirber, Gisela/ Langenstein, York (Hg.): Möglichkeiten und Wege der Zusammenarbeit der Museen in Mittel- und Osteuropa. Dokumentation der gemeinsamen Tagung mit der Landesstelle für die nichtstaatlichen Museen in Bayern. Kloster Banz 17.-19. Juni 1998. München 1999, 115-122.

Kalinowski, Konstanty: Veränderungen in der Museumslandschaft Polens. Zmiany w krajobrazie muzeów w Polsce. In: Museumskunde 65/2 (2000), 56-68.

Kaliński, Janusz/Landau, Zbigniew: Gospodarka Polski w XX wieku [Die Wirtschaft Polens im 20. Jahrhundert]. Warszawa 1998.

Kaluza, Karoline: Reimagining the Nation in Museums: Poland's Old and New National Museums. In: Knell, Simon J. et al. (Hg.): National Museums. New Studies from around the World. London, New York 2011, 151-162.

Kaplan, Flora E.S.: Exhibitions as Communicative Media. In: Hooper-Greenhill, Eilean (Hg.): Museum, Media, Message. London, New York 1995, 37-58.

Karp, Ivan/Lavine, Steven D. (Hg.): Exhibiting Cultures. The Poetics and Politics of Display. Washington, London 1991.

Karp, Ivan / Mullen Kreamer, Christine/Lavine, Steven D. (Hg.): Museums and Communities. The Politics of Public Culture. Washington, London 1992.

Keding, Ekaterina: Sieghafter Durchbruch oder vernichtende Niederlage? Deutsche Besatzung, sowjetischer Partisanenwiderstand und Kollaboration in Museen des Vitebsker Gebiets. In: Makhotina, Ekaterina et al. (Hg.): Krieg im Museum. Präsentationen des Zweiten Weltkriegs in Museen und Gedenkstätten des östlichen Europa. Göttingen 2015, 29-59.

Keneally, Thomas: Schindler's Ark. London 1982.

Keneally, Thomas: Schindler's List. New York 1982.

Kersten, Krystyna: Czy można rozliczyć się z historią PRL? [Kann man mit der Geschichte der VRP abrechnen?]. In: Borodziej, Włodzimierz (Hg.): Obrachunki $\mathrm{z}$ historią [Abrechnungen mit der Geschichte]. Warszawa 1997, 15-28. 
Kivelitz, Christoph: Die Propagandaausstellung in europäischen Diktaturen. Konfrontation und Vergleich: Nationalsozialismus in Deutschland, Faschismus in Italien und die UdSSR der Stalinzeit. Bochum 1999.

Klein, Nina: Die polnische Erinnerung an Auschwitz am Beispiel des staatlichen Museums Auschwitz-Birkenau. Konstanz 1999.

Knigge, Volkhard: Gedenkstätten und Museen. In: Ders./Frei, Norbert (Hg.): Verbrechen erinnern. Die Auseinandersetzung mit Holocaust und Völkermord. Bonn 2005, 398-409.

Knigge, Volkhard/Mählert, Ulrich (Hg.): Der Kommunismus im Museum. Formen der Auseinandersetzung in Deutschland und Ostmitteleuropa. Köln u. a. 2005.

Knigge, Volkhard et al. (Hg.): Arbeit am europäischen Gedächtnis. Diktaturerfahrung und Demokratieentwicklung. Köln u. a. 2011.

Kobylarz, Renata: Walka o pamięć. Polityczne aspekty obchodów rocznicy powstania w getcie warszawskim 1944-1989 [Der Kampf um die Erinnerung. Politische Aspekte der Gedenkfeiern zu den Jahrestagen des Warschauer Ghettoaufstandes 1944-1989]. Warszawa 2009.

Kochanowski, Jerzy/Kosmala, Beata (Hg.): Deutschland, Polen und der Zweite Weltkrieg. Geschichte und Erinnerung. Potsdam, Warschau 2009.

Köhr, Katja: Die vielen Gesichter des Holocaust. Museale Repräsentationen zwischen Individualisierung, Universalisierung und Nationalisierung. Göttingen 2012.

Kończal, Kornelia / Wawrzyniak, Joanna: Polskie badania pamięcioznawcze: tradycje, koncepcje, (nie)ciągłości [Erinnerungsforschung in Polen. Traditionen, Konzepte, (Dis-)Kontinuitäten]. In: Kultura i Społeczeństwo 55 / 4 (2011), 11-63.

Kończal, Kornelia/Wawrzyniak, Joanna: Traditionen, Konzepte, (Dis-)Kontinuitäten. Erinnerungsforschung in Polen. In: Osteuropa 62 / 5 (2012), 19-46.

Korff, Gottfried: Bildwelt Ausstellung. Die Darstellung von Geschichte im Museum. In: Borsdorf, Ulrich / Grütter, Heinrich Theodor (Hg.): Orte der Erinnerung. Denkmal, Gedenkstätte, Museum. Frankfurt am Main, New York 1999, 319-335.

Korff, Gottfried: Vom Verlangen, Bedeutungen zu sehen. In: Borsdorf, Ulrich/ Grütter, Heinrich Theodor/Rüsen, Jörn (Hg.): Die Aneignung der Vergangenheit. Musealisierung und Geschichte. Bielefeld 2004, 81-103.

Korff, Gottfried: Speicher und / oder Generator. Zum Verhältnis von Deponieren und Exponieren im Museum. In: Ders.: Museumsdinge. Deponieren - Exponieren. Köln u. a. 2007, 167-178.

Korff, Gottfried: Museumsdinge. Deponieren - Exponieren. 2. Aufl. Köln u. a. 2007.

Korzeniewski, Bartosz: Wystawy historyczne jako nośnik pamięci na przykładzie wystawy o zbrodniach Wehrmachtu [Historische Ausstellungen als Erinnerungsträger am Beispiel der Wehrmachtsausstellung]. In: Kultura Współczesna 53/3 (2007), 68-84.

Korzeniewski, Bartosz: Transformacja pamięci. Przewartościowania w pamięci przeszłości a wybrane aspekty funkcjonowania dyskursu publicznego o przeszłości w Polsce po 1989 roku [Die Transformation der Erinnerung. Die Veränderung der Bedeutung der Vergangenheit in der Erinnerung und ausgewählte Aspekte des öffentlichen Diskurses über die Vergangenheit in Polen nach 1989]. Poznań 2010 . 
Kosicki, Piotr H.: Les lieux de la mémoire polonaise de Katyn 1943-2010: d'une forêt à un musée. In: El Kenz, David/Nérard, François-Xavier (Hg.): Commémorer les victimes en Europe. XVIe-XXIe siècles. Seyssel 2011, 265-288.

Kosmala, Beata: Lange Schatten der Erinnerung: Der Zweite Weltkrieg im kollektiven Gedächtnis. In: Flacke, Monika (Hg.): Mythen der Nationen. 1945 - Arena der Erinnerungen. Bd. 2. Mainz 2004, 509-540.

Kosmala, Beata: Der Aufstand im Warschauer Ghetto 1943 und der Warschauer Aufstand 1944 in der Geschichtspolitik der Volksrepublik. In: Brumlik, Micha/Sauerland, Karol (Hg.): Umdeuten, verschweigen, erinnern. Die späte Aufarbeitung des Holocaust in Osteuropa. Frankfurt am Main u. a. 2010, 179-202.

Kossert, Andreas: >Promised Land`? Urban Myth and the Shaping of Modernity in Industrial Cities: Manchester and Lodz. In: Emden, Christian/Keen, Catherine/ Midgley, David (Hg.): Imaging the City. Bd.2: The Politics of Urban Space. Bern 2006, 169-192.

Kostro, Robert / Wóycicki, Kazimierz/ Wysocki, Michał (Hg.): Historia Polski od-nowa. Nowe narracje historii i muzealne reprezentacje przeszłości [Polnische Geschichte von Neuem/Erneuerung. Neue historische Narrationen und museale Geschichtsrepräsentationen]. Warszawa 2014.

Kowitz, Stephanie: Jedwabne. Kollektives Gedächtnis und tabuisierte Vergangenheit. Berlin 2004.

Koźmińska-Frejlak, Ewa: Świadkowie zagłady - holocaust jako zbiorowe doświadczenie Polaków [Die Zeugen der Vernichtung - der Holocaust als kollektive Erfahrung der Polen]. In: Przegląd socjologiczny 49/2 (2000), 181-206.

Koźmińska-Frejlak, Ewa: Wdzięczność i zapomnienie. Polacy i Żydzi wobec Sprawiedliwych (1944-2007) [Dankbarkeit und Vergessen. Das Verhältnis von Polen und Juden gegenüber den Gerechten (1944-2007)]. In: Tych, Feliks/AdamczykGarbowska, Monika (Hg.): Następstwa zagłady Żydów. Polska 1944-2010 [Die Folgen der Vernichtung der Juden. Polen 1944-2010]. Lublin 2011, 813-852.

Kraft, Claudia: Geschichte im langen Transformationsprozeß in Polen. In: Altrichter, Helmut (Hg.): GegenErinnerung. Geschichte als politisches Argument im Transformationsprozeß Ost-, Ostmittel- und Südosteuropas. München 2006, 129-150.

Kraft, Claudia: Die Debatte über polnisches Nationalbewusstsein und polnische Erinnerungskultur heute. In: Faulenbach, Bernd/Jelich, Franz-Joseph (Hg.): »Transformation« der Erinnerungskulturen in Europa nach 1989. Essen 2006, 93-112.

Kranz, Tomasz: Die NS-Hinterlassenschaft und die historisch-politische Bildung heute. In: Ders. (Hg.): Die Verbrechen des Nationalsozialismus im Geschichtsbewußtsein und in der historischen Bildung in Deutschland und Polen. Lublin 1998, 157-169.

Kranz, Tomasz: Muzea-miejsca pamięci w wymiarze społeczno-politycznym [MuseenGedenkorte in politisch-gesellschaftlicher Dimension]. In: Przeszłość i Pamięć 3 (1998), 6-12.

Kranz, Tomasz: Niemiecka koncepcja muzeów-miejsc pamięci [Die deutsche Konzeption von Museen-Gedenkorten]. In: Przeszłość i Pamięć 4/ 1 (1999), 75-78.

Kranz, Tomasz: Edukacja historyczna w miejscach pamięci. Zarys problematyki [Historische Bildung in Gedenkstätten. Problemabriss]. 2. Aufl. Lublin 2009. 
Kretschmann, Vasco: Die neue Dauerausstellung des Breslauer Stadtmuseums und das multikulturelle historische Erbe der Stadt. Berlin: Freie Universität Berlin 2012. Unveröffentlichte Masterarbeit.

Kroh, Jens: Das erweiterte Europa auf dem Weg zu einem gemeinsamen Gedächtnis? Die Stockholmer »Holocaust-Konferenz« und ihre Bedeutung für die europäische Erinnerung. In: Frölich, Margrit/Jureit, Ulrike/Schneider, Christian (Hg.): Das Unbehagen an der Erinnerung - Wandlungsprozesse im Gedenken an den Holocaust. Frankfurt am Main 2012, 201-216.

Król, Marcin: Romatyzm. Piekło i niebo Polaków [Die Romantik. Hölle und Himmel der Polen]. Warszawa 1998.

Krupa, Bartłomiej: Die Intensivierung der Holocaust-Diskussion. Der Streit um "Die dunklen Seiten des Aufstands« von Michał Cichy. In: Wolff-Powęska, Anna/ Forecki, Piotr (Hg.): Der Holocaust in der polnischen Erinnerungskultur. Frankfurt am Main u. a. 2012, 195-213.

Krzeminsski, Adam: Polen. In: Knigge, Volkhard/Frei, Norbert (Hg.): Verbrechen erinnern. Die Auseinandersetzung mit Holocaust und Völkermord. Bonn 2005, 282-291.

Krzymianowska, Justyna: Der Warschauer Aufstand zwischen Tabuisierung und Heroisierung. In: Schmid, Harald/Krzymianowska, Justyna (Hg.): Politische Erinnerung. Geschichte und kollektive Identität. Würzburg 2007, 211-222.

Kucia, Marek: Auschwitz jako fakt społeczny. Historia, współczesność i świadomość społeczna KL Auschwitz w Polsce [Auschwitz als gesellschaftliche Tatsache. Geschichte, Gegenwart und gesellschaftliche Wahrnehmung des KZ Auschwitz in Polen]. Kraków 2005.

Kula, Marcin: Dyskusja o Jedwabnem czy o Polsce? [Diskussionen über Jedwabne oder Polen?]. In: Ders. (Hg.): Uparta Sprawa. Żydowska? Polska? Ludzka? [Eine hartnäckige Sache. Jüdisch? Polnisch? Menschlich?]. Kraków 2004, 131-138.

Kurilo, Olga (Hg.): Der Zweite Weltkrieg im Museum: Kontinuität und Wandel. Berlin 2007.

Kurz, Iwona: Przepisywanie pamięci: przypadek Muzeum Powstania Warszawskiego [Das Umschreiben der Erinnerung: der Fall des Museums des Warschauer Aufstands]. In: Kultura Współczesna 3 / 53 (2007), 150-161.

Kwiatkowski, Piotr T.: II wojna światowa jako doświadczenie narodowe [Der Zweite Weltkrieg als nationale Erfahrung]. In: Ders. et al.: Między codziennością a wielką historią. Druga wojna światowa w pamięci zbiorowej społeczeństwa polskiego [Zwischen Alltag und großer Geschichte. Der Zweite Weltkrieg in der kollektiven Erinnerung der polnischen Gesellschaft]. Gdańsk, Warszawa 2010, 133-199.

$Ł a d a$, Agnieszka: Debata publiczna na temat powstania Centrum przeciw Wypędzeniom w prasie polskiej i niemieckiej [Die öffentliche Diskussion über die Entstehung des Zentrums gegen Vertreibungen in der polnischen und deutschen Presse]. Wrocław 2006.

Lagrou, Pieter: Europa als Ort gemeinsamer Erinnerungen? Opferstatus, Identität und Emanzipation von der Vergangenheit. In: François, Etienne et al. (Hg.): Geschichtspolitik in Europa seit 1989. Deutschland, Frankreich und Polen im internationalen Vergleich. Göttingen 2013, 298-308. 
Lamnek, Siegfried: Qualitative Sozialforschung. Band 2: Methoden und Techniken. 3., korrigierte Aufl. Weinheim 1995.

Leggewie, Claus/Meyer, Erik: »Ein Ort, an den man gerne geht«. Das HolocaustMahnmal und die deutsche Geschichtspolitik nach 1989. München, Wien 2005.

Lehrer, Erica: Kann Erbe Versöhnung stiften? Juden und Polen im Krakauer Stadtteil Kazimierz. In: Marszałek, Anna/Molisak, Alina (Hg.): Nach dem Vergessen. Rekurse auf den Holocaust in Ostmitteleuropa nach 1989. Berlin 2010, 47-74.

Leociak, Jacek: Dyskurs o pomocy [Der Diskurs über die Hilfe]. In: Zagłada Żydów 4 (2008), 7-13.

Leociak, Jacek: Zraniona pamięć. Rocznice powstania w getcie warszawskim w prasie polskiej 1944-1989 [Verletzte Erinnerung. Die Jahrestage des Aufstands im Warschauer Ghetto in der polnischen Presse 1944-1989]. In: Michnik, Adam (Hg.): Przeciw antysemityzmowi. 1936-2009 [Gegen den Antisemitismus. 1936-2009]. Bd. 3. Kraków 2010, 257-277.

Levy, Daniel/Sznaider, Natan: Erinnerung im globalen Zeitalter: Der Holocaust. Frankfurt am Main 2001.

Libionka, Dariusz (Hg.): Akcja Reinhardt. Zagłada Żydów w Generalnym Gubernatorstwie [Die Aktion Reinhardt. Die Vernichtung der Juden im Generalgouvernement]. Warszawa 2004.

Libionka, Dariusz: Polskie piśmiennictwo na temat zorganizowanej i indywidualnej pomocy Żydom (1945-2008) [Die polnische Literatur zum Thema der organisierten und individuellen Hilfe für Juden (1945-2008)]. In: Zagłada Żydów 4 (2008), 17-80.

Libionka, Dariusz: Sprawiedliwi - jako wyzwanie. Die Gerechten als Herausforderung. The Righteous as a Challenge. In: Dabrowska, Anna (Red.): Światła w ciemności. Sprawiedliwi Wśród Narodów Świata. Relacje/Lichter in der Finsternis. Gerechte unter den Völkern. Berichte/Lights in the Darkness. The Righteous Among the Nations. Testimonies. Lublin 2008, 11-16.

Libionka, Dariusz: Debata wokół Jedwabnego [Die Jedwabne-Debatte]. In: Tych, Feliks / Adamczyk-Garbowska, Monika (Hg.): Następstwa zagłady Żydów. Polska 1944-2010 [Die Folgen der Vernichtung der Juden. Polen 1944-2010]. Lublin 2011, 733-773.

Lipinsky, Jan: Das Geheime Zusatzprotokoll zum deutsch-sowjetischen Nichtangriffsvertrag vom 23. August 1939 und seine Entstehungs- und Rezeptionsgeschichte von 1939 bis 1999. Frankfurt am Main 2004.

Lis, Daniel (Hg.): Wokół »Złotych żniw«. Debata o książce Jana Tomasza Grossa i Ireny Grudzińskiej-Gross [Über die »Goldene Ernte«. Die Diskussion über das Buch von Jan Tomasz Gross und Irena Grudzińska-Gross]. Kraków 2011.

Liss, Andrea: Trespassing Through Shadows. Memory, Photography, and the Holocaust. Minneapolis, London 1998.

Loew, Peter Oliver: Helden oder Opfer? Erinnerungskulturen in Polen nach 1989. In: Osteuropa 58 / 6 (2008), 85-102.

Logemann, Daniel: Streit um das Museum des Zweiten Weltkriegs in Gdańsk. Wie soll man "polnische Geschichte« zeigen? In: Zeitgeschichte-online, April 2017, URL: www.zeitgeschichte-online.de/geschichtskultur/streit-um-das-museum-deszweiten-weltkriegs-gdansk (am 26.5.2017). 
Loose, Ingo: »Das Gesicht des Gettos«. Photographien und Photographen im Ghetto Litzmannstadt 1940-1944. In: Das Gesicht des Gettos. Bilder jüdischer Photographen aus dem Getto Litzmannstadt 1940-1944. The Face of the Ghetto. Pictures Taken by Jewish Photographers in the Litzmannstadt Ghetto 1940-1944 [Ausstellungskatalog]. Hg. v. der Stiftung Topographie des Terrors. Berlin 2010, 25-37.

Lotz, Christian: Das (Re-)Arrangieren von Feindbildern im geteilten Deutschland, in Polen und Bulgarien in der unmittelbaren Nachkriegszeit, 1945-1952. In: Bingen, Dieter/Loew, Peter O./Wóycicki, Kazimierz (Hg.): Die Destruktion des Dialogs. Zur innenpolitischen Instrumentalisierung negativer Fremd- und Feindbilder. Polen, Tschechien, Deutschland und die Niederlande im Vergleich, 1900-2005. Wiesbaden 2007, 146-161.

Löw, Andrea: Juden im Getto Litzmannstadt. Lebensbedingungen, Selbstwahrnehmung, Verhalten. Göttingen 2006.

Löw, Andrea: Ordnungsdienst im Getto Litzmannstadt. In: Samuś, Paweł/Puś, Wiesław (Hg.): Fenomen getta łódzkiego [Das Phänomen des Łódźer Ghettos]. Łódź 2006, 155-167.

Łukasiak-Mikłasz, Joanna (Hg.): Ofiary czy współwinni. Nazizm i sowietyzm w świadomości historycznej [Opfer oder Mitschuldige. Nazismus und Sowietismus im historischen Bewusstsein]. Warszawa 1997.

Macdonald, Sharon: Theorizing Museums: An Introduction. In: Dies./Fyfe, Gordon (Hg.): Theorizing Museums. Representing Identity and Diversity in a Changing World. Cambridge, MA 1996, 1-18.

Macdonald, Sharon: Exhibitions of Power and Powers of Exhibition. An Introduction to the Politics of Display. In: Dies. (Hg.): The Politics of Display. Museums, Science, Culture. London, New York 1998, 1-24.

Macdonald, Sharon: Nationale, postnationale, transkulturelle Identitäten und das Museum. In: Beier, Rosmarie (Hg.): Geschichtskultur in der zweiten Moderne. Frankfurt am Main, New York 2000, 123-148.

Macdonald, Sharon: Museen erforschen. Für eine Museumswissenschaft in der Erweiterung. In: Baur, Joachim (Hg.): Museumsanalyse. Methoden und Konturen eines neuen Forschungsfeldes. Bielefeld 2010, 49-69.

Machcewicz, Paweł (Hg.): Wokół Jedwabnego [Rund um Jedwabne]. 2 Bde. Warszawa 2002.

Madajczyk, Czesław: Między neutralną współpracą ludności terytoriów okupowanych a kolaboracją z Niemcami [Zwischen neutraler Zusammenarbeit der Bevölkerung der besetzten Gebiete und Kollaboration mit den Deutschen]. In: Studia nad Faszyzmem i Zbrodniami Hitlerowskimi 21 (1998), 181-196.

Madajczyk, Piotr: Bedeutung und Nutzen des Begriffs »Kollaboration« für Forschungen über die Zeitgeschichte Polens. In: Tauber, Joachim (Hg.): »Kollaboration« in Nordosteuropa. Erscheinungsformen und Deutungen im 20. Jahrhundert. Wiesbaden 2006, 314-323.

Madajczyk, Piotr: Die Rolle antideutscher Instrumentalisierungen in Polen, 1944-1989. In: Bingen, Dieter / Loew, Peter O./ Wóycicki, Kazimierz (Hg.): Narrative des Nationalen. Deutsche und polnische Nationsdiskurse im 19. und 20. Jahrhundert. Osnabrück 2010, 131-145. 
Maischein, Hannah: »Sekundäre Augenzeugen« der Shoah? Zur fotografischen Kommunikation in Erinnerungsdiskursen. In: Heinemann, Monika et al. (Hg.): Medien zwischen Fiction-Making und Realitätsanspruch - Konstruktionen historischer Erinnerungen. München 2011, 3-23.

Majewski, Piotr: Konzept und Organisation des »zivilen Kampfes«. In: Chiari, Bernhard (Hg.): Die polnische Heimatarmee. Geschichte und Mythos der Armia Krajowa seit dem Zweiten Weltkrieg. München 2003, 303-323.

Majewski, Piotr M.: Die Musealisierung des Zweiten Weltkrieges in Polen. In: Troebst, Stefan/Wolf, Johanna (Hg.): Erinnern an den Zweiten Weltkrieg. Mahnmale und Museen in Mittel- und Osteuropa. Leipzig 2011, 153-160.

Majewski, Tomasz/Zeigler-Janiszewska, Anna (Hg.): Memory of the Shoah. Cultural Representations and Commemorative Practices. Lodz 2010.

Makhotina, Ekaterina: Erinnerungen an den Krieg - Krieg der Erinnerungen. Litauen und der Zweite Weltkrieg. Göttingen 2017.

Mańkowski, Zygmunt (Hg.): Hitlerowskie więzienie na Zamku w Lublinie 1939-1944 [Das hitleristische Gefängnis im Lubliner Schloss 1939-1944]. Lublin 1988.

Mańkowski, Zygmunt: Die polnische Geschichtsschreibung über die NS-Verbrechen. In: Kranz, Tomasz (Hg.): Die Verbrechen des Nationalsozialismus im Geschichtsbewußtsein und in der historischen Bildung in Deutschland und Polen. Lublin 1998, 75-98.

Markiewicz, Tomasz: Der Kampf um die Erinnerung. Denkmäler der Heimatarmee in Warschau seit 1945. In: Chiari, Bernhard (Hg.): Die polnische Heimatarmee. Geschichte und Mythos der Armia Krajowa seit dem Zweiten Weltkrieg. München 2003, 753-775.

Marshall, Christopher R.: When Worlds Collide. The Contemporary Museum as Art Gallery. In: Macleod, Suzanne (Hg.): Reshaping Museum Space: Architecture, Design, Exhibitions. London 2005, 170-184.

Marszalec, Janusz: Der Polnische Untergdrundstaat und die polnischen Kommunisten. In: Böhler, Jochen/Lehnstaedt, Stephan (Hg.): Gewalt und Alltag im besetzten Polen 1939-1945. Osnabrück 2012, 449-476.

Marszałek, Józef: Żydzi warszawscy w Lublinie i na Lubelszczyźnie w latach 1940-1944 [Warschauer Juden in Lublin und der Lubliner Region in den Jahren 1940-1944]. In: Radzik, Tadeusz (Hg.): Żydzi w Lublinie. Materiały do dziejów społeczności żydowskiej Lublina [Juden in Lublin. Materialien zur Geschichte der jüdischen Gemeinde Lublins]. Bd. 1. Lublin 1995, 257-271.

Marszałek, Magdalena: Einleitung. In: Dies./Molisak, Alina (Hg.): Nach dem Vergessen. Rekurse auf den Holocaust in Ostmitteleuropa nach 1989. Berlin 2010, 7-23.

Marszałek, Magdalena: Holocaust. Die Tragödie der Nachbarn. In: Hahn, Hans Henning/Traba, Robert (Hg.): Deutsch-Polnische Erinnerungsorte. Bd.2: Geteilt/ Gemeinsam. Paderborn 2014, 641-660.

Martinz-Turek, Charlotte: Folgenreiche Unterscheidungen. Über Storylines im Museum. In: Dies./Sommer-Sieghart, Monika (Hg.): Storyline. Narrationen im Museum. Wien 2009, 15-29.

Martinz-Turek, Charlotte/Sommer-Sieghart, Monika: Vorwort. In: Dies. (Hg.): Storyline. Narrationen im Museum. Wien 2009, 7-14. 
Mazur, Grzegorz: Der »Bund für den bewaffneten Kampf - Heimatarmee« und seine Gliederung. In: Chiari, Bernhard (Hg.): Die polnische Heimatarmee. Geschichte und Mythos der Armin Krajowa seit dem Zweiten Weltkrieg. München 2003, 111-149.

Mazur, Grzegorz: Der Widerstand im Generalgouvernement 1939-1945. In: Młynarczyk, Jacek Andrzej (Hg.): Polen unter deutscher und sowjetischer Besatzung 1939-1945. Osnabrück 2009, 405-425.

Mazur, Zbigniew: Centrum przeciwko Wypędzeniom. (1999-2005) [Das Zentrum gegen Vertreibungen. (1999-2005)]. Poznań 2006.

Mazur, Zbigniew: Widoczny Znak (2005-2009) [Das Sichtbare Zeichen (2005-2009)]. Poznań 2009.

Megargee, Geoffrey P. (Hg.): Encyclopedia of Camps and Ghettos, 1933-1945. Bd. 1, Part A-B. Bloomington, Indianapolis 2009.

Melchior, Małgorzata: Zagłada i stosunki polsko-żydowskie w opracowaniach socjologicznych [Der Holocaust und die polnisch-jüdischen Beziehungen in soziologischen Arbeiten]. In: Zagłada Żydów 1 (2005), 52-72.

Meroń, Katarzyna: Dziedzictwo żydowskie Podgórza w działaniach samorządu terytorialnego [Das jüdische Erbe von Podgórze in den Aktivitäten der Gemeindeselbstverwaltung]. Kraków: Uniwersytet Jagielloński 2009. Unveröffentlichte Magisterarbeit.

Michlic, Joanna B.: Coming to Terms with the »Dark Past«. The Polish Debate About the Jedwabne Massacre. Jerusalem 2002.

Michlic, Joanna Beata: Poland's Threatening Other. The Image of the Jew from 1880 to the Present. Lincoln, London 2006.

Michlic, Joanna B.: Łódź in the Post-Communist Era: In Search of a New Identity. In: Center for European Studies. Program on Eastern and Central Europe. Working Paper Series 65 (2008), 1-18.

Michlic, Joanna B.: »Pamiętanie dla upamiętnienia», "pamiętanie dla korzyści» i "pamiętanie, żeby zapomnieć«: różne modele pamięci o Żydach i Zagładzie w postkomunistycznej Polsce [»Erinnerung zum Gedenken«, »Erinnerung zum Nutzen« und »Erinnerung, um zu vergessen«: verschiedene Modelle der Erinnerung an Juden und den Holocaust im postkommunistischen Polen]. In: Kultura i Społeczeństwo 55/ 4 (2011), 225-245.

Michlic, Joanna Beata/Melchior, Małgorzata: The Memory of the Holocaust in Post1989 Poland. Renewal - Its Accomplishments and Its Powerlessness. In: Himka, John-Paul/Michlic, Joanna Beata (Hg.): Bringung the Dark Past to Light. The Reception of the Holocaust in Postcommunist Europe. Lincoln, London 2013, 403-450.

Młynarczyk, Jacek Andrzej: Zwischen Kollaboration und Verrat. Zum Problem der Kollaboration im Generalgouvernement 1939-1945. In: Ders. (Hg.): Polen unter deutscher und sowjetischer Besatzung 1939-1945. Osnabrück 2009, 345-383.

Motyka, Grzegorz: Der polnisch-ukrainische Gegensatz in Wolhynien und Ostgalizien. In: Chiari, Bernhard (Hg.): Die polnische Heimatarmee. Geschichte und Mythos der Armia Krajowa seit dem Zweiten Weltkrieg. München 2003, 531-547.

Mroczka, Ludwik: Dynamika rozwoju i struktura społeczno-zawodowa głównych grup etnicznych w Łodzi w latach 1918-1939 [Entwicklungsdynamik und gesell- 
schaftlich-berufliche Struktur der größten ethnischen Gruppen in Łódź in den Jahren 1918-1939]. In: Samuś, Paweł (Hg.): Polacy - Niemcy - Żydzi w Łodzi w XIX-XX w. Sąsiedzi dalecy i bliscy [Polen - Deutsche - Juden in Łódź im 19. und 20. Jahrhundert. Nahe und ferne Nachbarn]. Łódź 1997, 99-117.

Münkler, Herfried / Fischer, Karsten: „Nothing to kill or die for ...« Überlegungen zur politischen Theorie des Opfers. In: Leviathan 28/3 (2000), 343-362.

Murzyn, Monika A.: Kazimierz. Środkowoeuropejskie doświadczenie rewitalizacji [Kazimierz. Eine mitteleuropäische Erfahrung der Revitalisierung]. Kraków 2006. Murzyn-Kupisz, Monika: Przywracanie pamięci czy masowa konsumpcja? Dylematy odkrywania żydowskiego dziedzictwa kulturowego krakowskiego Kazimierza [Wiederherstellung der Erinnerung oder Massenkonsum? Dilemmata der Wiederentdeckung des jüdischen Kulturerbes im Krakauer Kazimierz]. In: Dies./ Purchla, Jacek (Hg.): Przywracanie pamięci. Rewitalizacja zabytkowych dzielnic żydowskich w miastach Europy Środkowej [Wiederherstellung der Erinnerung. Die Revitalisierung historischer jüdischer Stadteile in mitteleuropäischen Städten]. Kraków 2008, 363-398.

Murzyn-Kupisz, Monika/Purchla, Jacek (Hg.): Przywracanie pamięci. Rewitalizacja zabytkowych dzielnic żydowskich w miastach Europy Środkowej [Wiederherstellung der Erinnerung. Die Revitalisierung historischer jüdischer Stadteile in mitteleuropäischen Städten]. Kraków 2008.

Musiał, Bogdan: Deutsche Zivilverwaltung und Judenverfolgung im Generalgouvernement. Eine Fallstudie zum Distrikt Lublin 1939-1944. Wiesbaden 1999.

Musiał, Bogdan (Hg.): »Aktion Reinhardt«. Der Völkermord an den Juden im Generalgouvernement 1941-1944. Osnabrück 2004.

Musiał, Bogdan: Die Zivilverwaltung und der Holocaust. Verfolgung und Vernichtung der Juden im Generalgouvernement. In: Löw, Andrea/Robusch, Kerstin/ Walter, Stefanie (Hg.): Deutsche - Juden - Polen. Geschichte einer wechselvollen Beziehung im 20. Jahrhundert. Festschrift für Hubert Schneider. Frankfurt am Main, New York 2004, 97-117.

Muttenthaler, Roswitha/Wonisch, Regina: Gesten des Zeigens. Zur Repräsentation von Gender und Race in Ausstellungen. Bielefeld 2006.

Napiórkowski, Marcin: Powstanie umarłych. Historia pamięci 1944-2014 [Der Aufstand der Toten. Die Geschichte der Erinnerung 1944-2014]. Warszawa 2016.

Niewiara, Aleksandra: Procesy kategoryzacyjne a kulturowe konstruowanie obrazu »innego" (Moskwicin - Moskal - Rosjanin) [Prozesse der Kategorisierung und die kulturelle Konstruktion des »Anderen « (Moskowiter - Moskal - Russe)]. In: Lazari, Andrzej De (Hg.): Katalog wzajemnych uprzedzeń Polaków i Rosjan [Katalog der gegenseitigen Vorurteile von Polen und Russen]. Warszawa 2006, 49-72.

Nijakowski, Lech M.: Polska polityka pamięci. Esej socjologiczny [Die polnische Geschichtspolitik. Ein soziologischer Essay]. Warszawa 2008.

Nijakowski, Lech M.: Pamięć o II wojnie światowej a relacje Polaków z innymi narodami [Die Erinnerung an den Zweiten Weltkrieg und die Beziehungen der Polen zu anderen Nationen]. In: Kwiatkowski, Piotr T. et al.: Między codziennością a wielką historią. Druga wojna światowa w pamięci zbiorowej społeczeństwa polskiego [Zwischen Alltag und großer Geschichte. Der Zweite Weltkrieg in der 
kollektiven Erinnerung der polnischen Gesellschaft]. Gdańsk, Warszawa 2010, 239-286.

Offe, Sabine: Ausstellungen, Einstellungen, Entstellungen. Jüdische Museen in Deutschland und Österreich. Berlin u. a. 2000.

Ostolski, Adam: Przestrzeń muzeum a polityka traumy [Der Museumsraum und die Politik des Traumas]. In: Kultura i Społeczeństwo 53 / 3 (2009), 67-87.

Ostow, Robin: Remusealizing Jewish History in Warsaw: The Privatization and Externalization of Nation Building. In: Ders. (Hg.): (Re)Visualising National History. Museums and National Identities in Europe in the New Millennium. Toronto u.a. 2008, 157-180.

Paczkowski, Andrzej: Czy historycy dokonali »obrachunku« z PRL? [Haben die Historiker eine "Abrechnung« der VRP vorgenommen?]. In: Łukasiak-Mikłasz, Joanna (Hg.): Ofiary czy współwinni. Nazizm i sowietyzm w świadomości historycznej [Opfer oder Mitschuldige. Nazismus und Sowietismus im historischen Bewusstsein]. Warszawa 1997, 13-29.

Paul, Stefan: Kommunizierende Räume. Das Museum. In: Geppert, Alexander C.T./ Jensen, Uffa / Weinhold, Jörn (Hg.): Ortsgespräche. Raum und Kommunikation im 19. und 20. Jahrhundert. Bielefeld 2005, 341-357.

Pawlicki, Aleksander: Sonderwege der Zensurpolitik in der Volksrepublik Polen. In: Bock, Ivo (Hg.): Scharf überwachte Kommunikation. Zensursysteme in Ost(mittel) europa (1960er-1980er Jahre). Berlin 2011, 209-361.

Pękala, Teresa: Ocaleni i ocalająca - funkcjonowanie pamięci o Zagładzie w realizacjach artystycznych lubelskiego Ośrodka Brama Grodzka [Die Geretteten und die Retter - Die Holocaust-Erinnerung in den künstlerischen Aktivitäten des Lubliner Zentrums Burgtor]. In: Korzeniewski, Bartosz (Hg.): Przemiany pamięci społecznej a teoria kultury [Veränderungen der gesellschaftlichen Erinnerung und die Kulturtheorie]. Poznań 2007, 101-118.

Petermann, Sandra: Rituale machen Räume. Zum kollektiven Gedenken der Schlacht von Verdun und der Landung in der Normandie. Bielefeld 2007.

Pieper, Katrin: Die Musealisierung des Holocaust. Das Jüdische Museum Berlin und das U.S. Holocaust Memorial Museum in Washington D.C. Ein Vergleich. Köln u.a. 2006.

Pieper, Katrin: »üdisches« ausstellen. Allgemeine Betrachtungen über museale Konzeptionen und Eindrücke im Jüdischen Museum Berlin. In: Ernst, Petra/Lamprecht, Gerald (Hg.): Konzeptionen des Jüdischen. Kollektive Entwürfe im Wandel. Innsbruck u. a. 2009, 414-437.

Pieper, Katrin: Resonanzräume. Das Museum im Forschungsfeld Erinnerungskultur. In: Baur, Joachim (Hg.): Museumsanalyse. Methoden und Konturen eines neuen Forschungsfeldes. Bielefeld 2010, 187-212.

Piluk, Piotr: Lodz Bałuty. Memory of the Shoah in an Urban Landscape. In: Majewski, Tomasz/Zeigler-Janiszewska, Anna (Hg.): Memory of the Shoah. Cultural Representations and Commemorative Practices. Lodz 2010, 99-104.

Piskorski, Jan M.: Od kultu herosów do adoracji ofiar. Przemiany w kulturze pamięci [Vom Kult der Heroen zur Verehrung der Opfer. Veränderungen der Erinnerungskultur]. In: Więź 53 / 2-3 (2010), 5-20. 
Pleitner, Berit: Zeitgeschichte in polnischen Museen - zwischen »amtlicher « und »kritischer» Geschichte. In: Kotte, Eugen (Hg.): Kulturwissenschaften und Geschichtsdidaktik. München 2011, 219-233.

Podolska, Joanna: Przekroczono wszelkie normy etyczne. Stary Cmentarz przy Wesołej [Es wurden alle ethischen Normen überschritten. Der alte Friedhof an der Wesoła Straße]. In: Kronika miasta Łodzi 3-4 (2003), 97-99.

Podolska, Joanna: Litzmannstadt - getto. Ślady. Przewodnik po przeszłości [Das Ghetto Litzmannstadt. Spuren. Führer durch die Vergangenheit]. Łódź 2004.

Podolska, Joanna: Spacerownik. Łódź żydowska [Spaziergänge. Das jüdische Łódź]. Łódź 2009.

Podolska, Joanna: The Memory of the Lodz Ghetto. In: Majewski, Tomasz/ZeiglerJaniszewska, Anna (Hg.): Memory of the Shoah. Cultural Representations and Commemorative Practices. Lodz 2010, 105-114.

Polonsky, Antony: Stosunki polsko-żydowskie od roku 1984. Refleksje uczestnika [Die polnisch-jüdischen Beziehungen seit 1984. Reflexionen eines Teilnehmers]. In: Baczkowski, Michał et al. (Hg.): Widziane z zewnątrz [Von Außen betrachtet]. Warszawa 2011, 231-250.

Polonsky, Antony/Michlic, Joanna B. (Hg.): The Neighbors Respond. The Controversy Over the Jedwabne Massacre in Poland. Princeton, N. J. u. a. 2004.

Polska - Ukraina: trudna odpowiedź [Polen - Ukraine: eine schwierige Antwort]. Hg.v. Naczelna Dyrekcja Archiwów Państwowych und Ośrodek Karta. Warszawa 2003.

Pomnik Dekalogu [Das Dekalog-Denkmal]. In: Kronika miasta Łodzi 1 (1996), $40 \mathrm{f}$.

Popczyk, Maria (Hg.): Muzeum sztuki. Od Luwru do Bilbao [Das Kunstmuseum. Vom Louvre bis Bilbao]. Katowice 2006.

Porter, Brian: When Nationalism Began to Hate. Imganing Modern Politics in Nineteenth-Century Poland. New York, Oxford 2000.

Porter-Szücs, Brian: Faith and Fatherland. Catholicism, Modernity, and Poland. Oxford, New York 2011.

Potel, Jean-Yves: Zbyt często powtarzane stereotypy [Allzu häufig wiederholte Stereotype]. In: Engelking, Barbara et al. (Hg.): Zagłada Żydów. Pamięć narodowa a pisanie historii w Polsce i we Francji [Die Vernichtung der Juden. Nationale Erinnerung und Geschichtsschreibung in Polen und Frankreich]. Lublin 2006, 185-191.

Potel, Jean-Yves: Koniec Niewinności. Polska wobec swojej żydowskiej przeszłości [Das Ende der Unschuld. Polen im Angesicht seiner jüdischen Vergangenheit]. Kraków 2010.

Przewoźnik, Andrzej/Adamska, Jolanta: Katyń. Zbrodnia, prawda, pamięć [Katyń. Verbrechen, Wahrheit, Erinnerung]. Warszawa 2010.

Puś, Wiesław: Zmiany liczebności i struktury narodowościowej ludności Łodzi do roku 1939 [Veränderungen der Bevölkerungszahlen und -struktur von Łódź bis 1939]. In: Koter, Marek et al. (Hg.): Wpływ wielonarodowego dziedzictwa kulturowego Łodzi na współczesne oblicze miasta [Der Einfluss des multinationalen kulturellen Erbes auf das heutige Stadtbild]. Łódź 2005, 9-39.

Puttkamer, Joachim von/Warneck, Dorothea (Hg.): Exhibiting Violence. Przegląd Historyczny 57 / 1 (2016). 
Radzik, Tadeusz (Hg.): Żydzi w Lublinie. Materiały do dziejów społeczności żydowskiej Lublina [Juden in Lublin. Materialien zur Geschichte der jüdischen Gemeinde Lublins]. Bd. 1. Lublin 1995.

Radzik, Tadeusz: Lubelska dzielnica zamknięta [Der geschlossene Wohnbezirk von Lublin]. Lublin 1999.

Radziszewska, Krystyna: Żydzi zachodnioeuropejscy w getcie łódzkim w świetle dzienników i wspomnień z getta [Westeuropäische Juden im Łódźer Ghetto im Spiegel von Tagebüchern und Erinnerungen aus dem Ghetto]. In: Samuś, Paweł/ Puś, Wiesław (Hg.): Fenomen getta łódzkiego [Das Phänomen des Łódźer Ghettos]. Łódź 2006, 309-325.

Radziszewska, Krystyna: Die Darstellung des deutschen Anteils an der Stadtgeschichte in den Museen der Stadt Łódź. In: Dyroff, Stefan / Krzoska, Markus (Hg.): Geschichtsbilder und ihre museale Präsentation. Ausgewählte Beiträge zur Geschichte der Deutschen in Polen in Vergangenheit und Gegenwart. München 2008, 161-172.

Radziszewska, Krystyna: Deutschsprachige Juden im Getto Lodz/Litzmannstadt 1941-1944. In: Dyroff, Stefan / Radziszewska, Krystyna / Röskau-Rydel, Isabel (Hg.): Lodz jenseits von »Fabriken, Wildwest und Provinz«. Kulturwissenschaftliche Studien über die Deutschen in und aus den polnischen Gebieten. München 2009, 129-150.

Raffler, Marlies: Museum - Spiegel der Nation? Zugänge zur Historischen Museologie am Beispiel der Genese von Landes- und Nationalmuseen in der Habsburgermonarchie. Wien 2007.

Rahe, Thomas: »Höre Israel«. Jüdische Religiösität in nationalsozialistischen Konzentrationslagern. Göttingen 1999

Raulff, Ulrich: Erinnerung an Kriegsgeschehen des Ersten und Zweiten Weltkriegs in westeuropäischen Museen und Gedenkstätten. In: Museumskunde 64/ 1 (1999), 55-63.

Rév, István: The Terror of the House. In: Ostow, Robin (Hg.): (Re)Visualising National History. Museums and National Identities in Europe in the New Millennium. Toronto u.a. 2008, 47-89.

Rezler-Wasielewska, Violetta / Grudzińska, Marta: Lublin, Lipowa 7. Obóz dla Żydów polskich jeńców wojennych (1940-1943) [Lublin, Lipowa Straße 7. Das Lager für Juden - polnische Kriegsgefangene (1940-1943)]. In: Kwartalnik Historii Żydów 4 (2008), 490-514.

Röger, Maren: Verdrängter Besatzungsalltag: Intime Kontakte zwischen Deutschen und Polen 1939-1945 und ihre Nachgeschichte. In: Historie. Jahrbuch des Zentrums für Historische Forschung Berlin der Polnischen Akademie der Wissenschaften 7 (2013/2014), 170-181.

Romanowski, Gustaw/Strąkowski, Marek: Miejsca wymagają pamięci. Z Symchą Kellerem - przewodniczącym Gminy Wyznaniowej Żydowskiej - o sprawach duchowych i świeckich rozmawiają Gustaw Romanowski i Marek Strąkowski [Orte brauchen Erinnerung. Gustav Romanowski und Marek Strąkowski sprechen mit Symcha Keller, dem Vorsitzenden der Jüdischen Gemeinde, über geistige und weltliche Dinge]. In: Kronika miasta Łodzi 2 (2004), 13-20. 
Rottermund, Andrzej: Muzealnictwo warszawskie. Próba charakterystyki [Das Warschauer Museumswesen. Ein Versuch der Charakterisierung]. In: Ders./Sołtan, Andrzej/ Wrede, Marek (Hg.): 200 lat muzealnictwa warszawskiego. Dzieje i perspektywy. Materiały z sesji naukowej. Zamek Królewski w Warszawie. 16-17 listopada 2005 roku [200 Jahre des Warschauer Museumswesens. Geschichte und Perspektiven. Materialien der wissenschaftlichen Konferenz. Königsschloss in Warschau. 16.-17. November 2005]. Warszawa 2006, 25-38.

Ruchniewicz, Krzysztof: Zeitgeschichte in Polen nach 1989. Forschungsschwerpunkte, "weiße Flecken« und historische Kontroversen. In: Jahrbuch für Europäische Geschichte 4 (2003), 39-69.

Ruchniewicz, Krzysztof: Die Erinnerung an die Opfer des Stalinismus als Thema öffentlicher Diskussion in Polen. In: Faulenbach, Bernd/Jelich, Franz-Joseph (Hg.): »Transformation« der Erinnerungskulturen in Europa nach 1989. Essen 2006, 79-92.

Ruchniewicz, Krzysztof: Polen: Abschied von der Martyrologie? In: Schmid, Harald/ Krzymianowska, Justyna (Hg.): Politische Erinnerung. Geschichte und kollektive Identität. Würzburg 2007, 210-196.

Ruchniewicz, Krzysztof: Geschichtsstunde. Der Zweite Weltkrieg im polnischen Schulbuch. In: Osteuropa 58 / 6 (2008), 285-305.

Ruchniewicz, Małgorzata/Ruchniewicz, Krzysztof: Katyn 1940. In: Ueberschär, Gerd R. (Hg.): Orte des Grauens. Verbrechen im Zweiten Weltkrieg. Darmstadt 2003, 71-82.

Rüsen, Jörn: Was ist Geschichtskultur? Überlegungen zu einer neuen Art, über Geschichte nachzudenken. In: Rüsen, Jörn/Füßmann, Klaus/Grütter, Theo (Hg.): Historische Faszination. Geschichtskultur heute. Weimar 1994, 3-26.

Sabor, Agnieszka: W poszukiwaniu tożsamości [Auf der Suche nach Identität]. In: Murzyn-Kupisz, Monika/Purchla, Jacek (Hg.): Przywracanie pamięci. Rewitalizacja zabytkowych dzielnic żydowskich w miastach Europy środkowej [Wiederherstellung der Erinnerung. Die Revitalisierung historischer jüdischer Stadteile in mitteleuropäischen Städten]. Kraków 2008, 117-120.

Sabrow, Martin: Die postheroische Gedächtnisgesellschaft. Bauformen des historischen Erzählens in der Gegenwart. In: François, Etienne et al. (Hg.): Geschichtspolitik in Europa seit 1989. Deutschland, Frankreich und Polen im internationalen Vergleich. Göttingen 2013, 311-322.

Sakowska, Ruta: Ludzie z dzielnicy zamkniętej. Z dziejów Żydów w Warszawie w latach okupacji hitlerowskiej. Październik 1939-marzec 1943 [Die Menschen aus dem geschlossenen Bezirk. Aus der Geschichte der Juden in Warschau in den Jahren der hitleristischen Besatzung. Oktober 1939-März 1943]. 2. korr. und erw. Aufl. Warszawa 1993.

Samsonowska, Krystyna: Pomoc dla Żydów krakowskich w okresie okupacji hitlerowskiej [Die Hilfe für Krakauer Juden während der hitleristischen Besatzung]. In: Żbikowski, Andrzej (Hg.): Polacy i Żydzi pod okupacją niemiecką, 1939-1945. Studia i materiały [Polen und Juden während der deutschen Besatzung, 1939-1945. Studien und Materialien]. Warszawa 2006, 827-890.

Samuś, Paweł (Hg.): Polacy - Niemcy - Żydzi w Łodzi w XIX-XX w. Sąsiedzi dalecy i bliscy [Polen - Deutsche - Juden in Łódź im 19. und 20. Jahrhundert. Nahe und ferne Nachbarn]. Łódź 1997. 
Samuś, Paweł (Hg.): Fenomen getta łódzkiego. 1940-1944 [Das Phänomen des Ghettos von Łódź. 1940-1944]. Łódź 2006.

Sanford, George: Katyn and the Soviet Massacre of 1940. Truth, Justice and Memory. London, New York 2005.

Sarkisova, Oksana / Apor, Péter (Hg.): Past for the Eyes. East European Representations of Communism in Cinema and Museums after 1989. Budapest, New York 2008.

Saryusz-Wolska, Magdalena: Spotkania czasu z miejscem. Studia o pamięci i miastach [Begegnungen zwischen Zeit und Raum. Studien zu Gedächtnis und Städten]. Warszawa 2011.

Sauerland, Karol: Polen und Juden zwischen 1939 und 1968. Jedwabne und die Folgen. Berlin, Wien 2004.

Sauerland, Karol: Die polnische Gesellschaft in der deutschen Besatzungszeit aus jüdischer Sicht. In: Löw, Andrea/Robusch, Kerstin / Walter, Stefanie (Hg.): Deutsche Juden - Polen. Geschichte einer wechselvollen Beziehung im 20. Jahrhundert. Festschrift für Hubert Schneider. Frankfurt am Main, New York 2004, 137-156.

Sauerland, Karol: Polen und Juden innerhalb der polnischen Erinnerungskultur. In: Kissel, Wolfgang Stephan/Liebert, Ulrike (Hg.): Perspektiven einer europäischen Erinnerungsgemeinschaft. Nationale Narrative und transnationale Dynamiken seit 1989. Berlin 2010, 59-70.

Schäfer, Hermann: Was können Museen? Möglichkeiten und Grenzen der musealen Vermittlung von Zeitgeschichte. In: Knigge, Volkhard/Mählert, Ulrich (Hg.): Der Kommunismus im Museum. Formen der Auseinandersetzung in Deutschland und Ostmitteleuropa. Köln u. a. 2005, 85-98.

Schlögel, Karl: Suche nach dem »Gelobten Land«. In: Stadtbauwelt. Vierteljahreshefte der Bauwelt 48 (1997), 2694-2701.

Schlutow, Martin: Das Migrationsmuseum. Geschichtskulturelle Analyse eines neuen Museumstyps. Berlin u.a. 2012.

Schoder, Angelika: Die Vermittlung des Unbegreiflichen. Darstellungen des Holocaust im Museum. Frankfurt am Main, New York 2014.

Scholze, Jana: Medium Ausstellung. Lektüren musealer Gestaltung in Oxford, Leipzig, Amsterdam und Berlin. Bielefeld 2004.

Schröder, Vanessa: Geschichte ausstellen - Geschichte verstehen. Wie Besucher im Museum Geschichte und historische Zeit deuten. Bielefeld 2013.

Schulze Wessel, Martin: Einleitung. In: Franzen, K. Erik/Schulze Wessel, Martin (Hg.): Opfernarrative. Konkurrenzen und Deutungskämpfe in Deutschland und im östlichen Europa nach dem Zweiten Weltkrieg. München 2012, 1-8.

Schuster, Frank M.: Die verborgene Stadt. Die Wiederentdeckung der polyethnischen Vergangenheit der Stadt Łódź. In: Convivium 16 (2008), 143-170.

Seibert, Jutta: Lexikon christlicher Kunst. Themen, Gestalten, Symbole. Freiburg u. a. 1980.

Seuthe, Rupert: »Geistig-moralische Wende«? Der politische Umgang mit der NS-Vergangenheit in der Ära Kohl am Beispiel von Gedenktagen, Museums- und Denkmalprojekten. Frankfurt am Main u. a. 2001.

Siepracka, Dorota: Stosunki polsko-żydowskie w czasie okupacji hitlerowskiej. Stan badań i perspektywy badawcze [Polnisch-jüdische Beziehungen während der 
Besatzung. Forschungsstand und Forschungsperspektiven]. In: Samuś, Paweł/Puś, Wiesław (Hg.): Fenomen getta łódzkiego [Das Phänomen des Łódźer Ghettos]. Łódź 2006, 335-345.

Siepracka, Dorota: Stosunki polsko-żydowskie w Łodzi podczas okupacji niemieckiej [Die polnisch-jüdischen Beziehungen in Łódź während der deutschen Besatzung]. In: Żbikowski, Andrzej (Hg.): Polacy i Żydzi pod okupacją niemiecką, 1939-1945. Studia i materiały [Polen und Juden während der deutschen Besatzung, 1939-1945. Studien und Materialien]. Warszawa 2006, 691-735.

Sobiczewski, Bernard: Źródła do dziejów getta łódzkiego w zasobie Archiwum Państwowego w Łodzi [Quellenmaterial zur Geschichte des Łódźer Ghettos im Bestand des Staatsarchivs in Łódź]. In: Samuś, Paweł/Puś, Wiesław (Hg.): Fenomen getta łódzkiego [Das Phänomen des Łódźer Ghettos]. Łódź 2006, 401-405.

Sparing, Frank: Das »Zigeunerwohngebiet« im Ghetto Lodz 1941 / 42. In: Dieckmann, Christoph / Quinkert, Babette (Hg.): Im Ghetto 1939-1945. Neue Forschungen zu Alltag und Umfeld. Göttingen 2009, 136-170.

Steffen, Katrin: Jüdische Polonität. Ethnizität und Nation im Spiegel der polnischsprachigen jüdischen Presse 1918-1939. Göttingen 2004.

Steffen, Katrin: Ambivalenzen des affirmativen Patriotismus. Geschichtspolitik in Polen. In: Osteuropa 56/11-12 (2006), 219-233.

Steffen, Katrin: Formen der Erinnerung. Juden in Polens kollektivem Gedächtnis. In: Osteuropa 58/8-10 (2008), 367-386.

Steinlauf, Michael C.: Pamięć nieprzyswojona. Polska pamięć Zagłady [Die nicht angenommene Erinnerung. Die polnische Erinnerung an den Holocaust]. Warszawa 2001. - Erstpublikation: Steinlauf, Michael C.: Bondage to the Dead. Poland and the Memory of the Holocaust. Syracuse, New York 1997.

Steinlauf, Michael C.: What Story to Tell? Shaping the Narrative of the Museum of the History of Polish Jews. In: Polin. Studies in Polish Jewry 20 (2008), 318-323.

Stephan, Anke: »Banditen« oder »Helden«? Der Warschauer Aufstand in der Wahrnehmung deutscher Mannschaftssoldaten. In: Chiari, Bernhard (Hg.): Die polnische Heimatarmee. Geschichte und Mythos der Armia Krajowa seit dem Zweiten Weltkrieg. München 2003, 473-496.

Sternfeld, Nora: Aufstand der unterworfenen Wissensarten - museale Gegenerzählungen. In: Martinz-Turek, Charlotte/Sommer-Sieghart, Monika (Hg.): Storyline. Narrationen im Museum. Wien 2009, 30-56.

Stobiecki, Rafał: Die Zeitgeschichte in der Republik Polen seit 1989/1990. In: Nützenadel, Alexander/Schieder, Wolfgang (Hg.): Zeitgeschichte als Problem. Nationale Traditionen und Perspektiven der Forschung in Europa. Göttingen 2004, 329-346.

Stobiecki, Rafał: Rok 1945 w polskiej debacie historycznej [Das Jahr 1945 in der polnischen Geschichtsdebatte]. In: Dzieje Najnowsze 37 / 4 (2005), 5-17.

Stobiecki, Rafał: Rosja i Rosjanie w polskiej myśli historycznej XIX i XX wieku [Russland und die Russen im polnischen historischen Denken des 19. und 20. Jahrhunderts]. In: Lazari, Andrzej De (Hg.): Katalog wzajemnych uprzedzeń Polaków i Rosjan [Katalog der gegenseitigen Vorurteile von Polen und Russen]. Warszawa 2006, 159-201.

Strobel, Georg W.: Łódź: wielonarodowa polis w Polsce [Łódź: multinationale Polis in Polen]. In: Kobylińska, Ewa/Lawaty, Andreas/Stephan, Rüdiger (Hg.): Polacy 
i Niemcy. 100 kluczowych pojęć [Polen und Deutsche. 100 Schlüsselbegriffe]. Warszawa 1996, 431-436.

Stroop, Jürgen: Es gibt keinen jüdischen Wohnbezirk in Warschau mehr! (StroopBericht). Hg.v. Andrzej Wirth. Neuwied u.a. 1960.

Szacka, Barbara: Czas przeszły, pamięć, mit [Vergangenheit, Erinnerung, Mythos]. Warszawa 2006.

Szarota, Tomasz: Okupowanej Warszawy dzień powszedni. Studium historyczne [Der Alltag des besetzten Warschaus. Eine historische Studie]. 2. erw. Aufl. Warszawa 1978 (Erstauflage 1973).

Szarota, Tomasz: V - jak zwycięstwo. Symbole, znaki i demonstracje patriotyczne walczącej Europy 1939-1945 [V - wie Sieg. Symbole, Zeichen und patriotische Manifestationen des kämpfenden Europa 1939-1945]. Warszawa 1994.

Szarota, Tomasz: Atak na Gęsiówkę 5 VIII 1944 r. [Der Angriff auf die Gęsiówka am 5. August 1944]. In: Ders.: Karuzela na placu Krasińskich. Studia i szkice z lat wojny i okupacji [Das Karussell auf dem Krasiński-Platz. Studien und Skizzen zu den Kriegs- und Besatzungsjahren]. Warszawa 2007, 57-67.

Szarota, Tomasz: Polski autostereotyp w konfrontacji z doświadczeniami lat wojny i okupacji [Das polnische Autostereotyp in der Gegenüberstellung mit den Erfahrungen der Kriegs- und Besatzungsjahre]. In: Ders.: Karuzela na placu Krasińskich. Studia i szkice z lat wojny i okupacji [Das Karussell auf dem Krasiński-Platz. Studien und Skizzen zu den Kriegs- und Besatzungsjahren]. Warszawa 2007, 419-437.

Szarota, Tomasz: Kolaboracja z okupantem niemieckim i sowieckim w oczach Polaków - wówczas, wczoraj i dziś [Die Kollaboration mit dem deutschen und sowjetischen Besatzer aus polnischer Sicht - damals, gestern, heute]. In: Ders.: Karuzela na placu Krasińskich. Studia i szkice z lat wojny i okupacji [Das Karussell auf dem Krasiński-Platz. Studien und Skizzen zu den Kriegs- und Besatzungsjahren]. Warszawa 2007, 71-92.

Szarota, Tomasz: Kolaboranci pod pręgierzem [Kollaborateure am Pranger]. In: Ders.: Karuzela na placu Krasińskich. Studia i szkice z lat wojny i okupacji [Das Karussell auf dem Krasiński-Platz. Studien und Skizzen zu den Kriegs- und Besatzungsjahren]. Warszawa 2007, 93-106.

Szarota, Tomasz: Kolaboranci w kraju bez Quislinga [Kollaborateure im Land ohne Quisling]. In: Ders.: Karuzela na placu Krasińskich. Studia i szkice z lat wojny i okupacji [Das Karussell auf dem Krasiński-Platz. Studien und Skizzen zu den Kriegs- und Besatzungsjahren]. Warszawa 2007, 107-115.

Szpociński, Andrzej / Kwiatkowski, Piotr Tadeusz: Przeszłość jako przedmiot przekazu [Die Vergangenheit als Gegenstand der Vermittlung]. Warszawa 2006.

Szurek, Jean-Charles: Między historią a pamięcią: polski świadek Zagłady [Zwischen Geschichte und Erinnerung: Der polnische Zeuge des Holocaust]. In: Engelking, Barbara et al. (Hg.): Zagłada Żydów. Pamięć narodowa a pisanie historii w Polsce i we Francji [Die Vernichtung der Juden. Nationale Erinnerung und Geschichtsschreibung in Polen und Frankreich]. Lublin 2006, 174-184.

Thiemeyer, Thomas: Fortsetzung des Krieges mit anderen Mitteln. Die beiden Weltkriege im Museum. Paderborn u. a. 2010.

Thiemeyer, Thomas: Geschichtswissenschaft: Das Museum als Quelle. In: Baur, Joachim 
(Hg.): Museumsanalyse. Methoden und Konturen eines neuen Forschungsfeldes. Bielefeld 2010, 73-94.

Thiemeyer, Thomas: Zwischen Helden, Tätern und Opfern. Welchen Sinn deutsche, französische und englische Museen heute in den beiden Weltkriegen sehen. In: Geschichte und Gesellschaft 3 (2010), 462-491.

Thum, Gregor: Die fremde Stadt. Breslau nach 1945. München 2006.

Tokarska-Bakir, Joanna: Sprawiedliwi niesprawiedliwi, niesprawiedliwi sprawiedliwi [Die gerechten Ungerechten, die ungerechten Gerechten]. In: Zagłada Żydów 4 (2008), 170-214.

Tomczyk, Józef: Rada Żydowska w Lublinie 1939-1942 - organizacja, działalność i pozostałość aktowa [Der Judenrat in Lublin 1939-1942 - Organisation, Tätigkeit und Aktenbestände]. In: Radzik, Tadeusz (Hg.): Żydzi w Lublinie. Materiały do dziejów społeczności żydowskiej Lublina [Juden in Lublin. Materialien zur Geschichte der jüdischen Gemeinde Lublins]. Bd. 1. Lublin 1995, 245-255.

Traba, Robert: Pamięć i »choroba murów«, czyli o obecności Żydów w świadomości zbiorowej Litwinów, Niemców i Polaków. Kilka refleksji zamiast wstępu [Erinnerung und die »Krankheit der Mauern«. Über die Anwesenheit von Juden in der kollektiven Wahrnehmung von Litauern, Deutschen und Polen. Einige Überlegungen anstelle einer Einleitung]. In: Traba, Elżbieta/Traba, Robert (Hg.): Tematy żydowskie. Historia, literatura, edukacja [Jüdische Themen. Geschichte, Literatur, Erziehung]. Olstyn 1999, 7-25.

Traba, Robert: Kraina tysiąca granic. Szkice o historii i pamięci [Das Land der tausend Grenzen. Skizzen zu Geschichte und Erinnerung]. Olsztyn 2003.

Traba, Robert: Regionalismus in Polen. Die Quellen des Phänomens und sein neues Gesicht nach 1989. In: Ther, Phillipp/Sundhaussen, Holm (Hg.): Regionale Bewegungen und Regionalismen in europäischen Zwischenräumen seit der Mitte des 19. Jahrhunderts. Marburg 2003, 275-283.

Traba, Robert: Historia - przestrzeń dialogu [Geschichte als Dialograum]. Warszawa 2006.

Traba, Robert: Przeszłość w teraźniejszości. Polskie spory o historię na początku XXI wieku [Die Gegenwart der Vergangenheit. Polnische Geschichtsdebatten zu Beginn des 21. Jahrhunderts]. Poznań 2009.

Traba, Robert: Zu den Leitmotiven der kollektiven Erinnerung in Polen. In: Knigge, Volkhard et al. (Hg.): Arbeit am europäischen Gedächtnis. Diktaturerfahrung und Demokratieentwicklung. Köln u. a. 2011, 71-81.

Traba, Robert: Der Opferdiskurs als zentraler identitätsstiftender Faktor der polnischen Meistererzählung. In: Bingen, Dieter/Loew, Peter O. (Hg.): Polen. Jubiläen und Debatten. Beiträge zur Erinnerungskultur. Wiesbaden 2012, 27-36.

Troebst, Stefan: Jalta versus Stalingrad, GULag versus Holocaust. Konfligierende Erinnerungskulturen im größeren Europa. In: Faulenbach, Bernd/Jelich, FranzJoseph (Hg.): »Transformation« der Erinnerungskulturen in Europa nach 1989. Essen 2006, 23-49.

Troebst, Stefan: Der Hitler-Stalin-Pakt - ein Moment europäischer Erinnerung? In: Raabe, Stephan/Womela, Piotr (Hg.): Der Hitler-Stalin-Pakt und der Beginn des Zweiten Weltkrieges. Warszawa 2009, 31-39. 
Troebst, Stefan/Wolf, Johanna (Hg.): Erinnern an den Zweiten Weltkrieg. Mahnmale und Museen in Mittel- und Osteuropa. Leipzig 2011.

Tych, Feliks: Świadkowie Shoah. Zagłada Żydów w polskich pamiętnikach i wspomnieniach [Zeugen der Shoah. Die Vernichtung der Juden in polnischen Tagebüchern und Memoiren]. In: Ders.: Długi cień zagłady. Szkice historyczne [Der lange Schatten der Vernichtung. Historische Skizzen]. Warszawa 1999, 9-54.

Tych, Feliks: Typologia gett utworzonych przez okupantów niemieckich w Polsce (1939-1944) [Eine Typologie der von den deutschen Besatzern geschaffenen Ghettos in Polen (1939-1944)]. In: Samuś, Paweł/Puś, Wiesław (Hg.): Fenomen getta łódzkiego [Das Phänomen des Łódźer Ghettos]. Łódź 2006, 77-89.

Tych, Feliks / Adamczyk-Garbowska, Monika (Hg.): Następstwa zagłady Żydów. Polska 1944-2010 [Die Folgen der Vernichtung der Juden. Polen 1944-2010]. Lublin 2011.

Ungváry, Krisztián: Orte der Erinnerung an kommunistische Verbrechen. Das »Haus des Terrors" und der »Zentralfriedhof«. In: Weber, Matthias et al. (Hg.): Erinnerungsorte in Ostmitteleuropa. Erfahrungen der Vergangenheit und Perspektiven. München 2011, 219-233.

Urynowicz, Marcin: Stosunki polsko-żydowskie w Warszawie w okresie okupacji hitlerowskiej [Die polnisch-jüdischen Beziehungen in Warschau während der hitleristischen Besatzung]. In: Żbikowski, Andrzej (Hg.): Polacy i Żydzi pod okupacją niemiecką, 1939-1945. Studia i materiały. Warszawa 2006, 537-689.

Vogel, Sabine: Ausstellungs-Rezension zu: Krakau in der Okkupationszeit 1939-1945. In:H-Soz-u-Kult, 2.4.2011,URL:http://hsozkult.geschichte.hu-berlin.de/rezensionen/ $\mathrm{id}=143 \&$ type $=$ rezausstellungen $(\mathrm{am} 26.6 .012)$.

Völkering, Tim: Flucht und Vertreibung im Museum. Zwei aktuelle Ausstellungen und ihre geschichtskulturellen Hintergründe im Vergleich. Berlin 2008.

Völkering, Tim: »Flucht und Vertreibung« ausstellen - aber wie? Konzepte für die Dauerausstellung der »Stiftung Flucht, Vertreibung, Versöhnung« in der Diskussion. Bonn 2011.

Wahnich, Sophie (Hg.): Fiction d'Europe. La guerre au musée. Paris 2002.

Wahnich, Sophie: XXth Century History Museums in Europe: Ambiguous Messages. In: Dies./Lášticová, Barbara / Findor, Andrej (Hg.): Politics of Collective Memory. Cultural Patterns of Commemorative Practices in Post-War Europe. Wien, Berlin 2008, 43-56.

Wahnich, Sophie/Lášticová, Barbara/Findor, Andrej (Hg.): Politics of Collective Memory. Cultural Patterns of Commemorative Practices in Post-War Europe. Wien, Berlin 2008.

Waidacher, Friedrich: Handbuch der Allgemeinen Museologie. Wien u. a. 1993.

Waingertner, Przemysław: Problematyka getta łódzkiego w źródłach drukowanych i literaturze naukowej [Das Thema des Łódźer Ghettos in gedruckten Quellen und in der Forschungsliteratur]. In: Samuś, Paweł/Puś, Wiesław (Hg.): Fenomen getta łódzkiego [Das Phänomen des Łódźer Ghettos]. Łódź 2006, 389-399.

Warzecha, Małgorzata: Kustosz znaczy obrońca. Marek Budziarek (1951-2006) [Der Kustos als Verteidiger. Marek Budziarek (1951-2006)]. In: Kronika miasta Łodzi 1 (2006), 193-196. 
Wawrzyniak, Joanna: On the Making of Second World War Myths. War Veterans, Victims and the Communist State in Poland, 1945-1969. In: Stegmann, Natali (Hg.): Die Weltkriege als symbolische Bezugspunkte: Polen, die Tschechoslowakei und Deutschland nach dem Ersten und Zweiten Weltkrieg. Prag 2009, 189-208.

Wawrzyniak, Joanna: ZBoWiD i pamięć drugiej wojny światowej. 1949-1969 [Der ZBoWiD und die Erinnerung an den Zweiten Weltkrieg. 1949-1969]. Warszawa 2009.

Weber, Matthias et al. (Hg.): Erinnerungsorte in Ostmitteleuropa. Erfahrungen der Vergangenheit und Perspektiven. München 2011.

Weigel, Phillip: Schrecken erzieht nicht: Zum Einsatz von Fotografien in den Ausstellungen polnischer Shoah-Gedenkstätten. In: Ganzenmüller, Jörg/Utz, Raphael (Hg.): Orte der Shoah in Polen. Gedenkstätten zwischen Mahnmal und Museum. Köln u.a. 2016, 49-65.

Weinberg, Jeshajahu/Elieli, Rina: The Holocaust Museum in Washington. New York 1995.

Weiss, Yfaat: Deutsche und polnische Juden vor dem Holocaust. Jüdische Identität zwischen Staatsbürgerschaft und Ethnizität. 1933-1940. München 2000.

Williams, Paul: Memorial Museums. The Global Rush to Commemorate Atrocities. Oxford, New York 2007.

Wiśniewski, Michał: Zabłocie - modelowa rewitalizacja? [Zabłocie - beispielhafte Revitalisierung?]. In: Herito 4 (2011), 58-77.

Wojalski, Mirosław Zbigniew: Cmentarz Żydowski w Łodzi [Der jüdische Friedhof in Łódź]. Łódź 2002.

Wolff-Powęska, Anna: Polskie spory o historię i pamięć. Polityka historyczna [Polnische Diskussionen über Geschichte und Erinnerung. Geschichtspolitik]. In: Przegląd zachodni 1 (2007), 3-44.

Wolff-Powęska, Anna/Forecki, Piotr (Hg.): Der Holocaust in der polnischen Erinnerungskultur. Frankfurt am Main u. a. 2012.

Wóycicka, Zofia: Przerwana żałoba. Polskie spory wokół pamięci nazistowskich obozów koncentracyjnych i zagłady 1944-1950 [Unterbrochene Trauer. Polnische Auseinandersetzungen um die Erinnerung an die nationalsozialistischen Konzentrations- und Vernichtungslager 1944-1950]. Warszawa 2009.

W poszukiwaniu formuły nowoczesnego muzeum [Auf der Suche nach dem Format des modernen Museums]. In: Borussia 47 (2010), 123-134.

Wrzesiński, Wojciech: Niemiec w stereotypach polskich XIX i XX wieku [Der Deutsche in den polnischen Stereotypen des 19. und 20. Jahrhunderts]. In: Walas, Teresa (Hg.): Narody i stereotypy [Nationen und Stereotype]. Kraków 1995, 183-189.

Zaremba, Marcin: Komunizm, legitymizacja, nacjonalizm. Nacjonalistyczna legitymizacja władzy komunistycznej w Polsce [Kommunismus, Legitimierung, Nationalismus. Die nationalistische Legitimierung der kommunistischen Herrschaft in Polen]. Warszawa 2001.

Zaremba, Marcin: Das organisierte Vergessen des Holocaust in der Ära Gierek: Kontinuität und Wandel. In: Wolff-Powęska, Anna / Forecki, Piotr (Hg.): Der Holocaust in der polnischen Erinnerungskultur. Frankfurt am Main u. a. 2012, 161-174.

Żbikowski, Andrzej (Hg.): Polacy i Żydzi pod okupacją niemiecką, 1939-1945. Studia 
i materiały [Polen und Juden während der deutschen Besatzung, 1939-1945. Studien und Materialien]. Warszawa 2006.

Żbikowski, Andrzej: Die Erinnerung an den Holocaust in Polen. In: Brumlik, Micha/ Sauerland, Karol (Hg.): Umdeuten, verschweigen, erinnern. Die späte Aufarbeitung des Holocaust in Osteuropa. Frankfurt am Main u. a. 2010, 115-124.

Ziątkowski, Leszek: Die Geschichte der Juden in Breslau. Wrocław 2000.

Ziębińska-Witek, Anna: Wizualizacje pamięci - upamiętnianie Zagłady w muzeach [Visualisierungen der Erinnerung - die Erinnerung an den Holocaust in Museen]. In: Kwartalnik Historii Żydów 3 (2006), 366-378.

Ziębińska-Witek, Anna: Problemy wizualizacji Holokaustu - ekspozycje w muzeach miejscach pamięci [Fragen der Visualisierung des Holocaust - Ausstellungen in KZ-Gedenkstätten]. In: Konferencja »Od Westerplatte do Norymbergi. II wojna światowa we współczesnej historiografii, muzealnictwie i edukacji« w Muzeum Stutthof (2-5 września 2009 r.) [Konferenz »Von der Westerplatte nach Nürnberg. Der Zweite Weltkrieg in Geschichtswissenschaft, Museumswesen und Bildung der Gegenwart« im Museum Stutthof (2.-5. September 2009)]. Hg. v. Muzeum Stutthof. Sztutowo 2009, 293-296.

Ziębińska-Witek, Anna: Historia w Muzeach. Studium Ekspozycji Holokaustu [Geschichte im Museum. Eine Untersuchung von Holocaust-Ausstellungen]. Lublin 2011.

Ziębińska-Witek, Anna/Żuk, Grzegorz (Hg.): Muzea w kulturze współczesnej [Museen in der gegenwärtigen Kultur]. Lublin 2015.

Ziegler, Meinrad: "Dichte Beschreibung" - Essayistisches Theoretisieren und persönlicher Standort in der Interpretation. In: Kannonier-Finster, Waltraud/Ziegler, Meinrad (Hg.): Exemplarische Erkenntnis. Zehn Beiträge zur interpretativen Erforschung sozialer Wirklichkeit. Innsbruck 1998, 65-91.

Zimmerer, Katarzyna: Zamordowany Świat. Losy Żydów w Krakowie 1939-1945 [Die vernichtete Welt. Das Schicksal der Juden in Krakau 1939-1945]. Kraków 2004.

Zubrzycki, Geneviève: The Crosses of Auschwitz. Nationalism and Religion in PostCommunist Poland. Chicago, London 2006.

Zybura, Marek: Breslau und Wrocław. In: Kobylińska, Ewa/Lawaty, Andreas (Hg.): Erinnern, vergessen, verdrängen. Polnische und deutsche Erfahrungen. Wiesbaden 1998, 367-380.

Zybura, Marek: Von der »deutschen Gefahr« zum »deutschen Tor nach Europa«. Polnische Deutschland und Deutschenbilder im Wandel. In: Ders. (Hg.): Querdenker Vermittler Grenzüberschreiter. Beiträge zur deutschen und polnischen Literaturund Kulturgeschichte. Dresden 2007, 353-371.

Zybura, Marek: Krzyżak. Zur Entstehung des negativen Deutschenbildes in der polnischen Romantik. In: Surynt, Izabela/Zybura, Marek (Hg.): Narrative des Nationalen. Deutsche und polnische Nationsdiskurse im 19. und 20. Jahrhundert. Osnabrück 2010, 147-158.

Żychlińska, Monika: Muzeum Powstania Warszawskiego w służbie pamięci zbiorowej [Das Museum des Warschauer Aufstands im Dienste der kollektiven Erinnerung]. Warszawa: Uniwersytet Warszawski 2006. Unveröffentlichte Magisterarbeit.

Żychlińska, Monika: Muzeum Powstania Warszawskiego jako wehikuł polskiej pa- 
mięci zbiorowej [Das Museum des Warschauer Aufstands als Vehikel der polnischen kollektiven Erinnerung]. In: Kultura i Społeczeństwo 53 / 3 (2009), 89-114. Żyndul, Jolanta: Z getta do asymilacji. Żydzi w poszukiwaniu tożsamości [Aus dem Ghetto in die Assimilation. Juden auf Identitätssuche]. In: Traba, Elżbieta/Traba, Robert (Hg.): Tematy żydowskie. Historia, literatura, edukacja [Jüdische Themen. Geschichte, Literatur, Erziehung]. Olsztyn 1999, 55-72. 


\section{Bildnachweis}

Alle in dieser Publikation abgedruckten Fotografien wurden mit freundlicher Genehmigung der Museen von der Verfasserin angefertigt. 



\section{Personenregister}

Aleksandrowicz, Julian 257

Anders, Władysław 393

Anderson, Benedict 15

Anielewicz, Mordechaj 188, 196, 324

Assmann, Aleida 12

Assmann, Jan 12

Bach-Zelewski, Erich von dem 87

Baczyński, Krzysztof Kamil 315, 413, 416

Baliński, Stanisław 300

Banaś, Zbigniew 380

Bartoszek, Franciszek 203

Bartoszewski, Władysław 192, 472

Bednarek, Monika 104

Berling, Zygmunt 130, 385, $387 \mathrm{f}$.

Bielecki, Czesław 242, 244

Bierut, Bolesław 389

Błaszkowski, Bartłomiej 103

Błoński, Jan 147, 268

Bogumił, Zuzanna 24, 70, 77, 98

Borejsza, Jerzy 388

Borejsza, Jerzy Wojciech 425, 433

Borodziej, Włodzimierz 346

Borowski, Tadeusz 416

Borowy, Wacław 328

Broniewski, Władysław 184f., 291

Bryan, Julien 408, 462

Bryskier, Henryk 447

Buczek, Edward 478

Budziarek, Marek 73f., 223 f., 361

Bürkle, Franz 349

Bursche, Edmund 303 f., 363

Bytnar, Jan 349

Cholewa, Władysław 123, 125, 308, 358

Chruściel, Antoni 423

Churchill, Winston 397

Chwalba, Andrzej 269

Cichy, Michał 148, 191
Cornelißen, Christoph 11

Cukierman, Icchak 189, 469

Czerniaków, Adam 200, 206, 447 f.

Czuj, Łukasz 45, 256

Czuma, Walerian 354

Davies, Norman 332

Demjaniuk, John 460

Dirlewanger, Oskar 80 f., 319

Dmitrów, Edmund 396

Domańska, Regina 289

Duda, Eugeniusz 173

Durko, Janusz 116

Edelman, Marek 188-191, 196, 236, 324, 381, 387, 423 f., 469

Elczewska, Halina 246

Engelking, Barbara 152, 199, 426, 444

Fedorowicz, Halina 475

Fieldorf, August Emil 124, 308

Flacke, Monika 16, 414

Frank, Hans 67 f., 75, 80, 92, 135, 324

Gąsiorowski, Teodor 74

Gawron, Edyta 269

Geertz, Clifford $57 \mathrm{f}$.

Genewein, Walter 222, 232-234, 478

Gertner, Haim 263

Gliński, Piotr 11, 458

Goeth, Amon 68, 75

Goror, Baruch 445

Grabowski, Jan 426, 432

Grossman/Grosman, Mendel 234, 478

Gross, Jan Tomasz 9, 148-151, 183, 249

Grynszpan, Herschel $208 \mathrm{f}$.

Haber, Lili 98, 263

Halbersztadt, Jerzy 443 
Herbert, Zbigniew 476

Hilberg, Raul 478

Himmler, Heinrich 81, 84, 92, 304

Hirschberg, Aleksander 167

Hirszfeld, Ludwik 200, 202, 206

Hitler, Adolf 67, 69, 71 f., 75 f., 100, 157, 467

Höß, Rudolf 450

Indelak, Jacek 216

Iranek-Osmecki, Kazimierz 391

Iwanicki, Ryszard 73, 229, 361

Iwaszkiewicz, Jarosław 183, $185 \mathrm{f}$.

Jacob, Lilly 452

Jakóbiec, Jan 367

Jankowski, Jan Stanisław 391

Jaroszewiczowa, Halina 363

Jasiński, Zbigniew 397, 413

Johannes Paul II. 318, 336

Kaczyński, Jarosław 459

Kaczyński, Lech 35, 283

Kamiński, Aleksander 349

Kaminskij, Bronislav Vladislavovič 87

Karski, Jan 203, 224, 236, 246 f., 446, 473

Keding, Ekaterina 19, 491

Keneally, Thomas 265

Kiersnowski, Ryszard 303

Kirshenblatt-Gimblett, Barbara 448

Kiwerski, Jan W. 380

Klepfisz, Michał 195, 314

Klukowski, Zygmunt 473, 475

Knigge, Volkhard 293

Kobylarz, Renata 145

Kolbe, Maximilian 192, 295, 303 f., 318, 363

Komorowski, Tadeusz 393, 399

Konev, Ivan 112

Koppe, Wilhelm 75, 253, 352

Korboński, Stefan 192

Korczak, Janusz 197, 313 f., 327

Korff, Gottfried 15, 26

Kossak-Szczucka, Zofia 301
Kossert, Andreas 227

Kowal, Paweł 315, 323

Kranz, Tomasz 282

Krauze, Andrzej 239

Kropiwnicki, Jerzy 238f., 244-246

Krüger, Friedrich 75, 352

Kruk 167

Krzemiński, Adam 9

Krzymianowska, Justyna 395

Kubalski, Edward 92

Kucia, Marek 24

Kułak, Jerzy 396

Kuler, Andrzej 74

Kuroń, Jacek 147

Kusociński, Janusz 408

Kutschera, Franz 342, 357

Łagiewski, Maciej 103, 177, 208, $211 \mathrm{f}$.

Lanckorońska, Karolina 92, 418

Lanzmann, Claude 147, 167

Laurentowicz-Granas, Małgorzata

74,224

Łazowertówna, Henryka 201

Leociak, Jacek 197, 199, 247, 444

Leszczyńska, Zofia 74

Libionka, Dariusz 146, 149, 275

Ligocka, Roma 257f., 335

Linke, Bronisław Wojciech 35, 196

Litzmann, Karl 216

Löbe, Paul 331

Lorentz, Stanisław 328

Löw, Andrea 218, $230 \mathrm{f}$.

Lubetkin, Cywia 189

Lüdemann, Hermann 331

Macdonald, Sharon 14

Machcewicz, Paweł 459

Mache, Karl 331

Majewski, Piotr 425

Makhotina, Ekaterina 19, 491

Makower, Henryk $200 \mathrm{f}$.

Małecki, Ryszard 76, 410

Margolis, Alina 236

Marshall, Christopher 97, 378

Martinz-Turek, Charlotte 14, 16 
Matuszewska, Ewa 315

Melchior, Małgorzata 249

Michlic, Joanna Beata 142, 148, 152 f., 249

Mika, Kazimiera 462

Moorhouse, Roger 332

Mościcki, Ignacy 355, 365, 445

Müller, Bruno 334

Muttenthaler, Roswitha 57, 59

Niedziałkowski, Mieczysław 344, 354, 408

Niewiara, Aleksandra 62

Niezabitowski, Michał 56

Nijakowski, Lech 141

Nowak-Jeziorański, Jan 391

Ołdakowski, Jan 433

Ostolski, Adam 416

Pankiewicz, Tadeusz 258, 264, 269, 335, 473

Pawlak, Grażyna 443

Pawłowski, Roman 480

Peisert, Stanisław 210, 333

Penderecki, Krzysztof 329

Petermann, Sandra 298

Pieper, Katrin 12, 15

Piekałkiewicz, Jan 186, 343, 360, 363

Pietrasiewicz, Tomasz 275

Pius XII. 397

Podolska, Joanna 244

Polański, Roman 335

Polonsky, Antony 148

Potel, Jean-Yves 244

Przedborski, Samuel 445

Quisling, Vidkun 431

Raczkiewicz, Władysław 365, 397

Radzymińska, Józefa 301

Rapoport, Nathan 145

Rataj, Maciej 408

Reagan, Ronald 394

Reinefarth, Heinrich-Friedrich 81, 319
Reinisch, Rozalia 473

Ringelblum, Emanuel 200, 202, 206, 447, 454

Rokossovskij, Konstantin 130

Rómmel, Juliusz 354

Ross, Henryk 234

Rumkowski, Mordechaj Chaim 231

Rüsen, Jörn 11

Rydz, Edward 419

Sapieha, Adam 192, 297, 336, 384

Sauerland, Karol 432

Schenk, Mathias $88 \mathrm{f}$.

Schindler, Oskar 43, 96-98, 264-267, 270

Scholze, Jana 456

Siepracka, Dorota $230 \mathrm{f}$.

Sikorski, Władysław 163, 359, 367

Smorawiński, Mieczysław $113 \mathrm{f}$., 125, 306

Sołtan, Andrzej 396

Sommer-Sieghart, Monika 14, 16

Spielberg, Steven 98, 265

Spychalski, Józef 367

Stalin, Iosif 129-131, 133 f., 137, 386-389, 396, 467

Stanek, Józef $317 \mathrm{f}$.

Starzyński, Stefan 344f., 354, 406

Steffen, Katrin 143

Stein, Edith 318

Steinlauf, Michael 144, 147, 153, 210, 239, 278

Stroop, Jürgen 187, 203

Szarota, Tomasz 430

Szylling, Antoni 352

Thiemeyer, Thomas 55-57, 438

Tmej, Zdeněk 478

Traba, Robert 322

Trachman, Michail 478

Tumidajski, Kazimierz 125, 308, 358, 380

Ueberlhoer, Friedrich 76

Umińska, Apolonia 206 
Urban, Michał 45, 256

Uzarówna-Krysiakowa, Ludwika 363

Vašenko, Ivan Ivanovič $88 \mathrm{f}$.

Wajda, Andrzej 382, $475 \mathrm{f}$.

Wałęsa, Lech 114

Wawrzyniak, Joanna 70, 77, 344, 347, 349

Wierzyński, Kazimierz 299 f.

Williams, Paul 27

Wittlin, Józef 300

Wöhler, Otto 452
Wojtyła, Karol 336

Wonisch, Regina 57, 59

Zachwatowicz, Jan 328

Zarawski, Jerzy 48, 103, $211 \mathrm{f}$.

Zaremba, Marcin 344

Zarembina, Natalia 184

Żbikowski, Andrzej 152

Zbroja, Barbara 269

Ziębińska-Witek, Anna 24, 270

Zimmerer, Katarzyna 269

Zörner, Ernst 92

Zygielbojm, Szmul 184f., 203, $313 \mathrm{f}$. 